\title{
Systematic Gender Violence and the Rule of Law: Aboriginal Communities in Australia and Post-War Liberia
}

\author{
by \\ Veronica Patience Fynn Bruey \\ BSc Honours (Ghana), BA (British Columbia), MPH (Nottingham), \\ LLM (Osgoode), and LLB (London) \\ National Centre for Indigenous Studies \\ The Australian National University
}

October 2018

A thesis submitted for the degree of Doctor of Philosophy of

The Australian National University 
I confirm that this thesis is entirely my own work and contains no material which has been accepted for a degree or diploma by the Australian National University or any other institution, except by way of background information and duly acknowledged in the dissertation. To the best of my knowledge and belief this dissertation contains no material previously published or written by another person except where the due acknowledgement is made in the text of the dissertation, nor does it contain any material that infringes copyright.

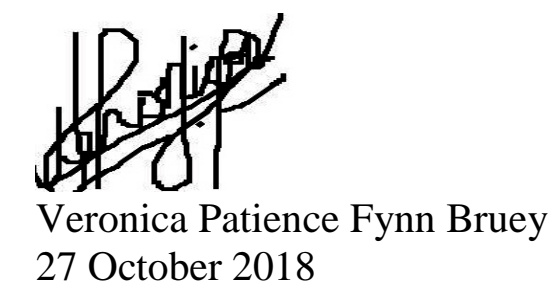




\section{ABSTRACT}

The gender-agenda is borderless. Arguably, legal justice for Indigenous girls and women survivors of violence is unfair, inequitable, and sometimes arbitrary. Systematic violence against girls and women pervades cultures and societies; operates at three main levels: institution and state, structural and cultural, and community and individual; and manifests in myriad shapes, forms and categories. Systematic violence in this research comprises historical, colonial and contemporary aspects of violence and its impact on Indigenous girls and women. Unlike comparative studies, this research is founded on heuristic arguments derived from validating the formation, establishment and continuity of the voices of Indigenous peoples in Liberia and Australia. While many studies isolate 'gender-based violence' and the 'rule of law' in separate contexts, none has explored the extent to which the Western concept of the rule of law impacts systematic violence against Indigenous girls and women in Australia and post-war Liberia.

The research assesses the efficacy of the 'rule of law' in dispensing justice to Indigenous girls and women who have suffered systematic gender-based violence. The scope of the research demands a comprehensive and complex systematic empirical approach that draws on the principles of phenomenology, community-based participatory research, and feminist and Indigenous methods. The study adopts an interdisciplinary mixed-methods approach informed by theories of decolonization, feminist jurisprudence, intersectionality, critical legal/race studies, and social determinants of health. Data is drawn from case law, secondary data, empirical evidence, textual/content analysis, electronic mailing and informal participant observation. Over a period of two years, a survey of 231 social service providers working with Indigenous girls and women; in-depth interviews with 29 Indigenous Women Advocates; and 22 informal email exchanges with male colleagues were conducted in both Australia and Liberia. Statistical analyses were carried out on records of 127708 convicts to Australia; 14996 former slave returnees to Liberia; 2701 sexual and gender-based violence cases reported to the Ministry of Gender, Children and Social Protection in Liberia; seven case files from the Sexual and Genderbased Crimes Unit in Liberia; and 1200 interview entries from the Longitudinal Study of Indigenous Children in Australia. This analysis of historical documents, jurisprudence and case studies triangulates a philosophical inquiry intended to migrate issues of violence against Indigenous girls and women from the margins of complex socio-legal structures towards the core of Western-centric perspectives, such as the rule of law. Situated between dominant academic conventions and resistance, the research provokes readers to consider ontological, epistemological and ethical arguments regarding access to justice outcomes for Indigenous girls and women.

Contrary to the research hypothesis and despite socioeconomic differences between Australia and Liberia, findings show that: although the principle of the rule of law is an emancipatory tool for justice and redress generally, it can also be an apparatus for persistent systematic violence against Indigenous girls and women. Furthermore, the intersection of colonial history, race, gender, class and social status exacerbates the ongoing perpetration of institutional/state, structural/cultural and interpersonal/community violence against Indigenous girls and women. In conclusion, the research recommends adopting a holistic approach to educating girls and women and encouraging boys and men to participate equally in the gender justice agenda, to ensure justice for Indigenous girls and women. The research also suggests incorporating diverse and comprehensive conceptual and methodological frameworks into further research. Finally, throughout the work, this dissertation attempts to give agency to Indigenous ways of being, knowing and doing justice.

Keywords: Aboriginal, Indigenous, Australia, Liberia, rule of law, gender justice, customary law, systematic violence, Indigenous women advocate 


\section{TABLE OF CONTENTS}

ABSTRACT ................................................................................................................................. i

TABLE OF CONTENTS ……………………....................................................................... iii

LIST OF TABLES, FIGURES \& APPENDICES............................................................... vii

ABBREVIATIONS ................................................................................................................... viii

ACKNOWLEDGEMENTS ............................................................................................... ix

DEDICATION .................................................................................................................. $\mathrm{x}$

CHAPTER 1: INTRODUCTION............................................................................................... 1

$1.0 \quad$ Background ....................................................................................... 1

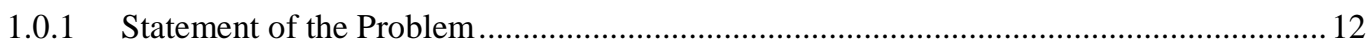

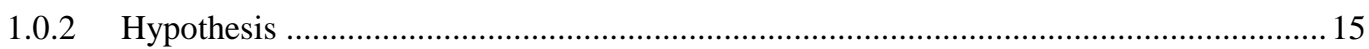

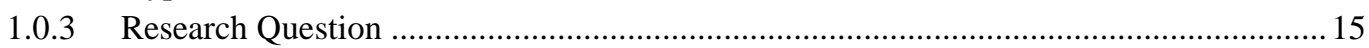

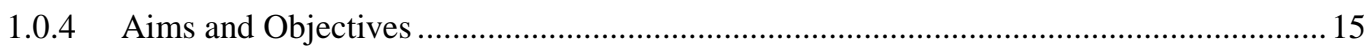

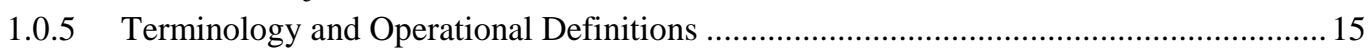

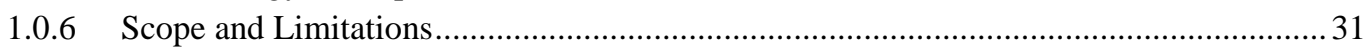

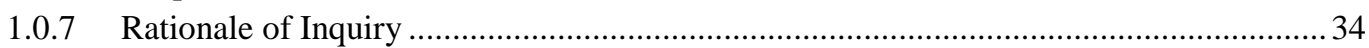

1.1 Theoretical, Conceptual and Legal Framework ............................................... 34

1.2 Contribution and Significance of Research................................................. 44

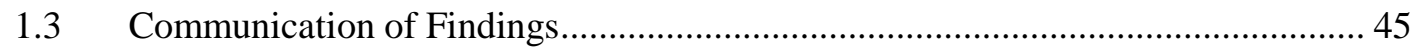

1.4 Personal Challenge................................................................................ 45

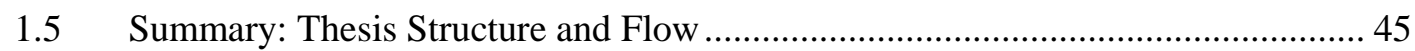

CHAPTER 2: A REVIEW OF THE LITERATURE.................................................... 47

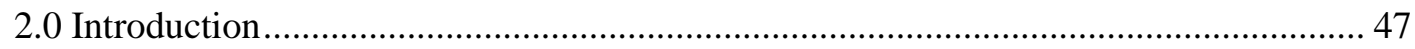

2.1 Thematic Components ................................................................................... 49

2.1.1 Theme 1: History, Indigeneity/Aboriginality, Politics and Governance ........................... 49

2.1.2 Theme 2: White Supremacy, Patriarchy and Racism ........................................................69

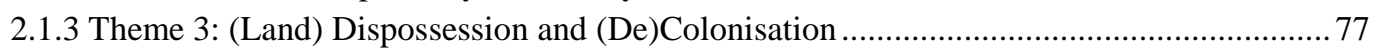

2.1.4 Theme 4: (Mental) Health, Education, Housing, Employment \& Development..................81

2.1.5 Theme 5: (Aboriginal) Feminism, International Human Rights Law and Protection ..........89

2.1.6 Theme 6: (Harmful) Religious and Traditional Practices ................................................. 94

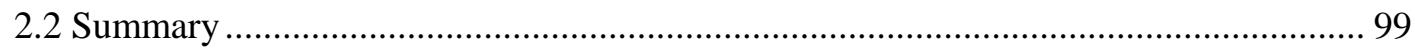

CHAPTER 3: VIOLENCE AGAINST INDIGENOUS GIRLS AND WOMEN ........ 100

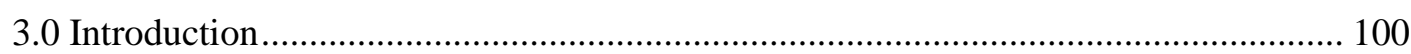

3.1 What is Violence? - Interpersonal, Structural and Institutional ............................. 102

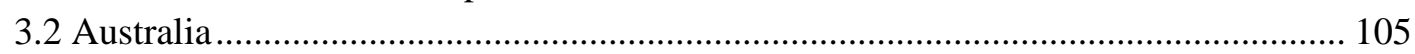

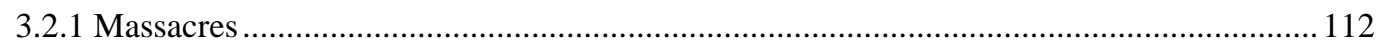

3.2.2 Genocide, Miscegenation, and Eugenics.................................................................... 116

3.2.3 Stolen Generation/Forced Adoption/Bringing Them Home............................................. 119

3.2.4 Social Services and Child Abuse ............................................................................. 122

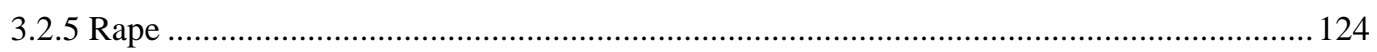

3.2.6 Domestic, Family, Intimate and Community Violence .................................................... 128

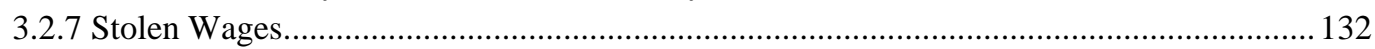

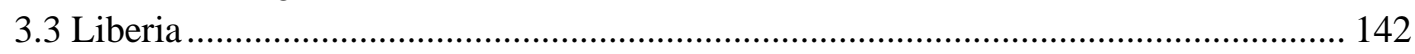

3.3.1 Extraction from Indigenous Lands: the case of Firestone, Bong Mines, and LAMCO..... 145

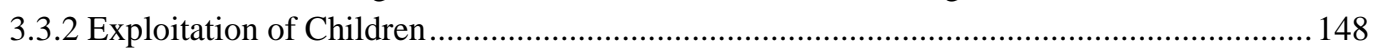

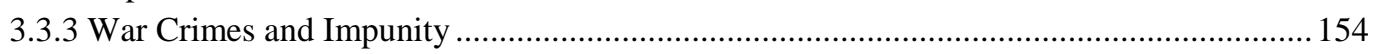

3.3.4 The Truth and Reconciliation Commission of Liberia ..................................................... 155

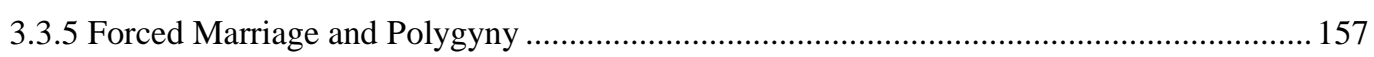

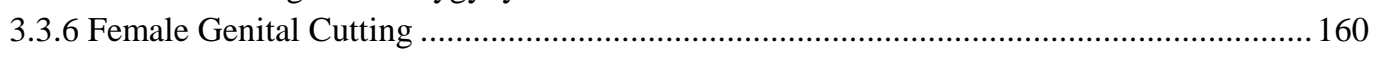

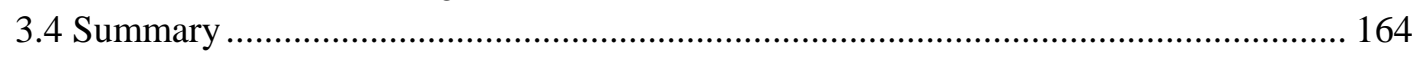

CHAPTER 4: THE RULE OF LAW ....................................................................................... 169 


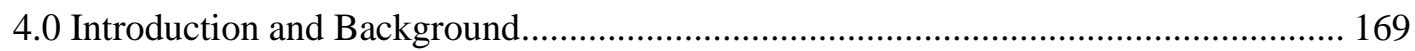

4.0.1 Historical and Conceptual Philosophy of the Rule of Law ........................................ 170

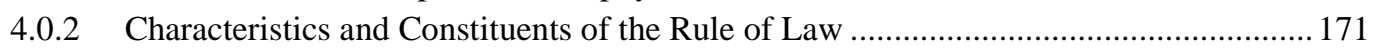

4.0.3 Creating the Nation without Its Citizens: The Birth of State Violence .......................... 176

4.1 Indigenous Customary Laws Internationally, Regionally and Nationally ............ 185

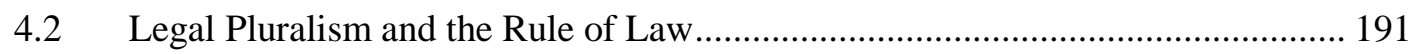

4.2.1 Accommodating Indigenous Customary Laws: Colonial and Indigenous Courts........... 197

4.3 Male-Dominant Traditional, Political and Legal Establishments ......................... 201

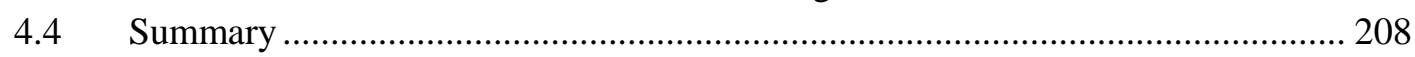

CHAPTER 5: RESEARCHER'S POSITIONALITY AND REFLEXIVITY ............... 212

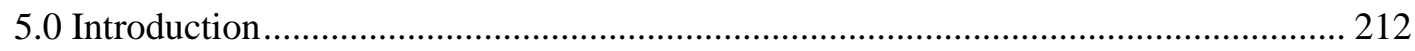

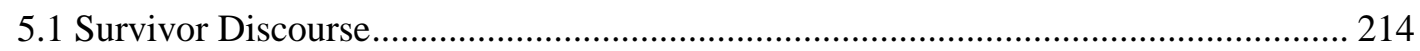

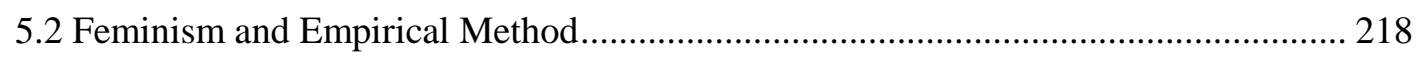

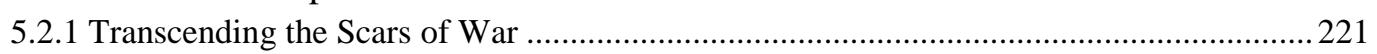

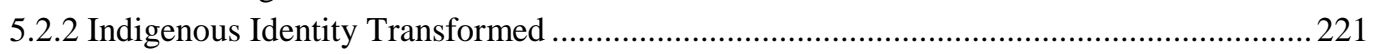

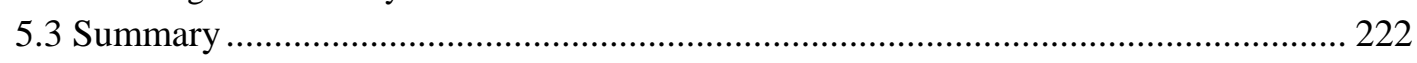

CHAPTER 6: METHODOLOGY AND DESIGN_.................................................... 224

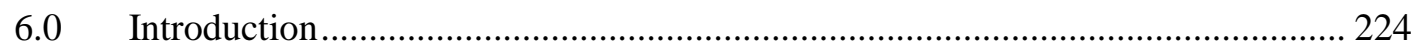

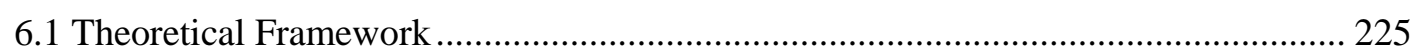

6.2 Complex System Design ........................................................................................ 230

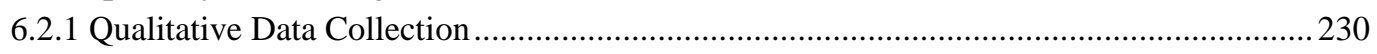

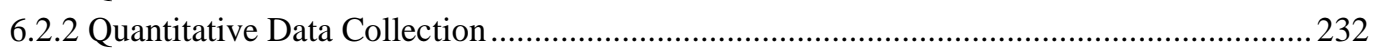

6.3 Participant Sampling, Selection and Recruitment.............................................. 233

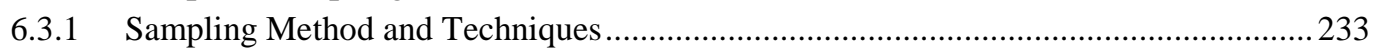

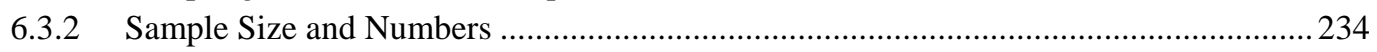

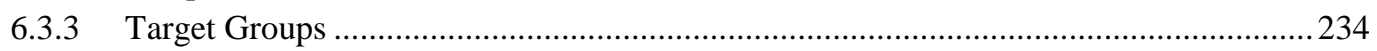

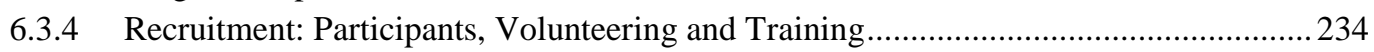

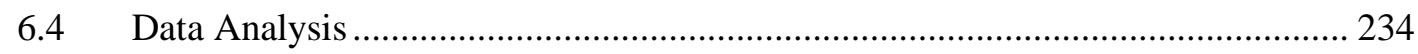

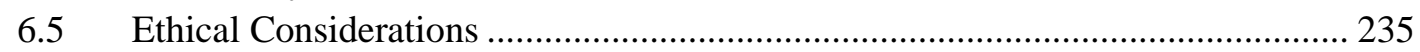

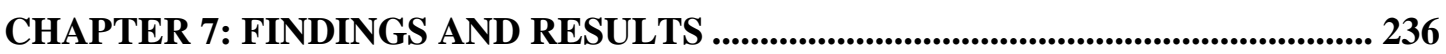

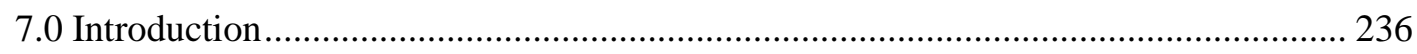

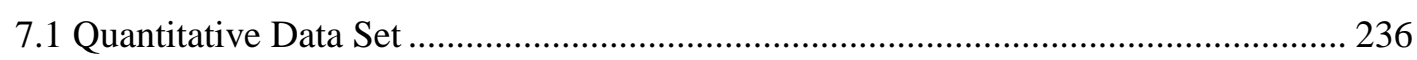

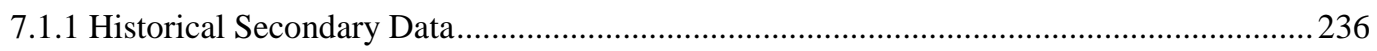

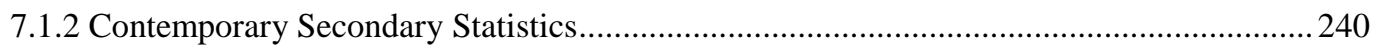

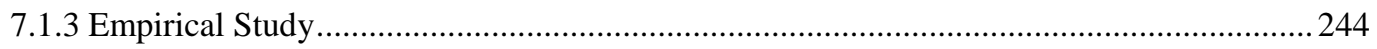

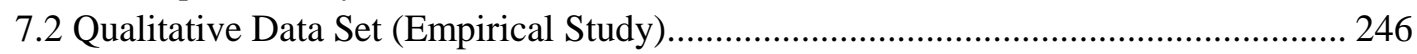

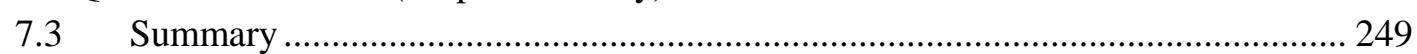

CHAPTER 8: DISCUSSION AND ANALYSIS .............................................................. 267

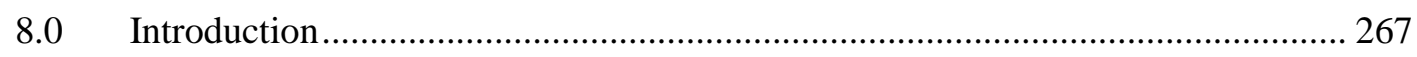

8.1 A Pervasive Culture of Violence (Nature, Type and Impact of Violence) ................. 268

8.2 Traditions, Culture and Customs........................................................................ 279

8.2.1 Violent Patterns: Domestic, Family and Intimate Partner Abuse ....................................228

8.2.2 Female Genital Cutting: Girls' Education, Statutory Rape and Forced Marriage ...........284

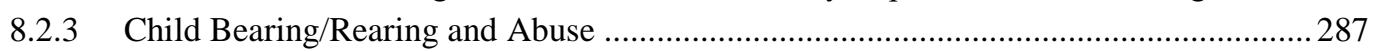

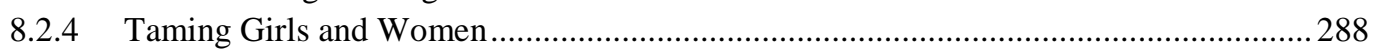

8.2.5 Superiority of and Conflict with Settler-Colonist Law ................................................2.28

8.3 Access to Services: Housing, Health, Education and Employment ...................... 291

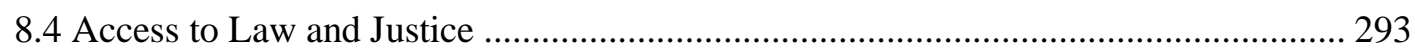

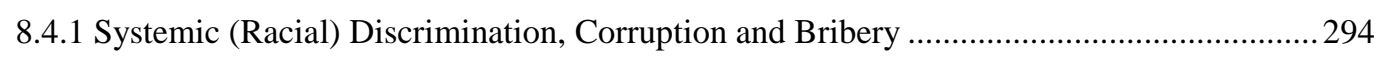

8.4.2 Law Enforcement, Courts and Legal Assistance .............................................................. 296

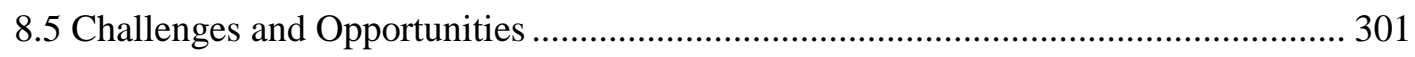

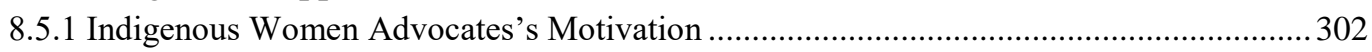




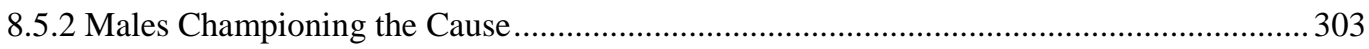

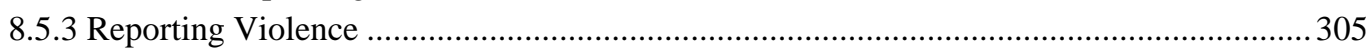

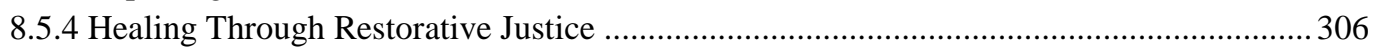

8.6 Summary ................................................................................................... 310

CHAPTER 9: CONCLUSION AND RECOMMENDATIONS ................................... 312

9.0 Chapters Summaries ................................................................................. 312

9.1 Dissertation Summary ............................................................................. 315

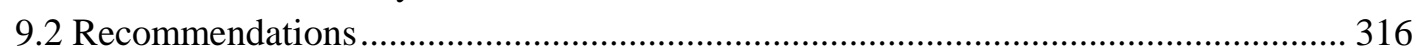

9.2.1 Further Research: Expansion of the Complex System Approach .......................................... 316

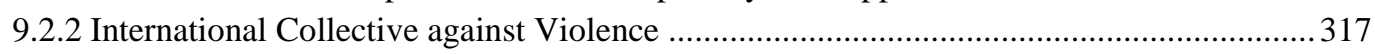

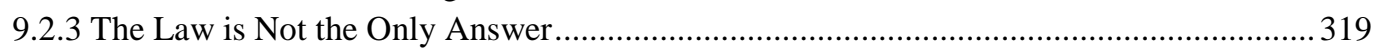

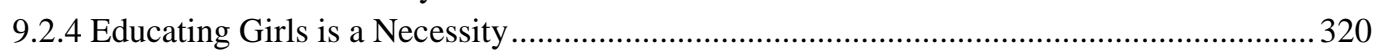

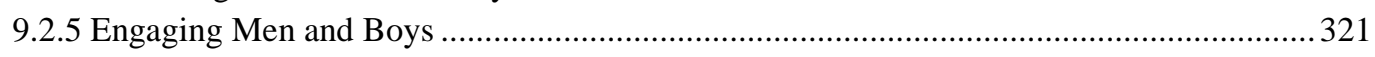

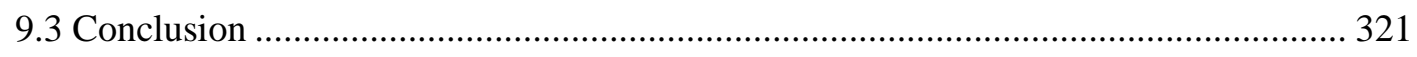

APPENDICES ...................................................................................................... 323

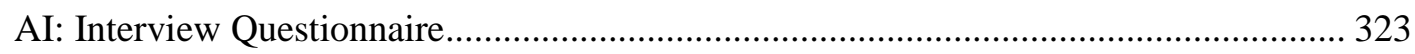

AII: Paper/Online Survey Questions.................................................................... 324

AIII: Summary of Research Models, Design, Question and Description ...................... 326

AIV: Historical Timeline (Liberia and Australia).................................................. 327

AV: Internal Deadly Conflicts Between Indigenous and Settlers................................ 336

AVI: Sexes of Judges and Magistrates in Liberia and Australia.................................. 337

AVII: Presidents and Prime Ministers of Australia .................................................. 340

AVIII: List of Major Legal Instruments Used to Protect Women against Violence........ 341

AIX: Demographic Profile of Australian Convicts and Liberian Freed Slaves ............... 342

AX: Deceased Females Whose Deaths Were Within the Jurisdiction of the Royal Commission into Aboriginal Deaths in Custody ......................................................... 344

AXI: Excerpts from Informal Emails to Male Colleagues........................................... 345

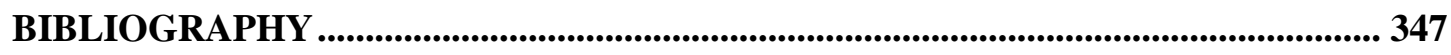

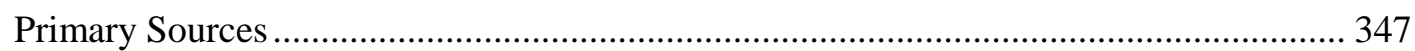

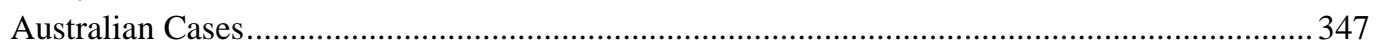

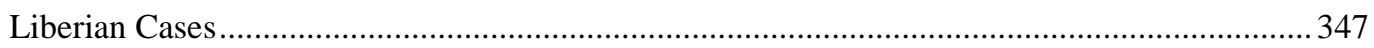

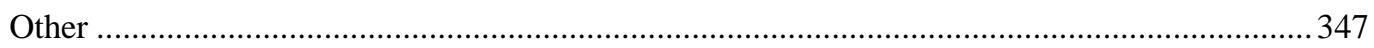

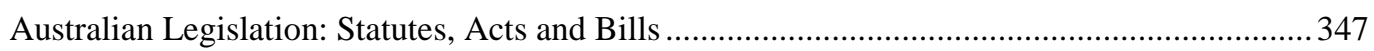

Liberian Legislation: Statutes, Acts and Bills ..................................................................... 348

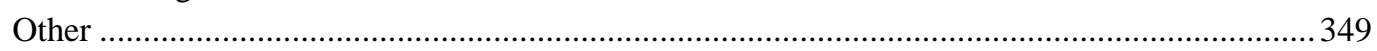

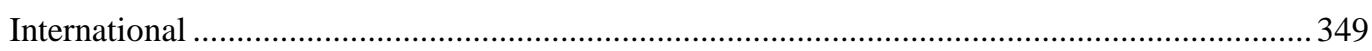

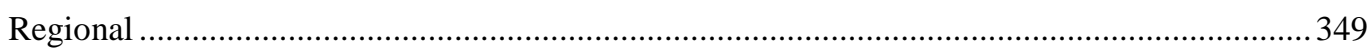

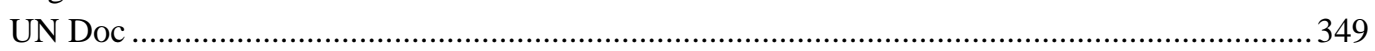

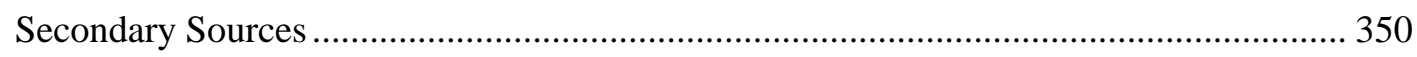

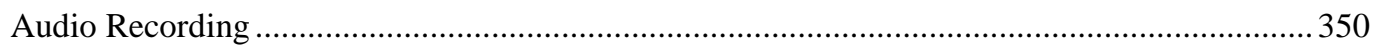

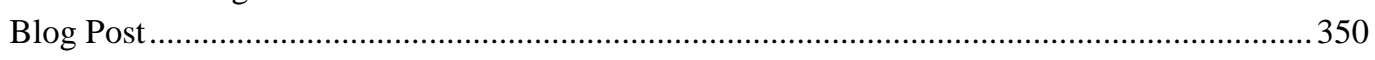

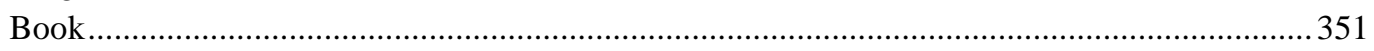

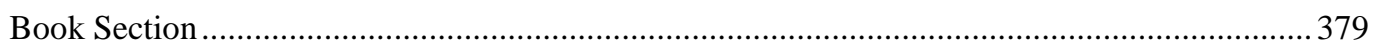

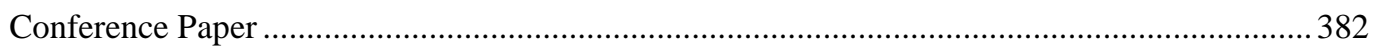

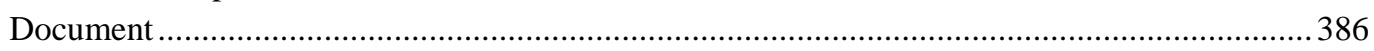

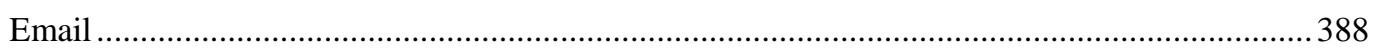

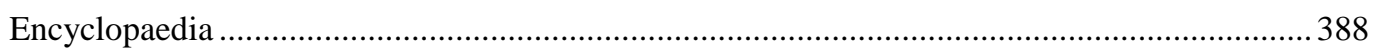

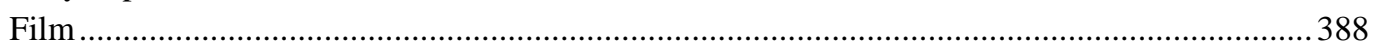

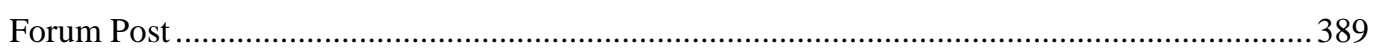

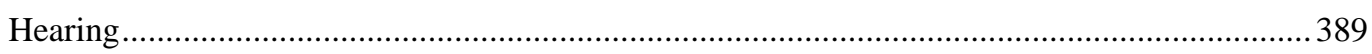

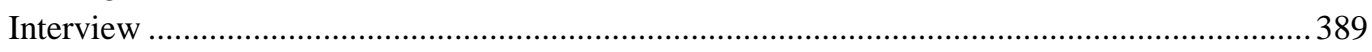

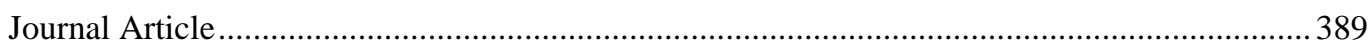


Letter......

Magazine Article..

Manuscript

Newspaper Article

Podcast

Presentation.

Radio Broadcast . 430

Report. 431

TV Broadcast 446

Thesis . .446

Video Recording 447

Webpage 448 


\section{LIST OF TABLES, FIGURES \& APPENDICES}

\section{Tables}

Table 2.1: Population characteristics of Liberia 1992 and $2008 \quad 52$

Table 2.2: Population distribution in Liberia: sex ratio, health, and educational facilities 55

Table 2.3: Nineteen strongly spoken Aboriginal languages in Australia $\quad 64$

Table 2.4: Population characteristics of Australia, 1901 and $2011 \quad 67$

Table 2.5: Population distribution showing sex, health and educational facilities $\quad 68$

Table 4.1: List of Aboriginal Women Member of Parliament in Australia 204

Table 4.2: Numbers, percentages and sex of Indigenous representatives in Liberia and Australia 208

Table 7.1: Select cases prosecuted by the Sexual Violence Crimes Unit between 2009-2011 251

Table 7.2: Select Stolen Generation Cases in Australia 252

Table 7.3: Incidence of sexual assault and other violent crime submitted to the Ministry of Gender in 2013

Table 7.4: Characteristics of sexual violence reported to the Ministry of Gender in $2013 \quad 254$

Table 7.5: Age-Sex Contingency Table 255

Table 7.6: Longitudinal Study of Indigenous Children respondents' experiences of adoption, $\begin{array}{ll}\text { homelessness, racism and bullying } & 257\end{array}$

$\begin{array}{ll}\text { Table 7.7: Summary of survey } & 258\end{array}$

Table 7.8: Responses to survey questions on whether the law is helpful or just 259

Table 7.9: Aboriginal women advocates interviewed in Australia 260

Table 7.10: Indigenous women advocates interviewed in Liberia $\quad 260$

Table 7.11: Sample responses from service providers $\quad 261$

Table 7.12: Select quotes reflecting thematic representation of Indigenous women advocates 264

\section{Figures}

Figure 2.1: Pyramid of social class in Liberia $\quad 72$

$\begin{array}{ll}\text { Figure 3.1: Flow diagram showing interaction of systematic violence } & 104\end{array}$

Figure 7.1: Relationship of the perpetrator to the survivor of sexual and domestic violence 243

Figure 7:2: Institutions where cases of sexual and domestic assault are first reported 243

Figure 7:3: Word Cloud of 1000 most frequent words used in the research survey 247

Figure 7.4: Age distribution of survivors and perpetrators of sexual and domestic violence 256 


\section{ABBREVIATIONS}

\begin{tabular}{|c|c|}
\hline ABS & Australian Bureau of Statistics \\
\hline ACRWC & African Charter on the Rights and Welfare of the Child \\
\hline ACS & American Colonization Society \\
\hline AASC & African American Settler-Colonists \\
\hline AFELL & Association of Female Lawyers in Liberia \\
\hline AHRC & Australian Human Rights Commission \\
\hline AIATSIS & Australian Institute of Aboriginal and Torres Strait Islanders Studies \\
\hline AIC & Australian Institute of Criminology \\
\hline AIWH & Australian Institute of Health and Welfare \\
\hline $\mathrm{AU}$ & African Union \\
\hline CEDAW & Convention on the Elimination of All Forms of Discrimination \\
\hline $\mathrm{CRC}$ & Convention on the Rights of the Child \\
\hline C107 & Indigenous and Tribal Populations Conventions, 1957 \\
\hline C169 & Indigenous and Tribal Populations Conventions, 1989 \\
\hline DHS & Demographic Health Survey \\
\hline DSS & Department of Social Services \\
\hline FaHCSIA & Families, Housing, Community Services and Indigenous Affairs \\
\hline $\mathrm{HCA}$ & High Court of Australia \\
\hline ICC & International Criminal Court \\
\hline ICJ & International Court of Justice \\
\hline ICL & Indigenous Customary Laws \\
\hline INCHR & Independent National Commission on Human Rights \\
\hline IWAs & Indigenous Women Advocates \\
\hline LISGIS & Liberia Institute of Statistics and Geo-Information Services \\
\hline LNP & Liberia National Police \\
\hline LSIC & Longitudinal Study of Indigenous Children \\
\hline MoGC\&SP & Ministry of Gender, Children and Social Protection \\
\hline $\mathrm{MoH}$ & Ministry of Health \\
\hline NTI & Northern Territory Intervention \\
\hline OAU & Organisation of African Unity \\
\hline RCIADIC & Royal Commission into Aboriginal Death in Custody \\
\hline RCIRCSA & Royal Commission into Institutional Responses to Child Sexual Abuse \\
\hline RoL & Rule of Law \\
\hline SGBV & Sexual and Gender-based Violence \\
\hline SGBV CU & Sexual and Gender-based Violence Crimes Unit \\
\hline TAST & Trans-Atlantic Slave Trade \\
\hline TIP & Trafficking in Persons \\
\hline TRC & Truth and Reconciliation Commission of Liberia \\
\hline UDHR & Universal Declaration of Human Rights \\
\hline UNDP & United Nations High Development Program \\
\hline UNDRIP & United Nations Declaration on the Rights of Indigenous Peoples \\
\hline UNFPA & United Nations Populations Fund \\
\hline UNHCHR & United Nations High Commission for Human Rights \\
\hline UNICEF & United Nations Children's Fund \\
\hline UNMIL & United Nations Mission in Liberia \\
\hline VAIG/C\&W & Violence Against Indigenous Girls/Children and Women \\
\hline SVAW & Systematic Violence Against Women \\
\hline WACPS & Women and Children Protection Section \\
\hline
\end{tabular}




\section{ACKNOWLEDGEMENTS}

This dissertation encompasses years of collaborative effort. First and foremost, I am indebted to all those special people, especially Indigenous Women Advocates in Liberia and Australia, who taught me patience and how to listen. Mama Josephine Harmon Fynn, thank you for giving birth to me. Above everyone else, my foremost appreciation goes to my husband, Douglas Christopher Bruey and our son Aeden, for their unwavering love, support, strength and encouragement. Aunty Miatta Montgomery, you are so special. Thank you for looking after me since my refugee days in Ghana. My profound gratitude goes to my supervisory team: Professors Michael Dodson, D. Elwood Dunn, and Shafik Dharamsi - three distinguished beautiful men of colour who I carefully and consciously selected to guide me through this lifechanging journey. Asmi Wood, in simple terms, I say thank-you! To my extended families and friends in Canada, Shirin and Daniel Theophilus, Jo-Ann Osei-Twum, Ruth Angela Situma, Kofi and Rosemary Gbolonyo, Anna and Rory McIvor, Carole and Torkild Christensen, Yemisi Dina, Nancy Gallini, and Jenny Francis, I say thanks for been there for me through thick and thin.

In Liberia, Theophilus Addey (my childhood bosom friend) and the entire Ministry of Finance's Liberia Development Alliance Office team, thank you for providing me with electricity, technology, food, water and best of all, genuine friendship. Jessie Korboi, you surprised me on several occasions, I thank you. Cousins Varney and Joyce Sherman, how can I ever repay you for opening your hearts and home to me when I was in dire straits? My deepest gratitude goes to Counsellor Betty Lamin-Blamo, Solicitor General of Liberia; Daniel Garway, Ministry of Education; Yondeh Moore, Monrovia City Corporation; Deddeh Kwekwe and Siemon Kwein of the Ministry of Gender, Children and Social Protection; Monica Tulchinsky, Carter Centre; Reverend Dr Yar Gono and Daibah Tozay of Nimba Community College; Uncle James C Mulbah (deceased), Uncle Akoi Tellewuyan (deceased), Aunty Varbah, Cousin Wuyan Kollie and Pastor Ericsson Boikai all of Lofa County; and Uncle Mle Harmon, Aunty Comfort Harmon, Cousin Glei (and Wife) Harmon, Tobias Wiah, Dr Nathaniel and Sylvestine Gbessegee, all of Maryland county.

In Australia, Ed Wensing, Magali McDuffie, Kate Ogg, Michael and Dr. Melanie Blair, Dr. Johannes Krebs, Costanza Maffi, Anna Buckley, Tamai Heaton, Veronica Wensing and all my NCIS 'homies', I shout out thanks mates. Bob Forrester, you ensured that my statistical data and analyses were properly done. Professors Don Rothwell and Simon Rice, you kept me alive with part-time jobs. Hans-Joerg Kraus, words are not enough to express how awesome you are! Professors Nick Peterson, Bruce Symth, Gillian Triggs, Jeremy Farrall, your constant feedback help improved the quality of my thesis proposal and ethics application. Dr. Adam Tomison, Janine Chandler, Lepa Petrovic and Samantha Bricknell, all of the Australian Institute of Criminology, your commitment to research is phenomenal. Professor Michael Flood, you are a role model and mentor to all, especially boys and men!

In the United States, Patrick Kutu-Akoi (Uncle P), you are a true family member. Professors Dana Raigrodski, Michele Storms, William Covington and Jane Fulcher of University of Washington School of Law, you made the write-up possible. Judy Davis and Gallagher Law Library staff members, you were exceptional for putting through the rarest interlibrary loans. Professor Bender your exceptional mentoring came when I was in dire need of guidance. Thank you for taking the time away from your extremely busy schedule to proof-read the chapters.

Veronica Fynn Bruey

Seattle, Washington

United States of America 


\section{DEDICATION}

To a very strong woman (my mother), a very special man (my husband) and our future (our son); and all Indigenous girls and women in Liberia and Australia...your strength, quiet patience, teachings and resilience produced this work. 


\title{
CHAPTER 1: INTRODUCTION
}

\begin{abstract}
I'm a mother of 11. My first daughter I born her in 1975, June 5. I am not educated but I remember. My first daughter got pregnant for one boy. At the time, I was selling small small thing. That boy looked at the girl and said, "ohn that belly you have, it is not for me". So, my husband looked at the situation and said, "will it be OK to take someone who has no money to the police station who might end up being jailed? What would I get out of it? It will be all right. Let me take care of my daughter'. So, we took care of our daughter until she delivered. We also helped to take care of our grandchild until she walked. After the baby was one year six months, my daughter took the baby back to the same person who said he's not the father. That's the man she's with right now. [Martha, Liberia]

I am an Indigenous woman from Wakka Wakka Wulli Wulli. I suppose as a young person I saw a lot of violence, not in my own family so much, but you in the broader community there was just the violence of people's lives because of drinking, depression and trauma. In Queensland, where I grew up, even though I was sexually abused at school by white people. It happened when I went away to a boarding school. Of course, you don't tell your family anything. You just get over it and get on with your life. I went through this court case and a whole negotiation with the Catholic Church in the 1990s, where I had to put a Catholic priest in jail for sexually abusing me as a child. [Alison, Australia]
\end{abstract}

\subsection{Background}

The persistence of violence against Indigenous girls and women in Australia and Liberia reflects the breakdown of the rule of law. This dissertation argues that the relatively high prevalence of systematic violence against Indigenous girls and women is a result of institutions established by the state through law and policies; or of stereotypes and beliefs held by dominant (white) males in a social system that values patriarchy and misogyny handed down through cultural constructs that otherwise determine societal structure; or of direct and physical infliction of interpersonal violence at home, in the workplace and in the community. The root of systematic violence is inextricably tied to the colonial history of nation-building founded in the imposition of settlers' law, emblemised in the creation of a constitution that denied recognition of Indigenous Peoples as the original custodians of the land prior to the arrival of the settler-colonists in Australia and Liberia. Generally, the constitution of any nation, in tandem with specific legislation, and public policies, is created with a declared intent to guarantee legal justice and equal protection to all citizens. However, findings from this research project suggest that several factors, including the existence of discriminatory law and policy, lack of access to courts, poor health, high illiteracy rate, corruption, and extremely low participation in political, judicial, public and community life, disproportionately deny Indigenous girls and women equal protection under the law. The critical gap in access to justice and services between Indigenous and non-Indigenous populations shown in this research clearly indicates a failure in the implementation of the rule of law. This failure of the law to adequately address systematic violence leads to questions about whether the concept of the 'rule of law' is an effective mechanism for restoring justice to Indigenous girls and women survivors of such violence. 
Although this research is specifically focused on systematic violence against Indigenous women in Australia and Liberia, it is worth pausing to accentuate the complex, widespread and manifold impacts of the fatal and indelible occurrences of violence against women, as disclosed by Martha and Alison - two Indigenous Women Advocate interviewees quoted above. Consider the following three instances. In an incident dubbed the Delhi Gang Rape, ${ }^{1}$ a 23-year-old young female, whilst using local public transportation, was fatally beaten and raped on 16 December 2012 in Munirka, India by five imposters claiming to be local public transport servicemen. Fortunately, the deceased young woman of the Delhi Gang Rape received some justice when the four of the accusers were convicted and sentenced to death on 13 September 2013. ${ }^{2}$ In the early hours of 23 March 2013, 14-year-old South African Thandeka Madonsela met her untimely death after being raped, disemboweled, and murdered by two boys, aged 16 and 17 years. ${ }^{3}$ The last heard of Madonsela's accusers is that they were released into the custody of their parents after their initial arrest and appearance in court. ${ }^{4}$ On 4 April 2013, in Nova Scotia, Canada, 17year old Rehteah Parsons took her life 17 months after photos of her were circulated on the Internet by the four boys who allegedly gang-raped her. In Parsons's case, not only did the justice system ${ }^{5}$ fail to arrest or charge anyone until four months after the incident occurred, ${ }^{6}$ but also there was no jail time for the perpetrators so that '[i]n the end, she did not receive the support and assistance a young person in crisis required'. These stories of shocking violence evidence the pervasive nature of violence against women as a scourge of global proportions. As narrated by Martha and Alison above, violence against girls and women comes in various forms and is not confined to Indigenous women. Diverse occurrences of violence against women are predicated on, inter alia, the intersection of gender, race, class, social status and identity - a concept described as intersectionality ${ }^{8}$ in sociological studies or the public health principle social determinants of health. ${ }^{9}$

\footnotetext{
${ }^{1}$ Maitreyee, 'Delhi Gangrape Redux? This Time a Minor Raped inside a Bus' One India (Online), 15 April 2013 <Read more at: http://news.oneindia.in/2013/04/15/delhi-minor-raped-inside-a-bus-driver-held-1193979.html>. ${ }^{2}$ BBC News, 'Death Penalties for Delhi Gang Rape' BBC News (London, UK), 13 September 2013 <http://www.bbc.com/news/world-asia-india-24078339>.

${ }^{3}$ Tankiso Makhetha, 'Teens Accused of Rape, Murder of Girl, 14' IOL News (Pretoria), 27 March 2013 <http://www.iol.co.za/news/crime-courts/teens-accused-of-rape-murder-of-girl-14-1.1492436\#.UWw7i7_UO5o〉. ${ }^{4}$ Tankiso Makhetha, 'Teens Accused of Girl's Rape, Murder Released | IOL News' IOL News (Pretoria, Johannesburg), 28 March 2013 <https://www.iol.co.za/news/crime-courts/teens-accused-of-girls-rape-murderreleased-1493161>.

${ }_{5}^{5}$ CBC News, 'Rehtaeh Parsons Case to Get Independent Review' Canadian Broadcasting Corporation (Halifax, NS), 15 April 2013 <http://www.cbc.ca/news/canada/nova-scotia/story/2013/04/15/ns-rehtaeh-bully-independentreview.html>.

${ }^{6}$ CBC News, 'Rehtaeh Parsons Suspects in Court to Face Child Porn Charges' Canadian Broadcasting Corporation (Halifax, NS), 15 August 2013 <http://www.cbc.ca/news/canada/nova-scotia/story/2013/08/15/ns-rehtaeh-parsonsaccused-appearance.html>.

${ }^{7}$ Murray D Segal, 'Independent Review of the Police and Prosecution Response to the Rehtaeh Parsons Case' (Ministry of Justice and Attorney General Office, 8 October 2015) 157, iii <https://novascotia.ca/segalreport/ParsonsIndependent-Review.pdf>.

${ }^{8}$ Kimberlé Crenshaw, 'Mapping the Margins: Intersectionality, Identity Politics, and Violence against Women of Colour' (1991) 43(6) Stanford Law Review 1241.)

${ }_{9}^{9}$ Richard G Wilkinson and Michael G Marmot (Eds.) The Solid Facts (World Health Organization, Regional Office for Europe, 2nd Ed., 2003) 7.
} 
Whilst intersectionality and social determinants of health are two separate concepts derived from different disciplines, this study attempts to bridge conceptual gaps in correspondence with the 'multiplier effect' ${ }^{10}$ of violence against Indigenous girls and women."

Through interdisciplinary lenses, the multiplier effect of violence argues that many factors, such as the colonial history of nation-building, discriminatory laws, patriarchy, and dominant Western $^{12}$ hegemony, act together to exacerbate the incidence of systematic violence. Therefore, without acknowledging and thoroughly examining these factors, any other explanation of the current state of affairs regarding systematic violence is incomplete. In Silencing the Past, Michel-Rolph Trouillot highlights the many ways uneven distribution of power between competing groups and individuals results in unequal access to the production of history. ${ }^{13}$ For Trouillot, '[h]istory is the fruit of power, but power itself is never so transparent that its analysis becomes superfluous. The ultimate mark of power may be its invisibility; the ultimate challenge, the exposition of its roots'. ${ }^{14}$ Thus, a brief overview of the colonial history, initiated by the subjugation of Indigenous Peoples in Australia and Liberia is in order.

In Australia, the historical trajectory of the colonising project, which began with the arrival in the 1700s of convicts, lends itself to violent affairs of massacre, ${ }^{15}$ land dispossession, ${ }^{16}$ denial of Aboriginal citizenship, ${ }^{17}$ forced adoption, ${ }^{18}$ disenfranchisement, ${ }^{19}$ stolen wages, ${ }^{20}$ sexual abuse, ${ }^{21}$ deaths in custody, ${ }^{22}$ unlawful state interventions, ${ }^{23}$ and outright exclusion of Indigenous

\footnotetext{
${ }^{10}$ This research uses the concept of the 'multiplier effect' to underpin the cumulative effect of several socio-political, physical, health, and economic factors acting simultaneously to exacerbate the effect of violence against Indigenous girls and women in Liberia and Australia.

${ }^{11}$ Contrary to conventions, in this dissertation, 'girls' and 'children' are put before 'women' and 'boys' and 'children' precede 'men' as a sign of prioritising younger generation over the older ones.

${ }^{2}$ In this research, the term Western European including English culture. Even though Australia is in the Southern end of the global hemisphere, it is perceived as Western because of its colonial history.

${ }^{13}$ Michel-Rolph Trouillot, Silencing the Past: Power and the Production of History (Beacon Press, 2001) xix. ${ }^{14}$ Ibid.

${ }^{15}$ John Summons, Massacre at Myall Creek (Cambridge University Press, 1993); La Trobe University, 'The Myall Creek Massacre with Richard Broome' <http://www.latrobe.edu.au/news/articles/2012/podcasts/podcasts/the-myallcreek-massacre/transcript>; Mark Tobin and Mark Colvin, Campaign for Recognition of Massacre Victims $(8$ November 2010) PM with Mark Covin <http://www.abc.net.au/pm/content/2010/s3060567.htm?source=rss>.

${ }^{16}$ Mabo v Queensland (No 2) (1992) 175 CLR 1.

${ }^{17}$ Bain Attwood, The 1967 Referendum: Race, Power and the Australian Constitution (Aboriginal Studies Press, 2nd Ed, 2007); Faith Bandler, Turning the Tide: A Personal History of the Federal Council for the Advancement of Aborigines and Torres Strait Islanders (Aboriginal Studies Press, 1989); Michael Mansell, 'Law Reform and the Road to Independence' in Proceedings of a conference held 23-25 June 1992 (Australian Institute of Criminology, 1993) 9; Jonathan Pearlman and Joel Gibson, 'When I Was Fauna: Citizen's Rallying Call' Sydney Morning Herald (Sydney, NSW), 23 May 2007 <http://www.smh.com.au/news/national/when-i-was-fauna-citizens-rallyingcall/2007/05/22/1179601412706.html>.

${ }^{18}$ Cubillo and Gunner v The Commonwealth [2001] FCA 1213.

${ }^{19}$ Kevin Gilbert, Aboriginal Sovereignty: Justice, the Law and Land (Burrambinga Books, 3rd Ed. 1993); Sue Taffe, Black and White Together FCAATSI: The Federal Council for the Advancement of Aborigines and Torres Strait Islanders, 1958-1973 (University of Queensland Press, 2005); Andrew Schaap, Gary Foley and Edwina Howell (Eds.) The Aboriginal Tent Embassy: Sovereignty, Black Power, Land Rights and the State (Routledge, 2013); Alycia Muir, Why All the Secrecy? A History of the Aboriginal Activism of Redfern (Bachelor Honours of Arts (Honours) Thesis, The University of Newcastle, 2005).

${ }^{20}$ Government of Queensland, History of Stolen Wages and Savings in Queensland - Aboriginal and Torres Strait Islander Affairs, Department of Aboriginal and Torres Strait Islander and Multicultural Affairs (29 April 2011) Aboriginal and Torres Strait Islander Affairs, Department of Aboriginal and Torres Strait Islander and Multicultural Affairs (Queensland Government) <http://www.datsima.qld.gov.au/atsis/aboriginal-torres-strait-islanderpeoples/claims-and-entitlements/history-of-stolen-wages-and-savings-in-queensland>.

${ }^{21}$ Chris Cunneen, 'Judicial Racism' in Proceedings of a conference held 23-25 June 1992 (Australian Institute of Criminology, 1993) 1.
} 
Peoples from equal protection provided in the Australian Constitution. ${ }^{24}$ Indigenous Peoples are the original custodians of land in Australia, their cultures and way of life has survived for at least 60000 years. ${ }^{25}$ Conflicts with settlers and destruction caused by introduced diseases and alcohol reduced the Aboriginal population from 300000 to 60000 in the first hundred years of the convicts' arrival. ${ }^{26}$ The purpose of transporting convicts to Australia was not only to punish and reform criminal offenders. James Edward Gillespie suggests that at the onset of English colonisation, statesmen, reformers and businessmen also sought to utilise new lands for solving troublesome social problems whilst simultaneously adding material wealth to the motherland. ${ }^{27}$ Convict transportation to Australia was meant not only to reform and punish criminal offenders but also to yield 'a profitable service to the commonwealth'. ${ }^{28}$ In solving the 'convict problem', judges imposed sentences of transportation for terms of seven years, 14 years or life, thereby 'shovelling out' English paupers and vagrants to Australia. ${ }^{2}$

With time, as colonial attitudes toughened, the expansion of settlement saw deadly clashes against the First Peoples at the frontier, which threatened to wipe out Indigenous Peoples. ${ }^{30}$ For example, during the Black War in Tasmania, the effects of white settlement nearly brought Indigenous Peoples to the verge of extinction. ${ }^{31}$ A moderate estimate puts violent deaths of Aboriginal Queenslanders at 10000 between 1824 and $1908 .{ }^{32}$ For those Aborigines who managed to survive frontier battles, their traditional ways of knowing and being either completely destroyed or intentionally suppressed. The reduction in the Aboriginal population and prolonged human rights abuses, combined with the quest for sovereignty, selfdetermination and recognition ${ }^{33}$ create an ever-present need for (customary) law reform to achieve gender justice and equality under the law, ${ }^{34}$ even as Aboriginal children became more vulnerable to laws and policies that forcibly separated them from their mothers. Although race

\footnotetext{
${ }^{22}$ Patrick L Dodson, 'Royal Commission into Aboriginal Deaths in Custody: National Report Volumes 1-4' (Government Report, Royal Commission into Aboriginal Deaths in Custody, 15 April 1991).

${ }^{23}$ Northern Territory. Board of Inquiry into the Protection of Aboriginal Children from Sexual Abuse, Rex Wild and Pat Anderson, Ampe Akelyernemane Meke Mekarle Little Children Are Sacred (Department of the Chief Minister, Office of Indigenous Policy, 2007).

${ }^{24}$ RECOGNISE, Constitutional Recognition of Indigenous Australians - RECOGNISE (2013) RECOGNISE

$<$ http://www.recognise.org.au/>; Mick Dodson, 'Constitutional Recognition of Indigenous Australians' (2012) 57

Papers on Parliament 11.

${ }^{25}$ The Uluru Peoples, 'Uluru Statement from the Heart'

<https://www.referendumcouncil.org.au/sites/default/files/2017-05/Uluru_Statement_From_The_Heart_0.PDF>.

${ }^{26}$ Australian Law Reform Commission, 'Recognition of Aboriginal Customary Laws (ALRC Report 31)'

(Government Report 31, Australian Law Reform Commission, 12 June 1986) 737, 18

<http://www.alrc.gov.au/publications/report-31>.

${ }^{27}$ James Edward Gillespie, 'The Transportation of English Convicts after 1783' (1922) 13(3) Journal of the American Institute of Criminal Law and Criminology 359, 359.

${ }^{28}$ Ibid 360.

${ }^{29}$ Ibid 361.

${ }^{30}$ Australian Law Reform Commission, 'Recognition of Aboriginal Customary Laws (ALRC Report 31)', above $\mathrm{n}$ 26, 24.

${ }^{31}$ Henry Reynolds, A History of Tasmania (Cambridge University Press, 2012) 47.

${ }^{32}$ Australian Law Reform Commission, 'Recognition of Aboriginal Customary Laws (ALRC Report 31)', above $\mathrm{n}$ 26, 18.

${ }^{3}$ Shelley Bielefeld, 'The Intervention, Stronger Futures and Racial Discrimination: Placing the Australian Government under Scrutiny' in Elisabeth Baehr and Barbara Schmidt-Haberkamp (Eds.) And there'll be NO

Dancing'. Perspectives on Policies Impacting Indigenous Australia Since 2007 (Cambridge Scholars Publishing, 2017) $145,145$.

${ }^{34}$ The Uluru Peoples, above n 25.
} 
was a significant factor of the development of law and policy in Australia, much can be learned about other aspects of colonial nation building that contribute to violence against Indigenous girls and women by observing the parallel colonial effort undertaken half a world away, in Liberia.

In Liberia, a century and a half of compounding factors instigated by the trans-Atlantic slave trade ${ }^{35}$ resulted in the establishment of a settler-colonist state following Paul Cuffe and Marcus Garvey's Back-to-Africa Movement. ${ }^{36}$ The social disparity between Indigenous Peoples in Liberia and so-called Americo-Liberians ${ }^{37}$ began with the American Colonisation Society's ${ }^{38}$ founding of the 'Colony' of Liberia in 1816 as a 'haven' ${ }^{39}$ for freeborn persons and emancipated slaves in the Americas. This population of colonist-settlers expanded to include those recaptured across the Atlantic between 1808 and 1860 during Britain and the United States' interdiction on slavery. ${ }^{40}$ According to William E. Allen, unlike Paul Cuffe and Marcus Garvey's Back-to-Africa Movement, Reverend Robert Finley of New Jersey provided the most crucial impetus for the colonisation movement. Similar to the idea of the 'convict problem' in England, Finley was convinced that the United States had a moral ${ }^{41}$ obligation to 'repair the injuries' and solve the 'negro problem' resulting from the slave trade. Noting that, '[e]verything connected with their [the slaves'] condition, including their colour, is against them', ${ }^{42}$ Finley was committed to returning the slaves to Africa as a solution to the 'negro problem' in America's Deep South. Interestingly, the partitioning of Africa during the Berlin Conference in 1884-85, when colonisers scrambled for Indigenous African lands, happened amid the Back-toAfrica Movement. Thus, as European colonisers scuffled for Indigenous African lands, Liberia remained in the hands of Black settler-colonists, supported by the philanthropic American Colonisation Society. One would imagine that such an arrangement would shield Indigenous Peoples in Liberia from exploitation, abuse and disenfranchisement since their Black settlercolonists were an oppressed minority and Africans themselves. Quite the contrary occurred, as a population once in search of refuge, security and safety instigated a system of social hierarchy that would forever relegate Indigenous Peoples in Liberia to a lower class and status, branded as

\footnotetext{
${ }^{35}$ Gerald Horne, The Deepest South: The United States, Brazil, and the African Slave Trade (New York University Press, 2007) 2.

${ }^{36}$ James Ciment, Another America: The Story of Liberia and the Former Slaves Who Ruled It (Hill and Wang, 1st Ed, 2013) xix; Henry Louis Gates Jr., 100 Amazing Facts About the Negro (Pantheon Books, 2017) 28-30.

${ }^{37}$ The term 'Americo-Liberian' is put into inverted commas to assert the author's hesitation and disproval of its pejorative meaning. Refer to the terminology section for alternative replacement of the term.

${ }^{38}$ Fox Early Lee, The American Colonisation Society 1817-1840 (The John Hopkins Press, 1919) vol 3; Library of Congress, American Colonization Society (Prints and Photographs Reading Room, Library of Congress) (22 October 2010) Records and photographs of the American Colonization Society <http://www.loc.gov/rr/print/coll/007.html〉.

${ }^{39}$ Merran Fraenkel, Tribe and Class in Monrovia (Oxford University Press, 1966) 9.

${ }^{40}$ John HT McPherson, History of Liberia (Forgotten Books, 2010).

${ }^{41}$ David Kazanjian describes Liberia's unique characteristic as a 'colony' over which no state formally exercised sovereignty, having been founded and ruled by a private philanthropic organisation, the American Colonisation Society (see, David Kazanjian, The Brink of Freedom: Improvising Life in the Nineteenth-Century Atlantic World (Duke University Press, 2016) 54.

${ }^{42}$ William E Allen, 'Historical Methodology and Writing the Liberian Past: The Case of Agriculture in the Nineteenth Century' (2005) 32 History in Africa 21, 23.
} 
'country', 'uncivilised' and 'bush'. ${ }^{43}$ Liberia declared its independence from the American Colonisation Society in 1847 , and, from that time until $1980,{ }^{44}$ this elite oligarchy of former slave settler-colonists perpetrated oppression, ${ }^{45}$ disenfranchisement, ${ }^{46}$ land expropriation, ${ }^{47}$ denial of entry of Indigenous Peoples in Liberia into the Commonwealth of Liberia, ${ }^{48}$ prohibition of property inheritance in customary marriages, ${ }^{49}$ and withholding access to education ${ }^{50}$ from Indigenous Peoples in Liberia, whilst subjecting them to labour exploitation ${ }^{51}$ and pervasive violence. ${ }^{52}$ As discussed in this dissertation, especially in chapters 2 and 7, systematic violence against Indigenous Peoples in Liberia is examined through the lenses of slavery, ${ }^{53}$ language group discrimination, ${ }^{54}$ tribalism and classism ${ }^{55}$ Christianisation of the 'country people', ${ }^{56}$ travel bans, ${ }^{57}$ land dispossession, ${ }^{58}$ exploitation, ${ }^{59}$ dehumanising treatment, ${ }^{60}$ and oppressive elite

\footnotetext{
${ }^{43}$ In Liberia, freed slave returnees to Liberia see themselves as more civilised and enlightened than Indigenous Peoples in Liberia, hence derogatorily refer to Indigenous Peoples in Liberia as 'country or 'bush' people.

${ }^{44}$ Carl Patrick Burrowes, Power and Press Freedom in Liberia, 1830-1970: The Impact of Globalization and Civil Society on Media-Government Relations (Africa World Press, 2004) 87-89. The True Whig Party of Liberia, the only political party in the country, began its rule in 1869 until 1980 except when briefly interrupted with a coup d'état in 1871.

${ }^{45}$ Anecdotally, The Onion, a satirical media house, illustrates racism in Liberia with two fountains having a description on top of each, which says, 'Blacks only'.

${ }^{46}$ Veronica Strong-Boag et al, Africa Women Suffrage and beyond: Confronting the Democratic Deficit (2013)

Women Vote <http://womensuffrage.org/?page_id=203>. Indigenous women and men in Liberia got the right to vote in 1946 .

${ }^{47}$ Yekutiel Gershoni and Makhon le-mehḳar 'al shem Heri S. Țruman, Black Colonialism: The Americo-Liberian Scramble for the Hinterland (Westview Press, 1985).

${ }^{48}$ The American Colonization Society, Liberia's 1839 Constitution (2013) TLC Africa

<http://www.tlcafrica.com/constitution-1839.htm>; Hilary Teage, Liberian Declaration of Independence (1847) One Liberia <http://onliberia.org/con_declaration.htm>. The Commonwealth of Liberia Constitution 1839 and the Declaration of Independence 1847 did not recognise Indigenous Peoples in Liberia rights.

${ }^{49}$ See, section 3.5 of the Act to Govern the Devolution of Estates and Establish Rights of Inheritance for Spouses of Both Statutory and customary marriages 2003.

${ }^{50}$ Government of Liberia and UNICEF, 'National Policy on Girls' Education' (Policy Report, Ministry of Education, $2005)$ 40, 95-97; Mary Antoinette Grimes Brown, Education and National Development in Liberia, 1800-1900 (PhD Thesis, Faculty of Graduate Studies, Cornell University, 1967) 94-97. According to Mary Antoinette Grimes Brown, schools afforded in pre- and colonial Liberia were established and intended to educate settlers' children. The number of natives involved tended to be relatively small and that funds were not available to increase the number of natives being educated at the time.

${ }^{51}$ The Analyst, Exploitation in Liberia | International Labour Rights Forum (2006) Stop Child \& Forced Labour:

Stop Firestone <http://www.laborrights.org/stop-child-labor/stop-firestone/news/10929> at 16 June 2013.

${ }^{52}$ Truth and Reconciliation Commission of Liberia, 'Truth and Reconciliation Report' (Government Report Volume

1-2, Government of Liberia, 19 December 2009) 107; Truth and Reconciliation Commission of Liberia, Press

Releases: Prince Johnson Displayed Doe's Skull...Commany Wesseh (2013) Press Release

$<\mathrm{http} / / /$ trcofliberia.org/press_releases/91>.

${ }^{53}$ Christian Abayomi Cassell, Liberia: History of the First African Republic (1970) vol. 1.Ibid; Robert T Brown,

'Simon Greenleaf and the Liberian Constitution of 1847' (1980) 9(2) Liberian Studies Journal 51; Charles Henry

Huberich, The Political and Legislative History of Liberia (The Lawbook Exchange, 2010) vol 1 and 2.

${ }^{54}$ Benjamin G. Dennis, Slaves to Racism: Racism's Impact on National Character in America to Liberia (2008).

${ }^{55}$ Fraenkel, above n 39; Stephen S Hlophe, Class, Ethnicity, and Politics in Liberia: A Class Analysis of Power Struggles in the Tubman and Tolbert Administrations, from 1944-1975 (University Press of America, 1979); Alan Huffman, Mississippi in Africa: [The Daga of the Slaves of Prospect Hill Plantation and Their Legacy in Liberia Today] (University Press of Mississippi, 2010); J Gus Liebenow, Liberia: The Evolution of Privilege (Cornell University Press, 1969).

${ }^{56}$ Amos Jones Beyan, 'The American Colonization Society and the Socio-Religious Characterization of Liberia: A Historical Survey, 1822-1900’ (1984) 10(2) Liberian Studies Journal 1.

${ }^{57}$ John McCorquodale, Aborigines and the Law: A Digest (Aboriginal Studies Press, 1987) 5. See sections 12 and 13 of the Emigration Act 1910 (No 26 of 1910).

${ }^{58}$ Claude Andrew Clegg, The Price of Liberty: African Americans and the Making of Liberia (The University of North Carolina Press, 2004); Gershoni and Makhon le-meḥ̣ar 'al shem Heri S. Țruman, above n 47.

${ }^{59}$ Eugene P Plotzki, 'The Bong Mine Venture' (1992) 17(1) Liberian Studies Journal 66.RJ Harrison Church, 'The Firestone Rubber Plantations in Liberia' (1969) 54(4) Geography 430; ibid; Alfred Lief, The Firestone Story: A

History of the Firestone Tire \& Rubber Company (Whittlesey House, 1951).
} 
regimes of former slave settler-colonists. ${ }^{61}$ Over more than a century, perpetration of these acts by the settler-colonists' single-party government culminated in a 14-year civil war from 1989 through 2003. ${ }^{62}$ Even in the attempt to balance the power dynamic between settler-colonists and Indigenous Peoples in Liberia, the war itself brought a new wave of intense and systematic violence against girls and women.

Systematic violence against Indigenous Peoples in Australia and post-war Liberia is gendered and racialised, with Indigenous girls and women disproportionately represented amongst survivors of such abuse. Although Indigenous girls and women are more vulnerable to systematic violence than non-Indigenous girls and women, often, their voices are silenced, their stories are not believed, or their desires to participate in the gender-agenda to effect local change are not supported. Whether an Indigenous woman's voice will be heard depends on an intersection of her race, class, social status, language group, and political clout, inter alia. Therefore, it is important to recognise the disproportional representation of Indigenous girls and women in the gender-agenda. Building its performance on transnational feminist ${ }^{63}$ essentialism, ${ }^{64}$ womanism, ${ }^{65}$ motherism, ${ }^{66}$ and indigeneity, ${ }^{67}$ the feminist gender-agenda has made significant improvements to the lives of women. On the one hand, accomplishments claimed by women's movements and social justice activists are described resulting from mere chance rather than from a calculated effort. On the other hand, inherent convergence of race, education, or geographical location convolutes the dynamics of gender equality with inconsistent outcomes. An assessment of the gender-agenda through the lens of the white feminist movement in Australia indicates a significant level of favouritism and preference for racial superiority. In

\footnotetext{
${ }^{60}$ Claire Scobie, 'The Long Road Home: Aborigines Reclaim Their Ancestors' Remains from British Museums' The Guardian (Sydney, NSW), 27 June 2009 <http://www.theguardian.com/world/2009/jun/28/aborigines-reclaimancestors-remains>; Lyndon Ormond-Parker, 'Aboriginal Remains Return Home' (2003) 5(24) Indigenous Law Bulletin 4; David Langsam, 'Quest for the Missing Dead' The Guardian (Sydney, NSW), 24 February 1990 <http://dingonet.com/questfor.htm>; Rachel Perkins, The First Australians: Episodes 1-7 (Blackfella Films, 2008). On 24 February 1990, Robert Langsam of the Guardian reported that, ' $[\mathrm{t}]$ he remains of thousands of Australian Aborigines are scattered throughout Britain's public and private museums... In 1803, knighted and famous for his work, [Joseph] Banks received a gift from the New South Wales Governor, Philip Gidley King ... the preserved head of the Aboriginal Warrior Pemulwoy'. Pursuant to Article 12 (1) and (2) of the UN Declaration on the Rights of Indigenous Peoples, Aboriginal and Torres Strait Islander Peoples remains around the world are gradually being repatriated to Australia (see, <http://ncis.anu.edu.au/research/heritage_history_repatriation.php>).

${ }^{61}$ Amos Sawyer, The Emergence of Autocracy in Liberia: Tragedy and Challenge (Institute for Contemporary Studies, 1992).

${ }^{62}$ Stephen Ellis, The Mask of Anarchy: The Destruction of Liberia and the Religious Dimension of an African Civil War. (New York University Press, 2007); Eckhard Hinzen and Robert Kappel, Dependence, Underdevelopment, and Persistent Conflict: On the Political Economy of Liberia (Übersee-Museum, 1980) vol 11; George Klay Kieh, Liberia's State Failure, Collapse and Reconstitution (Africana Homestead Legacy Publishers, 2012).

${ }^{63}$ Chandra Talpade Mohanty, Feminism Without Borders: Decolonizing Theory, Practicing Solidarity (Duke University Press, 2003) 2; Sylvanna M Falcón, 'Transnational Feminism and Contextualized Intersectionality at the 2001 World Conference Against Racism' (2012) 24(4) Journal of Women's History 99, 100.

${ }^{64}$ Susan D Carle (ed), Lawyers' Ethics and the Pursuit of Social Justice: A Critical Reader (New York University Press, 2005) $226<$ https://nyupress.org/books/9780814716403/>.

${ }^{65}$ Patricia Hill Collins, 'What's in a Name? Womanism, Black Feminism, and Beyond' (1996) 26(1) The Black Scholar: Journal of Black Studies and Research 9.

${ }^{66}$ Catherine Obianuju Acholonu, Motherism: The Afrocentric Alternative to Feminism (Afa Publications, 1995).

${ }^{67}$ Kathleen Birrell, Indigeneity: Before and Beyond the Law (Routledge, 2016) 9.
} 
spite of their struggles, white women were given more opportunity to push the gender-agenda forward whilst Indigenous women were simultaneously dehumanised and dismissed ${ }^{68}$

In Australia, early nineteenth century First Wave ${ }^{69}$ western feminists transmuted women's identity and societal role. At the time, women's right to vote was a crucial indicator of social justice and equality. During the Inaugural meeting of the Dawn Club in July 1889, Louisa Lawson, a notable suffragist who started the first all-women newspaper (The Dawn), conveyed the significance of women's right to vote: 'A woman's opinions are useless to her, she may suffer unjustly, she may be wronged, but she has no power to weightily petition against man's laws, no representatives to urge her views, her only method to produce release, redress, or change, is to ceaselessly agitate'. ${ }^{70}$ Whilst Lawson's observation is considered true for all women, including Indigenous women in Australia, reality suggested otherwise. Although New Zealand was the first country to grant women the right to vote in 1893, Australia was the first country $^{71}$ to accord white women ${ }^{72}$ both the right to vote in federal elections and the right to be elected to the national parliament in 1902. ${ }^{73}$ Notably, Section 41 of the Commonwealth Constitution ${ }^{74}$ provided for the colony of South Australia to grant suffrage to Aboriginal women as early as 1894. ${ }^{75}$ However, despite this achievement for white Australian women, and Indigenous Peoples in one jurisdiction, six decades elapsed before Indigenous Peoples were granted the right to vote in federal elections in 1962. The debate over whether Indigenous or white women should be accorded the same right to vote raises the issue of diversion whereby feminism, for all its divergence and convergence, ${ }^{76}$ is still mired in traditional norms that perpetuate patriarchal values. ${ }^{77}$ That is, asserts Patricia Smith, feminists get caught in a double bind as outsiders seeking reform whilst criticising the very procedures that they must use to achieve the desired change. ${ }^{78}$ Here, is the situation of Lawson critiquing a patriarchal system that endorses and allows men to flourish as political beings, and at the same time blocking the opportunity for Indigenous women in Australia to vote because they are not white. In another example, unlike for white Australian women, discriminatory law and policy also extended to the

\footnotetext{
${ }^{68}$ Uncommon Ground: White Women in Aboriginal History (Aboriginal Studies Press for the Australian Institute of Aboriginal and Torres Strait Islander Studies, 2005) xxiv.

${ }^{69}$ Rebecca West, Black Lamb and Grey Falcon (Penguin Books, 2014) <http://rbdigital.oneclickdigital.com>; Mary Wollstonecraft, A Vindication of the Rights of Woman: With Structures on Political and Moral Subjects (J Johnson, 1792) 〈https://scholarsbank.uoregon.edu/xmlui/bitstream/handle/1794/785/vindication.pdf>.

${ }^{70}$ Australian Broadcasting Corporation, Women and Democracy (1998) Women and Votes <http://www.abc.net.au/ola/citizen/women/women-home-vote.htm>.

${ }^{71}$ Douglas A. Brownridge, Violence Against Women: Vulnerable Populations (2009) 4.

${ }^{72}$ Australian women who were British subjects and 21 years and older. See Australia Electoral History available at <http://www.aec.gov.au/Elections/australian_electoral_history/wright.htm>.

${ }^{73}$ Marion Simms, 'Women in Parliament' in Brian Galligan \& Winsome Roberts (eds) Oxford Companion to Australian Politics (2007) 686, 639-43.

${ }^{74}$ Australian Electoral Commission, History of the Indigenous Vote (Australian Electoral Commission, 2007) 5.

${ }^{5}$ Australian Government, above n 71.

${ }^{76}$ Drucilla Cornell, 'The Philosophy of the Limit: Systems Theory and Feminist Legal Reform' in Drucilla Cornell, Michel Rosenfeld and David Gray Carlson (eds), Deconstruction and the Possibility of Justice (Taylor and Francis, 2016) 68.

${ }^{77}$ Patricia Smith, 'Four Themes in Feminist Legal Theory: Difference, Dominance, Domesticity, and Denial' in The

Blackwell Guide to the Philosophy of Law and Legal Theory (Blackwell Pub, 2005) 90.

${ }^{78}$ Ibid 91.
} 
children of Aboriginal women as the Australian state instituted a program that separated 'mixed blood' children from their mothers, to be raised by white Australians.

During the Aboriginal Welfare Conference in Canberra in 1937, the States and Commonwealth of Australia agreed that the objective of Aboriginal affairs should be an 'absorption of natives not of full blood'. ${ }^{79}$ The States and the Commonwealth were concerned with protecting the future of most 'mixed blood' Aborigines in settled areas. The racist and patriarchal sentiment underlying this policy of 'absorption' is clear in former Prime Minister John Curtin's (1941-45) assertion that, '[t]his country shall remain forever the home of the descendants of those people who came here in peace in order to establish in the South Seas as an outpost of the British race'. ${ }^{80}$ The primacy of Curtin's white Australia policy statement not only embellishes an arrogant doctrine of terra nullius (a land without owners) ${ }^{81}$ but it also silences the truth about Australian history by displaying an institutional denial of Aboriginal value and agency from the highest levels of the government. Furthermore, Curtin's expression exemplifies the blatant distortion of written history (rather than 'herstory' ${ }^{82}$ - i.e., history viewed from a female or feminist perspective) as a structural tool of discrimination, subjugation, and systematic violence against Indigenous Peoples in Australia. By 1961, 'assimilation' as a widely-held goal for all Aboriginal Peoples was adopted into policy by the Commonwealth and all States at the Native Welfare Conference of Federal and State Minister. ${ }^{83}$ The white Australian policy is only one example of discriminatory law and policy that precipitated systematic violence against Aboriginal girls and women. Since Australia's founding, white Australians' refusal to acknowledge the existence of the First Australians, maintenance of a white Australia policy, and infantilising Indigenous Peoples in Australia resulted in a history of massacres, ${ }^{84}$ ethnic cleansing, ${ }^{85}$ forced removal of children, ${ }^{86}$ the imposition of foreign laws and sustained social and political exclusion. ${ }^{87}$ Similarly, the cultural biases of an elitist-colonist class led to the political and legal disenfranchisement of Indigenous Peoples in Liberia.

\footnotetext{
${ }^{79}$ Australian Law Reform Commission, 'Recognition of Aboriginal Customary Laws (ALRC Report 31)', above $\mathrm{n}$ 26, 19.

${ }^{80}$ Commonwealth of Australia, Australian Immigration Fact Sheet 8. Abolition of the 'White Australia' Policy (15 April 2013) Fact Sheet 8 - Abolition of the 'White Australia' Policy $<$ http://www.immi.gov.au/media/factsheets/08abolition.htm>.

${ }^{81}$ NSW Department of Education, Racism. No Way.: Fact Sheets - Terra Nullius (2010) Teaching Resources

<http://www.racismnoway.com.au/teaching-resources/factsheets/10.html>.

${ }^{82}$ Hazel V Carby and Heidi Safia Mirza, 'White Woman Listen! Black Feminism and the Boundaries of Sisterhood' in Black British Feminism: A Reader (Routledge, 1997) 45, 44.

${ }^{83}$ Australian Law Reform Commission, 'Recognition of Aboriginal Customary Laws (ALRC Report 31)', above $\mathrm{n}$ 26, 19.

${ }^{84}$ La Trobe University, 'The Myall Creek Massacre with Richard Broome', above n 15.

${ }^{85}$ Russell McGregor, "“Breed out the Colour” or the Importance of Being White' (2002) 33(120) Australian Historical Studies 286.

${ }^{86}$ Australian Broadcasting Corporation, The Apology to the Stolen Generations of Australia (ABC, 2008) <http://australia.gov.au/about-australia/australian-story/sorry-day-stolen-generations>.

${ }^{87}$ Alisoun Neville, 'Cubillo v Commonwealth: Classifying Text and the Violence of Exclusion' (2005) 5 Macquarie Law Journal 31. Also see, Cubillo v Commonwealth (200) 174 ALR 97.
} 
Regarding Liberia's experience, in addition to applying the fallacy of terra nullius, ${ }^{88}$ two primary perspectives informed the settler-colonists' development of early Liberia. One was the idea of creating a 'Little America' in $19^{\text {th }}$ century West Africa. The other was an attempt to forge an 'African nationality' by incorporating ideas from both Indigenous African culture and Western culture. Eventually, the 'Little America' idea prevailed, though it had regularly faced challenges with a certain level of regularity since the $1850 \mathrm{~s} .{ }^{89}$ Whilst disenfranchising Native Liberians by generating antagonistic ethnic and class distinctions, ${ }^{90}$ former slaves basked in pride over the colonisation of Liberia..$^{91}$ As in the women's suffrage movement in Australia, the sentiment amongst the empowered class was one of support for equality, rights, and freedom. Washington Watts McDonogh, a Former Slave Returnee to Liberia, writes back to his previous master in the United States from Liberia on 7 October 1847 expressing satisfaction with his new found freedom: 'I'll never consent to leave this country for all the pleasures of America combined together to live, for this is the only place where a coloured person can enjoy his liberty, for there exists no prejudice of colour in this country, but every man is free and equal'. ${ }^{92}$ However, from its founding, it was clear that the sentiment 'every man is free and equal' did not apply to Indigenous Peoples in Liberia. The American flag was first raised on arrival of the settler-colonists to Providence Island in 1822. At the time, Elijah Johnson, a Black settlercolonist and agent of the American Colonisation Society, declared: '[f]or two long years I have sought a home; here I have found one, here I remain'. ${ }^{93}$ Later on, when 'threatened by attacks from surrounding savage tribes ${ }^{{ }^{94}}$ (e.g., the Grebo Attacks on 8 September $1876^{95}$ and the GolaBandi Hut Tax Resistance of $1918^{\circ}$ ), Johnson refused assistance from a British marine force, telling the commander, '[w]e want no flagstaff put up here that will cost more to get it down than it will to whip the natives'. ${ }^{97}$ Johnson's statement highlights the duality of projecting independence from white colonial violence, whilst simultaneously projecting violence toward fellow Native Africans. As in Australia, the disenfranchisement of Indigenous Peoples led to a gap between the rights afforded women in the settler-colonist and Indigenous populations.

\footnotetext{
${ }^{88}$ Huberich, above n 53, 254; Niels Nagelhus Schia, 'Reforms, Customs and Resilience: Justice for Sexual and Gender-Based Violence in Liberia' in Anastasia Powell, Nicola Henry and Asher Flynn (eds), Rape Justice: Beyond the Criminal Law (Palgrave Macmillan, 2015) 143, 12 and 16-17. African American settler-colonists applied the doctrine of Terra Nullius to the formation of Liberia in the sense that, though lands were purchased (however unfairly traded), the parts of Liberia settler-colonists were living on have not been subjected to the sovereignty of any state, or over which any prior sovereignty has expressly or implicitly relinquished sovereignty under international law.

${ }^{89}$ D Elwood Dunn, 'Liberia and Independent Africa, 1940s to 2012: A Brief Political Profile' 1, 4-6

$<$ https://books.google.com/books?id=seTnAgAAQBAJ\&dq=building+little+america+in+liberia\&source=gbs_navlin ks_s>.

${ }^{90}$ David Kazanjian, The Brink of Freedom: Improvising Life in the Nineteenth-Century Atlantic World (Duke

University Press, 2016) 54.

${ }^{91}$ Ibid 3.

${ }^{92}$ Ibid.

${ }^{93}$ Colin M Waugh, Charles Taylor and Liberia: Ambition and Atrocity in Africa's Lone Star State (Zed Books, 2011) 17.

${ }^{94}$ American Colonisation Society, 'A Visit to Monrovia' (1876) LII(1) The African Repository 13, 16.

${ }^{95}$ American Colonisation Society, 'The Grebo Attacks' (1976) LII(1) The African Repository 11, 12.

${ }^{96}$ Monday B Abasiattai, African Resistance in Liberia: The Vai and Gola-Bandi (Liberia Working Group, 1988) 21.

${ }^{97}$ American Colonisation Society, above n 94, 16.
} 
In Liberia, women's suffrage is also an indicator of social justice and equality. Upon the declaration of independence of Liberia in 1847, Former Slave Returnee women seized the right to vote by virtue of being wives of Former Slave Returnee males. However, it took almost 100 years to accord similar political rights to Indigenous women in Liberia. Additionally, whilst Former Slave Returnee women persistently fought for equality in the workplace, access to education and other social and welfare rights, similar concerns of Native Liberians were dismissed because they were perceived by the dominant culture as 'uncouth', 'country' and 'primitive'. Unfortunately, women's suffrage was only one aspect of political life from which Indigenous Peoples in Liberia were excluded.

Underrepresentation of Indigenous Peoples in Liberia in legal, political, and economic life culminated in a 14-year civil war. Liberia is recognised for being Africa's oldest republic and the second republic (after Haiti) founded by displaced Africans. ${ }^{98}$ Joseph Saye Guannu argues that between 1822 and 1839 Liberia, mainly Montserrado County, was a colony of the American Colonisation Society until African settler-colonists from the United States broke ties by signing Liberia's Declaration of Independence on 26 July 1847..$^{99}$ The Liberian Declaration of Independence, ${ }^{100}$ copied from that of the United States, was followed by a constitution drafted, in part, by Simon Greenleaf, a Harvard Law Professor ${ }^{101}$ and an African American settlercolonists to Liberia. After 133 years of rule by the Liberian True Whig Party, ${ }^{102}$ the first Indigenous leader, Samuel Kanyon Doe, seized power through a bloody coup d'état on 12 April 1980. ${ }^{103}$ The coup left former president William R. Tolbert dead, with 13 cabinet ministers, executed extra-judicially for 'high treason'. Many others were arrested, detained and tortured. ${ }^{104}$ This was the 'evolution of authoritarianism and deceptive inclusion' in Liberia, writes Jeremy Levitt. ${ }^{105}$ Nearly 10 years after Doe came to power, Liberia's violent civil war began on 24 December 1989. Fourteen years of Liberia's civil war resulted in some 250000 deaths with

\footnotetext{
${ }^{98}$ Huberich, above n 53, v.

${ }^{99}$ See One Liberia, available at <http://onliberia.org/con_declaration.htm $>$.

${ }^{100}$ Joseph Saye Guannu, Liberian History Before 1857: A Reference for Elementary Pupils (Exposition Press, 1st ed, 1977) 27.

${ }^{101}$ Amos Sawyer, Beyond Plunder: Toward Democratic Governance in Liberia (L. Rienner Publishers, Inc, 2005) $17-21$.

${ }^{102}$ Liebenow, above n 55, 112.

${ }^{103}$ D Elwood Dunn, Liberia: A National Polity in Transition (Scarecrow Press, 1988) 86-98; Conan Le Cilaire, Liberia Execution $(1980)<\mathrm{https}$ //www.youtube.com/watch?v=DnDGgvrD2bM>; Leon Dash, 'Liberian Soldiers Taunt, Shoot 13 Former Leaders' The Washington Post (Monrovia, Liberia), 23 April 1980

http://www.washingtonpost.com/wp. After 133 years of a one-party state, former President William R. Tolbert was assassinated in a coup d'état that eventually sizzled into a Kangaroo Military Court treason trials against and subsequent execution of thirteen cabinet ministers of African Emigrant heritage. Those executed by firing squad were, Frank E Tolbert Sr., President of Pro-Temp of the Liberian Senate and brother of President Tolbert; C Cecil Dennis Jr., Minister of State and Foreign Affairs; Cyril A Bright, Minister of Planning and Economic Affairs; James A A Pierre, Chief Justice of Liberia; Richard A Henries Sr., Speaker of the House of Representatives; Frank Stewart, Direct of the Budget; John W F Sherman, Minister of Commerce; Clarence Parker III; Chairman of the National Investment Council; James T Phillips Jr.; Joseph J F Chesson Sr.; E Reginald Townsend; and D Franklin Neal Sr. ${ }^{104}$ D Elwood Dunn and Svend E Holsoe, Historical Dictionary of Liberia (Scarecrow Press, 1985) 50-51.

${ }^{105}$ Jeremy I Levitt, The Evolution of Deadly Conflict in Liberia: From 'Paternaltarianism' to State Collapse (Carolina Academic Press, 2005) 181.
} 
approximately 500000 persons being internally and internationally displaced. ${ }^{106}$ Mostly fought by males, the civil war demolished infrastructure and perpetuated a societal collapse that gave way to injustice and human rights abuses, which ultimately saw girls and women used as the spoils of war and weapons of war. ${ }^{107}$ A study conducted by the World Health Organization in 2005 with 1628 women in six of Liberia's 15 counties revealed that 90.8 percent experienced multiple acts of sexual violence, including having objects, such as corn sticks, cassava, and flashlights, forced into their vagina or anus. These acts of violence directly resulted in 16.8 percent pregnancy and 15.6 percent vesicovaginal fistula. ${ }^{108}$ In addition, the rate of forcible abduction was relatively high at 48.5 percent. ${ }^{109}$ Given Australia and Liberia's histories of political and legal disenfranchisement of Indigenous Peoples, the violence that such disenfranchisement perpetrates or permits against Indigenous women and girls, and the history of abuse without justice that accompanies it, it is necessary to ask whether Indigenous girls and women could be considered equal before the law.

\subsubsection{Statement of the Problem}

Equality before the law is a basic human right that should be protected by the rule of law in order to guarantee equal treatment in all aspects of governance, including rights to fair trial, impartial jury and unbiased judges. The United Nations and dominant Western societies promote the rule of law as a fundamental principle of governance. A cadre of international instruments provides for the rule of law. For example, Articles 6, 7 and 8 of the Universal Declaration of Human Rights 1948; Article 5 of the International Convention on the Elimination of all Forms of Racial Discrimination 1965; Article 26 of the International Covenant on Civil and Political Rights, 1966; Article 3 of the International Covenant on Economic, Social and Cultural Rights 1966; and Article 3(1) of the African Charter on Human and Peoples' Rights 2005 all provide for equal treatment of all persons before the law. Nationally, Article 11(c) of the Liberian Constitution 1986 states that '[a]11 persons are equal before the law and are therefore entitled to the equal protection of the law'. Even though the Australian Constitution 1901 contains no explicit provision on equality for all persons before the law, Article 10 of the Australian Racial Discrimination Act 1975 (Cth.) guarantees 'rights to equality before the law'. Ultimately, the rule of law is enshrined in these international and

\footnotetext{
106 'The Liberian Civil War: Child Soldiers, Rape, and Higher Education' in International Association of University Presidents (African Methodist Episcopal Zion University, 2014) 1, 1-2; Robert M Press, "'Guided by the Hand of God”: Liberian Women Peacemakers and Civil War' (2010) 8(1) The Review of Faith \& International Affairs 23, 1. ${ }^{107}$ Spoils of war (vis-à-vis rape as a weapon of war) is not a new concept. In Deuteronomy 20:14 God told the Israelites to enjoy and take for themselves Canaanite women, children, animals and all that is in the city as their spoil. ${ }^{108}$ Government of Liberia, 'National Plan of Action for the Prevention and Management of Gender Based Violence in Liberia (GBV-POA)' (Government Policy, Ministry of Children, Gender and Social Development, November 2006) $43,9$.

${ }^{109}$ Government of Liberia, 'National Plan of Action for the Prevention and Management of Gender Based Violence in Liberia' 9.
} 
national instruments to monitor changes in the performance of the justice system, ${ }^{110}$ and as a means to uphold individual dignity and maintain civil, political, and social rights..11

Some international legal instruments have been established to guarantee rights for women and Indigenous Peoples. In 1975 in Mexico City, the first United Nations (UN) World Conference on Women established the 'decade of women', an event that marked the birth of International Women's Day. Five years later, in Copenhagen, Denmark, 64 States signed the Convention on the Elimination of All Forms of Discrimination Against Women (CEDAW) 1979. To date, 187 countries have ratified CEDAW. ${ }^{112}$ With respect to CEDAW, the gender-agenda is progressing at a moderate pace, considering the recent establishment of UN Women in 2010, a global institution governed by CEDAW. Addressing justice for survivors of sexual violence in war by categorising rape as a crime against humanity, the International Criminal Court of the Rome Statute was established in 1998. ${ }^{113}$ A little over a decade ago, the United Nations General Assembly adopted the Declaration on the Rights of Indigenous Peoples (UNDRIP) 2007 with a majority vote of 144 states. Australia was one of four countries (the others being Canada, New Zealand and the United States) that voted against the UNDRIP. However, two years later, Australia expressed support for UNDRIP. Interestingly, the UNDRIP mentions women only three times, leaving Rauna Kuokkanen, Damien Short and Corinne Lennox to question whether the landmark instrument addresses the rights of Indigenous women. ${ }^{114}$ James Anaya believes that, as the most prominent manifestation of international concerns for Indigenous Peoples, the UNDRIP represents widespread recognition of the ongoing effects of historical forces of oppression linked to colonialism and invasive settlement. ${ }^{115}$ Despite these modest advances (inter)nationally, there are inconsistencies with the application of uniform legal standards in restoring fairness and justice to Indigenous girl and women survivors of systematic gender violence. As noted above, the principle of the rule of law, entrenched in the constitution of the State, is the fundamental requirement for legal justice. By reducing, if not eliminating, arbitrariness and abuse of discretionary power, whether exercised by the judiciary, executive or legislature, the rule of law accords due process of law as a basis for securing substantive rights whereby like cases are treated alike (vis-à-vis the binding precedents doctrine). ${ }^{116}$ Thus, given the theoretical underpinnings of the rule of law, this study asks: At what level of certainty can

\footnotetext{
${ }^{110}$ Department of Peacekeeping Operations and Officer of the High Commissioner for Human Rights, 'The United Nations Rule of Law Indicators: Implementation Guide and Project Tools' (UN Report, United Nations Publications, 2011) 137, v <http://www.un.org/en/events/peacekeepersday/2011/publications/un_rule_of_law_indicators.pdf〉.

${ }^{111}$ Joseph Raz, The Authority of Law: Essays on Law and Morality (Oxford University Press, 1979) 210-211.

${ }^{112}$ Australia ratified CEDAW on 28 July 1983 and Liberia on17 July 1984 (see,

<http://treaties.un.org/Pages/ViewDetails.aspx?src=TREATY\&mtdsg_no=IV-8\&chapter=4\&lang=en>.

${ }^{113}$ As at 12 April 2012, 121 countries had ratified the Rome Statute including Liberia (22 September 2004) and Australia (1 July 2002). See <http://www.iccnow.org/documents/RATIFICATIONSbyRegion_2Arpil2012_eng.pdf>.

${ }^{114}$ Corinne Lennox and Damien Short, 'Indigeneity' in Damien Short and Corinne Lennox (Eds.), Handbook of Indigenous People's Rights (Routledge: Taylor \& Francis Group, 2015) 1, Abstract.

${ }^{115}$ S James Anaya, International Human Rights and Indigenous Peoples (Wolters Kluwer Law \& Business, 1 st Ed. 2009) 1-2.

${ }^{116}$ Tom H Bingham, The Rule of Law (Penguin, 2011) 37-109.
} 
all citizens be treated equally before the law, irrespective of whether the law arises from AngloAmerican-Liberian, Anglo-Australian or Indigenous Customary Law?

Australian and Liberian law and policy sometimes ignore, contradict, or supersede the rule of law from the perspective of Indigenous women and girls. For example, the Liberian Penal Law did not mention sexual violence against women until 2011. In Australia, the Commonwealth Government of Australia suspended the Racial Discrimination Act 1975 (Cth.) in order to deny protection of Aboriginal Peoples affected by the Northern Territory National Emergency Response. ${ }^{117}$ In light of this duality, this research explores the efficacy of the rule of law for Indigenous girls and women. For the purpose of this research, the rule of law comprises four aspects. That is, to achieve the rule of law: 1) all should be treated fairly and equally before the law; 2) all (especially the state) should be accountable to and be bound by the law and the courts; 3) everyone should benefit from public laws; and 4) in constitutional democracies, government should be based on the political doctrine of the separation of powers. By reducing, if not eliminating, arbitrariness and abuse of discretionary power, whether exercised by the judiciary, executive or legislature, the rule of law accords due process as a basis for securing substantive rights whereby like cases are treated alike (vis-à-vis the binding precedents doctrine). ${ }^{118}$ This research critically assesses how the enactment of discriminatory laws not only impacts the implementation of the four major aspects of the rule of law, listed above, to inflict systematic violence against Indigenous Peoples in Liberia and Australia but also compromises the efficacy of the rule of law. Grounded in empirical data, this research is based on content analysis, textual evidence and empirical examination of the rule of law, including an assessment of procedural fairness in the legal system, access to courts, legal representation, reliability of evidence, constitution of an impartial and independent judiciary, jury representation, sentencing and judicial review. ${ }^{119}$ The desired outcome of the research is to determine whether justice, as perceived by research participants, coupled with analyses of case law, historical documents, government reports, newsprint and secondary data, can be restored to Indigenous girls and women who have experienced systematic gender violence in Australia and Liberia.

\footnotetext{
${ }^{117}$ The Australian Human Rights Commissions reports on the suspension and reinstatement of the Racial Discrimination Act 1975 (Cth): in June 2007, the Northern Territory Board of Inquiry into the Protection of Aboriginal Children from Sexual Abuse provided its report, Little Children are Sacred, to the Chief Minister of the Northern Territory. On 21 June 2007, in response to the Board of Inquiry's findings, the Howard Government announced the 'national emergency response to protect Aboriginal children in the Northern Territory' from sexual abuse and family violence. Also, on 21 June 2007 the Government enacted the Northern Territory National Emergency Response legislation. The Northern Territory National Emergency Response (NTER) legislation applied to a wide range of 'prescribed areas' in which Aboriginal people are the sole or predominant inhabitants, including Aboriginal land, declared town camps and other declared areas (see:

$<$ https://www.humanrights.gov.au/publications/suspension-and-reinstatement-rda-and-special-measures-nter-1 >).

${ }^{118}$ Bingham, above n 116, 37-107.

${ }^{119}$ Hilaire Barnett, Constitutional and Administrative Law (Routledge, 9th Ed - 2011) vol 1.
} 


\subsubsection{Hypothesis}

The principle of the rule of law is applied fairly and adequately when restoring justice to Indigenous girls and women survivors of systematic gender violence in Australia and post-war Liberia.

\subsubsection{Research Question}

Is the rule of law, an accepted truth that all are equal before the law, an essential axiom for restoring justice to Indigenous girl and women survivors of systematic gender violence in Australia and Liberia?

\subsubsection{Aims and Objectives}

The study investigates the application of the rule of law in restoring justice to Indigenous girl and women survivors of systematic gender violence in Australia and post-war Liberia by:

1) identifying and assessing the types, severity, prevalence and incidence rates of systematic gender violence in Australia and Liberia, drawing on case law, secondary data and textual analysis of historical documents, reports, newsprint and other public documents;

2) assessing the extent to which social service providers working in the area of violence against women perceive the law to be just (or unjust) as applied to Indigenous girls and women in Australia and post-war Liberia, using a survey instrument; and

3) examining the extent to which Indigenous women advocates working in the area of violence against women perceive the law to be just (or unjust) as applied to Indigenous girls and women in Australia and Liberia, using a semi-structured interview.

\subsubsection{Terminology and Operational Definitions}

Violence, like gender, is not a simple concept, but varies widely in its severity, ranging from minor forms ${ }^{120}$ to aggressive acts of physical brutality including battery and rape, inflicted domestically or by a stranger. ${ }^{121}$ Although it is a representative category of injury, pain, and death, Sally Engle Merry argues that violence 'is very much shaped by cultural implications'. ${ }^{22}$ Merry adds that the social and cultural dimensions of violence are what give violence power and meaning. Violence is not senseless but almost always a manifestation of conscious human behaviour. ${ }^{123}$ The socio-cultural dimensions of violence are varied. Some are subtle and nuanced, whilst others are overt. Language, in the form of words, phrases, idioms, and metaphors used to describe Indigenous Peoples in Liberia and Australia, is a social construct that may embody a

\footnotetext{
${ }^{120}$ Douglas A Brownridge, Violence Against Women: Vulnerable Populations (Routledge, 2009) 4.

${ }^{121}$ Nahid Toubia, 'Women's Reproductive and Sexual Rights' in Gender Violence and Women's Human Rights in Africa (Centre for Women's Global Leadership, 1994) 42, 5.

${ }^{122}$ Sally Engle Merry, Gender Violence: A Cultural Perspective (John Wiley and Son Ltd., 2009) 5.

${ }^{123}$ Ibid 
form of cultural/structural violence. Perpetrators of structural and cultural violence do not hesitate to exercise mastery of semantics and morphology to exclude or denigrate Indigenous Peoples and women. This function of language prompts the application of extreme care when operationalising key terms in this research, lest the study fall prey, inadvertently, to perpetuating the very violence it is attempting to prevent. Following is a brief etymology, description and explanation of major terms used in the dissertation.

Aboriginal, Indigenous or Native: The word 'Indigenous', as a global expression of identity and concomitant struggle of First Peoples, connotes not merely 'nativeness' to land or region but also a political, legal, and cultural identity with international valency. ${ }^{124}$ The capitalised plural proper noun 'Indigenous Peoples' signifies a 'collective, rather than purely individual, dimension to [Indigenous] livelihoods, and an extension of self-determination to those who may not yet, or indeed ever, be defined as nations' ${ }^{125}$ Kathleen Birrell reasons that irrespective of the heterogeneity of Indigenous Peoples, which persist despite colonization, indigeneity itself has become a varied cohesive marker of unity, distinctively defined by cultural resistance to colonial imposition and a spiritual and ancestral agitation against neo-colonial expansion. Through international recognition, marginalised groups labelled as 'local', 'native', 'tribal' or 'peasant' are now empowered to identify as Indigenous Peoples. Nevertheless, the term is laden with the delusion that only people conforming to a white colonial image of an Aboriginal person, as in those sitting in the desert with a spear, qualify as authentic Indigenous persons. ${ }^{127}$ Deconstructing the politics of indigeneity, Manuhuia Barcham et al argue that prioritisation of identity over difference leads to the creation of an existential dichotomy of being and non-being that has effectively excluded recognition of the dynamic process of becoming for Indigenous Peoples. ${ }^{122}$

Challenged interpretations that reduce indigeneity to issues of authenticity, are ever present amongst Indigenous Peoples in Africa, and certainly in Liberia. Cheryl Suzack explains that problems of definition and representation affect Indigenous communities, especially Indigenous women in Africa, more generally through law's pervasive ideological devaluation and confinement of indigeneity. ${ }^{129}$ For example, some conceptions of indigeneity recognised and accepted as Indigenous Peoples only within the restricted sense of First Peoples in Australia, New Zealand, Canada and the United States. A growing consensus considers some communities of hunter-gatherers and pastoralists as Indigenous Peoples in Africa. In an attempt to identify Indigenous groups, a list compiled by the African Commission on Human and Peoples' Rights

\footnotetext{
${ }^{124}$ Birrell, above n 67, 7 .

${ }^{125}$ Ibid.

${ }^{126}$ Ibid 8.

${ }^{127}$ Ibid $9-10$.

${ }^{128}$ Manuhuia Barcham, '(De)Constructing the Politics of Indigeneity' in Duncan Ivison, Paul Patton and Will Sanders (eds), Political Theory and the Rights of Indigenous Peoples (Cambridge University Press, 2002) 137, 138.

${ }^{129}$ Cheryl Suzack, 'Emotion before the Law' in Cheryl Suzack et al (eds), Indigenous Feminism: Politics, Activism,

Culture (University of British Columbia Press, 2010) 126, 131.
} 
(ACHPR) and the International Working Group on Indigenous Affairs (IWGIA) names 59 different Indigenous groups across 26 African countries as Indigenous Peoples. ${ }^{130}$ Finding ways to define indigeneity outside of a settler-colonist perspective is an active area of development.

Felix Ndahinda, Korir Sing'Oei and Ridwan Laher contend that the case of recognition and protection of Indigenous Peoples in Africa builds on the idea that such communities share common experiences of subjugation, marginalisation, dispossession, exclusion or discrimination with other Indigenous Peoples worldwide. ${ }^{131}$ A case in point is the 40-year struggle of the Endorois community that resulted in a landmark ruling on Indigenous Land Rights by the African Commission on Human and Peoples' Rights. ${ }^{132}$ On 2 February 2010, the Endorois community case set a precedent for identifying Indigenous Africans as the original landowners. Challenging the myth that special rights of Indigenous Peoples are discriminatory, applicants of the Endorois community argued that 'Indigenous Peoples' in the African context did not necessarily mean 'First Inhabitants' as it does in the Americas and Australia. ${ }^{133}$ A key instrument for advocacy by the African Commission on Human and Peoples' Rights is the African Commission's Working Group of Experts on the Situation of Indigenous Populations/Communities in Africa, which is noted for recognising the existence of particularly marginalised groups in Africa. This instrument helps support Indigenous Peoples, such as the Endorois community, whose rights are protected by the African Charter on Human and Peoples' Rights 2005. ${ }^{134}$ Beyond the African region, international institutions are also actively finding ways to recognise the world's Indigenous Peoples.

Even though a number of different international legal instruments define or imply a definition of Indigenous Peoples, there is no universally agreed definition of Indigenous Peoples in international law. The International Labour Organisation (hereafter the ILO) provides the first internationally adopted labour standards of Indigenous workers in the Abolition of Penal Sanctions (Indigenous Workers) Convention (No 104) 1955. Also, the ILO's Conventional Concerning the Protection and Integration of Indigenous and Other Tribal and Semi-Tribal Populations in Independent Countries (No 107) 1957 (hereafter ILO C107) was the first international instrument to expressly recognise the rights of Indigenous Peoples. Since 2 June 1959, when ILO C107 entered into force, only 27 countries have ratified - Liberia and Australia are not included. Not only are governments reluctant to ratify ILO C107 but Indigenous Peoples are concerned that 'its ideology promoted the assimilation and integration of Indigenous

\footnotetext{
${ }^{130}$ Felix Ndahinda, 'Historical Development of Indigenous Identification and Rights in Africa' in Korir Sing'Oei and Ridwan Laher (eds), Indigenous People in Africa: Contestations, Empowerment and Group Rights (Africa Institute of South Africa, 2014) 24, 24.

${ }^{131}$ Ibid.

${ }^{132}$ Centre for Minority Rights Development (Kenya) and Minority Rights Group International on behalf of Endorois Welfare Council v Kenya, 276 / 2003

${ }^{133}$ Cynthia Morel, 'The Endorois Community versus Kenya' in Korir Sing'Oei and Ridwan Laher (eds), Indigenous Peoples in Africa: Contestation, Empowerment and Group Rights (Africa Institute of South Africa, 2014) 194, 4.

${ }^{134}$ George Mukundi and Tuuli Karjala, 'Advocacy for Indigenous Peoples' Rights in Africa: Dynamics, Methods and Mechanisms' in Korir Sing'Oei and Ridwan Laher (eds), Indigenous People in Africa: Contestations, Empowerment and Group Rights (Africa Institute of South Africa, 2014) 104, 108. Article 20 of the African Charter on Human and Peoples' Rights provide for self-determination of all oppressed and colonised peoples.
} 
Peoples into the dominant society'. ${ }^{135}$ Concerns of States and Indigenous Peoples led to the creation of ILO's Convention Concerning Indigenous and Tribal Peoples in Independent Countries (No 169) 1989 (hereafter ILO C169), which is the only international treaty open for ratification that is concerned exclusively with the rights of Indigenous Peoples.

Without a clear definition of who Indigenous Peoples are, Article 1(a) of ILO C169 states that the Convention applies to 'tribal peoples in independent countries whose social, cultural and economic conditions distinguish them from other sections of the national community, and whose status is regulated wholly or partially by their own customs or traditions or by special laws or regulations'. Although ILO C169 expanded recognition for Indigenous rights, it still did not receive support from Indigenous Peoples because of two concerns: 1) its refusal to recognise a right to self-determination, and 2) its requirement on governments to facilitate Indigenous participation and consultation rather than obtain consent from Indigenous Peoples. ${ }^{136}$ This is why, as with ILO C107, only 22 countries have ratified ILO C169 (entered into force 5 September 1991), again not including Australia and Liberia. A more thoughtful consideration for Indigenous Peoples' needs came in 1971: The Sub-Commission on Prevention and Protection of Minorities was mandated by the Economic and Social Council (hereafter ECOSOC) to direct Jose R. Martinez Cobo, then Special Rapporteur, to conduct a study on discrimination against Indigenous Peoples. ${ }^{137}$ Cobo's study concluded in 1987, crafted a working definition of Indigenous Peoples. According to Cobo,

Indigenous communities, peoples and nations are those which, having a historical
continuity with pre-invasion and pre-colonial societies that developed on their
territories, consider themselves distinct from other sectors of the societies now
prevailing on those territories, or parts of them. They form at present non-dominant
sectors of society and are determined to preserve, develop and transmit to future
generations their ancestral territories, and their ethnic identity, as the basis of their
continued existence as peoples, in accordance with their own cultural patterns, social
institutions and legal system. ${ }^{138}$

The United Nations Permanent Forum on Indigenous Issues (hereafter UNPFII), established in July 2000, is an advisory body to ECOSOC, with a mandate to discuss Indigenous issues regarding their social, economic, cultural, development, environmental, and human rights. The UNPFII asserts that the diversity of Indigenous Peoples makes agreeing on an official definition challenging. However, the term 'Indigenous' should be understood based on the following: self-identification accepted at the individual and community levels; historical continuity with pre-colonial-settler societies; strong link to territories and natural resources; distinct social, economic or political systems; distinct language, culture and beliefs; status as

\footnotetext{
${ }^{135}$ Jill Webb, 'Indigenous Peoples and the Right to Self-Determination' (2012) 7(13) Journal of Indigenous Policy $75,83$.

${ }^{136}$ Sarah Pritchard and Charlotte Heindow-Dolman, 'Indigenous Peoples and International Law: A Critical Overview' (1998) 3(4) Australian Indigenous Law Reporter 473, 479.

${ }^{137}$ José R Martínez Cobo, Study of the Problem of Discrimination Against Indigenous Populations (United Nations, 1987); Netherlands Centre for Indigenous Peoples, Definition of Indigenous Peoples (1 November 2010) Indigenous Peoples Definition <http://indigenouspeoples.nl/indigenous-peoples/definition-indigenous>.

${ }^{138}$ Martínez Cobo, above n 137.
} 
non-dominant groups of society; and a resolve to maintain and reproduce their ancestral environments and systems as distinctive peoples and communities.

Most recently, the UN Declaration on the Rights of Indigenous Peoples was adopted by the General Assembly on 13 September 2007, with Peru as the main sponsor, supported by other European and Latin American countries as co-sponsors. During the UN General Assembly (GA10612), the Declaration on the Rights of Indigenous Peoples was adopted by a majority of 144 states in favour; 11 abstentions (Azerbaijan, Bangladesh, Bhutan, Burundi, Colombia, Australia, Kenya, Nigeria, Russian Federation, Samoa, and Ukraine); and four votes against (Australia, Canada, United States and New Zealand). Since the adoption of the Declaration on the Rights of Indigenous Peoples, Australia and the other three countries that voted against, have all reversed their decision. Nearly 20 years after Cobo's definition, the Declaration on the Rights of Indigenous Peoples still has no clear-cut definition of Indigenous Peoples. It was the absence of a formal definition of Indigenous Peoples that partly informed the African Group's decision to defer consideration of the Draft Declaration in 2006. ${ }^{139}$ Megan Davis asserts that for some states, particularly in Asia and Africa, Cobo's definition of Indigenous Peoples is unacceptable. The argument is that, since Africa is the origin of humankind, in some places, no Indigenous Peoples existed. ${ }^{140}$ Therefore, it is more appropriate to describe Indigenous Peoples in Africa as Minority Groups.

In Australia, there are examples of earlier legislation defining Aboriginality by reference to degrees of blood using phrases such as 'octoroon', 'quadroon', 'half-caste' ${ }^{141}$ 'native', or 'full-blood'. ${ }^{142}$ In 1985, a survey of definitions of 'Aboriginal' or derivative terms in some 700 examples of Australian legislation found about 67 identifiable classifications used from the time of white settlement to the present. The classifications can be grouped under six broad headings of Aboriginality: 'according to anthropometric or racial identification; territorial habituation, affiliation or attachment; blood or lineal grouping, including descent; subjective identification; exclusionary and other; and Torres Strait Islanders' ${ }^{143}$ Although the definitions of Aboriginal Peoples in Australia differ from each other, RoaRane Meghana suggests that certain commonalities exist - such as cultural distinctiveness, self-identification, the experience of subjugation, and occupation of the land prior to outside settlers - that are significant to understanding the term 'Indigenous Peoples'. ${ }^{144}$ Aware of the growing debates concerning appropriate terminology, Mick Dodson proposes the usage of 'First Australian' when in the

\footnotetext{
${ }^{139}$ Megan Davis, 'Indigenous Struggles in Standard-Setting: The United Nations Declaration on the Rights of Indigenous Peoples' (2008) 9(2) Melbourne Journal of International Law 439, 3.

${ }^{140}$ Ibid 5.

${ }^{141}$ James Crawford, 'Legal Pluralism and Indigenous Peoples' in Oliver Mendelsohn and Upendra Baxi (eds), The Rights of the Subordinated Peoples (Oxford University Press, 1996) 178, 189.

${ }^{142}$ Law Reform Commission of Western Australia, 'Aboriginal Customary Laws: The Interaction of Western Australian Law with Aboriginal Law and Culture' (Private Report Project 94, Law Reform Commission of Western Australia, September 2006) 432, 61 <http://www.lrc.justice.wa.gov.au/_files/p94_fr.pdf>.

${ }^{143}$ Ibid.

${ }^{144}$ RaoRane Meghana, 'Aiming Straight: The Use of Indigenous Customary Law to Protect Traditional Cultural Expressions’ (2006) 15(3) Pacific Rim Law and Policy Journal 827, 831.
} 
Australian Capital Territory. ${ }^{145}$ The Social Justice Report (2012) uses Aboriginal and Torres Strait Islander Peoples to refer to the 'First Peoples'. ${ }^{146}$ So, in the Australian context as in Africa, the definition of Indigenous is still evolving.

Notwithstanding the controversy regarding a universally accepted definition of Indigenous Peoples, this research draws on Cobo's working definition of Indigenous Peoples as the First Peoples in Liberia and Australia before the arrival of the settler-colonists. The central connection to the land, importance of historical pre-colonial-settler-societies, and desire to preserve ancestral environments and systems, as iterated by the UNPFII above, make Cobo's definition more meaningful for this research study. The terms Aboriginal and Indigenous are used interchangeably when referring to the First Peoples in Australia and Liberia prior to the arrival of settler-colonists. Whilst the term 'Aboriginal' seems more culturally accepted in Australia, 'Indigenous' or 'Native People' is commonplace in reference to the First Peoples in Liberia. Though well-meaning, this usage is contrary to that of Guannu's (considered an apologist for the Indigenous Peoples in Liberia perspective), who classifies the 'tribal people' of Liberia as 'Natives, Africans, and Aborigines'. ${ }^{147}$ To this end, this research uses the capitalised versions of Aboriginal and Indigenous to connote a collective proper noun of Aboriginal and Torres Strait Islanders in Australia and Indigenous or Native Peoples in Liberia. Although the terms 'Indigenous' and 'Aboriginal' arouse some rancour amongst Native Peoples in Liberia ${ }^{48}$ and Aboriginal Peoples in Australia, ${ }^{149}$ there is some level of acquiescence internationally, which would make coining new terminology unnecessarily onerous.

Indigenous Customary or Traditional Laws: Generally, Indigenous Customary Laws ensure effective protection of the traditional cultural expressions of Indigenous Peoples. ${ }^{150}$ In Australia, Aboriginal Customary Laws govern all aspects of Aboriginal life, from establishing a person's rights and responsibilities to others to controlling land and natural resources. ${ }^{151}$ Aboriginal

\footnotetext{
${ }^{145}$ Dodson, 'Constitutional Recognition of Indigenous Australians', above n 24. In response to a question asking his preference for the term 'First Australians' rather than 'Traditional Owners' Dodson (2012) responds: 'To some people it's [traditional owner] an artefact of anthropological thinking that has been grasped by lawyers and put into legal form and doesn't truly reflect the status in a way that the "first peoples" or the "first Australians" or "first nations" does. Again, it is like native title, it's something that came over on the ships and it is not about our status before those ships arrived. We weren't called Australia back then but when we say first Australians everybody in this room would know who we were talking about. There are some Aboriginal and Torres Strait Islander peoples who object to that term. If I was in the Northern Territory I would say "traditional owners"”.

${ }^{146}$ Australian Human Rights Commission, 'Social Justice Report 2012: Aboriginal and Torres Strait Islander Social Justice Commissioner' (Government Report ABN 47996232602, Australian Human Rights Commission, 26 October 2012) 240 .

${ }^{147}$ Guannu, above n $100,7$.

${ }^{148}$ Heneryatta Ballah, 'Ethnicity, Politics and Social Conflict: The Quest for Peace in Liberia' [2003] CiteSeerX 52, 52.

${ }^{149}$ Katherine Lambert-Pennington, “"Real Blackfellas”: Constructions and Meanings of Urban Indigenous Identity' (2012) 20(2) Transforming Anthropology 131, 132; Shannan Dodson, 'Too White, Too Black, or Not Black Enough? This Is Not a Question for Others to Decide' The Guardian (Sydney, NSW), 8 June 2017

<http://www.theguardian.com/commentisfree/2017/jun/09/too-white-too-black-or-not-black-enough-this-is-not-aquestion-for-others-to-decide>; McCorquodale, above n 57, 9. According to McCorquodale, the term 'native' (like co-equal 'tribal') was first replaced with 'people' at the enactment of the Australian Institute of Aboriginal Studies Act 1964.

${ }^{150}$ Meghana, above n 144, 827.

${ }^{151}$ Law Reform Commission of Western Australia, above n 142, 61.
} 
customs and laws are part of an oral culture that is called 'the law' rather than laws. James Crawford asserts that the singularity of Indigenous Customary Law emphasises its unity and immutability rather than variety and change. ${ }^{152}$ In Milirrpum v Nabalco Pty Ltd 1971, although Justice Richard Blackburn found that native title rights were extinguished during British colonisation, he did not hesitate to rule that the Yolngu People's communal landholding and kinship rules were a system of laws. ${ }^{153}$ Although there are multiple perspectives on what is identified as Indigenous Customary Laws, the Australian Law Reform Commission characterises 'Aboriginal Customary Laws' as a 'body of rules, values and tradition....accepted as establishing standards or procedures to be followed or upheld'. ${ }^{154}$ In Liberia, a distinction is also drawn between Anglo-American-Liberian law and Liberian Customary Laws.

In Liberia, as in Australia, the exact meaning of customary law has not been strictly defined. At the founding of Liberia, African American settler-colonists created the Ministry of Interior to regulate the 'uncivilised Natives' whilst adopting Anglo-American statutory law for themselves. ${ }^{155}$ Later, the obsolete Rules and Regulations Governing the Hinterland, 1949 (revised in 2000), were instituted to 'provide adequate protection for all persons travelling through, or who desire to dwell permanently in those parts [of Liberia]...in keeping with the true spirit, purpose and intent of our Declaration of Independence and the Organic Law of the Country'. ${ }^{156}$ Executive Order No 20 established the Liberia Law Reform Commission on 11 June 2009 pursuant to the Accra Comprehensive Peace Agreement 2003, which recognised the need for an extensive overhauling of Liberia's governance framework. ${ }^{157}$ Even though the Law Reform Commission acknowledges a dual legal system in the country, it makes no mention of reforming Indigenous Customary Laws in its Strategic Plan 2011-16. ${ }^{158}$ Although the dual legal system has been acknowledged, neither the Ministry of Interior nor the Law Reform Commission published a definition of customary or traditional law. Notwithstanding, research conducted by the United States Institute of Peace (2009) and the International Crisis Group (2010) suggests that Indigenous Customary Laws in Liberia include (but are not limited to) the following: trial by ordeal in traditional courts (e.g., sassywood); ${ }^{159}$ sorcery and magical

\footnotetext{
${ }^{152}$ Crawford, above n 141, 190.

${ }^{153}$ Milirrpum v Nabalco (The Gove Land Rights case) 197117 FLR 141. The Gove Land Rights case was the first litigation on native title in Australia. The final decision noted that the British Crown had the authority to extinguished native title rights of Aboriginal Peoples if it existed. The Milirrpum decision led to the establishment of the

Woodward Royal Commission, which eventually resulted in the recognition of Aboriginal Land rights in the

Northern Territory. In 1975, then Prime Minister Gough Whitlam also drafted the Aboriginal Land Rights Act 1976.

Two decades later, Mabo v Queensland (No 2) (1992), the High Court of Australia overruled Milirrpum.

${ }^{154}$ Australian Law Reform Commission, 'Recognition of Aboriginal Customary Laws (ALRC Report 31)', above $\mathrm{n}$ 26, 98-101.

${ }^{155}$ International Crisis Group, 'Liberia: Resurrecting the Justice System' (107, International Crisis Group, 6 April 2006) 1,7 <http://www.operationspaix.net/IMG/pdf/ICG_liberia_resurrecting_the_justice_system_2006-0406_.pdf $>$.

${ }^{156}$ Rules and Regulations Governing the Hinterland 1949 (forward).

${ }^{157}$ Ministry of Foreign Affairs, 'Law Reform Commission of Liberia: Strategic Plan 2011-2016' 9

<http://liblrc.org/uploads/3/2/5/8/3258104/lrc_strategic_plan.pdf.>.

${ }^{158}$ Ibid $1-66$.

${ }^{159}$ International Crisis Group, above n 155, 14, 9; Deborah H Isser, 'Looking for Justice: Liberian experiences with and perceptions of local justice options' (USIP Report 63, United States Institute of Peace, 2009) 104, 8, 10, 38, 49,
} 
powers; ${ }^{160}$ Sande and Poro Institutions (also known as Secret Society); ${ }^{161}$ and spiritual rituals performed by elders. ${ }^{162}$ This study uses the composite 'Indigenous Customary Law' to distinguish diverse recognition of Aboriginal customs and lore from that of "customary international law'. Thus, Indigenous Customary Laws encompass oral, religious and sacred customs, traditions, rules and practices, which may differ amongst individual communities as practiced and applied by Indigenous Peoples in Liberia and Australia.

Tribe, Ethnicity, Country and Language Group: As with the political disenfranchisement of Indigenous Peoples through the colonial nation-building process, classification of indigeneity and the denigrating terminology used to describe those classifications disproportionately affect Indigenous women more than men. For example, consider a social placement and gender construct ascribed to Indigenous Glebo women by their Former Slave Returnee immigrant sisters from across the Atlantic. Mary Moran (1990) presents a challenge facing Glebo women in the social ranking order of Maryland County in Liberia:

The opposite of civilised [or kwi in Kru language] is country, tribal, or native. Most terms opposed to kwi are not neutral but denigratory. (...) Glebo women achieve civilized status in much the same manner as men, through formal education and training, yet they remain almost totally economically dependent on male wage earners. Being civilized severely constrains a woman's ability to support herself by limiting her to economic activities in which she must compete (often unequally) with men. Men have the advantage, on the whole, of higher levels of education because parents are usually more willing to invest in the schooling of sons than of daughters. A common rationale offered for the preference... [is that] they [boys] cannot 'spoil themselves' with early pregnancies, (...) ideally a civilized woman should resemble a Western-style housewife, (...) [yet] their [Glebo women] claim to civilize status is tenuous, depending both on their daily public behaviour and on the financial situations of their husbands, lovers, and fathers. (...) Men acquire civilized status for life, and though they may experience downward social and economic mobility through unemployment, alcoholism, or criminal behaviour, they do not return to the status of natives. Civilized women [on the contrary] lose prestige by engaging in the 'wrong' types of work, such as subsistence farming or marketing. 'She used to be civilized' is frequently heard to describe a literate woman who has been forced by economic necessity to 'tie lappa and make market,' giving up the most visible symbol of civilized womanhood, the Western-style dress. ${ }^{163}$

Such categorisation of the Glebo woman shows that Native Liberian women are denigrated not only by males but also by Former Slave Returnee females. However, the irony presented in Moran's observation is the fact that the development of social stigmas and cultural beliefs are discriminatory towards women simply because of their sex. No matter how downtrodden men are by experience, they can never lose their social status of being 'civilised' or superior to women. At the same time, when an educated woman decides to farm or sell products in the

\footnotetext{
63, 68, 97 <http://www.usip.org/publications/looking-justice-liberian-experiences-and-perceptions-local-justiceoptions $>$.

${ }^{160}$ International Crisis Group, above n 155, 14; Isser, above n 159, 20, 24, 65, 67.

${ }^{161}$ International Crisis Group, above n 155, 3, 12, 13; Isser, above n 159, 7, 24, 37, 55, 79.

${ }^{162}$ Isser, above n 159, 8, 36, 46, 51.

${ }^{163}$ Mary H Moran, Civilized Women: Gender and Prestige in Southeastern Liberia (Cornell University Press, 1990)

2-5. Lappa is a rectangular traditional fabric, worn like a wrap by Liberian women. It is usually associated with poor, illiterate, Indigenous women who earn their living by selling in the market (market women).
} 
market, she instantly loses her civilised status. Avoiding the perpetration of these negative social constructs requires thoughtful consideration of the term tribe.

The term 'tribe' originates from the Latin word tribus meaning 'a group of persons forming a community and claiming descent from a common ancestor'. ${ }^{164}$ The word 'tribe' with 'no consistent meaning' was later popularised by European settler-colonialists and has come to 'promote a myth of primitive African timelessness' ${ }^{165}$ As the term seeped into the Continent, Africans (scholars and laypersons) ${ }^{166}$ and foreign researchers ${ }^{167}$ followed suit in its usage with less hesitation for the etymology and social construct of the terminology. Teah Wulah writes, 'very recently in Liberia, it was an insult to be called a 'countryman', which meant you were from a tribe'. ${ }^{168}$ Today everyone in Liberia wants to have a 'country name' to reflect the complexity of what it actually means to identify as a Native Liberian or an African American Former Slave. ${ }^{169}$ Abayomi Karnga, a Liberian historian whose heritage lies with recaptured slaves ${ }^{170}$ from the Belgian Congo region of Africa, writes, '[t]he Kwia, or Bele, group consists of the Gbetars, Gabos and Betus (all being commonly known as "Kru")... [a]ll these spoke practically the same tongue, and could more or less understand each other... [t]hese tribes lived formerly in the interior of Africa before coming to the sea coast' ${ }^{171}$ As early as 1869, 22 years after Liberia declared its independence from the American Colonisation Society, the word 'tribe' was used by then ex-President Joseph Jenkins Roberts ${ }^{172}$ to denigrate Indigenous Peoples in

\footnotetext{
${ }^{164}$ Robert J Gregory, 'Tribes and Tribal: Origin, Use, and Future of the Concept' (2003) 1(1) Studies of Tribes and Tribals 1 .

${ }^{165}$ Chris Lowe, 'The Trouble with Tribe'.

${ }^{166}$ Tuan Wreh, The Love of Liberty: The Rule of President William V. S. Tubman in Liberia, 1944-1971 (C. Hurst, 1976) 132-133.

${ }^{167}$ Liebenow, above n 55, 30-52.

${ }^{168}$ Helene Cooper, The House at Sugar Beach: In Search of a Lost African Childhood (Simon and Schuster, 2008) 6; Helene Cooper, The House at Sugar Beach: In Search of a Lost African Childhood (University of Maryland, Baltimore Campus, 2010) <https://www.youtube.com/watch?v=v8oR6g5rgzs>. Cooper, a supposedly renowned Liberian-born American journalist who is currently a New York Time's correspondent at the Pentagon, flaunts her historical and ancestral ignorance in calling Indigenous Peoples in Liberia 'native country people' and BLACK African-American emigrants 'American': 'Liberia is nowhere near the Congo River, but the term Congo is endemic. We are called the Congo people - my family and the rest of the descendants of the freed American slaves who founded Liberia in 1822. It is a somewhat derogatory term invented by the native Liberians back in the early nineteenth century, after Britain abolished slave trade on the high seas....the native Liberians, many of whom happily engaged in the slave trade and didn't like this new business of freeing the slaves and dumping them in Liberia, called the newcomers Congo People....We got the native Liberians back by calling them Country People, far more derogatory, in our eyes' (p6). Cooper also boasts of her great, great, great great, grand-father, Elijah Johnson, who boarded the first ship from New York in 1820 to West Africa and the four Cooper brothers (along with one Ann Cooper) from Norfolk Virginia, who boarded the Harriet in 1829 (also see her presentation at the University of Maryland, Baltimore available at: <https://www.youtube.com/watch?v=v8oR6g5rgzs >). What is interesting to note of Elijah Johnson and the Cooper brothers is that, the former boarded the Elizabeth in New York on 9 March 1820 as a freeborn person who 'reads' and had an 'unknown' occupation; whilst the latter, also 'freeborn', were counted amongst those with 'unknown' literacy, and two marked as 'seaman' for occupancy and the other two 'unknown'. Johnson, who was friends with Jehudi Ashmun, first colonial agent of the ACS, was one of the original signers of the Declaration of Independence in 1847.

${ }^{169}$ Teah Wulah, The Forgotten Liberian: History of Indigenous Tribes (AuthorHouse, 2005) iv.

${ }^{170}$ Tom W Shick, Behold the Promised Land: A History of Afro-American Settler Society in Nineteenth-Century Liberia (Johns Hopkins University Press, 1980) 66-72. Between 1846 and 1860, a total of 5457 Africans from originating mainly from the Congo River and Key West, Florida en route to be sold into slavery in the Americas were recaptured and settled in Liberia.

${ }^{171}$ Abayomi Karnga, History of Liberia (D. H. Tyte, 1926) 11.

${ }^{172}$ Abayomi Karnga describes former President Roberts as an Octoroon - a person who is one-eighth Black by descent (see Karnga, History of Liberia (1926) xiv. Tom Shick (1980) affirms that '[o]ne conspicuous mark of the free Afro-American community was the high percentage of mulattoes' who, based on their skin tone, residence in
} 
Liberia. In responding to the editor of the North American and United States Gazette on charges that 'slavery is being practiced in Liberia', President Roberts writes:

...-while it accords to the people of Liberia much credit for their governmental capacity, their courage and steadiness in maintaining themselves amongst the savages, and for their conciliatory and human policy toward the barbarous tribes which they have come in contact - places both Liberia and myself in a decidedly false position, (...) I am guided in my estimate solely by personal visits to the several tribes within the jurisdiction of the Republic, and those occasions computing the numbers of their respective inhabitants (...) at six hundred thousand souls, (...) these tribes never engaged in the sale of slaves to foreign dealers; and as far as I know, never tolerated domestic slavery amongst themselves. ${ }^{1}$

Aboriginal Australians were also relegated to inferior status by white settler-colonists who used language as a tool of exclusion and denigration. According to Honourable William Henry Mackie, Advocate General and Colonist of the Western Australian Legislative Council (1831-34) in $R v$ Wewar $1842,{ }^{174}$

There are two cases in which such a right may be exercised. First, in the case of an
uninhabited country; which is not the present case. Secondly when a large extent of
country is roamed over by wandering savages, who make no use, or a very trifling use,
of the soil, and subsist by the chase and spontaneous products of the earth. (...) Those
savage tribes have no right to exclude the rest of mankind from which they themselves
make no proper use. (...) But as jurisdiction is clearly an inseparable incident of
sovereignty, it follows that the British nation having, under the principle of the law of
nations just stated, taken possession and assumed the sovereignty of a territory bounded
by certain parallels and meridians, the law of that nation must be paramount
coextensively with that territorial sovereignty. ${ }^{175}$

The fascination with Mackie's profession in $R v$ Wewar is the sheer audacity and arrogance displayed of applying settler law to justify such violation during the process of dispossessing sovereign Indigenous nations of their land. What is even more disturbing is the use of derogatory language to describe Aboriginal Peoples, their cultures and their way of life, thereby initiating a belief system that seeped into the structural formation of long-held traditions that are violent and abusive towards Indigenous Peoples in Australia. A striking similarity with these degrading social constructs as stated above (.g, tribal and ethnicity) mandates that this research use terms that invoke respect for and dignity of Indigenous Peoples in Liberia and Australia.

cities and economic opportunities, were able to accumulate property and maintain social connections of value over time. Apart from twice being elected as president of Liberia, former President Roberts was a successful businessman. As an elite Liberian, he accumulated land, property and money during his lifetime and died 'a venerated statesman in 1876' (see Shick, Behold the Promised Land (1980) pp. 13, 49).

${ }^{173}$ ACS, The African Repository (American Colonization Society, 1869) vol XLV, 14-15, 17.

${ }^{174} R v$ Wewar 1842 was the first casein New South Wales Supreme Court to debate jurisdictional issue Western Australia. In the case published in the Perth Gazette (1842) Wewar was captured and charged with 'wilful murder' of Dyung under British law. As stated on Kaartdijin Noongar's website, 'Henry Trigg interpreted Weewar as saying: 'I cannot understand why the Governor is sulky or severe with me, if a white man kills a white man we never interfere. Sometime back the white man killed many of the natives and the Governor took no notice, now why should the Governor take any notice of me if I kill a fellow native that steals my wife, or kills my brother, when it is according to our law'. See Kaartdijin Noongar - Noongar Knowledge, 'Impacts of the Law Pre-1905' (2012), available at: <http://www.noongarculture.org.au/impacts-of-law-pre-1905/>

${ }^{175}$ Ann Hunter, 'The Boundaries of Colonial Criminal Law in Relation to Inter-Aboriginal Conflict ('inter Se Offences') in Western Australian in the 1930s-1840s' (2004) 8(4) Australian Journal of Legal History 251. 
In Australia, the words 'brute' and 'miserable' coupled with 'tribal' or 'native' are used sparingly, ${ }^{176}$ mostly by non-Aboriginal social scientists to group cultures and customs. William Dampier, ${ }^{177}$ as quoted by Sharman Stone, reports that, '...the natives, lacking any of the refinements necessary for dignified human existence, were closest to the "brutes". ${ }^{178}$ As quoted by Kay Anderson and Collin Perrin, Dampier elaborates, 'there is reason to believe that we have as yet seen only the most destitute of the whole nation; and that there are tribes farther to the northward, perhaps in inland countries of the great Austral land, who are by no means so miserable or so savage as the people near the southern shores' ${ }^{179}$ Here, the term 'tribe' as referenced by Dampier still seems to convey the relative subordination of Aboriginal cultures. Due to the negative connotation of the terms, 'tribe' and 'tribal' are not used to refer to Indigenous groups in this research.

'Language (or Language Group) ${ }^{\text {180 }}$ or 'Country' (rather than 'ethnicity'), connotes the diversity of Aboriginal peoples in Australia. Whilst the term 'country' ${ }^{181}$ is used in both Liberia (infrequently) and Australia to denote Indigenous connection to land and family origins, 'ethnicity' seems unattractive because of its roots in paganism and heathenism, i.e., one who is not a Christian or a Jew. ${ }^{182}$ Kevin Dunn et al (2010) warn that Indigeneity is not synonymous with a broad cultural diversity which sees Aboriginal Australians as an ethnic group in the scramble for equal opportunity and equal sense of belonging in the multicultural confabulation.

\footnotetext{
${ }^{176}$ Robert MW Dixon, Searching for Aboriginal Languages: Memoirs of a Field Worker (University of Chicago Press, 2011) 133.

${ }^{177}$ Henry Reynolds, Dispossession: Black Australians and White Invaders (Allen and Unwin, 1996) 97-98 <http://www.contentreserve.com/TitleInfo.asp?ID=\{BA893BD4-818E-47F0-B657-3EC1F37227BF $\} \&$ Format=410>. Reynolds quotes Dampier's description of Australia's Indigenous, in which he compares the Aborigines to Negroes: '[t]he inhabitants of this Country are the miserable People in the World... [They] have no Houses, and skin Garments, Sheep, Poultry, and Fruits of the Earth... and setting aside their Humane Shape, they differ but little from Brutes. They are tall, strait-bodied, and thin, with small long limbs. They have great Heads, round Foreheads, and great Brows. Their Eye-lids are always half closed, to keep the Flies out of their Eyes; they being so troublesome here, that no fanning will keep them from coming to one's Face; and without the Assistance of both Hands to keep them off, they will creep into ones Nostrils, and Mouth too, if the Lips are not shut very close; so that from their Infancy being thus annoyed with these Insects, they do never open their Eyes as other People: And therefore they cannot see far, unless they hold up their Heads, as if they were looking at somewhat over them. They have great Bottle-Noses, pretty full Lips, and wide Mouths. The two Fore-teeth of their Upper-jaw are wanting in all of them. Men and Women, old and young; whether they draw them out, I know not: Neither they any Beards. They are longvisaged, and of a very unpleasing Aspect, having no one graceful Feature in their Faces. Their hair is black, short and curl'd, like that of the Negroes; and not long and lank like the common Indians. The Colour of their Skins, both of their Faces and the rest of their Body, is Coal-back, like that of the Negroes of Guinea. They have no sort of Cloaths, but a piece of the Rind of a Tree or four small green Boughs full of Leaves, thrust under their Girdle, to cover their Nakedness. They have no Houses but lie in the open Air without any covering; the Earth being their Bed, and the Heaven their Canopy. Whether they cohabit one Man to one Woman, or promiscuously, I know not; but they do live in Companies, 20 or 30 Men, Women, and Children together...' (97-8).

${ }^{178}$ Sharman Nance Stone, Aborigines in White Australia: A Documentary History of the Attitudes Affecting Official Policy and the Australian Aborigine, 1697-1973 (Heinemann Educational, 1974) 13

<http://catalog.hathitrust.org/api/volumes/oclc/1655220.html>.

${ }^{179}$ Kay Anderson and Colin Perrin, "“The Miserablest People in the World": Race, Humanism and the Australian Aborigine' (2007) 18(1) The Australian Journal of Anthropology 18, 9.

${ }^{180}$ Patrick McConvell, Doug Marmion and Sally McNicol, 'National Indigenous Languages Survey Report 2005' (Government Report, Australian Institute of Aboriginal and Torres Strait Islander Studies, 2005) 255, 3

<http://aiatsis.gov.au/publications/products/national-indigenous-languages-survey-report-2005>. The NILS report states that of the 250 original Australian Indigenous languages (i.e., before arrival of the colonisers), only 145 are still spoken today - 110 of which are critically endangered.

${ }^{181}$ Anthony Appiah and Henry Louis Gates (eds), Africana: The Encyclopedia of the African and African American Experience (Oxford University Press, 2nd ed, 2005) 477.

${ }_{182}$ Douglas Harper, Online Etymology Dictionary (2014) Online Etymology

<http://www.etymonline.com/index.php?term=ethnic $>$.
} 
Instead, 'the political position of Indigenous Australians [should be] perceived as revolving around the cleavage between Indigenous and non-Indigenous Peoples particularly within the context of colonisation and such issues as land, health, heritage, identity, education and forced removal of children in settler society'. ${ }^{183}$ In light of the above, the use of 'language' or 'Language Group' when characterising Indigenous Peoples in Liberian and Australian cultures, customs, traditions, mother tongue/lingua and ancestral lineages is more appropriate than 'ethnicity'.

Former Slave Returnee or African American Settler-Colonist: Tony Martin, the renowned Trinidadian-born Africanist, used the term Afro-American to describe the various ancestral lineages of African peoples forced into slavery across the Americas. ${ }^{184}$ The label, which later morphed into 'African-American' and displaced the enslaved 'negro' descriptor, ${ }^{185}$ commands more respect than the term 'Americo-Liberian', which was crafted in Liberia. Terms like these were used by white agents of the American Colonisation Society to aid in the process of separating Former Slave Returnees from Indigenous locals. D. Elwood Dunn and Svend Holsoe (1985) argue,

\begin{abstract}
The long struggle for social and political integration and unification represents the attempt to overcome this basic problem. First there was the task of developing a community amongst the various settlements of early nineteenth-century Liberia (i.e., amongst black American emigrants from Georgia, New York, Mississippi, etc.). This process underscored the distinction between immigrant and indigenous groups. Agents of the American Colonisation Society themselves identified in the 1820's the two principal population groups as: 1) black American immigrants who were referred to interchangeably as "Americans," "colonists," "settlers," "Americo-Liberians," "citizens," and "civilized"; and 2) the indigenous population groups variously identified as "native," "savages," "heathens," "aborigines," "country people," "uncivilised element," [bush] and "indigenous Liberians". ${ }^{186}$
\end{abstract}

Given the nature of their emigration as Former Slaves in search of refuge, it is reasonable to describe the historical analogues of the term 'Americo-Liberian' as synonymous to that of 'refugee', ${ }^{187}$ 'expatriate', ${ }^{188}$ or 'deportee' ${ }^{189}$ descending from formally enslaved Africans. However, contrary to the negative connotation of these terms, the term 'Americo-Liberian' carries a connotation of superiority over Indigenous Peoples in Liberia. To a settler-colonist in Liberia, the moniker 'Americo-Liberian' implies 'we are not Africans but civilised

\footnotetext{
${ }^{183}$ Kevin M Dunn et al, 'Indigenous Australians' Attitudes towards Multiculturalism, Cultural Diversity, "race" and Racism’ (2010) 13(4) Journal of Australian Indigenous Issues 19.

${ }^{184}$ Tony Martin, The Pan-African Connection: From Slavery to Garvey and Beyond (Majority Press, 1st Majority Press, 1984) 3.

${ }^{185}$ Lerone Bennett, Jr., 'What's in a Name? Negro vs. Afro-American vs. Black' (1967) 23 Ebony 46.

${ }^{186}$ Dunn and Holsoe, above n 104, 178-179.

${ }^{187}$ The Declaration of Independence of the Constitutional Convention of 1847 confirms the returnees desire to seek refuge in Africa: 'All hope of a favourable change in our country was thus wholly extinguished in our bosoms, and we looked with anxiety abroad for some asylum from the deep degradation.' See Charles Henry Huberich, 'The Political and Legislative History of Liberia' (1947) 829.

${ }^{188}$ Fraenkel, above n 39, 8.

${ }^{189}$ Henry Noble Sherwood, 'Mississippi Valley Historical Review 2' in Staudenraus (ed), The African Colonization Movement, 1816-1865 (Columbia University Press, 1961) 484; Penelope Campbell, Maryland in Africa: The Maryland State Colonization Society, 1831-1857 (University of Illinois Press, 1971) 3.
} 
Americans' ${ }^{190}$ As such, the juxtaposition of 'Americo-Liberian' with 'country people' vilifies Indigenous Peoples in Liberia, whilst elevating Former Slave Returnees to a higher social class. Furthermore, the term is a misnomer as it fails to recognize the distinction between Liberians of African descent taken to the Americas as slaves, Africans snatched from various locales before embarking on the 'middle passage', ${ }^{191}$ and Africans from ships bound for the Americas that were intercepted at sea by the British Navy and sent to Liberia. ${ }^{192}$ In this dissertation, the terms African American settler-colonists or Former Slave Returnees are used collectively to represent all newcomers of African descent arriving in Liberia after 1820. The 'African' in the phrase 'African American' encompasses all Africans whether they came from the United States or other parts of Africa. The term 'settler-colonist' is applied more generally to include both white English and Black African American emigrants in Australia and Liberia, respectively.

The term 'Negritude' is not frequently used in this research. However, it is included here to clarify the origin of the discourse in relation to the conceptual mindset behind such term as 'civilised Americo-Liberian' and 'inferior uncivilised ${ }^{193}$ Indigenous Liberians'. According to Tony Martin and Franz Fanon, the word Negritude arose as a sign of resistance on the part of African writers, refuting the view of European cultural imperialists by stating that, '...everything white was not pretty, that everything black was not ugly; that whites were not inherently superior in intelligence, and Africans were not naturally stupid'. ${ }^{194}$

Systematic Violence and Violence Against Women: Governments of both Liberia ${ }^{195}$ and Australia, ${ }^{196}$ in their National Action Plans on violence against women, adopt the UN Declaration on the Elimination of Violence against Women's 1993 (hereafter DEVAW)

\footnotetext{
${ }^{190}$ See the Liberian Declaration of Independence 1847, available at <http://www.onliberia.org/con_declaration.htm>. ${ }^{191}$ Charles Johnson, Middle Passage (Simon \& Schuster, 1998).

${ }^{192}$ After the enactment of the Abolition of the Slave Trade Act 1807 in the UK Parliament.

${ }^{193}$ Barbara A West, A Brief History of Australia (Facts On File, 2010) 266; Ingereth Macfarlane and Mark Hannah (eds), Transgressions: Critical Australian Indigenous Histories (ANU E Press, 2007) 195-196. The term '(un)civilize' also invokes similar negative connotation in Australia. In 1810, the same year Lachlan Macquarie takes over as governor of the New South Wales colony, violence against Indigenous Peoples in Australia increased Macquarie believed the best way relate to Aboriginal Peoples was to 'civilize' them by replacing their traditional with a European way of life. During his regime, he opened the first Aboriginal mission in Parramatta called Parramatta Native Institution for Aboriginal children (also see Governor Macquarie's Proclamation to the Aborigines of 4 May 1816, available at <http://www.historyservices.com.au/resource_material_proclamation04051816.htm〉). The purpose of the mission school was to 'civilise, educate and foster habits of industry and decency in the Aborigines', (i.e., to train Indigenous in domestic, agricultural and other forms of labour). He later passed laws mandating that any Aboriginal who resisted subjection to British control should be shot down. Ingereth Macfarlane (2007 at 90) further explains Russell Clarks choice of works in describing Aboriginal Australian as uncivilised: 'Clark compared jagged mountain peaks to the sharpened teeth of savages and divided Aboriginal people into two categories: 'semi-civilised' allies like Kennedy's faithful guide Jacky Jacky and 'primitive' tribal enemies. The latter were presented as either wandering marauders or treacherous cowards'.

${ }^{194}$ Martin, above n 184, 24. Unfortunately, Macquarie (Macquarie University is named in his honour) was not the only one to 'legalise' violence against Aborigines. Sir Thomas Brisbane (Brisbane, Queensland's capital city, is named in his honour) also issued a Declaration of Martial Law in 1824 - which gave setters the right to murder Aborigines 'lawfully' (see <http://www.nma.gov.au/engage-learn/schools/classroomresources/multimedia/interactives/bells_falls_gorge_html/cabinet_items/transcript_declaration_of_martial_law >).

${ }^{195}$ Government of Liberia, 'National Plan of Action for the Prevention and Management of Gender Based Violence in Liberia', above n 109, 8 .

${ }^{196}$ Council of Australian Government, 'The National Plan to Reduce Violence against Women and Their Children 2010 - 2022 (The National Plan)' (Department of Families, Housing, Community Services and Indigenous Affairs, 2010) $61,2$.
} 
definition of violence against women. Article 1 of DEVAW states that, "“violence against women means" any act of gender-based violence that results in, or is likely to result in, physical, sexual or psychological harm or suffering to women, including threats of such acts, coercion, or arbitrary deprivation of liberty, whether occurring in public or private life'. ${ }^{197}$ In this research, gender violence or violence against women encompasses physical, psychological and sexual harm inflicted (whether by commission or omission) upon Indigenous girls and women. Gender violence is examined at three levels: the state or institutional, structural or cultural, and community or interpersonal infliction of physical, psychological and sexual harm against Indigenous girls and women. Systematic gender violence is a collective reference to the three levels as described above ${ }^{198}$ and in more detail in chapters 3 and 8.

Genocide, War Crimes, and Crimes Against Humanity: Article 6 of the Rome Statute of the International Criminal Court 1998 (hereafter the Rome Statute) defines genocide as any of the following acts committed with intent to destroy, in whole or in part, a national, ethnical, racial or religious group by a) killing members of the group; b) causing serious bodily or mental harm to members of the group; c) deliberately inflicting on the group conditions of life calculated to bring its physical destruction in whole or in part; d) imposing measures intended to prevent births within the group; and e) forcibly transferring children of the group to another group. Article 7 of the Rome Statute defines crimes against humanity as widespread acts or parts of systematic attack directed against any civilian population, which include murder, extermination, enslavement, sexual slavery, torture, rape, forced prostitution, forced pregnancy, and religious persecution, amongst others. Article 8 of the Rome Statute states that the International Criminal Court shall have jurisdiction over war crimes, in particular when committed as part of a plan or policy or as part of a large-scale commission of such crimes. War crimes of this type include grave breaches of the Geneva Conventions, wilful killing, inhumane treatment, wilfully causing great suffering, and appropriation of property, amongst others. In this research, systematic gender violence broadly encapsulates all components of Articles 6, 7 and 8 of the Rome Statute.

Victims/Survivors: In this study, the term 'survivor(s)' rather than 'victim(s)' is preferred. Theories of rape and feminist studies have long engaged with the connotation and ideological distortions of labelling women and girls as 'survivors' or 'victims' of gender violence. Whilst victimhood tends to imply a level of passivity, survivorship is associated with empowerment. Preference for the latter term over the former adopts a more psychological approach to engendering a greater sense of self-worth and respect.

\footnotetext{
${ }^{197}$ Declaration on the Elimination of Violence against Women, GA, $85^{\text {th }}$ plen mtg, UN doc, A/RES/48/104 (20 December 1993) and Commission on the Status of Women, Report on the fifty-seventh session Supplement 7, UN ECOSOC, 57 th sess., UN Doc E/CN.6/2013/11 (4-15 March 2013).

${ }^{198}$ Limited space does not permit a comprehensive examination of violence against queer/gay Indigenous persons in this research, since doing justice to such a topic requires additional research method and design.
} 
Rule of Law: The Duhaime Legal Dictionary explains the principle as a concept whereby 'individuals, persons and government shall submit to obey and be regulated by law, and not arbitrary action by an individual or a group of individuals'. ${ }^{199}$ Former Lord Chief Justice of England and Wales, Thomas Bingham, wary about global diversity and the generalisation of applying foreign concepts to all, purports that the rule of law means 'all persons and authorities within the State, whether public or private should be bound by and entitled to benefits of laws publicly made, taking effect (generally) in the future and administered in courts' ${ }^{200}$ The $U N$ Secretary-General, in his report on the rule of law and transitional justice in conflict and postconflict societies (2004), defines the phrase as

\begin{abstract}
a principle of governance in which all persons, institutions and entities, public and private, including the State itself, are accountable to laws that are publicly promulgated, equally enforced and independently adjudicated, and which are consistent with international human rights norms and standards. It requires, as well, measures to ensure adherence to the principles of supremacy of law, equality before the law, accountability to the law, fairness in the application of the law, separation of powers, participation in decision-making, legal certainty, avoidance of arbitrariness and procedural and legal transparency.
\end{abstract}

From the three definitions stated above, the three major characteristics of the rule of law are centred on 1) indiscriminate submission and obedience to laws publicly made; 2) administration of the law in the courts; and 3) avoidance of arbitrariness of the law when dispensing justice. To this end, this research operationalises the rule of law as an umbrella phrase comprising the following attributes pertinent to equal treatment for all Australian and Liberian citizens: equality before the law, access to the law, integrity of the law, public confidence in the law, transparency and accountability, administration of justice by independent adjudicators, competency of the law, and limitation on the exercise of power by the executive, judicial and legislative branches of government. Chapter 4 further expands on the concept of the rule of law.

Restorative Justice: The concept of restorative justice, conceived out of the frustration with retributive and rehabilitative justice models, ${ }^{202}$ gained recognition with Howard Zehr's ${ }^{203}$ victimoffender reconciliation programmes. The victim-offender reconciliation programme is an independent organisation working outside the criminal justice system wherein the offender, the victim and community members who have been affected by criminal offence ${ }^{204}$ are brought together in a 'Peacemaking Circle'. ${ }^{205}$ As opposed to the over-emphasis on punishment,

\footnotetext{
${ }^{199}$ See Duhaime Learn Law at <http://www.duhaime.org/LegalDictionary/R/RuleofLaw.aspx>.

${ }^{200}$ Tom H Bingham, 'The Rule of Law' (2007) 66(01) The Cambridge Law Journal 67.

${ }^{201}$ UN Security Council, 'UN Secretary General Report: The Rule of Law and Transitional Justice in Conflict and Post-Conflict Societies’ (UN Document S/2004/616, United Nations, 23 August 2004) 24, 4.

${ }^{202}$ Tali Gal, Victims to Partners: Child Victims and Restorative Justice (PhD Thesis, The Australian National University, 2006) 7.

${ }^{203}$ Howard Zehr, Changing Lenses: A New Focus for Crime and Justice (Herald Press, 3rd ed, 1990) 160.

${ }^{204}$ Elmar GM Weitekamp and Hans-Jürgen Kerner, Restorative Justice: Theoretical Foundations (Willan Pub, 2002) 3-5.

${ }^{205}$ Howard Zehr, 'Doing Justice, Healing Trauma: The Role of Restorative Justice in Peacebuilding' (2008) 1(1) South African Journal of Peacebuilding 1. Peace Circles is not mediation. Usually facilitated by a 'circle keeper' who uses talking piece and a circular process to guide the exchange, it draws on the core values of all its participants.
} 
retribution and rehabilitation found in criminal legal processes, Gerry Johnstone (2002) argues, that restorative justice prioritises the needs of the survivors whilst simultaneously ensuring that the offender is fully aware of the damage and liability she or he has caused to people. ${ }^{206} \mathrm{~A}$ form of 'Indigenous restorative justice' is practiced in the Community/Koori Courts ${ }^{207}$ in Australia and the Palava Hut Forum ${ }^{208}$ in Liberia. A Community Court is a 'modified summary court sentencing process that allows community participation' ${ }^{209}$ According to Mary Spiers-William (2013), Community Court is grounded in the ethos of pluralism. That is, without necessarily applying Indigenous Customary Laws in Australia, Community Court suggests that there are other ways of knowing and doing justice. ${ }^{210}$ Supporting cultural strengths, Community Court (like circle sentencing processes) influences Indigenous communities through restorative justice paradigms. Similarly, Kylie Cripps (2011) asserts that the Victoria Koori Court, established by the enactment of the Magistrates' Court (Koori Court) Act 2002, is an 'inclusive, innovative, culturally appropriate and modern approach to strategically reduce Aboriginal overrepresentation within the criminal justice system. ${ }^{211}$ In rural Liberia, a Palava Hut is a simple round open-space structure in the centre of a village built with thatch roofing and mudbricks. It is a meeting point for all villagers to resolve disputes and settle conflicts, usually headed and guided by the local chief and elders. During the Palava Hut, offenders are given the opportunity to admit to wrongdoing with the aim of seeking forgivingness from the elders and the community. ${ }^{212}$ Although there are many definitions of restorative justice as described by Zehr, and the Community Court and the Palava Hut paradigms, ${ }^{213}$ this research uses the Restorative Justice Council's definition, which states, '[r]estorative processes bring those harmed by crime or conflict, and those responsible for the harm, into communication, enabling everyone affected by a particular incident to play a part in repairing the harm and finding a

\footnotetext{
${ }^{206}$ Gerry Johnstone, Restorative Justice: Ideas, Values, Debates (Routledge, 2nd ed, 2011) 1-2.

${ }^{207}$ Karen Wilcox, 'Connecting systems, protecting victims: towards vertical coordination of Australia's response to domestic and family violence' (2010) 33(3) University of New South Wales Law Journal 1013-1037; Mary SpiersWilliams, 'Why are there no adult community courts operating in the Northern Territory of Australia?' (2013) 8(4) Indigenous Law Bulletin 7-11; Magistrates' Court of Victoria, Koori Court (2012) Magistrates' Court of Victoria <http://www.magistratescourt.vic.gov.au/jurisdictions/specialist-jurisdictions/koori-court> at 3 September 2014; Health Info Net, Galambany Circle Sentencing Court (2014) Australian Indigenous <http://www.healthinfonet.ecu.edu.au/key-resources/programs-projects?pid=1470> at 4 September 2014; Kyllie Cripps, 'Speaking up to the silences: Victorian Koori Courts and the complexities of Indigenous family violence' (2011) 7(26) Indigenous Law Bulletin 31-34. Also see the Magistrates' Court (Koori Court) Act 2002 (Vic).

${ }^{208}$ Truth and Reconciliation Liberia, 'Towards National Reconciliation and Dialogues: The Palava Hut or Peace Forums' (Government Policy 3, The Truth and Reconciliation Commission, 2009) 148, 1-2; Ellen Johnson Sirleaf, 'Annual Message on the State of the Republic: Consolidating for Continuity' (Presidential Annual Address at the Fourth Session of the 53rd National Legislature of the Republic of Liberia, Capitol Hill, Monrovia, 26 January 2015) $29<\mathrm{http} / / / \mathrm{www}$. emansion.gov.lr/2content.php?sub=55\&related=24\&third=55\&pg=sp>. The TRC recommendation for ensuring peace and reconciliation is exemplified by the Palava Hut or Peace Forums. The National Palaver Hut Program is a traditional mechanism used in rural (Indigenous) Liberia to resolve conflicts and adjudicate matters of grave concern to the community. Palava hut derives legitimacy from a host of cultural influences including the Poro, Sande, and Bodio traditional institutions and has the utmost viability in rural areas. Decisions reached through the Palava Hut are binding.

${ }^{209}$ Williams, above n 207.

${ }^{210}$ Ibid.

${ }^{211}$ Cripps, above n 207, 31.

${ }^{212}$ UN Women, Liberian Women Building Peace - Progress of the World's Women (2011) UN Women: Progress of the World's Women $<$ http://progress.unwomen.org/case-study-liberia/>.

${ }^{213}$ Marian Liebmann, Restorative Justice: How It Works (Jessica Kingsley Publishers, 2007) 25.
} 
positive way forward' ${ }^{214}$ Chapters 8 elaborates on these principles and on research participants' lived experiences of restorative justice.

\subsubsection{Scope and Limitations}

This research is not a comparative study for reasons embedded in the diverse nature of both countries' cultures, traditions, and histories. A robust comparative study necessitates the maintenance of constant environmental conditions to examine similarities and differences based on empirical observation. Since conducting such study is beyond the scope of this Ph.D. research, for the purpose of fostering debate and critical thinking, this study is limited to select Indigenous communities in Australia and Liberia.

The study considers the following polarities whilst refraining from imposing limited dichotomies such as advanced (eg, Australia) versus developing (e.g., Liberia) countries. Liberia is a post-war recovering State and Australia is not. Political, social and economic stability (e.g., access to justice or implementation of the rule of law) in Australia is relatively more organised and systematised, compared to Liberia. Australia is a continent-country (7.7 million square kilometres) whilst Liberia is one of Africa's smallest countries (111369 square kilometres), slightly bigger than the Australian state of Tasmania which is 90758 square kilometres. The population of Liberia is 4.1 million, whilst that of Australia is 24 million. Historians use the concept of Indirect Rule ${ }^{215}$ to explain the colonial governing of Indigenous Peoples in Liberia. In Australia, the strategy of assimilation describes the process of genetic admixture (i.e., miscegenation) to rid Indigenous Peoples in Australia of their existence. ${ }^{216}$ Even though the continent of Africa is considered the cradle of humankind, generally, Indigenous Peoples in Liberia do not share a common linguistic heritage or social experience with Indigenous Peoples in Australia. For example, there are only 16 major language groups ${ }^{217}$ in Liberia today, whereas about 145 of the 250 original languages still exist in Australia. ${ }^{218}$ Unlike Australia, in the earlier history of Liberia, Indigenous Peoples were recognised by the state in

\footnotetext{
${ }^{214}$ Restorative Justice Council, What Is Restorative Justice / Restorative Justice Council (2013) Restorative Justice: Providing Quality Assurance and the National Voice for Restorative Practice <http://www.restorativejustice.org.uk/what_is_restorative_justice/\#.UjBvORYm5WA>.

${ }^{215}$ Mahmood Mamdani, Define and Rule: Native as Political Identity (Harvard University Press, 1st ed, 2012); Levitt, above $\mathrm{n} 105,138$. In explaining the engrained nature of Liberia's indirect rule system, Levitt (2005) asserts that it was during the Arthur Barclay's regime that an increasingly centralised and authoritarian rule sparked a sociopolitical order that resulted in several settler-native conflicts between 1910 and 1931 . He argues that the underlying philosophy of the indirect rule system 'was to control the ruling lineages or indigenous elite who in turn controlled the African masses. The well-designed system allowed the settler ruling elite (the dominant class/authority) to use and manipulate indigenous structures to rule over the native population'.

${ }^{216}$ Catriona Elder, 'What Is the White in White Australia? A Reading of A. O. Neville, Australia's Coloured Minority' [1998] The Olive Pink Society Bulletin 28; Katherine Ellinghaus, “Absorbing the "Aboriginal Problem": Controlling Interracial Marriage in Australia in the Late 19th and Early 20th Centuries' (2003) 27 Aboriginal History 183; Katherine Ellinghaus, 'Biological Absorption and Genocide: A Comparison of Indigenous Assimilation Policies in the United States and Australia' (2009) 4(1) Genocide Studies and Prevention 59; Anna Haebich and RHW Reece, Neville, Auber Octavius (1875-1954) (1988) Australian Dictionary of Biography

<http://adb.anu.edu.au/biography/neville-auber-octavius-7821>; Auber Octavius Neville, Australia's Coloured

Minority: Its Place in the Community (Currawong Publishing, 1947).

${ }^{217}$ Wulah, above n 169.

${ }^{218}$ McConvell, Marmion and McNicol, above n 180, 3.
} 
various legal, political and social instruments via the Supreme Court jurisprudence of 'separate but equal', ${ }^{219}$ similar to the arrangement in apartheid South Africa. ${ }^{220}$ See chapter 2 for more detail on the history of Indigenous Peoples in Liberia and Australia.

Whilst there is little or no research comparing historical and cultural experiences, the parallel occurrence of systematic gender violence in the two countries is worth exploring; since, the essence of this study is to examine the 'common collective' of Indigenous experiences, whilst contributing to global gender-agenda advocacy. Indigenous groups in both Liberia and Australia refer to their social identity as 'black' even though the term has different connotations in each cultural setting. Both countries have a history of invasion and subjugation by alien settler-colonists who once had a troubled past (i.e., former convicts from the United Kingdom versus former slaves from the United States). Both States are colonies of settlers who arrived by 'boats' and dispossessed Indigenous Peoples of their native lands based on the doctrine of terra nullius. ${ }^{221}$ In both countries, the transplantation of colonial Anglo-Australian/Anglo-AmericanLiberian common law usurps Indigenous Customary laws and traditional lore. ${ }^{222}$ Although both countries have had their first female president/prime minister - indicative of some level of gender equality - the relatively high prevalence of systematic gender violence disproportionately affects Indigenous children and women. Generally, mainstream political leadership excludes Indigenous women from participating in both countries. Also, Indigenous Peoples in both countries have little or no representation within structures that govern their community or group, a diagnostic phenomenon William Easterly borrows from Rudyard Kipling called 'the Whiteman's burden'. ${ }^{223}$ That is, Indigenous Peoples are generally perceived as children who are incapable of managing their own affairs, and, hence, must be controlled by

\footnotetext{
${ }^{219}$ Marie Tyler-McGraw, An African Republic: Black \& White Virginians in the Making of Liberia (The University of North Carolina Press, 2007) 176 <http://www.amazon.com/African-Republic-Virginians-Franklin-

American/dp/0807831670>; Lawrence D Taplah, Liberia, a Bulwark of Rage My First Home (Authorhouse, 2015) 2.

${ }^{220}$ John Dugard, Human Rights and the South African Legal Order (Princeton University Press, 2015) 64 <https://doi.org/10.1515/9781400868124>. According to Dugard, in the seminal decision of Plessy v Ferguson 1896, the Supreme Court of the United States approved the constitutionality of 'separate but equal' facilities for different racial groups. In South Africa, the doctrine was approved by the Appellate Division only in 1934 in respect of subordinate legislation.

${ }^{221}$ Henry Reynolds, Aboriginal Sovereignty: Reflections on Race, State, and Nation (Allen and Unwin, 1996) 1-15; Huberich, above n 53, 254. Reynolds asserts that up until Mabo v Queensland, no. 2 (1992), European settlers and their descendants in Australia use terra nullius to set-up the Colony's legal, political and constitutional framework. He provides an insight into the case put forward by Queensland, that: '.. when in 1879, in the name of the Queen the colonial government annexed the Murray Islands it gained both sovereignty and the ownership of all the property, that from that moment forward the Islanders were only in occupation of their land with permission of the government, that in point of law they could have been driven into the sea at the time'. But of course, six of the seven judges ruled in favour of Mabo, noting that, '...Murray Islanders were entitled, as against the whole world, to possession, occupation, use and enjoyment of their traditional land. The Islanders had owned their land before 1879; they had not been disposed by the claim of sovereignty; nothing the Queensland Government had done between 1879 and 1992 had extinguished their native title' (Reynolds (1996) p2). Justice Brennan reasoned, '[t]he fiction by which the rights and interests of indigenous inhabitants in land were treated as non-existent was justified by a policy which has no place in the contemporary law of this country. The policy appears explicitly in the judgment of the Privy Council in In re Southern Rhodesia in rejecting an argument (66) ibid., at p 232 that the native people 'were the owners of the unalienated lands long before either the Company or the Crown became concerned with them and from time immemorial ... and that the unalienated lands belonged to them still' (Mabo v Queensland (No 2) [1992] HCA 23; (1992) 175 CLR 1 (3 June 1992) para 42).

${ }^{222}$ Mick Dodson, 'Customary Law and the Sentencing of Indigenous Offenders' (2008) 20(5) Judicial Officers' Bulletin 37.

${ }^{223}$ William Easterly, The White Man's Burden (Penguin Books, 2007).
} 
settler-colonists. Liberian and Australian Indigenous communities also experience land dispossession at the hands of the State.

Indigenous Peoples in Liberia and Australia have both experienced land dispossession, perpetrated by the State, in favour of multinational extraction industries and are still inundated with misappropriation of their lands, hunting grounds, water holes and sacred sites in the interest of neoliberalism (vis-à-vis greed, capitalism and exploitation). ${ }^{224}$ Susan Lawler ${ }^{225}$ describes a case in point in a La Trobe University podcast, where she discusses the utility of water in mining. Centring her presentation on the historical significance of the 'gold rush' ${ }^{226} \mathrm{era}^{2}$ in Victoria, Australia, where mining companies constructed 127 dams, Lawler examines the specific manner in which mining had impacted the environment and Aboriginal communities in the Victoria area. According to her, tunnel races as long as 24 kilometres diverted water from an upper catchment area and reintroduced it for power, steam boilers, hydraulic loosing, rock crushing and gold washing, resulting in sludge formation and water pollution. Today, projects such as Save the Kimberly ${ }^{227}$ raise awareness around the threats faced by some 30 Aboriginal language groups impacted by mining industries. Similarly, in Liberia, a report prepared by Forest Peoples Programmes highlights the struggles Indigenous Gola Peoples are experiencing with the Sime Darby Plantation project, where the government of Liberia is 'giving away' traditional lands to a foreign company for agricultural use without permission from the local people. ${ }^{228}$ Such practices are all too common in Liberia, where American, Swedish and German companies such as Firestone, the Liberian-American-Swedish Minerals Company and Bong Mining Company left track records of extraction and plundering of natural resources in exchange for little or no benefits to Indigenous communities. ${ }^{229}$ Chapter 2 provides more insights on various types of institutions/state violence inflicted against Indigenous Peoples in Liberia and Australia.

Considering these parallels between the two countries, the intention of this research project is to capture similar topical issues within a realistic time frame, insofar as available funding allows. In-depth analyses of the study include the history of colonialism and nation building, access to justice, access to social services (e.g., health, education and employment) and the practical application of Indigenous Customary Laws with respect to systematic gender violence and the rule of law. Harmful traditional practices, such as female genital cutting, forced

\footnotetext{
${ }^{224}$ Irene Watson, 'Aboriginality and the Violence of Colonialism' (2009) 8(1) Borderlands 1.

${ }^{225}$ Susan Lawler, 'Environmental Impact of Mining in Victoria (29 August 2012)'

$<$ https://itunes.apple.com/us/itunes-u/australian-history/id391323919?mt=10>.

${ }^{226}$ The discovery of gold in the early 1800s in the Fish River of Victoria converged prospectors from Asia, Europe and American, not only resulted in massive transformation of the built/natural environment but also welled up social tensions of race and division as they relate to the land usage, ownership, and destruction.

${ }^{227}$ Kirsti Melville, Red Dirt Dreaming Part One - The Kimberley (Australia Broadcasting Corporation, 2013); Save the Kimberly, Save the Kimberley: Wilderness, Culture, Heritage (2013) Home

$<\mathrm{http}: / /$ www.savethekimberley.com/>.

${ }^{228}$ Green Advocates and Forest Peoples Programme, "WWe Who Live Here Own the Land" - Customary Land Tenure in Grand Cape Mount, and Community Recommendations for Reform of Liberia's Land Policy \& Law' (Forest Peoples Programme, December 2012) 26.

${ }^{229}$ Plotzki, above n 59.
} 
marriage and denial of land and property ownership to Indigenous girls and women are also considered. An analysis of multiple data sources informs and enriches the scope and robustness of the study. Chapter 6 provides a detailed description of the research methodology.

\title{
1.0.7 Rationale of Inquiry
}

The main logic behind the study lies in a simple fact - a lack of high-quality, evidence-based research on the topic area. Herewith are three justifications for embarking on this research project:

- The pervasiveness of gender violence presents a unique opportunity to explore the effectiveness of global alliances amongst groups of similar identity struggle;

- The mechanisms by which gender violence persists have common roots which allow for a useful parallel study between Liberia and Australia;

- The perception that advanced countries are superior to developing countries in terms of political governance, economic wealth and institutional arrangements are pervasive and counterproductive. This research stands to test this perception using two globally distinct communities that are experiencing and addressing a common problem;

- Highlighting similar struggles in diverse cultures and geographies promotes the value of global alliances - termed a common collective in this research. An observation deliberated during the $57^{\text {th }}$ Meeting of the Commission on the Status of Women between 4 and 15 March 2013 affirms the need to form global alliances in responding to systematic violence against girls and women. ${ }^{230}$ According to the Commission on the Status of Women:

\begin{abstract}
that violence against women and girls is rooted in historical and structural inequality in power relations between women and men, and persists in every country in the world as a pervasive violation of the enjoyment of human rights (...) [We must] carry out continued multidisciplinary research and analysis on the structural and underlying cause of, cost and risk factors for violence against women and girls and in its types and prevalence, in order to inform the development and revisions of law (...) [and] promote the sharing of best practices and experiences, as well as feasible, practical and successful interventions and experiences in other settings.
\end{abstract}

Against this background, it is assumed that comprehensive research of this sort will provide for robust and valuable evidence-based findings that are not only needed for effective, global, legal reform to address systematic violence against girls and women and whose design can also be replicated in other jurisdictions to effect social change.

\subsection{Theoretical, Conceptual and Legal Framework}

According to the United Nations, there are approximately 370 million Indigenous Peoples in the world living across 90 countries. Indigenous Peoples across the globe speak some 7000

\footnotetext{
${ }^{230}$ Commission on the Status of Women, 57 Meeting on the Status of Women; Concluding statements aimed at eliminating and preventing all forms of violence against women and girls, 4-15 March 2013.
} 
languages and represent 5000 different cultures. Though less than five percent of the world's population, Indigenous Peoples account for 15 percent of the poorest peoples in the world. Based on mixed methodology, which includes surveys, secondary data, in-depth interviews, electronic mailing and participant observation, this research shows that contextualising the concept of intersectionality informed by multiple interrelated theoretical frameworks not only enables, but also legitimises more complex dialogues about systematic violence against this extremely diverse group of people. As Indigenous girls and women in Liberia and Australia are not homogenous, the five interrelated theories are drawn on in this research, befittingly explain the varying simultaneous locations of systematic violence and how they function together to sustain global prevalence.

Endorsers of the Convention on the Elimination of All forms of Discrimination 1965 (CERD), more importantly, recognise the effects of the by-products of systematic violence as having broader implications beyond Indigenous struggles. Hence there is a need for Indigenous women activists to link their marginalization to that of other communities such as Indigenous Africans, a concept Chandra Mohanty describes as feminism without borders. Feminism without borders is not the same as borderless feminism. Feminism without borders acknowledges the fault lines, conflicts, differences, fears, and containment that borders represent. ${ }^{231}$ That there is no one sense of a border means the lines between and through nations, races, classes, sexualities, religions, and disabilities are real; and that feminism without borders must envisage change and social justice work across these lines of demarcation and division. ${ }^{232}$ Mohanty asserts that silences and exclusions tend to draw attention to the tension between the simultaneous plurality and narrowness of borders and the emancipatory potential of crossing through and over these borders in our everyday lives. ${ }^{233}$ Angela Harris critiques feminist essentialism regarding intersections of gender, race, and other social identity as attributes relating to person value formation. ${ }^{234}$ As all women are not considered the same along the intersecting socio-economic spectrum, Harris warns against equating more powerful female voices in the legal academy, usually those of educationally privileged middle-class white women, with the perspective of all women. ${ }^{235}$ Forging the concept of a global Indigenous women's common collective, this research agrees with Mohanty's position, that adopting an anti-racist feminist perspective, beyond conceptual barriers and walls, matters in the struggle for social justice in decolonising Indigenous girls and women in both advanced economies (e.g., Australia) and the Global South (e.g., Liberia).

Patricia Smith says it may be viewed as a question mark. ${ }^{236}$ Smith argues that women are traditionally viewed not only as different but also as subordinate, a status enforced by

\footnotetext{
${ }^{231}$ Mohanty, above n 63, 2.

${ }^{232}$ Ibid.

${ }^{233}$ Ibid.

${ }^{234}$ Carle, above n 64, 226.

${ }^{235}$ Ibid 261.

${ }^{236}$ Smith, 'Four Themes in Feminist Legal Theory: Difference, Dominance, Domesticity, and Denial', above n 77, 91.
} 
institutional, cultural and interpersonal interactions and social practices of coercion and violence. ${ }^{237}$ These attitudes and practices, Smith laments, are being combated by feminist activists, but are yet widely discounted in law and largely denied in popular discourse. Smith asserts that, whilst 'male dominance' is often considered a laughable topic reserved for radical feminist fanatics, its effects (e.g., domestic violence, sexual harassment, and rape) are serious social problems that speak to the complexity of tackling systematic violence from a collective feminist movement approach, whereby, Indigenous women in Australia may not necessarily see their struggle against gender violence as similar to that of Native women in Liberia.

Notwithstanding, the issues of colonisation, racism, patriarchy, class, gender and (mental) health are all pertinent to the common experience of girls and women in both Australia and Liberia. That being said, caution is required when performing a critical analysis of the root causes of systematic gender violence and theorizing the kinds of legal mechanisms that could be harnessed to augment justice, fairness and equality for Indigenous girls and women in these two countries. A thought process that resonates with themes of the Commission on the Status of Women's $57^{\text {th }}$ Meeting is needed to end impunity by punishing perpetrators of violence, ${ }^{238}$ which is nuanced in 'other factors' referenced by the Commission on the Status of Women's definition of gender violence. Some legal feminists' support for punishing perpetrators under both national and international law attracts a pessimistic view that feminism is partly responsible for the pervasive nature of male violence against women as a 'laughable topic' ${ }^{239}$ Others believe that feminist ideology is a driving force behind the heightening levels of women inflicting violence against other women and children. Nonetheless, systematic violence is not a joke and should be targeted head-on by women of all backgrounds and identities.

Regarding feminism being responsible for the heightened level of violence against girls and women, Audrey Bolger's ${ }^{240}$ and Kerry Carrington's ${ }^{241}$ research work substantiates the assumption that female violence against children, women and men is on the rise. With particular respect to Indigenous communities, whilst it is evident that state/institutional violence exacerbates intersections of race, class, gender and indigeneity, in-group violence is arguably prevalent. Chapters 2, 3 and 4 argue that seemingly high occurrences of in-group violence are partly due to harmful traditional practices (e.g., male-only inheritance of land and property, and male elders' entitlement to sacred sites and performance of rituals). Since statistically speaking, male violence against women is disproportionately higher than the reverse relationship, this research focuses on male violence against women and the extent to which competing factors

\footnotetext{
${ }^{37}$ Ibid 93.

${ }^{238}$ Ibid at 6-7.

${ }^{239}$ Smith, 'Four Themes in Feminist Legal Theory: Difference, Dominance, Domesticity, and Denial', above n 77, 93.

${ }^{240}$ Audrey Bolger, Aboriginal Women and Violence: A Report for the Criminology Research Council and the

Northern Territory Commissioner of Police (Australian National University, North Australia Research Unit, 1991) 1. Bolger references an 18 month research study conducted in Numbulwar between 1977 and 1978 which shows that of the 101 fights recorded 51 participants were women and 53 were men, suggesting that women were involved in fighting almost as often as men, with 47 per cent of fights taking place between husband and wife.

${ }^{241}$ Young Women and Crime: Australasian Youth Justice Conference, Australian Institute of Criminology 2013 (Criminology TV, 2013) <https://www.youtube.com/watch?v=4pAZc61lWiY>.
} 
such as colonial history, race, class, gender, and indigeneity intersect to impact the applicability of restorative justice ${ }^{242}$ for survivors of systematic violence.

Cognisant of the diverse nature of gender violence, this research takes an interdisciplinary approach. It would be unrealistic to attempt a complete application of five farreaching theoretical perspectives in one study. Notwithstanding, the motivation and justification for using specific, relevant aspects of each theory to inform the study stem from the need to innovate holistic, evidence-based, multi-faceted modus operandi that represent the complexity of addressing the problem of systematic gender violence as alluded to by the Commission on the Status of Women above. The entrenched, pervasive and persistent nature of systematic violence against Indigenous girls and women demands (both practically and ethically) the incorporation of diverse techniques that are supported by hard evidence. ${ }^{243}$ It is against this backdrop that five related theories are drawn on to inform the conceptual framework of this study in hopes of bringing Aboriginal women's gender justices concerns from the margins to the centre. They are: First, intersectionality, ${ }^{24}$ which addresses the multiple ways in which race, gender, class, and the law interact to shape Indigenous girls and women's experiences of violence. Second, critical race/legal theory ${ }^{245}$ argues that the idea of race and racism should be critically analysed from a legal point of view; since social systems, such as the international and domestic law regime in settler-colonist cultures, are structured on white privilege, elitism, supremacy and power of the law. Third, feminist jurisprudence ${ }^{246}$ suggests that the law is

\footnotetext{
${ }^{242}$ James Ptacek, Restorative Justice and Violence Against Women (Oxford University Press, 2010).

${ }^{243}$ Commission on the Status of Women, Report on the fifty-seventh session Supplement 7, UN ECOSOC, $57^{\text {th }}$ sess., UN Doc E/CN.6/2013/11 (4-15 March 2013) 2. The Commission on the Status of Women 57t meeting affirms this complex and pervasive entrenchment of violence against women in general: ' 10 . Commission affirms that violence against women and girls is rooted in historical and structural inequality in power relations between women and men and persists in every country in the world as a pervasive violation of the enjoyment of human rights'.

${ }^{244}$ Crenshaw, 'Mapping the Margins: Intersectionality, Identity Politics, and Violence against Women of Colour', above n 8; Nina Lykke, Feminist Studies: A Guide to Intersectional Theory, Methodology and Writing (Routledge, 2010); Evelyn M Simien, 'Doing Intersectionality Research: From Conceptual Issues to Practical Examples' (2007) 3(02) Politics \& Gender 264; Anna Carastathis, 'The Concept of Intersectionality in Feminist Theory' (2014) 9(5) Philosophy Compass 304; Thinking Girl, Feminist Friday - Intersectional Identity (12 May 2006) Thinking Girl because women are people too <https://thinkinggirl.wordpress.com/2006/05/12/feminism-friday-intersectionalidentity/>; Susanne V Knudsen, Intersectionality - A Theoretical Inspiration in the Analysis of Minority Cultures and Identities in Textbooks, Private Document, 2006; Lykke.

${ }^{245}$ Kimberlé Crenshaw, Critical Race Theory: The Key Writings That Formed the Movement (New Press, 1995); Makau Mutua, 'Critical Race Theory and International Law: The View of an Insider-Outsider' (2000) 45 Villanova Law Review 841; Richard Delgado, Critical Race Theory: An Introduction (New York University Press, 2nd ed, 2012); Richard Delgado and Jean Stefancic, Critical Race Theory: The Cutting Edge (Temple University Press, 2nd ed, 2000); Cynthia Levine-Rasky, Whiteness Fractured (Ashgate, 2013); Emily J Cross, Critical Legal Studies: Challenging Tradition Legal Thought, National Collegiate Honours Council, 2012 <nchchonors.org/wp.../CrossEmily-University-of-Montana-Paper.pdf>; Myra Williamson, 'Critical Legal Studies, Feminism and Critical Race Theory’ (Class Lecture at the Kuwait International Law School Class, Social Theory and Law 336, Kuwait, 2012) <http://webcache.googleusercontent.com/search?q=cache:dyr8p9uzLYgJ:www.drmyrawilliamson.com/lectures/stude nt-presentations-task-sheet2.pdf $+\& \mathrm{~cd}=2 \& \mathrm{hl}=\mathrm{en} \& \mathrm{ct}=\mathrm{clnk} \& \mathrm{gl}=\mathrm{au}>$; Cornell University Law School, Critical Legal Theory (26 June 2014) Legal Information Institute <http://www.law.cornell.edu/wex/critical_legal_theory>; Matthew H Kramer, Critical Legal Theory and the Challenge of Feminism: A Philosophical Reconception (Rowman \& Littlefield, 1995); Balakrishnan Rajagopal, 'Culture, Resistance, and the Problems of Translating Human Rights' (2006) 41 Texas Journal of International Law 419; Harvard University Law School, Legal Theory: Critical Theory (26 June 2014) The Bridge <http://cyber.law.harvard.edu/bridge/CriticalTheory/criticall.htm>.

${ }^{246}$ Cheryl Suzack, Indigenous Women and Feminism: Politics, Activism, Culture (UBC Press, 2010); Joyce A Green, Making Space for Indigenous Feminism (Fernwood Pub. ; Zed Books ; Distributed in the USA exclusively by Palgrave Macmillan, 2007); bell hooks, Ain't I A Woman: Black Women and Feminism (South End Press, 1981); Patricia Hill Collins, Black Feminist Thought: Knowledge, Consciousness, and the Politics of Empowerment (Routledge, 2nd ed, 2009); bell hooks, Feminism Is for Everybody: Passionate Politics (South End Press, 2000); bell
} 
comparable to a torsion spring whereby the same law that liberates girls and women from social injustices is also responsible for their being discriminated against and subjugated. Fourth, decolonisation $^{247}$ is a fundamental element of political violence (either perpetrated by the colonised or the colonisers) that is tightly associated with the liberation and self-determination revolution and process. Fifth, social determinants of health ${ }^{248}$ is a public health principle which states that the conditions in which people are born, live, work, grow, and age, are shaped by the distribution of a host of social factors that each impact the physical, mental and spiritual health of the individual. This study further explores the concept of the law as a social determinant of health. Social determinants of health can be considered an application of intersectionality within the field of public health.

Patricia Hill Collins describes intersectionality as a way of understanding and analysing the complexity in the world, in both women and human experiences. ${ }^{249}$ Arguing that the events and conditions of social life, political and legal life and the self can seldom be understood as shaped by one factor, Collins maintains that intersectionality encapsulates the many factors in

hooks, Feminist Theory: From Margin to Centre (South End Press, 2nd ed, 2000) vol 5; Mary Jane Mossman, 'Feminism and Legal Method: The Difference It Makes' (1987) 3(147) Wisconsin Women's Law Journal 147; Hilary Charlesworth, Christine Chinkin and Shelley Wright, 'Feminist Approaches to International Law' (1991) 85 The American Journal of International Law 613; Rosemary C Hunter et al, Feminist Judgments: From Theory to Practice (Hart, 2010); Morrison Torrey, 'Feminist Legal Scholarship on Rape: A Maturing Look at One Form of Violence against Women' (1995) 2(1) William and Mary Journal of Women and the Law 35; Susan Armstrong, 'Is Feminist Law Reform Flawed? Abstentionists and Sceptics' (2004) 20(43) Australian Feminist Law Journal 43; Heather Douglas et al (eds), The Australian Feminist Judgments Project Righting and Re-Writing Law. (Hart Publishing, 2014); Diane Bell, 'White Women Can't Speak?' (1996) 6(2) Feminism and Psychology 197; Philomina E Okeke, 'Postmodern Feminism and Knowledge Production: The African Context' (1996) 43 Africa Today 223.

${ }^{247}$ Frantz Fanon, The Wretched of the Earth (Grove Press, 2004); Frantz Fanon, Haakon Chevalier and Adolfo Gilly, A Dying Colonialism (Grove Press, 1994); Reiland Rabaka, Africana Critical Theory: Reconstructing the Black Radical Tradition, from W.E.B. Du Bois and C.L.R. James to Frantz Fanon and Amilcar Cabral (Lexington Books, 2009); Radhika Mohanram, Black Body: Women, Colonialism, and Space (University of Minnesota Press, 1999) vol 6; Frantz Fanon, Black Skin, White Masks (Pluto Press, 2008); Joseph Celucien, 'Prophetic Religion, Violence, and Black Freedom: Reading Makandal's Project of Black Liberation through a Fanonian Postcolonial Lens of Decolonization and Theory of Revolutionary Humanism' (2012) 3(4) Journal of Race, Ethnicity, and Religion 1; Frantz Fanon, Toward the African Revolution: Political Essays (Grove Press, Grove Press, 1994).

${ }^{248}$ Michael Marmot, 'Social Determinants of Health Inequalities' (2005) 365(9464) Lancet 1099; Bronwyn Carson, Social Determinants of Indigenous Health (Allen and Unwin, 2007); Tom Calma, 'Creating Futures: Influencing the Social Determinants of Mental Health and Wellbeing in Rural, Indigenous and Island Peoples' (2011) 15(s1) Australas Psychiatry S5; Carson; Henrique F Tokpa, Education and Other Determinants of Income Among Heads of Households in Rural Liberia (PhD Thesis, Florida State University, 1988); Stephen R Zubrick et al, 'Social Determinants of Aboriginal and Torres Strait Islander Social and Emotional Wellbeing' in Nola Purdie, Pat Dudgeon and Roz Walker (eds), Working Together: Aboriginal and Torres Strait Islander Mental Health and Wellbeing Principles and Practice (Commonwealth of Australia, 2010) 76; Nola Purdie et al, Working Together: Aboriginal and Torres Strait Islander Mental Health and Wellbeing Principles and Practice (Australian Institute of Health and Welfare, 2010) <http://www.ichr.uwa.edu.au/files/user5/Working_Together_book_web.pdf>; Darren Dick and Tom Calma, 'Social Determinants and the Health of Indigenous Peoples in Australia - a Human Rights Based Approach' in International Symposium on the Social Determinants of Indigenous Health (Australian Human Rights Commission, 2007) 10; Wilkinson and Marmot, above n 9; Indigenous Health Adelaide, 'Social Determinants and Indigenous Health: The International Experience and Its Policy Implications' (Symposium Report, Commission on Social Determinants of Health, Government of South Australia, Canadian National Collaborating Centre for Aboriginal Health, 30 March 2007) 41

<http://www.who.int/social_determinants/resources/indigenous_health_adelaide_report_07.pdf>; Nicholas Biddle, 'Measures of Indigenous Wellbeing and Their Determinants Across the Lifecourse' (CAEPR Lecture Series 2, Centre for Aboriginal Economic Policy Research, Australian National University, 19 May 2011) 1

$<$ http://caepr.anu.edu.au/sites/default/files/page/2011/01/Lecture02Paper.pdf>; Paul Hunt, 'Missed Opportunities: Human Rights and the Commission on Social Determinants of Health' (2009) 16(1 Suppl) Global Health Promotion 36; Michael Flood and Bob Pease, 'Factors Influencing Attitudes to Violence against Women' (2009) 10(2) Trauma, Violence, and Abuse 125.

${ }^{249}$ Patricia Hill Collins and Sirma Bilge, Intersectionality (Polity Press, 2016) 2

<http://www.wiley.com/WileyCDA/WileyTitle/productCd-0745684491,subjectCd-SO10.html>. 
diverse and mutually influencing ways that generally shape the experiences of women. ${ }^{250}$ These many axes, be they race, class, gender, colonial history, or indigeneity, simultaneously work together and influence each other. ${ }^{251}$ In this regard, intersectionality, as an analytical tool, expounds and enhances access to the complexity of intersecting factors of systematic violence that Indigenous girls and women face. The idea of intersectionality helps critical legal theorists appreciate the complexity of social life by broadening the range of social and legal subordinated groups, thereby demonstrating why such analysis of intersecting factors of systematic violence on the racial impact of the law and the legal system must be highly contextualised. ${ }^{2}$

Combining political struggles for racial justice, critical race theory critiques conventional legal norms which are viewed as part of illegitimate hierarchies. ${ }^{253}$ In the 1970s, shared commitments to criticise not merely particular legal rules or outcomes but also larger structures of conventional legal thought and practice, occasioned a family of new radical legal theories called critical legal theory (CLT), which later centred on race to form critical race theory (CRT). Critical race theory is ainterpretive device scholars use to examine systematic racism across dominant legal cultures. ${ }^{254}$ According to 258 critical legal scholars, most of whom are people of colour, dominant legal doctrines and conceptions perpetuate patterns of injustice and dominance by whites, men, the wealthy, employers, and heterosexuals. ${ }^{255}$ Proponents of this school of thought argue that law is politics ${ }^{256}$ in such a way as to permit and benefit 'white privilege' ${ }^{257}$ and maintain white peoples' favoured place in society for the purpose of 'legitimately' keeping the marginalised populations down. ${ }^{258}$ Although in Liberia the dominant force of law was not the white man, but privileged Black elitist African American Former Slave Returnees, the legal framework adopted and implemented was white-male engineered AngloAmerican law. According to Crenshaw, espousers of critical race theory seeks to understand how white/elitist supremacy maintains and subordinates people and examines the relationship between social structure, racial power and professed ideals such as the 'rule of law' and 'equal protection'. ${ }^{259}$ Informed by critical race theorists, this research questions dominant modes of

\footnotetext{
${ }^{250}$ Ibid.

${ }^{251}$ Ibid.

${ }^{252}$ Mark V Tushnet, 'Critical Legal Theory' in Martin P Golding and William A Edmundson (eds), The Blackwell Guide to the Philosophy of Law and Legal Theory (Blackwell Pub, 2005) 80, 88.

${ }^{253}$ Allen Brizee et al, 'Literary Theory and Schools of Criticism' <https://owl.english.purdue.edu/owl/owlprint/722/>.

${ }^{254}$ Ibid.

${ }^{255}$ Abram Chayes et al, Critical Race Theory (2017) The Bridge - Legal Theory: Critical Theory

$<$ https://cyber.harvard.edu/bridge/index.htm>.

${ }^{256}$ Alan Hunt, 'The Theory of Critical Legal Studies' (1986) 6(1) Oxford Journal of Legal Studies 1, 3.

${ }^{257}$ Allen Brizee et al describes white privilege as various social, political, and economic advantages white individuals experience in contrast to non-white citizens based on their racial membership. These advantages can include both obvious and subtle differences in access to power, social status, experiences of prejudice, educational opportunities and much more. For critical race theory scholars, the notion of white privilege offers a way to discuss dominant culture's tendency to normalize white individuals' experiences and ignore the experiences of non-whites (see Brizee et al, Literary Theory and Schools of Criticism, 2017).

${ }^{258}$ Crenshaw, Critical Race Theory, above n 245, xiii; Osagie K Obasogie, 'Foreword: Critical Race Theory and Empirical Methods' (2013) 3(2) UC Irvine Law Review 183, 183; Roberto Mangabeira Unger, The Critical Legal Studies Movement: Another Time, A Greater Task (Verso, 2015) 2.

${ }^{259}$ Crenshaw, Critical Race Theory, above n 245, xiii; Chayes et al, above n 255.
} 
legal reasoning that pretend to be neutral and objective in dispensing justice to Indigenous girls and women, whilst sheltering structures of power. ${ }^{200}$

Critical theorists also maintain that despite claims of being just, determinate and governing expressions of power, the law mystifies outsiders about its legitimate outcomes in courts and legislatures. ${ }^{261}$ Denouncing rights as 'illusions' and 'myths' designed to mask fundamental social, political and economic inequalities, ${ }^{262}$ critical race theory maintains that judges (for instance) in the court system do not simply apply logic to the law as written, but rather seek to impose rulings that support and reinforce the status quo by looking for provisions in the law that will support their interpretation. ${ }^{263}$ Reinforcing the status quo in this manner attracts arbitrariness that the very rule of law claims to avoid because it perpetuates stereotypical cultural beliefs and stigmas. These cultural beliefs and stigmas are often racial. Therefore, empirical critical race theory attempts to critique the legal system by highlighting the effects of racial stereotypes on legal outcomes. Empirical critical race theory interrogates stereotypical descriptions of what is known as a 'crime of identity' by relying on narrative or storytelling. ${ }^{264}$ Richard Delgado captures the essence of empirical critical legal theory when he writes that, '[o]ur social world, with its rules, practices, and assignments of prestige and power, is not fixed; rather, we construct with its words, stories and silence. But we need not acquiesce in arrangements that are unfair and one-sided. By writing and speaking against them, we may hope to contribute to a better, fairer world' ${ }^{265}$ Contributing to a better world, the empirical form of critical race theory lends itself to phenomenological inquiry ${ }^{266}$ and feminist legal theory by emphasising the importance of finding ways for individuals from diverse backgrounds to share their experiences through locating their own uniqueness in their racial, class, gender, Indigenous identity and colonial history. ${ }^{2}$

Feminist legal theory or feminist jurisprudence draws from the experiences of women of diverse backgrounds and from critical perspectives developed within other disciplines to offer powerful analyses of the relationship between law and gender, thereby creating new understandings of the limits of the law, and opportunities for legal reform ${ }^{268}$ As the laws governing Indigenous women around the world have their roots in settler-colonist law, Indigenous women the world over share similar experiences in their relationship to the legal system. For Indigenous women, the scar of colonisation involves their removal from positions

\footnotetext{
${ }^{260}$ Chayes et al, above n 255 .

${ }^{261}$ Ibid.

${ }^{262}$ Ian Ward, Introduction to Critical Legal Theory (Cavendish, 2nd ed, 2004) 157.

${ }^{263}$ Anthony Walsh and Craig Hemmens, Law, Justice, and Society: A Sociolegal Introduction (Oxford University Press, Fourth, 2016) 23 <https://global.oup.com/academic/product/law-justice-and-society9780190272753 ? $\mathrm{cc}=$ us\&lang=en\&\#>.

${ }^{264}$ Mario L Barnes, 'Empirical Methods and Critical Race Theory: A Discourse on Possibilities for a Hybrid Methodology' [2016] Wisconsin Law Review 443, 444-446.

${ }^{265}$ Delgado and Stefancic, above n 245, xviii.

${ }^{266}$ Kramer, above n 245, 39.

${ }^{267}$ Brizee et al, above n 253.

${ }^{268}$ Katharine T Bartlett and Rosanne Terese Kennedy (eds), Feminist Legal Theory: Readings in Law and Gender

(Westview Press, 1991) 1 <https://westviewpress.com/books/feminist-legal-theory/>.
} 
of power, the replacement of their traditional gender roles with Western patriarchal practices, and the exertion of colonial control over their communities through the management of women's bodies and acts of sexual violence. ${ }^{269}$ In recent times, Indigenous politics have increasingly encompassed issues that cut across boundaries of nation, language, and culture. As these shifts have facilitated critical engagement with women's shared experience of the collusion between colonialism and patriarchy, the foundation has been laid for Indigenous feminists to also conceptualise their cultural and political practices. ${ }^{270}$

As gender perspectives began to reshape Indigenous politics, the growing legal recognition in settler-colonist countries of the rights of Indigenous Peoples to cultural and political autonomy brought to the fore questions about Indigenous women's access to civil rights and sovereignty. This claim to political autonomy forces Indigenous women to navigate between the private and public spheres. Entering the public sphere to advocate for justice or reforms that would improve their lives in the private sphere often leads to challenges, as women are perceived as being weak for exposing their 'dirty laundry' in public. Carol Hanisch, in her ground-breaking piece, The Personal Is Political, debunks the idea that to admit to having problems in one's life implies one is weak. ${ }^{271}$ For Hanisch, there is no 'weakness' in discussing gender violence as there is no personal solution, only collective ones in combating issues as grave as systematic violence. ${ }^{272}$ So, when private problems become a political discussion, then the personal is political. The political then becomes legal when women seek justice and equality before the law for private or domestic abuse. Therefore, feminist legal theory is especially applicable to the challenge Indigenous women face. However, it is important to recognise that feminism and feminist legal theory are predominantly Western concepts in themselves and may not apply completely to all cultures.

Indigenous African women occupy an alternative space to contemporary discourse on feminism called womanism. Resisting the stereotype of passivity and invisibility, womanism is Indigenous African women scholars' call to break the yoke of silence and challenge mainstream Western women's theorising of gender issues, which poses as a global concept for all women..$^{273}$ The concept of womanism aligns with Harris' warning regarding generalising powerful and educated white women's view of feminism to include all women. Similarly, educated Indigenous women in Western cultures do not represent Indigenous African women voices. In a way, womanism exemplifies bell hooks' phenomenon of migrating vulnerable women 'from the margins to the centre' by resisting 'exclusionary practices of privileged women who dominate

\footnotetext{
${ }^{269}$ Shari M Huhndorf and Cheryl Suzack, 'Indigenous Feminism: Theorising the Issues' in Cheryl Suzack et al (eds), Indigenous Women and Feminism: Politics, Activism, Culture (University of British Columbia Press, 2010) $1,1$. ${ }^{270}$ Ibid.

${ }^{271}$ Carol Hanisch, 'The Personal Is Political' in Shulamith Firestone and Anne Koedt (eds), Women's Liberation (Notes From the Second Year - Radical Feminism, 1969) 76, 75

<http://library.duke.edu/digitalcollections/wlmpc_wlmms01039/>.

${ }^{272}$ Ibid.

${ }^{273}$ Mary Ebun Modupe Kolawole, Womanism and African Consciousness (Africa World Press, 1997) 1-2, 18.
} 
feminist discourse, making it impossible for new and varied theories to emerge' ${ }^{274}$ Like some Indigenous women in Australia, as products of multiple subjugation (e.g., patriarchy, harmful tradition, colonialism, racism, and gender imperialism), Indigenous African women perceive womanism as the totality of feminine self-expression, self-retrieval, and self-assertion, which embraces the intersection of race, gender, class and cultural consciousness. ${ }^{275}$ Many African women, such as Ama Ata-Aidoo, Daphne Williams-Ntiri, Molara Ogundipe-Leslie, Micere Mugo, Bolanle Awe, Rebecca Njau, Ellen Kuzwayo, Chikwenye Okonjo Ogunyemi, Nawal El Saadawi and Amina Mama, who have been crying out against all forms of oppression as women, resist subscribing to the Western concept of feminism as a rejection of the imperialistic attempt to force them to accept a foreign 'ism'. ${ }^{276}$ Indeed Rose-Marie Tong acknowledges that feminist theory, like many other theories or perspectives, attempts to describe women's oppression by explaining its causes and consequences and prescribing strategies for their liberation. ${ }^{2}$

Feminism, for all its divergence, continues to join in a united call for justice for women for the fundamental purpose of reversing gender inequality. ${ }^{278} \mathrm{And}$, it is this fundamental purpose that gives rise to women's effort to explain how gender hierarchy intersects with the law to undermine the legitimacy of Indigenous women's demand for justice as paramount. This suggests that another way to strengthen a collective Indigenous feminist movement approach to gender justice is to evaluate subjugation and oppression through the lens of the decolonisation project.

Decolonisation theory recognises the effects of colonisation are intergenerational and persist after legal independence, not only in state institutions but also in cultural institutions and individuals' psyches. In 1945, when the UN was established, some 750 million people, almost a third of the world's population, were dependent on colonial powers and lived in territories that were non-self-governing. ${ }^{279}$ Articles 73 and 74, Chapter XI of the United Nations Charter 1945 declare principles to support decolonisation efforts including respect for self-determination of all peoples. To hasten the process of decolonisation, on 14 December 1960, the United Nations General Assembly adopted the Declaration on the Granting of Independence to Colonial Countries and Peoples. ${ }^{280}$ Article 1 of that Declaration affirms that ' $[\mathrm{t}]$ he subjection of peoples to alien subjugation, domination and exploitation constitutes a denial of fundamental human rights, contrary to the Charter of the United Nations and an impediment to the promotion of world peace and co-operation' ${ }^{281}$ Article 2 of the Declaration on the Granting of Independence

\footnotetext{
${ }^{274}$ bell hooks, Feminist Theory From Margin to Centre (South End Press, 1984) 9.

${ }^{275}$ Kolawole, above n 273, 24-25.

${ }^{276}$ Ibid 20-21.

${ }^{277}$ Rosemarie Tong, Feminist Thought A Comprehensive Introduction (Taylor and Francis, 2013) 1.

${ }^{278}$ Cornell, above n 76, 68.

${ }^{279}$ United Nations, The United Nations and Decolonisation (2017) History

<http://www.un.org/en/decolonization/history.shtml>.

${ }^{280}$ UN General Assembly, Declaration on the Granting of Independence to Colonial Countries and Peoples, 14 December 1960, A/RES/1514(XV), available at: http://www.refworld.org/docid/3b00f06e2f.html [accessed 16 August 2017].

${ }^{281}$ Ibid.
} 
to Colonial Countries and Peoples states that '[a]11 peoples have the right to self-determination; by virtue of that right they freely determine their political status and freely pursue their economic, social and cultural development' ${ }^{2}{ }^{282}$ More recently, Article 3 of the Declaration on the Rights of Indigenous Peoples affirms that 'Indigenous peoples have the right to selfdetermination [and] by virtue of that right they [can] freely determine their political status and freely pursue their economic, social and cultural development'. Although, since the founding of the United Nations in 1945, more than 80 former colonies have gained independence, some 17 Non-Self-Governing Territories across the globe remain colonised. Unfortunately, Indigenous Nations, which include one-half of Indigenous women, are part of the estimated two million people living in these 17 non-governing territories across the world. ${ }^{2}$

Colonisation, the imposition of the foreign laws and a central government on Indigenous Peoples, has consistently been marked by violence and armed conflict, ${ }^{284}$ as indicated by Fanon. ${ }^{285}$ However, the subjection of Aboriginal peoples to a foreign state authority does not necessarily extinguish the traditions and ways of life of its peoples. Survival of Indigenous cultures in recognisable form implies persistence of Indigenous Customary Laws. ${ }^{286}$ Hence, the question arises as to whether the acknowledgement of Indigenous custom entails some recognition of Indigenous Laws. The answer is not certain. Paul Keal argues that decolonisation from British rule in once colonised states did not necessarily give self-determination to Indigenous Peoples. ${ }^{287}$ For many, Keal maintains, decolonisation means merely exchanging one set of colonial masters for another without ordinarily acknowledging First Peoples' customs and laws. ${ }^{288}$ In former settler-colonist states such as Australia and Liberia, achieving independent status did nothing to change the situation of Indigenous Peoples who had been dispossessed of their lands, lost control of their affairs and were denied the rights of full citizenship. ${ }^{289}$ Rosa Brooks characterises supplanting colonial laws over Indigenous customs and laws as "The New Imperialism'. That is, '[i]t should go without saying that the project of intervening in "other" cultures in order to change and "improve" them is a fundamentally arrogant and imperialist project, with many pitfalls'. ${ }^{290}$ To this end, this dissertation borrows from critical legal pluralists, such as Brooks, endeavouring to listen, critique, express their view and think critically about the impact of colonial law on Indigenous Peoples. For Indigenous Peoples, the unending process of decolonisation is inextricably tied to their health and wellbeing.

\footnotetext{
${ }^{282}$ Ibid.

${ }^{283}$ United Nations, above $\mathrm{n} 279$.

${ }^{284}$ Crawford, above n 141, 178-179.

${ }^{285}$ Fanon, Toward the African Revolution, above n 247; Fanon, above n 247; Fanon, above n 247.

${ }^{286}$ Crawford, above n 141, 178-179.

${ }^{287}$ Paul Keal, European Conquest and the Rights of Indigenous Peoples: The Moral Backwardness of International Society (Cambridge University Press, 2003) 113.

${ }^{288}$ Ibid.

${ }^{289}$ Ibid

${ }^{290}$ Rosa Ehrenreich Brooks, 'The New Imperialism: Violence, Norms, and the "Rule of Law"' (2003) 101(7) Michigan Law Review 2275, 2339.
} 
The social determinants of the health model encompass conditions in which we live, work and grow. These social factors (e.g., education, employment, health and the legal system) act together to impact us, intersecting with our race, gender, class, and social status, in complex ways to produce, perpetuate and sustain inequality and injustice. Widening gaps in equity lead to repeated calls for innovative, multifaceted approaches that promote health and wellbeing, through action on social and economic determinants of health to create conditions that are conducive to improving Indigenous girls and women's growth and development. ${ }^{291}$ Both the Commission on the Status of Women's definition of gender violence ${ }^{292}$ and the five conceptual frameworks of this study underscore the complex nature of the legacy of systematic violence, a process crystallised in settler-colonists' law, yet manifested across diverse socio-economic statuses that would benefit from critical analysis and application of the social determinants of health. To address the complexity of systematic violence, such a research study must move beyond a traditional mode of simplistic and direct causal relationships towards unconventional, complex matrices of relations. Therefore, this research is informed by a cadre of theoretical and methodological approaches to appreciate the multiple interwoven factors that contribute to systematic violence against Indigenous girls and women and suggest opportunities for restoring justice to those affected.

\subsection{Contribution and Significance of Research}

Various research studies have been conducted on sexual and gender-based violence. Most are small, skilled consultancy projects sponsored by the United Nations, and few are independent academic research studies focused on health implications. Of the academic research studies conducted, almost all focus on large urban areas with few directly addressing Indigenous populations and the rule of law. Liberia and Australia were chosen as part of this Ph.D. study partly because one is considered a developing country and the other is perceived as an advanced country. As a matter of fact, during an Internet and Research Training session at Australian National University on 13 March 2013, when keywords of 'gender violence' AND 'rule of law' AND 'Australia' AND 'Liberia' were typed into Google Scholar, this research title surfaced as the number one search result. This study promises to bridge a major research gap in examining the efficacy of the rule of law in addressing gender injustices against Indigenous children and women. This research is vital and unique in that the situation of a war survivor with lived experiences of trauma and abuse returning as a researcher to the very community that once inflicted violence upon her to collect data is rare. Beyond the rarity of this research is the unusual position of the researcher's empathy and ability to gain community trust in gathering valuable data on such a sensitive topic having had a similar experience. The impetus for taking

\footnotetext{
${ }^{291}$ Paula Hanasz, 'The Social Sciences Shape the Nation' (Public Report, Academy of the Social Science in Australia Inc., 2017) $154,100<\mathrm{http} / / / w w w . a s s a . e d u . a u /$ publication/the-social-sciences-shape-the-nation/>.

${ }^{292}$ Commission on the Status of Women, 57 Meeting on the Status of Women; Concluding statements aimed at eliminating and preventing all forms of violence against women and girls, (4-15 March 2013) 2.
} 
this stance is the fact that not all are equal under the law. Hence the quest is to not only assess the efficacy of the rule of law but also to ultimately allow Indigenous girls and women to voice out their own opinions about how to engineer social change to advance their own ways of knowing, being and doing justice.

\subsection{Communication of Findings}

Upon successful completion of the study, findings and results will be disseminated using four major avenues: 1) peer-reviewed journal publications; 2) academic conference presentations; 3) seminars and colloquia organised by the National Centre for Indigenous Studies at the Australian National University, and other universities and local institutions; and 4) engagement with communities that participated in the research project.

\subsection{Personal Challenge}

Irrespective of the challenges faced by virtue of being a war survivor exposed to many forms of abuse, thinking of better ways to address systematic gender violence beyond successfully completing this Ph.D. study is personally important. The journey and process in itself are therapeutic and empowering. Thus, with years of experience advocating for gender justice and equality, coupled with strong support from the supervisory panel, the challenge is tackled headon, which adds to the value and authenticity of an original idea such as this one.

\subsection{Summary: Thesis Structure and Flow}

In summary, this dissertation adopts an interdisciplinary approach to investigating theoretical, empirical, and practical concerns of the application of the rule of law for restoring justice to Indigenous girls and women who are survivors of systematic violence in Australia and post-war Liberia. As befits interdisciplinary research, five theoretical frameworks drawn from Indigenous studies, gender studies, feminist jurisprudence, psychology, public health and international law inform the study design. Researching this topic from a legal perspective requires a law-incontext approach to robustly assess the multifaceted nature of systematic gender violence. It particularly requires the dissection of various laws and policies and an intuitive understanding of gender violence at the local, national and international levels.

Further, the role of the international community and Indigenous girls and women in these legal processes of assessing justice for all must also be considered, if any viable reform is probable. In light of these considerations, the dissertation is structured in nine chapters grouped into three major sections. The first part comprises chapters 1: Introduction, 2: Review of the Literature, 3: Violence Against Indigenous Women, and 4: The Rule of Law, which covers the background, concept and thematic review of the core literature gathered during the research. Chapter 1 introduces the historical background of violence against Indigenous women, provides key definitions operationalised in the dissertation and discusses the theoretical framework 
underpinning the research. Chapter 2 surveys relevant literature to establish existing knowledge in addition to identifying corresponding gaps in the subject area. Chapter 3 identifies the three interconnected levels of systematic violence (i.e., institutional/state, structural/cultural and interpersonal/community) and discusses their sources, prevalence and impact, using diverse case examples to explain the complex nature of systematic gender violence against Indigenous girls and women. Chapter 4 examines the efficacy of the principle of the rule of law (or equality before the law) in guaranteeing access to justice for Indigenous girls and women survivors of systematic violence. Relevant application of the Indigenous Customary Laws is also considered as a viable alternative to dispensing justice alongside the Western dominant legal system.

The second part of the dissertation includes chapters 5: Researcher's Positionality and Reflexivity, 6: Methodology and Design and 7: Findings and Results. Chapter 5 narrates a personal reflection on the research process that discloses my personal story as a survivor of gender violence. The survivor discourse used here not only frees my mind of the inherent biases I am conflicted with internally but most importantly, opens public space for me to 'speak-out' about my experience in the academy. Chapter 6 describes the methodological design of the research, outlining the procedure used to obtain, analyse, interpret and conclude the research findings. Chapter 7 presents the major findings and results gleaned from historical, textual, statistical, electronic and empirical data gathered through stationary, observatory and fieldwork studies.

The final part entails chapters 8: Discussion and Analysis and 9: Conclusion and Recommendation. Chapter 8 discusses, critically analyses, synthesises, assimilates and collates major findings produced from the research data by interweaving theoretical frameworks with textual materials and empirical findings to explore possible relationships, parallels and associations between systematic gender violence and the rule of law pertinent to Indigenous girls and women in Australia and post-war Liberia. The relationships and connections induced from the research are not intended to be generalizable, as the data collected is not structured to show statistical significance. Chapter 9 concludes the dissertation with some useful recommendations for law and policy reform to enhance gender justice for Indigenous girls and women. 


\title{
CHAPTER 2: A REVIEW OF THE LITERATURE
}

\begin{abstract}
Among those torn by the antipodal relationship between their democratic ideals and their tyrannical dominion over slaves, and thus attracted to the concept of black removal, was Thomas Jefferson, author of the Declaration of Independence, third president of the United States, and Virginia planter. As early as 1776, Jefferson, a member of the Virginia legislature, had come to the conclusion that the migration of blacks beyond American borders might resolve his own moral dilemma as a revolutionary slaveholder and free the country from this unflattering quandary as well. ${ }^{293}$

My Lords, the several goals and places for the confinement of felons in this Kingdom being in so crouded [sic] a State ... I ... signify to your Lordships His Majesty's Pleasure, that you do forthwith take such measures as may be necessary for providing a proper number of vessels for the conveyance of 750 convicts to Botany Bay, together with such Provisions, necessaries and implements for agriculture as may be requisite for their use after their arrival...294
\end{abstract}

\subsection{Introduction}

A survey of relevant literature in this research is crucial for determining established knowledge and corresponding gaps on systematic violence against Indigenous women. Although there is a wealth of resources on the three separate topics, no study combines 'gender violence' and the 'rule of law', against 'Indigenous Peoples in Liberia and Australia'. Informed by the five theoretical frameworks described in chapter 1, this chapter explores relevant data sources across disciplines (see Table 2.1). The literature review process of this research was conducted in three phases: the search phase, the gap identification phase, and the assessment phase. The first phase entailed locating relevant materials. In the second, the literature was examined to identify discrepancies in the research area. The final phase explored opportunities where this research study could expand and contribute to the field. The review of the literature is divided into three chapters comprising a general thematic overview (chapter 2), 'Violence against Indigenous Girls and Women' (chapter 3) and 'The Rule of Law' (chapter 4).

The literature review assesses systematic gender violence in Liberia and Australia broadly regarding its history, impact, and consequence since there is no comprehensive research on the topic. The review process offers an opportunity to delve into a small but detailed critical appraisal of what relevant resources are available. Conducting research in Australia in 2014, some 1400 items were scoured from diverse sources including the Australian National University Libraries; the Australian Institute of Aboriginal and Torres Strait Islander Studies; the National Library of Australia, the National Archives of Australia; the National Film and Sound Archive, the Australian Institute of Criminology; Parliament of Australia; the Australian Institute of Health and Welfare, the Department of Families, Housing, Community Services and Indigenous Affairs; University of Tasmania's Riawunna Centre, and the Cascade Female

\footnotetext{
${ }^{293}$ Clegg, above n 58, 21.

${ }^{294}$ Andrew Tink, Lord Sydney: The Life and Times of Tommy Townshend (Australian Scholarly Publishing, 2011) Back Cover.
} 
Factory, Port Arthur, amongst others. A considerable amount of literature, mostly historical, anthropological, and legal, has been published on 'gender violence against women and law', generally, and 'gender violence against Aboriginal women and law', specifically, in Australia. However, the same cannot be said for Liberia.

There is a dearth of contemporary academic resources concerning gender violence and the rule of law in Liberia. This lack of academic resources for Liberia exist primarily because the country has not gained the attention of Western research institutions interested in conducting research or publishing data. Moreover, the moderate infrastructure that was available to support academic research before 1989 was destroyed during the Liberian civil war and is still in dire need of repair or reconstruction. As a result, in the last two decades, the majority of the resources produced regarding gender violence in Liberia are grey literature, i.e. unpublished reports, dissertations, and out of print pamphlets. Currently, newsprint and United Nations publications are the most common sources of information about violence against girls and women in Liberia. Relevant journal articles and books on gender violence in Liberia tend to predate 1989 and are almost impossible to obtain. A visiting scholar position with the University of Washington School of Law, from January to December 2015, opened access to resources on the legal history and founding of Liberia, which was not easily available in Australia. These obstacles explain the relative over-reliance on newsprint and non-academic materials on Liberia. However, it also highlights the value of research such as this, as an opportunity to begin capturing and analysing primary sources of data and contributing them to the literature.

A rigorous and continuous method was applied to the literature review process. Although materials were continuously searched and used throughout the Ph.D. study, the focused literature review effort involved locating and reviewing sources using Zotero, EndNote and Excel over a period of 24 months. Materials obtained were sub-divided into six groups: 1) general readings; 2) introduction; 3) literature review; 4) methodology and design; 5) results and analysis; and 6) discussion. After each resource had been selected and summarised, six key themes emerged. Resources pertaining to each thematic component were further subdivided into three subcategories, $a, b$ and $c$, where ' $\mathrm{a}$ ' indicated essential material; ' $\mathrm{b}$ ' a somewhat important source; and 'c' a source generally or tangentially linked to the subject matter. All subcategory ' $a$ ' materials were examined thoroughly using a critical review grid. A composite matrix for comparison and distinction collated summary findings of the literature review. Discursive arguments and inferences arising from the themes situate systematic gender violence and the rule of law in Indigenous Australia and Post-war Liberia within a niche of work done in this area. As a result, this study is positioned to contribute to the wider discourse on violence against Indigenous Peoples. 


\title{
2.1 Thematic Components
}

The grounded theory approach informs the literature review in that keywords, phrases, and contents signal emerging themes. According to Glaser and Strauss, who first described the method, grounded theory is 'the discovery of theory from data - systematically obtained and analysed in social research... [which] fits empirical situations... [and] provides us with relevant predictions, explanations, interpretations and applications'. ${ }^{295}$ Following Glaser and Strauss' grounded theory for the literature review process directs the study to examine the research question in the context of existing knowledge. As a result, the six major themes discussed in this chapter were not predetermined but rather flowed out of resources obtained.

The themes discussed in this chapter are arranged in a logical order, starting with the history of Indigenous Peoples in both Australia and Liberia. Irrespective of the thematic topic, the literature review shows strained relationships between settler-colonisers and Indigenous Peoples. Whether explicitly written or implied, there is discernible evidence that the social, political, and legal interactions between settler-colonists and Indigenous Peoples during the formation of the colonial state were not always peaceful and respectful. In fact, in most instances, the law, legal system, and institutions were used as a colonial tool of control, authority, discrimination, subjugation, and exclusion of Aboriginal Peoples. The literature review also reveals some disturbing inter se relationships in Aboriginal society. However, many of those harmful inter se relationships have their roots in structural or cultural violence inflicted on Indigenous Peoples by settler-colonists through the nation-state building process. As a result, the entire nation-building process in both Liberia and Australia was underpinned by brute force and cultural and institutional violence.

\subsubsection{Theme 1: History, Indigeneity/Aboriginality, Politics and Governance}

\begin{abstract}
Those who have no record of what their forebears have accomplished lose the inspiration which comes from the teaching of biography and history, [but] what we need is not a history of selected races or nations, but the history of the world void of national bias, race hate, and religious prejudice. ${ }^{296}$ Carter Godwin Woodson, Distinguished author and Father of Black History
\end{abstract}

History, pertinent to the (de)colonisation process, sovereignty, and recognition of Indigenous Peoples, is integral to this research study. Antony Anghie affirms that colonial practices of cultural subordination and economic exploitation play a role in generating an important analytic understanding of contemporary institutional governance. ${ }^{297}$ Therefore, any possibility of curbing systematic gender violence involves a tie between Liberia's and Australia's historical pasts before settler-colonists arrived. Because settler-colonists' institutional governance is

\footnotetext{
${ }^{295}$ Barney G Glaser and Anselm L Strauss, The Discovery of Grounded Theory: Strategies for Qualitative Research (Aldine Transaction, 1967) 1.

${ }^{296}$ National Association for the Advancement of Coloured People, NAACP History: Carter G. Woodson (2015) NAACP History <http://www.naacp.org/pages/naacp-history-Carter-G.-Woodson>.

${ }^{297}$ Antony Anghie, 'Colonialism and the Birth of International Institutions: Sovereignty, Economy, and the Mandate System of the League of Nations’ (2002) 34 New York University Journal of International Law 513.
} 
characterised by systematic violence, the impact of colonial history on Indigenous peoples is assessed from two perspectives: a) documentation of Indigenous forebears' existence and their contribution to nation-building without bias, racial hate, and religious prejudice; and 2) composition of the current social, political, legal, and religious structures connecting indigeneity with exclusionary settler-colonists' governance, which constitute both subtle and explicit forms of systematic violence. An overview of four locations selected in each country for this study follows a law-in-context historical brief. The historical brief uniquely locates Australia and Liberia within the confines of the research methodology, data collection, findings, and discursive analysis (see Appendix III).

\title{
- Liberia (Land of the Free): The Grain Coast
}

The African continent prides itself on being the cradle of humankind. Recent fossil discoveries in the Afar region of Ethiopia establish the presence of Homo [our genus] at 2.80 to $2.75 \mathrm{Ma}$ [million years ago]. ${ }^{298}$ However, archaeological evidence to support prehistoric inhabitation of Liberia's Grain Coast (formally part of Upper Guinea Coast, remotely shielded from the outside world ${ }^{299}$ is scarce. In the early 1970s, archaeologists and anthropologists struggled to piece together the prehistoric habitation of the land area now called Liberia. Frederick D. McEvoy expresses frustration with difficulty in obtaining prehistoric human archaeological evidence on Liberia:

\begin{abstract}
At the conference on Liberian Research and Scholarship held at Robertsport in 1967, it was emphasized in some discussions that there existed at that time "a serious lag" in the development of knowledge pertaining to the prehistory of the region of West Africa which is now included within the boundaries of the Republic of Liberia. The final report of the conference concluded that, "no archaeological work has been done in Liberia, and no Liberians have been or are being trained in this field" ${ }^{300}$
\end{abstract}

Earliest accounts of migration to Liberia started in the $8^{\text {th }}$ century. The Dahn [Gio], Kpelle, Loma, Gbandi, Mende, Vai, ${ }^{301}$ and Mandingo involuntarily migrated at different times, between the $8^{\text {th }}$ and $18^{\text {th }}$ centuries, due to socio-political and economic crises within the Sudanic Empire. ${ }^{302}$ Unfortunately, since the arrival of African American settler-colonists to Liberia in the early 1800s, not much has changed by way of current scholarship on prehistoric Liberia. Of the estimated 270 resources consulted under this theme, none provided substantial information on

\footnotetext{
${ }^{298}$ Brian Villmoare et al, 'Early Homo at 2.8 Ma from Ledi-Geraru, Afar, Ethiopia' (2015) 347(6228) Science 1352.

${ }^{299}$ Guannu, above n 100, 10; Karnga, above n 171, 20. According to Guannu, the name Malaguetta pepper was given to the territory lying between Cape Mesurado and Cape Palmas. Later, when the British and French came, they named the same area the Grain or Pepper Coast. From Karnga's account, the settlers' third attempt to purchase land from Indigenous Liberia later landed them on Providence Island on 7 January 1822. By April of the same year, the Grain/Pepper Coast (as it was called by early Spanish explorer due to the high presence of Malaguetta pepper) was names Liberia (Liber $=$ free in Latin) by Goodloe Harper. Harper was a member of the US senate from Maryland in 1816. The capital city of Maryland County is name after him.

${ }^{300}$ Frederick D McEvoy, 'Some Proposals for Liberian Archeology' (1970) 111(1) Liberian Studies Journal 129.

${ }^{301}$ Nnamdi Azikiwe, Liberia in World Politics (University of Michigan, 1934) 22-23. NB: the Vai and Bassa, without European aid, invented a written language.

${ }^{302}$ Dunn, Liberia, above n 103, 9; Sawyer, The Emergence of Autocracy in Liberia, above n 61, 44-48.
} 
the existence of Liberia before the $1800 \mathrm{~s}^{303}$ except for the tangential reference to the regions by both Liberian and foreign scholars. ${ }^{304}$ Historians, who are often non-Africans or non-Liberians, begin Liberian history from 1820, when the first cargo of African American former slaves ${ }^{305}$ from New York, United States, embarked on their tumultuous journey to 'freedom' on the West African coastline. ${ }^{306}$ Assuming an 1820 historical beginning is not only disrespectful to Native Peoples in Liberia but is also highly contentious, as pre-Liberia existed long before African American settler-colonists arrived on the Grain Coast. ${ }^{307}$ The land was already occupied by Native Peoples when Europeans first arrived in the $15^{\text {th }}$ century.

By the $15^{\text {th }}$ century, Europe's insatiable thirst for trade, empire expansion and land grabbing, led them to the coast of Africa. The earliest European arrivals included the Portuguese, who entered the Grain Coast in 1461. They named Cestos, Sanquin, Cape Mount, Cape Palmas, and Cape Mesurado on the Atlantic coast of present-day Liberia. The $15^{\text {th }}$ century marks the beginning of the trans-Atlantic slave trade in Africa. A spike in the trans-Atlantic slave trade began at the end of Portuguese trade in the $15^{\text {th }}$ century, in which an estimated 300000 persons (or 11.6 percent) of the 5.6 million slaves exported out of Africa between 1690 and 1807 were from the Grain Coast. ${ }^{308}$ The slave trade left a mark on the whole of West Africa that also has unique implications for Liberia. By 1847, African-American settler-colonists had established

\section{Table 2.1: Population characteristics of Liberia 1992 and} 2008

\begin{tabular}{llllll} 
Language & $\mathbf{1 9 7 2}$ & $\mathbf{2 0 0 8}$ & Foreign Born & $\mathbf{1 9 7 2}$ & $\mathbf{2 0 0 8}$ \\
Kpelle & 211,081 & 705,554 & Guinea & 8,579 & 33,746 \\
Bassa & 165,856 & 466,477 & Ghana & 6,896 & 6,744 \\
Gio & 83,208 & 267,923 & Sierra Leone & 4,685 & 11,816 \\
Kru & 80,813 & 209,993 & Lebanon & 2,077 & 831 \\
\cline { 1 - 2 } Grebo & 77,007 & 348,758 & USA & 1,876 & 431
\end{tabular}

${ }_{303}$ Amos Jones Beyan, 'Transatlantic Trade and the Coastal Area of Pre-Liberia' (1995) 57(4) The Historian 757; Andreas W Massing, An Inferential History of Pre-Liberia, 1460-1490: Mapping Liberia - a Conjectural History of Earpy Laberia' (Liberian Studies, Associationly Annual Conference at the German Technical Corporation (GTZ), MGrablia, Liberia2,532March 320085 $\quad$ Mali $\quad 565 \quad 1,209$

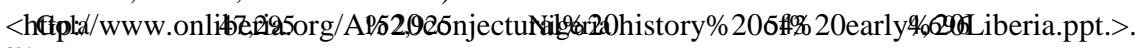

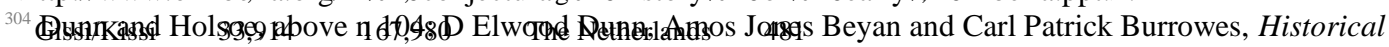

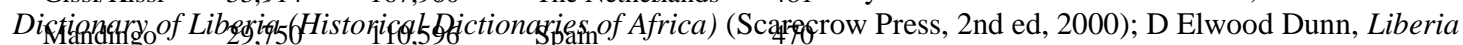
(CLIO Press, 1995); Karnga, above n 171; Cassell, above n 53; Wreh, above n 166; Guannu, above n 100; Huberich, above n 53; Liz APden Wily, ${ }^{2}$ So $^{2}$ tho Owhs the Forest? An Privestigation into Forest Ownership and Customary

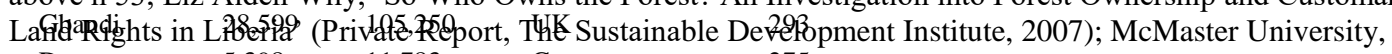

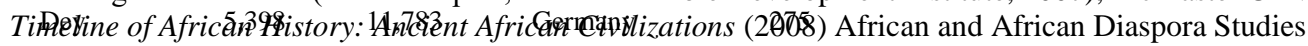

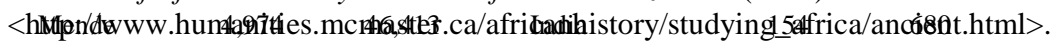

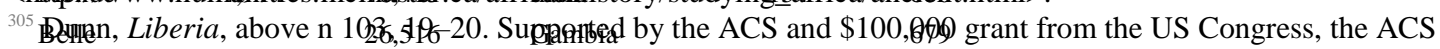

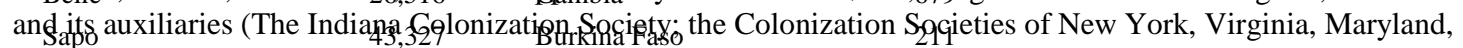
Mississippi, and the Young Men Colonization Spciety of Pennsylvania) begun an expedition from New York Harbour on 31 January 1820 .

${ }^{306}$ Ibid 17. According to Dunn and Tarr ' $[\mathrm{t}]$ he America sense of moral guilt (atonement) resulting from the inhumanities of the slave trade and slavery spanning the Revolutionary period througDther dyeafrionm the Liberian corbny. It involved as much the activities of private persons as of government officials. In 1691 the Virginia legislature enacted a law that forbade emancipation of slaves unless linked to deportation from thefrelpny. A group of Quakersin Germantown, Pennsylvanian, under George Keith's inspiration elaborated in 17,13 a colonization plan that envisaged the colonization of Africa of Westernized blacks as a means of bringing 'crivilization, Christianity and legitimate commerce' to Africans. The Rev. Samuel Hopkins of Rhode Island is credited for a 1773 idea of a missionary effort in Africa to be undertaken by properly trained black Americans'. N/African 117

${ }^{307}$ Fred PM van der Kraaij, 'The Grain Coastopdalaguetta Coast or Peppez (Coast before 1822'.

${ }^{308}$ Dunn, Liberia, above n 103, 12-14. Notempdthymednida930, former Presigtent Charles Dunbar Burgess King was accused of slavery by the League of Nationsafter rounding up Indigenouszziberians to work as labour on a cocoa plantation in Spanish Colonial Equatorial Gyinea with pay. 
Indigenous groups had on the development of modern Liberia because of a lack of research evidence. ${ }^{309}$ However, the trans-Atlantic slave trade is central to Liberia's history, as colonistsettlers to Liberia were descendants of Native Africans who were sold into slavery. ${ }^{310}$ AfricanAmerican returnees, whose ancestors walked their native lands of West Africa 400 years prior, became settler-colonists in the land of their forebears. These African descendants with their newfound identity as 'freed slaves' participated in violent frontier battles and unfair land negotiations with their Native African brothers and sisters. In years to come, they would claim control and assert political, legal, and social power over Native Peoples in Liberia for at least 133 years (1847-1980) but with very little development of the country.

Azikiwe recognises Liberia's peculiar position as Africa's oldest republic:

It is one of the few independent sovereignties of that vast continent, and is the only one on the whole Atlantic seaboard. It has exercised sovereign attributes for half a century, competently contracting treaties with foreign states, and preserving its sphere of legitimate control peacefully among the interior tribes and along the coast, in virtue of formal treaties of cession dating back to its earliest history. At no time has Liberia trespassed on the domain of its neighbours or invaded their comparatively recent sphere of influence. Ever paying due respect to the rights of other sovereignties, its attitude has entitled it to unquestioning respect for its own vested right and to especial sympathy for is fruitful mission to fulfil what Baron Lambermont has well called 'une mission civilisatrice pour la Cote de Guinee'. ${ }^{311}$

However, as will be seen in chapters 3 and 4, systematic violence orchestrated against Native Peoples in Liberia during state formation undermines Liberia's claim to being 'a civilising mission for the coast of Guinea'. ${ }^{312}$

Despite Liberia's being the oldest republic in Africa, the 'civilising' efforts of the country's founders did not result in economic, legal, or social systems that benefit Liberia's Indigenous citizens. Though perceived as one of the richest countries in natural resources, ${ }^{313}$ Liberia is also one of the world's poorest countries. ${ }^{314}$ Writing in the 1930s, Azikiwe saw

\footnotetext{
${ }^{309}$ Liebenow, above n 55, 36.

${ }^{310}$ Cassell, above n 53, 1 .

${ }^{311}$ Azikiwe, above n 301, 18-19.

${ }^{312}$ Ibid 19.

${ }^{313}$ Government of Liberia, 'Liberia Demographic and Health Survey 2013' (Government Report, Liberia Institute of Statistics and Geo-Information Services, August 2014) 480, 7, 9 <http://dhsprogram.com/what-we-do/survey/surveydisplay-435.cfm>; Kira Kay, 'For Liberia, Natural Resources Are Blessings, Curses on Road to Democracy' $P B S$ Newshour (Arlington, VA), 31 October $2011<$ http://www.pbs.org/newshour/bb/world-july-dec11-liberia_10-31/>. Of the 9333 household interviewed in the Liberia Demographic Health Survey, 2013, only 14 per cent of household use improved toilet facilities, 45 per cent have no toilet facility at all, 90 per cent have no access to electricity, 98 per cent use fuel [wood] for cooking, 1 in 4 children under 5 has a birth certificate, 47 per cent of females and 33 per cent of males age 6 years and old have never attended school. In the PBS Newshour report, President Ellen Johnson Sirleaf attests, 'Liberia is natural resource-rich. We have minerals. We have agriculture. We have marine resources. If we discover oil, added to the other natural resources we have, that transformation is very possible. Liberia's experience, in a way, has been a resource curse. We have always had these natural resources. They just haven't been used well for development of the people'. But PBS Special Correspondent, Kira Kay, squarely hammers down Liberia's main challenge to realising growth and development, '[u]nequal access to the benefits of natural resources created societal rifts that led to war in Liberia. Diamonds and timber bankrolled warlord President Charles Taylor'.

${ }^{314}$ Khalid Malik \& United Nations Development Programme, Human Development Report 2013: The Rise of the South: Human Progress in a Diverse World. (2014) 162, 166, 170, 174, 178, 187

<http://issuu.com/undp/docs/hdr_2013_en?mode=window> at 28 March 2013; Malcolm McPherson \& Kpedee Woiwor, National Human Development Report 2010: Liberia (2010) 14

<http://hdr.undp.org/sites/default/files/liberia_2010.pdf>; Economywatch, 'Why Liberia has not been able to break
} 
Liberia's agricultural system as primitive. Although, its 'native traditions predominate the society,' Azikiwe laments that 'there are no first-class harbours, there are no railroads, the principal highway routes total about 1000 mileage, and the postal system is not advanced'. ${ }^{315}$ Based on both the Liberia Demographic Health Survey ${ }^{316}$ and the United Nation's Human Development Report, ${ }^{317}$ Azikiwe's observations about Liberia remain valid today, especially regarding the court system. ${ }^{318}$

Despite the challenges still faced by Liberians, the country has grown significantly since 1847. According to the National Population and Housing Census the population of Liberia in 2008 was 3476 608, with an annual growth of 2.1 percent $^{319}$ (see Table 2.1). Then, 50 percent of Liberia's 3.4 million inhabitants were female. Although Monrovia is home to more than half of Liberia's population, Native Peoples occupy the vast majority of the 15 counties but have little or no access to basic amenities (see Table 2.2). ${ }^{320}$ Today, Liberia's rich population mosaic

its resource curse', Oil Price, 25 November 2012, at http://oilprice.com/Geopolitics/Africa/Why-Liberia-Has-NotBeen-Able-to-Break-its-Resource-Curse.html.

${ }^{315}$ Azikiwe, above n 301, 25, 28-29.

${ }^{316}$ Liberia Institute of Statistics and Geo-Information Services et al, 'Liberia Demographic and Health Survey 2013' (Government Report, LISGIS, 2014) 480. The UNDP Human Development Index (HDI) ranks Liberia at 177 out of 188 countries.

${ }^{317}$ UNDP, 'Human Development Report 2015: Liberia' (UN, United Nations Development Program, 2015) 7, 2 <http://hdr.undp.org/sites/all/themes/hdr_theme/country-notes/LBR.pdf>.

${ }^{318}$ Liberia Institute of Statistics and Geo-Information Services, 'National Population and Housing Census' (Government Report, Liberia Institute of Statistics and Geo-Information Services, 2009) 352, 7; Government of Liberia, 'Grand Kru County Development Agenda' (Government Report, Ministry of Planning and Economic Affairs, 2008) 76, 18 <http://www.mia.gov.lr/doc/Grand\%20Kru\%20CDA_web.pdf>. According to the Grand Kru County Development Agenda (2008), majority of these facilities are in extremely deplorable conditions. Some are actually non-functioning or non-existent. For example, here is what the CDA report has to say about the rule of law: ' $[\mathrm{t}$ ] here is a Circuit Court in Barclayville [capital city of Grand Kru) but it is not operational due to the absence of the Circuit Judge. There is no Resident Judge for the 12th Judicial Circuit Court. The November Term of Court [in 2008] was opened ceremonially without a judge. There is also a Debt Court, Traffic Court, Revenue Court and a Magisterial Court in Barclayville. There are twenty-eight magisterial courts, operated by 28 stipendiary magistrates and 56 associate magistrates in the rest of the County, all operating from private homes'.

${ }^{319}$ Liberia Institute of Statistics and Geo-Information Services, above n 318, 6-7.

${ }^{320}$ Government of Liberia, 'Bomi County Development Agenda' (Government Report, Ministry of Planning and Economic Affairs, 2008) 70, 24 <http://www.mia.gov.lr/doc/Bomi\%20CDA_web.pdf>. During the civil war, some of the schools were burnt down whilst others were looted. Few have been rehabilitated. Approximately 50 per cent of 95 primary schools in Bomi have no latrines or safe drinking water; The total number of schools in Bong includes fourteen high schools with one private university and one 1 technical college (also see LISGIS, 'Bong county profile' (2013), available at

<http://www.lisgis.net/county.php?\&fd0e78b77a58d689bbb27b3e1c037717=Qm9uZw\%3D\%3D>. Government of Liberia, 'Grand Kru County Development Agenda', above n 318, 25. Grand Kru has an education supervisory team with a County Educational Officer (CEO) and eight District Education Officers (DEOs). However, of the 166 schools counted, only five are equipped with desks, chairs, students and trained teachers. Government of Liberia, 'Margibi County Development Agenda' (Government Report, Ministry of Planning and Economic Affairs, 2008) 70, 26 <http://www.mia.gov.lr/doc/Margibi\%20CDA_web.pdf>. NB: Of the 290 educational facilities in Margibi, only 50 are functional. Government of Liberia, 'Maryland County Development Agenda 2008-2012' (Government Report, Ministry of Planning and Economic Affairs, 2008) 68, 29. The education sector in Maryland is in a very poor state, with most schools dilapidated from years of neglect. Government of Liberia, 'Sinoe County Development Agenda' (Government Report, Ministry of Planning and Economic Affairs, 2012) 84, 29-30

<http://www.emansion.gov.lr/doc/SinoeCDA.pdf>. All of the schools operating in Sinoe County are below minimum standards and are either run from private homes or church buildings or mosques. A total of 730 teachers (mainly based in Greenville, the capital city) serving the 17,715-enrollment population, three hold a Master of Science degree, three Bachelor of Arts, 17 Bachelor of Science, six Associate degrees, and the remainder 172 hold either A or B certificates to teach only elementary level. Many of Grand Bassa 257 educational facilities are operated by volunteers in makeshift fixtures in churches and private accommodations, sometimes with no chairs and desks available for students use (Government of Liberia, Grand Bassa County Development Agenda (2012) 28). Of the 1096 schools reported in Montserrado, 757 is found in greater Monrovia alone, serving a population of $\sim 750000$. In 2006, the Norwegian Refugee Council recorded only 209 functioning schools in Montserrado. Government of Liberia, Montserrado County Development Agenda (2008) 30). There is a general lack of modern school buildings in River 
comprises Native Peoples, American and Caribbean returnees, ${ }^{321}$ and expatriates of Lebanon, India, Europe, and other African and American countries (see Table 2.2). ${ }^{322}$ The 16 major Language Groups in Liberia are part of the Niger-Congo area and belong to four families: 1) Atlantic-Congo (Kru, Bassa, Belle, Dei, Grebo, and Krahn: 2) Atlantic-Mel (Gola and Kissi); 3) Mande (Gbandi, Gio, Kpelle, Loma, Mandingo, Mano, Mende, and Vai); and 4) Indo-European. All of the Language Groups in Liberia are phonetically related, which is an indication of some level of connection between Native Peoples in that region of Africa. ${ }^{323}$ Of the 15 counties in Liberia, this research focused on four counties that represent a variety of geographic locations, with diverse Language Groups and varying economic conditions.

\section{Lofa County}

Lofa County, located in the north-western corner of Liberia, was established in 1964. The political establishment of Lofa is a symbol of unity, as displayed in the regional flag. Lofa has seven political districts: Foya, Kolahun, Salayea, Vahun, Voinjama (the capital), Zorzor, and Quardu Gbondi with one township. Lofa has six major language groups: Lorma, Kissi, Gbandi,

\begin{tabular}{|c|c|c|c|c|c|c|c|}
\hline County & Female & Males & Total $(\%)$ & $\begin{array}{l}\text { Sex } \\
\text { Ratio }\end{array}$ & College $^{1}$ & School & Health \\
\hline Bomi & 41,179 & 42,940 & $84,119(2.42)$ & 104.3 & 1 & 105 & 17 \\
\hline Bong & 168,622 & 164,859 & $333,481(9.62)$ & 97.8 & 1 & 367 & 33 \\
\hline Gbarpolu & 39,482 & 43,906 & $83,388(2.40)$ & 111.2 & 0 & 63 & 12 \\
\hline Grand Bassa & 110,780 & 110,913 & $221,693(6.39)$ & 100.1 & 1 & 257 & 31 \\
\hline Grand Cape Mount & 62,133 & 65,679 & $127,943(3.70)$ & 105.7 & 1 & 124 & 33 \\
\hline Grand Gedeh & 60,264 & 64,994 & $125,258(3.61)$ & 107.8 & 1 & 266 & 17 \\
\hline Grand Kru & 28,265 & 29,648 & $57,913(1.67)$ & 104.9 & 0 & 166 & 12 \\
\hline Lofa & 143,252 & 133,611 & $276,863(7.98)$ & 93.3 & 1 & 297 & 49 \\
\hline Margibi & 104,083 & 105,840 & $209,923(6.05)$ & 101.7 & 1 & 290 & 36 \\
\hline Maryland & 65,083 & 70,855 & $135,938(3.92)$ & 108.9 & 1 & 151 & 23 \\
\hline Montserrado & 568,508 & 549,733 & $1,118,241(32.25)$ & 96.7 & 2 & 1096 & 165 \\
\hline Nimba & 231,913 & 230,113 & $462,026(13.32)$ & 99.2 & 1 & 554 & 41 \\
\hline River Cess & 34,285 & 37,224 & $71,509(2.06)$ & 108.6 & 0 & $\begin{array}{l}\text { No } \\
\text { data }\end{array}$ & 10 \\
\hline River Gee & 31,926 & 34,863 & $66,789(1.93)$ & 109.2 & 0 & 120 & 14 \\
\hline Sinoe & 47,624 & 54,767 & $102,391(2.95)$ & 115.0 & 0 & 175 & 5 \\
\hline Total & $1,739,945$ & $1,736,663$ & $3,467,608(100.27)$ & 100.2 & 11 & 4031 & 481 \\
\hline
\end{tabular}

Source: Adopted from LISGIS' National Population and Health Census Data (2009) available at $<$ http://www.lisgis.net $>$ and the County Development Agendas (2008) prepared by the Ministry of Planning and Economic Affairs available at < http://www.mia.gov.lr/>

Kpelle, Mande, and Mandingo, all of which maintain the Poro and Sande institutions, which are

Gee. Most schools have not chairs and/or desks for student use. There is an immense lack of trained teachers, even though there is one primary school teacher training institute: the Webbo Rural Teacher Training Institute (see, Government of Liberia, River Gee County Development Agenda (2008) 26).

${ }^{321}$ Martin, above n 184, 9. In 1859 a Jamaican, Robert Campbell (a teacher and chemist) joined Afro-American, Martin R. Delany, in an expedition to explore the Niger Valley (present day Nigeria) with the purpose of returning and re-settling West Africans there. As a result of the US Civil War, couple with British occupation of Nigeria, the plan did not pan out. In 1965, in consultation with President Daniel Bashiel Warner (who was also concerned about integrating Indigenous Liberians in to the wider society) and Edwin Wilmot Blyden (then Secretary of State) 346 Barbadians sponsored by the ACS emigrated to Liberia and settled in Crozerville. ${ }^{321}$ Springing out of the Barbadian emigrants to Liberia is (to name but a few) Arthur Barclay (president, 1904-1912), Edwin Barclay, nephew of Arthur (Secretary of State, 1920-1930 and Acting President, 1930-1944), and Mary Antoinette Brown Sherman, first female president of the University of Liberia. Other emigrant to Liberia of Afro-Caribbean heritage were Edwin Wilmot Blyden born in St Thomas, Danish West Indies (US Virgin Islands) to free black parents from the Igbo tribe of present-day Nigeria. Blyden is considered the father of pan-Africanism. As a writer, he was the editor of the Liberian Herald and the president of Liberia College (now the University of Liberia), 1880-1884.

${ }^{322}$ Dunn, Liberia, above n 103, 27; Wreh, above n 166, 133-134.

${ }^{323}$ Liebenow, above n 55, 1; ibid 37. 
responsible for ushering boys and girls into adulthood, respectively. Its lush tropical rainforest and fertile soil produce rice, cocoa, and coffee, whilst its mineral wealth includes gold and diamonds. Two colleges, 469 schools, and 49 health centres serve the county's 276863 inhabitants. ${ }^{32}$ Lofa had 53 health facilities: four hospitals, six health centres and 41 clinics, all of which were destroyed during the civil war. However, 49 have been rehabilitated ${ }^{325}$ with the help of the World Health Organization, the United Nations Children's Fund, and other major international non-profits. ${ }^{326}$ In 2007, Lofa had six doctors, three dentists, four pharmacists, and two registered nurses as full-time health workers of the Ministry of Health and Social Welfare.

\section{Nimba County}

Nimba County, like Bong and Lofa, was one of the original nine counties of Liberia. Along with Lofa, in 1964, Nimba became a county after former president William V S Tubman abolished the original five Provincial political sub-divisions of which the hinterland (mostly Indigenous Peoples) was not a part. Once part of the Central Province of Liberia, which included Bong and Lofa counties, Nimba is 2300 square kilometres, comprising five major Indigenous Language Groups (Maan, Daan, Mandingo, Krahn and Gbii), 17 districts, and over 100 towns, with many clans and chiefdoms. Nimba is home to 13.32 percent of Liberia's population, mostly of the Mano and Gio Language Groups. Dominated by mountains, rivers, and lush vegetation, this county has natural resources (mainly iron ore, diamonds, gold, timber, and rubber) that have been exploited for over half a century (see chapter 3 for more detail). Sanniquellie, the capital city of Nimba, is the birthplace of the Organisation of African Unity (now the African Union). ${ }^{327}$ Until 2013, there was no public college or university in Nimba. The African Bible College is a private institution established in 1977 that was granted full university status in 2008. To date, there are 554 schools for a student population of $145272 .{ }^{328}$ A total of 526 assigned health workers, including one medical doctor, staff the entire 41 functioning health facilities, serving a population of 732195 in Nimba. ${ }^{329}$

\section{Maryland County}

Maryland was first established as a colony of the Maryland State Colonisation Society on 12 February 1834. In 1857, by an act of legislation, Maryland joined the Republic of Liberia. Harper City, which sits in the centre of Cape Palmas, honours a prominent American politician

\footnotetext{
${ }^{324}$ Government of Liberia, 'Lofa County Development Agenda 2008-2012' (Government Report, Ministry of Planning and Economic Affairs, 2008) 116, 23 and 24. Total population of Lofa is obtained from LISGIS' Lofa County Profile, 2013 available at: https://www.lisgis.net/pg_img/CSIO\%20Lofa\%20December,2013\%20Reports.pdf. 
and member of the American Colonisation Society, Robert Goodloe Harper. The main Language Group in Maryland is Grebo. Maryland has seven administrative districts, 15 chiefdoms and 26 clans across 47 townships. ${ }^{330}$ An estimated 98 percent of the county is said to be Christian, dividing the last two percent between Muslims and Traditionalists. A land dispute is of serious concern in Maryland. Arbitrary allocation of land during former President Charles Taylor's regime escalated inter-town and inter-clan conflicts, resulting in security intervention. Rubber, gold, manganese, and bauxite are vital economic resources of the Maryland economy. The education and health sectors of Maryland are in a deplorable state from years of neglect. There are 151 schools serving a population of 29823 (44 percent of whom are girls) with 1071 teachers (26 percent of whom are female). Maryland has one tertiary institute, William VS Tubman University, established in 1978 as a technical college but now raised to a full university status since April 2009 (see Table 2.2). ${ }^{331}$ Maryland's 135938 inhabitants have only 16 health clinics and one referral hospital.

\footnotetext{
${ }^{330}$ Government of Liberia, 'Maryland County Development Agenda 2008-2012', above n 320, 5-8.

${ }^{331}$ Government of Liberia, 'Bomi County Development Agenda', above n 320, 21-22. Less than 15 per cent of the population in Bomi has access to health care. Of the 17 (one hospital and 16 clinics) functional health facilities, nine are run by World Vision Liberia, three by Save the Children UK and two by African Humanitarian Action. Government of Liberia, 'Bong County Development Agenda' (Government Report, Ministry of Planning and Economic Affairs, 2008) 86, 28 <http://www.mia.gov.lr/doc/Bong\%20CDA_web.pdf>. Of the 33 health clinics in Bong County, 26 are supported by international NGOs as there is no formal health system administration ever in the County. Government of Liberia, Gbarpolu County Development Agenda (2008) 17 <http://www.emansion.gov.lr/doc/GbarpoluCDA.pdf>. Government of Liberia, 'Grand Cape Mount County Development Agenda' (Government Report, Ministry of Planning and Economic Affairs, 2008) 107, 29 <http://www.mia.gov.lr/doc/Grand\%20Cape\%20Mount\%20CDA_web.pdf>. The 33 functional health facilities in Grand Cape Mount include one hospital, one health centre, 30 clinics and one health post. Government of Liberia, 'Grand Kru County Development Agenda', above n 318, 22-23. The health sector in Grand Kru is in dire need of assistance with health professionals are completely absent or inadequately trained. According to the Comprehensive Food Security and Nutrition Survey, Grand Kru has the highest chronic child malnutrition rates (47.3 per cent) with more than 70 per cent of households having no access to basic food. Access to health services such as immunization, Vitamin A supplementation and de-worming is extremely low, and infant and child feeding practices are poor due to poverty and lack of information. Like its health sector, education in Gbarpolu is next to destroyed and not yet fully function (p. 17). Government of Liberia, 'Lofa County Development Agenda 2008-2012', above n 324, 23. Prior to the civil war, all 53 of Lofa's health facilities (4 hospitals, 6 health centres and 41 clinics) were destroyed. To date, 49 of these facilities have been rehabilitated and currently managed mainly by international organizations. Government of Liberia, 'Margibi County Development Agenda', above n 320, 27. Apart from the two hospitals, the Government owns 19 clinics amongst the 36 functioning health facilities in the Margibi. Government of Liberia, 'Maryland County Development Agenda 2008-2012', above n 320,30. According to the County Health Team in Maryland, before the civil crisis, there were 23 health facilities. However, only 17 are in operation. The remaining six are yet to be reactivated. Government of Liberia, 'Nimba County Development Agenda 2008-2012', above n 328, 24. Access to health care facilities for the estimated population of 732195 in Nimba is 435:1. The 526 health workers include 21.2 per cent nurse aids, 17 per cent registered, 13 per cent trained traditional midwifes, and 0.9 per cent medical doctor. Government of Liberia, 'Sinoe County Development Agenda', above n 320, 27-28. Sinoe has one of the lowest presence of the Ministry of Health assigned workers in Liberia. Of the 33 health facilities, existing prior to the civil war only five are functional. By March 2007, only three medicine stores and no pharmacy were present in the County. Of the 17 basic health units in Grand Gedeh, only 11 are functional in three districts, including one hospital, all of which are run by three NGO's (MSF, Merlin and Caritas). No pharmacy or medicine stories available in Grand Gedeh (Government of Liberia, Grand Gedeh County Development Agenda (2008) 24-25). Of the 165 functioning health facilities in Monsterrado, six are hospitals, 44 clinics, and 10 health centres. This county alone has 96 pharmacies, 228 drug stores, 97 full-time medical doctors, 106 physician assistants, 6 dentists, 188 register nurses, 65 lab technicians, and 30 full-time counsellors (see, Government of Liberia, Montserrado County Development Agenda (2008) 28). The closest hospital to River Cess is the public facility in Buchanan, Grand Bassa. The County does not have an assigned doctor and most health workers are untrained (see, Government of Liberia, River Cess County Development Agenda (2008) 21). River Gee's 14 health facilities include three health centres and 11 public clinics which have not had any regular assistance from NGO's, UN or government agencies. The County has no referral hospital, no medical doctor, and a serious need for trained and qualified health workers (Government of Liberia, River Gee County Development Agenda (2008) 22-23).
} 


\section{Montserrado County}

As one of three original counties signatory to Liberia's Declaration of Independence 1847, Montserrado is as old as the Republic. Partly because of rural-urban drift, which was compounded by forced internal migration during the civil war, Montserrado houses 43 percent (1.5 million people) of Liberia's population. A century-old centralised government headed by early immigrant settler-colonists directed internal migration towards the nation's capital, Monrovia. The high density of Monrovia's population, in part, explains the disproportionate focus of public and private socio-political development in the capital. Montserrado has 21 townships, seven cities, one borough, two chiefdoms and two statutory districts. Todee is the most rural district in Montserrado and is home to many Indigenous Liberians. ${ }^{332}$ To date, all of Liberia's 16 major Language Groups populate Montserrado County. To the neglect and detriment of rural counties such as Gbarpolu, ${ }^{333}$ Grand Kru, ${ }^{334}$ River Cess, ${ }^{335}$ River Gee, ${ }^{336}$ and Sinoe, ${ }^{337}$ Montserrado has almost one third (27 percent) of the estimated 4031 schools; ${ }^{338}$ one third (34 percent) of all health facilities; ${ }^{339}$ and two of the eleven tertiary institutions in Liberia. Currently, tertiary institutions in Liberia offer only bachelor and master's degrees. ${ }^{340}$ There is no Ph.D. program offered in Liberia (see Table 2.2). ${ }^{341}$ Although Montserrado has been transformed over the last century from being domination by the English speaking African American settlercolonists ${ }^{342}$ to constituting multi-lingual abode for all Liberians, it is still relatively underdeveloped and unsophisticated. As iterated by Azikiwe earlier (1930), Montserrado (like all of Liberia) has no public electricity grid (except for dotted areas in Monrovia), no potable

\footnotetext{
${ }^{332}$ Government of Liberia, 'Montserrado County Development Agenda 2008-2012' (Government Report, Ministry of Planning and Economic Affairs, 2008) 82, 1-3.

${ }^{333}$ Government of Liberia, 'Gbarpolu County Development Agenda' (Government Report, Ministry of Planning and Economic Affairs, 2008) $68<\mathrm{http} / / /$ www.emansion.gov.lr/doc/GbarpoluCDA.pdf $>$.

${ }^{334}$ Government of Liberia, 'Grand Kru County Development Agenda', above n 318.

${ }^{335}$ Government of Liberia, 'River Cess County Development Agenda' (Government Report, Ministry of Planning and Economic Affairs, 2008) 66 <http://emansion.gov.lr/doc/RivercessCDA.pdf〉.

${ }^{336}$ Government of Liberia, 'River Gee County Development Agenda' (Government Report, Ministry of Planning and Economic Affairs, 2008) 76 <http://www.emansion.gov.lr/doc/RiverGeeCDA.pdf>.

${ }^{337}$ Government of Liberia, 'Sinoe County Development Agenda', above n 320.

${ }^{338}$ Government of Liberia, 'Montserrado County Development Agenda 2008-2012', above n 332, 30.

${ }^{339}$ Ibid 28.

${ }^{340}$ See, Starz, National Commission on Higher Education, 'List of tertiary institutions in Liberia' (2014) available at $<$ http://starzit.com/wp-content/uploads/2014/12/NCHE.pdf> and Ministry of Education, 'List of higher education institutions in Liberia' (2013) available at $<\mathrm{http} / /$ www.moe.gov.lr/pages1.php?pgID=62>.

${ }^{341}$ It must be emphasised here that the number of health facilities, schools and colleges are simply mere numbers. There is a total of 34 tertiary institutions in Liberia, four of which offers bachelors and/or masters' degrees: University of Liberia (public) in Montserrado, William V S Tubman University (public) in Maryland, Cuttington University (private and faith-based) in Bong, and Stella Maris Polytechnic (private and faith-based) in Montserrado. The remaining 30 colleges: 17 are faith-based, 8 public and 5 private schools; 17 are based in Monrovia/Montserrado County and 18 offers associate degrees. Interestingly, 26 of the 34 institutions were established after the civil war. In other words, only eight higher education institutions served Liberia's 1.8 million population before 1990 . There is no $\mathrm{PhD}$ granting institutions ever in Liberia. Note that only public tertiary institutions are listed in this column (see, Starz, National Commission on Higher Education, 'List of tertiary institutions in Liberia' (2014) available at $<$ http://starzit.com/wp-content/uploads/2014/12/NCHE.pdf> and Ministry of Education, 'List of higher education institutions in Liberia' (2013) available at <http://www.moe.gov.lr/pages1.php?pgID=62>).

${ }^{342}$ Government of Liberia, 'Montserrado County Development Agenda 2008-2012', above n 332, 6. Note that at the time of founding, three main Indigenous language groups occupied Monrovia, the Dey, Kpelle and Gola.
} 
water delivery system, no public transportation systems, no public telecommunications facilities and extremely limited road access to other parts of the country.

Interestingly, most cities, townships, and districts in Montserrado are named after early settlers, places or plantations from in the United States. For example, New Georgia was named after Georgia in the United States by recaptured slaves who waited seven years for the outcome of a court decision in Georgia regarding their fate. ${ }^{344}$ The Virginia Colonization Society, 'the prototypal state that had set the tone and pace of colonial settlement, American republicanism, and plantation slavery', ${ }^{345}$ put immense pressure on policymakers to mandate provisions to ensure the deportation of Black Africans from the United States, and is remembered in Liberia as Virginia Township. ${ }^{346}$ When 309 freed African American former slaves immigrated to Liberia from Louisiana, they created a colonial duplex called Mississippi by a river in Sinoe County Liberia, 'not unlike the geographical intimacy characterising their former homes'. ${ }^{347}$ These borrowed names highlight a generational link between former slave setter-colonists and the philosophical founding of Liberia that is scarred with cyclical impacts of social inequality and injustice between recent immigrant settler-colonists and Native Peoples in Liberia. It is this painful reminiscence of slavery, deprivation, and abuse, tainted with the love for heritage, which fastens African American settler-colonists to the nostalgia of recreating place names that give meaning to their existence in Liberia.

\section{- Australia}

If he should locate Terra Australis, Cook was to explore the coast and to return with charts, views, and hydro-graphic details. In addition, he was to gather information about the nature of its soil, products, beasts, birds, fishes, and minerals and to report on the nature of its inhabitants. ${ }^{348}$ Board of Admiralty to James Cook, 1768-1771.

Aboriginal Australians are believed to owe their heritage to ancient Egyptian voyagers who arrived on the Australian shores 50000 years ago. ${ }^{349}$ Archaeological evidence shows that Aboriginal culture is one of the earliest centres of civilisation, spanning at least 40 000-50 000 years. ${ }^{350}$ Well-documented archaeological records from the last 200 years establish Aborigines as the original dwellers of Australia.

[A lock] of hair taken from an unknown young man near Kalgoorlie in the 1920s has provided solid genetic evidence that Aboriginal Australians are descended from the first

\footnotetext{
${ }^{343}$ Government of Liberia, 'Liberia Demographic and Health Survey 2013', above n 313; Liberia Institute of Statistics and Geo-Information Services, above n 318.

${ }^{344}$ Clegg, above n 58, 92.

${ }^{345}$ Ibid 21.

${ }^{346}$ Ibid 148.

${ }^{347}$ Timothy F Reilly, 'The Louisiana Colonization Society and the Protestant Missionary, 1830-1860' (2002) 43(4)

Louisiana History: The Journal of the Louisiana Historical Association 433.

${ }^{348}$ Alan Edwin Day, Historical Dictionary of the Discovery and Exploration of Australia (Scarecrow Press, 2003) xxxviii.

${ }^{349}$ Ibid xvii, xlii.

${ }^{350}$ Al J Grassby and Marji Hill, Six Australian Battlefields (Allen and Unwin, 1998) 1; Val Attenbrow, 'The Aboriginal Prehistory and Archaeology of Royal National Park and Environs: A Review' (2012) 134 Proceedings of the Linnean Society of New South Wales B39.
} 
modern humans to walk out of Africa nearly 75,000 years ago (...) The first Aboriginal genome reinforces archaeological evidence that people arrived on the Australian continent at least 50,000 years ago and that they share one of the oldest continuous cultures in the world. ${ }^{351}$

However, like Liberia, much of modern-day Australia is heavily influenced by European views. ${ }^{352}$ As with Liberia, Australia's history tends to begin with the arrival of Europeans in Australia's case, in 1770 when Captain James Cook, or other wandering Europeans, ${ }^{353}$ arrived. Telling Aboriginal history through the colonial worldview with particular regard to 'who owns the Australian past' is problematic, as it reinforces false assumptions about the sovereignty and agency of Aboriginal People. ${ }^{354}$

Australia was not terra nullius ${ }^{355}$ when Captain Arthur Phillip raised the British flag at Sydney Cove shortly after the First Fleet ${ }^{356}$ landed on the shores of Eora country on 18 January 1788. ${ }^{357}$ The estimated 1.6 million First Australians, organised by territorial boundaries, laws, culture and customs, lived across the entire continent. ${ }^{358}$ Of the more than 250 original languages, only about 145 are still spoken to some degree today and about 110 are severely endangered ${ }^{359}$ (see Tables 2.3 $3^{360}$ and 2.4 $4^{361}$ ). Richard Baker argues that 'Aboriginal people [specifically the Yanyuwa people] gave up their bush life out of choice', ${ }^{362}$ to come into European settlements.

\footnotetext{
${ }^{351}$ Leigh Dayton \& Stuart Rintoul, 'Genes map Aborigines'” arrival in Australia', The Australian, 23 September 2011, at http://www.theaustralian.com.au/news/health-science/genes-map-aborigines-arrival-in-australia/storye6frg8y6-1226144089835.

${ }^{352}$ Day, above n 348, xlii, 1-2.

${ }^{353}$ James Sykes Battye, Western Australia: A History From Its Discovery to the Inauguration of the Commonwealth (Clarendon Press, 1924) 11-16 <http://gutenberg.net.au/ebooks05/0500301h.html>.

${ }^{354}$ Telling Stories: Indigenous History and Memory in Australia and New Zealand (Allen and Unwin, 2001) xv, 2-7; Government of Australia, Convicts and the British Colonies in Australia: A Penal Colony (2014) Australian Stories <http://www.australia.gov.au/about-australia/australian-story/convicts-and-the-british-colonies>; Government of Australia, Convicts and the British Colonies in Australia (4 November 2014) Convicts and the British Colonies in Australia <http://www.australia.gov.au/about-australia/australian-story/convicts-and-the-british-colonies>. In his book, Attwood seek to provide an account what makes sense regarding the ongoing controversy over Aboriginal history (vis-à-vis the so-called 'history wars' by tracing the underlying roots of the debate, as well as critically examining the new conservative or revisionist authors claims about the frontier, and suggests approaches that Aboriginal history seems to demand of settler Australians as historians or/and citizens (p. 7). For example, for centuries, white Australians fabricated Aboriginal Australians' relationship with white settlers regarding the modern nation-State as Joseph Banks Penal Colony.

${ }^{355}$ Grassby and Hill, above n 350, ix. In Six Australian Battlefields, Grassby and Hill confide that the goal of the book is to 'demonstrate that Australia was not terra nullius when Captain Cook took possession of half the continent for the King of England....'

${ }^{356}$ The First Fleet to Australia comprised eleven ships bearing 751 British convicts, their children and 252 Marines and their families

${ }^{357}$ Government of Australia, above n 354. According to the Australian Government website, 'while the vast majority of the convicts to Australia were English and Welsh (70\%), Irish (24\%) or Scottish (5\%), the convict population had a multicultural flavour. Some convicts had been sent from various British outposts such as India and Canada. There were also Maoris from New Zealand, Chinese from Hong Kong and slaves from the Caribbean'.

${ }^{358}$ Perkins, above n 60.

${ }^{359}$ McConvell, Marmion and McNicol, above n 180, 3; Kazuko Obata and Jason Lee, 'Languages of Aboriginal and Torres Strait Islander Peoples - A Unique Australian Heritage'

<http://www.abs.gov.au/ausstats/abs@.nsf/Previousproducts/1301.0Feature\%20Article42009\%E2\%80\%9310?opend ocument\&tabname $=$ Summary \&prodno $=1301.0 \&$ issue $=2009 \% 9610 \&$ num $=\& v i e w=>$; Australian's International Public Affairs, Australia Facts (2015) About Australia <http://www.about-australia.com/facts/>; M Paul Lewis, Gary F Simons and Charles D Fennig, Languages of the World: Australia (2015) Ethnologue <http://www.ethnologue.com/country/AU/languages>.

${ }^{360}$ Table 2.5: shows the 38 strongly spoken Aboriginal languages (i.e. a 100 or more speakers) in 1996 and/or 2001.

${ }^{361}$ Table 2.6: shows the population distribution of Indigenous Australians between 1901 and 2013.

${ }^{362}$ Richard Baker, 'Coming in? The Yanyuwa as a Case Study in the Geography of Contact History' in Valerie Chapman and Peter Read (eds), Terrible Hard Biscuits: A Reader in Aboriginal History (Allen and Unwin, 1996) 123, 164.
} 
Baker identifies $^{363}$ the control of Aboriginal land by British settlers as a crucial factor in this migration from rural to urban living. Despite Baker's observation, white Australian settlercolonists dispossessed Indigenous Peoples in Australia of their land. As with the founding of Liberia, the arrival of the First Fleet was not without violent exchange. ${ }^{364}$ Rene Adams and Yasmin Hunter suggest that 'the colonisers tried to kill Aboriginal people with guns and diseases; [and] whole tribes were herded together and murdered'. ${ }^{365}$ Chapter 3 chronicles a number of frontier battles and other forms of systematic violence against Indigenous Peoples perpetrated by settler-colonists in Australia. Not only did white Australian settlers forcibly dispossess Indigenous Peoples of their land, but they also extended and imposed British common law in claiming jurisdiction over Aboriginal lands, property, and lives.

The Australian Federation was established between 1788 and 1863. ${ }^{366}$ On 5 July 1900, the Commonwealth of Australia Constitution Act (United Kingdom) was passed, received Royal Assent from Queen Victoria on 9 July 1900, and came into force on 1 January 1901, with Sir Edmund Barton sworn in as the first interim Prime Minister. ${ }^{367}$ For some, the birth of this modern-day Australian Constitution began a pattern of white colonial arrogance and disrespect for Indigenous Australians (see chapter 4) ${ }^{368}$ This research aligns with the Recognise Campaign that asserts,

\footnotetext{
${ }^{363}$ Ibid 165 .

${ }^{364}$ Mitch Torres, Jandamarra's War (Electric Pictures Pty Ltd., 2011); Bain Attwood, Telling the Truth About Aboriginal History (Allen \& Unwin, 2005) 106-123; Grassby and Hill, above n 350; Nicholas Clements, The Black War: Fear, Sex and Resistance in Tasmania (University of Queensland Press, 2014); La Trobe University, 'The Myall Creek Massacre with Richard Broome', above n 15; JL Kohen, 'Pemulwuy (1750-1802)' in Australian Dictionary of Biography (National Centre of Biography, Australian National University, 2005) http://adb.anu.edu.au/biography/pemulwuy.

${ }^{365}$ Rene Adams and Yasmin Hunter, 'Surviving Justice: Family Violence, Sexual Assault and Child Sexual Assault in Remote Aboriginal Communities in NSW' (2007) 7(1) Indigenous Law Bulletin 26; Adriana Vanden Heuvel et al, 'The Health and Welfare of Australia's Aboriginal and Torres Strait Islander Peoples' (Government Report, Australian Institute of Health and Welfare, 2015) 200, 2

<http://www.aihw.gov.au/WorkArea/DownloadAsset.aspx?id=60129551281>.

${ }^{366}$ Day, above n 348, xiv. New South Wales (1788), Van Diemen's Land (1825), Western Australia (1829), South Australia (1836), Victoria (1851), Queensland (1859), and Northern Territory (1863).

${ }^{367}$ Parliamentary Education Office, How Australian Formed Its Constitution (2015) The Australian Constitution

<http://www.peo.gov.au/learning/closer-look/the-australian-constitution/how-australia-formed-its-constitution.html>. Note the original colonies of the Federation of Australia were, New South Wales, Victoria, South Australia, Queensland and Tasmania. The Constitution provided for Western Australia to join the Commonwealth of Australia, of which it agreed on 31 July 1900 - just two weeks after the Act was passed. The original Commonwealth of Australia Constitution Act 1910 was legally bound to Britain, until series of statues were passed, progressively giving the Commonwealth greater constitutional independence. For example, the Statute of Westminster Adoption Act 1942 provided that Australian laws could no longer be overruled by an Act of British Parliament; the Privy Council (Limitations of Appeals) Act 1968 and the

Privy Council (Appeals from the High Court) Act 1975 limited and ended appeals from the High Court of Australia to the Privy Council in the UK; and the Australian Act 1986 finally removed all remaining legal links between the Australian and British governments, except that the Queen of England is still the Head of State of the Commonwealth.

${ }^{368}$ RECOGNISE, above n 24; Bain Attwood et al, The 1967 Referendum, or, When the Aborigines Didn't Get the Vote (Australian Institute of Aboriginal and Torres Strait Islander Studies, 1997); Gary Foley, 'How to Steal the Human Rights of Aboriginal People' <https://vu.academia.edu/GaryFoley>; Mansell, above n 17; Dan Harrison, 'Patrick Dodson Warns Aboriginal People Will Be Refugees in Their Own Country If Communities Close' The Sydney Morning Heralds (Sydney, NSW), 21 November 2014

http://www.smh.com.au/action/printArticle?id=63429039; Mick Dodson, 'Constitutional Recognition of Indigenous Australians' (Public Lecture at the National Centre for Epidemiology and Population Health Annual Lecture, Finkel Lecture Theatre, John Curtin School of Medical Research, 12 November 2014); Dodson, 'Constitutional Recognition of Indigenous Australians', above n 24; Mick Dodson, 'Citizenship in Australia: An Indigenous Perspective (A Call
} 
Before the Australian Constitution was written, Aboriginal and Torres Strait Islander people had lived here for more than 65,000 years, maintaining the oldest living culture on the planet. Yet the Constitution doesn't recognise this and still allows for racial discrimination. As it stands, the nation's founding document makes no mention of the First Australians and more than sixty-five thousand years of Australia's history, prior to British colonisation. RA [Reconciliation Australia] supports the public campaign to correct this wrong, and meaningfully recognise First Nations' people in the Australian Constitution. ${ }^{36}$

On the one hand, the rise to independence and the economic success of those once considered the 'scum of people' ${ }^{370}$ and 'illiterate freight of misery' ${ }^{371}$ by British society is a celebrated miracle. On the other, the colonisation of Aboriginal Australia perpetrated all manner of systematic violence against Indigenous Peoples. Stan Grant describes his thoughts on the experience of Australia's Aboriginal Peoples with colonisation by saying that they were '[e]stranged in the land of our ancestors, marooned by the tides of history on the fringes of one of the richest and demonstrably most peaceful, secure and cohesive nations on earth'. ${ }^{372}$ Without any redress or reparation to, or recognition of, the First Peoples in Australia, white colonistsettlers continue to use their legislative and constitutional powers to subjugate and oppress Aboriginal Peoples. It is due to the persistence of such injustice that this research questions the principle of equal treatment under the law. As with the Liberian side of this study, searching for answers to the research question in Australia focused efforts in four geographically, economically. And demographically diverse regions.

\section{Northern Territory}

The Northern Territory is home to one of the oldest living cultures in the world as archaeological records show that the Yolngu people settled in the Northern Territory some 50 000 years ago. According to the National Archives of Australia, originally, the 'Northern Territory was a part of New South Wales until ceded to South Australia in 1863 and then to the Commonwealth in 1911'. ${ }^{373}$ The Commonwealth granted the Northern Territory limited selfgovernment in $1978 .{ }^{374}$ Darwin, the capital city of the Northern Territory, was founded in 1869. Its population grew after gold was discovered near Pine Creek in $1871 .{ }^{375}$ The Northern Territory has an area of 1349142 square kilometres and a coastline that stretches over 1600

for Structured and Comprehensive Representation of Indigenous People in Australia's Constitution' (1997) 22(2) Alternative Law Journal 57.

${ }^{369}$ RECOGNISE, 'What Is Reconciliation?' < https://www.reconciliation.org.au/what-is-reconciliation/>.

${ }^{370}$ Years before English convicts were sent to Australia, Lord Bacon predicted 'that it was a shameful and unblessed thing to take the scum of people and wicked, condemned men to be the people with whom you plant, for they will ever live like rogues and not fall to work, but be lazy and do mischief and spend victuals, and be quickly weary'. (see, Gillespie, above n 27, 375.

${ }^{371}$ Bethia Penglase, '1788: That Illiterate "Freight of Misery”?. -Literacy of First Fleet Convicts-' (1989) 75(2) Journal of Royal Australian Historical Society 99.

${ }^{372}$ Stan Grant, 'I Can Tell You How Adam Goodes Feels. Every Indigenous Person Has Felt It' The Guardian (Sydney South, NSW), 30 July 2015 <http://www.theguardian.com/commentisfree/2015/jul/30/i-can-tell-you-howadam-goodes-feels-every-indigenous-person-has-felt-it $>$.

${ }^{373}$ National Archives of Australia, The Northern Territory of South Australia, 1863-1911 (2015) Commonwealth Government Records about the Northern Territory <http://guides.naa.gov.au/records-about-northernterritory/part1/chapter1/index.aspx>.

374 Also see the Northern Territory (Self-Government) Act 1978. 
$\mathrm{km}$ and holds approximately three percent of Australia's 21.6 million people and 30 percent of Australia's 669881 Aboriginal people. The Northern Territory also has the highest proportion of Aboriginal Peoples of any Australian state or territory (see Table 2.4).

Unfortunately, the Northern Territory's remote location and a large population of Aboriginal Peoples has made it the target of ridicule and State-sponsored violence throughout Australia's history. In 1915, Elsie Masson wrote of the Northern Territory that the rest of Australia seemed ignorant about or indifferent to the 'hopeless unwanted land... [but] it is part of Australia, and yet utterly remote from the civilised states, separated from them by a fortnight's journey by sea... with a swarming native population. ${ }^{376}$ A century after Masson's denigrating observation of the 'uncivilised territory with a swarming native population', Tony Abbott unfolded a 20-year plan for the development of the Northern Territory, from which respectful and equal participation by northern Aboriginal Peoples in Australia is completely absent. ${ }^{377}$ The Abbott government Coalition's 2030 Vision for Developing Northern Australia states that ' $[n]$ o longer will Northern Australia be seen as the last frontier, it is in fact, the next frontier'. ${ }^{378}$ Without a doubt, the infrastructural needs of Northern Australia are enormous. There are, for example, 36000 kilometres of road in the Northern Territory alone, connecting remote communities of Aboriginal Peoples in Australia. However, although Abbott's 2030 Vision envisages Northern Australia as containing a highway network providing the only paved road links between remote areas of the north and the rest of Australia, ${ }^{379}$ poor implementation of government projects in the Northern Territory risks remote Aboriginal dwellers becoming 'refugees in their own country'. ${ }^{380}$ Adequate roads are not the only challenge facing Aboriginal Peoples in the Northern Territory.

Access to health and education is a challenge for Aboriginal Australians in the Northern Territory. The expansive Northern Territory ${ }^{381}$ has only five public hospitals providing care to its 211945 residents (see Table 2.4). Health services include the Aerial Medical Service, which started in 1943. The Northern Territory Department of Health also funds the Royal Flying Doctor Service that delivers healthcare services to people living and working in rural and remote areas, which includes Northern and Central Australia. ${ }^{382}$ Of the 591503 people registered as health practitioners in Australia in 2013, only 310 were registered as Aboriginal Australians

\footnotetext{
${ }^{376}$ Elsie R Masson, An Untamed Territory: The Northern Territory of Australia (Macmillan, 1915) 3 <https://archive.org/details/untamedterritory00mass>.

${ }^{377}$ Shalailah Medhora, "Northern Australia Plan Aims to Make Region an "Economic Powerhouse"' The Guardian (Canberra, ACT), 18 June 2015 <http://www.theguardian.com/business/2015/jun/18/northern-australia-plan-aims-tomake-region-an-economic-powerhouse>.

${ }^{378}$ Government of Australia, 'The Coalition's 2030 Vision for Developing Northern Australia: A White Paper on Developing Northern Australia' (Government Report, Liberal Party, June 2013) 46, 2

<http://www.liberal.org.au/2030-vision-developing-northern-australia>.

${ }^{379}$ Ibid 23.

${ }^{380}$ Harrison, above n 368.

${ }^{381}$ Northern Territory Department of Health, Hospitals (29 June 2015) Hospitals <http://health.nt.gov.au/Hospitals/>.

${ }^{382}$ Northern Territory Department of Health, Aerial Medical Services (3 October 2014) Aerial Medical Services

<http://health.nt.gov.au/Hospitals/Aerial_Medical_Services/index.aspx>.
} 
and 70 percent of those practitioners work in the Northern Territory. ${ }^{383}$ The Northern Territory Clinical Schools based in Darwin, train and provide placement opportunities for medical students from Flinders and James Cook Universities. ${ }^{384}$ Generally, educational institutions are not well represented in the Northern Territory. According to the Australian Bureau of Statistics, there were 9393 schools recorded in Australia for the year 2013. Serviced by 5896 (75 percent females) in-school staff; ; 35 however, only two percent (192) of these schools are in the Northern Territory (see Table 2.5).

\section{Australian Capital Territory}

The Ngambra [now Galambany] Circle Sentencing Court is a specialised court within the ACT Magistrates Court established to sentence Aboriginal and Torres Strait Islander offenders who plead guilty to an offence. The majority of offenders before the Ngambra Circle Sentencing Court are for offences relating to domestic violence attributable to long-term alcohol and drug abuse. ${ }^{386}$

Table 2.3: Nineteen strongly spoken Aboriginal languages in Australia

\begin{tabular}{|c|c|}
\hline Languages & $\begin{array}{l}\text { \# of Speakers } 1996 \\
\text { South Australia }\end{array}$ \\
\hline Adnymanthanha & $\begin{array}{l}\quad 7 \\
\text { Western Australia }\end{array}$ \\
\hline Bardi & 380 \\
\hline Bunuba & 165 \\
\hline Jaru & 344 \\
\hline Kija & 408 \\
\hline Kuku Yalanji & 245 \\
\hline Miriwoong & 111 \\
\hline Nyangumarta & 259 \\
\hline Yindjibarndi & 332 \\
\hline Western Desert Language & $\begin{array}{l}4180^{1} \\
\text { Queensland }\end{array}$ \\
\hline \multicolumn{2}{|l|}{$\begin{array}{l}\text { Cape York Peninsula } \\
\text { Aboriginal }\end{array}$} \\
\hline Guugu Yirridhirr & 739 \\
\hline Kala Lagaw Ya & 0 \\
\hline Meriam Mir & 317 \\
\hline Wik Munghan & 49 \\
\hline \multirow[t]{2}{*}{ Torres Strait Creole (Broken } & 0 \\
\hline & Northern Territory \\
\hline Alyawarr & 1,452 \\
\hline Anindilyakwa & 1,240 \\
\hline Anmatyerre & 1,224 \\
\hline Arrernte & 3817 \\
\hline Burarra & 696 \\
\hline Dhuwaya & 3,645 \\
\hline Djinang & 120 \\
\hline Gunwinggu & 1405 \\
\hline Gurindji & 545 \\
\hline Maung & 239 \\
\hline Mudburra & 115 \\
\hline Murrinh-Patha & 1,430 \\
\hline Nunggubuyu & 356 \\
\hline Northern Aboriginal & 169 \\
\hline Tiwi & 1832 \\
\hline Iwaidja & 739 \\
\hline Walmajarri & 858 \\
\hline Warlpiri & 2,666 \\
\hline Warumugu & 0 \\
\hline \multirow[t]{2}{*}{ Yanyuwa } & 0 \\
\hline & Other \\
\hline
\end{tabular}

\# of Speakers 2001

107

235

190
575

527
203

203
140
245

140
245
233

4,292

236

581

816
182

668
1,240

1,373

1,310

864

2,444
780

1,387

1,387

916

553
315
57

57

1,157

39
3,992

2,050

581
596

2,937

396
78

10,697

Archaeological evidence suggests that the

Ngunnawal people inhabited the Canberra region of the Australian Capital Territory for some 21000 years. Taking advantage of road construction across the Blue Mountains and the Bathurst Plain in 1815 and 1820, settler-colonists brought disease (e.g. influenza, smallpox, and tuberculosis) to the Canberra area and disrupted land use and free movement of Aboriginal Peoples across the Continent. ${ }^{387}$ On 1 January 1911, the Australian Capital Territory was declared the capital city of Australia with the opening the first Commonwealth Parliament in 1927. Like the Northern Territory, the Australian Capital Territory became a self-governing

383 Alustradian Institute of Health and Welfare, Services, Workforce and Spending (March 2015) Health workforce $<$ htt Centtal Aboriginal

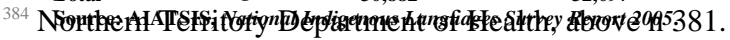

${ }^{385}$ David Unaipon College of Indigenous Education and Research, 'More Aboriginal and Torres Strait Islander Teachers Initiative' 5 <http://matsiti.edu.au/docs/MATSITI-project-plan.pdf>. In 2013, the ABS recorded, 448,711 in-school staff in all of Australia. In that same year, 3645516 students attended schools, of which Aboriginal students make up a pathetic five per cent (182 636). According to More Aboriginal and Torres Strait Islander Teachers Initiative, Aboriginal teachers comprise an estimated one per cent of the teaching communities in Australia. Despite the approximately 300 Aboriginal graduates from university each year, in 2008, there were 1977 A teachers in Australian Schools.

386 ‘ACT Aboriginal and Torres Strait Islander Population: A Demographic Analysis' (Government, Policy Division, ACT Chief Minister's Department, July 2010) 40, 31

<http://www.cmd.act.gov.au/_data/assets/pdf_file/0011/154487/ACT-Aboriginal-Torres-Strait-Islanders.pdf>.

${ }^{387}$ Department of Finance, Canberra - Australia's Capital City (4 February 2010) Australia's Stories

<http://www.australia.gov.au/about-australia/australian-story/canberra-australias-capital-city>. 
territory in 1989. ${ }^{388}$ Situated between Melbourne and Sydney, with a 2360 square-kilometre area, the Australian Capital Territory has the smallest population of Aboriginal Australians ( 6 200 people). Situating the nation's capital in the Australian Capital Territory led to rapid development of the capital city.

The Australian Capital Territory has well-developed health and education systems, but those systems are not working equally for Indigenous and non-Indigenous Australians. Currently, the Australian Capital Territory operates five public hospitals (58 facilities in all) and 130 schools for its 357222 residents. Investment in health by the Australian Capital Territory government stands at $\$ 1.3$ billion annually. ${ }^{389}$ The Australian Capital Territory enjoys the highest life expectancy in Australia; it stands at 85.1 years for females born today. ${ }^{390}$ However, according to the Chief Officer's Annual Report of the year 2011-2012, the Australian Capital Territory had the highest number (15.5 per cent) of mental and behaviour problems in Australia? ${ }^{391}$ Whilst more than three-quarters of Aboriginal and Torres Strait Islanders reported good to excellent health, the number hospitalised for chronic kidney disease was four times greater for non-Indigenous Australians. Also, low birth weight was more than twice as common amongst babies born to Aboriginal mothers as amongst their non-Aboriginal counterparts. ${ }^{392}$ Similar disparities are found in the education system.

Whilst pastoral stations and churches form the bases of early $19^{\text {th }}$-century schools in the Australian Capital Territory, in later years the Territorial government administered their own public-school education. The Australian Capital Territory Department of Education and Training School Census 2015 shows a steady increase in the enrolment of Indigenous children between 2011 and 2015. That is, 1569 and 2082 Indigenous children compared with 66144 and 71917 non-Indigenous student enrolments. ${ }^{393}$ However, in 2012, the retention rate of Aboriginal students in year 7-10 (96.3 percent) and 7-12 (63.1 percent) was much lower than that of non-Aboriginal students in year 7-10 (102.6 percent) and year 7-12 (90.4 percent)..$^{394}$

\footnotetext{
${ }^{388}$ Ibid. See, the Australian Capital Territory (Self-Government Act) 1988

389 ACT Health, "F.4 Asset Management", (20 August 2015), available at: <

http://www.health.act.gov.au/datapublications/reports/annual-reports/2013-2014-annual-report/section-f-financialmanagement/f4>.

${ }^{390}$ ACT Health, 'Annual Report 2013-2014' (Government, ACT Government Health Directorate, 2014) 280, 14 $<$ http://www.health.act.gov.au/datapublications/reports/annual-reports/2013-2014-annual-report/section-f-financialmanagement/f4>.

${ }^{391}$ ACT Government, 'The Australian Capital Territory Chief Health Officer's Report 2014' (Government Report, Department of Health, May 2014) 126, 5

<https://www.health.act.gov.au/sites/default/files/ACT\%20Chief\%20Health\%20Officers\%20Report\%202014.pdf>.

${ }^{392}$ Ibid 6.

${ }^{393}$ Department of Education and Training, 'ACT School Census' (Government Report, ACT Government, February 2015) 10, 2 <http://www.det.act.gov.au/_data/assets/pdf_file/0003/714522/2015-Feb-Census-Publication.pdf>.

${ }^{394}$ Ministry of Council of Education and Early Childhood Development and Youth Affairs, 'Aboriginal and Torres Strait Islander Education Action Plan 2010-2014' (Government Report, Ministry of Council for Education, 2012) 49, 36

<http://scseec.edu.au/site/DefaultSite/filesystem/documents/ATSI\%20documents/2012\%20ATSI\%20Report/ATSIE AP\%202012\%20Report.pdf >; Standing Council on School Education and Early Childhood, and Education Services Australia, 'Aboriginal and Torres Strait Islander Education Action Plan 2010-2014: 2012 Annual Report' (Education, Standing Council on School Education and Early Childhood, 2013) 378, 291

<http://www.scseec.edu.au/site/DefaultSite/filesystem/documents/ATSI\%20documents/2012\%20ATSI\%20Report/A TSIEAP\%202012\%20Report.pdf>.
} 
Unique to the Australian Capital Territory is the Galambany Circle Sentencing Court (hereafter the Galambany Court), which is one of 18 Indigenous sentencing courts in Australia. Established in 2004, the Galambany Court aims to offer an alternative criminal pathway for Aboriginal Peoples. The conceptual framework behind the Galambany Court was created with the intent of promoting Indigenous justice practices and mitigating the inefficiency and incompetence of the settler-colonist legal system. However, the Galambany Court has been criticised for 'using only white settler-colonists law to sentence offenders already deemed guilty through plea or finding' rather than applying any form of Indigenous customary laws. ${ }^{395}$

\section{Queensland}

[T] he Government is not going to allow white and near white children whether their parents are black or white to remain on the Settlements at the cost of the tax payer. You have to educate coloured people to make the sacrifice to have their children adopted and so give them the chance to enjoy the privileges of the white community. ${ }^{396}$

An original member of the Federation of Australia, Queensland separated from New South Wales in 1851. On 6 June 1859, Queen Victoria approved the establishment of the new colony. ${ }^{397}$ The 2011 Census in Australia puts the population of Aboriginal Peoples in Queensland at 155825 (see Table 2.4) from 48 communities (see Table 2.5) ${ }^{398}$ residing across its 1727000 square-kilometres. Historically, Queensland has had a relatively high proportion of settler-colonists in its population. The Commonwealth Bureau of Census and Statistics, 1966, indicated that 98 percent of Queenslanders were British (including Irish) born in (461 829) or outside (173 215) of Australia's second largest state. ${ }^{399}$ As in the Australian Capital Territory, these non-Indigenous Australians in Queensland are better served by the state's health and education system.

Despite progressive education policies, there is still a gap between Aboriginal and nonAboriginal students. Queensland abolished payment of fees to national schools, a move that prompted the State Education Act of 1875. ${ }^{400}$ February 2015 data from the Queensland Department of Education and Training reported that 9.4 percent (49 727) of its 524823 fulltime students enrolled in State School were Aboriginal students. However, the 2012 school

\footnotetext{
${ }^{395}$ Sarah Xin Yi Chua and Tony Foley, 'Implementing Restorative Justice to Address Indigenous Youth Recidivism and Over-Incarceration in the ACT: Navigating Law Reform Dynamics' (2014) 18(1) Australian Indigenous Law Reporter 138, 142-143.

${ }^{396}$ Bringing Them Home: Report of the National Inquiry into the Separation of Aboriginal and Torres Strait Islander Children From Their Families (Human Rights and Equal Opportunity Commission, 1997) 62.

${ }^{397}$ Queensland Government, Creation of a State (5 March 2013) About Queensland and its government <https://www.qld.gov.au/about/about-queensland/history/creation-of-state/>.

${ }^{398}$ Government of Queensland, Aboriginal and Torres Strait Islander Community Histories (2015) Government <http://www.qld.gov.au/atsi/cultural-awareness-heritage-arts/community-histories/index.html>.

${ }^{399}$ John Patrick O’Neill, 'Census of Population and Housing: Part 3 - Overseas-Born Population' (Population: Related Characteristics Volume 2, Commonwealth Bureau of Census and Statistics, Commonwealth of Australia, 30 June 1966) 90, 14

<http://www.ausstats.abs.gov.au/ausstats/free.nsf/0/EDE3C1DB8B4FD932CA257880008214E1/\$File/1966\%20Cens us\%20-\%20Volume $\% 202 \% 20$ Population\%20-\%20Related\%20Characteristics \%20-\%20Part\%203\%20OverseasBorn.pdf>.

${ }^{400}$ Greg Logan and Eddie Clarke, 'State Education in Queensland: A Brief History' (Government Report No. 2, Policy and Information Services Branch, Queensland Department of Education, 1984) 28, 2

<http://education.qld.gov.au/library/docs/edhistory/stateedu.pdf>.
} 
retention rate of Aboriginal and Torres Strait Islander students in years 7-12 (62.1 percent) is significantly lower than that of non-Aboriginal students (85.2 percent). ${ }^{401}$ Challenges also face Aboriginal Peoples in the health system.

The Queensland Chief Health Officer's Annual Report (2014) affirms that the State is 'outliving much of the world - of 187 countries, as Queensland ranked amongst the top 10' for higher life expectancy. In spite of the improvement in the State's health, Aboriginal Queenslanders' death rate is 60 percent greater than that of non-Indigenous Peoples. An estimated 40-50 percent more Indigenous Queenslander women smoke during pregnancy. Therefore, the infant mortality rate for babies born to Indigenous Queenslanders mothers is 87 percent higher than the non-Indigenous rate, with no change since 2002. ${ }^{402}$ The Chief Health Office Annual Report further stipulates that 'the leading causes of burden of Indigenous Queenslanders were mental disorders (17 percent), cardiovascular disease (15 percent), diabetes (10 percent) and chronic respiratory disease (9 percent) '. ${ }^{40}$

Table 2.4: Population characteristics of Australia, 1901 ${ }^{404}$ and 2011

\begin{tabular}{|c|c|c|c|c|c|}
\hline States & $1901(\%)$ & Foreign born (\%) & $2011(\%)$ & Indigenous (\%) & Foreign born (\%) \\
\hline Victoria & $1,201,070(31.8)$ & UK (18.0) & $5,354,042(24.9)$ & $37,990(0.18)$ & England (4.2) \\
\hline Queensland & $498,129(13.2)$ & Other Europe (2.0) & $4,332,739(20.1)$ & $155,825(0.72)$ & New Zealand (2.2) \\
\hline New South Wales & $1,354,846(35.9)$ & Asia (1.2) & $6,917,658(32.2)$ & $172,620(0.80)$ & China (1.5) \\
\hline South Australia & $363,157(9.6)$ & New Zealand (0.7) & $1,596,572(7.4)$ & $30,430(0.14)$ & India (1.4) \\
\hline Western Australia & $184,124(4.9)$ & Other $(0.8)$ & $2,239,170(10.4)$ & $69,664(0.32)$ & Italy (0.9) \\
\hline Tasmania & 172,475 (4.6) & Not Stated (0.2) & $495,354(2.3)$ & $19,625(0.09)$ & \\
\hline Northern Territory & N/A & & $211,945(1.0)$ & $56,776(0.26)$ & \\
\hline $\begin{array}{l}\text { Australian Capital } \\
\text { Territory }\end{array}$ & N/A & & $357,222(1.7)$ & $5,185(0.02)$ & \\
\hline Total & 3,773,801 (100) & $857,575(22.7)$ & $21,507,717(100)$ & $548,369(2.53)^{1}$ & $2,194,724(10.2)$ \\
\hline
\end{tabular}

Queensland also represents an Australian jurisdiction that perpetrated state violence against Indigenous women and girls through a policy of forced adoption. An Inquiry into the Separation of Aboriginal and Torres Strait Islander Children from their Families carried out by the Human Rights and Equal Opportunity Commission in 1997 found that between 1 in 10 and 3 in 10 Indigenous children were forcibly removed from their families between 1910 and 1970. ${ }^{405}$ Queensland and Western Australia governments confirmed that during that time all Indigenous children in their States were affected. On 13 February 2008, the Queensland

\footnotetext{
${ }^{401}$ Standing Council on School Education and Early Childhood, and Education Services Australia, above n 394, 142.

${ }^{402}$ Government of Queensland, 'The Health of Queenslanders 2014: Fifth Report of the Chief Health Officer Queensland' (Government Report, Department of Health, 2014) 208, vii

<https://www.health.qld.gov.au/publications/research-reports/reports/cho-report/cho-full-report.pdf>.

${ }^{403}$ Ibid 154.

${ }^{404}$ Dennis Trewin, 'Selected Social and Housing Characteristics' (Government Report, Australian Bureau of Statistics, 2001) 136, 5

<http://www.abs.gov.au/AUSSTATS/abs@.nsf/0/1EA78AFE3DE2EDCACA256BDA0073EB53?OpenDocument>.

${ }^{405}$ Reconciliation Australia, 'Apology to Stolen Generations: Questions and Answers' 2

<https://www.qcaa.qld.edu.au/downloads/approach2/indigenous_read012_0801.pdf〉.
} 
Parliament made an apology to pay tribute to Stolen Generations of Indigenous Peoples. ${ }^{406} \mathrm{In}$ spite of the apology, no compensation was given to Stolen Generations survivors.

\section{Western Australia}

Archaeological evidence from Perth and Albany suggests that the Noongar people have lived in the area for at least 45,000 years... Once the Europeans had arrived on the West Coast, Captain James Stirling noted that the Noongar people 'seemed angry at the invasion of their territory'... Conflict between the Noongar people and the European settlers continued until Governor Stirling believed that if the Noongar people attacked en masse the settlement may be under threat. Settlers had begun to take the law into their own hands after attacks on homesteads by Noongar people. This led to conflicts such as the Pinjarra Massacre in April 1834. ${ }^{407}$

Both archaeological records and historical facts establish the Noongar as First Peoples in Western Australia. The archaeological evidence shows that Aboriginal ancestors probably arrived in Western Australia around 38000 BC. But, James Sykes Battye ${ }^{408}$ writes that the discovery and history of Western Australia is generally credited to Dutch and English explorers beginning in the early 1600s. ${ }^{409}$ After Englishman William Dampier's denigration of Aborigines as 'the miserablist people in the world, who differ little from brutes' ${ }^{410}$ and Captain Cook's ‘discovery' of Terra Australis, Lieutenant George Vancouver claimed King George III Sound on behalf of the British Crown in 1791. King George Sound, present-day Albany, is home to the Menang Noongar people. The Menang Noongar people are composed of 66 Indigenous language groups. Captain James Stirling officially claimed the territory of Western Australia (then the Swan River Settlement) in 1829, becoming its first governor until 1832. ${ }^{411}$ The colony joined the Commonwealth of Australia on 1 January 1901.

\footnotetext{
${ }^{406} \mathrm{c}=\mathrm{AU} ; \mathrm{o}=$ The State of Queensland; ou=Parliament of Queensland, Queensland Parliament Marks Apology to Stolen Generations, 13 February 2008 (2011) The Queensland Parliament <https://www.parliament.qld.gov.au/getinvolved/events-and-activities/2008/2008-02-13-ApologyToStolenGeneration>.

${ }^{407}$ South West Aboriginal Land and Sea Council, The Noongar People (2015) History

<http://www.noongar.org.au/noongar-people-history.php>.

${ }^{408}$ James Sykes Battye (1871-1954) born to parents from Yorkshire, England, was the first chief librarian of the Victoria Public Library in Perth from 1894-1954. He died in office 60 years later. The State Library of Western Australia is named in his honour (see, http://adb.anu.edu.au/biography/battye-james-sykes-5156 and http://www.slwa.wa.gov.au/about_us/125_facts_for_125_years).

${ }^{409}$ Battye, above n 353, 6-11.

${ }^{410}$ Ibid 29.

${ }^{411}$ See, F. K. Crowley, 'Stirling, Sir James (1791-1865)', Australian Dictionary of Biography, National Centre of Biography, Australian National University, http://adb.anu.edu.au/biography/stirling-sir-james-2702/text3791, published first in hardcopy 1967, accessed online 13 August 2015.
} 


\begin{tabular}{|lllllll|}
\hline \multicolumn{6}{|c|}{ Table 2.5: Population distribution showing sex, health and educational facilities } \\
States & Females & Males & Total $(\mathbf{\%})$ & University & School $^{1}$ & Health \\
NSW & $3,504,780$ & $3,408,878$ & $6,917,653(32.2)$ & 11 & 3,081 & 269 \\
VIC & $2,721,423$ & $2,632,619$ & $5,345,042(24.9)$ & 9 & 2,219 & 286 \\
QLD & $2,184,518$ & $2,148,221$ & $4,332,739(20.1)$ & 10 & 1,719 & 150 \\
SA & 809,354 & 787,218 & $1,596,572(7.4)$ & 5 & 722 & 82 \\
WA & $1,112,992$ & $1,126,178$ & $2,239,170(10.4)$ & 5 & 1,067 & 70 \\
TAS & 252,679 & 242,675 & $495,357(2.3)$ & 1 & 263 & 48 \\
NT & 102,428 & 109,517 & $211,945(1.0)$ & 1 & 192 & 5 \\
ACT & 180,476 & 176,746 & $357,222(1.7)$ & 2 & 130 & 58 \\
Total & $\mathbf{1 0 , 8 7 3 , 7 0 4}$ & $\mathbf{1 0 , 6 3 4 , 0 1 3}$ & $\mathbf{2 1 , 5 0 7 , 7 1 7}(\mathbf{1 0 0})$ & $\mathbf{4 4}$ & $\mathbf{9 , 3 9 3}$ & \\
Source: Australian Bureau of Statistics (2013), State Department of Education and Health websites and annual reports \\
\hline
\end{tabular}

The size and scope of Western Australia and its health and education programs are quite large. Western Australia is the largest state in Australia with a total land area of 2529875 square kilometres, accounting for 33 percent of Australia's total land mass. ${ }^{412}$ Aboriginal Peoples constitute 2.75 percent (69 664) of Western Australia's 2239170 million inhabitants according to the Australian Bureau of Statistics Census 2011 (see Table 2.4). The Western Australia Country Health Service has the largest health delivery service in Australia and one of the largest in the world. The Western Australia Country Health Service has 70 hospitals, delivering care to 530000 people, including 480000 Aboriginal Australians across a 2.5 million square kilometre area (see Table 2.5).

In spite of its well-developed health and education systems, Western Australia still struggles to dispense services equitably to Aboriginal Peoples. In 2006, the leading causes of death amongst Indigenous Peoples in Western Australia were cardiovascular disease, injury and neoplasms (almost entirely cancers). The death rate from intentional self-harm was 3.1 times higher for Indigenous Peoples than for non-Indigenous Peoples. Between 2009 and 2011, mortality for Indigenous infants was 2.4 times higher than for non-Indigenous infants. ${ }^{414}$ In 2014 , 283739 students (48 percent girls) were enrolled in Western Australia's public school. Of these, 23219 (8 percent) were Aboriginal. Western Australia's Department of Education Annual Report (2014) laments that 'closing the gap between the performance of Aboriginal and nonAboriginal students in literacy, numeracy, attendance and retention continues to be a major challenge'. ${ }^{415}$ The overall retention rate for the 650 Aboriginal students in Year 8-12 for 2013 was 43.8 percent compared with 79.3 percent of all public-school students in Western Australia.

\footnotetext{
${ }^{412}$ For Teachers For Students, Australian Education Resources "Western Australia" (12 August 2015), available at: $<$ http://www.forteachersforstudents.com.au/site/themed-curriculum/western-australia/facts/>.

${ }^{413}$ Government of Western Australia, 'WA Country Health Service Annual Report, 2013-14' (Government Report, Western Australia Country Health Service, 2014) 158, 12

$<$ http://ww2.health.wa.gov.au/ /media/Files/Corporate/Reports\%20and\%20publications/Annual\%20reports/wachs_a nnual_report2014.ashx>.

${ }^{414}$ Neil Thomson et al, 'Overview of the Health of Indigenous People in Western Australia 2013' (Academic, Australian Indigenous HealthInfoNet, September 20131) 76, 1-4

<http://www.healthinfonet.ecu.edu.au/uploads/docs/wa-overview-2013.pdf >.

${ }^{415}$ Western Australia Government, 'Department of Education Annual Report 2013-14' (Government, Department of Education, 2014) 157, $14<\mathrm{http}: / /$ www.education.wa.edu.au/home/detcms/public-education/content/about-

us/publications/annual-reports/2012-2014/department-of-education-annual-report-2013-2014.en?cat-id=14662810>.
} 
Only 27.2 percent of Aboriginal students graduated from Year 12 compared to 70.5 percent of all students enrolled in public school. ${ }^{416}$ Notably, there were 96 Focus schools (69 government schools, 15 Catholic schools and 12 independent schools) in Western Australian that had 9723 Aboriginal students enrolled in 2012. Focus schools are mainly the lowest 5 percent of schools based on overall performance, and they are encouraged to use flexible and innovative approaches to address the educational needs of Aboriginal students. ${ }^{417}$

\title{
2.1.2 Theme 2: White Supremacy, Patriarchy and Racism
}

The twisted idea of white supremacy arms James Cowles Prichard and many other white people with the belief that Africans and Aboriginal Peoples in Australia are sub-humans, inferior and barbaric. For example, ethnographer and anthropologist James Cowles Pritchard claims that,

\begin{abstract}
Negroes, Hottentots, Esquimaux, and Australians are not, in fact, men in the full sense of the term, or beings endowed with mental faculties similar to our own. These and other barbarous tribes are inferior in their original endowments to the proper human family, which supplied Europe and Asia with inhabitants; that, being organically different, they are separated by an 'impassable barrier' from the race which displays in the highest degree all the attributes of humanity, and can never be raised to an equality with it...that the ultimate lot of the ruder tribes is a state of perpetual servitude; and that if, in some instances, they should continue to repel the attempts of the civilised nations to subdue them, they will at length be rooted out and exterminated from every country on the shores of which Europeans shall have set their feet. ${ }^{418}$
\end{abstract}

Many 'great' white men (e.g. Winston Churchill, ${ }^{419}$ Abraham Lincoln, and Thomas Jefferson) also espoused racism against Indigenous Peoples in Australia and Africa. ${ }^{420}$ According to Tom Heyden, '[i]n Churchill's view, Protestant Christians were at the top, above white Catholics, whilst Indians were higher than Africans'. ${ }^{421}$ In line with this thinking, 'Churchill saw himself and Britain as being the winners in a social Darwinian hierarchy'. ${ }^{422}$ The inherent nature of white superiority, propagated mostly by white males, has a destructive effect on the subjugated, even

\footnotetext{
${ }^{416}$ Ibid 149, 151.

${ }^{417}$ Standing Council on School Education and Early Childhood, and Education Services Australia, above n 394, 175.

${ }^{418}$ James Cowles Prichard, 'The Physical and National History of Mankind' (1847) XXIV(IV) The British and Foreign Medical Journal of Practical Medicine and Surgery 49-80; Henry Reynolds, This Whispering in Our Hearts (1998) 24. Also see, Appendix III.

${ }^{419}$ The Staff Reporter, 'The Churchill You Didn't Know' The Guardian (London, UK), 28 November 2002 <http://www.theguardian.com/theguardian/2002/nov/28/features11.g21>.

${ }^{420}$ Edward Long, History of Jamaica. Or, General Survey of the Ancient and Modern State of That Island:: With Reflections on Its Situation, Settlements, Inhabitants, Climate, Products, Commerce, Laws, and Government (Oxford University, 1774)

<http://books.googleusercontent.com/books/content?req=AKW5Qadfavo5XVmZMOIa29Jhw680STcnXqvy3MXHVY1bmEQtuQf8rTGI2i2SvaelLCMHMXVN9IK97JpJv5Da7tIw435FR_w5Y6DUjyryNfpwben_jgrlFdTImmK6IyaicjCU1tWpSPlqkO1wcKfKLRL9_4kTdAJ6wAPkWSIre54RZCDJ4e9P2euWTHYQXG5Q3HZ53SIX7ufWHblws YNJeIP75DsPVp_HzycMCZQICrg5cE-Dv2JSHH28jhF_VW8ldYMFlpejy>; Darren Curnoe, How Did We Get Here? - Are Races Real? (UNSWTV, 2015) <https://www.youtube.com/watch?v=8C4te2CTleo>. Edward Long claims that Africa is 'everything that is monstrous in nature, where these creatures [Africans] are frequent and familiar; where the passion rage without any control; and the retired wilderness presents opportunity to gratify them without fear of detection!' Notwithstanding, since all humans are one race. It is argued that the idea of race is based on pseudoscience.

${ }^{421}$ Tom Heyden, 'The 10 Greatest Controversies of Winston Churchill's Career' BBC News (London, UK), 21

January $2015<$ http://www.bbc.com/news/magazine-29701767>.

${ }^{422}$ Ibid.
} 
if it is done subliminally. Fanon, ${ }^{423}$ Malcolm X, ${ }^{424} \mathrm{~W}$ E B Du Bois, ${ }^{425}$ Walter Rodney, ${ }^{426} \mathrm{C}$ L R James $^{427}$ and Cornel West; ${ }^{428}$ all confront the issue of racism and self-hatred amongst Black people from colonial Africa within the specific context of consciousness-raising, enlightenment, and liberation of the masses from oppression. As a case in point, a former slave who returned to Liberia justified his vote for American-born settler-colonist, Stephen Allen Benson, who was of mixed heritage, by stating, ${ }^{429}$ ' [t] he folks [white slave owners in America] will think as how we darkies aint fitten to take care o' ourselves - aint capable. [Stephen Allen] Benson's 'coloured people all over'...I vote for Benson, sir, 'cause I wants to know if (sic) we's going to stay nigger or turn monkey'. ${ }^{430}$ Here the voter struggles with his own identity as a Black African, whilst placing his hopes for redemption in Benson, a process described by Fanon as 'revolutionary elite' ${ }^{\prime 31}$ and by E Franklin Frazier as 'Black Bourgeois', whereby, lighter-skinned Africans are seen as superior to darker ones in an acceptance of Churchill's hierarchy of social Darwinism. ${ }^{432}$ As a result of these attitudes, racism shaped the political evolution of Liberia and Australia.

Australia's history of racism within the political class begins at its founding. Henry Reynolds offers a disturbing overview of a discussion on race by Australia's first Federal Parliament, who were all white men. Reynolds recounts that there was little doubt that 'there was a demonstrable hierarchy of races with the northwest Europeans, the Nordics or Caucasians at the top and the Africans, Melanesians and Aborigines at the bottom' ${ }^{433}$ Isaac Isaacs, ${ }^{434}$ the future High Court judge and Governor-General, noted that in promoting the advancement of Australia, he 'would not suffer any black or tinted man to come in and block the path of progress'. ${ }^{435}$ On the contrary, he said he 'would resist to the utmost, if it were necessary, any murky stream from disturbing the current of Australian life'. ${ }^{436}$ Reynolds goes on, '[i]n the

\footnotetext{
${ }^{423}$ Fanon, Toward the African Revolution, above n 247, 78; Fanon, above n 247, 150.

${ }^{424}$ Malcolm X, 'Who Taught You to Hate Yourself?' (Video at the Funeral Services of Ronald Stokes, Los-Angeles,

5 May 1962) <https://genius.com/Malcolm-x-who-taught-you-to-hate-yourself-annotated>.

${ }^{425}$ WEB Du Bois, The Education of Black People: Ten Critiques 1906-1960 (Monthly Review Press, 1973) 62; WEB Du Bois, Black Reconstruction: An Essay Toward a History of the Part Which Black Folk Played in the Attempt to Reconstruct Democracy in America, 1960-1880 (Harcourt Brace and Company, 1st ed, 1935) 166.

${ }^{426}$ Walter Rodney, How Europe Underdeveloped Africa (Black Classic Press, 2011) 225.

${ }^{427}$ CLR James, The Black Jacobins: Toussaint L'Ouverture and the San Domingo Revolution (Vintage Books, 2nd revised, 1989) 163-164.

${ }^{428}$ Cornel West, Race Matters (Vintage Books, 2nd ed, 2001) 53-55.

${ }^{429}$ National Portrait Gallery, "Stephen Allen Benson (1816-1865)", (2015) available at:

<http://www.npg.si.edu/exh/awash/benson.htm>.

${ }^{430}$ Karnga, above n 171, xiv-xv.

${ }^{431}$ Fanon, above n 247, 200.

${ }^{432}$ E Franklin Frazier, Black Bourgeoisie: The Rise of a New Middle Class 112.

${ }^{433}$ Henry Reynolds, Nowhere People (Penguin, 2005) 85.

${ }^{434}$ Zelman Cowen, "Isaacs, Sir Isaac Alfred (1855-1948)", Australian Dictionary of Biography, National Centre of Biography, Australian National University, available at: http://adb.anu.edu.au/biography/isaacs-sir-isaac-alfred6805/text11773>, published first in hardcopy 1983, accessed online 14 August 2015.

${ }^{435}$ Reynolds, above n 433, 86.

${ }^{436}$ Ibid.
} 
House of Representatives Richard Edwards, ${ }^{437}$ the member for Oxley, [Queensland] referred to the danger of contamination and the "great desire we have to preserve the purity of our race". ${ }_{438}$

Resistance to stirring the racial pot by glorifying white supremacy can also be heard in the voices of Sir John Forrest and Sir George Reid. Forrest did not 'want to see any more colour in [his] race, at any rate of a black kind'. ${ }^{439}$ His colleague Reid ${ }^{40}$ was convinced that 'the current of Australian blood shall not assume the darker hues'. ${ }^{441}$ James Ronald, ${ }^{442}$ a member for South Melbourne, added, 'the country should never try to blend a superior with an inferior race'. ${ }^{43}$ South Sydney's G B Edwards ${ }^{44}$ proclaimed that 'racial contamination would proceed from the lowest strata of society and filter up until it comes to the highest, permeating the whole nation' ${ }^{45}$ John C Watson, ${ }^{446}$ former Prime Minister, declared that those of 'our daughters and sisters who married non-Europeans were regarded as self-sentenced outcasts' ${ }^{477}$ In his analysis of these racist views, Reynolds reflects on how unfathomable it is that settler-colonists had such a propensity to ignore their relatively recent past as outcast criminals from Britain whilst ascribing all things progressive to white people and reducing all things primitive to the darker race. Even more perplexing is the context in which such subjective ideologies have a quarter, in this case, the Federal Parliament of Australia, which is the law-making branch of government where the principle of equality and justice should be epitomised, respected, and promoted.

Settler-colonisers thrive on creating racial, class, and gender stratifications. Liberia's African American settler-colonist elite, like their fellow Australian settler-colonists, craved to be counted as equals in their new homes. Ultimately, they yearned for freedom from discrimination and abuse. For these troubled settler-colonists, being 'civilised' means attaining a superior social standing through adopting a white (i.e. 'Westernised') lifestyle. They regarded the civilised as those who followed the Western way of life, as opposed to an Indigenous African one. Upon their arrival from the Deep South, former slaves struggled to re-create Monrovia as an American 'westernised' capital city, ${ }^{448}$ leaving the primitive 'country people' in the bush. Merran Fraenkel, a white American who first visited Liberia in the late 1960s, argues that in colonised Liberia, 'civilisation is a process in which all Monrovians are involved, and

\footnotetext{
${ }^{437}$ Australian Senate, "Richard Edwards (1842-1915), Member for Oxley (Queensland) 1901-1913)”, (2015) available at: 〈http://exhibitions.senate.gov.au/pogg/members/pdf/edwards_r.pdf>.

${ }^{438}$ Reynolds, above n 433, 86-87.

${ }^{439}$ Ibid 87.

${ }^{440}$ W. G. McMinn, "Reid, Sir George Houstoun (1845-1918)", Australian Dictionary of Biography, National Centre of Biography, Australian National University, available at: <http://adb.anu.edu.au/biography/reid-sir-georgehoustoun-8173/text14289>, published first in hardcopy 1988, accessed online 14 August 2015.

${ }^{441}$ Reynolds, above $\mathrm{n} 433,87$.

${ }^{442}$ Australian Senate, "James Black Ronald (1861-1941), Member of Southern Melbourne (Victoria) 1901-1906", available at: 〈http://exhibitions.senate.gov.au/pogg/members/ronald.htm〉.

${ }^{443}$ Reynolds, above $n$ 433, 88.

${ }^{444}$ Member of Parliament (Liberal, NSW), 1910-1911

${ }^{445}$ Reynolds, above $\mathrm{n} 433,87$.

${ }^{446}$ Bede Nairn, "Watson, John Christian (Chris) (1867-1941)", Australian Dictionary of Biography, National Centre of Biography, Australian National University, available at: <http://adb.anu.edu.au/biography/watson-john-christianchris-9003/text15849, published first in hardcopy 1990, accessed online 14 August 2015>.

${ }^{447}$ Reynolds, above n 433, 93.

${ }^{448}$ Fraenkel, above n 39, 196. According to Fraenkel, the Kru used the term kwi klo to describe Monrovia as 'the white man's town' or Town Centre.
} 
theoretically a person's social position is measurable against a scale of ranking based on varying degrees of civilisation' (see Figure 2.1 below). ${ }^{449}$ Unfortunately, this social ranking is still in effect in Liberia today.

This social class ranking observed in Liberia is quite similar to the kind envisaged by Churchill, Edwards, Forrest, Reid, Ronald and Edwards described above. Earlier writers and thinkers, such as Edward Wilmot Blyden, an African American Returnee to Liberia from the US Virgin Island, critique Fraenkel's argument with respect to the validity of Liberian history told by non-Liberians. In contrast to Fraenkel's linear relationship of social ordering in Liberia, that is, the creation of a class system that places elites at the top and Indigenous Peoples at the base

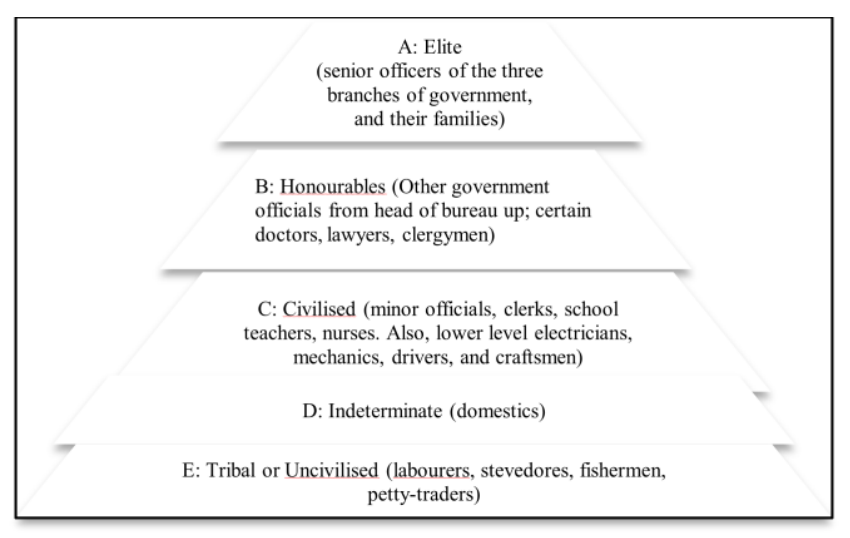

Figure 2.1: Pyramid of social class in Liberia

Source: Merran Fraenkel, Tribe and Class in Monrovia (London: Oxford University Press, 1966) 199. (see Figure 2.1), Blyden dissected a much more complex Liberia beneath the surface of what would generally pass for conventional wisdom regarding Liberia's elitism and classism. Blyden constantly challenged the conventional wisdom of using a simplistic analogy to describe black Africa as uncivilised and inferior. ${ }^{450}$ Another Liberian scholar, Abayomi Karnga, expands on Blyden's critique.

Karnga, a Liberian historian descending from recaptured slaves who were returned to Liberia, believes that some white people are 'true friends of the Negro race', although, he warns of an 'army of Negro-phobist among the same race'. ${ }^{451}$ Based on Blyden's and Karnga's divergent views, it can be argued that African American settler-colonists are internally conflicted by their Black Skin White Mask, ${ }^{452}$ as Frantz Fanon aptly titled his ground-breaking book. Fanon expanded on Karnga's concept that, driven by conditioning and indoctrination, ${ }^{453}$ 'Negro-phobists' developed a proclivity to reject their own. Malcolm X also vehemently spoke

\footnotetext{
${ }^{449}$ Ibid 197. Fraenkel describes social hierarchical structure in Liberia: the top social stratum is referred to locally as 'the elite', 'society', 'high society' or 'big shots' although the last of this term may have a much wider connotation. The nucleus of the elite consists of a number of Americo-Liberian.

${ }^{450}$ Ruth Blyden, Blyden, Edward Wilmont (1832-1912) (2015) Black Past <http://www.blackpast.org/gah/edwardwilmot-blyden-1832-1912>.

${ }^{451}$ Karnga, above $\mathrm{n} 171$, x.

${ }^{452}$ Fanon, above n 247.

${ }^{453}$ Carter Godwin Woodson, The Mis-Education of the Negro (The Associated Publisher, 1933) 1 <https://devontekwatson.files.wordpress.com/2013/10/miseducation-text.pdf>; Carter Godwin Woodson, The Education of the Negro Prior to 1861 - A History of the Education of the Coloured People of the United States from the Beginning of Slavery to the Civil War (Putnam, 1915) 3. Carter Woodson, the Father of African American History, opens The Mis-education of the Negro: 'The 'educated Negroes' have the attitude of contempt toward their own people because in their own as well as in their mixed schools Negroes are taught to admire the Hebrew, the Greek, the Latin and the Teuton and to despise the African'.
} 
against this kind of Negro-phobia ${ }^{454}$ that Gerald Taiaiake Alfred calls 'inward self-hating'. ${ }^{455}$ Unfortunately, the political and administrative structures established in Liberia generated similar problems of identity and social stratification amongst Indigenous Liberians.

A system of 'indirect rule' imposed on Indigenous Liberians by settler-colonists contributed to the stratification and denigration of Indigenous Liberians. Indirect rule is a strategy devised by settler-colonists and their descendants to maintain control over Indigenous Peoples through an efficient administrative service, whereby certain Indigenous Persons are selected by a settler-colonist administration and given special standing within the colonial structure and power over other Indigenous Peoples. In Liberia, this form of administration has a direct link to the settler-colonists' slave history, where slave masters infantilised Black slave men and rewarded disloyalty and deception shown by slaves towards fellow slaves. ${ }^{456}$ The practice of indirect rule typifies the unequal and traitorous relationship between servant and master, thereby breeding a culture of self-hatred and resentment amongst Black folks over time.

From its founding, Liberian settler-colonist leadership searched for ways to manage Indigenous Peoples. In his Annual Address to the Liberian Legislature on 15 December 1904, President Arthur Barclay (1904-1912), praised the effectiveness of indirect rule through Honourable HJ Moore, Secretary of the Interior, who was,

\begin{abstract}
...recognised as the Agent of the Government of Liberia among the tribes of the hinterland of Montserrado, among whom he was widely known. His tactful management maintained the peace of a great part of the province for many years, especially of the districts contiguous to the Americo-Liberia townships... Secretary Moore received from his father much useful information and sound advice as to the manner in which the native population ought to be controlled and governed. ${ }^{45}$
\end{abstract}

Warily recognising Native Peoples in Liberia as citizens, President Arthur Barclay sought to pattern control of Native Peoples in Liberian along the lines of indirect rule. He set out to use traditional chiefs as instruments of the central government to maintain law and order at the local level. The policy not only offered an economic advantage to African American settler-colonists by extending political power to them, but it also perpetuated social division within the hinterland. More than 20 Indigenous language groups were divided, a number much closer to the existing 16 language groups found in Liberia today. Irrespective of the socio-political

\footnotetext{
${ }^{454}$ X, above n 424. Malcolm X delivers a powerful speech at Ronald Stokes' funeral in Los Angeles on 5 May 1962: 'Who taught you to hate the texture of your hair? Who taught you to hate the colour of your skin to such extent that you bleach to get like the white man? Who taught you to hate the shape of your nose and the shape of your lips? Who taught you to hate yourself from the top of your head to the soles of your feet? Who taught you to hate your own kind? Who taught you to hate the race that you belong to, so much so that you don't want to be around each other'? ${ }_{455}$ Gerald Taiaiake Alfred, ‘Colonialism and State Dependency' (2009) 5(2) Journal de la Santé Autochtone 42. Alfred seamlessly connects the impacts of colonialism on Indigenous men and violence against Indigenous women: 'Indigenous men's difficulties in comprehending and dealing effectively with the source of their own disempowerment has led to a compounding of the problem for Indigenous women and children, who are frequently the targets of men's raging manifestations of internalized self-hatred. This problem exists in various forms and intensities across the entire economic and social spectrum...'

${ }^{456}$ Michelle Alexander, The New Jim Crow: Mass Incarceration in the Age of Colorblindness (New York, NY: The New Press, 2011) at 118; Jeff Forret, Slave Against Slave: Plantation Violence in the Old South (Baton Rouge, LA: Louisiana State University Press, 2015) at 41.

${ }^{457}$ D Elwood Dunn (ed), The Annual Messages of the Presidents of Liberia 1848-2010: State of the Nation Addresses to the National Legislature - from Joseph Jenkins Roberts to Ellen Johnson Sirleaf (De Gruyter, 2011) 430.
} 
impact on various language groups in Liberia, in the end, it created an opportunity for African American settler-colonists to capitalise on such political fragmentation to exploit Native Peoples. ${ }^{458}$ Even though, in later years, a more cohesive paramount chieftainship somehow reversed the process of fragmentation, to date, only the Dey, Mende, Gbandi, Kissi, and Belle Peoples unite under single paramount chiefs. The same cannot be said of the Kpelle, for example, who were dispersed amongst four administrative areas. In other cases, fragments of several mutually hostile ethnic groups were incorporated within single districts. Patterns of indirect rule in Liberia still exist today.

Currently, the indirect rule in Liberia is operationalised in the Department of the Interior (now the Department of Internal Affairs). ${ }^{459}$ According to Liebenow, the Liberian Department of the Interior was created during the presidency of James Spriggs Payne (1968). The effectiveness of the Department of the Interior was blunted by a lack of qualified African American settler-colonists interested in living in the hinterland. Difficulties posed by geography also hindered the systematic supervision of the administrative officers. These challenges eventually led to the absence of explicit policy to address dependency relationships between Native Peoples in Liberia and settler-colonist administrators. ${ }^{460}$ Even as indirect rule endeavours to stratify and separate, cultural forces of assimilation work to blur the lines between social and political classes.

The politics of assimilation juxtaposes the implementation of the indirect rule. Liebenow reasons that the challenge of assimilating and integrating Native Peoples into a foreign colonial style has everything to do with settler-colonists' unfamiliarity with their physical and human environment. Exacerbating this problem, rather than adapting to Indigenous customs, African American settlers tend to establish small 'protective' enclaves, which keep them in isolation and enable them to nurture and reconstruct of their previous lifestyles. ${ }^{461}$ Liebenow needs to be understood from a political, rather than a historical perspective, which takes Liberia from the 1960s and compares it with decolonizing the African States. His work has been criticised for completely ignoring the unique circumstances under which Liberia was formed. Nonetheless, Blyden entertains a different view.

Blyden's view is that the African American colonist-settlers' objective should be to achieve assimilation with Native Africans in Liberia rather than with Euro-Americans in the United States. Blyden's stance on embracing racial nationalism as a way to minimise the cultural difference between Native Africans and their distant New World cousins is founded in unity and collective force. Blyden believes that '[w]hen alien and hostile races have come

\footnotetext{
${ }^{458}$ Liebenow, above n 55, 57-58.

${ }^{459}$ Ibid.

${ }^{460}$ Ibid.

${ }^{461}$ Shick, above n 170, 31, 33-34; Cassell, above n 53, 13-29, 31-50, 108; Campbell, above n 189, 30-58. The American Colonisation Society raised funds to set colonies in Liberia by organising State auxiliary chapters. For example, the Bassa Cove settlement was founded in 1934 by land purchased by the Young Men's Colonisation Society of Pennsylvania and New York; the Sinoe settlement was founded in 1838 by the Mississippi State Colonisation Society in order to relocate slaves from Mississippi; and the most elaborate of them all was the Cape Palmas settlement organised by the Maryland State Colonisation Society in 1831.
} 
together, one has had to succumb to the other; but when different people of the same family have been brought together, there has invariably been a fusion and the result has been an improved and powerful class. ${ }^{462}$ Blyden's philosophy could be a long-term reality in the making, considering the significant amount of time it is taking to address the impact of colonisation on Native Peoples in Liberia. In Australia, the concept of assimilation became the dominant management strategy.

Native-Settler governance in Australia is fundamentally different from models seen across colonial Africa, including in Liberia. Whilst the idea of the indirect rule is not usually applied to Aboriginal-colonists relations in Australia, it can be seen through the Native Police, Colonial Secretary ${ }^{463}$ (now Indigenous Affairs directly under the surveillance of the Department of the Prime Minister and Cabinet ${ }^{464}$ or even supra-structurally by the establishment of the Governor General Office. ${ }^{465}$ Instead of indirect rule, Ben Silverstein argues that rather than by direct rule, Australia's settler-colonist management of Indigenous Peoples was articulated through affecting their elimination by controlling modes of production, as in the settler capitalism seen in Liberia and the rest of Africa. ${ }^{466}$

Aboriginal Peoples in Australia were eliminated through racist policies that enacted aggressive forms of extermination or assimilation, including massacres and forced adoption. Other policies were predicated on the racist idea of Aboriginal inferiority, including stolen wages, and the Northern Territory intervention. As examples of explicit state instituted violence against Aboriginal women and girls, these topics are covered in more depth in chapter 3. Fortunately, these attempts to eliminate Aboriginal Peoples have failed. However, they have left Aboriginal Peoples on the margins of political and legal life in Australia. Movements in Australia by Indigenous advocates are now focused on elevating the political and legal standing of Aboriginal Peoples, whether through constitutional recognition, self-determination, or sovereignty rather than indirect governance. ${ }^{467}$

Indigenous Peoples' desire for self-determination and their corresponding struggle to overcome patriarchy, white dominance, racism, and elitism in Liberia and Australia are constantly stymied. Any opportunity for them to interact with settler-colonist governments as

\footnotetext{
${ }^{462}$ Edward Wilmot Blyden, Liberia's Offering: Being Addresses, Sermons Etc. (John A Gray Printer, 1862) 88.

${ }^{463}$ Kathy Frankland, 'A Brief History of Government Administration of Aboriginal and Torres Strait Islander Peoples in Queensland' 1

<http://www.slq.qld.gov.au/_data/assets/pdf_file/0008/93734/Admin_History_Aboriginal_and_Torres_Strait_Island ers.pdf $>$.

${ }^{464}$ See, the Australian Government Department of the Prime Minister and Cabinet, available at:

$<$ https://www.dpmc.gov.au/indigenous-affairs>.

${ }^{465}$ See, the Governor-General of the Commonwealth of Australia, available: <https://www.gg.gov.au>. The office of Governor-General was established by the Constitution of the Commonwealth of Australia in 1901. Appointed at the pleasure of the Queen on the advice of the Prime Minister, the Governor General is a representative of the Queen in the Commonwealth. S/he may exercise such powers and functions of the Queen as she may be pleased to assign, but subject to the Constitution of Australia.

${ }^{466}$ Ben Silverstein, 'Indirect Rule in Australia: A Case Study in Settler-Colonial Difference' in Fiona Bateman and Lionel Pilkington (eds), Studies in Settler Colonialism (Palgrave Macmillan UK, 2011) 90, 96 <http://link.springer.com/10.1057/9780230306288>.

${ }^{467}$ Ben Worsley, 'Indigenous Referendum: Australians Invited to Join Community Conference on Recognition Vote' ABC News (Sydney, NSW), 6 July 2015 <http://www.abc.net.au/news/2015-07-06/australia-big-enough-forindigenous-referendum-says-abbott/6598144>.
} 
independent and sovereign nations with rights to freely determine their political status and pursue their social, economic, and cultural development, ${ }^{468}$ or even participate in public affairs, is solely dependent on the approval of settler-colonist governments. Jill Webb argues that, despite the explicit language used in Article 1 of both the International Covenant on Civil and Political Rights and the International Covenant on Economic, Social and Cultural Rights, there is still contention about whether the 'all peoples' who have the right to self-determination includes Indigenous Peoples. ${ }^{469}$ Reynolds argues that, for Aboriginal and Torres Strait Islanders, it is not simply about participating in public leadership roles or seeking inclusion in 'working out how to arrange the pieces on the board to construct the most desirable Australian nation'; rather, it is a question of the Board itself and the rules of the game. ${ }^{470}$ John Bern et al., see a recurring concern about how Indigenous self-government and representation should be structured, given the plurality of interests and the diversity of Aboriginal communities.

Reynolds suggests that self-determination should be understood as a single Aboriginal nation since white Australia sees itself as one sovereign nation since the colonisation. ${ }^{471}$ Michael Mansell's approach to Indigenous sovereignty highlights the relevance of maintaining Aboriginal local government control in communities, lest their sovereignty is lost to assimilation. ${ }^{472}$ Michael Dodson purports that self-determination is possible within the parameters of a modern nation-state; hence, it would be 'naïve to assume that self-determination equates with separatism'. ${ }^{473}$ Together Dodson and Mansell sum up two schools of thoughts regarding Indigenous Australians' desire to claim recognition as First Peoples, as narrated in Reynolds (1996):

If we are going to enjoy our rights, and more than that to survive as distinct peoples and cultures, creative new concepts and structures will have to be set in place. We assert, and will continue to assert, that there are indigenous political and legal systems which must be recognised as having a place, whether that place be within the basic structures underlying so-called mainstream society, or parallel to that society. But the fact is that the foundations of the Australian nation exclude and fail to recognise those pre-existing social and political orders. ${ }^{474}$

[Aboriginal] people must be allowed to go beyond struggling for better conditions. The right to control ourselves on our own land without interference from others is a basic right. To be and act as a nation of people independent of whites ought not to be a controversial issue but an entitlement. To impose our own laws in our own communities; to raise our own finances from our own portions of the continent; to have our own Olympic team and our own diplomats and passports is our right as a nation of people. Those rights are or should be the aim of our movement. ${ }^{43}$

\footnotetext{
${ }^{468}$ Article 1 of both the International Covenant on Civil and Political Rights and the International Covenant on Economic, Social and Cultural Rights states that, '[a]ll peoples have the right of self-determination. By virtue of that right they freely determine their political status and freely pursue their economic, social and cultural development'.

${ }^{469}$ Webb, above n $135,81$.

${ }^{470}$ Reynolds, Aboriginal Sovereignty, above n 221, 137.

${ }^{471}$ Reynolds, Aboriginal Sovereignty, above n 221.

${ }^{472}$ Michael Mansell, From Democracy to Statehood: Aboriginal Self-Determination (Federation Press, 2016).

${ }^{473}$ Michael Dodson, 'Assimilation versus Self-Determination: No Contest' (Sydney, NSW, 1996)

<https://www.humanrights.gov.au/news/speeches/assimilation-versus-self-determination-no-contest-dodson-1996>.

${ }^{474}$ Reynolds, Aboriginal Sovereignty, above n 221, 137-138.

${ }^{475}$ Ibid 138.
} 
Settler-colonists' encroachment upon Indigenous spaces and on-going denial of recognition have resulted in persistent cultural and structural violence with racism, patriarchy, white supremacy, and elitism at its helm. For some Indigenous Peoples, the connection amongst language, culture, the land, and full autonomy over Aboriginal Customary Laws requires fundamental constitutional recognition. ${ }^{476}$ The Referendum Council, appointed to advise the Prime Minister and Leader of the Opposition about options for constitutional reform, perceives Australia's nationhood as unfinished business. Substantive structural reform requires recognition of the ancient jurisdiction of First Nations law which was violated when the British came to Australia to possess ownership of sovereignty that was not ceded. ${ }^{477}$ As a result, a 'fuller expression of Australia's nationhood' is required, so that First Nation sovereignty can effectively and powerfully shine through. Although Indigenous research advocates suggest equal participation, recognition, and self-government as necessary ingredients for fair play in the politico-legal domain, such advancement is often complicated by other deeply rooted problems, such as land dispossession, decolonisation, and the post-colonial struggle of Indigenous Peoples.

\subsubsection{Theme 3: (Land) Dispossession and (De) Colonisation}

Having sold their ownership 'natives' became tenants of the state on government land. ${ }^{478}$

Studies have shown that Indigenous Peoples tend to live off the land through complex use of farming, hunting, and fishing across Africa and with complex rituals and languages; but their cultures and languages were shattered by colonisation. ${ }^{479}$ Captain Arthur Phillip attests to the fact that Indigenous Peoples in Australia (e.g., Cammerragal and Cadigal) are the original dwellers of Australia. ${ }^{400}$ In addition to Phillip's account, archaeological and anthropological findings, as noted above, show that Indigenous Peoples in Australia and Liberia inhabited the land long before settlers arrived. However, settler-colonists used discourse in the law to aid their justification for dispossessing Indigenous Peoples of their land. ${ }^{481}$ The historical legacy of dislocation and dispossession, characterised by social disadvantage ${ }^{482}$ and the forces that would see it continue, is ever-present. ${ }^{483}$

\footnotetext{
${ }^{476}$ The Referendum Council, 'Final Report of the Referendum Council' (Indigenous Employment and Recognition, Department of the Prime Minister and Cabinet, 30 June 2017) 183, 16 <https://www.referendumcouncil.org.au/finalreport>.

${ }^{477}$ Ibid 17.

${ }^{478}$ Wily, above n 304,73

${ }^{479}$ Heather Douglas, Indigenous Crime and Settler Law: White Sovereignty After Empire (Palgrave Macmillan, 2012) 37.

${ }^{480}$ Reynolds, Aboriginal Sovereignty, above n 221, 24-25.

${ }^{481}$ Paul Keal, European Conquest and the Rights of Indigenous Peoples: The Moral Backwardness of International Society (Cambridge University Press, 2003) 113

<http://www.ourpgs.com/books/law/European\%20conquest\%20rights\%20indigenous\%20people.pdf>.

${ }_{482}$ Australian Law Reform Commission, Aboriginal Customary Laws (30 July 2010) Australian Government:

Australian Law Reform Commission 21 <http://www.alrc.gov.au/inquiries/aboriginal-customary-laws〉.

${ }^{483}$ Keal, above n 481, 113.
} 
According to Reynolds, the concept of terra nullius is 'the single most important feature of the British expropriation of Aboriginal land'; it enabled the settler-colonists to convince themselves that they had a legal and moral right to the land. ${ }^{484}$ James Prichard opted for complete extermination should 'inferior and barbarous' Aboriginal Peoples reject European civilisation. For exhibiting such inhumane attitudes, June Oscar (2015) calls English settlercolonists, 'greedy to consume the worlds of others' ${ }^{485}$ Fanon (1963) rebukes the philosophical 'justification' of the settler-colonists in claiming ownership of what is not theirs:

\begin{abstract}
The settler makes history; his life is an epoch, an odyssey. He is the absolute beginning: "This land was created by us"; he is the unceasing cause: 'if we leave, all is lost, and the country will go back to the Middle Ages.' Over against him torpid creatures, wasted by fevers, obsessed by ancestral customs, form an almost inorganic background for the innovating dynamism of colonial mercantilism. The settler makes history and is conscious of making it. And because he constantly refers to the history of his mother country, he clearly indicates that he himself is the extension of that mother country. Thus, the history which he writes is not the history of the country which he plunders but the history of his own nation in regard to all that she skims off, all that she violates and starves. The immobility to which the native is condemned can only be called in question if the native decides to put an end to the history of colonization - the history of pillage - and to bring into existence the history of the nation - the history of decolonization. ${ }^{486}$
\end{abstract}

Unfortunately, terra nullius was an idea so repeatedly endorsed that it became a 'doctrine of discovery', ${ }^{487}$ accepted first by the settler-colonists and now by most Australians because of a distorted colonial curriculum taught in schools. ${ }^{488}$

European Australians, enamoured with false ideas founded in European common law and Christian beliefs, have attempted to address injustices done when they dispossessed Aboriginal Peoples of their lands. Moral and social justice approaches adopted by colonial Australians include (but are not limited to) apology ${ }^{489}$ and sorry ${ }^{40}$ days. Decolonising approaches and efforts to reinforce claims to original land ownership include (but are not limited to) Welcome to Country or Acknowledgement of Country. ${ }^{491}$ Legal justice has taken the form of

\footnotetext{
${ }^{484}$ Reynolds, Dispossession, above n 177, 67.

${ }^{485}$ June Oscar, 'Encountering Truth: The Real Life Stories of Objects from Empire's Frontier and beyond' (Menzies Lecture Seminar: British Museum Exhibition at the Indigenous Australia Enduring Civilisation, King's College, London, 29 April 2015) <http://www.kcl.ac.uk/artshums/ahri/eventrecords/2014-2015/MCAS/June-Oscar.aspx>.

${ }^{486}$ Fanon, above n 247, 51.

${ }^{487}$ Webb, above n 135, 76.

${ }^{488}$ Ashley M Foley, Terra Nullius: The Aborigines in Australia (Bachelor Honours of Arts (Honours) Thesis, Salve Regina University, 2009) 40

<http://digitalcommons.salve.edu/cgi/viewcontent.cgi?article=1033\&context=pell_theses>; Sarah Booth, Teaching Aboriginal Curriculum Content in Australian High Schools (Master of Education (Research), Edith Cowan University, 2014) 8 <http://ro.ecu.edu.au/cgi/viewcontent.cgi?article=2523\&context=theses>; Commonwealth of Australia, 'The Shape of the Australian Curriculum: History' (Government Policy, National Curriculum Board, May 2009) 16, 8 <http://docs.acara.edu.au/resources/Australian_Curriculum_-_History.pdf >.

${ }^{489}$ Australian Broadcasting Corporation, National Apology for Forced Adoptions (2013)

<http://www.youtube.com/watch?v=5hVbokTpYeg>; Julia Gillard, National Apology for Forced Adoptions (Attorney-General's Department, Government of Australia, 2013) <http://www.ag.gov.au/About/ForcedAdoptionsApology/Pages/default.aspx>.

${ }^{490}$ Paul Keating, Prime Minister Paul Keating's Speech at Redfern (AIATSIS, Government of Australia, 1992). A coalition of Australian community groups came together in 1998 and declared 26 May as 'National Sorry Day' - an annual day to be remorseful of colonial policies that stole some 50000 Aboriginal children from their families between 1910 and the 1970s.

${ }^{491}$ Reconciliation Australia, 'Welcome to Country Q \& A Factsheet' < http://www.unisa.edu.au/Documents/QAwelcome-to-country.pdf $>$. Welcome to Country is a ceremony performed (singing, dancing, smoking or a speech) by
} 
international law and domestic land dispute settlements. ${ }^{492}$ International law efforts include founding the United Nations Trusteeship Council and establishing the Declaration on the Granting of Independence to Colonial Countries and Peoples 1960. But according to Webb, none of these approaches rendered independence to Indigenous Peoples as they are not included in the 'all peoples' provision stated above. ${ }^{493}$ Domestic efforts include, but are not limited to, Terry v Wilson 1849, ${ }^{494}$ Mabo $1992^{495}$ and Akiba $2013 .{ }^{496}$ These land settlement cases identify Indigenous Peoples as the First Peoples of the land. However, implementation and acquisition of Native Title in Australia by virtue of being Indigenous is far from simple and direct ownership. Against this backdrop, a full acknowledgement of colonial possession of Indigenous land begs an assessment of what transpired when 427 convict vessels arrived on the shores of Indigenous lands between 1788 and 1868. Similarly, settler-colonists to Liberia found Indigenous peoples inhabiting the lands they 'discovered' and chose to inhabit.

As in Australia, appropriation of land by American colonists to settle African American Former Slaves in Liberia included violence against the land's Indigenous inhabitants. ${ }^{497}$ Although historical materials researched in this study do not point to a violent conflict between Indigenous Liberians and settlers, except for in the work of a few scholars such as Jeremy

\footnotetext{
Aboriginal Australians to welcome visitors to their traditional land. Acknowledgement of Country is a way of showing awareness of, respect for and recognising continuing connection of Aboriginal Australians as original owners of the land on which a meeting or an event is being held. Matilda House-Williams, a Ngambri, Ngunnawal and Wiradjuri elder, was the first Indigenous invited to offer a 'Welcome to Country' at the opening of the $42^{\text {nd }}$ Federal Parliament of Australia on 12 February 2008 (see, http://genderinstitute.anu.edu.au/australian-inspringwomen-matilda-house-williams-ngambri-ngunnawal-wiradjuri-elder).

${ }^{492}$ Glen Cordingley, 'Station Gives Yawuru a New Start' The West Australian (Broome, WA), 3 September 2014 <https://au.news.yahoo.com/thewest/business/wa/a/24881704/station-gives-yawuru-chance-to-rebuild/>.

${ }^{493}$ Webb, above n $135,82$.

${ }^{494}$ Reynolds, Dispossession, above n 177, 67.

${ }^{495}$ Diane Bell, 'Aboriginal Customary Law: What Is Law [and What Is Not]?' (Seminar at the SA Law Society Seminar, Adelaide, South Australia, 29 July 2006); Greg McIntyre, 'Mabo: A Catalyst for Social Change' (Public Lecture at the Public Lecture with Greg McIntyre, Sparke Helmore 2, ANU College of Law, 13 May 2013) $<$ http://ncis.anu.edu.au/events/past/index.php\#greg_mcintyre >; Henry Reynolds, 'After Mabo, What about Aboriginal Sovereignty' [1996] (April) Australian Humanities Review

http://www.australianhumanitiesreview.org/archive/Issue; Lisa Strelein, Compromised Jurisprudence: Native Title Cases Since Mabo (Aboriginal Studies Press, 2nd ed, 2009) 116; Henry Reynolds, Why Weren't We Told?: A Personal Search for the Truth About Our History (Penguin, 2000) 249; Reynolds, Aboriginal Sovereignty, above $\mathrm{n}$ 221, 1-2, 13-15; Henry Reynolds, The Law of the Land (Penguin Books, 1992) 187; Telling Stories: Indigenous History and Memory in Australia and New Zealand, above n 354, 31; Richard Broome, Aboriginal Australians: Black Responses to White Dominance, 1788-2001 (Allen and Unwin, 3rd ed, 2002) 233, 235-240; Chris Cunneen, Indigenous People and the Law in Australia (Butterworths, 1995) 108-118; Max Griffiths, Aboriginal Affairs: A Short History (Kangaroo Press, 1995); Sarah Keenan, 'Moments of Decolonization: Indigenous Australia in the Here and Now' (2014) 29(2) Canadian Journal of Law and Society 163, 239; An Unruly Child: A History of Law in Australia (Allen and Unwin, 1995) 11, 119-120; Martin Mhando, Liyarn Ngarn (2007)

<http://www.imdb.com/title/tt2199740/>; Practising Reconciliation?: The Politics of Reconciliation in the Australian Parliament, 1991-2000 (Department of Parliamentary Services, 2005) 47-77.

${ }^{496}$ Lauren Butterly, 'Unfinished Business in the Straits: Akiba v Commonwealth of Australia [2013] HCA 33' (2013) 8(8) Indigenous Law Bulletin 1.

${ }^{497}$ Dunn and Holsoe, above n 104, xiii-xiv. Dunn and Holsoe list several disputes between the colonists and Indigenous Liberians in the early days of establishment. For example, in 1822, the first major armed conflict between repatriate and Indigenous Liberians takes place. In 1838, Dei-Gola war in which Liberia first attempts mediation, then sides with the Gola. In 1856 war breaks out between the independent colony of Maryland and the Grebo Confederation. That same year, the Kru Confederation attacks settlement in Sinoe County. An instance worth noting here regarding frontier battles and Indigenous land dispossession in Liberia. As Liberia HIStory has been mostly written by descendants of Afro-Americans and foreigners a logical reasoning points to distortions in favour of 'his' or 'her' story. A case in point is the Matilda Newport account of the Crown Hill Battle. Children of Liberia was thought of her heroic feat in using a pipe to set-off a canon that wore off natives causing settler emigrates to defeat Indigenous Liberia. At present, this account is said to have been fabricated and distorted by African-American emigrates to elevate the persistent superiority and victory in conquering the fellow brothers and sisters.
} 
Levitt, ${ }^{498}$ neither is there any written documentation (e.g., title or deeds) to evidence land purchase by treaty nor fair deal, apart from a limited anecdotal citing, ${ }^{499}$ including an expropriation narrative stored in the Liberian National Archives. ${ }^{500}$ According to Fanon, conveniently distorting the history of violence is the settler-colonists' conscious effort to make and write the 'history of his own nation'. Unfortunately, the gluttony of settler-colonists spoken of by Oscar (above) is no longer an event of the past perpetrated by white settler-colonists in Australia but rather a present-day occurrence displayed by Black African American settlers against Black Native Africans in Liberia.

Government-sanctioned land disposition continues to plague Indigenous communities in Liberia. For example, Liberia now accounts for 45 percent of West Africa's remaining forest, over 60 percent of which has been offered to logging companies with no consultation or benefit to Native Peoples in Liberia. ${ }^{501}$ For example, Emmanuel Weedee narrates that when Chief Manjo of the Kpelle Language Group was asked how did 90000 hectares of their communityowned forest had been signed away to a logging company with nothing in return, he responded, 'I don't know book' (meaning he is not literate). However, a 13-page contract that shows the forests have been awarded to a Liberian company called Bopolu Development Corporation for the next 20 years carried Chief Manjo's signature. Notwithstanding, the Chief claims 'his hand' did not sign the agreement.

This alleged forging of Chief Manjo's signature to dispossess Native Kpelle People of their land is a serious offence that requires prosecution or at least investigation. But who will advocate for the Kpelle People if they have neither legal support nor educational aptitude to file a claim for such violation? As far back as 1926, Karnga wrote of settlers-colonists' landgrabbing exploits in Liberia. ${ }^{502}$ Karnga was writing at the time when Firestone Rubber Plantation purchased a million acres of Native Peoples' land for six cents per acre for 99 years (see chapters 3 and 6 for more details). For Indigenous Liberians, resistance to African American settlers-colonists' control over their land finally comes through a new Land Rights Draft Bill in

\footnotetext{
${ }^{498}$ Levitt, above n 105, 31-85.

${ }^{499}$ Karnga, above n 171, 21-27. Prior to their arrival on 15 December 1821, a small tract of land was bought by ACS from King Peter (probably Zolu Duma of Vai country), George, Yoda and Long Peter (of De/Dei and Mamba/Mahnbahn ethnic groups) on Bushrod Island. After the acquisition of Providence Island (Cape Mesurado) by Eli Eyers and Captain Robert Stockton, on 7 January 1822, the settler-colonists built town houses on the mainland of Monrovia (named after James Monroe in 1824). On the 18 December 1832, 33 volunteers set out from Monrovia to establish a new colony called Edina. In 1835, another settlement was founded by the Pennsylvania Society, called Bass Cove. In 1837, Marshall (in honour of James Marshall, Chief Justice, USA) was built at the mouth of the Farmington River and Thomas Buchanan (first Governor of the ACS and cousin of former US President James Buchanan) built Bassa Cove. In 1838 Greenville (named after James Green) was built by the Mississippi Colonisation Society and Bexley, on the St. John's River was built by Lewis Sheridan. Cape Palmas was founded by the State of Maryland in the US through the Maryland Colonisation Society in 1927. Dr James Hall in 1831 bought land from King Jude and other Grebo Chiefs to establish the Maryland settlement. By 1854, Maryland becomes an independent republic and later acceded to the Commonwealth of Liberia in 1857.

${ }^{500}$ Svend E Holsoe and Megan MacDonald, Liberian Government Archives, 1828-1911 (2016) Indiana University Archives Online <http://webapp1.dlib.indiana.edu/findingaids/view?doc.view=entire_text\&docId=VAB6927>.

${ }^{501}$ Emmanuel Weedee, 'Over 60 per Cent of Liberia's Rain Forest Offered to Logging Companies' Heritage

(Monrovia, Liberia), 4 September $2012<\mathrm{http} / / /$ allafrica.com/stories/201209200720.html〉.

${ }^{502}$ Karnga, above n 171, x.
} 
2014. Although the 2014 Draft Bill is a small step in comparison to the Mabo case in Australia, it is as good as it can get, for now, subject to its actual passage and implementation. ${ }^{50}$

\subsubsection{Theme 4: (Mental) Health, Education, Housing, Employment \& Development}

Socio-economic well-being (housing, education, employment, and health) of Indigenous Peoples is an ongoing concern. Although progress has been made in some areas, as noted above, significant change is slow and sometimes troubling. In 2009, the Government of Australia promised to improve housing conditions for Aboriginals living in the townships in the Northern Territory. The Rudd Government claimed to have allocated \$672 million for 750 new homes and 2500 refurbishments. ${ }^{504}$ By 2014, the National Commission of Audit found that the Abbott Government had cut \$534 million over a five-year period from Aboriginal funding for social services, ${ }^{505}$ whilst maintaining some $\$ 22$ billion for defence. Media reporting alleged that the government of Australia's political moves had a direct and fatal impact on 11-year old Peter Little $^{506}$ and Deadly Awards Founder Gavin Jones. ${ }^{507}$ The experiences of Little and Jones also suggest a direct link between public law and policy, mental illness, and access to employment as it pertains social services for Indigenous Peoples. In 2012-2013, the Australian Institute of Health and Welfare reported that 48 percent of Indigenous adults confided that either they or their relatives had been removed from their natural families. Of those taken away, 35 percent reported higher psychological stress compared with those who were not ( 29 percent). ${ }^{508}$ These outcomes point to government policy and the legal system as a social determinant of health for Aboriginal Australians, and the same is true in Liberia.

The intersectionality of government policy, poverty, education, and access to healthcare is also a problem for the mental and physical health of Indigenous Peoples in Liberia. Former Chief Medical Officer of Liberia (now Minister of Health) Bernice Dahn, disclosed that 400000 persons are suffering from mild mental illness and 115000 others from mental disorders, mainly attributable to the 14 -year civil $\operatorname{war}^{509}$ and the recent Ebola Virus Disease crisis. ${ }^{510}$

\footnotetext{
${ }^{503}$ EJ Nathaniel Daygbor, 'Land Bill Reaches Capitol Building' The New Dawn (Monrovia, Liberia), 7 August 2015 <http://www.thenewdawnliberia.com/news/8108-land-bill-reaches-capitol-building>. Daygbor reports that, the draft Land Reform Act (LRA) sets out a wide range of protection for customary land rights ensuring that communities are empowered to self-identity in defining the area of their customary land in pursuit of keeping with their custom, history and norms.

${ }^{504}$ Shar Adams, 'Inclusion the Key to “town Camps” Solution' Epoch Times (Sydney, NSW), 10 November 2009 http://www.theepochtimes.com/n2/australia/aborigines.

${ }^{505}$ Indigenous Affairs Commonwealth Parliament, Indigenous Affairs (2014) Parliament of Australia <http://www.aph.gov.au/about_parliament/parliamentary_departments/parliamentary_library/pubs/rp/budgetreview2 01415/indigenous?print $=1>$.

${ }^{506}$ Susan Allan, 'Eleven-Year-Old Aboriginal Boy Commits Suicide' World Socialist Web Site (Geraldton, WA), 8 December 2014 https://www.wsws.org/en/articles/2014/12/08/suic.

${ }^{507}$ Rick Feneley, 'Deadly Awards Founder Gavin Jones Dies after Funding Cut' The Sydney Morning Herald (Sydney, NSW), 14 July 2014 <http://www.smh.com.au/entertainment/deadly-awards-founder-gavin-jones-diesafter-funding-cut-20140714-zt78p.html>.

${ }^{508}$ Heuvel et al, above n 365, 50 .

${ }^{509}$ Basia Tomczyk et al, 'Women's Reproductive Health in Liberia: The Lofa County Reproductive Health Survey January-February 2007' (NGO, Centre for Disease Control and Prevention, 2007) 133, 20.

${ }^{510}$ Norimitsu Onishi, 'Clashes Erupt as Liberia Sets a Quarantine' The New York Times (Monrovia, Liberia), 20 August $2014<$ http://www.nytimes.com/2014/08/21/world/africa/ebola-outbreak-liberia-quarantine.html?smid=fbshare\&_r=1\#>.
} 
Emmanuel Bowier, a former Minister of Information turned trauma therapist, attests that 'Liberia is a big psychiatric ward'. ${ }^{511}$ Unstable housing and social environment not only cause long-term mental health problems for a relatively young population; ${ }^{512}$ but it is also a predeterminant for low literacy rates, substance abuse, ${ }^{513}$ and family violence in Liberia and Australia.

The prevalence of Aboriginal male violence contextualises the vulnerability of Indigenous girls' and women's experience of gender violence and the States' responsibility to provide such social services. Caroline Atkinson's 'Violence Continuum' shows that the State is not the only culprit for violent crimes; Aboriginal males are engaged in a complex cyclical web $^{514}$ of violence against Aboriginal girls and women to the extent that some perceive family violence as a norm in Aboriginal communities. ${ }^{515}$ Remote communities on the edges of towns and cities 'are plagued by violence and alcohol and they are creating communities of fringe dwellers', says Aboriginal and Torres Strait Islanders Social Justice Commissioner Mick Gooda. ${ }^{516}$ Jacqueline Fitzgerald and Don Weatherburn's (2000) study of police records in New South Wales found that Aboriginal people are between 2.7 times and 5.2 times more likely to become victims of violent crime.

Further, Fitzgerald and Weatherburn record that not only are Aboriginal women up to 6.6 times more likely to become victims of violent offences than New South Wales women as a whole ${ }^{517}$ but also that most violent offences against Aboriginal children and women are committed by Aboriginal men. ${ }^{518}$ Aboriginal Peoples in Australia are the most incarcerated people on the planet, says the Uluru Statement from the Heart. ${ }^{519}$ In a more recent study (2017), the Australian Law Reform Commission states that Aboriginal Peoples in Australia are at

\footnotetext{
${ }^{511}$ Helen Liebling-Kalifani et al, 'Women War Survivors of the 1989-2003 Conflict in Liberia: The Impact of Sexual and Gender-Based Violence' (2011) 12(1) Journal of International Women's Studies 1.

${ }^{512}$ Heuvel et al, above $\mathrm{n} 365,8$. According to the Institute of Health and Welfare's ATSI Health and Welfare report (2015) 36 per cent of all Aboriginal living in Australia in 2011 were aged 15 or under - a relatively young population.

${ }^{13}$ Peter D'abbs, 'Controlling "Rivers of Grog”: The Challenge of Alcohol Problems in Australian Indigenous Communities' (2010) 37 Contemporary Drug Problems 499.

${ }^{514}$ Ron Brown, 'Australian Indigenous Mental Health' (2001) 10 Australian and New Zealand Journal of Mental Health 33.

${ }^{515}$ Caroline Lisbeth Atkinson, The Violence Continuum: Australian Aboriginal Male Violence and Generational Posttraumatic Stress (PhD Thesis, Charles Darwin University, 2008) 237-238<http://laalespace.cdu.edu.au/eserv/cdu:44891/Thesis_CDU_44891_Atkinson_C.pdf $>$.

${ }^{516}$ Bridget Brennan, 'Rethink Aboriginal Town Camps: Mick Gooda' ABC News (Alice Springs, N.T), 3 March 2014 <http://www.abc.net.au/news/stories/2011/03/03/3153800.htm?site=alicesprings $>$.

${ }^{517}$ Haley Clark, 'Sexual Assault Forum, Melbourne: Organised by Victorian Women Lawyers, June 2007' (2008) 17 Australian Centre for the Study of Sexual Assault Newsletter 22, 5-6. A study analysis of 850 randomly selected rape cases reported to police around Victoria over three years (2000-2002) found that police laid charges in only 15 per cent of cases. This finding suggests that even when rape cases are reported to law enforcement, the chance that police will proceed with investigations is only 40 per cent.

${ }^{518}$ Jacqueline Fitzgerald and Don Weatherburn, 'Aboriginal Victimisation and Offending: The Picture from Police Records' (2001) 26(4) Aboriginal and Islander Health Worker 26; Diane Bell, 'Intra-Racial Rape Revisited: On Forging a Feminist Future beyond Factions and Frightening Politics' (1991) 14(5) Women's Studies International Forum 385.

${ }^{519}$ The Uluru Peoples, above n 25.
} 
higher risk of imprisonment and recidivism. ${ }^{520}$ The Law Reform Commission reports that up to 76 percent of Aboriginal and Torres Strait Islander prisoners in 2016 had been previously imprisoned; compared with 49 percent of the non-Indigenous prison population. ${ }^{521}$ Rene Adams and Yasmin Hunter describe how problematic and rampant Aboriginal male violence against Aboriginal girls and women is:

[w]omen can be walking around the town with black eyes, with some women believing that if their partners don't hit them, they don't love them. When a man is flogging his partner, people in the community will often not interfere because they believe that family violence is 'their business'. This makes it hard for victims to disclose violence or ask other community members for their support. When family violence occurs, the charges are frequently dropped because the victim does not attend court. Almost all of the women and children exposed to family violence and sexual assault are severely affected by the acts of violence. These disorders are usually undiagnosed and the victims are left to cope with these symptoms on their own. Drug and alcohol abuse is common among victims in these areas, and it is used as a means of blocking out memories of the abuse. A significant number of victims become suicidal. ${ }^{522}$

Unfortunately, the same social determinants of health that predispose Indigenous women and girls to violence are also those that perpetuate their continued vulnerability.

The literature affirms that the two most difficult aspects of leaving an abusive relationship are finding accommodation and securing employment; however, those elements of independence are even more difficult to achieve when the intersecting factors of access to employment and housing disproportionately affect Indigenous women and girls. For example, on Census night in 2011 in the Northern Territory, the highest rate of homelessness in Australia (731 per 10000 persons) was recorded. ${ }^{523}$ According to the Australian Capital Territory Shelter, even though Indigenous Peoples in Australia comprise approximately one percent of the resident population in the Australian Capital Territory, 16 percent of homeless service users identified as Indigenous in 2010-2011. ${ }^{524}$ A 2006 report by Chris Chamberlain and David Mackenzie found that homeless women outnumbered men by 53 to 47 percent. ${ }^{525}$ Whilst there is no exact pathway into homelessness for women affected by domestic and family violence, Selina Tually et al., argue otherwise. Tually et al. submit that 'women experiencing domestic and family violence generally reach what is known as a crisis point or tipping point in their lives'

\footnotetext{
${ }^{520}$ Australian Law Reform Commission, 'Incarceration Rates of Aboriginal and Torres Strait Islander Peoples' (Discussion Paper 84, Australian Law Reform Commission, 19 July 2017) 236, 93

<https://www.alrc.gov.au/publications/indigenous-incarceration-rates-dp84>.

${ }^{521}$ Ibid.

${ }^{522}$ Adams and Hunter, above n 365.

${ }^{523}$ Australian Bureau of Statistics, "Census of Population and Housing: Estimating homelessness, 2011 (12 November 2012), available at:

<http://www.abs.gov.au/ausstats/abs@.nsf/MediaRealesesByCatalogue/0DB52D24450CC7ACCA257A7500148E4C ?OpenDocument>.

${ }^{524}$ Staff Reporter, 'Homelessness in the ACT - a Snapshot' 2

<http://www.actshelter.net.au/_literature_93363/Homelessness_in_the_ACT $>$.

${ }_{525}$ Chris Chamberlain and David Mackenzie, 'Counting the Homeless 2006: Australian Capital Territory'

(Government, Australian Institute of Health and Welfare, June 2009) 59, 31

<http://www.aihw.gov.au/WorkArea/DownloadAsset.aspx?id=6442465036>.
} 
(i.e. a point where they fear for their or their children's safety). ${ }^{526}$ Therefore, Adams and Hunter (above) reason that Indigenous women fear to leave, fail to present in court or become suicidal.

Research also shows that discrimination against Aboriginal women hinders the potential for gainful employment especially in small businesses where employers tend to have a preference for light-skinned Aborigines. ${ }^{527}$ When Aboriginal girls and women lack a secure home, a stable income, and access to education, and when they face ongoing racism and other forms of prejudice, freedom from systematic violence is only a fanciful aspiration. Researchers often recommend education and awareness to fight deeply rooted issues of gender violence. Research evidence affirms that 'education is a powerful predictor of wealth'. ${ }^{528}$ Higher educational attainment for girls and women directly reduces gender violence and certainly delays childbearing. However, there are educational inequities facing Indigenous women and children in Australia that find their roots in the experiences of white settler-colonists in Britain.

Explaining how Indigenous Peoples in Australia were 'civilised' through the process of forced removal/adoption yet denied equal opportunity to move upward on the socio-economic ladder, Rosalind Kidd (1997) cites a historical trend, which started in the mother country, England. According to Kidd, a few 'ragged schools', mostly set up by philanthropic agencies in the 1840 s, operated in slums as preventive agencies for the suppression of crime. ${ }^{529}$ In addition to fostering order and obedience, ragged schools were meant to awaken moral and religious principles amongst the heathens, through behavioural indoctrination. ${ }^{530}$ On the other hand, a government education reform scheme removed children from so-called degenerate circumstances for retraining. Early on, parental consent (abolished in 1854 to widen the state's powers of compulsory committal) was sought for such 'removals'. ${ }^{531}$ However, 'paupers, mendicants, vagabonds, foundlings, and deserted children' as well as those deemed to be 'vicious or in mortal danger' were classified as delinquent and sent to reformatories. ${ }^{532}$ Further refinements in 1857 enabled children from 7 to 14 years to be sent to a certified industrial school if parents could not guarantee good behaviour. ${ }^{533}$ By the dawn of the $19^{\text {th }}$ century, one in every 230 juveniles between five and fifteen years in Britain was under the jurisdiction of reformatory and industrial schools..$^{5}$

\footnotetext{
${ }^{526}$ Selina Tually, Debbie Faulkner and Cecile Cutler, Women, Domestic and Family Violence and Homelessness a Synthesis Report (Office for Women, Department of Families, Housing, Community Services and Indigenous Affairs, 2008) 16

<http://www.ofw.facs.gov.au/publications/synthesis_report04/Women,\%20Domestic\%20and\%20Family\%20Violenc e\%20Synthesis\%20Report\%20(Flinders\%20University\%202008).pdf >.

${ }^{527}$ Wendy Anders, Family Violence in Indigenous Communities: What Is the Impact of Domestic Violence on

Indigenous Families? (Bachelor Honours of Arts (Honours) Thesis, Yooroang Garang School of Indigenous Health

Studies, University of Sydney, 1999) 20.

${ }^{528}$ Sean Coughlan, 'Asia Pops Biggest Global School Rankings' BBC News (London), 13 May 2015

$<$ http://www.bbc.com/news/business-32608772>.

${ }^{529}$ Rosalind Kidd, The Way We Civilise: Aboriginal Affairs - the Untold Story (University of Queensland Press, 1997) 19.

${ }^{530}$ Ibid.

${ }^{531}$ Ibid.

${ }^{532}$ Ibid.

${ }^{533}$ Ibid.

${ }^{534}$ Ibid 20.
} 
Reformatory conviction found its way into colonial Australia's benevolent societies, set up to promote 'the physical and moral well-being of the destitute labouring classes'. ${ }^{535}$ For example, after 1852, white children deemed to be 'at risk' from a corrupting environment in New South Wales were removed without parental consent and placed in service to responsible families. From the 1860s onwards, young females in Tasmania were forcibly removed from the streets to be given basic training or apprenticed out as domestic workers. ${ }^{536}$ Soon, Aboriginal children began to get caught in the net of the reformatory system. In Queensland, the Industrial and Reformatories School Act 1865 authorised the removal of any destitute child under 17 found wandering or begging in the streets, any child dwelling with a reputed thief, prostitute or drunkard, and any child born of an Aboriginal or half-caste mother. ${ }^{537}$ The police commissioner himself called for a girls' reformatory. He noted that ' $[t]$ here are in Brisbane alone over fifty girls, under 14 years of age, who are being "dragged up" in the lowest haunts of vice, and who, unless rescued in time, have no other life than one of infamy and crime'. ${ }^{538}$ Pursuant to the Establishment and Management of Asylums for Orphans and Deserted and Neglected Children Act 1879, children deemed to be deserted or neglected could be confined and later hired out in domestic or farm service. For Aboriginal children, removal from their families and incarceration within a reformatory threatened not only their mental health but also the persistence of their Aboriginal culture. Similarly, in Liberia, patterns of educational inequity in the Deep South of America were replicated by former slaves when they arrived in Africa.

In colonial America, education was forbidden to slaves. Fearing that 'literate slaves would forge passes or convince other slaves to revolt ${ }^{{ }_{539}}$ the General Assembly of the State of North Carolina at the Session of 1830 passed an Act to Prevent All Persons from Teaching Slaves to Read or Write, The Use of Figures Excepted. ${ }^{540}$ Antonio Bly, whilst contesting historians' presumption 'that most, if not all, slaves of that period [during the American revolution] were denied access to books and literacy,' admits that '[1]ess is known of those

\footnotetext{
${ }^{535}$ Ibid.

${ }^{536}$ Ibid.

${ }^{537}$ Ibid.

${ }^{538}$ Ibid 19-21.

${ }^{539}$ Kimberly Sambol-Tosco, The Slave Experience: Education, Arts, and Culture (2004) Slavery and the Making of America <http://www.pbs.org/wnet/slavery/experience/education/history2.html>.

${ }^{540}$ The Act provided, '[w] hereas the teaching of slaves to read and write, has a tendency to excite dis-satisfaction in their minds, and to produce insurrection and rebellion, to the manifest injury of the citizens of this State: Therefore, $B e$ it enacted by the General Assembly of the State of North Carolina, and it is hereby enacted by the authority of the same, That any free person, who shall hereafter teach, or attempt to teach, any slave within the State to read or write, the use of figures excepted, or shall give or sell to such slave or slaves any books or pamphlets, shall be liable to indictment in any court of record in this State having jurisdiction thereof, and upon conviction, shall, at the discretion of the court, if a white man or woman, be fined not less than one hundred dollars, nor more than two hundred dollars, or imprisoned; and if a free person of color, shall be fined, imprisoned, or whipped, at the discretion of the court, not exceeding thirty nine lashes, nor less than twenty lashes. II. Be it further enacted, That, if any slave shall hereafter teach, or attempt to teach, any other slave to read or write, the use of figures excepted, he or she may be carried before any justice of the peace, and on conviction thereof, shall be sentenced to receive thirty-nine lashes on his or her bare back. III. Be it further enacted, that the judges of the Superior Courts and the justices of the County Courts shall give this act in charge to the grand juries of their respective counties' see, History is a weapon, available at< http://www.historyisaweapon.com/defcon1/slaveprohibit.html>. Notice how the same law provides for different punishment based on skin colour.
} 
fugitive slaves who could read and write'. ${ }^{541}$ Bly estimates that of the 1000 runaway notices placed in the Virginia Gazette between 1736 and 1776, five percent (55) were described as literate. This suggests that some slaves were acquiring education in spite of policies forbidding them to do so. Kimberly Sambol-Tosco's historical overview of slave experiences of education suggests that,

[i]n the absence of formal education, slaves in both the rural and urban South often found alternative paths to learning. On plantations, the pursuit of education became a communal effort -- slaves learned from parents, spouses, family members, and fellow slaves and some were even personally instructed by their masters or hired tutors. Slaveholders were motivated by Christian convictions to enable Bible-reading among slaves and even established informal plantation schools on occasions in part because of slaveholders' practical need for literate slaves to perform tasks such as record-keeping. In the North, where black education was not forbidden, African-Americans had greater access to formal schooling and were more likely to have basic reading and writing skills than Southern Blacks. ${ }^{542}$

So, with the Christianising mission, education became partly accessible to slaves in America. The education of slaves in America is relevant to this research because a relatively high proportion of settler-colonists who returned to Liberia were illiterate, acting as a determinant of the type of socio-economic, political, and legal structures established in Liberia.

In Liberia, illiteracy and lack of education amongst settler-colonists contributed to the transposition of harmful policies to Liberia. Analysis of the 14996 former slave emigrants sent to Liberia between 1821 and 1904, compiled by Tom Shick, Robert Brown, ${ }^{543}$ and Peter Murdza Jr. ${ }^{544}$ shows that 52 percent $(7854)$ were from the Deep South. ${ }^{545}$ Of these, only 15 percent $(2$ 199) indicated that they could read, write, or spell. Woodson adds the provision that the listed 'read, spell, and write' indicated on the departure records for former slave emigrants referred to nothing more than basic skills. According to Woodson, ‘...not a few masters maintained that the more brutish the bondmen the more pliant they become for purposes of exploitation. It was this class of slaveholders that finally won the majority of Southerners to their way of thinking and determined that Negroes should not be educated'. ${ }^{546}$ Subsequently, the back-to-Africa mission brought mainly former Deep Southern ex-slaves to Liberia. Interestingly, in Liberia, strong (though not sustained) efforts were made by some African American settler-colonists ${ }^{547}$ not only

\footnotetext{
${ }^{541}$ Antonio T Bly, “"Pretends He Can Read”: Runaways and Literacy in Colonial America, 1730-1776' (2008) 6(2) Early American Studies: An Interdisciplinary Journal 261.

${ }^{542}$ Sambol-Tosco, above n 539.

${ }^{543}$ Robert T Brown, Immigrants to Liberia, 1844-1864: An Alphabetical Listing (Liberian Studies Association, 1980) vol no. 7.

${ }^{544}$ Peter J Murdza Jr., Immigrants to Liberia, 1865 to 1904: An Alphabetical Listing (Liberian Studies Association, 1975) vol 4.

${ }^{545}$ The Deep South can be defined as the seven states that seceded from the United States before the start of the American Civil War. These states originally formed the Confederate States of America. They are, (in order of secession): South Carolina, Mississippi, Florida, Alabama, Georgia, Louisiana, and Texas. The first six states were those that held the largest number of slaves. A broader definition of the 'Deep South' also includes the 'Cotton Belt', which, in addition to the Confederate States, includes, North Carolina, Tennessee, and Arkansas.

${ }^{546}$ Woodson, above $\mathrm{n} 453,3$.

${ }^{547}$ Marie Tyler-McGraw, Deborah Lee, Scot French, "Virginia Emigrants to Liberia: The Roberts Family" (1 May 2008), available at:

<http://www.vcdh.virginia.edu/liberia/index.php?page=Stories\&section=The\%20Roberts\%20Family>.
} 
to attain the highest level of education but also to abolish slavery ${ }^{588}$ in any shape or form in their newly established colony. ${ }^{549}$ Nevertheless, given the setter-colonists' challenging background of having relatively low access to education and professional employment, one can understand their inability to establish and sustain a high-quality education system in Liberia whilst, at the same time, denying Indigenous populations access to an equal educational opportunity. These inequities are still being addressed today.

Liberian and international institutions are still trying to address the educational and economic inequities facing Indigenous women and girls. For example, recognising some of the barriers and impacts of unemployment, Liberia's Ministry of Gender, Children and Social Protection partnering with the World Bank, Nike Foundation, and Bilateral Door, established an economic empowerment program for adolescent girls and young women in 2008. Empowering Girls and Young Women in Liberia: Adolescent Girls Initiative focuses on practical training and skills with the aim of providing safe, sustainable employment to 2500 young Liberian women between the ages of 16 and 27. ${ }^{50}$ Evaluation of the adolescent empowerment program shows an overall 47 per cent increase in employment of the 2042 randomly assigned trainees assessed, compared with those in the control group ( $\sim 33$ per cent). ${ }^{551}$ This empowerment scheme shows that creating holistic and comprehensive socio-economic programs to address the long-term impact of discrimination and violence is not only critical but also self-sustaining. In Liberia, increased access to education also produced Indigenous youths who later became aware of social inequality. Dissatisfied with a second-class status in their country, Indigenous Peoples in

\footnotetext{
38 Paul Korvah narrates a personal account: '[i]n 1929, I had the opportunity to go along with my uncle Akoi Tellewoyan to Voinjama Headquarters. This was my first visit to the seat of our District government. The Secretary of the Interior, James Cooper, was coming up from Monrovia and all the chiefs were summoned to meet with him. The purpose of the meeting was not exposed to the people until the council was ready. Here in this council a proclamation was read setting all slaves as well as all persons pawned free. It abolished slavery completely in the country. Until then, domestic slavery was rampant in the interior. A man in financial distress or otherwise could pawn his son, daughter, nephew, niece, his younger brother, or wife to settle his obligations. Until he had money to redeem his pawn, the pawn would stay in the custody of the lender of the money'.

${ }^{549}$ Brown, above n 50, 86-87. Korvah further attests to the Government of Liberia efforts to curb slavery in the hinterland: 'With the coming of Negro settlers from the United States of America in 1822, Western education with its emphasis on literacy was introduced into the non-literate setting of the Grain Coast, more than two centuries after its appearance on the Guinea Coast. Schools were begun and continued for approximately ten years by individual settlers who belonged to Christian Church societies organised before their arrival in Liberia. During these years, no schools were established by the American Colonisation Society which launched the settlement and at that time dominated the Colonial Government. The one effort made by the Society to affect a public-school system in 1826 was unsuccessful. In the early 1830 's, education shifted from the hands of individual settlers to benevolent associations of ladies in the United States of America, who were interested in aiding education development in Liberia, and to American Protestant Church Missions. Throughout this period, as we the case for the rest of the century, the Christianising - "civilizing" theme dominated education. Emphasis in the schools was on the teaching of the Christian religion...In the Mission schools planted amongst the Grebos, Krus, and Bassas, the vernacular language of the area was taught, mainly in connection with the reading of the Bible. Some manual activities were provided for, but technical skills which would have facilitated economic sufficiency were subordinated as were civic and social learning for adjustment in the new environment. Practically all of the schools planted were within the colonial settlements. Children who attended them were the children of settlers, children of recaptured Africans and Indigenous native African children residing in the Colony. Children of tribes outside the Colony, even those tribes under the influence of the Colonial Government, were served only by the "bush" schools.'

${ }^{550}$ World Bank Group, 'Empowering Girls and Young Women in Liberia: Adolescent Girls Initiative’ 1 <http://siteresources.worldbank.org/EXTGENDER/Resources/AGILiberiaBrief.pdf>.

${ }^{551}$ World Bank Group, 'Can Skills Training Increase Employment for Young Women? The Case of Liberia' (UN, Adolescent Girls Initiative - The World Bank, 1 January 2015) 17, 3-4, 9 $<$ http://documents.worldbank.org/curated/en/2015/01/23805000/can-skills-training-increase-employment-youngwomen-case-liberia>.
} 
Liberia mobilised through protests and civil actions to fight against discrimination and injustice. ${ }^{552}$

Whilst education access can improve quality of life and potentially reduce injustices, one must be mindful of problems associated with Western dominated formal education, which may also be a conduit of colonial systematic violence. Ralph Beals and Harry Hoijer perceive education as a continuous process which includes all of the learning (formal and informal) that results in both the acquisition of culture by the individual and accommodation to living as a member of society. ${ }^{553}$ Indeed, the lasting effects of formal and informal education depend on its quality and type. Sometimes formal education, which is mostly seen as Western-imposed education, can cause harm to a person, society, or country. For example, the belief that traditional schools in Liberia are primitive and inferior to Western formal education has denigrated and marginalised Native Peoples' cultural practices in Liberia. This denigration is not always perpetrated by Western actors. Through the 'tyranny and viciousness of Eurocentric orthodoxy ... some uninformed, brainwashed African scholars themselves categorize their own indigenous ways of knowing as "myths", "superstition", and "non-science". ${ }^{554}$ As described earlier by Fanon et al., the convention is that Western education is perceived as superior to Indigenous knowledge. The fact that elders practice oral and living Indigenous knowledge to educate the next generation, presents no justification for dismissing unwritten traditional knowledge as non-existent. In support of traditional schools (i.e. the Poro and Sande Institutions) in Liberia, Augustus Caine warns that, '[a]ny failure on the part of the older generation to impart its values to the coming generation or to train new individuals for particular positions inevitably means that the society and its culture will be impoverished'. ${ }^{555}$ This problem is even more pronounced in Australia, where generations of children were

\footnotetext{
${ }^{552}$ Liebenow, above $\mathrm{n} 55,78$. The influx of foreigners under Tubman's Open-Door Policy exposed Indigenous Liberians to individuals from several continents and reversed the long-standing attempt by the Americo-Liberian to insulate the tribal people against alien influences.

${ }_{553}$ Ralph L Beals, Harry Hoijer and Virginia More Roediger, An Introduction to Anthropology (MacMillan, 1953) 570.

${ }_{554}^{5}$ Gloria Emeagwali and George J Sefa Dei, African Indigenous Knowledge and the Disciplines (2014) vii, ix <http://dx.doi.org/10.1007/978-94-6209-770-4>.

${ }_{555}$ Augustus Feweh Caine, A Study and Comparison of the West African 'Bush' School and the Southern Sotho Circumcision School (Master of Arts, Northwestern University, 1959) 7; Bai T Moore, Liberian Culture at a Glance: A Review of the Culture and Customs of the Different Ethnic Groups in the Republic of Liberia (Ministry of Information, Cultural Affairs and Tourism, 1979) 17. The Poro and Sande Institutions (derogatorily called Bush School) emphasise the individual's place and function in the society by clearly defining their role and status from childhood to old age. Poro and Sande education involves a cycle of initiation sessions, four years for boys and three years for girls. During the initiation sessions, the boys are carried away from the village and kept in a grove for four years, where they are not seen by women. Likewise, the girls are kept in a grove for three years where they are not seen by men. Usually, at the end of these initiation sessions, the boys and girls are ushered back into the village by elaborate ceremonies. They are required to exhibit the skills they have learned whilst in the initiation groves, such as dancing, singing, arts and crafts, to mention a few. Western education introduced here by the settlers, and later by missionaries, did not take into account the cultural value of the Indigenous systems. Rather, the latter was looked upon as something inferior. Although Western education has made a tremendous impact on the Indigenous systems, adaptations have been made to retain the roots which support the accumulated experiences which Caine calls our cultural heritage. Caine asserts that the aim of the Sande and Poro Schools (i.e. the traditional education system for boys) is to transform boys to men and girls to women. As training is separated into male only and female only initiations, to become a 'man', a boy must be familiar with the history of his group, its legal and moral principles. He must learn to work to support his family and discharge his other kinship obligations. These trainings are charged to elders who, by oral traditions, learned from the fore-bearers to pass down onto new generation.
} 
forcibly removed from Aboriginal communities for education in Western institutions. Some interventions to prevent this cultural damage are now being attempted in Australia. For example, charged with a moral and cultural obligation, an Aboriginal outstation in remote Arnhem Land is preparing to open its own school that blends Indigenous and Western teaching. The school at Kabulwarnamyo, located on the west Arnhem Land plateau about 650 kilometres south-east of Darwin, will be launched starting with ten children. It is a move that rejects the federal government's push to send children from outstations to larger regional communities and towns..$^{556}$

A well-thought-out system of health, education, housing, and employment may intersect to provide a holistic approach to addressing the developmental needs of Indigenous Peoples in Liberia and Australia. A probable reason why Liberia has not been able to 'break its resource curse' $^{557}$ lies in its ongoing failure to implement a multi-faceted intervention that seeks to unearth the causes of violence against women and children. Or, as Alfred puts it, typically, all colonised Indigenous societies have 'entrenched dependencies, in physical, psychological and financial terms, on the very people and institutions that have caused the near erasure of our existence and who have come to dominate us'. ${ }^{558}$ Indigenous Peoples in Liberia's and Australia's ongoing struggle to attain equal access to socio-economic wealth and resources partly reflect a failure of law and policy, which this research examines.

\subsubsection{Theme 5: (Aboriginal) Feminism, International Human Rights Law and}

\section{Protection}

The arrival of settlers in Liberia and Australia brought a new legal order with racist and gender ideologies that perceived Indigenous women ${ }^{59}$ as subservient to men. ${ }^{560}$ See chapter 3 for more discussion on gender relations between Indigenous Peoples and settlers in Liberia and Australia. Pervasive gender inequalities compelled white women in Australia and elite African American settler-colonist women in Liberia to fight for gender parity. Albeit contentious, ${ }^{561}$ feminism was built on the affluence of Western white women, as discussed in chapter 1 . Therefore, white feminists inherently leverage white privilege, i.e., advantages and benefits that white people derive socially, politically, legally, and economically, as a result of being white, to help them

\footnotetext{
${ }^{556}$ Emma Masters, 'Remote Indigenous Outstation Rejects Federal Policy and Opens Own School' ABC News (Darwin, NT), 22 July 2015 <http://www.abc.net.au/news/2015-07-22/remote-nt-indigenous-community-opens-ownschool/6639220>.

${ }^{557}$ Kay, above n 313; ibid; Economywatch, above n 314; Staff Reporter, 'Liberia: Rich but Poor - African Progress Panel Lists Resource Cursed' Front Page Africa (Monrovia, Liberia), 8 May 2014

$<$ http://www.frontpageafricaonline.com/index.php/politic/1585-liberia-rich-but-poor-africa-progress-panel-listsresource-cursed-nations $>$.

${ }^{558}$ Alfred, above n 455.

${ }^{559}$ Libby Connors, 'Women on the South-East Queensland Frontier' (2008) 15(2) Queensland Review 19.

${ }^{560}$ Carol Thomas and Joanne Selfe, 'Aboriginal Women and the Law' in Proceedings of a conference held 23-25 June 1992 (Australian Institute of Criminology, 1993) 1, 168

<http://www.aic.gov.au/media_library/publications/proceedings/21/thomas.pdf>.

${ }^{561}$ Bell, 'XIV. 'White Women Can't Speak?', above n 246; Jackie Huggins et al, 'Letter to the Editors: Response to "Speaking About Rape Is Everyone's Business"' (1991) 14(5) Women's Studies International Forum 505; Rebecca Stringer, 'Impractical Reconciliation: Reading the Intervention through the Huggins-Bell Debate' (2012) 27(71) Australian Feminist Studies 19.
} 
gain some level of gender equality with white men. ${ }^{562}$ Notwithstanding the general lack of support from Western feminism, ${ }^{563}$ Indigenous women in both post-war Liberia and Australia have been making invaluable contributions to the gender-justice and equality agenda for a long time (e.g., Truganini ${ }^{564}$ in Australia and Chief Suakoko in Liberia). For example, during the civil war in Liberia, Indigenous women movements spearheaded the peace process that not only brought the civil war ${ }^{565}$ to an end in 2003 but also instigated the creation of United Nations Security Council Resolutions (UNSCR) 13252000 (on women and peace and security) ${ }^{566}$ and United Nations Security Council Resolutions (UNSCR) 18202008 (on sexual violence in war). ${ }^{567}$ Similarly, in Australia, Aboriginal women's advocacy for change cuts across disciplines, ages, and professions. ${ }^{568}$ However, serious gaps in Indigenous women's treatment within social, political, and legal spheres still exist.

Violence against Indigenous women and girls in Australia is still not adequately understood or addressed by the people and institutions charged with its elimination. Carol Thomas and Joanna Selfe lament a problematic lack of statistical data on violence against women in the legal system. ${ }^{569}$ The lack of data feeds into a widespread ignorance of systematic gender violence, rights of the abused, and a resulting reluctance to name violence for what it is: abuse of girls and women, says Diane Bell. ${ }^{570}$ Bell argues that the task of confronting violence against women who are already on the margins of society requires theorising around the issues of race, indigeneity, and gender intersectionality. ${ }^{571}$ Openly discussing the issue of rape in Aboriginal society is particularly difficult, partly because of a genuine fear of reinforcing racial

\footnotetext{
${ }^{562}$ Victoria Hovane, 'White Privilege and the Fiction of Colour Blindness: Implications for Best Practice Standards for Aboriginal Victims of Family Violence' (2006) 27 Australian Domestic \& Family Violence Clearinghouse Newsletter 8.

${ }^{563}$ Third World Women and the Politics of Feminism (Indiana University Press, 1991) 3.

${ }^{564}$ Max Delano Beers, Max Adventures: Redemption of Truganini (Max Delano Beers and Amazon Digital Services, Smashwords, 2012).

${ }^{565}$ Leymah Gbowee and Ali Benton, 'Leymah Gbowee: An Extraordinary Life'

<http://www.abc.net.au/radionational/programs/drive/leymah-gbowee3a-an-extraordinary-life/4626452>; UN

Women, above n 212; Press, above n 106; Pari Farmani, Etweda Cooper (April 2007) Inclusive Security

$<$ https://www.inclusivesecurity.org/experts/etweda-cooper/>; Peace Women Across the Globe, 'Mary Brownell

(Liberia)' <http://wikipeacewomen.org/wpworg/en/?page_id=3096>; Ghana Business News, 'Dr. Evelyn Kandakai, First Woman to Head WAEC after 62 Years' Ghana Business News (Accra, Ghana), 11 April 2015

<https://www.ghanabusinessnews.com/2015/04/11/dr-evelyn-kandakai-first-woman-to-head-waec-after-62-years/>.

${ }^{566}$ The UNSCR 1325 was created six years after the Liberia Women Mass Movement. Understanding that the impact of armed conflict on women and girls mandates effective institutional arrangements to guarantee their protection and full participation in promoting international peace and security, paragraph 1 of UNSCR 1325 ' $[\mathrm{u}] \mathrm{rges}$ Member States to ensure increased representation of women at all decision-making levels in national, regional and international institutions and mechanisms for the prevention, management, and resolution of conflict'.

${ }^{567}$ Reaffirming commitment to UNSCR 1325 (2000), UNSCR 1820 (2008) specifically focused on the impact, prevention and cessation of widespread systematic wartime sexual violence against girls and women.

${ }^{568}$ Larissa Behrendt, Indigenous Legal Relations in Australia (Oxford University Press, 2009)

<http://www.amazon.com/Indigenous-Relations-Australia-Larissa-Behrendt/dp/0195562011>; Concerned

Australians, Enough Is Enough - Statement on the Stronger Futures in the Northern Territory Bill 2011 and Two Related Bills (2011) < http://vimeo.com/33827160>; Megan Davis, 'How Do Aboriginal Women Fare in Australian Democracy?' (2007) 6(28) Indigenous Law Bulletin 9; National Centre of Biography, Peris, Nova (1971-?) (10 August 2017) Indigenous Australia <http://ia.anu.edu.au/biography/peris-nova-17821>; Anita Heiss, Government Policy in Relation to Aboriginal People (2013) Barani <http://www.sydneybarani.com.au/sites/government-policy-inrelation-to-aboriginal-people/>; Marilyn Lake, Faith: Faith Bandler, Gentle Activist (Allen and Unwin, 2002).

${ }^{569}$ Thomas and Selfe, above $\mathrm{n}$ 560, 170-171.

${ }^{570}$ Bell, 'Intra-Racial Rape Revisited: On Forging a Feminist Future beyond Factions and Frightening Politics', above n 518 .

${ }^{571}$ Ibid.
} 
stereotypes of retribution and exhibiting cultural arrogance. ${ }^{572}$ Rather than prioritising women in research and law reform, their suffering is being clumped together and branded as 'domestic violence', 'customary practice', or an 'expression of distress'. ${ }^{573}$ When an opportunity does arise to offer Indigenous women meaningful participation in addressing social ills that befall them, doing so is still a challenge. For example, Elena Marchetti criticises the Royal Commission into Aboriginal Deaths in Custody (hereafter RCIADIC) for failing to consider the problems confronting Indigenous women. ${ }^{574}$ Marchetti argues that RCIADIC did not dedicate a chapter to considering the problems of Indigenous women and '...expressly referred to Indigenous women in only five of its 339 recommendations ${ }^{575}$ (see Appendix AX for more detail). This lack of focus on Indigenous women's suffering allows the perpetuation of violence with modes specific to Indigenous Peoples.

Indigenous women face unique threats of violence that require targeted interventions to eliminate. Kerry Arabena submits that Aboriginal and Torres Strait Islander women's reproductive health has been so subjected to colonial control that it constitutes structural violence. According to Arabena, Indigenous Peoples are not only seen as property that benefits Western medicine but also is degraded to sex symbols. Arabena's themes and Bell's thesis both contain references to sexual and reproductive violence against Aboriginal girls and women committed by both settlers and Indigenous males. Assessment of Bell's and Arabena's views acknowledges that protection for Aboriginal girl and women survivors of systematic violence must extend beyond physical safety and physical location to incorporate cultural safety, protection from threats to cultural identity, cultural appropriateness, and cultural relevance. Clearly, protecting Indigenous girls' and women's rights must be seen through a human rights lens. Otherwise, mainstream services will continue to employ colour-blind practices ${ }^{576}$ and implement white models that disempower and fail to promote the safety of Aboriginal survivors. ${ }^{577}$ International, regional, national, and local legal instruments and mechanisms may serve to define and protect those human rights.

Liberia and Australia ${ }^{578}$ have legal obligations under both domestic and International law to protect Indigenous women's rights. International women scholars are raising the gender justice platform to prominence, subject to the adoption of Convention on the Elimination of all forms of Discrimination against Women 1979, the United Nations Convention on the Rights of

\footnotetext{
${ }^{572}$ Ibid.

${ }^{573}$ Ibid.

${ }^{574}$ Elena Marchetti, Missing Subjects: Women and Gender in the Royal Commission into Aboriginal Deaths in Custody (PhD Thesis, Faculty of Arts, Griffith University, 2005) 2-3.

${ }^{575}$ Ibid 3.

${ }^{576}$ Lorana Bartels, Indigenous Women's Offending Patterns: A Literature Review (Australian Institute of Criminology, 2010) 30. A point is worth noting here of Bartels research, which observed that 'Indigenous women are increasingly over-represented in criminal justice processes, occurring at an intolerably high level of family violence, over policing for selected offences, ill health, unemployment and poverty'.

${ }^{577}$ Hovane, above $\mathrm{n} 562$.

${ }^{578}$ Andrew Byrnes, 'The Convention on the Elimination of All Forms of Discrimination against Women and the Committee on the Elimination of Discrimination against Women: Reflections on Their Role in the Development of International Human Rights Law and as a Catalyst for National Legislative and Policy Reform' 12

<http://law.bepress.com/cgi/viewcontent.cgi?article=1212\&context=unswwps-flrps $10>$.
} 
the Child 1989, the Cairo Conference on Population and Development $1994^{579}$ and the United Nations Declaration on the Rights of Indigenous Peoples 2007. Sub-regionally, Liberia is party to the African Charter on the Rights and Welfare of the Child 1990 and the Protocol to the African Charter on Human and Peoples' Rights on the Rights of Women in Africa 2003. However, it is important to examine these instruments beyond signing and ratifying, to evaluate their ability to address the intersecting factors affecting humans who are both Indigenous and women. For example, Rauna Kuokkanen (2015) points out that the Declaration on the Rights of Indigenous Peoples 2007 is widely understood to reflect rights already found in other international human rights treaties, '[y]et out of 46 Articles the UNDRIP mentions women only in three'. ${ }^{580}$ The Convention on the Elimination of all Forms of Discrimination against Women 1979 is a non-binding international human rights instrument. Apart from the fact that General Comments made by its 23 all-female committee members include no enforcement mechanism, the document makes no reference to Indigenous women. Therefore, CEDAW must be interpreted in tandem with other human rights documents such as the UNDRIP. ${ }^{581}$ Further, international and regional instruments must still be domesticated in State law and policy to affect individuals in those States.

Apart from the Australian Human Rights Commission and the Independent National Human Rights Commission (a national body in Liberia), states and counties have been slow to establish and implement local human rights institutions and laws to protect Indigenous women's rights. Although the Liberian Constitution 1986 contains a bill of rights, there are no public human rights laws have been established at the county level in Liberia. ${ }^{582}$ Conversely, the Commonwealth of Australia has no Bill or Charter of Rights ${ }^{583}$ and the Australian Capital Territory is the first of only two States in Australia to pass a Human Rights Act 2004. According to Jon Stanhope, the Human Rights Act was part of a broad program of the Australian Capital Territory Government, which included commissioning Hillary Charlesworth's inquiry into a

\footnotetext{
${ }^{579}$ UNFPA, International Conference on Population and Development, available at < http://www.unfpa.org/icpd $>$. ${ }^{580}$ Lennox and Short, above n 114, 1-2. Available at SSRN: <http://ssrn.com/abstract=2414293>, 1-2. Article 21.2 calls for states to take effective measures to ensure the improvement of Indigenous peoples' economic and social conditions whilst paying particular attention to 'the rights and special needs of Indigenous elders, women, youth, children and persons with disabilities.' Article 22.1 reiterates the need to attend to 'the rights and special needs of Indigenous elders, women, youth, children and persons with disabilities' in implementing the Declaration. Finally, Article 44 states that the Declaration applies equally to 'male and female Indigenous individuals.' Besides these three articles, the language of the UNDRIP is gender-neutral and it does not elaborate what the 'rights and special needs' of women or the other aforementioned groups might be.

${ }^{581}$ Helen Tugendhat and Eleanor Ditaan-Bang-oa, Realising Indigenous Women's Rights: A Handbook on the CEDAW (Tebtebba Foundation, Forest Peoples Program and Asia Indigenous Women's Network, 2013) x. Also see, Committee on the Elimination of Discrimination against Women (CEDAW), Concluding Observations of the Committee on the Elimination of Discrimination against Women: Australia, 12-30 July 2010, CEDAW/C/AUS/CO/7, 7-8 and Committee on the Elimination of Discrimination against Women (CEDAW), Concluding Observations of the Committee on Combined Seventh and Eighth Periodic Reports of Liberia: Liberia, 24 November 2015, CEDAW/C/LBR/CO/7-8, 4-6, and 8.

${ }^{582}$ Seodi White and Rosemarie James, 'An Analysis of Laws from a Gender Perspective in Liberia: Final Assessment Report' (Government Report, Office of the Gender Advisor (UNMIL) and Ministry of Gender Development, 1 August 2009) 55, 12-16.

${ }_{583}$ Bills of Rights in Australia: History, Politics and Law (University of New South Wales Press, 2009) 23

$<$ http://www.amazon.com/Bills-Rights-Australia-History-

Politics/dp/1921410175/ref=sr_1_2?s=books\&ie=UTF\&\&qid=1362561405\&sr=1-

$2 \&$ keywords=Bills+of+rights+in+australia $>$.
} 
Bill of Rights for the Australian Capital Territory, to decriminalise abortion. ${ }^{584}$ Note that the focus on abortion is not an issue unique to Aboriginal women. Although the Australian Capital Territory's Human Rights Act applies only to territorial law, Jeremy Gans argues that the Human Rights Act has had three major, albeit precarious, national impacts:

1) its enactment on 10 March 2004 broke a century-long taboo on domestic human rights law protection in Australia;

2) as the first Australian domestic human rights law, it has now generated the first decade's worth of human rights precedents to be considered in other Australian jurisdictions; and

3) its enactment led directly to the formation of the Charter of Human Rights and Responsibilities Act 2006 (Vic) and the Human Rights (Parliamentary Scrutiny) Act 2011 (Cth.). ${ }^{585}$

The Attorney General of the Australian Capital Territory, Simon Corbell, remembers the difficulties of implementing the Human Rights Act:

Those of us who remember the lead up to the Human Rights Act being passed by the Legislative Assembly might remember the grim warnings in the media around the effect a Human Rights Act would have on the Territory. Despite the evidence, we had about the kinds of effects Human Rights legislation had had in other jurisdictions, we were given to understand that everything would become a human rights issue, people would prosecute outlandish rights, and the courts would grind to a halt under the weight of human rights litigation. And then 1 July 2004 came and went, and life continued..$^{586}$

Heidi Yates affirms that the Australian Capital Territory's Human Rights Act shines a ray of hope on other jurisdictions where, anecdotally, public servants may feel less empowered in their decision-making, and where it may help to identify potential conflicts even when the ruling government is antagonistic towards such legislation. ${ }^{57}$ The existing Australian Human Rights Commission and the establishment of the Human Rights Acts in the Australian Capital Territory and Victoria have been met with much enthusiasm. However, their impact on Aboriginal women has yet to be determined.

Ensuring that local implementation of human rights law will benefit Indigenous women requires understanding the issues and perspectives of those women. Bell argues that new understandings tend to emerge when women are allowed to speak, as in the gutsy provocation of renowned Australian film actress and Aboriginal activist Rosalie Kunoth-Monks:

I am not something that fell out of the sky for the pleasure of somebody putting another culture into this cultured being ... I am not an Aboriginal, or indeed indigenous, I am ... [a] first nation's person...a sovereign person from this country. I speak my language,

\footnotetext{
${ }^{584}$ Jon Stanhope, 'ACT Human Rights Act - Tenth Anniversary' (University Gathering at the Ten Years of the ACT Human Rights Act Continuing the Dialogue, Acton, ACT, 2014).

${ }^{585}$ Jeremy Gans, 'The Impact of the Human Rights Act 2004 (ACT) on Other Australian Jurisdictions' (University Gathering at the Ten Years of the ACT Human Rights Act Continuing the Dialogue, Acton, ACT, 2014).

${ }^{586}$ Simon Corbell, ' 10 Years of the Human Rights Act Conference: Speech by the Attorney-General of ACT' (University Gathering at the Ten Years of the ACT Human Rights Act Continuing the Dialogue, Acton, ACT, 1 July 2014)

<http://www.hrc.act.gov.au/res/10\%20Years\%20of\%20the\%20Human\%20Rights\%20Act\%20Conference\%20Speec h.doc>.

${ }^{587}$ Heidi Yates, 'The Impact of the Human Rights Act in the Community' (University Gathering at the Ten Years of the ACT Human Rights Act Continuing the Dialogue, Acton, ACT, 2014).
} 
and I practice my cultural essence of me...don't try and suppress me, and don't call me a problem, I am not the problem. ${ }^{588}$

However, Bell warns that women's perceptions of themselves present analytical challenges to understanding their contribution to a society that is constrained by male dominance. ${ }^{589}$ An example is Caroline Bledsoe's controversial assertion about Liberian traditional female society, '...that Sande seeks to produce symbolically pure adult women as well as bonds of female solidarity...[however,] Sande elite often side with elite men and exploit subordinate women'. ${ }^{590}$ Against this backdrop, extreme care must be taken when addressing systematic gender violence in collective terms such as 'feminism' or human rights, since both males and females are capable of inflicting harm, albeit at different rates; and, international law instruments that protect women are not implemented and enforced simply because a state party signs or ratifies them. The goal of this research is to seek insights from Indigenous Women Advocates and other participants into how such challenges should be tackled.

\subsubsection{Theme 6: (Harmful) Religious and Traditional Practices}

The only means of rendering this colony what it was intended to be made, a truly Christian and civilized asylum of an outcast race of men, [was] the immediate engagement of at least one laborious Christian minister, of the most respectable qualifications; but above all, of the most ardent piety, and untiring zeal. ${ }^{51}$

Ignoring these brutalizing and dehumanizing conditions [of the slave trade], westerners persisted in the perception of the black man as degraded and consequently lacking in civilization - hence the need for combining the Christianizing mission with a "civilizing" effort. Such a perception led to the belief that the slave trade was a blessing in disguise. This is why American slavery was projected, in the thinking of providentialists, as a part of God's plan to uplift Africa by bringing [its] degraded children into contact with the more elevated culture of the Americas. ${ }^{592}$

According to Dunn's quotation (above), no amount of dehumanisation, torture, or abuse, whether through the slave trade, violent frontier battles, or massacres can ever make settlercolonists criminals because they are the true executors of God's divine plan to Christianise and civilise Indigenous heathens. Given that they consider their own to be the one true monotheistic religion, settler-coloniser Christians do not acknowledge Indigenous religion in Australia and Liberia. Aboriginal religion has been viewed as myth, magic, superstition, rituals, and ceremonies but certainly not 'in the sense of propitiation or conciliation of the higher powers' ${ }^{593}$ Although, according to Archbishop George Daniel Browne, as referenced by Dunn, some missionaries discovered their mistake, which was critical in converting believers of African

\footnotetext{
${ }^{588}$ ABC News, 'Rosalie Kunoth-Monks Inspires with Her Q\&A Speech: "I Am Not the Problem"' ABC News $Q \& A$ (Sydney, NSW), 10 June $2014<$ http://www.news.com.au/national/rosalie-kunothmonks-inspires-with-her-qa-speechi-am-not-the-problem/story-fncynjr2-1226949124486>.

${ }^{589}$ Diane Bell, Daughters of the Dreaming (Spinifex Press, 3rd ed, 2002) 230.

${ }^{590}$ Reverend Jehudi Ashmun (1794-1828) the First Colonial Agent of ACS in Liberia. Caroline Bledsoe, 'The Political Use of Sande Ideology and Symbolism' (1984) 11(3) American Ethnologist 455.

${ }^{591}$ D Elwood Dunn, A History of the Episcopal Church in Liberia, 1821-1980 (American Theological Library Association and The Scarecrow Press, 1992) 17.

${ }^{592}$ Ibid 19.

${ }^{593}$ Ronald M Berndt, Australian Aboriginal Religion (Brill, 1974) vols 1-4, 1.
} 
Traditional Religion to Western Christianity. ${ }^{594}$ Irrespective of missionaries' efforts to shrug off African Traditional Religion, these beliefs are still real in the lives of many African Christians, a phenomenon known as African syncretism, ${ }^{595}$ where two or more different religious practices are mixed or combined. ${ }^{596}$

Indigenous Peoples the world over have a strong relationship with their creator; ${ }^{5}$ however, this relationship is not considered valid by settler-colonists. Teah Wulah lists the different names used to identify the Creator in Indigenous Liberia. They are Gala, Ngala, Wala vo, Go, Zena, Abi, and Nyesoa ${ }^{598}$ According to Wulah, when someone harms another in the village, the villagers would say, Nyesoa mu jae (Kru) meaning God or our Creator will see you. When a child is born with any defects, it is believed to be the work of the Creator. The seat of their Creator is the Sky. She is inescapable because she lives everywhere. ${ }^{599}$ The belief is that the Creator made good and evil, and whoever was bad was to go to her through death. The Creator also gives human intelligence, compassion, mercy, and conscience. When a person dies, their soul joins the company of their ancestors and automatically becomes a candidate for reincarnation. ${ }^{600}$ However, settler-colonists to both Australia and Liberia believed in the truth and superiority of their own conception of a Creator, resulting in the denigration of Indigenous religious beliefs and practices. In a condescending tone, Basedow attests to the existence of Aboriginal religion in Australia:

\begin{abstract}
It has often been written that the Australian aboriginal is without religious ideas and without religious ceremonies. Such assertions are grossly incorrect and by no means portray the psychological side of the primitive man in its true light. He has, to the contrary, religious institutions and obligations which verge on the basis of all modern conceptions and recognition of divine supremacy. If we can class Nature-worship, Ancestor-worship, and Sex-worship as the beginnings of all religious teachings, then the Australian aboriginal has certainly inherited by instinct and tradition a valid solid foundation from which we might trace the origin of many, if not most, of our most sacred beliefs in Christianity. At the same time, it must not be forgotten that it is really a difficult matter to distinguish clearly between mythological beliefs and what we class as religion. ${ }^{601}$
\end{abstract}

Although Basedow recognises a shared foundation between Christianity and Indigenous Religion, his assessment still portrays Indigenous peoples as 'primitive' and conveys the classification of practices as religious or not is within the purview of the settler-colonists. As a result of views like these, settler-colonists felt justified in embarking on a Christianising mission in Liberia and Australia.

\footnotetext{
${ }^{594}$ Dunn, above n 591.

${ }^{595}$ Kasomo Daniel, 'An Assessment of Religious Syncretism. A Case Study in Africa' (2012) 2(3) International Journal of Applied Sociology 10.

${ }^{596}$ Emmanuel Dolo, Ethnic Tensions in Liberia's National Identity Crisis: Problems and Possibilities (Africana Homestead Legacy Publishers, 2007) 91.

${ }^{597}$ Patricia R Derrington, The Serpent of Good and Evil: A Reconciliation in the Life and Art of Miriam-Rose

Ungunmerr-Baumann (Hyland House, 2000).

${ }^{598}$ Wulah, above n 169, 209.

${ }^{599}$ Ibid 210.

${ }^{600}$ Ibid 211.

${ }^{601}$ Herbert Basedow, The Australian Aboriginal (F. W. Preece and Sons, 1925) 257-258.
} 
Religion has always played a vital role in the civilising and Christianising of Indigenous Peoples in Liberia ${ }^{602}$ and Australia ${ }^{603}$ Modern Liberia derives, in part, from deep stirrings within the American conscience about how to address questions of slavery and race. One of the factors that spurred religious revivals in $18^{\text {th }}$-century America was the situation of black slavery. These crusades paved the way for the Great Awakening of the early 1740s. Some white Christians began to look upon black people as objects 'of God's loving concern', who were 'entitled to share in His redeeming grace in alignment with white humanity'. ${ }^{604}$ The Reverend Robert Finley of New Jersey was the apparent initiator of the debate with the founding of the American Colonisation Society, which spearheaded the return of African American settler-colonists to Liberia. ${ }^{605}$

Religious organizations engaged in the Christianising mission in Liberia began imposing their beliefs on Indigenous people when they arrived in Africa. Immigrants constructed churches almost as quickly as they built their homes. In 1859, news reached America that scores of children and youths had converted to Christianity. Christianity was but one element of a 'civilised' culture that the settlers struggled to preserve. The immediate influences of African society, many of which the settler-colonists considered unfavourably, forced the settlers to maintain an exaggerated, yet often a pompous alternative, ${ }^{606}$ that is, Christianity is next to civilisation and is superior to Traditional African Religion. One of the dominant religious groups involved in Christianising Indigenous Liberians was the Episcopal Church.

The Episcopal Mission Church contributed significantly to Christianising Indigenous Liberians and affording 'bush boys' the white man's education. Paul Degein Korvah's narrates his experience regarding white missionaries replacing 'country names' with civilised Christian/Western names: 'Father Patrick became interested in me because I was good in my catechism. It was he who baptised us, my friend Mawolo and me. He gave us the Christian names of Peter and Paul, respectively'. ${ }^{607}$ Christian missionaries went even further with disciplining Christian 'converts' who entered the traditional schools or sent their children there. The new Christian mission schools also created competition for traditional schools. Indigenous children who entered the Christian schools were often withdrawn after brief periods to attend traditional schools. In fact, the majority of Indigenous Liberian children attended only the traditional schools in the early 1800s. ${ }^{608}$ Conflicts between Indigenous and Western educational systems persist to the present day, challenging the effective education of Liberian children in

\footnotetext{
${ }^{602}$ Cassell, above n 53, 124.

${ }^{603}$ Christine Choo, Mission Girls: Aboriginal Women on Catholic Missions in the Kimberley, Western Australia, 1900-1950 (University of Western Australia Press, 2001); Tony Swain, Deborah Bird Rose and Australian Association for the Study of Religions (eds), Aboriginal Australians and Christian Missions: Ethnographic and Historical Studies (Australian Association for the Study of Religions, 1988).

${ }^{604}$ Dunn, above n 591, 13.

${ }^{605}$ Ibid 15.

${ }^{606}$ Shick, above n $170,53$.

${ }^{607}$ Korvah, above n 548, 111.

${ }^{608}$ Brown, above n 50, 62.
} 
both institutions. However, this conflict highlights that despite the imposition of settlercolonists' values on Indigenous Peoples, traditional knowledge persisted. Unfortunately, the cultural violence of stripping Indigenous Peoples of their Indigenous names and traditional education was not the only effect of the Christianising mission, as a policy of Christian superiority was also adopted by the State.

The settler-colonists of Liberia, borrowing from their slave masters, initially envisaged Liberia as a Christian nation with an evangelical mission. For example, a name considered for the capital city of Liberia was 'Christopolis'. A close interconnection of church and state is implicit in the political ideology of the nation-building process in Liberia (e.g. Jehudi Ashmun, a missionary and administrator, was appointed as the first governor of the colony of Liberia from 1822 to 1828). ${ }^{609}$ In later years, former president Tubman (1944-1971) explained his stance as a religious man: ' $[w]$ hen I state that the history of Church is coeval with that of the founding of the State I do not intend only to imply that that is a thing or fact apart but to give the impression that their respective fabrics are indissolubly interwoven...Y You may be assured that Liberia, having always been, shall continue to be a Christian state.... ${ }^{610}$ Meanwhile, adherents to the Muslim religion have also always existed peacefully alongside Christians in Liberia, flanked by devotees of Traditional African Religion, save for a number of disputes in Lofa and other places in the past years. Arguably, like Liberian traditional religious practices, Islam was gradually pushed out of the cities and relegated to Indigenous communities such as the Vai, Gola, Mende, and Mandingo. ${ }^{611}$ Today, the Government of Liberia continues to claim that the country is a Christian nation even though the country is 86 percent Christian, 11 percent Muslim and 0.5 percent Indigenous religious beliefs, according to the National Population and Housing Census 2013. ${ }^{612}$ In Liberia, Christian affiliation was the most conspicuous example of settler solidarity, but the settler elite also found other ways to insulate themselves and consolidate power.

Parallel to Christianity was the existence of fraternal organisations in Liberia, once again borrowed from colonial masters in hopes of building a 'little America' in Africa. The first independent Masonic Order of Liberia started in 1851. Undoubtedly, many settler-colonists were already initiated Prince Hall Masons when they came to Liberia. ${ }^{613}$ Several leading settlers convened and established the Independent Restoration Grand Lodge. The first president of Liberia Roberts (1848-1856 and 1872-1876) held the first Grand Master position between 1869 and $1872 .{ }^{614}$ The conveners believed that they had full right and authority to act, noting that American Masons had established the precedent when they broke away from the original

\footnotetext{
${ }^{609}$ Arthur Orrmont, Fighter against Slavery: Jehudi Ashmun (J. Messner, 1966).

${ }^{610}$ The Article 1 and the Preamble of the Constitution of Liberia 1847 and 1986, respectively, acknowledge the goodness of God, the Divine Creator in the existence of a 'Free, Sovereign and Independent State'. Also see, Fraenkel, above n 39, 153.

${ }^{611}$ Ibid $155-156$.

${ }^{612}$ Government of Liberia, 'Liberia Demographic and Health Survey 2013', above n 313, 24.

${ }^{613}$ Shick, above n $170,53$.

${ }^{614}$ Ibid.
} 
English Grand Lodge after the American Revolution. ${ }^{615}$ A settler-colonists association, created through the order, offered the opportunity to transmit the accepted societal values of Christian propriety, which included good moral character and charitable nature. It also was clearly a political institution serving the needs of the settler-colonist elite in much the same way that the Poro and Sande Societies functioned within traditional Liberia. ${ }^{616}$ The secrecy that shrouded the Masons as with the Sande and Poro traditional schools probably lent additional legitimacy to the highly placed elites and gave them a safe forum to discuss differences of opinion. ${ }^{617}$ Whilst the fraternal orders continued to exclude women from the political elite, the traditional societies also perpetrate cultural violence against Indigenous women and girls.

Although the Sande and Poro societies represent a valuable decolonising force in Liberia, some of their practices still adversely affect women and girls. Legalisation of the Poro and Sande traditional institutions, previously banned as potential political threats to settlercolonists' rule, appears to fortify traditional participation in national politics. ${ }^{618}$ However, as CEDAW's concluding statement asserts:

The Committee notes the State party's efforts to address stereotypes and harmful practices by, among other things, issuing circulars banning certain practices that perpetuate discriminatory gender stereotypes. The Committee is, however, concerned at the persistence of adverse cultural practices and traditions, as well as patriarchal attitudes and deep-rooted stereotypes regarding the roles and responsibilities of women and men in society and in the family, which are perpetuated by secret tribal societies such as the Sande and the Poro. The Committee notes that such stereotypes contribute to the increase in child and/or forced marriage, the abduction of girls and polygamy, and hence to the disadvantaged and unequal status of women in society. The Committee is particularly concerned that the secret tribal societies continue to perpetrate harmful practices, including female genital mutilation, through their initiation rites, and that practices such as trial by ordeal for women and girls accused of witchcraft, as well as ritual murders, are rife. ${ }^{619}$

Therefore, this study further explores the effects of these harmful traditional practices on Indigenous women and girls in Liberia. Also, similar complex intersections of history, religion, and state institutions affect Aboriginal women and girls in Australia.

In Australia, according to Reynolds, missionaries, clergymen, and other humanitarians were inspired to lead Aboriginal Peoples in the 1830s and 1840s. ${ }^{620}$ Based on the premise that one God created humankind as descendants from Adam and Eve, Reynolds asserts that Christian missionaries went out to redeem their 'brethren' from the scourge of everlasting torment in hell. Whilst some missionaries endeavoured to save Aboriginal Australians as equal heirs to the Lord's kingdom (the 'saviours'), many despised them with a passion (the

\footnotetext{
${ }^{615}$ Ibid 57.

${ }^{616}$ Ibid.

${ }^{617}$ Ibid.

${ }^{618}$ J Gus Liebenow, Liberia: The Quest for Democracy (Indiana University Press, 1987) 57-58.

${ }^{619}$ Committee on the Elimination of Discrimination against Women (CEDAW), Concluding Observations of the Committee on Combined Seventh and Eighth Periodic Reports of Liberia: Liberia, 24 November 2015, CEDAW/C/LBR/CO/7-8, para 21.

${ }^{620}$ Reynolds, above n 418, 22.
} 
'destroyers'). ${ }^{621}$ A case in point is that of Reverend William Horton, the first resident Wesleyan Methodist minister to arrive in Van Damien's Land in 1821. About Aboriginal Peoples in Tasmanian, he wrote, 'I should affirm, without hesitancy that they are a race of being altogether distinct from ourselves and class them amongst the inferior species of irrational animals' ${ }^{622}$ It is this twisted perception that armed settler-colonists with boldness to dehumanise and denigrate Indigenous Peoples in the name of religion and civilisation.

\subsection{Summary}

This chapter identifies themes that highlight the complex intersection of race, gender, class, indigeneity, colonial history, religion, health, and education that contribute to systematic gender violence against Indigenous Peoples. This intersectionality necessitates the use of theories drawn from the critical race, decolonisation, social determinants of health, and feminist jurisprudence to effectively analyse the material. Although research data and resources collected on the literature review do not directly address Indigenous women and girls specifically, materials obtained situate major issues regarding violence against Indigenous women by providing a broad understanding of work done, which helps identify gaps and challenges in the topic area. The next two chapters focus on the specifics of systematic gender violence and the rule of law as they pertain to Indigenous girls and women in post-war Liberia and Australia.

${ }^{621}$ Reynolds, Dispossession, above n 177, 155-182.

${ }^{622}$ Reynolds, above n 418, 23. 


\title{
CHAPTER 3: VIOLENCE AGAINST INDIGENOUS GIRLS AND WOMEN
}

\begin{abstract}
Violence is generally seen as a manifestation of patriarchal values of male supremacy involving factors such as ownership of property, power and control, female subordination, and the institution of marriage and the family. Male violence relates to gender inequity. Thus, it is a political issue. It is not only women who are traumatized by the violence. Children do not only observe their parents' conflict, there is increasing evidence that the abuse of children is endemic in Australia. ${ }^{623}$
\end{abstract}

For two long years, I have sought a home. Here I have found one, and here will I remain. ${ }^{624}$ We want no flagstaff put up here that will cost us more to take down than to whip the natives. ${ }^{225}$

\subsection{Introduction}

Wendy Anders's quotation captures the quintessence of systematic violence against Indigenous girls and women, the complexity of that violence, and its correlation to various facets of society. The prevalence of violence against girls and women is disproportionately higher and mostly perpetrated by men. Global estimates published by the World Health Organisation show that roughly 1 in 3 women (35 percent) worldwide have experienced either physical and/or sexual intimate partner violence or non-partner sexual violence in their lifetime. ${ }^{626}$ Worldwide, 38 percent of murdered women dies at the hands of their male intimate partner. ${ }^{627}$ Due to their intersectional identity as both women and Indigenous, which is shaped by socio-economic factors, Aboriginal women are susceptible to male need for power, control and dominance, the impetuses of men's incessant desire to inflict violence on girls and women. According to the principle of the social determinants of health, socio-economic conditions, such as good education, quality health, and meaningful employment reduce inequities.

Although there has never been a better time to be born a female, ${ }^{628}$ the global gender disparity, which is inextricably linked to physical, sexual and psychological violence against women, shows that the status of girls and women is still lagging behind. Women makeup two thirds (496 million) of the world's 781 million illiterate adults aged 15 and over, a proportion that has not changed for two decades. ${ }^{62}$ Out of 142 countries worldwide, Liberia ranks 111th on the Global Gender Gap index (the relative gaps between women and men across health, education, economics, and politics) and occupies the second lowest rank on literacy. Australia

\footnotetext{
${ }^{623}$ Anders, above n 527, 3; Steven Sovran, 'Understanding Culture and HIV/AIDS in Sub-Saharan Africa' (2013) 10(1) SAHARA-J: Journal of Social Aspects of HIV/AIDS 1.

${ }^{624}$ Azikiwe, above n 301, 49. According to Azikiwe, upon arrival to the West African coast, many of the former slaves succumbed to disease and persistent resistance from the Indigenous. The Above quotation is Elijah Johnson's to Dr Elijah Ayres, when faced with the possibility of returning to the United States.

${ }^{625}$ Staff Reporter, 'History and Us: Elijah Johnson, Great Liberian Pioneer' Daily Observer (Monrovia, Liberia), 10 December 2013 <http://www.liberianobserver.com/history-us/history-and-us-elijah-johnson-great-liberian-pioneer>; Cooper, The House at Sugar Beach, above n 168, 69.

${ }^{626}$ World Health Organisation, Violence against Women (November 2016) WHO

$<$ http://www.who.int/mediacentre/factsheets/fs239/en/>.

${ }^{627}$ Ibid.

${ }^{628}$ Ibid

${ }^{629}$ United Nations, 'The World's Women 2015: Trends and Statistics' (UN Report, Statistic Division, Department of Economic and Social Affairs, 2015) 260, 79.
} 
ranks 24th overall and first in literacy on the same index. ${ }^{630}$ Whilst, globally, life expectancy is higher for women (67-72 years) than for men (63-68 years), sub-Saharan Africa has the narrowest gender gap. This region contains all 30 countries in the world with the lowest life expectancy of 60 years and under. In Liberia, life expectancy at birth is 61 years for women and 59 years for men. In Australia, life expectancy at birth is 85 years for women and 80 years for men. According to the World's Women Report 2015, across all sectors and occupations, women earn less than men earning between 70 and 90 percent of what men earn in full-time employment in most countries. ${ }^{631}$ Globally, women occupy only 22 percent of seats in national legislatures. ${ }^{632}$ As of 1 January 2015, women represented eight out of 73 and three out of 30 seats in the Liberian House of Representatives and the Senate, respectively. ${ }^{633}$ In Australia, women occupied 40 out of 150 and 29 out of 76 seats in the House of Representatives and Senate, respectively. ${ }^{634}$ These statistics underscore the prevalence of social and political factors which intersect to place women in Liberia and Australia in an increased state of vulnerability to men in their families, communities, and governments. However, is it also important to consider the additional factors affecting girls?

By virtue of being children, Indigenous girls are at even greater risk of becoming targets of violence. According to Behrendt, Aboriginal children, by nature of being smaller, feeble and less powerful, are more susceptible to generalised violence. In a recent TEDx talk, ${ }^{635}$ Susan Bissell affirmed that ' 1 in 8 children disclose that they have experienced violent discipline in the very place that they are supposed to feel most safe'. ${ }^{636}$ As with women, systematic violence against Indigenous girls is sustained through both the multiplier effect phenomenon ${ }^{637}$ and intersecting factors. Anna Carastathis affirms that intersecting factors are operative and equally salient in constructing 'institutionalised practices and lived experiences, since a real-life person is not, for example, a [girl or] woman on Monday, a member of the working class on Tuesday... ${ }^{638}$ But that girls and women are often at a crossroads of diverse violence on a daily basis with increased exposure to traumatic death. Therefore, it is necessary to identify the various intersecting sources of violence that determine the conditions under which women and girls live.

Understanding violence against women and girls requires mapping out the interconnecting systems that enable or directly perpetrate that violence. E Hunter's honest

\footnotetext{
${ }^{630}$ Yasmina Bekhouche et al, The Global Gender Gap Report 2014 (World Economic Forum, 2014) 28, 104 <http://www3.weforum.org/docs/GGGR14/GGGR_CompleteReport_2014.pdf>.

${ }^{631}$ United Nations, 'The World's Women 2015: Trends and Statistics', above n 630, 87.

${ }^{632}$ Inter-Parliamentary Union, 'Women in Politics: 2015'

$\langle$ http://archive.ipu.org/pdf/publications/wmnmap15_en.pdf>.

${ }^{633}$ Ibid.

${ }^{634}$ Ibid.

${ }^{635}$ TED is a nonpartisan non-profit devoted to spreading ideas, usually in the form of short, powerful talks (see: https://www.ted.com).

${ }^{636}$ Susan Bissell, 'Unveiling a New Superpower' (You-tube videos at the TEDx Talks, India, 13 August 2015) <https://www.youtube.com/watch?t=219\&v=I-BKGebLy28>.

${ }^{637}$ That is intersecting factors of race, class, social status and gender exacerbates Aboriginal women and girls' vulnerability to generalised violence.

${ }^{638}$ Carastathis, above n 244.
} 
attempt to explicate the diverse intercultural and historical contexts underlying Aboriginal personal violence, based on his three years of experience living in the Kimberley, ${ }^{639}$ attracts Joseph Reser's critique:

His [E Hunter's] 'analysis' also typifies a particular type of perspective and thinking with respect to Aboriginal issues as a historical, system level, 'sympathetic' account, written by a non-Aboriginal, of the cumulative and devastating impact of culture contact and rapid social and cultural change on Aboriginal communities and consciousness.... While the argument and perspective [re the period of destabilisation and increased alcohol availability where males appeared to be more vulnerable to the consequences of their own reckless behaviour and females increasingly likely to be the victim of male's behaviour] in the initial section of Hunter's paper is interesting, it does not really say very much about the nature or causes of intercultural violence, nor does it in any way explain why the violence described was intercultural or the dynamics of this violence. Rather, what is presented is a selective and superficial overview of diverse and unintegrated perspectives on alcohol and aggression, with none of the qualifications one might expect with respect to unresolved issues and cultural bias. ${ }^{640}$

The 'superficiality', 'selectivity' and 'unintegrated' perspectives Reser alludes to demand that this research adopt systematic praxis and theory to find the nature and causes of violence against women. However, a phenomenological approach that values survivor discourse requires that generalised data be interwoven with personal lived experiences to help shed light on the complicated nature of violence against Indigenous girls and women. Therefore, this chapter defines violence, discusses how three intertwined levels of systematic violence affect Aboriginal Peoples and describes select sources of the violence which permeates the lives of Indigenous societies in post-war Liberia and Australia. Unique case examples from both countries and ongoing challenges faced by remedying interventions illustrate the prevalence, sources, impact, and severity of violence. As a framework, this dissertation maintains that systematic violence, socially constructed by patriarchal and parochial arrangements, occurs at three levels: state/institutional, structural/cultural and community/interpersonal levels, and encompasses acts, omissions, or threats to life. ${ }^{641}$

\subsection{What is Violence? - Interpersonal, Structural and Institutional}

Greg Barak argues that whilst there appears to be more demonising of perpetrators of violence, the sources, origins, or causes of violence get relatively little attention and even less concern compared with the historical explanation of non-violence. ${ }^{62}$ As a proponent of James Gilligan's 'germ theory' ${ }^{643}$ of violence, Barak reasons that theories of violence (and non-violence) are efficient in that they 'frame the problem of social violence in an appreciation of its genesis or

\footnotetext{
${ }^{639}$ EM Hunter, 'The Intercultural and Socio-Historical Context of Aboriginal Personal Violence in Remote Australia' (1991) 26(2) Australian Psychologist 89. Hunter, (though wary of 'unwisely' stating that alcohol is the direct cause of violence) draws some positive correlations between the year alcohol became freely available to Aborigines in the Kimberley (1957-1971 and that of infant and adult mortality rates.

${ }^{640}$ Joseph P Reser, "The "Socio-Historical" Argument and Construction of "Aboriginal Violence": A Critical Review of Hunter (1991)' (1991) 26(3) Australian Psychologist 209.

${ }^{641}$ Susan SM Edwards, Sex and Gender in the Legal Process (Blackstone Press, 1996) 1.

${ }^{642}$ Gregg Barak, Violence and Nonviolence: Pathways to Understanding (Sage Publications, 2003) 9.

${ }^{643}$ James Gilligan, Violence: Reflections on a National Epidemic (Vintage Books, 1997) 89; Barak, above n 643, 10.
} 
roots rather than in condemnation or repudiation of the behaviour. ${ }^{944}$ Feminist theory states that to curb personal violence and societal structures that perpetuate gender inequalities, male dominance must be tackled. ${ }^{645}$ From a decolonisation perspective, Frantz Fanon suggests that,

The violence which has ruled over the ordering of the colonial world, which has ceaselessly drummed the rhythm for the destruction of native social forms and broken up without reserve the systems of reference of the economy, the customs of dress and external life, that same violence will be claimed and taken over by the native at the moment when, deciding to embody history in his own person, he surges into the forbidden quarters. ${ }^{646}$

In the context of the combined theories of feminism, decolonisation, intersectionality and critical legal theory, examining three interconnecting levels of systematic violence ${ }^{647}$ promises to explicate the complex layers of violence with respect to the role of law as a mechanism for justice, equality and fairness. The three levels of violence assessed in this research are 1) personal/community violence; 2) structural/cultural violence; and 3) institutional/state violence. Together they are referred to as systematic violence because of their ability to be organised methodically and purposefully.

Personal and community violence: If separated, the three levels of violence could be broken down into six distinct types of violence. However, for the purpose of this research interpersonal violence is grouped with community violence. The reason stems from the perception that interpersonal and community violence occurs at the lowest social stratum, i.e., it occurs at home and in the local community, between individuals. At this level, violence is a direct source happening in private settings. That is, a human being is a direct object or perpetrator of the violence, ${ }^{648}$ rather than an entity such as an employer or other institution. ${ }^{649}$ This form of violence is perpetuated by individuals (e.g., family members, neighbours, or friends) and is, for the most part, tied to the home and their locale. Examples of personal and community violence in this research include rape, domestic violence, and the exploitation of children.

Structural and cultural violence: Johan Galtung suggests that the major distinction between personal and structural violence has to do with identifying the aggressor or actor.

\footnotetext{
${ }^{644}$ Barak, above n 643, 9. Drawing on public health and preventive medicine, Gilligan purports that violence is neither biological nor universal, nor is it found in genetic materials or evolutionary development. Like germs the pathogens that cause deadly forms of violence are human emotions (e.g., shame) located in social sewer systems (e.g., prisons and mental hospitals) which are like waste receptacles for human garbage. 'As incarcerated others, belonging to the internal worlds of 'society of captives', these violent and nonviolent persons become victims of the institutional and structural relations of violence that accumulate and intensify behind prison walls'.

${ }^{645}$ Carrie L Yodanis, 'Gender Inequality, Violence against Women, and Fear: A Cross-National Test of the Feminist Theory of Violence Against Women' (2004) 19(6) Journal of Interpersonal Violence 655.

${ }^{646}$ Fanon, above n 247, 40.

${ }^{647}$ Kumar Rupesinghe, Marcial Rubio Correa and United Nations University (eds), The Culture of Violence (United Nations University Press, 1994) 46. Felipe MacGregor and Marcial Rubio defines violence as '[a] physical, biological or spiritual pressure, directly or indirectly exercised by a person on someone else, which, when exceeding a certain threshold, reduces or annuls that person's potential for performance, both at an individual and group level, in the society in which this takes place'.

${ }^{648}$ Johan Galtung, 'Violence, Peace and Peace Research' (1969) 6(3) Journal of Peace Research 167.

${ }^{649}$ Barak, above n 643, 23.
} 
Unlike personal (or direct) violence, where the aggressor or is an acting subject, ${ }^{650}$ the perpetrator in structural or cultural violence tends to be hidden, embedded within societal structures (e.g., traditions, stereotypes and stigmas, or social groups). ${ }^{651}$ The vectors of structural violence are shaped, maintained, and eventually transformed with the margins of humans' ability to mould and form behaviour. In many cases, victims of structural and cultural violence are shaped by the same intangible beliefs. ${ }^{652}$ Felipe MacGregor and Marcial Rubio's argue that

Figure 3.1: Flow diagram showing interaction of systematic violence

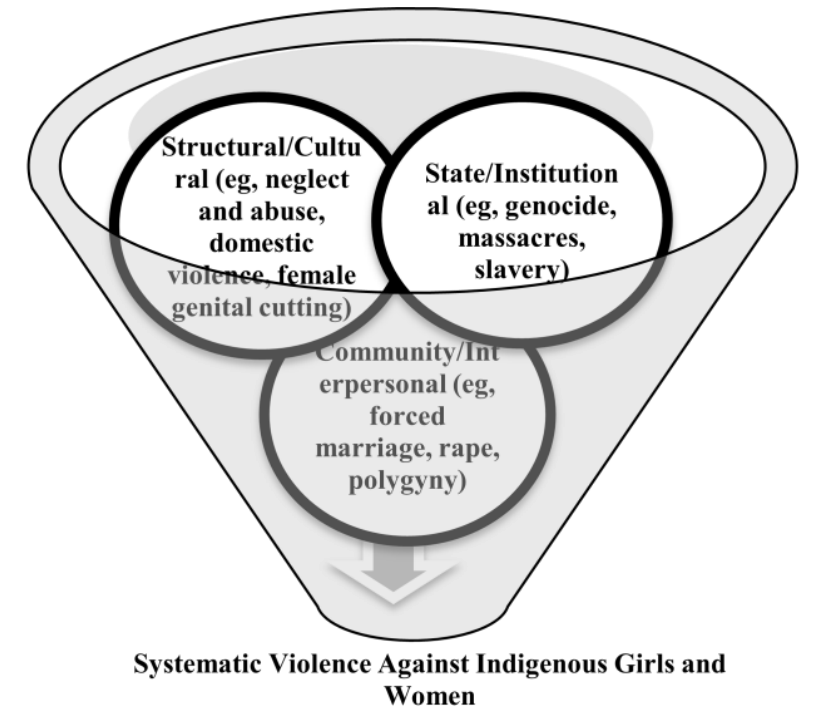
structural violence results from the working of social structures which are closely related to cultural violence. ${ }^{6}$ Barak observes two kinds of group structural violence. One establishes, defends and extends hierarchy and inequality through the beating, exploiting, harassing, killing and torturing of persons. The other is pursued to decrease privilege and increase liberty, by attacking those persons, symbols, and things that represent the 'establishment' or the 'powers that be'. ${ }^{654}$ Galtung's

definition of cultural violence is also linked to structural violence. According to Galtung, cultural violence is '. . any aspect of a culture [the symbolic sphere of our existence exemplified by religion and ideology, language and art, empirical/formal science] that can be used to legitimize violence in its direct or structural form. ${ }^{655}$ Examples of structural and cultural violence in this research include abuse and neglect by social services, racism and stigmatisation of Indigenous Peoples, female genital cutting, forced marriage, and polygyny.

Institutional and State Violence: Although the State is a type of institution, this study identifies state violence as a unique form of violence using legal instruments and authority to promulgate systematic violence against Indigenous girls and women. MacGregor and Rubio conceptualise institutional violence as a 'type of structural violence which is formally implanted in the institutions and is accepted or at least tolerated, with the complicity of the people'. ${ }^{656}$ Barak describes the 'people' MacGregor and Rubio mention as institutional agents (e.g., corporate, workplace, military, religious and state). ${ }^{657}$ Institutional violence may be impersonal

\footnotetext{
${ }^{650}$ Rupesinghe, Rubio Correa and United Nations University, above n 648, 47.

${ }^{651}$ Ibid 50.

${ }^{652}$ Ibid 4, 49.

${ }^{653}$ Ibid $42,49$.

${ }^{654}$ Barak, above n 643, 5 .

${ }^{655}$ Johan Galtung, 'Cultural Violence' (1990) 27(3) Journal of Peace Research 291.

${ }^{656}$ Rupesinghe, Rubio Correa and United Nations University, above n 648, 51.

${ }^{657}$ Barak, above n 643, 23.
} 
but still causes emotional, psychological and physical trauma to individuals. Some institutional violence is overt, whilst some are covert, making it challenging to pinpoint ${ }^{658}$ Examples of state and institutional violence in this research include massacres, land dispossession, state-sponsored genocide, and military actions against Indigenous civilians.

A caveat is in order when interpreting the three levels of systematic violence. Each component of systematic violence overlaps and touches the others to form a web of interactions (see Figure 3.1). This complex interaction of systematic violence against Indigenous girls and women demands a comprehensive theoretical framework to address the research question both from both the literature review and an empirical perspective.

\subsection{Australia}

Drawing on decolonisation theory, it is not possible to assess the impact of colonial violence on Aboriginal Peoples, without briefly considering Australia's convict history as an explanation, in part, of why 'the oppressed, instead of striving for liberation, tend themselves to become oppressors or sub-oppressors [because] the very structure of their thought has become conditioned by the contradictions of the concrete, existential situation by which they were shaped'. ${ }^{659}$ Furthermore, white Australian convict history provides ample evidence that systematic violence is not confined to Aboriginal girls and women, but affects all women. Chapter 7 presents a statistical analysis of convict transportation to Australia.

After decades of feeling ashamed to admit to their convict past, ${ }^{600}$ Australians now feel a sense of pride ${ }^{661}$ about their journey from being convicts to playing an integral role in building the Australian nation-state. ${ }^{662}$ Today, roughly one in seven Australians are descended from

\footnotetext{
${ }^{658}$ Deane Curtin (ed), Institutional Violence (Rodopi, 1999) xii.

${ }^{659}$ Paulo Freire, Pedagogy of the Oppressed (Continuum International, 30th Anniversary, 2005) 45.

${ }^{660}$ Shick, above $\mathrm{n} 170,21$. A sense of pride filters through the echo of Historian Michael Cathcart, as he presents Rogue Nation. He rhetorically posits the essence of the documentary, '...how a remote convict settlement, a place of misery in exile begin to change into a place of opportunity and hope? How a group of outcast and people on the make begin to transform themselves into a nation...' Interestingly, the same can be said for the Afro-American settlers in Liberia, who despite their dehumanising experience enslavement for well over three centuries and their bravery in treading those perilous voyages back to Africa (i.e., 4571 Afro-Americans immigrated to Liberia between 1820-43, Liberian census record showed only 2388 persons living in that year; still to this date, embody a deep sense of pride, entitlement and superiority over 'uncivilised' Indigenous Liberians.

${ }^{661}$ PBS, 'Voyage of the Courtesans', Secrets of the Dead, 2005 <http://www.pbs.org/wnet/secrets/voyage-of-thecourtesans/159/>. Although the history of convicts arrival in the penal colony of Australia (carefully orchestrated by English white males) cannot always be glorified, female convicts, one the other hand, who were referred to by colonists as 'an unfortunate and unnecessary cargo' / 'a cargo have been praised as the founding mothers; who will restore the dying colony, breathing life and civilisation into it'. In responding to Captain Phillip's request to redeem the colony by sending more food and women, British Under Secretary Evan Nepean, rounded up 225 condemned women mostly of child-bearing age including five infants on board the Lady Juliana, potentially, the same ship used to haul shackled slaves from Africa. Women, whether consenting or not, became 'wives' of crewmembers and prisoners so that after ten months at sea, Ann March (along with seven others) was pregnant for John Nicol, the Ship Surgeon. Mary Wade, Ann March and Elizabeth Barnsley will all go on to be successful founding mothers of the colony adding significantly to its economic wealth.

${ }^{662}$ Port Arthur Historic Sites, Pack of Thieves? 52 Port Arthur Lives (Port Arthur Historic Site Management, 2001) 5; Peter Gunn and Rebecca Kippen, 'Household and Family Formation in Nineteenth Century Tasmania Dataset' <http://www.femaleconvicts.org.au/index.php/convict-institutions/children/pregnancy-and-children>. In Pack of Thieves? 52 Port Arthur Lives, The Port Arthur Historic Sites writes, '[w]e tend to think of convicts as shadowy figures. They skulk in dimly lit back lanes of an imagined Dickensian London or they clank down Australian roads in long shuffling chain gangs, their backs bent. We see them, not as individuals, but as something other and alien perhaps even as dangerously subhuman. This is particularly true of the convicts sent to Port Arthur, Australia's most
} 
convicts, ${ }^{663}$ including former Prime Ministers John Howard ${ }^{664}$ and Kevin Rudd. ${ }^{665}$ But the sense of pride descendants of convicts feels today was not always there. In fact, the grim reality of Australian convict history is also plagued with trauma, discrimination and abuse against both females and males. Between 1787 and 1868, the British transported approximately 160000 convicts to Australia ${ }^{666}$ on 825 voyages (using 423 convict ships), though few came from Canada, America, Bermuda and other British colonies. ${ }^{67}$ A majority ${ }^{668}$ of the convicts were

\begin{abstract}
famous convict settlement. As these men had been sentence to transportation twice (once in the British Isle and effectively a second time by a colonial court before being banished to the confines of a penal station) they are regarded as doubly banished damned 'hardened' repeat offenders - the sweepings of the Australian transportation system'. The seemingly twisted sense of pride perceived by the author of Pack of Thieves: 52 Port Arthur Lives was actually experienced during the researcher's visit to Port Arthur, Tasmania between 31 October and 6 November 2014 when a tour guide commented that (paraphrased), life at Port Arthur was good, considering how poor England was at the time, people lied and admitted to crimes they did not even commit in order to come to VDL for warm bath, clothes, some bread and soup. He went on to say that, "women and girls were happy to bear children for prison staff, commanders and prisoners who became paupers after their freedom. He claimed women were happy to be mothers, even if they were raped' because such a life was never to be had given the conditions under which they came from in England. Suffice to say, prior to visiting Port Arthur, almost three hours were spent at the Cascade Female Factory in Hobart where facts and record showed that 21 per cent (241) of all the children (1 148) born to female convicts in Hobart nursery between 1845 and 1857, were born to women under sentence in the Cascade Female Factory. According to Gunn and Kippen: '[p]regnant convicts were usually returned to the Government for their confinement and remained with their babies until they were weaned - initially, weaning occurred at six months, but was later extended to nine months in an attempt to reduce the death rate of infants in the nurseries. After weaning, the mother had to serve six-month imprisonment in the Crime Class at a female factory as punishment for getting pregnant. The children, if they survived the terrible conditions, remained in the various nurseries until they reached the age of 2 or 3 years when they were removed to the Orphan Schools, unless their mother had gained her freedom in the meantime or could prove she could support the child'. A brief statistical overview of Gunn and Kippen (2006) data, shows not only that 21 per cent of all 525 children born to mothers from the Cascade Female Factor died from diarrhoea; but that only four of these children had a father name recorded.

${ }^{663}$ Parramatta Female Factory Precinct, Convicts and Characters (2015) Parra Girls

<http://www.parragirls.org.au/convict-connections.php>; Tony Rennell, 'The Founding Fathers of Australia: The Story of Convicts Shipped to the New World' Daily Mail (London), 25 July 2007

$<$ http://www.dailymail.co.uk/news/article-470887/The-founding-fathers-Australia-The-story-convicts-shipped-NewWorld.html>; John N Molony, The Native-Born: The First White Australians (Melbourne University Press, 2000) 1. In other words, Molony suggests that, '[t]here is an abundance of evidence that the early native-born, 90 per cent of whom sprang from convict parentage, were made to feel second-rate and outsiders to society because of their parentage'.
\end{abstract}

${ }_{664}$ Melissa Stevens, 'Howard's Secret Criminal Past' The Daily Telegraph (London, UK), 14 February 2007 <http://www.dailytelegraph.com.au/news/nsw/howards-secret-criminal-past/story-e6freuzi-1111112988170>. According to Stevens, Howard's maternal great-great-great-grandfather, William Tooley was convicted of complicity in the theft of a tortoiseshell watch and transported for life on the Fanny in 1816. His mother's maternal ancestor also began through a convict forebear, Thomas Barker, who was transported for life after being convicted of two counts of robbery, arriving on the Bengal Merchant in 1835. Noteworthy, it was during the Howard government that Northern Territory National Emergency Response Act 2007 was enforced. The NTERA was a legislative response of the Commonwealth Government's inquiry into the protection of Aboriginal children from sexual abuse.

${ }_{665}$ Bonnie Malkin, ‘Australian Prime Minister Kevin Rudd Descended from Thieves' The Telegraph (London, UK), 31 July 2008 <http://www.telegraph.co.uk/news/worldnews/australiaandthepacific/australia/2479134/Australianprime-minister-Kevin-Rudd-descended-from-thieves.html>; Mary Wade History Association, Mary Wade To Us: A Family History 1778-1986 (MacArthur Press, 1986) 4-8, 72. As documented by the Mary Wade History Association, in addition to being a former Prime Minister of Australia, Kevin Rudd is also known for being a descendant of Mary Wade, the youngest convict to Australia aboard the all-female vessel Lady Juliana arriving in Sydney on 3 June 1790. On 14 January 1789, 10 years old Mary Wade was found guilty of stealing one cotton frock, value at 3s, one linen tippet, value $2 \mathrm{~d}$, and one linen cap, value at $2 \mathrm{~d}$. She was sentenced death by hanging. It is quite frightening how the Lord Chief Baron likened 10-year-old Mary (and her friend Jane Whiting) act to that of a violent crime, even though he admitted to the Jury (apparently, all men) at the trial that her crime was less than a robbery: On the other hand, Rudd's paternal great-great-great-great father, Thomas Rudd arrived on board the Earl Cornwallis in 1801, having been convicted of stealing a bag of sugar.

${ }^{666}$ The Penal Servitude Act 1857, repealed sections 1, 2, 3, and 4, of the Penal Servitude Act 1853, which provided for the sentencing of transportation of any person contrary to the Transportation Act 1717 (4 Geo. 1 cap XI). Although the last transportation of 281 convicts on board the Hougonmont arrived in Western Australia on 9 July 1868.

${ }^{667}$ Port Arthur Historic Sites, above n 663, 5-8; Port Arthur Historic Sites, Pack of Thieves? 52 Female Factory Lives (Port Arthur Historic Site Management, 2014) 8-11; State Library of Queensland, 880 Convict Voyages to Australia 
penalised unjustly for petty crimes. Not only were their sentences disproportionate to the crimes committed, but some were put in gaols that were unfit for habitation. ${ }^{669}$ They were ripped from their homeland and social support system to endure long treacherous journeys by sea. ${ }^{670}$ On arrival in Australia, they were condemned to hard labour spending an average of nine years in prison in addition to facing deliberate starvation. ${ }^{61}$ Their sweat and blood produced food, clothing, furniture, and infrastructure, and girls and women (consenting or not) were at the mercy of males' sexual desire, ${ }^{672}$ both on board the ships ${ }^{673}$ and during imprisonment in Australia. ${ }^{674}$ As one of the few British penal colonies in the world, Australia accepted a large

(2015) Convict Records <http://www.convictrecords.com.au/timeline>; Perth Dead Persons Society, Convict Ships to Australia (2002) Convicts to Australia <http://members.iinet.net.au/ perthdps/convicts//shipNSW1.html>.

${ }^{668}$ Of the 127470 convict records collected by the State Library of Queensland, there were total of 873623 years of sentences, 28000 of which were life sentences. The top five crimes committed were, stealing (17.9 per cent); larceny (10.2 per cent); burglary (5.6 per cent); sheep stealing ( 4.4 per cent); and theft ( 3.3 per cent).

${ }^{669}$ Siân Rees, The Floating Brothel: The Extraordinary True Story of an Eighteenth-Century Ship and Its Cargo of Female Convicts (Hyperion, 2002) 5, 35-36. Consider Rees description of the Newgate gaol condition: '[b]y December 1788, 151 female convicts in Newgate Gaol were living in three cells built to house a maximum of 70 . They lived on rations fixed for that theoretical maximum and not the number actually confined. Each cell had one window opening onto an interior wall. There were no beds; a ramp at one end of the room with a wooden beam fixed to its top end served as mattress and pillow. To sleep on the ramp and beam was a privilege, to be paid for weekly. To rent a blanket woven of raw hemp cost extra. Those who could afford neither curled up together on stone slabs awash with saliva and urine. Before the cells were opened each morning, turnkeys would drink a class of spirits to keep them from fainting, for the 'putrid stream or myasma' was enough to knock them off their feet. The population of Newgate was malnourished, debilitated, cold, inadequately clothed and infested with disease-bearing lice. Its cells were a happy home for typhus. ... the gaol went into crisis each winter and generally staggered through until spring, providing nothing terrible happened. But the winter of 1788 was exceptionally severe; the gaols were hopelessly crowded and there were not enough funds in the pot to pay for food, let alone medicine'. Unfortunately, it did not help that in 1783, some 130,000 males were discharge when the American colonies defeated King George's British and German forces forcing London to house tens of thousands of ex-soldiers'.

${ }^{670}$ Robert Hughes, The Fatal Shore: A History of the Transportation of Convicts to Australia, 1887-1868 (Vintage Books, 1st ed, 1988) 1-2, 83, 129-130. According to Hughes, the founding of the Australian nation-state is framed on England's pursuit to eliminate the 'criminal class'. He writes, '[b]ut here [Australia], the process was to be reversed: not Utopia, but Dystopia; not Rousseau's natural man moving in moral grace amid free social contracts, but man coerced, exiled, deracinated, in chains.... In their most sanguine moments, the authorities hoped that it would eventually swallow a whole class - the "criminal class," whose existence was one of the prime sociological beliefs of late Georgian and early Victorian England. Australia was settled to defend English property not from the frog-eating invader across the Channel but from the marauder within. English lawmakers wished not only to get rid of the "criminal class" but if possible to forget about it. Australia was a cloaca, invisible, its contents filthy and unnameable'. Hughes also documents the experiences of Thomas Hodden and Peter Withers as they reflect on their 'transportation' in letters to their dear wives. Thomas Hodden: 'It's with sorrow that I have to acquaint you that I this day receiv'd my Tryal and has receiv'd the hard sentance of Seven Years Transportation beyond the seas....' Peter Withers: 'My Dear Wife belive me my Hark is almost broken to think I must lave you behind. O my dear what shall I do i am all Most destracted at the thoughts of parting from you whom I do love so dear'. In spite of their fear, pain and trauma, the first fleet (11 ships) set sail on 13 May 1787. After 252 days via Rio de Janeiro and Cape Town, the crammed ships with 48 dead (40 convicts, five convicts' children, one marine's wife, one marine's child and a marine) docked in Sydney Cove on 18 January 1788 (p. 83).

${ }^{671}$ Ibid 84.

${ }^{672}$ Rees, above n 670, 5-11. On 29 July 1789, Lady Juliana left England with 226 female convicts, heading for Port Jackson, Australia. The real purpose for their 'transportation' after being pardon by mad King George III, was to appease the sexual needs of ever expanding male convict population in Australia. In Rees's words, '[b]y the first week in December 1788, all these "disorderly women" (and Francis Bunting) were awaiting trial in Newgate Gaol, London, part of a turbulent population of seven hundred accused or convicted prisoners' (p. 5).

${ }^{673}$ Babette Smith, A Cargo of Women: Susannah Watson and the Convicts of the Princess Royal (Allen and Unwin, 2nd ed, 2008) 51. Smith acknowledges the stereotypical perception of female convicts being naughty. She writes, ' $[\mathrm{t}]$ he female convict ships were also notorious for the relationships that developed between the women prisoners and the crew. In 1829 women convicts no longer travelled on the same ship as male prisoners and this, had reduced the outright prostitution of female prisoners which had occurred in earlier years. Nevertheless, the women were largely at the mercy of the male passengers, officers and crew, even if it was only to exchange sex willingly for extra privileges'.

${ }^{674}$ Deborah Oxley, Convict Maids: The Forced Migration of Women to Australia (Cambridge University Press, 1996) 12. Contrary to common belief that convict women were 'damned whores originating from a professional criminal class, unskilled in all but vice and unfit to contribute anything positive to colonial development', Oxley presents are inventory of data to prove otherwise. 
number of female convicts. At least 24960 female convicts (15 percent of all convicts to Australia) were shipped to Australia, with more than 9000 occupying at least one of 12 female factories built across the colony. ${ }^{67}$

Van Diemen's Land, modern-day Tasmania, is one example of the Australian penal colony system. Colonised by the British in 1803 as a primary penal settlement, mostly for repeat offenders ${ }^{676}$ in Australia, 75000 (40 percent) of all convicts to Australia were shipped to Van Diemen's Land up until 1853. Van Diemen's Land hosted roughly half (13 000) of all female convicts between 1803 and 1853. The Cascades Female Factory, one of five correction facilities constructed in Van Diemen's Land, held approximately 6000 prisoners. ${ }^{677}$ Some of those prisoners were children as young as 11 years old. Violence against female convicts took root in England, occurred on board as they were being transported to Australia, and persisted during their imprisonment in Australia. This violence was enabled by the convicts' stigmatisation as being immoral and bad. ${ }^{678}$ They were often labelled as prostitutes and compelled to share factories with men and young boys. ${ }^{679}$

The stories of Elizabeth Hayward and Charlotte Williams bring alive the collective experience of women's vulnerability to male violence during Australia's colonial period. On 13 May 1787, when the First Fleet departed from Portsmouth, England, the youngest female, Elizabeth Hayward, was aboard The Lady Penrhyn. Prior to leaving, 13-years old Elizabeth had stolen a linen gown, a silk bonnet and a bath cloth cloak, all at the value of seven shillings. ${ }^{680}$ Tried and found guilty by the second Middlesex Jury before Mr. Recorder Thomas Cross at the Justice Hall in the Old Bailey, Elizabeth was sentenced to transportation for seven years. ${ }^{681}$ Charlotte, an illiterate Welsh mother of nine children, was sentenced to transportation for 14 years along with her son, 13-year old Evan. ${ }^{62}$ Her two older sons, Thomas and James, were convicted of sheep stealing on the testimony provided by Charlotte's 11-year-old daughter,

\footnotetext{
${ }^{675}$ National Archives of Australia, Social History: Your Story, Our History (2015) Women transported: myth and reality <http://www.naa.gov.au/collection/publications/papers-and-podcasts/social-history/women-transported.aspx>. ${ }^{676}$ All early convicts from England were sent to Botany Bay. By the dawning of the 1800 s settlers' authority recreated now penal settlement for repeat offenders in Botany Bay, Norfolk Island, Van Diemen's Land, Port Macquarie and Moreton Bay (see http://members.iinet.net.au/ perthdps/convicts/res-02.html).

${ }^{677}$ Port Arthur Historic Sites, The Australian Convict Sites (2011) Cascades Female Factory Historic Site <http://www.femalefactory.org.au/history/the_australian_convict_sites>; Government of Australia, above n 354; Female Convicts Research Centre Inc, Female Convicts (2015) Female Convicts Research Centre $<$ http://www.femaleconvicts.org.au>; La Trobe University, 'The First Fleet: The Real Story with Alan Frost' $<$ http://www.latrobe.edu.au/news/articles/2011/podcasts/the-first-fleet-the-real-story/transcript>; Port Arthur Historic Sites, above n 668,8 .

${ }^{678}$ There were three phases of female transportation to Van Diemen's Land: exile or open prison (1803-13), assignment (1814-42), and probation (1843-53). In each, the numbers of convict women arriving in Van Diemen's Land increased, and they were subjected to more severe penal conditions (see, http://www.utas.edu.au/library/companion_to_tasmanian_history/F/Female\%20convicts.htm).

${ }^{679}$ The Point Puer Boys' Prison at Port Arthur ('lauded as an inescapable prison where prisoners committed crimes just to be killed rather than endure the bad conditions') was the first reformatory built exclusively for juvenile male convicts in the British Empire. Renowned for its stern discipline and harsh punishment, the Boys' Prison held some 3 000 boys, as young as nine years, who were sentenced between 1834 and 1849 (see,

http://www.portarthur.org.au/index.aspx?base=1923).

${ }^{680}$ Cheryl Timbury, 'Elizabeth Hayward'.

${ }^{681}$ Ibid.

${ }^{682}$ Port Arthur Historic Sites, above n 668, 92-14.
} 
Rachel, the prosecution's key witness - all of whom were sentenced to life. ${ }^{683}$ During the trial, the judge asked Rachel about her mother, Charlotte: could she read? Could she say prayers? Rachel replied 'no' to both questions. ${ }^{684}$ The judge continued asking, did she know it was wicked to tell lies? And, did she know where people who tell lies went to after they were dead? 'Yes,' Rachel replied to both questions, adding 'to hell' after her affirmation of the former question. ${ }^{685}$ Today, in English law, not only is an 11-year-old not competent to testify except in carefully guided circumstances provided by law, ${ }^{686}$ but she or he also cannot be sentenced for life, except for very serious offences, such as murder ${ }^{67}$ Unfortunately, this pattern of over sentencing, separating families, and mass incarceration were repeated in Australia as a means to subdue and control Aboriginal Peoples.

\subsubsection{Aboriginal Incarceration and Deaths in Custody}

Settler-colonists in Australia began incarcerating Aboriginal Peoples soon after the arrival of the First Fleet, ${ }^{688}$ and Aboriginal Peoples in Australia are still overrepresented in Australia's prisons. Although Aboriginal Peoples in Australia make up 2.8 percent of the country's population, they account for 27 percent of the total Australian prisoner population, with sexual assault being the fifth most common offense after acts intended to cause injury; unlawful entry with intent; offences against justice and robbery and extortion. ${ }^{68}$ Alarmingly, a report released by the Human Rights Law Centre and the Change the Record Campaign in May 2017 found Aboriginal women comprise 34 percent of the total adult female prison population in Australia, an increase of 148 percent since the Royal Commission into Aboriginal Deaths in Custody

\footnotetext{
${ }^{683}$ Ibid 92-94.

${ }^{684}$ Ibid.

${ }^{685}$ Ibid.

${ }^{686}$ Ibid. Later, Rachel's father (Charlotte's husband) would die on 2 March 1835 in the River Thames prison, Thomas died on 16 July 1833 in the colonial hospital, less than a year after he was transported. After her arrival on the Frances Charlotte, the master to whom Charlotte was assigned charged her with neglect of duty, and she was reprimanded to VDL to serve out her sentence. As a model convict, she gained conditional pardon on 18 November 1841. The rise in female convicts was guarded by policies that focused on morality and economics where convict females were encouraged to reform and be rewarded. Upon arrival, they were assigned to colonial masters as servants. On sustaining a 'good behaviour' record, rendered female convicts' permission to receive a ticket-of-leave (a kind of parole document initially issued in Britain, and later in the Australian Colony) - which allowed the holder to work for wages, and choose her own residence, but could not leave the district without permission of the resident magistrate. Men with ticket-of-leave were permitted to marry, bring their family from England, and permitted to acquire property (also see,

http://www.utas.edu.au/library/companion_to_tasmanian_history/F/Female\%20convicts.htm).

${ }^{687}$ Sentencing Council, Sentencing Children and Young People: Overarching Principles and Offence Specific Guidelines for Sexual Offences and Robbery - Definitive Guideline (Sentencing Council for England and Wales, 2017) 20.

${ }^{688}$ Donald James Weatherburn, Arresting Incarceration: Pathways Out of Indigenous Imprisonment (Aboriginal Studies Press, 2014) 1.

${ }^{689}$ Australian Bureau of Statistics, Aboriginal and Torres Strait Islander Prisoner Characteristics (8 December 2016) 4517.0 - Prisoners in Australia, 2016

<http://www.abs.gov.au/ausstats/abs@.nsf/Lookup/by\%20Subject/4517.0 2016 Main\%20Features Aboriginal\%20a nd\%20Torres\%20Strait\%20Islander\%20prisoner\%20characteristics 5>; Australian Bureau of Statistics, Census: Aboriginal and Torres Strait Islander Population (27 June 2017) Australian Bureau of Statistics: Media Release <http://www.abs.gov.au/ausstats/abs@.nsf/MediaRealesesByCatalogue/02D50FAA9987D6B7CA25814800087E03? OpenDocument>.
} 
1991. ${ }^{600}$ The most common charge for incarceration of Aboriginal males in Australia is 'acts intended to cause injury ${ }^{691}$ To the contrary, Indigenous females, Indigenous women, who tend to be younger, or more likely to have a mental disability, or subjected to sexual violence, are most prosecuted for driving and traffic violations, assault, thefts, and offences against justice. ${ }^{62}$ This over-representation of Aboriginal males in the Australian prison system today reflects multiple layers of disadvantage and marginalisation, ${ }^{693}$ which partly explains why intergenerational trauma caused by interpersonal, cultural and institutional violence recur in Indigenous communities.

Mass incarceration is a clear example of institutional violence whereby the state inflicts violence directly or indirectly on Indigenous women and girls. Weatherburn describes five impacts of over-representation of Indigenous Peoples in the Australian prison system. They are 1) inability of the criminal justice system to fulfil its objective of deterrence; 2) criminogenic effect resulting from protracted contact with the criminal justice system; 3) economic and social disadvantages; 4) international criticism; and 5) detrimental and unabated consequence of European settlement and colonisation of Aboriginal lands. ${ }^{644}$ Without a doubt, the protracted situation of mass incarceration of Aboriginal Peoples has significant risk factors. For example, losing a parent (or both parents) to incarceration heightens a child's susceptibility to neglect, deviant behaviours, poor parental care, violence and abuse, and delinquency. ${ }^{695}$ These vulnerabilities exacerbate a child's inability to access education, perform well and stay in school. The multiplier effect of the impact of incarceration heightens intersectionality concepts and worsens the impact on Aboriginal girls and women, who are already affected by many other disadvantages. The impact on individuals and families reaches a peak when incarcerated Aboriginal Peoples die in custody.

Aboriginal deaths in custody have become a large enough problem to warrant national attention. In response to growing public concerns about the deaths of Aboriginal Peoples in Australia whilst in the custody of law enforcement, Prime Minister Bob Hawke announced the establishment of the Royal Commission into Aboriginal Deaths in Custody on 10 August

\footnotetext{
${ }^{690}$ Adrianne Walters and Shannon Longhurst, 'Over-Represented and Overlooked: The Crisis of Aboriginal and Torres Strait Islander Women's Growing Over-Imprisonment’ (NGO Report, Human Rights Law Centre, May 2017) 51,10 .

${ }^{691}$ Australian Bureau of Statistics, Chapter - Division 02 - Acts Intended to Cause Injury (2 June 2011) 1234.0 Australian and New Zealand Standard Offence Classification (ANZSOC) <http://www.abs.gov.au/ausstats/abs@.nsf/Latestproducts/604F197FD705B5ADCA2578A200140AEC?opendocume nt>. According to the Australian Bureau of Statistics, 'acts intended to cause injury exclude attempted murder and those resulting in death, which are intended to cause non-fatal injury or harm to another person and where there is no sexual or acquisitive element.

${ }^{692}$ Walters and Longhurst, above n 691, 12.

${ }^{693}$ Ibid 16.

${ }^{694}$ Weatherburn, above n 689, 7-10. In March 2000, the Committee for the noted 'with grave concern that the rate of incarceration of Indigenous Peoples [in Australia] is disproportionately high compared with the general population.' When more than 1 in 10 Aboriginal have been imprisoned and 1 in 5 have at some stage lost a parent to prison then continuously populating prison cells with Aboriginal does not deter them from committing crimes. Research shows that having a prior criminal record reduce employability, which leads to higher crime rates. Research data confirms that difference in arrest rates for Indigenous and non-Indigenous Australians may explain about 15 per cent of the difference in levels of employment between the two groups.

${ }^{695}$ Ibid 74, 77.
} 
1987. ${ }^{696}$ The Royal Commission into Aboriginal Deaths in Custody was tasked with inquiring into the deaths of Aboriginal and Torres Strait Islanders between 1 January 1980 and 31 May 1989 whilst in police custody, in prison or in any other place of detention. ${ }^{697}$ Initially, the inquiry embarked upon a six-month examination of 44 cases. A body of five male ${ }^{698}$ Commissioners, working with a budget of $\$ 44$ million concluded their report in $1991{ }^{699}$ with 339 recommendations after four years of investigating 99 deaths of Aboriginal Peoples in custody. ${ }^{700}$ Three findings of the Royal Commission are relevant. First, Aboriginal deaths in custody are not the product of deliberate violence or brutality by police or prison officers. Second, deaths in custody are particularly distressing for families and friends and engender suspicion and doubt in their minds. Third, 63 deaths occurred in police custody, 33 in prison custody and three in juvenile detention. Unfortunately, Aboriginal deaths in custody continue to rise. Of the 99 deaths in custody examined by the Royal Commission, 11 percent $(n=11)$ were females between the ages of 14 and 62. However, a study conducted by the Australian Institute of Criminology's Lisa Collins and Jenny Mouzos shows an overall increase in the number of deaths in custody of Indigenous Peoples since 1989. Aboriginal women continue to be represented in these numbers.

Aboriginal women's deaths in custody are particularly concerning. According to Collins and Mouzos, of the 1442 people who died 'in all forms of custody in Australia', five percent $(\mathrm{n}=75)$ were females, including 24 Aboriginal women. ${ }^{701}$ At the time of their deaths, Collins and Mouzos (2002) report, the 'most serious offence' of Aboriginal females in custody was a violation of 'good order' (such as public drunkenness, prostitution and disorderly conduct). Furthermore, Collins and Mouzos's findings suggest that the most serious offence resulting in incarceration (and eventually death) of both Aboriginal females in custody is nearly twice as high as that of non-Aboriginal females. ${ }^{702}$ The death of Faith Barnes in custody, 'a picture now familiar to the Commission', is a case in point:

At about 11.00 am on 26 October 1982, she [Faith Barnes] was found lying apparently asleep in the street beside the Kalgoorlie Police Station. She had, it seems, been there for at least an hour. Known to have an alcohol problem, she was thought to be drunk, and taken to the lockup without any further inquiry being made as to the cause of her unconsciousness. She could not be roused and had to be carted or partly dragged, to the

\footnotetext{
${ }^{696}$ National Archives of Australia, Royal Commission into Aboriginal Deaths in Custody - Fact Sheet 112 (2015) Fact Sheets <http://www.naa.gov.au/collection/fact-sheets/fs112.aspx>.

${ }^{697}$ Pursuant to the Commission of Inquiry (Deaths in Custody) Act 1987 as amended on 15 June 1988 and 15 June 1989 ,

${ }^{698}$ The five commissioners of were, Patrick Dodson, a Yawuru man from Broome and former Chairman of the Council of Aboriginal Reconciliation of Australia; D.J. O'Dea, Hal Wootten, AC, QC, L.F. Wyvill, QC and Elliott Johnston. QC. Hal Wootten was a former judge of the Supreme Court of NSW and Elliott Johnston was a judge of the Supreme Court of SA.

Aboriginal activist Rob Riley was appointed Head of the Aboriginal Issues Unit of the Commission until Ruby Hammond was appointed to the position in 199

${ }^{699}$ The 99 cases comprised 32 Women in Western Australia, 27 in Queensland, 21 in SA and the NT and 19 across NSW, VIC and TAS.

${ }^{700}$ Max Blenkin, 'Hawke Govt Launched Aboriginal Death Probe' The Australian (Sydney South, NSW), 1 January 2014 <http://www.theaustralian.com.au/news/latest-news/hawke-govt-launched-aboriginal-death-probe/storyfn3dxiwe-1226792800340>.

${ }^{701}$ Lisa Collins and Jenny Mouzos, 'Deaths in Custody: A Gender-Specific Analysis' [2002] (238) Australian Institute of Criminology Trends and Issues 1.

${ }^{702}$ Ibid.
} 
exercise yard where she was left lying on the bare concrete. A number of cell checks were made between that time and 4.00 in the afternoon, when it was noticed that there was dried blood on the side of her head. After further attempts to rouse her were unsuccessful, an ambulance was called, and she was taken to the Kalgoorlie Regional Hospital. There, Barnes was found to be semi-conscious but unresponsive to spoken command. Later that night, after her condition had failed to improve, she was transferred to the Royal Perth Hospital. Admitted in the early hours of the following morning, she was found to have a severe head injury. An emergency operation was performed to remove blood clots from inside her skull. After surgery had been completed, she suffered an unexpected cardiac arrest. Resuscitation was unsuccessful, and she was declared dead at 7.36 on the morning of 27 October 1982. Faith Barnes had a severe alcohol problem. Her treatment by those who took her into custody at Kalgoorlie for the last time was totally devoid of kindness or humane consideration. Her treatment at the hands of some members of her own community was even worse. Between 1975 and her death, she received medical treatment for head injuries on at least sixteen occasions, being admitted to hospital on at least five of these occasions. A proportion of these injuries resulted from severe assaults. She was also treated for other traumatic injuries at various times. At the time of her death she was approximately 27 years old. It is not known how she came by the severe head injury which caused her death. (...) However, she came by her injuries, the neglect demonstrated by the Kalgoorlie police responsible for her custody is disgraceful. She should never have been placed in custody in her semi-conscious condition without a prior medical examination to ensure that her unconsciousness was alcohol-related as thought, and not caused by injury or illness. (...) Not much is known of Faith Barnes, save what may be gleaned from public records. What is known presents a depressing picture. It is even not certain when or where she was born. Various birth dates appear in government records. 4 December 1954 is the most likely date. She was probably born in Kalgoorlie, as this was more commonly given as her place of birth on government records. Her mother was Hazel Wuni. She died in August 1957 when Faith was not yet three. Her father Bordie Parker, was usually employed as a station hand in the Leonora area. He died in August 1966. Faith had a younger sister Christine born in July $1956 .^{703}$

Aboriginal deaths in custody, an extension of mass incarceration, constitute more state violence against Aboriginal women. However, there was a time in Australia's colonial past, before Aboriginal Peoples were fully subject to the penal system when Aboriginal Peoples were not tried and convicted for perceived crimes. Rather, Aboriginal Peoples were massacred by settler-colonists and agents of the colonial government.

\subsubsection{Massacres}

From the moment the British invaded Australia in 1788, they encountered resistance from Aboriginal and Torres Strait Islander Peoples, who are the original owners and custodians of their land. In the frontier wars, which continued from the point of European contact until the 1960s, massacres became the defining strategy to curb resistance posed by Indigenous Peoples in Australia. Ryan reasons that a massacre on Australia's frontier included six or more deaths of people who were defenceless against assault. ${ }^{704}$ Countless violent attacks took place between settler-colonists ${ }^{705}$ and Aboriginal Peoples in Australia, resulting in thousands of Aboriginal

\footnotetext{
${ }^{703}$ Daniel John O’Dea, 'Faith Barnes' (Royal Commission into Aboriginal Deaths in Custody, 5 November 1990) 25, 3-4 <http://www.austlii.edu.au/au/other/IndigLRes/rciadic/individual/brm_fb/2.html>.

${ }^{704}$ Lyndall Ryan et al, Colonial Frontier Massacres in Eastern Australia: $1788-1872$ (2017) The Centre for 21st Century Humanities, University of Newcastle <https://c21ch.newcastle.edu.au/colonialmassacres/>.

${ }^{705}$ Daley (2013) estimated that at least 2, 000 early soldiers, police and settlers died at the hands of Aboriginal raiders who resisted the pastoral settlement on traditional lands, stole livestock and carried out retaliatory raids.
} 
children, women and men being killed ${ }^{706}$ (see Appendix IV). The first map of massacres constructed by Lyndall Ryan presents timelines, sites and information of massacres in Eastern Australia from 1794 until 1872. Daley asserts that '[a]ccording to very conservative estimates, at least 20000 Indigenous Australians ${ }^{707}$ died at the hands of Australian-based military regiments, police forces and settlers' militia from 1788 until the last known "massacre" at Coniston, Northern Territory, in 1928. ${ }^{908}$ This is a clear example of state-sponsored violence against Aboriginal Peoples, but there is also concern about the effects that linger effects to the present day.

Massacres of Aboriginal Peoples are not properly represented in Australian history. Accurate data that accounts for the full span of massacres against Aboriginal Peoples in Australia is hard to find. Nevertheless, Ian Clark suggests that an estimated 107 separate massacres and killings occurred in western Victoria between 1803 and 1859. ${ }^{709}$ However, Clark also discloses that 'generally, the violent history of western Victoria has been repressed, and many people who were in effect murderers have been honoured by memorials to pioneers, and by street and town names. ${ }^{{ }^{710}}$ Paul Daley critiques the failure to include frontier violence ${ }^{711}$ against Aboriginal Peoples in Australia as part of Australia's War Memorial history. This absence from historical record represents structural violence which still affects Aboriginal Peoples in the present day. In keeping with the phenomenological approach of this research and promoting the historical record of Aboriginal history, herewith is a selection of nine major massacres and violent conflicts that took place between settlers and Aboriginal Peoples in Australia between 1804 and 1928.

\footnotetext{
${ }^{706}$ Ryan et al, above $\mathrm{n} 705$.

${ }^{707}$ Stephen Glynn Foster, Bain Attwood and National Museum of Australia (eds), Frontier Conflict: The Australian Experience (National Museum of Australia, 2003) 88-91.

${ }^{708}$ Paul Daley, 'Why Does the Australian War Memorial Ignore the Frontier War? The Battle between Aboriginal People and the Settlers Is at the Heart of Nationhood but Absence from War Dead Commemorations' The Guardian (Canberra, ACT), 12 September 2013 <http://www.theguardian.com/world/2013/sep/12/australian-war-memorialignores-frontier-war>.

${ }^{709}$ Ian D Clark, Scars in the Landscape: A Register of Massacre Sites in Western Victoria, 1803-1859 (Australian Institute of Aboriginal and Torres Strait Islander Studies, 1995) 9.

${ }^{710}$ Ibid 4.

${ }^{711}$ Reynolds, Dispossession, above n 177, 24; Personal from Samson Ceasar, 'Liberian Letters: Samson Ceasar to Henry F. Westfall 1835 August 3', 3 August 1835 <http://search.lib.virginia.edu/catalog/uva-lib:501742>; Azikiwe, above n 301, 71; Foster, Attwood and National Museum of Australia, above n 708, 6-8. Reynolds argues that, ' $\ldots$ [t] he traditional account [of Australian history] is of peaceful settlement, of a struggle against the land, not against other human beings for possession of land. The bloodshed has often been conveniently forgotten. Yet the issue of frontier violence was frequently at the forefront of public debate during the $19^{\text {th }}$ century. Explorers were often quite frank about their part in the violent dispossession of the Aborigines. Some glorified the struggle, seeing it as one of the achievements of settlement...' Interestingly, Caesar's letter to a friend, after his arrival in Liberia from the United States, commands a personal touch to frontier violence in Liberia. He writes, 'I am sorry to have to inform you that we have been attacked by the natives at the place called Bassaw Cove about one hundred miles from here they killed about 15 or 20 Americans our people attacked them twice and the first time we lost one man they sent up for more men they went down and made the second attack and drove the natives all out of Town....'
} 
Risdon Cove Massacre 1804: On 3 May, British soldiers were ordered to fire a cannon at some 300 Aboriginal women, children and men, who approached the Risdon Cove settlement in Van Diemen's Land in resistance to the occupation of their homeland by colonists. ${ }^{71}$

Appin Aboriginal Massacre 1816: Ordered by then New South Wales Governor Lachlan Macquarie, an estimated 14 Aboriginal children, women, and men were killed whilst others were driven off a cliff in Appin, southwest Sydney (now a Crown land). ${ }^{713}$ Macquarie, whom Macquarie University is named after, is celebrated as the most popular governor to tirelessly advocate for emancipists and convicts.

Bathurst/Wiradjuri/Bell Falls Massacre 1824: A battle between three settler stockmen and Aboriginal Peoples over stolen cattle left seven white settlers and 16 Aboriginal Peoples dead. Sir Thomas Makdougall Brisbane, then governor at Brisbane House, later declared martial law, ordering that, 'any retaliatory bloodshed be stopped by any means necessary, with the use of firearms against the Wiradjuri in the area west of Mount York on the Great Dividing Range'. ${ }^{715}$ However, the very same martial law justified the killing of many more Aboriginal Peoples by white settlers. ${ }^{76}$ The capital city of Queensland and the Brisbane River, the longest in southeast Queensland, are named after Major-General Brisbane, who was also knighted as a soldier serving with distinction. ${ }^{71}$

Pinjarra Battle/Massacre 1834: Led by Governor James Stirling, 15-30 Aboriginal Peoples of Binjareb country were massacred by white Australian settler-colonists in Pinjarra, Western Australia. According to the Museum Without Walls, 'All accounts acknowledge that women

\footnotetext{
${ }^{712}$ Lyndall Ryan, 'Risdon Cove and the Massacre on 3 May 1804: Their Place in Tasmanian History [Paper Presented at the "Tasmanian Aboriginal History: Fabrication or Fact?" Conference, University of Tasmania, Launceston, 16 May 2003]' (2004) 9 Tasmanian Historical Studies 107.

${ }^{713}$ Tobin and Colvin, above n 15; Grassby and Hill, above n 350, 161-168. Regarding the oppressed loyalty to the oppressor, in making relocations venues a constant reminder of ties to the 'master', the city Sydney was named after Lord Sydney, aka Thomas Townshend, 1st Viscount Sydney (1732 - 1800) who as member of the House of Lords in 1783 responsible for prisons and colonies, sculpted the idea of Botany Bay as a penal colony. Andrew Tink quotes Lord Sydney, '[t]he several Goals and Places for the Confinement of Felons in this Kingdom being in so crouded a State ... I ... signify to your Lordships His Majesty's Pleasure, that you do forthwith take such Measures as may be necessary for providing a proper number of vessels for the conveyance of 750 Convicts to Botany Bay, together with such Provisions, necessaries and Implements for agriculture as may be requisite for their use after their arrival...' (also see, http://www.scholarly.info/book/276/).

${ }^{714}$ ND McLachlan, 'Macquarie, Lachlan (1762-1824)' in Australian Dictionary of Biography (National Centre of Biography, Australian National University, 1967) <http://adb.anu.edu.au/biography/macquarie-lachlan-2419>.

${ }^{715}$ JD Heydon, 'Brisbane, Sir Thomas Makdougall (1773-1860)' in Australian Dictionary of Biography (National Centre of Biography, Australian National University, 1966) <http://adb.anu.edu.au/biography/brisbane-sir-thomasmakdougall-1827>; Sonia Feng and Melanie Pearce, 'Bloody Part of Australian History Laid Bare in Bathurst' $A B C$ News (Orange, NSW), 15 August 2017 <http://www.abc.net.au/news/2017-08-15/scars-of-martial-law-laid-bare-inbathurst/8804586>.

${ }^{716}$ Grassby and Hill, above n 350; Robbie Thorpe, The Bathurst Massacres (2015) Treaty Republic $<$ http://treatyrepublic.net/content/bathurst-massacres>; Staff Reporter, Transcript: Declaration of Martial Law (2015) Bells Falls Gorge: An Interactive Investigation <http://www.nma.gov.au/engage-learn/schools/classroomresources/multimedia/interactives/bells_falls_gorge_html/cabinet_items/transcript_declaration_of_martial_law >; Foster, Attwood and National Museum of Australia, above n 707, 152-157.

${ }^{717}$ Royal London, 'How Did the City of Brisbane Get Its Name?' The Telegraph (London, UK), 23 July 2016

<http://www.telegraph.co.uk/only-in-britain/thomas-makdougall-brisbane-born/>.
} 
and children were amongst the dead. ${ }^{718}$ Stirling Highway, a suburb in Perth, and the Royal Australian Navy Base, HMAS Stirling, are all named in honour of Stirling, the first Governor of Western Australia. ${ }^{71}$

Waterloo Creek/Slaughterhouse Creek/Australia Day Massacre, 1838: On 26 January, a clash broke out between white mounted police in Sydney and Aborigines. Dispatched by Lieutenant Governor Colonel of Van Diemen's Land and later acting Governor of New South Wales Kenneth Snodgrass, the Sydney mounted police attacked a group of Kamilaroi people in remote bushland killing approximately eight to 50 Aborigines. ${ }^{720}$

Myall Creek Massacre 1838: According to Jeffrey Grey, in 1838 a 'war of extirpation' was waged along the Gwydir River as Aboriginal Peoples in the district were consistently pursued by mounted and armed stockmen, for the purpose of killing them. ${ }^{721}$ On 10 June, 28 Aboriginal Peoples were killed at Myall Creek, New South Wales; the resulting trial and verdict were considered the first successful prosecution and conviction of European settlers for the mass murder of Aboriginal Peoples in Australia. ${ }^{722}$ In July, 14 Aboriginal Peoples were killed near Murrumbidgee and Murray rivers for stealing sheep belonging to the Bowman, Ebden and Yaldwyn stations in New South Wales. Edmund Denny Day, a local magistrate, offered reports of a 'war of extirpation' around the same time along the Gwydir River. Denny stated that 'Aborigines in the district were repeatedly pursued by parties of mounted and armed stockmen, assembled for the purpose, and that great numbers of them had been killed at various spots' ${ }^{223}$

Kilcoy and Whiteside Poisonings ( 1842-67): Known as the largest and most documented massacres in southeast Queensland. Sometime in January or February 1842, bags of flour laced with strychnine were given to Indigenous Peoples. Although exact numbers are unknown, up to 70 Aboriginal Peoples lost their lives. Aboriginal Peoples in Whiteside, Central Queensland, 'had been murdered in cold blood by giving them arsenic and strychnine in their foods.' ${ }^{724}$

\footnotetext{
${ }^{718}$ Staff Reporter, 'Pinjarra Battle/Massacre 1834' (Public-Private, Mudurah Community Museum, 2015) 4 <http://www.mandurahcommunitymuseum.org/downloads/Pinjarra\%20Massacre.pdf >; Grassby and Hill, above $\mathrm{n}$ 350, 192-199.

${ }^{719}$ Royal Australian Navy, HMAS Stirling (2018) About the Royal Australian Navy

<http://www.navy.gov.au/establishments/hmas-stirling>; City of Stirling, Stirling (2016) City of Stirling

<http://www.stirling.wa.gov.au:80/Council/Suburbs/Pages/Stirling.aspx>.

${ }^{720}$ Foster, Attwood and National Museum of Australia, above n 708; Bain Attwood and Tom Griffiths, Frontier, Race, Nation: Henry Reynolds and Australian History (Australian Scholarly Pub, 2009); Attwood, above n 364, 57.

${ }^{721}$ Jeffrey Grey, A Military History of Australia (Cambridge University Press, 2008) 37.

${ }^{722}$ La Trobe University, 'Aboriginal Australian History with Richard Broome'

<http://www.latrobe.edu.au/news/articles/2010/podcasts/aboriginal-australian-history/transcript >; Summons, above n

15; La Trobe University, 'The Myall Creek Massacre with Richard Broome', above n 15; James C Docherty,

Historical Dictionary of Australia (Scarecrow Press, 2007) 210

$<\mathrm{http} / / /$ search.ebscohost.com/login.aspx ?direct=true \&scope=site $\& \mathrm{db}=$ nlebk\&db=nlabk\&AN=238232>.

${ }^{723}$ Grey, above n 119, 37.

${ }^{724}$ Robert Ørsted-Jensen, Frontier History Revisited: Queensland and the 'History War' (Lux Mundi Publisher, 2011) 79,88 .
} 
Forrest River Massacre 1926: On 20 May Moran reports, in East Kimberley, Constable St. Jack left Wyndham on patrol to Nulla Nulla station to investigate complaints by the co-owner, Leopold Overheu, of Aboriginal Peoples killing cattle on his lease. ${ }^{725}$ The next day, Ernest Umbah (an Aboriginal man) was arrested for trespassing on Nulla Nulla, a place that was 'designed to keep bush Aborigines from possibly corrupting contact with whites in the town'. ${ }^{226}$ By the third day, it is reported that white pastoralists raided a Corroboree in Durridgee and shot at a gathering of approximately 250 Aborigines. With the killing of Frederick Hay from Nulla Nulla station by Lumbia (an Aboriginal man) in a dispute over cattle killing, Reverend E R G Gribble is accused of spreading wildfire rumours of the massacre of Aborigines in Durridgee. ${ }^{727}$ Like Keith Windschuttle's ${ }^{728}$ dismissal of the black war, a period marked by a series of conflicts between Tasmanians and British settlers, ${ }^{729}$ Rod Moran disputes the claims of mass murder of Aboriginal Peoples at Forest River in 1926. He argues that with no 'legal or empirical substantive basis of the allegations put forward by Rev Gribble, what remains is myth and rumours' ${ }^{730}$

Coniston Massacre 1928: On 7 August, Frederick Brooks, a dingo trapper and prospector on Coniston station, Central Australia, was murdered, allegedly by Aboriginal men, Padygar and Arkikra, who was later arrested, tried and acquitted in Darwin. ${ }^{731}$ It was reported that Aboriginal Peoples pushed his mutilated body into a rabbit burrow for allegedly interfering with an Indigenous man's wife. Led by Gallipoli, veteran and hardened bushman Mounted Constable George Murray and a party of eight well-armed horsemen murdered approximately 100 Aboriginal Peoples between 16 August and 18 October near Yuendumu, Alice Springs, Northern Territory. ${ }^{73}$

\subsubsection{Genocide, Miscegenation, and Eugenics}

The genocide Australia needs to recognize is not the one that may have been envisioned in the removal policy, but the one the removal policy was intended to complete. The racist categories of 'half-castes', 'quadroons' and 'octoroons', the inhuman calculus of

\footnotetext{
${ }^{725}$ Reynolds, above n 418, 178-188.

${ }^{726}$ Rod Moran, Massacre Myth: An Investigation into Allegations Concerning the Mass Murder of Aborigines at Forrest River, 1926 (Access Press, 1999) xvi.

${ }^{727}$ Ibid xvii-xix.

${ }^{728}$ Keith Windschuttle, The Fabrication of Aboriginal History (Macleay Press, 2002); Keith Windschuttle, 'White Settlement in Australia: Violent Conquest or Benign Colonisation?' (2003) 31 Melbourne Historical Journal 1.

${ }^{729}$ Clive Turnbull, The Black War: The Extermination of the Tasmanian Aborigines (F. W. Cheshire, 1948); James Bonwick, The Last of the Tasmanians or The Black War of Van Diemen's Land (Sampson Law, Son \& Marston, 1870) 30. Bonwick (1807) provides an interesting reason why the Black War ensued between British settlers and Aborigines, '[t]he misfortune of the Natives of both New South Wales and Van Diemen's Land was, that the men who came to settle amongst them were chiefly of a class expatriated for their non-observance of rules of propriety; and who, having been indifferent about the virtues when with their countrymen at home, were not likely to be more courteous and conscientious in dealing with savages abroad'.

${ }^{730}$ Moran, above n 727, 205.

${ }^{731}$ Staff Reporter, Coniston Massacre (2015) First Australians

<http://www.nma.gov.au/exhibitions/first_australians/resistance/coniston_massacre>.

${ }^{732}$ Reynolds, above n 418, 190-200; Mitchell Rolls and Murray Johnson, Historical Dictionary of Australian Aborigines (Scarecrow Press, 2011) xxxiii, 51.
} 
'breeding out the colour,' and the progression from biological 'absorption' to societal 'assimilation' were the twentieth century outgrowths of a nineteenth century catastrophe. ${ }^{733}$

The Australian state perpetrated genocide against Aboriginal Peoples late into the $20^{\text {th }}$ century through marriage laws, miscegenation, and eugenics. In 1944, Raphäel Lemkin in 1944 coined the term genocide, which means the destruction of a nation or an ethnic group. ${ }^{734}$ Article 2 of the Convention on the Prevention and Punishment of the Crime of Genocide $1948^{735}$ defines genocide as acts 'committed with the intent to destroy, in whole or in part, a national, ethnical, racial or religious group'.

One tool of genocide used against Aboriginal Peoples was a program of controlling miscegenation, by isolating Aboriginal Peoples through the administration of discriminatory marriage laws. Oxford Dictionary defines miscegenation as 'the interbreeding of people considered to be of different racial types'. As a British colony, white Australian settler-colonists inherited and administered marriage law based on British common law tradition. ${ }^{736}$ The Aboriginal Protection Act 1869 (Vic) authorised the Board for the Protection of Aboriginal Peoples to refuse marriage applications from Indigenous Peoples in Victoria. ${ }^{737}$ The Aboriginal Protection and Restriction of the Sale of Opium Act 1897 (Qld) restricted the Aboriginal woman to marry only an Aboriginal man, except where permission was granted by the Aboriginal Protector to marry a non-Aboriginal person. ${ }^{738}$ The Aborigines Act 1905 (WA) attempted to regulate relationships between white men and Aboriginal women by requiring that the Chief Protector approve all marriages of Aboriginal women to non-Aboriginal men, as well as transferring guardianship of mixed-race children to the Protector. ${ }^{79}$ Regardless, since 'Europe is male [and] the conquered land is female', irrespective of the colonising project's aim to displace or replace Indigenous Peoples, Aboriginal girls and women were sexually abused by white, male settler-colonists. ${ }^{740}$ Sexual exploitation of and abuse of Aboriginal women by white settlers is a paradox that developed into a new problem for proponents of a white Australia.

Mixed-race children were often the result of violence against Aboriginal women. ${ }^{74}$ As during the trans-Atlantic slave trade, where paradoxically, the 'abhorrent' young slave girls

\footnotetext{
${ }^{733}$ Tony Barta, 'Sorry, and Not Sorry, in Australia: How the Apology to the Stolen Generations Buried a History of Genocide' (2008) 10(2) Journal of Genocide Research 201, 209.

${ }^{734}$ Raphael Lemkin, Axis Rule in Occupied Europe: Laws of Occupation, Analysis of Government, Proposals for Redress (Lawbook Exchange, Ltd, 2nd ed, 2008) 79.

${ }^{735}$ Australia ratified the Convention on the Prevention and Punishment of the Crime of Genocide 1948 on 8 July 1949 and Liberia's 20 June 1950.

${ }^{736}$ House of Representatives Standing Committee on Social Policy and Legal Affairs, 'Advisory Report: Marriage Equality Amendment Bill 2012 and Marriage Amendment Bill 2012' (Text, The Parliament of the Commonwealth of Australia, June 2012) 67, 9

<https://www.aph.gov.au/Parliamentary_Business/Committees/House_of_Representatives_Committees?url=spla/bill $\% 20$ marriage/report/final.pdf $>$.

${ }^{737}$ Katherine Ellinghaus, 'Regulating Koori Marriages: The 1886 Victorian Aborigines Protection Act' (2001) 25(67)

Journal of Australian Studies 22, 23.

${ }^{738}$ Ellinghaus, 'Absorbing the "Aboriginal Problem": Controlling Interracial Marriage in Australia in the Late 19th and Early 20th Centuries', above n 216, 197.

${ }^{739}$ Ibid 187.

${ }^{740}$ Patrick Wolf, 'Nation and Miscegenation: Discursive Continuity in the Post-Mabo Era' (1994) 36 Social Analysis:

The International Journal of Social and Cultural Practice 93, 93-95.

${ }^{741}$ Phillip Noyce, Rabbit-Proof Fence (2002).
} 
provided gruesome pleasure for white abusers, such as the affliction of Aboriginal lasses, handmaidens, mission girls, wards of the state and 'other wives' in Australia. ${ }^{742}$ The dilemma of striving to eliminate Aboriginal Peoples, whilst at the same time, sexually abusing Indigenous women not only feed into the idea of miscegenation but also caused a disruption. Patrick Wolf asserts that, '.. the chronic negator of the logic of elimination had been the White penis.' ${ }^{743}$ Whilst uncovering his Aboriginal 'family secret', Reynolds ${ }^{74}$ reflects, '[i]f all humankind was one species then all people could intermarry and produce fertile and healthy offspring. If on the other hand, polygenetic is right, then intermarriage was unnatural, i.e., sexual intercourse across colour lines is akin to bestiality. In cases where children resulted, then they could be unhealthy, degenerate and infertile'. ${ }^{745}$ The latter viewpoint, according to Reynolds, is the fundamental basis upon which white Australian settler-colonists feared mixed blood people and eventually sought to exterminate them. ${ }^{746}$ Hence arose their resolve to legally prohibit miscegenation, promote eugenics and commit genocide against Indigenous Peoples. Therefore, preventing interracial marriage with Aboriginal Peoples and promoting assimilation by 'breeding out the colour' became the solution for addressing the 'half-caste problem'.

To address the increasing number of biracial children in Australia, the state adopted policies intended to separate those children from their Aboriginal communities and breed them with white Australians until their offspring were no longer black in colour. In 1883, Francis Galton, a cousin of Charles Darwin, coined the term 'eugenics', which has its root in Greek meaning 'good birth' or 'noble in heredity'. ${ }^{748}$ Eugenics denote 'the science of improving human stock by giving the more suitable races or strains of blood a better chance of prevailing speedily over the less suitable'. ${ }^{749}$ Assimilation policies in Australia that nurtured and sustained genocide and miscegenation are founded in eugenics theories. ${ }^{750}$ Russell McGregor describes 'breeding out the colour' as 'an intensely racist' assumption of 'hybrid inferiority' that is both a form of eugenics and 'a stratagem to erase colour, to bleach Australia white through programs of related reproduction'. ${ }^{751}$ The eugenics policy of removing interracial children from their families to be raised in parochial institutions and white Australian families has become known as the Stolen Generation.

\footnotetext{
${ }^{742}$ William E Allen, 'Making History in the Bedroom: Americo-Liberians and Indigenous Liberians Sexual Unions, 1880s- c. 1950s' (2009) 34(2) Liberian Studies Journal 16, 20.

${ }^{743}$ Wolf, above $\mathrm{n} 740,94,112$.

${ }^{744}$ Reynolds, above n 433, xi-xxii, 29-49, 227-241.

${ }^{745}$ Ibid 19.

${ }^{746}$ Ibid 227-241.

${ }^{747}$ McGregor, above n 85, 1 .

${ }^{748}$ Daniel J Kevles, In the Name of Eugenics: Genetics and the Uses of Human Heredity (Harvard University Press, 1st Harvard University Press paperback, 1995) xiii.

${ }^{749}$ Ibid.

${ }^{750}$ Jessica Schimmel, 'Killing without Murder: Aboriginal Assimilation Policy as Genocide' (2005) 13(7) The Lehigh Review 35, 35.

${ }^{751}$ McGregor, above n 85, 1. 


\subsubsection{Stolen Generation/Forced Adoption/Bringing Them Home}

For many years past under successive governments, the policy has been that, where half-caste children are found living in camps of full-blood natives, they should, if possible, be removed to better care so that they may have a better opportunity for education. The theory behind this policy is, that if the half-caste child remains with the bush tribe, he will grow up to have neither the full satisfaction in life which the tribal native has nor the opportunity to advance to any other status. Paul Hasluck, Minister of External Affairs (1964-1969) 752

As you well realize, dark children could not possibly be absorbed as whites, therefore, it is my wish that every care be taken in the admittance of children in order to ensure that they are fair enough to be regarded as white... C L McBeath, Acting Commissioner of Aboriginal Affairs (1947) 753

Assimilation policy, the civilising mission and the Christianising project perfected the practice of eugenics, miscegenation, genocide, and forced adoption (inter alia) of Indigenous Peoples, as is evident in Hasluck and McBeath's assertions above. Peter Read, a renowned Australian historian who started his academic research in Indigenous history, coined the phrase 'The Stolen Generation'. ${ }^{754}$ The term refers to the practice of forcibly removing Aboriginal children from their families ${ }^{755}$ supported by settler-colonist policy, which demonstrates how the law can be used as an effective tool of systematic violence. ${ }^{756}$ The works of Auber Octavius Neville

\footnotetext{
${ }^{752}$ Reynolds, above n 433, 211-212.

${ }^{753}$ Ibid 213.

${ }^{754}$ Tripping Over Feathers: Scenes in the Life of Joy Janaka Wiradjuri Williams: A Narrative of the Stolen Generations (UWA Pub, 2009) xiv.

${ }^{755}$ Darlene Johnson, Stolen Generations (Ronin Films, 2000) <www.tomzubrycki.com>. In Stolen Generations, Johnson tells the story of three Aboriginal Peoples that were separated from their families: Bobby Randall, a Yankunytjatjara elder, artist and Indigenous Person of the Year (1999) who was removed at the age of four and placed in a mission dormitory. Cleonie Quayle, a mother of four, remember being coerced at the age of five to sit in the back seat of a black car. Hoping that she was going for vacation, Cleonie spent the next 12 years in foster care where she experienced sexual abuse. Daisy Howard, an Indigenous woman from Kimberley, was separated from her half-sister for 50 years. Daisy who was removed to a cattle station became a domestic worker whilst her sister remained in Country with their parents (see, http://aso.gov.au/titles/documentaries/stolen-generations/clip3/).

${ }^{756}$ The Aborigines Protection Act 1869 (Vic) establishes an Aborigines Protection Board in Victoria to manage the interests of Aborigines. The Act empowers the Governor to order the removal of any child from their family to a reformatory or industrial school. In 1883, the New South Wales Aborigines Protection Board was established to manage the lives of 9000 Aboriginal Peoples. The Aboriginal Protection and Restriction of the Sale of Opium Act 1897 (QLD) allowed the Chief Protector to remove local Aboriginal Peoples onto and between reserves and hold children in dormitories. Until 1965 the Director of Native Welfare was the legal guardian of all 'Aboriginal' children whether their parents are living or not. Under the Aborigines Act 1905 (WA), the Chief Protector was made the legal
} guardian of every Aboriginal and 'half-caste' child under 16 years old. Other states followed suit, for example, Victoria (1910) and New South Wales, (1909). Under the Neglected Children and Juvenile Offenders Act 1905 (NSW), if a court found a child to be neglected, the Aborigines Protection Act 1909 (NSW) gave the Aborigines Protection Board power to assume full control and custody of the child of any Aborigine. The Aborigines Act 1911 (SA) made the Chief Protector the legal guardian of every Aboriginal and 'half-caste' child with additional wideranging powers to remove Indigenous Peoples to and from reserves. The Northern Territory Aboriginals Ordinance 1911 (Cth) gave the Chief Protector power to assume 'the care, custody or control of any Aboriginal or half caste if in his opinion it is necessary or desirable in the interests of the Aboriginal or half-caste for him to do so'. The Aborigines Ordinance 1918 (Cth) extended the Chief Protector's control even further. The Aborigines Protection Amending Act 1915 (NSW) gives power to the Aboriginal Protection Board to separate Indigenous children from their families without having to establish in court that they were neglected. The Infants Welfare Act 1925 (Tas) was introduced, allowing the removal of Indigenous children on Cape Barren Island from their families. Between 1928 and 1980, the head teacher on Cape Barren was appointed as a special constable with the powers and responsibilities of a police constable, including the power to remove a child for neglect under child welfare legislation. In 1940, the NSW Aborigines Protection Board lost its power to remove Indigenous children and renamed the Aborigines Welfare Board, which was finally abolished in 1969. The Aboriginal Child Placement Principle, developed on the efforts of the Aboriginal and Islander Child Care Agencies, was incorporated in NT welfare legislation to ensure that Indigenous children are placed with Indigenous families when adoption or fostering is necessary. Other states followed suit, NSW (1987), Victoria (1989), South Australia (1993), Queensland and the ACT (1999), Tasmania (2000) and Western Australia (2006). See, the Australian Human Rights Commission's "Timeline - History of 
describe a carefully planned and implemented approach to perpetrate violence against Aboriginal Peoples. As a Chief Protector of Aboriginal Peoples (1915-36) and Commissioner for Native Affairs (1936-40), Neville shaped official policy affecting Aboriginal Peoples in Australia. ${ }^{757}$ According to A Haebich and R H W Reece, the purpose of regulations instigated by Neville under the Aborigines Act 1905 was to 'bring about permanent segregation of Aborigines of full descent, who were believed to be near extinction'. ${ }^{758}$ As a way of wiping out Indigenous blood, the white Australia policy segregated and trained part descent Aborigines and reintegrated them into society as domestics and farm workers in hopes of blending them with the white population by way of intermarriage. ${ }^{759}$ Segregating biracial Aboriginal children required removing them from their mothers and placing them in the care of institutions. Forced adoption of Aboriginal children was in effect in Australia for approximately 60 years and affected generations of Aboriginal women and children. Even though it is challenging to estimate the exact number of Aboriginal children who were forcibly removed from their families, the Bringing Them Home report suggests that 'between one in three and one in ten Indigenous children were forcibly removed from their families and communities in the period from approximately 1910 until 1970. ${ }^{760}$ Joy Janaka Wiradjuri Williams's story highlights the intergenerational violence inflicted on many Aboriginal women and their children.

Joy Janaka Wiradjuri Williams (1942-2006), a Wiradjuri woman, was one of those Aboriginal children forcibly removed by the State of New South Wales. ${ }^{761}$ Read narrates the events of Joy's life, beginning in 1943 before she was born. Joy's mother, Doretta Williams, became pregnant by a white soldier soon after she left the Cootamundra Training Home for Aboriginal Girl's in New South Wales to work as a domestic servant for a white family. The

separation of Aboriginal and Torres Strait Islander children from their families - text version", available at $<$ https://www.humanrights.gov.au/timeline-history-separation-aboriginal-and-torres-strait-islander-children-theirfamilies-text\#date-1869>.

${ }^{757}$ Reynolds, above n 433, 210, 212, 214-216.

${ }^{758}$ Haebich and Reece, 'Neville, Auber Octavius (1875-1954)', above n _.. Also see, Museum Victoria for "breeding out" images of Aborigines from his book, "Australia's Coloured Minority: It's Place in the Community" (1947), available at, http://museumvictoria.com.au/collections/items/1496210/book-a-o-neville-australia-s-colouredminority-its-place-in-the-community-currawong-publishing-co-1947.

${ }^{759}$ Haebich and Reece, 'Neville, Auber Octavius (1875-1954)', above n _. Also see, Museum Victoria for "breeding out" images of Aborigines from his book, "Australia's Coloured Minority: It's Place in the Community" (1947), available at, http://museumvictoria.com.au/collections/items/1496210/book-a-o-neville-australia-s-colouredminority-its-place-in-the-community-currawong-publishing-co-1947.

${ }^{760}$ Commonwealth of Australia, 'Bringing Them Home: National Inquiry into the Separation of Aboriginal and Torres Strait Islander Children from Their Families' (Government Report, Human Rights and Equal Opportunity Commission, 1997) 524, 31.

${ }^{761}$ National Library of Australia, Bringing Them Home Oral History Projects (2013) Oral Projects <http://pandora.nla.gov.au/pan/133365/20120410-1246/www.nla.gov.au/oh/bth/index.html>; State of Tasmania, 'Stolen Generations of Aboriginal Children Act 2006: Report of the Stolen Generations Assessor' (Government Report, Office of the Stolen Generations Assessor, Department of Premier and Cabinet, February 2008) 30, 4-5. The force removal of Aboriginal children did not only occur in NSW, but across Australia. Between 1998 and 2002, the National Library of Australia (NLA) chronicled over 300 interviews of Indigenous Peoples and others involved in or affected by the process of child removals. Before the 1930s Indigenous children living in and around Cape Barren were not disturbed. As such, Tasmania had no specific race policies for Indigenous children (see, the Adoption Act 1920 (Tas)). However, creation of child welfare legislature between 1935-1975 saw the force removal of Aboriginal children from their families (see the Infants Welfare Act 1935 (Tas); Adoption Act 1968 (Tas) and the Child Welfare Act 1960 (Tas)). In 2006, the State of Tasmania established the Stolen Generations of Aboriginal Children Act, an AUD $\$ 5$ million fund to enable the Tasmanian government to make ex-gratia payments to members of the stolen generations. The question of whether the objective of this Act has been achieved cannot be attended to adequately given constrains of the dissertation. 
Aborigines Welfare Board 'snatched' baby Joy from her mother and placed her in the United Church's Bomaderry Aboriginal Children's Home. At the age of four and a half years, Joy was transferred to the Lutanda Children's Home at Wentworth Falls. There she remained until she was 18 years old, subject to s7 (2) of the Aborigines Protection Act 1909-43. However, the cycle of forced adoption did not stop with Joy.

Joy's experience exemplifies the profound intergenerational trauma associated with forced adoption. ${ }^{72}$ Like her mother, young Joy grew up in an institution, and she later became a trained nurse in Sydney. Joy had a daughter, like her mother, who was also taken away by the New South Wales Department of Child Welfare. Eventually, Joy's daughter found her. However, as for her grandmother and mother, forced separation created a lifelong legacy of pain and suffering. ${ }^{763}$ Though Joy went on to be a successful author and poet, earning a Master of Arts degree in Creative Literature in 1989, her fight for justice was impossible. Joy initiated Australia's first Aboriginal compensation test case in 1993, based on three generations of family history. She sued the New South Wales government for negligence, breach of fiduciary duty, breach of statutory duty and trespass against the Aboriginal Welfare Board for her removal, psychiatric injury, and harm whilst in care. ${ }^{764}$ Joy lost her case in the Supreme Court in August 1999. ${ }^{765}$ Her appeal to the New South Wales Court of Appeal in 2000 also failed. Finally, the High Court of Australia rejected her application for leave to appeal on 22 June 2001. ${ }^{766}$ Joy is not alone in her struggle for justice, healing and restoration.

A search for justice for the Stolen Generation has garnered apology from some political figures, but no reparation scheme has been created. After decades of the abuse of Indigenous Peoples, on 10 December 1992, at the launch of the International Year of the World's Indigenous Peoples, Prime Minister Paul Keating delivered his Redfern speech. Keating admits that 'we did the dispossessing, we took the traditional lands and smashed the traditional way of life, we brought the diseases and the alcohol, we committed the murders, we took the children from their mothers...' ${ }^{767}$ On 21 March 2013, former Prime Minister Julia Gillard delivered another solemn national apology for forced adoption of Aboriginal Peoples in Australia on behalf of Australia's settler-colonist government. In an emotionally charged environment, Gillard said she was sorry for forced adoption or removal policies and practices. Gillard acknowledged that, 'today this Parliament on behalf of the Australian people takes

\footnotetext{
${ }^{762}$ Read, above n 754 , xiv-xv.

${ }^{763}$ Ibid.

${ }^{764}$ Williams $v$ The Minister, Aboriginal Land Rights Act 1983 and Anor [1999] NSWSC 843

${ }^{765}$ In his ruling, Judge Abadee held, 1) there was no duty of care, breach of duty or relevant causation established. The plaintiff's action in negligence failed; 2) No trespass was established. No private action for breach of statutory duty was available; 3 ). Assuming a fiduciary relationship (not decided) there was no breach of fiduciary duty. In any event had a fiduciary duty or breach of fiduciary duty been established there would have been a basis for denying equitable compensation by reason of laches, prejudice or delay; 4) Any assessment of damages or equitable compensation was highly speculative, however, a 'contingent' assessment of damages was appropriate in the circumstances; and 5) There was no entitlement to exemplary or aggravatory damages in any contingent assessment (see Williams $v$ The Minister, Aboriginal Land Rights Act 1983 and Anor above).

${ }^{766}$ Read, above n 754, xxvii-xxviii. Also see, the AustLit biographical page of Joy Williams.

<http://www.austlit.edu.au/austlit/page/OLD?id=A1 gy\&idtype=oldid $>$

${ }^{767}$ Keating, above n 490 .
} 
responsibility and apologises for the policies and practices that forced the separation of mothers from their babies which created a lifelong legacy of pain and suffering..., ${ }^{768}$ Although former Prime Minister John Howard refused to apologise to The Stolen Generation, ${ }^{769}$ remorse expressed by Keating and Gillard produced some positive outcomes in the states of New South Wales ${ }^{770}$ and South Australia, ${ }^{771}$ but not without critique. ${ }^{772}$ However, a National Stolen Generation Reparations scheme is yet to be established. ${ }^{773}$ In Nulyarimma v Thompson 1999, even though the Federal Court of Appeal acknowledged that many Indigenous Peoples were wiped out by 'exotic disease', 'direct killing' and 'removal' from their families, the 'social devastation' it caused is not considered genocide. ${ }^{774}$ Hence the case was dismissed. Questioning whether the 'moral gene' of white Australians is being protected, Colin Tatz asserts that genocide denialists 'are not men with credentials in history, or in any other disciplines [because] they won't be writing the textbooks for our schools and university curricula. ${ }^{975}$ Tragically, the creation of a reparations scheme was hindered when it became clear that one of the effects of removing children from their families was an increased vulnerability to sexual abuse and exploitation at the hands of the institutions that were supposed to protect them.

\subsubsection{Social Services and Child Abuse}

Children have always been vulnerable to adults' neglect and abuse, whether by forced marriage, denial of access to social services or forcibly conscripted as child soldiers during the war and violent conflict. ${ }^{776}$ In Australia, the removal of Aboriginal children as a form of genocide and

\footnotetext{
${ }^{768}$ Commonwealth of Australia, 'Bringing Them Home: National Inquiry into the Separation of Aboriginal and Torres Strait Islander Children from Their Families', above n 761, 4; Gillard, above n 489; Frederick Douglass, Narrative of the Life of Frederick Douglass (Anti-Slavery Office, 1845) 2. The long-suffering alluded to in Gillard's National Apology can be felt through the expressions of a confidential submission made to the Human Rights and Equal Opportunity Commission's National Inquiry into Separation of ATSI children from their families: 'Our life pattern was created by the government policies and are forever with me, as though an invisible anchor around my neck. The moments that should be shared and rejoiced by a family unit, for [my brother] and mum and I are forever lost. The stolen years that are worth more than any treasure is irrecoverable'. Former slaves returning to Liberia had experienced separation from their mothers for centuries past. Frederick Douglass, the great African-American abolitionists and reformist, once wrote, 'My father was a white man. He was admitted being such by all I ever heard speak of my parentage. The opinion was also whispered that my master was my father; but of the correctness of this opinion, I know nothing; the means of knowing was withheld from me. My mother and I were separated when I was but an infant - before I knew her as my mother. It is a common custom, in the part of Maryland from which I ran away, to part children from their mothers at a very early age'.

${ }^{769}$ Australian News, John Howard Restates Opposition to Indigenous Apology (You Tube, 2008)

<https://www.youtube.com/watch?v=pn4I-NhhR1w>.

${ }^{770}$ Aboriginal Affairs, Stolen Generation Reparations Scheme and Funeral Assistance Fund (2017) New South Wales <https://www.aboriginalaffairs.nsw.gov.au/healing-and-reparations/stolen-generations/reparations-scheme>.

${ }^{771}$ Department of State Development, Stolen Generations Reparations Scheme (2017) Government of South Australia $<$ https://statedevelopment.sa.gov.au/aboriginal-affairs/stolen-generations-reparations-scheme>.

${ }^{772}$ Barta, above n 734, 209.

${ }_{773}$ Australian Human Rights Commission, 'National Stolen Generations Reparations Scheme Needed' AHRC Media Releases (Sydney, NSW), 21 November 2017 <https://www.humanrights.gov.au/news/media-releases/nationalstolen-generations-reparations-scheme-needed>.

${ }^{774}$ Nulyarimma $v$ Thompson [1999] FCA 1192, paras 5, 6.

${ }^{775}$ Colin Tatz, 'Confronting Australian Genocide' (2001) 25 Aboriginal History 16, 34.

${ }^{776}$ Peter W Singer, Children at War (University of California Press, 2006) 19, 77, 82-83. According to Singer, the UN reports that 27000 children were combatants during the Liberian civil war, 80 per cent of which were direct combatants. Fourteen-year-old Z recounts his experience: 'My missions included diamond mining near Kono [Sierra Leone], drug purchasing, collecting ammunition in Liberia, looting villages and capturing civilians. I used to buy drugs at the Liberian border from a man called Papi. They forced us to take them. This is where they would cut and put the 'brown-brown' [cocaine mixed with heroine and gun powder]. We would then inhale cocaine. During
} 
eugenics. Placement against their will with white foster parents, on missions, and in religious institutions condemned them to sexual and physical abuse, leaving traumatic scars that will last for generations. ${ }^{777}$ For 35 years, the Aboriginal Legal Service of Western Australia has been striving for Aboriginal justice through reparation schemes. One concern they share in advocating for reparations for the forced removal of Aboriginal children in institutional care is that 'the extent of institutional child sexual abuse against Aboriginal children will be underreported to the Commission [the Royal Commission into Institutional Response to Child Sexual Abuse]. ${ }^{778}$ Alice Barter, Sarouche Razi and Victoria Williams ${ }^{779}$ describe the primary problem in Redress Western Australia:

\begin{abstract}
[Aboriginal Legal Service of Western Australia] submitted over 1000 redress applications and participation in the scheme was traumatic for all involved. The primary issue that arose in [Western Australia] was the strong sense of injustice over the change in compensation offered by the State Government and the fact that the quantum offered was extremely low. When the scheme was first announced, the maximum payment available under the scheme was $\$ 80$ 000. However, when the number of applications and potential costs became apparent, the Government reduced the upper ceiling to $\$ 45000$. Given this significant and unexpected change, combined with the fact that the amount was lower than what was potentially available under victim compensation schemes, and drastically lower than damages payable in a successful civil litigation matter, there was a sense of injustice in the community. Gulmina Miocevich, Managing Solicitor of the Civil and Human Rights Unit at [Aboriginal Legal Service of Western Australia] during [Western Australia's] redress scheme, described it as 'a slap in the face...it was a complete betrayal of trust. It left a bitter taste in everyone's mouth from there onwards.' From the Government's perspective, the reasons behind the somewhat arbitrary monetary figure were pragmatic, as there would be significant evidentiary problems with claims and there was a huge potential cost to the Government in providing large amounts of compensation. ${ }^{780}$
\end{abstract}

Stolen Generation children were often moved into mission schools run by the church, which made Aboriginal children vulnerable to abuse by members of those institutions. In Australia, a recent report of the Royal Commission into Institutional Responses to Child Sexual Abuse identified nearly 1880 alleged perpetrators (diocesan and religious priests, religious brothers, religious sisters, lay employees or volunteers) in claims of child sexual abuse. ${ }^{781}$ The Catholic Church authorities show the highest number of alleged perpetrators by religious status, they include priests, religious brothers and lay people of the Archdiocese of Melbourne and the

\footnotetext{
operations, I sometimes would take it two or three times a day. I felt strong and powerful. I felt no fear. When I was demobilised, I felt weak and cold and had no appetite for three weeks'.

${ }^{777}$ Royal Commission into Institutional Responses to Child Sexual Abuse, 'Analysis of Claims of Child Sexual Abuse Made With Respect to Catholic Church Institutions in Australia' (Royal Commission into Institutional Responses to Child Sexual Abuse, 2017) 282, 12-13

$<$ https://childabuseroyalcommission.gov.au/getattachment/f0b33690-aea6-4f56-9e12-88e72157273f/Analysis-ofclaims-of-child-sexual-abuse-made-with>.

${ }^{778}$ Alice Barter, Razi Sarouche and Victoria Williams, 'Why the Caged Bird Sings: Issues with the Royal Commission into Institutional Responses to Child Sexual Abuse' (2014) 8(13) Indigenous Law Bulletin 7.

${ }^{779}$ The Redress Western Australia (WA) Scheme was established by the Government of WA to acknowledge and apologise to adults who, as children, were abused and/or neglected whilst they were in the care of the state. It ran from 2008 to 31 December 2011 (see, http://www.findandconnect.gov.au/ref/wa/biogs/WE00505b.htm\#tab5).

${ }^{780}$ Barter, Sarouche and Williams, above n 779.

${ }^{781}$ Royal Commission into Institutional Responses to Child Sexual Abuse, 'Analysis of Claims of Child Sexual Abuse Made With Respect to Catholic Church Institutions in Australia', above n 777, 15.
} 
Christian Brothers in Australia. ${ }^{72}$ Whilst the Royal Commission into Institutional Responses to Child Sexual Abuse recommends that appropriate redress for survivors should include: direct personal response; counselling and psychological care, and payments, it did not hold the Catholic Church criminally liable. ${ }^{783}$

Difficult socio-economic situations increase Native children's vulnerability to sexual abuse. For Indigenous communities in both Liberia and Australia, not only is child sexual abuse significantly higher than in non-Indigenous communities, but the degree of under-reporting is also severe. ${ }^{784}$ For instance, of 566 incident reports of child sexual abuse analysed in two Indigenous jurisdictions in Australia, 125 cases (22.1 percent) were from Indigenous children and 441 (77.9 cases) were from non-Indigenous children. ${ }^{785}$ Low reporting of sexual abuse against Indigenous children reduces access to services and increases neglect as the cycle of abuse continues.

It is clear from the literature that the intergenerational systematic violence perpetrated by the state against Aboriginal Peoples extends from Australia's convict history through to the present day. Cultural stereotypes enabled state policies that resulted in the massacres of Aboriginal Peoples. Those massacres gave way to a system of segregation and genocidal eugenics enshrined in law that continued to destroy Aboriginal families and disrupt Aboriginal culture for nearly a century. The effects of those programs further enabled structural violence against Aboriginal children as clergy and other adults in power at mission schools and other foster homes sexually abused and exploited Aboriginal girls and boys. However, the state policy of forced adoption is not the only social determinant predisposing Aboriginal women and girls to sexual violence. Looking for more intersecting factors, the next sections consider these factors starting from the level of interpersonal violence, rape and intimate partner abuse.

\subsubsection{Rape}

Rape has been perpetrated by Aboriginal and non-Aboriginal men in Australia, against Aboriginal and non-Aboriginal women and girls, but the penalties for Aboriginal men were often more severe. The prevalence of inter-racial sexual crimes in colonial New South Wales resulted in the execution of many Aboriginal men. According to Fred Cahir and Ian Clark, ${ }^{786}$ even though white offenders of attempted rape received two years of hard labour, Aboriginal men were hanged. Moowattin was the first Indigenous man executed for raping a white woman in 1812. The State of New South Wales hanged Mickey Mickey and transported Charley Myrtle

\footnotetext{
${ }^{782}$ Ibid.

${ }^{783}$ Royal Commission into Institutional Responses to Child Sexual Abuse, 'Final Report Recommendations' (Government, Commonwealth of Australia, November 2017) 115, 51-55, 73

<https://www.childabuseroyalcommission.gov.au/recommendations>.

${ }^{784}$ Cate Bailey, Martine Powell and Sonja Brubacher, 'Reporting Rates of Child Sexual Abuse in Indigenous

Communities in Two Australian Jurisdictions' (2017) 68 Child Abuse \& Neglect 74, 74.

${ }^{785}$ Ibid 76.

${ }^{786}$ Fred Cahir and D Ian Clark, 'The Case of Peter Mungett: Born out of the Allegiance of the Queen, Belonging to a Sovereign and Independent Tribe of Ballan' (2009) 8 Provenance: The Journal of Public Record Office Victoria 15.
} 
to Van Diemen's Land for life in 1835, also for rape. Paddy, an Aboriginal man, received capital punishment for rape in 1854. ${ }^{787}$ Peter Mungett, a member of the Marpeang Baluk clan, was brought before the criminal sessions in Melbourne on a charge of rape against a 6-year-old non-Aboriginal girl. On 20 February 1860, Mungett was found guilty and sentenced to death.7

Rape as a form of systematic violence is not confined to Indigenous communities but rather is perpetrated by both Aboriginal and non-Aboriginal men. ${ }^{789}$ Therefore, rather than dealing with simplistic dichotomies (e.g., rape by Aboriginal men versus rape by non-Aboriginal), the research seeks to assess the issue of systematic violence holistically as a common but relevant scourge in society.

Susan Brownmiller believes that from prehistoric times to the present, rape has played a critical function, being nothing more than a conscious process of intimidation by which all men keep all women in a state of fear. Brownmiller goes on to say that from the humblest beginnings of the social order based on a primitive system of retaliatory force (i.e., the lex talionis: an eye for an eye), woman was unequal before the law. ${ }^{700}$ Brownmiller argues that not only might women be subjected at will to a thoroughly detestable physical conquest for which there could be no retaliation in kind (vis-à-vis a rape for a rape), but the consequences of such a brutal struggle might be death, injury, impregnation or the birth of a dependent child. ${ }^{791}$ Brownmiller asserts that 'female fear of an open season of rape, and not a natural inclination toward monogamy, motherhood or love, was probably the single causative factor in the original subjugation of women by man, the most important key to her historic dependence, her domestication by protective mating. ${ }^{{ }^{7} 92}$

Brownmiller's ground-breaking work, Against Our Will, was written in 1975. In 2017, the United Nations Children's Fund report that around 120 million girls worldwide, just over one in 10, still experience 'forced intercourse or other forced sexual acts' at some point in their lives $^{793}$ is troubling. Whilst rape and sexual abuse against girls and women are everyday violent occurrences affecting close to a billion women and girls over their lifetimes, law and policy intended to protect or prevent such violence are often insufficient, inconsistent, not systematically enforced, and sometimes even promote more violence against them. ${ }^{794}$ Patricia Smith assesses two pervading concerns of rape law: 1) that the law tends to protect male

\footnotetext{
${ }^{787}$ Ibid.

${ }^{788}$ Ibid.

${ }^{789}$ Lani Brennan and Hazel Flynn, Lani's Story: Not a Victim. A Survivor (HarperCollins, 2013); Joan Kimm, A Fatal Conjunction: Two Laws, Two Cultures (Federation Press, 2004) <http://www.amazon.com/Fatal-Conjunction-TwoLaws-Cultures/dp/186287509X/ref=sr_1_1?s=books\&ie=UTF8\&qid=1361924786\&sr=1-

$1 \&$ keywords=a+fatal+conjunction>; Cathy Eatock, 'End Violence against Aboriginal Women' [2013] (954)

Greenleft Weekly <https://www.greenleft.org.au/content/end-violence-against-aboriginal-women>.

${ }^{790}$ Susan Brownmiller, Against Our Will: Men, Women, and Rape (Fawcett Columbine, 1st Ballantine Books, 1993) 16.

${ }^{791}$ Ibid.

${ }^{792}$ Ibid.

${ }^{793}$ Equality Now, 'The World's Shame: The Global Rape Epidemic - How Laws Around the World Are Failing to Protect Women and Girls from Sexual Violence' (Private Report, Equality Now, 2017) 68, 5

<https://www.equalitynow.org/sites/default/files/EqualityNowRapeLawReport2017_Single\%20Pages.pdf〉.

${ }^{794}$ Ibid.
} 
interests in pursuing sexual intimacy; and 2) men fearing that women could bring false charges against them. ${ }^{75}$ Though legitimate concerns, Smith opines that such a focus has virtually no recognition of women's competing interest in the self-determination of their own intimate relations. ${ }^{796}$ Thus, a major problem with rape law, according to Schulhofer as noted by Smith, is its failure to recognise women's right to sexual autonomy, which requires freedom of choice, the right to accept and decline sexual advances. ${ }^{797}$

The legal definition of rape affects the core of women's right to control their own sexual relations. Data obtained from 11 focus group sections held in Victoria, Australia, shows that 'many participants were critical that the rape definition effectively maintains the onus on a rape survivor to unequivocally demonstrate non-consent'. ${ }^{798}$ According to Larcombe, a legal definition of rape in Australia exonerates an accused who 'reasonably believes in consent'. The assumption that a woman reasonably consented to rape is shrouded with myths and stereotypes held by cultural beliefs propagated mostly by men. Larissa Gabrielle Johnson says, 'rape myths include attitudes and beliefs that are generally false but are widely and persistently held, and that serve to deny and justify male sexual aggression against women' ${ }^{799}$ Such male aggression is not restricted to sexual offenders but is also pervasive in law, policy, and the court system. This is an example of how cultural violence infiltrates the legal system to result in laws that codify that violence and contribute to its persistence. A case in point is that of a 15-year-old Aboriginal girl in the Northern Territory of Australia.

In the case of Jackie Pascoe Jamilmira, the structural violence of cultural stereotypes combined with the machinations of the legal system to deny justice to an Aboriginal girl survivor of rape. According to Sonia Shah, a state judge defended the right of an Aboriginal man (Jackie Pascoe Jamilmira) to have sex with an underage girl, claiming it was a 40000 -yearold traditional practice. This judgement set off a national debate over the role of culture in practices that deny women autonomy. ${ }^{800}$ It was reported that the girl's parents had 'promised' her as a wife to the man, who was later convicted of slaughtering his former wife. When the girl resisted his advances, she said, he punched her, 'put his foot onto my neck' and raped her. ${ }^{801}$ When the police arrive to arrest Pascoe, he brandished a shotgun to showcase his bravery and confidence. ${ }^{802}$ Fearing for her safety the young girl declined to speak with prosecutors, though

\footnotetext{
${ }^{95}$ Smith, 'Four Themes in Feminist Legal Theory: Difference, Dominance, Domesticity, and Denial', above n 77, 95.

${ }^{796}$ Ibid.

${ }^{797}$ Ibid.

${ }^{798}$ Wendy Larcombe et al, “'I Think It's Rape and I Think He Would Be Found Not Guilty': Focus Group Perceptions of (Un)reasonable Belief in Consent in Rape Law' (2016) 25(5) Social \& Legal Studies 611, 1.

${ }^{799}$ Larissa Gabrielle Johnson and Anthony Beech, 'Rape Myth Acceptance in Convicted Rapists: A Systematic Review of the Literature' (2017) 34 Aggression and Violent Behavior 20, 1.

${ }^{800}$ Sonia Shah, 'Judge Rules Rape of Aboriginal Girl "Traditional"' Women's eNews (North Queensland, Australia),

29 November $2002<$ http://womensenews.org/2002/11/judge-rules-rape-aboriginal-girl-traditional/>.

${ }^{801}$ Ibid.

${ }^{802}$ Ibid.
} 
the judge was able to press rape charges against Pascoe. ${ }^{803}$ Government-sponsored legal aid lawyers provided Pascoe's defence, netting him a nominal 24-hour-sentence on appeal. ${ }^{804}$

Moral relativism applied by a white anthropologist was instrumental in reducing Pascoe's sentence. Expert testimony submitted by an anthropologist in the case called the man's arrangement with the girl 'traditional' and therefore 'morally correct' ${ }^{805}$ The judge ruled that a 15-year-old Aboriginal girl 'knew what was expected of her [and] didn't need protection' when a 50-year- old man committed statutory rape against her and shot a gun into the air when she complained about it. ${ }^{806}$ Several high-ranking government officials nodded with approval when the appeal judge upheld Pascoe's defence, explaining that whilst Pascoe knew he had done something wrong in the eyes of western law, his conduct was 'Aboriginal custom' and part of his culture. ${ }^{807}$ The above case is yet another sad example that such violence is justified and supported by men and the law. It also exemplifies a legal system upholding the myth that sexual violence is widespread and acceptable in Aboriginal cultures.

Contrary to widespread belief, ${ }^{808}$ Indigenous cultures do not condone abuse, despite Aboriginal children and women's relatively high vulnerability to family violence. ${ }^{809}$ Cases of fatal rape cited in chapter one corroborate this fact, that all societies, ethnicities and classes denigrate and abuse children and women. ${ }^{810}$ Notwithstanding, the unique risk factors and attributes of persistent systematic gender violence against Indigenous girls and women make it challenging to prevent and eradicate. Larissa Behrendt elaborates,

[s]exual abuse of women and children has never formed part of traditional cultural practices and is considered abhorrent by Indigenous men and women of all generations. Sexual abuse and violence are behaviours that are learned, and studies and reports have found them to be generational and cyclical; abusers have often been victims of abuse themselves. (...) The colonisation of Australia left a legacy of abuse in many Indigenous communities. In 1898, a Northern Territory judge proposed laws to prohibit European settlers from kidnapping Aboriginal children "for the purpose of having carnal knowledge or intercourse" on stations far away from their homelands. The recent report on abuse in the Northern Territory by Pat Anderson and Rex Wilde, Little Children are Sacred, observed that the sexual abuse of children has not only been perpetrated by Aboriginal people, the report said, "The phenomenon knows no racial, age or gender borders. It is a national and international problem". ${ }^{811}$

It should be noted that it is not in all cases that the legal system endorses stereotypes and myths of sexual violence in Aboriginal culture. In her article 'Speaking About Rape is Everyone's Business', Diane Bell cites a case in the Northern Territory of Australia where the

\footnotetext{
${ }^{803}$ Ibid.

${ }^{804}$ Ibid.

${ }^{805}$ Ibid.

${ }^{806}$ Ibid.

${ }^{807}$ Ibid.

${ }^{808}$ Gender Relations in Aboriginal Society: What Can We Glean from Early Explorers' Accounts?, 19915

<http://www.anu.edu.au/polsci/marx/interventions/gender.htm>.

${ }^{809}$ Sue Gordon, Kay Hallahan and Darrell Henry, 'Putting the Picture Together, Inquiry into Response by

Government Agencies to Complaints of Family Violence and Child Abuse in Aboriginal Communities' (2002) 7(4)

Australian Indigenous Law Reporter 49.

${ }^{810}$ Fraenkel, above n 39, 145-150.

${ }^{811}$ Larissa Behrendt, Indigenous Australia for Dummies (For Dummies, a branded imprint of Wiley, 2012) 411.
} 
presiding judge doubts that forcible sexual intercourse is normative behaviour in Aboriginal culture. In $R v$ Dennis Narjic $1988^{812}$ :

Dennis Narjic of Port Keats, Northern Territory had pleaded guilty to four counts of rape of one young Aboriginal woman and to two of another young woman in 1986. When defence counsel indicated that the pre-sentence report would canvass the customary elements of the case, viz the tribal elders had indicated that there was 'little likelihood of any payback', Mr. Justice Maurice asked: Are you telling me it's normative behaviour to have forcible sexual intercourse with your wife's younger sisters...never once have I had a glimmer that it's normal part of cultural life for Aboriginal people to treat women in this way...for the kind of sadistic behaviour involved... ${ }^{813}$

Rape is one form of interpersonal or community violence, although it is clear that structural and state violence can also play a part in denying Aboriginal women and girls the justice they deserve. However, rape is not the only prevalent form of violence against women in their families and communities. Domestic violence perpetrated by women's intimate partners is also a dominant source of systematic violence, and cultural and state factors are also at work in those situations.

\subsubsection{Domestic, Family, Intimate and Community Violence}

Intimate partner violence against women includes any violence (physical, sexual, psychological, or emotional) or use of threat by a partner or a former partner. Partner violence against women is defined as physical, sexual or emotional abuse with coercive control of a woman by a man or a woman who is, or was, in an intimate relationship with the woman. ${ }^{814}$ Intimate partner abuse, often used interchangeably with the terms 'domestic violence' and 'intimate partner violence', is 'behaviour occurring within the context of a relevant relationship that is physically, sexually, emotionally, psychologically or economically abusive, threatening, coercive, controlling or dominating and causes a person to fear for their safety or wellbeing or that of someone else' ${ }^{815}$ Approximately four decades ago, before it gained attention in community public health, family violence was seen as a private home affair requiring no little or no interference from the state or legal system. ${ }^{816}$ Now, intimate partner abuse is strongly correlated with deleterious physical and mental health consequences in survivors, leading to post-traumatic stress disorder, substance abuse, suicide, sexually transmitted diseases and traumatic brain injury. ${ }^{817}$

Unfortunately, this type of abuse is prevalent in Australia. The Australian Bureau of Statistics's Bridging the Data Gaps for Family, Domestic and Sexual Violence, Australia (2005)

\footnotetext{
${ }^{812} R$ v Dennis Narjic (Unreported, NT Supreme Court, 1988).

${ }^{813}$ Diane Bell, 'Speaking about Rape Is Everyone's Business' (1989) 12(4) Women's Studies International Forum 403.

${ }^{814}$ Naira Kalra, Gian Luca Di Tanna and Claudia García-Moreno, 'Training Healthcare Providers to Respond to Intimate Partner Violence against Women' [2017] (2) Cochrane Database of Systematic Reviews 1, 1.

${ }^{815}$ Anna Towler, Areana Eivers and Ron Frey, 'Warning Signs of Partner Abuse in Intimate Relationships: Gender Differences in Young Adults' Perceptions of Seriousness' [2017] Journal of Interpersonal Violence 088626051769686, 2.

${ }^{816}$ Fadwa Al-Yaman, Family Violence Among Aboriginal and Torres Strait Islander Peoples (Australian Institute of Health and Welfare, 2006) 1.

${ }^{817}$ Towler, Eivers and Frey, above n 816, 2.
} 
estimates that 40 percent of all women (3 065 800) and 50 percent of men (3 744 900) had experienced some form of violence. In 2011-12, 6.4 million incidents of physical or threatened assault occurred, affecting an estimated 1.1 million people in Australia. ${ }^{818} \mathrm{~A}$ further 19.1 percent (1 469500 ) of women and 5.5 percent (408 100) of men from the above survey experienced sexual violence; of which 1.7 million constituted violence from a current and previous partner in their lifetime, and of these, 76 percent were women. ${ }^{819}$

Intersecting factors of gender, age, ability and mental health all contribute to the vulnerability of women in abusive relationships. An Australian study examining 49 males and 152 females between the ages of 18 and 26 reveal that females were more likely to rate all early warning sign behaviours (i.e., dominance-possessive, denigration, and conflict-retaliation) more seriously than males. ${ }^{820}$ Findings from a study carried out by Gary Byrne confirm that children and adults with intellectual disability are at a higher risk of abuse than their non-disabled peers. ${ }^{821}$ Another Australian study of 109 high school girls, ages 14-17, found not only that more physical and sexual violence is associated with longer relationship length but also that depressive symptom contributed significantly to recent domestic violence experiences. ${ }^{822}$ The Government of Victoria's establishment of the Royal Commission into Family Violence reflects the importance of the issue. Findings and recommendations of the Victoria Government's Royal Commission into Family Violence show that over the past five years the number of family incidents recorded by Victoria Police increased substantially, from 53633 in the year ending September 2012 to 78819 in the year ending September 2016.

Aboriginality is also an intersecting factor that increases the risk of women facing intimate partner abuse, which comes at a significant cost to the state. In Australia, Aboriginal women are 35 times more likely than non-Indigenous women to sustain a serious injury requiring hospitalisation due to violence committed by a spouse or partner. ${ }^{824}$ The cost of domestic violence alone in 2002-03 was $\$ 8.1$ billion, with the largest cost ( $\$ 3.5$ billion) resulting from pain, suffering and premature mortality. ${ }^{825}$ Nearly a decade later, the Department of Families, Housing, Community Services and Indigenous Affairs expressed serious concerns over the extremely high economic cost caused by violence against women. In 2009, an

\footnotetext{
${ }^{818}$ Australian Bureau of Statistics, 'Bridging the Data Gaps for Family, Domestic and Sexual Violence, Australia' (Government Report, Australian Bureau of Statistics, 2013) 68, 2

<http://www.abs.gov.au/ausstats/abs@.nsf/Lookup/4529.0.00.002main+features132013>.

${ }^{819}$ Ibid.

${ }^{820}$ Towler, Eivers and Frey, above n 816, abstract.

${ }^{821}$ Gary Byrne, 'Prevalence and Psychological Sequelae of Sexual Abuse among Individuals with an Intellectual Disability: A Review of the Recent Literature' [2017] Journal of Intellectual Disabilities 1, 1.

${ }^{822}$ Christie J Rizzo et al, 'Individual and Relationship Characteristics of Adolescent Girls With Histories of Physical Dating Violence' [2017] Journal of Interpersonal Violence 1, 1-2.

${ }^{823}$ Sarah Coghlan and Melanie Millsteed, 'Identifying the Differences between Generalist and Specialist Family Violence Perpetrators: Risk Factors and Perpetrator Characteristics' (2017) 8 Crime Statistics Agency Briefing Note 1,1 .

${ }^{824}$ Australian Bureau of Statistics, 'Defining the Data Challenge for Family, Domestic and Sexual Violence Australia' (Government Report 4529.0, Australian Bureau of Statistics, 2013) 79, 12 <http://www.abs.gov.au/ausstats/abs@.nsf/mf/4529.0/>.

${ }^{825}$ Al-Yaman, above n 817, 1.
} 
estimated $\$ 13.6$ billion was spent on violence against women; a figure predicted to increase to $\$ 15.6$ billion by $2021 .{ }^{826}$

Andrea Pickett's story of intimate partner abuse captures the vulnerability of women, especially when cultural biases intersect to prevent effective law enforcement. Domestic abuse against Aboriginal women in Australia is a 'sick situation [that] is severely perverted', says Marcia Langton. ${ }^{827}$ According to the Australian Bureau of Statistics' National Aboriginal and Torres Strait Island Social Survey 2008, of the 171048 Aboriginal women aged 15 years and over surveyed, 25 percent (42 255) experienced physical violence in the last 12 months leading up to the survey. Of this group, 32 percent identified a current or previous partner, and 28 percent a family member, as the perpetrator of their most recent incident of physical assault. ${ }^{828}$ Unfortunately, unlike Lani Brennan, ${ }^{829}$ Andrea Louise Pickett did not survive to tell the story of abuse she suffered at the hands of her husband. As a matter of fact, Andrea's case is one of 'very few, if any, inquests into domestic violence-related homicides of Aboriginal women that have been held, despite the high rate of homicides and evidence of systematic failures'. ${ }^{830}$

Andrea was married to Kenneth Charles Picket for 23 years and bore him three children. In 2008, she finally gathered the courage to leave her husband, citing domestic violence and abuse as the reason. Kerry O'Brien affirms that 'with a demonstrably violent husband threatening again and again to kill her, she repeatedly went to police and other agencies for help. They failed her. In fear and despair, she predicted her death and she was proved right' ${ }^{3}{ }^{81}$ On 12 January 2009, Andrea was stabbed to death on the front lawn of a relative's house in North Beach, Western Australia by her estranged husband. According to the Coroner's report at the time of her death, Kenneth was on a violence restraining order intended to protect Andrea and

\footnotetext{
${ }^{826}$ The National Council to Reduce Violence against Women and their Children, 'The Cost of Violence against Women and Their Children' (Government Report, Department of Families, Housing, Community Services and Indigenous Affairs, March 2009) 84, 5

<https://www.dss.gov.au/sites/default/files/documents/05_2012/vawc_economic_report.pdf>.

${ }^{827}$ Gail Boserio, 'Domestic Abuse of Indigenous Women a "National Crisis"' Australian Broadcasting Corporation (Sydney, NSW), 4 May 2015 <http://www.abc.net.au/radionational/programs/latenightlive/crisis-of-domestic-abuseof-indigenous-women/6442954>.

${ }^{828}$ Australian Bureau of Statistics, 'National Aboriginal and Torres Strait Islander Social Survey, 2008' (Government Report, Australian Bureau of Statistics, 2013) 119, 42-43 <http://www.abs.gov.au/ausstats/abs@.nsf/mf/4714.0/\#>.

${ }^{829}$ Brennan and Flynn, above n 790. In her book, (Lani's Story), Lani Brennan, an Aboriginal woman of Maori and Murri heritage, recounts how she escaped a physically and sexually abusive relationship and later survived the criminal justice system for four years in search of justice. On Lani's book promo video, a Crown Prosecutor disclosed, 'she's [Lani] been hit with iron bar, bottle, hammer, chisels, golf club, had an electric cord tied around her neck' (see http://www.harpercollins.com.au/9780732293482/lanis-story).

${ }^{830}$ Australian Human Rights Commission, 'Independent Interim Report on CEDAW: Australian Human Rights Commission Report to the Committee on the Elimination of All Forms of Discrimination against Women' (Government Report, Australian Human Rights Commission, 31 August 2012) 25, 54

<http://www2.ohchr.org/english/bodies/cedaw/docs/followup/ngos/AHRC_Australia.pdf>. Of interest to note here is that the relatively high neglect on the part of government service to address domestic violence in Western Australia does not tally with the exponential rate at which it occurs. The Western Australian Coroner's Inquest into the Death of Andrea Louise Pickett states domestic and family violence incidents steadily increased from approximately 22000 in 2005 to 35 000, a 59 per cent increase in just five years. As signatory to CEDAW, Australia is required subject to Article 18, to submit report, at least every four years and further whenever the Committee so requests, legislative, judicial, administrative or other measures which they have adopted to give effect to the provisions of the Convention.

${ }_{831}$ Quentin McDermott, A Matter of Life and Death (News 24, ABC iView, 2012).
} 
was paroled on a charge that he had threatened to kill Andrea. ${ }^{832}$ 'Why was so little done by police, prisons, parole services, the courts and child protection departments to stop her predictable, brutal murder? ${ }^{9}{ }^{83}$ Quentin McDermott and Peter Cronau's question regarding the failure of the law and the law enforcement agency to protect Andrea casts doubt on whether she is part of the 'all are equal under the law' principle of the rule of law. ${ }^{834}$

It might seem acceptable to dismiss Andrea's case as an outlier. However, consider that the life of each individual the law protects is valuable, irrespective of race, colour or national or ethnic origin (s10 of the Racial Discrimination Act). But sadly, comments made by individuals in A Matter of Life and Death highlight structural factors that ultimately denied Andrea the social protections otherwise guaranteed by the state for effective social services and law enforcement: ${ }^{835}$

Unfortunately, a number of the first times Andrea made complaints to the police, it didn't appear as though her complaints were taken seriously. Richard Bannerman, Lawyer for Andrea's Family

One in two women are still being turned away from crisis accommodation and so we worry; we're concerned about what happens for those women. I think we've had two new refuges funded in the metropolitan area in about 20 years and so with the population growth, with the increased demand, refuges cannot possibly cope with being able to accommodate. Angela Hartwig, Western Australia Domestic \& Family Violence Council

She had been to the police. Crisis Care couldn't help her; she had too many kids for 'em and no way was she splitting them because she thought he'd use the kids against her. I know he's going to do it [kill me] and she said one way or another he'll do it. Lorraine Bentley, Andrea's mother

Look as an Aboriginal person in Western Australia, one of the most redneck states probably in the world, it's just standard procedure for us; you're not gonna get help from the police, you know, when it comes to dealing with our issues. Dennis Simmons, Andrea's Cousin

As a father, as a husband and as a former police officer, I'm very sorry ah in relation to what happened to Mrs. Pickett and her extended family. Um but I want to reassure the people of Western Australia that the government hasn't been sitting back idly waiting for a coroner's report...there have been some fundamental failures on behalf of a number of government departments in respect to this. Murray Cowper, Western Australia Minister for Corrective Services

When Andrea Pickett most needed help, officers here at Mirrabooka Police Station failed to provide it, and as a result, Kenneth Pickett was free to hunt her down and kill her. As anger grew over the failings in the system which had enabled him to carry out

\footnotetext{
${ }^{832}$ Western Australia Coroner, 'Inquest into the Death of Andrea Louise Pickett' (Coroner Inquest, Perth Coroners Court, 2012) 64, 3 <http://www.aph.gov.au/DocumentStore.ashx?id=f5aa63db-14c1-4ef4-9705-

02e $10 \mathrm{e} 7 \mathrm{fdb} 42 \&$ subId $=303034>$.

${ }^{833}$ McDermott, above n 832.

${ }^{834}$ Official Response to Andrea Pickett and Saori Jones from Karl J O'Callaghan, 'Response to Four Corners from Western Australia Police', July 2012 1-2

<http://www.abc.net.au/4corners/documents/domestic2012/WA_Police_Response.pdf >. In his response to Four Corners, the Commissioner of Police, WA (Karl J O'Callaghan) elaborates Western Australia Police approach in curbing over 42000 incidents of family and domestic violence across the state in financial year 2011. The report also highlights the significant reduction in homicides involving family and domestic relations from 19 in 2002 to 112012 (at the time of completing the report). Whether the lower death rates is as a result of the WA Police Department's direct effort to address domestic violence against Indigenous women is beyond the scope of the chapter.

${ }^{835}$ McDermott, above n 832.
} 
his crime, changes were announced in the way the police respond to threats of domestic violence. Quentin McDermott, Four Corners Reporter

As in the rape case described above, cultural stereotypes and structural problems combined with ineffective or biased institutions to deny justice and protection for Andrea Pickett. However, it is also important to recognise how state violence affects Aboriginal communities in ways that promote interpersonal violence.

The marginalisation and disenfranchisement of Aboriginal men, often perpetrated by the state, is a determining factor in the prevalence of intimate partner abuse. The main reasons that domestic violence against Indigenous girls and women result in a disproportionately higher mortality rate lie in the historical, political, social and cultural contexts within which it occurs. 'High unemployment, low economic status, poor housing and overcrowding, poor health, high mortality, poor governance in local communities, and a lack of support services ... ${ }^{936}$ are all results of Australia's colonial legacy and contributing factors that increase incidence rates of domestic violence. Alcohol and drug abuse are also closely linked to domestic violence. ${ }^{837}$ In Judy Atkinson's Beyond Violence, when asked, '[w] hy are men violent?' a research participant from Western Australia responded: 'men are unhappy - no job - angry - bored - they feel they have nothing. They don't talk about their problems, not to anyone, so they drink, and the grog lets them take it out on their women' ${ }^{838}$ Discriminatory policies of wage dispossession, land dispossession, and human rights violation are all social determinants of Aboriginal health that lead to the depression and anger described by Atkinson's research participant.

\subsubsection{Stolen Wages}

Perceived as 'children' requiring 'parental' care, settler-colonists felt the need to redeem Indigenous Peoples from themselves by 'managing' their monies, property, and other possessions. ${ }^{839}$ As employers of Aboriginal Peoples in Australia, states, territory governments and their agencies (e.g., Aboriginal Protection Boards) were empowered ${ }^{840}$ to withhold up to 75 percent of earnings of any property belonging to tens of thousands of Aboriginal Peoples for

\footnotetext{
${ }^{836}$ Al-Yaman, above n 817, 3-4.

${ }^{837}$ Anders, above $\mathrm{n} 527,17$.

${ }^{838}$ Judy Atkinson, Beyond Violence: Finding the Dream (The Aboriginal and Islander Sub-program, National Domestic Violence Education Program, Office of Status of Women, 1990) 14.

${ }^{839}$ John Thomas Bigge, 'Report of the Commissioner of the Inquiry on the State of Colony of New South Wales' (Government Report, Colonial Parliament of New South Wales, 1822) 186

<http://www.jenwilletts.com/commissioners_of_enquiry.htm>. According to Judge and Royal Commissioner John

Bigge's recommendation concerning care of convict's property (including their money) on their arrival in the colony, convicts '...Clothes and Beddings should be taken care of on their Landing and that the Money belonging to Individuals be taken and deposited... and not allowed to be held by the Superintendent or any other person'.

${ }^{840}$ Mark Copland, 'Stolen Wages - An Opportunity for Justice?' (Background Report, Australian Catholic Social Justice Council, 2006) 8, 2-3 <http://www.socialjustice.catholic.org.au/publications/discussion-guides/60-stolenwages-an-opportunity-for-justice>; Rosalind Kidd, Trustees on Trial: Recovering the Stolen Wages (Aboriginal Studies Press, 2006) 27. Pursuant to the Aborigines Act 1869 (NSW); Industrial Schools Act 1867 (TAS); Aboriginal Protection and Restriction of Sale of Opium Act 1897 (QLD); Aborigines Act 1905 (WA); Aborigines Act 1910 (Vic); Aborigines Act 1911 (SA); and the Native Welfare Act 1963 (WA), the Chief Protector of Aboriginals became the legal guardian of every child under 21 years even when parents were living, with power to authorise adoption or marriage.
} 
well over 150 years. ${ }^{841}$ The 'safe-keeping' of Aboriginal finances included the management of funds they had earned through sweat and blood (often splashed with violence and abuse). ${ }^{842}$ In addition to a formal apology and the return of \$40 million of some \$187 million underpaid during an 11-year period, ${ }^{843}$ the Human Rights and Equal Opportunity Commission sought information about stolen wages between 1975 and 1986. The main concerns of the Human Rights and Equal Opportunity Commission, which was conducted by the Senate Legal and Constitutional References Committee, were claims of racial discrimination regarding underpayment of wages to Aboriginal Peoples. ${ }^{844}$ In the conclusion of its Inquiry into Stolen Wages, the Senate Legal and Constitutional References Committee recommended that the Commonwealth government fund the establishment of a national oral history and archival research project in order to aid Indigenous Peoples in Australia who were subjected to protection regimes in telling their stories as evidence for receiving repayment monies from the government. ${ }^{845}$

Following complaints of racial discrimination against Aboriginal Peoples in Queensland, the court in Bligh and Others $v$ State of Queensland (1996) (otherwise known as the Palm Island Stolen Wages Case) found that six of the complainants experienced discrimination by the State. ${ }^{846}$ Commissioner William Carter concluded that,

I am more than comfortably persuaded that in the case of each of the above complainants that they were afforded less favourable terms of employment and less favourable conditions of employment than those offered by another employer to other persons having the same qualifications and employed in the same circumstances on work of the same description. The complainants were demonstrably the victims of racial discrimination. The sole source of that discrimination was in each case the fact that each was an Aborigine.

Commissioner Carter's affirmation of differential treatment based on the complainant's Aboriginal identity affirms that the program was outright racist and patronising.

\footnotetext{
${ }^{841}$ Department of Aboriginal Affairs, Stolen Wages Reparation Scheme WA (2012) Stolen Wages <http://www.daa.wa.gov.au/en/Stolen-Wages/>.

${ }^{842}$ Reynolds, above n 126, 35; Queensland AnTAR, 'Queensland Stolen Wages Fact Sheet' 1

<http://www.reconciliation.qut.edu.au/issues/recweek/StolenWagesFactSheet.pdf >. Reynolds narrates an exchanged between George Augustus Robinson (1791-1866) and a bunch of stockmen whilst en route to take up a new position as Chief Protector of Aborigines in 1938: 'Robinson concluded that the general feeling towards the Aborigines was fierce and hostile. The [stock] men openly asserted that they would not hesitate to "get rid" of the blacks provided they could do so without detection... The overlanders wished them 'to be burnt-hung-drown- by any means they wished them got rid of'.

${ }^{843}$ Copland, above n 841, 4.

${ }^{844}$ The Human Rights and Equal Opportunity Commission, 'Submission of the Human Rights and Equal Opportunity Commission to The Senate Legal and Constitutional References Committee: Inquiry into Stolen Wages S'

(Government, Human Rights and Equal Opportunity Commission, 1 August 2006) 10, 2

<https://www.humanrights.gov.au/inquiry-stolen-wages>.

${ }^{845}$ Standing Committee on Legal and Constitutional Affairs, 'Unfinished Business: Indigenous Stolen Wages'

(Government, The Senate, December 2006) 124

<https://www.aph.gov.au/ /media/wopapub/senate/committee/legcon_ctte/completed_inquiries/2004_07/stolen_wag es/report/report_pdf.ashx.>.

${ }^{846}$ Human Rights and Equal Opportunity Commission, 'Inquiry into Stolen Wages' (Human Rights and Equal Opportunity Commission, 2006) 10, 16 <https://www.humanrights.gov.au/inquiry-stolen-wages〉.
} 
The Queensland government estimate put wages stolen from Aboriginal Peoples throughout the $19^{\text {th }}$ and $20^{\text {th }}$ centuries at $\$ 500$ million in Queensland alone. ${ }^{847}$ To provide some redress for stolen wages of Aboriginal Peoples, the Western Australia Cabinet approved the establishment of the Stolen Wages Taskforce. The primary goal of the Stolen Wages Taskforce was to identify the scope and extent of stolen wages and to suggest policy options and administrative remedies for those affected. ${ }^{448}$ Having examined the practice of government control over Aboriginal Peoples' finances between 1905 and 1972, the Stolen Wages Taskforce arrived at two findings. First, direct control of Aboriginal Peoples' lives, property and monies were under the legal guardianship of the Chief Protector or Commissioner. Second, the most extensive control was common amongst those living on Government Settlements under the guardianship of the Chief Protector. ${ }^{849}$ Furthermore, three recommendations offered by the Stolen Wages Taskforce are crucial to this research. One, the Western Australia Constitution Act 1889 must be amended to recognise Aboriginal Peoples as the original inhabitants of Australia. Two, the state must establish an ex gratia 'common experience payment' scheme for survivors of stolen wages. Three, Australia must create a community healing program and provide therapeutic services for survivors, their families, and community members. ${ }^{850}$

A study conducted by Andrew Gunstone between 2008 and 2009 not only demonstrated that 'there had been a range of stolen wages practices imposed upon numerous generations of Indigenous Victorians', ${ }^{851}$ but also equally criticised the Queensland and the Western Australia stolen wages schemes for being insufficient in providing appropriate reparations to Indigenous Peoples. ${ }^{852}$ In Trustees on Trial: Recovering the Stolen Wages, Rosalind Kidd identifies 'coerced dependency' as a long-term impact of deliberate legal abuse and discrimination against Aboriginal Peoples with respect to stolen wages. Kidd argues that because 'Indigenous Peoples were hostage to the extraordinary discretionary powers of their colonisers, ${ }^{853}$ the Aboriginal Affairs Act (1965) made Aboriginal Peoples free from state control except for those selected as needing assistance by the magistrate. Although Aboriginal Peoples were supposed to be 'free from state controls', Kidd asserts that state power was still 'maintained overall personal finances and property, and over wages, terms and conditions of 5000 workers in the pastoral industry and 2500 on reserves'. ${ }^{854}$ In 1968, the Queensland government set wages of Aboriginal Peoples at less than 45 percent of the minimum amount for white families' ${ }^{855}$ Kidd's assertion

\footnotetext{
${ }^{847}$ Kidd, above n 841, 9.

${ }^{848}$ Stolen Wages Taskforce, 'Reconciling the Past: Government Control of Aboriginal Monies in Western Australia, 1905-1972' (Department of Indigenous Affairs, Western Australia, 2008) 108

<http://www.daa.wa.gov.au/Documents/Stolen\%20Wages/Report_of_the_Stolen_Wages_Taskforce_2008.pdf >;

Department of Aboriginal Affairs, above $\mathrm{n} 842$.

${ }^{849}$ Stolen Wages Taskforce, above n 849, 5-6.

${ }^{500}$ Ibid 7-8.

${ }^{851}$ Andrew Gunstone, 'Indigenous Stolen Wages and Campaigns for Reparations in Victoria' (2014) 8(12)

Indigenous Law Bulletin 3.

${ }^{852}$ Ibid.

${ }^{853}$ Kidd, above n 841, 22.

${ }^{854}$ Ibid 27.

${ }^{855}$ Ibid.
} 
supports Bligh's view that white Australian settlers' control over Aboriginal Peoples' lives and property did not stop with declaring them 'free from state control', but rather, sustained a coercive culture of dependency into 'inter-generational spokes' of trauma, domestic/family violence, apathy and 'slavery ${ }^{856}$ (as Stephen Gray refers to it). ${ }^{857}$ Unfortunately, not only has the state dispossessed Aboriginal Peoples of their wages, but their land has also been forfeit to the state since Australia's colonial beginnings.

\subsubsection{Native Title (The Mabo Case)}

The idea of terra nullius asserts that the land was devoid of human inhabitants before the arrival of settler-colonists, which gives the 'discoverers' the right to claim that land. Of course, this idea comes with the absurd implication that Aboriginal Peoples in Australia mysteriously 'appeared' from somewhere, ignoring their connection to that land for the previous 40000 years. Before Mabo shattered this Deceptive Act, Justice Blackburn affirmed in Miliripum v Nabalco Pty Ltd and the Commonwealth (the Gove Land Rights Case) 1971 that, 'Australian common law did not recognise native title and that the plaintiffs did not have rights which could be recognised as property rights in Australian law'. ${ }^{858}$ On 20 May 1982, Eddie Koiki Mabo (193692), a Torres Strait Islander from Mer, Murray Island, and four others filed a lawsuit in the State of Queensland claiming customary ownership of their land. ${ }^{859}$ On 3 June 1992, Mabo's case progressed from the Queensland Supreme Court to the High Court of Australia. The High Court held that the Queensland Coast Islands Declaratory Act $1985^{860}$ conflicted with s10 of the Racial Discrimination Act (Cth.) 1975. ${ }^{861}$ Hence, it was invalid (see Mabo v Queensland (No 1) (1988)). The High Court also ruled ${ }^{862}$ (on a six to one majority, Dawson dissenting ${ }^{863}$ ) that,

\footnotetext{
${ }^{856}$ Andrew Gunstone, 'Indigenous Stolen Wages: History and Reparations' < https://www.tasa.org.au/wpcontent/uploads/2014/12/Gunstone.pdf>.

${ }^{857}$ \{Citation

${ }^{858}$ Behrendt, above n 568, 204.

${ }^{859}$ Duncan Kennedy, 'Eddie Mabo, the Man Who Changed Australia' BBC News (London, UK), 6 June 2012 <http://www.bbc.com/news/magazine-18291022>.

${ }^{860}$ Behrendt, above n 568, 248. Note that the Queensland Coast Islands Declaratory Act 1985 (QLD) was passed during the litigation of Mabo (No 2) in an attempted to enforce Deceptive Act of Terra Nullius.

${ }^{861}$ Section 10 of the RDA (Rights to equality before the law) states (with the purpose of effecting Article 2 of the ICERD 1965): (1) If, by reason of, or of a provision of, a law of the Commonwealth or of a State or Territory, persons of a particular race, colour or national or ethnic origin do not enjoy a right that is enjoyed by persons of another race, colour or national or ethnic origin, or enjoy a right to a more limited extent than persons of another race, colour or national or ethnic origin, then, notwithstanding anything in that law, persons of the first-mentioned race, colour or national or ethnic origin shall, by force of this section, enjoy that right to the same extent as persons of that other race, colour or national or ethnic origin. (2) A reference in subsection (1) to a right includes a reference to a right of a kind referred to in Article 5 of the Convention. (3) Where a law contains a provision that: (a) authorizes property owned by an Aboriginal or a Torres Strait Islander to be managed by another person without the consent of the Aboriginal or Torres Strait Islander; or (b) prevents or restricts an Aboriginal or a Torres Strait Islander from terminating the management by another person of property owned by the Aboriginal or Torres Strait Islander; not being a provision that applies to persons generally without regard to their race, colour or national or ethnic origin, that provision shall be deemed to be a provision in relation to which subsection (1) applies and a reference in that subsection to a right includes a reference to a right of a person to manage property owned by the person.

${ }^{862}$ Racism No Way, Fact Sheet: Edward Koiki Mabo 1936-1992 (2015) Teaching Resources <http://www.racismnoway.com.au/teaching-resources/factsheets/54.html>.

${ }^{863}$ In para 2, Mabo v Queensland [No 2] (1992) 175 CLR 1, Dawson J was of the opinion that Aboriginal Title was a type of occupancy the existence of which depended on the permission of the Crown, the withdrawal of which (which was the same as the extinction of aboriginal title) might be effected by specific legislation or inferred from a course of action by the Crown inconsistent with the continued existence of Aboriginal Title; in this case any rights of the
} 
putting to one side the Islands of Dauar and Waier, the land leased to the Board of Missions and any land which was validly appropriated for use for administrative purposes the use of which is inconsistent with the continued enjoyment of the rights or privileges of the Meriam people under native title, the Meriam people are entitled as against the whole world to possession, occupation, use and enjoyment of the lands of the Murray Islands. ${ }^{864}$

Following the High Court decision in Mabo (No 2), the Commonwealth Parliament passed the Native Title Act 1993 (Cth.), enabling Aboriginal Peoples in Australia to claim traditional rights to unalienated land. According to the Federal Court of Australia, Native Title is the Australian legal system's recognition of Aboriginal Peoples in Australia's inherent right to lands and waters according to their Traditional Laws and customs. ${ }^{865}$

The significance of Mabo to this research lies in its connection to Indigenous women. Although Eddie Mabo did not live to see the outcome of his case, he left behind his wife and 10 children (including six daughters) and generations of Aboriginal women and men who remain in a struggle to repossess their stolen land from settler-colonists in Australia. Aboriginal Australians' fight for their land rights after Mabo includes the following cases: Wik Peoples (1996), ${ }^{866}$ Fejo (1998), ${ }^{867}$ Yanner (1999), ${ }^{868}$ Yarmirr (2001), ${ }^{869}$ Ward (2002), ${ }^{870}$ Yorta Yorta

Native inhabitants which might have existed in the land were not recognized by the Crown or were extinguished by the Crown on annexation.

${ }^{864}$ Mason C.J., Brennan, Deane, Toohey, Gaudron and McHugh JJ at para 2, Mabo v Queensland [No 2] (1992) 175 CLR 1.

${ }^{865}$ Federal Court of Australia, Native Title Guide (2015) Law and Practice <http://www.fedcourt.gov.au/law-andpractice/areas-of-law/native-title>. Further described by the FCA, Native Title may include co-existing rights of several Indigenous groups' right to access an area of land or participate in decisions concerning how the land or waters may be used. Native Title cannot be bought or sold. It can be transferred by Traditional Laws or customs, or surrendered to government, which can then pay compensation to the Native Title holders in the same way as it does when acquiring rights to other property.

${ }^{866}$ Wik Peoples v Queensland [2004] FCA 1306. In Wik, the High Court of Australia held that: (I) that the [pastoral] leases did not confer rights to exclusive possession of the areas on the grantees. (2) That the grants of the [pastoral] leases did not necessarily extinguish all incidents of Native Title in respect of the areas. The decision of the Federal Court of Australia (Drummond J): Wik Peoples v Queensland (1996) 63 FCR 450, varied.

${ }^{867}$ Fejo and Another on behalf of Larrakia People v Northern Territory v Northern Territory (1998) 195 CLR 96. In Fejo, the High Court of Australia held that, '(1) Native Title is completely extinguished by the grant of a freehold estate. The rights under fee simple are inconsistent with the continued existence of any form of Native Title and no co-existing or concurrent rights can survive; (2) the grant of freehold extinguishes Native Title permanently regardless of the land being held by the Crown in the future; (3) whilst the existence of Indigenous law is necessary to establish Native Title, it is not sufficient to invite recognition under the common law; (4) statutory rights under the Native Title Act are valuable rights that may warrant protection by injunctions. General principles of injunctive relief apply' (also see http://www.atns.net.au/agreement.asp?EntityID=1613). The HCA ordered the appellants to 1) 'remit the matter to the Full Court of the Federal Court of Australia to be dealt with consistently with the reasons for judgment of this Court; and 2) the appellants pay the respondents' costs of the proceedings in this Court'.

${ }^{868}$ Yanner v Eaton (1999) 201 CLR 351; 166 ALR 258. In Yanner, the High Court of Australia held that, '(1) the Native Title rights or interests relied on by the [Aboriginal] man had not been extinguished by the way in which the Fauna Conservation Act regulated the exercise of those rights...(2) [t] hat by the operation of s 211 of the Native Title Act and s 109 of the Constitution, the Fauna Conservation Act did not prohibit or restrict the [Aboriginal] man, as a Native Title holder, from hunting or fishing for the crocodiles he took for the purpose of satisfying personal, domestic and non-commercial communal needs'. The decision of the Supreme Court of Queensland (Court of Appeal) reversed.

${ }^{869}$ The Commonwealth of Australia v Yarmirr [2001] HCA 56. In Yarmirr, it was held by the High Court of Australia that, 'that native title rights and interests were capable of being recognised by the common law in respect of the sea and sea-bed beyond the low-water mark'. Decision of the Federal Court of Australia (Full Court): The Commonwealth $v$ Yarmirr (1999) 1010 FCR, affirmed.

${ }^{870}$ Western Australia $v$ Ward [2002] HCA 28. In Ward, it was held by the High Court of Australia that 'where claims are made under the NTA [Native Title Act] for rights defined in that Act the determination of native title rights and interests is governed by the Act. The Act provides for the partial extinguishment or suspension of native title rights... Native title rights and interests are a bundle of rights the individual components of which may be extinguished 
(2002), ${ }^{871}$ and Wilson (2002) ${ }^{872}$ These cases are testaments first, to the resilience of Indigenous Peoples; and second, to the double standard in the application of the principle of the rule of law regarding equality under the law. For Aboriginal Peoples in Australia, equality under the law principle applies differently, especially when it comes to settler-colonists control over their land. Whilst a safer aspiration of making the law efficient dwells in the idea of 'progressive realisation', Aboriginal Peoples' repossession of their land after Mabo is still a long time coming. For example, the most recent policy on Northern Australia not only epitomises paternalistic leadership ${ }^{873}$ but also suggests that '[n]ative title should be seen as a source of Indigenous economic opportunity, ${ }^{874}$ rather than as an inherent right. Beyond Native Title issues, recent policy in the Northern Territory has even stripped Aboriginal Peoples of the human rights they were entitled to under the Australian Constitution.

\subsubsection{Northern Territory Intervention, Little Children are Sacred}

The diverse sources of violence against Indigenous girls and women provide evidence that misery is not only Aboriginal girls and women's palava (business). ${ }^{875}$ In fact, the colonial legacy of systematic gender violence that Behrendt alluded to above is aptly articulated by Paul Wilson,

separately...resumption of land under s 109 [of the Constitution] did not extinguish native title'. Decision of the Federal Court of Australia (Full Court) Western Australia v Ward (2000) 99 FCR 316 reserved.

${ }^{871}$ Members of the Yorta Yorta v Victoria [1998] FCA 1606. In Yorta Yorta, it was held by the High Court of Australia that, " $[\mathrm{t}] \mathrm{h}$ e native title rights and interests that were the subject of the Act were those which existed at sovereignty, which survived that fundamental change in legal regime and which, by resort to the processes of the new legal order, could be enforced and protected'. Decision of the Federal Court of Australia (Full Court): Yorta Yorta Aboriginal Community v Victoria (2001) 110 FCR 244, affirmed.

${ }^{872}$ Wilson v Anderson (2002) 213 CLR 401; 190 ALR 313; 76 ALJR 1306. In Wilson, the High Court of Australia held that, 'it was inappropriate to answer the questions reserved otherwise than to say that, by the operation of ss $23 \mathrm{~B}$ and 23E of the NTA and s 20 of the Native Title (New South Wales) Act 1994 (NSW), the grant of the lease extinguished any Native Title in relation to the land covered by the lease and that the extinguishment was taken to have happened when the lease was granted...[t]here was sufficient material before the Court to provide substantial answers to the questions reserved. Questions (a) and (b) should be answered in the affirmative and question (c) that Native Title rights were extinguished, not suspended, by the grant of the lease at the time of that grant'. The questions asked (a) whether by virtue only of the Western Lands Act and regulations in force at the time of the lease, or (b) by virtue of the Act and those regulations and one or more of the terms and conditions of the lease, the lease conferred on the lessee a right to exclusive possession of the leased land; and if (a) or (b) is answered affirmatively, (c) whether any Native Title rights the exercise of which involved the presence on the leased land by the holders of Native Title were extinguished by the grant of the lease or suspended on its grant for its duration. Decision of the Federal Court of Australia (Full Court): Anderson v Wilson (2000) 97 FCR 453, reversed.

${ }^{873}$ Medhora, above n 377. Claiming to transform Northern Australia into an economic powerhouse with little or no sign of consulting Indigenous Australia, four grey-headed white men graced the cover of the online news. The Abbott government arrogance ranges from the release of AUD \$110m per year over a four-year period to expedite Native Title claims, to establishing Australia as a 'dam-loving' country, whilst at the same time, fast-tracking visas for Indian and Chinese temporary workers for ten years. Comments made by a reader called 'Halycon', captures the worrying effect of this White Paper: 'I wish our leaders would spend a few more weeks in northern Australia. They clearly don't know what they are talking about on some issues, such as water and soils. There does not seem to be any allowance in this plan for Indigenous employment and training. Whilst we are letting in potential workers from India and China and other places, we ignore the huge unemployment rate for Aboriginal Australians in the north. All the talk of dams and transport infrastructure are just rehashing of the last 100 years in the north. Look how long it took to finally get a railway from Adelaide to Darwin. These people (our politicians) must live in their own little dream world' (see, http://www.theguardian.com/business/2015/jun/18/northern-australia-plan-aims-to-make-region-aneconomic-powerhouse\#comments).

${ }^{874}$ Commonwealth of Australia, 'Our North, Our Future: White Paper on Developing Northern Australia' (Policy Document, Department of the Prime Minister and Cabinet, 2015) 189, 6

<https://northernaustralia.dpmc.gov.au/sites/default/files/papers/northern_australia_white_paper.pdf>.

${ }^{875}$ Bell, 'Speaking about Rape Is Everyone's Business', above n 814; Huggins et al, above n 561. In her article, 'Speaking about rape is everyone's business', Diane Bell expresses discontent for the 'resounding silence of social scientists' regarding rape against Aboriginal women by Aboriginal men. 
who noted that '[w]hites have, by political, legal and sometimes police action, created conditions which foster murder and assault in Aboriginal communities ... [and] [w]e cannot divorce the sense of hopelessness and futility that exists amongst Aborigines - born of dispossession and exploitation... ${ }^{876}$ Wilson's insightful analysis of a sui generis case of Peter Alwyn ${ }^{877}$ reveals a relatively high occurrence of violence in Aboriginal communities. As indicated by the testimony above and supported by examples of traumatising disenfranchisement, it would be overly simplistic to blame Aboriginal men for the relatively high incidence rates of violence in Indigenous societies. Nevertheless, without excusing Aboriginal male perpetrators of violent crimes committed against Aboriginal children and women, the state's reaction to that interpersonal violence can constitute an act of state violence in itself. A primary example of such state violence is Australia's Northern Territory Intervention.

On 15 May 2006, the Australian Broadcasting Corporation's Late-Line broadcasted 'Crown Prosecutor Speaks Out About Abuse in Central Australia'. In her interview with presenter Tony Jones, Nanette Rogers, then Crown Prosecutor in Alice Springs, Northern Territory, said,

I think there are a number of reasons for that [abuse in Central Australia]. The first is that violence is entrenched in a lot of aspects of Aboriginal society here. Secondly, Aboriginal people choose not to take responsibility for their own actions. Thirdly, Aboriginal society is very punitive so that if a report is made or a statement is made implicating an offender then that potential witness is subject to harassment, intimidation and sometimes physical assault if the offender gets into trouble because of that report or police statement. ${ }^{87}$

When asked to provide more details on the case of the rape of a two-year-old in 2004, Rogers responded,

Yes, the two-year-old was playing outside with some other children. Her mother was away from the house, drunk in a small town. The offender woke up, took the small child, carried it out bush, had the child out bush for some hours. Undressed the child and inserted, simultaneously, two fingers in her vagina and two fingers in her anus and moved his fingers up and down a number of times causing injuries. He then - I'm sorry, he had his trousers off while this was happening. Then he placed the child on his lap and had his penis next to the child's vagina and tried to masturbate and so on. And eventually returned the child back to his father's camp. He was carrying the child with

\footnotetext{
${ }^{876}$ Paul R Wilson, Black Death, White Hands (Allen \& Unwin, 1982) 9, 118-119. In his book, Paul Wilson assesses the trial of Alwyn Peter, a young Aboriginal man from Weipa South charged with killing his girlfriend. Interesting to note, as Wilson recounts, was that Bill O'Connor, the Public Defender of Peter chose to make his trial a test case by examining whether Alwyn's actions could be explained, if not justified, by historical events surrounding his life. In concluding his book, Wilson offers two choices in an attempt to addressing the issue of violence in Aboriginal community: 1) government should continue with the piecemeal reforms (improved Aboriginal health, housing, education, etc.,) even though there's a little change that result from it; and 2) Aboriginal people should have the right to determine their own future and to own their own land, unburdened by white officials and white rules. By so doing, '[o]nly then can we begin to erase from our collective conscience the guilt of all those black deaths that have, directly and indirectly, flowed from our white hands'.

${ }^{877}$ Ibid 1-2; Bernadette Brennan (ed), Just Words? Australian Authors on Writing and Justice (University of Queensland Press, 2008) 167-168. Alwyn Peter, a 24-year old Aboriginal man from Queensland was acquitted from stabbing his 19-year old girlfriend, Deidre Gilbert, to death. By the time Peter appeared in Court on 8 September 1981, he was the fifteenth Aboriginal male in three years (at the time) to have killed another Aboriginal person on an Aboriginal government reserve, where living conditions were said to have been 'intolerable from most white Queenslanders'. Also see, Rv Alwyn Peter Supreme Court of Queensland, Brisbane (Dunn J.) [1983].

${ }_{878}$ Australian Broadcasting Corporation, 'Crown Prosecutor Speaks out about Abuse in Central Australia', Lateline, 15 May 2006 <http://www.abc.net.au/lateline/content/2006/s1639127.htm>.
} 
its legs on the side. The child was crying throughout the assault. The child was still crying and bleeding. He handed the child to his drunken father. He himself had been drinking. The father then took the child back to the area that the child had been removed from and when the mother returned from town, where she'd been drinking, the child was crying, and the other children indicated that the offender had taken her away some time before and it was then that the bleeding and so on was noticed in her nappy. ${ }^{879}$

The former Crown Prosecutor's revelation of such 'horrific cases' ${ }^{880}$ of sexual assaults in Central Australia shocked many. Subsequently, the release of the Ampe Akelyernemane Meke Mekarle (Little Children are Sacred) Report (2007) ${ }^{881}$ served as a catalyst for the Commonwealth Government's launch of an emergency intervention response barely six days ${ }^{882}$ after the report was released: The Northern Territory Intervention. ${ }^{883}$ On 21 June 2007, Prime Minister John Howard announced a series of measures to be introduced in Aboriginal communities across the Northern Territory to address what it described as the 'national emergency confronting the welfare of Aboriginal children' on child abuse and family violence. ${ }^{884}$ The Northern Territory National Emergency Response Act 2007 (hereafter the Northern Territory Emergency Response $A c t$ ) formed the legal basis of the Northern Territory Intervention. ${ }^{885}$ Legitimising the Northern Territory Emergency Response Act meant that the Federal Parliament of Australia had to suspend the Racial Discrimination Act. In essence, the Howard government stayed provisions (precisely, Part II, ss 9 (1),,$^{886} 9(1 \mathrm{~A})^{887}$ and $\mathrm{s} 10^{888}$ ) of the Racial Discrimination Act so as to

\footnotetext{
${ }^{879}$ Ibid.

${ }^{880}$ Terri Libesman, Decolonizing Indigenous Child Welfare Comparative Perspectives (Taylor and Francis, 2013) 165 <http://public.eblib.com/choice/publicfullrecord.aspx?p=1576079>.

${ }^{881}$ Northern Territory. Board of Inquiry into the Protection of Aboriginal Children from Sexual Abuse, Wild and Anderson, above n 23, 16-18. Pursuant to the Inquiries Act 1945 (NT) (amended by the Act 2011 (NT), Rex Wild, QC and Patricia Anderson, an Alyawarr woman; were appointed co-chairs of the board of Inquiry into the Protection of Aboriginal Children from Sexual Abuse on 8 August 2006 (see, http://www.inquirysaac.nt.gov.au/tor.html). The Inquiry Board main term of reference was to 'examine the extent, nature and contributing factors to sexual abuse of Aboriginal children, with a particular focus on unreported incidences of such abuse'. Having held 260 meetings/consultations/forums with stakeholders across some 10 sub-regional communities in the Northern Territory coupled with 65 'strong' written submissions received from individuals and organisation the Board of Inquiry emphasised that '...the Inquiry has not spent its time investigating the extent and nature of all cases of alleged sexual abuse in the Territory'. Notwithstanding, 'the Inquiry accepts that sexual abuse of Aboriginal children is common, widespread and grossly under-reported'. Urging the Commonwealth government to lead and 'accept responsibility to protect our kids' because they are sacred, the Board of Inquiry's primary concern was twofold: 1) their dismay at the miserable school attendance rates for Aboriginal children and the apparent complacency with that situation; and 2) that unless alcoholism is conquered, there is little point in attending to any of the other recommendations made in the report. Alarmingly, the Howard government birthed the Northern Territory Intervention.

${ }_{882}$ Australian Human Rights Commission, 'Social Justice Report 2007' (Government Report 2, Office of the Aboriginal and Torres Strait Islander Social Justice Commissioner, 11 February 2008) 435, 205

<https://www.humanrights.gov.au/sites/default/files/content/social_justice/sj_report/sjreport07/pdf/sjr_2007.pdf〉.

${ }^{883}$ Behrendt, above n 568, 81-84.

${ }^{884}$ Australian Human Rights Commission, 'Social Justice Report 2007', above n 882, 197; Behrendt, above n 568, 71. ${ }^{885}$ Australian Human Rights Commission, 'Social Justice Report 2007', above n 882, 205-209. The Northern Territory Emergency Response is a package of policy changes to Aboriginal land rights, community living, alcohol usage, computer utility, welfare funding, cessation of applying Aboriginal customary law in bail/sentencing, deployment of the Australian Federal Police, amongst others. All five bills (480 pages long) containing legislations needed to enforce the NTI passed through the House of Representatives on the same day (7 August 2007) and received Royal Assent, thus enacted as legislation on 17 August 2007.

${ }^{886}$ Part II, Section 9 (1) of the RDA: It is unlawful for a person to do any act involving a distinction, exclusion, restriction or preference based on race, colour, descent or national or ethnic origin which has the purpose or effect of nullifying or impairing the recognition, enjoyment or exercise, on an equal footing, of any human right or fundamental freedom in the political, economic, social, cultural or any other field of public life.

${ }^{887}$ Part II, Section 9 (1A) of the RDA: Where (a) a person requires another person to comply with a term, condition or requirement which is not reasonable having regard to the circumstances of the case; and (b) the other person does not or cannot comply with the term, condition or requirement; and(c) the requirement to comply has the purpose or
} 
implement the Northern Territory Emergency Response Act in the Northern Territory. The 'legality' (or breach ${ }^{889}$ ) of such parliamentary procedure denied any protection afforded by the Racial Discrimination Act to Aboriginal Peoples in the Northern Territory who were subjected to the imposition of the Northern Territory Emergency Response Act.

In 2011, four years after the implementation of the Northern Territory Intervention, the Australian Human Rights Commission expressed five ongoing concerns regarding the 'special measures':

\begin{abstract}
Although, since the 2010 Welfare Reform Act, ${ }^{890}$ the Government has repealed the sections under the [Northern Territory Emergency Response] legislation that deemed the entire [Northern Territory Emergency Response] legislation to be a 'special measure', the Commission continues to be concerned about the characterisation of the measures as a 'special measure' under the [Racial Discrimination Act] for 5 key reasons: 1) the measures intentionally discriminate on the basis of race and were formulated without the appropriate participation and acceptance of Indigenous Peoples; 2) they were developed without an appropriate evidence base to show that the measures were required and likely to be effective; 3) simply stating that the measures are 'special measures' in an objects clause, rather than substantively redesigning the measures, does not satisfy the criteria necessary for a measure to be a 'special measure' - but may reduce the ability of the measures to be challenged under the [Racial Discrimination Act] because courts are required to interpret legislation consistently with its stated purpose; 4) there are inadequate mechanisms for monitoring and evaluating the previous and redesigned measures to ensure that they are working effectively and to determine whether their objectives have been met; and 5) the characterisation of fiveyear leases as a 'special measure' is inconsistent with the [Racial Discrimination Act]. ${ }^{891}$
\end{abstract}

Members of the Aboriginal communities in Intervention: Stories from the Inside (2007) exemplify the Australian Human Rights Commission's concerns. ${ }^{892}$ One said, 'ask Jenny

effect of nullifying or impairing the recognition, enjoyment or exercise, on an equal footing, by persons of the same race, colour, descent or national or ethnic origin as the other person, of any human right or fundamental freedom in the political, economic, social, cultural or any other field of public life; the act of requiring such compliance is to be treated, for the purposes of this Part, as an act involving a distinction based on, or an act done by reason of, the other person's race, colour, descent or national or ethnic origin.

${ }^{888}$ Part II, Section 10: If, by reason of, or of a provision of, a law of the Commonwealth or of a State or Territory, persons of a particular race, colour or national or ethnic origin do not enjoy a right that is enjoyed by persons of another race, colour or national or ethnic origin, or enjoy a right to a more limited extent than persons of another race, colour or national or ethnic origin, then, notwithstanding anything in that law, persons of the first-mentioned race, colour or national or ethnic origin shall, by force of this section, enjoy that right to the same extent as persons of that other race, colour or national or ethnic origin. (2) A reference in subsection (1) to a right includes a reference to a right of a kind referred to in Article 5 of the Convention. (3) Where a law contains a provision that: (a) authorizes property owned by an Aboriginal or a Torres Strait Islander to be managed by another person without the consent of the Aboriginal or Torres Strait Islander; or (b) prevents or restricts an Aboriginal or a Torres Strait Islander from terminating the management by another person of property owned by the Aboriginal or Torres Strait Islander; not being a provision that applies to persons generally without regard to their race, colour or national or ethnic origin, that provision shall be deemed to be a provision in relation to which subsection (1) applies and a reference in that subsection to a right includes a reference to a right of a person to manage property owned by the person.

${ }^{889}$ Australian Human Rights Commission, 'The Suspension and Reinstatement of the RDA and Special Measures in the NTER' (Government Report, Australian Human Rights Commission, 2011) 24, 6

<https://www.humanrights.gov.au/sites/default/files/content/racial_discrimination/publications/rdanter/NTERandRDAPublication12\%20December2011.pdf $>$.

${ }^{890}$ Schedule 1 of the Welfare Reform and Reinstatement of Racial Discrimination Act 2010 (Cth) basically repealed the laws limited anti-discrimination laws provided in the Northern Territory National Emergency Response Act 2007. ${ }^{891}$ Australian Human Rights Commission, 'The Suspension and Reinstatement of the RDA and Special Measures in the NTER', above n 889,4 .

${ }^{892}$ Tangentyere Research and Vincent Lamberti, Intervention: Stories From the Inside (Ronin Films, 2007). 
Macklin to send someone to my house to explain what pornography is because my son has never heard the word before' ${ }^{8}{ }^{83}$

Mary Spiers-William (criminal lawyer): There is no data. There is no means of tracking alcohol purchase. Personally, I have seen people drinking excessively on highways before they get back into town, which makes it more dangerous... The [Northern Territory Emergency Response] legislation allowed police to engage intrusively in a lawful way because this was a special act under the Racial Discrimination Act. ${ }^{894}$

Anhelke Namatjira's Camp (Frank Curtis): The [Northern Territory] intervention created more workload than the police can take. More people are going to jail; they will find a way to buy alcohol. They need to talk to the right people. They should have consulted before coming up with the law. We could have been working together. ${ }^{89}$

By 2012, the Northern Territory Intervention mutated into the Stronger Future Legislation, ${ }^{896}$ which extends the project another 10 years and creates a new set of challenges. ${ }^{897}$

The harmful effects of the Northern Territory Intervention have not gone unnoticed. Stop the Northern Territory Intervention ${ }^{898}$ and a petition signed by 43464 supporters in 2012 are two few resistance ${ }^{899}$ advocacies that brought attention to 'a policy that has attracted United Nations condemnation for its racial discrimination against Aboriginal Peoples and their cultures'. ${ }^{900}$ Ultimately, the Northern Territory Intervention exemplifies the continuation of paternalistic, state-sponsored policies that undermine Aboriginal human rights and further disenfranchise Aboriginal Peoples and disrupt Aboriginal families through police action and incarceration. The resulting intergenerational trauma caused by state violence, reinforced by the structural violence of stigmatisation and stereotypes of Aboriginal communities, are all social determinants of the health of Aboriginal Peoples. These negative health impacts affect Aboriginal women and children directly when their family's incomes are stolen, lands are removed, or family members are incarcerated. Indirectly, women and children are further affected when the disenfranchisement of the men in their communities predisposes them to substance abuse and acts of interpersonal violence, such as intimate partner abuse. However, these patterns are not confined to Australia; many parallels can be drawn when considering the plight of Indigenous children and women in Liberia.

\footnotetext{
${ }^{893}$ Ibid.

${ }^{894}$ Ibid.

${ }^{895}$ Ibid.

${ }^{896}$ The Stronger Futures in the Northern Territory Act 2012 aims to build stronger futures for Aboriginal people in the Northern Territory and for related purposes. From tackling alcohol abuse (Part 2) to land reform (Part 3) and food securities (Part 4) the Government of Australia is committed to using the law to control Aboriginal people.

${ }^{897}$ Nerida Currey, 'Barb Shaw Speaks on Stronger Futures Legislation'.

${ }^{898}$ Stop the NT Intervention, "Stronger Futures Legislation" (2012), available at: < http://stoptheintervention.org/facts/stronger-futures-legislation>.

${ }^{899}$ Staff Reporter, Stronger Futures Laws Condemned after Passing Senate (28 June 2012) ABC News

<http://www.abc.net.au/news/2012-06-29/stronger-futures-laws-rushed-through-senate/4100288>.

${ }_{900}$ Stand for Free, Australian Government: Stop 'Stronger Futures' and Support Aboriginal Self-Determination in the $N T$ (2012) Change.org <https://www.change.org/p/australian-government-stop-stronger-futures-and-supportaboriginal-self-determination-in-the-nt $>$.
} 


\subsection{Liberia}

As with convict history in Australia, a decolonisation perspective requires investigating the link between colonial violence against Indigenous Peoples in Liberia and the colonist's own slave history. The trans-Atlantic slave trade had a profound impact across Africa, the Americas and the Caribbean with a direct effect on Native Peoples in Liberia. Centuries of experience being shot, beaten, lynched ${ }^{901}$ raped and forcibly separated from one's parents and children ${ }^{902}$ suggest why African American settlers perpetrated similar violent behavioural patterns against Indigenous Peoples in Liberia.

Many afflictions befall Indigenous Peoples. Some are horrendously evil, whilst others are integrated into the habits of everyday life. The trans-Atlantic slave trade was one horrendous evil that inflicted centuries-long trauma, pain and suffering on Native Peoples of Africa. According to the trans-Atlantic slave trade database, between 1500 and 1800 , more Africans than Europeans arrived in the Americas, whilst recent research suggests that between 12 and 20 million Africans were transported as human cargo by Europeans and European colonists to the New World. ${ }^{903}$ Between 1600 and 1850, approximately 4.5 million enslaved Africans went to Brazil, 10 times as many as went to North America and more than the total number of Africans transported to the Caribbean and North America combined. ${ }^{904}$ It is estimated that 100 million Africans lost their lives as a result of the maritime slave trades. Notwithstanding, roughly 10 million survived the dreaded Middle Passage. ${ }^{905}$ As this illicit business rose in the 1840s, enslaved Native Peoples in Africa were transported disproportionately on ships made and registered in the United States and flying the United States' flag. ${ }^{906}$

The perception is that Indigenous Peoples in Africa, Europe and the Americas inflicted violence on Native Peoples in Africa during the slave trade. It is argued that Indigenous Peoples in Africa contributed to the slave trade, ${ }^{907}$ as chiefs and local West Africans conspired with Europeans to ship Native Peoples in Africa as articles of commerce (e.g., firearms, beads, and salt);08 across the Americas. ${ }^{909}$ Although they resisted with all their might, ${ }^{910}$ Native children and women were forcibly removed from their homelands, ${ }^{911}$ subjected to domestic servitude, ${ }^{912}$ sexually abused by their masters, and seen as lowlifes who were nonetheless exotic enough to

\footnotetext{
${ }^{901}$ Guannu, above n 100, 12.

${ }^{902}$ Staff Reporter, 'Archaeologists Find Graves Containing Bodies of 5000 Slaves on Remote Island: Africans Died in Custody of Royal Navy in 1800s, after Being Seized from Ships of Slave Traders, and Were Buried on St. Helena'

The Guardian (London, UK), 8 March 2012 http://www.theguardian.com/world/2012/mar/08/slave.

${ }^{903}$ Horne, above n 35, 2.

${ }^{904}$ Ibid.

${ }^{905}$ Henry Louis Gates Jr., Slavery Secret: 'Africans Sold Other Africans into Slavery' (PBS, 2010)

<https://www.youtube.com/watch?v=TtRaG_bokds>.

${ }^{906}$ Horne, above n 35, 3.

${ }^{907}$ Gates Jr., above n 906.

${ }^{908}$ Basil Davidson, The African Slave Trade (Little, Brown, A revised and expanded, 1980) 242.

${ }^{909}$ Ibid 40.

${ }^{910}$ Levitt, above n 105, 132. According to Levitt (2005), when Indigenous Kru and Grebo tried resisted assimilation, acculturation and subjugation by the African American settlers, President Joseph J. Cheeseman, ordered gunboat Gorronammah ('an African word signifying a new defence') built in Liverpool, to bombard Settra Kru, and all Kru boats unloading illegal cargo in 1894.

${ }^{911}$ Sawyer, The Emergence of Autocracy in Liberia, above n 61, 61.

${ }^{912}$ Kathleen E Sheldon, Historical Dictionary of Women in Sub-Saharan Africa (Scarecrow Press, 2005) 229-231.
} 
become sexual objects for wealthy Europeans. ${ }^{93}$ Whilst undergoing this abuse, stripped of every ounce of human dignity, Native Peoples in Africa 'became the creators of the wealth that made the flowering of capitalism possible in the nineteenth century'. ${ }^{914}$ It was not until some 400 years later that Indigenous Peoples in Africa 'escaped slavery, reunited with a lost fatherland, and established an imperial future [in Liberia]' ${ }^{91}$

As in Australia, the onset of Liberia's colonisation, riddled with frontier violence, racism, discrimination and land dispossession, uniquely predisposed Indigenous girls and women to systematic violence. ${ }^{916}$ When analysing violence against Indigenous women, it is important to understand that irrespective of income, age, or education, generally, females are more susceptible to physical, sexual, psychological and economic violence than males. Elijah Johnson's utterance in the above quotation regarding 'whipping' fellow Indigenous Africans upon arrival in Liberia bears witness to settler-colonists' mindset and intention to inflict violence upon Indigenous Peoples even before landing on their shores of the West African Coast.

Settler-colonists used military force, exile, and coercion (e.g., direct physical force; deportation and forced marriage ${ }^{917}$ to secure compliance from Native Peoples in Africa ${ }^{918}$ Former President Arthur Barclay affirmed the use of direct physical force in his inaugural speech (1904) when he said that, 'the militia, largely lower-class Americo-Liberians and tribal people ... was tending to become a greater danger to the loyal citizen and his property, which it ought to protect'. ${ }^{919}$ The aim here was to sever inter-Indigenous contact ${ }^{220}$ in response to Indigenous Peoples' resistance to government authority, as the Liberian State tried to establish full control over Native Peoples in Africa and their land. Eventually, Indigenous Peoples in Liberia lived with the dilemma of both acceptance and rejection alongside the settler-colonists' culture, which is deemed as superior to theirs to this day. ${ }^{9}$

The European Christianising project aided slave-trade and colonisation, as discussed in chapter 2; but Christians struggled to access the interior of Africa. ${ }^{922}$ For Liberia, this Christianising project took hold with the arrival of Black African colonist-settlers in 1822. Some of the progeny resulting from the rape of Indigenous slave girls and women by white slave owners settled in Liberia to become the elite mixed-race founding settler-colonists who

\footnotetext{
${ }^{913}$ Davidson, above n 909, 79. According to Davidson, 'in 1701 the value of British ex0orts of cotton goods and yarns stood at little more than 23,000, yet in 1800 the total was nearly 51/2 millions. Industrialism was born, and it was the West Africa trade in all its ramifications that helped to preside over the event'.

${ }^{914}$ Frazier, above n 432, 9-13.

${ }^{915}$ Kazanjian, above n 90, 54.

${ }^{916}$ United Nations, 'The World's Women 2015: Trends and Statistics', above n 630, 139.

${ }^{917}$ Anonymous, Liberia from 1930 to 1944: The Kru Campaign (2016) Liberia

$<$ http://personal.denison.edu/ waite/liberia/history/30-44.htm>. The circumstances of 'deportation' surfaced in the case of Chief Juan Nimley, removed from his Native Sasstown home and imprisoned in Gbarnga to curb his military activities against the settler government.

${ }^{918}$ Liebenow, above $\mathrm{n} 55,43$.

${ }^{919}$ Ibid 54.

${ }^{920}$ Ibid 55.

${ }^{921}$ Ibid 26-27.

${ }^{922}$ Davidson, above n 909, 23; Guannu, above n 100, 11.
} 
monopolised political power ${ }^{923}$ and offered citizenship to alien Negroes (e.g., the Congoes). ${ }^{924}$ In an effort to be accepted as citizens (a right that was denied) ${ }^{925}$ and to minimise tensions, Native Peoples in Liberia struggled to assimilate with settlers-colonists. At the same time, settlercolonists' desire to extend their dominance over the 'heathen savages' systematically dispossessed Native Peoples of their land.

At the core of assimilation, tensions were land tenure issues between settler-colonists and Native Peoples in Liberia, which led to violent conflicts both at the frontier and during their political regime. J Gus Liebenow provides some insights regarding dispossession of Native Peoples' land in Liberia to further illuminate the 'oppressed becomes the oppressors' view:

[The land tenure issue] was compounded by the subsequent failure of the settlers or the American Colonization Society to pay even the low prices agreed upon; by the seizure of land for alleged insults against the colonists or for non-payment of debts; and by constant disputes over land boundaries. The land question was subsequently complicated by the policies and practices in the use of native labor on the farms of Liberian settlers. The outrageous wage differentials, the lack of amenities, the unregulated power of farmers to 'fine' their employees and the abuses of the apprenticeship system under which young natives were assigned to Americo-Liberian families until they came of age created a situation in Africa not unlike the very one against which the repatriated Americo-Liberians had rebelled in America... ${ }^{926}$

Liebenow's observation not only affirms that the oppressed became the oppressors but it also attests to how, as humans, we are prone to the long-term effects of psychological and physical abuse. Such intergenerational trauma has destroyed Native Peoples' ability to thrive, recuperate and succeed in the face of ongoing injustice, discrimination and neglect. Notwithstanding, a

${ }^{923}$ Cooper, The House at Sugar Beach, above n 168, 6, 7, 10, 11 13, 15, 18, 19, 29, 30, 31, 36, 39, 41, 4-49, 52-56, 65-66, 75, 79-80, 84; Jerry Gbardy, Painful Journey: A Story of Escape and Survival (Friesen Press, 2014) 2; Personal from Samson Ceasar, 'Liberian Letters: Samson Ceasar to Henry F. Westfall 1834 June 2', 2 June 1834 $<$ http://search.lib.virginia.edu/catalog/uva-lib:501740>; Azikiwe, above n 301, 38; Shick, above n 170, 61. Cooper's memoir is littered with the resented phrase 'country people/children' over 60 times. It appears the resentment stems from the very notion of African chiefs selling their own into slavery, towards the rape of her mother and the execution of her uncle Cecil Dennis by former President Samuel Doe's soldiers. Gbardy's autobiographical piece opens with an interesting historical account of how his father, who served the Liberian Armed Forces (formerly the Liberia Frontier Force) and his cousins 'escaped the porter system in the hinterland in which Indigenous men were forced to carry Americo-Liberian government officials in hammocks to villages and towns with no motor roads'. The lack of infrastructure in the hinterland was highlighted by 28-year old Sampson Caesar, an emancipated slave from Virginia who arrived on Jupiter 1 January 1834. Barely six months after his arrival, he writes to a friend, 'I must say that I am afraid that our Country never will improve as it ort until the people in the United States keep their slaves that they have raised like as dumb as horses at home and send those here who will be A help to improve the Country as for Virginia as far as my knowledge extends I think She has sent out the most Stupid Set of people in the place whilst they have them their the cow hide is hardly ever off of their backs and when they come here they feel So free that they walk about from morning till evening without doing one Stroke of work by those means they become to Suffer people in the United States ort to have more regard for Liberia than to Send Such people here Some think that everything grows by in this Country without labour but they are mistaken...'. Sampson's observation is interestingly real today, as Liberia tops the fourth poorest country globally.

${ }^{924}$ Dunn and Holsoe, above n 104, 45. Dunn and Holsoe describe the Congo-re-captives (or Congoes) individuals who were captured by the American government navy ships flying the American flag. Most of these people were en route from Africa to the New World as slaves. One of the reasons why the United States government was willing to assume some of the financial expenses for the creation of Liberia was to find a secure haven at which to land the recaptured slaves. From the very beginning of the colony such individuals were brought to Liberia. The earliest group was settled at Thompson Town on the upper part of Cape Mesurado. A second important settlement was formed in 1824 at New Georgia on Stockton Creek. The largest contingent came in 1860, when over 4000 people landed. Since nearly all of these individuals came from the Congo River area, hence their name. Congo Settlements were formed along the coastal region of Liberia from Robertsport to Harper. In recent years, the term 'Congo' has come to refer to anyone, particularly in the rural communities who is of settler/Congo descent.

${ }^{925}$ Liebenow, above n 55, 27.

${ }^{926}$ Ibid 25. 
glimmer of hope lurks regarding a recent land rights policy in Liberia. A policy report released on 21 May 2013 by the Land Commission of Liberia affirms that, not only has there never been a clearly defined land rights policy in Liberia, but also, transfers of public land in the past substantiated poor 'land governance, corruption, political patronage and discriminatory treatment' against Native Peoples in Liberia ${ }^{927}$ Historically, Customary Land ownership in Liberia is not recognised as private land and duly protected because it is not deeded, and hence is deemed public. ${ }^{928}$ Therefore, the Liberian government can get away with dispossessing Native Peoples in Liberia of land they have survived on for centuries. The current land dispossession challenge in Liberia centres on various government concessions to large multinational extraction industries.

\subsubsection{Extraction from Indigenous Lands: the case of Firestone, Bong Mines, and}

\section{LAMCO}

Extractive industries in Liberia exemplify one means whereby the law can inflict systematic violence against Native Peoples. Liberian settlers' objective in forming colonies was to 'provide a home for the dispersed and oppressed children of Africa, [in efforts] to regenerate and enlighten this benighted continent, [it was decided that] none but persons of colour shall be admitted to citizenship in this Republic'. ${ }^{229}$ First and foremost, settler-colonists did not recognise Native Peoples in Africa (section 15, Article V, 1847 Constitution) as the original inhabitants of the land since they were not recognised as citizens of Liberia until 1904. Settler-colonists' claim to have purchased land from the Native Peoples in Africa through a fair deal (section 14, Article V, 1847 Constitution) is not substantiated by the numerous occurrences of frontier violence, which indicate that the land contracts were controversial at best. ${ }^{93}$

Since Native Peoples in Africa were dispossessed of their lands pursuant to section 14, Article V, of the 1847 Constitution, extraction industries such as Firestone, Bong Mines and Liberian-American Mining Company's ownership of Native lands in Liberia is questionable.

\footnotetext{
${ }^{927}$ Land Commission, 'Land Rights Policy' (Government Policy, Land Reform Commission, 21 May 2013) 26, 5, 9 $<$ http://www.sdiliberia.org/sites/default/files/publications/Liberia's\%20Land\%20Rights\%20Policy\%202013_0.pdf >. ${ }^{928}$ Ibid 6, 18.

${ }_{929}$ Article V, Section 13 is amended in the most recently revised Constitution of Liberia 1986, though the racist component still remains (see Chapter IV, Article 27 (a) and (b)). It reads, (a) [a]ll persons who, on the coming into force of this Constitution were lawfully citizens of Liberia shall continue to be Liberian citizens; (b) [i]n order to preserve, foster and maintain the positive Liberian culture, values and character, only persons who are Negroes or of Negro descent shall qualify by birth or by naturalisation to be citizens of Liberia. (Also see s13, Article V of the Liberian Constitution 1847)

${ }^{930}$ Jackie Sayegh, 'Support for Dual Citizenship in Liberia' (Annual Meeting at the Union of Liberian Association in the Americas - Wisconsin Branch Annual Conference, Madison, WI, 29 August 2013) <https://ulaalib.org/content/drjackie-sayegh-supports-dual-citizenship-liberia-0>. Sayegh profoundly expressed African American settlers in Liberia conscious efforts to deny Indigenous Peoples any constitutional right, in spite of their implied efforts: 'The Liberian Commonwealth Constitution of 1839 limited the privileges of citizenship to all coloured persons of the United States and its territories. The 1847 Constitution distinguished between the rights of citizens and Indigenous persons. As a result, the Indigenous Peoples were considered subjects, but not citizens, of Liberia. Hence, they were denied all the privileges that citizenship affords including land ownership, free movement within country, a say in the governing of the country, and the right to vote. This bond between the state and the individual was not granted to the Indigenous Liberians until 1904 (57 years after independence) and it was not until 1946 (99 years after independence) that Indigenous Liberians obtained the right to vote and participate in elections'.
} 
Melvin Johnson explains the state of land ownership in Native Liberia prior to settler-colonists arrival. According to Johnson, 'land can never be the possession of any individual ... [i]n tribal societies, the land is neither sold nor bought. Land apportioning to individuals is by family needs (e.g., construction of a home or establishing a farm) ${ }^{9} .{ }^{931}$ However, settler-colonists use their imported Anglo-American law and policy to steal and sell Native lands to foreigners for the extraction of natural resources and environmental exploitation. A case in point is that of Firestone Rubber Plantation.

In 1926, Harvey Samuel Firestone, an American businessman from Ohio sought to break Britain's monopoly over global rubber export. ${ }^{932}$ Capitalising on Liberia's economic debt crises, he lent \$5 million to the government of President Charles D B King (1920-1930) in exchange for one million acres of pristine virgin forestland at the cost of six cents per acre for a concession period of 99 years (1926-2025). As the largest rubber plantation in the world, Liberia's Firestone Rubber Plantation exports of unprocessed rubber is worth a little less than \$200 million a year, ${ }^{933}$ accounting for 99569 tonnes in 2002..$^{934}$ Following the establishment of the rubber industry in Liberia was the period of the Open Door Policy, ${ }^{935}$ at which time former President Tubman (1944-1971) led and sustained foreign investment concessions on Native Peoples' land. The Liberian Mining Company, Bong and the Liberian-American Mining Company were three prominent beneficiaries of Tubman's Open Door Policy.

The Liberian Mining Company concession agreement was concluded a year after President Tubman's inauguration in 1945. ${ }^{936}$ Between 1951 and 1977, the Liberian government received $\$ 84$ million (excluding rental) of the $\$ 540$ million worth of iron ore that the Liberian Mining Concession had shipped out of Liberia. By 1977, the ore deposits at Bomi Hills had been depleted and Liberia's oldest ore mining company closed its doors. ${ }^{937}$ What the Liberian Mining Company contributed to the development of rural Bomi and what the Liberian Government did with the revenue it received from the extraction of Bomi's ore are major questions of concern. ${ }^{938}$ The Bong Mining Company concession (now run by China Union) covers a 115 square km area between Bong Mine (Bong County) and Freeport (Montserrado County). The Bong Mining Company enjoys a 70-year-old agreement signed in 1958 between

\footnotetext{
${ }^{931}$ Melvin J Mason, Land and Language: Issues in Liberian Development (Brentwood Christian Press, 2005) 10-11. ${ }^{932}$ Benjamin S Lawson, ‘A 1930s African-American View of Liberia: George S Schuyler' (1995) XX(2) Liberian Studies Journal 247.

${ }^{933}$ Staff Reporter, 'Liberia Suspends Exports of Unprocessed Rubber' Reuters (Monrovia, Liberia), 19 April 2013 <http://www.reuters.com/article/2013/04/19/liberia-rubber-idUSL5N0D62RV20130419>.

${ }^{934}$ UN Mission in Liberia, 'Human Rights in Liberia's Rubber Plantations: Tapping into the Future' (UN Mission in Liberia, 2006) 88, 20 <http://www.refworld.org/docid/473dade10.html>.

${ }_{935}$ Fred PM van der Kraaij, The Open Door Policy of Liberia: An Economic History of Modern Liberia (Im Selbstverlag des Museums, 1983).

${ }_{936}$ Augustus M Bailey, Pieces of the Mind: My Experiences and Memories of Liberia (Xlibris, 2013) 18.

${ }^{937}$ Fred PM van der Kraaij, Iron Ore: The Start of Operations of Liberia's First Iron Ore Mine (2015) Liberia: Past and Present <http://www.liberiapastandpresent.org/ODP/IronOre/IronOreC.htm>.

${ }_{938}$ Ibid. Interestingly, the UN Human Development Index (2014) ranks Liberia at a 175 of 187 countries. Enough for development and growth in Liberia after many years of natural resources extraction (see,

http://hdr.undp.org/en/content/table-1-human-development-index-and-its-components).
} 
the Liberian Government and Delimco (a group of German and Italian investors). ${ }^{939}$ In 1955, although the concession agreement with the Liberian-American Minerals Company included the provision of social services for the local rural community, ${ }^{940}$ Bong County has little to show by way of development. Now operated by Arcelor Mittal ${ }^{941}$ (after the dissolution of Bethlehem Steel in 2001), the Liberian-American Mining Company operated for 26 years (1963-1989) and produced a total of 230 million metric tonnes of ores. ${ }^{942}$

Native Peoples in Liberia lament the continuous oppression and injustice they received from the settler-colonist government. ${ }^{943}$ Benjamin Lawson captures Native Peoples' experience of subjugation by settler-colonists writing that, '[a]n allegedly corrupt and exploitative Americo-Liberian minority.... [still] have not led to the creation of a truly better or "modern" state'. ${ }^{944}$ Back in 1966, even Swedish citizens at home questioned the validity of the LiberianAmerican Mining Company's claim regarding social service development in rural Liberia: '[w]hat is Granges Company doing in Liberia? Does LAMCO develop Liberia or exploit it ${ }^{945}-$ apart from human rights abuses and war crime allegations? ${ }^{946}$ In recent years, the extension of Firestone's concession to $2041^{947}$ and the initiation of Sime Darby's 63-year concession by President Sirleaf's government are also seen as a neo-liberal/neo-capitalist shift in the

\footnotetext{
${ }^{939}$ Bailey, above n 937, 19.

${ }_{940}$ Ibid 21; Mohammad Latifi, Multinational Companies and Host Partnership in Rural Development - A Network Perspective on the Lamco Case (PhD Thesis, Department of Business Studies, Uppsala University, 2004) 103-104 〈http://www.diva-portal.org/smash/get/diva2:165468/FULLTEXT01.pdf〉.

${ }^{941}$ Kay, above n 313. According to Kira Kay, PBS Special Correspondent, Arcelor Mittal, the world's largest steel company, started work in Liberia since 2007 with the aim of exporting 15 million tons of ore a year by 2015. Liberia received an up-front payment of $\$ 15$ million to this effect.

${ }^{942}$ International Business Publications, 'Liberia: Export-Import, Trade and Business Directory' (Private Document, International Business Publications, 2011) 294, 50-51.

${ }^{943}$ Staff Reporter, 'Arcelor Mittal Attack Is Attack on Liberia's Economy, Sirleaf Says' Front Page Africa (Monrovia, Liberia), 11 July 2014 <http://www.frontpageafricaonline.com/index.php/politic/2266-arcelormittalattack-is-attack-on-liberia-s-economy-sirleaf-says>; Mae Azango, 'Taking More, Giving Less - Nimba Decry Arcelor Mittal's Operation' Front Page Africa (Monrovia Liberia), 2014

<http://www.frontpageafricaonline.com/index.php/business-tech/280-ta...-more-giving-less-nimba-citizens-decryarcelor-mittal-s-operations>; UN Mission in Liberia, above n 934, 32-55; International Labour Right Forum, Stop Firestone Coalition Celebrates Victory as Liberian Supreme Court Decision Approves Union Election on Firestone Plantation (21 December 2007) Press Release <http://www.laborrights.org/releases/stop-firestone-coalitioncelebrates-victory-liberian-supreme-court-decision-approves-union>; William Rosenau et al, 'Corporations and Counterinsurgency' (Private Report, RAND National Defense Research Institute, 2009) 57, 17-24

<http://www.rand.org/content/dam/rand/pubs/occasional_papers/2009/RAND_OP259.pdf>; T Christian Miller, Jonathan Jones and ProPublica, Firestone and the Warlord: The Untold Story of Firestone, Charles Taylor and the Tragedy of Liberia (PBS Frontline, 2014); Patrice Taddonio, How We Uncovered Firestone's Deal with Charles Taylor - Firestone and the Warlord (18 November 2014) FRONTLINE

<http://www.pbs.org/wgbh/pages/frontline/inside-frontline/how-we-uncovered-firestones-deal-with-charles-taylor/>; William Baue, Alien Tort Claims Act Lawsuit Alleges Slavery and Child Labour on Liberian Plantation (30 December 2005) Social Funds Sustainable Investment News 47-69

$<$ http://www.socialfunds.com/news/article.cgi/1897.html>; Rodney Sieh, 'Firestone Mirred in Slave Labour Charges in Liberia' All Africa (Monrovia, Liberia), 21 November $2005<$ http://www.laborrights.org/in-the-news/firestonemirred-slave-labor-charges-liberia>; Lief, above n 59; Church, above n 59; Wayne C Taylor, The Firestone Operations in Liberia (National Planning Association, 1956); Niels Hahn, 'The Experience of Land Grab in Liberia' in Handbook of land and water grabs in Africa: foreign direct investment and food and water security (Routledge, 2012) 512.

${ }^{944}$ Lawson, above n 933.

${ }^{945}$ Latifi, above n 941, 106.

${ }^{946}$ Staff Reporter, 'Arcelor Mittal Attack Is Attack on Liberia's Economy, Sirleaf Says', above n 943; Azango,

'Taking More, Giving Less - Nimba Decry Arcelor Mittal's Operation', above n 943.

${ }_{947}$ See, An Act Ratifying the Amended and Restated Concession of Agreement Between the Republic of Liberia and Firestone Liberia Inc. 2008 and An Act Ratifying the Amended and Restated Concession of Agreement Between the Republic of Liberia and Sime Darby Plantation (Liberia) Inc. 2009.
} 
sophistication of the rubber and oil palm 'plantation slavery' industry. ${ }^{948}$ State-sponsored expansion of extraction industries in Liberia continues to disrupt Native Peoples' ways of life. The Christianising mission in Liberia has also left lasting detrimental effects on Indigenous children and women.

\subsubsection{Exploitation of Children}

Although the Australian state forcibly removed children from their homes to be educated in mission schools, Liberia's exploitation of children manifests as structural violence. As discussed in chapter 2, the Christianising mission to Liberia also brought Western education. Social and economic pressure on Native Peoples in Africa to move toward the mission schools along the coast, adopt biblical names, and assimilate into the settler-colonist communities was significant. A pull factor in this dynamic was that female settler-colonists, although also discriminated against by male immigrants, masterminded 'adoption' of 'country' and 'outside' ${ }^{949}$ wards in hopes of civilising them. ${ }^{950}$ However, this civilising effort was not particularly altruistic, as it usually involved domestic servitude and accompanying abuses.

\footnotetext{
${ }^{948}$ Sam Zota, Jr., 'At Sime Darby Plantation: Workers Drink from Creeks, Dwell in Makeshift Structures' <http://amazingliberia.blogspot.com.au/2011/07/at-sime-darby-plantation-workers-drink.html>; Richard Valdmanis, 'Exclusive: Resource Deals Audit Overshadows Liberia Anti-Graft Push' Reuters (Dakar), 1 May 2013 <http://www.reuters.com/article/2013/05/01/us-liberia-resources-idUSBRE9400QY20130501>; Staff Writer, 'Green Advocates Wants EPA Revoke Sime Darby’s Permit' Public Agenda News (Monrovia, Liberia), 2013 $<$ http://www.publicagendanews.com/index.php?option=com_content\&view=article\&id=3191:green-advocateswants-epa-revoke-sime-darbys-permit-\&catid=1:latest-news\&Itemid=2>; Green Advocates and Forest Peoples Programme, above n 228.

${ }_{949}$ Moran, above n 163, 59-60. Note that, 'country children' were perceived as 'full-blooded' Indigenous Liberians. 'Outside' children, on the other hand, are issues resulting from coupling between elite emigrant married men and their 'country-mistresses'. Some 'outside' children were issues of teenage girls serving as a 'house girl' in the homes of the upper-class Emigrants. As with the Plantation mentality, 'outside children' of repatriated men by their 'country mistresses' were, over time, merged into official family histories, augmenting the supposedly endogamous group without challenging the myth of 'pure' settler descent.

${ }^{950}$ Cooper, The House at Sugar Beach, above n 168, 29, 64-65,; Cooper, above n 168; Wendy Kann, 'Homecoming: A Journalist Returns to Africa to Find Her "Country Sister."' Washington Post (Washington, DC), 31 August 2008 http://www.washingtonpost.com/wp; Brown, above n 50, 87; Anita L Wills, Pieces of the Quilt: The Mosaic of an African American Family (Booksurge, 2009) 51-54; Azikiwe, above n 301, 76-77; Shick, above n 170, 46-48; Marie Tyler-McGraw, Martha Ann Ricks: Domestic Patriot (1 May 2008) Virginia Emigrants to Liberia, Virginia Centre for Digital History, University of Virginia <http://www.vcdh.virginia.edu/liberia/index.php?page=Stories\&section=Martha\%20Ricks $>$. In the House on Sugar book, a seemingly insensitive narrative of exploitation and subjugation in Liberia; Helene Cooper arrogantly boast of her family (violently) dispossessing Indigenous Liberians of their land and amassing inter-generational wealth. Cooper's American ancestor, Anita Wills - great-grand daughter of Elijah Johnson's daughter, Sarah Johnson accounts for the other lives Elijah Johnson left behind in the United States in her book, Pieces of the Quilt. According to Wills, Sarah was 'left' in the Chester County Poor House at the age of nine years along with her brother (Elijah Johnson Jr., 8 years) whilst Johnson journey to the Western coast of Africa as an agent of the American Colonisation Society. There is no record on who left Johnson's children at the poor house as Elijah Johnson, a Negro was listed as father, but no mention of their mother was made. For whatever reason, the situation of an apparent abandonment of his children invokes the thought of why an American war veteran, a Methodist minister who is so highly esteemed in Liberia would do such a thing. In the book, Power and Press Freedom in Liberia, 1830-1970, it states that, 'As a child Hillary (Johnson), saw little of his father, who spent much of his time away as a Methodist Minister, to the Gola and Kpelle [Indigenous groups]'. As a product of slavery, trauma and abuse, it appears Johnson was a mixed-race brainwashed colonist charged with delivery of the Christainising and civilising projects even at the cost of neglecting his own. In spite of the aforementioned, a curious mind might be tempted to ponder Judge Stewart's view, as narrated by Azikiwe - 'Judge Stewart has been bold enough to challenge the conscience of these settlers and their descendants: "[t]he former American slave treated the African freeman as if he had no rights which were worthy of respect!" The African was defrauded, beaten with stripes, made to feel like an inferior being, excluded from churches and schools, given back-seats at camp meetings, and made to enter homes of the emigrants by the back-door'. Nevertheless, let's not lose sight of the tremendous courage, endurance and resilience of former female slave emigrants to Liberia. For example, Martha Ann Ricks, born a slave in Tennessee, emigrated to Clay Ashland, Liberia and became 'an
} 
This adoption of Native Peoples in Liberia is not a legal process as is practiced in most traditional African settings, where the family structure is extended to both blood and non-blood relations. ${ }^{951}$ Often, these young ones were coercively (sometimes with the approval of their parents) taken from their 'bush' or 'illiterate' families and forced into domestic servitude by the $q u e e^{952}$ people in the capital cities. If they managed to survive the strain of their daily chores, which sometimes started as early as 2:00 a.m., ${ }^{953}$ then they could imagine the possibility of acquiring education to escape further risks of abuse and neglect. This pattern of exploiting atrisk children, especially Native ones from the interior of the country, is still alive and well in the present day. Native children, who are either displaced as a result of the civil war or economically displaced from rural areas, are seen working the streets of Monrovia on a daily basis. Some are street hawkers, navigating vehicles in heavy traffic to sell petty goods, whilst others are engaged in transactional sex in exchange for money to buy food, pay rent, or tend to family needs. ${ }^{954}$ Fuelled by the civil conflict between Native Peoples in Liberia and settlercolonists, ${ }^{955}$ coupled with incessant greed for power and wealth, ${ }^{956}$ children's propensity to perpetrate violence is on the rise. Scarred by being ex-combatants, many Native children and adolescents in Liberia are mentally ill and traumatised with no possibility of receiving care in the face of harsh social and economic conditions. ${ }^{957}$ One story of a young Native girl adopted from her Indigenous lands only to be abused by her foster parents is that of Angel Mardea Togba.

Angel Togba (affectionately known as Little Angel), a 13-year-old student at Christ the King Catholic School hailed from the Kpelle Language Group in Central Liberia. She lived with her foster parents, Hans Capehart Williams and Mardia P Williams on the Old Road, Sinkor, a suburb of Monrovia. According to Supreme Court Chief Justice Korkpor (see Williams $v$ RL

\footnotetext{
Industrious farm woman who raised turkeys, ducks, and sheep, she won a prize for her stockings, made of Liberian cotton silk, at an 1858 agricultural fair'. She spent over 25 years designing a cotton quilt, which she had the opportunity to present to Queen Victoria of England in 1892.

${ }^{951}$ Ekanem Okon, 'Towards Defining the "right to a Family" for the African Child' 12(2) African Human Rights Law Journal 373, 379.

${ }^{952}$ Moran, above n 163, 4-5; Wreh, above n 166, 130. Quee is another parlance for 'civilise' in perceptual Liberian connotation. Civilized women lose prestige by engaging in the 'wrong' types of work, such as subsistence farming or marketing. In unison, Wreh affirms Moran's description of Liberian lame view of what a civilised person is. In Wreh's own words, to be civilized, one 'must wear coat and tie, top hat, and tail coat for ceremonial occasions, be able to converse in English, attend church on Sunday regularly, be monogamous, and so forth'.

${ }^{953}$ The researcher's mother (Mama), though she was born unto a father of enslaved heritage (her mother was an Indigenous Liberia of the Gio Language group) was sent to live with the quee people in Millsburg so that she can acquire education. She did acquire some education (up to high school certification), but as she narrates, the journey was an extremely tough one.

${ }^{954}$ During a fieldwork visit to Liberia in 2010, disguising as clubbers, the author, supported by the UNMIL Gender Unit, visiting several nightclubs in Liberia to observe activities of under-aged children. Three things were quite obvious during these observations at the clubs in Sinkor, Fiahma, on Gurley street, and Broad street: 1) no ID cards were required for entry so children appearing to be under 18 years of year were everywhere; 2 ) the presence of white expatriate men were relatively vivid; and 3) men 'engaging' (dancing, kissing or in intimate closeness) with teenagers seem much older (perhaps 50 years and above).

${ }^{955}$ For example, settler-colonists against the Krahns and Mandingos symbolises the root of the inter-ethnic war.

${ }^{956}$ Noah Berlatsky and Frank Chalk, Liberia (Greenhaven, 2014) 41, 72. For example, the illicit diamond, rubber and timber trades.

${ }^{957}$ Christina PC Borba et al, 'A Mental Health Needs Assessment of Children and Adolescents in Post-Conflict

Liberia: Results from a Quantitative Key-Informant Survey’ (2016) 9(1) International Journal of Culture and Mental

Health 56, 56.
} 
[2014]), on 30 November 2007 at approximately 7:00 PM, Little Angel was found hanging by a rope in the bathroom of the Old Road residence. Medical examination, autopsy and police investigation show that Little Angel was sexually assaulted before succumbing to death by asphyxiation. Subject to the above findings, on 12 February 2008 the accused foster parents were arrested and charged with the crime of murder on 22 August 2008. The First Judicial Circuit Court, Criminal Assizes sentenced the accused to death by hanging on 19 March 2010.958 After spending almost seven years in prison and filing several appeals, ${ }^{959}$ the Williamses were released from detention. The lower court's conviction was reversed by the Supreme Court of Liberia on 15 August 2014, which found that the trial court verdict was contrary to the weight of the evidence. What is troubling about the Little Angel story is that to this date, no one is held responsible for her death. How is it possible in a country with an extremely low suicide rate that a thirteen-year-old will be raped and killed; yet eight years later, the legal system cannot hold anyone responsible for her death? Who is responsible for the rape and death of Angel Mardea Togba? ${ }^{960}$ Another example of how elite members of Liberian society avoid the full prosecution of Liberian law is that of David Waines.

The case of David Waines, the Head of Equip, a Canadian faith-based human rights organisation, ${ }^{961}$ highlights not only the injustice of rape against Native girls in Liberia but also that this form of sexual violence is not committed only by Indigenous men. On 13 November 2013, Waines was arrested on charges of statutory rape of a 13 -year-old Native girl ${ }^{962}$ contrary to section 14.70(1) (b) of the Rape Law, 2006. ${ }^{963}$ Allegedly, in the process of attempting to abort the pregnancy, a nurse on duty filed an incident report with the local police subject to section 4(4.4) of the Liberia Children's Law 2011. ${ }^{964}$ Section 4(a) (i) and 4(b) of the Rape Law provides that Waines could have served a maximum life sentence if convicted of statutory rape. However, as is told in the recent documentary, Saving David Waines ${ }^{965}$ he has returned to Canada without trial, mainly based on medical grounds and a religious petition. ${ }^{966}$ Meanwhile, according to

\footnotetext{
${ }^{958}$ TLC Africa, 'Justice for Angel: Hans Williams and Mardea Paykue, Sentence to Death by Hanging' The Liberian Connection (Monrovia, Liberia), 10 March 2014 http://www.tlcafrica.com/news_justice_for_angel_3_10.htm.

${ }^{959}$ George J Borteh, 'Angel Togba's Mother Pushes Supreme Court to Act' All Africa (Monrovia), 21 May 2013 <http://allafrica.com/stories/201305220776.html>.

${ }^{960}$ On 15 November 2015, the ECOWAS Court of Justice dismissed the Williamses case stating that the Republic of Liberia did not violate their human rights under any International Human Rights Instruments (see Williams v Republic of Liberia 2015 ECW/CCJ/JUD/25/15).

${ }^{961}$ Laurel Gregory, 'Equip Liberia' Global News (Vancouver, BC), 28 May 2012

$<$ http://globalnews.ca/news/249834/blog-equip-liberia/>.

${ }^{962}$ Staff Writer, 'Statutory Rape: Equip-Liberia Country Director Arrested' Microscope News (Monrovia, Liberia), $2013<$ http://microscopeliberia.com/news.html>.

${ }^{963}$ Section 14.70(1) of the Act to Amend the New Penal Code Chapter 14 Sections 14.70 and 14.71 and to Provide for Gang Rape (otherwise known as the Rape Law) states, a person who has sexual intercourse with another person (male or female) has committed rape if: (1) (b) the victim is less than eighteen years old provided the actor is eighteen years of age or older.

${ }^{964}$ Section 4(4.4) states, any service provided, parent and community or town member shall report sexual and other forms of abuse to the police.

${ }^{965}$ Canadian Broadcasting Corporation, 'Saving David Waines', The Fifth Estate, 5 February 2015

<http://www.cbc.ca/fifth/episodes/2014-2015/saving-david-waines>.

${ }^{966}$ Kent Corbin, Petitioning President of the Republic of Liberia President Ellen Johnson Sirleaf to Liberate David

Waines (2014) Change.Org <https://www.change.org/p/president-ellen-johnson-sirleaf-liberate-david-

waines\#petition-letter>.
} 
media reports, the teenage survivor and her baby remain in rural Liberia with no recourse, justice or fairness. Waines claims that the baby could pass for a Negro child, asserting that he is being framed by the Liberian authority. ${ }^{967}$ Even if DNA testing absolves Waines of being the father of the child, it is worth considering that a failed paternity test provides no proof against the accusation of repeated rape committed against the minor. ${ }^{968}$ Waines returned to Canada without trial predicated on his identity as a white man with power and authority enough to exonerate him of such hideous allegations without a trial. Unfortunately, the legal system often fails to protect or secure justice for Native girls who survive rape in Liberia.

In Liberia, compromising justice for survivors of rape is often the handiwork of law enforcement agencies, the very legal entities charged with protecting girls and women from violence. In the last decade, women's non-profit organisations ${ }^{66}$ in Liberia are helping to shape police perceptions with reporting and prosecuting rape cases. Despite the improvement, Peace Medie laments that ' $[\mathrm{r}]$ eferring a rape case to court is no guarantee that it will be prosecuted, but it is a necessary step for victims to get justice...getting cases to court is an uphill battle for survivors of rape in Liberia...' ${ }^{970}$ One example that shows the intersection of structural violence and the ineffectiveness of state institutions is the story of Bibiana Satu Abu.

The detailed information regarding the case of Bibiana Abu, an 18-year-old young woman hailing from the Mandingo Language Group, is unavailable apart from a personal email exchange between the researcher and the Sexual and Gender-Based Crimes Unit in August 2010. ${ }^{971}$ Limited information gleaned about the story is disturbing, suggesting the extent to which systematic violence against girls and women in Liberia is condoned and politicised. Justice for survivors of sexual violence is blatantly perverted by a male-dominant society (as discussed in chapter 2) and is encumbered by complex intersections of gender, class, status and ethnicity. Jina Moore, a correspondent for the Christian Science Monitor, observes,

[Special] Court E had all the marks of innovation -- an in-camera room so that the victim could testify without having to physically sit before her rapist, a jury and the members of the public admitted to the courtroom (which isn't open; access is controlled by the judge) and a Sexual and Gender-Based Crimes Unit of the justice department, assigned to prosecute the cases but also to give support services to victims and their families... Court E is hosting its most famous accused, Caesar Freeman...the seniorlevel civil servant, who works at the Government Services Agency, has been indicted for rape, gang rape and kidnapping. ... The victim allegedly asked Freeman for a ride, and he had an unidentified friend allegedly took her to three different places and asked her for sex; she refused each time. Freeman denies the charges; his family alleges they are politically-motivated fabrications. ... Freeman tried to get bail, even though gang rape is not a bailable offense in Liberia... He demanded a speedy trial after being held for about three weeks - in a country where people spend months and months in jail

\footnotetext{
${ }^{967}$ Rodney Sieh, “I Was Framed”: Canadian Accused of Rape in Liberian Pins Hope on DNA' Front Page Africa (Monrovia, Liberia), 25 June $2014<$ <ttp://www.frontpageafricaonline.com/index.php/news/2057-i-was-framedcanadian-accused-of-rape-in-liberian-pins-hope-on-dna>.

${ }^{968}$ Staff Writer, 'Statutory Rape: Equip-Liberia Country Director Arrested', above n 963.

969 Dara Kay Cohen and Amelia Hoover Green, 'Duelling Incentives: Sexual Violence in Liberia and the Politics of Human Rights Advocacy' (2012) 49(3) Journal of Peace Research 445.

${ }_{970}$ Peace A Medie, 'Fighting Gender-Based Violence: The Women's Movement and the Enforcement of Rape Law in Liberia' (2013) 112(448) African Affairs 377.

${ }^{971}$ Tenneh Seah, 'Survivor's Assistant', 20 August 2010.
} 
before seeing the inside of a courtroom...that set off a debate in the press, and among Liberia's lawyers, about whether the 'rape law' is unconstitutional. ... Some lawyers have since spoken out against the rape law. ... Meanwhile, [sources say] the victim has been intimidated and witnesses threatened. At least one local media outlet, meanwhile, named the victim... The case also sparked another notable news moment: blaming the victim. 'The law on rape should also take account of our young ladies and women who entice men into immorality and sin... ${ }^{972}$

All efforts to access The Daily Observer's op-ed 'Blaming the victim' amongst other things ${ }^{973}$ were to no avail. Nevertheless, The National Chronicle newspaper, in violation of all criminal justice rules against tampering with evidence, launched a series of investigations into the Caesar Freeman rape case. Coincidentally, all those interviewed during The National Chronicle newspaper's investigation were males:

Since the story of the Caesar Freeman's rape case hit the newsstand, the National Chronicle has been investigating the circumstances that led to the alleged gang raped of Bibiana Abu on October 21, 2009, at Caldwell Road. Freeman being a former basketball player of T-Cons in the [Liberian Basketball Federation] National league, played small forward in the early 80s. ... Freeman was six feet one inch tall, but was [a] very quiet and respectful lad... Our investigation took the National Chronicle Newspaper to Point Four on many occasions, different days, around the hours of 9:3010:30 p.m., the time stated by Miss Abu in her testimony, but on each and every occasion the highest one was able to drive due to traffic jam, causing a go-slow at all times of our visit, was between 20-30 kilo meters per hour. ... So, the claim and probability that Freeman took up speed is too far from possibility. The victim in our investigation may not be telling the truth. Miss Abu, from our investigation ... alleged gang rape was committed, totals about five hours (from 9:50 p. m. to 2:30 a m). Was Freeman that desperate to detain a lady for five hours just to have about ten minutes of fun? (...) Contrary to the victim's statement, it is almost impossible for a six-footer, 270 pounds to have sex in the back of a Toyota Four Runner due to the height and the space of the vehicle. According to an expert in the sale of vehicles...it is too far from the truth, especially when the person is not willing to go along. Interestingly, when the paper interviewed a medical doctor at the John F Kennedy Hospital who begged for anonymity, he said unless the lady is in the habit of having anus sex where the muscle is relaxed for penetration, it will be almost impossible, giving one's ability to manoeuver one's body in such a tight space for penetration. The doctor said like the vagina, it is almost impossible without calm and willingness on the part on the victim for one to be de-virgin unless one is completely incapacitated, which still poses serious challenge because the penis must be up-right, and both the penis and anus must be properly lubricated to achieve such task. "Well anything is possible, but in my expert opinion that seems too far-fetched". ${ }^{974}$

Concerns with dominant males in political positions wielding power and with media tampering of evidence in the Freeman rape trial inform Emmanuel Saffa Abdulai's evaluation of

\footnotetext{
${ }^{972}$ Jina Moore, 'Liberia's “Rape Court”: Progress for Women and Girls Delayed?' Christian Science Monitor (Kigali, Rwanda), 10 October 2010 <http://www.csmonitor.com/World/Africa/Africa-Monitor/2010/1010/Liberia-s-RapeCourt-Progress-for-women-and-girls-delayed>.

${ }^{973}$ Julius Kanubah, Rape Suspect's Family Raises Concern (7 September 2010) Operation We Care for Liberia <https://owcl.wordpress.com/2010/09/07/rape-suspects-family-raises-concern/>; Staff Reporter, 'Caldwell Residents Want Speedy Trial in Freeman's Rape Case' The Analyst (Monrovia, Liberia), 4 June 2010 <http://allafrica.com/stories/201006040191.html>. In the All Africa (2010) short newspaper article, the residents of Caldwell, District \#11 Montserrado County appealed to the Liberian Government conduct a speedy trial of one of their friends, Mr. Caesar Freeman who has been detained, for quite a whilst now (approximately seven months). In line with Moore's (2010) piece, Caesar's family call-out for his 'speedy trial' is not only unnecessary but also unrealistic.

${ }^{974}$ Staff Reporter, 'A Bloody Lie! - As Caesar Freeman Victim Vanishes in Tin Air: Freeman Lingers behind Bars, Victim Runs Free' National Chronicle (Monrovia, Liberia), 28 July 20101.
} 
the Sexual and Gender-Based Violence Crimes Unit. ${ }^{975}$ In the 51-page report, Abdulai affirms that the arrest and detention of Freeman (Director of Fleet of the General Services Agency) by the Sexual and Gender-Based Violence Crimes Unit caused political rancour amongst Liberia's elites (see Figure 2.1 above). Especially, those in law enforcement who sought an opportunity to revisit Liberia's rape law. ${ }^{976}$ According to Abdulai (2010):

The [Sexual and Gender-Based Violence Crimes Unit] had initially operated freely and cordially with the police force without any problem, but since the Caesar Freeman case was indicted, the police force has cut ties with the [Crimes Unit] ... because the accused is well placed in society and has many friends in the police, instructions from above, ordered the police not to cooperate with the [Crimes Unit], on the processing of the [Freeman] case ... the over-politicization of certain trials, in the short lifespan of the [Sexual and Gender-Based Violence Crimes Unit] and the Criminal Court 'E', has only reinforced the mistrust in Government legal institutions. The Caesar Freeman case is notorious for having a split of support among the powers-that-be. The media is biased against the victim, the [Liberian National Police] has taken sides and the elites of the governing class have shifted more to left against the court and fair play. This display of partisan divide reinforced the pre-war Liberia where the state colluded with rogue elites to violate the rights of people and destroy the country. ${ }^{977}$

Five months after the indictment, Freeman was eventually tried by the First Judicial Circuit, Criminal Court Assizes 'E' (a special court established in 2008 to fast-track cases of sexual violence in Liberia). ${ }^{978}$ It is clear that, in a society such as Liberia where the wheels of justice for survivors of violence turn very slowly (also see the Olivia Zinnah story), ${ }^{979}$ one must be mindful of ethics and safeguarding victims' rights to privacy and confidentiality. Article 6(d) of the $U N$ Declaration of Basic Principles of Justice for Victims of Crime and Abuse of Powers 1985 urges States to take measures that would minimise inconvenience to and protect the privacy of crime victims. Contrary to this provision, the Freeman case is an example of intimidation and retaliation against Abu and her family. Unfortunately, there is not enough information regarding the outcome of this case to conduct a critical assessment. Freeman's case raises issues of perverting justice, contaminating evidence, and assuming guilt on the part of the survivor. Until Bibiana's story is adequately revealed, one can only wonder why the justice system tends to protect the powerful. One nation-wide example of powerful people in Liberian politics avoiding prosecution for crimes against Native Peoples in Liberia is a result of the Liberian civil war.

\footnotetext{
${ }^{975}$ As noted earlier, the SGBV Crimes Unit is an entity of the Ministry of Justice with the sole purpose of prosecuting perpetrators of gender and sexual-based violence, especially rape in Liberia (also see Abdulai 2010 p. 2).

${ }^{976}$ Emmanuel Saffa Abdulai, 'Strengthening of Prosecution of SGBV Offences Through Support to the Sexual and

Gender Based Crimes Unit (SGBV CU)' (Government Report, United Nations Populations Fund (UNFPA) and

Government of Liberia, November 2010) 51, 13 <http://mdtf.undp.org/document/download/6383>.

${ }_{977}$ Ibid 23, 35.

${ }^{978}$ Staff Reporter, 'Over Five Months in Jail on Rape Claims, a Govt. Official Appears for Trial' All Africa (Monrovia, Liberia), 28 September $2010<\mathrm{http} / / /$ allafrica.com/stories/201010041090.html >.

${ }^{979}$ Gboko Stewart, 'Desperate Times Call for Unorthodox Measures: Unchecked Rape Crisis Could Barren Liberian Women' Front Page Africa (Monrovia, Liberia), 29 November 2013 <http://www.frontpageafricaonline.com/old/oped-editorial/lettercom...ox-measures-unchecked-rape-crisis-could-barren-liberian-women.html>; Jessica Vale, Small Small Thing: The Olivia Zinnah Story (Independent, 2012) <http://www.jessicavale.com>.
} 


\subsubsection{War Crimes and Impunity}

During Liberia's civil war, armed groups engaged in widespread sexual violence that went severely unreported. ${ }^{900}$ Civilians made up 90 percent of the estimated 200000 killed in Liberia's war. ${ }^{981}$ A study carried out by the Centre for Abused Women and Girls reports that women and girls between the ages 10 and 36 years accounted for 80 percent of sexual abuse between 1990 and 1993. ${ }^{982}$ In many cases, rape was committed against older women by young men. A violation of a cultural norm where deep respect is paid to older women in society, wherein a 'son' rapes his 'mother', exacerbated the inherent trauma associated with the civil war. Rape and other forms of violence were carried out by rebel forces and the Liberian armed forces. A particularly stark example of state-sponsored violence based on cultural divisions during the war is the Lutheran Church Massacre.

Civilians, mostly Native girls and women belonging to the Gio and Mano Language Groups, sought safety in Monrovia from massive rebel attacks in north-eastern Liberia at the inception of the civil war in 1989. The St Peter's Lutheran Church, located on $14^{\text {th }}$ Street in Monrovia, provided a make-shift accommodation for some 2000 internally displaced persons who were fleeing the rebel attacks in Nimba county. During the Truth and Reconciliation Council's commemoration program, two survivors of the St Peter's Lutheran Church massacre recounted their stories. ${ }^{983}$ On 29 July 1990, some 30 soldiers of the Armed Forces of Liberia stormed the Lutheran Church to terrify, rape, and slay approximately 200-300 persons. ${ }^{984}$ Survivors said the soldiers were from the Krahn Language Group of former President Doe. Some believed that the soldiers were ordered by the late President Doe to massacre the internally displaced Gio and Mano Peoples because they were supporters of the rebel group that started the civil war in Liberia. To date, it seems all that has remained of the St Peter's Lutheran Church massacres (apart from the Truth and Reconciliation Council's and St Peter's Lutheran Church's ${ }^{985}$ commemorative gesture) is trauma and pain etched on the memories of those who survived the mayhem. Despite 14 years of brutality and fatality, including the St Peter's Lutheran Church massacre, war crimes charges in Liberia have yet to be brought.

\footnotetext{
${ }^{980}$ Elizabeth Jean wood, 'Conflict-Related Sexual Violence and the Policy Implications of Recent Research' [2015] (894) International Review of the Red Cross 1, 3.

${ }^{981}$ Association of Female Lawyers in Liberia, 'Hundreds of Victims Silently Grieving' in Meredeth Turshen and Clotilde Twagiramariya (eds), What Women Do in Wartime: Gender and Conflict in Africa (Zed Books Ltd, 1998) $128,130$.

${ }_{982}$ Ibid 131.

${ }^{983}$ Reuters, 'Liberian Troops Accused of Massacre in Church' The New York Times (Monrovia, Liberia), 31 July 1990 <http://www.nytimes.com/1990/07/31/world/liberia-troops-accused-of-massacre-in-church.html>; Times Wire Services, 'Hundreds Die in Massacre by Liberian Troops: Civil War - as Many as 600 Refugees Are Killed in a Church, Survivors Say the Soldiers Were President Doe's' Los Angeles Times (Monrovia, Liberia), 31 July 1990 <http://articles.latimes.com/1990-07-31/news/mn-1189_1_civil-war>; Gbardy, above n 924, 69.

${ }^{984}$ Truth and Reconciliation Commission of Liberia, Lutheran Church Massacre Victim: 'My Body Was Covered with Blood and Human Brain' (2009) Press Release <http://trcofliberia.org/press_releases/129>.

${ }_{985}$ Tecee Boley, 'Walking Dead - Liberia's Lutheran Church Massacre Victims Still Carry Bullets, Scars' All Africa (Monrovia, Liberia), 31 July 2013 <http://allafrica.com/stories/201307310769.html>.
} 


\subsubsection{The Truth and Reconciliation Commission of Liberia}

The government made some progress in implementing the recommendations the Truth and Reconciliation Commission has made since 2009. In June, the government released a plan for promoting national peacebuilding and reconciliation, and in October launched the National Palava Hut Program, envisioned to foster reconciliation through community and grassroots dialogue. The plan advocates for reparations but ignores the commission's call for prosecutions of those responsible for war crimes committed during Liberia's two armed conflicts, for which there has still been no accountability. ${ }^{986}$

To date, Australia has not set up any Truth and Reconciliation Commission to deal with the historical injustices done to Aboriginal Peoples in Australia. In contrast, Liberia established its Truth and Reconciliation Commission ${ }^{97}$ in response to over a century of subjugation of Native Peoples in Liberia, which culminated in a 14-year civil war. Article IV of the Truth and Reconciliation Act 2005 mandates the Truth and Reconciliation Commission to address the persistent occurrence of systematic gender violence and ingrained ethnic conflicts. To achieve its objective, the Truth and Reconciliation Commission deliberated over a period of three and a half years, collecting some 22000 written statements and 500 live public testimonies from across Liberia and in the United States ${ }^{988}$ In its two-volume report, the Truth and Reconciliation Commission submitted 18 summary findings to the Government of Liberia in 2008. Five of the findings summarise the origin, perpetrators, survivors and possible redress to historical violence in Liberia: ${ }^{98}$

1. The conflict in Liberia has its origin in the history and founding of the modern Liberian State.

2. All factions engaged in the armed conflict, violated, degraded, abused and denigrated, committed sexual and gender-based violence against women including rape, sexual slavery, forced marriages, and other dehumanizing forms of violence.

3. Both individual and community reparation is a duty and obligation of the state, to promote justice and genuine reconciliation.

4. Lack of human rights culture and education, deprivation and over a century of state suppression and insensitivity, and wealth accumulation by a privileged few created a debased conscience for massive rights violations during the conflict thus engendering a culture of violence as a means to an end, with an entrenched culture of impunity.

5. External State Actors in Africa, North America and Europe, participated, supported, aided, abetted, conspired and instigated violence, war and regime change against constituted authorities in Liberia and against the people of Liberia for political, economic and foreign policy advantages or gains.

Against this backdrop of the Truth and Reconciliation Commission findings, several

\footnotetext{
${ }^{986}$ Human Rights Watch, 'Liberia: Country Summary' (NGO Report, Human Rights Watch, 2014) 5, 2 <http://www.hrw.org/sites/default/files/related_material/liberia_3.pdf >.

${ }^{987}$ The Truth and Reconciliation Commission Act of Liberia 2005 establish the Truth and Reconciliation Commission (TRC) of Liberia was enacted by the National Transitional Legislative Assembly on 12 May 2005. Part of the Preamble of the TRC Act reads, 'Whereas the nation, since its independence, has been confronted with challenges and socio-economic and political conflicts, which polarized the nation and culminated into the violence of the late 70 's leading to the military coup in 1980; and [w] hereas the violence during the 1980 s created even greater violence and armed conflict during the 1990s, decimating and displacing much of the population, internally and externally, ravaging the economy, polarizing the population further and thereby necessitating an intervention by the international community to restore peace and security to Liberia...'

${ }^{988}$ Truth and Reconciliation Commission of Liberia, 'Truth and Reconciliation Report', above n 52, v-vi.

${ }^{989}$ Ibid 6-7.
} 
recommendations were made. The sheer breadth of the Truth and Reconciliation Commission's recommendation exemplifies the severity of abuses needing attention. ${ }^{900}$ All those responsible for committing 'war crimes and egregious violations against the generality of the population' are included in the recommendation lists as perpetrators. ${ }^{991}$ Many accused of war crimes have yet to be prosecuted. For example, the former President of Liberia and a Nobel Peace Prize laureate, Ellen Johnson Sirleaf; ${ }^{992}$ current Supreme Court of Liberia Associate Justice Kabineh Ja'neh; ${ }^{993}$ and Weade Kobbah-Wureh, current Chairperson and Professor of Mass Communications Department, University of Liberia, ${ }^{994}$ have all been accused of inciting war and violence in Liberia.

Considering her alleged war crime accusation, the Human Rights Watch reprimands President Sirleaf for making very little progress in implementing the Truth and Reconciliation recommendations. Some local Liberian human rights advocates criticise the establishment of the National Independent Human Rights Commission and the Palava Hut as a dysfunctional façade that shields alleged war-criminals in Liberia. The election of individuals such as Prince $\mathrm{Y}$ Johnson, current senior senator of Nimba Country and former leader of the Independent National Patriotic Front of Liberia continues to distort and pervert the justice system for Native girls and women survivors of violence during Liberia's civil war. But for the International Criminal Court's Special Court for Sierra Leone and the United States' legal system, Charles Taylor (former president of Liberia) ${ }^{995}$ and his son, Chucky Taylor, ${ }^{996}$ would not be serving 50 and 97-years sentences for war crimes committed in Sierra Leone and Liberia, respectively. Tom Woewiyu, the former senior member of Charles Taylor's rebel group, is charged for lying on his United States Application for Naturalisation by failing to disclose affiliation with the

\footnotetext{
${ }^{990}$ Ibid 268.

${ }^{991}$ Ibid 270.

${ }^{992}$ Bendu Koryon, 'Ellen Johnson-Sirleaf: Presidential Aspirant or War Criminal' [2005] TLC Africa

$<$ http://www.tlcafrica.com/politics_ejs2.htm>; Nicholas Kristof, 'Ellen Johnson Sirleaf and War Crimes?!' New York Times (Monrovia, Liberia), 3 July 2009 <http://kristof.blogs.nytimes.com/2009/07/03/ellen-johnson-sirleaf-and-warcrimes/?_r=0>; Glenna Gordon, 'In Liberia, Sirleaf's Past Sullies Her Clean Image' Time (Monrovia, Liberia), 3 July $2009<\mathrm{htt}$ ://content.time.com/time/world/article/0,8599,1908635,00.html>; Bernard Gbayee Goah, 'Is President Ellen Johnson-Sirleaf of Liberia Immune from Prosecution, or Not?' Front Page Africa (Monrovia, Liberia), 18 October 2013 <http://www.frontpageafricaonline.com/old/op-ed-editorial/lettercomments/7273-is-president-ellenjohnson-sirleaf-of-liberia-immune-from-prosecution-or-not.pdf>; Staff Reporter, 'Profile: Ellen Johnson-Sirleaf' Al Jazeera (Monrovia, Liberia), 7 October 2011

$<$ http://www.aljazeera.com/news/africa/2011/10/201110794610186521.html>; James Sirleaf, 'Ellen Johnson Sirleaf Unconsciously Supported Charles Taylor' The Perspective (Atlanta, GA), 8 September 2014 http://www.theperspective.org/2014/0908201404.php.

${ }_{993}$ J Aloysius Toe, Liberia: Elections, Justice, Corruption and the Role of the International Community (24 February 2011) National Endowment for Democracy <http://www.ned.org/liberia-elections-justice-corruption-and-the-role-ofthe-international-community>.

${ }^{994}$ Staff Reporter, “"War Crimes List” - Cultures of Impunity Unlikely to Continue' All Africa (Monrovia, Liberia), 5 March 2015 <http://allafrica.com/stories/201503051419.html>.

${ }_{995}$ Waugh, above n 93; Chernor Jalloh and Alhagi Marong, 'Ending Impunity: The Case for War Crimes Trials in Liberia' (2005) 1 African Journal of Legal Studies 53; Wayne Jordash and Penelope Van Tuyl, 'Failure to Carry the Burden of Proof: How Joint Criminal Enterprise Lost Its Way at the Special Court for Sierra Leone' (2010) 8 Journal of International Criminal Justice 591; Valerie Oosterveld, 'Gender and the Charles Taylor Case at the Special Court for Sierra Leone' (2012) 19(1) William \& Mary Journal of Women and the Law 7. Also see, The Prosecutor of the Special Court v Charles Ghankay Taylor [2012] SCSL and the Residual Special Court for Sierra Leone at http://www.rscsl.org/Taylor.html.

${ }^{996}$ Staff Reporter, Florida Teen, War Criminal: The Life of an 'American Warlord' (4 April 2015) Author Interviews <http://www.npr.org/2015/04/04/396384872/florida-teen-war-criminal-the-life-of-an-american-warlord>.
} 
National Patriotic Front of Liberia, 'a violent political group'. ${ }^{997}$ Arguably, the Truth and Reconciliation Commission's provision to grant immunity from prosecution or tort actions ${ }^{998}$ to all persons who testified about past crimes enables a culture of impunity in Liberia. Thus, alleged war criminals, including Johnson Sirleaf, Johnson, Ellen Johnson Sirleaf and Ja'neh, are able to flaunt and display violence publicly with little or no remorse. ${ }^{999}$ Justice, redress and reparations for systematic violence against girls and women must start with one basic principle: full implementation of every recommendation made by the Truth and Reconciliation Commission. However, as Indigenous women in rural Liberia wait for restorative justice for the violence they survived during the civil war, they are still subject to structural violence perpetrated by patriarchal traditional systems.

\subsubsection{Forced Marriage and Polygyny}

Inability to harmonise both Anglo-American-Liberian law and Liberian Customary law poses serious challenges to addressing cultural and structural violence especially where there is inconsistency regarding the age of marriage, payment of dowry, and enforcement of Native women rights to inherit property or take custody of their minor children when there are multiple wives. Whilst, Article 2, Chapter 1 of the Liberian Constitution 1986 states that the Constitution is the supreme and fundamental law of the country, in reality, Liberian Customary Laws are still practiced in Native traditions.

Cultural, structural and interpersonal factors are important determinants of coercive practices of marriage (e.g., dowry), associated with systematic violence against Indigenous girls and women. ${ }^{1000}$ In Liberian traditional or customary marriage, a dowry is the payment of money and breaking of kola nut, perceived as a permit for a man to treat a woman as his chattel. The

\footnotetext{
${ }^{997}$ Staff Writer, ‘America Ready for Liberians Accused of War Crimes?’ Heritage (Monrovia, Liberia), 29 July 2014 <http://allafrica.com/stories/201407291149.html>; Alphonso W Nyenuh, 'The War Crimes Case against Tom Woewiyu - Why the US Must Prosecute' Front Page Africa (Monrovia, Liberia), 13 June 2014

$<$ http://www.frontpageafricaonline.com/index.php/op-ed/commentaries-features/1938-the-war-crimes-case-againsttom-woewiyu-why-the-u-s-must-prosecute>; Staff Reporter, 'Woewiyu Pleads Not Guilty - Judge Denies Him Bail in Fraud Case' Front Page Africa (Monrovia, Liberia), 19 May 2014

<http://allafrica.com/stories/201405201200.html>; Tewroh-Wehtoe Sungbeh, 'Woewiyu's Arrest by US Officials Confirms Our Inability to Pursue Our Own War Criminals' The Liberian Dialogue (Atlanta, GA), 15 May 2014 $<$ http://theliberiandialogue.org/2014/05/15/woewiyus-arrest-by-us-officials-confirms-our-inability-to-pursue-ourown-war-criminals/>; The US District Court, Pennsylvania, Indictment of Jucontee Thomas Woewiyu, Court Indictment, 30 January 2014.

${ }_{998}$ Article VIII, section 30 of the TRC Act 92005) states that, '[t] he TRC shall grant immunity to all persons or groups of persons, organizations or institutions from prosecution or tort actions on account of statements made or evidence given before the TRC in advancement of the public interest objective inherent in the functions and objects of the TRC and pursuant to the successful execution of its mandate, and which therefore, shall not be used in any court of law against the person making the statement'.

${ }_{999}$ Daniel Howden, 'Warlord to Kingmaker: An Audience with Prince Johnson' The Independent (London, UK), 15 October 2011 http://www.independent.co.uk/news/world/africa/warlord; Christian Purefoy, 'Former Liberian Warlord “finds God," Seeks Presidency' CNN (Monrovia, Liberia), 5 August 2010

$<$ http://www.cnn.com/2010/WORLD/africa/08/05/johnson.liberia.religion/>; Wade CL Williams, 'As War Crimes Prosecution Debate Heats up; Prince Johnson Threatens Trouble If' Front Page Africa (Monrovia, Liberia), 25 May $2012<\mathrm{http} / / / \mathrm{www}$.frontpageafricaonline.com/old/news/general-news/3231-as-war-crimes-prosecution-debate-heatsup-prince-johnson-threatens-trouble-if-.html>. Also see the TRC video testimonies of Prince Johnson available at http://trcofliberia.org/videos/1201.

${ }^{1000}$ Manjula O’Connor, 'Dowry-Related Domestic Violence and Complex -Post-Traumatic Stress Disorder: A Case Report' [2017] Australasian Psychiatry 1, 1.
} 
Liberian Rules and Regulations Governing Hinterland 2000, which forms part of Liberian Customary Laws, provides for the payment of dowry in traditional marriage. Legal dowry is \$40 (Article 55(i)) for a girl 15 years and older (Article $55(\mathrm{~g})$ ) and \$48 dollars for a virgin girl (Article 55(p)). A payment of $\$ 100$ is refunded upon dissolution of a marriage to a civilised man (Article 55(c)) or a Native man wherein it is the woman's fault (Article 55(c)). Subject to the Liberian Rules and Regulations Governing Hinterland, only children in a dissolved traditional marriage are entitled to inherit from the father (Article 55(c)). However, the Act to Govern the Devolution of Estates and Establish Rights of Inheritance for Spouses of Both Statutory and Customary Marriages 2003 passed in 1998 (hereafter the Equal Rights of the Customary Marriage Law of 1998) prohibits the recovery of dowry (section 2.2, Chapter 2), entitles a customary wife to one-third of her husband's property immediately upon marriage (section 2.3, Chapter 2), and unlawful for females under the age of 16 to be given in customary marriage to a man (section 2.9). Here is a perfect example of a conflict of laws between AngloAmerican-Liberian law and Liberian Customary Law.

In a male-dominant society, the very act and process of establishing the idea of marriage are encumbered with inequality, injustice, abuse, discrimination and violence against women. Usually, the colonial state or the Traditional Council authorises and regulates the process of marriage in Liberia. As noted above in the Liberian Rules and Regulations Governing Hinterland and in the Equal Rights of the Customary Marriage Law of 1998, the State or Traditional Council's involvement in customary marriage can inflict systematic gender violence on Indigenous girls and women. For example, the marriage amongst the Kpelle people in Liberia is patrilineal. According to Caroline Bledsoe, dissatisfied men are compensated with rights over people, property and labour based on traditional rules:

a man or his lineage may demand the return of bride-wealth if a woman wants to divorce her husband...rules ensure that a woman and her children remain the property of the lineage that paid bride-wealth, even if the husband dies. Though seldom practiced, the Kpelle levirate legally transfers a widow to one of her husband's brothers or other male lineage mates as his wife. A widow may be transferred to one of her husband's sons by another marriage, usually if she is the same age or younger, though many of my informants regarded this dubiously, calling it a marriage between a man and his 'mother'. Conversely, the surrogate allows a widower to claim another woman from his dead wife's lineage. ${ }^{1001}$

Section 3.4, Chapter 3 of the Equal Rights of the Customary Marriage Law of 1998 makes it unlawful to compel a widow to marry her deceased husband's kin. Notwithstanding, as indicated earlier, even though there is a conflict between the Anglo-American-Liberian law and Liberian Customary law, all things being equal, a uniform application and implementation of settler-colonist law should prevent or at least minimise such cultural/structural violence against Native women in Liberia.

${ }^{1001}$ Caroline H Bledsoe, Women and Marriage in Kpelle Society (Stanford University Press, 1980) 82-83. 
Under the Liberian Rules and Regulations Governing Hinterland and the Equal Rights of the Customary 2000, a lawful marriage is where a settler-colonist court allows a husband or his lineage to claim an adultery fee from his wife's lover. Such a fee can then be reinvested into payments for more wives for himself or his dependents. ${ }^{1002}$ Although under such traditional marriage law is not an alternative for ensuring justice or helping to advance Native girls and women rights politically, it is an additional avenue for boys and men to legally justify their right to own, control and abuse Native girls and women as chattels. Wulah's explanation of the different reasons why women and men file for a divorce rather than choosing the reverse (i.e., claiming an adultery fine) marks the injustice associated with divorce:

Most common grounds for husbands doing so [i.e., pursuing divorce] are desertion;
waywardness; persistent, flagrant unfaithfulness; wilful stubbornness; carelessness and
negligence in the household; incompatibility; continued 'bewitching' of the husband;
and barrenness. A wife may demand to be released from her husband for continued and
brutal abuse, impotence, and nonfulfillment of marital duties ... all children born to a
woman during the time she has been the wife of a man belong to him. ${ }^{1003}$

The perception is that a man's wealth is partly embodied by his children and wives. Children are also seen as the 'future old-age pension for the elders, as they will take care of their parents when they grow old.' ${ }^{1004}$ Wulah offers another perspective that justifies male dominance and control over women whilst at the same time professing that women have agency and ability to consent to abuse. ${ }^{1005}$ He states,

[f]idelity is nowhere to be found in most marriages. A woman may be 'loan' for a time by her husband; however, no woman will consent to being simply handed over to another man without her consent. ... Amongst some tribes, if a man comes to town and wants a woman if he intends to stay for a long period, he will ask the husband to allow him to have his wife, promising to be the husband's servant and helping during this time, provided she is not his favourite wife..$^{100}$

It is humiliating enough for a wife to have her husband agree to let a stranger have sexual intercourse with her. But to say, that she wilfully consents to share her body with anyone who seeks permission from her husband to do so is an outright violation. Andrea Powell describes that violation as dehumanising and 'intrinsically destructive to women's anatomy.' ${ }^{1007}$ Sadly, promising women to men without their consent is also the reality for girls in Native Language Groups in Liberia.

Although customary and Anglo-American law prohibits the marriage of children younger than 18 years, girls are often promised to men, sometimes even before they are even

\footnotetext{
${ }^{1002}$ Article 55(m), Liberian Rules and Regulations Governing Hinterland and the Equal Rights of the Customary 2000 (revised).

${ }^{1003}$ Wulah, above n $169,189$.

${ }^{1004}$ Waris Dirie and Cathleen Miller, Desert Flower: The Extraordinary Journey of a Desert Nomad (HarperCollins, 2011) 30 .

${ }^{1005}$ Sheldon, above $\mathrm{n} 913,48$. Sheldon suggests that even in colonial era across Africa 'women were as disadvantage as "customary" laws were established based on male testimony that gave men, especially elite men, advantages over women in issues of marriage and divorce'.

${ }^{1006}$ Wulah, above n 169, 186.

${ }^{1007}$ Andrea Powell, 'Problematizing Polygyny in the Historical Novels of Chinua Achebe: The Role of the Western Feminist Scholar' (2008) 39(1) Research in African Literatures 166, 166.
} 
born. Article 16(2) of the Convention on the Elimination of All Forms of Discrimination against Women 1979; Article 21(2) of the African Charter on the Rights and Welfare of the Child 1990; and section 4, Article VI of the Act to Establish the Children's Law of Liberia 2011 provide that marrying or betrothing any person under the age of 18 is prohibited. However, there are situations in which, after a man learns that he has impregnated a young female, he may say to the young woman, 'if what you are going to bear is a girl, I will take her to be my wife. If it is a boy, I will be his uncle. ${ }^{\prime}{ }^{1008}$ With the parents' consent, a binding ceremony is performed as a symbol of sealing the contract. Thus, even before her birth, a young girl is already betrothed, sealing her destiny for life. In other cases, the birth of a girl is perceived as a sign of 'fruitfulness', which triggers a higher bride price or dowry. ${ }^{1009}$ In many Language Groups, children belong only to the father or paternal grandfather, who is the authorised recipient of her dowry, if the child is a girl. It may also be the case that the girl could become only one of several of the man's wives.

Polygyny, a practice wherein a man has more than one wife, is relatively widespread amongst Native Peoples in Liberia. ${ }^{1010}$ Kathleen Sheldon reasons that girls and women who are socially and mentally indoctrinated into believing that being one of many wives is beneficial could opt for polygyny. ${ }^{1011}$ Feminist researchers suggest that in the absence of patriarchy, male chauvinism and misogyny, young girls do not choose a polygynous relationship. In fact, some argue that polygyny dehumanises women in many ways. However, although the voice of Indigenous women who denigrate such marital arrangements must not be objectified or silenced, it is only fair to note that others see the practice as beneficial to girls and women. Although polygyny increases overall family size, it tends to reduce the number of children each wife may bear because of the reduced chance that she will have sexual intercourse or because of observance of other traditional practices (e.g., abstinence from sex after having a baby). ${ }^{1012}$ In Liberia, polygyny is also tied to religion. Research conducted by Konia Kollehlon found that polygyny is lowest amongst Catholics and more prevalent amongst Muslims, who tend to marry women of slightly younger age. ${ }^{1013}$

\subsubsection{Female Genital Cutting}

This research prefers the phrase 'female genital cutting' over 'female genital mutilation', which seems to reflect denigration for a tradition. Female genital cutting is more representative of the

\footnotetext{
${ }^{1008}$ Wulah, above n $169,187$.

${ }^{1009}$ Sheldon, above n 913, 37. Dowry or bride price is preferred over bride wealth because not only has Wulah (2005) infer its cultural significance as a mechanism for building men's wealth and validity their complete dominance over women but also that the literal essence of collecting money and other material possessions in exchange for women (rather than men) mean exactly that - women are being sold.

${ }^{1010}$ Soniia David, 'Health Expenditure and Household Budgets in Rural Liberia' (1993) 3(1) Health Transition Review 57, 61, 579-600.

${ }^{1011}$ Sheldon, above n 913, 201.

${ }^{1012}$ Konia T Kollehlon, 'Religious Affiliation and Fertility in Liberia' (1994) 26(04) Journal of Biosocial Science 493, 499.

${ }^{1013}$ Ibid.
} 
type of procedure in Liberia. 'Female genital removal', 'female surgery', and 'female circumcision' are a few other contentious phrases used to describe the procedure of 'a destructive operation, during which the female genitals are partly or entirely severed or injured with the goal of inhibiting a woman's sexual feelings'. ${ }^{1014}$ Though the origin of the procedure is unclear, contrary to public perception, it is not a practice based on religion. Elizabeth Boyle submits that as recently as the 1950s, female genital cutting was performed on white women in Western countries to treat nymphomania. ${ }^{1015}$ Historically, the term 'female circumcision' has been used to compare the procedure to that of male circumcision. However, Rebecca Cook and Bernard Dickens argue that female genital cutting 'bears no relationship to male circumcision', ${ }^{1016}$ which has a possible health benefit and a relatively low risk of harm. ${ }^{1017}$

There are many types of female genital cutting, performed by various cultures. Cook and Dickens describe four types of female genital cutting. They are 1) clitoridectomy, 2) excision, 3) infibulation and 4) unclassified procedures. Clitoridectomy involves partial or entire removal of the clitoris. Excision is the removal of the clitoris and the labia minora. Infibulation is the severing of the clitoris, the labia minora and sometimes the labia majora. The final stage of infibulation includes stitching or sealing together the vagina with a small opening left for the flow of urine and menstrual blood. Unclassified procedures encompass the following:

a) pricking, piercing or stretching of the clitoris and/or the labia;

b) Cauterisation (i.e., burning of the clitoris and surrounding tissues);

c) Scraping of the vaginal orifice; and

d) Introduction of herbs or corrosive materials to cause bleeding or narrowing/tightening of the vagina. ${ }^{1018}$

Although there is no evidence to support which kind of procedure is common in Liberia, many dispute the existence of types $b$ and $c$. The age at which these procedures are performed also varies.

In many Indigenous cultures, puberty rites validate the psychological adulthood of young women in preparation for marriage. ${ }^{1019}$ Usually, female genital cutting is performed before puberty, often on girls between the age of four and eight years, ${ }^{1020}$ although in Liberia puberty rites in the Sande School for girls take place between the ages of 10 and 13 years. Recently, according to Waris Dirie's Desert Flower Foundation, genital cutting is increasingly carried out

\footnotetext{
${ }^{1014}$ World Health Organisation, WHO: Female Genital Mutilation (2014) Female Genital Mutilation <http://www.who.int/mediacentre/factsheets/fs241/en/>.

${ }^{1015}$ Elizabeth Heger Boyle, Female Genital Cutting: Cultural Conflict in the Global Community (Johns Hopkins University Press, 2005) 24.

${ }^{1016}$ World Health Organisation, above n 1015.

${ }^{1017}$ Rebecca Cook, Reproductive Health and Human Rights : Integrating Medicine, Ethics, and Law (Clarendon Press, 2003) 262.

${ }^{1018}$ Ibid 264.

${ }^{1019}$ Linda Pressly, 'Saving Girls from the "Cutting Season"” BBC News (Dar es Salaam, Tanzania), 1 April 2015 http://www.bbc.com/news/magazine.

${ }^{1020}$ Caine, above n 555, 39.
} 
on nurslings who are only a couple of days, weeks or months old. ${ }^{1021}$ In Liberia, female circumcision or female genital cutting ${ }^{1022}$ is practiced only in the North-western parts of the country. It marks the full initiation of young girls into the traditional institution and emphasises rigid enforcement of 'chastity', ${ }^{1023}$ 'purification' or 'cleansing'. ${ }^{1024}$ The procedure is performed as part of a traditional ceremonial initiation of girls and young women, as a rite of passage ${ }^{1025}$ into the traditional institutions known as the Sande (secret) society. ${ }^{1026}$ Caine states that the emphasis of the Vai people's Sande society is on the chastity ${ }^{1027}$ of a young bride before her marriage. ${ }^{1028}$ A more reliable source of data on the occurrence of female genital cutting in Liberia is that of the Department of Health Survey. ${ }^{1029}$ Of the 7092 women who said they have heard about the Sande

\footnotetext{
${ }^{1021}$ Waris Dirie, 'What Is FGM? - Desert Flower Foundation' <http://www.desertflowerfoundation.org/en/what-isfgm/>; Dirie and Miller, above n 1005, 2; Sheldon, above n 913, 61. Waris Dirie, the author of Desert Flower (2011), is a Somali nomad of the Galkayo People who experienced female genital circumcision at the tender age of 5; escaped an arranged marriage to an older man at the tender age of 13 and survive several rapes, child molestation and violence. An international model, Waris later resigned from modelling to establish the Desert Flower Foundation. She served as the UN Special Ambassador from 1997-2003.

${ }^{1022}$ Sheldon, above $\mathrm{n} 913,80$. Female Genital Mutilation is a term coined by Western feminist who claim that the procedure mutilates young girls' bodies thereby promotion the notion that Africans are barbaric. Thus, this research prefers Female Genital Cutting or Female Genital Surgery so as to elicit constructive open discussion on the issue. ${ }^{1023}$ Wulah, above $\mathrm{n} 169,185$. According to Wulah, sexual indulgence by the initiates in the bush school was one of two offences punishable by death. For girls in the Sande School teachings are focused on husbands and babies, yet intercourse is thought of as completely forbidden.

${ }^{1024}$ Boyle, above n 1016, 24.

${ }^{1025}$ Caine, above n 555, 8; Sheldon, above n 913, 218-219. Caine distinguishes the role of the traditional school in the lives of men to that of women. Whilst a boy is pruned into adulthood where he must learn to work to support his family and discharge other kinship duties; ' .... women, the adult one trained in domestic activities, mother-craft, the art of graceful carriage, and tribal history. A girl must know the rules of morality and how to respect her body as a 'temple' of a husband. She must learn to listen to those who know better, the elders'.

${ }^{1026}$ Government of Liberia, 'Study on Operations of Sande School' (Government Report, Ministry of Children, Gender and Social Development, April 2011) 3; Bledsoe, above n 590; Dunn and Holsoe, above n 104, 140, 153. According to Ministry of Gender, Children and Social Protection - The Sande Society is a women's institution that initiates girls into womanhood, confers fertility, instils notions of morality and maintains an interest in the well-being of its members throughout their lives. As part of its practice, initiation rite into womanhood may include FGC and forced marriage. The Sande School is conducted in north-eastern Liberia amongst the Kpelle, Bassa, Vai, Dan (Gio), Mano, Dei, Lorma, Mandingo, Mende, Kissi, Gbandi, and Gola language groups. The School sessions may last up to three years. The main spirit of the society is represented by a helmet-masked figure which presents as significant social events. The male counterpart of the Sande institution is the Poro Society.

${ }^{1027}$ Wulah, above n $169,184-185$.

${ }^{1028}$ Caine, above $\mathrm{n} 555,70$. Caine writes, ' $[\mathrm{t}]$ raining for moral character development constitutes a cardinal point in
} Sande instruction. Under this general rubric virginity and marital fidelity are the most important. Instruction takes the form of reciting certain moral imperatives to the pupils and linking the violation of these to supernatural punishment, such as barrenness, sudden illness, or death. For example, a girl must obey her husband or lose "heave"; if she committed adultery before or during pregnancy, she must make a confession to her husband or delivery will be so difficult that she might die in labor. She cannot love two brothers without exposing herself to the anger of the ancestors. But a more practical means of teaching morals lies in tying a girl's success or failure as wife to conformity with the rules. An example of the pscyho-economic aspects of morality will make clear how the Sande stress on premarital and marital chastity is made to carry conviction to the pupil. Before marriage the parents of a bride must receive and amount $[\sim 300]$ from the prospective husband. This payment does not constitute a purchase of wife, as anthropologists have taken the pains to point out, and she does not become a mere chattel. On the contrary, it serves to stabilize the union, to validate the social paternity of children. But bride-wealth has another significance which provides some insight into why parents insists on the payment of it. It confers prestige upon the receiver and prestige is one of the few blessings the Vai pray for. The very fact that very little of the amount is kept by the parents themselves suggest that economic incentives are secondary in the demand for bride-wealth. But whether this amount will be paid at all, or the maximum realized, depends on whether the girl is chaste. A woman who on the night of her nuptial turns out to be unchaste is a disgrace to her family, for she has belied the implied pledge of her parents that she was a virgin'.

${ }^{1029}$ UN Children's Fund, 'Female Genital Mutilation/Cutting: A Statistical Overview and Exploration of the Dynamics of Change' (UN Report, United Nations Children's Fund, 2009) 194, 2-3, 26. According to this report, 125 million girls worldwide have been subjected to the 'blade'. However, after a closer look, the statistics appear to be wrongly presented, at least for Liberia. An email to UNICEF on 9 March 2015 explains that, 'I'm writing to express a concern that your data presented on page 2-3 and 26 about Liberia's FGC's statistics (66 per cent and 44 per cent) is perceptually wrong. The DHS does not say that 66 per cent or 46 per cent of all women in Liberia have 
society in Liberia, 66 percent were members who had experienced female genital cutting, i.e., assuming that being a member of the Sande society is proxy for genital cutting. ${ }^{1030} \mathrm{~A}$ baseline study by the Open Society Initiative for West Africa (2013) reveals that, of the 352 women participants, 59.7 percent were members of the Sande society. ${ }^{103}$

The practice of female genital cutting amongst Native Peoples in Liberia is secretive, controversial and tenuous. As such, it is challenging to find documented cases of the practice in Liberia. Therefore, discussion on the topic will be presented through the experiences of women from other countries in Africa. It must be noted that some scholars support the ritual as a tradition to be upheld. ${ }^{1032}$ Ahmadu argues that '[w]estern feminist sisters insist on denying us this critical aspect of becoming a woman in accordance with our unique and powerful cultural heritage.' ${ }^{1033}$ Shweder opines that '[w] esterners conveniently ignore the fact that they produce their own kinds of genital mutilation in the form of the vaginal rejuvenation of women and circumcision for boys'. ${ }^{1034}$ In contrast to Ahmadu and Shweder's arguments are Waris Dirie's and Nawal El Saadawi's lived experiences. Thirteen-year-old Dirie, a Somali nomad, ran away from home to escape marriage after having endured female genital cutting at age three. Dirie later became an internationally famed supermodel, the UNFPA Special Ambassador for the Elimination of Female Genital Cutting (1997) and the African Union Peace Ambassador (2010). ${ }^{1035}$ El Saadawi, a renowned Egyptian feminist, whom this researcher regards as the 'Mother of Islamic Feminism', was circumcised at the tender age of six and escaped an arranged marriage at 10 years, but later went on to qualify as a medical doctor and became the Director of Public Health in Egypt. ${ }^{1036}$ Dirie and El Saadawi's stories are examples of African women rising from the effects of harmful cultural practices imposed by male-dominated society towards their independence and freedom. The experiences of Dirie and Saadawi as young

undergone FGC. In fact, what the DHS tries to present very clearly is an inference or an assumption that if membership to the Sande Society (NOT Bush Society) implies a female had underwent genital cutting, then 66 per cent of the 7092 women that were asked in the survey experienced the procedure. LISGIS' National Housing and Population Census (2008) estimates Liberia's population at 3.5 million, 50 per cent of which were females. The manner in which you've presented your statistics seriously neglect to take into consideration that the entire southeastern part of Liberia does not practice FGC. And, that the DHS is solely limited to an infinitesimal percentage $(0.2$ per cent) of the entire population - yet with a caveat. Moreover, it appears to me that you've jumbled statistics from various countries without standardising the statistics. You CANNOT compare raw statistics like so. Otherwise, you risk unintentionally sending out the wrong (and definitely troubling) impression that 66 per cent of all Liberia women have undergone FGC.

${ }^{1030}$ Liberia Institute of Statistics and Geo-Information Services et al, 'Liberia Demographic Health Survey 2007' (Liberia Institute of Statistics and Geo-Information Services, June 2008) 410, 241

<http://www.measuredhs.com/pubs/pdf/FR201/FR201.pdf>.

${ }^{1031}$ Women Solidarity, 'Baseline Study Report: On the Knowledge, Perceptions and Attitudes of the Practice of Female Genital Mutilation in Six Districts in Nimba, Bong and Margibi County/Liberia' (Private Report, Open Society Initiative of West Africa (OSIWA), 25 April 2013) 32, 1.

${ }^{1032}$ Richard Shweder and Fuambai S Ahmadu, 'Disputing the Myth of the Sexual Dysfunction of Circumcised Women: An Interview with Fuambai S. Ahmadu' (2009) 25(6) Anthropology Today 14; Bettina Shell-Duncan and Ylva Hernlund, Female 'Circumcision' in Africa: Culture, Controversy, and Change (Lynne Rienner Publishers, 2000) 183-312.

${ }^{1033}$ John Tierney, ‘A New Debate on Female Circumcision' TierneyLab (New York, NY), 30 November 2007 <https://tierneylab.blogs.nytimes.com/2007/11/30/a-new-debate-on-female-circumcision/?hp>.

${ }^{1034}$ Jessica Jessica, African Doctor: Is Female Circumcision so Awful? (30 November 2007) Jezebel

<http://jezebel.com/328601/african-doctor-is-female-circumcision-so-awful〉.

${ }^{1035}$ Dirie and Miller, above n 1005.

${ }^{1036}$ Nawāl Sa'dāwī, A Daughter of Isis: The Autobiography of Nawal El Saadawi (Zed Books, 1999) 12-13; Nawāl Sa'dāwī, The Nawal El Saadawi Reader (Zed Books, 1997) 2-3. 
children who were submitted to the practice against their will raise the question of children's right to consent to such a life-changing procedure, which has a relatively high health risk.

The debate around accepting polygamy and female genital cutting as long-standing tradition is unsubstantiated by international, national and domestic law. Article 2 (f) of the Convention on the Elimination of All Forms of Discrimination Against Women 1979 and Article 5 of the Protocol to the African Charter on Human and Peoples' Rights on the Rights of Women in Africa 2003 considers polygamy and female genital cutting as harmful customs and traditional practices against girls and women. Domestically, though, Liberia is one of only three countries in West Africa yet to ban female genital cutting. ${ }^{1037}$ Notwithstanding, outgoing President Ellen Johnson Sirleaf gave the Domestic Violence Bill that abolishes female genital cutting, a bill which has suffered many setbacks from the Liberian Legislature, an Executive Order on 19 January $2018 .^{10}$

\subsection{Summary}

This chapter reviews the literature on systematic violence against Indigenous girls and women in a broad sense. The chapter also moves away from limiting the analysis of Indigenous girls and women's experience of violence to sexual, domestic, family and intimate partner abuse towards mapping the complex interactions of three intertwining levels of systematic violence. ${ }^{1039}$ Building on strategies, resistance and movements by Indigenous girls and women advocates, the chapter covers the manifestation of systematic violence against Indigenous girls and women in diverse root causes, forms, and sources drawing unique institutional/state, structural/cultural and interpersonal/community case examples. Through the review, a web of intersecting factors constituting systematic gender violence emerged. Gender violence occurs at the interpersonal/community, structural/cultural, and state/institutional levels, is inflicted institutionally, psychologically, and sexually ${ }^{1040}$ and occurs in workplaces, churches, schools and the community at large. ${ }^{1041}$ However, Indigenous girls and women are not victims but survivors, despite the overwhelming traumatic experiences they have endured as a result of colonial legacies of systematic violence perpetrated against them.

\footnotetext{
${ }^{1037}$ Cholo Brooks, 'The Purge of Female Genital Mutilation In Liberia, Family Urges Victim to "Conform to Cultural Practice of FGM or Encounter Death"' $<$ http://gnnliberia.com/2017/01/09/purge-female-genital-mutilation-liberiafamily-urges-victim-conform-cultural-practice-fgm-encounter-death/>; Mary Wandia, 'Liberia Needs to Muster the Courage to Ban FGM' The Guardian (Monrovia, Liberia), 27 April 2016 <http://www.theguardian.com/globaldevelopment/2016/apr/27/liberia-courage-to-ban-fgm-ellen-johnson-sirleaf $>$.

${ }^{1038}$ Mae Azango, 'Outgoing President Sirleaf Abolishes Female Genital Mutilation, Signs Domestic Violence Bill' FrontPageAfricaonline.com (Monrovia, Liberia), 22 January 2018

$<$ https://frontpageafricaonline.com/index.php/news/6691-outgoing-president-sirleaf-abolishes-female-genitalmutilation-signs-domestic-violence-bill>.

${ }^{1039}$ INCITE! (ed), Colour of Violence: The INCITE! Anthology (Duke University Press, 2016) backcover.

${ }^{1040}$ Bettie Johnson, ‘ 49 Year-Old Alleged Rapist Indicted on Multiple Charges' Front Page Africa (Monrovia, Liberia), 9 March 2015 <http://frontpageafricaonline.com/index.php/news/4679-49-year-old-alleged-rapist-indictedon-multiple-charges>; Comfort M Johnson, 'Judge Sentences Man to 25 Years for Killing His Girlfriend' Liberian News Agency (Monrovia, Liberia), 9 March $2015<$ http://www.liberianewsagency.org/pagesnews.php?nid=4178>; Martine B Powell, 'Investigating and Reporting Child Sexual Abuse: Review and Recommendations for Clinical Practice' (1991) 26(2) Australian Psychologist 77.

${ }^{1041}$ Johanna Bond, 'Violence against Women' in Voices of African Women: Women's Rights in Ghana, Uganda, and Tanzania (Carolina Academic Press, 2005) 75, 75.
} 
Although Indigenous girls and women's contribution to history tends to be ignored, supporting evidence shows that they have always resisted foreign dominance, exhibited strong leadership skills, and propagated the maintenance of peace, especially where men have failed. One such woman is Truganini, a negotiator, diplomat and guerrilla fighter, who is considered 'one of the foremost Tasmanian Aboriginal leaders of the 1800s'. ${ }^{1042}$ Also, Liberia's first female paramount Chief, Nye Suakoko, who used her 'excellent diplomatic skills' to resolve violent conflicts between her Native Peoples in Liberia and settler-colonists, is laudable. ${ }^{1043}$ Bissell reaffirms the voices of the $57^{\text {th }}$ Session of the UN Commission on the Status of Women, noting 'we need data so that we can end impunity, we need to report acts of violence and we need to hold the people who commit violence against children [and women] accountable... ${ }^{1044}$ In spite of their bravery, resistance and leadership abilities, Indigenous women's strengths and resilience do not come without challenges, especially when it comes to conducting research on systematic violence against them. One challenge is their exclusion from the historical narrative.

In colonial history, whilst men are often adorned in glory and splendour, with the specific characterisation of leadership, rulership, and authority, children and women are relegated to collectives (e.g., 'native girls' or 'country women'). Sometimes tokenistic references to Indigenous women are made without much context or substance. ${ }^{1045}$ In many instances, Indigenous women are sexualised with disparaging images ${ }^{1046}$ of their half-naked bodies as nameless servants, or cultural exhibits unequally placed amongst their male counterparts. ${ }^{1047}$ For example, Professor Amos Sawyer dedicates an entire sub-section of chapter 3 of The Emergence of Autocracy in Liberia to the Poro (male) society, ${ }^{1048}$ with nine pages of references, but none to the Sande (female) ${ }^{1049}$ society. ${ }^{1050}$ Of the hundreds of historical resources

\footnotetext{
${ }^{1042}$ Beers, above n 564; Department of the Prime Minister and Cabinet, Aboriginal Women (5 March 2010) Women in Colonial Times <http://www.australia.gov.au/about-australia/australian-story/women-in-colonial-times>.

${ }^{1043}$ Filomina Chioma Steady, Women and Leadership in West Africa: Mothering the Nation and Humanizing the State (Palgrave Macmillan, 1st ed, 2011) 108-109, 128; Selma Lomax, 'Rural Boost - EJS Dedicates Chief Suakoko Centre for Women' All Africa (Monrovia, Liberia), 11 June 2014 <http://allafrica.com/stories/201406110497.html〉.

${ }^{1044}$ Bissell, above n 637.

${ }^{1045}$ Bonwick, above n 730, 26.

${ }^{1046}$ Reynolds, Dispossession, above n 177, 25, 51, 112, 124.

${ }^{1047}$ Dunn, Liberia, above n 103, 13; Karnga, above n 171, 6; Caine, above n 555, 55.

${ }^{1048}$ The teaching in the Poro society covers everything from drumming to bird-driving on the farm. Apart from stringently segregating men and women's role, the Institution appears to not only foster some form of discrimination against women but also authorise men to decide what role women should play in the social structure and order (see Caine (1959) at 42). The Vai male society is called Beli. One of the teachings here is the 'death and resurrection' theory whereby persons not member of the society is forbidden to enter the Institution without making known their presence through loud sounds. Male non-members guilty of trespassing will be seized and initiated forcibly and that of females banished or killed (see Caine (1959) at 39). Another instance amongst the Vai is a woman may properly leave her husband without refunding the bride-wealth if he fails to rotate amongst co-wives in proper order. She can also quit the conjugal relationship if he beats her unnecessarily or excessively (see Caine (1959) at 46). The implication here being that he is allowed to beat her but just not 'unnecessarily' or 'excessively'. In the Beli society, a 'man's wife (or womankind in general as a matter of fact) is so physically weak and simple-minded that she deserves the pity of strong and sophisticated man. Thus, to refer to another man as one's wife is to say he is ignorant - a gross insult'.

${ }^{1049}$ Brown, above n 50, 61-85. According to Brown, the Sande and Poro societies date back to the $17^{\text {th }}$ century. As secret societies, the Institutions promised death as punishment for betrayal for revealing the oath of secrecy taken after full initiation. Settler emigrants referred to the Institution as 'devil-bush' for the lack of understanding and respect on their part, perceiving that its main goal was to subjugate women. Whilst there is no age limit for enrolling into the Institution, boys entered between the ages of 7-10 (because that is when they are more "tractable) and girls, between the ages of 4-12 years.
} 
examined in this research, mainly written by males, a substantial majority failed to document Indigenous women's role in the formation and building of their nations. This continuous exclusion of Indigenous women from history, a form of systematic violence that is seamless with structural and cultural norms, fails to recognise any contribution they have made to nation building and development. Furthermore, the absence of violence against women in the historical narrative is not only the work of colonist-settlers.

Persistent violence against Indigenous women enacted by Indigenous men is often not spoken about in Indigenous communities. Australia's renowned writer and playwright, Louis Nowra expresses profound respect for Aboriginal culture but with a troubling concern. Lamenting the grim reality of violence against Aboriginal women by Aboriginal men, Nowra narrates his experience reading of the anal rape of a 13-year-old girl 'promised' to an Aboriginal elder and observing mutilated girls and women in the Alice Springs Hospital. Nowra expresses frustration that no male had written about this problem, although a few brave women had. He reasons that since physical and community violence against women is also an Aboriginal man's problem, society must deal with the issue immediately. ${ }^{1051}$ However, as discussed above, many intersecting factors contribute to the totality of systematic violence against women and girls, including systematic violence against Indigenous men.

Intersectionality theory affirms that the systematic violence Indigenous girls and women face is exacerbated by their dual identities: being both female and Indigenous. First, being Indigenous subjects Indigenous girls and women to differentiated treatment within the family, community and state. Second, being Indigenous predisposes Indigenous girls and women to various forms of human rights abuses, particularly because of their culture, which attached them to the land as First Peoples. ${ }^{1052}$ Such differential treatment may be a result of colonial history, discrimination, racism, sexism, and social status, amongst other components. Impacts and consequences of systematic violence against Indigenous Peoples come as a direct or indirect cause of historical factors such as convict transportation to Australia, the transAtlantic slave trade, massacres, and the civil war in Liberia. The impact of systematic gender violence goes beyond physical injuries to include stress-related illness including mental and emotional trauma. ${ }^{1053}$ The psychological pain and suffering resulting from forced adoption, forced marriage or intimate partner abuse, has a lasting inter-generational impact, accentuated by denial of (or insufficient) access to essential social services. Yet amidst such ongoing hurt, settler-colonists manage to stereotype Indigenous Peoples as lazy, drinkers, inferior and not as

\footnotetext{
${ }^{1050}$ Sawyer, The Emergence of Autocracy in Liberia, above n 61, 47, 49-51, 55, 68, 199, 235, 298.

${ }^{1051}$ Louis Nowra, Bad Dreaming: Aboriginal Men's Violence Against Women and Children (Pluto Press, 2007) abstract.

${ }^{1052}$ Soyata Maiga, 'Gender and Indigenous Peoples' Rights' in Korir Sing'Oei and Ridwan Laher (eds), Indigenous People in Africa: Contestations, Empowerment and Group Rights (Africa Institute of South Africa, 2014) 64, 64.

${ }^{1053}$ Anders, above n 527, 4. 
intelligent as white people. ${ }^{1054}$ This stigmatisation then inhibits Indigenous Peoples' access to justice through the Anglo-American or Anglo-Australian legal system.

Law and policy are beginning to address Indigenous girls and women's disproportionate vulnerability to systematic violence. Although still marginal to the state's political process, Diana Bell argues that within the context of law and policy on self-determination (for example), that Indigenous women may raise an agenda on equal rights and justice for systematic violence against them. ${ }^{1055}$ However, Bell contests that the self-determination movements of Indigenous Peoples in Australia still tend to privilege race over gender. ${ }^{1056}$ In Liberia, the legal system is also still attempting to address the disparity between Indigenous Peoples and settler-colonists.

Violence against Indigenous girls and women has its origin in the constitutional choices made at critical historical periods in Liberia. ${ }^{1057}$ For almost two centuries (1821-2015), the Liberian State has been marred by violence, which resulted in the dominant rule of settlercolonists and presidential autocracy. The rule of William V S Tubman (1944-71) was the longest and that of Samuel Doe (1980-1989) ${ }^{1058}$ was a dictatorship that began with a bloody coup d'état that collapsed into a senseless civil war. Today, Liberia is still grappling with impunity, corruption and ongoing challenges with implementing effective law and policy to protect girl and women against violence. Whilst most countries in Africa have enshrined some form of gender equality in their constitution, 'Liberia is one low-income country without this provision'. ${ }^{1059}$ The establishment of a Constitutional Review Committee in 2012 by the Government of Liberia aims to review the effectiveness of the Liberian Constitution 1986 in addressing issues of social justice, equality, and the importance of Indigenous tradition, inter alia, in Liberia. Some 10000 Liberians from the 73 constituencies in all 15 counties and the Diaspora, including traditional leaders and women's groups participated in these public consultations. The 52308 suggestions produced by the Constitutional Review Commission in its final report presented to then President Ellen Johnson Sirleaf on 18 August 2015, have yet to be followed. ${ }^{1060}$ Therefore, in Liberia, as in Australia, the struggle to recognise Indigenous women's contribution to both the nation-building process and the sustenance of a cohesive societal structure continues. Finally, the historical exclusion of Indigenous women during nation-building, the foreign and patriarchal origins of Anglo-American-Liberian and AngloAustralian law, cultural stereotypes infiltrating legal proceedings, and direct-state sponsored

\footnotetext{
1054 'First Contact', 2014.

${ }^{1055}$ Diane Bell, 'Representing Aboriginal Women: Who Speaks for Whom?' in Oliver Mendelsohn and Upendra Baxi (eds), The Rights of Subordinate Peoples (Oxford University Press, 1996) 221, 226.

${ }^{1056}$ Ibid.

${ }^{1057}$ Sawyer, Beyond Plunder, above n 101, 20.

${ }^{1058}$ Lawyers Committee for Human Rights, 'First Steps: Building the Justice System in Liberia' (Public Report, Lawyers Committee for Human Rights, December 1991) 3-9, 23-26.

${ }^{1059}$ Mary Hallward-Driemeier and Tazeen Hasan, Empowering Women: Legal Rights and Economic Opportunities in Africa (International Bank of Reconstruction and Development / The World Bank, 2013) 47.

${ }^{1060}$ Ekuru Aukot, Augusta Pshorr and Sam Zota, Constitution Review Committee Presents Final Report to President Sirleaf (18 August 2015) UNDP in Liberia

<http://www.undp.org/content/liberia/en/home/presscenter/articles/2015/08/18/constitution-review-committee-

presents-final-report-to-president-sirleaf.html>.
} 
violence against Indigenous women, lead to an examination of whether the foundational legal axiom 'the rule of law' is effective in Indigenous women's search for restorative justice. 


\section{CHAPTER 4: THE RULE OF LAW}

Before 1967 Aboriginal and Torres Strait Islander peoples were denied citizenship. We were not free, for example, to travel between imposed State borders nor within States, no matter where the borders of our country lay - and we were not entitled to an Australian passport although many of us had already fought and died overseas in two World Wars. We had to have permission to marry and we were not even counted in the census of the people of this nation country. In fact, for more than a century of nonIndigenous presence in our country, our humanity was actively denied - in many places the births of our children were recorded on livestock records. ${ }^{1061}$

Power must be exercised according to the rule of law; the majority cannot abuse the rights of the minority. ${ }^{1062}$

\subsection{Introduction and Background}

In the last two decades of the twentieth century, the 'rule of law' has been one of the most common formulas in law and governance employed by Western political and legal thinkers. ${ }^{1063}$ The 'rule of law', though typical of Anglo-Saxon culture, is nonetheless used everywhere, including in Indigenous societies across the world. ${ }^{1064}$ In fact, every continuous human enterprise or activity, whether individual or collective, is assumed to be rule-governed in some sense. Without this feature of rule-governance, individual and social behaviour will most likely lapse into randomness and radical contingency. ${ }^{1065}$ The expression 'the rule of law' is also popular in scholarly literature, political journals and international development work, especially in recent times. The international community, including the United Nations Development Program, World Bank and donor countries, uses 'good governance' and 'rule of law' principles as conditions for foreign aid, democracy, human rights promotion and sustainable development, especially when focusing on developing nations affected by the crisis. ${ }^{1066}$

A good government or ideal regime of governance is defined by rule-governance, that is, as a 'government of laws and not of men' ${ }^{1067}$ This doctrine aligns with central premises and hierarchical postulates that are endemic to so-called Western civilisation. That is, the rule of reasoning is a 'universal principle' that prioritises the law over arbitrary will, discretion or authority exerted by a single person. ${ }^{1068}$ Depending on the interests at stake, the concept of 'rule of law' invokes a number of ideals. For example, the rule of law opposes individual freedom

\footnotetext{
${ }^{1061}$ Dodson, 'Citizenship in Australia: An Indigenous Perspective (A Call for Structured and Comprehensive Representation of Indigenous People in Australia's Constitution', above n 368.

${ }^{1062}$ Staff Reporter, 'Triggs Marks 800 Years of Magna Carta at ANU Event' ANU News (Canberra, ACT), 16 June 2015 <http://www.anu.edu.au/news/all-news/triggs-marks-800-years-of-magna-carta-at-anu-event>.

${ }^{1063}$ Danilo Zolo, 'The Rule of Law: A Critical Reappraisal' in Pietro Costa and Danilo Zolo (eds), The Rule of Law, History, Theory and Criticism (Springer, 2007) 3, 3.

${ }^{1064}$ Pietro Costa, 'The Rule of Law: A Historical Introduction' in Pietro Costa and Danilo Zolo (eds), The Rule of Law, History, Theory and Criticism (Springer, 2007) 73, 73.

${ }^{1065}$ Fred Dallmayr, 'Hermeneutics and the Rule of Law' in Drucilla Cornell, Michel Rosenfeld and David Gray Carlson (eds), Deconstruction and the Possibility of Justice (Taylor and Francis, 2016) 283, 283.

${ }^{1066}$ United Nations Development Programme, 'Global Programme on Strengthening the Rule of Law and the Human Rights for Sustaining Peace and Fostering Development: 2016 Annual Report' (UN Report, United Nations

Development Programme, 2017) 148, 2-3; Attorney-General's Department, Rule of Law (2017) Australian

Government <https://www.ag.gov.au/About/Pages/Ruleoflaw.aspx>.

${ }^{1067}$ Dallmayr, above n 1066, 284.

${ }^{1068}$ Ibid.
} 
and totalitarian rule yet supports the importance of individual rights or individual autonomy against bureaucratic intrusiveness. ${ }^{1069}$ But who makes the law as a rule? Most certainly it is men, and overwhelmingly, white men in positions of power, authority and control over Indigenous Peoples. It is against this backdrop that this research assesses the rule of law as the constitutional basis for Liberia's and Australia's democracies as it imposes differential treatment on Indigenous girls and women.

This chapter examines how the same document (the constitution) can accord rights to all under the equality principle but somehow manage to exclude Indigenous Peoples from the 'all'. In analysing equal treatment under the law, the chapter questions whether there is an inherent contradiction with the concept of the rule of law or whether the principle is an illusion created by men in power with authority. Therefore, the basis for which such fundamental law legitimises discrimination against Indigenous girls and women is appraised and critiqued.

\subsubsection{Historical and Conceptual Philosophy of the Rule of Law}

The principle of the rule of law implies that individual rights and freedom must be protected by law, independently of the will of the ruler or the arbitrary power of public authorities. ${ }^{1070}$ Lon Fuller states that governance is based on the simple fact that we should have some kind of general rules, however fair or unfair. ${ }^{1071}$ Many legal scholars trace the origins of the phrase "the rule of law' to the Code of Hammurabi. ${ }^{1072}$ Even though Plato ${ }^{1073}$ and Aristotle ${ }^{1074}$ created exemplary models for legal authority that were consistent with the rule of law, Brian Tamanaha warns that the Greeks' thought was nearly lost to the West for half a millennium during the Dark Ages. ${ }^{1075}$ However, in medieval times, the Magna Carta ${ }^{1076}$ was used to restrain nobles, based on Aristotle's belief that laws based on the rule of law should be sovereign. ${ }^{1077}$ From a Western perspective, A V Dicey re-coined the conceptual meaning of the phrase in An Introduction to the Study of the Law of the Constitution. ${ }^{1078}$ Dicey, in contrast to Ronald Dworkin, ${ }^{1079}$ also envisioned the idea of the rule of law as distinct to England. He reasoned that

\footnotetext{
${ }^{1069}$ Costa, above n 1065, 73.

${ }^{1070}$ Magdalena Sepúlveda et al, Human Rights Reference Handbook (University of Peace, 3rd Revised, 2004) 32.

${ }^{1071}$ Lon L Fuller, The morality of law (1969) 46-47.

${ }^{1072}$ Lillian Goldman Law Library, Yale Law School, The Code of Hammurabi (2008) The Avalon Project:

Documents in Law, History and Diplomacy <http://avalon.law.yale.edu/subject_menus/hammenu.asp> at 17

November 2014.

${ }^{1073}$ Glenn R Morrow, 'Plato and the Rule of Law' (1941) 50(2) The Philosophical Review 105.

${ }^{1074}$ Steve Wexler \& A Irvine, 'Aristotle and the rule of law' (2006) 23(1) Polis: The Journal of the Society for Greek Political Thought 116-138; UN, UN Rule of Law Website (2013) United Nations Rule of Law

$<$ http://www.unrol.org > at 5 April 2013; Antonin Scalia, 'The Rule of Law as a law of rules' (1989) 56(4) The

University of Chicago Law Review 1175-1188.

${ }^{1075}$ Brian Z Tamanaha, On the Rule of Law: History, Politics, Theory (Cambridge University Press, 2004) 7.

${ }^{1076}$ Ibid 25.

${ }^{1077}$ Lenn Evan Goodman and Robert B Talisse, Aristotle's Politics Today (State University of New York Press, 2008) 63.

${ }^{1078}$ Albert Venn Dicey, Introduction to the Study of the Law of the Constitution (London, 1889) 21.

${ }^{1079}$ Trevor RS Allan, 'Dworkin and Dicey: The Rule of Law as Integrity (Reviews)' (1988) 8(2) Oxford Journal of

Legal Studies 266.
} 
[i]n England, no man can be made to suffer punishment or to pay damages for any conduct not definitely forbidden by law; every man's legal rights or liabilities are almost invariably determined by the ordinary Courts of the realm and each man's individual rights are far less the result of our constitution than the basis on which that constitution is founded. ${ }^{1080}$

\title{
4.0.2 Characteristics and Constituents of the Rule of Law
}

\begin{abstract}
In a recent complaint, the AHRC found that four Aboriginal men with intellectual and cognitive disabilities had been held for many years in a maximum-security prison in the Northern Territory. ... Sadly, such detention disproportionately impacts Aboriginal and Torres Strait Islanders; a problem exacerbated by the Northern Territory's 'paperless arrest' powers introduced late last year permitting detention for four hours without being brought to a court for offences that do not in some cases, attract the sanction of imprisonment. Such detentions have dramatically increased the rate of detention of Aboriginal Australians and deaths in custody continue, as recently as last week, 25 years after the Royal Commission Report into Deaths in Custody. ${ }^{1081}$
\end{abstract}

Testing the validity and legitimacy of the rule of law is an ongoing struggle for Aboriginal Peoples, as noted by Gillian Triggs, President of the Australian Human Rights Commission, in her Alice Tay Lecture on law and human rights commemorating 800 years of the Magna Carta, as quoted above. Lawyers and laypersons alike use the phrase 'rule of law' as politico-legal jargon. However, there is not a clear consensus on what this expression actually means. Richard Dworkin suggests two conceptual frameworks of the rule of law. They are 1) the 'rule-book' theory, which purports that the power of the state 'should never be exercised against individual citizens except in accordance with rules explicitly set out in a public rule book available to all'; and 2) the conception of the right, which 'assumes that citizens have moral rights and duties with respect to one another, and political rights against the state as a whole'. ${ }^{1082}$ The rule-book concept is a narrower view with less focus on the content of the rules but more emphasis on following them, whereas the rights approach recognises citizens' moral rights and duties with respect to one another and political rights against the state. Dworkin prefers the rights concept because it more closely aligns with the rule of law and substantive justice ${ }^{1083}$ (that is, the recommendation that, 'equal basic rights be assigned to all persons').

The efficacy of the rule of law in promoting justice depends largely on adopting the conception of the right. Dworkin, Fallon and Rawls draw a distinction between written rules on the one hand and practical application of rights, procedures and morals on the other, and emphasise on how these ideas inherently conflict with justice and fairness. Trevor R S Allan expands on how Dworkin's theory of integrity of the law is tied to its content and imposes an

\footnotetext{
${ }^{1080}$ Dicey, above n 1079, 21.

${ }^{1081}$ Gillian Triggs, 'Gillian Triggs on Magna Carta: Alice Tay Lecture in Law and Human Rights - in Full' The Guardian (Canberra, ACT), 15 June 2015 <http://www.theguardian.com/australia-news/2015/jun/15/australia-andthe-magna-carta-how-the-coalition-and-labor-agree-on-laws-that-violate-our-freedoms $>$.

${ }^{1082}$ Ronald M Dworkin and British Academy, Political Judges and the Rule of Law (British Academy, 1980) vol 23, 261-262.

${ }^{1083}$ Ibid 263-264.

${ }^{1084}$ John Rawls, A Theory of Justice (Belknap Press, Original, 2005) 77.
} 
obligation of obedience, ${ }^{1085}$ and Tamanaha discusses the rule of law as a situation in which governments must act through laws. In its extreme form, a government that conducts its affairs solely according to rules runs the risk of disintegrating the substantive legal formality or abrogating its legal responsibility. ${ }^{1086}$ As Joseph Raz clearly illustrates,

A non-democratic legal system, based on the denial of human rights, on extensive poverty, on racial segregation, sexual inequalities, and racial persecution may, in principle, conform to the requirements of the rule of law better than any of the legal systems of the more enlightened Western democracies. ... It will be an immeasurably worse legal system, but it will excel in one respect: in its conformity to the rule of law. ${ }^{1087}$

The validity of Raz's view regarding potential fallacies of the rule of law (that is, strict obedience to the rule of law even when it violates human rights) turns the concept into a meaningless slogan. Raz believes that the illusory ideals of the rule of law have captured the imagination of humans as long as the existence of Western democracies:

The function of the legislature in a free society under the Rule of Law is to create and maintain the conditions that will uphold the dignity of man [Indigenous girl or woman] as an individual. This dignity requires not only the recognition of his [her] civil and political rights but also the establishment of the social, economic, education and cultural conditions which are essential to the full development of his [her] personality. ${ }^{1088}$

Joseph Raz asserts that since the rule of law is just one of the virtues of a legal system, it should not be 'confused with democracy, justice, equality (before the law or otherwise), human rights, respect for persons or for dignity of man.'

Judges and legislatures affect the creation and implementation of the rule of law by adopting the rule-book or the rights concept. According to Raz, it matters not only that outlining rights in constitutions give authority to the courts to interpret those rights in dispensing fairness and justice, but also that the kinds of rights protected are paramount to the development of individual citizens, which includes Indigenous Peoples. The rule-book concept in Australia and in Liberia supports conventional views about the role of political judges that are similar to views held by their colonial masters. The legislature uses words to enact rules, which direct judges in forming semantic theories. Thus, each judge, in good faith, tries to follow the ideals of the rule of law to discover the intention and the meaning provided in the rule-book. ${ }^{1090}$ The rights concept, on the other hand, insists that judges consider the moral rights of the parties involved ${ }^{1091}$ in adjudicating hard cases. However, these judges are still people with biases and their own

\footnotetext{
${ }^{1085}$ Trevor RS Allan, 'Law, Justice and Integrity: The Paradox of Wicked Laws' (2009) 29(4) Oxford Journal of Legal Studies 705.

${ }^{1086}$ Tamanaha, above n 1076, 93.

${ }^{1087}$ Raz, above n 111, 209.

${ }^{1088}$ Ibid.

${ }^{1089}$ Ibid.

${ }^{1090}$ Dworkin and British Academy, above n 1083, 264-265.

${ }^{1091}$ Ibid 267-268.
} 
moral conceptions. Therefore, who they are and who places them in a position of authority directly influences their moral considerations.

Citizens' participation in government is a key factor affecting the rule of law. The power of individual citizens, including Indigenous Peoples, in democracies such as Liberia and Australia, who elect legislators but not judges, tends to threaten the very nature of justice and fairness as the crux of the rule of law. ${ }^{1092}$ Richard Fallon identifies the disconnect concerning citizens' ability to elect legislators but not judges as a difference between 'the rule of law' and 'the rule of man'. ${ }^{1093}$ Rawls seems wary of what characterises 'true democracy' if it actually exists. For instance, regardless of whether having a constitution reflects the existence of 'true democracy', Rawls's reasoning transcends the mere packaging of a constitution with the inclusion of a bill of rights. ${ }^{1094}$ Rawls argues that the political public must play an educational role to ensure citizens' understanding of basic rights and liberties through interpretation of rights (by judges) as articulated in and consistent with the constitution. This argument presupposes that equality of political power in constitutional democracies is embedded in genuine political decisions taken by the legislature and interpreted in courts, as well as in equal participation of all citizens. Therefore, assuming the rights concept, there must be some characteristics of the rule of law that define the law's relationship to the rights of a politically and legally active citizenry.

In response to Raz, Tom Bingham identifies eight clusters of principles that define what the political ideal of the rule of law means:

- Accessibility of the law: If we are liable to prosecution, fine, or imprisonment in breach of the law, then we must be cognizant of how to avoid penalty. Having full knowledge of the law authenticates the rule of law principle. ${ }^{1093}$

- Law, not discretion: Though the court or tribunal does not make every decision affecting the rights or liabilities of citizens (implying that some legal authority is discretionary), the rule of law requires that no discretion should be unconstrained so as to be potentially arbitrary. ${ }^{109}$

- Equality before the law: The law should be unquestionable because the laws of the land should apply equally to all, except to the extent that objective differences justify differentiation. ${ }^{1097}$

- The exercise of power: Judges have authority in reviewing the lawfulness of actions or decisions taken by public and private administrators and individuals. ${ }^{1098}$

\footnotetext{
${ }^{1092}$ Ibid 280.

${ }^{1093}$ Richard H Fallon Jr., “"The Rule of Law” as a Concept in Constitutional Discourse' (1997) 97(1) Columbia Law Review 1.

${ }^{1094}$ John Rawls, Justice as Fairness: A Restatement (Harvard University Press, 2001) 145-146.

${ }^{1095}$ Bingham, above n 116, 37.

${ }^{1096}$ Ibid 50, 54; Bureau of Democracy Human Rights and Labour, 'Liberia: 2013 Human Rights Reports' (International Report, United States Department of State, 27 February 2014) 27, 1-2

<https://www.state.gov/documents/organization/220339.pdf>. Although the US Department of State report suggests 'no reports that the [Liberian] government or its agents committed arbitrary or unlawful killings', there is a cited example of police arbitrary brutality against civilians: ' ... while a citizen was waiting to use an air pump at a service station, uniformed Liberia National Police (LNP) officers ordered him to move. The officers, directed by top-ranking LNP officer Gbor Phil Tougbay (assistant director of police for administration and professional standards) in a police vehicle, assaulted and beat him, removed his car battery, tore his clothes, handcuffed him to the back of the police pickup truck, threw him into the truck bed, and jailed him overnight. The same assistant inspector general of police was also involved in abusing a lower-ranked officer during the year and remained under investigation for both incidents. Also, during the year an inspector at a local police station reportedly raped a woman who was visiting someone being held for questioning. This case was being prosecuted, and a trial date was set'.

${ }^{1097}$ Bingham, above n 116, 55.

${ }^{1098}$ Ibid 61.
} 
- Human rights: The concept of human rights is not universally codified in law because states as power-holders decide which rights to protect by law and what sanctions to impose for breach. Notwithstanding, the law must make some effort to protect fundamental human rights adequately.

- Dispute resolution: This principle speaks to the accessibility and affordability of legal aid. As the legal maxim states, 'justice delayed is justice denied'. Thus, legal redress must be provided to resolve disputes expeditiously and without prohibitive cost. ${ }^{11}$

- A Fair Trial: A trial is not fair if the legal procedure favours one party over another. A trial can only be fair if it is (a) recognised as fairness on both sides; and (b) accepted that fairness is an evolving concept, rather than being frozen in time.

- The Rule of Law in the International Legal Order: The rule of law requires compliance by the State with its obligation in international law as in national law. Note a distinction between monism and dualism regarding the impact of international law on domestic law. ${ }^{1102}$

Bingham's eight characteristic ideals of the rule of law are not without critique, as is discussed below. However, one of the fundamental principles of the rule of law, justice and fairness is that like cases are decided alike (that is, binding precedents), ${ }^{1103}$ which speaks to Bingham's 'law, not discretion', 'the exercise of power', and 'fair trial'. The questions of whether judges should stick to decisions previously taken in court and the kinds of reasoning employed in deciding cases are central to the rule of law. Judges are expected to be fair, independent, impartial and non-arbitrary in treating everyone equally before the law. But we can question whether judges' decisions are legal, ${ }^{1104}$ political ${ }^{1105}$ or free from any influence that might 'tilt the scale of justice' ${ }^{1106}$. Even principles of precedence that are intended to strengthen the rule of law can add biases that undermine it.

Stare decisis is a legal principle adopted to reduce arbitrariness of the law by establishing precedence, but it may also counteract the rule of law in some situations. In Latin, the phrase stare decisis et non quieta movere means 'to stand by decisions and not to disturb settled matters'. ${ }^{1107}$ By so doing, the law ensures constancy, predictability and generality in treating like cases alike. ${ }^{1108}$ In essence, the driving force of the rule of law's justification for

\footnotetext{
${ }^{1099}$ Ibid 66, 68.

${ }^{1100}$ Ibid 85, 87.

${ }^{1101}$ Ibid 90.

${ }^{1102}$ Jordan J Paust, 'Basic forms of international law and monist, dualist, and realist perspectives' in Marko Novkovic (ed) Basic Concepts of Public International Law - Monism and Dualism (2013) 244-265, 245-247. Paust distinguishes monism from dualism in international law: monism assumes one system of human law whereby international law (including jus cogens) is universal in its reach to all actors both horizontally and vertically and that inconsistent domestic authorizations or law provide no excuse with respect to violations of customary international law. Dualism views all forms of international law as entirely separate from domestic legal processes and that international law merely operates at an international level in a community of independent states. If international law must operate domestically then it has to be implemented or transformed by some formal conduct of domestic political entity (e.g., legislation).

${ }^{1103}$ James Penner, The Law of Trusts (Oxford University Press, 9th ed, 2014) 4.

${ }^{1104}$ Neil Duxbury, The Authority of Precedent: Two Problems (Faculty of Law, University of Toronto, 2005) <http://www.mcgill.ca/files/legal-theory-workshop/Neil-Duxbury-McGill-paper.pdf>.

${ }^{1105}$ Dworkin and British Academy, above n 1083, 259. Dworkin affirms, '[o]f course the decisions that judges make must be political in one sense' since in fact, the decision judges make are somehow approved by one political group as in MPs dual roles influenced by both the executive and legislative branches.

${ }^{1106}$ The Australian Judiciary (Cambridge University Press, 2nd ed, 2013) 5-7.

${ }^{1107}$ Paul M Perell, 'State Decisis and Techniques of Legal Reasoning and Legal Argument' (1987) 3(2) Legal Research Update 1.

${ }^{1108}$ Jeremy Waldron, 'Stare Decisis and the Rule of Law: A Layered Approach' (2011) 11(75) Public Law and Legal Theory Research Paper Series 1.
} 
binding decisions is the reasoning behind the principle of stare decisis. ${ }^{1109}$ In a hierarchical legal structure, ${ }^{1110}$ a higher court within the same jurisdiction usually acts as a binding authority on a lower court within the same jurisdiction. That is, when the same issue arises again in court, a lower court should follow the precedent established by the higher court. ${ }^{111}$ These precedence theories of legal doctrine tend to necessitate consistency in the processing of legal decisions, serving both practical and educational purposes in law. ${ }^{1112}$ However, there is an irony about the stare decisis doctrine when a court chooses to stand by a precedent notwithstanding suspicions about its correctness, or worse, its wrongness. Indeed, courts laud stare decisis as possessing 'fundamental importance to the rule of law, promoting the even-handed, predictable, and consistent development of legal principles, and contributing to the actual and perceived integrity of the judicial process'. ${ }^{1113}$ Yet stare decisis has a remarkable tendency to incite disagreements that contradict the very principles it is supposed to foster, wherein the court's treatment of the stare decisis doctrine may yield unusually scathing dissents. Such wrongful decisions reveal that the application of the doctrine is driven by outcome preferences and that 'power, not reason, is the currency of the court's decision-making'. ${ }^{1114}$ Troubling though they may be, these charges are hardly surprising, ${ }^{115}$ especially with respect to some of the case examples highlighted in Chapter 3. Courts have cautioned repeatedly that stare decisis is a 'principle of policy as opposed to an inexorable command'. ${ }^{1116}$ A legal principle claiming to be both consistent and adaptable only raises brows regarding its legitimacy and authority. Furthermore, factors that inform the stare decisis inquiry are lengthy and uncertain, supposedly befitting a doctrine whose core is a fluctuating 'series of prudential and pragmatic considerations'."

From the literature, it is clear that a legal system conforming to the rule of law must embody several key characteristics to be effective in delivering justice; but those characteristics are not always satisfied for Indigenous women. The rule of law must be grounded in human rights, not merely an arbitrary set of rules. However, human rights are not always guaranteed to Indigenous Peoples by the state's constitution or other legal instruments. Legislators must consider human rights when drafting laws, and judges must reinforce that conceptualization by considering the rights of the people when passing judgement. However, stigmas and stereotypes often prevent legislators from upholding human rights and judges from ruling without bias. Citizens must also be effectively engaged in the political process. Yet Indigenous Peoples in Liberia and Australia have been systematically excluded from the political process since the

\footnotetext{
${ }^{1109}$ Arthur Goodhart L, 'Determining the Ratio Decidendi of a Case' (1930) 40(2) Yale Law Journal 161.

${ }^{1110}$ Gary Slapper, The English Legal System (Routledge, 11th ed, 2010) 112.

${ }^{1111}$ Neil Duxbury, The Nature and Authority of Precedent (Cambridge University Press, 2008) 30; Hannah Berryman, Explaining the Advantages and Disadvantages of the Doctrine of Stare Decisis, Strode's College Essay Competition Paper, 2014 <http://www.peterjepson.com/law/SL1-Berryman.pdf>.

${ }^{112}$ Niklas Luhmann, Klaus A Ziegert and Fatima Kastner, Law as a Social System (Oxford University Press, 1st ed, 2008) 8.

${ }^{1113}$ Randy J Kozel, ‘State Decisis as Judicial Doctrine’ (2010) 67 Washington and Lee Law Review 411, 412.

${ }^{1114}$ Ibid 413.

${ }^{1115}$ Ibid.

${ }^{1116}$ Ibid 414

${ }^{1117}$ Ibid.
} 
founding of these nations. Also, concepts intended to set precedence have the potential to carry forward discriminatory laws or judgements, thereby contributing to intergenerational state violence. Therefore, this chapter assesses the political and legal development of Liberia and Australia in an effort to identify and critique major factors that affect the efficacy of the rule of law as it is applied to Indigenous women.

\subsubsection{Creating the Nation without Its Citizens: The Birth of State Violence}

The first fleet of 11 ships carrying convicts from Portsmouth, England, arrived at Botany Bay in 1788 with no legal text except for instructions that were given to Captain Phillip at the 'will and pleasure of the King' to disembark 600 male and 180 female convicts on Aboriginal country. ${ }^{1118}$ White Australian settlers' claim of terra nullius ${ }^{1119}$ under international law justified the dispossession of Aboriginal Peoples' land and the consequential refusal to recognise First Peoples in the nation-building process. According to Reynolds, Australia became British by 'the assertion of sovereignty on four occasions, in 1788, 1824, 1829 and 1879'. ${ }^{1120}$ Reynolds confirms that 'when the British arrived in Australia in 1788 they knew nothing about Aboriginal customs or law'. Evidence for Reynolds's assertion is found in a quotation he provides from Marine captain Watkin Tench in 1789: 'Whether any law exists among them for the punishment of offences committed against society ... I will not positively affirm ... It would be trespassing on the reader's indulgence were I to impose on him an account of any civil regulations, or ordinances, which may possibly exist among this people. I declare to him, that I know not of any'. ${ }^{1121}$ It is with such ignorance and disregard for Indigenous Customary Laws that the Commonwealth of Australia (formerly six independent British colonies, which later morphed into six federal states and two territories) was birthed on 1 January 1901 by virtue of a British Act of Parliament, the Commonwealth of Australia Constitution Act 1901.

Ignorance of the exclusion of Aboriginal Peoples from the drafting of the Australian Constitution persists to this day. Honourable Stephen Parry, President of the Senate; Honourable George Brandis, Attorney-General; and Bronwyn Bishop, Speaker of the House of Representatives, are the three signees to the introductory comments made in Australian

\footnotetext{
${ }^{1118}$ See original transcript of Governor Phillip's Instructions 25 April 1787 at <http://foundingdocs.gov.au/resources/transcripts/nsw2_doc_1787.pdf>

${ }^{1119}$ Reynolds, Dispossession, above n 177, 67.

${ }^{1120}$ Reynolds, Aboriginal Sovereignty, above n 221, 86. On 24 January 1778, the First Fleet of 11 ships led by HMS Sirius arrived at Botany Bay with more than 1483 women, children and men; including 759 convicts (192 women and 586 men). In 1824, Britain transplanted English Common Law to Australia through the establishment of the first Chief Justice of the Supreme Court Francis Forbes (5 March); the first Supreme Court of Tasmania by Letters Patent (7 May); the Supreme Court of New South Ways by Letters Patent (17 May); and the first-sitting of the Legislative Council of New South Wales (25 August). Sir James Stirling (the first Governor of Western Australia) lands at the mouth of the Swan River to establish present day Perth. On 2 May 1829, Sir Howe Fremantle hoisted the Union Jack on the south head of the Swan River, thereby 'formally' claiming New Holland (Western Australia) for Britain. Murray Island was unclaimed until 1879 when Britain annexed it to Queensland (noteworthy, Mabo overturned the 'fiction' of terra nullius). NB: Letter Patents is a legal instrument published by written order from the Queen, literally granting complete monopoly and right to an office. In this case, the Monarch in England, granting power and authority of these legal institutions over Aboriginal Australians without permission, consultation, negotiation or treaty agreement.

${ }^{1121}$ Ibid 60-85.
} 
Constitution (Pocket Edition) 2014. The introductory comment of the Pocket Edition of the Australian Constitution states that '[i]n reality, however, the Constitution is a document which was conceived by Australians, drafted by Australians and approved by Australians' ${ }^{1122}$ and therefore 'reflects the pragmatic, no-nonsense attitude which we like to think is among the most attractive features of the Australian character'. ${ }^{1123}$ However, the fact that 49 white men ${ }^{1124}$ crafted the Australian Constitution clearly indicates the exclusion of Aboriginal Peoples from the formation of settler-colonist Australia. Further, the use of the phrase 'Australian character' in the introductory comment of the Pocket Edition of the Australian Constitution questions whether Aboriginal Peoples form part of this national personality, which is dominated by white settler-colonists by virtue of section 25. In fact, Mick Dodson's view is that 'at present, the Constitution is far from Indigenous friendly as it does not affirm that Indigenous Peoples are equal' ${ }^{125}$ to white Australian settler-colonists (see s25 and s51(xxvi) of the Australian Constitution). ${ }^{1126}$ Refusal to acknowledge Aboriginal Peoples as the original custodians of the land also signals the 'legal birth' of a carefully constructed state and of institutional violence against Aboriginal Peoples.

Aboriginal Peoples could have benefited from a general statement of human rights in the Australian constitution, but the drafters consciously excluded it. Unlike its Westminster contemporaries (Britain, Canada and New Zealand), the Australian Constitution, which attempted to borrow from that of the United States, rejected clauses such as 'legal rights', 'civil and political rights', and 'an equal protection clause'. Whilst these clauses form the cornerstone of a constitutional bill of rights in the above 'colonies', the original drafters of the Australian Constitution saw the clauses 'as having the potential to restrict colonial laws that limited the employment of Asian workers'. ${ }^{1127}$ Therefore, unlike the Liberian Constitution 1986 (Article 11(c)), the Australian Constitution 1902 does not guarantee equal protection of the law for all.

\footnotetext{
${ }^{1122}$ Commonwealth of Australia, Australia's Constitution Paper Edition: With Overview and Notes by the Australian Government Solicitor (Parliamentary Education Office and the Australian Government Solicitor, 10th ed, 2014) ix. ${ }^{1123}$ Ibid vii.

${ }^{1124}$ Byrnes, above n 583, 24; Behrendt, above n 568, 257. Andrew Inglis Clark, Attorney General, Tasmania, selected member of a drafting sub-committee prepared a preliminary draft proposal for the Australian constitution after the 1890 Australasian Federation Conference held in Melbourne 6-14 February 1890. Also see

<http://www.aph.gov.au/About_Parliament/Senate/Research_and_Education/Records_of_the_Australasian_Federal_ Conventions_of_the_1890s>

${ }^{1125}$ Dodson, 'Constitutional Recognition of Indigenous Australians', above n 368.

${ }^{1126}$ Section 25: Provisions as to races disqualified from voting states: For the purposes of the last section, if by the law of any State all persons of any race are disqualified from voting at elections for the more numerous House of the Parliament of the State, then, in reckoning the number of the people of the State or of the Commonwealth, persons of that race resident in that State shall not be counted. Supporting the RECOGNISE campaign, informed by the Expert Panel Report on Recognising Aboriginal and Torres Strait Islander Peoples in the Constitution (January 2012), Mick Dodson reiterated the goal of an upcoming referendum that would remove ss 25 and 51(xxvi) whilst inserting a new section 51A (to recognise Aboriginal and Torres Strait Islander peoples and to preserve the Australian Government's ability to pass laws for the benefit of Aboriginal and Torres Strait Islander peoples); a new section 116A (banning racial discrimination by government); and a new section 127A (recognising Aboriginal and Torres Strait Islander languages were this country's first tongues, whilst confirming that English is Australia's national language). See <http://www.recognise.org.au>.

${ }^{1127}$ Byrnes, above n 583, 25-26.
} 
To be clear, the phrase 'the rule of law' cannot be found anywhere in the Australian Constitution; ${ }^{1128}$ however, section 5 states:

This Act, and all laws made by the Parliament of the Commonwealth under the Constitution, shall be binding on the courts, judges, and people of every State and of every part of the Commonwealth, notwithstanding anything in the laws of any State; and the laws of the Commonwealth shall be in force on all British ships, the Queen's ships of war excepted, whose first port of clearance and whose port of destination are in the Commonwealth.

In other words, section 5 of the Australian Constitution (and s10 (3) of the Racial Discrimination Act 1975) ${ }^{1129}$ provide that everyone is subject to the rules of the Australian Constitution, including the Commonwealth Parliament, with an exception of the Queen's Ship of War. Section 5 of the Australian Constitution could be broadly extended to include equal protection for all, as is boldly stated on the Attorney-General website. ${ }^{1130}$ However, since the Australian Constitution does not recognise Aboriginal Australians as the original owners of the land with autonomous and sovereign power, efforts to guarantee Aboriginal Peoples in Australia individual rights continue to be responded to with apathy, neglect and violence on the part of settler-colonists.

Since settler-colonists in Australia believed that Indigenous Peoples would die out, they could not imagine a future in which Aborigines would play a role in a nation-building project. ${ }^{1131}$ The Constitution of Australia serves as an example in which rule-governing legislation intentionally neglected Aboriginal Peoples. Section 127 of the Australian Constitution (titled 'Aborigines not to be counted in reckoning populations') substantiated the non-existence of Aboriginal Peoples in Australia until repealed by the Constitutional Alteration (Aboriginals) 1967. The Expert Panel on Recognising Aboriginal and Torres Strait Islander Peoples in the Constitution 2012 reasons that the purpose of section 127 was to prevent Queensland and Western Australia from using their large Aboriginal population to gain seats in the Commonwealth Parliament. ${ }^{1132}$ Notwithstanding, the Australian Constitution failed to define the term 'Aboriginal Natives' in section 127. Following an opinion obtained from the attorney general, the first Commonwealth statistician confined the expression to 'full-bloods' Aboriginal Peoples, thereby excluding Torres Strait Islanders from section 127. ${ }^{1133}$ Josiah Symon, a prominent member of the Australian Federation Convention, made known his disapproval and

\footnotetext{
${ }^{1128}$ A last alteration made to the Australian Constitution was 1 October 2010.

${ }^{1129}$ Section 10(3) of the Racial Discrimination Act 1975 confers rights to equality before the law by virtue of section 5 of the International Convention on the Elimination of All forms of Racial Discrimination (CERD) 1969. Of particular interest is Article 5(a) of CERD, which states in prohibition and elimination of racial discrimination, States must ensure 'the right to equal treatment before the tribunals and all other organs administering justice' of all citizens.

${ }^{1130}$ Attorney-General's Department, above n 1067.

${ }^{1131}$ Elizabeth M Muller, Absorption and Assimilation: Australia's Aboriginal Policies in the 19th and 20th Centuries (Bachelor Honours of Arts (Honours) Thesis, Boston College, 2011) 38-39 <https://dlib.bc.edu/islandora/object/bcir:102082/datastream/PDF/view>.

${ }_{1132}$ Patrick L Dodson et al, Recognising Aboriginal and Torres Strait Islander Peoples in the Constitution: Report of the Expert Panel. (Dept. of Families, Housing, Community Services \& Indigenous Affairs, 2012) 14.

${ }^{1133}$ Ibid 21.
} 
concerns: 'It is monstrous to put a brand on these people once you admit them. It is degrading to us and to our citizenship to do such a thing. If we say they are to be admitted amongst us, we ought not to degrade them by putting on them the brand of inferiority'. ${ }^{113}$

Aboriginal Peoples in Australia continue to resist systematic violence against them by advocating for the repeal of discriminatory laws. A case in point is the landmark 1967 referendum. The 1967 Federal Referendum ${ }^{1135}$ repealed s127 of the Australian Constitution, which was worded: 'In reckoning the numbers of the people of the Commonwealth, or of a State or other part of the Commonwealth, aboriginal natives shall not be counted. ${ }^{{ }_{1136}}$ The 1967 Referendum also amended section 51 (xxvi) Australian Constitution, which referred to 'the people of any race, other than the aboriginal race in any State, for whom it is deemed necessary to make special laws.' The words 'other than the aboriginal race in any State' were deleted after the victory of the 1967 Referendum. This historic moment is sometimes perceived as 'evidence that Australians recognise Aborigines are part of the nation'.

The exclusion of Indigenous Peoples in Australia from the framing of the nation's Constitution continued a pattern of marginalisation and systematic discrimination, the consequences of which endure today, along with questions about the principle of the rule of law. ${ }^{1138}$ In a country that takes pride in its liberal and democratic traditions, it is surprising for many to learn that the birth of the Australian nation was attended to by racially discriminatory sentiment and continues to contain racially discriminatory provisions in its Constitution. ${ }^{1139}$ Indigenous Peoples' struggle for recognition in Australia reflects racial and discriminatory attitudes expressed in the opening quotation at the beginning of chapter 4 . The quotation is an extract taken from a speech made by Professor Michael Dodson at the Culture and Citizenship Conference in 1996. The main point here is not only that nearly two decades after the conference, Dodson's tireless efforts with the RECOGNISE campaign persist with the aim of securing constitutional acknowledgment of Indigenous Peoples as the First Peoples of Australia; ${ }^{1140}$ but also that concerns about the legitimacy of constitutional provisions which exclude Indigenous Peoples from power-sharing in Australia shows a deeply flawed legal system that still promotes an idea of Aboriginal Peoples' inferiority. Unfortunately, similar flaws also stem from the colonial origins of Liberia.

The legal foundation of Liberia also excluded Indigenous Peoples. In 1821, when the American Colonization Society began resettling African American settler-colonists on the western shores of Africa, the first agent, Samuel A Crozer, was given only special instructions

\footnotetext{
${ }^{1134}$ Ibid 17.

${ }^{1135}$ Attwood, above n 17, 54-64.

${ }^{1136}$ The Commonwealth of Australia Constitution Act 1900 (Cth) s.127 (repealed).

${ }^{1137}$ Russell McGregor, Indifferent Inclusion: Aboriginal People and the Australian Nation (Aboriginal Studies Press, 2011) 158.

${ }^{1138}$ Dodson et al, above n 1133, 19.

${ }^{1139}$ Ibid 18.

${ }^{1140}$ RECOGNISE is a people's movement to recognise Aboriginal and Torres Strait Islander peoples in the Australian Constitution.
} 
regarding the allotment of Indigenous lands. ${ }^{1141}$ The Board of Managers of the American Colonization Society drafted the first Constitution for the Government of the African Settlement 1820. ${ }^{1142}$ The 1820 Constitution provided that the United States' common law would be applied to the people and would be in force in the colony of Liberia. Rules of evidence and judicial proceedings were to be accorded using the laws of the United States. ${ }^{143}$ The Constitution of the Commonwealth 1839 later superseded the 1820 Constitution. Karnga and Cassell (respectively) attest to the fact that the original Constitution of Liberia was significantly modelled after that of the United States:

The Constitution [of Liberia] that had just been adopted, having been framed and worked by the gifted American law authority, Simon Greenleaf, in America, was not evolved out of conditions [of] Liberia. Evidently the Republican leaders had not had time to study the deleterious effect which would result to an already poor community like theirs from the biennial upheavals of general elections toward the running of which the state coffers had to contribute. ${ }^{1144}$

In 1839 the parent society and its chief auxiliaries agreed to combine administration of the several colonies, except for the Maryland Society... The result was the Commonwealth of Liberia. The eminent jurist Simon Greenleaf was chosen to draft the necessary new law... The new executive was to be called 'the President of Liberia and Governors of the other Colonies.' Judicial power was to be vested in a Supreme Court and such other courts as the legislature might establish. In substance, the constitution laid the foundation for the future republic. ${ }^{1.45}$

Similar to what happened in Australia, 12 African American settler-colonists signed the Liberian Declaration of Independence and Constitution 1847, granting a legal license to encroach upon Indigenous Peoples' land and transplant foreign norms without consultation. The Liberian Declaration of Independence, ${ }^{1146}$ a historical epic ${ }^{1147}$ drafted by 12 men who were former slaves, stated:

While announcing to the nations of the world the new position which the people of this Republic have felt themselves called upon to assume, courtesy to their opinion seems to demand a brief accompanying statement of the causes which induced them, first to expatriate themselves from the land of their nativity and to form settlements on this barbarous coast, and now to organize their government by the assumption of a sovereign and independent character. Therefore, we respectfully ask their attention to

\footnotetext{
${ }^{1141}$ Huberich, above n 53, 145; Campbell, above n 189, 35-58. Note the exception of the Maryland Colonisation Society that migrated immigrants to Cape Palmas based on legal texts created prior to arrival on the African coast. ${ }_{1142}$ Huberich, above n 53, 145.

${ }^{1143}$ Ibid 154.

${ }^{1144}$ Karnga, above n 171, xiv.

${ }^{1145}$ Cassell, above n 53, 115; Hanatu Kabbah, 'A Guide to the Liberian Legal System and Legal Research' 7 <http://www.nyulawglobal.org/globalex/Liberia1.htm>.

${ }^{1146}$ Cassell, above n 53, 137. The signers of Liberia Declaration of Independence were twelve Afro-American settler men - Samuel Benedict, Elijah Johnson, Hilary Teage, Beverly R. Wilson, J. R. Gripon and John Naustehlau Lewis for Montserrado County; John Day, Anthony W. Gardiner, Amos Herring, and Ephraim Titler for Grand Bassa County; and Jacob Prout and Richard E. Murray for Sinoe County.

${ }^{1147}$ Azikiwe, above n 301, 63. Consider Azikiwe's perspective on Liberia's Declaration of Independence: ‘This

Declaration of Independence is an historical epic and a literary masterpiece. It is a matchless document in the records of African political institutions. It is destined to arouse the lethargy of millions of Africans, at home and abroad, to a realization of the political destiny of the black man in the history of the world. Unfortunately, this document failed to give the Liberian indigenes the praise due to them for not only accommodating the immigrants, but also assimilating and amalgamating with them. It failed to recognize the political acumen and the social and material cultures of the African tribes, which inhabit these regions. This little oversight, due probably to Christian zealousness, might have averted the ever-persistent bugaboo of the aboriginal problem.'
} 
the following facts: We recognize in all men certain inalienable rights; among these is life, liberty, and the right to acquire, possess, enjoy, and defend property. ... We, the people of the Republic of Liberia, were originally inhabitants of the United States of North America... Under the auspices of the American Colonization Society, we established ourselves here, on land, acquired by purchase from the lords of the soil.

After the Declaration of Independence, elite Black settler-colonists drafted the first Liberian Constitution. Dr. Simon Greenleaf, ${ }^{1148}$ though contested, ${ }^{149}$ also contributed to the original drafting of the Constitution 1847 of the Colony of Liberia. Upper-class patriotic white Americans belonging to the American Colonization Society and the elite Black settler-colonists, looking upon Native Peoples in Liberia with disdain, modelled the 1847 Constitution after that of the United States of America. According to Carl Patrick Burrowes, the 1847 Constitution reflected a fusion of black nationalism, Protestant Christianity and republicanism, which formed constituent elements of a Liberian ideology that came to be crystallized between 1822 (colonistsettlers' arrival) and 1847 (Declaration of Independence from the American Colonization Society). ${ }^{1150}$ Unfortunately, as in Australia, this founding legal document did not adequately account for the inclusion of Indigenous Peoples.

Even with a stronger commitment to human rights than that of Australia, the Liberian Constitution 1947 fell short of extending those rights to Native Africans. In contrast to the Australian Constitution, the Liberian Constitution has a Bill of Rights embedded in Chapter III: Fundamental Rights. However, even though the Commonwealth of Liberia and subsequently the Republic of Liberia's Constitution 1947 (Section 13 ${ }^{\text {th }}$ ) granted citizenship to 'none but Negroes or persons of Negro descent', Native Peoples in Liberia were excluded as 'dispersed and oppressed children of Africa'. Native Peoples in Liberia were not afforded citizenship until 1904 and were only granted the right to vote in 1946. The Liberian Constitution 1847 remained in force until a military coup d'état occurred in 1980, at which time the Constitution was suspended; it was revised in $1986 .{ }^{115}$

Article 11 (c) of the Liberian Constitution provides for equality before the law but falls short of recognising the rights of Indigenous Peoples in Liberia. In 1984 a second chance to include Native Peoples in the Liberian Constitution arose at the drafting of a completely new constitution. In his article, The Making of the 1984 Liberian Constitution: The Major Issues and Dynamic Forces, 1987 Amos Sawyer, a renowned political scientist and former Interim

\footnotetext{
${ }^{1148}$ Dunn and Holsoe, above n 104, 47. Note Dunn \& Holsoe's caveat - '[w]hile it has been conventional wisdom among students of Liberian history that Professor Greenleaf wrote the constitution of 1847, recent scholarship indicates Greenleaf's unfamiliarity with nineteenth-century Liberian settler society as reflected in the five constitutional articles. In addition, it was assumed that neither Greenleaf nor the ACS, controlled as it was by EuroAmericans, could have been responsible for sections 12 and 13 of Article V, which restricted the ownership of property and citizenship rights in Liberia to blacks. The ACE appeared to have desired the exact opposite. Likewise, Professor Greenleaf could hardly have been credited with sections 10 and 11 regarding women's rights, when in 1840 , he had argued against such rights.'

${ }^{1149}$ Brown, 'Simon Greenleaf and the Liberian Constitution of 1847', above n 53, 51.

${ }^{1150}$ Carl Patrick Burrowes, 'Textual Sources of the 1847 Liberian Constitution' (1998) 23(1) Liberian Studies Journal 1,1 .

${ }^{1151}$ Leon Dash, 'Liberian Revolt Preserves Old Structure' Washington Post (Washington, DC), 29 December 1980 <https://www.washingtonpost.com/archive/politics/1980/12/29/liberian-revolt-preserves-old-structure/aaeb287407bd-4ecd-8f4e-fb5a58f442e8/>.
} 
President of Liberia, provides little evidence to show purposive efforts to engage Native Peoples in the national constitution revision process. References to Native Peoples are subtle and limited, ${ }^{1152}$ which certainly cast doubts on equal treatment under the law (Article 11(a)). ${ }^{1153}$ Mention made of Native Peoples' contribution during the drafting of the 1986 Constitution refers to 'rural Liberia's links between citizenship and land ownership' ${ }^{154}$ and 'observation of economic self-reliance and increased self-help capacity in the rural population'. ${ }^{1155}$ The Liberian Constitution 1986 also fails to acknowledge Native Peoples as the original owners of the land. The original Declaration of Independence 1847 took for granted that when the settler-colonists arrived at Cape Mesurado, ${ }^{1156}$ the lands they acquired were not 'purchased' respectfully by fair deal and negotiations. ${ }^{1157}$ It took 167 years for rural communities to gain recognition of ownership of their lands. A new Land Rights Act 2014 established the legal basis for recognition of customary land rights. ${ }^{1158}$ However, land rights are not the only rights that were granted settler-colonists but denied Native Africans.

Decolonisation concepts apply in layers to the legal founding of Liberia and to settlercolonists' attitudes toward Native Africans. Despite being 'debarred by law from all the rights and privileges of men " 1159 in the United States of America, settler-colonists somehow did not see the African shores as a place where their ancestors once lived. Their references to the African coast as 'barbaric', whilst at the same time an 'asylum' or 'promised land', reflects a confused

\footnotetext{
${ }^{1152}$ Liberia Constitution 1986, Article 5: preserving, protecting and promoting Liberian culture, to ensure traditional values are compatible with public policy and in Article 23: enacting statutes to regulation customary marriages as it pertains devolution of estate.

${ }^{53}$ Liberian Constitution 1986, Article 11: a) All persons are born equally free and independent and have certain natural, inherent and inalienable rights, among which are the right of enjoying and defending life and liberty, of pursuing and maintaining the security of the person and of acquiring, possessing and protecting property, subject to such qualifications as provided for in this Constitution.
}

\footnotetext{
${ }^{1154}$ Amos Sawyer, 'The Making of the 1984 Liberian Constitution: Major Issues and Dynamic Forces' (1987) 12(1) Liberian Studies Journal 1, 11.

${ }^{1155}$ Ibid 15.

${ }^{1156}$ Dunn and Holsoe, above n 104, xiii and 1. Present day Liberia grew out of Cape Mesurado as a cluster of settlements ceded in 1821 by Eli Ayres and Robert Stockton, agents of the ACS.

${ }^{1157}$ Wulah, above n 169, 34-50, 54-70, 79-98, 123-143; Hannah Abeodu Bowen Jones, The Struggle for Political and Cultural Unification in Liberia, 1847-1930 (PhD Thesis, Northwestern University, 1962) 69-86; Shick, above $\mathrm{n}$ 170, 92-101; Sawyer, The Emergence of Autocracy in Liberia, above n 61, 125-139; Levitt, above n 105, 31, 57, 62, 70, 77, 94, 99, 102, 129, 132, 147, 152, 164, 169, 181, 194, 206; Shick, above n 170, 91-101. Referencing Nnamdi Azikiwe's Liberia in World Politics, Bowen (1962) writes, '[i]t was generally believed by Western powers that treaties and agreements with African chieftains were never clearly defined in international law. These powers maintained that such treaties were not legal obligations since primitive peoples were thought to be wholly without any sense of understanding and capacity for self-government, which would make them the proper subjects of legal rights and duties. The foreigners, as such, could not be held accountable for any lawless deeds to the same extent as if they were committed upon civilized peoples'. Amos Sawyer writes: 'From its inception, Liberia faced a double dilemma. The creation of a Western settler state required the support of the Western powers in imposing settler authority in the area; however, in warding off imperialist claims, the Liberian state needed the support of the [I]ndigenous communities...In order to establish control over the western area near the Gallinas, the Liberian government engaged in three types of activities. It concluded treaties of trade and friendship with [I]ndigenous leaders; undertook armed campaigns of pacification; and established the settlement of Robertsport near the Gallinas... During the early years of the settlements, the initial cause of instability in this area [Monrovia] was the efforts of the settlers to acquire territory, gain control of the coastal terminus of this trade, and ensure a more accommodative and secured environment'. Notable among the land dispute hostilities were: conflict with the Gola people in the 1840's; the Sinoe war of 1855; Grebo Wars of 1857, 1875, 1887-1893, and 1896. Dunn and Tarr (1988) confirm that, US Navy Captain Robert Field Stockton's 'brandishing of a pistol at the head of King Peter seems a clear indication of the duress under which Cape Mesurado was ceded' under the 'Ducor Contract'.

${ }^{1158}$ Sirleaf, above n 208, 22.

${ }^{1159}$ The Liberian Declaration of Independence 1847.
} 
identity ${ }^{1160}$ that remains to this day. Because they had been denied the right to vote in the United States, the right to vote became an 'inalienable' inheritance of settler-colonist men. However, perpetuating the same patriarchal system they had experienced in the United States, Native Peoples and settler-colonist women were forced to struggle for the same right. Finally, the Constitutional Referendum on 3 May 1955 granted all women in the hinterland the right to vote and be elected to Legislature. Having been excluded from the drafting of the United States' constitution, Liberian settler-colonists now excluded Native Africans.

The exclusion of Indigenous People and women from the legal founding of the nation calls into question the validity of the legal system with respect to the rule of law. Dworkin asks how the constitution can uphold the integrity of the rule of law when

the framers of the original constitution were remarkably unrepresentative of the people as a whole. They were not chosen in any way sanctioned by prior national law, and a majority of the population, including [Indigenous] women, slaves, and the poor, was excluded from the process that selected them and ratified the constitution. ${ }^{1161}$

Thus, the concepts of equality and fairness seem unsuitable to explain why people should be governed by a document created by officials who were arbitrarily chosen long ago, especially when the constitution permits racial segregation. ${ }^{1162}$ As a result, both Liberia and Australia seem burdened with systems of government that are irrelevant to Indigenous Peoples, primarily because they have constitutions that were written by unrepresentative bodies who were blind to the historical and social conditions of Indigenous Peoples. Today, especially in post-conflict countries such as Liberia, the nation-building process continues to rely on imported Western concepts.

Wealthy Western nations import legal systems based on the rule of law into postconflict countries as part of reconstruction efforts. According to Costa Pietro and Danilo Zolo, contemporary discontent with centralised power, the crisis of the welfare state, ${ }^{1163}$ extraordinary proliferation of rights, and the exhaustion of alternatives to Western democracies have all given new life to the notion of rule of law. ${ }^{1164}$ Rosa Ehrenreich Brooks argues that dominant Western society believes that the rule of law is central to a stable and modern democratic society. ${ }^{1165}$ The challenge of establishing the rule of law, especially in developing and post-conflict societies such as Liberia, is complex and multifaceted. The desirability of such projects is usually

\footnotetext{
${ }^{1160}$ above $n$ 247, 6. Fanon (2008) concedes, '[w] hite civilization and European culture have forced an existential deviation on the Negro. I shall demonstrate elsewhere that what is often called the black soul is a white man's artefact'.

${ }^{1161}$ Ronald Dworkin, Law's Empire (Belknap Press, 1986) 364.

${ }^{1162}$ Ibid 364-365.

${ }^{1163}$ The Editors of Encyclopaedia Britannica, 'Welfare State' $<$ https://www.britannica.com/topic/welfare-state>. The welfare state is a concept of government in which the state or a well-established network of social institutions plays a key role in the protection and promotion of the economic and social well-being of citizens. It is based on the principles of equality of opportunity, equitable distribution of wealth, and public responsibility for those unable to avail themselves of the minimal provisions for a good life. The general term may cover a variety of forms of economic and social organization.

${ }^{1164}$ Costa, above n $1065,73$.

${ }^{1165}$ Rosa Ehrenreich Brooks, 'The New Imperialism: Violence, Norms, and the "rule of Law"' (2003) 101(7) Michigan Law Review 2275, 2278.
} 
assumed, as reflected in reports of Justice Anthony Kennedy's remarks at Stanford University's 2009 Commencement, which included the observation that 'more than half the world's population lives outside the law, and ... the new graduate should work to spread American principles of justice, especially in places that resist them.' The imperialistic tone of the latter injunction is deeply problematic for the rule of law enterprise, however, as attempts to import foreign (usually Western) legal concepts and structures can be a bitter reminder of the colonial history of many of these societies. ${ }^{1166}$ Accordingly, in any project undertaken to promote the rule of law abroad, rhetoric like that attributed to Justice Kennedy must be studiously avoided, whilst those involved must carefully accommodate local cultural and political sensitivities.

Contemporary efforts to reform the rule of law in Indigenous communities are mostly funded and disseminated by Western nations and international organisations, including the World Bank and UNDP. ${ }^{1167}$ Demonstrating compliance with the rule of law tends to be a prerequisite for investment in post-war countries, such as Liberia, by financial institutions like the World Bank and International Monetary Fund. The difficult truth is that some aspects of Indigenous Customary Laws are simply incompatible with basic principles of Anglo-American or Anglo-Australian law to be able to enjoy official recognition, only if it does not conflict with settler-colonist law. ${ }^{1168}$ In instances where the Supreme Court of Liberia (for example) overrules Indigenous Customary Laws to guarantee compliance with constitutional protection, indicates a remarkable resemblance of the rule of law to colonialism without any tolerance for (critical) legal pluralism. As a result, the imposition of Western ideals concerning the rule of law tends to fuel ongoing clashes between formal state power and Indigenous justice.

International efforts to promote the rule of law in Liberia, for instance, are fundamentally based on false expectations about the relationship between law, order and violence, because such assumptions cannot be justified. ${ }^{1169}$ The Handbook for Civil Society Partners published in 2008 by the Carter Centre presents a case in point. The Carter Centre Handbook aims to promote community education regarding and awareness of the rule of law in Liberia. In explaining the illegality of Sassywood ${ }^{1170}$ or trial by ordeal, the Handbook asserts that Article 73 of the Rules and Regulations Governing the Hinterland 1942 and the Supreme Court of Liberia in a 1916 case outlaw the practice. ${ }^{1171}$ The Handbook continues in Liberian parlance: 'when there is a big problem like rape or murder, the community people should get the consent

\footnotetext{
${ }^{1166}$ David Pimentel, 'Legal Pluralism in Post-Colonial Africa: Linking Statutory and Customary Adjudication in Mozambique' (2011) 14(1) Yale Human Rights and Development Journal 1, 2-3.

${ }^{1167}$ Ibid 6.

${ }^{1168}$ David Pimentel, 'Can Indigenous Justice Survive?: Legal Pluralism and the Rule of Law' (2010) 32(2) Harvard International Review 32, 34.

${ }_{1169}$ Brooks, above n 290, 2301.

${ }^{1170}$ Sassywood is a trial by order where a hot cutlass, hand in oil, drinking Sassywood tree bark or other plant materials may be used to solicit confession or 'truth telling'.

${ }^{1171}$ The Carter Centre and The Ministry of Justice, Handbook for Civil Society Partners: Community Education and Awareness Program on the Rule of Law (The Carter Centre, 2008) 20

$<$ https://www.google.com/\#q=What+is+a+Constitution?++Black's+Law+Dictionary+Fifth+Edition+defines+" Consti tution"+as:+"The+organic+and+fundamental+law+of+a+nation+or+state, $>$.
} 
of the victim to call the police. ${ }^{1172}$ Interestingly, the population this handbook targets, Native Peoples in rural Liberia, are mostly illiterate and often have little or no contact with government agencies, including law enforcement, court personnel or public administrators. As the law, in and of itself, has no inherent ability to reduce violence or suffering, it may appear that at least some of the time, people prefer violence and suffering to peace and prosperity, ${ }^{1173}$ which explains why Western society's efforts to transplant the legal axiom emphasises reducing violence. Unfortunately, unlike most African states that recently gained independence from colonial rule in the 1960s, Liberia has done little to resuscitate and reinvigorate its Indigenous Customary Laws and Institutions with respect and integrity.

Liberia adopts a constitution that gives only a weak nod to Native customs, whilst at the same time establishing a Western-style (Anglo-American) triumvirate. Requiring the Republic to preserve, protect and promote Liberian culture to ensure the adoption of compatible traditional values (Article 5 (b) of the Liberian Constitution 1986) is counterintuitive. Article 5 (b) both expresses disapproval of colonial influence and rejects Indigenous Customary Laws. Liberia's Anglo-American-style government exemplifies the dominance of colonial priorities associated with the principles of human rights and maintenance of the rule of law. As noted above, the challenge of promoting settler-colonists' 'one law' comes not with expressing the need for mutual respect, but in finding ways to permit Indigenous Customary Laws to function simultaneously with the same respect and integrity as states' law.

\subsection{Indigenous Customary Laws Internationally, Regionally and Nationally}

The source of any law, whether international, national or Indigenous, are the customs, traditions and cultures of peoples, which may be based on religion, social norms and beliefs held by individuals in the community. Wulah submits that 'from the day one is born to the time of death and even burial, the [traditional] law by which we are governed tells us what to do.' ${ }^{1174}$ There is a ritual, initiation and ceremony performed at every milestone in life, including birth, naming a newborn, a first haircut, puberty, marriage and death; which are tribal laws and customs that are known and recognised locally. ${ }^{1175}$ According to Sharman Stone, Captain James Cook's reflection on 'Aboriginal Australians' peaceful relationship with the environment...' ${ }^{1176}$ indicates their ability to maintain law and order. Ronald and Catherine Berndt suggest that within any given unit of Aboriginal Australian culture, 'certain rules and standards are acknowledged, certain patterns of behaviour considered right, as against others which are wrong. Informal as well as formal sanctions are likely to greet any obvious deviation from those patterns'. ${ }^{1177}$

\footnotetext{
${ }^{1172}$ Ibid 21.

${ }^{1173}$ Costa, above n 1065, 73.

${ }^{1174}$ Wulah, above n 169,145

${ }^{1175}$ Ibid.

${ }^{1176}$ Stone, above n $178,13$.

${ }^{1177}$ Ronald M Berndt and Catherine H Berndt, The World of the First Australians: Aboriginal Traditional Life Past and Present (Aboriginal Studies Press, 5th ed, 1996) 338.
} 
Indigenous Customary Laws have been used to maintain social harmony, justice, and fairness for as long as Indigenous cultures in Australia and Liberia have existed and continue to be used thus. In Australia, Indigenous Customary Laws pre-dated colonial Anglo-legal principles. Diane Bell implies that Indigenous Customary Laws, 'which operated in a moral universe where people are rigorously socialised into beliefs and practices, are not accidental but self-regulating and unchanging. ${ }^{1178}$ Rather than being inferior to Western common law system and 'unchanging', Calma points out, Indigenous Customary Laws are not frozen in the past but are a 'living changing system that reflects its times ... [by providing] structure and order in Indigenous communities'. ${ }^{1179}$ The 'changing' and 'self-regulating' characteristics of Indigenous Customary Laws sustain their propagation above and beyond the limits of settler-colonists' foreign law. Although histories in Indigenous cultures tend to be oral living culture and documentation of legal philosophy and jurisprudence is rare, the argument that Indigenous Customary Laws is oral and hence does not exist is baseless.

As with Western legal systems, not all aspects of Indigenous systems of justice conform to the rule of law. Indigenous systems of justice also promote traditional values. However, like Western-dominant legal systems, some traditional values may be discriminatory, showing little respect for principles of gender equality, child protection or religious rights. In the specific case of Liberia, a country emerging from the devastation of mass violence, some argue that Indigenous Customary Law challenges and 'obstructs the goals of stability and the rule of law. ${ }^{1180}$ One example of Customary Laws in Liberia that does not conform to rule of law principles is a tradition of trial by ordeal.

Trial by ordeal in Native communities in Liberia is one example of Customary Laws that do not conform to rule of law concepts including a fair trial, human rights and arbitrariness of judgement. Prior to 2000, Article 73 of the Liberian Rules Governing the Hinterland 1949 permitted trial by ordeal (or Sassywood). Jallah (2007) explains that trial by ordeal

\begin{abstract}
is an unscientific method, according to western standards, where a person accused of the commission of a crime or other offense is subjected to physical examination by either ingesting a substance or by placing a hot cutlass or machete on the legs of all persons suspected of having committed the crime to determine the guilty or innocence of the accused. The belief is that the person who committed the crime would be burned in the case of use of the machete or severely ill or even die in the case of the ingestion of the substance and the innocent would go unharmed. This method of trial, although declared illegal by the Supreme Court, is still being practiced in certain areas of Liberia. The problem with ensuring the total abolition of this practice is the lack of capacity of the Executive Branch to enforce the Supreme Court Decisions. ${ }^{1181}$
\end{abstract}

\footnotetext{
${ }^{1178}$ Diane Bell, 'What Is Law [and What Is Not]?' (Seminar at the SA Law Society Seminar, Adelaide, SA, 2006).

${ }^{1179}$ Tom Calma, 'The Integration of Customary Law into the Australian Legal System' (Speech at the National Indigenous Legal Conference, Sydney, NSW, 2006).

${ }^{1180}$ Deborah Isser (ed), Customary Justice and the Rule of Law in War-Torn Societies (United States Institute of Peace Press, 2011) xi.

${ }^{1181}$ David Jallah, 'Notes, Presentation by Professor and Dean of the Louis Arthur Grimes School of Law, University of Liberia' in Conference Learning from Each Other - Enriching the Law School Curriculum in an Interrelated World (Kenneth Wang School of Law, 2007) 4, 3 <http://www.ialsnet.org/meetings/enriching/JallahDavid.pdf>.
} 
Article 73 of the Liberia Rules and Regulations Governing the Hinterland 2000 (revised) prohibits trial by ordeal in cases where potions or concoctions ingested internally endanger a person's life. However, ordeals of a minor nature which do not endanger the lives of individuals shall be allowed. As indicated by Jallah, the absence of settler-colonist courts and legal systems in Native Liberia makes the enforcement of the Liberia Rules and Regulations Governing the Hinterland 2000 (revised) regarding permission of minor ordeal and prohibition of dangerous ordeal challenging. The unintended consequences resulting from Indigenous Customary Laws' arbitrary system of ascertaining the truth about crimes committed is inimical to the principles of the rule of law. It is for this reason and others that Indigenous Customary Laws can benefit from reform and renewal.

However, in the absence of settler-colonists' legal institutions, Indigenous Customary Laws play a crucial role in filling the social needs of the community and in providing alternative justice mechanisms for survivors of crime. From the management of the land; to performing rituals on birth, marriage, and deaths; to conducting rites of passage; to conserving sacred sites; to resolve disputes - and all that lie in between and beyond human existence - Indigenous Customary Laws 'represent a common denominator of shared values and practices'. Accordingly, limits and prohibitions should be selectively applied, rather than categorising Indigenous Customary Laws as mere oral tradition and thereby suggesting that only written settler-colonist law is viable. Such a perspective is not only offensive but also misguided. Moreover, forcing Indigenous Customary Laws into written form does serious systematic violence, as doing so reduces its flexibility, vitality, and responsiveness to community needs and external forces. ${ }^{1183}$ In a worst-case scenario, producing a written code or "“ascertainment" of customary law will deprive community members of the ownership and control of their own law. ${ }^{1184}$

Accordingly, Customary Indigenous Laws have proven to be a double-edged sword. On the one hand, they provide critically important access to dispute resolution for Indigenous Peoples who have little or no access to the settler-colonists' court systems due to distance, costs, language barrier, cultural misunderstanding, lack of training, and limited access to basic resources. ${ }^{1185}$ However, in spite of their daily customary practice, Indigenous communities find that their systems of traditional justice are under continual attack and are regularly misconstrued by settler-colonists. To be exact, some practices that are related to gender inequity and harmful traditions that adversely affect girls and women are supported culturally, institutionally and individually by Indigenous Customary Laws. Harmful traditional practices, such as trial by ordeal, corporal punishment, female genital cutting and child marriages, all make getting access

\footnotetext{
${ }^{1182}$ Leon Shaskolsky Sheleff, The Future of Tradition: Customary Law, Common Law, and Legal Pluralism (F. Cass, 2000) 1 .

${ }^{1183}$ Pimentel, above n 1169, 36.

${ }^{1184}$ Ibid.

${ }^{1185}$ Laura A Young and Abraham Korir Sing'Oei, 'Access to Justice for Indigenous Peoples in Africa' in Indigenous Peoples' Access To Justice, Including Truth And Reconciliation Processes (Academic Commons, Columbia

University, 2014) 89, 94-95 〈https://academiccommons.columbia.edu/catalog/ac:184797>.
} 
to justice extremely difficult for Indigenous girls and women. Although some efforts have been made on the part of settler-colonists governments to ban some of these practices, such prohibitions are often put forward without providing viable and culturally valid alternatives for Indigenous Peoples. ${ }^{1186}$ Furthermore, challenges related to accessing and establishing the formal court systems in Indigenous communities make implementation and enforcement of settlercolonist law impossible.

In Liberia, a primary reason these challenges exist is that Indigenous Peoples are poorly studied. The few studies that focus on Indigenous Peoples in Liberia are outdated, inaccessible, conducted by non-Liberians or not focused on Indigenous Customary Laws. ${ }^{1187}$ If such studies are about Indigenous Customary Laws, then they tend to contain information that is haphazard, derogatory, stereotypical, distorted or inaccurate. ${ }^{1188}$ Additionally, Liberia's colonial legacy and corresponding struggles for political independence across Africa created unique barriers to engaging respectfully with Native Peoples in Liberia. Hence the persistent lack of high-quality data and legal cases to evidence Native Peoples' access to justice in Liberia. Throughout this research and especially in chapters 3 and 8, case examples are highlighted and discussed to illustrate diverse ways in which Native Peoples in Liberia are discriminated against and deliberately denied access to justice.

The treatment of Indigenous girls and women in customary justice systems, which hinge on access to justice, is often analysed with little understanding of the diversity and nuance within traditional systems regarding their loci of power for females in Indigenous cultures. ${ }^{1189}$ Whilst the dangers of patriarchy and inequality are very real obstacles to accessing justice, the potential to effectively exploit customary systems for the benefits of Indigenous girls and women has often been underestimated. ${ }^{1190}$ Despite the fact that there are instances where access to justice is challenged and sometimes lacking for girls and women (for example, $R v G J$ 2005), ${ }^{1191}$ in Australia, an Indigenous person who commits a crime suffers double punishment, being punished by both the settler-colonist legal system and the Aboriginal customary system. ${ }^{1192}$

As Australian settler colonists began prosecuting inter se crimes, the jurisdiction of Indigenous Customary Laws and Anglo-Australian law began to intersect. In Australia, Chief Justice Forbes reasoned that 'to interfere with the savage tribes, whose countries we have taken possession ... the laws that are imported have reference only to the subjects of the parent state; I am not aware that those laws were ever applied to the transactions taking place between the

\footnotetext{
${ }^{1186}$ Ibid 96.

${ }^{1187}$ Moore, above n 555; Bledsoe, above n 1002; Moran, above n 163; Wulah, above n 169; Government of Liberia, 'Study on Operations of Sande School', above n 1027; Korvah, above n 548.

${ }^{1188}$ The Carter Centre, Liberia Access to Justice Project Partnerships (4 October 2013) The Carter Centre: Waking Peace. Fighting Disease. Building Hope <http://www.cartercenter.org/news/features/p/access_to_information/liberiamama-tumeh.html>.

${ }^{1189}$ Young and Sing'Oei, above n 1186, 96.

${ }^{1190}$ Ibid.

${ }^{1191}$ In $R v G J$ Unreported, Supreme Court of the Northern Territory (Yarralin) SCC 20418849, Martin CJ, 11 August 2005: A 55-year-old Aboriginal male Elder pleaded guilty to having sexual intercourse with a 14-year-old girl child, contending that he was entitled to because she was his promised wife.

${ }^{1192}$ Law Reform Commission of Western Australia, above n 142, 81.
} 
original Natives themselves'. ${ }^{1193}$ However, as settler-colonists came in regular contact with Indigenous Peoples, the pressure to exert legal control over them became real. Initially, response to inter se crimes arose from complaints made by settler-colonists about increased street violence amongst groups of Aboriginal Peoples. ${ }^{1194}$ Culturally, settler-colonists' perception of crimes committed by Aboriginal People became known as 'the Aboriginal problem'. ${ }^{1195}$ Douglas and Finnane argue that discussion of solving 'the Aboriginal problem' provides evidence of an unsettled 'legal business' between settler-colonists and Aboriginal Peoples. ${ }^{1196}$ The 'Aboriginal problem' intensified when 'inter $s e^{1197}$ offences had initially arisen out of complaints by settlers of increased street violence in Perth amongst groups of Aborigines'. ${ }^{1198}$ Douglas and Finnane also suggest that 'changing attitudes towards violence against women in the cultures from which the settlers came may well have played their part in the Settler's intervention' ${ }^{1199}$ to prosecute inter se offences of Aboriginal people. The 'test' came as the prosecution of Helia, the first criminal trial of an Aboriginal person of Swan River, originating in an intervention by settlers who witnessed his armed and fatal assault of [an Aboriginal] woman [Yatoobung], an action that demanded response in a (British) culture that was itself undergoing a reconstruction of its precepts about gender and cruelty and physical punishment'. ${ }^{1200}$ However, asserting the supremacy of Anglo-Australian law on Aboriginal People met with some resistance.

In $R v$ Murrell and Bummaree 1836, the case that declared Aboriginal Peoples as British subjects of settler-colonist law, Jack Tango Murrell resisted the assertion that Aboriginal People were subject to the laws of Britain:

And now the said Jack Congo Murrell in his own proper person comes and having heard the Information aforesaid read, and protesting that he is not guilty of the premises charged in the said Information or any part thereof, for plea, nevertheless saith that he ought not to be compelled to answer to the said Information; because, he saith that the said Territory of New South Wales before and until the occupation thereof by his late Majesty King George the third, was inhabited by tribes of native blacks, who were regulated and governed by usages and customs of their own from time immemorial, practised and recognised amongst them, and not by the laws of statutes of Great Britain, and that ever since the occupation of the said Territory as aforesaid, the said tribes have continued to be, and still are regulated and governed by such usages and customs as aforesaid, - and not by the laws and statutes of Great Britain. And the said Jack Congo Murrell further saith that he is a native Black belonging to one of such tribes aforesaid, and that he is not now, nor at any time heretofore was a subject of the King of Great Britain and Ireland, nor was nor is subject to any of the laws or statutes of the Kingdom of Great Britain and Ireland. And the said Jack Congo Murrell further saith that the said Jabbingee in the said information named, and with the wilful murder of whom the said Jack Congo Murrell is and by the said information charged, was at the time of such supposed murder a native Black belonging to one of such Tribes as aforesaid, and was not then nor at any time theretofore a subject of the King of Great Britain and Ireland;

\footnotetext{
${ }^{1193}$ R. v. Ballard or Barrett [1829] NSWSupC 26.

${ }^{1194}$ Hunter, above n $175,1$.

${ }^{1195}$ Ibid.

${ }^{1196}$ Douglas, above n 479, 13.

${ }^{1197}$ Reynolds, Aboriginal Sovereignty, above n 221, 61-62.

${ }^{1198}$ Hunter, above n 175.

${ }^{1199}$ Douglas, above n 479, 28.

${ }^{1200}$ Ibid 27-34.
} 
nor at any time was subject to any of the laws or statutes of the Kingdom of Great Britain and Ireland, or under the protection of the same. ${ }^{1201}$

In an honest, albeit distorted, attempt to apply the rule of law, the Attorney General of New South Wales responded:

In this case, the prisoner was charged with murder in a populous part of the King's territory; it was laid in the information to have been committed within the jurisdiction of the Court. The reply to this had been, that the prisoner was not amenable to the British laws, but his principle could not be admitted, the laws of Great Britain did not recognise any independent power to exist in a British territory, but what was recognised by law. This country was merely held by occupation, not by conquest, nor was it ceded; and where lands were so taken possession of, the King was bound to protect by his kingly power all parties living in it, or who came to visit it; was it to be supposed that breaches of the peace, and murders, were to be committed within the jurisdiction of the Court, and yet that the Court should have no controlling power? The law would be bound to protect every person who came to this colony, and to it they would be amenable. He, the Attorney General, stood there to protect the whites from the blacks, and the blacks from the whites; the colour made no difference to him. If the man could not be tried, their Honours would be sitting there to say they had no jurisdiction over a case of murder committed within the jurisdiction of the Court.

Early colonial judicial decisions that denied the recognition of Indigenous laws also portended formal equality between Indigenous and non-Indigenous Peoples in the Anglo-Australian justice system. The same legal institutions that anticipated equality of Indigenous Peoples and settlercolonists sympathised with, legitimised and authorised the murdering of Aboriginal Australians. ${ }^{1203}$ Since the colonisation, Indigenous Peoples have experienced levels of criminalisation disproportionate to non-Indigenous Peoples. As explained in chapter 3, the relatively high incarceration rate of Indigenous Peoples is explained, in part, by the negative judicial portrayals of Indigenous offenders. ${ }^{1204}$ Efforts to reconcile Indigenous Customary Laws and Anglo Law in Australia and Liberia continue, as Indigenous Peoples work for recognition and accommodation of their ways of being, knowing and doing justice.

Recognising and accommodating Indigenous Customary Laws requires respect for its ability to evolve and recognition that Western precepts of human rights may be best protected if a (critical) legal pluralism regime allows traditional customs and institutions to survive. ${ }^{1205}$ Persistence of Indigenous Customary Laws depends on resistance from importation, transplantation and imposition of settler-colonist law. Indigenous Customary Laws can and will continue to evolve, not through vague legislative amendments the way Western law has changed, but instead through influence from both inside and outside Indigenous communities. Such flexibility and openness should be embraced, not frowned upon if critical legal pluralism

\footnotetext{
${ }^{1201} R v$ Murrell and Bummaree (1836) 1 Legge 72; [1836] NSWSupC 35.

${ }^{1202}$ Forbes C.J., Dowling and Burton JJ, 19 February 1836 in Sydney Gazette, 23 February 1836[ 3] available at

<http://www.law.mq.edu.au/research/colonial_case_law/nsw/cases/case_index/1836/r_v_murrell_and_bummaree/>

${ }^{1203}$ Stone, above n 178, 27.

${ }^{1204}$ Thalia Anthony, Indigenous People, Crime and Punishment (Routledge, 2013) 55-56.

${ }^{1205}$ Pimentel, above n 1167, 10.
} 
is a vital option. ${ }^{1206}$ The challenge facing legal institutions is to create a pluralistic legal framework that accommodates Indigenous Customary Laws.

\subsection{Legal Pluralism and the Rule of Law}

Legal pluralism is defined as a situation wherein two or more different legal systems exist and operate in a single political unit or geographical locale. Legal pluralism is a practical reality, most notably in Indigenous Liberia and Australia. Critical legal pluralism is the knowledge that maintains and creates realities whilst 'challenging the traditional social-scientific legal pluralism of reified cultures and communities'. ${ }^{1207}$ The critical legal pluralist 'imagines legal subjects as law "inventing" and not merely "law abiding". ${ }^{2008}$ Employing critical legal pluralism, this dissertation cultivates deep listening through the voices of research participants to reflect on how the law affects Indigenous Peoples' lives and how the interpretation of legal documents is often shaped by the interpreter's view. Unlike Australia, the Liberian Constitution 1986 (Article 5 (b) $)^{1209}$ vaguely reserves a role for Native Liberian culture, which recognises the inevitability of legal pluralism. However, the same Liberian Constitution (1986) deems void, of no legal effect and unconstitutional '[a]ny laws, treaties, statutes, decrees, customs and regulations found to be inconsistent' (Article 2, Liberian Constitution 1986), which is why Liberia has yet to find a functional and effective way of implementing legal pluralism or harmonising relationships between Indigenous Customary Laws and settler-colonist legal systems. This balancing act is a condition David Pimentel observes in British colonial regimes, where Indigenous Customary Law 'functions only as long as it did not run afoul of now-notorious 'repugnancy clauses', which assumed the superiority of British legal and cultural norms and invalidated any indigenous law repugnant to those values. ${ }^{1210}$

Pimentel asserts that it is necessary to recognise and preserve the virtues inherent in Indigenous legal systems, which are historically undervalued as 'primitive' and are still under attack by those who see them as threats to the protection of human rights whilst imposing foreign models of governance and justice on Indigenous communities. ${ }^{1211}$ Pimentel sees nothing wrong or new with legal pluralism, as it has always proved easier to govern a conquered people according to their own laws. ${ }^{1212}$ To counteract the historical devaluation of traditional culture of colonised states, Pimentel suggests a compelling reason to embrace and pursue legal pluralism: that is, to preserve and respect Indigenous Customary Laws. Rather than perceiving them as a meaningful way of appreciating Indigenous cultures, colonial regimes have used legal pluralism

\footnotetext{
${ }^{1206}$ Pimentel, above n 272, 36.

${ }^{1207}$ Martha-Marie Kleinhans and Roderick A Macdonald, 'What Is a Critical Legal Pluralism?' (1997) 12(02)

Canadian Journal of Law and Society 25, 26.

${ }^{1208}$ Ibid.

${ }^{1209}$ Article 5 (b) of the Liberian Constitution 1986 states the Republic shall preserve, protect and promote positive Liberian culture, ensuring that traditional values which are compatible with public policy and national progress are adopted and developed as an integral part of the growing needs of the Liberian society.

${ }^{1210}$ Pimentel, above n 1169, 33.

${ }^{1211}$ Pimentel, above n $1167,3,6$.

${ }^{1212}$ Ibid 4.
} 
to foster and exploit political disadvantage by forcing settler-colonists' legal institutions to persist under their rule (of law). ${ }^{1213}$

Indigenous Customary Laws persist and maintain their separateness and customary justice. ${ }^{1214}$ Notwithstanding the supposedly fair and just settler-colonist legal system, jurisdictional tensions are inevitable. Colonisation and its corresponding imposition of AngloAmerican and English Common Laws on Indigenous Peoples have consistently been marked by conflict. ${ }^{1215}$ However, The Australian Law Reform Commission confirms that 'despite the lack of detailed knowledge in certain areas, there are many indications that Aboriginal Customary Laws and traditions continue as a real controlling force in the lives of many Aborigines. ${ }^{1216}$ Since the subjection of Aboriginal Peoples, whether in Australia or Liberia, does not extinguish Indigenous laws and customs, the question of concern here is whether the formal legal system can recognise Indigenous Customary Laws and exist alongside them. Crawford and the Law Reform Commission of Australia identify a common argument against legislative recognition of Indigenous Customary Laws. The issue is that recognition of Aboriginal Customary Laws would in some way be discriminatory or unequal or would violate the principle that all Australians (or Liberians) are, and should be, subject to 'one law'.

By acknowledging different treatment on the basis of Aboriginality [race], recognition of Indigenous Customary Laws may seem to violate the principle of equality and nondiscrimination. ${ }^{1218}$ In international law, the principle of equality is expressed in a number of instruments, including the Universal Declaration of Human Rights 1948, the Convention on the Elimination of Racial Discrimination 1965, and the International Covenant and Civil and Political Rights 1966. In Ngatayi v The Queen 1980, Justice Murphy opines that '[ $\mathrm{t}$ ] he existence of two systems of law side by side, the prevailing one and Aboriginal Customary Laws, with their very different attitudes to guilt and responsibility, creates serious problems and the question of how far our laws should apply to aboriginals and how far their law should be allowed to apply to them is controversial. ${ }^{1219}$ However, an International Court of Justice case, the South West Africa Cases (Ethiopia v South Africa; Liberia v South Africa) 1966, shows otherwise. In the South West African Cases, Judge Tanaka held that 'the alleged norm of nondifferentiation as between individuals within a State on the bases of membership of a race, class or group could not be transferred by way of analogy to international relationship, otherwise it

\footnotetext{
${ }^{1213}$ Ibid 7.

${ }^{1214}$ Pimentel, above n 1169, 33.

${ }^{1215}$ Huberich, above n 53, 475-477.

${ }^{1216}$ Australian Law Reform Commission, 'Recognition of Aboriginal Customary Laws (ALRC Report 31)'

(Government Report 31, Australian Law Reform Commission, 12 June 1986) 737, 38

<http://www.alrc.gov.au/publications/report-31>.

${ }^{1217}$ Crawford, above n 141, 193; Australian Law Reform Commission, 'Recognition of Aboriginal Customary Laws (ALRC Report 31)', above n 26, 128.

${ }^{1218}$ Law Reform Commission of Western Australia, above n 142, 7.

${ }^{1219}$ Ngatayi $v$ The Queen (1980) HCA 18, 147 CLR 1, 14.
} 
would mean that all nations are to be treated equally despite the difference of race, colour, etc., a conclusion which is absurd'. ${ }^{222}$

Critical legal pluralism is a mechanism states can use to combat discrimination against Indigenous Peoples. Australia's obligations under the Convention on the Elimination of Racial Discrimination 1965, which was domesticated into the Racial Discrimination Act 1975 (Cth.) and other international and domestic instruments listed above, prohibit discrimination on grounds of race, colour, nationality or ethnic origin. The Law Reform Commission of Australia agrees that Australia's international and national obligations do not preclude taking reasonable and special measures to distinguish particular groups and to respond in a proportionate way to the special characteristics of Aboriginal Peoples. ${ }^{1221}$ Thus, 'special measures for the recognition of Aboriginal Customary Laws will not be racially discriminatory, or will not involve a denial of equality before the law or of equal protection' provided such measures are reasonable responses to the special needs of Aboriginal Peoples affected, are generally accepted and do not deprive individual Aborigines of basic human rights or access to justice. ${ }^{1222}$ Therefore, when dispensing justice, there are some cases involving Indigenous Peoples where concrete conditions of inequality require nation-states to take affirmative action that appears to be discriminatory in favour of a minority group so that genuine and substantive equality can actually be achieved. ${ }^{1223}$

Perhaps one of the most persuasive arguments supporting differential treatment for Aboriginal Peoples by recognition of certain customary laws and practices is found in Indigenous Peoples' unique status as the First Peoples of Australia. ${ }^{1224}$ Aboriginal Peoples' prior possession of Australia and the existence of their complex systems of laws, traditions and customs were deciding factors in the High Court's recognition of Native Title in Mabo $v$ Queensland [No.2] 1982. Therefore, Indigenous Peoples, as First Peoples and members of a distinct Indigenous culture, have the right to practice and maintain a legal system necessary to allow their culture to survive and flourish. ${ }^{1225}$ However, tensions still exist between Anglo and Indigenous Customary Laws in Australia.

Assimilation policies in Australia eclipsed the separate legal and administrative apparatuses for colonist-settlers and Aboriginal Peoples established under various legislations. Because Indigenous Peoples no longer occupied exclusive legal zones since the mid-20 ${ }^{\text {th }}$ century, settler-colonists' laws governed and released them from institutions to the peripheries of towns, especially those full-bloods who would not conform to a single white Australia. The law and legal system, in the form of discriminatory Aboriginal Acts, normalised the settler-

\footnotetext{
${ }^{1220}$ South-West Africa Cases (Ethiopia v. South Africa; Liberia v. South Africa); Second Phase, International Court of Justice, [18 July 1966] 434 at 296.

${ }^{1221}$ Australian Law Reform Commission, 'Recognition of Aboriginal Customary Laws (ALRC Report 31)', above $\mathrm{n}$ $26,158$.

${ }^{1222}$ Ibid 165.

${ }^{1223}$ Law Reform Commission of Western Australia, above n 142, 7.

${ }^{1224}$ Ibid 10.

${ }^{1225}$ Ibid 11.
} 
colonist regime of control over Indigenous Peoples. ${ }^{1226}$ For instance, the Northern Territory Chief Protector of Aborigines, redesignated as the Director of Welfare, became the guardian of all Indigenous wards. ${ }^{1227}$ Liberia also struggles to find respectful and constructive ways to integrate Indigenous Customary Laws into a pluralistic legal system.

The Liberian legal system makes a greater effort to accommodate legal pluralism. The Republic of Liberia has a dual legal system based on an Anglo-American Common Law and on Indigenous Customary Laws. Liberia's Indigenous Customary Laws, complex and far older than the settlers-colonists' law, is based on unwritten customary practices of Native Peoples. In the early 1800s, when the Tribal Chiefs in Liberia were first brought into the folds of AngloAmerican-Liberian law, they were given jurisdiction only over 'domestic disputes, especially matrimonial cases' emanating from Indigenous Customary laws. ${ }^{1228}$ Five District Commissioners regulated by the three branches of government safeguarded the rights of Paramount Chiefs, granting Indigenous Peoples in Liberia the right to make complaints to the Secretary of the Interior. ${ }^{1229}$ Davis $v$ Republic of Liberia $[1862]^{1230}$ decided that Native Liberians are bona fide subjects of the State. ${ }^{1231}$ In Ditchfield v Dossen et al [1907], ${ }^{1232}$ the court ruled that 'the organic and statutory laws of Liberia, in legal matters put every man on equal footing in securing to himself the rights that are guaranteed to him ... by the law [and] international treaties... ${ }^{1233}$ Gofah et al v Peter [1905] ${ }^{1234}$ decided that, '[I]ndigenous customs were to be respected and taken into consideration when a judicial interpretation was necessary. ${ }^{1235}$ No doubt the sources of Liberian law today include aspects of Indigenous Customary Laws. ${ }^{1236}$ However, settler-colonists law is still considered superior.

Anglo-American Law in Liberia still supersedes Customary Laws. In spite of the above jurisprudence, Chapter VII, Article 65 of the Liberian Constitution 1986 states that '[t]he courts shall apply both statutory and customary laws in accordance with the standards enacted by the Legislature.' Chapter I, Article 2 of the Liberian Constitution 1986 affirms the supremacy of the Constitution over Indigenous Customary Laws: [t]his Constitution is the supreme and fundamental law of Liberia and its provisions shall have binding force and effect on all authorities and persons throughout the Republic. Any laws, treaties, statutes, decrees, customs and regulations found to be inconsistent with it shall, to the extent of the inconsistency, be void and of no legal effect. These exclusions set the stage for continued conflict within the pluralistic system.

\footnotetext{
${ }^{1226}$ Anthony, above n 1204, 36.

${ }^{1227}$ Ibid 40.

${ }^{1228}$ Fraenkel, above n 39, 94.

${ }^{1229}$ Azikiwe, above n 301, 79; Huberich, above n 53, 1107.

${ }^{1230}$ Davis v RL [1862] LRSC 2; 1 LLR 17 (1862).

${ }^{1231}$ Azikiwe, above n 301, 79.

${ }^{1232}$ Ditchfield v Dossen et al [1907] LRSC 1; 1 LLR 492 (1907).

${ }^{1233}$ Azikiwe, above n 301, 80.

${ }^{1234}$ Gofa et al v Peter [1905] LRSC 5; 1 LLR 458 (1905).

${ }^{1235}$ Azikiwe, above n 301, 80.

${ }^{1236}$ Kabbah, above n 1145, 5; Fraenkel, above n 39, 70-109. The Federal State of 
Regardless of Indigenous Customary Laws' crucial role, conflicts and clashes between it and settler-colonists' rule of law system are inevitable. For example, before the Equal Rights of the Customary Marriage Law of 1998 was approved in 2003, customary marriages in Liberia were not legally recognised by the Liberian State. ${ }^{1237}$ Therefore, widows in customary marriages were denied Dower Rights to their dead husband's property (see chapter 3). David Jallah, former Dean of the University of Liberia's Louise Arthur Grimes School of Law, confirms that the age of consent under customary marriage was 12 years whilst in the urban areas the age of consent was 16 years. ${ }^{1238}$ Pursuant to section 16.15 of the Liberian Children's Act 2011, it is felonious to subject a person under 18 years to marry. However, in practice, an unborn girl child can still be betrothed to a man or his son ${ }^{1239}$ (see chapter 3 ).

Further research is required to understand the extent of the conflict between Indigenous Customary Laws and Anglo-American Law in Liberia. There is very little empirical research to support the operation of Liberia's dual legal systems to establish the extent to which settlercolonist law accommodates traditional practices. ${ }^{1240}$ According to Huberich, Liberia started off with a clear (but informal) understanding that there existed two legal systems: 1) statutory and common law and 2) traditional laws and customs. ${ }^{1241}$ The variability of the traditional legal systems of many language groups made it difficult to apply only Anglo-American Liberian law. Insofar as Indigenous Customary Laws did not violate the Constitution of Liberia or expressed provisions of statutory law, it was applied in common law courts. For example, in New York Krp eh v Harding 1936, ${ }^{1242}$ Justice Grimes opines that the common law includes customs and unwritten law, which includes Indigenous Customary Laws in the specific context of Liberia:

The court desires, first of all, to observe that going back to Blackstone's Commentaries, the first written authority form which has sprung the common law of most, if not all, English speaking countries, he states that the lex non scripta, or unwritten law 'includes not only general customs, or the common law properly so called; but also, the particular laws that are by custom observed only in certain courts and jurisdictions. ${ }^{1243}$

However, Ballah Karman v John L. Morris, Secretary of the Interior and Major John H. Anderson, Commanding the Liberian Frontier Force $1920^{124}$ affirms the constitutional supremacy and subjection of Indigenous Customary Laws to Liberia's common law jurisdiction. In these cases, local chiefs of the Todee and Ding of the Gola Country were held responsible for theft committed in the settlement of White Plains by Indigenous men. ${ }^{1245}$ Under international law,

\footnotetext{
${ }^{1237}$ Jallah, above n 1181, 4.

${ }^{1238}$ Ibid 3-4.

${ }^{1239}$ Mae Azango, 'Liberia: Married at 13 - Young Girls Forced Into Adulthood in Liberia' FrontPageAfrica (Monrovia, Liberia), 7 November 2014 <http://allafrica.com/stories/201411071717.html>.

${ }^{1240}$ Stephen C Lubkemann, Deborah H Isser and Philip AZ Banks, 'Unintended Consequences: Constraint of Customary Justice in Post-Conflict Liberia' in Deborah H Isser (ed), Customary Justice and the Rule of Law in War-

Torn Societies (United States Institute of Peace Press, 2011) 193.

${ }^{1241}$ Huberich, above n 53, 1231.

${ }^{1242}$ New York Krp eh $v$ Harding 1936 (unpublished but printed opinions) 107.

${ }^{1243}$ Huberich, above n 53, 1198.

${ }^{1244}$ Ballah Karman v John L. Morris, Secretary of the Interior and Major John H. Anderson, Commanding the Liberian Frontier Force 1920 (Judgment Book, p247, Unpublished).

${ }^{1245}$ Huberich, above n 53, 1207.
} 
the conquest of land can confer sovereignty. ${ }^{1246}$ However, sovereignty does not confer upon Liberian settler-colonists the absolute right to land and property when in fact Indigenous lands were dispossessed and allocated as government land (or Crown land in British colonies such as Australia $^{1247}$ ). Although Chief Justice Joseph J Dossen ruled otherwise in Ballad, the AttorneyGeneral argued that since Indigenous Peoples in Liberia had not given their consent to settlercolonist law, the government had no jurisdiction over Indigenous Peoples and their land in Liberia. $^{12}$

The clash between Indigenous customs and Anglo-American-Liberian law also creates significant access to justice challenges for Indigenous Peoples in Liberia. ${ }^{1249}$ Daily, Indigenous Peoples are compelled to interact with formal or state legal systems for various reasons, for instance, because of land and natural resource disputes, disputes with corporate bodies, and criminal prosecution. ${ }^{1250}$ Ongoing attempts to contain dynamic, adaptive Indigenous Customary Law systems within the legal reasoning of the formal settler-colonist system have proven impossible, sometimes resulting in an arbitrary and unpredictable legal system. ${ }^{1251}$ Indigenous Peoples in Liberia face two major challenges when it comes to accessing justice: 1) recognition of Indigenousness as a valid and distinct identifier for communities with unique histories and relationships to their lands; and 2) loss of the meaning of Indigenousness because of a mistaken notion that all black Africans are Indigenous to Africa. ${ }^{1252}$

As stated above, constitutionally in Liberia, legislatures and courts preference AngloAmerican-Liberian jurisprudence over that of Indigenous Customary Laws' jurisprudence even though there is no doubt of the existence of a dual legal system. ${ }^{1253}$ Yet there is a belief that Liberian Indigenous Customary Laws are non-existent or even dead, which demonstrates a level of passivity in research based on the wealth of Indigenous traditional knowledge. The assumption that Liberia's court system is based on Western common law, administers justice in the best way possible and makes law relevant to the socio-economic and political demands of Native Peoples today is problematic. ${ }^{1254}$ Anglo-American-Liberian law has failed to provide redress for injustice caused by colonial violence against Native Peoples in Liberia, and alleged

\footnotetext{
${ }^{1246}$ Asmi Wood, 'Constitutional Reform 2013: What Are We Trying to Achieve?' (2012) 37(3) Alternative Law Journal 156. Also see, Island of Palmas Case (or Miangas), United States v Netherlands, Award, (1928) II RIAA 829, ICGJ 392 (PCA 1928), 4th April 1928, Permanent Court of Arbitration [PCA].

${ }^{1247}$ In $R$ v Bonjon [1841] NSWSupC 92 (16 September 1841), Willis J quotes Charles Clark's A Summary of Colonial Law (1834), as stated by Mr Redmond Barry, who represented Bonjon '[c]olonies... are acquired by conquest; by cession under treaty; or by occupancy. By occupancy where an uninhabited country is discovered by British subjects and is upon such discovery adopted or recognised by the British Crown as part of its possessions. In case a colony be acquired by occupancy, (he adds) the law of England then in being, is immediately and ipso facto in force in the new settlement.... New South Wales and Van Diemen's Land, were acquired by discovery or simple occupation. New South Wales was not however unoccupied, as we have seen, at the time it was taken possession of by the colonists, for "a body of the aborigines appeared on the shore, armed with spears, which they threw down as soon as they found the strangers had no hostile intention". This being the case, it does not appear there was any conquest, and it is admitted there has hitherto been no cession under treaty'.

${ }^{1248}$ Huberich, above n 53, 1210-1221.

${ }^{1249}$ Young and Sing'Oei, above n 1186, 97.

${ }^{1250}$ Ibid.

${ }^{1251}$ Ibid.

${ }^{1252}$ Ibid $90-91$.

${ }^{1253}$ Lubkemann, Isser and Banks, above n 1240, 199.

${ }^{1254}$ Peter Onyango, African Customary Law: An Introduction (LawAfrica Publishing (K) Ltd, 2013) 4.
} 
perpetrators of war crimes against Indigenous girls and women have yet to be brought to court despite the existence of carefully written laws and legislative acts. Written laws also lack the power to make people observe and respect them. ${ }^{1255}$ Therefore, Indigenous Peoples in Liberia and Australia benefit by incorporating norms that contribute effectively to the changing nature of Indigenous Customary Laws. ${ }^{1256}$ The revival of Indigenous Customary Laws as a legal discourse is alive and active in Indigenous communities, posing serious challenges to Westerndominant juridical orders. ${ }^{1257}$ Thus, being challenged with remedying Indigenous gender justice

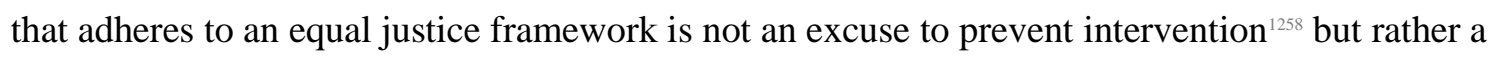
call to action for establishing legal approaches that are pluralistic, decolonising, intersectional, critical-race focused, feministic and informed by social determinants of health principles.

\subsubsection{Accommodating Indigenous Customary Laws: Colonial and Indigenous Courts}

Evidence in this research shows that since colonisation began, criminalising Indigenous Peoples has been the excuse for imposing discriminatory laws, coercive policies and unfair treatment on Indigenous Peoples. As certain aspects of Indigenous Customary Laws are incorporated in settler-colonist law in both Liberia (Tribal Chief Courts) and Australia (for example, Sentencing Circle Courts), there are situations that make Indigenous Peoples subjected and entitled to the protection of the states' formal legal system. ${ }^{1259}$ It is this unique duality of Indigenous Customary Laws that creates the need to assess the efficacy of the rule of law in the sense of how Aboriginal lore, customs and practices are accommodated in settler-colonist law. To this end, in considering any attempts to accommodate Indigenous Customary Laws in Australian and Liberian formal legal systems, keep in mind that settler-colonist laws take precedence over Indigenous Customary Laws. With time, the establishment of the colonial legislature and courts helped legalise systematic violence against Indigenous Peoples.

Australia was established in May 1788, as the first penal settlement, when a fleet of English ships sailed for Botany Bay carrying over a thousand convicts, officers and staff. ${ }^{1260}$ It took 48 years (1788-1836) after the arrival of Captain Cook for white colonists to subject Indigenous Peoples in Australia to British common law by establishing their first Supreme Court in New South Wales. The codification of British rule in Australia provided a legal dimension to colonisation under both written statute and judge-made law. ${ }^{1261}$ Heather Douglas and Mark Finnane argue that 'in that moment, Australian law was British law', leaving 'the modern complex known as Indigenous customary laws' with little recognition or formal

\footnotetext{
${ }^{1255}$ Ibid 5.

${ }^{1256}$ Calma, above n 1179; Lubkemann, Isser and Banks, above n 1240, 212.

${ }^{1257}$ Onyango, above n 1254, 5.

${ }^{1258}$ Thomas Kleven, 'The Supreme Court, Race, and the Class Struggle' (1981) 9(3) Hofstra Law Review 795.

${ }^{1259}$ Douglas, above n $479,36$.

${ }^{1260}$ Stone, above n $178,17$.

${ }^{1261}$ Cahir and Clark, above n 787; Douglas, above n 479, 125.
} 
substance. ${ }^{1262}$ The New South Wales Supreme Court formalised and imposed its exclusive criminal jurisdiction over Indigenous offenders, paving the way for the normalisation of colonial punitive authority over Indigenous Peoples. ${ }^{1263}$ The progression of control over Indigenous Peoples is enshrined in Chapter III, section 73 (iii) of the Australian Constitution 1901, which states that 'the judgments of the High Court in all such cases shall be final and conclusive'. Douglas and Finnane acknowledge that prior reasons for the imposition of British law on Aboriginal 'subjects' resulted in decades of violent conflict between settler-colonists and Aboriginal Peoples in Australia.

Punishment for crimes meant that the repression and restraint of Indigenous persons were not an abuse of power, but rather justifications for the use of power. In the penal colony of Australia, 'conflicts between Aboriginal people and settlers ... often ended in summary execution or mass murder rather than in arrest and prosecution.' ${ }^{1264}$ Settler-colonists continuously inflicted violent punishment on Indigenous Peoples for alleged crimes of trespassing or cattle killing. Indigenous Peoples' resistance to criminal punishment, land appropriation or cultural assimilation drew even harsher penalties, some of which resulted in mass murders and genocide. For example, the infamous Black Line in Van Diemen's Land instigated by Governor George Arthur in 1830 set out to remove insurgent Tasmanian Aboriginal nations from their homelands to a designated reserve on the Tasman Peninsula. ${ }^{1265}$ Courts made an example of those who resisted colonisation by handing down corporal punishment (e.g., whipping) or ordering public executions of Indigenous Peoples. As administrative and penal institutions detained Indigenous People, instruction and labour became the means of transforming Indigenous lives. ${ }^{1266}$ Lawmakers believed Indigenous Peoples could learn only through might and hence inserted special provisions into criminal laws to permit such sentencing options exclusively for them. ${ }^{1267}$ However, Australian courts' asserting jurisdiction over Aboriginal Peoples came with unexpected opportunities.

The prospect of a judge exerting complete jurisdiction over Aboriginal 'subjects' and land increased the possibility for Aboriginal Peoples in Australia to be treated as equal under the law. For example, in 1837, Lord Glenelg's Directive from the Colonial Office in London asserted that colonial authorities should take steps to protect Indigenous Peoples of the Empire by holding inquests. ${ }^{1268}$ The following year, Governor George Gipps of the colony of New South Wales issued a declaration to protect Aborigines. ${ }^{1269} \mathrm{He}$ also introduced an act to make Aboriginal Peoples 'competent witnesses' in courts, but it did little to provide Aboriginal Peoples equal status as British subjects. Instead, Aborigines giving evidence in court was

\footnotetext{
${ }^{1262}$ Douglas, above n 479, 35 .

${ }^{1263}$ Anthony, above n 1204, 36.

${ }^{1264}$ Weatherburn, above n 689, 25.

${ }^{1265}$ Lyndall Ryan, 'The Black Line in Van Diemen's Land (Tasmania), 1830' (2013) 37(1) Journal of Australian Studies 1.

${ }^{1266}$ Anthony, above n 1204, 31.

${ }^{1267}$ Ibid.

${ }^{1268}$ Douglas, above n 479, 51.

${ }^{1269}$ Ibid.
} 
likened to 'the chattering of orang-outang' in $1844 .{ }^{1270}$ Ultimately, these efforts still fell short of providing equity in Australia's judicial system.

With the decline of violent punishment of Indigenous Peoples over the last 50 years, settler-colonist sentencing courts have provided some leniency for Indigenous offenders, ${ }^{1271}$ but Aboriginal Peoples are still overrepresented in the court system. Section 16A of the Crimes Act 1914 (Cth.) outlines the general conditions the settler-colonists courts must consider when sentencing an individual. These relevant matters include:
a) the nature and circumstances of the offence;
b) other offences (if any) that are required or permitted to be taken into account;
c) if the offence forms part of a course of conduct consisting of a series of criminal acts of the same or a similar character — that course of conduct;
d) the personal circumstances of any victim of the offence; and
d) any injury, loss or damage resulting from the offence.

However, in 1980, after the consolidation of legal jurisdiction in Australia, violence was the main reason for Aboriginal Peoples' presence in settler-colonist courts. ${ }^{1272}$ In 2017, a report by the Australian Law Reform Commission stated that Aboriginal and Torres Strait Islander female offenders are the fastest growing prison cohort in Australia, increasing at a rate which significantly exceeds the growth rate of other offenders, including Aboriginal and Torres Strait Islander male offenders. ${ }^{1273}$ Australia is beginning to adopt more pluralistic judicial methods to address this inequity.

The statutory framework of settler-colonist law used for prosecuting and sentencing Aboriginal offenders still does not address the root causes of systematic violence. In Aboriginal Australia, similar to a Palava Hut ${ }^{1274}$ in Native Liberia, disputes and grievances are usually resolved in formal meetings facilitated by elders (mostly elder men) in a sort of 'embryonic court'. The establishment of traditional courts and specific sentencing options commensurate with Aboriginal Australians' unique historical backgrounds are two mechanisms consistent with the combined characteristics of the rule of law regarding access to justice and equality before the law. Modifications to the formal court system were aimed at providing a more culturally sensitive space to help minimise Aboriginal Peoples' mistrust of and dissatisfaction with the formal judicial system. ${ }^{1275}$ It is against this backdrop that the first Aboriginal Sentencing Courts were established in June 1999. Aboriginal Circle Sentencing Courts are an attempt to incorporate Indigenous Customary Laws within the Anglo-Australian legal system but only after an Aboriginal person has been tried in the common law system. ${ }^{1276}$ The Aboriginal Nunga

\footnotetext{
${ }^{1270}$ Ibid 57-58.

${ }^{1271}$ Anthony, above n 1204, Preface.

${ }^{1272}$ Douglas, above n 479, 55.

${ }^{1273}$ Australian Law Reform Commission, 'Incarceration Rates of Aboriginal and Torres Strait Islander Peoples', above $\mathrm{n} 520,161$.

${ }^{1274}$ Wulah, above n $169,152$.

${ }^{1275}$ John Tomaino, 'Aboriginal (Nunga) Courts' 1-2

<http://www.ocsar.sa.gov.au/docs/information_bulletins/ib39.pdf>.

${ }^{1276}$ Elena Marchetti and Kathleen Daly, 'Indigenous Courts and Justice Practices in Australia' (2004) 277 Trends \&

Issues in Crime and Criminal Justice 1; Shane Madden, 'The Circle Court in the ACT - An Overview and Its Future'
} 
Courts are presided over by a Magistrate assisted by an Aboriginal Elder and Respected Persons, a system which was established as a pilot in South Australia. The purpose of the Nunga Courts is to provide 'an opportunity for Aboriginal court users to have their voice heard in a culturally appropriate manner. Family members and support persons are encouraged to attend and speak directly to the court. ${ }^{1277}$ By 2009, a total of 51 such sentencing courts had taken place across Australia. ${ }^{1278}$ In spite of efforts made on the part of the Australian government to reform the adverse impact of the criminal procedure on Aboriginal Australians, ${ }^{1279}$ challenges remain. A major roadblock facing the Circle Sentencing Courts is the increase in the number of such community courts, which makes even more apparent the ongoing failure of the judicial system to take Aboriginal Peoples' cultural background and rehabilitation needs into account when sentencing. ${ }^{1280}$ Similar challenges and solutions exist in Liberia's judiciary.

Liberia has implemented a combination of statutory and Tribal Courts to accommodate the pluralistic nature of Liberia's legal system. Chapter 1, Article 3 of the Liberian Constitution 1986 and the African Charter on Human and People's Rights 1981 provide for Liberia's judiciary. In broad terms, three levels of courts make up the Judiciary: 1) Justice of Peace and Magistrate Courts, 2) the Circuit Court and other specialised courts, and 3) a five-judge Supreme Court. ${ }^{1281}$ Judicial power is characterised by a 'unified judicial system' reified in the Supreme Court and its subordinate courts, which are the circuit, debt, probate, magistrate and other specialised courts. ${ }^{1282}$ Notably, judicial power excludes that of the Tribal Courts, whose exclusive jurisdiction over tribal persons in tribal matters is laid out in the Local Government Laws Constituting Title 20 of the Liberian Code of Laws Revised 2011. The traditional courts (bound by customary and unwritten laws in domestic disputes, land disputes and petty crimes) are presided over by Indigenous chiefs operating alongside the Anglo-American Liberian legal system. However, traditional courts cannot rule on issues that are governed by statutory law. Their decisions may be reviewed by the statutory court system or appealed to a hierarchy of

(Government, ACT Magistrate Court, 1 September 2007) 28

<http://www.aija.org.au/Ind\%20Courts\%20Conf\%2007/Papers/Madden.pdf>.

${ }^{1277}$ See the Aboriginal Sentencing Courts and Conferences in South Australia, available at

$<$ http://www.courts.sa.gov.au/OurCourts/MagistratesCourt/Pages/Aboriginal-Sentencing-Courts-and-

Conferences.aspx>

${ }^{1278}$ Elena Marchetti, 'Indigenous Sentencing Courts' (2009) 5 Indigenous Justice Clearinghouse Research Briefs 1.

${ }^{1279}$ Weatherburn, above n 689, 25-29.

${ }^{1280}$ The Australasian Institute of Judicial Administration, Indigenous Issues and Indigenous Sentencing Courts (11 November 2014) Australasian Therapeutic Jurisprudence Clearinghouse

$<$ http://www.aija.org.au/index.php/research/australasian-therapeutic-jurisprudence-clearinghouse/indigenous-issuesand-indigenous-sentencing-courts>. Also see Bugmy v The Queen (2013), where the appellant, an Aboriginal man who has been exposed to alcohol and violence including watching is father stab his mother 15 times led him to frequent contact with the criminal justice system between the ages of 12 and 29 as reiterated by Judge Lerve noted Mr Lawrence's submission that the appellant is 'an Aboriginal man who grew up in a violent, chaotic and dysfunctional environment' and that 'Fernando type considerations' applied.

Hoeben JA said that consideration of the appellant's background of social deprivation remained a matter of relevance, which could properly be taken into account in sentencing. However, any reduction on this account would be 'modest'.

${ }^{1281}$ Lawyers Committee for Human Rights, above n 1058, 18.

${ }_{1282}$ Judiciary Branch of Liberia, Judiciary Law - Title 17 - Liberian Code of Laws (Revised) (Ministry of Commerce and, 1972) 2 <http://www.moci.gov.lr/doc/Judiciary\%20Law\%201.pdf>. 
chiefs, the Ministry of Internal Affairs and, in some cases, the President. ${ }^{1283}$ Therefore, Indigenous Peoples in Liberia are still beholden to the Western legal system in Liberia and all of its biases.

When Indigenous People in Australia and Liberia interact with the settler-colonist court system, they still face significant racial bias. ${ }^{1284}$ As discussed in chapter 3, systemic issues of concern affecting the dispensation of justice for Indigenous Peoples by the settler-colonist legal system include racism and discrimination, whether implicit, explicit or unconscious. Ambiguous and difficult to compile, claims of pervasive, unconscious racism and discrimination in the court system are branded as 'microaggressions', which are devalued as egregious defamation and irresponsible aura. ${ }^{1285}$ Peggy Cooper Davis finds claims of racism and discrimination are well founded and should be examined and understood. ${ }^{1286}$ Angela Harris warns that unconscious racism, ${ }^{1287}$ though arguably less offensive than purposeful discrimination, is no less harmful ${ }^{1288}$ and is more perilous in many ways because it is often unrecognisable to both the survivor and the perpetrator. ${ }^{129}$ By emphasising blame rather than injury, restoration and rehabilitation, settler-colonist courts tend to satisfy the psychological needs of the uninjured party whilst leaving survivors without relief. ${ }^{.290}$ Legal pluralism and racial discrimination affect Indigenous women by virtue of their Indigeneity. Moreover, gender bias is also present in the legal systems of Liberia and Australia. Therefore, it is also important to examine how patriarchy in the legal system affects Indigenous women by virtue of their gender.

\subsection{Male-Dominant Traditional, Political and Legal Establishments}

Traditional and Anglo legal systems spring from patriarchal societies and, as a result, are dominated by males. Traditional Law tends to respect 'old wise men', who are respected as elders with accumulated knowledge and experience, as well as guardians or protectors of law, peace and order. Children, young adults and women ${ }^{1291}$ are expected to accept and conform to the dictates of cultural norms without question, which is a form of subjugation. ${ }^{1292}$ The affairs of a local unit are under the jurisdiction of a small council of old men, qualified by seniority and distinction, who have their discussions in secret conclave. ${ }^{1293}$ Whenever there is a breach of sacred law, Indigenous ritual leaders decide on appropriate punishment during their secret

\footnotetext{
${ }^{1283}$ Lawyers Committee for Human Rights, above n 1058, 18.

${ }^{1284}$ Berndt and Berndt, above n 1177, 347.

${ }^{1285}$ Peggy C Davis, 'Law as Microagression' (1989) 98 Yale Law Journal 1559, 1559, 1565.

${ }^{1286}$ Ibid 1560.

${ }^{1287}$ Charles R Lawrence III, 'The Id, the Ego, and Equal Protection: Reckoning with Unconscious Racism' (1987) 39(2) Stanford Law Review 317, 327. Professor Charles Lawrence defines unconscious racism as the ideas, attitudes, and beliefs developed in American historical and cultural heritage that cause Americans unconsciously to 'attach significance to an individual's race and [which] induce negative feelings and opinions about non-whites'.

${ }^{1288}$ Angela J Davis, 'Prosecution and Race: The Power and Privilege of Discretion' in Susan D Carle (ed), Lawyers' Ethics and the Pursuit of Social Justice: A Critical Reader (New York University Press, 2005) 245, 253.

${ }^{1289}$ Ibid.

${ }^{1290}$ Ibid.

${ }^{1291}$ Basedow, above n 601, 224.

${ }^{1292}$ Berndt and Berndt, above n 1177, 338.

${ }^{1293}$ Basedow, above n 601, 225.
} 
meetings. ${ }^{1294}$ The practice of the tribal council ${ }^{1295}$ or town or paramount chief ${ }^{1296}$ (a hereditary position similar to the hereditary peerage system of the male-dominant House of Lords) is the single physical authority for maintaining social order. ${ }^{1297}$ As the head of a monocratic system in Indigenous Liberia, the king or chief is sovereign, though he is subject to the traditional council and abides by tribal sanctions and customs. ${ }^{1298}$ However, patriarchy is not only a characteristic of Indigenous Customary Law.

Liberia and Australia maintain legal systems that are male dominant, paternalistic and patriarchal whilst professing to be equal and just. Liberia and Australia inherited legal systems from the governments of the United States and England, which sustained the colonial status quo by effecting discriminatory law and policy that excluded Indigenous women from participating in political and social states of affairs (see Table 4.1 below). For example, it took England 900 years to gain its first white woman judge in the House of Lords, Dame Brenda Hale. ${ }^{1299}$ Native American women have yet to be represented in the United States Congress. ${ }^{1300}$ It is fair to note that Australia has continued to reform its legal system since colonisation.

Reforms in Australia have reduced male dominance, but rights for Aboriginal women lag behind. Australia is hailed as one of Western society's most progressive democracies. It is the second country in the world to grant (white) women the right to vote, having done so with the Commonwealth Franchise Act 1902. Although South Australia and Western Australia granted women the right to vote in 1895 and 1899 respectively, Aboriginal Peoples as a group were not granted the right to vote in federal elections until 1962 via amendments to the Commonwealth Electoral Act 1918. Further hampering advancement, the Australian Constitution 'has no Bill of Rights, which prevents a legislature from passing laws that infringe upon basic human rights, such as freedom of speech'. ${ }^{1301}$ Passing laws that ensure equal rights for Indigenous women is made more difficult by their underrepresentation in the political system.

\footnotetext{
${ }^{1294}$ Berndt and Berndt, above n 1177, 343.

${ }^{1295}$ Ibid 348, 350.

${ }^{1296}$ Dunn and Holsoe, above n 104, 38. Dunn and Holsoe describe a Liberian Chief as one who derives power from traditional customs, inheritance, and mutual consent. Once power was conferred, the Chief was at liberty to exercise wide discretion in matters related to the protection and preservation of life, liberty and property of his people. If the Chief was found to be tyrannical, authoritarian, or despotic, power may be lost. Upon exhibition of good character, generosity, and charisma, chieftaincy was increased. When the modern Liberian state was set-up, it coexisted with that of the Indigenous political systems. In 1904, the Liberian state altered the traditional chieftaincy and created a single structure under a central authority. Paramount, town and village chiefs represented 'native' authority below state appointed district commissioners. A second reform took place in the 1920's that divided the Hinterland into three provinces, subdivided into districts, which were subdivided into clans. This then subjected the nomination of paramount chief to council of clan chiefs, who were in turn selected based on presidential appointment.

${ }^{297}$ Wulah, above n $169,145$.

${ }^{1298}$ Azikiwe, above n 301, 24.

${ }^{1299}$ House of Lords Information Office, 'History of the House of Laws' 1

<http://www.lordspublications.parliament.uk/pdf/H-076.pdf>.

${ }^{1300}$ Adrian Jawort, Denise Juneau: First American Indian Congresswoman? (6 November 2015) Indian Country Today Media Network.com <http://indiancountrytodaymedianetwork.com/2015/11/06/denise-juneau-first-americanindian-congresswoman-162341>.

${ }^{1301}$ See page $\mathrm{xx}$ of the Pocket Edition of Australia's Constitution (2014).
} 
The Australian Constitution established the Commonwealth of Australia, a Federal Government, founded in Montesquieu's tripartite system, ${ }^{1302}$ known as the separation of powers. The Federal Government of Australia comprises three branches: executive, judiciary and the legislature (Parliament). The executive is the administrative arm, made up of government employees responsible for operating and upholding the law. Under the Federal system in Australia, powers are shared between the States and the central government. Generally, the specific areas of legislative power, also called 'heads of power' given to the Commonwealth government, are taxation, defence, foreign affairs, and postal and telecommunications services. The States, on the other hand, retain legislative power over other matters and elements that exist within their borders, including police, hospitals, education and public transport. ${ }^{1303}$ The judiciary is particularly critical for protecting Aboriginal rights, as described above.

The judiciary is responsible for interpreting all of Australia's laws by way of making judgments about the law but lacks equal participation by women. The High Court of Australia is the highest court in the country and has had 12 Chief Justices and 42 justices since its establishment in 1903 up to 2015. Of the 54 justices ever appointed to the High Court of Australia, 50 (93 percent) were white men and four (7 percent) were white women. The first female justice in Australia, Honourable Mary Gaudron, was appointed by former Prime Minister Hawke on 6 February 1987. Eighteen years later, ${ }^{1304}$ over a period of four years (200509), three female justices were added. Former High Court Justice Michael Kirby shared his thoughts about the court after Justice Gaudron retired 10 years before mandatory retirement, stating that The High Court was now a more 'blokey place'. ${ }^{1305}$ Twenty-eight percent (303) of all judges (1 052) in Australia in 2014 were female. A list of female judges and magistrates in Australia compiled by the Australian Institute of Judicial Administration (12 March 2014) shows that 86 ( 28 percent) of the 226 judges and magistrates across Australia were females (also see Appendix V). ${ }^{1306}$ Of the 30 female judges and magistrates across Australia, only three (Sue Gordon, Pat O'Shane and Rosa Falla) were widely identified as Indigenous Peoples in Australia.

Women are also underrepresented in the Australian legislature, including in the position of Prime Minister. The role of the Parliament, which comprises the legislature, is to make and amend the law. By convention, the Prime Minister is a member of the House of Representatives and also a Member of Parliament. Since the establishment of the constitutional monarchy in

\footnotetext{
${ }^{1302}$ Charles de Secondat Baron de Montesquieu, The Spirit of Laws: The Complete Works (T Evans, 1777) vol 1, 234-236.

${ }^{1303}$ See the Government of Australia website available at <http://www.australia.gov.au>.

${ }^{1304}$ From 1987 to 2005 when the second female justice, Susan Crennan, was appointed by former Prime Minister John Howard

${ }^{1305}$ Hon Justice Michael Kirby, 'Women in Law - Doldrums or Progress?' (Public Lecture at the Women Lawyers of Western Australia, Perth, Western Australia, 22 October 2003) $<$ http://www.hcourt.gov.au/assets/publications/speeches/former-justices/kirbyj/kirbyj_22oct.html>.

${ }^{1306}$ See AIJA at <http://www.aija.org.au/JudgesMagistrates2014.pdf> 
1901, there have been 28 prime ministers, ${ }^{1307}$ all of whom were white males, except for one female, Julia Gillard. Even farther from being Indigenous, seven ( 25 percent) of the 28 Prime Ministers, including Julia Gillard, was born in the United Kingdom. Former Prime Minister Chris Watson was born in Chile. The underrepresentation of women in the role of Prime Minister is representative of their underrepresentation in the legislature as a whole.

Table 4.1: List of Aboriginal Women Members of Parliament in Australia

\begin{tabular}{|c|c|c|c|c|c|c|c|}
\hline$\#$ & Member & Part & Parliament & Constituency & Indigeneity & Term & Notes \\
\hline 1 & Pat O'Shane & $y$ & NSW & $\begin{array}{l}\text { Aboriginal } \\
\text { Affairs }\end{array}$ & Yalangi & 1981-1986 & $\begin{array}{l}\text { First Aboriginal person to become a } \\
\text { permanent head of a ministry in } \\
\text { Australia, first Aboriginal to earn a } \\
\text { law degree, and the first Aboriginal } \\
\text { barrister }\end{array}$ \\
\hline 1 & $\begin{array}{l}\text { Carol Anne } \\
\text { Martin }\end{array}$ & ALP & WA & Kimberley & Noongar & $\begin{array}{l}10 \text { Feb } 01 \\
-9 \text { Mar } 13\end{array}$ & $\begin{array}{l}\text { First Indigenous woman to be elected } \\
\text { to an Australian parliament }\end{array}$ \\
\hline 2 & $\begin{array}{l}\text { Marion } \\
\text { Scrymgour }\end{array}$ & ALP & NT & Arafura & Tiwi & $\begin{array}{l}18 \text { Aug } 01 \\
-6 \text { Aug } 12\end{array}$ & $\begin{array}{l}\text { First Indigenous woman to become a } \\
\text { Minister }\end{array}$ \\
\hline 3 & Kathryn Hay & ALP & TAS & Bass & Noongar & $\begin{array}{l}20 \text { Jul } 02 \\
-18 \text { Mar } 06\end{array}$ & Former Miss Australia \\
\hline 4 & Linda Burney & ALP & NSW & Canterbury & Wiradjuri & 22 Mar 03 - & \\
\hline 5 & Alison Anderson & ALP & NT & $\begin{array}{l}\text { MacDonnell/ } \\
\text { Namatjira }\end{array}$ & Arrente & $\begin{array}{l}18 \text { Jun } 05 \\
-\end{array}$ & \\
\hline 6 & $\begin{array}{l}\text { Malarndirri } \\
\text { McCarthy }\end{array}$ & ALP & NT & Arnhem & Yanyuwa & $\begin{array}{l}18 \text { Jun } 05 \\
-6 \text { Aug } 12\end{array}$ & \\
\hline 7 & Larisa Lee & CLP & NT & Arnhem & Jawoyn & 25 Aug 12 - & \\
\hline 8 & Bess Price & CLP & NT & Stuart & Arrente & 25 Aug 12 - & \\
\hline 9 & Josie Farrer & ALP & WA & Kimberley & Kija & 9 Mar 13 - & \\
\hline 10 & Nova Peris & ALP & $\mathrm{CTH}$ & Senator for NT & $\begin{array}{l}\text { Gija, Yawuru, } \\
\text { Iwatja }\end{array}$ & 7 Sep 13 - & $\begin{array}{l}\text { First Indigenous woman elected to } \\
\text { Federal Parliament }\end{array}$ \\
\hline 11 & Jacqui Lambie & PUP & $\mathrm{CTH}$ & Senator for TAS & $\begin{array}{l}\text { Plangermaireene } \\
\mathrm{r}\end{array}$ & $1 \mathrm{Jul} 14$ - & \\
\hline 12 & Leanne Enoch & ALP & QLD & Algester & $\begin{array}{l}\text { Nunukul - } \\
\text { Nughi }\end{array}$ & $\begin{array}{l}31 \text { Jan } 2015 \\
-\end{array}$ & \\
\hline
\end{tabular}

The Australian Parliament consists of two Houses (the House of Representatives and the Senate) and the Queen, represented in Australia by the Governor-General. In 2014, the 150 members of the House of Representatives each represented an electorate. Of these, 110 (73 percent) were males ( 1 percent of whom are of Aboriginal descent $)^{1308}$ and 40 (27 percent) were white females. The 76 members of the Senate were evenly distributed amongst the six states, with each having 12 senators. Northern Territory and the Australian Capital Territory have two senators each. Of the 76 Senators, 29 (38 percent) were women, with Nova Peris of the Gija, Yawuru, and Iwatja heritage becoming the first Indigenous woman to be elected in 2013. Mario Scrymgour, a Tiwi woman, was the first Indigenous woman government minister. Since 15 August 1971, when Neville Bonner became the first Indigenous politician to enter the

\footnotetext{
${ }^{1307}$ See the National Archives of Australia, Australia's Prime Ministers at $<$ http://primeministers.naa.gov.au/primeministers/>.

${ }^{1308}$ Kenneth George Wyatt is the first and only Aboriginal House of Representative Member of Parliament in the Federal Government of Australia. He represents the Hasluck electoral division in Western Australia for the Liberal Party. He is a Noongar, Yamatji and Wongi of Indian, English and Irish descent (see

<http://www.aph.gov.au/Senators_and_Members/Parliamentarian?MPID=M3A>).
} 
Australian Senate, there have been 32 Indigenous members of the 10 Australian Legislatures. Of these, 17 were elected to the Northern Territory Legislative Assembly, five to the Australian Federal Parliament, four to the Western Australia Parliament, three to the Queensland Parliament and one each to Tasmania, New South Wales and the Australian Capital Territory. Of the 32 Aboriginal members represented in the Australia Legislature between 1971 and 2014, 12 were Aboriginal women. These 12 women constitute 6 percent of the total number of members, compared to the 27 percent representation of white women in the Federal Parliament (see Table 4.1). Unfortunately, women are similarly underrepresented in the Liberian political system.

Liberia inherited a flawed political and legal system from the United States. Before the arrival of settler-colonists, political institutions in Native Liberia emphasised chieftaincy rule over family, clan, kingdom and confederacy. For example, in the $15^{\text {th }}$ century, the Kru Confederacy of Liberia, founded by the Abron (a subgroup of the Akan Language Group of West Africa) was described as 'well organised' socially, legally and politically. ${ }^{1309}$ However, after 1822, the establishment of Liberia's political structure was heavily influenced by its colonial and slave master, the United States, represented by the ACS. The republican form of government, adopted by both the United States and Liberia, has vestiges of the Westminster System, particularly regarding the organisation and legislative ability of both the Senate and the House of Representatives. Chapters V, VI and VII of the Liberian Constitution 1986 distribute powers amongst legislative, executive and judicial branches of the government. However, the independence of the three branches of government is not a straightforward separation of powers in terms of the ideal of modern democracies. The extent to which the branches of government fuse and interfere with each other's authority is elusive in some regards and can be paralysing in others. For example, in the republican form of government, it is assumed that no one is above the law. However, in Liberia (and Australia), presidential privileges and immunities allow the Head of State to pardon prisoners, ${ }^{1310}$ enforce executive orders ${ }^{1311}$ and exempt themselves from war-crime prosecutions whilst in power. ${ }^{13}$

\footnotetext{
${ }^{1309}$ Azikiwe, above n 301, 23.

${ }^{1310}$ Executive Mansion of Liberia, 'President Sirleaf Grants Executive Clemency to 32 Inmates in Prison across the Country’ Executive Mansion News (Monrovia, Liberia), 23 December 2014 http://www.emansion.gov.lr/2press.php?news_id=3166.

${ }_{1311}$ James Butty, 'Backlash over Liberian President's Executive Order' Voice of America (Monrovia, Liberia), 8 December 2014 <http://www.voanews.com/content/backlash-over-liberian-presidents-executiveorder/2549911.html>.

${ }^{1312}$ Truth and Reconciliation Commission of Liberia, Truth and Reconciliation Report (2008) 271-272; FPA Staff Reporter, 'War Crimes Lists', Front Page Africa, 5 March 2015, at

http://www.frontpageafricaonline.com/index.php/news/4664-war-crimes-list-culture-of-impunity-unlikely-tocontinue; Staff Reporter, 'As Liberia govt seeks clarification from U.S. on visa revocations, Kabineh J'aneh, Eugene Nagbe, and Geraldine Doe-Sheriff prevented from entering the USA', Hints News Network, 24 July 2014, at http://hintsnewsnetwork.com/?p=3646; Staff Reporter, 'Sirleaf starts to form government, some appointments spark protest', IRIN News, 14 February 2006, at http://www.irinnews.org/report/58143/liberia-sirleaf-starts-to-formgovernment-some-appointments-spark-protest; US Immigration and Customs Enforcement, Liberian human rights violator removed from US (2012) News Releases - ICE Newsroom <http://www.ice.gov/news/releases/liberianhuman-rights-violator-removed-us> at 6 March 2015; FPA Staff Reporter, 'Woewiyu pleads not guilty - Judge denies him bail in fraud case', Front Page Africa, 19 May 2014, at http://allafrica.com/stories/201405201200.html; TewrohWehtoe Sungbeh, 'Woewiyu's arrest by US officials confirms our inability to pursue our own war criminals', The
} 
The republican model was further degraded by the rise of a single-party political system in Liberia. The Liberian Constitution 1820, 1839 and 1847 were silent on the matter of political parties. Historically, two major political parties were formed along racial or pigmentation lines in Liberia after its independence in 1847. The Republican Party, made up of African American settler-colonists with mixed African and European ancestries, disappeared after the death of the first President, Roberts, in 1876. Modelled after the United States Whig Party, the Liberian True Whig Party was founded on Western expansionism ideology that arose in 1869 in Clay-Ashland (a settler-colonist colonial settlement). Daniel Webster, Henry Clay (co-founder of the United States Whig Party), and Abraham Lincoln, all members of the United States Whig Party, also happened to be founding members of the ACS. The Liberian True Whig Party, composed of dark-skinned elite settler-colonists, began its century-long reign from 1878 to 1980 with the election of former President Anthony William Gardiner. ${ }^{1313}$ The existence of a one-party state has been criticised as the main root cause of Liberia's political and legal travesty, ${ }^{1314}$ and particularly its exclusion of and discrimination against Indigenous Peoples in Liberia. ${ }^{3}$

As with Australia, many Liberian heads of state were not born in the country and most were not Indigenous Peoples. Liberia has had a total of 29 presidents (27 males and two females) along with six interim leaders. The first 12 Liberian presidents were all born in the United States. The remaining 17 were born in Liberia, but only two were of Indigenous descent (Samuel Doe and Moses Blah). The longest serving was President Tubman, who ruled for 27 years (1944-71). Of the three female heads of state in Liberia, Ellen Johnson Sirleaf is the first and only one democratically elected, not just in Liberia but in all of Africa (see Appendix VI for more details). Also, as in Australia, women are also underrepresented in the other branches of government.

Liberian Dialogue, 15 May 2014, at http://theliberiandialogue.org/2014/05/15/woewiyus-arrest-by-us-officialsconfirms-our-inability-to-pursue-our-own-war-criminals/; Alphonso W. Nyenuh, 'The war crimes case against Tom Woewiyu - Why the US must prosecute', Front Page Africa, 13 June 2014, at

http://www.frontpageafricaonline.com/index.php/op-ed/commentaries-features/1938-the-war-crimes-case-againsttom-woewiyu-why-the-u-s-must-prosecute; The US District Court, Pennsylvania, 'Indictment of Jucontee Thomas Woewiyu' (2014); Anonymous, 'America ready for Liberians accused of war crimes?', Heritage, 29 July 2014, at Online. Page 268 of the Truth and Reconciliation Commission Report 2009 lists eight leaders of warring factions in Liberia, including Charles G. Taylor who is currently service 50 years sentence in Den Haag for war crimes and crimes against humanity committed in Sierra Leone (not Liberia); George Boley, former Minister of Education and Minister of State and Presidential affairs who was deported from the US under the Child Soldiers Accountability Act 2008; and Prince Y. Johnson, former Commanding General of the Armed Forces of Liberia, now Senior Senator (elected) of Nimba County. Pages 271-272 of the TRC (2009) list 50 persons including President Ellen Johnson Sirleaf, Associate Supreme Court Justice, Kabineh Ja'neh, and Tom Woewui, former Defense Minister of Charles Taylor's government who is undergoing trial in the US for fraud.

${ }^{1313}$ Harold D Nelson, Liberia: A Country Study (Headquarters, Department of the Army, 3rd ed, 1985)

<http://www.globalsecurity.org/military/library/report/1985/liberia_1_truewhigascend.htm>.

${ }_{1314}$ above n 1096, 12-14. The US State Department Human Rights Report asserts that the Liberian law does not provide criminal penalties for official corruption, even when so blatantly display be legal authorities: '[j] udges were susceptible to bribes to award damages in civil cases. Judges sometimes requested bribes to try cases, release detainees from prison, or find defendants not guilty in criminal cases. Defense attorneys and prosecutors sometimes suggested defendants pay bribes to secure favorable rulings from or to appease judges, prosecutors, jurors, and police officers. The Ministry of Justice continued its calls to reform the jury system'.

${ }^{1315}$ William Q Harmon, ‘TWP Warned against Political Dominance, Exclusion' The Daily Observer (Monrovia, Liberia), 9 July 2015. 
Women are not equally represented in the Liberian legislature. The Liberian Legislature comprises the Senate and the House of Representatives, elected for nine- and six-year terms, respectively. ${ }^{1316}$ Of the 30 senators in the $53^{\text {rd }}$ Legislature of Liberia, only three (10 percent) were females, two (7 percent) of whom come from an Indigenous background. Of the 64 members of the House of Representatives of the 53rd Legislature of Liberia, seven (11 percent) were females, of which four ( 6 percent) are believed to come from an Indigenous background. However, regardless of their underrepresentation, women in Liberia have made significant contributions.

Liberian women have made noteworthy contributions to national and international politics throughout the $20^{\text {th }}$ century. The Liberian Constitution 1847 was also silent on women's election to political offices, which have been held mostly by males. Also, Liberian women (including Indigenous women and men) only acquired the right to vote on 7 May 1946, almost 100 years after Liberia's founding. ${ }^{1317}$ However, evidence of Native Liberian women's participation in political leadership dates back to 1892, when Queen Famata Bendu Sandemani of Vai country ruled the Gawula district of Cape Mount. ${ }^{1318}$ Angie Brooks-Randolph (19282007), who is of settler-colonist heritage, was the first female minister (Attorney-General, 1953-58) and the first female Associate Justice of the Sixth Judicial Circuit Court (1977-80) in Liberia. She was also the first female president of the $24^{\text {th }}$ Session of the UN General Assembly and the second woman from any nation to head the UN General Assembly (1969-70). ${ }^{1319}$ Ruth Perry served as interim president (and the first woman Head of State in Africa) from November 1996 to August 1998. ${ }^{1320}$ Nyorblee Karngar-Lawrence is the first Indigenous Female Senator of Grand Bassa County. Also, despite the relatively low percentage of Liberian women's participation in politics, 35 percent of Liberia's cabinet members were female during President Johnson-Sirleaf's leadership.

Identifying Liberian politicians as strictly Indigenous is challenging given the generations of structural violence that robbed Liberians of their Indigenous roots. As indicated in chapter 2 and 3 above, historically, the Christianising project plucked Indigenous children from their traditional locales and put them into settler-colonist enclaves for the purpose of 'civilising' them. Through this process, many took on English names and adopted an 'American' way of living. The process of acquiring a new 'Americanised' identity resulted in the loss of Native Liberians' Indigenous roots. Furthermore, partly due to the social stigma associated with being a Native Liberian, many shied away from identifying as an Indigenous person for fear of experiencing discrimination. In some cases, having an English surname, such as Johnson or Henries, means that a person is of settler-colonist heritage. An illustration in point is that of the

\footnotetext{
${ }^{1316}$ Article 46 of the Liberian Constitution states that, 'all Senators shall be elected to serve a term of nine years', and Article 48 states that: '[t]he House of Representatives shall be composed of members elected for a term of six years'.

${ }^{1317}$ Rosemarie Skaine, Women Political Leaders in Africa (McFarland and Co, 2008) 120-122.

${ }^{1318}$ Dunn and Holsoe, above n 104, 153; Sheldon, above n 913, 219.

${ }^{1319}$ Jennifer S Uglow, Frances Hinton and Maggy Hendry (eds), The Northeastern Dictionary of Women's Biography (Northeastern University Press, 3rd ed, 1999) 91; Sheldon, above n 912, xxii, 38; Dunn and Holsoe, above n 104, 30.

${ }^{1320}$ Sheldon, above n 913, 96.
} 
current president of Liberia, Ellen Johnson-Sirleaf, who has a mixed-race (part German) mother and an Indigenous father of the Gola Language Group from Bomi County. When her father was 'sent to the city' (or informally adopted) to be raised by the McGrity family, his first name, 'Karnley', was Westernised to 'Carney' and his last name changed to 'Johnson'. His longstanding association with the settler-colonist Liberians filtered down to his daughter Ellen, who later reaped benefits from being identified with former slave immigrant settlers. Until the publication of her memoir, wherein she reveals her Indigenous identity, many Liberians misidentified President Johnson-Sirleaf as descending from the elite settler-colonists. ${ }^{1321}$

Table 4.2: Numbers, percentages and sex of Indigenous representatives in Liberia and Australia

Description

\begin{tabular}{|c|c|c|c|}
\hline & $\#$ & Males (\%) & Females $(\%)$ \\
\hline Representatives & 150 & $110(73)$ & $40(27)$ \\
\hline Senate & 76 & $48(63)$ & $28(37)$ \\
\hline Cab-Ministers & 19 & $16(84)$ & $3(16)$ \\
\hline $\begin{array}{l}\text { High Court / } \\
\text { Supreme Court } \\
\text { Justices }\end{array}$ & 7 & $4(57)$ & $7(43)$ \\
\hline TOTAL & 252 & $178(71)$ & $78(31)$ \\
\hline
\end{tabular}

AUSTRALIA

Aboriginal
Female
$0(0)$
$1(1)$
$0(0)$
0
$2(0.8)$

LIBERIA

\begin{tabular}{|c|c|c|}
\hline $\begin{array}{l}\text { Males } \\
(\%)\end{array}$ & $\begin{array}{l}\text { Females } \\
(\%)\end{array}$ & $\begin{array}{l}\text { Indigenous } \\
\text { Females }\end{array}$ \\
\hline $27(90)$ & $3(10)$ & $2(7)$ \\
\hline 57 (89) & $7(11)$ & $4(3)$ \\
\hline $15(79)$ & $4(21)$ & $0(0)$ \\
\hline $3(80)$ & $2(40)$ & $1(20)$ \\
\hline 103 (87) & $16(14)$ & 7 (6) \\
\hline
\end{tabular}

Sources: http://www.aph.gov.au and http://legislature.gov.lr and legislature.gov.lr (now-defunct website).

The underrepresentation of women in the Liberian and Australian political systems is in direct conflict with the rule of law. Unequal representation in the legislative, executive and judicial branches of government represents unequal access to the process of drafting, executing and interpreting laws. Also, it demonstrates unequal legal and political participation by Indigenous women, whereas the rule of law requires that Indigenous women participate equally. Male-dominance also limits the ability of women to develop a legal system that guarantees their human rights, which is critical for a rights-based conception of the rule of law. Given the challenges facing women in their States' governments, it is clear why international legal instruments are necessary.

\subsection{Summary}

There are many relevant international legal instruments that promise to uphold the rule of law. The rule of law in this research is a rights-based concept that implies equality before the law. Equality before the law is a basic human right as stipulated by the Universal Declaration of Human Rights 1948, the International Convention on the Elimination of Racial Discrimination 1965, the International Covenant on Civil and Political Rights 1966, the International Covenant on Economic, Social and Cultural Rights 1966, the African Charter on Human and Peoples'

\footnotetext{
${ }^{1321}$ Ellen Johnson-Sirleaf, This Child Will Be Great: Memoir of a Remarkable Life by Africa's First Woman President (Harper, 2009) 11-12.
} 
Rights 2005, the Racial Discrimination Act 1975 (Cth.) and the Liberian Constitution 1986. These instruments guarantee equal protection and treatment for everyone and in all aspects of the judicial system. However, the literature has shown that the very same law that can be used to protect Indigenous Peoples can also discriminate against them. ${ }^{1322}$ This phenomenon demonstrates a 'double-edged nature of the law' or the torsional lever of the law. The metaphor suggests that, depending on which authority anchors the fulcrum, the law can be twisted to protect or abuse rights. Notwithstanding, in many instances, positive law has proven capable of safeguarding the rights of Indigenous Peoples in Liberia and Australia. It is for this reason that this research applies international law instruments where national statutes and domestic law have failed to address systematic violence against Indigenous girls and women. Appendix VII provides a list of relevant international law instruments drawn on in this research to invoke equal protection and treatment of Indigenous girls and women who have suffered systematic violence in Liberia and Australia.

There is no single way to define justice and therefore no single theory of justice that satisfies requirements for easy access, whether one is Indigenous or not. ${ }^{1323}$ Generally, theories of justice, including questions and concerns about allocation of goods, personal opportunities, access to decision-making processes, fundamental respect amongst people, and basic structures of society, tend to focus on the broader aspect of distributive justice. ${ }^{1324}$ Notwithstanding, justice in the 'real' world is a constant process of compromise with the realities of inequity and unfairness, a process that speaks to the challenges of accessing justice that is common to Indigenous Peoples in both Liberia and Australia. Access to justice for Indigenous Peoples in post-war Liberia and Australia encompasses the need to recognise them as individuals with rights to claim their Indigenous identity. Whilst formal legal frameworks tend to undermine and dilute Indigenous collective rights, Indigenous Customary Laws' systems of dispute resolution, community governance, family law and land management are still dominant in the lives of most rural communities.

Because settler-colonists in Liberia and Australia needed a legal system that would protect their interest in the economic exploitation of the colony, Indigenous Customary Laws were accepted only to the extent that Western-imposed rule of law principles was not compromised. Nevertheless, the implementation of (critical) legal pluralism is possible under careful consideration - that is, a conscious reflection on how Western-dominant principles of the rule of law and human rights should be applied to Indigenous colonised bodies. ${ }^{1325}$ The rule of law does not necessarily need to be at odds with Indigenous Customary Laws because in

\footnotetext{
${ }^{1322}$ Garth Nettheim, International Commission of Jurists (1952- ) and University of New South Wales (eds), Aborigines Human Rights and the Law (Australia and New Zealand Book Co, 1974) 15, 23, and 30.

${ }^{1323}$ Karen Lebacqz, Six Theories of Justice: Perspectives from Philosophical and Theological Ethics (Augsburg Publishing House, 1986) 9.

${ }^{1324}$ Ibid 10.

${ }^{1325}$ Pimentel, above n 1169, 34.
} 
many cases, preservation of traditional and indigenous justice systems may be the best means of establishing and preserving the rule of law. ${ }^{1326}$

Although Indigenous Customary Laws issue from social practices, in settler-colonist societies such as Liberia and Australia, Indigenous Customary Laws are perceived as inferior to legislation and judicial decisions. ${ }^{1327}$ The reason for the neglect of and disregard for Indigenous Customary Laws is that settler-colonist states endorse legislation and precedence as the primary sources of law and not unwritten customs couched in oral history and ritualised activity. Irrespective of settler-colonists' perception, Indigenous Customary Laws are an expansive legal system with unique ideas of justice for controlling behaviours, ideas that are central features of Indigenous culture and society.

Although the analytical, critical, and evaluative applications of the rule of law tend to be matters that are properly dealt with by philosophers, jurists, politicians and courts of law, ${ }^{1329}$ Dallmayr contends that courts and lawyers cannot maintain lawfulness or the rule of law in a society rent by deep ethnic, economic or other fissures or where there is a widespread sense of corruption, unfairness and inequity. ${ }^{1330}$ Dallmayr suggests that only by remedying or healing these crevices through concrete engagement (or a struggle for recognition, as in the case of Indigenous Peoples) will it be possible to restore the common reasonableness of the law which is the nourishment of legal rule-governance. ${ }^{1331}$ Therefore, the function of ascertaining the meaning of the constitution of a state, which is regarded as the fundamental law, as well as of the meaning of acts and statutes made by the legislative body, belongs to the judges and courts who are considered interpreters of the law. ${ }^{1332}$

Although it took a relatively long time to achieve, the rights of Indigenous Peoples are protected and enshrined in several international law instruments. ${ }^{1333}$ Affirming that 'Indigenous Peoples have the right to self-determination' (article 3, United Nations Declarations on the Rights of Indigenous Peoples), Anaya argues that 'increased sensitivity to the oppression of indigenous peoples and the resulting international response have been brought about by a burgeoning worldwide social movement in which indigenous peoples themselves are the principal protagonists'. ${ }^{134}$ Such promising social movements involve Indigenous Women Advocates, such as Irene Watson, who are fighting for justice and equality regarding the

\footnotetext{
${ }^{1326}$ Ibid.

${ }^{1327}$ James AR Nafziger, Robert K Paterson and Alison Dundes Renteln, Cultural Law: International, Comparative, and Indigenous (Cambridge University Press, 2010) 166-167.

${ }^{1328}$ Ibid 168.

${ }^{1329}$ Costa, above n $1065,73$.

${ }^{1330}$ Dallmayr, above n 1066, 301.

${ }^{1331}$ Ibid 302.

${ }^{1332}$ Ibid 289

${ }^{1333}$ Joshua Castellino and Niamh Walsh (eds), International Law and Indigenous Peoples (M. Nijhoff Publishers, 2005) xvii; S James Anaya, Indigenous Peoples in International Law (Oxford University Press, 2nd ed, 2004) 49-55; Patrick Thornberry, Indigenous Peoples and Human Rights (Manchester University Press, 2002) 116-241.

${ }^{1334}$ Anaya, above n 115, 2; Anaya, above n 1333, 56-57. 
intersection of Aboriginal women's laws and 'their intersection with Anglo-Australian laws and contemporary patterns of violence' ${ }^{1335}$ (see chapter 8 ).

Finally, consider Rosalind Kidd's thought-provoking argument about the legal system inherited by colonial Australians, premised on the supremacy of the Crown:

The former colonies of Canada, Australia and the United States inherited their law from Britain (even after the Revolution, United States courts 'did little to disturb' their inherited legal system). They inherited a legal doctrine premised on the supposed impossibility of the Crown committing an illegal act. This derived from the maxim that 'the King can do no wrong', an immunity that endured in common law as, over time, the King's officer became the public officer. A citizen could only sue the government if the government gave permission. In mid-nineteenth-century England, the doctrine had been practically abandoned with permission to sue routinely granted. But in the colonies such action was deemed interference in government powers. ${ }^{133}$

This chapter argues that the principles of the rule of law do not offer an appropriate mechanism for Indigenous Peoples to receive fair treatment or access equal justice as survivors of systematic violence. Kidd's quotation above is a good example of the arbitrary nature of the law when it is tilted toward the protection of the powerful elite and their cronies. Winning recognition and acceptance of Indigenous Customary Laws as a respectable and valid legal system is a continuous struggle for Indigenous Peoples. Embracing critical legal pluralism, a great leap towards constitutional recognition in both Liberia and Australia could guarantee equal protection under the law. Whilst openness to critical legal pluralism is a viable alternative, the onus is on Indigenous Peoples to persistently resist the imposition of settler-colonist law on Indigenous communities, especially where such rule of law amounts to differential treatment. It is hoped that in the absence of domestic legal protection for Indigenous Peoples, international law will suffice to buffer Indigenous Customary Laws.

\footnotetext{
${ }^{1335}$ Irene Watson, ‘Aboriginal Women's Laws and Lives: How Might We Keep Growing the Law?' in Elliott Johnston, Martin Hinton and Daryle Rigney (eds), Indigenous Australians and the Law (Routledge-Cavendish, 2nd ed, 2008) 15, 16.

${ }^{1336}$ Kidd, above n 841, 28.
} 


\title{
CHAPTER 5: RESEARCHER'S POSITIONALITY AND REFLEXIVITY
}

\begin{abstract}
[A]dvocacy efforts become a contentious undertaking where advocacy activities appear to aim to bolster popularity and recognition of the advocates at the expense of the people that advocacy activities are meant to serve. Advocates must be mindful of the adverse outcomes that may result from their advocacy efforts. Although they may have benign intentions, advocates are no less obliged to critically reflect on their work. Advocates who make an effort to reflect on their work through a critical ethical lens can limit the potential for similar 'invisible violence' to occur as a result of their advocacy efforts. ${ }^{1337}$
\end{abstract}

\subsection{Introduction}

Too often in my relatively short lifespan, I have wondered why people say, 'It's the law, I'm just doing my job' or 'No one is above the law', or 'Ignorance of the law is no excuse.' Really? What law are they talking about? Is it the same law that still fails to prosecute the boys and men who violently abused innocent civilian children and women ${ }^{1338}$ during the armed conflict in Liberia, even a decade after the war is over? Is it the same law that allowed Western Australia's Adoption of Children Act 1896 to steal some 210000 to 250000 Aboriginal and Torres Strait Islander children from their families between 1940 and 2012? ${ }^{1339}$ Should 'saying sorry ${ }^{1340}$ or 'divulging bestiality to the Truth and Reconciliation Commission' ${ }^{1341}$ atone for such hideous crimes against humanity? Is it then safe to assume that Western democracies' rhetoric about the 'rule of law' is a façade? ${ }^{1342}$ Or am I being too cynical?

My entire research is based on cynicism about fairness and justice when it comes to applying the principle of the rule of law. This dissertation consists of an honest attempt to subject this complex concept to a close examination, as it pertains to dispensing justice to Indigenous girl and women survivors of systematic violence in Australia and post-war Liberia. The rule of law is widely researched, discussed and glorified as the foundation of the commonlaw system. It is hailed as the fortress upon which constitutional democracies build legitimacy. Nevertheless, its effectiveness in restoring justice for Indigenous survivors of systematic violence has been spotty at best. From the outset of the research proposal to typing the very last

\footnotetext{
${ }^{1337}$ Shafik Dharamsi et al, 'Saving Africa: A Critical Study of Advocacy and Outreach Initiatives by University Students' (2013) 3(1) Journal of Global Citizenship \& Equity Education 53.

${ }^{1338}$ Truth and Reconciliation Commission of Liberia, 'Truth and Reconciliation Report', above n 52, 44. TRC Findings show that about 70 per cent of all sexual based violations reported were against women and girls.

${ }^{1339}$ The Senate - Community Affairs Reference Committee, 'Commonwealth Contribution to Former Forced Adoption Policies and Practices' (Government Report, February 2012) 337, 8.

${ }^{1340}$ Australian Broadcasting Corporation, above n 489; Australian Broadcasting Corporation, above n 86; ibid; Johnson, above n 755; 'Sorry? Nothing's Changed!' Uncle Bob Randall on the National Apology - Part 1 of 2 (The Juice Media, 2009) <http://www.youtube.com/watch?v=GK6n1UGPeBc\&feature=youtube_gdata_player>.

${ }^{1341}$ Sungbeh, above n 997; The US District Court, Pennsylvania, Indictment of Jucontee Thomas Woewiyu, Court Indictment, 30 January 2014; Truth and Reconciliation Commission of Liberia, above n 52; Jerome Verdier, Prince Johnson: Contemporary History of the Conflict" Institutional and Thematic Inquiry Hearing 2014 ("Prince Johnson: Contemporary History of the Conflict" Institutional and Thematic Inquiry Hearing'").

${ }_{1342}$ In Liberia, Ellen Johnson Sirleaf, president of Liberia; Prince Yormie Johnson, Senator for Nimba County; and Liberia's Ambassador Extraordinary and Plenipotentiary, and Commany Wesseh, Liberia Permanent Representative to the United Nations have all been accused of war crimes and crimes against humanity in Liberia.
} 
sentence, I have been challenged to produce a logical, coherent critical analysis that could provoke law and policymakers to seriously rethink moral and legal justice for all women. I have also been constantly challenged to reflect on my experiences as a survivor of violence and war on one hand, and a Western-educated Liberian with identity concerns on the other. How do I capitalise on my new-found Indigenous identity to help raise the voices of marginalised girls and women, so that they can take ownership in creating and producing knowledge and the stories of their lives? This question led to persistent internal and external discordance, which in turn resulted in many sleepless nights of reflection.

Past personal trauma and re-traumatisation through the research process inform the goals and methodological underpinnings of this research. For a survivor of war and gender violence, listening to countless testimonies of vulnerability, exploitation and abuse gives rise to anger and rage. It also triggers personal memories of traumatic experiences from years ago with associated feelings of injustice. However, my aim is not to destroy or hurt, but to seek justice, equality and fairness. In this way, I consciously opt to make public my private experience as a survivor of abuse struggling to locate her Indigenous roots, using the doctoral dissertation as a platform that, by its nature and design, strives to be critical and objective. Because my personal experience drives my passion in the field but also threatens the perception of objectivity, it is important to draw on methodologies that lend validity to the research and dissertation.

Two theories help bridge the gap between the subjectivity of personal experience and the objectivity of an academic inquiry. Survivor narrative and a phenomenologically focused theory fit comfortably with identity politics, to which critical race theory is also connected. ${ }^{1343}$ Phenomenological inquiry leads to a focus on private individual actors, including survivors and perpetrators, rather than to only the structural sources of systematic violence. ${ }^{1344}$ The phenomenological version of critical legal theory supports a critique of the public-private distinction. Also, generally, people experience themselves as isolated individuals with private complaints that they could not, without substantial assistance, turn into public ones. ${ }^{1345}$ However, with validity reinforced by phenomenology, survivor narrative adds agency by acknowledging the healing and knowledge-generating power of recounting survivor experiences.

I reveal my private individual experience only to the extent that deep reflection and institutional support affords me the confidence, audacity and trust to do so in a fashion that restricts my biases and improves research outcomes. Trust I have built with community members over the years gives me the confidence to share my own experiences and to provide a platform for their narratives. Also, working with three outstanding supervisors and mentors of colour allows me to trust that my perspectives will be understood and valued. Finally, I find confidence in academia's ability to embrace novelty without necessarily aligning with Western hegemonies of 'how Ph.D. research should be done'. Such freedom of inquiry has enabled me

\footnotetext{
${ }^{1343}$ Tushnet, above n 252, 87 .

${ }^{1344}$ Ibid 85.

${ }^{1345}$ Ibid 84.
} 
to explore innovative ideas and to reflect on personal influences affecting this dissertation. . $^{134}$ However, as a survivor of gender violence, I find that approaching the subject from within the academy places me in a dual role.

Situating me as an Indigenous survivor of gender violence and an academic advocate, the research design hybridises me into the insider-outsider researcher role. This role poses personal challenges, ethical questions and obstacles to objectivity. However, reflecting on the insider-outsider role fuels my resolve to articulate my personal biases, assumptions and challenges in designing this research. It also offers me an opportunity to navigate to a mental space of acceptance, legitimacy and validity throughout the data collection phase, a space difficult to claim when it bridges the physical trauma of one's painful past and the mental distress resulting from not knowing one's identity. Therefore, an examination of the insideoutside role is important to understand its impact on the research.

The goal of this chapter is to articulate the subjectivity my experiences bring to this research. The purpose is to aid readers in taking a scholarly exploration with me as I traverse the public/private, critical/sensitive, qualitative/quantitative and academic/pragmatic aspects of this work. It is worth noting that the essence of this work is not to elevate or condemn any one research approach or country over another but to illustrate the novelty, validity and richness of conducting such sensitive research with passion and purpose. In an attempt to promote a deeper understanding of this kind of work, I intend to unpack my thoughts and lived experiences and to incorporate them into the research process. Before discussing the two lines of personal reflection emerging from the research thought process, I will first consider a conceptual underpinning of survivor discourse as it relates to the insider-outsider viewpoint of feminist legal theory. A duality of thought which promotes my motivation for this chapter is grounded in 1) my efforts to transcend the scars left as a result of Liberia's civil war; and 2) my ongoing experience of transforming my Indigenous identity.

\subsection{Survivor Discourse}

Indigenous narratives have been sustaining Indigenous Peoples for centuries, regardless of the traumatising and coercive impacts of European and African American colonisation in Australia and Liberia, respectively. As discussed above, colonisation intended to disrupt Indigenous knowledge systems, yet elements of Indigenous epistemology, cosmology, culture and lived experiences persist in diverse ways. Advancing the idea of decolonisation, Taiaiake Alfred asserts that the larger process of regeneration, as with the process of decolonisation, begins with the self - a 'reconstruction of traditional communities' based on original narratives of Indigenous Peoples. Taiaiake, agreeing with Paul Keal, argues that institutional approaches (including conventional research methods and design) do not lead to decolonisation or self-

\footnotetext{
${ }^{346}$ Shafik Dharamsi, Discursive Constructions of Social Responsibility (PhD Thesis, University of British Columbia, 2003) $90<$ https://circle.ubc.ca/handle/2429/15940>.
} 
determination but rather embed Indigenous Peoples in colonial institutions. ${ }^{1347}$ Linda Tuhiwai Smith supports the insertion of Indigenous knowledge when developing and implementing conventional research projects in Indigenous communities. Collectively, the thoughts and words of Indigenous Peoples represent a foundation of knowledge where, through survivor storytelling narratives, they can seek guidance and support in their efforts to decolonise their minds and communities. ${ }^{1348}$ Ethnographic research is one small method Indigenous feminist researchers can use to explore the power of storytelling as a tool for knowledge creation and production. The social skills used to perform ethnographic research attach us to real human beings in deep ways. Using reflective practice, informed by standpoint epistemology, Indigenous feminist researchers are able to make privileged data visible, identify historical forces at work and potentially affect the creative role of subjectivity, as survivors seeking to understand ours and others' experiences. ${ }^{1349}$ However, a challenge to the infusion of power between researcher and participants in the reflective and dialogic techniques employed in this research is the way intimacy between researchers and informants can mask objectification of the research. ${ }^{13}$

This research challenges my integrity, my story and the very purpose of examining such a delicate topic. Indigenous feminist dilemmas in ethnographic fieldwork of this sort are as much ethical and personal as academic and political. Reflecting on the goals of my fieldwork, I am forced to question the legitimacy of my identity and my ability to conduct the research. The core of this dilemma revolves around the power dynamic between irreconcilable contradictions in my position as a survivor of abuse. Being born in Liberia (an insider) but lacking confidence in identifying as a bona fide Indigenous Liberian (an outsider) coupled with being a survivor of abuse (an insider) yet having the opportunity to leave Liberia to acquire higher education (an outsider) stirs up conflicted feelings but also yields a position of power. It leaves me asking: am I a valid member of the population being studied (Indigenous women survivors of systematic gender violence)? ${ }^{1351}$ Therefore, the power dynamics of carrying out research are confronted and treated throughout the fieldwork and post-fieldwork process, creating an identity crisis and enabling re-traumatising encounters. The first dimension of power difference (that is, the researcher-participant phase) is unavoidable when studying marginalized populations. ${ }^{1352}$ The second dimension of power (that is, the self-reflection phase) is especially pertinent to an insider-outsider viewpoint.

Identifying challenges associated with insider-outsider research and using strategies to mitigate them, I strive to effectively use an insider position in conjunction with a storytelling

\footnotetext{
${ }^{1347}$ Taiaiake Alfred and Jeff Corntassel, 'Being Indigenous: Resurgences against Contemporary Colonialism' (2005) 40(4) Government and Opposition 597, 611-612.

${ }^{1348}$ Lloyd L Lee, 'The Fundamental Laws: Codification for Decolonization?' (2013) 2(2) Indigeneity, Education and Society 117, 118.

${ }^{1349}$ Nancy A Naples, Feminism and Method: Ethnography, Discourse Analysis, and Activist Research (Routledge, 2003) 37-38.

${ }^{1350}$ Ibid 40 .

${ }^{1351}$ Sonya Corbin Dwyer and Jennifer L Buckle, 'The Space between: On Being an Insider-Outsider in Qualitative Research' (2009) 8(1) International Journal of Qualitative Methods 54, 1.

${ }^{1352}$ Diane L Wolf (ed), Feminist Dilemmas in Fieldwork (Westview Press, 1996) 2.
} 
research design to raise the profile and prioritise gender justice interventions for Indigenous women. ${ }^{1353}$ The use of an insider approach is beneficial to research study design because it helps with recruitment and rapport, enabling collaboration, and generating stories rich in content. Using an intersectional approach, Couture, Zaidi, and Maticka-Tyndale explore the fluidity of a researcher's multiple insider-outsider identities which can significantly shape interactions between the researcher and her participants. ${ }^{1354}$ Couture, Zaidi, and Maticka-Tyndale found that possessing multiple intersecting identities (for example, Liberian female survivor of war and abuse who is struggling to locate her Indigenous roots) has the potential to increase the comfort of research participants discussing sensitive issues, such as violence against Indigenous women. ${ }^{1355}$ However, the outsider position must also be confronted.

The reflexivity and positionality of a researcher must be engaged to overcome some of the challenges of the outsider perspective. One key challenge imposed by an outsider perspective is the presumed superiority or authority of the researcher. Rather than dwelling on the 'weak reading of reflexivity', ${ }^{1356}$ this research engages with 'strong reflexivity' to disrupt the authority of the researcher over the participants in the field. ${ }^{1357}$ To this end, making the personal political and moving Indigenous women from the margins toward the centre strengthens my insider-outsider approach. Because I am an insider-outsider, my positions in the research are not static, but rather fluid and malleable. My varied connections to the community are never expressed definitively but are ever-shifting across permeable locations in general terms. My position is also negotiated and renegotiated with participants and the community on a persistent basis throughout the data collection period. ${ }^{1358}$ This constant process is undergone in an attempt to overcome biases against research participants and assumed power hierarchies. However, the dialogic and reflexive process also reveals an inadequacy in the distinction between outsider and insider.

We all start from different standpoints, which means there are numerous dimensions on which we can relate to members of various communities. In the context of this study, my positionality in this research helps shape the manner in which I enter the 'field' as an Indigenous academic advocate and how I relate to different participants within a particular group. ${ }^{1359}$ Recognizing the shifting nature of outsider and insider positions does not negate the significance of situated knowledge for generating more relevant knowledge. Therefore, my experience as a survivor of war and abuse who recently connected to my Indigenous roots

\footnotetext{
${ }^{1353}$ Stacy Blythe et al, 'The Challenges of Being an Insider in Storytelling Research' (2013) 21(1) Nurse Researcher 8,8 .

${ }^{1354}$ Amanda L Couture, Arshia Zaidi and Eleanor Maticka-Tyndale, 'Reflexive Accounts: An Intersectional Approach to Exploring the Fluidity of Insider/Outsider Status and the Researcher's Impact on Culturally Sensitive Post-

Positivist Qualitative Research' (2012) 8(1) Qualitative Sociology Review 86, 86.

${ }^{1355}$ Ibid.

${ }^{1356}$ Naples, above n 1349, 41.

${ }^{1357}$ Ibid 42.

${ }^{1358}$ Ibid 49.

${ }^{1359}$ Nancy A Naples and Emily Clark, 'Feminist Participatory Research and Empowerment: Going Public as Survivors of Childhood Sexual Abuse' in Heidi Gottfried (ed), Feminism and Social Change: Bridging Theory and Practice (University of Illinois Press, 1996) 160, 177.
} 
provides me a unique vantage point from which to view the experiences of other survivors with identity concerns and the basis for fostering an honest and open dialogue. Notwithstanding, sharing my account does not guarantee mutual understanding on a wide variety of relevant issues. ${ }^{1360}$ Through the dialogic process, some disparities between my own and participants' experiences are identified and reconciled. Yet others remained unresolved. This phenomenon is not an isolated case. Nancy Naples, Emily Clark and Heidi Gottfried confirm that many oppressed groups have successfully defied negative constructions through insider and outsider storytelling narratives, and in the process, created powerful social movements. ${ }^{1361}$ Going public with my survivor story is a key component of my success as an Indigenous Liberian woman, demonstrating a mutually reinforcing relationship between feminist theorizing, activism and resistance. My experience also highlights the ongoing challenge of maintaining egalitarian and participatory research strategies through the collective consensus of decolonisation and traditional research approaches. Accordingly, my commitment to explicate systematic violence against Indigenous women within the intersections of gender, race, class and social status, and lived experience as a survivor influence my diverse perspectives, which are exemplified by the adoption of a multi-theoretical framework. ${ }^{13}$

Approaching survivor discourse through the lens of intersectionality is a natural outcome of my lived experience and is also supported by the literature. Naples argues that contemporary analyses of survivor discourse have yet to explore intersectionality as the multiple sites through which survivors of abuse come to identify as survivors and interpret their experiences. ${ }^{1363}$ Naples offers a materialist feminist analysis of survivor discourse that attends to the discourse and institutional practices that shape who may speak and who is heard and offers the potential to challenge the depoliticisation and reprivatisation of survivor discourse. ${ }^{1364}$ Naples argues that giving greater attention to the material context in which survivors 'come to voice', go public with their experiences of abuse, or engage with each other in defining the meaning of these experiences in their lives, might better address two of the main problems faced within contemporary survivor politics. ${ }^{1365}$ First, how to determine when and where certain strategies offer more effective challenges than others; and second, how to remain sensitive to the myriad ways class, race and gender differentially affect survivors' experiences. ${ }^{1366}$ Materialist feminist scholars argue for an intersectional approach and resist abstracting gender from other dimensions of social identity. But the dynamics of gender, race, class and social status are

\footnotetext{
${ }^{1360}$ Ibid 178.

${ }^{1361}$ Ibid 179.

${ }^{1362}$ Naples, above n 1349, 52.

${ }^{1363}$ Ibid 164; Nancy A Naples, 'Deconstructing and Locating Survivor Discourse: Dynamics of Narrative, Empowerment, and Resistance for Survivors of Childhood Sexual Abuse' (2003) 28(4) Signs: Journal of Women in Culture and Society 1151, 1154.

${ }^{1364}$ Naples, above n 1363, 1152.

${ }^{1365}$ Ibid.

${ }^{1366}$ Ibid.
} 
embedded in the diverse contexts through which survivor discourse is generated and challenged. ${ }^{136}$

Unfortunately, one persistent challenge to the legitimacy of survivor discourse comes from the very people charged with dispensing justice. Survivor discourse is often positioned in contrast to expert discourse, which is legitimised through a distinction between different forms of knowledge production, one that derives from personal experience and emotional pain versus one grounded in more systematic, and presumably objective, truth claims. ${ }^{1368}$ Given the extent to which Indigenous girls and women are abused by men in society, the experience of abuse is a common occurrence that becomes generalized and laden with social stigmas, myths and misunderstandings that remain unchallenged in law enforcement and legal settings, leaving the actual experiences of survivors unrecognized or even dismissed as false. But valuing the standpoint of Indigenous women means believing their description of abusive experiences and treating them as credible representatives of their own experiences. Empowerment as a form of healing can include a confrontation with perpetrators through legal action or as a public declaration. This dissertation is both an opportunity to validate survivor discourse as related by Indigenous women advocates and supported by academic research and to act as my own empowering and healing public declaration.

\subsection{Feminism and Empirical Method}

Although this is an empirical study, it is important to consider the limits and biases inherent in an empirical inquiry. The theory of knowledge known as empiricism and the scientific paradigm of positivism assume that research is akin to measuring. However, despite the stringent precautions demanded by the scientific methodology in taking account of overt variables, limitations may persist where submerged cultural considerations have been overlooked because they are not always readily identifiable or acknowledged by researchers. ${ }^{1369}$ The challenge for understanding the social world is developing operational definitions of phenomena which are reliable and valid. Tuhiwai-Smith argues that Western research draws from an 'archive' of knowledge and systems, rules and values which stretch beyond the boundaries of Western science to the system now referred to as the West. ${ }^{1370}$ Cultural archives do not embody a unitary system of knowledge but should be conceived of as containing multiple traditions, if knowledge and ways of knowing are valued. ${ }^{1371}$ Within a Western paradigm, dissent is manageable because that dissent also implicitly conforms to these rules. However, to include Indigenous traditions, knowledge and values it is important to step outside of Western paradigms. For instance, though Western feminism provides a radical challenge to conventional knowledge, it has itself been

\footnotetext{
${ }^{1367}$ Ibid.

${ }^{1368}$ Ibid 160 .

${ }^{1369}$ Graham Smith, The Issue of Research and Maori (Research Unit for Maori Education, University of Auckland, 1992) 7 <http://link.kotui.org.nz/portal/The-Issue-of-research-and-Maori-ed-Research/yCmT1jGvddc/>.

${ }^{1370}$ Linda Tuhiwai Smith, Decolonizing Methodologies: Research and Indigenous Peoples (University of Otago Press, 2nd ed, 2012) 44.

${ }^{1371}$ Ibid.
} 
challenged by African women for conforming to fundamentally Western European worldviews, value systems and attitudes. Nevertheless, Smith laments that differences between Western and Indigenous/African beliefs are still considered shocking, abhorrent and barbaric, and therefore are prime targets of missionary and civilising projects. ${ }^{1372}$ Many such oppressive beliefs held by settler-colonists are embedded in Indigenous languages and stories and are etched in the memories of Indigenous Peoples. ${ }^{1373}$ Therefore, the question must be asked: are Western research methodologies capable of taking full account of Indigenous cultural perspectives? ? $^{13}$

The first step toward reaching Indigenous women's perspectives is adopting feminist research principles. If research is about satisfying one's need to know by extending boundaries of existing knowledge through a process of systematic inquiry, then this dissertation is certainly research. In feminist research, gender operates as a basic organising principle which profoundly shapes and mediates the concrete conditions of women's lives. Through the questions that feminism poses and the absences it locates, feminism argues for the centrality of gender in shaping our consciousness, skills and institutions, and in distributing power and privilege. ${ }^{1375}$ When our lived experience of theorising is fundamentally linked to processes of self-recovery and collective liberation, then no gap exists between theory and practice. ${ }^{1376}$ For African and Australian Indigenous women, within the production of the theory lies the hope for our liberation and the possibility of naming all our pain and making all our hurt go away. Creating feminist theory and advocacy that address the pain and trauma we experience helps reduce the challenge of building a mass-based feminist resistance struggle, thereby removing the chasm between feminist theory and feminist practice.

Feminist theory, itself, is multifaceted and open to the inclusion of various theories and methods, based on the researcher's epistemological stance. Responding to concerns about whether there should be a distinctive feminist method of inquiry, whether it takes the shape of direct interaction with perpetrators of violence, going public with one's story or taking legal action, Sandra Harding differentiates the relationship between three things: epistemology - a theory of knowledge; methodology - a theory and analysis of applying general structure to scientific disciplines; and method - a technique for gathering evidence. ${ }^{1379}$ Whilst Catherine MacKinnon suggests that raising consciousness is the major feminist technique of analysis, structure, method, and theory of social change, ${ }^{1380}$ Harding debunks the common but sexist practices of disciplines that pigeonhole methods into general categories of concrete research

\footnotetext{
${ }^{1372}$ Ibid 45.

${ }^{1373}$ Ibid.

${ }^{1374}$ Smith, above n $1369,8$.

${ }^{1375}$ Heidi Gottfried (ed), Feminism and Social Change: Bridging Theory and Practice (University of Illinois Press, 1996) 1.

${ }^{1376}$ Ibid 2.

${ }^{1377}$ bell hooks, 'Theory as Liberatory Practice' (1991) 4(1) Yale Journal of Law and Feminism 1, 12.

${ }^{1378}$ Ibid.

${ }^{1379}$ Sandra Harding, 'The Method Question' (1987) 2(3) Hypatia 19, 23-25.

${ }^{1380}$ Catharine A MacKinnon, 'Feminism, Marxism, Method, and the State: An Agenda for Theory' (1982) 7(3) Signs $515,519$.
} 
practices. ${ }^{1381}$ According to Harding, in doing research, feminists discover gender and its consequences, value women's experiences as a scientific resource, and embrace a robust gender-sensitive reflexivity practice. ${ }^{1382}$ Also, Naples argues that the specific methods employed by feminists are significantly shaped by their epistemological stance, which is indicative of the multi-theoretical framework on which this research thrives. ${ }^{1383}$ Irrespective of the approach and specificity, feminist inquiry simultaneously challenges norms and contributes power to feminist research. This dissertation combines the power of a multi-theoretical, empirical feminist inquiry with the healing powers of survivor 'speak-outs'.

The principal tactic adopted by Indigenous feminist survivors has been to encourage and make possible survivors' disclosure of traumas, whether in private or public contexts. This strategic practice of breaking the silence is virtually ubiquitous, wherein survivor pronouncements are called 'speak-outs'. Speaking out educates society at large about this dimension of systematic gender violence, to reposition the problem from the individual psyche to the social, political and economic spheres, where it rightfully belongs. Alcoff and Gray argue that survivor 'speak-outs' are transgressive in that they challenge conventional arrangements and presume objects antithetical to the dominant discourse. ${ }^{1384}$ To preclude disempowering survivors who speak, Alcoff and Gray suggest that, before speaking out, one must look at where the incitement to speak originates and what relations of power and domination may exist between those who incite and those who are asked to speak and to whom disclosure is directed. ${ }^{1385}$ This Ph.D. also endeavours to empower survivors, including the author, to act constructively on their own behalf and thus make the transition from passive to active survivor.

My dissertation is my 'speak-out' moment. For this dissertation, without a doubt, the origin of the need to speak stems from trauma, anger, pain, suffering and revenge, as clearly articulated by bell hooks. In discussing Theory As Liberatory Practice, hooks discloses that she came to Black feminist theory because 'I was hurting, the pain within me was so intense that I could not go on living. I came to theory desperate, wanting to comprehend, to grasp what was happening around and within me. Most importantly, I wanted to make the hurt go away. I saw in theory then a location for healing'. ${ }^{1387}$ I replace hooks' 'theory' with 'my dissertation' in agreeing that it hurts, stings and bruises my ego, self-esteem, identity and every aspect of me to write about systematic violence against Indigenous women. The challenge has always oscillated between the moral impetus of engineering social change and the conscious awareness of exposing my vulnerability. Ultimately, the result feels more like liberation than suppression,

\footnotetext{
${ }^{1381}$ Harding, above n 1379, 22.

${ }^{1382}$ Ibid 29-31.

${ }^{1383}$ Naples, above n 1349, 3.

${ }^{1384}$ Linda Alcoff and Laura Gray, 'Survivor Discourse: Transgression or Recuperation?' (1993) 18(2) Signs: Journal of Women in Culture and Society 260, 267-268.

${ }^{1385}$ Ibid 284.

${ }^{1386}$ Ibid 261-262.

${ }^{1387}$ hooks, 'Theory as Liberatory Practice', above n 1377, 1.
} 
self-fulfilment than underachievement, and resistance than subjugation to patriarchy and racism. Albeit restrictive, the writing space and location of the dissertation offers an opportunity to combine the clout and influence of objective empirical studies with the healing power of emotional 'speak-out'. Obviously, this 'speak-out' is directed towards the public in general but is precisely relevant to dispensers of gender justice striving for the ideal of equality for all.

\subsubsection{Transcending the Scars of War}

Growing up as one of eight children of a single mother meant I faced many challenges in life, but it never stopped me from dreaming big. I believe the biggest dream was rejecting poverty. In spite of a tough upbringing, I never imagined experiencing violent conflict, being internally displaced, becoming a refugee or immigrating alone to Canada. Apart from the first 14 years of life, I was self-bred. I survived those tragic years on my own through education! Mama always said education was the equaliser. To break this generational chain of poverty, she said, 'don't follow boys but stick your head in the books'. Education was the single factor that enabled me to transcend every appalling experience that could have relegated me to a life of poverty or abuse. This admonition from my mother was the impetus for this Ph.D.

It is my belief that hard work should not only reap bountiful positive rewards, but it should also propel the achiever upwards. With a positive attitude, this research journey of a thousand miles began with one step: when my passion for gender justice became a search for Professors Dodson, Dunn and Dharamsi as supervisors. At this juncture, there are no final products or limits to the outcome of the research journey but a continuous process of commitment and sacrifice in advocating against systematic violence against Indigenous girls and women. In fact, this dissertation is a point of departure and the beginning of a life-long journey for gender justice.

\subsubsection{Indigenous Identity Transformed}

Before leaving Liberia in 1992, I had little connection to my ethnic and familial roots. I knew that my mother hailed from Maryland County (because of her African American settlers' ancestral background) and that my father was an Indigenous man from Lofa County. My father's absence made it difficult to learn any more of his heritage. My being born and raised in Monrovia complicated the search for my identity, since Monrovians are diverse inhabitants from across the country. African American settlers' mission to 'civilise and Christianise heathens' translated into the view that speaking one's ethnic language was uncouth. To spare me the 'shame' of speaking my mother's native tongue, my mother chose not to teach me any Indigenous Liberian language. By the time I became old enough to search for my own roots, I had been displaced by war.

As a refugee in Ghana for nine years, I observed Ghanaians displaying pride for their traditions and culture, which brought a new sense of self and a yearning to learn of my heritage. 
I embraced an opportunity to learn Twi (the most popular Ghanaian language) and repositioned myself as a proud African. By the time I left Ghana for Canada in 2001, I confidently shared a piece of Ghanaian heritage, which added meaning to my sense of self. In Vancouver, I submerged again into feelings of low self-esteem and invisibility, this time caused by racial discrimination. Reading about pan-Africanism and what it means to be a Black African woman in Canada caused a reawakening. I took pride and honour in learning about other African histories, cultures and peoples. My identity was transformed, and I began identifying as an Indigenous Liberian. However, the evolution of my Indigenous identity required a search for acceptance.

I questioned the validity and legitimacy of going into Indigenous Liberia to extract information from the community for this dissertation. But I also adopted a humble spirit and a willingness to submit to and learn from my elders. I imagined that a complex interdisciplinary research design reflective of the challenges associated with gender violence might offer me an opportunity to locate my identity, physically and spiritually. Indeed, it did. After spending two months collecting data in Australia, I embarked on a seven-month journey to Indigenous Liberia. The inclusion of Maryland, Lofa, Nimba, and Montserrado counties as target areas were deliberate. The insider-outsider approach helped me connect to the spiritual roots of my ancestors in Gbenelou (my mother's village) and Suwomai (my father's village). It was an overwhelming experience, yet it brought internal peace as if a raging storm had been calmed. At long last, my identity as an Indigenous person was realized.

\subsection{Summary}

I was asked by an elder in Maryland, 'Do you really want to know about your heritage?' I responded, 'Yes.' Then I asked why he posed the question. He said, 'I want to be sure you understand the innate problems associated with finding your roots.' For him, the struggle lies in having full knowledge of an ancestral connection to people who are accused of perpetrating violence against Indigenous Liberians. He could not have been more accurate. At the beginning of this chapter, I discussed the validity and legitimacy of doing this work. Many a time I felt 'I do not belong here' or 'No one will talk to me - I'm not Indigenous enough.' I thought being a war survivor could only partially afford me the voice of a real insider-outsider. Fortunately, I was wrong. Both in Australia and in Liberia, I was wholeheartedly welcomed into Indigenous communities. I was supported and encouraged to continue this work. Indigenous women advocates embraced me. They trusted me with their experiences, wisdom and knowledge. In spite of the acceptance I received from Indigenous communities in both Liberia and Australia, I still struggle with my newfound identity. I still do not know enough about my Indigenous ancestral roots. Notwithstanding, whose responsibility is it to define my identity or legitimise my claim to conduct research on such a sensitive topic in Indigenous communities? 
There is nothing worse than acquiring a world-class education that builds confidence and self-esteem, whilst still being reduced to an object of abuse. What is the value of earning a law degree, when a man can still force himself on me whilst I am in the process of asking him, 'What do you think of violence against women in Liberia?' And, if that man represents the judiciary in Liberia, how can I respond? Shut down the research? Ask myself, 'What am I doing here? Why did I focus on this topic? What should I do?' As a survivor of abuse and an Indigenous Liberian academic advocate, I resolved to design and conduct a complex research study on systematic violence grounded in a multi-theory approach. To that end, a reflection that discloses my personal story of survivor discourse not only frees my mind of the inherent biases I am conflicted with internally but most importantly, opens a public space in which to 'speakout' in the academy. 


\title{
CHAPTER 6: METHODOLOGY AND DESIGN
}

\begin{abstract}
Many authors have compared and contrasted between qualitative and quantitative research methods. ... The debate over the legitimacy of qualitative versus quantitative research is ongoing and seemingly endless. ... The distinction is not just about counting things against not counting them. Qualitative researchers can and do count things. Rather the distinction lies in the deep philosophical foundations underlying the methods or technique in the 'doing' of research ... and I agree, that the researcher needs to understand that the different types of research methods originate from different theoretical frameworks within the social sciences and humanities. ${ }^{13}$
\end{abstract}

\subsection{Introduction}

The rigour, robustness and credibility of findings and conclusions heavily depend on the quality of the research process, which includes its design, data collection, management and analysis. In essence, this chapter outlines the procedure used to obtain, analyse, interpret and conclude the research findings. The chapter begins with the philosophical paradigms that dictate an interdisciplinary ${ }^{1399}$ and complex study that straddles conformity ${ }^{1390}$ and resistance. ${ }^{1391}$ A desire to migrate Indigenous girls' and women's issues of violence from the margins of social consciousness towards the edges of Western centrality redefines the scope of this mixed method $^{1392}$ research design. Such a complex system approach, that is, a combination of empirical, statistical and textual data as a nexus between systematic gender violence and the rule of law, is novel but required by the subject matter. Borrowing Yilo's view as asserted by Anders, ${ }^{1393}$ 'systematic due diligence' (vis-à-vis complex system design) must be grounded in the understanding that systematic gender violence cannot be adequately addressed unless seen as intersecting constituents of gender, critical race, and class. ${ }^{1394}$ Having established those conceptual and theoretical underpinnings of the study in chapter 1, I follow here with a discussion of the methodological design and framework.

To gather the necessary data, this study adopts a sociological approach, which includes both qualitative and quantitative, or mixed research, methods. ${ }^{1395}$ Mixed method design is descriptive in nature and is particularly useful in assessing the impact of the law in action.

\footnotetext{
${ }^{1388}$ Dharamsi, above n 1346, 53-55.

${ }^{1389}$ Robert Post, 'Debating Disciplinarity' (2009) 35(Summer) Critical Inquiry 749.

${ }^{1390}$ James Chandler, 'Introduction: Doctrines, Disciplines, Discourses, Departments' (2009) 35(4) Critical Inquiry 729.

${ }^{1391}$ Smith, Decolonizing Methodologies, above n 1370.

${ }^{1392}$ Jennifer C Greene, 'Is Mixed Methods Social Inquiry a Distinctive Methodology?' (2008) 2(1) Journal of Mixed Methods Research 7.

${ }^{1393}$ Anders, above n 527, 15.

${ }^{1394}$ Kimberlé Crenshaw, 'Demarginalising the Intersection of Race and Sex: A Black Feminist Critique of AntiDiscrimination Doctrine, Feminist Theory and Antiracist Politics' (1989) 140 The University of Chicago Legal Forum 139; Crenshaw, Critical Race Theory, above n 245; Kimberlé Crenshaw, 'Race, Gender, and Sexual Harassment' (1992) 65 California Law Review 1467; Carastathis, above n 244.

${ }^{1395}$ Jennifer C Greene, 'Toward a Methodology of Mixed Methods Social Inquiry' (2006) 13(1) Research in the Schools 93; Sage Handbook of Mixed Methods in Social and Behavioural Research (SAGE Publications, 2nd ed, 2010); R Burke Johnson and Anthony J Onwuegbuzie, 'Mixed Methods Research: A Research Paradigm Whose Time Has Come' (2004) 33(7) Educational Researcher 14; John W Creswell and Vicki L Plano Clark, Designing and Conducting Mixed Methods Research (SAGE Publications, 2nd ed, 2011).
} 
Additionally, a sociological method provides empirical knowledge ${ }^{1396}$ of how the law and other social factors intersect to affect the lives of Indigenous female survivors of systematic violence. The mixed method design is also supported by a variety of data sources.

The research uses a wide range of data sources to triangulate key issues pertaining to violence against Indigenous girls and women and the rule of law. Indigenous Women Advocates selected in this study responded to a semi-structured interview questionnaire. Service providers completed an online survey in Australia and a paper survey in Liberia. To corroborate field data, triangulate diverse data sources, ${ }^{1397}$ and enhance rigour and robustness, secondary data on socio-economic status, social services, court cases and crime statistics were collected from various public institutions in both Liberia and Australia. The results of the interviews were assessed using NVIVO software. Values of both the online survey and secondary data were computed using simple statistics, that is, weighted means, percentages, inferences and associations, using SPSS and Excel. Also, relevant publications are cited to support findings gathered in the research.

This chapter describes the challenges of conducting high-quality research on gender violence to produce results that will inform evidence-based law and policy reform. Qualitative and quantitative components of the research are highlighted. The sampling technique that was used to select and recruit participants is described, and the sources of data are explained. Finally, ethical considerations pertaining to risk-benefit analysis and challenges of gathering research data on an extremely sensitive topic are discussed.

\subsection{Theoretical Framework}

In this study, four conceptual models were employed in a triangulation strategy: ${ }^{1399}$ communitybased participation, phenomenology, Indigenous decolonizing methods and feminist legal theory. According to Hacker (2013), community-based participatory research is designed to ensure and establish structures for participation by communities affected by the issue being studied to improve the outcome of social change. ${ }^{1400}$ In essence, community-based participation is about community members having an equal partnership in the research idea, design and process for the purpose of promoting empowerment, respect, reciprocity, autonomy and spiritual integrity. ${ }^{1401}$ The adoption of community-based participatory research exercises an

\footnotetext{
${ }^{1396}$ Jennifer C Greene, Mixed Methods in Social Inquiry (Jossey-Bass, 1st ed, 2007); Greene, 'Is Mixed Methods Social Inquiry a Distinctive Methodology?', above n 1392; David Gray, Doing Research in the Real World (SAGE, 2nd ed, 2009).

${ }^{1397}$ Janice M Morse, 'Principles of Mixed Methods and Multimethod Research Designs' in Abbas Tashakkori and Charles Teddlie (eds), Handbook of Mixed Methods in Social and Behavioural Research (Sage, 2nd ed, 2003) 189, 190. According to Morse, a research that combines and compares the results of several study methods has the propensity to guarantee rigour, originality and comprehensive design - a process described as triangulation.

${ }^{1398}$ Mary Ellsbert and Lori Heise, Researching Violence Against Women: A Practical Guide for Researchers and Activists (World Health Organization, PATH, 2005) 27.

${ }^{1399}$ Morse, above n 1397, 190.

${ }^{1400}$ Karen Hacker, Community-Based Participatory Research (SAGE, 2013) 1-2.

${ }^{1401}$ National Health and Medical Research Council, Values and Ethics: Guidelines for Ethical Conduct in Aboriginal and Torres Strait Islander Health Research (Commonwealth of Australia, 2003) 7-20; Meera Viswanathan et al,
} 
opportunity for educating and raising the consciousness of participants and including local and Indigenous knowledge, particularly of poor rural women, based on a process of mutual learning, reflection and analysis. As a form of qualitative research, community-based participatory research seeks to understand and change the world through the eyes of participants without necessarily endorsing the proving or disproving of hypotheses, but with a flexible plan attempting to explore a phenomenon or a community problem. The crux of community-based participatory research is the empowerment of disempowered groups and the search for a practical methodology to decentralise, disrupt and resist Western conventions, and to promote diversity and sustainability through community participation. ${ }^{1402}$ From the inception to the completion of the project, several individuals in both academic and non-academic communities provided valuable feedback that shaped the direction of the research for the better.

Feminist legal theory dovetails with community-based participatory research to improve results. Too often, attempts to bridge theory and practice are made at the level of theory rather than of practice. Feminists argue for a methodology designed to break the false separation between the subject of research and the research. ${ }^{1403}$ The objectification of research subjects limits our understanding of the social construction of meaning and experience and the process by which the 'relations of ruling' organise consciousness and daily life. ${ }^{1404}$ Community-based participatory researchers enter 'the field' in a variety of ways, with each entry influencing relationships in the community. ${ }^{1405}$ Whilst some feminists search for community-based sites through which they might assist in the political agendas defined by community members, others access 'the field' as participants who are personally affected by the issue that is the focus of this research. ${ }^{1406}$ Since most personal and community-based problems are politically constituted, activists in the course of struggling against institutionalized relations of ruling inevitably discover the value of social science research to support social justice efforts. ${ }^{1407}$ Although the journey of bridging theory with practice may not always be linear, the process illustrates the value of Indigenous African women call for feminist theory and self-reflective dialogue to enhance community-based participatory research.

A key feminist legal theory technique employed in this research is known as 'asking the woman question'. According to Katherine Bartlett, if women's perspectives in the law are not understood, their claims to legal discourse will not be perceived as legitimate. As a question becomes a method when it is asked regularly, so is the concept of 'asking the woman question'. The woman question is a rhetorical phraseology used in the feminist legal method to explore

\footnotetext{
'Community-Based Participatory Research: Assessing the Evidence.' (Volume 99, Agency for Healthcare Research and Quality, 2004) 296, 3-4.

${ }^{1402}$ Gillian Creese and Wendy Frisby, Feminist Community Research: Case Studies and Methodologies (University of British Columbia Press, 2012) 41 <http://www.ubcpress.ca/search/title_book.asp?BookID=299173502>.

${ }^{1403}$ Naples and Clark, above n 1359, 160-162.

${ }^{1404}$ Ibid.

${ }^{1405}$ Ibid.

${ }^{1406}$ Ibid.

${ }^{1407}$ Ibid.
} 
gender implications of a social practice of rule. In this research, Bartlett's ${ }^{1408}$ 'asking the woman question' ${ }^{1409}$ employs the assumption that some features of the law are neutral and male-focused. Asking Indigenous Women Advocates the 'woman question' exposes those masculine features, how they operate, and how they might be corrected. ${ }^{1410}$ The use of 'womanism' ${ }^{1411}$ in place of 'feminism' by Black feminists demands greater attention to African women's unique role as mothers and leaders in the struggle to regain, reconstruct and create cultural integrity that espouses the ancient Ma'atic principles of reciprocity. ${ }^{142}$ In feminism or womanism, carefully 'asking the woman question' challenges patriarchy and paternalism and yields inclusive outcomes. In the end, women are given more latitude to theorise, contribute, participate, direct and question the law and to seek justice. However, a comprehensive feminist legal theory incorporates more than simply 'asking the woman question'.

Adopting feminist legal theory also offers mechanisms to expose bias in the judicial process, critique legal precedent, and reclaim laws written by and for men. Mary Jane Mossman offers three principles of legal methods that validate the feminist theory. According to Mossman, feminist legal theory:

1) characterises women's issues with respect to inconsistencies between appropriate legal methods declared by judges and their actual decision-making processes which tend to both mask and legitimate women's personal views about women's proper sphere;

2) uses precedents ${ }^{1413}$ in common law tradition (for instance, women's incompetence to be admitted to the legal profession or public life participation, justified by common law precedents where women were denied property rights); and

3) interprets statutes and parliament's intent in the construction of legal statutes awash with the word 'men', inferring that the drafter's intention was to exclude women from statutory rights. ${ }^{1414}$

A feminist legal method is incorporated into the study to highlight Indigenous Women Advocates' journey of consciousness-raising, giving them a platform to 'discuss and understand their experiences from their viewpoint'. ${ }^{1415}$ In this regard, not only can the principle of consciousness-raising be conveniently situated within certain realms of community-based

\footnotetext{
${ }^{1408}$ Katharine T Bartlett, 'Feminist Legal Methods' (1990) 103(4) Harvard Law Review 829.

${ }^{1409}$ Katherine Bartlett argues, "[i]n law, asking the woman question remains examining how the law fails to take into account the experiences and values that seem more typical of women than of men, for whatever reason, or how existing legal standards and concepts might disadvantage women. The question assumes that some features of the law may be not only non-neutral in a general sense, but also 'male' in a specific sense. The purpose of the woman question is to expose those features and how they operate, and to suggest how they might be corrected.

${ }^{1410}$ Bartlett, above $\mathrm{n} 1408$.

${ }^{1411}$ Clenora Hudson-Weems, Africana Womanism: Reclaiming Ourselves (Bedford Publishers, 2004); Nah Dove, 'African Womanism: An Afrocentric Theory' (1998) 28(5) Journal of Black Studies 515. According to Dove (1998), 'womanism is a concept that brings to the forefront the role of African mothers as leaders in the struggle to regain, reconstruct, and create a cultural integrity that espouses the ancient Maatic principles of reciprocity, balance, harmony, justice, truth, righteousness, order, and so forth. In that sense, I believe voicing Maat may be a term that will further develop Afrocentric theory'.

${ }^{1412}$ Collins, above n 65; Amina Mama, The Hidden Struggle: Statutory and Voluntary Sector Responses to Violence Against Black Women in the Home (Whiting and Birch Ltd, 1996); Dove, above n 1411; Hudson-Weems, above $\mathrm{n}$ 1411. Otherwise known as 'voicing Maat", the Ma'atic principles of reciprocity is the foundation of Afrikan womanist theory that exist when power relations between feminine and masculine are right.

${ }^{1413}$ Until the enforcement of the Equal Rights of the Customary Marriage Law 1998, Indigenous widow in customary marriages were not allowed to inherit property after the death of their husband.

${ }^{1414}$ Mossman, above n 246.

${ }^{1415}$ Shulamit Reinharz, Feminist Methods in Social Research (Oxford University Press, 1992) 220.
} 
participatory research and 'asking the woman questions', but it also neatly accommodates the aspect of phenomenology whereby a sui generis experience of a single Indigenous woman is as worthy as that of thousands of other women.

Phenomenology is a philosophical method of qualitative research inquiry that centres on and values the meaning of individual common lived experiences. ${ }^{1416}$ Rather than isolating a single experience, phenomenology aims to create a universal composite description applied to all (Indigenous women). ${ }^{1417}$ Unlike quantitative data that generates more numbers (that is, 'how many?'), the phenomenological method asks 'how', 'why', and 'what' kinds of social factors influence violence against Indigenous girls and women in Liberia and Australia. Instead of enforcing a researcher's authority over potential participants, phenomenology emphasises the importance of what philosophical motivations and social actions drive Indigenous women's existence. ${ }^{1418}$ Stan Lester describes phenomenology as an inquiry that is based on conscious experiences so as to identify and elucidate the unique perspectives of actors in a specific situation. ${ }^{149}$ In this regard, through the conducting of interviews with Indigenous Women Advocates, not only is that individual's subjective interpretation of her experiences not taken for granted, but a participant's conscious understanding of their journeys is considered unique. Phenomenological methods also strive to eliminate oppressive research practices.

Both community-based participation and phenomenology embrace the idea of an antioppressive research style. ${ }^{1420}$ Anti-oppressive or resistant research mandates a sensitising strategy ${ }^{1421}$ that is grounded in Indigenous, ${ }^{1422}$ decolonising ${ }^{1423}$ and feminist legal methodologies. ${ }^{1424}$ Margaret Kovach suggests that Indigenous methodologies are the infusion of the Indigenous knowledge system and research frameworks informed by the distinctiveness of cultural epistemologies that can transform and disrupt the nature of the Western academy based

\footnotetext{
${ }^{1416}$ Husserl Edmund, 'Pure Phenomenology, Its Method, and Its Field of Investigation' in The Phenomenology Reader (Routledge, 2002) 624.

${ }^{1417}$ John W Creswell, Qualitative Inquiry and Research Design: Choosing Among Five Approaches (SAGE Publications, 3rd ed, 2013) 57-59; Edmund, above n 1416, 124-128; Steinar Kvale, Interviews: An Introduction to Qualitative Research Interviewing (Sage Publications, 1996) 52-54; Carol Grbich, Qualitative Research in Health: An Introduction (Sage, 1999) 167-170; Analise Poropat, 'Understanding Women's Rape Experiences and Fears' in Proceedings of a Conference held 27-29 October 1992 (Australian Institute of Criminology, 1993) 115 <http://aic.gov.au/media_library/publications/proceedings/20/propata.pdf $>$.

${ }^{1418}$ Stan Lester, An Introduction to Phenomenological Research, Academic paper, 19999 <www.sld.demon.co.uk/resmethy.pdf>.

${ }^{1419}$ Stan Lester, An Introduction to Phenomenological Research, Academic paper, 1999.

${ }^{1420}$ Potts and Brown, self-identified as social workers using research methods toward social justice goals, acknowledge the dynamism of anti-oppressive theory. In their view, the concept is an extension of Marxist, feminist, and most predominantly critical theory - conveniently situated in the idea that knowledge is socially constructed (see, Karen Potts and Leslie Brown, 'Becoming an Anti-Oppressive Research' in Leslie Brown and Susan Strega (eds),

Research as Resistance: Critical, Indigenous and Anti-Oppressive Approaches (Canadian Scholars' Press, 2005) 268, 259.

${ }^{1421}$ Morse, above $\mathrm{n} 1397,190$. Sensitizing strategy is one or more strategies of the major modes of data collection that supplements either qualitative or quantitative in nature.

${ }^{1422}$ Karen Martin and Booran Mirraboopa, 'Ways of Knowing, Being and Doing: A Theoretical Framework and Methods for Indigenous and Indigenist Re-search' (2003) 27(76) Journal of Australian Studies 203.

${ }^{1423}$ Smith, Decolonizing Methodologies, above n 1370, 5.

${ }^{1424}$ Mossman, above n 246.
} 
on colonial history. ${ }^{1425}$ The utility and acceptance of Indigenous decolonising methodologies are constrained by inadequacies of homogenous conventional models in which '[Indigenous] women have been studied as objects for centuries, just as slaves, barbarians and workers. ${ }^{1426}$ Linda Tuhiwai Smith critiques the term 'research' as the 'dirtiest' word 'inextricably linked to European imperialism and colonialism. ${ }^{1427}$ Smith adds that persistent arrogance of Western researchers' intellectual assumption that they 'know all that is possible to know of us [Indigenous Peoples] ${ }^{1428}$ is a continuous threat to an emancipatory model. ${ }^{129}$ Leslie Brown and Susan Strega suggest that the challenge posed by Western research convention requires an ability to think against dominant knowledge that is grounded in the diverse ways of knowing termed Indigenous knowledges.

Avoiding oppressive research is particularly important in colonised communities. Imperialism and colonialism frame the Indigenous experience. It is part of Indigenous stories and their version of modernity. Writing and researching experiences under imperialism and its more specific expression of colonialism has become a significant project of the Indigenous world. ${ }^{1430}$ The concepts of imperialism and colonialism are crucial in terms of their interconnection to economic expansion, to the subjugation of 'others' and as a discursive field of knowledge and methodology. ${ }^{1431}$ Whilst imperialism is often thought of as a system which draws everything back into the centre, it was also a system which distributed materials and ideas outwards, discovering, extracting, appropriating and distributing Indigenous knowledge in the process. ${ }^{1432}$ This process became organised and systemic and informed disciplines of knowledge and 'regimes of truth'. ${ }^{1433}$ It is through these disciplines that the Indigenous world has been represented to the West and researched as fragments to be taken, catalogued, studied and stored. ${ }^{1434}$ One such discipline is the legal field itself.

Particular care is taken in the research to honour Indigenous ways of knowing, being and doing justice. As an academic activist, advocating for Indigenous women's rights for well over three decades, Rosalva Aída Hernández Castillo confronts epistemological and political tension resulting from consistent maintenance of critical perspective of positive law whilst simultaneously supporting political struggles for Indigenous recognition. ${ }^{1435}$ Castillo contends that law and rights are not ends in and of themselves for Indigenous women but rather are

\footnotetext{
${ }^{1425}$ Margaret Kovach, Indigenous Methodologies: Characteristics, Conversations and Contexts (University of Toronto Press, 2009) 12-15

<http://search.ebscohost.com/login.aspx?direct=true\&scope $=$ site $\& d b=n l e b k \& d b=n l a b k \& A N=682652>$.

${ }^{1426}$ Jill McCalla Vickers, 'Memoirs of an Ontological Exile: The Methodological Rebellions of Feminist Research' in Geraldine Finn and Angela Rose Miles (eds), Feminism in Canada (Black Rose Books, 1982) 57, 32.

${ }^{1427}$ Smith, Decolonizing Methodologies, above n 1370, xi.

${ }^{1428}$ Ibid 1.

${ }^{1429}$ Ibid 177.

${ }^{1430}$ Ibid 20.

${ }^{1431}$ Ibid 22.

${ }^{1432}$ Ibid 61.

${ }^{1433}$ Ibid.

${ }^{1434}$ Ibid.

${ }^{1435}$ Rosalva Aída Hernández Castillo, Multiple Injustices: Indigenous Women, Law, and Political Struggle in Latin America (The University of Arizona Press, 2016) 33.
} 
another language into which their demands for justice and a dignified life are translated. ${ }^{1436}$ Thus, systematic analysis of the possibilities and limitations of communitarian justice for Indigenous women is crucial for considering alternative spaces to transform, understand, reconstruct and acknowledge the multiple sites of Indigenous Customary Laws and Indigenous justice systems. ${ }^{1437}$ Of course, Indigenous Customary Laws and justice systems are only a subset of more holistic Indigenous knowledge.

Being a Native Liberian promoting Indigenous knowledge within a Western academy requires adopting a resistance research approach. Resistance research involves Indigenous scholars creating meaning about their world, producing knowledge and expressing various ways of being. Gloria Emeagwali and George Sefa-Dei ${ }^{1438}$ offer an expansion of Indigenous knowledge to include an accumulation of intellectual values not confined to the material sphere but interconnected with the spiritual realm. ${ }^{1439}$ It is through such epistemological and ontological paradigms that this study seeks to validate Indigenous Peoples' stories of systematic violence in Liberia and Australia and to transcend an objectified 'field' of study to a more 'intimate, human and self-defined space'. ${ }^{1400}$ This act of cultivating Indigenous knowledge whilst refusing to conform to traditional research paradigms is what Indigenous scholars, critical race theorists, and feminist legal experts such as Brown and Strega describe as resistance or socially just research. ${ }^{141}$

This framework of study methods creates an interdisciplinary approach that incorporates theoretical, practical and personal experiences. The overarching objective is not to draw inferences based on sample size and statistical significance, not to show direct causal relationships or neatly compare Indigenous girl's and women's experiences in Liberia and Australia. Rather, this research inductively formulates general theories from the field study, textual analysis, and secondary data and draws on established theory to interpret empirical and normative observations. The study makes conscious effort to bridge the researcher-participant gap entrenched in dominant Western research traditions.

\subsection{Complex System Design}

\subsubsection{Qualitative Data Collection}

The qualitative aspect of this research is threefold: a) textual analysis of selected case studies, case law and public/national document; b) semi-structured interviews with Indigenous Women Advocates; and c) informal email exchange with male colleagues and acquaintances.

\footnotetext{
${ }^{1436}$ Ibid 34.

${ }^{1437}$ Ibid 123.

${ }^{1438}$ Emeagwali and Sefa Dei, above n 554.

${ }^{1439}$ Ibid 1.

${ }^{1440}$ Smith, Decolonizing Methodologies, above n 1370, 127.

${ }^{1441}$ Leslie Brown and Susan Strega, Research as Resistance: Critical, Indigenous and Anti-Oppressive Approaches (Canadian Scholars' Press, 2005) 2-4.
} 


\subsubsection{Textual analysis of selected case studies, case law and public/national} documents

To minimise risks associated with conducting interviews with Indigenous Women Advocates and reduce other forms of bias associated with under-reporting, self-reporting and overreporting, the study analyses the cases of the following women: Angel Mardea Togba, ${ }^{142}$ Bibiana Abu, ${ }^{1443}$ Joy Janaka Wiradjuri Williams, ${ }^{144}$ and Andrea Pickett. ${ }^{1445}$ Key reports such as those of the Truth and Reconciliation Commission of Liberia ${ }^{146}$ and the Stolen Generation, ${ }^{1447}$ amongst others, ${ }^{1448}$ are also considered to establish histories of systematic violence against Indigenous Peoples. ${ }^{149}$

\subsubsection{Semi-Structured Interviews of Indigenous Women Advocates}

A two-page semi-structured interview instrument (see Appendix I) was designed, piloted and validated by selected community members before the fieldwork study commenced. A semistructured interview is a qualitative method of inquiry that combines open-ended questions with opportunities for the interviewer to explore further responses. ${ }^{1400}$ Each interview session lasted 1-1.5 hours. Conversations took place in public (for example, in a government office and coffee shops) or in private (for example, at home) to ensure privacy, confidentiality and safety. A total of 29 Indigenous Women Advocates participated. A semi-structured interview allows the researcher to build interpersonal relationships with participants, especially important

\footnotetext{
${ }^{1442}$ Potts and Brown, above n 1420. Thirteen-year-old Angel Mardea Togba was allegedly murdered by her foster parents in 2007. For 7 years, the Supreme Court of Liberia has been unable to pass final judgment regarding the alleged murder, although the defendants remain in jail. (See George J. Borteh, 'Liberia: Angel Togba's mother pushes Supreme Court to Act' (21 May 2013).

${ }^{1443}$ On 21 October 2009, Bibiana Abu, a Caldwell resident in Greater Monrovia area, reported that Caesar Freeman (a high ranking public servant in Liberia) and others, had allegedly ganged raped her after she requested and accepted a free lift home. Lack of corporation from the police, according to SGBV Crimes Unit Evaluation Report (2010) resulted in stalling of the prosecution process. (See, 'A bloody lie! Freeman lingers behind bars, victim runs free', The National Chronicle (28 July 2010) at 1, 6. Abdulai, above n 977, 9.

${ }^{1444}$ Joy Janaka Wiradjuri Williams, member of the Aboriginal Stolen Generations, spent ten years in court suing the Australia's State Government for negligence. Having lost the case, in addition to two separate appeals, Joy was found dead several years later after suffering from abuse, anger, violence, and mental illness. (See, Read, above n 754, book cover.

${ }^{1445}$ Angela Louise Pickett, an Aboriginal woman from Western Australia, was finally murdered on 12 January 2009, by her husband, Kenneth Pickett. She enduring several years of domestic violence, Andre lodge several complaints but received after little or no support from local police, women's shelter and the court systems, even though she had correctly predicted her imminent death from her violent husband (see, McDermott, above n 832.

${ }^{1446}$ Truth and Reconciliation Commission of Liberia, 'Truth and Reconciliation Report', above n 52.

${ }^{1447}$ Carmel Bird, The Stolen Children: Their Stories; Including Extracts from the Report of the National Inquiry into the Separation of Aboriginal and Torres Strait Islander Children from Their Families (Random House Australia, 1998).

${ }^{1448}$ Plotzki, above n 59; Lief, above n 59; Government of Australia, above n 354; Bird, above n 1447; Australian Human Rights Commission, 'Social Justice Report 2007', above n 882, 3; Dodson, 'Royal Commission into Aboriginal Deaths in Custody: National Report Volumes 1-4', above n 22; National Library of Australia, above $n$ 761; Azango, 'Taking More, Giving Less - Nimba Decry Arcelor Mittal's Operation', above n 943; Staff Writer, 'Green Advocates Wants EPA Revoke Sime Darby's Permit', above n 948; Green Advocates and Forest Peoples Programme, above n 228; Northern Territory. Board of Inquiry into the Protection of Aboriginal Children from Sexual Abuse, Wild and Anderson, above n 23; Aboriginal and Torres Strait Islander Social Justice Commissioner, 'Social Justice and Native Title Report 2014' (Government Report 5, Australian Human Rights Commission, 2014) $148<$ https://www.humanrights.gov.au/our-work/aboriginal-and-torres-strait-islander-socialjustice/publications/social-justice-and-nati-0>.

${ }^{1449}$ Reynolds, above n 495.

${ }^{1450}$ Kvale, above n 1417, 124-129.
} 
considering the sensitivity of gender violence. One-on-one interviews also offer a chance to follow up, clarify and elaborate on interesting comments and findings. To ensure accuracy, attentiveness and organic rapport building, interviews were digitally recorded with participants' consent. In a few cases where participants did not consent to be recorded, notes were taken with participants' permission. Recording interviews assisted with the iterative process of refining questions, strategies and methods as the interview process continued. ${ }^{1451}$ Audio filing affords an opportunity to reflect upon each interview in real time after completion with the aim of reassessing the relationship between the research question and responses. Reflection enhances the validity, reliability and consistency of the interview process whilst reducing variables that introduce bias. ${ }^{1452}$ In Australia, conducting phone and Skype interviews reduced cost. In Liberia, almost all interviews, except one, took place in person. Even though in-person interviews have some advantages, adopting a phenomenological paradigm supports each response irrespective of the method used to obtain it.

\subsubsection{Informal Email Responses from Male Friends, Colleagues and Acquaintances}

On 29 October 2015, 27 males (15 Africans and 12 North Americans) were sent informal email requests. The email asked, 'Would you speak out about violence against women? How? When? Where?' By the deadline (6 November 2015), 22 responses were returned. See chapter 8 for further discussion and analysis and Appendix XI for summary responses.

\subsubsection{Quantitative Data Collection}

The quantitative portion of this research is two-fold: a) a collection of secondary data, and b) an electronic and paper survey of health service providers.

\subsubsection{Secondary Data Collection}

Secondary data on socio-economic status (for example, health); crime (for example, imprisonment), and burden/risk factors of disease (for example, alcohol use) collected from major institutions helps to corroborate, triangulate diverse data sources, and enhance robustness. These institutions included the Australian Bureau of Statistics, the Longitudinal Study of Indigenous Children and the Australian Institute of Criminology in Australia; and the Liberian Institute of Statistical and Geo-Information Services, the Ministry of Gender, Children and Social Protection; and the Sexual and Gender-based Violence Crimes Unit in Liberia. Persistent attempts to acquire specific legal and crime statistics on Aboriginal and Torres Strait Islander girls and women from the courts, law enforcement units and the Australian Institute for Health and Wellness were met with challenges resulting from concerns about privacy and

\footnotetext{
${ }^{1451}$ Steinar Kvale and Svend Brinkmann, InterViews: Learning the Craft of Qualitative Research Interviewing (Sage Publications, 2nd ed, 2009) 178.

${ }^{1452}$ William Lawrence Neuman, Basics of social research: qualitative and quantitative approaches (2nd ed. 2007) $167-193$.
} 
confidentiality, claims of having no such data, or outright refusal. In Liberia, the challenges were different. Due to the lack of a public electrical grid, technology, and data storage tools, access to data was scant, especially in rural communities. If staff were competent enough to collect and keep data, the sense was that it was not meant for public use but only for the individual who collected it. Sometimes, public institutions requested non-accountable (noreceipt) fees in exchange for data resources. Overall, it appears that public institutions, given the above challenges, struggle to maintain and store the hard evidence needed for academic research.

\subsubsection{Survey}

A survey was designed, piloted and conducted with service providers (male and female) in Liberia and Australia (see Appendix II). In Liberia, a paper survey, appropriate given the lack of access to electricity and computer technology, yielded 77 responses over a seven-month period. In Australia, an electronic version produced 154 responses over six weeks. Eligibility criteria were used to eliminate unusable responses. Service providers eligible to participate including prison staff, police officers, researchers, counsellors, teachers, healthcare practitioners, lawyers, judges and government officials. The electronic version of the survey was administered using Lime Survey, hosted by the University of British Columbia, where the researcher held an adjunct teaching position. Privacy and storage concerns drove the preference for Lime Survey over services such as SurveyMonkey, with the former stored at the University of British Columbia and the latter in the United States.

\subsection{Participant Sampling, Selection and Recruitment}

\subsubsection{Sampling Method and Techniques}

Purposive sampling is the selection of participants, based on the knowledge of the target population. Even though this method of sampling is inherently biased, thereby raising issues of reliability and competence of informant participants, using a non-representative sample selection is crucial for this kind of research given its sensitive nature. To address possible confounds associated with gathering perceptual information from informants and participants, the researcher made a concerted effort to document observed biases. ${ }^{1453}$ Furthermore, data collected were not interpreted and applied beyond the limited sample population, although the research design considers the diverse nature of the target groups. The interview and survey participants represented varied backgrounds, contexts and locales: rural versus urban, school versus work, academic versus advocate and medical versus legal. A snowball and referral

\footnotetext{
${ }^{1453}$ Steven J Coombs and Ian D Smith, 'The Hawthorne Effect: Is It a Help or a Hindrance in Social Science Research?' (2003) 6(1) Change: Transformations in Education 97. The Hawthorne Effect, a well-documented phenomenon in social science research, is an observed changed behavioural pattern of human participants in research simply because they are aware of being studied. Whilst the process is assumed to be one of the toughest built-in biases to get rid of, Steven \& Smith suggest that the Hawthorne effect has the ability to validate the use of participatory action research from within any social setting.
} 
system was the main sampling technique used to identify and connect with participants. Invitation letters sent to community members asked potential participants to refer to others. Ultimately, the contact lists of potential participants obtained via networking totalled 2588 individuals and groups.

\subsubsection{Sample Size and Numbers}

Initially, the study anticipated having 400-500 respondents for the survey and 50-60 participants for the interview. However, lack of funding for travel to selected areas, coupled with limited access to electricity and computer technology in Liberia, affected response rates for both the survey and the interview (see Appendix III). By the end of the fieldwork, a total of 231 survey responses were received; 29 in-depth interviews with Indigenous Women Advocates were carried out; and 22 informal email exchanges with male colleagues were conducted. By way of secondary data, historical and statistical analyses were performed on 127708 convicts to Australia; 14996 former slaves to Liberia; 2701 sexual and gender violence cases reported to the Ministry of Gender, Children and Social Protection in Liberia; seven case files from the Sexual and Gender-based Crimes Unit in Liberia; and 1200 interview entries from the Longitudinal Study of Indigenous Children in Australia. See chapter 7 for a breakdown of the results and findings obtained.

\subsubsection{Target Groups}

The two target groups in the survey and interview research are:

1. Service Providers (Public \& Private): individuals who currently work on the issues of gender violence and the law and the legal system concerning Indigenous girls and women in Liberia and Australia. They include volunteers, researchers, community leaders, religious leaders, healthcare practitioners, counsellors, teachers, lawyers, judges, police officers, prison staffs and nongovernmental organisations workers.

2. Indigenous Women Advocates: adult women who identify as Indigenous Peoples in Liberia or Australia. They work in one or more of the following areas: civil service, humanitarian services, counselling, pastoral ministry, teaching, legal institutions, law enforcement institutions, health, research, higher education, community service, and traditional or tribal systems.

\subsubsection{Recruitment: Participants, Volunteering and Training}

General eligibility criteria for participating in the survey and the interviews were set at a) 18 years and above; b) resident of Australia or Liberia; and c) work in areas of gender violence and law. As informal conversations and observations characterised the daily conduct of the research in both Australia and Liberia, local community members, students and acquaintances were constantly encouraged to partner with and contribute to the research process.

\subsection{Data Analysis}

Simple descriptive univariate statistics are used to analyse quantitative and demographic data collected from both secondary sources and the survey. Percentages and weighted averages show 
summary statistics using SPSS and Excel. For the qualitative portion of the study, interviews were conducted in simple English (sometimes Liberian English) with literate adults. Each interview was transcribed verbatim, coded, and assessed thematically using word processing and NVIVO software. A crosscheck of tentatively identified key themes and categories was run against data collected and subsequently refined in an iterative process. That is, after the interview documents were imported and explored, they were coded and queried in a reflective manner. The iterative process continued during the final coding whilst comparing the interview text with the written descriptors. In instances where data did not fit existing themes, categories were refined to accommodate novel ideas. Responses to open-ended questions were analysed using general themes induced from the data collected, which serve to identify commonalities within the respondents' experiences. An iterative process based on reflection on audio files, diary entries, field notes, informal observation, follow-up questions and feedback from community members helped triangulate all data collected.

\subsection{Ethical Considerations}

The study requires ethical approval since it requires interviewing human participants regarding gender violence against Indigenous girls and women. The Australian National University's Human Research Ethics Committee and the University of Liberia's Institutional Review Board granted ethical approval to conduct the study in Australia and Liberia. 


\section{CHAPTER 7: FINDINGS AND RESULTS}

\subsection{Introduction}

Chapter 6 discussed the method and design used to collect the research data. This chapter presents the findings and results obtained. This chapter unfolds into two major sections: quantitative and qualitative data sets. The quantitative portion submits statistical findings gathered from historical, contemporary and fieldwork material on systematic gender violence. Responses from open-ended questions in both the interviews and the surveys are highlighted in the qualitative section. Two fundamental goals drove the collection and subsequent analysis of the data collected in chapter 8 . The first is to triangulate varied research sources in corroborating the prevalence of systematic gender violence against Indigenous Peoples in Australia and Liberia. The second is to validate Indigenous Women Advocates' perspectives on equality and justice in the legal system. The comprehensive data sets showcased in this chapter underpin the holistic, complex and diverse materials used to inform the critical analysis of the topic.

\subsection{Quantitative Data Set}

\subsubsection{Historical Secondary Data}

- Historical Roots of Intergenerational Violence and Trauma: Convicts and Slave Emigrants

To fully comprehend the prevalence of systematic violence, a contextual background of the colonial history of Indigenous Peoples' experiences in Australia and post-war Liberia is crucial. Liberia's unique history of hosting African American former slaves exemplifies a situation where the oppressed becomes the oppressor. Likewise, Australia's convict transportation saga arouses similar curiosity in efforts to understand why a people once denigrated (convicts) commit such acts of violence against another (Indigenous Peoples in Australia). Both the transAtlantic slave trade and the transportation of convicts to Australia offer interpretative and analytical lenses through which a genuine effort is made to comprehend the complex interconnections between groups of people who once oppressed later become the oppressors. Without justifying the repressive behaviours of former slaves and convicts toward Indigenous Peoples in Australia and Liberia, scholars do well to embrace empathy and to explore philosophical and practical space in light of the indeterminacy of the human condition.

The trans-Atlantic slave trade spanned approximately 374 years, from 1574 to $1875,{ }^{1454}$ although 'trading and raiding in the interior for resale elsewhere in equatorial Africa lasted at least until about 1911'. ${ }^{1455}$ A total of 34087 voyages took about 12521337 women, men and

\footnotetext{
${ }^{1454}$ David Eltis and Martin Halbert, Voyages: Summary Statistics (2013) The Trans-Atlantic Slave Trade Database <http://www.slavevoyages.org $>$.

${ }^{1455}$ Jan Vansina, 'Upstarts and Newcomers in Equatorial Africa (C1815-1875)' in Philip Curtin et al (eds), African History: From Earliest Times to Independence (Longman Pearson, 1995) 376, 379.
} 
children from across Africa to Europe, the Caribbean and the Americas. ${ }^{1456}$ At least 2 million deaths occurred during the trans-Atlantic slave trade. ${ }^{1457}$ A one-hundred-year period (1725 to 1825) marks the 'high-water mark of the slave trade, as Europeans sent more than 7.2 million people to forced labour, disease, and death in the new world'. ${ }^{1458}$ Of the estimated 12.5 million slaves taken from Africa, ${ }^{1459}$ despite their revolt and resistance, ${ }^{1460}$ more than 361424 chained Africans disembarked in mainland North American. ${ }^{1461}$ One cannot overemphasise the resulting intergenerational impact of the mayhem on Indigenous Peoples in Africa. ${ }^{1462}$ William Hardy observes that:

[t]he possible negative consequences of the trade were not only economic. Politically, as African rulers organised the capture of slaves, traditions were created of brutal and arbitrary intervention by the powerful in people's lives. Meanwhile, as rival African rulers competed over the control of slave-capture and trading, wars could result. On both counts, the Atlantic trade badly affected the political landscape of Africa and set disturbing precedents for the future [of Africa].

In Liberia, the 'future' spoken of by Hardy was placed in the hands of some 14996 slaves who were emancipated, purchased, or recaptured by the British Royal Navy between 1807 and $1866,{ }^{1464}$ hoping to redefine their destiny alongside Indigenous Peoples in Africa upon arrival on the West African shores.

In Australia, the First Fleet consisting of 11 vessels, ${ }^{1465}$ was the largest single contingent of ships to sail into the Pacific Ocean. Its purpose was to establish a convict settlement on the

\footnotetext{
${ }^{1456}$ Eltis and Halbert, above n 1454.

${ }^{1457}$ Ibid.

${ }^{1458}$ Andrew Kahn and Jamelle Bouie, 'The Atlantic Slave Trade in Two Minutes' [2015] Slate

<http://www.slate.com/articles/life/the_history_of_american_slavery/2015/06/animated_interactive_of_the_history_o f_the_atlantic_slave_trade.html $>$.

${ }^{1459}$ Babacar M'baye, 'The Economic, Political, and Social Impact of the Atlantic Slave Trade on Africa' (2006) 11(6)

The European Legacy 607.

${ }^{1460}$ Lorenzo T Greene, 'Mutiny on the Slave Ships' (1944) 5(4) Phylon 346.

${ }^{1461}$ Kahn and Bouie, above n 1458; Eltis and Halbert, above n 1454.

${ }^{1462}$ Michaela Alfred-Kamara, Elizabeth Khawajkie and David Mason, Impact on Africa, Caribbean, Americas and Europe (2015) Breaking the Silence: Learning About the Trans-Atlantic Slave Trade

<http://old.antislavery.org/breakingthesilence/main/07/index.shtml>. 'Quilimane, on the coast of modern

Mozambique, is now the greatest mart for slaves on the east coast... The riches of Quilimane consisted, in a trifling degree, of gold and silver, but principally of grain, which was produced in such quantities to supply Mozambique. But the introduction of the slave trade stopped the pursuits of industry and changed those places where peace and agriculture had reigned into a seat of war and bloodshed. Contending tribes are now constantly striving to obtain mutual conflict prisoners as slaves for sale to the Portuguese, who excite these wars and fatten on the blood and wretchedness they produce. The slave trade has been a blight on its prosperity; for at present Quilimane and Portuguese possessions in the whole colony of the Rios de Senna do not supply themselves with sufficient corn for their own consumption.' Captain WFW Owen, British Naval Officer, 1820s.

${ }^{1463}$ William Hardy, Riches \& Misery: The Consequences Of The Atlantic Slave Trade (25 February 2014) OpenLearn <http://www.open.edu/openlearn/history-the-arts/history/riches-misery-the-consequences-the-atlantic-slave-trade>. ${ }^{1464}$ Tom W Shick, Emigrants to Liberia, 1820-1843; An Alphabetical Listing (Department of Anthropology, University of Delaware, 1971); Brown, above n 543; Amos Jones Beyan, African American Settlements in West Africa: John Brown Russwurm and the American Civilizing Efforts (Palgrave Macmillan, 1st ed, 2005); Murdza Jr., above $n$ 544; Debra Lynn Newman, The Emergence of Liberian Women in the Nineteenth Century (PhD Thesis, Howard University, 1985) 390

<http://books.google.com.au/books/about/The_Emergence_of_Liberian_Women_in_the_N.html?id=pd22pwAACA AJ\&redir_esc=y>; Burleigh Holder, 'A History of Crozierville' (1970) 3(1) Liberian Studies Journal 21.

${ }^{1465}$ Torres, above $n$ 364. Oscar, Chief Executive Officer of Marninwarntikura Fitzroy Women's Resource Centre and a proud Bunuba woman (same language group as colonial resistant and rebellious warrior Jandamarra) from the remote town of Fitzroy Crossing, captures the birth of state/institutional violence against Aboriginal Australians: '...both British and Australian museum collections, has conjured a range of contradictory emotions for Indigenous Peoples across Australia - joy and wonderment at our remarkable living cultural heritage, and pain, outrage and
} 
east coast of Australia. The First Fleet sailed from England on 13 May 1787 and arrived at Botany Bay eight months later, on 18 January 1788. Governor Phillip rejected Botany Bay, choosing Port Jackson to the north instead as the site of the new colony. The First Fleet finally arrived at Port Jackson on 26 January 1788. The number of convicts transported in the First Fleet is unclear. However, it is estimated that between 750 and 780 convicts and around 550 crew, soldiers and family members were on board. ${ }^{1466}$ The Second Fleet arrived in Sydney Cove in 1790; it consisted of six ships, four transport ships, and two store ships. Three of the transport ships carried mostly male convicts and the other transport ship, The Lady Juliana, carried only women. The Lady Juliana was the first all-female transport ship. The female population of Sydney more than doubled when Juliana arrived. Reports confirm that the maltreatment of convicts on all the ships wherein they received poor food rations and sickness was on the rise throughout the journey. Of the approximately 1250 male convicts transported by the Second Fleet, over 25 percent died en route to New South Wales (in comparison to just 2.8 percent deaths of those on the First Fleet). Many convicts also died within a year of reaching Sydney. ${ }^{1467}$ Almost half of the convicts who arrived in Sydney required immediate hospitalisation and about 80 died within three weeks of arrival. ${ }^{1468}$ The exact number of convicts sent to Australia is unclear. However, it is estimated that between 160000 and 164000 convicts were transported

\footnotetext{
resentment emanating from the colonial wars, never fully acknowledged by the Australian state. Wars that saw countless violent deaths causing profound cultural and societal loss and intergenerational grief. I know these emotions first-hand, I have been a part of this exhaustive and meaningful journey every step of the way.... This cultural wealth is the strange and wonderful repercussions of Britain's Empire, greedy to consume the worlds of others. Still, in colonisation's hunger to extract wealth the lands of others were dominated. In too many instances colonisation has driven conflict and destruction, it has forced societies just like mine to the brink of eradication. Whether this was the intention or not, it is the truth of what happened. My Bunuba ancestors were not engulfed by the tidal wave of first British settlement, instead we felt the violent wash of frontier wars in the late 19th century. When I was standing on the Thames embankments yesterday I imagined the ports with ships preparing to journey for Australia. Their maiden voyage, the genesis of my future identity. When I would no longer be wholly Bunuba, or collectively Aboriginal but also an Australian. My heritage was tied to yours the day ships set sail with a cargo of chained human-beings. Between 1788 and 1870160000 English and Irish men, women and children were transported to an Island prison. No other society in the history of humanity has forcibly transported so many of its own subjects to a distant colony. I've learnt in the last few days that these people, our shared national ancestors, probably came from where I'm staying now, from the squalid overcrowded streets of an 18th century Covent Garden and Holborn. Just like rapidly growing urban centres today, London's population boom and the by-product were poverty. Inequality is dangerous. It breeds fear and anger between the materially prosperous and powerful and the poor and marginalised. The result - the first displaced populations of Australia were condemned for the crimes of the impoverished, fighting for survival. When this population was released from the shackles of the crown, I imagine they advanced with trepidation and determination to conquer and prosper. They pronounced Australia Terra Nullius, so they could own what had always been denied - land. To them we were the flora and fauna, ripe for domination.... By the time the unrelenting flow of settlers hit our countries in the far north, the continent was well on its way to being federated the Australian nation -state in 1901. The entire Aboriginal population had almost been reduced to a 10th of its size, while the new settlers swelled to a population of three million. Still, when white people set foot on the rocky crevassed limestone ranges of Bunuba country, Australia was yet to be formally named as a nation. It remained six British colonies under the lawmaking power of the British parliament, sitting in Westminster, just down the road.'

${ }^{1466}$ See, the State Library of New South Wales, "Convicts: Bound for Australia" (18 May 2015), available at: <http://guides.sl.nsw.gov.au/content.php?pid=400401\&sid=3291413>.

${ }_{1467}$ See, Flynn, M (2001), The Second Fleet: Britain's grim convict armada of 1790, Library of Australian History, Sydney (available at: < http://guides.sl.nsw.gov.au/content.php?pid=400401\&sid=3291414>.

${ }^{1468}$ ibid
} 
to Australia. ${ }^{1469}$ The most reliable online data reports records of 130536 convicts, transported on some 825 voyages between 1787 and $1867 .^{1470}$

Whilst there are online data, several books and archival records documenting convicts transported to Australia between 1788 and 1868, none were available that showed the complete literacy of convicts over the 80 -year period. ${ }^{1771}$ The most comprehensive records on former slaves returned to Liberia was obtained from hard copies of the roll of emigrants compiled by Shick (1971) ${ }^{1472}$ Murdza (1975), ${ }^{1473}$ and Brown (1980). ${ }^{1474}$ Challenges associated with gleaning statistical information from the above material centred on the lack of searchable online data which made an in-depth analysis of the 14996 former slaves a painstaking process. Hundreds of pages listing males, females, state of origin, education, occupation, and settlement in Liberia were counted manually. Therefore, caution must be applied when making generalisations and inferences from the data analysis (see Appendix IX). ${ }^{1475}$

The essence of compiling historical statistics on Liberia's former slave and Australia's convict record is deeply rooted in the persistence of systematic violence and the resulting traumatic impact on Indigenous Peoples as colonised bodies of these two countries. Both convicts and former slaves were dehumanised, rejected and forced to separate from their families and loved ones, yet denied access to education and skilled employment (see Appendix IX). For example, the youngest convict transported to Australia was only 11 years old. ${ }^{1476}$ According to the 1871 Census (during the height of convict transportation), 27 percent of Australians could not read or write. Similarly, former slaves to Liberia endured over three centuries of enslavement, racism, and discrimination as chattels. Only about 15 percent of the former slaves to Liberia could read or write; nine percent were farmers (mostly cotton growers), and six percent were carpenters (see Appendix IX). Yet, many convicts and former slaves and their descendants rose to later become law and policymakers who directed the legal and political development of both Australia and Liberia.

\footnotetext{
${ }^{1469}$ Steve Thomas, Convicts Records of Australia (2018) Convict Records <https://convictrecords.com.au>; Government of Australia, above n 354.

${ }^{1470}$ Thomas, above n 1469.

${ }^{1471}$ Email correspondence with ANU library and the National Library of Australia between 5 and 18 May 2015 reveal the lack of complete data on Australian convict literacy. Both institutions were very helpful in researching diverse resources over a period of two weeks but could only find fragmented resources. To this end, serious care needs to be taken when reading the Australian portion of Appendix IX as the information collected is fragmented and incoherent. ${ }^{1472}$ Shick, above n 1464.

${ }^{1473}$ Murdza Jr., above n 544.

${ }^{1474}$ Brown, above $\mathrm{n} 543$.

${ }^{1475}$ Apart from human errors, in some cases, sex was not indicated, thus an educated guess had to be made using the names of emigrants. In other cases, ages were not stated making it difficult to decide whether an emigrant was an infant, child or adult. Along with the challenge of distinguishing an adult from a child/infant is the educational level (i.e., an infant is unable to read or write but there is no accurate way of the age of the unknowns). This implies the percentage of unknown may include infants and young children who are not school ready.

${ }^{1476}$ Mary Wade History Association, above n 665; Rachel Roth, Making Women Pay: The Hidden Costs of Fetal Rights (Cornell University Press, 2000) <http://www.amazon.com/Making-Women-Pay-HiddenRights/dp/0801436079/ref=sr_1_7_title_1_har?s=books\&ie=UTF8\&qid=1361921359\&sr=1 -

7\&keywords=the+hidden+gender+of+law>.
} 


\subsubsection{Contemporary Secondary Statistics}

- Royal Commission into Aboriginal Deaths in Custody

In a 'knee-jerk' ${ }^{1477}$ response to public outcry about reports of Aboriginal deaths in custody, former Prime Minister Bob Hawke announced the formation of the Royal Commission into Aboriginal Deaths in Custody (hereafter the Royal Commission) pursuant to the Commission of Inquiry (Deaths in Custody) Act 1987. Over a period of four years, the Royal Commission investigated the causes of deaths of Aboriginal Peoples held in State and Territory gaols. Of the 99 deaths the Royal Commission examined between 1987 and 1991, 11 were females between the ages of 14 and 59. The most frequent offences committed by females who died in State and Territory custody were drunkenness, breaking and entry, and other public-order crimes. Nearly twice ( $n=63$ ) as many deaths occurred in police care as in prison custody ( $n=33$ ), the latter included three in juvenile detention centres. Aboriginal deaths in custody were highest in Western Australia $(n=32)$ and Queensland $(n=27)$. There were no deaths in custody recorded in the Australian Capital Territory. Thirty-seven deaths were due to diseases and other natural causes, 30 were caused by hanging, and 12 by head injury (see Appendix X). A total of 339 recommendations were made, 'mainly concerned with procedures for persons in custody, liaison with Aboriginal groups, police education and improved accessibility to information'. ${ }^{147}$

The Australian Institution for Criminology's 22-year National Deaths in Custody Program was established in 1992 in response to the Royal Commission's concerns regarding scarcity of reliable statistics on Indigenous contact with the criminal justice system. ${ }^{1479}$ Of the total prison population, (30 775) documented by the Australian Institute of Criminology, 27 percent ( 8 430) were Indigenous Peoples in Australia. A total of 2325 deaths (96 percent males and four percent females) occurred in prison and police custody between 1 January 1980 and 30 June 2011 (450 Indigenous deaths; 19 percent). ${ }^{1480}$ Over this time period, approximately 470 (six percent) members of the 8430 Indigenous prison population died in custody compared with 1 993 (nine percent) of the 22345 non-Indigenous Australian prison population. ${ }^{1481}$ Although the Australian Institute of Criminology findings corroborate the Royal Commission's conclusion that Aboriginal deaths were not any different from non-Aboriginal deaths in custody, the quality of care and response provided for Aboriginal women who died in custody is of particular interest to this study.

\footnotetext{
${ }^{1477}$ Jonathan Swan, 'Wooten warns of unrealistic hopes for finding closure', The Sydney Morning Herald, 14 November 2012, at http://www.smh.com.au/federal-politics/political-opinion/wootten-warns-of-unrealistic-hopesfor-finding-closure-20121113-29aj2.html.

${ }^{1478}$ National Archives of Australia, Royal Commission into Aboriginal Deaths in Custody - Fact Sheet 112 (2015) Government <http://www.naa.gov.au/collection/fact-sheets/fs112.aspx>.

${ }^{1479}$ Matthew Lyneham and Andy Chan, 'Deaths in Custody in Australia to 30 June 2011' (Monitoring Reports 20, Australian Institute of Criminology, 2013) 222, 6 <http://www.aic.gov.au/publications/current\%20series/mr/120/20.html>.

${ }^{1480}$ Ibid Abstract.

${ }^{1481}$ Ashleigh Baker and Tracy Cussen, 'Deaths in Custody in Australia: National Deaths in Custody Program 2011-12 and 2012-13' (Monitoring Reports 26, Australian Institute of Criminology, 2015) 76, x-xi

<http://aic.gov.au/publications/current\%20series/mr/21-40/mr26.html>; Lyneham and Chan, above n 1479, xv.
} 
- Sexual and Gender-based Violence Crimes Unit

The Sexual and Gender-Based Violence Crimes Unit (hereafter the Crimes Unit) was initially established as a pilot project in Monrovia (2009-11) by the United Nations Populations Fund, the United Nations Development Program and the Government of Liberia to prosecute perpetrators of gender and sexual-based violence, particularly rape, in Liberia. ${ }^{1482}$ During fieldwork in Liberia, accessing information at many public institutions was challenging. As discussed above, the lack of a public electrical grid and other infrastructural problems made obtaining any electronic data nearly impossible. Even more challenging, formal requests made to review cases already tried at Criminal Court ' $E$ ' were consistently denied. A judge said during an in-person interview that, 'Special Court "E" case law is not available for public use.' Fortunately, shortly before departing Liberia, assistance from the Attorney General's Office helped expedite the process of retrieving information from the Crimes Unit. The Crimes Unit reports that Criminal Court 'E' received and documented 169 cases between July 2011 and January 2014 and prosecuted 35. Of these, 24 defendants were convicted and sentenced, 10 were acquitted, and one verdict was hung. At the time of compiling this information (28 March 2014), one pre-trial screening was ongoing. The Attorney-General's Office granted access to the 34 State-prosecuted case files. Given the time limitation placed on reviewing each voluminous file at restricted times between 10:00 am and 5:00 pm, only seven record files were scrutinised (see Table 7.1).

\section{- Stolen Generation}

The Bringing Them Home Report 1997 resulted from an inquiry by the Human Rights and Equal Opportunity Commission into the removal of Aboriginal and Torres Strait Islander children from their families. The report confirms that '[i]t is not possible to state with any precision how many children were forcibly removed...' due to loss of documentation or failure to record children's Aboriginality. ${ }^{1483}$ The Human Rights and Equal Opportunity Commission concluded that between 1 in 3 and 2 in 10 Indigenous children were forcibly removed from their families and communities from around 1910 until 1970. ${ }^{1484}$ Researching AusLII and other relevant journal articles (e.g., those authored by Chris Cunneen, ${ }^{1485}$ Peter Read, ${ }^{1486}$ Randall Kune, ${ }^{1487}$ and Christine Forster), ${ }^{1488}$ this study identifies seven Stolen Generation Cases in Australia, of which only one has been compensated (see Table 7.2).

\footnotetext{
${ }^{1482}$ Abdulai, above n 977, 1.

${ }^{1483}$ Commonwealth of Australia, 'Bringing Them Home: National Inquiry into the Separation of Aboriginal and

Torres Strait Islander Children from Their Families', above n 761, 30.

${ }^{1484}$ Ibid 31 .

${ }^{1485}$ Chris Cunneen and Julia Grix, 'The Limitations of Litigation in Stolen Generations Cases' (2004) 15 An AIATSIS Research Discussion Paper 1.

${ }^{1486}$ Peter Read, 'The Stolen Generations, the Historian and the Court Room' (2002) 26 Aboriginal History 51.

${ }^{1487}$ Randall Kune, 'The Stolen Generations in Court: Explaining the Lack of Widespread Success Litigation by Members of the Stolen Generations' (2011) 30(1) University of Tasmania Law Review 32.
} 
- Ministry of Gender, Children and Social Protection Database

The Ministry of Gender, Children and Social Protection's (hereafter the Ministry of Gender) Research Unit provided invaluable assistance during fieldwork data collection in Liberia (2013-

\section{Perpetrator's Relationship to Survivor}

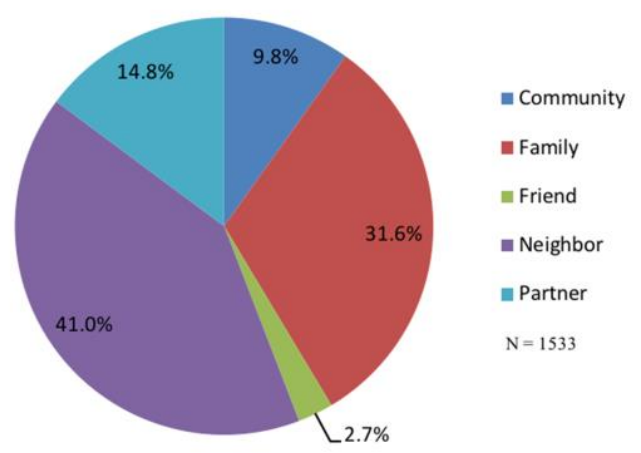

Figure 7.1: Relationship of perpetrator to survivor of sexual and domestic violence
14). As noted above, Liberia lacks access to public grid electricity; generators power most government ministries, or electricity is rationed or provided ad hoc by the Liberia Electricity Corporation. Regardless of the source, power is shut down by 5:00 pm daily, making it difficult to work longer hours. With permission from the Assistant Minister and the Gender-Based Violence Coordinator,

Ministry of Gender's Research Unit allowed a review of five years (2009-13) worth of data collected on gender violence across Liberia. Over a two-month period, a total of 12000 cases reported to the Ministry of Gender were photographed with an iPad and a digital camera. ${ }^{1489}$ Once again hundreds of hours were spent imaging, converting and cleaning up the digital files obtained from the Ministry of Gender. Due to time limitations, only the 2701 cases reported in 2013 were organised and assessed.

\section{Case First Reported To...}

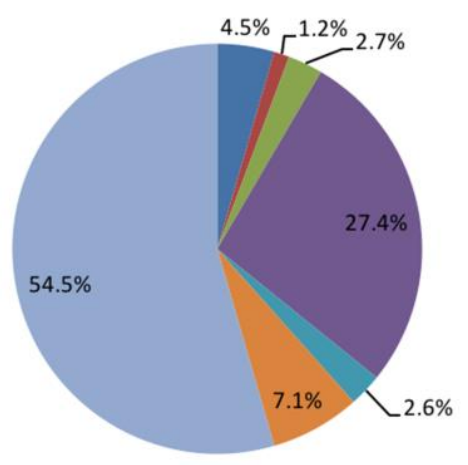

$\begin{aligned} & \text { Community } \\ & \text { Member } \\ & \text { Court }\end{aligned}$
Family Member
nealth Care
MoGD
$\mathrm{N}=2226$

Figure 7.2: Institutions where cases of sexual and domestic assault are first reported
Table 7.3 shows more gaps in reporting as one moves further into the legal processes of a reported case. For example, the sex of the perpetrator is reported in 100 percent of the cases, compared with 30 percent reporting on the results of the court hearing. Overall, 414 (15 percent) of cases received an assignment to legal counsel. Of

\footnotetext{
${ }^{1488}$ Christine Forster, 'The Stolen Generation and the Victims Compensation Tribunal: The "writing in" of Aboriginality to "Write out" a Right to Compensatory Redress for Sexual Assault' (2002) 25(1) University of New South Wales Law Journal 185.

${ }^{1489}$ All variables in each report for the year 2013 (some up to 15 pages long) were cleaned up to ensure consistency before entering into a spreadsheet (e.g., LGH was changed to Liberian Government Hospital, and Bassa to Grand Bassa county). Individual case reports were then cleaned up for consistencies whilst adding more analysable columns. For example, time of day was broken down to day and night, days were grouped into months, and offenses were categorised collectively - say child beating grouped under child abuse and neglect). Further, some locations had to be checked and verified and grouped by county and districts using LISGIS Census data (see, http://www.lisgis.net) and then National Elections Commission political divisions (see, http://www.necliberia.org).
} 
these only 250 (nine percent) were specified as having provided actual legal counsel to the survivors in question.

Table 7.4 shows that rape had the highest incidence of all sexual assaults recorded, making up 62 percent of 2198 cases. Of these, 96 percent were male perpetrators (see Table 7.5), and most were neighbours (41 percent) or family members (31 percent) (also see Figure 7.1). Figure 7.2 shows that whilst the court is not the first point of contact for reporting sexual and domestic assault cases, the hospitals comprised 55 percent of the 2226 cases recorded. Survivors of sexual assaults were mostly females (96 percent) ranging from the ages of 0 to $60+$ years of age, with girls between the ages 10 and 15 being the most affected (see Figure 7.3). A total of 579 cases documented the number of days that survivors spent in safe houses (provided the option was available to them). Of these, only 167 (28 percent) of the cases documented survivors spending one or more days in a safe house. Some 1019 cases sent to court were recorded on the reporting form. Of these, only 546 (54 percent) were documented as having actually gone to court or planning to go to court. Regarding the outcome of trials that actually made it to court, 45 (four percent) of the cases recorded that the perpetrator was found 'guilty' $(n=42)$ or sent to 'prison' $(n=3)$.

Notably, the Ministry of Gender's paper reports is not perfect. For example, up to 84 percent of entries are missing. There are inconsistencies in the usage and processing of variables from different agencies. However, the data are the best available to establish base rate information on the incidence and prevalence of sexual violence in Liberia, tracking the entire life-cycle of a case file across health/medical, law enforcement, and the judiciary systems. Unfortunately, months of communication (ordinary and electronic mails and physical visits) with the Australian Institute of Criminology and government institutions including state police departments in the Australian Capital Territory, Western Australia, Northern Territory and Queensland proved futile with regards to similar data collection. Either the response indicated that 'there is no data of that sort' collected in Australia, 'statistical information is available on our website', or 'we do not have access to or the authority to release data, we only coordinate requests for research'. ${ }^{49}$

\section{- The Longitudinal Study of Indigenous Children}

The Longitudinal Study of Indigenous Children (hereafter the Longitudinal Study), also called Footprints in Time, is an initiative of the Australian Government. Conducted by the Department of Social Services under the guidance of the Footprints in Time Steering Committee and chaired by Professor Mick Dodson, the Longitudinal Study includes two groups of Aboriginal and Torres Strait Islander children. One group (B cohort) was aged 6-18 months and the other (K cohort) $3 \frac{1}{2}-5$ years when the study began in 2008. The Longitudinal Study releases its findings in waves. A total of eight waves have been produced so far, with data collection for the most

\footnotetext{
${ }^{1490}$ Personal email exchange with the Western Australia Police Department on 7 July 2014.
} 
recent cohort starting in February 2015. The Longitudinal study does not collect direct data on violence against Aboriginal and Torres Strait Islander children in Australia. Nevertheless, this study extracted data from wave 1 (base rate information), ${ }^{1491}$ wave 2 (stolen generation), wave 3 (homelessness and racism) and wave 7 (bullying) because these are the strongest indicators relating to systematic violence against Aboriginal children in Australia. Footprints in Time interviewers have successfully contacted and interviewed over 1200 of the original families in subsequent waves. New families were added in wave 2 and have shown similarly strong commitment. The Longitudinal Study data must be interpreted with a caveat, as it is not a probability sample, but rather secondary data collected from volunteer families selected from 11 original sites. To this end, Maggie Walters asserts that the Longitudinal Study data cannot be readily compared with that of non-Indigenous children. However, dichotomous comparisons of this type are not required to give substance and meaning to the data. Rather, "what [the Longitudinal Study of Indigenous Children] cumulative data are revealing is a compelling, previously hidden portrait of how Aboriginal and Torres Strait Islanders can "be" family and "do" raising children' (see Table 7.6).

\subsubsection{Empirical Study}

\section{- Paper/Online Survey}

In Liberia, service providers in the health, education and legal areas of both private and public institutions were surveyed using a paper questionnaire. After sending out 1200 electronic mails, posting notices at various ministries, schools, hospitals, and using word-of-mouth to promote the survey, a total of 78 responses were received. Initially, an assumption was made that respondents might not have been able to complete the survey due to their inability to comprehend high-level information or for logistical reasons (e.g., no available stationery). In instances where respondents could not complete the survey on their own, assistance was provided. Midway into the fieldwork, 90-minute survey interview meetings were conducted, at which time responses to survey questions were recorded by the researcher. The respondent interview ran for a period of six months in Liberia. Respondents were concentrated in four professional areas pertinent to providing services for survivors of systematic gender violence. They were: 1) legal, law enforcement and human rights, 2) education, literacy and skills building, 3) community and grass-roots advocacy, and 4) administration, coordination,

\footnotetext{
${ }^{1491}$ In wave 1, over 1680 interviews were conducted with the children's parents or primary care-providers (usually the mothers) and over 265 interviews were conducted with fathers or other significant care providers. Subsequent waves experienced strong support from these initial interviewees (see, Department of Social Services, 'Footprints in Time - The Longitudinal Study of Indigenous Children (LSIC)' (20 July 2015), available at: < https://www.dss.gov.au/about-the-department/publications-articles/research-publications/longitudinal-datainitiatives/footprints-in-time-the-longitudinal-study-of-indigenous-children-lsic>.

${ }^{1492}$ Fiona Skelton et al, 'Footprints in Time: The Longitudinal Study of Indigenous Children Up and Running' (Government 95, Australian Institute of Family Studies, 2014) 11, 37

<https://aifs.gov.au/sites/default/files/fm95d.pdf>.
} 
monitoring and evaluation. Other professional areas in which survey respondents worked included mental health, psychosocial support, medical care and prison care.

In Australia, which has much easier access to the internet and electronic resources, 2 500 emails went out in a similar fashion. Over a period of six weeks, 154 survey participants responded (see Table 7.7). The top three professions of survey respondents in Australian were: 1) law and legal service, 2) crises and victim support, and 3) physical and mental health. Other respondents reported that they worked in domestic violence, homelessness and housing, volunteer and advocacy, law enforcement, corrections, and research.

Table 7.8 shows service providers' responses to four key survey questions. When asked whether the law is helpful in their work on violence against Indigenous women, 21 per cent of service providers said 'yes' (compared with 14 percent who said 'no') in Australia and 53 percent said, 'yes' (compared with 17 percent who said 'no') in Liberia. However, when asked whether they perceive the Australian legal system as 'just' toward Indigenous girls and women, 26 percent of service providers said 'yes' compared with eight percent who responded 'no'. In Liberia, 44 percent of service providers perceived the legal system to be 'just' toward Indigenous girls and women who have suffered gender violence, whilst 26 percent did not. Twenty-seven percent of survey participants in Australia and 74 percent in Liberia agreed that the customary law and the local community (34 percent in Australia and 91 percent in Liberia) have a crucial role to play in addressing systematic violence against Indigenous girls and women.

\section{- Semi-Structured Interview}

A similar snowballing method that was used to recruit service providers was applied in identifying Indigenous Women Advocates to participate in the research interview. Of the 61 and 27 Indigenous Women Advocates contacted in Liberia and Australia, 21 and 7, respectively, agreed to participate in the interview (see Tables 7.11). Due to financial constraints, five out of seven of the Australian interviewees were conducted in the Australian Capital Territory. With one exception, Indigenous Women Advocates in Australia were Ph.D. recipients or candidates. Only one interviewee did not identify with a 'mob' (i.e., an Aboriginal Language Group in Australia). ${ }^{1493}$ Ages of interview participants ranged from 54 to 60 years. One participant was not comfortable revealing her age.

More than three times as many Indigenous Women Advocates in Liberia participated in the interviews as in Australia (see Table 7.10). Ninety-five percent of all participants in Liberia were interviewed in person across four counties. Given the breadth of geographical locations covered in Liberia, educational levels of participants varied more widely than in Australia (see Table 7.9), although a relatively high number of participants in Liberia (71 percent) were

\footnotetext{
${ }^{1493}$ Mob is an Aboriginal English word for family, kin, or group of people (see: http://www.ipswich.qld.gov.au/_data/assets/pdf_file/0008/10043/appropriate_indigenous_terminoloy.pdf). 
university educated. Ages of interview participants varied more widely in Liberia than in Australia. Indigenous Women Advocates' ages ranged from 35 to 67 in Liberia compared with Australian advocates whose ages spanned 54 to 60 . One Liberian participant did not feel comfortable revealing her age.

\subsection{Qualitative Data Set (Empirical Study)}

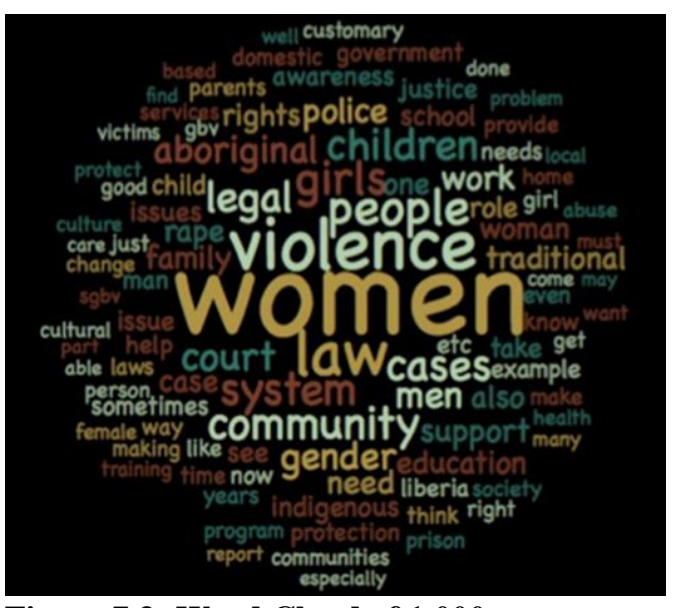

Figure 7.3: Word Cloud of 1000 most frequent words used in the research survey
Over a period of four months, approximately 640 hours were spent transcribing, coding and analysing 15 audio interviews (eight in Liberia $^{1494}$ and seven in Australia) and 32 openended responses to the survey questions (16 each in Liberia and in Australia) (see Appendix I). Using NVIVO software, Excel and Microsoft Word, a total of 377 nodes (or themes) (189 for Australia and 188 for Liberia) were retrieved from responses to the openended survey questions. A combination of 28

nodes (a total of 83 pages) emerged from the coded interviews. Each coding process lasted between 1.5 and 2.5 hours. Since a response usually speaks to more than one issue, nodes emerging from a single response tended to overlap with several other nodes, thereby creating repetition. Although such repetitive responses strengthened the iterative process, it would be erroneous, to sum up or average nodes to 100 percent.

A simple but visibly profound way of testing the research validity was to assess the 1 000 most frequent words to identify common keywords at a minimum length of three letters. The resulting word cloud (see Figure 7.4) reveals that 'women' (979x), 'violence' (537x), 'law' (455x), 'people' (328x), and 'girls' (296x) surfaced as the top five most frequent words respondents used when answering the interview and open-ended survey questions.

\section{- Service Providers' Responses to Open-Ended Survey Questions}

As the key research questions focused on how 'just' or 'helpful' the law is in responding to violence against Indigenous girls and women in Liberia and Australia, nine of the 16 openended survey questions were relevant for a closer examination. The top five nodes for each of the nine selected questions, each represented by a sample quotation, are presented in Table 7.11. Interestingly, Table 7.8 shows that more service providers responded to the question of whether the law is 'just' and 'helpful' when addressing violence against Indigenous girls and women than to other survey questions. Each of the closed-ended key queries listed in Table 7.8 was

\footnotetext{
${ }^{1494}$ Due to time constrains and word limit imposed on this piece of research work, rather than transcribing and analysing all 21 interviews conducted in Liberia, only 8 interviews were transcribed and coded assessed to sort of even up with the seven interviews conducted in Australia.
} 
followed by an open-ended format that prompted respondents to provide reasons for and examples of why they perceived the law as '(un)helpful' or '(un)just'. Table 7.11 below shows responses contrary to those shown in Table 7.8, which partly explains why survey respondents hesitated to give full responses to some of the open-ended questions. A relatively high percentage of respondents did not return a 'yes' or 'no' answer to whether the law or legal system is 'helpful' or 'just' ( $s e e$ the 'Blank' columns in Table 7.8 for clarification).

For questions 1 and 2 in Table 7.11, survey participants provided more reasons why they think the law is 'unhelpful' in addressing violence against Indigenous girls and women. To be clear, 87 survey responses in Liberia and 52 in Australia provided reasons why the law was 'unhelpful' compared with 47 in Liberia and 45 in Australia that provided reasons why the law is 'helpful'. Survey participants tended to associate 'helpfulness' (see questions 1 and 2 in Table 7.11) of the law with perceptions of 'justice' (see questions 3 and 4 in Table 7.11) in the legal system. Survey participants provided more reasons for why they think the legal system is 'unjust' (136 responses in Liberia and 60 in Australia) when addressing violence against Indigenous girls and women than for why the legal system is 'just' (35 responses in Liberia and nine in Australia). Whilst service providers acknowledged the significant role played by the legal system (44 responses in Liberia and 66 in Australia), Indigenous Customary Laws (125 responses in Liberia and 53 in Australia), and the community (69 responses in Liberia and 80 in Australia), 24 respondents commented that the traditional system in Liberia has little or no role to play in protecting Indigenous girls and women against violence.

Respondents indicated that Indigenous Customary Law in Australia is complicated and complex; hence, it is hard to clearly articulate its role in addressing violence against Indigenous girls and women. The survey is replete with comments provided by survey participants regarding the challenges (76 responses in Liberia and 40 in Australia) and recommendations on how to improve the law and change attitudes (164 responses in Liberia and 151 in Australia). That being said, recurring themes that ran through responses to the above question emphasised the need for high-quality education, dialogue, awareness, and advocacy to assist in the prevention of violence against Indigenous girls and women.

\section{- Indigenous Women Advocates' Responses to Interview Questions}

Nodes gathered from all 15 coded interviews with Indigenous Women Advocates revealed interesting parallels between Australia and Liberia in the prevalence of systematic gender violence. Though Indigenous Women Advocates from these two countries differ culturally, historically, and contextually, they expressed similar concerns regarding the pervasive, ingrained and persistent nature of violence inflicted on Indigenous girls and women. They also lamented the serious challenges faced when addressing the issue of systematic gender violence. Indigenous Women Advocates in Australia, partly due to their high academic level, were more cognisant of the interconnections between the three levels of systematic gender violence 
(institutional/state, structural/cultural and community/interpersonal). Such awareness is exemplified by Alison's quote under 'religious abuse' in Table 7.12 and stands in contrast to survey participants in both countries (e.g., Sia's quote under 'Female Genital Cutting' in Table 7.12), who tended to reduce gender violence to the community or interpersonal violence.

Indigenous Women Advocates in both countries responded to issues of patriarchy and settlers' control of the legal system responsible for propagating systematic gender violence against Indigenous girls and women (e.g., Sia's and Jaky's quotes under 'Female Lawyers/Police Officers' in Table 7.12). Indigenous Women Advocates also highlighted the need to address the occurrence of violence against boys and men (e.g., Sia's and Dallas' quotes under 'Violence against Men' in Table 7.12). Like the survey participants, Indigenous Women Advocates cited numerous challenges associated with dispensing justice for Indigenous girl and women survivors of systematic gender violence. Indigenous Women Advocates repeatedly emphasised the importance of males championing the cause of violence against girls and women (e.g., Abigail's and Jaky's quotes under 'challenges' in Table 7.12). Education, awareness and attitudinal changes (e.g., Yaa's and $K$ 's quotes in Table 7.12) were front and centre in Indigenous Women Advocates' recommendations. Lara focused on the education of the judiciary:

There needs to be better training of the judiciary in dealing with Aboriginal issues. There needs to be better programs in dealing with underlying issues - particularly in literacy. There needs to be better pathways to provide support. There absolutely needs to be investment in the services for victims in taking a holistic approach - not just the service but where they can go to be safe; but also, in long-term care, as in employment and counselling. That's the kind of a broader holistic approach that people need to be able to get their lives back together. [Lara, Australia]

Amelia suggested incorporating violence against girls and women issues in curricula designed for health sciences students at the university level:

\begin{abstract}
At the Ministry of Health and Social Welfare, what we've done and continue to do is to train our health professionals how to manage survivors when they are raped. We've conducted the training for a couple of years now. What we've been trying to push for is to make this training part of the curriculum for all health training institutes in the country. So that once you enrol at say, the Tubman National Institute of Medical Arts [University of Liberia's Nursing School], in your studies, you'll learn how to manage rape cases. After graduation, when you're assigned to a health facility, you'll only do in-service rather than receiving on-the-job training. [Amelia, Liberia]
\end{abstract}

- Informal Email Responses from Male Friends, Colleagues and Acquaintances

My perspective in researching violence against Indigenous girls and women was informed by my experience as a female survivor of personal and systematic violence. Although soliciting male input was not initially part of this research, upon re-reading survey and interview participants' suggestions for including male voices in the gender justice agenda, I decided to seek input from a select few male colleagues, friends and acquaintances. In all, the 22 responses received from male participants via electronic mail exchange affirmed that most men at least intend to speak out against gender violence subject to certain conditions around safety. Overall, 
male colleague responses about speaking out expressed concerns regarding the context, localities or type of gender violence. For example:

In male conversations, I have been fortunate to be surrounded by mostly caring and respectful men in my life. However, when some people are maturing, they may try out misogynistic or objectifying language to try and fit into social groups. There have been a couple instances where I have called out a peer within a group of friends/colleagues, to hold them accountable and demonstrate that objectifying or denigrating women is not acceptable behaviour in my social groups. Respondent \#2

It is a little difficult to answer your question because the many contexts in which I can imagine speaking out about violence against women are not easy to delineate. Respondent \#6

I would speak out about violence against women, but only in a comfortable context. Respondent \#18

The where is oftentimes the key element. If I am at work or attending a public meeting, yes and not only because I believe it is wrong but additionally the societal norm in my circles views violence against women as a particularly loathsome act. Respondent \#5

Interestingly, male colleague respondents did not mention the law or legal system as an instrument of systematic gender violence or as a tool for addressing violence against girls and women. See chapter 8 for further discussion and analysis and Appendix XI for more responses from male colleagues.

\subsection{Summary}

The findings and results in this chapter achieved the three research objectives stated in chapter 1. Drawing on historical, secondary data, surveys and interviews to examine systematic gender violence, data collected in the chapter substantiate the basis for critical analysis of the efficacy of the rule of law in restoring justice to Indigenous girl and women survivors of systematic violence. Intergenerational trauma caused by the Trans-Atlantic Slave Trade on African American settlers and convict transportation on White Australian settler-colonists partly explain the persistence of systematic violence inflicted on Indigenous girls and women in these countries. Incident reports from various institutions in Australia and Liberia show that males closely related to Indigenous survivors of gender violence disproportionately perpetrate violence against them. Courts and criminal data highlight difficulties in using the law or legal system as a viable mechanism for restoring justice to Indigenous girls and women survivors of systematic gender violence. Responses from survey participants suggest a need for change in males' attitudes towards girls and women to effectively address systematic gender violence. Interview results show that even though Indigenous Women Advocates are resilient survivors of systematic gender violence, male leadership in preventing such violence is paramount. Ad hoc responses from a select few male colleagues via email reaffirms that the law or legal system is not a primary avenue for restoring justice to girls and women survivors of systematic gender violence. 
Table 7.1: Select cases prosecuted by the Sexual and Gender-Based Violence Crimes Unit 2009-2011

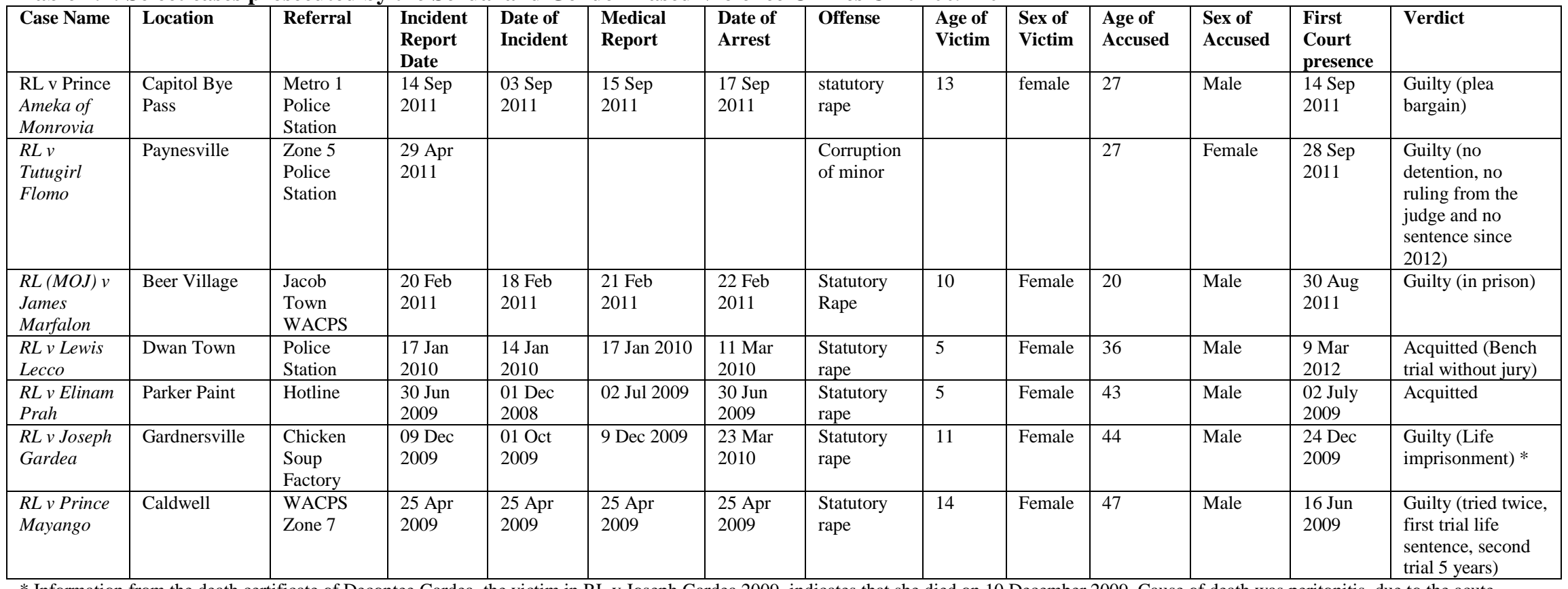


Table 7.2: Select Stolen Generation Cases in Australia

\begin{tabular}{|c|c|c|c|c|c|c|}
\hline$\#$ & Case & Year & Court & Issue/Claim & Decision/Held & Comments \\
\hline 1 & $\begin{array}{l}\text { Joy Williams v The } \\
\text { Minister, Aboriginal } \\
\text { Land Rights Act } 1983 \\
\text { \& Anor }\end{array}$ & 1999 & $\begin{array}{l}\text { New South } \\
\text { Wales } \\
\text { Supreme } \\
\text { Court }\end{array}$ & $\begin{array}{l}\text { Damages for negligence, breach of fiduciary duty, breach of statutory duty } \\
\text { and trespass as a result of wrongful removal, causing physical and mental } \\
\text { illness. }\end{array}$ & $\begin{array}{l}\text { There was no duty of care, breach of duty, trespass or relevant } \\
\text { causation established. Action in negligence failed. }\end{array}$ & $\begin{array}{l}\text { First case by an Indigenous } \\
\text { person in Australia claiming } \\
\text { remedy for losses suffered } \\
\text { due to forced removal. }\end{array}$ \\
\hline 2 & $\begin{array}{l}\text { Kruger v } \\
\text { Commonwealth } \\
\text { ('Stolen Generation } \\
\text { Case') }\end{array}$ & 1997 & $\begin{array}{l}\text { High Court of } \\
\text { Australia }\end{array}$ & $\begin{array}{l}\text { Challenge the constitutional validity of the Aboriginals Ordinance } 1918 \text { (NT) } \\
\text { which provided that the Chief Protector of Aborigines had extensive powers. } \\
\text { Authority includes 1) the discretion to undertake care, custody and control of } \\
\text { any 'aboriginal or half-caste' (s 6(1)) and 2) remove any 'aboriginal or half- } \\
\text { caste' to any 'reserve' or 'aboriginal institution. The plaintiffs argued that } \\
\text { breach of their implied constitutional rights gave rise to damage recovery } \\
\text { from the Commonwealth. }\end{array}$ & $\begin{array}{l}\text { The High Court of Australia held that the Ordinance was } \\
\text { not 'contrary to an implied constitutional right to freedom.' } \\
\text { Although the Ordinance targets one racial group, it was not an } \\
\text { example of legislation designed to be punitive towards that racial } \\
\text { group. The Court further held that the power to order involuntary } \\
\text { detention is not 'necessarily judicial power, whether or not } \\
\text { subject to exceptions...' The court rejected the plaintiffs' } \\
\text { freedom of movement argument for invalidation of the } \\
\text { Ordinance. }\end{array}$ & $\begin{array}{l}\text { The plaintiffs include eight } \\
\text { inhabitants of the Northern } \\
\text { Territory removed from their } \\
\text { families between } 1925 \text { and } \\
1944 \text { under the Aboriginal } \\
\text { Ordinance } 1918 \text { and a } \\
\text { mother whose child had been } \\
\text { taken away under the same } \\
\text { law. }\end{array}$ \\
\hline 3 & $\begin{array}{l}\text { Johnson v Department } \\
\text { of Community } \\
\text { Services \& Others }\end{array}$ & 1999 & $\begin{array}{l}\text { New South } \\
\text { Wales } \\
\text { Supreme } \\
\text { Court }\end{array}$ & $\begin{array}{l}\text { The plaintiff, removed from the care and custody of his family and parents } \\
\text { since he was } 4 \text { and placed into the care of the Minister for Youth and } \\
\text { Community Services by order of the Children's Court at Wilcannia, pursuant } \\
\text { to the Child Welfare Act } 1939 \text {. He claims damages for negligence, breach of } \\
\text { statutory duty and breach of fiduciary duty. The plaintiff further applied for } \\
\text { an extension of within which proceedings could commence subject to the } \\
\text { Limitation Act } 1969 \text {. }\end{array}$ & Extension of limitation period declined. & $\begin{array}{l}\text { Decision reserved for appeal } \\
\text { like Williams (1994). }\end{array}$ \\
\hline 4 & $\begin{array}{l}\text { Cubillo \& Gunner } v \\
\text { The Commonwealth }\end{array}$ & 2000 & $\begin{array}{l}\text { Federal Court } \\
\text { of Australia }\end{array}$ & $\begin{array}{l}\text { Lorna Cubillo was taken away at age eight from Phillip Creek Settlement and } \\
\text { Peter Gunner and removed at aged seven from Utopia Station. She claims that } \\
\text { their removal and detention caused them pain and suffering, loss of } \\
\text { enjoyment of life and loss of cultural heritage. They also alleged that the } \\
\text { Commonwealth was legally responsible for the wrongs done to them and was } \\
\text { liable to compensate them for damages. }\end{array}$ & $\begin{array}{l}\text { Primary judge dismissal of claims held as he did not err in } \\
\text { rejecting the appellants' false imprisonment claims. The primary } \\
\text { judge correctly held that there was no basis for the appellants' } \\
\text { claims founded on an alleged breach of fiduciary duties said to be } \\
\text { owed by the Commonwealth to the appellants. }\end{array}$ & \\
\hline 5 & $\begin{array}{l}\text { Valerie Wenberg } \\
\text { Linow }\end{array}$ & 2002 & $\begin{array}{l}\text { New South } \\
\text { Wales } \\
\text { Victims } \\
\text { Compensation } \\
\text { Tribunal } \\
\end{array}$ & $\begin{array}{l}\text { The plaintiff, taken from her mother at the age of two and placed in the } \\
\text { Bombaderry Children's Home; claimed compensation based on sexual } \\
\text { assaults endured after being placed with a family at age 16, as a domestic } \\
\text { worker by the Aboriginal Welfare Board in } 1958\end{array}$ & $\begin{array}{l}\text { The plaintiff claim accepted on the balance of probabilities. } \\
\text { However, the applicant experienced a series of indecent and } \\
\text { sexual assaults by the alleged offender. The Assessor denied the } \\
\text { plaintiff's claim based on dissatisfaction 'on the balance of } \\
\text { probabilities that the injury resulted from the sexual assaults.' }\end{array}$ & \\
\hline 6 & $\begin{array}{l}\text { State of South } \\
\text { Australia } v \text { Lampard- } \\
\text { Trevorrow }\end{array}$ & 2010 & $\begin{array}{l}\text { Supreme } \\
\text { Court of } \\
\text { South } \\
\text { Australia } \\
\text { [Full Court] }\end{array}$ & $\begin{array}{l}\text { The plaintiff, an Aboriginal child, was fostered without the consent of his } \\
\text { parents after having been admitted to hospital in late 1957. Appeal against } \\
\text { the award of damages by a trial Judge in respect of injuries caused by the } \\
\text { fostering (s } 10 \text { of the Aborigines Act } 1934 \text { (SA)) provided that the Aborigines } \\
\text { Protection Board (APB) be 'the legal guardian of every Aboriginal child.' } \\
\text { Does s10 give the APB the power to foster an Aboriginal child without the } \\
\text { consent of the child's parents? }\end{array}$ & $\begin{array}{l}\text { Under to } 222 \text { of the Acts Interpretation Act } 1915 \text { (SA) in } \\
\text { explicating the ambiguity of 'legal guardian,' the Supreme Court } \\
\text { held that s } 10 \text { did not give the APB the power to foster an } \\
\text { Aboriginal child without the consent of the child's parents. }\end{array}$ & $\begin{array}{l}\text { The Supreme Court of } \\
\text { Australia upheld a } 750000 \\
\text { award to the late Bruce } \\
\text { Trevorrow in } 2011 .\end{array}$ \\
\hline 7 & $\begin{array}{l}\text { Collard } v \text { The State of } \\
\text { Western Australia }[\text { No } \\
\text { 4] }\end{array}$ & 2013 & $\begin{array}{l}\text { The Supreme } \\
\text { Court of } \\
\text { Western } \\
\text { Australia in } \\
\text { Civil }\end{array}$ & $\begin{array}{l}\text { Sometime between } 1958 \text { and 1961, the children (Ellen, Donald, William, } \\
\text { Glenys, Eva, Wesley, Beverly, Darryl and Bonnie of Don and Sylvia, were } \\
\text { removed, subject to the Children's Court at Brookton, and committed to the } \\
\text { care of the Child Welfare Department. The plaintiffs claimed that the State } \\
\text { was subject to fiduciary duties to them during the wardship because it was the } \\
\text { guardian of the children. The plaintiffs brought this action seeking a } \\
\text { declaration that the State breached its duties to them, and equitable } \\
\text { compensation or damages, including exemplary damages and aggravated } \\
\text { damages, for the injuries, loss and damage they claim to have suffered as a } \\
\text { result of the alleged breach by the State of its duties to them. }\end{array}$ & Plaintiff actions dismissed. & $\begin{array}{l}\text { The first case of its kind in } \\
\text { Western Australia. The State } \\
\text { sought an order that the } \\
\text { plaintiffs pay its costs of the } \\
\text { action. }\end{array}$ \\
\hline
\end{tabular}


Table 7.3: Incidence of Sexual Assault and Other Violent Crimes Submitted to the Ministry of Gender in 2013

\begin{tabular}{|c|c|c|c|c|c|c|c|c|}
\hline 2013 Total Cases $=2701$ & Recorded & $\begin{array}{l}\% \text { of } \\
\text { Total }\end{array}$ & Missing & $\begin{array}{l}\% \text { of } \\
\text { Total }\end{array}$ & Unknown & $\begin{array}{l}\% \text { of } \\
\text { Total }\end{array}$ & Known & $\begin{array}{l}\% \text { of } \\
\text { Total }\end{array}$ \\
\hline IncCounty & 2701 & $100 \%$ & 0 & $0 \%$ & 0 & $0 \%$ & 2701 & $100 \%$ \\
\hline PerpNumber & 2701 & $100 \%$ & 0 & $0 \%$ & 27 & $1 \%$ & 2674 & $99 \%$ \\
\hline PerpSex & 2700 & $100 \%$ & 1 & $0 \%$ & 18 & $1 \%$ & 2682 & $99 \%$ \\
\hline IncReportDate & 2698 & $100 \%$ & 3 & $0 \%$ & 0 & $0 \%$ & 2698 & $100 \%$ \\
\hline SurvSex & 2696 & $100 \%$ & 5 & $0 \%$ & 0 & $0 \%$ & 2696 & $100 \%$ \\
\hline IncType & 2692 & $100 \%$ & 9 & $0 \%$ & 13 & $0 \%$ & 2679 & $99 \%$ \\
\hline SurvAge & 2689 & $100 \%$ & 12 & $0 \%$ & 3 & $0 \%$ & 2686 & $99 \%$ \\
\hline CaseFirstReportedTo & 2677 & $99 \%$ & 24 & $1 \%$ & 0 & $0 \%$ & 2677 & $99 \%$ \\
\hline IncTown & 2665 & $99 \%$ & 36 & $1 \%$ & 2 & $0 \%$ & 2663 & $99 \%$ \\
\hline IncDate & 2593 & $96 \%$ & 108 & $4 \%$ & 161 & $6 \%$ & 2432 & $90 \%$ \\
\hline IncTimeOfDay & 2584 & $96 \%$ & 117 & $4 \%$ & 77 & $3 \%$ & 2507 & $93 \%$ \\
\hline PerpRelationship & 2538 & $94 \%$ & 163 & $6 \%$ & 134 & $5 \%$ & 2404 & $89 \%$ \\
\hline PerpAge & 2476 & $92 \%$ & 225 & $8 \%$ & 119 & $5 \%$ & 2357 & $87 \%$ \\
\hline SurvivorReferralCode & 2278 & $84 \%$ & 423 & $16 \%$ & 0 & $0 \%$ & 2278 & $84 \%$ \\
\hline MedicalFormProvided & 2058 & $76 \%$ & 643 & $24 \%$ & 0 & $0 \%$ & 2058 & $76 \%$ \\
\hline TypeOfMedCareProvided & 1919 & $71 \%$ & 782 & $29 \%$ & 0 & $0 \%$ & 1919 & $71 \%$ \\
\hline SurvHasDisabiliity & 1442 & $53 \%$ & 1259 & $47 \%$ & 0 & $0 \%$ & 1442 & $53 \%$ \\
\hline PerpOccupation & 1340 & $50 \%$ & 1361 & $50 \%$ & 158 & $12 \%$ & 1182 & $44 \%$ \\
\hline PerpArrested & 1320 & $49 \%$ & 1381 & $51 \%$ & 7 & $1 \%$ & 1313 & $49 \%$ \\
\hline IncDistrict & 1243 & $46 \%$ & 1458 & $54 \%$ & 0 & $0 \%$ & 1243 & $46 \%$ \\
\hline CaseHealthCareProvider & 1242 & $46 \%$ & 1459 & $54 \%$ & 0 & $0 \%$ & 1242 & $46 \%$ \\
\hline CasePoliceStation & 1203 & $45 \%$ & 1498 & $55 \%$ & 1 & $0 \%$ & 1202 & $45 \%$ \\
\hline CaseSentToCourt & 1164 & $43 \%$ & 1537 & $57 \%$ & 0 & $0 \%$ & 1164 & $43 \%$ \\
\hline CasePshychosocial & 1010 & $37 \%$ & 1691 & $63 \%$ & 0 & $0 \%$ & 1010 & $37 \%$ \\
\hline PrevReported & 990 & $37 \%$ & 1711 & $63 \%$ & 0 & $0 \%$ & 990 & $37 \%$ \\
\hline ResultOfHearing & 820 & $30 \%$ & 1881 & $70 \%$ & 24 & $3 \%$ & 796 & $29 \%$ \\
\hline SurvNumDependents & 721 & $27 \%$ & 1980 & $73 \%$ & 1 & $0 \%$ & 720 & $27 \%$ \\
\hline DaysInSafeHouse & 659 & $24 \%$ & 2042 & $76 \%$ & 21 & $3 \%$ & 638 & $24 \%$ \\
\hline CaseLegal & 488 & $18 \%$ & 2213 & $82 \%$ & 0 & $0 \%$ & 488 & $18 \%$ \\
\hline CaseSafeHouse & 453 & $17 \%$ & 2248 & $83 \%$ & 0 & $0 \%$ & 453 & $17 \%$ \\
\hline CaseEmpowerment & 438 & $16 \%$ & 2263 & $84 \%$ & 0 & $0 \%$ & 438 & $16 \%$ \\
\hline
\end{tabular}

Note: Total numbers recorded in May included incidences occurring in December 2012 but were reported sometime in 2013. 
Table 7.4: Characteristics of Gender Violence Reported to Ministry of Gender in 2013

\begin{tabular}{|c|c|c|}
\hline Indicator & Number & Percentage \\
\hline \multicolumn{3}{|l|}{ Incident Type } \\
\hline Community Violence & 13 & $0.6 \%$ \\
\hline Domestic Violence & 513 & $23.3 \%$ \\
\hline Emotional Abuse & 5 & $0.2 \%$ \\
\hline Neglect & 71 & $3.2 \%$ \\
\hline Rape & 1378 & $62.7 \%$ \\
\hline Sexual Exploitation and Abuse & 199 & $9.1 \%$ \\
\hline Trafficking & 19 & $0.9 \%$ \\
\hline Total & 2198 & $100.0 \%$ \\
\hline \multicolumn{3}{|l|}{ Case First Reported To } \\
\hline Community Member & 100 & $4.5 \%$ \\
\hline Court & 27 & $1.2 \%$ \\
\hline Family Member & 61 & $2.7 \%$ \\
\hline Health Care & 609 & $27.4 \%$ \\
\hline Ministry of Gender & 58 & $2.6 \%$ \\
\hline Non-Governmental Organisation & 158 & $7.1 \%$ \\
\hline Police & 1213 & $54.5 \%$ \\
\hline Total & 2226 & $100.0 \%$ \\
\hline \multicolumn{3}{|c|}{ Perpetrator Age } \\
\hline $1-18$ & 220 & $25.3 \%$ \\
\hline $19-25$ & 148 & $17.0 \%$ \\
\hline $26-35$ & 219 & $25.1 \%$ \\
\hline $36-45$ & 199 & $22.8 \%$ \\
\hline $46-55$ & 65 & $7.5 \%$ \\
\hline $55+$ & 20 & $2.3 \%$ \\
\hline Total & 871 & $100.0 \%$ \\
\hline \multicolumn{3}{|c|}{ Perpetrator Adult/Minor } \\
\hline Adult & 1540 & $77.6 \%$ \\
\hline Minor & 444 & $22.4 \%$ \\
\hline Total & 1984 & $100.0 \%$ \\
\hline \multicolumn{3}{|c|}{ Perpetrator Sex } \\
\hline Male & 2166 & $96.4 \%$ \\
\hline Female & 75 & $3.3 \%$ \\
\hline Both & 5 & $0.2 \%$ \\
\hline Total & 2246 & $100.0 \%$ \\
\hline \multicolumn{3}{|c|}{ Perpetrator's Relationship to Survivor } \\
\hline Community & 151 & $9.8 \%$ \\
\hline Family & 484 & $31.6 \%$ \\
\hline Friend & 42 & $2.7 \%$ \\
\hline Neighbour & 629 & $41.0 \%$ \\
\hline Partner & 227 & $14.8 \%$ \\
\hline Total & 1533 & $100.0 \%$ \\
\hline \multicolumn{3}{|c|}{$\frac{1}{\text { Survivor Age }}$} \\
\hline $0-5$ & 179 & $8.0 \%$ \\
\hline $5-10$ & 340 & $15.2 \%$ \\
\hline $10-15$ & 719 & $32.2 \%$ \\
\hline $15-20$ & 410 & $18.4 \%$ \\
\hline $20-25$ & 181 & $8.1 \%$ \\
\hline $25-30$ & 156 & $7.0 \%$ \\
\hline $30-35$ & 115 & $5.2 \%$ \\
\hline $35-40$ & 73 & $3.3 \%$ \\
\hline $40-45$ & 28 & $1.3 \%$ \\
\hline $45-50$ & 15 & $0.7 \%$ \\
\hline $50-55$ & 7 & $0.3 \%$ \\
\hline $55-60$ & 2 & $0.1 \%$ \\
\hline$>60$ & 5 & $0.2 \%$ \\
\hline Total & 2230 & $100.0 \%$ \\
\hline \multicolumn{3}{|c|}{ Survivor Adult/Minor } \\
\hline Adult & 671 & $30.0 \%$ \\
\hline Minor & 1567 & $70.0 \%$ \\
\hline Total & 2238 & $100.0 \%$ \\
\hline \multicolumn{3}{|c|}{ Survivor Sex } \\
\hline Female & 2155 & $96.3 \%$ \\
\hline Male & 83 & $3.7 \%$ \\
\hline
\end{tabular}




\begin{tabular}{|c|c|c|}
\hline Total & 2238 & $100.0 \%$ \\
\hline \multicolumn{3}{|c|}{ Survivor Received Medical Care } \\
\hline Yes & 1406 & $87.9 \%$ \\
\hline No & 194 & $12.1 \%$ \\
\hline Total & 1600 & $100.0 \%$ \\
\hline \multicolumn{3}{|c|}{ Survivor Received Legal Aid } \\
\hline Yes & 250 & $60.4 \%$ \\
\hline No & 164 & $39.6 \%$ \\
\hline Total & 414 & $100.0 \%$ \\
\hline \multicolumn{3}{|c|}{ Survivor Received Empowerment Services } \\
\hline Yes & 193 & $51.5 \%$ \\
\hline No & 182 & $48.5 \%$ \\
\hline Total & 375 & $100.0 \%$ \\
\hline \multicolumn{3}{|c|}{ Days In Safe House } \\
\hline $1+$ & 167 & $28.8 \%$ \\
\hline None & 412 & $71.2 \%$ \\
\hline Total & 579 & $100.0 \%$ \\
\hline \multicolumn{3}{|c|}{ Case Sent to Court } \\
\hline Yes & 546 & $53.6 \%$ \\
\hline No & 473 & $46.4 \%$ \\
\hline Total & 1019 & $100.0 \%$ \\
\hline
\end{tabular}

Table 7.5: Age-Sex Contingency Table

\begin{tabular}{|c|c|c|c|c|c|c|c|c|}
\hline & \multicolumn{7}{|c|}{ Survivors } \\
\hline & & \multicolumn{3}{|c|}{ Female } & \multicolumn{3}{|c|}{ Male } & \multirow[b]{2}{*}{ Grand Total } \\
\hline Perpetrators & & Adult & Minor & Total & Adult & Minor & Total & \\
\hline \multirow[t]{3}{*}{ Male } & & 549 & 1297 & 1846 & 14 & 46 & 60 & 1906 \\
\hline & Adult & 547 & 884 & 1431 & 14 & 31 & 45 & 1476 \\
\hline & Minor & 2 & 413 & 415 & & 15 & 15 & 430 \\
\hline \multirow[t]{3}{*}{ Female } & & 8 & 39 & 47 & 7 & 12 & 19 & 66 \\
\hline & Adult & 8 & 27 & 35 & 7 & 12 & 19 & 54 \\
\hline & Minor & & 12 & 12 & & & & 12 \\
\hline Grand Total & & 557 & 1336 & 1893 & 21 & 58 & 79 & 1972 \\
\hline
\end{tabular}




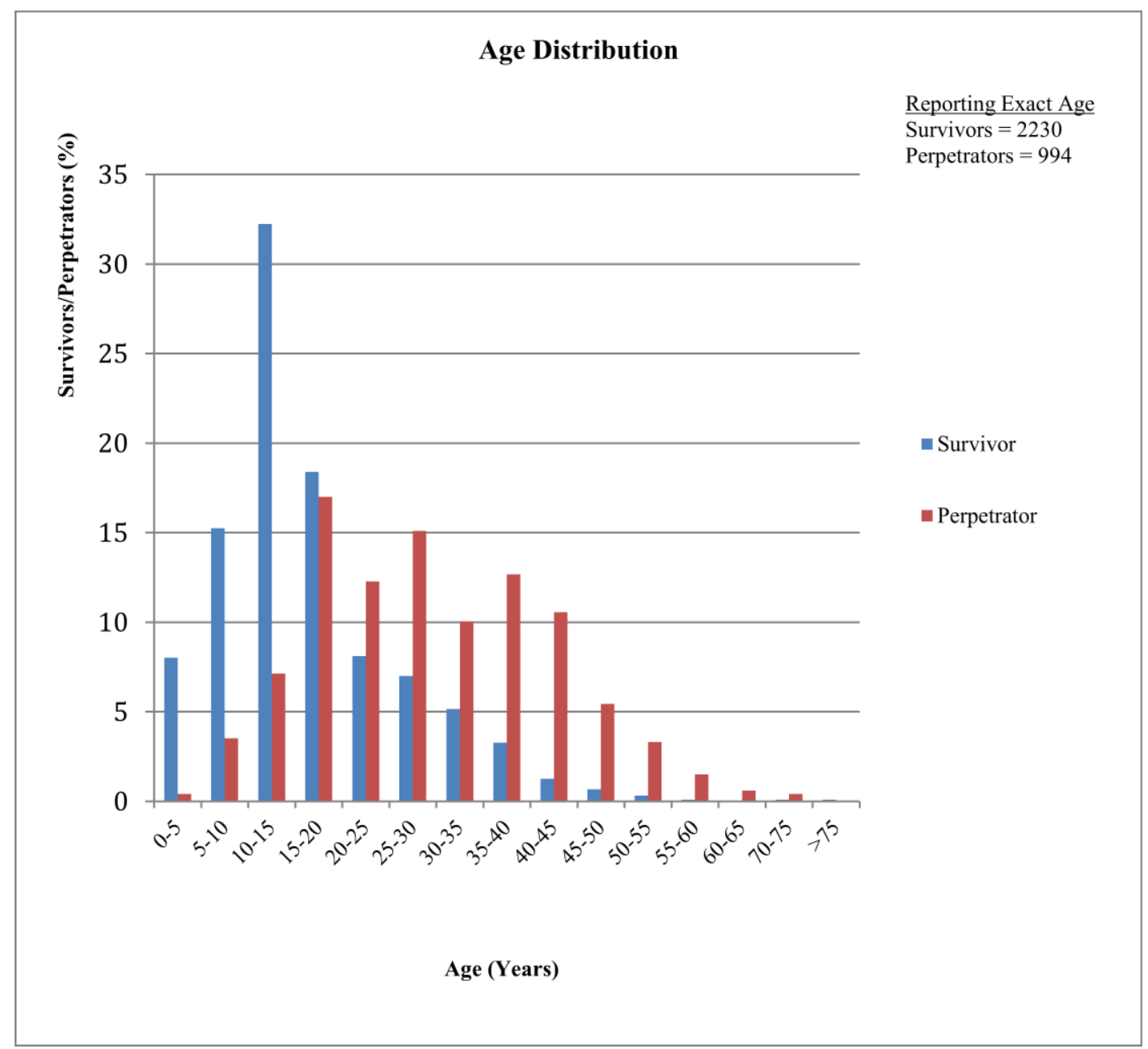

Figure 7.4: Age distribution of survivors and perpetrators of sexual and domestic violence 
Table 7.6: Longitudinal Study of Indigenous Children Respondents' Experiences of Adoption, Homelessness, Racism and Bullying

\begin{tabular}{|c|c|c|c|}
\hline $\begin{array}{l}\text { Wave 1: Base Rates } \\
(\mathbf{2 0 0 8 )}\end{array}$ & $N=1687$ & Wave 2: Stolen Generation (2009) & $N=1436$ \\
\hline \multirow[t]{2}{*}{ Age (Months) } & \multirow[t]{2}{*}{$\#(\%$} & Description & $\#(\%)$ \\
\hline & & Primary parents* & 1000 \\
\hline $0-5$ & $15(0.8)$ & Not prepared to answer the questions & $425(42.5)$ \\
\hline $6-18$ & $677(40.1)$ & Didn't answer & $98(9.8)$ \\
\hline $19-30$ & $272(16.1)$ & & \\
\hline $31-41$ & $37(2.2)$ & Of the 1000 respondent... & $\#(\%)$ \\
\hline $42-54$ & $497(29.5)$ & Yes, self or relative taken & $520(52)$ \\
\hline+55 & $189(11.2)$ & No relative taken & $350(35)$ \\
\hline Missing & 1 & & \\
\hline \multirow[t]{2}{*}{ Total } & $1687(99.9)$ & Don't know & $120(12)$ \\
\hline & & Other & $10(1)$ \\
\hline Gender & $\#(\%)$ & & \\
\hline Female & $860(51.0)$ & Which primary carer's relatives were taken away? & $\#(\%)$ \\
\hline Male & $827(49.0)$ & Self & $26(3.6)$ \\
\hline \multirow[t]{2}{*}{ Total } & $1687(100)$ & Partner & $10(1.4)$ \\
\hline & & Own children & $4(0.6)$ \\
\hline Region & $\#(\%)$ & Mother & $81(11.1)$ \\
\hline Major cities & $439(26.0)$ & Father & $53(7.2)$ \\
\hline Inner regional & $428(25.4)$ & Siblings & $24(3.3)$ \\
\hline Outer regional & $227(13.5)$ & Grandparents (mother/father) & $277(37.9)$ \\
\hline Remote & $256(15.2)$ & Great-grandparents & $72(9.8)$ \\
\hline Very remote & $337(20.0)$ & $\begin{array}{l}\text { Aunts, uncles, cousins, nieces, nephews, and other } \\
\text { family members }\end{array}$ & $185(25.3)$ \\
\hline Total & $1687(100)$ & Total & $732 * *(100)$ \\
\hline $\begin{array}{l}\text { Wave 3: Homelessness } \\
\text { and Racism (2012) }\end{array}$ & $\mathrm{N}=1404$ & Wave 5: Bullying (2015) & $\mathrm{N}=1258$ \\
\hline $\begin{array}{l}\text { No experience of } \\
\text { homelessness in } 5 \text { years } \\
\text { before interview }\end{array}$ & $1279(91.1)$ & $\begin{array}{l}\text { Study child was bullied at school+ } \\
\text { Preschool (A) } \\
\text { Preschool (NA) } \\
\text { Pre-Year } 1 \text { (A) } \\
\text { Pre-Year } 1 \text { (NA) } \\
\text { Year } 1 \text { (A) } \\
\text { Year } 1 \text { (NA) } \\
\text { Year } 2 \text { (A) } \\
\text { Year } 2 \text { (NA) } \\
\text { Year } 3 \text { (A) } \\
\text { Year } 3 \text { (NA) }\end{array}$ & $\begin{array}{l}\#(\%) \\
728(-) \\
135(-) \\
812(19.9) \\
181(27.7) \\
548(24.8) \\
100(31.6) \\
430(32.1) \\
75(35.7) \\
191(29.3) \\
28(48.1) \\
\end{array}$ \\
\hline $\begin{array}{l}\text { Experienced } \\
\text { homelessness in } 5 \text { years } \\
\text { before interview }\end{array}$ & $70(5.0)$ & $\begin{array}{l}\text { Study child bullied at school for being Indigenous+ } \\
\text { Preschool (A) } \\
\text { Preschool (NA) } \\
\text { Pre-Year } 1 \text { (A) } \\
\text { Pre-Year } 1 \text { (NA) } \\
\text { Year } 1 \text { (A) } \\
\text { Year } 1 \text { (NA) } \\
\text { Year } 2 \text { (A) } \\
\text { Year } 2 \text { (NA) } \\
\text { Year } 3 \text { (A) } \\
\text { Year } 3 \text { (NA) }\end{array}$ & $\begin{array}{l}\#(\%) \\
728(4.6) \\
135(4.6) \\
812(9.4) \\
181(9.3) \\
548(7.8) \\
100(12.1) \\
430(8.7) \\
75(20.7) \\
191(-) \\
28(-) \\
\end{array}$ \\
\hline Not stated & $55(3.9)$ & Total & 3228 \\
\hline
\end{tabular}

N.B.: Region: Based on an indicator of the level of relative isolation (LORI) as developed in the Western Australian Aboriginal Child Health Survey. LORI is an extension of the 18-point ARIA (Accessibility/Remoteness Index of Australia) called ARIA++.

* Primary parents, mostly mothers, asked if they are willing to answer questions about Stolen Generations

** Total is higher than the total of primary carers responding as more than one category of relative may have been affected.

$+\mathrm{A}=$ attended every day; $\mathrm{NA}=$ not attended every day 
Table 7.7: Summary of Survey Responses

\begin{tabular}{|c|c|c|c|c|c|}
\hline Australia & $\#$ & $\%$ & Liberia & \# & $\%$ \\
\hline Total & 154 & 100 & Total & 77 & 100.00 \\
\hline Sex & \# & $\%$ & Sex & $\#$ & $\%$ \\
\hline Transgender & 1 & 0.65 & Transgender & 0 & 0.00 \\
\hline Male & 10 & 6.49 & Male & 66 & 84.62 \\
\hline Female & 42 & 27.27 & Female & 12 & 15.38 \\
\hline Other & 1 & 0.65 & Other & 0 & 0.00 \\
\hline No answer & 0 & 0 & No answer & 0 & 0.00 \\
\hline Not completed & 100 & 64.94 & Not completed & 0 & 0.00 \\
\hline Age range (years) & $\#$ & $\%$ & Age range (years) & $\#$ & $\%$ \\
\hline $18-25$ & 2 & 1.3 & $18-25$ & 1 & 1.28 \\
\hline $26-35$ & 8 & 5.19 & $26-35$ & 25 & 32.05 \\
\hline $36-45$ & 12 & 7.79 & $36-45$ & 30 & 38.46 \\
\hline $46-55$ & 16 & 10.39 & $46-55$ & 16 & 20.51 \\
\hline $55+$ & 16 & 10.39 & $55+$ & 5 & 6.41 \\
\hline Other & 0 & 0 & Other & 0 & 0.00 \\
\hline No answer & 0 & 0 & No answer & 1 & 1.28 \\
\hline Not completed & 100 & 64.94 & Not completed & 0 & 0.00 \\
\hline Religious affiliation & \# & $\%$ & Religious affiliation & $\#$ & $\%$ \\
\hline Christian & 20 & 12.99 & Christian & 72 & 92.31 \\
\hline Muslim & 0 & 0 & Muslim & 1 & 1.28 \\
\hline $\begin{array}{l}\text { Aboriginal/Indigenous } \\
\text { Religion }\end{array}$ & 9 & 5.84 & Aboriginal/Indigenous Religion & 0 & 0.00 \\
\hline Other & 25 & 16.23 & Other & 2 & 2.56 \\
\hline No answer & 0 & 0 & No answer & 2 & 2.56 \\
\hline Not completed & 100 & 64.94 & Not completed & 0 & 0.00 \\
\hline Profession & \# & $\%$ & Profession & \# & $\%$ \\
\hline Lawyer & 5 & 3.25 & Lawyer & 9 & 11.54 \\
\hline Judge & 0 & 0 & Judge & 3 & 3.85 \\
\hline Law enforcement officer & 2 & 1.3 & Law enforcement officer & 5 & 6.41 \\
\hline Community leader/head & 3 & 1.95 & Community leader/head & 4 & 5.13 \\
\hline Researcher & 4 & 2.6 & Researcher & 7 & 8.97 \\
\hline Prison staff & 4 & 2.6 & Prison staff & 1 & 1.28 \\
\hline Healthcare provider & 7 & 4.55 & Healthcare provider & 16 & 20.51 \\
\hline Counsellor & 5 & 3.25 & Counsellor & 5 & 6.41 \\
\hline Teacher Advocate & 5 & 3.25 & Teacher Advocate & 9 & 11.54 \\
\hline Traditional elder & 1 & 0.65 & Traditional elder & 1 & 1.28 \\
\hline Religious leader & 0 & 0 & Religious leader & 0 & 0.00 \\
\hline Other & 17 & 11.04 & Other & 17 & 21.79 \\
\hline No answer & 0 & 0 & No answer & 1 & 1.28 \\
\hline Not completed & 101 & 65.58 & Not completed & 0 & 0.00 \\
\hline $\begin{array}{c}\text { Length of work experience } \\
\text { (Years) }\end{array}$ & \# & $\%$ & $\begin{array}{c}\begin{array}{c}\text { Length of work experience } \\
\text { (Years) }\end{array} \\
\end{array}$ & $\#$ & $\%$ \\
\hline $0-5$ years & 9 & 5.84 & $0-5$ years & 39 & 50.00 \\
\hline $6-10$ years & 11 & 7.14 & $6-10$ years & 26 & 33.33 \\
\hline $11-20$ years & 19 & 12.34 & $11-20$ years & 9 & 11.54 \\
\hline $20+$ years & 14 & 9.09 & $20+$ years & 4 & 5.13 \\
\hline No answer & 0 & 0 & No answer & 0 & 0.00 \\
\hline Not completed & 101 & 65.58 & Not completed & 0 & 0.00 \\
\hline
\end{tabular}




\begin{tabular}{|c|c|c|c|c|c|}
\hline Area of work & $\#$ & $\%$ & Area of work & & \\
\hline Health and Wellness & 12 & 7.79 & Health and Wellness & 27 & 34.62 \\
\hline Education & 8 & 5.19 & Education & 22 & 28.21 \\
\hline Native Title/Land Claims & 0 & 0 & Native Title/Land Claims & 1 & 1.28 \\
\hline Legal/Paralegal & 13 & 8.44 & Legal/Paralegal & 19 & 24.36 \\
\hline Policy & 1 & 0.65 & Policy & 1 & 1.28 \\
\hline Employment & 2 & 1.3 & Employment & 0 & 0.00 \\
\hline Arts and Culture & 0 & 0 & Arts and Culture & 0 & 0.00 \\
\hline $\mathrm{R} \& \mathrm{D}$ & 3 & 1.95 & $\mathrm{R} \& \mathrm{D}$ & 3 & 3.85 \\
\hline Housing & 1 & 0.65 & Housing & 0 & 0.00 \\
\hline Other & 13 & 8.44 & Other & 4 & 5.13 \\
\hline No answer & 0 & 0 & No answer & 1 & 1.28 \\
\hline Not completed & 101 & 65.58 & Not completed & 0 & 0.00 \\
\hline Location & & & Location & & \\
\hline $\mathrm{ACT}$ & 11 & 7.14 & Nimba & 20 & 25.64 \\
\hline NSW & 10 & 6.49 & Monsterrado & 24 & 30.77 \\
\hline NT & 6 & 3.90 & Maryland & 18 & 23.08 \\
\hline WA & 12 & 7.79 & Lofa & 10 & 12.82 \\
\hline VIC & 2 & 1.30 & Grand Gedeh & 5 & 6.41 \\
\hline SA & 2 & 1.30 & No answer & 0 & 0.00 \\
\hline QLD & 5 & 3.25 & Not completed & 0 & 0.00 \\
\hline No answer & 0 & 0.00 & & & \\
\hline Not completed & 106 & 68.83 & & & \\
\hline
\end{tabular}

Table 7.8: Responses to Survey Questions on Whether the Law is Helpful or Just?

\begin{tabular}{|c|c|c|c|c|c|c|c|c|}
\hline \multirow[b]{2}{*}{ Question } & \multicolumn{4}{|c|}{ Australia } & \multicolumn{4}{|c|}{ Liberia } \\
\hline & $\begin{array}{l}\text { Yes } \\
(\%)\end{array}$ & No $(\%)$ & $\begin{array}{c}\text { Blank } \\
(\%)\end{array}$ & Total & $\begin{array}{l}\text { Yes } \\
(\%)\end{array}$ & No $(\%)$ & $\begin{array}{c}\text { Blank } \\
(\%)\end{array}$ & $\begin{array}{c}\text { Total } \\
(\%)\end{array}$ \\
\hline $\begin{array}{l}\text { Is the law helpful in the } \\
\text { specific work that you do } \\
\text { on violence against } \\
\text { Aboriginal girls and } \\
\text { women? }\end{array}$ & $32(21)$ & $22(14)$ & $100(65)$ & $154(100)$ & $41(53)$ & $13(17)$ & $24(31)$ & $78(100)$ \\
\hline $\begin{array}{l}\text { Is the legal system just } \\
\text { toward Aboriginal girls } \\
\text { and women? }\end{array}$ & $13(8)$ & $40(26)$ & 101 (66) & $154(100)$ & $34(44)$ & $20(26)$ & $24(31)$ & $78(100)$ \\
\hline $\begin{array}{l}\text { Does customary law have } \\
\text { a role to play in } \\
\text { addressing violence } \\
\text { against Indigenous girls } \\
\text { and women? }\end{array}$ & $42(27)$ & $12(8)$ & $100(65)$ & $154(100)$ & $58(74)$ & $16(21)$ & $4(5)$ & $78(100)$ \\
\hline $\begin{array}{l}\text { Does the local community } \\
\text { have a role to play in } \\
\text { addressing violence } \\
\text { against Indigenous girls } \\
\text { and women? }\end{array}$ & $53(34)$ & $1(1)$ & $100(65)$ & $154(100)$ & $71(91)$ & $0(0)$ & $7(9)$ & $78(100)$ \\
\hline
\end{tabular}

N.B.: The columns with "Blank" headings indicate numbers and percentages of service providers who provided no responses. 
Table 7.9: Aboriginal Women Advocates Interviewed in Australia

\begin{tabular}{|l|l|l|l|l|l|l|l|l|}
\hline$\#$ & Mode & DOB & Location & Relationship & $\begin{array}{c}\text { Highest } \\
\text { Education }\end{array}$ & $\begin{array}{c}\text { Indigenous } \\
\text { Group }\end{array}$ & $\begin{array}{c}\text { Religion } \\
\text { Status }\end{array}$ \\
\hline 1 & In person & 1953 & ACT & Married & Year 4 & $\begin{array}{l}\text { Aboriginal } \\
\text { Wiradjuri }\end{array}$ & Christian & Full-time \\
\hline 2 & Paper & 1957 & ACT & Married & Ph.D. (c) & Cadigal & $\begin{array}{l}\text { Latter Day } \\
\text { Saints }\end{array}$ & Full-time \\
\hline 3 & In person & 1960 & ACT & Single & Ph.D. (c) & $\begin{array}{l}\text { Aboriginal } \\
\text { Bundalung }\end{array}$ & $\begin{array}{l}\text { Free Spirit } \\
\text { Dimension }\end{array}$ & Full-time \\
\hline 4 & Phone & 1960 & NSW & Married & Ph.D. & $\begin{array}{l}\text { Eualeyai / } \\
\text { Kamillaroi }\end{array}$ & Catholic & Full-time \\
\hline 5 & In person & 1958 & ACT & Single & Ph.D. (c) & Wakka, Wulli & $\begin{array}{l}\text { Aboriginal } \\
\text { Spirituality }\end{array}$ & Full-time \\
\hline 6 & In person & 1960 & ACT & Married & Ph.D. & $\begin{array}{l}\text { Ngarigu- } \\
\text { Snowy Mts }\end{array}$ & $\begin{array}{l}\text { Church of } \\
\text { England }\end{array}$ & Full-Time \\
\hline 7 & Phone & 1958 & NT & De Facto & Ph.D. & No Mob & No Religion & Unemployed \\
\hline
\end{tabular}

Table 7.10: Indigenous Women Advocates Interviewed in Liberia

\begin{tabular}{|c|c|c|c|c|c|c|c|c|}
\hline$\#$ & Mode & DOB & Location & $\begin{array}{l}\text { Relationshi } \\
\text { p }\end{array}$ & $\begin{array}{l}\text { Highest } \\
\text { Education }\end{array}$ & $\begin{array}{l}\text { Indigenous } \\
\text { Group }\end{array}$ & Religion & $\begin{array}{l}\text { Employment } \\
\text { Status }\end{array}$ \\
\hline 1 & In person & -- & $\mathrm{Nimb}$ & Married & Elementary & Gio & Catholic & Part-time/Vol \\
\hline 2 & In person & 1965 & $\mathrm{Nimb}$ & Married & College & Gio & Christian & Full-time \\
\hline 3 & On phone & 1968 & Lofa & Married & University & Kissi & Catholic & Full-time \\
\hline 4 & In person & 1966 & Lofa & Abandoned & Adult Literacy & Lorma & Christian & $\begin{array}{l}\text { Self- } \\
\text { employed/Vol }\end{array}$ \\
\hline 5 & In person & 1967 & Mont & $\begin{array}{l}\text { Legally } \\
\text { single }\end{array}$ & Masters & Kru & Catholic & Full-time \\
\hline 6 & In person & 1976 & Mary & Single & High Sch & Grebo & Christian & Full-time \\
\hline 7 & In person & 1978 & Mary & Single & University & Grebo & Christian & Full-time \\
\hline 8 & In person & 1956 & Mont & Married & University & Vai & Christian & Full-time \\
\hline 9 & In person & 1963 & Mont & Married & University & Kru & Christian & Full-time \\
\hline 10 & In person & 1947 & Mont & Married & Masters & Gbandi & Christian & Full-time \\
\hline 11 & In person & 1975 & Mont & Single & Masters & Kpelle & $\begin{array}{l}\text { Christian / } \\
\text { Traditionalist }\end{array}$ & Full-time \\
\hline 12 & In person & 1978 & Mont & Single & Lawyer & $\begin{array}{l}\text { Gola, Grebo } \\
\text { Krahn \& A- } \\
\text { L }\end{array}$ & Christian & Full-time \\
\hline 13 & In Person & 1974 & Mont & Married & Masters & Lorma & Christian & Full-time \\
\hline 14 & In person & $?$ & Mont & Single & Adult Literacy & Kissi & Christian & Full-time \\
\hline 15 & In person & 1962 & Mont & Single & University & Lorma & Christian & Full-time \\
\hline 16 & In person & 1959 & Mont & Married & Master of Law & Mandingo & Christian & Full-time \\
\hline 17 & In person & 1971 & Mont & Married & University & Gola & Christian & Full-time \\
\hline 18 & In person & 1970 & Mont & Married & Masters & Gola & Christian & Self-employed \\
\hline 19 & In person & 1968 & Mont & Single & Law Graduate & $\begin{array}{l}\text { Vai \& } \\
\text { Grebo }\end{array}$ & Christian & Full-time \\
\hline 20 & In person & 1979 & Mont & Married & Law Graduate & Grebo & Christian & Full-time \\
\hline 21 & In-person & 1948 & Mary & Divorce & College & Grebo & LDS & Part-time \\
\hline
\end{tabular}

Key: Vol = Volunteers, A-L = Americo-Liberia; LDS = Church of Jesus Christ of Latter Day Saints 


\begin{tabular}{|c|c|}
\hline LIBERIA & AUSTRALIA \\
\hline $\begin{array}{l}\text { 1. Why is the law helpful? (47) } \\
\text { 'Rcessible and effective with protection and punishment (22) } \\
\text { 'Rape is a non-bailable crime in Liberia. Several have gone to jail, and so that tells that a legal system is doing everything to } \\
\text { protect girls and women.' } \\
\text { 'Personally, it is still or diffical system but there are efforots to make it better for women because our president is a woman. In the past, } \\
\text { 'Pomen always had to fight for their rights, property etc. Now there is awareness around. Women are now knowledgeable about } \\
\text { their rights. For now, we are better. It's getting somewhere.' } \\
\text { S Supportive and receptive (5) } \\
\text { 'The magistrates here are quite receptive to our concerns.' } \\
\text { Public education and awareness (4) } \\
\text { 'The government has done lots of education on the rape law.' } \\
\text { Enhanced reporting (4) } \\
\text { 'Even though we lack forensic labs for providing hard evidence, more people are reporting such crime, and the perpetrators are not } \\
\text { being punished.' }\end{array}$ & 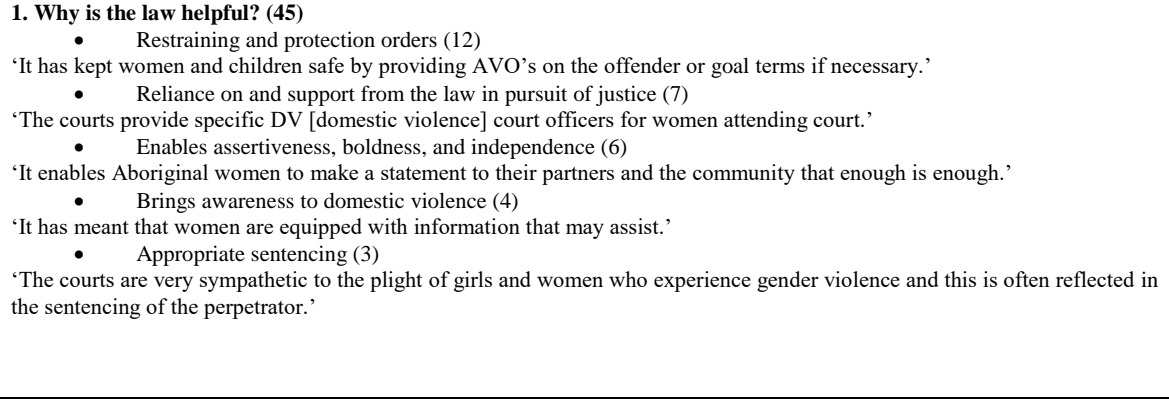 \\
\hline $\begin{array}{l}\text { 2. Why is the law unhelpful? (87) } \\
\text { Poor implementation, ineffective and inaccessible (31) } \\
\text { 'The problem is with the judges. When we send cases to court, it will delay until the person is freed. Sometimes the rape suspects } \\
\text { are usually freed. You can't keep suspect for six months or one year. When someone commits a crime, he's supposed to be } \\
\text { punished. So, it is not right.' } \\
\text { The legal system is corrupt, exploitative and abusive (19) } \\
\text { 'Sometimes the willingness of the relatives compromising the cases because they are implicated. If there is a law to prevent case } \\
\text { compromising, it would be good. In Liberia, if you don't have money you may not get legal redress.' } \\
\text { Conflict with traditional system and social norms (11) } \\
\text { 'The Rape Law } 2005 \text { says any child under the age of } 18 \text { is statutory rape. But we have a customary law in the rural area, which } \\
\text { says } 16 \text { years and above are able to marry. There is a need to harmonise the two laws. The rape law supersedes all the customary } \\
\text { law so you're still liable.' } \\
\text { The law is unfair (to boys and men) (7) } \\
\text { 'New Rape Law is too severe and incoherent with Indigenous cultures thereby deterring SGBV survivors and their families from } \\
\text { prosecution.' }\end{array}$ & 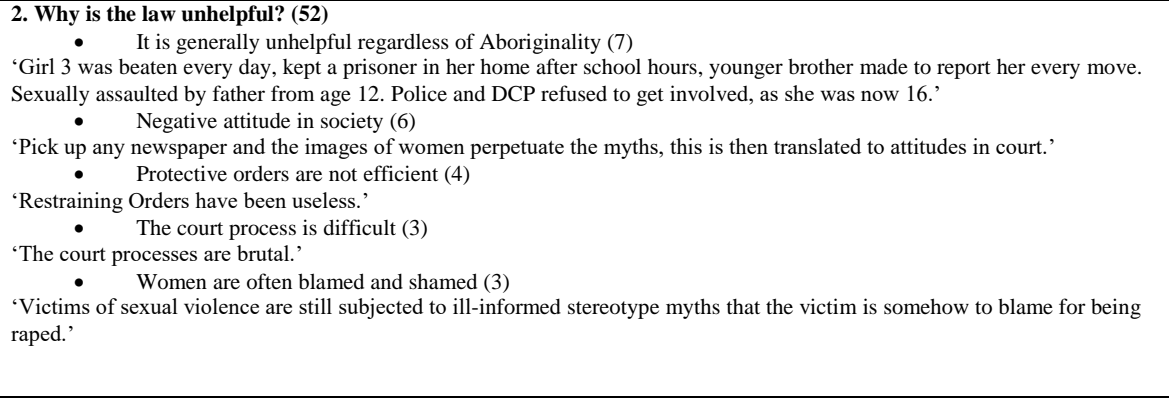 \\
\hline 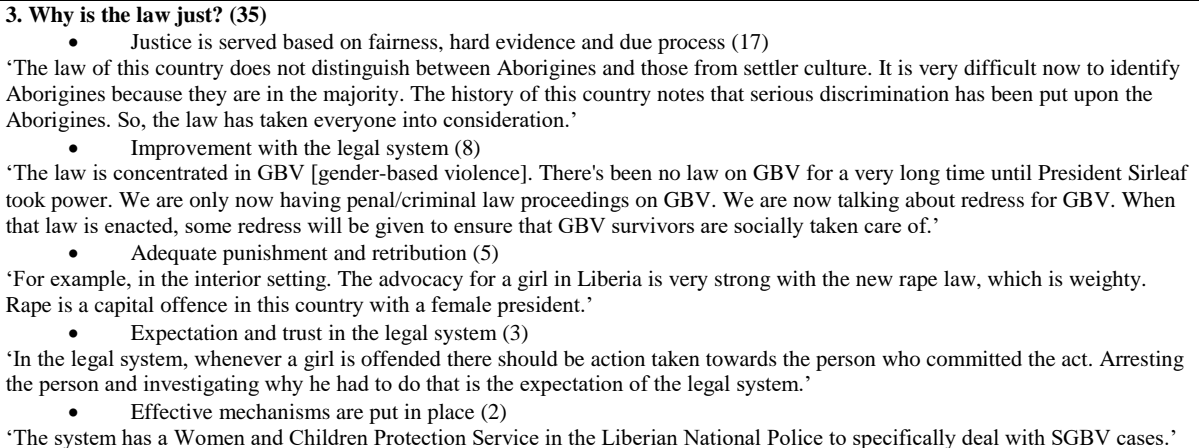 & $\begin{array}{l}\text { 3. Why is the law just? (9) } \\
\text { Justice is served to all (4) } \\
\text { 'It is my experience that offenders are remanded based on circumstances rather than race.' } \\
\text { 'Oerpetrators are punished (2) } \\
\text { 'Offenders have been remanded in custody to prevent further violence.' } \\
\text { 'In the eyes of the law, Abotection under the law (2) } \\
\text { women.' } \\
\text { 'Therls and women experiencing gender violence are treated equally with all other girls and } \\
\text { 'Teduction in violence against women (1) } \\
\text { (1) minumization of the violence against Indigenous children and women.' }\end{array}$ \\
\hline
\end{tabular}




\section{Why is the law unjust? (136)}

- Inefficient, poor implementation, lack of competence and accountability (33)

'Indigenous women are not adequately protected by the Liberian legal system. Yes, there are laws that may be used to protect the

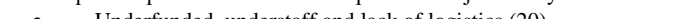

- Underfunded, understaff and lack of logistics (20)
'From our observation, the WACPs are not capacitated. They usually don't have a motorbike or any vehicle for that matter. If they - Corruption and bribery (19)

'I summoned two magistrate judges because they received bribes. One beat a woman - I filed a complaint, and the other was for rape but was illegally released because they claimed there was not enough evidence. The judge had no right to do that and so was fined. The police officer was disrobed for corrupting a rape case in Ganta. Another was a policewoman - the first female commander. She sent officers to put up unauthorised checkpoints for the purpose of collecting money from pempem [commercia Com. We fis a a

Comise and social pressure (15)

cases are not reported to the police because it's been handled in the family way. Even if they try to report they are pressured and suppressed to handle it at the traditional level through mediation."

- Lack of effective protection for children (14)

'The interest of the child is not taken seriously. How can a 51-year old rape a 6-year old? We have the cases where a 14-year old is said to be dating a 40-year old man. I see it to be very ugly. There's no protection.

Equal protection for Indigenous children and women (12)

'The role of the Liberian legal system in protecting Indigenous girls and women who have experienced gender violence is a) equal opportunity; b) equal rights, equal protection and security.

'More female lawyers should be employed to fast-track gender violence cases. Most of the perpetrators are males so maybe that is impacting on the outcome of the case.

Validate and enforce legislation (6)

'More need to be done for new and effective laws including unconditionally executing existing laws.'

Educate and create awareness about the law $(5$

Dispens juctice in a timely fahion (5)

'Cases need to be very punctual and justifiable [or justiciable].

\section{What is the role of the traditiona//Indigenous Customary Laws? (125)}

- $\quad$ No or little role (24)

'The traditional system does not regard women's rights. We'll see that a 16-year old will be given to a 40-year old in marriage. If she refused, she'd be forced to marry him. If we look at female genital mutilation, they force women to cut them, then they say, it's

(n)

'Tditional leaders must be invol in the adjudication of violence against Indigenous girls and women cases.'

'Indigenous law rules in most communities outside Montserrado county. There has to be dialogue with Indigenous leaders as to how these issues need to be dealt with in a manner that is acceptable to the state and the community to provide consistency."

- $\quad$ Prosecute and punish perpetrators (13)

'The Indigenous law should impose fines for violation of GBV but they have limited law on GBV because they feel women and children are the property of men.

'Cases should not remain between family members. It should be reported to the police and the police should also make sure to send these cases to court.'
4. Why is the law unjust? (60)

Discrimination and racism $(9)$

( Unfair to all women $(9)$

don't think the law is just in relation to any girls and women including

'

Whilst the legislation and some specific champions of change in the legal response to Aboriginal girls and women who experience violence have produced opportunities for better protection and stronger outcomes, this is not a universal response and the outcomes for Aboriginal girls and women can still be characterised as ad hoc and chancy."

Failure of the law to connect to past trauma (3)

cone the connection between the past experiences and trauma at the hands of the state against Aboriginal people. Hence the over-representation [of Aboriginal people] in the criminal and out-of-homecare system.'

The legal system isn't well placed to consider alternative responses to those available in the traditional criminal justice system.
For example, Aboriginal women may be more likely to want to engage in conferencing, mediation or restorative justice disputeresolution models that better reflect traditional ways of managing the use of violence in aboriginal communities."

\section{What is the role of the Australian legal system? (66)}

- Think outside the box (18)

'However, increasingly I think the law should be challenged to consider more creative, alternative criminal justice responses that

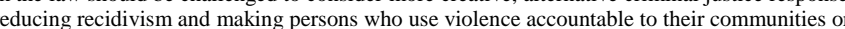

- Protect equally and respond quickly $(10)$

'Treat complaints seriously, address inequities, set standards and make appropriate rulings.'

'Australian legal system anen and children from violence (8) weak and vulnerable is not acceptable in any form- If the law doesn't protect people who will?

- Educate and bring awareness (6)

do more to educte the pers. violent situation.

(2) and reoffending more seriously (2)

\section{What is the role of the Aboriginal customary law? (5}

- $\quad$ Complicated and complex, difficult to say (13)

If Aboriginal customary law had mechanisms in place to deal with violence against women, then it is appropriate to look at hese mechanisms and see if they are appropriate to draw on in helping Aboriginal people deal with the issue of family violence in their communities. It probably depends on whether perpetrators respect Aboriginal customary law and what if the perpetrator

- Accord women and children equal standing in the justice system (7)

An that I think the role of customary law has, but to ensure that women don't experience a lesser form of unt of it.

or aboriginal people who still practice much of their customary law e.g., remote communities need to have both laws considered. Currently, white man law happens then customary happens as well. Whatever works to hold the perpetrators of the

- An alternative to court prosecution (4)

An alternative to prosecution in the courts for offenders. Instructions/chastisement from elders may be more effective than . A

trators respect for customary law (4)

Dertant that the role of Elders in the delivery of traditional lore be seen as an important part of the way in which violence is addressed when women and children have been violated. The most important aspect here is not only the support that Elders
can give but most importantly the integrity of the information given about cultural lore is critical in order to prevent any misus o justify an act of violence by a perpetrato 
7. What is the role of the local community (e.g., home, school, church, mosque, etc.)? (69)

- Promote education and awareness (27)

'The local community firstly has to be aware of issues which violate Indigenous women rights and engage relevant actors for swif actions. Make people aware of the long-term effect especially the adverse effect on women and childre.'

"The local community has the greatest role. They have the responsibility to watch the government and the legal system. They have

- Report violence and abuse $(10)$

They should report SGBV cases to police even where the victim is not a relation. Currently, the local community has served as a

"hindrance" as they have actively helped to "settle" SGBV cases out of court.

- Develop social cohesion through respect for human rights (6)

velop a culture of understanding respecting and practicing hiunan rights.

- Promote girls and women advancement (4)

When men acknowledge that women deserve respect. violence would become a thing of the past.'

\section{Challenges with addressing violence against Indigenous girls and women (76)}

- Implementing evidence-based intervention (12)

How do you give back to the community? What impact do these researches have on the community?'

- Taming and blaming girls and women (10)

Why can't we allow women to fight rather than giving them 30 percent of political seats? Pretty soon we might have the situatio of violence against men, i.e., if we keep on that direction. The drawback is that we are creating many options for women and

- What are the root causes and factors of violence against women? (8)

What is the mental chemistry behind the evolution of all this wicked act of violence against women in the name of tradition and culture? Does it have historical commonalities across all culture? Does it have a spiritual or legal bearing?

- High-quality education needed (5)

'Is the government paying teachers well so that they can teach qualified students who are competent and able to dispense their
responsibitites well?? responsibilities well?

- Cultural class, conflict and confusion (4)

How possible is it to reconcile the age of 18 with that of 14 years. Around the world, 18 years is the age of consent. I didn't think is a good idea for a girl to get married at the age of 14 . To reconcile is to modify the tradition in order to get in with the rest of the

\section{Recommendations on how to improve the law and change attitudes (164)}

Education, dialogue, awareness, and advocacy (31)

toward gender violence against Indigenous girls and women ' chool, by media, by sensitizing the girls and women about the gender violence against them.

- Gender equality - equal opportunity (28)

Equal job opportunity. If you have the same job but get less pay because you're a woman, it's an injustice. The distribution of resources is always unequal to women. I want to see women and men as equal partners. An example is seeing my mom bringing (

'Involving girls/women in decision making (equal rights); premature minds of women as house-keeper should be erased; girls and omen seeing themselves as dependent in the home should be erased by educating them and empowering them.

- Love, peace and harmony (11)

Then homes will be happy, the relationship between women and men will be cordial, and Liberia will boom.'

By leading by examples, demonstrating restraints, self-respect, and integrity, promoting punitive measures against perpetrator and ensuring that victims receive adequate care and suppor.'
7. What is the role of the local community (e.g., home, school, church, etc.)? (80)

Reporting and speaking out against violence (23)

"The local community should be adrinssing vilonce against all members of the community, including and not limited to 作 communities

- Offer practical support (13)

(

Having safe houses within town camps and remote communities that operate 24/7.'

- Educating and knowledge sharing (11)

'Understanding the First Australians (Aboriginals) history. A Whole understanding of our history and ongoing issues. Education having a responsibility too, as in providing the correct history and having an "re labelled as naughty' and things may be happening for his child at home."

gainst Women Collaboration have produced several ads for TV with local men from sport, education, pubs, police and

8. Challenges with addressing violence against Aboriginal girls and women (40)

\section{- The definition of violence against Aboriginal women is too narrow (10)}

I think the topic of gender violence against Aboriginal women and children has often been reduced to 'domestic and family violence' whereas your definition is clearly much broader including state violence, institutional violence, structural violence as well as 'private abuse. I Think your approach is much more realistic and relevant han approaches which mainly or only focus on how Aboriginal women and young people and Aboriginal people generally are able to address these issues - i.e. what power are they accorded, what resources are within the control of Aboriginal people, what policy control do Aboriginal people have, to what extent are Aboriginal people listened to or negotiated with - all of which are major problems as I've indicated in my

responses to some of the previous questions.

- Leaving violent relationships is not an option in renote communities (4)

'Leaving a violent relationship is not an option if the woman is from a remote community, it may mean leaving her country.' Educating young men (4)

oung men and women; sexual health; addiction; general health issues and most importantly,

better deals can be in place for their safety.

-specific education (3)

"Cultural specific traditions need to be educated to the wider community with special liaison agencies.

- The interplay of class, privilege and race (2) 'How does class
racism play?'

\section{Recommendations on how to improve the law and change attitudes (151)}

Through education and awareness (51)

Der the ctions, DO NOT accept violence as a norm.'

More males, elders, and leaders should voice out the unacceptability of violence (27) 作 against Aboriginal women and children."

One law for all is how it needs to be. Having more women and children refuges also establishing time out a location for our males; and the sober up centre has a very low number regarding ATSI males.'

- Educating law enforcement officers (17)

suring those officers with responsibility for enforcing the law understand what violence is and implement the legal measures vailable appropriately. 
Table 7.12: Select Quotes Reflecting Thematic Representation of Indigenous Women Advocates Institutional and State Violence

\section{- Mental Health}

'I hear that people are saying rather than giving the convicted person life imprisonment, he should be given 10 or 5 years. Life imprisonment, they claim, is killing a person and taking away their life. But, when you've committed rape, you've killed a person and you've traumatised them. If it is a deadly rape where the survivor ends up dying or where the perpetrator destroys the survivor's reproductive organs, then that's killing somebody. This is more traumatising and deadly than a convicted criminal being just being in jail.' [Klade]

\section{- Police, Court and Prison Support}

'I think it was some time last year [2013] that we introduced the collection of forensic evidence. It is now being piloted at the James N Davis Jr Memorial Hospital in Neezo, here in Montserrado. Once we pilot that and we see that it is working with the necessary trained staff, we will think about spreading the services across the county. Very soon, forensic evidence will be a part of the examination and evidence collected to prosecute cases in court.' [Amelia]

- Alternative Dispute Resolution

'Some of the cases we mediate are about persistent non-support, child support, domestic violence, land disputes, and many more. Cases that we are unable to mediate include aggravated assault, rape, and murder. For these cases, we simply make a referral to the LNP. However, we still follow-up on those cases because most of our people are not educated or informed about the criminal justice system.' [Tracy]

\section{- $\quad$ Safe-Homes and Transitional Houses}

'The safe-home is managed by the Ministry of Gender. It has four rooms including a recreation centre. The UNFPA that was sponsoring the administration of it has also closed their activity for the services. There's only one safe-home for all of Nimba and it is based in Sanniquellie. Since the circuit court is here, dealing with all the cases, it is natural for the safe-home to be located here too.' [Yaa]

\section{- Homelessnes}

'As I speak with you, if we were in Pleebo, say at 8:30 pm, I'd say let's take a tour. You'll find many children sleeping in the street. In the morning, they will go to the Cold Bowl Shop and wash dishes in exchange for leftover food eaten by patrons. At night, they sleep on the market tables in the open market area. Sometimes the police will arrest them and take them to the police station. But where do they keep them? Sometimes, the police will call the Ministry of Gender. Having spoken with the kids, we find out that some of the children are taken from the village by family members with the intention of bringing them to the city to give them an education. Only to later find out that these children are later used as slaves.' [Abigail]

\section{- $\quad$ High Illiteracy Rate}

'Yes, we work with Indigenous women. First of all, when you take the statistics and look at literate and illiterate, you'll find that 61 percent of Liberian women is illiterate. Some will say 85 percent. But I can tell you that technology is advancing so lots more women are going to school. However, 61 percent are illiterate and very deeply into tradition. You can't root out this factor in working with the only specific type of people.' [Yaa]

$$
\text { - Law/Legal Service }
$$

'But for the rule of law, we say we are governed by the rule of law, but no one obeys the law in Liberia. Sometimes the victim will say 'I leave the outcome to God', meaning that they are helpless in seeking a fair solution through the law.' [Sia]

\section{- Reporting Violence}

'Sometimes people report rape cases willingly. But most people are not comfortable reporting because of the way our system stigmatise survivors. For instance, when a rape case is being processed in the hospital, rather than conducting examination privately, everyone ends up knowing the survivor is and what she's presenting for. There is no privacy in the health centre. The same can be said for the courthouse. According to the law, rape cases should be held in camera. But it is not in Maryland. Regardless, we encourage them, against the trauma, pain, and humiliation, to continue with the trial because they do not know the effect the rape could have on them in the future.' [Tracy]

\section{Institutional and State Violence}

\section{- Royal Commission into Responses to Child}

'But what I don't agree with is a lot of people saying that the Royal

Commission was about making sure that Aboriginal people don't spend that much time in custody. Therefore, when they commit an offence no matter what they are, we should take that into account and look for lesser alternatives. The Royal Commission said the overall representation that it was concerned about were offences of minor nature. So, things like being locked up for being drunk in public etc. They never said that there should not be a harsh penalty for the horrendous crime.' [Lara]

- Royal Commission into Aboriginal Deaths in Custody 'I have had a difficult time partly because of the physical and sexual abuse. The sexual abuse I experienced was very extreme... I contacted the Royal Commission, the Attorney General and the Victims of Crime. The Royal Commission told me when they came here if I were willing to testify against that institutional abuse, and I said, "yes" I would. The next thing I heard was that they were here. I called and said to them, I meant to be testifying. And they said ahhhh we have budget cut by Tony Abbott. I then got told that my testimony wasn't in their parameter. When I asked why they said it was because the abuse happened in a government institution and not like the church or the scouts or something else where the government wouldn't be responsible for compensation.' [S]

\section{- Aboriginal Children in Care}

'Often the children that are taken away are in non-Aboriginal foster-care. Now a stolen generation is shielded under the guise of family services that our kids get taken away. And you know because it is on such a well-organized credible health service that also have territorial responsibility as the ACT affiliates, e.g., the NT.' [Sally]

$$
\text { - Homelessness and Refuges }
$$

'There is no Aboriginal hostel. That's it. A lot of problems is homelessness and couch surfing or living rough or living at the tent embassy, etc. It's hard to couch surfing or living rough or living at the tent embassy, etc. It's hard to
work with people. I mean, how can people have a job? And how damaged is the job if they haven't got good health. Health underpins all of those things.' [Sally]

\section{- $\quad$ Police, Court and Prison Support}

'One of the hardest groups I ever had to train around domestic violence in the Aboriginal community is the NSW Police Service. I did a training workshop at the Goldburn Police Academy. They are the worst group I ever had to deal with. They just did not get it, did not understand. Their culture of overt racism towards Aboriginal people was terrible. I think in the justice system, there's so much more that needs to be done, - so much more training, education and understanding.' [Alison]

$$
\text { - Law/Legal Service }
$$

'Legal aid is being defunded. The government also do not fund women's 'Legal aid is being defunded. The government also do not fund women's
refuges, and they do not fund legal services for women. There's always less available for poorer women, particularly. Sometimes if you're wealthy you can access such service privately but if you're a working-class woman or a stay home mom; that is not an option for you. It is a policy decision by the government to not fund those services. I think that there are fewer programs to support women around now for women than they were ten years ago. I think it has gone backward.' [Lara]

\section{- Reporting Violence}

'Yes, I think there has been an increase in reporting violence against Aboriginal women. In fact, I know that because the response system has really improved. So, there is certainly greater reporting. The challenge is though when women report, they don't get the best response. A lot of people probably wouldn't agree, but that's my view and perception from over 20 years' experience.' [Dallas]

\section{- $\quad$ Stolen Generation}

'In Queensland, even though I was sexually abused at school, it was by a white person. I saw more violence in the white community than I ever saw in the Aboriginal community. Of course, people would yell at each other. Some would say, 'get out of the house', but there wasn't the kind of violence that was in the next generation of Aboriginal children. In my mother generation, people were very Catholic or Christian, they sent their kids to school and they tidy up their house or they got taken away. They were frightened. So, they did what they were supposed to do. They were assimilated. But the next generation, like my cousins', were more traumatised.' [Alison]

$$
\text { - Aboriginal Reserves and Stations }
$$

'Violence is always there. We were violently forced into reserves, missions; we were locked away. We had to have passes to come and go. If people wanted to come and visit us, they had to have passes. It was so systematised and institutionalised that there's nobody who haven't some experience of the violence of government policies and physical violence that was used to implement those policies.' [Jaky]

\section{Structural/Cultural Violence}

know there's certain time of the year that things get really explosive and that's around Christmas time and around Easter time. I don't know whether it is because people drink more around that time or people are getting depressed because they don't have the money to buy presents and all that sort of things. And then, you often see a lot of blow ups and... I always say to my staff, just be mindful that Christmas is on its way.' [Sally]

$$
\text { - } \quad \text { Breaking the Cycle of Violence }
$$

'I just had a very strong determination to not have my child grow up with the same effects going on to the next generation. I'm not going to let this happen. That's why I got sober and clean. It took a year and a half, but when I did, I knew from that point on that my daughter would have a different story. As a result, she's a better person.' [Alison]

- $\quad$ Single Mothering/Parenting 
getting skill to help themselves. Because, if you are not able to feed your children, what is the use of going up and down to court?' [Damawa]

$$
\text { - } \quad \text { Single Mothering/Parenting }
$$

'The men are leaving the women because the men do not like to work hard. When the men realise their responsibility, i.e., he has five children and wondering how he would feed them and provide their basic need; then he late decided to leave and find a woman who does not have those kinds of responsibilities. That's how they are abandoning their women around here every day.' [Damawa]

\section{Customary/Traditional Laws}

'When we have conflicts of law and tradition, the first thing we do is to call meeting where a committee will be set up to discuss the issue. The committee then sets up a meeting with the parties involve. We also have partners dealing with psychosocial counselling. During the psychosocial counselling, the parties will be told the implications of compromising a case by solving it the 'traditional way.' If you wish, you take the legal side, if you will, then follow your tradition. The implication is presented to you, the consequences of what has happened to you will also be told you. And you can now decide.' [Yaa] Female Genital Cutting

'The traditional is very strong in Lofa especially when it comes to child marriages and female genital cutting. So, even if you want to change it, it is not easy. For example, there is a conflict between the rule of law and the customary law in Liberia when it comes to the age of consent for marriage. In the traditional practice, they say 15 years is the age of marriage. The law on the books say 18. So, how are we supposed to change this? There is a problem, but we can't do anything about it. That's the problem that we are facing.' [Sia] Forced Marriage

'They should bring all the heads of the Sande and Poro Institutions together and educate them about the rule of law. The rule of law should not deny that there is no culture. But there is a law that protects everyone. So, it is important for the traditional leaders to understand this law and apply it to their practices. A15-year old cannot marry because she is still a child. The culture is that whe a woman is pregnant, a man will show up with a dowry stating that if it's a gir child, then she will be my wife. So right from the womb the girl's fate is seal.' [Sia]

\section{Land and Property Ownership}

'In customary marriages, if I am married to a man and he dies, I will be passed on to his brother. If I refuse, then I will lose the property that both of us have worked for together and accumulate. The husband family will take the kids away, kick me out of the house, and deny me of any marital rights. The Female Lawyers have been looking at some of these issues. Now, the Inheritance law also protects women's rights to ownership of marital property after the marriage has been dissolved or the husband has died.' [Klade]

\section{- Taming Girls and Women}

'Sometimes, if a woman says I want to make suggestion about what will happen in our home, the man would silence her. If she insists, there will be problem at the end of the day, which will result into violence. Other men feel they have power and control over women's lives. They will love [having intimate relationship] to these women, have children by them, and neglect and abandon the children. Many women are experiencing persistent non-support because men will intentionally have children with these women, leave them without support making her to suffer as a single parent. There are women who are beaten severely by their husbands who end up in the hospital with 10-15 stiches. If the women are lucky, these husbands will be arrested and taken to the police station. But the men will end up inciting fear and violence so much so that the women feel pressured to compromise with the police.' [Abigail]

\section{Interpersonal/Community Violence}

\section{- Violence Against Women}

My clients are girls, mostly girls who have been raped or have experienced sexual violence. The youngest is about 9 months to one year old and the oldest, at most, will be 15 years. Few are 16 years old. When it comes to domestic violence, abandonment and persistent non-support, then our clients are mostly 20 years of age and above. Usually, they are married to someone who is usin their power to abuse them because they've paid dowry for the woman. These men feel they have right over the woman. If the woman is supposed to put food on the table, and the food is not there, the men use their power to beat them up. Sometimes women get killed in the process.' [Yaa]

- Violence Against Men

'Sometimes women do abuse men. There was a case where a woman beat her husband. The man took the case to the police. Rather than launching an investigation into his complaints, the police started to laugh at the man. They mocked the man by saying, 'you're lazy that's why the woman beat on you.' So, for that reason men don't lay complain.' [Sia]

\section{- $\quad$ Prostitution and Human Trafficking}

'There's also trafficking, where they take the children and sell them for cheap labour or sex. It is practice here, though not often but once in a while I come across those kinds of cases, especially in border counties such as Nimba, Cape Mount, Maryland and in Monrovia too. Even in a year if one or two cases appear, it means that it is happening.' [Yaa]

$$
\text { - Intergenerational Trauma }
$$

'I had the opportunity to educate women and community members about the rights of women. We educate women about the effects of domestic violence and sexual assault so that tomorrow they can reduce the impact on them. When I say domestic violence, I mean men beating on their wives, which also affect their children and the family as a whole. If the children witness their father beating on their mother in the home, they tend to copy that behaviour. So, we tell community members about the negative effect of such behaviour on the children.' [Tracy]

$$
\text { - Domestic violence }
$$

'My clients are mostly girls and women. They report wife-beating, family abandonment and rape. But the most cases that we receive in Lofa are women/children abandonment. Men who have children with the women, and
'But what I know is true as an Aboriginal woman is that a lot of Aboriginal women end up raising children on their own. A lot of the time the men are very absent. Or just drop off out of the scene. I think a lot of Aboriginal men just lost their roles, basically, and got really lost, leaving women to be the stronger force.' [S]

\section{- Aboriginal/Indigenous Law}

'We still practice our laws, just that they are not recognised in the legal system. The Circle Sentencing is like that. But the problem is, you've got to be guilty before you can go through that process. So, what's that all about?' [Jaky]

$$
\text { - Mental Health }
$$

'We had a lot of psychological violence in our marriage for the last three years. I would go to the women's refuge and try to explain what was going. No one could say that I was suffering from psychological violence. The fact that he never hit me, no one could help me. Because he hadn't assaulted me, no one could say, I could stay here. But here I was, going home to someone who was psychologically violent. I realise it was the PTSD and, also the issue of control. By the time I had the child, I said, he's going to control me and make sure that I don't leave with this child.' [Alison]

$$
\text { - Denial and Shame }
$$

'We did a report and presented it to the first Aboriginal women's conference in NSW. Quite a few women got up and started the backlashing, - complete denial. They are really traumatised by what has happened to them, but at the same time, very afraid to have it spoken about in public. It was affecting their kids in school and all that. After we gave the talk, a bunch of older Aborigina women came up and said, 'thank God someone is talking about this. This is what happened to us and we've never been able to talk about it'. There are so many Aboriginal women and Aboriginal people who are carrying these terrible stories inside themselves; full of the anxiety, dissociation disorders and traum that comes from having those stories inside you and not being able to share them.' [Alison]

\section{- Protecting Aboriginals from themselves}

'One young girl she just keeps having babies and every time she has a babe it gets taken by Child Protection. But she just wants one to keep. You know like, we are talking...we do the implants and all, but she would go somewhere else and have it taken out. Next thing we know she's pregnant again. It's a really really sad thing you know. Here in Canberra, there are 600 children in Care and 300 are Aboriginal.' [Sally]

\section{- Adult Children of Violence and Abuse}

'So, I started to say that we needed to deal with the generational adult children who were growing up in violence and then becoming violent. Then, abusing their children, - their children will grow up with the same thing.' [Alison]

\section{- Religious Abuse}

'Generational sexual violence is pervasive in the Aboriginal community because of forced Christianity and violence associated with forcing Aboriginal people to live on missions. Christianity was very fundamentalist. So, right down into the generations we were working with Aboriginal men who had been subjected to generational sexual violence by their uncles or whatever. Men who were on the verge of committing sexual violence against their own children started to have flashbacks of sexual abuse by their own relatives. The whole thing goes hand in hand - the drinking, the generational abuse as children, not growing up properly emotionally and developing as a normal person into a functional human being. Rather an Aboriginal child was compelled to grow up as an adult child or having a small damaged child inside their adult person. [Alison]

\section{- $\quad$ Sleeping Language}

'For many Aboriginal Peoples, it is a shame to think that we can't speak our language. This gives a sense of great deep personal sorrow that knowing the loss of what it is to have all that knowledge taken away from you in many ways. So much knowledge and cultural practices are embedded in language. When you speak a language, you take on the persona of that language.' [Jaky] Interpersonal/Community Violence

\section{- Violence Against Women}

'I dealt with a case in the past. It was four young kids, who were related to each other. They were brought up with their mother. They had one foster sister, who wasn't biologically related. This girl talked to me about a sexual abuse was happening in their household. The entire family went to the police. The abuse was their uncle. This man got off because they said the girl was sort of changing her story. She was very traumatised, this poor girl. The uncle had abused her mother, and he had abused her as well.' [Alison]

- Violence Against Men

'I also see and read cases where there is intergenerational violence and it doesn't make me happy. I'm reading about young men who fathers were dealt with as offenders. But I'm not surprised by that at all, why would I be? Why would the child of a man who had committed extreme violence against his wife for more than 12 years, not be violent? Why would he turn out any different? [Giggle] I mean I'm not laughing really. Some people say well, if all these good things have happened then the violence should stop. Oh no, we're just starting to get response to it right.' [Dallas]

\section{- Child Abuse}

'When my daughter went to school a few years ago when she was in kindergarten, she was asking her teacher if she could go to genuah, which is word saying to go to the bathroom in our language. Her teacher made her sit until she would say it in English. So, she peed in her pants. She's 12 now, so this was only about 5 or 6 years ago.' [Jaky]

\section{- Intergenerational Trauma}

'When I started to talk about intergenerational trauma, alcohol abuse, family violence and recovery, I started to get huge response from Aboriginal men (who were maybe in the middle of abusing their partners or children) - but Aboriginal women and men in general. You know people like Charlie Perkins, Michael Mansell and Mick Dodson will encourage you to talk about this kind of stuff. But other men, who were doing it to their women/children and didn't want it to come out, didn't want me to talk about it. People would sit at the back of the room with newspaper in front of their faces. Or send me message saying, 'you're a fucking slut'. I'd get this terrible feedback from people, just random feedback, saying, 'how dare you talk about this?' [Alison]

- Domestic violence 
then they end up abandoning them. Even this rape we are talking about all too strong is the family abandonment because here you have a woman being abandoned by her husband. She has no means of support her children. At the end of the day, she will put peanuts and water on the child's head to go and sell. Whilst the child is selling, some guy may appear from nowhere claiming he wants to buy peanuts or oranges. The innocent child, not knowing the intention of this buyer who is calling out to buy what she's selling, will end up being raped by this man. Later we'll discover that our teenage daughters are being impregnated by these rapists.' [Sia]

$$
\text { - Rape }
$$

'Some of the women were so traumatised that they found it difficult to talk about their experience. I remember interviewing a lady I met in Nimba. She said, 'I need to tell you this since you are a woman like myself. I need some help right now. I am smelling'. I don't even know the number of men who had sex with me. They started to finger me day and night when I was as young as 12 years. One time she was asleep when a Commando asked that she be brought in. He brutally raped her that night. When he was done, she could hardly walk so he called other girls that he's been sleeping with to take care of her. They picked herbs added it to hot water for her to sit over it and heal the wound. She said you think this would make them stop? They did not stop. Once I started feeling better, he resumed. Since then I have lost all sense of moral responsibility. I don't care anymore; I sleep with any man recklessly. But not only that, I know that I have a problem, something is wrong with me. later linked her with the MSF-Spain who treated her. They told her that the damage to her reproductive organ is so serious that she wouldn't be able to bear children.' [Klade]

$$
\text { - Murder }
$$

'Most of the perpetrators are family members or close friends to the survivor We heard of a case in one of the counties where a 60-year old man raped his sister's baby (I mean his niece) of 24 months old baby to death. He escaped and so could not face prosecution. Now, the men are saying that the rape law punishment is too harsh, but in the case of this baby, the accuser has committed a felony and it is also a first-degree murder.' [Klade] Challenges

\section{- Access to Service}

'County-wise, our service is not really accessible to people who are far away. Sometimes the victim has no means of even contacting us even if they wanted to get here on their own because there may not be Cellcom or Lonestar services. This can sometimes lead to compromising of rape cases withou reaching for our services. So, it is still a challenge.' [Yaa]

$$
\text { - Justice through the Legal System }
$$

'It is already known in Liberia or maybe across Africa, that justice for women is justice denied. If there is a land dispute between a woman and her husband for equal share of the property, you will hear the men saying, 'these women are taking on the white people way of life.' But mind you, it is these same me that will move to Europe or America and adapt to the white man's way of life. So, what's the issue here? The issue is that the systems are not working. We need to train people properly to deal with violence against girls and women Consider that there are 8 cases on the docket but only one is being prosecuted say for a whole year. It just doesn't serve as a deterrent. Sometimes people linger in jail for 8 months. At the end of the day, the UN and Human Right Groups will say, you have violated the man's rights, so the prisoners should be released. Then he goes to another community and commits the same act of violence.' [Klade]

$$
\text { - Female Lawyers/Police Officers }
$$

'The accessibility of our services is challenged by the fact that we don't have female lawyers for our women clients. The lawyers we have here in Lofa are all males. The county attorney who is the prosecutor is a male. But the Judge is a female. We really need a female lawyer to prosecute our SGBV cases.' [Sia]

- Males Championing the Cause of Violence against Girls and Women

'I think the only way forward is for good men to be advocate and speak on behalf of women. Those men who are refusing to understand, when they listen to a woman's voice, they go crazy, saying that 'their women are following people who want to spoil their relationship'. They are destroying tradition. Tradition has been here ever since. We've been living with it and so no one can change it'. So maybe if men are adding their voices, i.e., men talking to men, we believe that the violence and negative stereotypes men hold agains women, which lead to on-going violence, will reduce. Good men can pose as role models. They could announce to other men, 'you see, my wife is not a slave to me. I don't beat on my wife. I discuss everything about our home wit my wife. My wife is working and I'm working too. We come home and take care of our children together.' [Abigail]

$$
\text { - Advance Girls/Women }
$$

'Like before, how many women we had in our security apparatus? Now we set a benchmark in our Poverty Reduction Strategy goal, that at least all security institution should have 30\% female officer. The Bureau of Immigration has reached and passed that benchmark. The police are still dragging on. The military is still saying, it is a no-go area for women. But I know gradually, it will take hold. The other day, I saw a female officer driving a massive articulator truck. I started clapping. I even took her picture out of excitement go girl, go girl. Everything for women is hard. Job stereotypes - a woman can only become a nurse, receptionist, etc. But now you have girls going into science, engineering and law. It may be slow, but they say, he that endureth to the end shall be saved.' [Klade]

$$
\text { - } \quad \text { Self-empowerment }
$$

'Then again, all the prosecutors are mostly men. You will hear them say, you're a man who wants to bring your fellow man down for him to be put in jail for ten years? Remember he's the only breadwinner for his family. But everybody is a breadwinner now. Women are breadwinners. There are some households headed by women, so why must women be treated like this?' [Amelia]

Corruption and Bribery

'Travel on the highway, you'll see government vehicles transporting goats, chicken, charcoal, cassava leaves and food produce as it they are commercial transport. Sometimes, they go on the highway and set their own roadblock.
'I had a situation with a middle-class non-Aboriginal woman who you wouldn't think will end up in a domestic violent relationship, but she did. She had moved into her husband's house only recently. He threw a glass table at her in front of her kids. He had given her a broken nose and all that. She had to do a surgery; she had to go to hospital... She rang me up sometime and said, how do I get some support? I don't know where to go.' [Alison]

$$
\text { - Rape }
$$

'I went away to boarding school and got abused by a priest. When I came home, I was completely in my own world. At the time, my parents were going through a difficult period in their marriage. So, I started to see a kind of emotional violence in their marriage. I had to get away from my family.' [Alison]

\section{- Murder}

'In 2003, got asked to do some work in Tasmania. At the time, there was no law in Tasmania around domestic violence. It wasn't criminal to domestically abuse a woman. The police couldn't really do anything. The month before I had actually got there, this man went home and shot his wife. He'd already been asked to their home. But on this day, the wife decided to return home to pick up some clothes. In the process of doing so, she notified the policy to watch out for her. While the police were coming after her to make sure she was safe, he outran the police and shot her in the house.' [Alison]

$$
\text { - Neglect }
$$

'Even 10 years ago or even longer, maybe probably 20 years ago, it was all about the parents. My own experience was like Aboriginal versus nonAboriginal. They try to give my grandkids back to their non-Aboriginal mother who was an alcoholic, drug-user who was very neglectful of the children, and my son like, maybe because he was an Aboriginal - it changed where it was all about the kid.' [Sally]

\section{Challenges}

- Access to Service

'The legal services were seen largely not to be representing Indigenous women because Indigenous women were the victims of male violence. It's only in the last 14-15 years, or even before then, probably about 1994-95, there was specialised domestic violence - family violence legal services set-up. There were just a few State-based ones and then there was Indigenous ones set up around early 2000 (I can't exactly recall when). The Indigenous one was set up in recognition of and dedicated to support Indigenous women only, not only with violence but also with law matters as well.' [Dallas]

$$
\text { - Justice through the Legal System }
$$

'I think the system is inherently problematic for Aboriginal people, both offenders and victims, but particularly for victims (particularly women and children). The reason why that is the case (complex but...), is that it's not that easy to access legal services. A lot of people don't know their rights. They sit in the most vulnerable parts of the community, with the least resources, the least knowledge, and the least information they've been given. You have to be able to access the law to be able to make it work for you. But that's the first thing, the access to justice issue for Aboriginal people is a huge trap. That is the first way that the law doesn't fulfil its role. The second is the amount of bias within the system. In the research work I do with Aboriginal offenders, we see Aboriginal women (and men) as victims of crimes. There was this murder case that I worked on where three Aboriginal kids were killed by a white man. Even the police now say if the accused had not been white, he wouldn't have gotten away with it. There is so much that reinforces the idea that Aboriginal people (women and children) are worth much less than their white counterparts.' [Lara]

\section{- $\quad$ Female Lawyers/Police Officers}

'Our legal system is very male-centred. It is male dominated. You know mos judges, most magistrates, most senior legal counsel are still men? So, how can women deal with that? Particularly, back to when traditional practices were still very much alive and kicking, women still prefer to talk to other women about women's business. So, with a male-dominated legal system, there is no place for an Aboriginal woman's point of view in our legal system. And I mean, an Aboriginal woman point of view that is not cast or couched in a male point of view. I'll make that statement. I would think that through your research you'd probably be getting a sense of that. I doubt through all your interviews, we are like most women in the world. Women are gagged through one-way or the other, by male dominance.' [Jaky]

- Males Championing the Cause of VAW\&G

'I think violence is still happening behind closed doors across the country. You can't pick it to say that it [violence] would happen to a particular kind of person. But certainly, I'd say lower social-economic group and minority that it is more common. I think it is partly driven by men having to lash out because they feel powerless themselves, as well. Which I think men have to take the responsibility to heal themselves and make pledges to treat women properly, and family properly. I think there's been a bit of a movement worldwide of people trying to do that. Even that young woman who they nearly killed and so bright and intelligent - spoke at the UN [Malala]. She's got her father supporting her.' [S]

$$
\text { - Advance Girls/Women }
$$

'White Australian law is all about retribution and punishment, crime and punishment and isolation. It's not about the community wellbeing or healing practices. As soon as you start saying that then people go like 'oh that's a bit of a touchy feeling'. In my experience, women are not particularly about touchy feeling. Women are pretty summary, feisty, good thinking, and clear thinking. Most of our lives (as women) we spend time working to modify and shape the behaviour of other people because we raise the children. Yet, nobody listens to what we've got to say. Even books about child's rights are written by men. A woman's voice in our legal system is absent. And, an Aboriginal woman's voice is pretty much absent.' [Jaky]

\section{- $\quad$ Self-empowerment}

'Now I think it is harder for people to oppress us. But there's a whole lot of 
They do this publicly without shame. There is no law and order in the country, starting for the heads. If there were stiff justice and I violate the law, I'll be obliged to obey and follow my punishment. But seeing that I can easily bribe the police to get away with my crimes, I'll not be afraid to commit such crime. Even my little niece knows that the police take bribery.' [Klade]

$$
\text { - Collaboration and Partnership }
$$

'You have to work with Indigenous women who have no knowledge of academic learning. You have to bring them on board with those who are educated. Then you'll see that they do have some wisdom in them that needs to be passed onto younger generation who are coming up. Even though the younger generation may seem more educated, they may go to school and acquire degrees, but they need the traditional women wisdom. So, we work with Indigenous women to help make them part of the movement.' [Yaa]

\section{Recommendations and Attitudinal Changes}

'Now we should not lose hope. It takes a long process. This is the way of our people for a very long time. They grew up in this system. So, for an outsider to change this system it takes time. It requires more awareness, more sensitisation and more training and empowerment. Because if you just talk, say you tell the Indigenous Zoe that there should be no Sande activity, what would you provide as a replacement? This is the will of the people. This is how they generate income. If you then take away this income, what do you put in there? These are things that are lacking in the whole strategy for addressing GBV in Liberia. If you want them to leave this practice, can you now design strategies, empower them and build capacity where they would leave that behind? In strategizing, you have to start by building a centre side-by-side with the Sande House to carry out skills training for illiterate women. So that after Sande School, they can come out with a set of skills that can be used for income generation.' [Yaa]

'I will start with myself. My daughter is a grown girl. But she was not going to school. She used to just go around doing nothing. One day I said to myself, I'm working at the college, wouldn't it be good for my children to benefit? I walked to her and told her, stop wasting time with your friends. Tell them that you want to go to school. I am illiterate, but I don't want you and your friends to be illiterate. I am a hardworking person, but I don't know book. I told her, 'I want you to go to school and learn something'. At the time, she was in $7^{4}$ grade. She listened and now she's taken her school seriously.' [Martha]

'We really need to pray to God. Or we can say when a man does something like that [violate a woman terribly], then he should be killed on the spot!' [Damawa]

'The traditional people need more education; the survivors need financial assistance to encourage them in pursuing prosecution route.' [Abigail]

'At the MoHSW, what we've done and continue to do is to train our health professionals how to manage survivors when they are raped. We've conducted the training for a couple of years now. What we've been trying to push for is to make this training part of the curriculum for all health training institute in the country. So that once you enrol at say, the Tubman National Institute of Medical Arts [University of Liberia's Nursing School], in your studies, you'll learn how to manage rape cases. After graduation, when you're assigned to a health facility, you'll only do in-service rather than receiving on-the-job training.' [Amelia]

'The whole system needs to be restructured, particular the justice and health system. For the health system, there needs to be training on forensics, re vagina smear when there is a rape. The current situation here is the public health nurses who carry out these swaps for investigation. Within few months, you'll hear that they've got a new job with a private health organisation and have abandon that post. For us following up on such cases, we will visit the hospital on several occasions only to find that no one is there. Sometimes, the slides are kept for so long without medical examination that they become outdated. There are several factors responsible for the inefficiency. Imagine our roads during the rainy season. If the evidence samples are too many, you run the risk of damaging them because there is no proper storage.' [Klade]

'When it comes to domestic labour there is serious problem with women being overlooked. Women do most of the farming. They also carry heavy loads, do overlooked. Women do most of the farming. They also carry heavy loan,
childcare, cooking, cleaning and more. At times, you will see a woman carrying this heavy load, with the child tied on her back, and a basket in her hand. But the man will walk freely ahead of her, swinging his hands. Women are always victimised in these rural communities because men believe that women are supposed to do X, Y, Z.' [Tracy] other way to oppress and suppress us, like all these crazy dialogues in the media, people like Andrew Bolt, - what right has he got to comment on me and my people or anyone. But that's OK. It' is OK for him to talk about Aboriginal people in those sort of terms - the way he talks about us. But it's not OK, you know? Society still allows it to happen.' [Jaky]

$$
\text { - Corruption and Bribery }
$$

'I think that... you know, people think that those kinds of people [men who abuse women] you can pick them out. But the truth is that people who act in those ways, often - and I have experienced this when I worked as a youth worker where we had a separate book, like a black book. In that book there was doctors' names, ambulance drivers' names, anaesthetist names, of perpetrators; that we weren't able to get through court. There were judges, lawyers, people who were in positions where they appear in public as good upstanding citizens and professionals and caring about the welfare of others, especially children; they were actually the ones in paedophile rings - not just acting on their own. In that town, particularly, where you had a black-book of certain powerful people (I won't name who they are), but they were powerful people in that town, who were abusing the young women and going home to their family as if everything was normal.' $[\mathrm{S}$

\section{Recommendations and Attitudinal Changes}

'Better education, decrease poverty, empower our men, so they don't do this, increase maternity services on country (evidence suggests that decreases family violence)' $[\mathrm{K}]$

'I would have a block of flats. Hostel. Where you have workers with them 24/7.' [Sally]

'Ceremony is one of the ways that people can heal, definitely. Not for everyone but...reconnecting with culture, reconnecting with identity, all of those sorts of things.' $[\mathrm{S}]$

'I had an issue that the legal services also had a strong focus on doing criminal injury compensation claims. So, women would come and want to claim compensation for their injuries rather than the focus being on preventative an protective work for them. I think it is important that women have access to legal services and protection through the law. But that needs to go together with a suite of other services and support.' [Dallas]

'There needs to be better training of the judiciary in dealing with Aboriginal issues. There needs to be better programs in dealing with underlining issues particularly in literacy. There needs to be better pathways to provide support. There absolutely need to be investment in the services for victims in taking a holistic approach - not just the service but where they can go to be safe; but also, in long-term care, as in employment and counselling. That's the kind of a broader holistic approach that people need to be able to get their lives back together.' [Lara]

'I think as part of society, parliament should provide funds for Aboriginal women to establish houses and safe refuges either in communities if people believe in community, or in cities or urban areas aside from non-Indigenous refuges.' [Alison]

'I do think re-investing in people cultural practice and language is a key element in cultural practice. It is actually a very powerful healing mechanism. There's something magical about speaking one's own language. It is fundamental. It is a UN basic human right. If you want to disempower people, you make them speechless, really.' [Jaky] 


\section{CHAPTER 8: DISCUSSION AND ANALYSIS}

Actually, working in this area is quite challenging. Sometimes it has been easy to work with other women. You know, women have not been heard for a very long time. Their business has been put aside in the past. Now, for them to have the opportunity to speak out, participate, and be a part of everything that is happening in this county; they feel very proud about it. From the beginning, it wasn't that easy to get them on board because they fear refusal and resistance from their husbands. You would hear them say, "I can't join you because my husband will have problem with me". OR, "I should not be part of this women's program". But now they are beginning to understand that being a part the women's program [is a good idea] because they are seeing the impact of the women participation across the county. [Abigail, Liberia]

\subsection{Introduction}

This chapter is confined to a careful selection of subtopics that are representative of the major issues emerging from the empirical study and speak directly to objectives \#2 and \#3 of the dissertation: They are:

1) assessing the extent to which service providers working in the areas of gender violence against Indigenous females in Australia and Liberia perceive the law to be just (or unjust), using a survey instrument; and

2) examining the extent to which Indigenous Women Advocates working in the areas of violence against women perceive the law to be just (or unjust) against Indigenous girls and women in Australia and post-war Liberia using a semi-structured interview.

This research is grounded in 'asking the [Indigenous] woman [the law] question' to incorporate an Aboriginal legal feminist perspective. Demonstrably, this chapter honours and validates the voices of Indigenous Women Advocates informed by a phenomenological inquiry (see chapter 6). Thus, a significant portion of the chapter dwells on interview and survey responses from Indigenous Women Advocates (to a larger extent) and service providers (to a lesser extent), respectively. As input from Indigenous Women Advocates is critical for reforming the law and policy that impact the lives of Indigenous girls and women, it is imperative that the chapter achieve research objective \#3. Notably, the majority of the survey participants were males who did not overtly identify as Indigenous (see Table 7.6). As expected, themes emerging from the empirical data and the literature review appear to align with the responses from interview and survey participants.

Given that Indigenous females are the survivors of systematic violence, they are in a unique position to identify challenges, issues and possible remedies that could result in effective comprehensive intervention programs. This chapter cites direct and indirect quotations by Indigenous Women Advocates and survey participants throughout to highlight and illustrate analytical views. All direct excerpts by Indigenous Women Advocates are cited using their pseudonyms (e.g., Yaa or S), followed by their country of origin (Australia or Liberia). However, in the case of responses from the questionnaire participants, 'a survey participant' or 'survey participants' is used to indicate who is speaking (singly or collectively), followed by the country of origin. 'Research participants' is used jointly for both survey and interview 
participants. Unless otherwise stated in a direct quote, the study does not mention precise locality (e.g., Maryland or Northern Territory) to protect participants' privacy and identity. Since it would make for a cumbersome read, 'survey participant' or 'research participant' are not referenced in all cases.

The chapter opens with the many forms of violence Indigenous girls and women endure on a daily basis. Describing the types of violence most frequently identified by research participants, the subsection highlights some selected participants' quotes to articulate the impact and implications of systematic gender violence perpetrated against Indigenous girls and women. As mentioned above, violence against Indigenous girls and women does not happen in a vacuum. An essential question to ask is: Why does it occur in the first place and what are the root causes of such persistent violence? Research participants' candid responses offer deeper insights into society's beliefs and attitudes toward girls and women that predispose them to ongoing violence. These beliefs and attitudes are held mostly by men but also by some girls and women. Survivors exposed to ongoing violence, internalise self-destructive beliefs and harmful attitudes about themselves and about females in general. If preventing systematic gender violence is impossible, and if there are entrenched and harmful cultural beliefs at the root of violence, then this chapter assesses whether there are social services available to provide any relief or remedy for Indigenous girls and women survivors. The research findings show that violence is not only a legal issue. Therefore, incorporating public health's social determinants of health can marshal a comprehensive intervention mechanism, broadly and strategically. Finally, since this research pertains to applying the principles of the rule of law and justice to address systematic gender violence, access to the law and legal services is discussed in a separate subsection.

\subsection{A Pervasive Culture of Violence (Nature, Type and Impact of Violence)}

Historical evidence gathered in this research points to a pervasive culture of violence against Indigenous Peoples in Australia and Liberia. Whether through the trans-Atlantic slave trade or convict transportation to Australia, both forms of violence eventually bred inter-generational perpetrators (e.g., African American former slave elites in Liberia or white settler-colonists of English descent in Australia). Being the subjects of such systematic, protracted savagery has been the portion of Indigenous Peoples since colonisation. One survey participant laments, 'How will our people ever be able to heal from our elders' past mistreating is something that lives in all our hearts and families, and the hurt is very real and society just brushes it away'. Not many Indigenous women advocates are cognisant of the nuances and intricacies of systematic violence. Notwithstanding, Alison clearly understands the nature and impact of intergenerational violence (also see chapter 2): 
missions. Christianity was very fundamentalist. So, right down into the generations we were working with Aboriginal men who had been subjected to generational sexual violence by their uncles or whatever. Men who were on the verge of committing sexual violence against their own children started to have flashbacks of sexual abuse by their own relatives. The whole thing goes hand in hand - the drinking, the generational abuse as children, not growing up properly emotionally and developing as a normal person into a functional human being. Rather an Aboriginal child was compelled to grow up as an adult child or having a small damaged child inside their adult person. [Alison, Australia]

Alison recognises how collusion between institutions (such as the Church and the State), coupled with an individual's (such as a priest's) wilful desire to harm others can inflict trauma. A survey participant in Australia corroborates the myriad forms systematic violence can assume over a period of time. According to the participant, 'gender and family violence are very closely connected to the ongoing traumatic removal of children from their families, which is currently being discussed as "the next stolen generations." I think these are interesting connections that seriously deserve consideration.'

Tied to state and institutional orchestration of systematic violence are the invisibility of Aboriginal Peoples' experiences of colonialism, systemic racism, patriarchy, and land dispossession in Australia, which is why research participants often restrict violence against Indigenous women to sexual or physical violence:

The issues of colonisation, racism, and oppression have meant that Aboriginal women's experiences of patriarchy and gender inequality have been often made invisible. Aboriginal women are constantly put in an untenable position of having to choose between culture and gender. Any further work in this area must support women to find language and opportunities to have complex and nuanced conversations about their experiences of racism and misogyny. [Survey Participant, Australia]

'Since the invasion of the white man', a survey participant opines, Aboriginal women have been at greater risk of domestic violence and generational trauma, mainly due to the intersecting interplay of class, privilege and racism. Research participants point out that '[s]ystemic racism often prevents women from accessing the legal system or receiving high-quality service as remedies for systemic racism are focussed on male criminals in response to death in custody issues, but rarely supporting Aboriginal women to seek justice'. Thus, a lack of change in the conversation about 'colonisation, settlement, dispossession, and political power distribution has partly resulted in any possibility of providing reparations for historical injustices even as Aboriginal children and women continue to be marginalised', affirms a Survey Participant..

Despite the fact that violence against Indigenous girls and women encompasses a broad spectrum of systematic exploitation, it appears that the Australian government is reinventing violence and abuse. Survey participants elaborate on the Australian government's reinvention of systematic violence in the form of 'policy hardening' with particular regard to accessing housing and child protection services:

The policy "hardening" which impacts vulnerable and at-risk communities will only see increases in stress and violence within communities. For example, the "three strikes policy" in public housing in Western Australia is seeing Aboriginal Peoples being 
evicted from homes. This example speaks volumes when one section of government can impact other service providers and increase service costs relating to police, health education and child protection. This is crazy stuff. I mean its 2014, where is the learning from past mistakes? [Survey Participant, Australia]

Child protection has a policy of applying for an order that places a child under 12 months in state care until they are 18 years old after that child has been in care for 12 months. But it takes mothers more than 12 months to deal with social issues that come from violence. [Survey Participant, Australia]

Government cutbacks in subsidised housing are primarily responsible for increasing the number of homeless people in New South Wales, says an Indigenous Woman Advocate. She further notes that 'there's a whole range of issues for women, especially when they've got children; yet they have nowhere to live with their kids, if they need to escape violent situations.' Lara believes that policymakers in Australia design austerity measures with full cognition as ' $[\mathrm{i}] \mathrm{t}$ is a policy decision by government to not fund those services.' Lara's understanding is that cutbacks are made mostly because social service programs do not work. She fears that 'there's going to be less and less support for women, particularly to women's refuges and Aboriginal legal service' due to severe cutbacks by the Labour party. For $S$, the reality of the government defunding programs is agonising:

\begin{abstract}
I have had a difficult time partly because of the extreme physical and sexual abuse I experienced as an adopted child. I spent seven months making statements to the Australian Federal Police and they assured me that my case would go to court, that my adopted brother would get a jail sentence. Just around the time my case was about to go to court, the government started the Royal Commission into Institutional Responses to Child Sexual Abuse. I contacted the Royal Commission, the Attorney General and the Victims of Crime. The Royal Commission told me when they came here, if I was willing to testify against that institutional abuse (because I ended up in an institution)? I said, "yes". They said OK. The next thing I heard was that they were here. I called and said to them, I meant to be testifying. And they said, "ahhhh we have budget cut, because Tony Abbott cut the budget to pay out compensation." Then I got told that my testimony wasn't in their parameter because the abuse happened in a government institution and not like the church or the scouts where the government wouldn't be responsible for compensation. So, here again, a whole lot of Aboriginal women (particularly) and men can't get justice. I have had to come to terms with the fact that there is no justice. I don't believe that there is any justice. [S, Australia]
\end{abstract}

Section (f) of the Letters of Patent regarding the Royal Commission into Institutional Responses to Child Sexual Abuse (hereafter the Royal Commission into Child Sexual Abuse) mandates that the commissioners focus their inquiry and recommendations on systemic issues, recognising that individual cases will inform their investigation. Since 'they may need to make referrals to appropriate authorities in individual cases', the Royal Commission into Child Sexual Abuse is limited in the scope of their inquiry. Interestingly, the Royal Commission into Child Sexual Abuse held formal public hearings on evidence about child sexual abuse within institutions. The inquiry does not focus on individual situations but instead on case studies of how organisations have responded to allegations and proven instances of child sexual abuse. ${ }^{1496}$

\footnotetext{
${ }^{496}$ Royal Commission into Institutional Responses to Child Sexual Abuse, About Us, Redress, and Public Hearings (2015) Government <https://www.childabuseroyalcommission.gov.au>.
} 
The experience of Indigenous Women Advocates validates this dissertation's broader view of systematic violence as occurring at state/institutional, structural/cultural, and community/interpersonal levels. $S$ 's experience not only highlights the interwoven relationship between interpersonal, ${ }^{1497}$ structural $^{1498}$ and state/institutional ${ }^{1499}$ violence, but it also validates the unsuccessful outcomes of court cases regarding forced adoption, sexual abuse and discrimination against Aboriginal children in Australia (see chapter 7). Affirming the approach of this research to assessing systematic violence against Aboriginal girls and women, a survey participant sheds light on the causes of systematic violence:

\begin{abstract}
I think the topic of gender violence against Aboriginal women and children has often been reduced to "domestic and family violence" whereas your definition is clearly much broader including state violence, institutional violence, structural violence as well as "private" abuse. I think your approach is much more realistic and relevant than approaches which mainly or only focus on domestic and family violence... The dominant paradigm in Australia is that governments and agencies will work preventatively etc., to address Aboriginal domestic and family violence, which is a continuation of external interventions and external controls as well as self-defeating. Prevention is political, and it is about power - what power is being accorded to Aboriginal women and young people to act for themselves in ways they determine, i.e., to allow them to build their capacity? [Survey Participant, Australia]
\end{abstract}

Whilst participants in Australia also cited domestic violence incidents, institutional/state violence is often referenced as gender violence (see Lara's Alison's and S's quotes). For example, although the Aboriginal and Torres Strait Islander Social Justice Commissioner submits that Aboriginal and Torres Strait Islander women are 45 times more likely than nonIndigenous women to be victims of domestic violence, ${ }^{1500}$ survey and interview participants mention occurrences of institutional/state violence more often than interpersonal/community violence, which includes domestic violence. In contrast, in Liberia violence against women is still often viewed as interpersonal and private.

Aligning with the idea that violence against Indigenous girls and women is confined to the private domain, research participants in Liberia cited physical, domestic, and sexual assaults as leading forms of systematic violence. They also mention other types of violence such as human trafficking, child/forced labour, prostitution and persistent non-support as a direct result of males abandoning familial responsibilities. The types of domestic violence identified by survey participants in Liberia generally include rape, wife/child beating, and witchcraft:

Two cases in Ganta and Flompart - one shot a woman with gun and the other wasted [poured] acid on someone's face. This resulted in a familial conflict and now there is a clan dispute going on. [Survey Participant, Liberia]

\footnotetext{
${ }^{1497}$ That is sexual assault taking place in the home.

${ }^{1498}$ Meaning discrimination leading to injustice.

${ }^{1499}$ Precisely the cutbacks from the government resulting in the Royal Commission's refusal to include $S$ 's case.

${ }^{1500}$ Australian Human Rights Commission, 'Social Justice Report 2012: Aboriginal and Torres Strait Islander Social Justice Commissioner' (Government Report, Australian Human Rights Commission, 26 October 2012) 242, 27-28 $<$ http://www.humanrights.gov.au/our-work/aboriginal-and-torres-strait-islander-social-justice/publications/socialjustice-report-11>.
} 
There was a specific case here where a convict beat his wife and killed her. [Survey Participant, Liberia]

For example, here is a man who always beat on his wife. That wasn't brought before me. But later it became clear that the man tied his wife foot [wife's feet] apart from each other and had sex with her. We have nowhere else to send such cases. [Survey Participant, Liberia]

We had one situation where a 16-year-old was raped by a 50-year-old, she bled so much after the rape incident that we had to airlift her to Monrovia with the help of Samaritan's Purse. She underwent surgery. [Survey Participant, Liberia]

A former rebel general raped a 12-year-old in a village and nothing was done about it. [Survey Participant, Liberia]

A former driver of mine raped a 14-year-old girl in the community. He wanted to escape but I fought to ensure that he was arrested and sent to central prison. I'm monitoring the case in Brewerville to make sure that it is transferred to Sexual and Gender-Based Violence Crimes Unit in Monrovia. [Survey Participant, Liberia]

Some men complained that their food wasn't ready on time or there has been mismanagement of the household funds, or the woman is not getting their laundry done on time. Some would ask questions, if the woman challenges them, then the men would get angry and beat her. Some were beaten because of extra-marital affairs or exboyfriend relationship. There were a few cases where the women were fighting the men because he was cheating or not providing food money for the house. [Survey Participant, Liberia]

Sexual violence, gender-based violence, and domestic violence where men beat on their women are common cases we get. Most cases of wife beating result when a woman asks the man for food money, or there is jealousy on the part of the man. I went to visit my friend and I was told by the husband that she didn't come home early enough, so he beat her. Sometimes, financial problems, phone communication, or if the woman refuses to eat with him. Anytime the man wants sex she should give it to him otherwise she would get beaten. The men don't come with the women to the hospital. But women tend to feel sorry for their abusers. So, they end up not bringing the case to court. It's very hard to have a woman beating on another woman here. [Survey Participant, Liberia]

Parents do beat on their children a lot too. In any case, excessive beating is violation of the law. Some come with broken bones, bruises, etc. because of stealing or refusing to fetch water. Sometimes the children don't want to go home. They range between the ages of 5 and 12 for domestic violence. For sexual and gender-based violence from as low as 2 to 13 years, children are raped all the time. [Survey Participant, Liberia]

Trafficking in persons (TIP) 'where they take children and sell them for cheap labour or sex is practiced in Liberia, especially in border counties', but is not common in Liberia, says Yaa. 'Even in a year if we see one or two cases [of trafficking in persons], then it means that it is happening' Yaa continues. Forced or child labour and sexual exploitation, including prostitution, go hand-in-hand with human trafficking in Liberia. According to the United States Department of Labor's 2014 Findings on the Worst Forms of Child Labour, 16.6 per cent (136 340) of children between the ages of 5 and 14 work in Liberia, mainly in the mining (diamond) and agricultural (rubber) industries. ${ }^{1501}$ Apart from the mayhem against girls and women caused

\footnotetext{
${ }^{1501}$ US Department of Labour, 'Findings on the Worst Forms of Child Labour: Liberia' (Government Report, United States Department of Labour, Bureau of International Labour Affairs, 2014) 7, 1

<http://www.dol.gov/ilab/reports/child-labor/findings/2014TDA/liberia.pdf>.
} 
by warlords during Liberia's 14 -year bloodbath, ${ }^{1502}$ in post-war Liberia, the exploitation of young girls, including by United Nations workers and international expats, forces them into sex work. ${ }^{1503}$ Sometimes, girls and women are even exploited by women and the very 'freedom fighters' who were supposed to protect them, as Yaa and Klade narrate (respectively):

There are cases of prostitution, mainly in the cities. Some are caused by men going around and collecting girls with the intention of sending them to school. But in the end, they become sex workers. Actually, those girls who are involved, it is not their will to be there, but someone has exposed them to it. They end up getting used to it because they get paid. They are usually paid indirectly at the end of the month by someone who collects their money. In Sanniquellie (2005), there was an established woman here. She went into the village, collected 15 girls, some between the ages of 15 and 17 . The lady had contact with the hotel. When a guest arrives, and they need a girl, they contact her and then she sends a girl in exchange for money. When we were informed, we traced her, located her and then hire [engage] the police to arrest her. After she was arrested, we took the girls and put them into skills training programs. Some are now working independently. So, it happens. Forced prostitution of young women can be the source of income for some. [Yaa, Liberia]

My first job was to conduct interviews with women survivors of the civil war. We were documenting their stories and their experience through the peace-building network. Out of every 3 to 5 females that I spoke with at least one was raped and/or experienced some form of abuse. Some were forced to be sex slaves during the war by various warring factions. Most of the girls did it to survive, as they had to cook for the rebels. But they could not escape. They were trapped and threatened with fear and violence. For some, their husbands or fiancés were killed in the process of capturing them to become the Commando's wife. [Klade, Liberia]

Pursuant to sections 18.1-18.9 (Offenses Against Public Morality) of Penal Law, Liberia Codes Revised, 1976, prostitution, brothel ownership, and pimping are all criminalised in Liberia. On 5 July 2005, Liberia enacted its first human trafficking law. Although the prevalence of human trafficking is perceived to be low, the Act to Ban Trafficking Within the Republic of Liberia 2005 (Trafficking in Persons Act) ${ }^{1504}$ reflects the occurrence of human trafficking in Liberia. Contravention of the Trafficking in Persons Act 2005 may result in a sentence of up to 12 years. However, 'To date, the government of Liberia has not convicted any Liberian trafficking offenders under Liberia's anti-trafficking law, despite the country's significant internal trafficking problem'. ${ }^{1505}$ Even worse, prosecution of alleged war criminals who trafficked and enslaved girls and women during the 14-year civil war in Liberia is yet to happen. Another form of child exploitation exists in Liberia that has all the characteristics of trafficking but has not been labelled as such.

\footnotetext{
${ }^{1502}$ Plan Liberia, Daughters of War (Plan Liberia, 2014) <http://www.trust.org/item/20140609105720me5ov/?source $=$ fiTheWire $>$.

${ }^{1503}$ UN Office of Internal Oversight Services, 'Evaluation of the Enforcement and Remedial Assistance Efforts for Sexual Exploitation and Abuse by the United Nations and Related Personnel in Peacekeeping Operations' (UN Report General Assembly A/RES/61/26 B, Inspection and Evaluation Division, Office of Internal Oversight Services, 12 July 2015) 52, $22<$ https://oios.un.org/page/download2/id/13>.

${ }^{1504}$ Section 2 of the Act to Ban Trafficking Within the Republic of Liberia 2005 states that: recruitment, transportation, transfer, harbouring or receipt of a person, by means of the threat or use of force or other means of coercion or by abduction, fraud, deception, abuse of power or of a position of vulnerability, or by giving or receiving of payments or benefits to achieve the consent of a person having control over another person for the purpose of exploitation shall be a criminal offense within the Republic of Liberia.

1505 'Trafficking in Persons Report' (Government, Office of the Under Secretary for Civilian Security, US Department of State, July 2015) 382, 225 <http://www.state.gov/documents/organization/245365.pdf>.
} 
An exploitative human trafficking practice begun by African American settler-colonists in Liberia persists to this day. However, the new Trafficking in Persons Act 2005 does not include this form of abuse, probably due to its resemblance to acceptable cultural practices and generalised abject poverty seen in the country. ${ }^{1506}$ Abigail explains the impact of this 'disguised child-trafficking' custom that is all too rampant in Liberia:

The cases we get on children are mostly for rape, abandonment and street children. As I speak with you, if we were in Pleebo, say at 8:30pm, I'd say let's take a tour. You'll find many children sleeping in the street. In the morning, they will go to the Cold Bowl Shop ${ }^{1507}$ and wash dishes in exchange for leftover food eaten by patrons. At night, they sleep on the market tables in the open market area. Sometimes the police will arrest them and take them to the police station. But where do they keep them? Sometimes, the police will call Ministry of Gender. Having spoken with the kids, we find out that some of the children are taken from the village by family members with the intention of bringing them to the city to give them education. only to later find out that these children are used as slaves. In dealing with the situation, we try to connect with their biological parents by putting pressure on the caregiver. Sometimes we threaten the caregivers with police arrest and court case. Knowing this, they then open up to say, "this is my cousin child and I would like to return the child to his/her family." Some of the kids are orphan so they have nowhere else to go. They don't even have a safe home to go to. In this case, you're left with no option but to talk to the same caretaker to take the child back. Seriously, it is not an easy problem. [Abigail, Liberia]

Amelia, on the other hand admits, '[w]e don't think about how we overuse the children to do house chores so that they have no time to study. Then at the end of the year we expect them to pass. With that expectation, they are then obliged to engage in all sorts of stuff, including sex for grades'. Women are often incentivised to send their children to cities for the promise of support and education because the child's father has abandoned the family.

Abandonment, neglect and persistent non-support of children and women are commonplace in Liberia as research participants have observed. Family laws protecting children and women are rare in Liberia. A little step forward came in 2005, when Liberia elected its first female president; a series of family law reforms was carried out to conform to international legal standards. ${ }^{1508}$ Section 16.5 of the newly adopted Domestic Relations Law 2011, which revised the Penal Law (Domestic Relations) 1973, provides that,

[a] person commits a misdemeanour of the first degree if he persistently fails to provide support which he can provide and which he knows he is legally obliged to provide to a spouse, child or other dependent, as specified in section 5.4 of the Domestic Relations Law.

\footnotetext{
${ }^{1506}$ Article 1 (100) of the Act to Ban Trafficking in Persons Within the Republic of Liberia 2005 defines 'Trafficking In Persons' as the recruitment, transportation, transfer, harbouring or receipt of a person by means of the threat or use of force or other means of coercion, or by abduction, fraud, deception, abuse of power or of a position of vulnerability, or by the giving or receiving of payments or benefits to achieve the consent of a person having control over another person, for the purpose of exploitation.

${ }^{1507}$ A 'cold bowl' is usually hot meals cooked early in the morning without being heated all through the day until it's all sold cold.

${ }^{1508}$ For example, since the election of President Ellen Johnson Sirleaf, Liberia has passed new laws to fulfil its obligation under the Convention on the Elimination of all forms of Discrimination against Women 1979, the United Nations Convention on the Rights of the Child 1989 and Protocol to the African Charter on Human and Peoples' Rights on the Rights of Women in Africa 2003 (see chapters 2 and 3 above).
} 
Section 5.4 of the Domestic Relations Law 2011 designates jurisdiction and power to the Circuit Court, Magistrate's Courts, and Justice of Peace to compel support of dependents from caregivers who are negligent. Section 5.3 of the Children's Law Act 2011, having regard to Penal Code Section 16.5, also empowers the Ministry of Health to act as a mediator in child support cases concerning persistent non-support. Experts' consultation on the Draft Domestic Violence Law in Liberia (2013) categorises persistent non-support as a form of economic violence. The Draft Domestic Violence Law suggests that, inter alia

1) [non-persistent support] violators should be given a sentence of 6 months to 1 year;

2) any police officer compromising persistent non-support should be suspended for 9 months; and

3) fathers should be jailed for 7 months and damages paid in monetary value for abandoning a mother and child or children. ${ }^{1509}$

Over and again, Indigenous research participants complained vehemently about the prevalence of persistent non-support of children directly resulting in a high number of mothers parenting children alone. Consider Yaa's, Martha's and Damawa's comments, respectively:

Besides rape and domestic violence, persistent non-support/child support is now a serious thing. You'll have men marrying women having kids with them and dumping them by the wayside to marry another person. They just don't care to support these women anymore. [Yaa, Liberia]

The boys will impregnate the woman and refuse to own up because he doesn't have the financial means. If you don't have money, why must you go and pregnant somebody child? The big belly needs to eat. She has to wear clothes, and all that. If they can sit down to think about it carefully, they can come out with ways to take care of the problem. But no, they don't think. After impregnating the girl, they end up saying, "that belly is not for me". So, the young girl will say, if he doesn't own up, I can't force him. I'll be by myself. When God help, I'll deliver and have my baby with me. [Martha, Liberia]

This man will come around and fool them into having sex. Once they are pregnant, he will then say, it's not his. The men are leaving the women because the men do not like to work hard. When the men realise their responsibility, i.e., he has five children and wondering how he would feed them and provide their basic need; then he later decides to leave and find a woman who does not have those kinds of responsibilities. That's how they are abandoning their women around here every day. [Damawa, Liberia]

Unfortunately, the exploitation of girls for work and the persistent non-support by fathers lead to a lack of education, which correlates to increased risk of sexual abuse. Amelia identifies a statistical link between girls' lack of education and their corresponding vulnerability to domestic and sexual abuse in Liberia (see chapter 2):

It is observed from the Ministry of Education statistics that more girls are enrolled between kindergarten to $6^{\text {th }}$ grade. By $7^{\text {th }}$ grade they start to drop out. In $12^{\text {th }}$ grade, there's almost no girl present. I visited a particular county. There were only five girls in the senior high school. When I asked why, I was told they all have babies. So, for those of us with daughters who finish high school and college, we need to merry-make

\footnotetext{
${ }^{1509}$ Madhumita Sarkar and Timothy Paulus, 'County Consultation on Draft Domestic Violence Law - Issue Paper' (Public Report, Ministry of Gender and Development, UNFPA, Embassy of Sweden, October 2013) 53, 12-13 <http://www.undp.org/content/dam/liberia/docs/docs/Domestic\%20Violence\%20Issue\%20Paper.pdf.>.
} 
because it looks like $10^{\text {th }}-12^{\text {th }}$ grades can be seen as college graduates for Liberian girls. [Amelia, Liberia]

Amelia's suggestion of 'merry-making' when a girl completes high school is concerning, especially when the sex ratio of Liberia's 3.4 million people is $1: 1$ (see chapter 2), yet 52 per cent of women cannot read compared with 28 per cent of boys who are literate. ${ }^{1510}$ Sadly, at the time in their lives that Liberian girls should be receiving a junior high school education, they are at their highest risk of being raped.

Rape and domestic violence are two prevalent forms of community/interpersonal violence against Liberian girls. The most egregious examples of violence against Indigenous girls and women are shattering, e.g., a 60-year-old man raped his sister's 24-month old baby to death, (also see Tables 7.3 and Appendix X). This case and many more are yet another reason survey and interview participants in Liberia perceived rape, wife beating, physical violence, domestic abuse, and sexual assault as characteristic of systematic gender violence. Even with the relatively low rate of reporting, research participants disclosed that having 12000 cases, mostly of rape and domestic violence, reported to the Ministry of Gender, Children and Social Protection over a five-year period (see Table 7.3) not only substantiates expressed concerns about taking the issue seriously but is also downright mind-boggling.

We have 817 cases involving children between the ages of 6 and 12. Some 1,005 cases were girls between the ages of 13 and 16 years. Only 300 of those cases involve women above the age of 18 years. Last year [2013], we had over 1000 cases that put children between 1 and 10 years. One girl died, she was about 10 years old. Something concrete needs to be done here about this. [Survey Participant, Liberia]

In 2011, over 2700 cases of rape were reported in Liberia. Some 2678 of those cases involve girls, 33 involve boys, and 305 cases were children between 0 and 5 years. Can you believe, even a four-month old baby was raped by a teacher? The teacher went scot-free. [Survey Participant, Liberia]

There are lots of case files, mostly from the police. Issues that come out include early marriage, forced marriage, and domestic violence (beating on women) etc. Others include allegations of witchcraft. At least 94 per cent of the files are child rape cases. Sometimes 65-70 cases [of domestic violence and rape are] reported a day. [Survey Participant, Liberia]

Actually, a major issue here is women and girls who are raped from 7-15 years. The teenage girls are the more affected. High incidence of women accused of witchcraft. Luckily, we have the sexual and Gender-based Violence Task-Force. For example, a 62 -year-old woman was abused by the traditional leaders, her right to movement and health was denied. She was seriously ill when we rescued her. After that, we were able to save her using Liberia National Police. [Survey, Liberia]

My work as a public defender sees the majority of rape cases and gang rape. Other crimes coming to my desk are property theft, burglary ... Murder is very low. Defenders are always doing rape cases, conferences between couples, boyfriends and girlfriends disputes, etc. [Survey Participant, Liberia]

\footnotetext{
${ }^{1510}$ Liberia Institute of Statistics and Geo-Information Services et al, above n 316, 38-39.

Note: The total number of women ages $15-49$ is 9,239 , includes ten cases for which information on literacy is missing; and the total number of men, ages, 15-49 is 4,118 includes eight cases for which information on literacy is missing.
} 
The Indigenous women and girls was banned out of their rights. They were forced into marriages. Banned out of education because they said women should be house servant and not allowed to work in the public service area. [Survey Participant, Liberia]

In my current work, we deal with students and they have these issues of abuse by teachers and workmates. We recommend that they leave the institution in case of molesting and requesting sex for grades especially the doer of the abuse. We have had molesting and attempted rape for about 3-4 persons over the last year. We asked them [the perpetrators] to leave. [Survey Participant, Liberia]

Men are in the prison for various charges. Some are here for murder. There are 20 here for rape, theft of property, burglary, aggravated assault, debt, etc. [Survey Participant, Liberia]

People subscribe to witchcraft. There is no provision to punish juvenile sex offender. Another reform and the issue of juvenile sex offender, people do deliberate things because they know that they can't be punished by law. County attorney should be prioritising gender-based violence cases. Jury selection compromises cases because of corruption. People practicing the traditional culture can't be prosecuted easily. Corruption of minors, involves a 14-year-old who was raped. And, another case is about a 3- or 4-year-old girl who was raped but the traditional person can't be prosecuted. Yet there was another case about a 25 -year-old caught in [a] rape claim but said that he was a 17-year-old. [Survey Participant, Liberia]

Interpersonal and community violence, including rape and domestic violence, are pervasive not only in Liberia.

Australian Aboriginal communities also face prevalent interpersonal and community violence. However, unlike survey participants in Liberia, those in Australia repeatedly mention alcohol and drug use as co-morbidity factors of domestic and sexual violence:

Also, the introduction of alcohol, drugs and Western ways may contribute to violence in Aboriginal families. Build the WHOLE family and the WHOLE community. No one person should be left out of the loop as this will contribute to the breakdown of the family nucleus. [Survey Participant, Australia]

Alcohol and drug use appeared to play a part in domestic violence when I worked at the New South Wales Aboriginal Legal Service. Substance abuse needs to be addressed. [Survey Participant, Australia]

Substance misuse and abuse has a significant connection to violence and is a critical part to be addressed to reduce violence towards Aboriginal women and children. [Survey Participant, Australia]

Alison's perspective on addiction (generally) and alcohol (specifically) points to a history based on religion and morality: '[i]t was unique to Australia that addiction wasn't a dirty word but rather a biological disease that people could recover. It was unusual for policy people too because, for them, it was all about the morality of drinking. It was very Christian for a man to be able to hold his drink and not hit his wife because with alcohol meant issues of rage, terror and grief stemmed from your family origin.' Dallas offers a pessimistic but realistic viewpoint. She adds that '[e]ven if we get all the response system right, and we're able to start changing men's attitude towards the use of violence, get control of access to alcohol, and a whole lot of things...we're still going to see violence occurring in a couple of generations'.

As in Liberia, sexual violence against Aboriginal girls and women persists mainly due to what Adams and Hunter describe as 'no-stranger danger' in Aboriginal communities in 
Australia, as 'perpetrators of child sexual assault are almost always known to the family, or are part of the family'. ${ }^{1511}$ In Australia, both survey and interview participants rationalise that poor understanding of Aboriginal culture is partly responsible for the underreporting of interpersonal/community violence, in spite of its high occurrence. For example, pressures from extended family, not necessarily acknowledged by white Australian law, may contradict safety issues and subsequently complicate reporting of a seemingly high occurrence of child removal ('the new stolen generation') and domestic violence in Australia. A rigid legal system, with a 'one-size-fits-all' approach (see $S$ 's concerns with the Royal commission into Institutional Responses to Child Sexual Abuse above), 'does not take into account past experiences of traumatic cultural aspects, power difference in educational standards and psychological responses to the trauma', critiques a survey participant in Australia. Such an approach risks harm to (and sometimes results in fatalities of) Aboriginal girls and women, mostly in remote areas, because, it is hard to obtain protection or restraining orders in such communities. However, even when these restraining orders are obtained, they are not always enough to protect women and girls.

An Aboriginal woman who is protected by an apprehended violence order ${ }^{1512}$ and who must hand over her children to an ex-partner continues to be in a threatening situation in Indigenous communities. It is in such cases that research participants reasoned that police restraints are 'useless', 'not able to keep women safe', or 'often insignificant because women and children find it difficult to escape violence'. Some research participants believe that police restraining orders are not always 'ad hoc' or 'chancy' as they '...can sometimes be helpful in protecting Aboriginal children and women'. Albeit, 'whether they are helpful depends on the support women are able to access throughout the process, the individual response of police officers, and defendant compliance with the orders', says another survey participant. For example, Aboriginal girls and women residing in remote communities often have difficulty notifying police of a breach or violation of a restraining order when they do not have a phone or when they live in an area with no phone coverage. Without safer alternatives, many women are forced to remain in abusing relationships, which exposes them to further state violence.

State policy and domestic abuse intersect at Aboriginal women in Australia, giving rise to a 'new stolen generation'. Anecdotes abound concerning the 'new stolen generation', citing examples of a lack of representation in the legal system, lack of consultation, and readiness of the Australian Government Department of Social Services to quickly remove, or threaten to remove, children from Aboriginal women who are experiencing domestic violence. According to Sally,

\footnotetext{
${ }^{1511}$ Adams and Hunter, above n 365.

${ }^{1512}$ Restraining or protection orders are called differently across jurisdictions in Australia. Restraining orders are usually issued by the Magistrates Court or by police. In NSW it is called Apprehended Violence Orders (AVO), domestic violence order (DVO) in QLD, ACT and NT or violence restraining order (VRO) in Western Australia. Section 13 of the Restraining Orders Act 1997 (WA) states that violence restraining order is an imposes restraints on the lawful activities and behaviour of the respondent as the court considers appropriate to prevent the respondent from committing an act of abuse against the person seeking to be protected.
} 
there are about 600 children in foster care and about 300 are Aboriginal kids. I have two grandchildren in my care. They try to give my grandkids back to their nonAboriginal mother who was an alcoholic drug-user who was very neglectful of the children. I put braces on my granddaughter's teeth. But I didn't realise that I had to ask family services if I could do it. I took my granddaughter out of a public school and put her into a private school and all hell breaks loose. I was supposed to tell them or talk to them before I moved her. You know, I think a lot of people are from England. Their system and the way they do things is a lot different from ours. Most Aboriginal children were brought up on missions. A lot of the younger generation are stolen generation people. That institutionalisation and intergenerational trauma just goes on and on. We are worried now about losing a couple of more kids if this cycle keeps happening. There's no Aboriginal childcare service here. There is no Aboriginal hostel. And, there's lot of problem with homelessness, couch surfing or living rough at the Tent Embassy. [Sally, Australia]

Sally's agony over losing more Aboriginal children will lingers, she says, until

all people working in jobs where they make decision about Aboriginal families have regular cultural appropriate classes, so they will hopefully understand our people and try to make our kids' future better with less Aboriginal Peoples in the court system and many less Aboriginal kids in family and child protection services ${ }^{1513}$ living away from their mobs... [Sally, Australia]

As a response to these concerns, on 5 January 2015, the Australian Capital Territory government appointed five cultural advisers to support Aboriginal and Torres Strait Islander children in care. Their role is to help 'articulate the needs of children and young people in care and would play a critical role in helping caseworkers to ensure their work and decision making is culturally respectful...by assisting with locating kin to support families and children in contact with the child protection system'. ${ }^{1514}$

\subsection{Traditions, Culture and Customs}

Throughout this research it is argued that violence against women is not confined to Aboriginal girls and women. Irrespective of one's identity, society in general is patriarchal and girls and women are disproportionately vulnerable to male dominance and systematic violence. The responses from research participants above affirm that in Indigenous customs, although violence against women occurs, there have always been remedies and redress for survivors of such violence.

When it comes to the issue of gender-based violence, rape, beating etc., the elders sit there and accept goats, cows or food in exchange for a woman's abuse. Rape and murders are not usually cases for traditional chiefs. These traditional practices are harmful when it comes to rape and murder of women. The tradition must be taken to task when criminal activity results. But they are not willing to assist and comply favourably with women. Before the war, children between the ages of 14 and 16 were given away in marriage. As young as age 8 , children were put to work to earn money. I know of a case where a man took a house girl (15 years old) even though he was

\footnotetext{
${ }^{1513}$ NSW Government's Department of Family and Community Services, available at $<$ http://NSW Government, Family \& Community Services (4 January 2015) About Us <https://www.facs.nsw.gov.au/about_us>.://www.facs.nsw.gov.au>.

${ }^{1514}$ Natasha Boddy, 'Cultural Advisers Appointed to Support Aboriginal and Torres Strait Islander Children in Care' Canberra Times (Canberra, ACT), 5 January $2015<\mathrm{http}: / /$ www.canberratimes.com.au/act-news/cultural-advisersappointed-to-support-aboriginal-and-torres-strait- islander-children-in-care-20150104-12hnpj.html>.
} 
married. He sent his wife to Monrovia so that he could abuse the 15 -year-old girl. There were four persons involved in the end. And they were all UN staff members. [Survey Participant, Liberia]

So, in our Traditional Laws, it is wrong to be violent towards women and children. Our laws are based on spiritual values. There is a punishment law called, 'little bit kill, big big kill'. If a man commits murder and rape, he's a 'big big kill' - it means he gets speared dead immediately because that's the punishment. It operated everywhere. There were paybacks for things that people did wrong. People lived that law and they were expected to live that law. If you run away, you got sunk or the bow pointed at you. 'Little bit kill' is for adultery and things like that. If you had a consensual sexual relationship with someone who's not in the right moiety group - that sort of thing. [Alison, Australia]

\begin{abstract}
When a man cusses his wife, all women are called to apprehend him. It is one way to prevent violence against women. If you afflict injury, you will be summoned by the paramount chief, who will in turn fine you. Everything is in seven, whether it is oil, goat or rice. If you continue to inflict violence against women, they will banish you from the town. [Abigail, Liberia]

This question should be put to Aboriginal people (I am not Aboriginal - I hope there is going to be a question which asks me that). Customary law is a complicated issue - the issue of 'bullshit customary law' (see Audrey Bolger and others) is one of the complications. Additional, customary law is not static. Whether Aboriginal women and Aboriginal people are able to reach consensus about whether and how customary law should apply, which aspects, and in what circumstances, are all questions to be addressed. [Survey Participant, Australia]
\end{abstract}

As is true of all traditions around the world, not everything about Aboriginal cultures in postwar Liberia and Australia is as deplorable as settlers may have assumed.

Indigenous Women Advocates and some survey participants recognise the importance and usefulness of Indigenous cultures despite the existence of harmful traditional practices that subject women to continuous violence and abuse. Indigenous cultures in both countries are not homogenised, simplistic and inflexible but diverse and resilient having survived for millions of years (see chapter 2). For example, according to Jaky, Aboriginal language would have thrived much better today had it not been intercepted by white settler-colonists:

\begin{abstract}
A lot of communities stop passing information to their children, so they would not be an easy target for white Australia. Disregarding their language made them seem somehow ready to assimilate. With that, our cultural practices were shut down, kept quiet, and went sort of underground... [but] language is the single greatest source of life. For many Aboriginal Peoples, it is a shame to think that we can't speak our language. This gives a sense of great deep personal sorrow that knowing the loss of what it is to have all that knowledge taken away from you in many ways. So much knowledge and cultural practices are embedded in language. There's a lot of evidence building up to show that Aboriginal students/kids who study their own language tend to have a better sense of engagement with schooling in general and that is across curricula. There's something magical about speaking one's own language. It is fundamental. It is a UN basic human right. If you want to disempower people, you make them speechless, really. [Jaky, Australia]
\end{abstract}

Sally also agrees that tampering with Aboriginal lore has caused personal denigration, trauma, and cultural dysfunction;

I think customary law more probably exist in remote places where there is more traditional lifestyle. But because of its dysfunction and desecration...I mean what we got was a lot of dysfunction, dislocation, anger, inter-generational trauma, and all of 
those things that impact through colonisation. We always say, "white Australia has a black history". I say, if Captain Cook would have landed in one of the other parts - no disrespect to the people in say Darwin - those fellows would look like us. We had assimilation and all of those things [Sally, Australia].

Notwithstanding the significance and diversity of Indigenous societies and some research participants' comments frowning on violence against women, others still view the occurrence of violence as normal in Aboriginal cultures:

[i]n the Kimberley violence against women and girls is normal. Last week I saw a man kicking a woman in the head in the middle of the road. A crowd stood around and watched as he drunkenly swung his booted foot at her head. She was screaming out. Cars were driving past, and people were laughing. I think there is a belief that they are just drunk Aboriginals and they need to sort it out by themselves. The community needs to learn to respond. Violence is so normal it is terrifying. [Research Participant, Australia]

Irrespective of the perceived acceptance of the 'natural occurrence' of violence in Aboriginal cultures, harmful traditional practices that subjugate females exist in Indigenous cultures and need to be tackled head on.

Harmful traditional practices related by research participants are not just simple conjectures but are alarmingly real lived experiences for Indigenous girls and women. Attempts to collaborate and rethink approaches on addressing the issue of systematic violence defy simple solutions. Joan Kimm calls it a 'fatal conjunction' that though different in concept, both AngloAustralian law and Indigenous Customary Laws have failed to prevent systematic gender violence against Indigenous girls and women. Kimm cautions that there are 'no safe places' for Aboriginal girls and women who experience violence. Even 'kinship connections make escaping violence often difficult', says a survey participant in Australia.

Domestic partner and other interpersonal and community violence exists within Aboriginal communities in Australia. Audrey Bolger, ${ }^{1515}$ Pam Greer, ${ }^{1516}$ Diane Bell, ${ }^{1517}$ Boni Robertson, ${ }^{1518}$ Paul Sutton, ${ }^{1519}$ and Joan Kimm ${ }^{1520}$ (also see chapter 3) have all documented the gory details of inter se sexual violence inflicted upon Aboriginal girls and women in Australia. For example, Joan Kimm discloses:

The 1980 Northern Territory case of Ivan Imitja Panka illustrates the kind of death, which women can suffer in town camps. The circumstances were a fatal mixture of alleged male rights under Traditional Laws and alcohol. Panka pleaded guilty to manslaughter on the grounds that his wife had offered him provocation in Traditional Laws because she refused to cook him some meat: that is, he was relying on a husband's traditional rights of chastisement. He 'decided to punish her for being cheeky'. Both were very drunk. After punching and hitting her he 'took a piece of rippled reinforcing steel and forced it into her vagina'. ${ }^{1521}$

\footnotetext{
${ }^{1515}$ Audrey Bolger, 'Wangkajunga Women: Stories from the Desert' (1997) 11 Aboriginal History 102.

${ }^{1516}$ Pam Greer, 'Report to Domestic Violence Committee' (1989) 13(4) Aboriginal and Islander Health Worker 14.

${ }^{1517}$ Bell, 'Speaking about Rape Is Everyone's Business', above n 814.

${ }^{1518}$ Boni Robertson, 'The Aboriginal and Torres Strait Islander Women's Task Force on Violence Report' (Queensland Department of Aboriginal and Torres Strait Islander Policy and Development, 2000) 328.

${ }^{1519}$ Peter Sutton, The Politics of Suffering: Indigenous Australia and the End of Liberal Consensus (Melbourne University Pub, 2011).

${ }^{1520}$ Kimm, above n 789 .

${ }^{1521}$ Ibid $11-12$.
} 
Research participants mention myriad issues related to traditional practices and violence; nevertheless, for lack of space and time, only the following five themes will be considered (below).

\title{
8.2.1 Violent Patterns: Domestic, Family and Intimate Partner Abuse
}

The Australian Human Rights Commission reports that approximately one woman is killed by her current or former partner every week in Australia, often after a history of domestic and family violence. ${ }^{1522}$ The Liberia Institute of Statistics and Geo-Information Services reports that the proportion of women aged 15-49 years experiencing intimate partner physical or sexual violence at least once in their life time is 39 percent. ${ }^{1523}$ Findings from this research document a pattern of interpersonal/community violence both in Liberia and in Australia (see chapters 3 and 7). In Australia, participants described this violent pattern regarding behavioural acculturation passed on from colonisation, and its resurfacing at certain times of the year, certainly fuelled by alcohol and drug abuse:

\begin{abstract}
Roz Middleton Moz who had worked with Native communities in Canada, coined the term, "acculturation". According to her, children of alcoholics have the same behaviour patterns as children of acculturation. If your country is colonised by a dominant culture, and you're violently colonised, then over generations, the children begin to exhibit the same signs that children exhibit when they grow up. She said, when you look at this behavioural pattern, they are all the same. In Australia, not only did Aboriginal people have alcoholism, introduced drugs, introduced violent colonisation, attempted genocide on our communities, but then we had our adaptation to survive meant that our children grew up with certain behavioural patterns. It was that that really catapulted me into the whole research topic because she saw it in the Canadian native communities, and they were so like us. [Alison, Australia]
\end{abstract}

You know there's certain times of the year that things get really explosive and that's around Christmas time and around Easter time. I don't know whether it is because people drink more around that time or people are getting depressed because they don't have the money to buy presents and all that sort of things - a bit like John Howard, previous Prime Minister, years ago wouldn't say sorry. And then, you often see a lot of blow-ups and ... I always say to my staff, just be mindful that Christmas is on its way. We see a lot more of that now. [Sally, Australia]

The Aboriginal and Torres Strait Islander Social Justice Commissioner describes family violence as involving any use of force, be it physical or non-physical, that is aimed at controlling another family or community member and that undermines that person's wellbeing. ${ }^{1524}$ Family violence can be directed towards an individual, family, community or a particular group, but it is not limited to physical forms of abuse. Family violence also includes cultural and spiritual abuse of both adults and children. ${ }^{1525}$ There are interconnecting and transgenerational experiences of violence within Indigenous families and communities. The family unit of Aboriginal societies is extended, with many relatives and often whole communities

\footnotetext{
${ }^{1522}$ AHRC Admin, About Family and Domestic Violence (25 September 2015) Australian Human Rights Commission <https://www.humanrights.gov.au/our-work/family-and-domestic-violence/about-family-and-domestic-violence>.

${ }^{1523}$ Liberia Institute of Statistics and Geo-Information Services et al, above n 1030, xxv.

${ }^{1524}$ Law Reform Commission of Western Australia, above n 142, 283.

${ }^{1525}$ Ibid.
} 
sharing childrearing responsibilities with biological parents. The relevance of culture in the context of Aboriginal family violence is not so much about Indigenous Customary Laws as about the life circumstances of many Aboriginal victims. ${ }^{1526}$ The United Nations Convention on the Rights of the Child 1989 'best interests of the child' principle requires that in all actions concerning children, the child's best interest is a primary consideration. ${ }^{1527}$ However, the best interests of an Aboriginal child may be quite different to those of a non-Aboriginal child. The Law Reform Commission of Western Australia argues that the relative subjective application of 'best interest of the child' principle by administrative decision-makers, the court and criminal legal system must be informed by relevant cultural considerations. ${ }^{152}$

Australia is taking steps to understand family violence, but translating that understanding into policy has not resulted in effective legal frameworks to address the problem. An inquiry from 230 consultations into family violence by the Australian Law Reform Commission and the New South Wales Law Reform Commission (the Commission) reflects intense and ongoing concern regarding the pattern and public cost of family violence. ${ }^{1529}$ Recognising that the Family Violence Inquiry concerns are only a narrow slice of the vast range of issues raised by family violence when women and children encounter the legal system, the Commission argues that fragmentation of the system has led to a fragmentation of practice. ${ }^{1530}$ The Commission also notes that a key element of the challenge of family violence is that, neither the Commonwealth nor the States and Territories have exclusive legislative competence in family law. Moreover, the boundaries between the various parts of the system are not always clear, and jurisdictional intersections and overlaps are 'an inevitable, but unintended, consequence'. ${ }^{1531}$ The Commission suggests that the legal framework applicable to patterns of family violence will improve when the following elements are present: a common interpretative framework based on core guiding principles, improved quality and use of evidence, and better interpretation or application of sexual assault laws. ${ }^{1532}$ Further efforts to measure family violence and understand its sources are underway.

Family violence has various intersecting causes, and officials are implementing new efforts to measure it. The Law Reform Commission of Western Australia examines the causes of Aboriginal family violence, which the Commission suggests is due to the breakdown of the community kinship systems and Indigenous Customary Laws, alcohol and drug abuse, the

\footnotetext{
${ }^{1526}$ Ibid 289.

${ }^{1527}$ Ibid 276.

${ }^{1528}$ Ibid 277.

${ }^{1529}$ Australian Law Reform Commission, 'Family Violence - A National Legal Response' (Government Report, Australian Law Reform Commission and the NSW Law Reform Commission, 2010) 2455, 10 <http://www.alrc.gov.au/sites/default/files/pdfs/publications/ALRC114_WholeReport.pdf>.

${ }^{1530}$ Australian Law Reform Commission and New South Wales Law Reform Commission, 'Family Violence and Commonwealth Laws - Improving Legal Frameworks' (Government Report ALRC Report 117, Australian Human Rights Commission, 2011) 581, 11-12

<http://www.alrc.gov.au/sites/default/files/pdfs/publications/whole_alrc_117.pdf>.

${ }^{1531}$ Australian Law Reform Commission and New South Wales Law Reform Commission, 'Family Violence - A National Legal Response: Summary Report' (2010) 78, 12

<http://www.alrc.gov.au/sites/default/files/pdfs/publications/Report\%20Summary.pdf>.

${ }_{1532}$ Australian Law Reform Commission and New South Wales Law Reform Commission, above n 1530, 16.
} 
effects of institutionalisation, previous government removal policies, and entrenched poverty. The problem of overcrowding in many Aboriginal households also appears to be a significant factor contributing to problems of family or interpersonal violence. ${ }^{1534}$ As family violence is a national emergency, on 17 May 2015 the Victoria Minister for the Prevention of Family Violence, Fiona Richardson, unveiled plans to develop a Family Violence Index. The Premier of Victoria, the Honourable Daniel Andrews, commissioned the Australia's National Research Organisation for Women's Safety (ANROWS) to define what measures, statistics and data should be included in the index. ${ }^{1535}$ Richardson's report: Measuring the Toll: The Family Violence Index 2014 states that, 'a family violence index would bring together data from across the fields of crime, justice, health, education and our community to create a single indicator of family violence'. ${ }^{1536}$ The multidisciplinary approach used to define the Family Violence Index builds on and lends to the complex system model adopted in this dissertation to assess systematic violence against Indigenous women. Additionally, the Victoria government admonishes the Royal Commission into Family Violence (Victoria) to place the Family Violence Index alongside its final report. The goal of the Royal Commission into Family Violence, inter alia, was to identify the most effective ways to develop and refine systemic responses to violence, including in the legal system by police, corrections, child protection, legal and family violence support services. ${ }^{1537}$

\subsubsection{Female Genital Cutting: Girls' Education, Statutory Rape and Forced Marriage}

Responses from research participants in Australia did not state that the practice of female genital cutting occurs in Aboriginal Australia, but it does occur in parts of Liberia. In Liberia, female genital cutting is closely tied to girls' chastity in preparing them for (early) marriage. In some Liberian language groups, a female will not be accepted into a marriage if she is not circumcised. Article 5(a) of the Protocol to the African Charter on Human and Peoples' Rights on the Rights of Women in Africa 2003, ${ }^{1538}$ Article 21(1) (a) and (b) of the African Charter on the Rights and Welfare of the Child 1990, ${ }^{1539}$ and Article 24(3) and Article 32(1) of the United

\footnotetext{
${ }^{1533}$ Law Reform Commission of Western Australia, above n 142, 283.

${ }^{1534}$ Ibid 284.

${ }^{1535}$ Daniel Andrews, World First Index To Measure Family Violence (17 May 2015) Premier of Victoria <http://www.premier.vic.gov.au/world-first-index-to-measure-family-violence/>.

${ }^{1536}$ State of Victoria, 'Measuring the Toll: The Family Violence Index' (Government Policy, Ministry for the Prevention of Family Violence, 2015) 8, 5 <https://www.viclabor.com.au/wp-content/uploads/2015/05/FamilyViolence-Index.pdf>.

${ }^{1537}$ State of Victoria, 'Royal Commission into Family Violence: Summary and Recommendations' (Parl Papers No 132, Victorian Government, March 2016) 1 〈http://files.rcfv.com.au/Reports/Final/RCFV-All-Volumes.pdf〉.

${ }^{1538}$ Article 5(a) urges Prohibition, through legislative measures backed by sanctions, of all forms of female genital mutilation, scarification, medicalisation and para-medicalisation of female genital mutilation and all other practices in order to eradicate them; by member states. 21(1) (a) and (b): 1. States Parties to the present Charter shall take all appropriate measures to eliminate harmful social and cultural practices affecting the welfare, dignity, normal growth and development of the child and in particular: (a) those customs and practices prejudicial to the health or life of the child; and (b) those customs and practices discriminatory to the child on the grounds of sex or other status.

${ }^{1539}$ Article
} 
Nations Convention on the Rights of the Child $1989^{1540}$ all prohibit harmful traditional practices against women and girls. At the time of writing this chapter in 2015, female genital cutting was not yet formally criminalised in Liberia. However, there was a common law prosecution on 8 July 2011, ${ }^{1541}$ in response to an incident where two Zoe women forcibly subjected Ruth Berry Peal to female genital cutting, which received a guilty verdict. ${ }^{152}$ The Peal verdict, coupled with award-winning journalist Mae Azango's ${ }^{1543}$ reporting on the issue and petition by local women's groups, was partly responsible for shutting down the Sande Schools and bringing an indefinite halt to issuing licenses to allow the practice across Liberia. ${ }^{154}$ In January 2018, prior to her leaving office, former President Ellen Johnson Sirleaf signed an executive order that put a oneyear ban on female genital cutting ${ }^{1545}$ (see chapter 3 ).

In Liberia, female genital cutting is part of a larger cultural practice of traditional schools that has other negative consequences for children. As discussed in chapter 3 , female genital cutting is practiced only in the north-western parts of Liberia. ${ }^{1546}$ Abigail confirms that the practice is not performed in the south-east, '[t]hey don't practice FGM as there are no female chiefs in Maryland'. In Liberia, research participants frequently expressed concerns about the traditional schools reinforcing the practices of cutting female genitalia, interrupting girls' education, committing statutory rape and forcing girls and young women into marriage. Young girls often attend traditional schools, where the idea is that the cutting of the clitoral hood quintessentially prepares them for marriage; this rite takes place around the same time school is in session. Sia retorts that in the northern part of Liberia where the practice of female genital cutting is relatively prevalent, ' $[t]$ he culture in Lofa no longer forces children to join their society bush'. However, a survey participant agrees that the practice does indeed interrupt girls' learning. He adds that,

\footnotetext{
${ }^{1540}$ 3. Article 24(3) States Parties shall take all effective and appropriate measures with a view to abolishing traditional practices prejudicial to the health of children; and article 32(1) 1. States Parties recognize the right of the child to be protected from economic exploitation and from performing any work that is likely to be hazardous or to interfere with the child's education, or to be harmful to the child's health or physical, mental, spiritual, moral or social development.

${ }^{1541}$ Jerome W Toe, ‘Zoes Convicted of Forced Initiation' Daily Observer (Monrovia, Liberia), 11 July 2011. According to Augustus Caine (1959) a 'Zo' is a term given to one who possesses, or is sophisticated in, some secret lore. Since this official has extra-human connections from which he can acquire information (Dadewe and the ancestral spirits are alleged to communicate with him), the title is appropriate. But since of all groups or individuals possessing secret knowledge Dadewe is regarded as the most powerful he is called Dazo, meaning Grand Zo or the Zo of Zos (see p33).

${ }^{1542}$ Equality Now, 'Liberia: Enact a Law Banning FGM as a Matter of Urgency'

$<$ http://www.equalitynow.org/take_action/fgm_action372>.

${ }^{1543}$ Mae Azango, 'The Cost of FGM to Liberian Girls' Front Page Africa (Monrovia, Liberia), 2014

$<$ http://www.asafeworldforwomen.org/global-news/africa/liberia/2184-mae-azango-the-cost-of-fgm-to-liberiangirls.html>.

${ }_{1544}$ Wade CL William, ‘Sande Shutdown: Traditional Leaders and GOL Suspend Women's Secret Society’ Front Page Africa (Monrovia, Liberia), 30 March 2012

$<$ http://www.frontpageafricaonline.com/index.php?option=com_content\&view=article\&id=2852:grebo-bushshutdown-traditional-leaders-gol-suspend-womens-secret-society\&catid=42:politics\&Itemid=109>.

${ }^{1545}$ Emma Batha, 'Liberia Bans Female Genital Mutilation - but Only for a Year' Reuters (Monrovia, Liberia), 25 January $2018<$ https://www.reuters.com/article/us-liberia-fgm-law/liberia-bans-female-genital-mutilation-but-onlyfor-a-year-idUSKBN1FE1N7>.

${ }^{1546}$ Phyllis Chesler, 'New Study Shows Half of Liberian Girls, Women Undergo Female Genital Mutilation' Breitbart (Los Angeles, CA), 14 December 2014 <http://www.breitbart.com/national-security/2014/12/11/new-study-showinghalf-of-liberian-girls-women-undergo-fgm-not-a-surprise/>.
} 
the legal system is not clear in certain aspects of Indigenous women's lives. For example, in attending or participating in cultural ceremonies - female genital mutilation - customary law takes precedence here. Schoolchildren or girls will usually miss out on two to three months into the academic semester, which may result in them not being allowed in school for the year. [Survey Participant, Liberia]

Forced child marriage is another traditional practice reinforced by Liberia's traditional female institution. Indigenous Women Advocates in Liberia hesitated to give direct responses to questions about the Sande Institution. What was learned later in the study is that due to the oath of secrecy taken by members of the Sande School, some Indigenous Women Advocates are prohibited from speaking against or about the institutional practice. Some Indigenous Women Advocates in Liberia are members of the Sande Society. Thus, regardless of their advocacy work, their loyalty was bound to the Sande Institution. Therefore, there was limited disclosure of information about the institutional practice of female genital cutting in the Sande Society. Notwithstanding, Sia divulges:

The traditional is very strong in Lofa especially when it comes to child marriages and female genital mutilation. So, even if you want to change it, it is not easy because there is a conflict between the rule of law and the customary law in Liberia when it comes to the age of consent for marriage. In the traditional practice, they say 15 years is the age of marriage. The law on the books says 18 . So, how are we supposed to change this? There is a problem, but we can't do anything about it. [Sia, Liberia]

According to Article 55(g) and (i) of the Liberia Rules and Regulations Governing the Hinterland 1942, it is unlawful to pay a dowry for a girl who has not attained the age of 15 years, and the proper dowry for a woman shall not exceed $\$ 40$ (see chapter 4). Klade confirms that even unborn girls are betrothed as guardians of the Indigenous Customary Laws in Liberia 'feel that the girl child withers away as she's married at about 12 years'. In fact, her dowry is paid when she's in her mother's womb, Sia says, explaining

[t]he culture is that when a woman is pregnant, a man will show up with a dowry stating that if it's a girl child, then she will be my wife. So right from the womb the girl's fate is sealed. When she's delivered, the man will continue to take care of the mother and the child until the child reaches 6 years of age at which time she would be given to the man. When she turns 15 years then she becomes his wife. Now is time to follow the rule of law in Liberia. We are not saying the tradition should be ignored but it is very important for the tradition to understand that there is a rule of law that protects everyone, and it has to obey this law. [Sia, Liberia]

Although the tradition varies across cultures in the 15 counties of Liberia, most rural communities follow the Indigenous Customary Laws pursuant to the Liberia Rules and Regulations Governing the Hinterland 1942, especially where Indigenous men dominate 'in a custom of reserving a girl for a man'.

Generally, traditional customs in Liberia are patrilineal. A survey participant affirms that in Liberia, 'the family of a husband is entitled to the wife's domestic and conjugal rights and all other assets, and products of the union'. ${ }^{1547}$ Sections 2.1 and 2.2 of the Act to Govern the

\footnotetext{
${ }^{1547}$ Ayodeji Olukoju, Culture and Customs of Liberia (Greenwood Press, 2006) 91.
} 
Devolution of Estates and Establish Rights of Inheritance for Spouses of Both Statutory and Customary Marriages 2003 (the Inheritance Law 2003) grants traditional marriages legal status ,entitling the wife to one-third of her husband's personal or real property (see Chapter 3). According to Klade, '[i]n customary marriages [in Liberia], if I am married to a man and he dies, I will be passed on to his brother. If I refuse, then I will lose the property both of us have worked together to accumulate. The husband's family will take the kids away, kick me out of the house, and deny me any marital rights'. Although Klade's comment contradicts the statutory settler-colonist law, the Rules and Regulations Governing the Hinterland 1942, which upholds this practice is still in force in Native Liberia (see chapter 4). Furthermore, it is lawful for parents to choose their daughter's husband (section 2.1 of the Inheritance Law) in Native Liberia because 'marriage is never a simple contract in between the couple, rather, it is a bond between the couple and their respective in-laws and kinsfolk' argues Ayodeji Olukoju. ${ }^{15}$

\subsubsection{Child Bearing/Rearing and Abuse}

Some Indigenous Women Advocates, whilst respecting the role of Indigenous Customary Laws in gender relations, especially regarding grandmothers passing down traditional knowledge to granddaughters believe that certain aspects of Indigenous oral customs are not appropriate for raising children. Indigenous practices of childrearing, specifically, betrothing an unborn child, paying a dowry for a 15-year-old girl, offering livestock as a remedy for rape, or performing genital cutting on a 6-year-old are consistent with several forms of abuse. Such practices infringe international, ${ }^{1549}$ regional ${ }^{1550}$ and domestic law ${ }^{1551}$ regarding the age of consent. Dallas disapproves of such harmful childrearing practices:

Customary law is a place where the two genders complement each other. There is a place for women and men in customary law. Although I think it disadvantages women. I think it also needs to really be examined when we're talking about childrearing practices. Work I have done in the past, supported changes to Northern Territory legislation where customary law could not be used as a defence in the case of underage sex, i.e., an adult man having sex with an underage girl. [Dallas, Australia]

Some survey participants who did not identify as Aboriginal Persons, were hesitant to share their opinions about the role of customary lore in Aboriginal Australia, but readily disapproved of its inability to prevent violence against children and women. Other survey participants argued 
that, "[t]raditional laws and practices can negatively impact women's rights in a "modern" Australia'. The fact that 'women want the violence to stop but often want to remain with their abusive partners' is not compatible with healthy childrearing practices. Reinstating 'the role of Elders in the delivery of traditional lore can be seen as an important part of addressing violence against women and children ... as accurate information is given about cultural lore in order to prevent any misuse to justify an act of violence by a perpetrator, especially when most elders are males, or the perpetrator is a white fella', says a survey participant.

\title{
8.2.4 Taming Girls and Women
}

In Liberia, Indigenous women have the obligation of taking care of their male partners, or else they can face retribution. 'It is my own understanding that the law in Monrovia governs everyone. But when we look at the customary law, people interpret it differently. In our traditional setting, men believe that women have no rights. They cannot be heads of the home. It means that they are not really abiding by the rule of law in the traditional system', says Sia. Although there is a sense that at some time in the past traditional practices did not resort to resolving gender violence in 'the family way', it appears women themselves have acculturated to enabling male chastisement and rebuke. A younger Indigenous Woman Advocate describes Monrovian young girls' obsession with older married men:

\begin{abstract}
Liberian women like married men, because they don't have control over the girls. If they [the men] try stupid jealousy the girl could threaten to blow [the] alarm [i.e., disclose the relationship to his wife]. So, they will succumb. Married men will do everything for the young girls. They can relax at the girl's house with not much problem. But for the young boys, they want to have too many girlfriends, they are too demanding, and they have roving eyes. Maybe in terms of dress code as an excuse for rape doesn't count since a 6-month-old baby dress code does not attract them. But we don't dress properly as young girls. Another thing is, men say women are weak, but they are weaker than us. If you took an oath in your marriage to commit to your wife, then whatever I do or wear should not attract you. [Tomah, Liberia]
\end{abstract}

Most male survey participants believe that girls and women are subjected to male dominance in Liberian society. The expression 'taming girls and women' describes this experience of patriarchy and paternalism in Liberia. Tomah's description of young girls' desire for older men suggests a level of denial of access to social services (e.g., education and employment), which subjects girls and women to the control of men. Notwithstanding males' propensity to subjugate girls and women by virtue of their higher socio-economic status in Liberia, not all research participants agree with the idea of condoning male abusive control and dominance over girls and women in Liberia. For example, a male social worker with a nonprofit organisation cites a no-nonsense traditional system that prohibits violence against girls and women:

[w] hen a man beats a woman, he's charged with a goat that goes to the elder. In Karluway District, if you insult a woman you have to buy soap for all the women. Sometimes they put pepper water into the eyes of the abusive partner. There's no compromising or solving violent abuse in the family way. There was a case in Cavalla 
where a 16-year-old boy raped an 11-year-old girl. The resolution was the perpetrator takes care of the child (i.e., provides food, medication) until she grows up. When she reaches childbearing age, if she can't have a child, they'll then force him to marry her, rather than let him go to prison - for fear of people saying, 'because of your daughter, my husband/son went to jail.' [Survey Participant, Liberia]

An issue of concern with the above survey participant's perspective is that retaliating with pepper water in the eyes of a perpetrator, asking him to buy soap for the survivor or compelling him to take care of her until she reaches child-bearing age is problematic. The trauma and lifelong suffering of violent abuse cannot be addressed with soap or pepper water. Moreover, subjecting an 11-year-old child to the care of a perpetrator and putting her life on hold until she reaches child-bearing age adds to the trauma for the survivor especially in a culture where women are blamed for being violated. However, there are still many people in Liberia who would sooner blame the girl than the perpetrator. A male pastor shares his thoughts, saying

[w]omen too should know their level in provoking or respecting their husbands. Also, the dress code is responsible for 75 per cent of the rape. The girls are dressing indecently, showing all their private parts. If women dress moderately they won't be abused. Loving [having a sexual relationship] out of the marital home is also another issue. Most of our girls are being sponsored by married men. If a girl is not 18 years old, it is statutory rape to sleep with a married man. Ninety-nine per cent of girls at Tubman University are sponsored by men. [Survey Participant, Liberia]

Having read and listened to numerous accounts of male participants' insensitive and pathetic blaming and justifications for inflicting violence on girls and women, Indigenous Women Advocates offered perspectives that tended to rise above the men's overall denigration of girls and women. An account by Klade provides another reason to heed the voices of Indigenous women in tackling systematic violence. Notice the technique Klade uses to neutralise what could have otherwise escalated into a violent attack:

\begin{abstract}
Few months ago, we had an incident where a husband went to get his wife out of class. He said he went home and there was no food at home. He didn't marry his wife to go to school. So, after a hard day's work, when he gets home, he needs food. Since there was no food at home, he had to go to school to get his wife out of class. I stepped out of class with the lady to speak with her husband. Seeing that he was very annoyed, we reasoned that if the lady follows her husband alone he might beat her. So, we followed both of them. He was huffing and puffing along, but we followed quietly. As we walked along, we started to calm him down and soothe him with nice words. He started smiling. We said, "you see how handsome you look when you smile rather than having that mean face"? I said to him, "he's right that his wife is supposed to prepare food for him before coming to class. But he should also understand". I asked, "how many children do you have?" He said, "four". I asked again, "how old are they"? He said, "the first is 19 years, the second is 14 , the third is 12 and the last one is 8 ". I asked, "how old he is"? He said, "55 years". I said, "God forbid something should happen to you and this woman has no means of supporting these children. Don't you think it is a good idea for her to get education"? I said, "she's in school, so you should be happy and give her a hug". He started to laugh, telling his wife that she should return to class and that he will wait for her after her classes. [Klade, Liberia]
\end{abstract}

\title{
8.2.5 Superiority of and Conflict with Settler-Colonist Law
}

When there is conflict between settler-colonist law and Indigenous Customary Laws, AngloAustralian and Anglo-American Liberian law are supposed to prevail (see chapter 4). Research 
participants recognised the contradictions and appealed for reconciling the two legal systems, despite having some reservations. Jaky's view on the relevance of Circle Sentencing in Australia illustrates this contradiction:

[w]e still practice our laws, just that they are not recognised in the legal system. The Circle Sentencing is like that. But the problem is, you've got to be guilty before you can go through that process. So, what's that all about? Instead of allowing us to deal with the situation first, we are brought in when the damage has already been done. To some extent, our customary practice is recognised, but you have to go through the Western business of being guilty and actually having a criminal charge/record before they can introduce Aboriginal customary law. [Jaky, Australia]

Yaa offers a direct method of dealing with the conflict between settler-colonist law and Indigenous Customary Laws as it pertains to rape cases in Liberia:

[w] hen we have conflicts of law and tradition, the first thing we do is to call a meeting where a committee will be set up to discuss the issue. The committee then sets up a meeting with the parties involved. We also have partners dealing with psychosocial counselling. During the psychosocial counselling, the parties will be told the implications of compromising a case by solving it the "traditional way". If you wish, you take the legal side, if you will, then follow your tradition. The implication is presented to you; the consequences of what has happened to you will also be told to you. And you can now decide. Besides that, we also contact the county attorney who is responsible for dealing with our cases to make sure all our cases are put on his file. If this case is one of those on his files, we notify him of the pending wish of the parties to solve the case the "traditional way". We then encourage the county attorney to put the case on the docket for prosecution. If it requires funding, then we generate the necessary amount needed to ensure that that case can be tackled. But like I said before, our partners are now closing down their activities, so we don't have available funding to deal with cases. [Yaa, Liberia]

Whilst Yaa's approach appears to be efficacious, it is not practiced in all jurisdictions.

In countries with huge disparities regarding access to social services, enforcing settlercolonist law in rural/remote communities is difficult. A research participant in Liberia affirms the challenges associated with implementing settler-colonist law in rural Liberia:

The law says if a man has sex with a girl under 18 years, it is statutory rape. But if you apply this to the interior, then you'll see thousands of rape cases because the girls are usually under 18-years when they get married. If you want to know who the child's father is and how many persons she's had sex with she could name 2-3 men who are probably underage. The girls love to [have relationships with] 2-3 men if they are able to provide food money for them. Girls are doing it for economic reasons. 1) They are poor, 2) lazy, 3) lack parental support, and 4) too materialistic, wanting clothes, shoes, etc. Girls dress to attract both men and women. In other Western countries, women compete with men. In Liberia, majority of the women are illiterate, they are lazy, they are too dependent on men. The Lofa women are highly prosperous. They can produce by themselves. So why do we have high single parent rate in Liberia? It is because the men cheat on the women. In Africa, men are mostly polygamous and in some cases it's OK because if the man is wealthy women are concerned about the property. It happened to Charles Taylor, he was polygamous, and his wife stayed in for the money. [Survey Participant, Liberia]

In Liberia, some progress has been made to reconcile Anglo-American Liberian law and Indigenous Customary Laws. First, Article 5(b) of the Liberian Constitution 1984 recognises Indigenous customs and tradition. In 2012, the House of Representatives enacted a law that 
accords the National Council of Chiefs and Elders of Liberia autonomous and legal status. ${ }^{1552}$ In Australia, the House of Representatives set up the Indigenous Affairs unit under the Department of the Prime Minister and Cabinet. ${ }^{153}$ In spite of these modest moves forwards, a research participant in Liberia questions whether such a male-centred body will have the credibility to 'amalgamate the Indigenous rule of law with that of the Republic of Liberia, in order to legitimise the new system'.

\subsection{Access to Services: Housing, Health, Education and Employment}

Several issues arose concerning Indigenous survivors of violence accessing social services. Research participants expressed concern over: 1) the obvious lack of services in remote communities; 2) inadequate provision of refuges and (safe) homes; and 3) abuse of grade-school girls. Chapter 2 establishes the deplorable lack of access to social services for Aboriginal Peoples, especially those residing in rural areas. The density of Indigenous Peoples in remote communities is relatively high compared with that in big urban cities in Liberia and Australia. At the same time, rural communities have gone for years without access to, for example, a counsellor, psychologist or sexual assault worker. Even when those services are available, in isolated communities, Indigenous survivors often worry about confidentiality and privacy when disclosing their experiences of violence or seeking care from support services. Schools and hospitals are few if not absent. ${ }^{1554}$ 'In the remote community, I am the only nurse. There are never enough services, but mostly women can access my service, but it is emergency and longterm housing which is hard for them to access', says $K$ in Australia. Employment and job facilities are rare, with 'city-trained' workers refusing deployment in these communities for obvious reasons: 'there is nothing here, no electricity, no tap borne water...life here is boring', says a survey participant in Liberia. Referring to the researcher, another United Nations human rights officer in Liberia commented that it is, 'seldom that you see an attractive young woman show up at your office to conduct a research interview in this part of Liberia'. The few community social workers who are able to commit to working in remote communities, experience high levels of stress and burnout, partly because authorities throw them into these towns with no supervision or briefing.

Access to housing, including refuges in Australia and safe homes or shelters in Liberia surfaced as major concerns for Indigenous girl and women survivors of abuse. Alison outlines a brief history of government policy on access to care, observing:

\footnotetext{
${ }^{1552}$ Ministry of Information, Culture and Tourism, Welcoming The National Traditional Council As An Autonomous Body (20 July 2012) Welcoming the National Traditional Council as an Autonomous Body

<http://www.micatliberia.com/index.php/media/new-liberia/opinions/editorials/744-welcoming-the-nationaltraditional-council-as-an-autonomous-body>.

${ }^{1553}$ Griffiths, above n 495. Also see, Aboriginal Affairs under the Department of the Prime Minister and Cabinet, available at $\langle$ http://www.dpmc.gov.au/indigenous-affairs/about>.

${ }^{1554}$ Adams and Hunter, above n 365.
} 
I actually don't think services for Aboriginal women who have suffered violence are accessible. When the government first started to provide that kind of service, they funded the accommodation assistance program that set up refuges for women. The service delivery agreement at that time was that they had to look after 30 per cent nonIndigenous women, 30 per cent non-English speaking background women and 30 per cent Aboriginal women. There weren't any Aboriginal women-specific services. A lot of these mainstream services didn't understand the cultural differences. They had their own form of covert racism, which made it difficult for an Aboriginal woman or family to go to them. But eventually, in the late 80s Aboriginal Peoples began to establish medium term accommodation services so Aboriginal women could stay with the children in houses, and then later move to their own accommodation. [Alison, Australia]

Sally is frustrated with the ongoing lack of housing for Aboriginal People in the Australian Capital Territory. When asked what she would do to protect Aboriginal girls and woman against violence, she blurted, 'I would have a block of flats, a hostel, where you have workers with them 24/7'. In Liberia, Yaa emphasises the financial and logistical challenges associated with providing such care:

Our office location in Sanniquellie is accessible. It is easy to find us; but, there's still a challenge. The reason is that at the county level we are still lacking resources especially when it comes to logistics. Nimba being so big, you cannot sit here and look at someone in Tappita and agree that the office is accessible. How can they reach here? What do you do to get them here? In making sure that the issue is resolved, we have set up an endowment fund, though it is not in place this year. If someone was raped in Tappita and they need access to health service, we ask that the person be taken to the referral hospital. The cost of transporting and providing other health services needed by the survivor is fully covered by the endowment fund. We also have a safe home ${ }^{1555}$ where the victim is taken for psychosocial counselling until they can agree to be relocated or go back to their community. [Yaa, Liberia]

In Liberia, research participants spoke of the issue of sex-for-grades as a way in which social services are exploited as mechanisms for gender violence. As Amelia's alluded to above, not only does girls' enrolment dwindle the higher the progress in grade school but their risk of being abused by male teachers, students and 'married men' increases. In the sex-for-grades situation, male teachers in public, private, secondary and university institutions ${ }^{1556}$ abuse their positions of power by molesting and assaulting female students in exchange for a passing grade on exams, tests and quizzes. A grade school principal shares his view on the topic:

Here we have lots of these women who have been abused. In my current work, we deal with students who have issues of being abused by teachers and workmates. We recommend that they [the abuser] leave the institution in case of molesting and requesting sex for grades, especially the doer of the abuse. We have had molesting and attempted rape for about 3-4 girls over the last year. School authorities should ensure that girls are not sexually harassed or abused for grades and other favours by male teachers. [Survey Participant, Liberia]

\footnotetext{
${ }^{1555}$ US Department of State, above n 1505, 222-223. During fieldwork, the only functioning Safe House was in Buchanan, Grand Bassa County. The United States Department of States' Trafficking in Person Report 2015 affirms that there are no government-run safe homes or shelters in Liberia. Non-governmental organisation run Safe Houses were located in Monrovia (3), Buchanan (1), and Sanniquellie (1).

${ }^{1556}$ Gloria T Tamba, 'MoE Vows to Stop "Sex for Grades" in Universities' Daily Observer (Monrovia, Liberia), 8 September 2015 <http://www.liberianobserver.com/education/moe-vows-stop-“sex-grades”-universities>.
} 
The issue of abusing girls before granting them access to education is grim, considering the frequency of its occurrence. According to Diana Quick, 45 percent of boys and 27 percent of girls in secondary schools are between the ages of 20 and $24 .{ }^{1557}$ The older girls are before starting school the greater their vulnerability to being harassed by male teachers or classmates (e.g., boys knocking their bums) and as a result there is a subsequent rise in dropout rates. Older girls also struggle to stay in school in the face of demands from their boyfriends and husbands that they stay home and perform their 'womanly' duties (see Klade's comments above) such as cooking or taking a sick child to the hospital. The establishment of the Indigenous Girls Academy ${ }^{1558}$ in Australia and of the Adult Literacy Program, ${ }^{1559}$ in Liberia is a small measure of progress.

\subsection{Access to Law and Justice}

Access to justice is critical for addressing systematic violence against Indigenous girls and women in that it is integral to improving broader sustainable development goals, protecting rights, and promoting public health in Liberia and Australia. Article 22(2) of the United Nations Declaration on the Rights of Indigenous Peoples 2007 provides for full protection of Indigenous children and women against violence and discrimination. ${ }^{1560}$ The Commission on the Status of Women emphasises that ad hoc international criminal tribunals recognise rape and other forms of sexual violence as war crimes. The Commission also stresses that gender violence should constitute genocide or torture and calls for 'the inclusion of gender-related crimes and crimes of sexual violence' in the Rome Statute of the International Criminal Court 1998. ${ }^{1561}$ According to the Open Foundation Society, violations of the human rights of socially excluded populations (e.g., Indigenous Peoples) can harm health and wellbeing. ${ }^{1562}$ In light of Australia's and Liberia's legal obligations regarding signing or ratifying international human rights laws (see chapter 4), the expectation is that the rule of law is capable of restoring justice to Indigenous girls and women survivors of systematic violence.

Systemic problems reduce Aboriginal girls' and women's access to justice in Australia. $S$ says, 'I had to come to terms with the fact that there is no justice, I don't believe that there is any justice'. A survey participant in Australia expressed frustration when responding to the research question about whether the law is just, saying: 'I hated answering this question. I am not sure that "just" is the right response. I think it tries to uphold justice, but there are many

\footnotetext{
${ }^{1557}$ Diana Quick, 'Rebuilding Education from Scratch in Liberia' (2005) 11(Supplement) Forced Migration Review 18.

${ }^{1558}$ Genine Unsworth, 'Indigenous Girls Academy Kicking Goals' Australian Broadcasting Corporation (South West, WA), 1 April 2010 <http://www.abc.net.au/local/stories/2010/04/01/2862623.htm>.

${ }^{1559}$ Jennifer Lazuta, 'Liberia Literacy Program Targets Women’ VOA (Dakar, Senegal), 7 August 2013 <http://www.voanews.com/content/liberia-literacy-program-reaches-women-in-mid-life/1725157.html>.

${ }^{1560}$ Article 22(2) states, 'States shall take measures, in conjunction with indigenous peoples, to ensure that indigenous women and children enjoy the full protection and guarantees against all forms of violence and discrimination.'

${ }^{1561}$ Commission on the Status of Women, Report on the fifty-seventh session Supplement 7, UN ECOSOC, $57^{\text {th }}$ sess., UN Doc E/CN.6/2013/11 (4-15 March 2013) 1.

${ }^{1562}$ Open Society Foundation, 'Justice Programs for Public Health: A Good Practice Guide' (Private Report, Open Society Foundation, 2015) 138, 6.
} 
systemic failures with protecting Aboriginal women and children. I do not think the law is "just" really on violence toward women and children generally'. Research respondents agreed that the law does not generally respond well to women who have been subjected to violence from men, in that there are so many negative outcomes that 'I cannot think of one that ever gave justice to an Aboriginal woman as a victim of sexual violence' (also see chapter 7). Some participants made an effort to point out that the law is not 'fair to all women, not just aboriginal women'.

Women and girl survivors face further discrimination if they are children or suffer from mental illness. Halay Clark related to Dr Vivian Waller's presentation on how legal limitations can thwart access to justice for survivors, particularly children and adult survivors of childhood sexual assault, and how recent reforms in Victoria have further eroded the rights of survivors to commence civil proceedings. Clark continues, 'the laws of limitation [specifically in Victoria] fail to appreciate and accommodate the unique presentation of the psychiatric injuries commonly suffered as a consequence of sexual assault, particularly in the sexual assault of a child' ${ }^{1563}$ How can survivors of abuse with psychological trauma access justice when settlercolonist laws and services limit or refuse to include such provisions? Sally explains the relationship amongst Indigenous Australians with mental health illness, their inability to access care and denial of access to justice:

\footnotetext{
There is no facility for people with serious mental health needs. We've got 853 clients with diagnosed mental illness and 353 of them have got a co-morbidity. So, they are pretty fragile in the minds. Their moods can go from happy to very angry very quickly. Yet, a lot of them were getting banned from the Centrelink ${ }^{1564}$ because they aren't well. I know that Professor Dodson and Jill Guthrie and others are working on that justice reinvestment. If you put more resources into people to stay out, they're more likely to stay out. But too many people are in prison now because they've got mental illness that could put them on probation parole. [Sally, Australia]
}

In spite of the situation described above, some survey participants in both Liberia and Australia suggest that there are instances where the law can be just and helpful to Indigenous survivors of systematic violence (see, chapters 3 and 7). However, Table 7.11 shows that the number of views expressing dissatisfaction with injustice far outweigh those perceiving the law to be just or helpful.

\subsubsection{Systemic (Racial) Discrimination, Corruption and Bribery}

If there is a systemic, institutional dimension to racial discrimination - as evidently there is towards Aboriginal and Torres Strait Islander people - one place to begin may be with Australia's Constitution. As one Aboriginal and Torres Strait Islander advocate in Adelaide stated, Constitutional recognition of Aboriginal and Torres Strait Islander

\footnotetext{
${ }^{1563}$ Clark, above n 517.

${ }^{1564}$ The Human Services Legislation Amendment Act 2011 integrated Medicare Australia and Centrelink into the Department of Human Services of the Commonwealth Government of Australia on 1 July 2011. Centrelink is responsible for developing service delivery policy and providing access to social, health and other payments and services.
} 
people would be an important step towards non-discrimination of Australia's first peoples and perhaps provide some explicit protections against racial discrimination. ${ }^{1565}$

Whereas in Liberia discrimination is based on classism and social status, in Australia ${ }^{1566}$ systemic racism ${ }^{1567}$ against Aboriginal Peoples exists, and a key feature of such racism is 'denialism'. ${ }^{1568}$ A recent report by the Australian Human Rights Commission, assessing four decades of the Racial Discrimination Act 1975, identifies systemic and institutional racism to be at the heart of a nation-wide debate on the issue. According to the report, "there was an agreement amongst Aboriginal and Torres Strait Islander participants in Perth, Darwin and Brisbane that systemic or institutional discrimination was the primary challenge in combating racism' as reflected in the alarming incarceration rates of Aboriginal Peoples who have little or no representation in Australia's judiciary. ${ }^{1569}$ Findings from this research show that the court and law enforcement systems are characterised by double standards, abuse of power and exploitation of vulnerable groups. 'As a reflection of society, the law cannot work outside the context of societal racism, thus, it seems unreasonable to expect a legal response to operate outside of systemic racism towards Aboriginal Peoples', says a survey participant in Australia. Doubts and fears expressed about justice for Aboriginal girls and women stem from the perceived impossibility of dealing with major structural issues, such as 'systemic racism and lack of adequate political power to Aboriginal Peoples', a survey participant in Australia asserts. Research respondents express 'shock over continuing failures of governments and the Australian community to face the issues of colonisation and settlement and the injuries inflicted on Aboriginal women, children and people', which make access to justice impossible. Despite some efforts made by the public institutions to address violence against Indigenous girls and women,

there is still a cultural and social stigma that many Aboriginal women and girls are confronted with when appearing before the court. Particular pertinence here relates to the appearance of Aboriginal women in the Family Courts when their children have been taken away because of unsubstantiated allegations or when they have been charged with offences related to trying to protect their children against the interest and encouragement of older men with young Aboriginal girls. [Survey Participant, Australia]

In Liberia, the judicial system is compromised by corruption, rather than racial bias. According to the Judicial Canon Twelve: Gifts and Favours of Liberian Penal

\footnotetext{
${ }^{1565}$ Tim Soutphommasane, Ting Lim and Anna Nelson, 'Freedom from Discrimination: Report on the 40th Anniversary of the Racial Discrimination Act - National Consultation Report' (Government, Australian Human Rights Commission, 5 November 2015) 104, 73

<https://www.humanrights.gov.au/sites/default/files/document/publication/RDA40_report_2015_AHRC.pdf>.

${ }_{1566}$ Australia signed on to the International Convention on the Elimination of Racial Discrimination (ICERD) in 1966 and ratified it in 1975 with the passing of its Racial Discrimination Act 1975.

${ }^{1567}$ Joe Feagin, Systemic Racism a Theory of Oppression (Taylor and Francis, 2013) 2

<http://www.123library.org/book_details/?id=109951>. According to Feagin, systemic racism surpasses individual prejudice. It is a material, social and ideological reality, which encompasses a broad range of attitudes, emotions, habits, actions and institutions of whites, for example land dispossession and slavery.

${ }^{1568}$ Helen Szoke, Racism exists in Australia - are we doing enough to address it? (14 December 2012) Australian Human Rights Commission <https://www.humanrights.gov.au/news/speeches/racism-exists-australia-are-we-doingenough-address-it>.

${ }^{1569}$ Soutphommasane, Lim and Nelson, above n 1565, 41.
} 
Law 2011, a judge should not accept any presents or favours from litigants, or from lawyers practicing before him or her, or from others whose interests are likely to be submitted to him or her for judgment. However, Henry Karmo suggests that the crux of discrimination against Native Liberians lies with a corrupt judiciary system. ${ }^{1570}$ According to the Liberian National Integrity Barometer Report and Transparency International, more than 75 per cent of police officers accept bribes. ${ }^{1571}$ Jerry Gbardy confirms research participants' accounts of gender violence cases being compromised by law enforcement officers' interference with or obstruction of the course of justice. Affirming that reform of Liberia's legal system is necessary, Gbardy argues that the 'Liberian way' of seeking redress is a fundamentally dysfunctional quick-fix approach that compromises the legal system. A rampant abuse of power by those in authority, the 'Liberian way' negates any legal path towards fair resolution. Such 'a process that has a wanton disregard for the rule of law [thus] encourages arbitrariness and perpetuates corruption'. ${ }^{1572}$ Klade's take on 'under-the-table justice' in Liberia is illustrative:

I shouldn't say incompetent because then I'll be condemning the lawyers that we have. We have some very good lawyers. But I think we should look at incentives. If lawyers are well paid, I'm sure the issue of under-the-table justice will be reduced if not eradicated. If lawyers are paid well, provided a car, house, and other amenities, they will not be so inclined to take bribes. The government Ministers are another one. Rather than parking government vehicles, they use them for personal transportation. Travelling on the highway, you'll see government vehicles transporting goats, chicken, charcoal, cassava leaves and food produce as if they are commercial transport. Sometimes, they go on the highway and set their own roadblock. They do this publicly without shame. There is no law and order in the country, starting from the heads. If there were stiff justice and I violate the law, I'll be obliged to obey and follow my punishment. But seeing that I can easily bribe the police to get away with my crimes, I'll not be afraid to commit such crime. Even my little niece knows that the police take bribery. [Klade, Liberia]

\subsubsection{Law Enforcement, Courts and Legal Assistance}

Many remote communities in Liberia and Australia do not have a government presence. There is either is no local court or, when a court exists, it may sit every fortnight or once per month. Even in some areas of the big cities such as Canberra, legal aid assistance is provided only once per week. Indigenous Peoples in remote communities have a long history of discrimination and racism. Discriminatory behaviour exhibited by law enforcement officers and the legal system makes it difficult for Aboriginal survivors of violence to trust the police. Research participants

\footnotetext{
${ }^{1570}$ Henry Karmo, "Most corrupt: National Integrity Barometer rates Liberia's judiciary with very low marks", Front Page Afr (20 December 2013) http://www.frontpageafricaonline.com/old/news/general; Henry Karmo, "Most corrupt-national integrity barometer rates Liberia's judiciary", Front Page Afr (20 December 2013) http://www.frontpageafricaonline.com/index.php/news/161. According to Karmo, of the 1,400 participants interviewed in 7 of 15 counties in Liberia, 38 per cent agreed and 6.8 per cent strongly agreed that they sometimes offer to pay court personnel extra money/gifts/favour for cases taken to court. On the other hand, 37 per cent and 15 per cent of respondents agreed and strongly agreed, respectively that they were often asked by judges or court personnel to pay extra money/gifts or do favour for cases taken to court.

${ }^{571}$ Deborah Hardoon and Finn Heinrich, 'Global Corruption Barometer' (Private Report, Transparency International, 2013) 48, 11 〈http://www.wingia.com/web/files/news/61/file/61.pdf>.

${ }^{1572}$ Gbardy, above n 924, 206-207.
} 
disclose that, 'many of our Aboriginal clients are concerned that engaging with the criminal justice system will result in them "losing control" of the situation and will just end up with their partner being locked up, or charged, which won't actually help the family in the long run'. Indeed, it can be tough for an Aboriginal survivor of violence to approach the police when they cast racial or discriminatory slurs at her or refuse to show up at her doorstep because the situation is 'another call from that house again' or they do not believe her story. There are stories of fatalities of Indigenous girls and women in families with a history of violent offences that the police do not take seriously (see Andrea Pickett's and Angel Togba's stories in chapter $3)$.

As some communities do not have a police station, the nearest law enforcement facility may be two or more hours' drive away. There may be a 'doorbell' that people can use to call officers of the law, but this is practically useless in an emergency situation, says a survey participant in Australia. If survivors of violence are lucky enough to get their cases heard in court, the challenge gets even worse as the cost and social impact associated with going to court is more deleterious for Indigenous survivors of systematic violence. According to Adams and Hunter, in criminal trials for family violence or sexual assault, victims sometimes find that the trial is just as bad as the actual attack. Their words get twisted by defence solicitors when they are giving evidence; they can easily get confused and intimidated by the system, and thus are frequently accused of lying or making up stories of violence to get compensation. When a survivor of violence makes an application for compensation, they encounter further difficulties. The Victims Compensation Tribunal can place too much emphasis on a victim's failure to report the violence to the police. Such demand on the part of the Tribunal can make it tough for survivors to receive compensation when they are severely injured by violence but feel unable to report to police.

Legal aid programs for Aboriginal Peoples do exist in Australia. The Aboriginal Legal Service, now a commonwealth government-funded program was first established in Redfern, New South Wales in 1971. The Aboriginal Legal Service has some offices across states and territories and provides representation and legal assistance to Aboriginal Peoples who lack financial means. ${ }^{1574}$ Their priority is to represent defendants in criminal matters, although they play a significant role in policy, advocacy and law reform. ${ }^{1575}$ However, they are severely underfunded (see Lara's comments above). In Liberia, however, there is no established government-funded legal aid program.

In addition to a lack of legal aid, female underrepresentation in the legal profession also hinders women's access to representation in the legal system in Liberia and Australia. Indigenous Women Advocates in both Australia and Liberia recognized a disparity in the

\footnotetext{
${ }^{573}$ Adams and Hunter, above n 365.

${ }^{1574}$ Ibid.

${ }^{1575}$ See Jonathan Hunyor's presentation on Aboriginal and Torres Strait Islander Legal Services and Access to Justice at the Commonwealth Regional Law Conference, Sydney, 21 April 2012, available at <http://www.naaja.org.au/wpcontent/uploads/2014/07/Aboriginal-and-Torres-Strait-Islander-Legal-Services-and-Access-to-Justice.docx > .
} 
representation of women in the legal profession. They also noted its detrimental impact on survivors' access to justice. They were asked, are there as many women as men in the legal profession?

No, AFELL [Association of Female Lawyers in Liberia] is in Monrovia. There are no female lawyers in Maryland. I strongly recommend that we have female lawyers in Maryland to help women with abuse and violence cases in court. Even at my level as an access to justice coordinator, I only give advice. I am not a lawyer. There are other areas in the access to justice process that having a female lawyer is crucial. [Abigail, Liberia]

Our legal system is very male-centred. It is male dominated. You know most judges, most magistrates, most senior legal counsel are still men? So, how can women deal with that? Particularly, back to when traditional practices were still very much alive and kicking, women still prefer to talk to other women about women's business. So, with a male-dominated legal system, there is no place for an Aboriginal woman's point of view in our legal system. And I mean an Aboriginal woman point of view that is not cast or couched in a male point of view. I'll make that statement. I would think that through your research you'd probably be getting a sense of that. I doubt through all your interviews, we are like most women in the world. Women are gagged through one way or the other, by male dominance. [Jaky, Australia]

In an effort to combat violence against women in Liberia, the Liberian government has established executive and judicial institutions. The United States Department of State's Human Rights Report on Liberia 2013 states that there were 52 Women and Children Protection Services of the Liberian National Police, 21 of them outside Montserrado County. ${ }^{1576}$ At the time of the report, one-third of the 210 Women and Children Protection Services officers assigned throughout the country were female. Additionally, the Sexual Pathways Referral program, a combined effort of the government and Non-Governmental Organisations, helps to improve access to medical, psychosocial, legal, and counselling assistance for survivors of abuse and violence. The report further discloses that the Women and Children Protection Services of the Liberian National Police stated that approximately 280 rape cases were reported to the unit. Of these, 83 were forwarded to Criminal Court Assizes 'E' (Sexual Offences) ${ }^{1577}$ and 37 to Criminal Court Assizes ' $\mathrm{C}$ ' (offences against Property, Narcotics and Hallucinogens), both of the First Judicial Circuit Court in Montserrado county. ${ }^{1578}$ Four rape cases were actually prosecuted; one resulted in conviction, one acquittal, and two cases remained pending (see chapter 7). ${ }^{1579}$ Notwithstanding the meagre progress made by Women and Children Protection Services, Sexual and Gender-Based Violence Crimes Unit and Criminal Court 'E', this research found that approximately 12000 cases of sexual assaults were reported to the Ministry of Gender in the past five years, a number that dwarfs the 37 cases adjudicated by Criminal Court 'E'. Even

\footnotetext{
${ }^{1576}$ Bureau of Democracy Human Rights and Labour, above n 1096, 15-16.

${ }^{1577}$ Amendment of Title 17 of the Revised Code of Laws of Liberia, known as the Judiciary Law of 1972 added a new Chapter 25 established Criminal Court ' $E$ ' (also called Sexual Offenses Court) of the Criminal Assizes of the First Judicial Circuit (Liberia Penal Law 2011).

${ }^{1578}$ Bureau of Democracy Human Rights and Labour, above n 1096, 15. Criminal Court ' $\mathrm{C}$ ' hears all criminal cases apart from those involving gender violence.

${ }^{579}$ Ibid $15-16$.
} 
if the government of Liberia were successful in establishing Special Court 'E' in all 15 counties, access to forensic evidence for survivors of sexual abuse would be a major obstacle.

Gathering forensic evidence to support the prosecution of rape cases is not accomplished effectively in Liberia or Australia. However, in spite of the challenge in producing forensic evidence to support survivors of violence during trial, Amelia (Liberia) has hope:

I think it was some time last year [2013] that we introduced the collection of forensic evidence. It is now being piloted at the James N Davis Jr Memorial Hospital in Neezo, here in Montserrado County. Once we pilot that and we see that it is working with the necessary trained staff, we will think about spreading the services across the county. Very soon, forensic evidence will be a part of the examination and evidence collected to prosecute cases in court. [Amelia, Liberia]

From Amelia's account, forensic evidence gathering does not exist in Liberia. Should the current pilot at the James $\mathrm{N}$ Davis Jr Memorial Hospital materialise, the hope is to extend services across Monsterrado County first. Rural communities, where Indigenous girls and women survivors of violence are more prevalent and vulnerable, will probably not have access to forensic evidence in the near future. The situation is not any better in Australia, say Maureen Phillip et al., who assert that '[a]ccess to forensic medical services for sexual assault victims post-assault is a pressing need throughout Australia, especially in rural and regional areas'. ${ }^{15}$

Having survived court trial, and if fortunate enough to see the perpetrator convicted, Indigenous girls and women next face achieving a feeling of fairness and justice, wherein adequate punishment is given to perpetrators. In the context of systematic gender violence against Indigenous girls and women, incarceration for wrongdoers is sometimes seen by research participants as a direct form of justice for interpersonal/community violence. The situation gets more complicated when it comes to state/institutional violence, where Aboriginal males, on the one hand, are over-represented in the prison system mostly for 'trivial crimes'; yet on the other hand, states and institutions responsible for systematic violence against Indigenous girls and women have received little or no punishment. This is where most research participants express lack of confidence or hope for justice in a legal system controlled by setter-colonist law.

With the decline of corporal punishment and the death penalty for Indigenous Australians by the late 1960s, the ultimate and universal form of punishment was imprisonment. Chapters 1, 2, and 4 discusses Fanon's decolonisation process as a violent one and offer an assessment of the link between incarceration, colonisation, marginalisation and other social ills. Inter se crimes that resulted in high imprisonment rates of Aborigines, starting with the establishment of the first Aboriginal prison for men in Rottnest Island, Western Australia, $1838,{ }^{1581}$ has also been discussed in chapter 4. In Discipline and Punish (1979) Michel Foucault

\footnotetext{
${ }^{1580}$ Cameron Boyd, Interview with Maureen Phillips, Angela Williams and Karen Willis, 'Forensic Medial Care for Sexual Assault Victim/Survivors in Australia' (2008).

${ }^{1581}$ Weatherburn, above n 688, 11-12; Sean O'Toole, The History of Australian Corrections (UNSW Press, 2006)

187. O'toole suggests that the initial plan for setting up a separate Indigenous offenders' facility on Rottnest Island
} 
regarded prisons as a reinvented discipline and a new technology of power exercised through the deprivation of liberty, which replaces public displays of torture and execution. He claims that imprisonment is not about deterrence but is simply part of the 'general tactics of subjection'. The tactic of detention translates into gross over-representation of Indigenous Peoples in state prisons and police custody. ${ }^{1582}$ Overall, Aboriginal Peoples suffered the calamity of incarceration on government-run settlements, Christian-run missions, and settler-owned pastoral properties. In Australia, prior to the 1960s, the research literature reported no more than 20 instances of conscious acts of self-destruction amongst Aboriginal People. ${ }^{1583}$ By 1980, the death of 21-yearold Eddie Murray in police custody at Wee Waa, New South Wales highlighted the self-harm of Aboriginal Peoples due to the effects of incarceration. ${ }^{1584}$ Unfortunately, incarceration causes structural harm in addition to physical and mental harm.

Imprisonment further reduces Aboriginal Peoples' access to justice and legal reforms. Angela Y Davis, an American political activist and scholar, calls 'racist violence' and mass incarceration of African-Americans in the United States a 'prison industrial complex', a coupling of capitalism and a structurally racist state. ${ }^{1585}$ As restated by Lara (see chapter 7), ${ }^{1586}$ Davis is not saying perpetrators of crimes should not be held accountable. However, there is no doubt that over-incarceration of Aboriginal people hinders their ability to vote and participate in the nation's democratic process, a violation of the basic principles of the rule of law. ${ }^{1587}$ In Liberia, incarceration of a person accused of sexual assault who has not yet gone to trial is even more complicated regarding deterrence, justice for survivors and violation of convicts' fundamental rights, says Klade:

It is already known in Liberia, or maybe across Africa, that justice for women is justice denied. So, what's the issue here? The issue is that the systems are not working. We need to train people properly to deal with violence against women and girls. Consider that there are eight cases on the docket but only one is being prosecuted for a whole year. It just doesn't serve as a deterrent. Sometimes people linger in jail for eight months. At the end of the day, the UN and Human Rights Groups will say, "you have violated the man's rights, so the prisoners should be released". Then he goes to another community and commits the same act of violence. [Klade, Liberia]

Also, in Liberia, when convicted or accused perpetrators are released, an absence of technology and low computer literacy of service providers prevent law enforcement and service providers

(i.e., to allow Indigenous offenders greater freed) turned out to be a disaster since the 150 -year-old special prison, where approximately 3700 Indigenous men and boys were imprisoned with 369 recorded deaths (mostly disease).

${ }^{1582}$ Anthony, above n 1204, 49.

${ }^{1583}$ Colin Tatz, Oliver Mendelsohn and Upendra Baxi, 'A Question of Rights and Wrongs' in The Rights of the Subordinated Peoples (Oxford University Press, 1996) 159, 162.

${ }^{1584}$ Ibid 161.

${ }^{1585}$ Stuart Jeffries, ‘Angela Davis: "Unbroken Line of Police Violence in US Back to Slavery”" The Guardian (London, UK), 14 December 2014 http://www.theguardian.com/global/2014/dec/14/angela.

${ }^{1586}$ 'But what I don't agree with is a lot of people saying that the Royal Commission was about making sure that Aboriginal people don't spend that much time in custody. Therefore, when they commit an offence no matter what they are, we should take that into account and look for lesser alternatives. The Royal Commission said the overall representation that it was concerned about were offences of minor nature. So, things like being locked up for being drunk in public etc. They never said that there should not be harsh penalty for horrendous crime.' [Lara, Australia]

${ }^{1587}$ Jeffries, above n 1585. 
from tracking these individuals to other locales. A case in point is that of Daniel Hamilton, who killed his wife in Maryland but broke jail and ran away to another county.

\subsection{Challenges and Opportunities}

Given the context, the difficulties associated with addressing systematic violence against Indigenous children and women are innumerable. Aboriginal Peoples are the poorest group in Australian society and remain the sickest sector of Australian society, with appalling levels of ill-health for a 'first world' nation. ${ }^{1588}$ Primarily, the empirical data from this research show that a primary challenge to overcome is the uncorroborated perceptions and beliefs that obscure the sources of systematic violence against Indigenous girls and women. For example:

Who are the perpetrators of violence against women?

I would think one of the most important tasks that is requiring urgent attention is the misnomer that all violence against Aboriginal women and children is at the hands of Aboriginal men when in fact a large percentage of our women have been violated by their non-Indigenous spouse or partner, which is very rarely identified, leaving many outside of the community believing that our men have a predisposition to violence and violence-related tendencies when this is not true. [Alison, Australia]

Is violence against Indigenous girls and women an acceptable and normal phenomenon in Aboriginal culture?

Violence in any form should be unacceptable regardless of the culture behind the perpetrators hands but it is equally important that this misnomer against all Aboriginal men be addressed accordingly because this is another critical aspect to address in terms of gender violence. [Lara, Australia]

Violence against women and girls is almost so "normalised" that the local community often dismisses the severity and impact of violence against their own women and girls. Although they don't like the violence perpetrated, often many Aboriginal women have experienced and survived violence and love their men, so they aren't always advocating for women/girls to lay charges against the perpetrator but just try and avoid the situation until the situation calms. This then doesn't assist either the men or women in understanding and getting help for their issues as victims and perpetrators of violence. [Survey Participant, Australia]

Has reporting increased and subsequently resulted in redressing violence against Indigenous girls and women?

Most families are not willing to report rape since most of those accused of the act are family members. The other side of the problem is based on people's perception. They do not report cases. People are afraid of the law. Even if it's reported they don't get legal redress because the perpetrator is not investigated properly. In between the police and the courts, there's not good evidence. The law is unhelpful because the cases are not reported. For example, rape cases are sometimes taken up the "family way", which means it can be resolved in secret between family members. [Survey Participant, Liberia]

Is violence against men increasing at an alarming rate?

${ }^{1588}$ Tatz, Mendelsohn and Baxi, above n 1583, 167. 
Another issue is violence against men. On the contrary, some women are more energetic than their husbands. Some women abuse men too. I had a friend where his wife slaps on her husband. When we go out in the field we make it clear that women can also abuse men. We encourage men to come forward about any abuse they experience from women. But 'no', I'm yet to receive my first violence against men by women case. [Survey Participant, Liberia]

I see the international community see gender to mean only women's issues and women's rights. It is not so. We talk about gender we talk about both women and men. There are lots of disadvantages men and women alike face. Even in this court, men are also disadvantaged. In the court system people are prosecuted based on evidence. But when it comes to rape and property rights the law is in defence of women. Since we have a woman president to protect women by giving power to the women, under her presidency, rape became a non-bailable crime. Men are afraid; this is why the 30 per cent participation in government is stuck in the House of Representatives. Men see that as breaking into the traditional norm. [Survey Participant, Liberia]

Cases we experience include where women/younger girls were lying that a man gives a woman lift and he's accused for raping her. How do you confirm such a situation? Through interviews, if the woman said she's taken to the hotel, then they can prove which hotel. This happened to an American visitor. He had to bribe LD \$300 so that it wasn't publicised. The new rape law is being abused by lying. The law doesn't take time to investigate, and then due to the problem with the legal system, most men are incarcerated for a long time, sometimes months or even years. [Survey Participant, Liberia]

How can these unsubstantiated statements, offered mostly by male survey respondents be dispelled? First and foremost, the need for high-quality evidence-based research that will effectively reform law and policy in this area is paramount. Second, ameliorating law and policy will eventually change cultural norms and beliefs by valuing and prioritising the voices of (Indigenous) women. However, parallel to these challenges are countless opportunities for providing lasting remedies.

\subsubsection{Indigenous Women Advocates'Motivation}

Indigenous girls and women have always advocated for safeguarding their rights. Although ethical approval restricted this researcher from directly interviewing Indigenous girl and women survivors of violence ( see chapter 6), coincidentally, most Indigenous Women Advocates who were interviewed happened to also be survivors of systematic violence. Thus, the legitimacy of Indigenous Women Advocates' contribution to legal reform solidifies their status as survivors and engineers of social change. Of interest to this research is the origin of Indigenous Women Advocates' motivation for continuing the work they do, in spite of the ongoing trauma they face. Herewith are select examples of the deep inner passion that propels Indigenous Women Advocates to tackle violence against women:

I just sort of fell into those roles. I think it is because I felt related to how off the rails young people could be if they didn't get cared for properly. Because that was my story, you know? I don't think I did it consciously, but I think that my own psyche, if you like, is looking for a homeostasis or a coming to some sort of balancing myself. And that I felt a lot of empathy, non-judgmental rapport with people who had gone through difficult things. I wasn't afraid of them. I wasn't shocked - shocked in the way that affected me to not hear. Also, people gravitated to me naturally. Well, because people 
sense that in you that it's gonna be OK to tell this person the story. They're not going to freak out and think I'm weird or something. I come across as very strong especially when I was younger - very positive, very strong, very determined. All of that is because I developed really strong survivor skills, because I had to. [S, Australia]

You know I love my job, but it is very difficult to work in a cultural area because the people here have special needs. The cultural practices in Lofa are too strong that even if you want to go into some of those deep cultural places to make sure that the perpetrator [will] be punished for what they've done. At the end of the day the people will say that's family talk, so they will end up compromising their case. Eventually, the caseworker, who may be trying to address the abuse, will be at risk. So that's the challenge, but I love my job because I want to make sure that the people of Liberia be free from sexual and gender-based violence. [Sia, Liberia]

Well I grew up in an Indigenous family and in an Aboriginal community. I have seen issues around Aboriginal rights all my life - from the contact that community had with the police, the actual policing of Aboriginal people, through the treatment of Aboriginal women (partly, the removal of kids). I grew up with a very strong sense of social justice. By the time I was a teenager I wanted to be a lawyer because I wanted to change the way things were. It didn't quite turn up the way I had thought it would, but that's why I developed a relationship for the law. [Lara, Australia]

For myself, I appreciate what I have achieved. As I said earlier, I'm doing a master's in conflict transformation. With the little knowledge in gender and human rights, I think I have achieved a lot. Of course, there are challenges. I don't care what you do, but there is always room for improvement and revision. I really enjoy my work, especially interacting with people at the lower level. Although we don't do as much fieldwork as before, whenever I go in the women are happy to see me. [Klade, Liberia]

In the course of working with Indigenous Peoples, I witnessed, observed, or heard about a lot of interpersonal violence, which was not spoken about. There was a big silence around violence against Aboriginal women. What became more public was probably some of that institutional and state violence against Aboriginal people. But the focus was still on Aboriginal men and not Aboriginal women. Then an Aboriginal man was shot dead by a police officer in Katherine. I was brought into the judicial response to assist an Aboriginal defendant in getting bail. Increasingly, I became aware of the violence against Aboriginal women by their partners. But really what highlighted it for me was the absolute silence and that the victims were just so absent. They were totally invisible in the legal process and the police responses. [Dallas, Australia]

\subsubsection{Males Championing the Cause}

As an historian and an educator, I try to build awareness and consciousness-raising surrounding gender issues into my teaching activities at every opportunity. I try to show that violence against women - not only physical violence, but also emotional, symbolic and other forms of violence against women - is, unfortunately, a deeply ingrained feature of the human past across many different societies, cultures and time periods. Through my teaching, I endeavour to speak directly to students about the importance of confronting and taking a stand against these multiple forms of violence against women, and to understand that gender inequality and violence against women belong not just to the past, but to the present as well. [Respondent \#19]

'Community' is not an easy concept, and many communities operate within external and internal constraints. An important part of a community response to systematic gender violence involves male engagement. Reponses to the informal emails sent to colleagues (see chapter 7) show that males were guarded in speaking out about violence against women, specifying where, when and how they would feel ready to do so. For example, Respondent \#18 said, 'yes, I would speak out, but only in a comfortable context i.e., in a small, private, familiar group setting'. In 
particular, when girls and women play the 'gender means only females' card, men habitually withdraw and sometimes become defensive. ${ }^{1589}$ Men and boys are afraid of the term 'feminism' because it appears to mean 'women going against the patriarchal norm'. ${ }^{1590}$ The fear males may have about feminism is validated when organisations such as the Commission on the Elimination of all Forms of Discrimination against Women ${ }^{1591}$ and United Nations Women ${ }^{1592}$ are run by predominantly women. At the same time, in a patriarchal world, girls and women are ever surrounded by male dominance, authority and abuse of power over them, which makes them feel justified in establishing a few all-women institutions. However, it is that male dominance that makes male allies so important.

Male allies in the fight for gender justice make significant contributions. Girls and women, as survivors of systematic gender violence, have always borne the brunt of tackling gender violence. However, they have not always done this alone (see more excerpts from informal email exchange with male colleagues in Appendix XI). Though bringing boys and men on board to prevent violence against women is not new, the concept of promoting and supporting males in taking a leadership role on the issue has not really crystallised. Many male advocates before us carry the torch as mentors and role models who are more than willing to champion the cause of reducing gender violence. By way of organisations, the White Ribbon ${ }^{1593}$ in Australia and the Journalists Against Sexual and Gender Based Violence in Liberia raise the gender advocacy bar. Individually, Michael Flood ${ }^{1594}$ and Alphonso Mouwon ${ }^{1595}$ are only two examples. Still the challenge is great. Certainly, we need more (Aboriginal) boys and men to step up as sons, brothers, fathers and husbands to mentor and guide the next generation to address systematic violence against Aboriginal girls and women. Respondent \#20 offers a thoughtful viewpoint in this regard:

I was raised singlehandedly by my mother; my entire makeup, the man I am who is now raising three boys, owe its roots to that mother of mine. May her soul rest in peace, for just as her presence in my life inspired me beyond words, her death passed me her torch. A torch that helps me find the light, kindness, softness and that power of emotion in every woman that crosses my path. If all men viewed and know women as I do,

\footnotetext{
${ }^{1589}$ Michael S Kimmel, 'Who’s Afraid of Men Doing Feminism?' in Tom Digby (ed), Men doing feminism (Routledge, 1998).

${ }^{1590}$ David French, For Hillary Clinton, Feminism Means 'Blame Men First,' and to Disagree Is 'Misogyny' (2015) National Review <http://www.nationalreview.com/article/430509/hillary-clintons-feminism-gender-gap-worksagainst-her>.

${ }^{1591}$ In 2007, the 23-member committee of CEDAW's are all females except for one male, Mr Cornelis Flinterman (Netherlands), (see < http://www.un.org/womenwatch/daw/cedaw/committee.htm>).

${ }^{1592}$ In 2014, Farhan Akhtar was the first male to be appointed as the UN Women Goodwill Ambassador to South Asia as part of its HeForShe campaign (see, <http://www.unwomen.org/en/news/in-focus/engaging-men> and <http://www.heforshe.org >).

${ }^{1593}$ White Ribbon engages men across Australia in the prevention of men's violence against women, through a national primary prevention campaign that currently focuses on awareness raising and attitudinal and behavioural change. Primarily campaigns and programs are run in workplaces and schools. According to a survey participant, '[o]ver 2200 men are White Ribbon Ambassadors, including more than 100 Aboriginal and Torres Strait Islander men. White Ribbon Ambassadors are formal representatives of White Ribbon and are responsible for driving the campaign in their communities'.

${ }^{1594}$ See, Michael Flood, (2015) XYonline, available at <http://www.xyonline.net/category/authors/michael-flood> ${ }_{1595}$ Alphonso Mouwon is a young man working with Tiyitien Health (renamed Last Mile Health) in Grand Gedeh, Liberia who responded to an invitation to participate in the research survey. He would later commit extra time and effort in recruiting more participants for the survey (see Last Mile Health available at <http://lastmilehealth.org >).
} 
women would need no protection at all, as they are the fruit-bearers of life. If there is nothing else I have taught my three boys, they all know just too well the importance of their grandmother, and the knowledge of their grandmother has shaped their view of their own mother. I refer to it as protection from within. [Informal Email Exchange Respondent \#20]

\subsubsection{Reporting Violence}

Sexual abuse and family violence are under-reported in all cultures and communities. However, the level of underreporting of violence by Aboriginal survivors may be more pronounced. Some of the reasons for the underreporting of family violence and sexual abuse by Aboriginal survivors include (but not limited to): distrust and fear of police, distrust and fear of the criminal system and other government agencies, lack of police presence, language and communication barriers, lack of knowledge about legal rights and legal services available, lack of appropriate support services for Aboriginal survivors, and cultural factors. ${ }^{1596}$ Although research shows that sexual assault reporting to police has increased, sexual assault is the most under-reported of all interpersonal crimes. According to the Australian Bureau of Statistics, of the estimated 51000 people 18 years and older who were survivors of sexual assault in 2013, only one-third reported the incident to police. ${ }^{1597}$ Even when cases of sexual abuse are reported, further investigation by law enforcement agencies can stall and dwindle. A study commissioned by the Office of Women's Policy Department of Victorian Communities shows that police charges were brought in only 15 per cent of the 850 rape cases reported to Victoria Police over a three-year period. Of these, 46.4 percent resulted in 'no further police action', and when combined with withdrawn complaints (15.1 percent), a total of 61.5 percent of cases did not proceed beyond the investigation stage. If total cases are expanded to include those still in process, no charges were brought in 80.8 percent of cases. ${ }^{1598} \mathrm{~A}$ high attrition rate is observed with cases of Aboriginal victims, survivors with a mental illness or psychiatric disability, and those influenced by alcohol or other drugs. ${ }^{1599}$ Several factors may hinder reporting. Yaa's comments above point to the logistical, sociological and cultural factors that inhibit reporting, and therefore the figures suggested in Zoe Morrison's and Wendy Anders's research above probably underestimate the incidence of violence. Distrust of the police and justice system contributes to reduced reporting, prosecution and conviction of perpetrators in cases of gender violence. ${ }^{1000}$ Thus, research participants suggest that survivors rarely report sexual crimes and that, when they do, those crimes are rarely prosecuted successfully, whereupon these tactics are not usually the immediate mechanism Indigenous girl and women survivors of violence undertake to address that violence.

\footnotetext{
${ }^{1596}$ Law Reform Commission of Western Australia, above n 142, 284-288.

${ }^{1597}$ Australian Bureau of Statistics, 'Bridging the Data Gaps for Family, Domestic and Sexual Violence, Australia', above $\mathrm{n} 819,2$.

${ }^{1598}$ Zoe Morrison, 'What Is the Outcome of Reporting Rape to the Police' (2008) 17 Australian Centre for the Study of Sexual Assault Newsletter 4, 4.

${ }^{1599}$ Morrison, above n 1598.

${ }^{1600}$ Australian Human Rights Commission, 'Social Justice Report 2012: Aboriginal and Torres Strait Islander Social Justice Commissioner', above n 1500, 27-28.
} 
Information received from a private email exchange on 4 August 2014 with an Australian Capital Territory Office of Women's staff member reveals that Aboriginal girls and women are reluctant to report domestic violence in Australian Capital Territory because of

1) efficiency of the Aboriginal 'telegraph pole' in a small community;

2) fear of guilt, shame and rejection by family and community members;

3) distress about legal consequences of criminal behaviour or concerns that the perpetrator will get in trouble;

4) worry of revenge, thus increasing risks and threats from the perpetrators to the survivor and her extended family;

5) lack of cultural understanding of service providers including women's refuges, police officers, and court/legal assistants; and

6) lack of culturally appropriate responses in which service is focused on family, community healing and restoration. ${ }^{160}$

Indigenous women and children are not the only ones who find reporting of abuse challenging.

Service providers also face challenges when deciding whether to report sexual abuse and family violence. Service providers, especially health workers, who see their major role as providing safety and support to survivors of violence, refrain from screening cases of violence for 'fear of offending the patient, powerlessness, loss of control and time pressures' ${ }^{1602}$ Some agencies claim that their focus is on service delivery rather than on collecting data on reporting. Other causes of underreporting may be the inherently difficult task of identifying survivors as Indigenous or legally complex conflicts of confidentiality, as Tracy (Liberia) indicates:

\begin{abstract}
There are a few cases where a person is raped, for example, but will tell us that they do not wish to get the police involved. This is the moment where we break confidentiality and contact the police to minimise risk and harm to the survivor. Even during mediation, when we sense threats from a conflicting party, at that moment, the person posing the threat is breaking confidentiality. There and then, we make referral to reduce any liability on our part. [Tracy, Liberia]
\end{abstract}

Section 4(4.4) of the Liberian Children's Law 2011 states that, '[a]ny service provider, parent and community or town member shall report sexual and other forms of abuse to the Police'. This provision does not seem to put an express duty on service providers (or anyone for that matter) regarding wrongful acts associated with not reporting abuse against children. The Children's Law is the first to protect Liberian children and it was passed only recently. The culture of jurisprudence in Liberia has not yet evolved to include a duty on parents, community members, traditional leaders, service providers, and individuals to report child abuse. In addition, there is widespread corruption and distrust of police, which some survey and interview respondents commented is not only problematic but makes reporting rape cases challenging.

\title{
8.5.4 Healing Through Restorative Justice
}

\footnotetext{
${ }^{1601}$ Information retrieved from a private email exchange on 4 August 2014 with an ACT Office of Women staff member.

${ }^{1602}$ Al-Yaman, above n 817, 18-19.
} 
I witnessed a lot of ceremonies being used for healing. Ceremony is one of the ways that people can heal, definitely. Not for everyone but ... reconnecting with culture, reconnecting with identity, all of those sorts of things. And learning, especially with domestic violence, it's a very difficult topic and often very hard for the victim to extract themselves from it. As you know, the perpetrators are often very manipulative, even if they don't mean to be, they're armed well... [S, Australia]

I do think re-investing in people's cultural practice and language is a key element in cultural practice. It is actually a very powerful healing mechanism. I think it is redressing. I think the research we do here tends to redress those issues. [Jaky, Australia]

Empirically, the concept of justice is immanently holistic, with procedural, distributive, restorative, and social justice positively correlated. Restorative justice may be about creating spaces where the various imperfectly correlated faces of holistic justice might cohere. ${ }^{1603}$ State institutions of justice, such as criminal courts, with deeply embedded traditions of narrowing the meaning of justice to proportional punishment are less fertile soil for holistic justice than civil society. ${ }^{1604}$ Whilst restorative justice programs are relatively common, they mostly remain marginal programs operating in the shadow of the dominant punitive legal system. ${ }^{1005}$ Compared with settler-colonists' legal system, restorative justice focuses more on problem solving or conflict resolution of any kind, which ultimately concerns less retribution and injustice. ${ }^{1606}$ An injustice does not need to be a criminal harm, such as family neglect or state failure to provide basic security for its Indigenous citizens. Restorative justice is perceived as more procedurally fair than courtroom justice because it gives direct voice to stakeholders rather than having to channel communication through a lawyer. ${ }^{1607}$ But restorative justice is more than procedural fairness in the courtroom and far exceeds the limits of procedural fairness and punishing offenders. Studies have shown that survivors and offenders seeking restorative justice are more likely to perceive their rights as respected, that they are not discriminated against, and that various other facets of their engagement with the procedural justice system beyond retribution arise. ${ }^{1608}$

Restorative justice is in its early days of research and development as research falls behind theory and theory behind practice. Restorative justice program development aims to design justice innovations that apply this research to finding alternatives to regulatory institutions. ${ }^{1609}$ In spite of growing attention on the utility of restorative justice in the criminal legal system in recent years, the concept still remains somewhat problematic to define, as numerous responses to criminal behaviour may fall under the so-called restorative umbrella. ${ }^{1610}$ The term has been used interchangeably with concepts such as community justice, transformative justice, peacemaking criminology, and relational justice. Although a universally

\footnotetext{
${ }^{1603}$ John Braithwaite, 'Doing Justice Intelligently in Civil Society' (2006) 62(2) Journal of Social Issues 393, 393.

${ }^{1604}$ Ibid.

${ }^{1605}$ Ibid 394.

${ }^{1606}$ Ibid 397.

${ }^{1607}$ Ibid.

${ }^{1608}$ Ibid 398.

${ }^{1609}$ Ibid 407.

${ }^{1610}$ Jeff Latimer, Craig Dowden and Danielle Muise, 'The Effectiveness of Restorative Justice Practices: A MetaAnalysis' (2005) 85(2) The Prison Journal 127, 128.
} 
accepted and concise definition of the term has yet to be established, Jeff Latimer, Craig Dowden and Danielle Muise suggest that Tony F. Marshall's definition reflects the main principles of restorative justice. According to Latimer, Dowden and Muise, '[r]estorative justice is a process whereby all the parties with a stake in a particular offence come together to resolve collectively how to deal with the aftermath of the offence and its implications for the future'. ${ }^{1611}$ According to the Justice Education Society, a 'restorative justice remedy is one that places emphasis on healing the trauma done by the offence and rehabilitating the offender to avoid future harms. Such processes are in line with traditional Aboriginal views of justice'. ${ }^{1612}$ The fundamental premise of restorative justice is that crime is a violation of people and relationships rather than merely a violation of law.

Proponents of restorative justice claim that the mechanism is beneficial to survivors and offenders in that it emphasises the recovery of the survivor through redress, vindication, and healing, and encourages recompense by the offender through reparation, fair treatment, and rehabilitation. ${ }^{1613}$ In the process of coming together to restore relationships, the community is also provided with an opportunity to heal through the reintegration of survivors and offenders. Twenty-two unique studies that examined the effectiveness of 35 individual restorative justice programs generated 66 effect sizes. ${ }^{1614}$ In these studies, restorative justice was found to be more successful at achieving each of its four major goals compared with traditional non-restorative approaches. ${ }^{1615}$ In other words, based on the findings of the current meta-analysis, restorative justice programs are a more effective method of improving survivor and offender satisfaction, increasing offender compliance with restitution, and decreasing the recidivism of offenders when compared with more traditional criminal legal responses. ${ }^{1616}$

Recognising the conflicts of retributive justice settler-colonist criminal system, and the need for healing between survivors and offenders, ${ }^{1617}$ restorative justice is apt in bringing together survivors, offenders and others who may have an interest in a particular offence to collectively deal with resolving the impact of an offence holistically. ${ }^{1618}$ Unlike retributive justice, restorative justice sees crimes as a violation of people and relationships and creates an obligation to make things right where survivors, offenders and the community are searching for solutions to promote, repair, reconcile and reassure themselves. ${ }^{1619}$ The restorative justice

\footnotetext{
${ }^{1611}$ Ibid.

${ }^{1612}$ Justice Education Society, Aboriginal Restorative Justice Remedies (2016) Aboriginal Restorative Justice

Remedies <http://www.justiceeducation.ca/research/aboriginal-sentencing/restorative-justice>.

${ }^{1613}$ Latimer, Dowden and Muise, above n 1610, 129.

${ }^{1614}$ Ibid 135.

${ }^{1615}$ Ibid.

${ }^{1616}$ Ibid 138.

${ }^{1617}$ Zehr, above n 203, 232.

${ }^{1618}$ Dennis Trewin, Year Book Australia 2001 (Australian Bureau of Statistics, Centenary of Federation, 2005) 493 <http://books.googleusercontent.com/books/content?req=AKW5Qae2u2Ol4EJpVaHz5PhoQUuwmdmwxrqnTBcnNbgzkDFjnt0md53MBrilsuusGk1oPiKj3tups73Sot1KGfM3rq024HUe1 2RBFCuLqWhqBU4E1Cs9nM7q79JsNxwTNrmMp7h9fSXynIN_Ym8MBSttP3m1ZKQRpqa1Sqr9sdhQM1XpH_3FqLTJu1To_e-uN61-

XwKjjmfUbphj4cmNsi5V8EBuxkM1OFPiafHasO3z9zL_p3ux9zFal30dfj4U4MRjIpINb1>.

${ }^{1619}$ Zehr, above n 203, 110.
} 
process is an inclusive one that involves all stakeholders' input when solving conflicts with the goal of providing restoration to the survivor and the offender. The conventional criminal legal system focuses on the offender whereas restorative justice invests in healing for all those who have been harmed by the offence, the survivors of systematic violence in this case. To this end, the role of public institutions and the state should be to maintain just order and peace at both national and community levels.

Restorative justice has deep roots in Indigenous ${ }^{1620}$ practices. Some examples are Ubuntu in South Africa, ${ }^{1621}$ Palava Hut in Liberia, ${ }^{1622}$ and Circle Healings amongst the First Nations in Canada and Maoris in New Zealand, ${ }^{1623}$ although contemporary programs started in 1974 in Ontario, Canada. ${ }^{1624}$ At the core of an Aboriginal restorative process is 'a healing circle, which endeavours to develop a consensus on how to repair the harmful results of the offence'. ${ }^{1625}$ The Aboriginal Health Project was established based on the idea that internal healing from historical and cumulative trauma caused by systematic violence and broader issues of poverty, inadequate housing and ill health reduces high levels of violence and potentially rehabilitates offenders. The Aboriginal Health Project, a kind of restorative justice process, was established in January 2006. A two-year project supported by state and federal funds, the Aboriginal Health Project provides healing services to Indigenous individuals and families affected by family and domestic/sexual violence. The goals of the Aboriginal Health Project are to, inter alia, promote group cohesion, value self-worth and ensure safety in efforts to reduce harm within families, ${ }^{1026}$ characteristics Indigenous Women Advocates in this research have emphasised.

Accordingly, the solution for Aboriginal communities requires a 'whole community approach, encompassing the individual, the family and the community with government [support focusing on] healing rather than a punitive approach'. ${ }^{1627}$ The Australian Capital Territory government has also enacted the Crimes (Restorative Justice) Act 2004 to empower survivors of offences when making decisions about how to repair the harm done by those offences. Rather than imagining one single replacement for existing mechanisms, it is important to envision an array of possibilities that will require concurrent radical transformations. Indisputably, alternatives that fail to address racism, male dominance, class bias, and other

\footnotetext{
${ }^{1620}$ Zehr, above n 203; Daniel W Van Ness, Restoring Justice: An Introduction to Restorative Justice (LexisNexis : Anderson Pub, 4th ed, 2010) 8; Zehr, above n 205.

${ }^{1621}$ O Oko Elechi, Sherill VC Morris and Edward J Schauer, 'Restoring Justice (Ubuntu): An African Perspective' (2010) 20(1) International Criminal Justice Review 73; Mechthild Nagel, 'Ubuntu and Indigenous Restorative Justice' $3<$ http://www.africaworkinggroup.org/>; AM Anderson, 'Restorative Justice, the African Philosophy of Ubuntu and the Diversion of Criminal Prosecution' 9

<https://www.ncjrs.gov/App/Publications/abstract.aspx?ID=202433>.

${ }^{1622}$ Truth and Reconciliation Liberia, above n 208, 2.

${ }^{1623}$ Van Ness, above n 1620, 14.

${ }^{1624}$ Kate Gleeson, 'The Money Problem: Reparation and Restorative Justice in Catholic Church's toward Healing Program’ (2015) 26(3) Current Issues in Criminal Justice 317.

${ }_{1625}$ Justice Education Society, above n 1612.

${ }^{1626}$ Deborah Cox, 'Aboriginal Healing Project' (2008) 17 Australian Centre for the Study of Sexual Assault Newsletter 18 .

${ }^{1627}$ Information retrieved from a private email exchange on 4 August 2014 with an ACT Office of Women staff member.
} 
structures of domination ${ }^{1628}$ will hardly advance the goal of addressing systematic violence against Indigenous girls and women. As a result, contemporary justice measures still fail to deliver justice to survivors of state/institutional violence.

Restorative and punitive justice measures are not effectively applied to the perpetrators of state and institutional violence. When a violent perpetrator goes to jail, Aboriginal girls and women acknowledge a sense of justice as a small step taken to remedy systematic violence. However, problems with justice arise when some perpetrators of systematic violence are not prosecuted and punished. The Australian Capital Territory government acknowledges that high rates of violence against Indigenous girls and women result from 'the impacts of colonisation, forced removal of children, disposition of lands and disruption of family and kinship ties'. ${ }^{1629}$ But Australian Parliamentarians who enacted law that forcibly took Aboriginal children from their mothers have not been prosecuted or punished. ${ }^{1630}$

\subsection{Summary}

In this chapter, research participants' responses provide evidence for examining vital concerns emerging from the efficacy of settler-colonist law in restoring justice to Indigenous girls and women. The research findings affirm that systematic violence against Indigenous girls and women in post-war Liberia and Australia is a chronic social ill, rooted in colonisation, an inefficient male-centred legal system, corruption, systemic racism, lack of social services, negative cultural and social stereotypes held against females, mental health illness and substance abuse. Although the law offers hope in some areas, it is neither the first nor the only recourse Indigenous girls and women seek for justice, fairness and equality. In spite of the challenges, Indigenous girls and women persist in their resolve to do whatever is necessary to curb systematic gender violence, and they are not alone on their advocacy journey. Therefore, rather than being exclusive, vindictive and retributive, law and society could exploit a window of opportunity with Aboriginal healing through restorative justice tenets. There is also a chance to support and promote Indigenous males in championing the cause of preventing systematic gender violence. In this vein, the 'need to be careful about constructing violence as a cultural rather than generic behaviour against vulnerable people' is crucial, says a survey participant. Ultimately, listening to Aboriginal girls and women, such as Jaky, can promote a genuine healing process that is holistic, comprehensive and restorative in nature:

White Australian law is all about retribution and punishment, crime and punishment and isolation. It's not about the community wellbeing or healing practices. As soon as you start saying that, then people go like "oh that's a bit of a touchy feely". In my experience, women are not particularly about "touchy feely". Women are pretty summary, feisty, good thinking, and clear thinking. Most of our lives, as women, we spend time working to modify and shape the behaviour of other people because we

\footnotetext{
${ }^{1628}$ Angela Y Davis, Are Prisons Obsolete? (Seven Stories Press, 2003) 108.

${ }^{1629}$ Information retrieved from a private email exchange on 4 August 2014 with an ACT Office of Women staff member.

${ }^{1630}$ Gillard, above n 489.
} 
raise the children. Yet, nobody listens to what we've got to say. Even books about child's rights are written by men. A woman's voice in our legal system is absent. And, an Aboriginal woman's voice is pretty much absent. [Jaky, Australia]. 


\title{
CHAPTER 9: CONCLUSION AND RECOMMENDATIONS
}

\begin{abstract}
Women are, in fact, so much degraded by mistaken notions of female excellence, that I do not mean to add a paradox when I assert, that this artificial weakness produces a propensity to tyrannize, and gives birth to cunning, the natural opponent of strength, which leads them to play off those contemptible infantile airs that undermine esteem even whilst they excite desire. ... Let men become more chaste and modest, and if women do not grow wiser in the same ratio, it will be clear that they have weaker understandings. ${ }^{1631}$
\end{abstract}

\subsection{Chapters Summaries}

Chapter 1 introduces the global scourge of violence against women and poses the question: "is the rule of law an essential axiom for restoring justice to Indigenous girl and women survivors of systematic gender violence in Australia and Liberia?' Violence against women is contextualised within colonised Australian and Liberian Indigenous communities for the purposes of this research. Also, terminology is defined and operationalised in an effort to constrain the scope of the research while avoiding further perpetration of structural violence through the use of derogatory terms. The complex system theoretical framework is introduced, which borrows concepts from intersectionality, critical race theory, feminist legal theory, decolonisation, and social determinants of health. After establishing the significance of the research and how findings will be communicated to the academy and Indigenous communities that participated in the research, the researcher discloses the personal challenges of performing this research as a war survivor and a survivor of gender violence. With this foundation established, a review of the relevant literature follows.

Chapter 2 lays the historical, social and cultural groundwork of past and contemporary discourse relating to violence against Indigenous girls and women in particular. The chapter views the literature through the lens of theories drawn from critical race, decolonisation, social determinants of health, and feminist theory to explicate the complex intersection of gender violence. The histories of politics and governance are explored, which introduce incidences of state-perpetrated systematic violence against Indigenous girls and women and highlights the continued lack of services in Indigenous communities. Histories of white supremacy, patriarchy and racism underscore intersecting sources of colonial violence that contribute in various ways to systematic violence against Indigenous girls and women. Further examining social determinants of the health of Indigenous Peoples, land dispossession and the intergenerational trauma of colonisation are established as situational sites of systematic violence against Indigenous Peoples. Additionally, harmful religious and traditional practices are discussed as other sources of gender violence and violence against Indigenous Peoples. In the face of such a violent history, the literature also shows that Indigenous women still struggle to achieve acceptable outcomes in health, education, housing and employment. Unfortunately, all these

\footnotetext{
${ }^{1631}$ Wollstonecraft, above n 69, 11.
} 
problems persist despite the global gains of feminism and the ascendency of international human rights law, policy, and advocacy. Hence, the value of continued research using a complex system method is validated.

Chapter 3 investigates the literature specifically pertinent to violence against Indigenous girls and women. The chapter pointedly discusses systematic gender violence at three overlapping levels: institutional or State, structural or cultural and interpersonal or community violence. Case examples in Australia and Liberia exemplify the prevalence of gender violence occurring at these three levels. In Australia, State violence includes massacres, over incarceration of Aboriginal Peoples, genocidal miscegenation and eugenics programmes, land dispossession, stolen wages and forced adoption. These violent acts are shown to predispose Aboriginal women and children to further abuse in their communities even when put under the 'protection' of social services provided by the State. In Liberia, a history of colonisation lead to land dispossession, child exploitation, and a bloody 14-year civil war that disproportionately harmed Liberian children and women. Even so, systems of class and patriarchy in the formal political and legal system foster a culture of impunity for the perpetrators of that violence. Meanwhile, patriarchal traditional systems also perpetrate systematic violence against Native women in Liberia through practices of female genital cutting, polygyny and forced marriage. However, in spite of the vulnerability to violence of Indigenous women, the chapter closes with a highlight of their strength and resilience in fighting for their cause. Given the prevalence and various sources of systematic violence against Indigenous girls and women, the next chapter dissects the rule of law and its efficacy in restoring justice to Indigenous survivors of gender violence.

Chapter 4 focuses on the concept of the 'rule of law' and how effectively it has been applied within settler-colonist and Indigenous legal systems in Australia and Liberia with respect to Indigenous girls and women. In Australia and Liberia, founding legal documents were authored without the input of Indigenous Peoples and by mostly males who questioned the civility or very humanity of Indigenous Peoples. As such, the rule of law as a constitutional basis for Liberia and Australia's democracies is questioned. Therefore, the concept of 'all are equal under the law' is examined regarding the colonial imposition of settler-colonist law on Indigenous Peoples. Further analysis of the extent to which Indigenous Customary Laws speak to systematic violence is also considered. The existence of Indigenous Customary Laws alongside Anglo-American-Liberian and Anglo-Australian Law in Indigenous communities constitutes a pluralistic legal system. Whether that pluralism can coexist with the rule of law is also scrutinised. Unfortunately, in addition to the challenges of constitutional exclusion, subjugation of Indigenous Customary Laws, and conflicts between Anglo and Traditional Law, both the traditional and the Anglo-American-Liberian/Australian legal and political systems are shown to be patriarchal. Women and particularly Indigenous women are still underrepresented in Liberian and Australian political and legal spheres. However, in the absence of domestic law, 
the chapter concludes that other international law instruments may help restore justice to Indigenous survivors of systematic gender violence.

Chapter 5 is a reflective piece acknowledging the researcher's experience and bias as a survivor of violence and a person in search of her Indigenous identity. Still struggling for acceptance and healing from past trauma, the researcher battles with the question, '[w]hose responsibility is it to define my identity or legitimise my claim to conduct research on such a sensitive topic in Indigenous communities?' Before the researcher enters the field, this chapter provides a space to contest the challenges of conducting research as both an insider and an outsider. As a woman, an Indigenous Liberian, and a gender violence survivor, I approach this chapter not only to establish the dissertation as an academic endeavour, but also as my 'speakout' moment.

Chapter 6 outlines the research method and design. A complex system methodology that combines empirical, statistical and textual data as a nexus between systematic gender violence and the rule of law informs the approach. Additionally, the conceptual framework draws on community-based participatory methods, phenomenology, Indigenous decolonising and feminist legal theories to conduct a mixed methods research study. The outcome is a research that is based on a mixed method design. Qualitative data was collected by analysing selected case studies and case law, semi-structured interviews with Indigenous Women Advocates, and an informal email exchange with male colleagues and acquaintances. Quantitative data was gathered through secondary data on socio-economic status, crime, and other risk factors from various government institutions. Also, a survey was designed, piloted, and conducted with service providers in Liberia and Australia. The findings from these data collection efforts are reported in chapter 7.

Chapter 7 reports the findings and the results of the study. This chapter achieves the three research objectives. Historical secondary data, surveys and interviews are employed to examine the incidence and prevalence of systematic gender violence. The data substantiate whether or not the rule of law is efficacious in restoring justice to Indigenous girl and women survivors of systematic violence. Court and criminal data highlight difficulties in using the law as a tool for restorative justice. Responses from survey participants suggest that changes in men's attitudes towards women are necessary to address gender violence satisfactorily. Interview results show that even though Indigenous Women Advocates are resilient survivors of systematic gender violence who speak out clearly on the issue, male leadership is paramount in preventing violence against girls and women. Ad hoc responses from a select few men via email reaffirms that the law is not the primary avenue for restoring justice to female survivors of gender violence.

Chapter 8 analyses the major themes, concerns and issues emanating from research participant responses, with greater emphasis placed on Indigenous Women Advocate responses. Grounded in 'asking the Indigenous woman question', issues discussed here range from the 
pervasive nature of gender violence against Indigenous girls and women, to culturally held myths and stereotypes that sustain persistent gender violence, to access to justice concerns in Indigenous communities, to challenges associated with addressing gender justice, and the application of a restorative justice paradigm. Research participants corroborate the pervasive nature of gender violence against Indigenous girls and women in Australia and Liberia at the state/institutional, structural/cultural and community/interpersonal levels. Whether gender violence stems from intergenerational trauma caused by racist or patriarchal colonial history or from harmful traditional practices, Indigenous Women Advocates and service providers recognise and address various aspects of it in their work. However, they also lament ineffective law and policy, hampered by racism, patriarchy, stigma, corruption, and underrepresentation of Indigenous women in the political and legal life of the nation. Ultimately, a lack of access to the legal system and social services continues to preclude justice for Indigenous girl and women survivors of systematic gender violence. However, several opportunities for positive change are highlighted by Indigenous Women Advocates, including engaging with Indigenous males to champion the cause of gender justice and incorporating the benefits of restorative justice programs. More Indigenous Women Advocates recommendations are discussed later in chapter 9.

Chapter 9 summarises the dissertation and emphasises research participants' recommendations for combating systematic gender violence against Indigenous girls and women. The research findings affirm that violence against Indigenous girls and women in postwar Liberia and Australia is a chronic social ill that is rooted in colonisation, an inefficient male-centred legal system, corruption, systemic racism, a lack of social services, negative cultural and social stereotypes held against females, mental health illness and alcohol abuse. Although the law offers some hope, it is not the only recourse in attempts to achieve justice, fairness and equality. In spite of grave challenges, Indigenous girls and women have persisted in their resolve to do whatever is possible to curb systematic gender violence. However, they are not alone in their advocacy. Thus, rather than being exclusive, vindictive and retributive, law and society could exploit a window of opportunity with Indigenous healing through restorative justice tenets. There is also a chance to support and promote Indigenous males to champion the cause of preventing systematic gender violence.

\subsection{Dissertation Summary}

Although the law is perceived as the panacea for justice, findings from this research show that the usefulness of the principles of the rule of law in achieving justice for Aboriginal girl and women survivors of violence is limited by challenges. As long as settler-colonist law continues to play 'catch-up' to Indigenous norms and issues, justice achieved by legal means will be elusive. The diverse contexts in which systematic gender violence against Indigenous children 
and women in Liberia and Australia take place demand public responsibility, ${ }^{1632}$ with primary onus on the State. In spite of the fact that this research does not attempt to reach general conclusions based on the limited data collected, those who care about this issue would do well to consider several factors when interpreting the findings:

1. Conducting research on systematic violence against girls and women is challenging, ethically, historically, empirically, and personally.

2. Violence against women is not confined to Indigenous girls and women in Australia and Liberia. It is a universal problem irrespective of whether a country is advanced and Western or underdeveloped and resource-poor. In any context, the impact of violence against Indigenous girls and women is exacerbated by colonisation, patriarchy, systematic racism, and the intersections of race, gender, class, and social status (vis-à-vis the social determinants of health).

3. Violence against women is often perceived as interpersonal/community violence with a focus on sexual assault and domestic/family violence. This research shows that institutional/state and cultural/structural violence are also major spokes in the wheel of interpersonal/community violence.

4. The legal system is officially perceived as an indispensable mechanism for restoring justice to survivors of violence. Many also regard Indigenous Customary Laws as harmful and "useless" as it pertains to violent crimes. In actuality, neither the principle of the rule of law nor traditional customs is an effective mechanisms of justice for Indigenous girls and women survivors of systematic violence. Justice (or the lack thereof) usually depends on one's gender, race, class, socio-economic status, ethnic identity, or political clout.

Space and time do not allow for individual representation of the numerous recommendations put forward by research participants. Five collective recommendations are presented below.

\subsection{Recommendations}

\subsubsection{Further Research: Expansion of the Complex System Approach}

The complex methodological design used in this study, which entails the triangulation of varied data sources grounded in a multi-theory conceptual framework, is apt for addressing inherent challenges associated with researching systematic violence against Indigenous girls and women. A combination of qualitative, quantitative, textual, and empirical information obtained from informal, physical, electronic, historical and observational sources made it possible to reach hard-to-access target populations and corroborate patchy records. In addition to the Commission on the Status of Women's broad definition of violence against women discussed in chapter 1, Rashida Manjoo emphasises the importance to employing diverse research methods to assess violence against women at the Fifty-eighth Session of the Status of Women in New York on 11 March 2004:

for a State to ascertain what constitutes effective fulfilment of its obligations, it is imperative for States to create an assessment framework which includes two categories: individual due diligence which States owe to individual victims of violence; and systemic due diligence which requires States to create a functioning system to eliminate violence against women. This dual assessment will allow for a more comprehensive and in-depth assessment by a State of its actions or inactions to address violence against women. Furthermore, I argue that due diligence also requires States to hold accountable

\footnotetext{
${ }^{1632}$ Raquel Aldunate, 'Sexual assault: A public responsibility' in Proceedings of a Conference held 27-29 October 1992 (1993) vol. 20 166-170.
} 
those [States, Institutions and Individuals] who fail to protect and prevent; as well as those who perpetrate violations of human rights of women. ${ }^{163}$

As complex system methodology helps unravel the intricacies of violence against women it is an important strategy for legitimising the voices of girls and women in reforming law, policy and attitudes.

\subsubsection{International Collective against Violence}

International organizations have identified violence against women as a critical problem to solve, but more work needs to be done. On paper, all major human rights treaties since 1945 recognise women's rights as equal to those of men before the law. However, it was not until the 1990s that violence against women became a pressing concern. The adoption of the United Nations Declaration on the Elimination of Violence against Women in 1993 brought the appointment of the first Rapporteur on Violence against Women. The following year saw the International Conference on Population and Development in Cairo, which pledged, 'Women's rights are human rights'. ${ }^{1634}$ Then the Beijing World Conference in 1995 placed 'violence against women squarely on the women's rights agenda, identifying it as one of twelve priority areas of concern' ${ }^{1635}$ Twenty years have elapsed, yet the World Economic Forum estimates that it will take at least 79 years to achieve women's equality in the workplace, alone. ${ }^{1636}$ However, it is also critical to consider violence against Indigenous women specifically.

This research illuminates commonalities between the experiences of violence against Indigenous women and girls in diverse economic and cultural settings, which suggests that common interventions and support mechanisms could be implemented. One survey respondent exclaimed, '[e]ven though Aboriginal women are more than five times more likely to experience DV [domestic violence] or family abuse than other women in Australia, ALL WOMEN IN AUSTRALIA AND THE WORLD EXPERIENCE GENDER VIOLENCE. It does not matter what race/nationality they may be'. Findings from this research corroborate the above statement. Even though the world is enamoured of dichotomous divisions such as "poor versus rich', 'white versus black', 'advanced versus underdeveloped', 'Western versus the rest', 'Global North versus Global South', 'Christian versus unbelievers', and 'civilised versus primitive', the idea of exploring an issue (i.e., systematic gender violence against Indigenous girls and women) that Australia and post-war Liberia have in common is not intuitive. However, both countries were violently colonised by settlers, nation building did (and is still does) overtly exclude Indigenous or rural dwellers from politico-legal leadership, and ongoing systematic

\footnotetext{
${ }^{1633}$ Rashida Manjoo, United Nations Human Rights Office of the High Commissioner (11 March 2014) United Nations Human Rights

<http://www.ohchr.org/EN/NewsEvents/Pages/DisplayNews.aspx?NewsID=14448\&LangID=E>.

${ }^{1634}$ See UNFPA website, "International Conference on Population and Development" available at

$\langle$ http://www.unfpa.org/icpd>.

${ }^{1635}$ Edwards, above n 641, 9.

${ }^{1636}$ Saadia Zahidi, 2095: The Year of Gender Equality in the Workplace, Maybe (28 October 2015) 2095: The Year of Gender Equality in the Workplace, Maybe / World Economic Forum

<https://www.weforum.org/agenda/2014/10/2095-year-gender-equality-work-maybe/>.
} 
violence against Aboriginal Peoples in both countries is pervasive, dehumanising and destructive. Therefore, rather than inciting divisions based on racism, discrimination and economic wealth, leaders could attain greater benefit from identifying violence as a common issue, in efforts to address the scourge globally.

In both Liberia and Australia, programs and institutions exist that are designed to combat violence against Indigenous women, which could be shared across borders. For example, Australia does not have a Government ministry like Liberia's Ministry of Gender, Children and Social Protection, which is committed to children and women. However, there is a Family and Children's Services office within the Department of Social Services. Unlike in Liberia, where the National Traditional Council (consisting mostly of male chiefs) is given autonomous status in the House of Representatives of Liberia, the Australian government has created no such space for Aboriginal people. In contrast to Liberia, Australia has established more comprehensive public and legal institutions headed mostly by Indigenous men (e.g., The Royal Commissions) to investigate systematic violence against Aboriginal people. In regard to research, Liberia has struggled to establish high-quality public research institutions to support evidence-based reform and intervention. However, Australia is far ahead, with institutions such as Australia's National Research Organisation for Women's Safety, the Australian Institute of Aboriginal and Torres Strait Islander Studies, and the Longitudinal Study of Indigenous Children. However, despite Liberia's lack of public research institutions with a focus on Indigenous populations, the country has the Ministry of Gender, Children and Social Protection's national database on violence against girls and women. No such data set exists in Australia. Although Australia has more law and policy to protect children and women, Liberia has established novel institutions such as the Women and Children Protection Services of the Liberia National Police; the fasttrack court (Special Court 'E') to try only gender violence cases; and the Sexual and GenderBased Violence Crimes Unit to prosecute only sexual crimes against girls and women. However, institutions common to both countries exist, and these provide other opportunities.

Where both countries have some similar institutions, such as a National/Federal Human Rights Commission, best practices could be exchanged. For example, the Australian Human Rights Commission and Social Justice Commissions could be a model to assist Liberia with devising measures that could help make Liberia's Independent National Commission on Human Rights more independent and free of government's influence in implementing the goals of the Truth and Reconciliation Commission. Australia could also seek advice from Liberia in setting up a national Truth and Reconciliation Commission to investigate historical violence against Aboriginal Australians and an Indigenous Council in the House of Commons to participate in political leadership. 


\title{
9.2.3 The Law is Not the Only Answer
}

The law and legal system are integral to protecting Indigenous girls and women against violence; but the law is not a panacea for curbing systematic violence against Indigenous girls and women. Research participants disagreed about whether the law and legal system are helpful in restoring justice to Indigenous girls and women survivors of systematic violence. In fact, a number of responses associate 'legal justice' with persistent patriarchy, corruption, racism, discrimination, high cost, and inaccessibility. Lara captured the essence of the law and the legal system's need to acknowledge its role as a part of a whole social system of respectful collaborative effort:

\begin{abstract}
I think as I work in the legal system it has made me realise that there are other fundamental things that were challenging that I would like to work on addressing. It has helped me get a framework for social justice. But I think I always see the law as a kind of tool for getting social justice. Probably the biggest thing I have learned along the way is that the law is not the only tool for social change. Changing laws (and within cases) is a very small way to make a difference. There are much more broader strategies that make the list as well. [Lara, Australia]
\end{abstract}

Why is the law a 'very small way to make a difference'? What are the broader strategies Lara refers to? Do lawyers and lawmakers recognise and understand the very small difference law can actually make in the lives of women and girls who have suffered violence? Adequate examination of these questions is beyond the scope of this research. However, research participants express deep concerns about any assumption that the law is indispensable, objective or infallible. Yaa recognises the challenge faced by legal professionals in working toward those ideals:

Well, I can say, it can be done only if we are committed to what we say we want to do. For example, if you commit to being a lawyer, a counsellor at law, a judge, or an attorney, you took oath $\mathrm{x}, \mathrm{y}, \mathrm{z}$, so I have to obey the rules strictly. Even though there may be challenges to sway me from obeying my oath, but I won't because I am pursuing justice. If we are committed to ourselves, we can provide durable change to the legal system. But indeed, if you put yourself first, i.e., "what can I get out of this?" the outcome will be different. [Yaa, Liberia]

That said, the law is significant in keeping peace and social order, and it must be reformed if it is to properly address violence against Indigenous women and girls.

Radical reform of the Anglo-American Liberian and Anglo-Australian legal systems is dependent on willingness to incorporate and reconcile Aboriginal healing and restorative justice processes. For example, in Australia, Aboriginal healing circles could be applied throughout the criminal adjudication process instead of limiting offenders them only to circle sentencing. In Liberia, the Palava Hut Forum could engage Indigenous girls and women in a more meaningful way by giving them equal participation. Thankfully, reform programs are ongoing in both Australia and Liberia.

Progress is underway, both in Australia and in Liberia, to address systematic gender violence. For example, acknowledging violence against Indigenous girls and women as 'one of 
the gravest human rights challenges of our time’, Dame Quentin Bryce launched a \$3.5 million research program run by Australia's National Research Organisation on Women's Safety. ${ }^{1637}$ Also, a model intervention program called Justice Reinvestment, ${ }^{1638}$ 'whereby taxpayer funds are reinvested into the community instead of being spent on imprisoning people for low-level criminal activity', ${ }^{1639}$ could be extrapolated to help prevent violence against Indigenous girls and women. With support from the United Nations Development Program, Liberia is embarking on a complete constitutional overhaul. A two-year national public consultative process with 73 constituents in all 15 counties and the Diaspora generated 52308 suggestions. ${ }^{1640}$ Of the top 25 suggestions selected, the following eight are relevant in preventing violence against girls and women:

1) Traditional people should own their land and be a party to any negotiation with investors or concessionaires on said lands

2) The Constitution should ensure women's participation in governance and national affairs

3) The Constitution and all legal documents should carry the pronouns 'he/she'

4) Age of marriage for girls should be at least 18 years

5) Women should have access to equal economic and social opportunities

6) The Constitution should guarantee inheritance rights for traditional women

7) People in prolonged co-habitation should enjoy marital rights and

8) Customary laws should be made constitutional

\subsubsection{Educating Girls is a Necessity}

The value of education to women and girls in preventing abuse and violence cannot be overemphasised. Many studies have shown a strong correlation between higher educational attainment and reduction in risk of violence for girls (see chapters 2 and 8). This fact is reiterated throughout the research, especially in responses from Indigenous Women Advocates. The key concern here is how the state, society and individuals collectively use formal and informal education as a forum to interrogate pervasive, engrained and entrenched roots of gender violence. Here are a select few examples of the recommendations put forward by research participants:

Students are the custodians of society. Teachers must teach those messages of violence against women. In the homes, parents should take the responsibility to get deeply involved with their children's education otherwise international organisation will spend millions with no end results. [Survey Participant, Liberia]

Understanding the First Australians' (Aboriginal Peoples') history. A whole understanding of our history and ongoing issues is required to be taught in schools.

\footnotetext{
${ }^{1637}$ Staff Reporter, '\$3.5m Study into Violence against Women’ The Australian (Canberra, ACT), 31 October 2014 <http://www.theaustralian.com.au/news/latest-news/m-study-into-violence-against-women/story-fn3dxiwe1227108578765>.

${ }^{1638}$ Staff Reporter, 'Milestone for Justice Research' Cowra Guardian (Cowra, NSW), 8 January 2016 <http://readnow.isentia.com/Temp/84653/522241051.pdf>.

${ }_{1639}$ Jill Guthrie, Reducing Incarceration Using Justice Reinvestment: An Exploratory Case Study (2016) National Centre for Indigenous Studies <http://ncis.anu.edu.au/cowra/>; Paul Simpson et al, 'Views on Alternatives to Imprisonment: A Citizens Jury Approach' (Private Document, Lowitja Institute, 2014) 48, 3

<https://www.lowitja.org.au/lowitja-publishing/L031>; Paul Simpson et al, 'Assessing the Public's Views on Prison and Prison Alternatives: Findings from Public Deliberation Research in Three Australia Cities' (2015) 11(2) Journal of Public Deliberation 1.

${ }^{1640}$ Aukot, Pshorr and Zota, above n 1060.
} 
Education having a responsibility too, as in providing the correct history and having understanding of family violence, as some children are labelled as "naughty" and things may be happening for this child at home. [Survey Participant, Australia]

The schools are critical in recognising an at-risk child. Supporting our kids in school and their families by not judging how they might be living. Give support when it is needed not when it's too late because Family and Children Services are involved. Include more education about what violence is in the curriculum. [Jaky, Australia].

The school moulds minds of people, especially in the vocational area. Most students end their education at the vocational level. We believe that we should teach them the right thing. They are going into the society to make a change. It's the expectation of the society that students should make positive change about their environment. Some go back to their village and others do not. Not everyone is successful in life. [Tracy, Liberia]

Firstly, in reducing gender-based violence, the school, which is the place of education and morals, can tell the students to behave well at home and in the society. The children can take this back to their parents too. The school can also have awareness and education program on violence against women. We are no longer living in the archaic age. So, if we are claiming to be civilised, then we should be ready to educate people about dealing with these issues. Educating students about their Constitutional rights, and teaching girls so that they can pass on the info to the community and homes. [Klade, Liberia]

\subsubsection{Engaging Men and Boys}

As survivors of violence, girls and women often bear the brunt of addressing its continuation. By the same token, this study shows that boys and men appear prepared to share the responsibility of speaking out against gender violence. Since reducing paternalism and patriarchy is at the core of feminist movements, a process to support and promote males in efforts to combat systematic violence against all girls and women would be a natural next step.

\subsection{Conclusion}

Is the rule of law an essential axiom for restoring justice to Indigenous girls and women survivors of systematic gender violence in Australia and Liberia? Unfortunately, the answer is currently 'no'. The foreign legal systems imported by settler-colonists to Indigenous communities have not evolved to provide equal access to legal aid, equal standing before courts, or equal treatment by law enforcement. Also, in many situations the law has been, and continues to be, a mechanism used to inflict state/institutional violence upon Indigenous women and girls. The ways in which Indigenous women and girls are affected by the legal system, positively or negatively, depends on several factors, including the intersection of gender, race, sex, indigeneity, location, political affiliation, social class, socio-economic status, and political and legal representation. The complexity of these intersections means that there is also a need to continue examining the efficacy of the rule of law principle regarding access to justice for Indigenous girls and women survivors of gender violence using a complex systematic research method and design. That research should contribute to a global language in law and social justice that represents Indigenous women's experiences, and rejects the idea that violence is a 
normal behaviour occurring only in a particular culture or community. Researchers, legal professionals and policy-makers must

emphasise developing strategies to educate girls and women while actively engaging boys and men in advocacy against violence against women, generally, and Indigenous women, particularly. Words of research participants provide an excellent conclusion: '[t]here is no onesize-fits-all approach...the response needs to be flexible, responsive and informed by the community's needs'. 


\title{
APPENDICES
}

\author{
AI: Interview Questionnaire \\ Pseudonym: \\ PART I: GENERAL WORK EXPERIENCE WITH INDIGENOUS/ABORIGINAL GIRLS AND WOMEN
}

I would like to get a sense of your past work experience with Indigenous/Aboriginal girls and women in general.

How would you describe the work you do?

Have you ever worked with Indigenous/Aboriginal girls and women?

- In what capacity?

- $\quad$ For how long?

- Where was it?

- The nature of the work?

Looking back now, how would you assess your experience with that job? Was it a good or challenging?

PART II: SPECIFIC WORK EXPERIENCE WITH INGENOUS GIRLS AND WOMEN WHO HAVE EXPERIENCE

VIOLENCE

Now I want to focus on your current work in relation to gender violence against Indigenous/Aboriginal girls and women.

Do you work with Indigenous/Aboriginal girls and women who have experienced gender violence?

Can you tell me more about the work that you do on gender violence against Indigenous/Aboriginal girls and women? For example,

- $\quad$ The kinds of clients you serve

- The types of violence reported

- The type of treatment, care or assistance provided

- Whether males are included?

- What is the nature of their visit?

PART III: ACCESS TO CARE AND SERVICES

Now I would like to explore the accessibility of services provided to your clients.

How accessible are the services provided to clients? Are clients able to reach care or assistance easily and quickly? Can you

elaborate?

What locality are services provided in? Can anyone from anyone access the service?

By what means are clients able to obtain services (phone, email, fax, referral etc.)?

Are there other services like yours around? How many?

If referrals are made for care, where do they come from? List as many sources (hospital, clinics, legal aid, police station, prison etc.,)

PART IV: ACCESS TO LEGAL SERVICE

You may not be familiar with the legal services provided. However, based on your interaction with your clients and the kinds of services you provide I would like to understand whether the legal system is involved in any way.

For the clients that present for care, are you in the position to suggest any form of legal assistance? Can you explain? If 'no' why not?

For the clients that present for care, are you able to predict whether they are interested in reporting the experience to the police? If 'yes', are you able to assist them with the process of filing a complaint? If 'no', are there other avenues of legal support that is provided?

PART V: JUSTICE AND THE ROLE OF [CUSTOMARY/TRADITIONAL] LAW AND THE COMMUNITY

This section explores your view on the role of the justice system and community in addressing gender violence against

Indigenous/Aboriginal girls and women

What is your understanding of the role of law in gender violence?

How does the law or legal system relate to the advocacy work that you do?

Are you aware of any particular law/policy that are used to protect Indigenous/Aboriginal girls/women? Can you name some?

How has the legal system e impacted on Indigenous/Aboriginal girls/women who have experienced gender violence? Can you explain further?

What is the role of the legal system in restoring justice to Indigenous/Aboriginal girls and women who have experienced gender violence?

What is your understanding of Customary/Traditional Laws in Liberia/Australia?

What is the place do customary law have in restoring justice to Indigenous/Aboriginal girls and women who have experienced gender violence?

What do you think can be done legally to protect Indigenous/Aboriginal girls and women from violence?

What specific change(s) would you like to see in addressing gender violence against Indigenous/Aboriginal girls and women?

Any comments, suggestions or questions regarding the law or legal system or traditions as it relates gender violence against

Indigenous/Aboriginal girls and women?

Is there any question you would have liked for me to ask?

Do you know someone you think might be interested in completing this survey? If yes, could you kindly pass on the information sheet to them to contact me if they are interested?

PART VI: BACKGROUND/DEMOGRAPH

We are almost done. Just before we close, can I ask you few basic demographic questions so that I get a good sense of the spread or mix of participants?

Which year were you born? What is your relationship status (married, single, common law, single, partner)? What is your highest level of education? You identify with any particular Indigenous group? Which one? You identify with any particular religion? Which one?

What is your current employment status?

Thank you very much for your time

If you know someone who might be interested in this research could you please pass on the information she 


\section{AII: Paper/Online Survey Questions}

Date:

ID:

\section{DEFINITIONS}

By "Indigenous" I mean native Liberians who identify as the original inhabitants before the arrival of the freed-slaves from America.

The "law" includes criminal, civil, family, sentencing, dispute resolution, child protection and unreported cases.

By "Just Law/Legal System" I simply mean that both Indigenous and non-Indigenous Liberians are treated equally before and/or under the law.

"Gender Violence" includes state violence (e.g., forced adoption, land dispossession, forced wage, etc.,); institutional violence (e.g., Industrial use of native lands e.g., Firestone, Bong Mines, LAMCO, Sime Darby Oil Palm project, environmental and mining affects, etc.,); structural (e.g., political, economical, educational, health/medical, arrangements) and private abuse (e.g., domestic violence, physical, psychological, sexual, etc.,).

By "Service providers" I mean individuals who currently work with/on the issues of gender violence and the law/legal system in relation to Indigenous women and girls in Liberia (e.g., advocates, volunteers, researchers, community leaders, religious leaders, healthcare practitioners, counselors, teachers, lawyers, judges, police officers, prison staffs, etc.,).

By "Customary/Traditional Indigenous Law" I mean traditional or customary practices unique to Indigenous cultures and independent of Anglo-Liberian legal system.

By "Local Community" I mean school, work, residential, educational, health, legal context in which the issues and concerns of gender violence is discussed, presented and experienced.

This section contains background questions to determine which sections of this survey are relevant to your particular circumstances.

1. Are you 18 years old and above?

2. Are you living in Liberia/Australia?

Yes $\square$

Yes $\square$

3. Do you provide service(s) to Indigenous/Aboriginal girls/women on issues relating to gender violence and/or the legal system?

Yes $\square$ No $\square$

\section{PART I: GENDER VIOLENCE AGAINST INDIGENOUS/ABORIGINAL GIRLS AND WOMEN}

This section contains some questions about your work with Indigenous/Aboriginal girls and women in relation to gender violence.

4. Have you worked with Indigenous girls and women in Liberia/Australia who have experienced gender violence? Yes $\square$ No

$\square$

If "Yes" proceed to question 5

If "No" proceed to question 14

5. Can you briefly describe the nature of the specific work you do in relation to gender violence against Indigenous women and girls in Liberia/Australia?

Filter Question

6. Does the specific work you do in relations to gender violence against Indigenous girls and women involve any aspect of the

Liberian/Australian legal system? Yes $\square \quad$ No $\square \quad$ If "Yes" proceed to question 7 If "No" proceed to question 14

7. Can you describe how this work is involved with the legal system?

Filter Question

8. In your view, has the law been helpful in the specific work that you do with Indigenous/Aboriginal girls and women who have?

Yes $\square$ No $\square$

If "Yes" proceed to question $9 \quad$ If "No" proceed to question 10

9. Can you briefly describe with examples how the law has been helpful in the specific work that you do in relations to gender violence against Indigenous/Aboriginal girls and women? (For privacy, please do NOT state any personal information).

10. Can you briefly offer some examples of how the law has been unhelpful in the specific work that you do in relation to gender violence against Indigenous/Aboriginal girls and women? (For privacy, please do NOT state any personal information).

Filter Question

11. In your view, has the Liberia/Australia legal system been "just" towards Indigenous women and girls who have experienced gender violence? Yes $\square \quad$ No $\square \quad$ If "Yes" proceed to question 12 If "No" proceed to question 13

12. Why do you think the law has been "just" in relation to gender violence against Indigenous/Aboriginal girls and women? Give examples. (For privacy, please do NOT state any personal information).

13. Why do you think the law has been unjust in relations to gender violence against Indigenous/Aboriginal girls and women? Give examples. (For privacy, please do NOT state any personal information).

\section{PART III: GENERAL VIEWS}

This section contains some general questions about the Liberian legal system in relation to Indigenous women and girls in Liberia/Australia.

14. Can you briefly describe the nature of the work you do in relation to Indigenous girls and women in Liberia/Australia?

15. How do you see the role of the Liberian/Australian legal system in protecting Indigenous/Aboriginal girls and women who have experienced gender violence? Explain. 
16. How would you improve the law in protecting Indigenous/Aboriginal children and women who have experienced gender violence in Liberia/Australia?

17. Do you think "customary (i.e., traditional) Indigenous/Aboriginal law" has a role to play in addressing gender violence against Indigenous/Aboriginal girls and women in Liberia/Australia? Yes $\square$ No $\square$ If "Yes" proceed to question 18 If "No" proceed to question 19

18. What is that role?

19. How would you improve the "customary/traditional Indigenous/Aboriginal" law in protecting Indigenous/Aboriginal children and women who have experienced gender violence in Liberia/Australia?

20. Do you think the "local community" has a role to play in addressing gender violence against Indigenous women/Aboriginal girls and women in Liberia/Australia? Yes $\square$ No $\square$ If "Yes" proceed to question 21 If "No" proceed to question 22

21. What is that role?

22. How do we change attitudes (e.g., in the home, school, church, community, workplace, etc.,) toward gender violence against Indigenous/Aboriginal girls and women?

23. What changes would you like to see (e.g., in the home, school, church, community, workplace) in relation to gender violence against Indigenous/Aboriginal girls and women?

\section{PART IV: COMMENTS AND DISTRIBUTION}

24. Is there anything important that you want to tell me on the topic of gender violence and Indigenous/Aboriginal girls and women that may not have covered in the survey?

25. Is there a question you would have wanted me to ask about gender violence against Indigenous children and women in Liberia/Australia?

\section{PART VI: SIMPLE DEMOGRAPHICS}

Finally, this section asks some questions about you to make sure that a good cross-section of people has participated in this survey.

26. What is your sex? $\square$ Transgender $\square$ Male $\square$ Female

27. What is your age range? $\square 18$ - 25 years $\square 26$ - 35 years $\square 36$ - 45 years $\square 46-55$ years $\square 55+$ years 28. What is your religious affiliation? $\square$ Christian $\square$ Muslim $\square$ African Traditional Religion Other:

29. What institution, organization or community do you work with?

30. What is your institutional position or community role?

31. Where are you located? State/Territory/County:

City/Town/Community: -

32. How would you describe your profession or expertise?

$\square$ Lawyer
$\square$ Judge
$\square$ Law enforcement officer
$\square$ Community leader
$\square$ Researcher
$\square$ Prison staff
$\square$ Healthcare provider

33. How long have you been working in this profession or area of expertise? $\square$ 0-5 years $\square$ 6-10 years $\square$ 11-20 years $\square$ 20+ years

34. In what capacity have you worked with Indigenous/Aboriginal peoples in Liberia/Australia (tick all that apply)

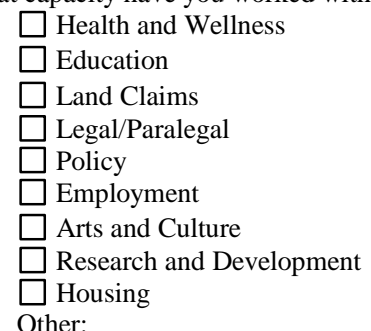

THANK-YOU

If you know of someone who might be interested in completing this survey, could you please pass on the information sheet? 


\section{AIII: Summary of Research Models, Design, Question and Description}

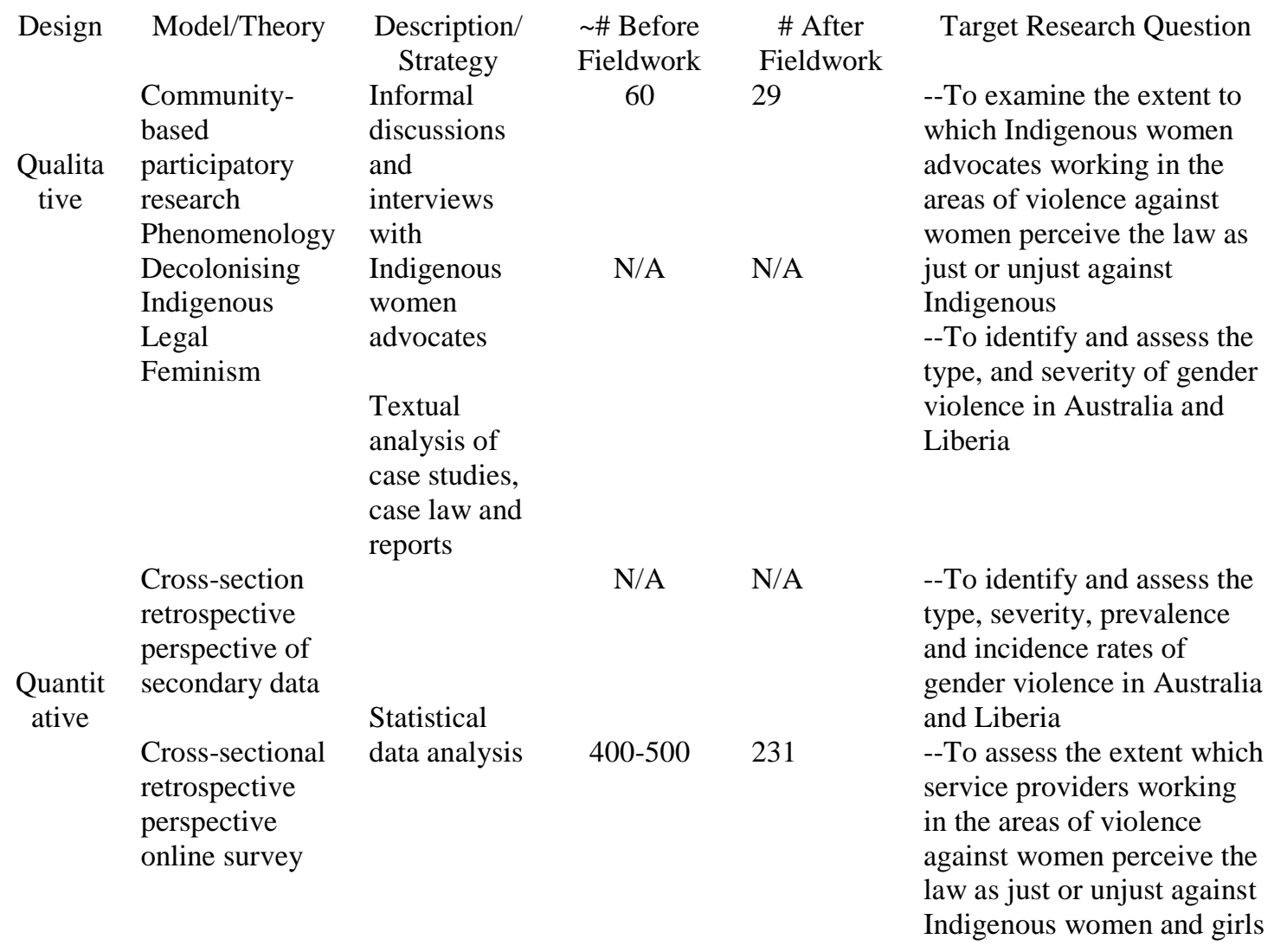


AIV: Historical Timeline (Liberia and Australia)

\begin{tabular}{|c|c|c|c|}
\hline Australia & Date & Date & Liberia \\
\hline $\begin{array}{l}\text { Rock engravings in South Australia suggest evidence of land inhabitancy. Aboriginal } \\
\text { society (now called Aboriginal and Torres Strait Islander) governed by customary laws } \\
\text { handed down by their creative ancestral beings. }\end{array}$ & $\begin{array}{l}45,000-60,000 \\
\text { yа }\end{array}$ & $\begin{array}{l}2.8-5 \text { million } \\
\text { ya }\end{array}$ & $\begin{array}{l}\text { The Afar, a part of East Africa Rift Valley, has produced plenty of hominins } \\
\text { remains, including the first Australopithecus afarensis (nickname Lucy) } \\
\text { pointing towards the fact that "Africa is the cradle of life" }\end{array}$ \\
\hline $\begin{array}{l}\text { Dutch explorers record the journeys of Macassan Trepangers (i.e., Indigenous traders } \\
\text { from Indonesia) to northern Australia. }\end{array}$ & $1451-1906$ & $570-470 \mathrm{BC}$ & $\begin{array}{l}\text { Supposition that there was a definite but highly probable account of an actual } \\
\text { landing on the Liberian Coast. }\end{array}$ \\
\hline $\begin{array}{l}\text { The Governor-General of the Dutch East Indies, Anthony Van Diemen, orders Abel } \\
\text { Tasman to seek and map New Holland. Abel Tasman misses Australia but lands on the } \\
\text { island and names it Van Diemen's Land, a name which British settlers will use for } 70 \\
\text { years before changing it to Tasmania. }\end{array}$ & 1642 & $800-1100 \mathrm{AD}$ & Rise of the great West African empires- Ghana, Mali, and Songhai \\
\hline $\begin{array}{l}\text { Scottish author John Callender publishes Terra Australis Incognita, and urges the British } \\
\text { to explore the 'unknown continent'. James Cook, a Yorkshire villager, apprentice grocer } \\
\text { is appointed to command HM Bark Endeavour to observe the transit of Venus at Tahiti, } \\
\text { and then to search for the 'Great South Land'. }\end{array}$ & 1768 & 1441 & $\begin{array}{l}\text { Start of European slave trading in Africa initiated by the capture of } 12 \text { Africans } \\
\text { in Cabo Branco (modern Mauritania) by Portuguese captains Antão Gonçalves } \\
\text { and Nuno Tristão. The captured Africans were taken to Portugal as slaves. }\end{array}$ \\
\hline $\begin{array}{l}\text { On } 20 \text { April 1770, Captain James Cook makes the first European sighting of eastern } \\
\text { coast for Australia. On } 29 \text { April, the Endeavour enters Botany Bay. Cook wrote in his } \\
\text { diary, 'all they seem'd to want was us to be gone'. He then charts the Eastern coast all } \\
\text { the way to the north tip of Cape York, claims it for England and calls it New South } \\
\text { Wales. }\end{array}$ & 1770 & 1562 & $\begin{array}{l}\text { Britain begins slave trade in Africa with increase in plantation development in } \\
\text { Brazil. Other countries involve in trading of slaves in Africa included, Spain, } \\
\text { North America, Holland, France, Sweden and Denmark. }\end{array}$ \\
\hline $\begin{array}{l}\text { On } 3 \text { March 1779, Joseph Banks, a botanist on Cook's } 1770 \text { voyage, strongly suggest to } \\
\text { an English Parliamentary Committee the founding a convict penal settlement at Botany } \\
\text { Bay. }\end{array}$ & 1779 & 1651 & Cash Crop Plantations and the Slave Plantations established in America. \\
\hline $\begin{array}{l}\text { Britain announces in Parliament that the settlement shall be made at NSW, King George } \\
\text { III declares a plan to transport convicts to Botany Bay to relieve the 'crowded goals'. } \\
\text { European settlement of Australia commenced. When colonising Australia, the British } \\
\text { Government used the term Terra Nullius (meaning land of no-one) to justify the } \\
\text { dispossession of Indigenous Peoples. }\end{array}$ & 1786 & $1775-1783$ & $\begin{array}{l}\text { The American Revolutionary War or the American War of Independence } \\
\text { resulted from constitutional resistance of Americans to taxes imposed by the } \\
\text { British parliament in the 1760s, which they claim were 'taxation without } \\
\text { representation'. }\end{array}$ \\
\hline $\begin{array}{l}\text { Arrival of the First Fleet at Botany Bay (then Sydney Cove) with } 1480 \text { on board } \\
\text { including } 742 \text { ( } 543 \text { men and } 189 \text { women) convicts, under Governor Arthur Phillip. At the } \\
\text { onset of British settlement in Australia, there were clashes between Aboriginal people } \\
\text { and the settlers over the next } 10 \text { years in the Parramatta and Hawkesbury areas. }\end{array}$ & 1788 & 1800 & $\begin{array}{l}\text { Gabriel Prosser's rebellion enlisted more than } 1000 \text { slaves and plotted the first } \\
\text { large-scale slaves revote in the United States. On the day of the revolt, the } \\
\text { bridges leading to Richmond are destroyed in a flood, and Prosser is betrayed. } \\
\text { The state militia attacks, and Prosser and } 35 \text { of his men are hanged. }\end{array}$ \\
\hline $\begin{array}{l}\text { Smallpox epidemic spreading down from the northern coast, wipes out about half of the } \\
\text { Indigenous populations around the Sydney settlement area. }\end{array}$ & 1789 & 1804 & $\begin{array}{l}\text { Creation of the Black Republic of Haiti, after slave uprising led by Toussant } \\
\text { l'Ouverture between } 1743 \text { and } 1803 \text {, where over } 55000 \text { blacks' waged guerrilla } \\
\text { and frontal war against the British. }\end{array}$ \\
\hline $\begin{array}{l}\text { After a 12-year war, Pemylwuy, Eora resistant fighter is hot and killed by two settlers. } \\
\text { His head is preserved and sent to Sir Joseph Banks in London by Governor King. King } \\
\text { writes: 'although a terrible pest to the colony, he was a brave and independent character' } \\
\text { Tedbury, Pemulwuy's son, continues the resistance for the next eight years. }\end{array}$ & 1802 & 1807 & $\begin{array}{l}\text { Britain banned the further conduct in British ships of slave trade that an earlier } \\
\text { Britain had done so much to extend and profit from (Basil Davidson Black } \\
\text { man's burden. }\end{array}$ \\
\hline $\begin{array}{l}\text { In Van Diemen's Land, bushrangers become more hostile, their rage exacerbates conflict } \\
\text { between Aborigines and Whites. }\end{array}$ & $1812-1819$ & 1811 & $\begin{array}{l}\text { On } 1 \text { March 1811, Paul Cuffe, a wealthy Quaker businessman of Aquinnah } \\
\text { Wampanoag and West African Ashanti descent, arrived in Sierra Leone to } \\
\text { investigate the social and economic conditions of the region in support of } \\
\text { colonising Africans as a viable option for resettling freed black slaves on the }\end{array}$ \\
\hline
\end{tabular}
Dutch explorers record the journeys of Macassan Trepangers (i.e., Indigenous traders to expl author John Callender publishes Terra Australis Incognita, and urges the British

On 20 April 1770, Captain James Cook makes the first European sighting of eastern III declares a plan to transport convicts to Botany Bay to relieve the 'crowded goals'. Arrival of the First Fleet at Beples. including 742 (543 men and 189 women) convicts, under Governor Arthur Phillip. At the onset of British settlement in Australia, there were clashes between Aboriginal people Indigenous populations around the Sydney settlement area. Tedbury, Pemulwuy's son, continues the resistance for the next eight years.

In Van Diemen's Land, bushrangers become more hostile, their rage exacerbates conflict colonising Africans as a viable option for resettling freed black slaves on 


\begin{tabular}{|c|c|c|c|}
\hline & & & continent. \\
\hline $\begin{array}{l}\text { In an attempt to foster better understanding between whites and blacks, Governor } \\
\text { Macquarie begins an annual meeting with Indigenous Australians and tribal heads, } \\
\text { distributing gifts at Christmas time from Parramatta. Simultaneously, he opens a school } \\
\text { for Aboriginal children at Parramatta called the "Native Institution". }\end{array}$ & 1814 & 1816 & $\begin{array}{l}\text { Between } 4 \text { and } 21 \text { December, white upper-class males including, James Monroe, } \\
\text { Bushrod Washington, Andrew Jackson, Francis Scott Key (author of the Star } \\
\text { Spangled Banner), Elijah Caldwell (Clerk of the US Supreme Court), Robert } \\
\text { Finley (a Presbyterian Minister and former president of the University of } \\
\text { Georgia), Samuel Mills, and Daniel Webster and several others, met at Capitol } \\
\text { Building/David hotel (respectively) in Washington D.C., with Henry Clay } \\
\text { presiding over the meeting to found the American Colonisation Society or 'The } \\
\text { Society of the Colonization of Free People of Color of America' - a solution to } \\
\text { the problem of free blacks in America. Congress released } \$ 100000 \text { in } 1819 \text { and } \\
\text { by January } 1820 \text {, the first ship; the Elizabeth sailed from New York to West } \\
\text { Africa with three white ACS agents. }\end{array}$ \\
\hline $\begin{array}{l}\text { Macquarie decides the Indigenous are behaving ungratefully and hostile. He organizes a } \\
\text { military drive to teach them a lesson. }\end{array}$ & 1816 & 1819 & $\begin{array}{l}\text { On } 3 \text { March, the United States Congress passed an act authorising President } \\
\text { James Monroe to return any recaptured Africans to that Continent. }\end{array}$ \\
\hline $\begin{array}{l}\text { First superior court of the Colony of New South Wales (Supreme Court of Civil } \\
\text { Judicature) established by letters patent. }\end{array}$ & 1823 & 1821 & $\begin{array}{l}\text { The American Colonization Society sent the first group of former slaves to } \\
\text { Africa - } 88 \text { passengers, including three white agents along with Charles } \\
\text { McCarthy, Governor of the Colony. Aided by John Kizzell, an influential } \\
\text { African trader who had been to the United States, the crew docked on Sherbro } \\
\text { Island, West Coast of Africa. }\end{array}$ \\
\hline $\begin{array}{l}\text { Martial law is declared in Bathurst, when several Europeans are killed by Aboriginal } \\
\text { people and conflict with Aborigines is seen as a serious threat to white settlement. }\end{array}$ & 1824 & 1822 & $\begin{array}{l}\text { A freed man, Denmark Vesay, who had won a lottery to purchase his } \\
\text { emancipation, plans a massive slave rebellion involving thousands of slaves on } \\
\text { surrounding plantations. Organized into cells, slaves started fire at night, and } \\
\text { then kill the slave owners and their families. Vesey was later betrayed and } \\
\text { hanged, but the cell structure prevented officials from identifying other leaders } \\
\text { of the revolt. } \\
\text { On } 25 \text { April, the survivors of Sherbro Island arrived at Cape Mesurado and } \\
\text { began to build their settlement, which would later become Liberia. } \\
\text { The Battle of Crown Hill ensued when the colony comes under attack from } \\
\text { some } 500 \text { members of two indigenous groups. This is among the first in a series } \\
\text { of armed clashes between the native population and the colonists in early } \\
\text { Liberia, indicative of the conflict of intentions and culture that marked the early, } \\
\text { uneasy relationship between the former slaves and Indigenous Liberians. } \\
\text { Jehudi Ashmun becomes fourth Governor the colony of Liberia as an ACS agent } \\
\text { and representative for the US. }\end{array}$ \\
\hline $\begin{array}{l}\text { British sovereignty extended to cover the whole of Australia - everyone born in } \\
\text { Australia, including Aborigines and Torres Strait Islanders, became a British subject by } \\
\text { birth. Captain Fremantle hoisted the Union Jack flag claiming New South Wales territory } \\
\text { for Britain. }\end{array}$ & 1829 & 1824 & $\begin{array}{l}\text { On } 20 \text { February, the American Colonization Society names the colony Liberia, } \\
\text { for liberty, and the capital Monrovia, after U.S. president James Monroe. }\end{array}$ \\
\hline $\begin{array}{l}\text { Van Diemen's Land Black Line - failed attempt to head the remaining free Indigenous } \\
\text { Tasmanian on Flinders Island without success. Later, the community is moved to Cape } \\
\text { Barren Island. } \\
\text { Truganini, probably the best known Tasmanian Aboriginal women of the colonial era, } \\
\text { spent } 20 \text { years imprisoned, with other Aboriginal Tasmanians, on Flinders Island, and } \\
\text { another } 17 \text { years in the Oyster Cove camp, south of Hobart. By the time she was } 17 \text { she } \\
\text { had lost her mother, sister, uncle and would-be partner to violent incidents involving }\end{array}$ & 1830 & 1831 & $\begin{array}{l}\text { Nat Turner plans a slave revolt in Southampton County, Virginia, the only } \\
\text { effective, sustained slave rebellion in the history of the United States. Sixty } \\
\text { whites are killed before Turner and his followers are captured and hanged. }\end{array}$ \\
\hline
\end{tabular}




\begin{tabular}{|c|c|c|c|}
\hline $\begin{array}{l}\text { sailors, sealers, soldiers and wood cutters. Despite witnessing the most horrific crimes } \\
\text { against humanity, Truganini believed the only way to fight against white invaders was to } \\
\text { learn their ways in order to gain empathy. }\end{array}$ & & & \\
\hline $\begin{array}{l}\text { In Western Australia, Governor Stirling leads } 25 \text { mounted police against the Aboriginal } \\
\text { people. Conflicting records exist regarding the number of people killed during the Battle } \\
\text { of Pinjarra. } \\
\text { George Augustus Robinson travels around Van Diemen's Land persuading Aborigines to } \\
\text { come into captivity, promising them a place where they could be fed and clothed, and } \\
\text { live unmolested by the settlers. }\end{array}$ & 1834 & 1833 & $\begin{array}{l}\text { Slavery Abolition Act: An Act of the Parliament of the United Kingdom } \\
\text { Abolishing Slavery throughout the British Empire with exceptions to the } \\
\text { Territories in the Possession of the East Indian Company, the Island of Ceylon } \\
\text { and the Island of Saint Helena. }\end{array}$ \\
\hline $\begin{array}{l}\text { Governor Bourke of New South Wales introduces annual squatting license fees to } \\
\text { regulate land use, and to try and stop squatters from killing Indigenous Australians. }\end{array}$ & 1836 & 1836 & $\begin{array}{l}\text { On } 1 \text { January, Thomas Buchanan, cousin of James Buchanan, former President } \\
\text { of the United States, arrives in Bassa Cove to serve as the second governor of } \\
\text { Liberia. Isaac Wade Ross, Revolutionary war hero, died in Mississippi. His will } \\
\text { stipulated that his slaves should be emancipated upon his death, but only if they } \\
\text { agreed to go to Liberia. The 1st of almost } 200 \text { were finally set free in } 1848 \text {. }\end{array}$ \\
\hline $\begin{array}{l}\text { British Select Committee examines the treatment of Indigenous Peoples in all British } \\
\text { colonies and recommends that 'Protectors of Aborigines' be appointed in Australia. }\end{array}$ & 1837 & 1838 & $\begin{array}{l}\text { All colonies but one join to create the Commonwealth of Liberia and adopt a } \\
\text { constitution that limits citizenship to persons of colour. Yet the } \\
\text { Commonwealth's first governor, appointed by the American Colonization } \\
\text { Society, is white: Thomas Buchanan, cousin of U.S. President James Buchanan. }\end{array}$ \\
\hline $\begin{array}{l}\text { Myall Creek Massacre where, settlers' shoot } 28 \text { Aboriginal people, mostly women and } \\
\text { children. } 11 \text { Europeans were charged with murder but are acquitted. A new trial is held, } \\
\text { and seven men are charged with the murder of one Aboriginal child. They are found } \\
\text { guilty and hanged. }\end{array}$ & 10 Jun 1838 & 1847 & $\begin{array}{l}\text { Constitution drafted by Simon Greenleaf and modelled after that of the US. In } \\
\text { July } 1947 \text { freed men of colour declared independence from the ACS. Joseph } \\
\text { Jenkins Roberts, the Virginia (USA) born son of free black slaves becomes the } \\
\text { first President of Liberia. During his presidency, the country's first university is } \\
\text { established and smuggling of slaves, still an active trade, is suppressed. }\end{array}$ \\
\hline $\begin{array}{l}\text { First parliamentary elections in Australia (for New South Wales Legislative Council) } \\
\text { were held. The right to vote was limited to men with a freehold valued at } £ 200 \text { or a } \\
\text { householder paying rent of } £ 20 \text { per year. }\end{array}$ & 1843 & 1857 & $\begin{array}{l}\text { On } 18 \text { March 1957, after signing an annexation treaty with the Republic of } \\
\text { Liberia, the Colony of Maryland is annexed to become part of Liberia. The } \\
\text { name Cape Palmas is used in general to cover the entire area of Maryland } \\
\text { County. }\end{array}$ \\
\hline $\begin{array}{l}\text { The Australian colonies become self-governing - all adult (21 years) male British } \\
\text { subjects were entitled to vote in South Australia from 1856, in Victoria from 1857, New } \\
\text { South Wales from 1858, and Tasmania from } 1896 \text {. This included Indigenous Peoples, } \\
\text { but they were not encouraged to enrol. Queensland gained self-government in } 1859 \text { and } \\
\text { Western Australia in } 1890 \text {, but these colonies denied Indigenous Peoples the vote. }\end{array}$ & $1850+$ & 1860 & $\begin{array}{l}\text { Following various treaties, purchases, and battles with indigenous chiefs, by } \\
1860 \text { Liberia's boundaries are extended to include a } 600 \text {-mile coastline. } \\
\text { Chief Nye Suakoko, the first female Paramount Chief in Western Kpellehland, } \\
\text { Liberia (now part of the Republic of Guinea) was a courageous and hospitable } \\
\text { woman who believed in oneness. She rose among her male counterparts } \\
\text { becoming an indelible diplomat and negotiator between her native people and } \\
\text { settlers to Liberia. }\end{array}$ \\
\hline Queensland Elections Act excluded all Indigenous Peoples from voting. & 1885 & $1861-1865$ & $\begin{array}{l}\text { The American Civil war. The American Colonization Society became inactive } \\
\text { as African Americans gained their freedom. As such, there was no need for } \\
\text { them to emigrate. }\end{array}$ \\
\hline Western Australian law denied the vote to Indigenous Peoples. & 1893 & 1862 & The United States formally recognise Liberia as an Independent sovereign state. \\
\hline All adult women in South Australia, including Indigenous women, won the right to vote. & 1895 & 1904 & $\begin{array}{l}\text { Indigenous chiefs meet in the National Legislature for the first time on } 7 \\
\text { December. } \\
\text { Between } 1822 \text { and } 1904 \text {, some } 23000 \text { former slave emigrants from the US, } \\
\text { Caribbean and around African settle in Liberia. }\end{array}$ \\
\hline All adult women in South Australia granted the right to seek election in Soutl & 1899 & 1907 & $\begin{array}{l}\text { On } 7 \text { May } 1907 \text {, the constitution is amended, changing the presidential term } \\
\text { from two years to four. }\end{array}$ \\
\hline
\end{tabular}




\begin{tabular}{|c|c|c|c|}
\hline $\begin{array}{l}\text { Commonwealth Constitution became operative }- \text { section } 41 \text { was interpreted to deny the } \\
\text { vote to all Indigenous Peoples, except those on state rolls. }\end{array}$ & 1901 & 1926 & $\begin{array}{l}\text { Firestone Tire and Rubber Company created the world's largest rubber } \\
\text { plantation on land granted by the Liberian government. Firestone signed a 99- } \\
\text { year concession agreement with the Liberian government purchasing a million } \\
\text { acre of land at the cost of six cent per acre. }\end{array}$ \\
\hline $\begin{array}{l}\text { The first Commonwealth Parliament passed the Commonwealth Franchise Act of } 1902 \text {, } \\
\text { which was progressive for its time in granting the vote to both men and women. It did } \\
\text { however; specifically exclude 'any aboriginal native of Australia, Asia, Africa or the } \\
\text { Islands of the Pacific, except New Zealand' from Commonwealth franchise unless } \\
\text { already enrolled in a state. The Aboriginal franchise was further reduced in practice by } \\
\text { admitting only those Aboriginal people already enrolled in a state in } 1902 \text {. }\end{array}$ & 1902 & 1930 & $\begin{array}{l}\text { League of Nation accused Liberia of slavery (forced labour) on Cocoa } \\
\text { plantations in Spanish Colonial Equatorial Guinea. }\end{array}$ \\
\hline $\begin{array}{l}\text { In } 1903 \text {, for the first time in the British Empire, Australian women were candidates for } \\
\text { election to a national parliament. In all, four women were nominated - three for the } \\
\text { Senate and one for the House of Representatives. Vida Goldstein ran for the Senate on } \\
\text { three occasions - in } 1903,1910 \text { and } 1917 \text {. She was also a House of Representatives } \\
\text { candidate in } 1913 \text { and } 1914 \text {. However, she was never successful in her bids for election. }\end{array}$ & 1903 & 1936 & Forced-labor practices are abolished. \\
\hline $\begin{array}{l}\text { A bill was introduced into Queensland Parliament allowing non-Aboriginal women to } \\
\text { vote. }\end{array}$ & 1905 & 1945 & $\begin{array}{l}\text { Liberia is } 1 \text { of } 50 \text { founding members to sign the UN Charter, thus becoming a } \\
\text { member of the UN. } \\
\text { Suffrage extended to women through a constitutional amendment. }\end{array}$ \\
\hline $\begin{array}{l}\text { A leading suffragette, Edith Cowan, was the first woman to be elected to an Australian } \\
\text { parliament when she won a seat in the Western Australian Legislative Assembly in } 1921 .\end{array}$ & 1921 & 1946 & $\begin{array}{l}\text { Suffrage extended to Indigenous Liberians by an "Act to regulate all Elections } \\
\text { in the Republic of Liberia". }\end{array}$ \\
\hline $\begin{array}{l}\text { Edith Cowan introduced and saw enacted the Women's Legal Status Act, which enabled } \\
\text { women to practice law - a major milestone in the achievement of women's rights. }\end{array}$ & 1923 & 1951 & $\begin{array}{l}\text { Reformation party candidate Didwho Twe, an Indigenous Liberian, challenges } \\
\text { WVS Tubman of the True Whig Party. }\end{array}$ \\
\hline $\begin{array}{l}\text { Regulations in the Northern Territory excluded Indigenous Peoples from voting. } \\
\text { Officials had the power to decide who was Indigenous. }\end{array}$ & 1922 & 1952 & Tubman begins his second presidential term. \\
\hline $\begin{array}{l}\text { Irene Longman became Queensland's first female parliamentarian in May 1929. Her } \\
\text { career ran for only one year. }\end{array}$ & 1929 & 1955 & $\begin{array}{l}\text { The constitution is amended to allow President Tubman to remain in office well } \\
\text { beyond the two-term limit. }\end{array}$ \\
\hline $\begin{array}{l}\text { Professor AP Elkin, the Aborigines Friends Association, and others agitated for better } \\
\text { conditions for Indigenous Peoples and their right to vote. }\end{array}$ & $1940 \mathrm{~s}+$ & 1956 & Tubman begins his third presidential term. \\
\hline $\begin{array}{l}\text { Nationality and Citizenship Act established that all Australian born people are citizens of } \\
\text { Australia rather than British subjects. }\end{array}$ & 1948 & 1959 & $\begin{array}{l}\text { Liberia hosts the Sanniquellie Summit to discuss the founding of the } \\
\text { Organisation of African Unity (now AU) with President of Guinea, Sekou Toure } \\
\text { and President of Ghana, Kwame Nkrumah. }\end{array}$ \\
\hline $\begin{array}{l}\text { The right to vote in federal elections was extended to Indigenous Peoples who had served } \\
\text { in the armed forces or were enrolled to vote in state elections. Indigenous Peoples in } \\
\text { Queensland, Western Australia, and the Northern Territory still could not vote in their } \\
\text { own state/territory elections. } \\
\text { Florence Cardell-Oliver, president of the Western Australian Nationalist Women's } \\
\text { Movement, won the State seat of Subiaco in 1936. She was especially concerned about } \\
\text { the health of children from low income families, thus the first woman in Australia to } \\
\text { attain full cabinet rank when she became Minister for Health in October 1949. Her } \\
\text { efforts created the school milk scheme, which ensured that generations of children } \\
\text { received a daily quota of free milk. }\end{array}$ & 1949 & 1960 & $\begin{array}{l}\text { Tubman begins his fourth presidential term. } \\
\text { Ethiopia and Liberia initiate proceedings at the International Criminal Court } \\
\text { regarding apartheid in South Africa. }\end{array}$ \\
\hline $\begin{array}{l}\text { First determination of a female basic wage, when the Commonwealth Arbitration Court } \\
\text { set female wage at } 75 \% \text { of the male basic wage. }\end{array}$ & 1950 & 1964 & $\begin{array}{l}\text { Tubman begins his fifth presidential term. County status extended to interior } \\
\text { provinces (Indigenous Liberians) placing them administratively on equal } \\
\text { political footing with the coastal counties (former slave settlements). }\end{array}$ \\
\hline Under the Northern Territory Welfare Ordinance, almost all Indigenous Peoples in the & 1957 & 1967 & Liberia becomes member of the OAU. \\
\hline
\end{tabular}




\begin{tabular}{|c|c|c|c|}
\hline Northern Territory were declared to be "wards of the state" and denied the vote. & & & \\
\hline $\begin{array}{l}\text { Commonwealth Electoral Act provided that Indigenous Peoples should have the right to } \\
\text { enrol and vote at federal elections, including Northern Territory elections, but enrolment } \\
\text { was not compulsory. Despite this amendment, it was illegal under Commonwealth } \\
\text { legislation to encourage Indigenous Peoples to enroll to vote. Western Australia extended } \\
\text { the State vote to Aboriginal people. Voter education for Aborigines began in the } \\
\text { Northern Territory. One thousand three hundred and thirty-eight (1 338) Aborigines } \\
\text { enrolled to vote in Northern Territory elections. }\end{array}$ & 1962 & 1968 & Tubman begins his sixth term. \\
\hline $\begin{array}{l}\text { Queensland allowed Aborigines to vote in State elections. Queensland was the last State } \\
\text { to grant this right. }\end{array}$ & 1965 & 1979 & $\begin{array}{l}\text { The Rice Riot - on } 14 \text { April 1979, hundreds of civilians protested the increase in } \\
\text { the price of rice - Liberia's staple food. }\end{array}$ \\
\hline $\begin{array}{l}\text { The bar on employment of married women in the Commonwealth Public Service was } \\
\text { abolished in } 1966 \text {. This restriction meant that married women could only be employed as } \\
\text { temporary staff, restricting their promotion opportunities (only permanent staff could be } \\
\text { in a supervisory position). Being a temporary employee also restricted the ability of } \\
\text { married women to accumulate superannuation and meant that they were the first to be } \\
\text { targeted for redundancies when significant downsizing of the Australian Public Service } \\
\text { (APS) occurred in the early 1950s. The Boyer Committee first recommended the } \\
\text { removal of the bar in 1958, although it took another eight years before these ideas came } \\
\text { to fruition. The lifting of the bar marked not only the trigger for greater numbers of } \\
\text { women working in the APS but also the evolution of the integration of women's issues } \\
\text { into public policy. }\end{array}$ & 1966 & 1980 & $\begin{array}{l}\text { The Coup: on } 12 \text { April 1980, William R. Tolbert, President of Liberia alongside } \\
27 \text { other government officials assassinated by } 16 \text { enlisted men headed by Master } \\
\text { Sergeant Samuel Doe (of the Indigenous Krahn language group). Thirteen top } \\
\text { ranking ministers and members of the Tolbert family were also executed. On } 13 \\
\text { April, a new revolutionary military government, the People's Redemption } \\
\text { Council (PRC), is formed with Doe as Commander-In-Chief. }\end{array}$ \\
\hline $\begin{array}{l}\text { A Referendum approved Commonwealth Constitutional change. Section } 127 \text { of the } \\
\text { Constitution was struck out in its entirety. This amendment allowed Indigenous Peoples } \\
\text { to be counted in the Commonwealth Census. Section } 51 \text { of the Constitution was amended } \\
\text { to allow the Commonwealth to make special laws for Indigenous Peoples. Both Houses } \\
\text { of the Parliament passed the proposed Act unanimously; consequently a 'No' case was } \\
\text { not submitted. More than } 90 \text { per cent of Australians registered a YES vote with all six } \\
\text { states voting in favour. }\end{array}$ & 1967 & 1981 & $\begin{array}{l}\text { The African States members of the Organization of African Unity, meeting in } \\
\text { Liberia, adopted a Charter on Human and People's Rights. Article } 5 \text { specifically } \\
\text { prohibited slavery. It became effective as of October } 21,1986 .\end{array}$ \\
\hline $\begin{array}{l}\text { Neville Bonner AO (1922-99) was the first Indigenous person to be appointed to Federal } \\
\text { Parliament in Australia. Neville Bonner was born on Ukerbagh Island in the Tweed } \\
\text { River in New South Wales. After many years of itinerant work, he stood unsuccessfully } \\
\text { as a candidate for the half Senate election in } 1970 \text {. In } 1971 \text { Neville Bonner was } \\
\text { appointed by the Queensland Parliament to replace the Queensland Liberal Senator, } \\
\text { Dame Annabel Rankin, who had retired from Federal Parliament. At the } 1972 \text { election he } \\
\text { was returned as a Liberal Senator for Queensland. Senator Bonner continued to represent } \\
\text { Queensland as a Liberal Senator until } 1983 \text {. At the } 1983 \text { election he stood as an } \\
\text { Independent candidate but was not re-elected. } \\
\text { Bank of New South Wales grants loans to women without requiring a male guarantor }\end{array}$ & 1971 & 1983 & $\begin{array}{l}\text { Former commanding General Thomas Quiwonkpa, of Indigenous Gio language } \\
\text { group, is accused of leading a plot to overthrow the PRC government. }\end{array}$ \\
\hline $\begin{array}{l}\text { Late on Australia Day 1972, four young Aboriginal men erected a beach umbrella on the } \\
\text { lawns outside Parliament House in Canberra and put up a sign, which read 'Aboriginal } \\
\text { Embassy'. Over the following months, supporters of the embassy swelled to 2000. This } \\
\text { political action was initiated and implemented by Aboriginal activists. The site became } \\
\text { known as the Aboriginal Tent Embassy. It was a powerful symbol. The original owners } \\
\text { of the land set up an "embassy" opposite the parliament, as if they were foreigners. This } \\
\text { act showed compellingly the strength of their sense of alienation. They were landless. }\end{array}$ & 1972 & 1985 & Doe wins first presidential election. \\
\hline
\end{tabular}




\begin{tabular}{|c|c|c|c|}
\hline $\begin{array}{l}\text { First national elections for Indigenous Peoples to elect } 41 \text { members of the National } \\
\text { Aboriginal Consultative committee. More than } 27000 \text { Indigenous Peoples voted. } \\
\text { Minimum voting age lowered from } 21 \text { to } 18 \text {. }\end{array}$ & 1973 & 1986 & $\begin{array}{l}6 \text { January 1986, General Samuel K. Doe was inaugurated the twenty-first and } \\
\text { first Indigenous president of Liberia. }\end{array}$ \\
\hline $\begin{array}{l}\text { Hyacinth Tungutalum (Country Liberal Party), from Bathurst Island was elected to the } \\
\text { Northern Territory Legislative Assembly, representing the electorate of Arafura. Eric } \\
\text { Deeral (National Party), became the first Indigenous person to be elected to the } \\
\text { Queensland Parliament representing the electorate of Cook. } \\
\text { Courtesy Drusilla Modjeska, Australia's first women's refuge established, when Sydney } \\
\text { feminists squatted in an unused house and set 'Elsie'. }\end{array}$ & 1974 & 1989 & $\begin{array}{l}24 \text { December 1989, the National Patriotic Front of Liberia (NPFL) led by } \\
\text { Charles Taylor begins an uprising against the government. }\end{array}$ \\
\hline $\begin{array}{l}\text { Family Law Act } 1975 \text { passed by the Federal Parliament brings in no fault divorce. The } \\
\text { first sex discrimination Act in Australia was passed by the South Australian parliament } \\
\text { in 1975. Elizabeth Evatt was the first Chief Judge of the Family Court and the first } \\
\text { woman to win the Sydney University Medal in Law. }\end{array}$ & 1975 & 1990 & $\begin{array}{l}\text { Economic Community of West African States (ECOWAS) sends peacekeeping } \\
\text { force. Doe is executed by a splinter group of the NPFL, led by Prince Yormie } \\
\text { Johnson on } 9 \text { September } 1990 .\end{array}$ \\
\hline $\begin{array}{l}\text { Rape in marriage becomes illegal in South Australia - that is for the first time in the } \\
\text { English-speaking world, rape in marriage became a criminal offence. }\end{array}$ & 1976 & 1997 & Charles Taylor wins the presidential election. \\
\hline $\begin{array}{l}\text { Neville Perkins (Australian Labour Party) was elected to the Northern Territory } \\
\text { Legislative Assembly. He became the first Indigenous person to hold a shadow portfolio } \\
\text { and was appointed deputy leader of the Northern Territory Australian Labour Party. }\end{array}$ & 1977 & 2003 & $\begin{array}{l}\text { Started by Leymah Gbowee and Comfort M Freeman, the Women of Liberia } \\
\text { mass Action for Peace organised thousands of local women for months, staging } \\
\text { silent non-violent protests (including sex strike and threat of curse) in efforts to } \\
\text { end the Liberian civil war. } \\
\text { Nigerian peacekeepers arrived. Charles Taylor leaves Liberia for exile. }\end{array}$ \\
\hline Australian Electoral Commission began the Aboriginal Electoral Education Program. & 1979 & 2004 & $\begin{array}{l}\text { On } 1 \text { October } 2004 \text {, the United Nations launched a massive voluntary } \\
\text { repatriation program to return an estimated 340,000 Liberian refugees still } \\
\text { scattered across West Africa. }\end{array}$ \\
\hline $\begin{array}{l}\text { Ernie Bridge (Australian Labour Party) became the first Indigenous member of the } \\
\text { Parliament of Western Australian when he won the seat of Kimberley. He later became } \\
\text { the first Indigenous person to hold a Ministerial office. Mobile polling first used in } \\
\text { remote Northern Territory and Western Australia for state/territory election. }\end{array}$ & 1980 & 2005 & $\begin{array}{l}\text { Ellen Johnson Sirleaf wins election becoming the first elected female president } \\
\text { in Liberia and Africa. }\end{array}$ \\
\hline $\begin{array}{l}\text { Patricia O'Shane, becomes the first woman to head a government department when she } \\
\text { was appointed permanent head of the New South Wales Ministry of Aboriginal Affairs } \\
\text { in 1981. }\end{array}$ & 1981 & 2006 & $\begin{array}{l}\text { Save the Children (UK) released report on } 8 \text { March } 2006 \text { stating that UN } \\
\text { peacekeepers, aid workers and teachers are having sex with Liberian girls as } \\
\text { young as } 8 \text { in return for money, food or favours, threatening efforts to rebuild a } \\
\text { nation wrecked by war. } \\
\text { Arcelor Mittal, the world's largest steel company, negotiated a deal with } \\
\text { Liberia's government to restart operations at the mine in Nimba County with a } \\
\text { new investment of } \$ 1.5 \text { billion. The company said it would create some 3,500 } \\
\text { jobs. } \\
\text { Liberia National Plan of Action for the Prevention and Management of Gender } \\
\text { Violence in Liberia released. }\end{array}$ \\
\hline $\begin{array}{l}\text { Wesley Lanhupuy (Australian Labour Party), from central coastal Arnhem land was } \\
\text { elected to the Northern Territory Legislative Assembly representing the electorate of } \\
\text { Arnhem. } \\
\text { Australia signed on to the United Nations Convention on the Elimination of all Forms of } \\
\text { Discrimination Against Women (CEDAW) in } 1983 \text {. }\end{array}$ & 1983 & 2007 & $\begin{array}{l}\text { In June, Taylor war crimes in Sierra Leone trial began in The Hague. } \\
\text { The first all-female UN peacekeeping unit, made up of } 103 \text { women from India, } \\
\text { arrived in Liberia to help the West African nation recover from } 14 \text { years of on- } \\
\text { and-off civil war. } \\
\text { Joshua Milton Blahyi (37), one of Liberia's most notorious rebel commanders, } \\
\text { known as General Butt Naked for charging into battle wearing only boots, spoke } \\
\text { of his role under Charles Taylor in the civil war. He confesses to the TRC of } \\
\text { terrorizing the nation and responsible for } 20,000 \text { deaths. Blahyi now claims to }\end{array}$ \\
\hline
\end{tabular}




\begin{tabular}{|c|c|c|c|}
\hline & & & be a born-again Christian and ordained pastor. \\
\hline $\begin{array}{l}\text { Mobile polling first used in remote Northern Territory and Western Australia for } \\
\text { Commonwealth elections. Enrolment and voting in Commonwealth elections made } \\
\text { compulsory for Indigenous Peoples. } \\
\text { Sex Discrimination Act } 1984 \text { passed by the Federal Government. This made } \\
\text { discrimination on the basis of gender, pregnancy and marital status illegal in Australia. }\end{array}$ & 1984 & 2009 & $\begin{array}{l}\text { President Johnson-Sirleaf admits to the Truth and Reconciliation Commission } \\
\text { that she mistakenly backed ex-President Taylor when he launched the 14-year } \\
\text { civil war in } 1989 \text {. } \\
\text { The Liberian National Action Plan for the Implementation of UN Resolution } \\
1325 \text { (women, peace and security) released. Liberia becomes the first post- } \\
\text { conflict country with a National Action Plan to implement Resolution } 1325 \text {. }\end{array}$ \\
\hline $\begin{array}{l}\text { Janine Haines became the first woman leader of a political party in the Federal } \\
\text { Parliament. }\end{array}$ & 1986 & 2010 & $\begin{array}{l}\text { Fighting erupts between Christians and Muslims in Lofa County after the killing } \\
\text { of a Christian student. }\end{array}$ \\
\hline $\begin{array}{l}\text { Stanley Tipiloura (Australian Labour Party), from Bathurst Island, was elected to the } \\
\text { Northern Territory Legislative Assembly, representing the electorate of Arafura. } \\
\text { The National Committee on Violence was established as the result of a joint agreement } \\
\text { between the Prime Minister, the State Premiers and the Chief Minister of the Northern } \\
\text { Territory at a meeting held in December } 1987 \text {. }\end{array}$ & 1987 & 2011 & $\begin{array}{l}\text { Leymah Gbowee, Liberian peace activist and Ellen Johnson Sirleaf, Liberian } \\
\text { president, share the } 2011 \text { peace prize with Yemen's peace activist, Yemen's } \\
\text { Tawakkul Karman. Gbowee led women to defy feared warlords and pushed } \\
\text { men toward peace during Liberia's 14-year civil war. }\end{array}$ \\
\hline $\begin{array}{l}\text { The then Prime Minister, Bob Hawke, launched the first National Agenda for Women in } \\
\text { 1988, based on the UN Nairobi Forward-Looking Strategies for the Advancement of } \\
\text { Women. The National Agenda for Women named violence as a major issue. }\end{array}$ & 1988 & 2012 & $\begin{array}{l}\text { President Johnson-Sirleaf wins second 6-year term election. } \\
\text { Ex-president Taylor is found guilty of war crimes in Sierra Leone and sentenced } \\
\text { to } 50 \text { years in jail. } \\
\text { George Boley, a former rebel leader of the Liberia Peace Council, is deported to } \\
\text { Liberia from the US over his role in the civil war in the 1990s. }\end{array}$ \\
\hline $\begin{array}{l}\text { In July 1989, the First International Indigenous Women's Conference was held in } \\
\text { Adelaide. The conference was attended by delegates from all States and Territories of } \\
\text { Australia and } 16 \text { other countries. }\end{array}$ & 1989 & 2013 & $\begin{array}{l}\text { In January 2013, UN High Commission for Refugee invokes its cessation clause } \\
\text { and closed-down the Buduburam Refugee Camp in Ghana, which hosted } \\
\text { Liberian refugees. Some 155,000 Liberians return home. }\end{array}$ \\
\hline $\begin{array}{l}\text { ATSIC (Aboriginal and Torres Strait Islander Commission) created - elected regional } \\
\text { councils and a board of commissioners made decisions on policy and funding. ATSIC } \\
\text { elections were conducted by the Australian Electoral Commission. } \\
\text { In a leadership change on } 12 \text { February 1990, Dr Carmen Lawrence made history by } \\
\text { becoming Premier of Western Australia and Australia's first woman Premier. }\end{array}$ & 1990 & 2014 & $\begin{array}{l}\text { On } 6 \text { August 2014, Liberia declares a state of emergency to combat the spread } \\
\text { of the Ebola Virus Disease (EVD) outbreak. } \\
\text { As at } 9 \text { May 2014, there were 10,666 total cases of Ebola and 4,806 deaths due } \\
\text { to Ebola. }\end{array}$ \\
\hline $\begin{array}{l}\text { The High Court of Australia unanimously rejects the so-called common law 'marital rape } \\
\text { immunity' in } R \vee L \text { [1991] HCA } 48 \text { (which had previously been abolished by statute). }\end{array}$ & 1991 & 2015 & $\begin{array}{l}\text { On } 10 \text { May 2015, the World Health Organisation (WHO) declared Liberia, } \\
\text { Ebola-free. In July, two new cases of Ebola discovered. }\end{array}$ \\
\hline $\begin{array}{l}\text { Maurice Rioli (Australian Labour Party), from Melville Island was elected to the } \\
\text { Northern Territory Legislative Assembly representing the electorate of Arafura. } \\
\text { The development of a National Peak Body to represent women's domestic violence } \\
\text { services across Australia, the Women's Emergency Services Network (WESNET), was } \\
\text { supported and funded by the Commonwealth Labour Government. It was later renamed } \\
\text { the Women's Services Network to reflect the increasing community education and } \\
\text { community development domestic and family violence services were undertaking. }\end{array}$ & 1992 & & \\
\hline $\begin{array}{l}\text { The AEC's Aboriginal Electoral Education Program became Aboriginal \& Torres Strait } \\
\text { Islander Electoral Information Service. }\end{array}$ & 1993 & & \\
\hline $\begin{array}{l}\text { John Ah Kit (Australian Labor Party), from Darwin was elected to the Northern Territory } \\
\text { Legislative Assembly representing the electorate of Arnhem. } \\
\text { In 1995, the Office for the Status of Women published a follow up to its } 1988 \text { work, } \\
\text { Community Attitudes to Violence Against Women. This important piece of research } \\
\text { demonstrated that there was still a large proportion of the population who had unhelpful } \\
\text { attitudes about violence against women. }\end{array}$ & 1995 & & \\
\hline Aboriginal \& Torres Strait Islander Electoral Information Service was abolished due to & 1996 & & \\
\hline
\end{tabular}


withdrawal of Commonwealth funds. Paul Harriss elected to the Legislative Council in Tasmania for the electorate for Huon.

A Commonwealth program called Partnerships Against Domestic Violence (PADV) committed $\$ 50$ million dollars for research and resources over a six-year period to 2003. Aden Ridgeway was the second Indigenous person elected to the Australian Federal Parliament. He was born in 1962 at Macksville, New South Wales. Aden Ridgeway took his seat in the Senate as an Australian Democrat for New South Wales on 1 July 1999 following his election at the October 3, 1998 federal election. His term expired on 30 June 2005 .

The Hon Jackie Kelly MP became the first woman to give birth while serving as a Federal Government Minister.

Carol Martin (Australian Labour Party) became the first Indigenous women to be elected to a State Parliament when she won the seat of Kimberley in the Parliament of Western Australia. Matthew Bonson (Darwin), Elliot McAdam (Tennant Creek) and Marion Scrymgour (Melville Island), were elected to the Northern Territory Legislative Assembly representing the electorates of Millner, Barkly and Arafura respectively. They join John Ah Kit as members of the first Labour Government in the Northern Teritory. Senator Na Kit as mespoja Senator Ah Kit as me became the youngest person of any party to hold such a position.

Kathryn Hay (Australian Labour Party) elected to the Tasmanian House of Assembly representing the electorate of Bass. Marion Scrymgour (Australian Labour Party) in the Northern Territory Assembly became the first female indigenous minister in any government in the history of Australia.

Linda Burney (Australian Labour Party) is the first Indigenous person elected to the New South Wales Parliament. She represents the electorate of Canterbury.

Tasmania abolished provocation as a defence to murder. In 1998, the Model Criminal Code Officers Committee recommended that the defence of provocation be abolished and that the defence of excessive self-defence not be reintroduced. In 2003, Tasmania became the first state to abolish the defence of provocation. In 2005, Victoria also abolished provocation and made other reforms including clarifying the defence of selfdefence to make it more available to battered women who kill, introducing legislative
guidance on the relevance of family violence evidence in relation to a defence of selfguidance on the relevance of family violence evidence in relation to a def
defence, and reintroducing the partial defence of excessive self-defence.

Following the Northern Territory Legislative Assembly election, Barbara McCarthy (Territory Labour) was elected to represent the electorate of Arnhem, and Alison Anderson (Territory Labour) was elected to represent the electorate of Macdonnell. They join Matthew Bonson, Elliot McAdam and Marion Scrymgour in the Northern Territory Government. One fifth of the Northern Territory Legislative Assembly electorates are represented by Indigenous Australians. Legislation was enacted to dissolve the

Aboriginal and Torres Strait Islander Commission and Regional Councils at the end of the 2005 financial year.

Ben Wyatt (Australian Labour Party) elected in a by-election to the Western Australian parliament for the electorate of Victoria Park. He was re-elected in 2008.

Julia Gillard becomes the first female Deputy Prime Minister of Australia

Marion Scrymgour (Australian Labour Party) in the Northern Territory Assembly

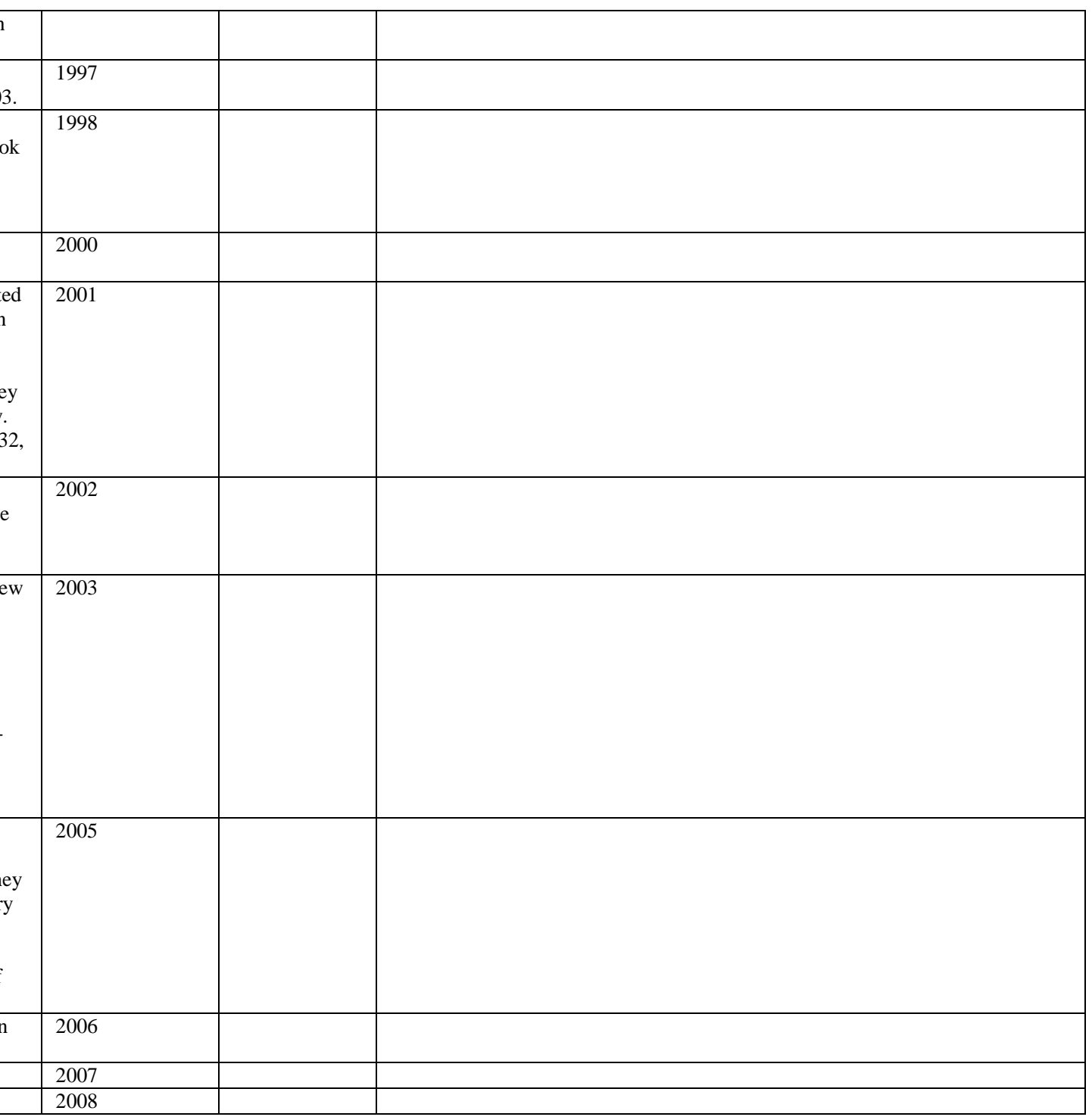


became the first female indigenous deputy chief minister.

Quentin Bryce becomes the first female Governor General of Australia on 5 September 2008.

In May 2008 the Prime Minister, the Hon. Kevin Rudd MP, and the Minister for the Status of Women, the Hon. Tanya Plibersek MP, announced the establishment of an eleven-member National Council to Reduce Violence against Women and their Children (the Council). They asked the Council to lead a public national conversation and produce a National Plan of Action to reduce the incidence and impact of domestic and family violence and sexual assault.

Ken Wyatt (Liberal Party of Australia) was elected as the first Indigenous member of the House of Representatives, representing the electorate of Hasluck in Western Australia. The Hon. Julia Gillard, Member of Parliament, was sworn in as the 27th Prime Minister of Australia on 24 June 2010 and re-sworn in as Prime Minister on 14 September 2010 following the 2010 Federal Election.

International Human Rights lawyer Megan Davis became the first Indigenous woman elected to a United Nations body. Ms Davis sits on the United Nations' Permanent Forum on Indigenous Issues, which advises on issues such as economic and social development, culture, health and human rights.

The Australian Government released the first ever National Plan to Reduce Violence Against Women.

Lara Giddings became Tasmania's first female Premier. When Lara Giddings was

elected to Parliament in 1996, she was the youngest person ever elected to Parliament.

Penny Williams, The First Ambassador for Women and Girls appointed for the Office of

the Ambassador for Women and Girls which was established in September 2011 to

engage in international advocacy in support of Australian Government policies and

programs.

Adam Giles (Country Liberal Party) was appointed the Northern Territory's Chief

Minister in March 2013 becoming Australia's first Indigenous head of government. Nova

Peris (Australian Labor Party) became the first Indigenous woman elected to the

Australian Parliament and was sworn in as a Senator representing the Northern Territory on 12 November 2013.

Rosie Batty named Australian of the Year. Since 2013 she has been a champion for the prevention of domestic violence after losing her son Luke that year, becoming an

inspirational leader who speaks candidly about her experience and the need for further

action by Government.

Sources: http://www.humanities.mcmaster.ca/africanhistory/studying_africa/ancient.html; http://www.blackpast.org/aah/american-colonization-society-1816-1964; http://personal.denison.edu/ waite/liberia/history/acs.htm;

https://www.humanrights.gov.au/timeline-history-separation-aboriginal-and-torres-strait-islander-children-their-families-text\#date-45000; http://www.pbs.org/independentlens/natturner/slave_rebellions.html; http://www.australia.gov.au/about-

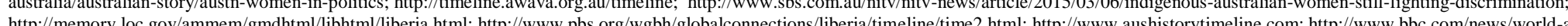

ld-africa-13732188; Azikiwe (1934) pp. 46. and Dunn \& Holsee (1985) pe xiii.

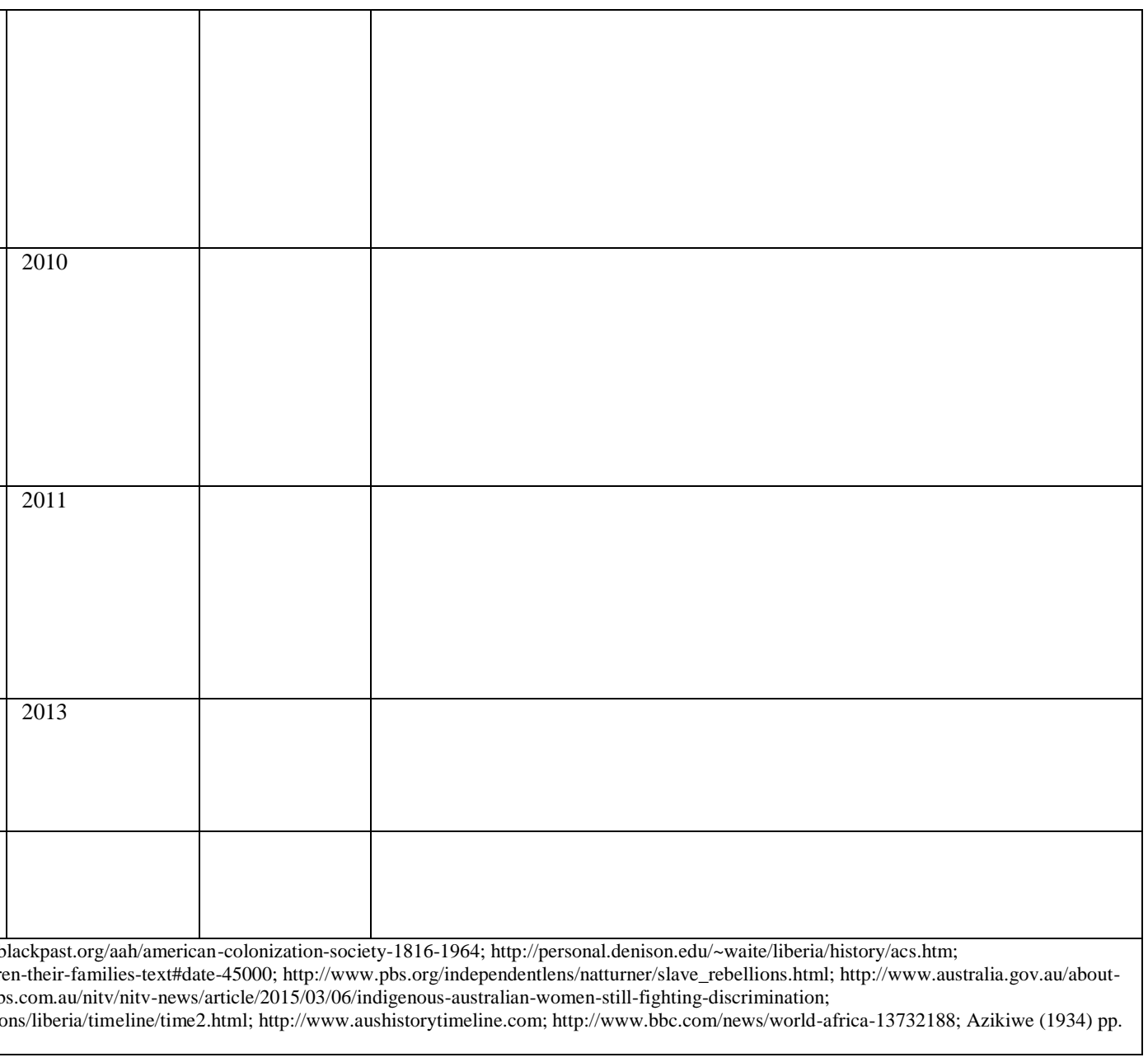




\section{AV: Internal Deadly Conflicts Between Indigenous and Settlers}

\begin{tabular}{|c|c|c|c|c|}
\hline$\#$ & Liberia & Year & Australia & Year \\
\hline 1 & Dei-British/Settler "Water Battle" & 1822 & $\begin{array}{l}\text { Aborigines suffer an outbreak of } \\
\text { smallpox }\end{array}$ & 1789 \\
\hline 2 & Dei-Settler War & 1822 & $\begin{array}{l}\text { Governor Arthur Phillip ordered } \\
\text { two captains, two subalterns and } 40 \\
\text { privates to bring in or kill six } \\
\text { natives near Botany Bay in } \\
\text { response to the spearing of John } \\
\text { McEntire, Governor's Phillip's } \\
\text { gamekeeper and convict who was } \\
\text { suspected committing violent } \\
\text { attacks on Aboriginal people. }\end{array}$ & 1790 \\
\hline 3 & Dei-Gola-Settler War & 1832 & Risdon Cove Massacre & 1804 \\
\hline 4 & Bassa-Settler War & 1835 & Appin Aboriginal Massacre & 1816 \\
\hline 5 & Kru-Settler "Fish" War & 1838 & Bathurst Massacre & 1824 \\
\hline 6 & Vai-Settler Battles & $1839-40$ & Cape Grim Massacre & 1828 \\
\hline 7 & Bassa-Government War & $1851-52$ & The Black War & $1828-32$ \\
\hline 8 & Kru-Government War & 1855 & $\begin{array}{l}\text { Convincing Ground Massacre of } \\
\text { Gunditjmara }\end{array}$ & $\begin{array}{l}1833- \\
1834\end{array}$ \\
\hline 9 & Grebo-Maryland War & $1856-57$ & Pinjarra Battle/Massacre & 1834 \\
\hline 10 & $\begin{array}{l}\text { Gedebo Reunited Kingdom } \\
\text { Revolution }\end{array}$ & $1875-76$ & $\begin{array}{l}\text { Waterloo Creek Massacre, Myall } \\
\text { Creek Massacre and the War of } \\
\text { Extirpation, Killing by the Broken } \\
\text { River in Benalla }\end{array}$ & 1838 \\
\hline 11 & Grebo-Government War & 1893 & & \\
\hline 12 & Kru-Government Battles & 1909 & Murrumbidgee Wiradjuri Wars & $\begin{array}{l}1830- \\
1840\end{array}$ \\
\hline 13 & Grebo-Government War & 1910 & Rufus River Massacre & 1841 \\
\hline 14 & Kru-Government Conflict & 1912 & $\begin{array}{l}\text { Evans Head Massacre } \\
\text { Nyngan Massacre/Goanna } \\
\text { Headland Massacre }\end{array}$ & 1842 \\
\hline 15 & $\begin{array}{l}\text { Kru Confederacy-Government } \\
\text { War }\end{array}$ & 1915 & Forest River Massacre & 1926 \\
\hline 16 & Coup d'état of Tolbert Regime & 1980 & Coniston/ Yuendumu Massacre & 1928 \\
\hline 17 & The Great War in Liberia & $1989-97$ & Risdon Cove & 1992 \\
\hline 18 & $\begin{array}{l}\text { Great War between LURD \& } \\
\text { MODEL }\end{array}$ & 1999-03 & & \\
\hline
\end{tabular}


AVI: Sexes of Judges and Magistrates in Liberia and Australia

\begin{tabular}{|c|c|c|c|c|c|c|c|}
\hline State/Territory & $\begin{array}{c}\text { Judges / } \\
\text { Magistrate }\end{array}$ & $\begin{array}{c}\text { Female } \\
\text { Judges }\end{array}$ & $\%$ & Counties & $\begin{array}{c}\text { Judges / } \\
\text { Magistrate }\end{array}$ & $\begin{array}{l}\text { Female } \\
\text { Judges }\end{array}$ & $\%$ \\
\hline AUSTRALIA & & & & LIBERIA & & & \\
\hline Commonwealth & & & & National & & & \\
\hline High Court* & 7 & 2 & & Supreme Court*** & 5 & $\overline{2}$ & \\
\hline Federal Court & 47 & 11 & & \multicolumn{2}{|c|}{ First Judicial Circuit, Criminal Assizes A } & & \\
\hline Family Court & 27 & $\overline{11}$ & & Sub-total & 5 & 2 & $\overline{40}$ \\
\hline Federal Circuit Court & 61 & 22 & & Nimba County & & & \\
\hline Sub-total & 142 & $\overline{46}$ & 32.39 & Circuit/Specialised Court & 1 & 0 & \\
\hline & & & & Magistrate Court & 30 & 2 & \\
\hline ACT & & & & Sub-total & 31 & 2 & 6.45 \\
\hline $\begin{array}{l}\text { Supreme Court/Court of } \\
\text { Appeal }\end{array}$ & 4 & 1 & & Maryland & & & \\
\hline Magistrate & 7 & 3 & & Circuit/Specialised Court & 2 & 0 & \\
\hline Sub-total & 11 & 4 & 36.36 & Magistrate Court & 15 & 0 & \\
\hline & & & & Sub-total & 17 & 0 & $\overline{0}$ \\
\hline New South Wales & & & & Grand Gedeh & & & \\
\hline $\begin{array}{l}\text { Supreme Court/Court of } \\
\text { Appeal }\end{array}$ & 48 & 11 & & Circuit/Specialised Court & 5 & 0 & \\
\hline Land \& Environment & 6 & 2 & & Magistrate Court & 12 & $\overline{0}$ & \\
\hline District Court & 66 & $\overline{16}$ & & Sub-total & 17 & $\mathbf{0}$ & $\overline{0}$ \\
\hline $\begin{array}{l}\text { Industrial Relations } \\
\text { Committee }\end{array}$ & 7 & 1 & & Sinoe & & & \\
\hline Magistrate & 134 & 56 & & Circuit/Specialised Court & 6 & $\overline{0}$ & \\
\hline Sub-total & 261 & $\overline{86}$ & $\mathbf{3 2 . 9 5}$ & Magistrate Court & 60 & $\overline{0}$ & \\
\hline & & & & Sub-total & 66 & $\mathbf{0}$ & $\mathbf{0}$ \\
\hline
\end{tabular}




\begin{tabular}{|c|c|c|c|c|c|c|c|}
\hline Northern Territory & & & & Lofa & & & \\
\hline Supreme Court & 11 & 0 & & Circuit/Specialised Court & 2 & $\overline{1}$ & \\
\hline Magistrate & 10 & 4 & & Magistrate Court & 19 & 0 & \\
\hline \multirow[t]{2}{*}{ Sub-total } & 21 & 4 & 19.05 & Sub-total & 21 & 1 & 4.76 \\
\hline & & & & Grand Cape Mount & & & \\
\hline Queensland & & & & Circuit/Specialised Court & 2 & 1 & \\
\hline $\begin{array}{l}\text { Supreme Court/Court of } \\
\text { Appeal }\end{array}$ & 28 & 7 & & Magistrate Court & 11 & 0 & \\
\hline District Court & 41 & 10 & & Sub-total & 13 & 1 & 7.69 \\
\hline Magistrate & 91 & 31 & & Grand Bassa & & & \\
\hline \multirow[t]{2}{*}{ Sub-total } & 160 & 48 & 30.00 & Circuit/Specialised Court & 1 & 0 & \\
\hline & & & & Magistrate Court & 17 & 1 & \\
\hline South Australia & & & & Sub-total & 18 & 1 & 5.56 \\
\hline $\begin{array}{l}\text { Supreme Court/Court of } \\
\text { Appeal }\end{array}$ & 14 & 2 & & Bong & & & \\
\hline District Court & 24 & 5 & & Circuit/Specialised Court & 3 & 0 & \\
\hline Magistrate & 37 & 14 & & Magistrate Court & 14 & 0 & \\
\hline \multirow[t]{2}{*}{ Sub-total } & 75 & 21 & 28.00 & Sub-total & 17 & $\overline{0}$ & $\overline{0}$ \\
\hline & & & & Montserrado & & & \\
\hline Tasmania & & & & Circuit/Specialised Court & 17 & $\overline{4}$ & \\
\hline $\begin{array}{l}\text { Supreme Court/Court of } \\
\text { Appeal }\end{array}$ & 7 & 2 & & Magistrate Court & 26 & 1 & \\
\hline Magistrate Court & 14 & 3 & & Sub-total & 43 & 5 & 11.63 \\
\hline \multirow[t]{2}{*}{ Sub-total } & 21 & 5 & 23.81 & Margibi & & & \\
\hline & & & & Circuit/Specialised Court & 2 & 1 & \\
\hline Victoria & & & & Magistrate Court & 9 & 2 & \\
\hline $\begin{array}{l}\text { Supreme Court/Court of } \\
\text { Appeal }\end{array}$ & 49 & 10 & & Subtotal & 11 & 3 & 27.27 \\
\hline District Court & 69 & 26 & & Bomi & & & \\
\hline
\end{tabular}




\begin{tabular}{|c|c|c|c|c|c|c|c|}
\hline Magistrate Court & 143 & 53 & & Circuit/Specialised Court & 2 & 0 & \\
\hline \multirow[t]{2}{*}{ Sub-total } & 261 & 89 & 34.10 & Magistrate Court & 7 & 1 & \\
\hline & & & & Sub-total & 9 & 1 & 11.11 \\
\hline Western Australia & & & & Gbarpolu & & & \\
\hline $\begin{array}{l}\text { Supreme Court/Court of } \\
\text { Appeal }\end{array}$ & 20 & 3 & & Circuit/Specialised Court & 2 & 0 & \\
\hline District Court & 29 & 7 & & Magistrate Court & 11 & 0 & \\
\hline Magistrate Court & 51 & 20 & & Sub-total & 13 & 0 & $\overline{0}$ \\
\hline Sub-total & 100 & 30 & 30.00 & Rivercess & & & \\
\hline \multirow[t]{12}{*}{ Grand Total } & 1052 & 303 & 28.80 & Circuit/Specialised Court & 2 & 0 & \\
\hline & & & & Magistrate Court & 6 & 0 & \\
\hline & & & & Sub-total & 8 & $\overline{0}$ & $\overline{0}$ \\
\hline & & & & Grand Kru & & & \\
\hline & & & & Circuit/Specialised Court & 8 & 1 & \\
\hline & & & & Magistrate Court & 48 & 0 & \\
\hline & & & & Sub-total & 56 & 1 & 2.00 \\
\hline & & & & River Gee & & & \\
\hline & & & & Circuit/Specialised Court & 3 & 0 & \\
\hline & & & & Magistrate Court & 18 & 0 & \\
\hline & & & & Sub-total & 21 & 0 & $\overline{0}$ \\
\hline & & & & Grand Total & 365 & 17 & 4.66 \\
\hline
\end{tabular}

* There have bet

** Since 1948, when the Liberian Supreme Court was established, of a total of 25 Chief Justices only two have served as females.

Sources: High Court of Australia, About the Judges <http://www.hcourt.gov.au/justices/about-the-justices>; ACT Supreme Court Judges, Current Judges and Associate Judge

$<$ http://www.courts.act.gov.au/supreme/page/view/740>; Supreme Court of New South Wales, Judicial Officer Contact Details

<http://www.supremecourt.justice.nsw.gov.au/Pages/SCO2_contactus/judicialcontacts/judicialcontacts.aspx>; Supreme Court of Victoria, Judicial Support Contacts

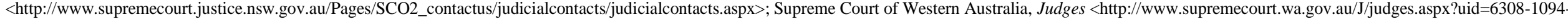
4408-1023>; Queensland Courts, Judges of the Supreme Court Contacts <http://www.courts.qld.gov.au/contact-us/judges-supreme-court>; Supreme Court of Tasmanian, Current Judges

<http://www.supremecourt.tas.gov.au/about_us/judges/current_judges>; Courts Administration Authority of South Australia, Judicial Officers <http://www.courts.sa.gov.au/OurCourts/SupremeCourt/Pages/Judicial-

Officers.aspx>; Supreme Court of the Northern Territory, Current Judges <http://www.supremecourt.nt.gov.au/about/judges/>; Liberia Judiciary, Chief Justices of Liberia from 1948 to present <http://judiciary.gov.lr>.

NB: List of female and male judges and magistrates was obtained through personal contact from the Supreme Court of Liberia in 2015. 


\section{AVII: Presidents and Prime Ministers of Australia}

\begin{tabular}{|c|c|c|c|c|c|c|}
\hline \# & Name & In Office & Birthplace & Name & In Office & Birthplace \\
\hline 1 & $\begin{array}{l}\text { Joseph Jenkins } \\
\text { Roberts }\end{array}$ & $\begin{array}{l}1848- \\
1856\end{array}$ & $\begin{array}{l}\text { Virginia, USA (First president, } \\
\text { elected 6x) }\end{array}$ & Edmund Barton & $\begin{array}{l}1901- \\
1903\end{array}$ & Sydney, Australia to English parents \\
\hline 2 & $\begin{array}{l}\text { Stephen Allen } \\
\text { Benson }\end{array}$ & $\begin{array}{l}1856- \\
1864\end{array}$ & Maryland, USA (elected 4x) & Alfred Deakin & $\begin{array}{l}1903- \\
1904\end{array}$ & $\begin{array}{l}\text { Melbourne, Australia to English parents. } 2^{\text {nd }}-\text { term, } \\
1905-1905 \text { and } 3^{\text {rd }} \text {-term, } 1909-1910 \text { (the only } \\
\text { prime minister to reject the "Right Honourable" } \\
\text { title and membership of the Privy Council). }\end{array}$ \\
\hline 3 & $\begin{array}{l}\text { Daniel Bashiel } \\
\text { Warner }\end{array}$ & $\begin{array}{l}1864- \\
1868\end{array}$ & Maryland, USA (elected 2x) & Chris Watson & 1904 & $\begin{array}{l}\text { Probably born in Chile to a German father and a } \\
\text { New Zealand mother. }\end{array}$ \\
\hline 4 & $\begin{array}{l}\text { James Spriggs } \\
\text { Payne }\end{array}$ & $\begin{array}{l}1868- \\
1870 \\
\end{array}$ & $\begin{array}{l}\text { Virginia, USA }\left(2^{\text {nd }} \text { Term } 1876-\right. \\
1878)\end{array}$ & George Reid & $\begin{array}{l}1904- \\
1904 \\
\end{array}$ & $\begin{array}{l}\text { Johnstone, Renfrewshire, Scotland (federation } \\
\text { father). }\end{array}$ \\
\hline 5 & Edwin James Roye & $\begin{array}{l}1870- \\
1871\end{array}$ & $\begin{array}{l}\text { Ohio, USA (first to be deposed } \\
\text { by coup d'état) }\end{array}$ & Andrew Fisher & $\begin{array}{l}1908- \\
1909\end{array}$ & $\begin{array}{l}\text { Crosshouse, Ayrshire, Scotland (Elected 2x: 1910- } \\
1913 \text { and 1914-1915 and his wife, Margaret } \\
\text { Fisher, led the Australian group in the British } \\
\text { suffrage march in London, 1911). }\end{array}$ \\
\hline 6 & James S. Smith & $\begin{array}{l}1871- \\
1872\end{array}$ & $\begin{array}{l}\text { South Carolina, USA (Vice } \\
\text { President) }\end{array}$ & Joseph Cook & $\begin{array}{l}1913- \\
1914\end{array}$ & Silverdale, Staffordshire, England. \\
\hline 7 & $\begin{array}{l}\text { Joseph Jenkins } \\
\text { Roberts }\end{array}$ & $\begin{array}{l}1872- \\
1876\end{array}$ & See \#1 above & $\begin{array}{l}\text { William Morris } \\
\text { Hughes }\end{array}$ & $\begin{array}{l}1915- \\
1923\end{array}$ & $\begin{array}{l}\text { Pimlico, London, England (Longest serving prime } \\
\text { minister ( } 7 \text { years) until } 1956 .\end{array}$ \\
\hline 8 & $\begin{array}{l}\text { James Spriggs } \\
\text { Payne }\end{array}$ & $\begin{array}{l}1876- \\
1878\end{array}$ & See \#1 above & $\begin{array}{l}\text { Stanley } \\
\text { Melbourne } \\
\text { Bruce }\end{array}$ & $\begin{array}{l}1923- \\
1929\end{array}$ & $\begin{array}{l}\text { St. Kilda, Victoria, Melbourne to a Scottish father } \\
\text { and an Irish mother (led first all Australian-born } \\
\text { Cabinet). }\end{array}$ \\
\hline 9 & $\begin{array}{l}\text { Anthony William } \\
\text { Gardiner }\end{array}$ & $\begin{array}{l}1878- \\
1883\end{array}$ & $\begin{array}{l}\text { Virginia, USA (elected three } \\
\text { times) }\end{array}$ & James Scullin & $\begin{array}{l}1929- \\
1932\end{array}$ & Trawalla, Victoria, Melbourne to Irish parents. \\
\hline 10 & $\begin{array}{l}\text { Alfred Francis } \\
\text { Russell }\end{array}$ & $\begin{array}{l}1883- \\
1884\end{array}$ & $\begin{array}{l}\text { Kentucky, USA (Vice } \\
\text { President) }\end{array}$ & Joseph Lyons & $\begin{array}{l}1932- \\
1939\end{array}$ & Lyons, Tasmania to Irish parents. \\
\hline 11 & $\begin{array}{l}\text { Hilary Richard } \\
\text { Wright Johnson } \\
\end{array}$ & $\begin{array}{l}1884- \\
1892 \\
\end{array}$ & $\begin{array}{l}\text { Liberia (Afro-American, } \\
\text { elected 4x) }\end{array}$ & Earle Page & 1939 & $\begin{array}{l}\text { Grafton, New South Wales to British parents (first } \\
\text { prime minister to win three successive elections). }\end{array}$ \\
\hline 12 & $\begin{array}{l}\text { Joseph James } \\
\text { Cheeseman }\end{array}$ & $\begin{array}{l}1892- \\
1896\end{array}$ & $\begin{array}{l}\text { Edina, Grand Bassa County } \\
\text { (Afro-American, elected 3x) }\end{array}$ & Robert Menzies & $\begin{array}{l}1939- \\
1941\end{array}$ & $\begin{array}{l}\text { Jeparit, Victoria, Melbourne to Scottish father and } \\
\text { a Cornish mother (longest serving prime minister, } \\
\text { two terms of } 18 \text { years). }\end{array}$ \\
\hline 13 & $\begin{array}{l}\text { William David } \\
\text { Coleman }\end{array}$ & $\begin{array}{l}1896- \\
1900 \\
\end{array}$ & Kentucky, USA (elected 2x) & Arthur Fadden & 1941 & Ingham, Queensland to Irish immigrant parents. \\
\hline 14 & $\begin{array}{l}\text { Garretson Wilmot } \\
\text { Gibson }\end{array}$ & $\begin{array}{l}1900- \\
1904\end{array}$ & Maryland, USA & John Curtin & $\begin{array}{l}1941- \\
1945\end{array}$ & $\begin{array}{l}\text { Creswick, Victoria, Melbourne to Irish immigrant } \\
\text { parents. }\end{array}$ \\
\hline 15 & Arthur Barclay & $\begin{array}{l}1904- \\
1912\end{array}$ & Bridgetown, Barbados & Francis Forde & 1945 & Mitchell, Queensland to Irish immigrant parents. \\
\hline 16 & $\begin{array}{l}\text { Daniel Edward } \\
\text { Howard }\end{array}$ & $\begin{array}{l}1912- \\
1920\end{array}$ & $\begin{array}{l}\text { Buchanan, Grand Bassa) } \\
\text { (elected } 2 \mathrm{x} \text { ) }\end{array}$ & Ben Chiefley & $\begin{array}{l}1945- \\
1949\end{array}$ & $\begin{array}{l}\text { Bathurst, New South Wales to Irish immigrant } \\
\text { parents. }\end{array}$ \\
\hline 17 & $\begin{array}{l}\text { Charles Dunbar } \\
\text { Burgess King }\end{array}$ & $\begin{array}{l}1920- \\
1930\end{array}$ & $\begin{array}{l}\text { Liberia (to Sierra Leonean } \\
\text { parents, first president to serve } \\
\text { a 4-year term) }\end{array}$ & Harold Holt & $\begin{array}{l}1966- \\
1967\end{array}$ & $\begin{array}{l}\text { Stanmore, Sydney to English } \\
\text { immigrant/Australian born parents. }\end{array}$ \\
\hline 18 & $\begin{array}{l}\text { Edwin James } \\
\text { Barclay }\end{array}$ & $\begin{array}{l}1930- \\
1944\end{array}$ & $\begin{array}{l}\text { Brewerville, Montserrado } \\
\text { (served 8-year term) }\end{array}$ & John McEwen & $\begin{array}{l}1967- \\
1968\end{array}$ & Chiltern, Victoria, Melbourne to Irish parents. \\
\hline 19 & $\begin{array}{l}\text { William Vacanarat } \\
\text { Shadrach Tubman }\end{array}$ & $\begin{array}{ll}1944- \\
1971 \\
\end{array}$ & $\begin{array}{l}\text { Harper, Maryland (elected 6x, } \\
\text { longest serving) }\end{array}$ & John Gorton & $\begin{array}{l}1968- \\
1971 \\
\end{array}$ & $\begin{array}{l}\text { Wellington, New Zealand to English immigrant } \\
\text { parents. }\end{array}$ \\
\hline 20 & $\begin{array}{l}\text { William Richard } \\
\text { Tolbert, Jr. }\end{array}$ & $\begin{array}{l}1971- \\
1980\end{array}$ & $\begin{array}{l}\text { Bensonville, Montserrado } \\
\text { (second to be deposed in a coup } \\
\text { d'état) }\end{array}$ & $\begin{array}{l}\text { William } \\
\text { McMahon }\end{array}$ & $\begin{array}{l}1971- \\
1972\end{array}$ & $\begin{array}{l}\text { Sydney, New South Wales of Irish descendant } \\
\text { parentage. }\end{array}$ \\
\hline 21 & Samuel Kanyon Doe & $\begin{array}{l}1980- \\
1990\end{array}$ & $\begin{array}{l}\text { Tuzon, Grand Gedeh } \\
\text { (Indigenous Krahn descend, } \\
\text { third to be deposed by coup } \\
\text { d'état) } \\
\end{array}$ & Gough Whitlam & $\begin{array}{l}1972- \\
1975\end{array}$ & Kew, Melbourne of British descendant parentage. \\
\hline 22 & Amos Sawyer & $\begin{array}{l}1990- \\
1993 \\
\end{array}$ & $\begin{array}{l}\text { Sinoe County (Afro-American, } \\
\text { interim) }\end{array}$ & Malcolm Fraser & $\begin{array}{l}1975- \\
1983 \\
\end{array}$ & $\begin{array}{l}\text { Toorak, Victoria, Melbourne to Canadian } \\
\text { immigrant father and a mother of Jewish descent. }\end{array}$ \\
\hline 23 & Bismarck Kuyon & 1993 & & Robert Hawke & $\begin{array}{l}1983- \\
1991\end{array}$ & Bordertown, South Australia. \\
\hline 24 & Phillip Banks & $\begin{array}{l}1993- \\
1994\end{array}$ & & Paul Keating & $\begin{array}{l}1991- \\
1996\end{array}$ & Bankstown, Sydney to Irish descendant parentage. \\
\hline 25 & David Kpormakor & $1994-$ & & John Howard & $1996-$ & $\begin{array}{l}\text { Dulwich Hill, Sydney to parents of Irish, Scottish } \\
\text { and Irish ancestors. }\end{array}$ \\
\hline 26 & Wilton Sankawulo & $\begin{array}{l}1995- \\
1996\end{array}$ & & Kevin Rudd & $\begin{array}{l}2007- \\
2010\end{array}$ & $\begin{array}{l}\text { Nambour, Queensland to parents of English and } \\
\text { Irish descent }\left(2^{\text {nd }} \text { term in } 2013\right) \text {. Rudd is also a } \\
\text { descendant of Mary Wade the youngest convict } \\
\text { transported to New South Wales in } 1789 .\end{array}$ \\
\hline 27 & Ruth Perry & $\begin{array}{l}1996- \\
1997\end{array}$ & (First female Head of State) & Julia Gillard & $\begin{array}{l}2010- \\
2013\end{array}$ & $\begin{array}{l}\text { First female Prime Minister born in Barry Wales } \\
\text { to parents of English, Welsh and Irish descent. }\end{array}$ \\
\hline 28 & $\begin{array}{l}\text { Charles Ghankay } \\
\text { Taylor }\end{array}$ & $\begin{array}{l}1997- \\
2003\end{array}$ & $\begin{array}{l}\text { Liberia (Afro-American father } \\
\text { and Indigenous Gola mother) }\end{array}$ & Tony Abbott & $2013-$ & $\begin{array}{l}\text { London, England to an Australian mother and an } \\
\text { English father. }\end{array}$ \\
\hline 29 & Moses Blah & 2003 & $\begin{array}{l}\text { Toweh Town, Nimba County } \\
\text { (second president of } \\
\text { Indigenous Gio descend) }\end{array}$ & & & \\
\hline 30 & $\begin{array}{l}\text { Charles Gyude } \\
\text { Bryant }\end{array}$ & $\begin{array}{l}2003- \\
2006\end{array}$ & $\begin{array}{l}\text { Maryland (Afro-American } \\
\text { descend) }\end{array}$ & & & \\
\hline 31 & $\begin{array}{l}\text { Ellen Johnson } \\
\text { Sirleaf }\end{array}$ & $2006-$ & $\begin{array}{l}\text { Monrovia (Indigenous Gola } \\
\text { father and mother of mixed } \\
\text { German heritage, first elected } \\
\text { female). }\end{array}$ & & & \\
\hline
\end{tabular}

NB: Both countries have had only one elected female president/prime minister). Note Ellen Johnson Sirleaf is the first female and $24^{\text {th }}$ President democratically elected president of Liberia. Julia Gillard is also the first female Deputy Prime Minister and the first female Prime Minister of Australia.

Source: D. Elwood Dunn \& Svend Holsoe, Historical Dictionary of Liberia (Scarecrow Press, 1985), William E Allen \& D Elwood Dunn, 'Ellen Johnson Sirleaf is the 24th not 23rd President of Liberia: A new interpretative history' (2008) 33(1) Liberian Studies Journal 64-68; Australian Women Against Violence Alliance, Australian women's timeline (2015)

<http://timeline.awava.org.au/timeline>, National Archives of Australia, Australian Government, Australia's Prime Ministers $<$ http://primeministers.naa.gov.au/primeministers/>; Fred Van der Kraaij, Liberia: Past and Present of Africa's Oldest Republic, The Presidents, <http://www.liberiapastandpresent.org/Presidents.htm\#22\%20Presidents,\%206\%20Interim\%20Presidents>. 
AVIII: List of Major Legal Instruments Used to Protect Women against Violence

\begin{tabular}{|c|c|c|c|c|c|}
\hline Instrument & $\begin{array}{l}\text { Adopted / } \\
\text { Enforced }\end{array}$ & $\begin{array}{l}\text { Liberia } \\
\text { Signature }\end{array}$ & $\begin{array}{l}\text { Liberia } \\
\text { Ratification }\end{array}$ & $\begin{array}{l}\text { Australia } \\
\text { Signature }\end{array}$ & $\begin{array}{l}\text { Australia } \\
\text { Ratification }\end{array}$ \\
\hline \multicolumn{6}{|l|}{ INTERNATIONAL } \\
\hline Universal Declaration of Human Rights & 10 Dec 1948 & $\begin{array}{l}\text { Founding } \\
\text { Member }\end{array}$ & & $\begin{array}{l}\text { Founding } \\
\text { Member }\end{array}$ & \\
\hline International Convention on the Elimination of All Forms of Racial Discrimination & 21 Dec 1965 & & $\begin{array}{l}\text { 05 Nov } 1984 \\
\text { (Acceded) }\end{array}$ & 12 Oct 1966 & 30 Sep 1975 \\
\hline International Covenant on Civil and Political Rights & 16 Dec 1966 & 18 Apr 1967 & 22 Sep 2004 & 18 Dec 1972 & 10 Dec 1975 \\
\hline International Covenant on Economic, Social and Cultural Rights & 16 Dec 1966 & 18 Apr 1967 & 22 Sep 2004 & 18 Dec 1972 & 13 Aug 1980 \\
\hline Convention on the Elimination of All Forms of Discrimination against Women & 18 Dec 1979 & & $\begin{array}{l}17 \text { Jul } 1984 \\
\text { (Acceded) }\end{array}$ & 17 Jul 1980 & 28 Jul 1983 \\
\hline $\begin{array}{l}\text { Protocol to Prevent, Suppress and Punish Trafficking in Persons, Especially Women and } \\
\text { Children, supplementing the United Nations Convention against Transnational Organized Crime } \\
\text { Preamble, supplementing the United Nations } \\
\text { Convention against Transnational } \\
\text { Organized Crime }\end{array}$ & 15 Nov 2000 & & 22 Sep 2004 & 11 Dec 2002 & \\
\hline $\begin{array}{l}\text { Convention for the Suppression of the Traffic in Persons and of the Exploitation of the } \\
\text { Prostitution of Others }\end{array}$ & 02 Dec 1949 & 21 Mar 1950 & & Not signed & \\
\hline Convention against Torture and Other Cruel, Inhuman or Degrading Treatment or Punishment & 10 Dec 1984 & & $\begin{array}{l}22 \text { Sep } 2004 \\
\text { (acceded) }\end{array}$ & 19 May 2009 & 08 Aug 1989 \\
\hline Convention on the Rights of the Child & 20 Nov 1989 & 26 Apr 1990 & 04 Jun 1993 & 22 Aug 1990 & 17 Dec 1990 \\
\hline $\begin{array}{l}\text { Optional Protocol to the Convention on the Rights of the Child on the involvement of children in } \\
\text { armed conflicts }\end{array}$ & 25 May 2000 & $22 \operatorname{Sep} 2004$ & & 21 Oct 2001 & 31 Jan 2005 \\
\hline $\begin{array}{l}\text { Convention concerning the Prohibition and Immediate Action for the Elimination of the Worst } \\
\text { Forms of Child Labour }\end{array}$ & 17 Jul 1999 & 02 Jun 2003 & & Not signed & \\
\hline Convention concerning Forced or Compulsory Labour & 28 Jun 1930 & & 1 May 1931 & $02 \mathrm{Feb} 1932$ & \\
\hline Convention against Discrimination in Education & 14 Dec 1960 & & 17 May 1972 & & Ratified \\
\hline Convention on the Prevention and Punishment of the Crime of Genocide & 09 Dec 1948 & 11 Dec 1948 & 09 Jun 1950 & 11 Dec 1948 & 08 Jul 1949 \\
\hline Rome Statute of the International Criminal Court & $17 \mathrm{Jul} 1998$ & $17 \mathrm{Jul} 1998$ & 22 Sep 2004 & 09 Dec 1998 & $01 \mathrm{Jul} 2002$ \\
\hline Declaration on the Rights of Indigenous Peoples & 13 Sep 2007 & & & 03 Apr 2009 & \\
\hline Convention on the Rights of Persons with Disabilities & 13 Dec 2006 & & & & \\
\hline \multicolumn{6}{|l|}{ REGIONAL } \\
\hline African [Banjul] Charter on Human and Peoples' Rights & 27 Jun 1981 & 31 Jan 1983 & 04 Aug 1982 & & \\
\hline $\begin{array}{l}\text { Protocol to the African Charter on Human and Peoples' Rights on the Rights of Women in Africa } \\
\end{array}$ & 13 Sep 2000 & 16 Dec 2003 & & & \\
\hline $\begin{array}{l}\text { Protocol to the African Charter on Human and Peoples' Rights on the Establishment of an } \\
\text { African Court on Human and Peoples' Rights }\end{array}$ & 09 Jun 1998 & 09 Jun 1998 & & & \\
\hline African Charter on the Rights and Welfare of the Child & 11 Jul 1990 & 14 May 1992 & & & \\
\hline ECOWAS Community Court & $06 \mathrm{Jul} 1991$ & Member & & & \\
\hline
\end{tabular}

NB: For Australia, only major national/federal acts are listed. State instruments will be referenced as and when appropriate. 
AIX: Demographic Profile of Australian Convicts and Liberian Freed Slaves

\begin{tabular}{|c|c|c|c|c|c|}
\hline \multicolumn{3}{|c|}{ Australia } & \multicolumn{3}{|c|}{ Liberia } \\
\hline Convict voyages 1787-1867 & \# & Ships & $\begin{array}{l}\text { Slaves Repatriation 1820- } \\
1904\end{array}$ & $\#$ & Ships \\
\hline 825 voyages & 130,536 & 427 & 57 voyages & 14,996 & 57 \\
\hline Gender & $\#$ & $\%$ & Gender & & \\
\hline Female & $24,960^{1641}$ & 15 & Female & 6,527 & 42 \\
\hline Male & 140,040 & 75 & Male & 8,382 & 56 \\
\hline & & & Infant & 67 & 0.4 \\
\hline Age & Youngest & Oldest & Youngest & Oldest & \\
\hline Range & 11 & 82 & 0 & - & \\
\hline Nationality & $\#$ & $\%$ & Top 15 State of Origin & & \\
\hline British and Welsh & 115,500 & 70 & Virginia & 3,522 & 23 \\
\hline Irish & 39,600 & 24 & Georgia & 2,010 & 13 \\
\hline Scottish & 8,250 & 5 & North Carolina & 1,821 & 12 \\
\hline Other (Canada, India, and NZ) & 1650 & 1 & South Carolina & 1,217 & 8 \\
\hline & & & Kentucky & 966 & 6 \\
\hline Port of Entry ${ }^{1642}$ & $\#$ & Year & Tennessee & 963 & 6 \\
\hline Botany Bay (NSW) & 80,000 & $1788-68$ & Louisiana & 872 & 6 \\
\hline Van Diemen's Land (TAS) & & & Maryland & 513 & 3 \\
\hline Other & 75,000 & $1803-53$ & Missouri & 473 & 3 \\
\hline Norfolk Island (NSW) & & & Pennsylvania & 354 & 2 \\
\hline Port Macquarie & & & New York & 276 & 2 \\
\hline Moreton Bay (QLD) & 700 & 1788-14, & Arkansas & 265 & 2 \\
\hline & & $1825-53$ & Alabama & 193 & 1 \\
\hline & 1100 & $1821-28$ & Illinois & 114 & 1 \\
\hline & 2,121 & $1823-39$ & Washington DC & 112 & 1 \\
\hline Literacy $^{1643}$ (from 1871 Census) $^{+}$ & $\#$ & $\%$ & Education & \# & $\%$ \\
\hline Read and write & $1,020,990$ & 62.5 & Read & 948 & 6 \\
\hline Read Only & 178,752 & 11.0 & Write & 396 & 3 \\
\hline Cannot read or write & 434,509 & 26.6 & Read and Write & 535 & 4 \\
\hline Total & $1,634,251$ & 100 & Spell & 248 & 2 \\
\hline & & & Good & 61 & 0 \\
\hline & & & Very Good & 6 & 0 \\
\hline & & & Illiterate & 48 & 0 \\
\hline & & & Unknown & 12,749 & 85 \\
\hline Top Ten Occupation* & $\#$ & $\%$ & Top Ten Occupation & \# & $\%$ \\
\hline Labourer & 1,275 & 16.5 & Farmer & 1,348 & 9 \\
\hline Farm labourer & 466 & 6.0 & Carpenter & 866 & 6 \\
\hline Farmer & 220 & 2.9 & Sawyer & 142 & 1 \\
\hline Shoemaker & 217 & 2.8 & Shoemaker & 80 & 1 \\
\hline Soldier & 207 & 2.7 & Blacksmith & 79 & 1 \\
\hline Housemaid & 200 & 2.6 & School Teacher & 65 & 0 \\
\hline Servant & 190 & 2.5 & Seamstress & 65 & 0 \\
\hline Weaver & 173 & 2.2 & Bricklayer & 35 & 0 \\
\hline Ploughman & 162 & 2.1 & Cooper & 34 & 0 \\
\hline Soldier/Labourer & 149 & 1.9 & Barber & 25 & 0 \\
\hline Top Ten Crime* & $\#$ & $\%$ & Top 10 Settlement & & \\
\hline Stealing & 1,692 & 17.6 & Monrovia & 1,840 & 12 \\
\hline Larceny & 9,386 & 9.8 & Caldwell & 1,255 & 8 \\
\hline Burglary & 530 & 5.5 & Brewerville & 708 & 5 \\
\hline Sheep Stealing & 407 & 4.2 & Bexley & 678 & 5 \\
\hline Highway Robbery & 318 & 3.3 & Arthington & 451 & 3 \\
\hline Theft & 311 & 3.2 & Cape Palmas & 348 & 2 \\
\hline
\end{tabular}

\footnotetext{
1641 'Passionate histories', above $\mathrm{n}$

${ }_{1642}$ (See, http://guides.sl.nsw.gov.au/content.php?pid=400401\&sid=3291414).

${ }^{1643}$ Richard H Steckel and Roderick Floud (eds), Health and Welfare During Industrialization (University of Chicago Press, 1997) 236-37; Stephen Nicholas (ed), Convict Workers: Reinterpreting Australia's Past (Cambridge University Press, Paperback version, 2007) 75-78, 91-94; Oxley, above n 674, 162, 253-254, 266-268; David Eltis, Coerced and Free Migration: Global Perspectives (Stanford University Press, 2002) 271; Eric Richards, 'An Australian Map of British and Irish Literacy in 1841' (1999) 53(3) Population Studies 345; Deborah Oxley, 'Living Standards of Women in Prefamine Ireland' (2004) 28(2) Social Science History 271; Malcolm D Prentis, The Scots in Australia (University of New South Wales Press, 2008) 53; Penglase, above n 371; Robin Haines and John McDonald, 'Skills, Origins and Literacy: A Comparison of the Bounty Immigrants into New South Wales in 1841, With the Convicts Resident in The Colony' (2002) 42(2) Australian Economic History Review 132; Bethia M Penglase, Literacy in Colonial New South Wales 1788-1881 (PhD Thesis, University of New Castle, 1986).
} 


\begin{tabular}{|c|c|c|c|c|c|}
\hline $\begin{array}{l}\text { Housebreaking } \\
\text { House Breaking } \\
\text { Horse Theft } \\
\text { Stealing money }\end{array}$ & $\begin{array}{l}260 \\
217 \\
206 \\
191\end{array}$ & $\begin{array}{l}2.7 \\
2.3 \\
2.1 \\
2.0\end{array}$ & $\begin{array}{l}\text { Liberia } \\
\text { Sinoe } \\
\text { Cape Mount } \\
\text { Careysburg } \\
\text { St. Pauls River }\end{array}$ & $\begin{array}{l}326 \\
315 \\
254 \\
218 \\
131\end{array}$ & $\begin{array}{l}2 \\
2 \\
2 \\
1 \\
1\end{array}$ \\
\hline Migrants (1788-1840) & \# & $\%$ & Status & \# & $\%$ \\
\hline $\begin{array}{l}\text { Free Immigrants } \\
\text { Convicts }\end{array}$ & 79,278 & 30,699 & $\begin{array}{l}\text { Freeborn } \\
\text { Freed } \\
\text { Emancipated } \\
\text { Purchased } \\
\text { Unknown }\end{array}$ & $\begin{array}{l}1,833 \\
2,188 \\
5,894 \\
197 \\
4,884\end{array}$ & $\begin{array}{l}12 \\
15 \\
39 \\
1 \\
32\end{array}$ \\
\hline TOTAL $^{1644}$ & $\begin{array}{l}\sim 165,000 \\
1645\end{array}$ & & & $\sim 14,996^{1646}$ & \\
\hline
\end{tabular}

* Except indicated, all computation on Australian convicts are based on a total population of 127,901 (as at 1 June 2015) entered on the Convict Records. + With assistance from ANU Reference and the Australian National Library, to date, there no is available data on convict literacy between 1788-1868. Therefore, the 1871 Colonial Census includes the entire population of free and forced (convict) migrants to Australian, excluding Chinese and Aboriginal.

\footnotetext{
${ }^{1644}$ Shick, above n 1464; Brown, above n 543; Murdza Jr., above n 544; Frederick Ludwig Hoffman, Race Traits and Tendencies of the American Negro (MacMillan, 1896). Also see, http://www.convictrecords.com.au; http://www.convictcentral.com; http://www.slq.qld.gov.au/resources/family-history/convicts;

http://www.records.nsw.gov.au; http://guides.sl.nsw.gov.au/content.php?pid=400401\&sid=3283052; and http://ada.edu.au/ada/home

${ }^{1645}$ David T Hawkings, Bound for Australia: A Guide to the Records of Transported Convicts and Early Settlers (History Press, 2012) backcover.

${ }^{1646}$ Anjali Mitter Duva, Liberia and the United States: A Complex Relationship (2002) Global Connections: Liberia <http://www.pbs.org/wgbh/globalconnections/liberia/essays/uspolicy/>.
} 


\section{AX: Deceased Females Whose Deaths Were Within the Jurisdiction of the Royal Commission into Aboriginal Deaths in Custody ${ }^{164}$}

\begin{tabular}{|c|c|c|c|c|c|}
\hline Name & Age & State & Facility & Cause of Death & Brief Overview of Arrest Record \\
\hline Faith Barnes & 27 & WA & Kalgoorlie Lockup & Head injury (severe) & $\begin{array}{l}\text { Between } 1974 \text { and her death, she was arrested on forty occasions for being found drunk in a public place. In most instances these offences resulted in the } \\
\text { imposition of a fine. However, it is also apparent from her prison record that on many occasions these fines were not paid, and she served a prison term in } \\
\text { default of payment. Between } 1980 \text { and her death, she was imprisoned in the Menzies lockup on nine occasions, having failed to pay fines imposed on } \\
\text { convictions for drunkenness. }\end{array}$ \\
\hline $\begin{array}{l}\text { Muriel Gwenda Catheryn } \\
\text { Binks }\end{array}$ & 38 & QLD & $\begin{array}{l}\text { Innisfail Watch- } \\
\text { house }\end{array}$ & Natural cause (asthma) & $\begin{array}{l}\text { A drunk outside the Conservatorium trying to walk along the highway - entry, Innisfail Police Occurrence Sheet, } 4.00 \mathrm{pm} \text { to midnight shift, } 22 \text { February } \\
1989 .\end{array}$ \\
\hline Nita Blankett & 40 & WA & $\begin{array}{l}\text { Bandyup Training } \\
\text { Centre }\end{array}$ & Natural cause (asthma) & $\begin{array}{l}\text { The deceased was an Aboriginal mother of five children. At the time of her death she was serving a sentence of six months, at Bandyup Training Centre, } \\
\text { (Bandyup) for driving offences related to the consumption of alcohol. }\end{array}$ \\
\hline Joyce Thelma Egan & 58 & SA & $\begin{array}{l}\text { Mount Gambier } \\
\text { Police Station }\end{array}$ & Drug overdose & $\begin{array}{l}\text { Joyce was arrested outside her home by police at about } 2.00 \mathrm{pm} \text { on } 5 \text { August } 1988 \text { on a charge of indecent language. Joyce had earlier telephoned the Mount } \\
\text { Gambier Police Station is requesting the police to attend at her home and arrest her. Before the arrival of the police, Joyce voluntarily ingested a large } \\
\text { quantity of prescription drugs, namely, Mogadon, Serepax and Doxepin, and during the morning had consumed a substantial volume of liquor. }\end{array}$ \\
\hline $\begin{array}{l}\text { Christine Lesley-Ann } \\
\text { Jones }\end{array}$ & 22 & WA & Midland Lockup & Hanging & $\begin{array}{l}\text { On } 22 \text { January 1964, Christine was declared a neglected child and was committed to the care of the Child Welfare Department until } 18 \text { years of age with a } \\
\text { recommendation that she be released to the custody of the Native Welfare Department and placed in a suitable foster home. Her death occurred within } \\
\text { fifteen minutes of being locked up in a single cell at Midland Police Station on } 18 \text { October } 1980 \text {. }\end{array}$ \\
\hline Karen Lee O'Rourke & 14 & QLD & $\begin{array}{l}\text { Birralee Children's } \\
\text { Home }\end{array}$ & $\begin{array}{l}\text { Burns from a fire } \\
\text { deceased had lit to } \\
\text { escape }\end{array}$ & $\begin{array}{l}\text { Karen had arrived in Rockhampton from Sydney only six weeks before her death. Those six weeks were a traumatic period for Karen. She fought with her } \\
\text { mother whom she had travelled to Rockhampton to see after a separation of some ten years. She was in three foster placements with senior members of the } \\
\text { local Aboriginal community all of which failed for various reasons. She was enrolled in and attended grade } 9 \text { at Rockhampton High School but could not } \\
\text { cope and later transferred to grade } 8 \text {. In the middle of all this she was sexually assaulted by a man fourteen years her senior while another man held her } \\
\text { down. Karen died as a result of bums to } 100 \% \text { of her body at Rockhampton Base Hospital on } 11 \text { February } 1980 \text {. The bums sustained when trapped in a } \\
\text { security room she set fire to at Birralee Children's Home earlier that same day resulted in Karen's death. }\end{array}$ \\
\hline Deidre Abigail Short & 30 & QLD & $\begin{array}{l}\text { Lockhart River } \\
\text { Watch-house }\end{array}$ & $\begin{array}{l}\text { Natural cause (coronary } \\
\text { atherosclerosis) }\end{array}$ & $\begin{array}{l}\text { Deidre was born into the Lockhart River Community in } 1958 \text {, the third of eight children born to Fury and Ethel Short, both highly respected Aboriginal } \\
\text { people. The family lived in inmoverished circumstances and three of the children had to be either fostered or adopted out. When she was } 14 \text { years of age } \\
\text { Deidre gave birth to a child whom she could not look after, so he too was adopted out. The extent of Deidre's education is unknown. Limited police records } \\
\text { show minor conflicts with the law for some five years before her death. As with many other Aboriginal people on former reserves and missions, alcohol } \\
\text { came to play a significant role in Deidre's life. On the night before her death Deidre was drinking at the canteen and started throwing beer cans at her } \\
\text { boyfriend. As she was drunk, the police arrested her and took her to the watchhouse. }\end{array}$ \\
\hline Barbara Ruth Tiers & 37 & QLD & $\begin{array}{l}\text { Rockhampton } \\
\text { Watch-house }\end{array}$ & $\begin{array}{l}\text { Natural cause } \\
\text { (haemorrhage resulting } \\
\text { from advanced liver } \\
\text { disease) }\end{array}$ & $\begin{array}{l}\text { From the age of } 20 \text {-years alcohol was a controlling factor in Barbara's life. Apart from periods of incarceration and hospitalisation Barbara Tiers was rarely } \\
\text { sober. Gradually as a result of her alcoholism, her heath seriously deteriorated. She became well-known to the Rockhampton police as an alcoholic. Since } \\
1982 \text { she had been arrested for drunkenness } 76 \text { times. She was, however, never convicted of any serious criminal offence. On the afternoon of } 1 \text { February } \\
1989 \text { Barbara Ruth Tiers was found dead on the floor of a police cell at the Rockhampton watchhouse. Barbara had been taken into custody by the police } \\
\text { early that morning after being found, apparently severely intoxicated, on a footpath in Rockhampton. }\end{array}$ \\
\hline Barbara Denise Yarrie & 29 & QLD & $\begin{array}{l}\text { Brisbane City } \\
\text { Watch-house }\end{array}$ & $\begin{array}{l}\text { Natural cause (profound } \\
\text { hypoglycaemia) }\end{array}$ & $\begin{array}{l}\text { Barbara Yarrie, like her younger sister Fay, had for many years lived the life of an itinerant alcoholic, spending her days seeking out alcohol and drinking } \\
\text { with friends and acquaintances. Between } 1974 \text { and } 1986 \text { she was arrested for drunkenness on at least } 40 \text { occasions and was taken to the wathhouse on } \\
\text { many other occasions for alcohol related-offences. Police apprehended Barbara and charged her with being drunk in a public place early on the afternoon of } \\
31 \text { January } 1986 \text {. She was taken to the Brisbane City watchhouse in a state of near unconsciousness, unable to walk, communicate or comprehend her } \\
\text { environment. Placed in a cell where at some time during the afternoon she lapsed into unconsciousness. }\end{array}$ \\
\hline Fay Lena Yarrie & 27 & QLD & $\begin{array}{l}\text { Brisbane City } \\
\text { Watch-house }\end{array}$ & $\begin{array}{l}\text { Injuries sustained from } \\
\text { assault by a fellow } \\
\text { inmate }\end{array}$ & $\begin{array}{l}\text { Fay was no stranger to the Brisbane City watchhouse. She had been arrested and detained for drunkenness on hundreds of occasions during her short life. } \\
\text { Police apprehended Fay for drunkenness after being detained by an off-duty police officer outside a hotel in Brisbane's Fortitude Valley on the afternoon of } \\
15 \text { December } 1988 \text {. She was taken to the Brisbane City watchhouse and eventually placed in a cell with two other Aboriginal women, one earlier observed } \\
\text { behaving aggressively toward her fellow inmates. She died that evening in the hospital as a result of the injuries she sustained while in custody. }\end{array}$ \\
\hline $\begin{array}{l}\text { Ceduna } \\
\end{array}$ & $\sim 30$ & SA & $\begin{array}{l}\text { Ceduna Watch- } \\
\text { house }\end{array}$ & $\begin{array}{l}\text { Natural cause (cardiac } \\
\text { arhythmia) }\end{array}$ & $\begin{array}{l}\text { A woman, whose name has been suppressed from publication, died in the cells of the police station at Ceduna on } 18 \text { February } 1983 \text {. She was a chronic } \\
\text { alcoholic with a life-long history of ill-health. Two days before her death, she was arrested on a warrant of commitment for unpaid fines totalling } \$ 36.30 \text {. } \\
\text { She was to have served two days in custody in default and was due for release on the day of her death. }\end{array}$ \\
\hline
\end{tabular}

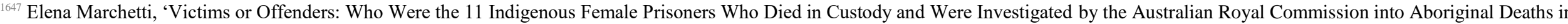
Custody?' (2012) 19(1) International Review of Victimology 37; Elliott Johnston, 'Royal Commission into Aboriginal Deaths in Custody (v1-5)' (Government Report, Royal Commission into Aboriginal Deaths in Custody, 1991) 600 


\section{AXI: Excerpts from Informal Emails to Male Colleagues}

Yes. I would speak out about violence against women; but the how, when, and where of speaking out depend on the given situation and particularly on the intended audience for the "spoken" message. [Respondent \#1]

In male conversations, I have been fortunate to be surrounded by mostly caring and respectful men in my life. However, when some people are maturing, they may try out misogynistic or objectifying language to try and fit into social groups. There have been a couple instances where I have called out a peer within a group of friends/colleagues, to hold them accountable and demonstrate that objectifying or denigrating women is not acceptable behaviour in my social groups. [Respondent \#2]

The simple answer is "yes," I would speak out about/against violence against women if/when I know it is taking place, or generally in advocating for policy and personal choices that support women's rights to live free from the threat of violence and discrimination. [Respondent \#3]

My job as an educator affords me many opportunities to address equality issues, including those conflicts surrounding violence against women. [Respondent \#4]

The where is often times the key element. If I am at work or attending a public meeting, yes and not only because I believe it is wrong but additionally the societal norm in my circle views violence against women as a particularly loathsome act. [Respondent \#5]

It is a little difficult to answer your question because the many contexts in which I can imagine speaking out about violence against women are not easy to delineate. [Respondent \#6]

Yes, I will. By actually engaging with others by taking concrete actions including educating, confronting, and/or reporting to the law enforcement agencies, anyone who I see committing such violence. [Respondent \#8]

Yes, anytime anywhere, giving my unscientific opinion, since that this is not my area of scientific work. [Respondent \#9]

I would speak about violence against women verbally or in writing as the situation demands or presents. [Respondent \#10]

Yes. There are no circumstances where I would feel compelled to keep silent about the issue. [Respondent \#11]

Education and enlightenment about who we are as people irrespective of gender or sexuality, society and our learning systems or worldviews have taught us conflicting things about dominance, alpha male, patriarchy and submission that is difficult to disentangle from violence in any form. On one hand, I am expected to control my home and use strong language and hand otherwise am seen gay or not manly enough, on the other - too much is seen as verbal or physical abuse. [Respondent \#15] 
Yes. I would definitely speak out about violence against woman. I feel like I do this tacitly by whom I vote for. [Respondent \#16]

Yes. I would speak out against violence against women any time. [Respondent \#17]

I would speak out about violence against women, but only in a comfortable context. [Respondent \#18]

As an historian and an educator, I try to build awareness and consciousnessraising surrounding gender issues into my teaching activities at every opportunity. [Respondent \#19]

I was raised singlehandedly by my mother, my entire makeup, the man I am who is now raising three boys, owe its roots to that mother of mine. May her soul rest in peace, for just as her presence in my life inspired me beyond words, her death passed me her torch. A torch that helps me find the light, kindness, softness and that power of emotion in every woman that crosses my path. If all men viewed and know women as I do, women would need no protection at all, as they are the fruit-bearers of life. If there is nothing else, I have thought my three boys, they all know just too well the importance of their grandmother, and the knowledge of their grandmother has shaped their view of their own mother, I refer to it as protection from within. [Respondent \#20]

Yes. I will speak out against violence generally, and in particular violence against women, because it goes against my principle. [Respondent \#12]

Yes, I will speak out about violence against women. The first and easy thing that I believe one can do is to live it in the day-to-day life. We are all surrounded by women (at home, work, etc.,) and need to refrain ourselves from being violent against them whatever situation we found ourselves in. [Respondent \#23]

I will answer the question broadly and say that it is the responsibility of any person to act when they see violence being perpetrated against another person be it a woman, child, or even a man. [Respondent \#24] 


\section{BIBLIOGRAPHY}

\section{Primary Sources \\ Australian Cases}

Akiba v Commonwealth of Australia [2013] HCA 33.

Bligh \& Others v State of Queensland [1997] 2 ALR 391.

Bugmy v The Queen [2013] HCA 37.

Commonwealth $v$ Yarmirr (1999) 101 FCR 171.

Cooper v Stuart (1889) App Case 286 (Privy Council).

Cubillo and Gunner $v$ The Commonwealth [2001] FCA 1213.

Fejo (on behalf of Larrakia People) v Northern Territory (1998) 195 CLR 96.

Mabo v Queensland (No 2) (1992) 175 CLR 1.

Mabo v Queensland (No 1) [1988] HCA 69.

Mabo v Queensland [1986] HCA 8.

Members of the Yorta Yorta $v$ Victoria [1998] FCA 1606.

Milirrpum v Nabalco Pty Ltd and the Commonwealth (The Gove Land Rights case) (1971) 17 FLR 141.

Neal v The Queen (1982) 149 CLR 305.

Ngatayi $v$ The Queen (1980) HCA 18, 147 CLR 1, 14.

Nulyarimma $v$ Thompson [1999] FCA 1192.

$R v$ Alwyn Peter [1983] Aboriginal Law Bulletin 21.

R. v. Ballard or Barrett [1829] NSWSupC 26.

$R v$ Bonjon [1841] NSWSupC 92.

$R v$ Dennis Narjic Unreported, NT Supreme Court, 1988.

$R v G J$ (Unreported, NT Supreme Court (Yarralin) SCC 20418849, Martin CJ, 11 August 2005.

$R v$ Murrell and Bummaree (1836) 1 Legge 72.

$R v$ Wewar (1842).

Terry $v$ Wilson [1849] NSWSupC 35.

Western Australia v Ward (2002) 213 CLR 1.

Wik Peoples v State of Queensland [2004] FCA 1306.

Williams v The Minister, Aboriginal Land Rights Act 1983 and Another [1999] NSWSC 843.

Wilson v Anderson (2002) 213 CLR 401.

Woolcock Street Investments Pty Ltd v CDG Pty Ltd [2004] HCA 16.

Yanner v Eaton (1999) 201 CLR 351; 166 ALR 258.

The Commonwealth of Australia v Yarmirr [2001] HCA 56.

\section{Liberian Cases}

Ballah Karman v John L. Morris, Secretary of the Interior and Major John H. Anderson, Commanding the Liberian Frontier Force [1920] unpublished Judgment Book 247.

Brownell v Brownell [1936] LRSC 3.

Davis v RL [1862] LRSC 2.

Ditchfield v Dossen et al [1907] LRSC 1.

Gofah et al v Peter [1905] LRSC 5.

New York Krp eh $v$ Harding [1936] unpublished but printed opinions 107.

$R L v$ Elinam Prah [2009] SGBV-CU unreported.

$R L v$ James Marfarlon [2011] SGBV-CU unreported.

$R L v$ Joseph Gardea [2009] SGBV-CU unreported.

$R L v$ Lewis Lecco [2012] SGBV-CU unreported.

$R L v$ Prince Ameka of Monrovia [2011] SGBV-CU unreported.

$R L v$ Prince Mayango [2009] SGBV-CU unreported.

RL v Tuttugirl Flomo [2011] SGBV-CU unreported.

Williams v RL [2014] (Judgment) LRSC 47.

Williams v RL [2014] (Appeal) LRSC 45.

\section{Other}

Centre for Minority Rights Development (Kenya) and Minority Rights Group International behalf of Endorois Welfare Council v Kenya 276/2003.

Island of Palmas Case (or Miangas), United States $v$ Netherlands, Award, (1928) II RIAA 829.

The Prosecutor of the Special Court v Charles Ghankay Taylor [2012] SCSL.

South-West Africa Cases (Ethiopia v. South Africa; Liberia v. South Africa); Second Phase, International Court of Justice, [18 July 1966] 434.

\section{Australian Legislation: Statutes, Acts and Bills}

Abolition of Penal Sanctions (Indigenous Workers) Convention 1957.

Aboriginal and Torres Strait Islander Affairs Act 1965 (QLD).

Aborigines Protection Amending Act 1915 (NSW).

Aborigines Protection Act 1909 (NSW).

Aboriginal Protection and Restriction of Sale of Opium Act 1897 (QLD).

Fynn Bruey: Systematic Gender Violence and the "Rule of Law" in Indigenous Liberia and Australia 347 
Aborigines Act 1869 (NSW).

Aborigines Act 1905 (WA).

Aborigines Act 1910 (Vic).

Aborigines Act 1911 (SA).

Aborigines Ordinance 1918 (Cth.).

Aboriginal Protection Act 1869 (Vic).

Adoption Act 1920 (Tas).

Adoption Act 1968 (Tas).

Adoption of Children Act 1896 (WA)

Australian Capital Territory (Self Government ACT) 1988.

Australian Human Rights Commission Act 1986.

Australia Institute of Aboriginal Studies Act 1964.

Australian Referendum 1967.

Charter of Human Rights and Responsibilities Acts 2006 (VIC)

Child Welfare Act 1960 (Tas).

Commonwealth Electoral Act 1918.

Commission of Inquiry (Deaths in Custody) Act 1987.

Commonwealth of Australia Constitution Act 1900 (Cth).

Constitution of the Commonwealth of Australia (1901).

Commonwealth Franchise Act 1902.

Crimes Act 1914 (Cth).

Crimes (Restorative Justice) Act 2004 (ACT).

Establishment and Management of Asylums for Orphans and Deserted and Neglected Children Act, 1879.

Family Law Act 1975 (Cth).

Human Rights Act 2004 (ACT).

Human Rights (Parliamentary Scrutiny) Act 2011 (Cth).

Human Services Legislation Amendment Act 2011.

Industrial and Reformatories School Act 1865.

Industrial Schools Act 1867 (Tas).

Infants Welfare Act 1935 (Tas).

Magistrates' Court (Koori Court) Act 2002 (Vic).

Marriage Amendment Act 2017 (Cth).

Marriage Act 1961 (Cth).

Native Title Act 1993 (Cth \& QLD).

Native Welfare Act 1963 (WA).

Northern Territory Aboriginals Ordinance 1911 (Cth).

Northern Territory National Emergency Response Act 2007 (NT).

Northern Territory (Self-Government) Act 1978.

Neglected Children and Juvenile Offenders Act 1905 (NSW).

Protection, Maintenance and Upbringing of Orphans and other Destitute Children and Aborigines Act 1844.

Queensland Coast Islands Declaratory Act 1985 (QLD).

Racial Discrimination Acts 1975 (Cth).

Sex Discrimination Act 1984 (Cth).

State Education Act 1875 (QLD).

Statute of Westminster Adoption Act 1942 (Cth).

Stolen Generations of Aboriginal Children Act 2006 (TAS).

Stronger Futures in the Northern Territory Act 2012 (Cth).

Violence Restraining Order Act 1997 (WA).

Welfare Reform and Reinstatement of Racial Discrimination Act 2010 (Cth).

Western Australia Constitution Act 1889 (WA).

\section{Liberian Legislation: Statutes, Acts and Bills}

An Act to Ban Trafficking in Persons Within the Republic of Liberia 2005.

An Act to Govern the Devolution of Estates and Establish Rights of Inheritance for Spouses of Both Statutory and Customary Marriages 2003.

An Act Ratifying the Amended and Restated Concession of Agreement Between the Republic of Liberia and Firestone Liberia Inc. 2008.

An Act Ratifying the Amended and Restated Concession of Agreement Between the Republic of Liberia and Sime

Darby Plantation (Liberia) Inc. 2009.

Act to Regulate all Elections in the Republic of Liberia 1946.

The Aborigines Law 1956.

Civil Procedure Law 1972.

Children's Law Act 2011.

Constitution for the Government of the African Settlement 1820.

Constitution of Liberia 1986.

Constitution of Liberia 1847.

Constitution of the Commonwealth 1939.

Criminal Procedure Law 1972.

Domestic Relations Law 1973. 
Draft Sexual and Reproductive Health Law 2012.

Establishing Criminal Court "E" (Sexual Crimes Court) 2008.

Equal Rights of the Customary Marriage Law 1998.

Gang Rape, Providing for (Amending Title 26) 2006.

Gender and Development Act 2001.

Independent National Commission on Human Rights Act 2005.

Judiciary Law 1972.

Law Reform Commission Act 2011.

Land Commission Act 2009.

Land Rights Draft Bill 2014 (not enacted)

Liberian Codes of Law Revised, Title 9 Domestic Relations Law 1998

Penal Law 1976.

Rules and Regulations Governing the Hinterland of Liberia (Revised 7 January 2001).

Trafficking in Persons Act 2005.

Truth and Reconciliation Commission Act 2005.

Truth and Reconciliation Commission (TRC) Tenure Act 2009.

The Virginia Declaration 2009.

\section{Other}

Abolition of the Slave Trade Act 1807 (UK).

Act to Prevent All Persons from Teaching Slaves to Read or Write, The Use of Figures Excepted 1831 (US).

Slavery Abolition Act 1833 (UK).

Transportation Act 1717 (UK).

\section{International}

Convention on the Prevention and Punishment of the Crime of Genocide 1948Abolition of Penal Sanctions (Indigenous Workers) Convention (No 104) 1955.

Convention Concerning Indigenous and Tribal Peoples in Independent Countries (No 169) 1989.

Conventional Concerning the Protection and Integration of Indigenous and Other Tribal and Semi-Tribal

Populations in Independent Countries (No 107) 1957.

Convention on the Elimination of All Forms of Discrimination Against Women 1979.

Convention on the Prevention and Punishment of the Crime of Genocide 1948.

Convention on the Rights of the Child 1989.

Convention on the Rights of Persons with Disabilities 2006.

Declaration on the Granting of Independence to Colonial Countries and Peoples 1960.

Declaration of the Basic Principles of Justice for Victims of Crimes and Abuse of Power 1985.

Declaration on the Elimination of Violence Against Women, 1993

Declaration on the Rights of Indigenous Peoples 2007.

Indigenous and Tribal Peoples Convention 1989

International Convention on the Elimination of All Forms of Racial Discrimination 1965.

International Covenant on Economic, Social and Cultural Rights 1966.

International Covenant on Civil and Political Rights 1966.

Rome Statute of the International Criminal Court 1998.

Slavery Convention 1926.

Universal Declaration of Human Rights 1948.

\section{Regional}

African [Banjul] Charter on Human and Peoples' Rights 1981.

African Charter on the Rights and Welfare of the Child 1990.

ECOWAS Community Court 1991.

Protocol to the African Charter on the Establishment of an African Court on Human and Peoples' Rights 1998.

Protocol to the African Charter on Human and Peoples' Rights on the Rights of Women in Africa 2000.

\section{UN Doc}

Committee on the Elimination of Discrimination against Women (CEDAW), Concluding Observations of the Committee on the Elimination of Discrimination against Women: Australia, 12-30 July 2010,

CEDAW/C/AUS/CO/7.

Committee on the Elimination of Discrimination against Women (CEDAW), Concluding Observations of the Committee on Combined Seventh and Eighth Periodic Reports of Liberia: Liberia, 24 November 2015, CEDAW/C/LBR/CO/7-8.

UN Security Council Resolution, Security Council Resolution 1325 (2000) [on women and peace and security], 31 October 2000, (S/RES/1325 (2000). 
UN Security Council Resolution, Security Council Resolution 1820 (2008) [on sexual violence during wars], 19 June 2008, (S/RES/1820 (2008).

\section{Secondary Sources \\ Audio Recording}

1. Calma, Tom, 'The Human Rights Perspective'

<http://www.humanrights.gov.au/social_justice/conference/oid/tom_calma.htm>

2. Currey, Nerida, 'Barb Shaw Speaks on Stronger Futures Legislation'

3. Dodson, Mick, 'Introduction: Indigenous Governance'

<http://www.humanrights.gov.au/social_justice/conference/oid/mick_dodson.htm>

4. Gbowee, Leymah and Ali Benton, 'Leymah Gbowee: An Extraordinary Life'

$<$ http://www.abc.net.au/radionational/programs/drive/leymah-gbowee3a-an-extraordinarylife/4626452>

5. La Trobe University, 'Native Authorities with Ben Silverstein'

<http://www.latrobe.edu.au/news/articles/2010/podcasts/aboriginal-australian-history/transcript>

6. La Trobe University, 'Aboriginal Sorcery with Henry Reynolds'

$<$ http://www.latrobe.edu.au/news/articles/2008/podcasts/aboriginal-sorcery-with-professorhenry-reynolds/transcript>

7. La Trobe University, 'Shattered ANZACS Marina Larsson' $<$ http://www.latrobe.edu.au/news/articles/2009/podcasts/shattered-anzacs-with-marinalarrson/transcript>

8. La Trobe University, 'An Australian Revolution? With Richard Broome'

9. La Trobe University, 'Drawing the Global Colour Line with Professor Marilyn Lake - Australian History'

10. La Trobe University, 'Melbourne Archaeology with Tim Murray'

11. La Trobe University, 'Aboriginal Australian History with Richard Broome' <http://www.latrobe.edu.au/news/articles/2010/podcasts/aboriginal-australian-history/transcript>

12. La Trobe University, 'Early Depictions of Australia with Tony Barta and Les Cowley'

13. La Trobe University, 'The First Fleet: The Real Story with Alan Frost' <http://www.latrobe.edu.au/news/articles/2011/podcasts/the-first-fleet-the-real-story/transcript >

14. La Trobe University, 'The Myall Creek Massacre with Richard Broome' $<$ http://www.latrobe.edu.au/news/articles/2012/podcasts/podcasts/the-myall-creekmassacre/transcript>

15. La Trobe University, 'How Australian Women Won the Vote with Clare Wright' <http://www.latrobe.edu.au/news/podcasts/transcript?mode=results\&queries_id_query=209645>

16. La Trobe University, 'A Talk with Mick Dodson' <https://itunes.apple.com/itunes-u/australianpolitics/id391322440>

\section{Blog Post}

1. Brooks, Cholo, 'The Purge of Female Genital Mutilation in Liberia, Family Urges Victim to "Conform to Cultural Practice of FGM or Encounter Death" $<$ http://gnnliberia.com/2017/01/09/purge-female-genital-mutilation-liberia-family-urges-victimconform-cultural-practice-fgm-encounter-death/>

2. Dirie, Waris, 'What Is FGM? - Desert Flower Foundation' $<$ http://www.desertflowerfoundation.org/en/what-is-fgm/>

3. Gates Jr., Henry Louis, 'How Many Slaves Landed in the U.S.? The African Americans: Many Rivers to Cross' <http://www.pbs.org/wnet/african-americans-many-rivers-to-cross/history/howmany-slaves-landed-in-the-us/>

4. Goldman, Sparrow, 'Institutional Violence: My Interview with Noam Chomsky' <http://isabeaudoucet.org/2010/08/24/my-interview-with-noam-chomsky/>

5. Kraaij, Fred PM van der, 'The Grain Coast, Malaguetta Coast or Pepper Coast before 1822'

6. Lowe, Chris, 'The Trouble with Tribe'

7. RECOGNISE, 'What Is Reconciliation?'<https://www.reconciliation.org.au/what-isreconciliation/>

8. Teff, Melanie, 'Looking for the Law in Liberia' <http://www.refugeesinternational.org/print/2267>

9. Timbury, Cheryl, 'Elizabeth Hayward'

10. Zota, Jr., Sam, 'At Sime Darby Plantation: Workers Drink from Creeks, Dwell in Makeshift Structures' <http://amazingliberia.blogspot.com.au/2011/07/at-sime-darby-plantation-workersdrink.html> 


\section{Book}

1. Aafjes, Astrid and Anne Tierney Goldstein, Gender Violence: The Hidden War Crime (Kumarian Press, 1998)

2. Abasiattai, Monday B, African Resistance in Liberia: The Vai and Gola-Bandi (Liberia Working Group, 1988)

3. Acholonu, Catherine Obianuju, Motherism: The Afrocentric Alternative to Feminism (Afa Publications, 1995)

4. Ackerly, Brooke A, Doing Feminist Research in Political and Social Science (Palgrave Macmillan, 2010)

5. Acorn, Annalise, Compulsory Compassion: A Critique of Restorative Justice (University of British Columbia Press, 2004)

6. ACS, The African Repository (American Colonization Society, 1869) vol XLV

7. Aginam, Obijiofor, Global Health Governance: International Law and Public Health in a Divided World (University of Toronto Press, 2005)

8. Agrast, Mark David et al, The World Justice Project Rule of Law Index, 2012-2013 (The World Justice Project, 2013)

9. Alaszewski, Andy, Using Diaries for Social Research (SAGE Publications, 2005)

10. Aldridge, Alan and Kenneth Levine, Surveying the Social World: Principles and Practice in Survey Research (Open University Press, 2001)

11. Alexander, Alison, Tasmania's Convicts (Allen and Unwin, 2010)

12. Alexander, Michelle, The New Jim Crow: Mass Incarceration in the Age of Colour-Blindness (The New Press, 2011)

13. Alfred, Gerald R, Peace, Power, Righteousness: An Indigenous Manifesto (Oxford University Press, 2nd ed. 2009)

14. Allan, John A et al (eds.), Handbook of Land and Water Grabs in Africa: Foreign Direct Investment and Food and Water Security (Routledge, 1st ed. 2013) <http://www.routledge.com/books/details/9781857436693/>

15. Allan, Trevor RS, Constitutional Justice a Liberal Theory of the Rule of Law (Oxford University Press, 2005)

16. Allen, Beverly, Rape Warfare: The Hidden Genocide in Bosnia-Herzegovina and Croatia (University of Minnesota Press, 1996) <http://www.amazon.com/Rape-Warfare-GenocideBosnia-HerzegovinaCroatia/dp/0816628181/ref=sr_1_6?s=books\&ie=UTF8\&qid=1361921359\&sr=1$6 \&$ keywords=the+hidden+gender+of+law $>$

17. Altman, Andrew, Critical Legal Studies: A Liberal Critique (Princeton University Press, Paperback, 1993)

18. Altman, Jon C and Melinda Hinkson (eds.), Coercive Reconciliation: Stabilise, Normalise, Exit Aboriginal Australia (Arena Publications Association, 2007)

19. Al-Yaman, Fadwa, Family Violence Among Aboriginal and Torres Strait Islander Peoples (Australian Institute of Health and Welfare, 2006)

20. American Colonization Society, Liberia (American Colonization Society, 1894)

21. Amnesty International, Maze of Injustice: The Failure to Protect Indigenous Women from Sexual Violence in the USA (Amnesty International USA, 2007) <http://www.amnestyusa.org/pdfs/MazeOfInjustice.pdf>

22. Anaya, S James, Indigenous Peoples in International Law (Oxford University Press, 2nd ed. 2004)

23. Anaya, S James, International Human Rights and Indigenous Peoples (Wolters Kluwer Law \& Business, 1st ed. 2009)

24. Ancheta, Angelo N, Scientific Evidence and Equal Protection of the Law (Rutgers University Press, 2006)

25. Anderson, Myrdene (ed.) Cultural Shaping of Violence: Victimization, Escalation, Response (Purdue University Press, 2004)

26. Anderson, Myrdene (ed), Cultural Shaping of Violence: Victimization, Escalation, Response (Purdue University Press, 2004)

27. Anderson, Robert Earle, Liberia America's African Friend (University of North Carolina Press, 2011)

28. Anghie, Antony, Imperialism, Sovereignty, and the Making of International Law (Cambridge University Press, 1st ed, 2007)

29. An-Na'im, Abdullahi Ahmed, Human Rights Under African Constitutions: Realizing the Promise for Ourselves (University of Pennsylvania Press, 2011)

30. Anthony, Karina and Parliamentary Library Research Service, The Political Representation of Ethnic and Racial Minorities (NSW Parliamentary Library Research Service, 2006)

31. Anthony, Thalia, Indigenous People, Crime and Punishment (Routledge, 2013) 
32. Anthropology at the Front Lines of Gender-Based Violence (Vanderbilt University Press, 2011)

33. Appiah, Anthony and Henry Louis Gates (eds), Africana: The Encyclopaedia of the African and African American Experience (Oxford University Press, 2nd ed, 2005)

34. Appiah, Kwame Anthony, The Ethics of Identity (Princeton University Press, 2007)

35. Arnfred, Signe, Sexuality \& Gender Politics in Mozambique: Rethinking Gender in Africa (James Currey, 2011)

36. Arrigo, Bruce A, The Ethics of Total Confinement: A Critique of Madness, Citizenship, and Social Justice (Oxford University Press, 2011)

37. Asante, Molefi K and Ama Mazama, Encyclopaedia of Black Studies (SAGE Publications, 2005)

38. Askey, Simon and T Ian McLeod, Studying Law (Palgrave Macmillan, 2011)

39. Atkinson, Judy, Beyond Violence: Finding the Dream (The Aboriginal and Islander Subprogram, National Domestic Violence Education Program, Office of Status of Women, 1990)

40. Atkinson, Judy, Trauma Trails, Recreating Song Lines: The Transgenerational Effects of Trauma in Indigenous Australia (Spinifex Press, 2002)

41. Attorney-General's Department and National Human Rights Consultation Secretariat, National Human Rights Consultation: Report (Attorney-General's Department, 2009)

42. Attwood, Bain, The Making of the Aborigines (Allen and Unwin, 1989)

43. Attwood, Bain et al., The 1967 Referendum, or, When the Aborigines Didn't Get the Vote (Australian Institute of Aboriginal and Torres Strait Islander Studies, 1997)

44. Attwood, Bain, Rights for Aborigines (Allen and Unwin, 2003)

45. Attwood, Bain, Telling the Truth About Aboriginal History (Allen \& Unwin, 2005)

46. Attwood, Bain, The 1967 Referendum: Race, Power and the Australian Constitution (Aboriginal Studies Press, 2nd ed, 2007)

47. Attwood, Bain and Tom Griffiths, Frontier, Race, Nation: Henry Reynolds and Australian History (Australian Scholarly Pub, 2009)

48. Atuahene, Bernadette, We Want What's Ours: Learning From South Africa's Land Restitution Program (Oxford University Press, 2014)

<http://public.eblib.com/choice/publicfullrecord.aspx?p=1727879>

49. Austin-Broos, Diane J, Arrernte Present, Arrernte Past: Invasion, Violence, and Imagination in Indigenous Central Australia (University of Chicago Press, 2009)

50. Australian Government and Housing Department of Families, Housing, Community Services and Aboriginal Affairs, Report on the Northern Territory Emergency Response Redesign Consultations. (Department of Families, Housing, Community Services and Indigenous Affairs, 2009)

51. Australian Indigenous and Torres Strait Islander Studies, Guidelines for Ethical Research in Australian Indigenous Studies (AIATSIS, 2012)

52. Australian Institute of Aboriginal and Torres Strait Islander Studies, The Social Archaeology of Australian Indigenous Societies (Aboriginal Studies Press, 2006)

53. Australian Institute of Judicial Administration and Stephanie Fryer-Smith, Aboriginal Benchbook for Western Australian Courts (Australian Institute of Judicial Administration, 2008)

54. Australian Women: Contemporary Feminist Thought (Oxford University Press, 1994)

55. Australia's History: Themes and Debates (University of New South Wales Press, 2005)

56. Ayittey, George BN, Indigenous African Institutions (Transnational Publishers, 2nd ed, 2006)

57. Azikiwe, Nnamdi, Liberia in World Politics (University of Michigan, 1934)

58. Bachman, Ronet, Death and Violence on the Reservation: Homicide, Family Violence, and Suicide in American Indian Populations (Auburn House, 1992)

59. Baehr, Elisabeth and Barbara Schmidt-Haberkamp, 'And There'll Be No Dancing': Perspectives on Policies Impacting Indigenous Australia Since 2007 (Cambridge Scholars Publishing, 2017) $<$ http://search.ebscohost.com/login.aspx?direct=true \&scope=site $\& d b=$ nlebk $\& d b=$ nlabk $\& A N=15$ 17716>

60. Bailey, Augustus M, Pieces of the Mind: My Experiences and Memories of Liberia (Xlibris, 2013)

61. Bailey, Peter H, Human Rights: Australia in an International Context (Butterworths, 1990)

62. Bailey, Peter H, The Human Rights Enterprise in Australia and Internationally (LexisNexis, 2009)

63. Bandler, Faith, Turning the Tide: A Personal History of the Federal Council for the Advancement of Aborigines and Torres Strait Islanders (Aboriginal Studies Press, 1989)

64. Banner, Stuart, Possessing the Pacific: Land, Settlers, and Indigenous People from Australia to Alaska (Harvard University Press, 2007)

65. Barak, Gregg, Violence and Nonviolence: Pathways to Understanding (Sage Publications, 2003)

66. Barker, Anthony, What Happened When: A Chronology of Australia from 1788 (Allen and Unwin, 3rd ed, 2000) 
67. Barnet, Sylvan and Hugo Adam Bedau (eds), Critical Thinking, Reading, and Writing: A Brief Guide to Argument (Bedford, St. Martins, 7th ed, 2011)

68. Barnett, Hilaire, Introduction to Feminist Jurisprudence (Cavendish, 1998)

69. Barnett, Hilaire, Constitutional and Administrative Law (Routledge, 9th ed, 2011) vol 1

70. Baron de Montesquieu, Charles de Secondat, The Spirit of Laws: The Complete Works (T Evans, 1777) vol 1

71. Barret-Kriegel, Blandine, The State and the Rule of Law (Princeton University Press, 1995) <http://www.dawsonera.com/depp/reader/protected/external/AbstractView/S9781400821761>

72. Bartels, Lorana, Indigenous Women's Offending Patterns: A Literature Review (Australian Institute of Criminology, 2010)

73. Barter, Alice, Violence Against Women Under International Human Rights Law (Cambridge University Press, 2013)

74. Bartlett, Katharine T and Rosanne Terese Kennedy (eds), Feminist Legal Theory: Readings in Law and Gender (Westview Press, 1991) <https://westviewpress.com/books/feminist-legaltheory/>

75. Bartlett, Peter and Ralph Sandland, Mental Health Law: Policy and Practice (Oxford University Press, 3rd ed, 2007)

76. Basedow, Herbert, The Australian Aboriginal (F. W. Preece and Sons, 1925)

77. Battiste, Marie (ed), Reclaiming Indigenous Voice and Vision (University of British Columbia Press, 2000)

78. Battiste, Marie Ann and Jean Barman (eds), First Nations Education in Canada: The Circle Unfolds (University of British Columbia Press, 1995)

79. Battye, James Sykes, Western Australia: A History From Its Discovery to the Inauguration of the Commonwealth (Clarendon Press, 1924) <http://gutenberg.net.au/ebooks05/0500301h.html>

80. Bauer, Gretchen and Josephine Dawuni, Gender and the Judiciary in Africa (Taylor and Francis, 2015) <http://public.eblib.com/choice/publicfullrecord.aspx?p=4085439>

81. Bayart, Jean-François, The State in Africa: The Politics of the Belly (Polity, 2nd ed, 2009) <http://www.amazon.com/State-Africa-Jean-Francois-Bayart/dp/0745644376>

82. Beals, Ralph L, Harry Hoijer and Virginia More Roediger, An Introduction to Anthropology (MacMillan, 1953)

83. Beauvoir, Simone de, The Second Sex (Alfred A. Knopf, 1st American, 2010)

84. Bederman, David J, The Spirit of International Law (University of Georgia Press, 2002)

85. Beers, Max Delano, Max Adventures: Redemption of Truganini (Max Delano Beers and Amazon Digital Services, Smashwords, 2012)

86. Behrendt, Larissa, Indigenous Legal Relations in Australia (Oxford University Press, 2009) <http://www.amazon.com/Indigenous-Relations-Australia-Larissa-Behrendt/dp/0195562011>

87. Behrendt, Larissa, Indigenous Australia for Dummies (For Dummies, a branded imprint of Wiley, 2012)

88. Bekhouche, Yasmina et al, The Global Gender Gap Report 2014 (World Economic Forum, 2014) <http://www3.weforum.org/docs/GGGR14/GGGR_CompleteReport_2014.pdf>

89. Bell, Diane and Pam Ditton, Law, the Old and the New: Aboriginal Women in Central Australia Speak Out (Published for Central Australian Aboriginal Legal Aid Service by Aboriginal History, 1980)

90. Bell, Diane and Renate Klein (eds), Radically Speaking: Feminism Reclaimed (Spinifex Press, 1996)

91. Bell, Diane, Ngarrindjeri Wurruwarrin: A World That Is, Was, and Will Be (Spinifex, 1998)

92. Bell, Diane, Daughters of the Dreaming (Spinifex Press, 3rd ed, 2002)

93. Benbenishty, Rami, School Violence in Context: Culture, Neighbourhood, Family, School, and Gender (Oxford University Press, 2005)

94. Bennett, Sue and Mona Pare, 20th Anniversary of The Convention on the Rights of the Child (University of Ottawa, 2010)

95. Berg, Bruce L, Qualitative Research Methods for the Social Sciences (Pearson, 8th ed, 2012)

96. Berkeley, Bill and Lawyers Committee for Human Rights (U.S.), Liberia, A Promise Betrayed: A Report on Human Rights (Lawyers Committee for Human Rights, 1986)

97. Berlatsky, Noah and Frank Chalk, Liberia (Greenhaven, 2014)

98. Berndt, Ronald M, Australian Aboriginal Religion (Brill, 1974) vols 1-4

99. Berndt, Ronald M, Robert Tonkinson and Australian Institute of Aboriginal Studies, Social Anthropology and Australian Aboriginal Studies a Contemporary Overview (Aboriginal Studies Press for the Australian Institute of Aboriginal Studies, 1988)

<http://public.eblib.com/choice/publicfullrecord.aspx?p=287020>

100.Berndt, Ronald M and Catherine H Berndt, The World of the First Australians: Aboriginal Traditional Life Past and Present (Aboriginal Studies Press, 5th ed, 1996) 
101.Bernhardt, Rudolf, Encyclopedia of Public International Law (North-Holland Publ. Co., 1983) vol 6

102.Beyan, Amos Jones, African American Settlements in West Africa: John Brown Russwurm and the American Civilizing Efforts (Palgrave Macmillan, 1st ed, 2005)

103. Bhatia, Michael V, War and Intervention: Issues for Contemporary Peace Operations (Kumarian Press, Inc., 2003)

104.Bingham, Tom H, The Rule of Law (Penguin, 2011)

105.Bird, Carmel, The Stolen Children: Their Stories; Including Extracts from the Report of the National Inquiry into the Separation of Aboriginal and Torres Strait Islander Children from Their Families (Random House Australia, 1998)

106.Birrell, Kathleen, Indigeneity: Before and Beyond the Law (Routledge, 2016)

107.Blagg, Harry, Crime, Aboriginality and the Decolonisation of Justice (Hawkins Press, 2008)

108. Blainey, Geoffrey, Triumph of the Nomads: A History of Aboriginal Australia (Overlook Press, 1993)

109.Bledsoe, Caroline H, Women and Marriage in Kpelle Society (Stanford University Press, 1980)

110.Bloor, Michael et al, Focus Groups in Social Research (SAGE, 2001)

111.Blyden, Edward Wilmot, Liberia’s Offering: Being Addresses, Sermons Etc. (John A Gray Printer, 1862)

112. Boas, Gideon et al (eds), International Criminal Procedure (Cambridge University Press, 2011) vol 3

113. Boley, George E Saigbe, Liberia: The Rise and Fall of the First Republic (St. Martin's Press, 1984)

114.Bolger, Audrey, Aboriginal Women and Violence: A Report for the Criminology Research Council and the Northern Territory Commissioner of Police (Australian National University, North Australia Research Unit, 1991)

115.Bolitho, Jane, Jasmine Bruce and Gail Mason, Restorative Justice: Adults and Emerging Practice (Sydney Institute of Criminology, 2012)

116.Bolker, Joan, Writing Your Dissertation in Fifteen Minutes a Day: A Guide to Starting, Revising, and Finishing Your Doctoral Thesis (H. Holt, 1st ed, 1998)

117.Bond, Johanna, Voices of African Women: Women's Rights in Ghana, Uganda, and Tanzania (Carolina Academic Press, 2004)

118. Bonwick, James, The Last of the Tasmanians or The Black War of Van Diemen's Land (Sampson Law, Son \& Marston, 1870)

119. Borrows, John, Freedom and Indigenous Constitutionalism (University of Toronto Press, 2016) $<$ http://search.ebscohost.com/login.aspx?direct=true \&scope=site $\& d b=$ nlebk $\& d b=$ nlabk $\& A N=12$ 34251>

120.Bourke, Joanna, Rape: A History from 1860 to the Present Day (Virago, 2008)

121. Bowden, Brett, Hilary Charlesworth and Jeremy Matam Farrall (eds), The Role of International Law in Rebuilding Societies After Conflict: Great Expectations (Cambridge University Press, 2009)

122.Boyce, James, Van Diemen's Land (Black Inc., 2010)

123.Boyle, Elizabeth Heger, Female Genital Cutting: Cultural Conflict in the Global Community (Johns Hopkins University Press, 2005)

124.Bradshaw, John, Healing the Shame That Binds You (Health Communications, 1988)

125.Brady, Maggie, Struggles Over Drinking Rights (Pirion Press, 2008) <http://www.esauboeck.com/index/grog6.pdf>

126. Braithwaite, John, Restorative Justice and Responsive Regulation (Oxford University Press, 2002)

127. Breckenridge, Jan and Moira Carmody (eds), Crimes of Violence: Australian Responses to Rape and Child Sexual Assault (Allen and Unwin, 1992)

128. Brender, Valerie and Human Rights Watch (Organization), 'No Money, No Justice': Police Corruption and Abuse in Liberia (Human Rights Watch, 2013) <http://www.hrw.org/sites/default/files/reports/liberia0813_forUpload_0.pdf>

129. Brennan, Bernadette (ed.) Just Words? Australian Authors on Writing and Justice (University of Queensland Press, 2008)

130.Brennan, Lani and Hazel Flynn, Lani’s Story: Not a Victim. A Survivor (HarperCollins, 2013)

131. Bringing Them Home: Report of the National Inquiry into the Separation of Aboriginal and Torres Strait Islander Children From Their Families (Human Rights and Equal Opportunity Commission, 1997)

132. Brock, Peggy, Words and Silences: Aboriginal Women, Politics and Land (Allen \& Unwin, 2001)

133.Broome, Richard, Aboriginal Australians: Black Responses to White Dominance, 1788-2001 (Allen and Unwin, 3rd ed, 2002) 
134.Broome, Richard, Aboriginal Victorians: A History Since 1800 (Allen and Unwin, 2005)

135. Broome, Richard, Aboriginal Australians: A History Since 1788 (Allen and Unwin, 4th ed, 2010)

136.Brown, Carl, Stories of the Ngunnawal (Journey of Healing (ACT) Inc., 2007)

137. Brown, Leslie and Susan Strega, Research as Resistance: Critical, Indigenous and AntiOppressive Approaches (Canadian Scholars' Press, 2005)

138. Brown, Robert T, Immigrants to Liberia, 1844-1864: An Alphabetical Listing (Liberian Studies Association, 1980) vol no. 7

139. Brownlie, Ian, Principles of Public International Law (Oxford University Press, 7th ed, 2008) $<$ http://books.google.com.au/books/about/Principles_of_public_international_law.html?id=mm A3AQAAIAAJ\&redir_esc=y>

140.Brownmiller, Susan, Against Our Will: Men, Women, and Rape (Fawcett Columbine, 1st Ballantine Books, 1993)

141.Brownridge, Douglas A, Violence Against Women: Vulnerable Populations (Routledge, 2009)

142.Buchan, Bruce A, The Empire of Political Thought: Indigenous Australians and the Language of Colonial Government (Pickering and Chatto, 2008)

143. Burbank, Victoria Katherine, Aboriginal Adolescence: Maidenhood in an Australian Community (Rutgers University Press, 1988)

144.Burbank, Victoria Katherine, Fighting Women: Anger and Aggression in Aboriginal Australia (University of California Press, 1994)

145.Burbank, Victoria Katherine, An Ethnography of Stress: The Social Determinants of Health in Aboriginal Australia (Palgrave Macmillan, 1st ed, 2011)

146.Burridge, Kenelm, Encountering Aborigines, A Case Study: Anthropology and the Australian Aboriginal (Pergamon Press, 1973)

147.Burrowes, Carl Patrick, Power and Press Freedom in Liberia, 1830-1970: The Impact of Globalization and Civil Society on Media-Government Relations (Africa World Press, 2004)

148. Burrowes, Carl Patrick, Between the Kola Forest and the Salty Sea: A History of the Liberian People Before 1800 (Know Your Self Press, 2016)

149.Butler, Judith, Bodies That Matter: On the Discursive Limits of Sex (Routledge, 1993)

150.Butler, Judith, Antigone's Claim: Kinship Between Life and Death (Columbia University Press, 2000)

151. Butler, Judith, Bodies That Matter on the Discursive Limits of 'Sex' (Routledge, 2011) <http://public.eblib.com/EBLPublic/PublicView.do?ptiID=683946>

152.Butler, Judith, Gender Trouble: Feminism and the Subversion of Identity (Routledge Classics, 2011)

153.Bylko-Bauer, Barbara and Paul Farmer, Structural Violence, Poverty, and Social Suffering (Oxford University Press, 2016)

<http://www.oxfordhandbooks.com/view/10.1093/oxfordhb/9780199914050.001.0001/oxfordhb -9780199914050-e-4>

154.Byrnes, Andrew, Bills of Rights in Australia: History, Politics and Law (University of New South Wales Press, 2009) <http://www.amazon.com/Bills-Rights-Australia-HistoryPolitics/dp/1921410175/ref=sr_1_2?s=books\&ie=UTF8\&qid=1362561405\&sr=1 $2 \&$ keywords $=$ Bills + of + rights + in + australia $>$

155.Camfoo, Tex, Gillian Cowlishaw and Nelly Camfoo, Love Against the Law: The Autobiographies of Tex and Nelly Camfoo (Aboriginal Studies Press, 2000)

156. Campbell, Penelope, Maryland in Africa: The Maryland State Colonization Society, 1831-1857 (University of Illinois Press, 1971)

157.Cane, Peter, Responsibility in Law and Morality (Hart, 2002)

158. Carbery, Graham, Towards Homosexual Equality in Australian Criminal Law - A Brief History (Australian Lesbian \& Gay Archives, Inc., 2nd ed, 2014) <http://www.alga.org.au/files/towardsequality2ed.pdf>

159. Carey, Hilary M, God's Empire: Religion and Colonialism in the British World, c.1801-1908 (Cambridge University Press, 2011)

160. Carle, Susan D (ed), Lawyers' Ethics and the Pursuit of Social Justice: A Critical Reader (New York University Press, 2005) <https://nyupress.org/books/9780814716403/>

161. Carothers, Thomas (ed), Promoting the Rule of Law Abroad: In Search of Knowledge (Carnegie Endowment for International Peace, 2006)

162.Carroll, Stuart (ed), Cultures of Violence: Interpersonal Violence in Historical Perspective (Palgrave Macmillan, 2007)

163. Carson, Bronwyn, Social Determinants of Indigenous Health (Allen and Unwin, 2007)

164.Carter, Jimmy, A Call to Action: Women, Religion, Violence, and Power (Simon \& Schuster, First Hardcover, 2014) 
165. Cary, Eve and Kathleen Willert Peratis, Woman and the Law (National Textbook Company, 1977)

166.Cassell, Christian Abayomi, Liberia: History of the First African Republic (Fountainhead Publishers, 1970) vol 1

167. Cassese, Antonio (ed), The Human Dimension of International Law: Selected Papers (Oxford University Press, 2008)

168. Castellano, Marlene Brant, Mike DeGagné and Aboriginal Healing Foundation (Canada), From Truth to Reconciliation Transforming the Legacy of Residential Schools (Aboriginal Healing Foundation, 2008) <http://london.cmha.ca/mental_health/from-truth-to-reconciliationtransforming-the-legacy-of-residential-schools/\#.UbsLVhamzI8>

169. Castellino, Joshua and Niamh Walsh (eds), International Law and Indigenous Peoples (M. Nijhoff Publishers, 2005)

170.Census and Identity: The Politics of Race, Ethnicity, and Language in National Census (Cambridge University Press, 2002)

171. Charlesworth, Hilary (ed), No Country Is an Island: Australia and International Law (University of New South Wales Press, 2006)

172. Charlesworth, Hilary and Gabrielle McKinnon, Australia's First Bill of Rights: The Australian Capital Territory's Human Rights Act (Federation Press, 2006)

173. Charlesworth, Hilary and Jean-Marc Coicaud (eds), Fault Lines of International Legitimacy (Cambridge University Press, 2010)

174. Charters, Claire and Rodolfo Stavenhagen (eds), Making the Declaration Work: The United Nations Declaration on the Rights of Indigenous Peoples (IWGIA; Distributors Transaction Publisher [and] Central Books, 2009) <http://www.internationalfunders.org/documents/MakingtheDeclarationWork.pdf >

175. Chesterman, John, Citizens Without Rights: Aborigines and Australian Citizenship (Cambridge University Press, 1997)

176. Chilisa, Bagele, Indigenous Research Methodologies (SAGE, 2012)

177. Chinweizu, Anatomy of Female Power: A Masculinist Dissection of Matriarchy (Pero Press, 1990)

178. Chinweizu, Ibekwe, The West and the Rest of Us: White Predators, Black Slavers, and the African Elite (NOK publishers, 1978)

179.Chitty, Clyde, Eugenics, Race and Intelligence in Education (Continuum, 2009)

180. Choo, Christine, Mission Girls: Aboriginal Women on Catholic Missions in the Kimberley, Western Australia, 1900-1950 (University of Western Australia Press, 2001)

181. Chua, Amy, World on Fire: How Exporting Free Market Democracy Breeds Ethnic Hatred and Global Instability (Anchor Books, 1st ed, 2004)

182. Chua, Amy, Day of Empire: How Hyperpowers Rise to Global Dominance-- and Why They Fall (Anchor Books, 2009)

183. Ciment, James, Another America: The Story of Liberia and the Former Slaves Who Ruled It (Hill and Wang, 1st ed, 2013)

184.Civil War and the Rule of Law: Security, Development, Human Rights (Lynne Rienner Publishers, 2008)

185.Clapham, Christopher S, Liberia and Sierra Leone: An Essay in Comparative Politics (Cambridge University Press, 2008)

186.Clark, Charles, A Summary of Colonial Law (Sweet, 1834)

187.Clark, Haley, Antonia Quadara and Australian Institute of Family Studies, Insights into Sexual Assault Perpetration: Giving Voice to Victim/Survivors' Knowledge (Australian Institute of Family Studies, 2010) <http://www.aifs.gov.au/institute/pubs/resreport18/index.html>

188. Clark, Ian D, Scars in the Landscape: A Register of Massacre Sites in Western Victoria, 18031859 (Australian Institute of Aboriginal and Torres Strait Islander Studies, 1995)

189.Clark, Jennifer, Aborigines \& Activism: Race \& the Coming of the Sixties to Australia (University of Western Australia Press, 2008)

190.Clarke, Marcus, For the Term of His Natural Life (Nonsuch, 2005)

191.Clegg, Claude Andrew, The Price of Liberty: African Americans and the Making of Liberia (The University of North Carolina Press, 2004)

192.Clements, Nicholas, The Black War: Fear, Sex and Resistance in Tasmania (University of Queensland Press, 2014)

193.Cling, B.J (ed), Sexualized Violence against Women and Children: A Psychology and Law Perspective (Guilford Press, 2004)

194.Clower, Robert W, Growth Without Development: An Economic Survey of Liberia (Northeastern University Press, 1966)

195.Coates, Kenneth, A Global History of Indigenous Peoples: Struggle and Survival (Palgrave Macmillan, 2004) 
196.Colnoe, Amos Gianjay, Emergency Assistance To Self-Reliance Of Liberian Refugees In Ghana: Survival Strategies Of Liberian Refugees in Gomoa-Buduburam, Ghana (LAP Lambert Academic Publishing, 2012)

197. Commonwealth of Australia and Department of Families, Housing, Community Services and Indigenous Affairs, Footprints in Time: The Longitudinal Study of Indigenous Children - Key Summary Report From Wave 1. (Department of Families, Housing, Community Services and Indigenous Affairs, 2009)

198. Commonwealth of Australia and Department of Families, Housing, Community Services and Indigenous Affairs, Footprints in Time: The Longitudinal Study of Indigenous Children: Key Summary Report From Wave 2. (Department of Families, Housing, Community Services and Indigenous Affairs, 2011)

199. Commonwealth of Australia and Department of Families, Housing, Community Services and Indigenous Affairs, Footprints in Time: The Longitudinal Study of Indigenous Children - Key Summary Report From Wave 3. (Department of Families, Housing, Community Services and Indigenous Affairs, 2012)

<http://fahcsia.gov.au/sites/default/files/documents/07_2012/fachsia_wave_3_accessible02_pdf. pdf>

200.Commonwealth of Australia and Department of Families, Housing, Community Services and Indigenous Affairs, Footprints in Time: The Longitudinal Study of Indigenous Children - Report From Wave 4. (Department of Families, Housing, Community Services and Indigenous Affairs, 2013)

201. Commonwealth of Australia, Australia's Constitution Paper Edition: With Overview and Notes by the Australian Government Solicitor (Parliamentary Education Office and the Australian Government Solicitor, 10th ed, 2014)

202.Connell, Raewyn W, Masculinities (University of California Press, 2nd ed, 2005)

203.Cook, Catriona, Tristan S Taylor and Geoff Pryor, Laying Down the Law (LexisNexis Butterworths, 2012)

204.Cook, Rebecca, Reproductive Health and Human Rights: Integrating Medicine, Ethics, and Law (Clarendon Press, 2003)

205. Cooper, Helene, The House at Sugar Beach: In Search of a Lost African Childhood (Simon and Schuster, 2008)

206.Corbetta, Piergiorgio, Social Research: Theory, Methods and Techniques (SAGE, 2003)

207. Cornell, Drucilla, Michel Rosenfeld and David Gray Carlson, Deconstruction and the Possibility of Justice (Taylor and Francis, 2016) $<$ http://public.eblib.com/choice/PublicFullRecord.aspx?p=4540813>

208. Cory, Hans and MM Hartnoll, Customary Law of the Haya Tribe, Tanganyika Territory (F. Cass, 1971)

209. Costa, Pietro and Danilo Zolo, The Rule of Law History, Theory and Criticism (Springer Netherlands, 2007)

210. Coumarelos, Christine et al, Legal Australia-Wide Survey Legal Need in Australia (Law and Justice Foundation of New South Wales, 2012)

211. Craven, Rhonda, Anthony Dillon and Nigel Parbury, In Black and White: Australians All at the Crossroads (Connor Court, 2013)

212.Crawford, James, Australian Courts of Law (Oxford University Press, 4th ed, 2004)

213.Creating Australia: Changing Australian History (Allen \& Unwin, 1997)

214.Creese, Gillian and Wendy Frisby, Feminist Community Research: Case Studies and Methodologies (University of British Columbia Press, 2012)

<http://www.ubcpress.ca/search/title_book.asp?BookID=299173502>

215.Crenshaw, Kimberlé, Critical Race Theory: The Key Writings That Formed the Movement (New Press, 1995)

216. Creswell, John W and Vicki L Plano Clark, Designing and Conducting Mixed Methods Research (SAGE Publications, 2nd ed, 2011)

217. Creswell, John W, Qualitative Inquiry and Research Design: Choosing Among Five Approaches (SAGE Publications, 3rd ed, 2013)

218. Critical Criminology: Issues, Debates, Challenges (Willan Pub, 2002)

219. Critical Interventions in the Ethics of Healthcare: Challenging the Principle of Autonomy in Bioethics (Ashgate, 2009)

220. Cryer, Robert et al, An Introduction to International Criminal Law and Procedure (Cambridge University Press, 2nd ed, 2010)

221.Cunneen, Chris, Indigenous People and the Law in Australia (Butterworths, 1995)

222. Curthoys, Ann, Freedom Ride a Freedom Rider Remembers (Allen and Unwin, 2003)

223. Curthoys, Ann, Rights and Redemption: History, Law and Indigenous People (University of New South Wales Press, 2008) 
224.Curtin, Deane (ed), Institutional Violence (Rodopi, 1999)

225.Damousi, Joy, Depraved and Disorderly: Female Convicts, Sexuality and Gender in Colonial Australia (Cambridge University Press, 1997)

226.Dampier, William, A New Voyage Round the World (Oxford University Press, 4th ed, 1699) vol 1

227.Dampier, William, Dampier's Voyages: Consisting of a New Voyage Round the World (E. Grant Richards, 1906)

228.Davidson, Basil, A History of West Africa, 1000-1800 (The Growth of African Civilization) (Longman, 1977)

229.Davidson, Basil, The African Slave Trade (Little, Brown, A revised and expanded, 1980)

230.Davidson, Basil, The Black Man's Burden: Africa and the Curse of the Nation-State (Times Books, 1992)

231.Davies, Margaret Jane, Asking the Law Question (Thomson Reuters, 3rd ed, 2008)

232.Davis, Angela Y, Women, Race and Class (Vintage Books, 1983)

233.Davis, Angela Y, Women, Culture and Politics (Vintage Books, 1st ed, 1990)

234.Davis, Angela Y, Are Prisons Obsolete? (Seven Stories Press, 2003)

235.Davison, Graeme, The Use and Abuse of Australian History (Allen and Unwin, 2000) $<$ http://www.amazon.com/Use-Abuse-AustralianHistory/dp/1864487208/ref=sr_1_1?s=books\&ie=UTF8\&qid=1362561323\&sr=1 $1 \&$ keywords=the+use+and+abuse+of+australian+history $>$

236. Day, Alan Edwin, Historical Dictionary of the Discovery and Exploration of Australia (Scarecrow Press, 2003)

237.Day, Andrew, Martin N Nakata and Kevin Howells (eds), Anger and Indigenous Men: Understanding and Responding to Violent Behaviour (Federation Press, 2008)

238.De Vaus, David A, Surveys in Social Research (Routledge, 5th ed, 2002)

239.De Vaus, David A, Surveys in Social Research (Routledge, 6th ed, 2014)

240.Dei, George J Sefa and Gurpreet Singh Johal, Critical Issues in Anti-Racist Research Methodologies (P. Lang, 2005)

241.Delgado, Richard and Jean Stefancic, Critical Race Theory: The Cutting Edge (Temple University Press, 2nd ed, 2000)

242.Delgado, Richard, Critical Race Theory: An Introduction (New York University Press, 2nd ed, 2012)

243.Deller Ross, Susan, Women's Human Rights: The International and Comparative Law Casebook. (University of Pennsylvania, 2009) <http://www.upenn.edu/pennpress/book/14460.html>

244.Dennis, Benjamin G, The Gbandes, a People of the Liberian Hinterland (Nelson-Hall, 1972)

245.Dennis, Benjamin G, Slaves to Racism: Racism's Impact on National Character in America to Liberia (Algora Publications, 2008)

246.Department of Peace-keeping Operations, United Nations Rule of Law Indicators: Implementation Guide and Project Tools. (United Nations, 2011) $<$ http://search.ebscohost.com/login.aspx?direct=true \&scope=site $\& d b=$ lebk $\& d b=$ nlabk $\& A N=38$ 7576>

247.Derrington, Patricia R, The Serpent of Good and Evil: A Reconciliation in the Life and Art of Miriam-Rose Ungunmerr-Baumann (Hyland House, 2000)

248.Development, Women, and War: Feminist Perspectives (Oxfam, 2004)

249.Diab, Robert, Guantánamo North: Terrorism and the Administration of Justice in Canada (Fernwood Pub, 2008)

250.Dicey, Albert Venn, Introduction to the Study of the Law of the Constitution (London, 1889)

251.Dickson-Gilmore, EJ and Carol La Prairie, Will the Circle Be Unbroken?: Aboriginal Communities, Restorative Justice, and the Challenges of Conflict and Change (University of Toronto Press, 2005)

252.Dignan, James, Understanding Victims and Restorative Justice (McGraw-Hill Education, 2004)

253.Dirie, Waris and Cathleen Miller, Desert Flower: The Extraordinary Journey of a Desert Nomad (HarperCollins, 2011)

254.Dixon, Robert MW, Searching for Aboriginal Languages: Memoirs of a Field Worker (University of Chicago Press, 2011)

255.Docherty, James C, Historical Dictionary of Australia (Scarecrow Press, 2007) $<$ http://search.ebscohost.com/login.aspx?direct=true \&scope $=$ site $\& d b=$ lebk $\& \mathrm{db}=$ nlabk $\& A N=23$ $8232>$

256.Dodson, Patrick L et al, Recognising Aboriginal and Torres Strait Islander Peoples in the Constitution: Report of the Expert Panel. (Dept. of Families, Housing, Community Services \& Indigenous Affairs, 2012)

257.Dolo, Emmanuel, Ethnic Tensions in Liberia's National Identity Crisis: Problems and Possibilities (Africana Homestead Legacy Publishers, 2007) 
258. Douglas, Heather, Indigenous Crime and Settler Law: White Sovereignty After Empire (Palgrave Macmillan, 2012)

259.Douglas, Heather et al (Eds), The Australian Feminist Judgments Project Righting and ReWriting Law. (Hart Publishing, 2014)

260.Douglass, Frederick, Narrative of the Life of Frederick Douglass (Anti-Slavery Office, 1845)

261.Du Bois, WEB, Black Reconstruction: An Essay Toward a History of the Part Which Black Folk Played in the Attempt to Reconstruct Democracy in America, 1960-1880 (Harcourt Brace and Company, 1st ed, 1935)

262.Du Bois, WEB, The Education of Black People: Ten Critiques 1906-1960 (Monthly Review Press, 1973)

263.DuBois, Ellen Carol, Woman Suffrage and Women's Rights (New York University Press, 1998)

264.Dugard, John, Human Rights and the South African Legal Order (Princeton University Press, 2015) <https://doi.org/10.1515/9781400868124>

265.Dunleavy, Patrick, Authoring a PhD: How to Plan, Draft, Write and Finish a Doctoral Thesis or Dissertation (Palgrave Macmillan, 2003)

266.Dunn, D Elwood, The Foreign Policy of Liberia During the Tubman Era, 1944-1971 (Hutchinson Benham, 1979)

267.Dunn, D Elwood and Svend E Holsoe, Historical Dictionary of Liberia (Scarecrow Press, 1985)

268.Dunn, D Elwood, Liberia: A National Polity in Transition (Scarecrow Press, 1988)

269.Dunn, D Elwood, A History of the Episcopal Church in Liberia, 1821-1980 (American Theological Library Association and The Scarecrow Press, 1992)

270.Dunn, D Elwood, Liberia (CLIO Press, 1995)

271.Dunn, D Elwood, Amos Jones Beyan and Carl Patrick Burrowes, Historical Dictionary of Liberia (Historical Dictionaries of Africa) (Scarecrow Press, 2nd ed, 2000)

272.Dunn, D Elwood, Liberia and the United States During the Cold War: Limits of Reciprocity (Palgrave Macmillan, 1st ed, 2009)

273.Dunn, D Elwood (ed), The Annual Messages of the Presidents of Liberia 1848-2010: State of the Nation Addresses to the National Legislature - from Joseph Jenkins Roberts to Ellen Johnson Sirleaf (De Gruyter, 2011)

274.Dunn, D Elwood, National Symbols Review Project (Governance Commission of Liberia, 2014)

275.Duxbury, Neil, Random Justice: On Lotteries and Legal Decision-Making (Oxford University Press, 2002)

276.Duxbury, Neil, The Authority of Precedent: Two Problems (Faculty of Law, University of Toronto, 2005) <http://www.mcgill.ca/files/legal-theory-workshop/Neil-Duxbury-McGillpaper.pdf>

277.Duxbury, Neil, The Nature and Authority of Precedent (Cambridge University Press, 2008)

278. Dworkin, Ronald, Taking Rights Seriously (Harvard University Press, 1978)

279.Dworkin, Ronald, Law's Empire (Belknap Press, 1986)

280.Dworkin, Ronald, Justice in Robes. (Belknap Harvard, 2008)

281.Dworkin, Ronald, Justice for Hedgehogs (Belknap Press of Harvard University Press, 2011)

282. Dworkin, Ronald M and British Academy, Political Judges and the Rule of Law (British Academy, 1980) vol 23

283.Dworkin, Ronald M, Sovereign Virtue: The Theory and Practice of Equality (Harvard University Press, 2002)

284.Dyer, Colin L, The French Explorers and the Aboriginal Australians 1772-1839 (QUP, 2005)

285.Dyson, Sue and Michael Flood, Building Cultures of Respect and Non-Violence: A Review of Literature Concerning Adult Learning and Violence Prevention Programs with Men (VicHealth and Australian Football League, 2008)

286.Easteal, Patricia Weiser and Louise McOrmond-Plummer, Real Rape, Real Pain: Help for Women Sexually Assaulted by Male Partners (Hybrid, 2006)

287.Easterly, William, The White Man's Burden (Penguin Books, 2007)

288.Eckstein, Sue and King's College London. Centre of Medical Law and Ethics, Manual for Research Ethics Committees (Cambridge University Press, 6th ed, 2011)

289.Eddy, John J and John Raymond Nethercote (eds), From Colony to Coloniser: Studies in Australian Administrative History (Hale \& Iremonger in association with the Royal Australian Institute of Public Administration, 1987)

290.Edgar, Kimmett, Restorative Justice in Prisons: A Guide to Making It Happen (Waterside Press; North American distributors, International Specialised Book Services, 2006)

291.Edwards, Susan SM, Sex and Gender in the Legal Process (Blackstone Press, 1996)

292.Elias, T Olawale, The Nature of African Customary Law (Manchester University Press, 1956)

293.Ella-Duncan, Marcia, New South Wales Aboriginal Child Sexual Assault Taskforce (N.S.W.) and Attorney General's Department, Breaking the Silence: Creating the Future - Addressing Child Sexual Assault in Aboriginal Communities in NSW (EcoDesign ecoPrint, 2006) 
294.Ellingson, Terry Jay, The Myth of the Noble Savage (University of California Press, 2001) $<$ http://www.amazon.com/Myth-Noble-Savage-TerEllingson/dp/0520226100/ref=sr_1_1?s=books\&ie=UTF8\&qid=1362561585\&sr=1 $1 \&$ keywords $=$ the+myth+of+noble+savages $>$

295.Ellis, Stephen, The Mask of Anarchy: The Destruction of Liberia and the Religious Dimension of an African Civil War. (New York University Press, 2007)

296.Ellsbert, Mary and Lori Heise, Researching Violence Against Women: A Practical Guide for Researchers and Activists (World Health Organization, PATH, 2005)

297.Eltis, David, Coerced and Free Migration: Global Perspectives (Stanford University Press, 2002)

298.Emeagwali, Gloria and George J Sefa Dei, African Indigenous Knowledge and the Disciplines (2014) <http://dx.doi.org/10.1007/978-94-6209-770-4>

299.Empires of Religion (Palgrave Macmillan, 2008)

300.Encyclopedia of Race, Ethnicity, and Society (SAGE Publications, 2008)

301.Epstein, Cynthia Fuchs, Women in Law (University of Illinois Press, 2nd ed, 1993)

302.Equity Now, A Guide to Using the Protocol on the Rights of Women in Africa for Legal Action (Equity Now on behalf of the Solidarity for African Women's Rights Coalition, 2011) <http://www.soawr.org/resources/Manual_on_Protocol_on_Women_Rights_in_Africa.pdf>

303.Eriksen, Thomas Hylland, A History of Anthropology (Pluto Press, 2001) $<$ http://www.amazon.com/History-Anthropology-CultureSociety/dp/074531385X/ref=sr_1_1?s=books\&ie=UTF8\&qid=1362529841\&sr=1 $1 \&$ keywords=history+of+anthropology>

304.Ethnic Politics in Australia (G. Allen and Unwin, 1984)

305.Evans, Gareth J, The Responsibility to Protect: Ending Mass Atrocity Crimes Once and For All (Brookings Institution Press, 2008)

306.Evans, Ilsa, Battle-Scars: Long-Term Effects of Prior Domestic Violence (Centre for Women's Studies and Gender Research, Monash University, 2007)

307.Evans, Julie (ed), Equal Subjects, Unequal Rights: Indigenous Peoples in British Settler Colonies, 1830-1910 (Manchester University Press, 2003)

308.Fallers, Lloyd A, Law Without Precedent: Legal Ideas in Action in the Courts of Colonial Busoga (University of Chicago Press, 1969)

309.Fanon, Frantz, Toward the African Revolution: Political Essays (Grove Press, Grove Press, 1994)

310.Fanon, Frantz, Haakon Chevalier and Adolfo Gilly, A Dying Colonialism (Grove Press, 1994)

311.Fanon, Frantz, The Wretched of the Earth (Grove Press, 2004)

312.Fanon, Frantz, Black Skin, White Masks (Pluto Press, 2008)

313.Fawcett, Barbara, Violence and Gender Relations: Theories and Interventions (Sage, 1996)

314.Feagin, Joe, Systemic Racism a Theory of Oppression (Taylor and Francis, 2013) <http://www.123library.org/book_details/?id=109951>

315.Fédération Internationale de Gynécologie et d'Obstétrique, Ethical Issues in Obstetrics and Gynecology (FIGO, 2012) <http://www.figo.org/about/guidelines>

316.Feminism and Antiracism: International Struggles for Justice (New York University Press, 2001)

317.Feminism and Masculinities (Oxford University Press, 2004)

318.Feminisms in Development: Contradictions, Contestations, and Challenges (Zed Books, 2006)

319.Feminist Perspectives on Contemporary International Law: Between Resistance and Compliance? (Hart Pub, 2011)

320.Fenrich, Jeanmarie, Paolo Galizza and Tracey E Higgins (eds), The Future of African Customary Law (2013)

321.Fernandez, Marilyn, Restorative Justice for Domestic Violence Victims: An Integrated Approach to Their Hunger for Healing (Lexington Books, 2011)

322.Fighting for Girls: New Perspectives on Gender and Violence (State University of New York Press, 2010)

323.Fletcher, Christine, Aboriginal Politics: Intergovernmental Relations (Melbourne University Press; International Specialized Book Services [distributor], 1992)

324.Fletcher, Christine, Aboriginal Self Determination in Australia (Aboriginal Studies Press, 1994)

325.Fletcher, Holly Berkley, Gender and the American Temperance Movement of the Nineteenth Century (Routledge, 2008)

326.Flood, Josephine, The Original Australians: Story of the Aboriginal People (Allen and Unwin, 2006)

327.Flood, Robert L and Norma Romm RA, Critical Systems Thinking Current Research and Practice (Plenum Press, 1996)

$<$ http://search.ebscohost.com/login.aspx?direct=true \&scope=site \&db=nlebk\&db=nlabk\&AN=39 391> 
328.Foreign and Commonwealth Office, International Protocol on the Documentation and Investigation of Sexual Violence in Conflict (Foreign and Commonwealth Office, 2014)

329.Forret, Jeff, Slave Against Slave: Plantation Violence in the Old South (Louisiana State University Press, 2015)

330.Foster, Stephen Glynn, Bain Attwood and National Museum of Australia (eds), Frontier Conflict: The Australian Experience (National Museum of Australia, 2003)

331.Foucault, Michel, Madness and Civilization: A History of Insanity in the Age of Reason (Vintage Books, 1988)

332.Foucault, Michel, Discipline and Punish: The Birth of the Prison (Vintage Books, 2nd ed, 1995)

333.Foucault, Michel, The Birth of the Clinic: An Archaeology of Medical Perception (Routledge, 2003)

334.Fraenkel, Merran, Tribe and Class in Monrovia (Oxford University Press, 1966)

335.Frankenberg, Ruth, White Women, Race Matters: The Social Construction of Whiteness (University of Minnesota Press, 1993)

336.Frazier, E Franklin, Black Bourgeoisie: The Rise of a New Middle Class

337.Fredman, Sandra, Women and the Law (Clarendon Press; Oxford University Press, 1997)

338. Freire, Paulo, Pedagogy of the Oppressed (Continuum International, 30th Anniversary, 2005)

339. French, Howard W, A Continent for the Taking the Tragedy and Hope of Africa (Recording for the Blind \& Dyslexic, 2004)

340.Fuller, Lon L, The Morality of Law (Yale University Press, 1969)

341.Fulu, Emma et al, Why Do Some Men Use Violence Against Women and How Can We Prevent It? Quantitative Findings from the UN Multi-Country Study on Men and Violence in Asia and the Pacific (Partners for Prevention, 2013) < http://www.partners4prevention.org/aboutprevention/research/men-and-violence-study>

342.Furphy, Samuel, Edward M. Curr and the Tide of History (ANU E Press, 2013)

343. Galton, Sir Francis, Essays in Eugenics (The Eugenics Education Society, 1909) <http://galton.org/books/essays-on-eugenics/galton-1909-essays-eugenics-1up.pdf>

344.Gammage, Bill, The Biggest Estate on Earth: How Aborigines Made Australia (Allen and Unwin, 2011)

345.Garvey, Marcus, Selected Writings and Speeches of Marcus Garvey (Dover Publications, 2004)

346.Gates Jr., Henry Louis, 100 Amazing Facts About the Negro (Pantheon Books, 2017)

347. Gaventa, John, Power and Powerlessness: Quiescence and Rebellion in an Appalachian Valley (University of Illinois Press, 1982)

348.Gbardy, Jerry, Painful Journey: A Story of Escape and Survival (Friesen Press, 2014)

349.Gender and Human Rights (Oxford University Press, 2004) vol 12/2 $<$ http://www.amazon.com/Gender-Human-Rights-Karen-

Knop/dp/0199260915/ref=sr_1_4?s=books\&ie=UTF8\&qid=1361921359\&sr=1 4\&keywords=the+hidden+gender+of+law>

350.Gender and Justice: New Concepts and Approaches (Willan, 2006)

351.Gender Identity, Equity, and Violence: Multidisciplinary Perspectives Through Service Learning (Stylus Pub, 1st ed, 2007)

352.Gender in Transitional Justice (Palgrave Macmillan, 2011)

353.Gender Relations in Australia: Domination and Negotiation (Harcourt Brace Jovanovich, 1992)

354.Gender's Place: Feminist Anthropologies of Latin America (Palgrave Macmillan, 1st ed, 2002) <http://www.amazon.com/Genders-Place-Feminist-Anthropologies-

America/dp/1403960402/ref=sr_1_9?s=books\&ie=UTF8\&qid=1361923087\&sr=1 9\&keywords=the+hidden+gender+of+law>

355.Gershoni, Yekutiel and Makhon le-meḥ̣ar 'al shem Heri S. Truman, Black Colonialism: The Americo-Liberian Scramble for the Hinterland (Westview Press, 1985)

356. Ghiglieri, Michael Patrick, The Dark Side of Man: Tracing the Origins of Male Violence (Perseus Books, 2000)

357.Gilbert, Kevin, Living Black: Blacks Talk to Kevin Gilbert. (Penguin Books, 1978)

358. Gilbert, Kevin, Aboriginal Sovereignty: Justice, the Law and Land (Burrambinga Books, 3rd ed, 1993)

359. Gilbert, Kevin, Because a White Man'll Never Do It (HarperCollins, 2013)

360.Gillham, Bill, A Case Study Research Methods (Continuum Research Methods) (Continuum International Publishing Group Ltd, 2000)

<http://www.bookdepository.com/a/9780826447968? redirected=true\&gclid=CPb6seItrYCFadMpgodHH4Asw>

361.Gillham, Bill, The Research Interview (Continuum, 2000) <http://public.eblib.com/EBLPublic/PublicView.do?ptiID=436490>

362. Gillham, Nicholas W, A Life of Sir Francis Galton: From African Exploration to the Birth of Eugenics (Oxford University Press, 2001) 
363.Gilligan, Carol, In a Different Voice: Psychological Theory and Women's Development (Harvard University Press, 1982)

364.Gilligan, James, Violence: Reflections on a National Epidemic (Vintage Books, 1997)

365.Girshick, Lori B, Woman-to-Woman Sexual Violence: Does She Call It Rape? (Northeastern University Press, 2002) <http://www.amazon.com/Woman---Woman-Sexual-ViolenceNortheastern/dp/1555535275/ref=sr_1_2?s=books\&ie=UTF8\&qid=1361921359\&sr=1 $2 \&$ keywords=the+hidden+gender+of + law $>$

366. Glaser, Barney G and Anselm L Strauss, The Discovery of Grounded Theory: Strategies for Qualitative Research (Aldine Transaction, 1967)

367.Global Masculinities and Manhood (University of Illinois Press, 2011)

368. Globalization and the Margins (Palgrave Macmillan, 2002)

369. Gluckman, Max, Anthony Nicolas Allott and International African Seminar (eds), Ideas and Procedures in African Customary Law: Studies Presented and Discussed at the Eighth International African Seminar at the Haile Sellassie I. University, Addis Ababa, January 1966 (Oxford University Press, 1969)

370.Goldberg, Carole E, Kevin Washburn and Philip P Frickey, Indian Law Stories (Foundation Press/Thomson Reuters, 2011)

371.Golding, Martin P and William A Edmundson (eds), The Blackwell Guide to the Philosophy of Law and Legal Theory (Blackwell Pub, 2005)

372.Goldshcheld, Julia (ed), Gender and Equality Law (Ashgate, 2013)

373. Goodman, Lenn Evan and Robert B Talisse, Aristotle's Politics Today (State University of New York Press, 2008)

374.Goodman, Richard A et al, Law in Public Health Practice (Oxford University Press, 2003) <http://www.amazon.com/Public-Health-Practice-Richard-Goodman/dp/019530148X\#sipbody>

375.Gottfried, Heidi (ed), Feminism and Social Change: Bridging Theory and Practice (University of Illinois Press, 1996)

376.Government of Australia - Community Affairs References Committee, Commonwealth Contribution to Former Forced Adoption Policies and Practices (Commonwealth of Australia, 2012)

377.Gqola, Pumla Dineo, What Is Slavery To Me?: Postcolonial/Slave Memory in Post-Apartheid South Africa (Wits University Press, 2010)

378.Gqola, Pumla Dineo, Rape: A South African Nightmare (MF Books Joburg, 2015)

379. Gramsci, Antonio, Selections from the Prison Notebooks of Antonio Gramsci (International Publishers, 1971)

380.Grassby, Al J and Marji Hill, Six Australian Battlefields (Allen and Unwin, 1998)

381.Gray, David, Doing Research in the Real World (SAGE, 2nd ed, 2009)

382. Graycar, Regina, The Hidden Gender of Law (Federation Press, 2nd ed, 2002)

383.Grbich, Carol, Qualitative Research in Health: An Introduction (Sage, 1999)

384.Grbich, Carol, New Approaches in Social Research (Sage Pub, 2004)

385. Green, David G et al, Institutional Racism and the Police: Fact or Fiction? (Institute for the Study of Civil Society, 2000)

386. Green, Edward C, Indigenous Theories of Contagious Disease (AltaMira Press, 1999)

387. Green, Joyce A, Making Space for Indigenous Feminism (Fernwood Pub.; Zed Books; Distributed in the USA exclusively by Palgrave Macmillan, 2007)

388. Green, Marjorie E et al, A Girl's Right to Learn Without Fear: Working to End Gender-Based Violence (Plan International, 2013)

389. Green, Neville, The Forrest River Massacres (Focus Education Services, 2nd ed, 2008)

390.Greene, Jennifer C, Mixed Methods in Social Inquiry (Jossey-Bass, 1st ed, 2007)

391. Grenfell, Laura, Promoting the Rule of Law in Post-Conflict States (Cambridge University Press, 2013)

392.Grey, Jeffrey, A Military History of Australia (Cambridge University Press, 2008)

393. Griffiths, Max, Aboriginal Affairs: A Short History (Kangaroo Press, 1995)

394. Grimshaw, Patricia, Katie Holmes and Marilyn Lake (eds), Women's Rights and Human Rights: International Historical Perspectives (Palgrave MacMillan, 2001)

395.Guannu, Joseph Saye, Liberian History Before 1857: A Reference for Elementary Pupils (Exposition Press, 1st ed, 1977)

396. Gyrus, War and the Noble Savage: A Critical Inquiry into Recent Accounts of Violence Amongst Uncivilized Peoples (Dreamflesh Press, 2009) <http://www.amazon.com/War-NobleSavage-Gyrus/dp/0955419611/ref=sr_1_1?s=books\&ie=UTF8\&qid=1362561478\&sr=1$1 \&$ keywords=war+and+noble+savage $>$

397.Hacker, Karen, Community-Based Participatory Research (SAGE, 2013)

398.Haebich, Anna and Doreen Mellor, Many Voices: Reflections on Experiences of Indigenous Child Separation (National Library of Australia, 2002) 
399.Hafner, Gerhard and Isabelle Buffard, International Law Between Universalism and Fragmentation: Festschrift in Honour of Gerhard Hafner (Martinus Nijhoff Publishers, 2008)

400.Hagay-Frey, Alona, Sex and Gender Crimes in the New International Law: Past, Present, Future (Martinus Nijhoff Publishers, 2011) vol 75

401.Hallward-Driemeier, Mary and Tazeen Hasan, Empowering Women: Legal Rights and Economic Opportunities in Africa (International Bank of Reconstruction and Development / The World Bank, 2013)

402.Hamel, John and Tonia L Nicholls, Family Interventions in Domestic Violence a Handbook of Gender-Inclusive Theory and Treatment (Springer Pub., 2007) $<$ http://site.ebrary.com/id/10265240>

403.Hamon, Bruce V, Alastair Greig and Sue Feary, They Came to Murramarang: A History of Murramarang, Kioloa and Bawley Point (ANU E Press, 2015)

404.Handbook of Restorative Justice (Willan, 2007)

405.Handbook of Restorative Justice: A Global Perspective (Routledge, 2006)

406.Hanmer, Jalna, Women, Violence, and Social Control (Hants Macmillan Press, 1989)

407.Harper, Erica (ed), Working With Customary Justice Systems: Post-Conflict and Fragile States (International Development Law Organization, 2011)

408. Harris, Stewart, It's Coming Yet--: An Aboriginal Treaty Within Australia Between Australians (Aboriginal Treaty Committee, 1979)

409.Harrison, Jane, Stolen (Currency Press in association with Playbox Theatre, Revised, 2000)

410.Harris-Short, Sonia, Aboriginal Child Welfare, Self-Government and the Rights of Indigenous Children: Protecting the Vulnerable Under International Law (Ashgate Publishing Ltd, 2012)

411.Hart-Fuller Colloquium, The Hart-Fuller Debate in the Twenty-First Century (Hart Pub, 2010)

412. Hatchard, John, Individual Freedoms \& State Security in the African Context: The Case of Zimbabwe (Baobab Books; Ohio University Press; James Curry, 1993)

413. Hawkings, David T, Bound for Australia: A Guide to the Records of Transported Convicts and Early Settlers (History Press, 2012)

414.Haywood, Chris and Mairtin Mac an Ghaill, Men and Masculinities: Theory, Research, and Social Practice (Open University, 2003)

415.Hazlehurst, Kayleen M (ed), Ivory Scales: Black Australia and the Law (UNSW Press, 1987)

416.Healy, Chris, Forgetting Aborigines (University of New South Wales Press, 2008)

417.Heckman, James J, Robert L Nelson and Lee Cabatingan (eds), Global Perspectives on the Rule of Law (Routledge, 2010)

418.Hendrix, Burke A, Ownership, Authority, and Self-Determination (Pennsylvania State University Press, 2008)

419.Hernández Castillo, Rosalva Aída, Multiple Injustices: Indigenous Women, Law, and Political Struggle in Latin America (The University of Arizona Press, 2016)

420.Hernlund, Ylva and Bettina Shell-Duncan (eds), Transcultural Bodies: Female Genital Cutting in Global Context (Rutgers University Press, 2007)

421. Heterosexual Masculinities: Contemporary Perspectives from Psychoanalytic Gender Theory (Routledge, 2009)

422. Heyns, Christof H and Magnus Killander, Compendium of Key Human Rights Documents of the African Union (Pretoria University Law Press, 4th ed, 2006)

423.Hill Collins, Patricia, Black Feminist Thought: Knowledge, Consciousness, and the Politics of Empowerment (Routledge, 2nd ed, 2009)

424.Hill, Lawrence, The Book of Negroes (HarperCollins, 2007)

425.Hinkson, Melinda and Jeremy Beckett (eds), An Appreciation of Difference: WEH Stanner and Aboriginal Australia (Aboriginal Studies Press, 2008)

426.Hinzen, Eckhard and Robert Kappel, Dependence, Underdevelopment, and Persistent Conflict: On the Political Economy of Liberia (Übersee-Museum, 1980) vol 11

427.Hirst, John Bradley, Australia's Democracy: A Short History (Allen and Unwin, 2002)

428. Hlophe, Stephen S, Class, Ethnicity, and Politics in Liberia: A Class Analysis of Power Struggles in the Tubman and Tolbert Administrations, from 1944-1975 (University Press of America, 1979)

429.Hoffman, Frederick Ludwig, Race Traits and Tendencies of the American Negro (MacMillan, 1896)

430. Hokowhitu, Brendan (ed), Indigenous Identity and Resistance: Researching the Diversity of Knowledge (Otago University Press, 2010)

431.Holder, Robin, We Don't Shoot Our Wounded ...: Aboriginal \& Torres Strait Islander Victims of Family Violence, Access to Justice and Access to Services in the ACT (ACT Victims of Crime Coordinator, 2009)

432.hooks, bell, Ain't I A Woman: Black Women and Feminism (South End Press, 1981)

433.hooks, bell, Feminist Theory From Margin to Centre (South End Press, 1984) 
434.hooks, bell, Yearning: Race, Gender, and Cultural Politics (South End Press, 1990)

435.hooks, bell, Black Looks: Race and Representation (Turnaround, 1992)

436.hooks, bell, Teaching to Transgress: Education as the Practice of Freedom (Routledge, 1994)

437.hooks, bell, Feminism Is for Everybody: Passionate Politics (South End Press, 2000)

438.hooks, bell, Feminist Theory: From Margin to Centre (South End Press, 2nd ed, 2000) vol 5

439.hooks, bell, Where We Stand: Class Matters (Routledge, 2000)

440.hooks, bell, We Real Cool: Black Men and Masculinity (Routledge, 2004)

441.Hopkins, Belinda, Just Care: Restorative Justice Approaches to Working with Children in Public Care (Jessica Kingsley Publishers, 2009)

442.Horne, Gerald, The Deepest South: The United States, Brazil, and the African Slave Trade (New York University Press, 2007)

443. Horne, Gerald, The White Pacific: U.S. Imperialism and Black Slavery in the South Seas After the Civil War (University of Hawai'i Press, 2007)

444.Horner, Jack, Seeking Racial Justice: An Insider's Memoir of the Movement for Aboriginal Advancement, 1938-1978 (Aboriginal Studies Press, 2004)

445.Horsfall, Jan, The Presence of the Past: Male Violence in the Family (Allen and Unwin, 1991)

446. Howe, Adrian, Punish and Critique: Towards a Feminist Analysis of Penality (Routledge, 1994) $<$ http://books.google.com.au/books/about/Punish_and_Critique.html?id=arsOAAAAQAAJ\&red ir_esc $=y>$

447.Huberich, Charles Henry, The Political and Legislative History of Liberia (The Lawbook Exchange, 2010) vol 1 and 2

448.Hudson-Weems, Clenora, Africana Womanism: Reclaiming Ourselves (Bedford Publishers, 2004)

449.Huffman, Alan, Mississippi in Africa: [The Daga of the Slaves of Prospect Hill Plantation and Their Legacy in Liberia Today] (University Press of Mississippi, 2010)

450.Hughes, Robert, The Fatal Shore: A History of the Transportation of Convicts to Australia, 1887-1868 (Vintage Books, 1st ed, 1988)

451.Human Rights of Women: National and International Perspectives (University of Pennsylvania Press, 1994)

452. Human Rights, Peace and Justice in Africa: A Reader (Pretoria University Law Press, 2006)

453.Hunter, Rosemary $C$ and Sharon Cowan, Choice and Consent Feminist Engagements with Law and Subjectivity. (Routledge-Cavendish, 2007)

454.Hunter, Rosemary C, Domestic Violence Law Reform and Women's Experience in Court: The Implementation of Feminist Reforms in Civil Proceedings (Cambria Press, 2008)

455.Hunter, Rosemary C et al, Feminist Judgments: From Theory to Practice (Hart, 2010)

456. Hunters and Gatherers in the Modern World: Conflict, Resistance, and Self-Determination (Berghahn Books, 2000)

457.Hutchinson, Allan C and Patrick Monahan, The Rule of Law: Ideal or Ideology (Carswell, 1987)

458.Hutchinson, Allan C, Evolution and the Common Law (Cambridge University Press, 2005)

459.Ignatieff, Michael and Amy Gutmann, Human Rights as Politics and Idolatry (Princeton University Press, 2001)

460.INCITE! (Ed), Colour of Violence: The INCITE! Anthology (Duke University Press, 2016)

461.Indigenous Cosmopolitans: Transnational and Transcultural Indigeneity in the Twenty-First Century (Peter Lang, 2010)

462. Indigenous Legal Issues: Commentary and Materials (Thomson Reuters (Professional) Australia, 4th ed, 2009) <http://www.thomsonreuters.com.au/indigenous-legal-issues-commentarymaterials-4th-edition/productdetail/96840>

463. International Guide to Literature on Masculinity: A Bibliography (Men's Studies Press, 2008)

464.International Human Rights in the 21st Century: Protecting the Rights of Groups (Rowman \& Littlefield Publishers, 2003)

465.International Law: Modern Feminist Approaches (Hart, 2005)

466.International Work Group for Indigenous Affairs and African Commission on Human and Peoples' Rights, Indigenous Peoples in Africa: The Forgotten Peoples? The African Commission's Work on Indigenous Peoples in Africa (African Commission on Human and Peoples' Rights; IWGIA, 2006)

467.Intervention Research: Developing Social Programs (Oxford University Press, 2009)

468.Isis-WICCE (Organization), Liberia and West Africa Network for Peacebuilding, A Situation Analysis of the Women Survivors of the 1989-2003 Armed Conflict in Liberia (Isis-WICCE, 2008)

469.Islamic Masculinities (Zed Books, 2006)

470.Isser, Deborah (ed), Customary Justice and the Rule of Law in War-Torn Societies (United States Institute of Peace Press, 2011) 
471.Jaccard, James, Theory Construction and Model-Building Skills: A Practical Guide for Social Scientists (Guilford Press, 2010)

472.Jacobs, Margaret D, White Mother to a Dark Race: Settler Colonialism, Maternalism, and the Removal of Indigenous Children in the American West and Australia, 1880-1940 (University of Nebraska Press, 2009)

473.Jallow, Baba Galleh (ed), Leadership in Postcolonial Africa: Trends Transformed by Independence (Palgrave Macmillan, 2014)

474.James A. A. Pierre Judicial Institute, Judiciary Law: Compilation of Liberian Laws (10 May 1972) (Government of Liberia, 2011) vol I <http://www.liberlii.org/cgi-bin/download.cgi/cgibin/download.cgi/download/lr/other/LRLRes/2011/5.pdf >

475.James, CLR, The Black Jacobins: Toussaint L'Ouverture and the San Domingo Revolution (Vintage Books, 2nd revised, 1989)

476.Jarrett, Stephanie, Liberating Aboriginal People From Violence (Connor Court Publishing, 2013)

477.Jennings, Ivor, The Law and the Constitution (Hodder and Stoughton, 1974)

478.Joachim, Jutta M, Agenda Setting, the UN, and NGOs: Gender Violence and Reproductive Rights (Georgetown University Press, 2007)

479.Johnson, Charles, Middle Passage (Simon \& Schuster, 1998)

480.Johnson-Sirleaf, Ellen, This Child Will Be Great: Memoir of a Remarkable Life by Africa's First Woman President (Harper, 2009)

481.Johnston, Elliott, Martin G Hinton and Daryle Rigney, Indigenous Australians and the Law (Cavendish Pub. (Australia) Pty Limited, 1997)

482.Johnston, Elliott, Daryle Rigney and Martin G Hinton (eds), Indigenous Australians and the Law (Routledge-Cavendish, 2nd ed, 2008)

483.Johnston, Harry, Liberia (Dodd, Mead and Co., 1906) vol 1

484.Johnston, Harry H, A History of the Colonization of Africa by Alien Races (Cambridge, University Press, 1930)

485.Johnstone, Gerry, Restorative Justice: Ideas, Values, Debates (Routledge, 2nd ed, 2011)

486.Jones, E Sumo, Courts and Trials in the Republic of Liberia, as Related to Law Enforcement and the Treatment of Criminals (Carlton Press, 1979)

487.Jones, Nicholas A, The Courts of Genocide: Politics and the Rule of Law in Rwanda and Arusha (Routledge, 2010)

488.Judicial Commission of NSW, Equality Before the Law Bench Book: Bench Book (Judicial Commission of New South Wales, 2006)

489.Judiciary Branch of Liberia, Judiciary Law - Title 17 - Liberian Code of Laws (Revised) (Ministry of Commerce and, 1972) <http://www.moci.gov.lr/doc/Judiciary\%20Law\%201.pdf>

490.Just Methods: An Interdisciplinary Feminist Reader (Paradigm Publishers, 2008)

491.Kaberry, Phyllis Mary, Aboriginal Woman: Sacred and Profane (Routledge, 2004)

492.Kälin, Walter, The Law of International Human Rights Protection (Oxford University Press, 2009)

493.Kamler, Barbara, Relocating the Personal: A Critical Writing Pedagogy (State University of New York Press, 2001)

494.Kamler, Barbara, Helping Doctoral Students Write: Pedagogies for Supervision (Routledge, 2006)

495.Kant, Immanuel, Anthropology, History, and Education (Cambridge University Press, 2007)

496.Karnga, Abayomi, History of Liberia (D. H. Tyte, 1926)

497. Kaspiew, Rae et al, Evaluation of the 2006 Family Law Reforms (Australian Institute of Family Studies, 2009)

498. Kazanjian, David, The Brink of Freedom: Improvising Life in the Nineteenth-Century Atlantic World (Duke University Press, 2016)

499.Keal, Paul, European Conquest and the Rights of Indigenous Peoples: The Moral Backwardness of International Society (Cambridge University Press, 2003)

$<$ http://www.ourpgs.com/books/law/European\%20conquest\%20rights\%20indigenous\%20people .pdf $>$

500.Keal, Paul, European Conquest and the Rights of Indigenous Peoples: The Moral Backwardness of International Society (Cambridge University Press, 2003)

501.Kenny, Chris, Women's Business (Duffy \& Snellgrove, 1996)

502. Kercher, Bruce, An Unruly Child: A History of Law in Australia (Allen and Unwin, 1995)

503. Kevles, Daniel J, In the Name of Eugenics: Genetics and the Uses of Human Heredity (Harvard University Press, 1st Harvard University Press paperback, 1995)

504.Kidd, Rosalind, The Way We Civilise: Aboriginal Affairs - the Untold Story (University of Queensland Press, 1997)

505.Kidd, Rosalind, Black Lives, Government Lies (UNSW Press, 2000) 
506.Kidd, Rosalind, Trustees on Trial: Recovering the Stolen Wages (Aboriginal Studies Press, 2006)

507.Kieh, George Klay, Africa and the New Globalization (Ashgate Pub. Co., 2008) <http://public.eblib.com/EBLPublic/PublicView.do?ptiID=438673>

508.Kieh, George Klay, The First Liberian Civil War: The Crises of Underdevelopment (Peter Lang Publishing Inc., 2008) vol 17

509.Kieh, George Klay, Liberia's State Failure, Collapse and Reconstitution (Africana Homestead Legacy Publishers, 2012)

510.Killing Women: The Visual Culture of Gender and Violence (Wilfred Laurier University Press, 2006)

511.Kilmartin, Christopher, Men's Violence Against Women: Theory, Research, and Activism (Lawrence Erlbaum Associates, 2007)

512.Kimm, Joan, A Fatal Conjunction: Two Laws, Two Cultures (Federation Press, 2004) $<$ http://www.amazon.com/Fatal-Conjunction-Two-LawsCultures/dp/186287509X/ref=sr_1_1?s=books\&ie=UTF8\&qid=1361924786\&sr=1 $1 \&$ keywords $=\mathrm{a}+$ fatal+conjunction>

513.Kimmel, Michael S and Amy Aronson, Men and Masculinities: A Social, Cultural, and Historical Encyclopedia (ABC-CLIO, 2004)

514.Kimmel, Michael S, The Gendered Society (Oxford University Press, 4th ed, 2011)

515.Klatt, Matthias, Making the Law Explicit: The Normativity of Legal Argumentation (Hart Pub, 2008) vol 7

516.Klein, Julie Thompson, Interdisciplinarity: History, Theory, and Practice (Wayne State University Press, 1990)

517.Knight, Rachel, Silas Kpanan'Ayoung Siakor and Ali Kaba, Protecting Community Lands and Resources: Evidence from Liberia (Namati, SDI and IDLO, 2013)

$<$ http://www.namati.org/publications/protecting-community-lands-and-resources-evidence-fromliberia-executive-summary/>

518.Kohn, Margaret, Political Theories of Decolonization: Postcolonialism and the Problem of Foundations (Oxford University Press, 2011)

519.Kolawole, Mary Ebun Modupe, Womanism and African Consciousness (Africa World Press, 1997)

520.Korvah, Paul Degein, The History of the Loma People (University of Michigan, 1995)

521.Koskenniemi, Martti, The Gentle Civilizer of Nations: The Rise and Fall of International Law, 1870-1960 (Cambridge University Press, 2002)

522. Koskenniemi, Martti, From Apology to Utopia: The Structure of International Legal Argument (Cambridge University Press, 2005)

523. Kovach, Margaret, Indigenous Methodologies: Characteristics, Conversations and Contexts (University of Toronto Press, 2009)

$<$ http://search.ebscohost.com/login.aspx?direct=true $\&$ scope $=$ site $\& \mathrm{db}=$ nlebk $\& \mathrm{db}=$ nlabk $\& \mathrm{AN}=68$ 2652>

524.Kraaij, Fred PM van der, The Open-Door Policy of Liberia: An Economic History of Modern Liberia (Im Selbstverlag des Museums, 1983)

525.Kramer, Matthew H, Critical Legal Theory and the Challenge of Feminism: A Philosophical Reconception (Rowman \& Littlefield, 1995)

526.Krammer, Arnold, War Crimes, Genocide, and the Law: A Guide to the Issues (Praeger, 2010)

527. Kressel, Neil J, Mass Hate: The Global Rise of Genocide and Terror (Westview Press, Updated, 2002)

528.Kuklick, Henrika, A New History of Anthropology (Blackwell Pub, 2008) $<$ http://www.amazon.com/New-History-Anthropology-Henrika-Kuklick/dp/0631226001>

529.Kumar, Ranjit, Research Methodology: A Step-by-Step Guide for Beginners (SAGE, 2011)

530.Kvale, Steinar, Interviews: An Introduction to Qualitative Research Interviewing (Sage Publications, 1996)

531.Kvale, Steinar, Doing Interviews (Sage Publications, 2007)

532.Kvale, Steinar and Svend Brinkmann, InterViews: Learning the Craft of Qualitative Research Interviewing (Sage Publications, 2nd ed, 2009)

533.Lacey, Nicola, Unspeakable Subjects: Feminist Essays in Legal and Social Theory (Hart Pub. ; Distributed in the United States by Northwestern University Press, 1998)

534.Lake, Marilyn, Faith: Faith Bandler, Gentle Activist (Allen and Unwin, 2002)

535.Lake, Marilyn, Drawing the Global Colour Line: White Men's Countries and the International Challenge of Racial Equality (Cambridge University Press, 2008)

536.Lambert, Caroline, Global Issues, Women, and Justice (Sydney Institute of Criminology and University of Sydney, 2004)

537.Language and Culture in Aboriginal Australia (Aboriginal Studies Press, 1993) 
538.Larsson, Marina, Shattered ANZACs: Living With the Scars of War (UNSW Press, 2009) <http://www.newsouthbooks.com.au/isbn/9781921410550.htm>

539.Law and Religion in Theoretical and Historical Context (Cambridge University Press, 2008)

540.Lebacqz, Karen, Six Theories of Justice: Perspectives from Philosophical and Theological Ethics (Augsburg Publishing House, 1986)

541.Lee, HP and Enid Mona Campbell, The Australian Judiciary (Cambridge University Press, 2nd ed, 2013)

542.Legacies of White Australia: Race, Culture, and Nation (University of Western Australia Press, 2003)

543.Lemkin, Raphael, Axis Rule in Occupied Europe: Laws of Occupation, Analysis of Government, Proposals for Redress (Lawbook Exchange, Ltd, 2nd ed, 2008)

544.Levenkron, Steven and Abby Levenkron, Stolen Tomorrows: Understanding and Treating Women's Childhood Sexual Abuse (W. W. Norton, 2008)

545.Levine, Philippa, Gender and Empire (Oxford University Press, 2004)

546.Levine-Rasky, Cynthia, Whiteness Fractured (Ashgate, 2013)

547.Levitt, Jeremy I, The Evolution of Deadly Conflict in Liberia: From 'Paternaltarianism' to State Collapse (Carolina Academic Press, 2005)

548.Levy, Barry S and Victor W Sidel (eds), Social Injustice and Public Health (Oxford University Press, 2006)

549.Levy, Barry S and Victor W Sidel (eds), War and Public Health (Oxford University Press, 2nd ed, 2008)

550.Libesman, Terri, Decolonizing Indigenous Child Welfare Comparative Perspectives (Taylor and Francis, 2013) <http://public.eblib.com/choice/publicfullrecord.aspx?p=1576079>

551.Liebenow, J Gus, Liberia: The Evolution of Privilege (Cornell University Press, 1969)

552.Liebenow, J Gus, Liberia: The Quest for Democracy (Indiana University Press, 1987)

553.Liebmann, Marian, Restorative Justice: How It Works (Jessica Kingsley Publishers, 2007)

554.Lief, Alfred, The Firestone Story: A History of the Firestone Tire \& Rubber Company (Whittlesey House, 1951)

555.Lifshey, Adam, Spectres of Conquest: Indigenous Absence in Transatlantic Literatures (Fordham University Press, 1st ed, 2010)

556.Lippmann, Lorna, Generations of Resistance: Aborigines Demand Justice (Longman Cheshire, 2nd ed, 1991)

557.Littell, Julia H, Jacqueline Corcoran and Vijayan K Pillai, Systematic Reviews and MetaAnalysis (Oxford University Press, 2008)

558.Long, Edward, History of Jamaica. Or, General Survey of the Ancient and Modern State of That Island:: With Reflections on Its Situation, Settlements, Inhabitants, Climate, Products, Commerce, Laws, and Government (Oxford University, 1774)

<http://books.googleusercontent.com/books/content?req=AKW5Qadfavo5XVmZMOIa29Jhw68 OSTenX-

qvy3MXHVY1bmEQtuQf8rTGI2i2SvaelLCMHMXVN9IK97JpJv5Da7tIw435FR_w5Y6DUjyr yN-fpwbcn_jgrlFdTImmK6Iy-

aicjCU1tWpSPlqkO1wcKfKLRL9_4kTdAJ6wAPkWSIre54RZCDJ4e9P2euWTHYQXG5Q3H Z53SIX7ufWHblwsYNJeIP75DsPVp_HzycMCZQICrg5cEDv2JSHH28jhF_VW81dYMFlpejy>

559.Loos, Noel, Invasion and Resistance: Aboriginal-European Relations on the North Queensland Frontier, 1861-1897 (Australian National University Press, 1982)

560.Louis, Anja, Women and the Law: Carmen de Burgos, an Early Feminist (Tamesis, 2005)

561.Lucero, Jose Antonio, Dale A Turner and Donna Lee Van Cott, The Oxford Handbook of Indigenous People's Politics (2013) <http://dx.doi.org/10.1093/oxfordhb/9780195386653.001.0001>

562.Luhmann, Niklas, Klaus A Ziegert and Fatima Kastner, Law as a Social System (Oxford University Press, 1st ed, 2008)

563.Luker, Kristin, Salsa Dancing into the Social Sciences: Research in an Age of Info-Glut (Harvard University Press, 2010)

564.Lykke, Nina, Feminist Studies: A Guide to Intersectional Theory, Methodology and Writing (Routledge, 2010)

565.Lyons, Peter, The Dissertation: From Beginning to End (Oxford University Press, 2010)

566. Maalouf, Amin and Barbara Bray, In the Name of Identity: Violence and the Need to Belong (Penguin Books, 2003)

567.Maathai, Wangari, The Challenge for Africa (Anchor Books, 1st ed, 2010)

568. Mac an Ghaill, Mairtin, Understanding Masculinities: Social Relations and Cultural Arenas (Open University Press, 1996) 
569.MacCormick, Neil, Rhetoric and the Rule of Law: A Theory of Legal Reasoning (Oxford University Press, 2005)

570.MacDonald, Joyce Green, Women and Race in Early Modern Texts (Cambridge University Press, 2010)

571.Macfarlane, Ingereth and Mark Hannah (eds), Transgressions: Critical Australian Indigenous Histories (ANU E Press, 2007)

572. Macintyre, Stuart, A Concise History of Australia (Cambridge University Press, 3rd ed, 2009)

573. MacKinnon, Catharine A, Toward a Feminist Theory of the State (Harvard University Press, 1989)

574. Malik, Khalid and United Nations Development Programme, Human Development Report 2013: The Rise of the South: Human Progress in a Diverse World. (United Nations Development Programme, 2014) <http://issuu.com/undp/docs/hdr_2013_en?mode=window>

575.Malik, Khalid and United Nations Development Programme, Sustaining Human Progress: Reducing Vulnerabilities and Building Resilience (Human Development Report Office, 2014) <http://hdr.undp.org/sites/default/files/hdr14-report-en-1.pdf>

576.Malinowski, Bronislaw, Sex and Repression in Savage Society (Routledge, 2001)

577.Mama, Amina, Beyond the Masks: Race, Gender and Subjectivity (Routledge, 1995)

578. Mama, Amina, The Hidden Struggle: Statutory and Voluntary Sector Responses to Violence Against Black Women in the Home (Whiting and Birch Ltd, 1996)

579. Mamdani, Mahmood, Define and Rule: Native as Political Identity (Harvard University Press, 1st ed, 2012)

580.Mandell, Nancy, Feminist Issues: Race, Class and Sexuality (Pearson Canada, 2009)

581.Manderson, Desmond, Songs Without Music: Aesthetic Dimensions of Law and Justice (University of California Press, 2000)

582.Manderson, Desmond, Kangaroo Courts and the Rule of Law: The Legacy of Modernism (Routledge, 2012)

583.Mansell, Michael, From Democracy to Statehood: Aboriginal Self-Determination (Federation Press, 2016)

584.Martin, Tony, The Pan-African Connection: From Slavery to Garvey and Beyond (Majority Press, 1st Majority Press, 1984)

585. Martínez Cobo, José R, Study of the Problem of Discrimination Against Indigenous Populations (United Nations, 1987)

586. Mary Wade History Association, Mary Wade To Us: A Family History 1778-1986 (MacArthur Press, 1986)

587.Masculinities in Text and Teaching (Palgrave Macmillan, 2008)

588. Mason, Gail, The Spectacle of Violence: Homophobia, Gender, and Knowledge (Routledge, 2002)

589.Mason, Melvin J, Land and Language: Issues in Liberian Development (Brentwood Christian Press, 2005)

590.Masson, Elsie R, An Untamed Territory: The Northern Territory of Australia (Macmillan, 1915) <https://archive.org/details/untamedterritory00mass>

591. Matthews, Glenna, American Women's History: A Student Companion (Oxford University Press, 2000)

592.May, Tim, Social Research (Open University Press, 4th ed, 2011) <http://www.myilibrary.com?id=315271>

593.McBeth, Adam, The International Law of Human Rights (Oxford University Press, 2011)

594.McCandless, Erin et al, Peace Research for Africa: Critical Essays on Methodology (University of Peace, 2007)

595.McCandless, Erin and Tony Karbo, Peace, Conflict, and Development in Africa: A Reader (University for Peace, Africa Programme, 2011)

596.McClintock, Anne, Imperial Leather: Race, Gender, and Sexuality in the Colonial Context (Routledge, 1995)

597.McCorquodale, John, Aborigines and the Law: A Digest (Aboriginal Studies Press, 1987)

598. McCoy, Brian, Holding Men: Kanyirninpa and the Health of Aboriginal Men (Aboriginal Studies Press, 2008)

599.McGlade, Hannah, Our Greatest Challenge: Aboriginal Children and Human Rights (Aboriginal Studies Press, 2012)

600.McGrath, Ann, Born in the Cattle: Aborigines in Cattle Country (Allen and Unwin, 1987)

601.McGrath, Ann, Contested Ground: Australian Aborigines Under the British Crown (Allen and Unwin, 1995)

602.McGrath, Ann, Saunders Kay and Jackie Huggins, Aboriginal Workers (Australian Society for the Study of Labour History, 1995) 
603.McGregor, Russell, Indifferent Inclusion: Aboriginal People and the Australian Nation (Aboriginal Studies Press, 2011)

604.McKnight, David, Of Marriage, Violence and Sorcery: The Quest for Power in Northern Queensland (Ashgate, 2005)

605.McPherson, John HT, History of Liberia (Forgotten Books, 2010)

606. Mendelsohn, Oliver and Upendra Baxi (eds), The Rights of Subordinated Peoples (Oxford University Press, 1996)

607.Merry, Sally Engle, Human Rights and Gender Violence: Translating International Law into Local Justice (The University of Chicago Press, 2006)

608.Merry, Sally Engle, Gender Violence: A Cultural Perspective (John Wiley and Son Ltd., 2009)

609.Miller, Christopher Allan, Mary E King and University for Peace, A Glossary of Terms and

Concepts in Peace and Conflict Studies (University for Peace, 2005)

610.Miller, Holly Ventura, Restorative Justice: From Theory to Practice (Emerald/JAI Press, 2008)

611.Miller, Randall M, 'Dear Master': Letters of a Slave Family (University of Georgia Press, 1995)

612.Miller, Robert J et al, Discovering Indigenous Lands: The Doctrine of Discovery in the English Colonies (Oxford University Press, 2010)

613.Milliss, Roger, Waterloo Creek: The Australia Day Massacre of 1838, George Gipps and the British Conquest of New South Wales (UNSW Press, 1994)

614.Ministry of Justice, Prosecution of Sexual and Gender-Based Violence in Liberia (American Bar Association, 2007) vol 1

<https://www.cartercenter.org/resources/pdfs/peace/conflict_resolution/liberia/SGBV-

ProsecutionHandbook-v1.pdf>

615. Ministry of Justice, Sexual Assault and Abuse Prosecution Handbook (American Bar Association, 2009)

616.Mirza, Heidi Safia (ed), Black British Feminism: A Reader (Routledge, 1997)

617.Mitchell, Adrian, Dampier's Monkey: The South Seas Voyages of William Dampier (Wakefield Press, 2010)

618. Mohanram, Radhika, Black Body: Women, Colonialism, and Space (University of Minnesota Press, 1999) vol 6

619.Mohanty, Chandra Talpade, Feminism Without Borders: Decolonizing Theory, Practicing Solidarity (Duke University Press, 2003)

620.Moloney, Lawrence and Australian Institute of Family Studies (eds), Allegations of Family Violence and Child Abuse in Family Law Children's Proceedings: A Pre-Reform Exploratory Study (Australian Institute of Family Studies, 2007)

621.Molony, John N, The Native-Born: The First White Australians (Melbourne University Press, 2000)

622.Monga, Célestin, The Anthropology of Anger: Civil Society and Democracy in Africa (Lynne Rienner Publishers, 1996) <http://www.amazon.com/Anthropology-Anger-Society-DemocracyAfrica/dp/1555878415/ref=sr_1_3?s=books\&ie=UTF8\&qid=1362531212\&sr=1 $3 \&$ keywords $=$ The + Anthropology+of + Anger $>$

623. Mongrue, Jesse, Liberia America's Footprint in Africa: Making the Cultural, Social, and Political Connections (iUniverse, 2011)

624.Moore, Bai T, Liberian Culture at a Glance: A Review of the Culture and Customs of the Different Ethnic Groups in the Republic of Liberia (Ministry of Information, Cultural Affairs and Tourism, 1979)

625.Moorehead, Alan, The Fatal Impact: The Invasion of the South Pacific, 1767-1840 (Harper \& Row, 1987) <http://www.amazon.com/The-Fatal-Impact-Invasion-1767-1840/dp/006015800X>

626. Moran, Mary H, Civilized Women: Gender and Prestige in Southeastern Liberia (Cornell University Press, 1990)

627.Moran, Mary H, Liberia: The Violence of Democracy (University of Pennsylvania Press ; University Presses Marketing [distributor], 2008)

628. Moran, Rod, Massacre Myth: An Investigation into Allegations Concerning the Mass Murder of Aborigines at Forrest River, 1926 (Access Press, 1999)

629.Moreton-Robinson, Aileen, Talkin' up to the White Woman: Indigenous Women and White Feminism (University of Queensland Press, 2000)

630.Moreton-Robinson, Aileen (ed), Whitening Race: Essays in Social and Cultural Criticism (Aboriginal Studies Press, 2004)

631.Moreton-Robinson, Aileen, Sovereign Subjects: Indigenous Sovereignty Matters (Allen and Unwin, 2007)

632.Morgan, Philip D and Sean Hawkins, Black Experience and the Empire (Oxford University Press, 2004)

$<$ http://search.ebscohost.com/login.aspx?direct=true \&scope $=$ site $\& d b=$ nlebk $\& d b=$ nlabk $\& A N=15$ 6818> 
633.Moser, Caroline ON and Fiona C Clark (eds), Victims, Perpetrators or Actors?: Gender, Armed Conflict and Political Violence (Zed Books, 2001)

634.Moses, A Dirk, Genocide and Settler Society: Frontier Violence and Stolen Indigenous Children in Australian History (Berghahn Books, 1st ed, 2005)

635. Mossman, Mary Jane, The First Women Lawyers: A Comparative Study of Gender, Law and the Legal Professions (Hart Pub, 2006)

636. Muecke, Stephen, Aboriginal Australians: First Nations of an Ancient Continent (Thames and Hudson, 2004)

637. Mukherji, Partha N and Chandan Sengupta (eds), Indigeneity and Universality in Social Science: A South Asian Response (Sage Publications, 2004)

638. Muller, Jake, Writing in the Social Sciences: A Guide for Term Papers and Book Reviews (Oxford University Press Canada, 2010)

639.Murdza Jr., Peter J, Immigrants to Liberia, 1865 to 1904: An Alphabetical Listing (Liberian Studies Association, 1975) vol 4

640.Murray, Rowena, How to Write a Thesis (Open University Press, 3rd ed, 2011)

641. Musharbash, Yasmine and Marcus Barber (eds), Ethnography and the Production of Anthropological Knowledge: Essay in Honour of Nicolas Peterson (ANU E Press, 2011)

642. Naffine, Ngaire, Female Crime: The Construction of Women in Criminology (Allen and Unwin, 1987)

643. Naffine, Ngaire, Law and the Sexes: Explorations in Feminist Jurisprudence (Allen and Unwin, 1990)

644.Naffine, Ngaire, Sexing the Subject of Law (LBC Information Services, 1997)

645.Nafziger, James AR, Robert K Paterson and Alison Dundes Renteln, Cultural Law: International, Comparative, and Indigenous (Cambridge University Press, 2010)

646. Nakata, Martin N and Aboriginal and Torres Strait Islander Commission (eds), Indigenous Peoples, Racism and the United Nations (Common Ground Publishing, 2001)

647.Nakata, Martin N, Disciplining the Savages: Savaging the Disciplines (Aboriginal Studies Press, 2007)

648. Naples, Nancy A, Feminism and Method: Ethnography, Discourse Analysis, and Activist Research (Routledge, 2003)

649. National Council to Reduce Violence against Women and their Children, Time for Action: The National Council's Plan for Australia to Reduce Violence against Women and Their Children, 2009-2021 (Department of Families, Housing, Community Services and Indigenous Affairs, 2009)

650.National Health and Medical Research Council, Values and Ethics: Guidelines for Ethical Conduct in Aboriginal and Torres Strait Islander Health Research (Commonwealth of Australia, 2003)

651.National Health and Medical Research Council, Keeping Research on Track: A Guide for Aboriginal and Torres Strait Islander Peoples About Health and Research Ethics (Australian Government, 2005)

652.National Research Council (U.S.), Protecting Participants and Facilitating Social and Behavioural Sciences Research (National Academies Press, 2003)

653.Nelson, Bell Agrippa, The Debt to Africa - The Hope of Liberia (American Church Review Press, 1881)

654.Nelson, Harold D, Liberia: A Country Study (Headquarters, Department of the Army, 3rd ed, 1985)

<http://www.globalsecurity.org/military/library/report/1985/liberia_1_truewhigascend.htm>

655.Nettelbeck, Amanda et al, Fragile Settlements: Aboriginal Peoples, Law, and Resistance in South-West Australia and Prairie Canada (University of Washington Press, 2016)

656.Nettheim, Garth, International Commission of Jurists (1952- ) and University of New South Wales (eds), Aborigines Human Rights and the Law (Australia and New Zealand Book Co, 1974)

657.Neuman, William Lawrence, Basics of Social Research: Qualitative and Quantitative Approaches (Pearson/Allyn and Bacon, 2nd ed, 2007)

658.Neuman, William Lawrence, Social Research Methods: Qualitative and Quantitative Approaches (Allyn and Bacon, 7th ed, 2011)

659.Neville, Auber Octavius, Australia's Coloured Minority: Its Place in the Community (Currawong Publishing, 1947)

660.New South Wales, Office for Women's Policy, Stop the Violence, End the Silence: NSW Domestic and Family Violence Action Plan (NSW Department of Premier and Cabinet, 2010)

661. Newcomb, Steven T, Pagans in the Promised Land Decoding the Doctrine of Christian Discovery (Fulcrum Publishing, 2008) <http://site.ebrary.com/id/10288642> 
662.Nicholas, Stephen (ed), Convict Workers: Reinterpreting Australia's Past (Cambridge University Press, Paperback version, 2007)

663.Niezen, Ronald, The Rediscovered Self: Indigenous Identity and Cultural Justice (McGillQueen's University Press, 2009)

664.Nkrumah, Kwame, Class Struggle in Africa (Panaf Books Ltd, 1970)

665.Northern Territory. Board of Inquiry into the Protection of Aboriginal Children from Sexual Abuse, Rex Wild and Pat Anderson, Ampe Akelyernemane Meke Mekarle Little Children Are Sacred (Department of the Chief Minister, Office of Indigenous Policy, 2007)

666. Northey, Margot, Making Sense: A Student's Guide to Research and Writing: Social Sciences (Oxford University Press, 5th ed, 2012)

667. Nowra, Louis, Bad Dreaming: Aboriginal Men's Violence Against Women and Children (Pluto Press, 2007)

668.NSW Department of Attorney General, Your Court, Your Safety: A Guide to Going to Court and Getting Help With Domestic Violence (Crime Prevention Decision, NSW Department of Justice and Attorney General, 2010)

669.NSW Rape Crisis Centre and Anne Cossins, A Best Practice Model for the Prosecution of Complaints of Sexual Assault by the NSW Criminal Justice System (NSW Rape Crisis Centre, 2007)

670.Nugent, Maria, Botany Bay: Where Histories Meet (Allen and Unwin, 2005)

671.Okafo, Nonso, Reconstructing Law and Justice in a Postcolony (Ashgate Pub, 2009)

672. Okafor, Obiora Chinedu, African Human Rights System: Activist, Forces and International Institutions (Cambridge University Press, 2007)

<http://www.cambridge.org/catalogue/catalogue.asp?isbn=9780521869065>

673. Olukoju, Ayodeji, Culture and Customs of Liberia (Greenwood Press, 2006)

674. Oñati International Institute for the Sociology of Law, Rethinking Equality Projects in Law: Feminist Challenges (Hart Pub, 2008) <http://www.amazon.com/Rethinking-Equality-ProjectsLaw-International/dp/1841138398/ref=sr_1_10?s=books\&ie=UTF8\&qid=1361923087\&sr=1 10\&keywords=the+hidden+gender+of+law>

675.O’Neill, NKF, Retreat from Injustice: Human Rights Law in Australia (Federation Press, 2nd ed, 2004)

676.Onyango, Peter, African Customary Law: An Introduction (LawAfrica Publishing (K) Ltd, 2013)

677. Orrmont, Arthur, Fighter against Slavery: Jehudi Ashmun (J. Messner, 1966)

678. Ørsted-Jensen, Robert, Frontier History Revisited: Queensland and the 'History War' (Lux Mundi Publisher, 2011)

679.O'Sullivan, Dominic, Indigeneity A Politics of Potential; Australia, Fiji and New Zealand. (Policy Press, 2017)

680.O'Toole, Laura L, Jessica R Schiffman and Margie L Kiter Edwards, Gender Violence: Interdisciplinary Perspectives (New York University Press, 2nd ed, 2007)

681.O'Toole, Sean, The History of Australian Corrections (UNSW Press, 2006)

682. Ouzgane, Lahoucine and Robert Morrell, African Masculinities: Men in Africa from the Late Nineteenth Century to the Present (Palgrave Macmillan and University of KwaZulu-Natal Press, 2005)

683. Oxley, Deborah, Convict Maids: The Forced Migration of Women to Australia (Cambridge University Press, 1996)

684.Pacific institute for Research and Evaluation - Africa Center, Institutional Review Board: Policies \& Procedures Handbook (University of Liberia, 2008)

685.Passionate Histories: Myth, Memory and Indigenous Australia (ANU E Press \& Aboriginal History, 2010)

686.Pateman, Carole, The Sexual Contract (Stanford University Press, 1988)

687.Patten, Jack T and William Ferguson, Aborigines Claim Citizen Rights! (The Publicist Bookshop, 1938) <http://www1.aiatsis.gov.au/exhibitions/dom/PDF/m0011348_a.pdf>

688.Penner, James, The Law of Trusts (Oxford University Press, 9th ed, 2014)

689.Perreau-Saussine, Amanda and James B Murphy, The Nature of Customary Law: Legal, Historical and Philosophical Perspectives (Cambridge University Press, 2009)

690.Peterson, Nicolas and Will Sanders (eds), Citizenship and Indigenous Australians: Changing Conceptions and Possibilities (Cambridge University Press, 1998)

691.Pettman, Jan, Living in the Margins: Racism, Sexism, and Feminism in Australia (Allen and Unwin, 1992)

692.Pitcher, Rod, Advice to a Troubled PhD Student (Obooko, 2012)

<http://www.obooko.com/obooko_reference/bookpages/ref0006-free-ebook-phd-student-advicepitcher.php> 
693.Pitcher, Rod, PhD Musings (Obooko, 2012)

<http://www.obooko.com/obooko_reference/bookpages/ref0007-free-ebook-phd-musingspitcher.php>

694.Pitcher, Rod, PhD Musings 2 (Obooko, 2013)

<http://www.obooko.com/obooko_reference/bookpages/ref0012-free-ebook-phd-musings2pitcher.php>

695.Pitts, Marian and Anthony Smith, Researching the Margins: Strategies for Ethical and Rigorous Research with Marginalised Communities (Palgrave Macmillan, 2007)

696.Poirier, Sylvie and Françoise Dussart, Entangled Territorialities: Negotiating Indigenous Lands in Australia and Canada (University of Toronto Press, 2017)

697.Political Theory and the Rights of Indigenous Peoples (Cambridge University Press, 2000)

698.Pope, Alan, One Law for All? Aboriginal People and Criminal Law in Early South Australia (Aboriginal Studies Press, 2011)

699.Port Arthur Historic Sites, Pack of Thieves? 52 Port Arthur Lives (Port Arthur Historic Site Management, 2001)

700.Port Arthur Historic Sites, Pack of Thieves? 52 Female Factory Lives (Port Arthur Historic Site Management, 2014)

701.Porter, Elisabeth J, Peacebuilding: Women in International Perspective (Routledge, 2007) $<$ http://www.unisanet.unisa.edu.au/staff/Homepage.asp?Name=elisabeth.porter >

702.Powell, Anastasia, Sex, Power and Consent: Youth Culture and the Unwritten Rules (Cambridge University Press, 2010)

703.Pratt, Angela, Practising Reconciliation?: The Politics of Reconciliation in the Australian Parliament, 1991-2000 (Department of Parliamentary Services, 2005)

704.Prentis, Malcolm D, The Scots in Australia (University of New South Wales Press, 2008)

705.Progressive Black Masculinities (Routledge, 2006)

706.Protecting Rights Without a Bill of Rights: Institutional Performance and Reform in Australia (Ashgate, 2006)

707.Ptacek, James, Restorative Justice and Violence Against Women (Oxford University Press, 2010)

708.Purdie, Nola et al, Working Together: Aboriginal and Torres Strait Islander Mental Health and Wellbeing Principles and Practice (Australian Institute of Health and Welfare, 2010) <http://www.ichr.uwa.edu.au/files/user5/Working_Together_book_web.pdf>

709.Purdie, Nola, Pat Dudgeon and Roz Walker, Working Together: Aboriginal and Torres Strait Islander Mental Health and Wellbeing Principles and Practice (Australian Department of Health and Ageing, 2014)

710. Rabaka, Reiland, Africana Critical Theory: Reconstructing the Black Radical Tradition, from W.E.B. Du Bois and C.L.R. James to Frantz Fanon and Amilcar Cabral (Lexington Books, 2009)

711. Raimondo, Fabián, General Principles of Law in the Decisions of International Criminal Courts and Tribunals (Martinus Nijhoff Publishers, 2008) <http://www.brill.com/general-principleslaw-decisions-international-criminal-courts-and-tribunals $>$

712. Randall, Bob and Australian Broadcasting Corporation, Songman: The Story of an Aboriginal Elder of Uluru (ABC Books for the Australian Broadcasting Corporation, 2003)

713.Rawls, John, Justice as Fairness: A Restatement (Harvard University Press, 2001)

714.Rawls, John, A Theory of Justice (Belknap Press, Original, 2005)

715.Raz, Joseph, The Authority of Law: Essays on Law and Morality (Oxford University Press, 1979)

716.Razack, Sherene, Looking White People in the Eye: Gender, Race, and Culture in Courtrooms and Classrooms (University of Toronto Press, 1998)

717.Razack, Sherene, Race, Space, and the Law: Unmapping a White Settler Society (Between the Lines, 2002)

718. Razack, Sherene, States of Race: Critical Race Feminism for the 21st Century (Between the Lines, 2010)

719.Read, Peter, A Hundred Years War: The Wiradjuri People and the State (Australian National University Press, 1988)

720.Read, Peter and Jay Read, Long Time, Olden Time: Aboriginal Accounts of Northern Territory History (Institute for Aboriginal Development Publications, 1991)

721.Read, Peter, Returning to Nothing: The Meaning of Lost Places (Cambridge University Press, 1996)

722. Read, Peter, A Rape of the Soul so Profound: The Return of the Stolen Generations (Allen and Unwin, 1999)

723.Read, Peter, Belonging: Australians, Place and Aboriginal Ownership (Cambridge University Press, 2000) 
724.Read, Peter, Indigenous Biography and Autobiography (Australian National University E Press, 2008) <http://epress.anu.edu.au/aborig_history/indigenous_biog/pdf/whole_book.pdf>

725.Read, Peter, Tripping Over Feathers: Scenes in the Life of Joy Janaka Wiradjuri Williams: A Narrative of the Stolen Generations (UWA Pub, 2009)

726. Realising Utopia: The Future of International Law (Oxford University Press, 2012)

727.Rees, Siân, The Floating Brothel: The Extraordinary True Story of an Eighteenth-Century Ship and Its Cargo of Female Convicts (Hyperion, 2002)

728. Reeser, Todd W, Masculinities in Theory: An Introduction (Wiley-Blackwell, 2010)

729. Rehn, Elisabeth and Ellen Johnson Sirleaf, Women, War and Peace: An Independent Experts' Assessment on the Impact of Armed Conflict and Women's Role in Peace-Building (United Nations Development Fund for Women (UNIFEM), 2002)

$<$ http://pendientedemigracion.ucm.es/cont/descargas/documento7201.pdf?pg=cont/descargas/do cumento7201.pdf $>$

730.Reinharz, Shulamit, Feminist Methods in Social Research (Oxford University Press, 1992)

731.Researching Violence in Africa: Ethical and Methodological Challenges (Brill, 2011)

732. Restorative Justice and Family Violence (Cambridge University Press, 2002)

733.Restorative Justice for Juveniles: Conferencing, Mediation and Circles (Hart Pub, 2001)

734. Reynolds, Henry, The Law of the Land (Penguin Books, 1992)

735.Reynolds, Henry, Aboriginal Sovereignty: Reflections on Race, State, and Nation (Allen and Unwin, 1996)

736.Reynolds, Henry, Dispossession: Black Australians and White Invaders (Allen and Unwin, 1996) <http://www.contentreserve.com/TitleInfo.asp?ID=\{BA893BD4-818E-47F0-B6573EC1F37227BF $\} \&$ Format $=410>$

737.Reynolds, Henry, This Whispering in Our Hearts (Allen and Unwin, 1998)

738. Reynolds, Henry, Why Weren't We Told?: A Personal Search for the Truth About Our History (Penguin, 2000)

739. Reynolds, Henry, Nowhere People (Penguin, 2005)

740.Reynolds, Henry, The Other Side of the Frontier: Aboriginal Resistance to the European Invasion of Australia (University of New South Wales Press, 2006)

741.Reynolds, Henry, A History of Tasmania (Cambridge University Press, 2012)

742.Rhode, Deborah L, Justice and Gender (Harvard University Press, 1991)

743.Rhode, Deborah L, Access to Justice (Oxford University Press, 2004)

744.Rhode, Deborah L, The Beauty Bias: The Injustice of Appearance in Life and Law (Oxford University Press, 2010)

745.Richardson, Benjamin J, Shin Imai and Kent McNeil, Indigenous Peoples and the Law: Comparative and Critical Perspectives (Hart, 2009) <http://www.amazon.com/IndigenousPeoples-Law-ComparativePerspectives/dp/1841137952/ref=sr_1_1?s=books\&ie=UTF8\&qid=1361919161\&sr=1 $1 \&$ keywords=indigenous+peoples+and+the+law+in+australia $>$

746.Richardson, Janice and Erika Rackley, Feminist Perspectives on Tort Law (Routledge, 2012) <http://www.myilibrary.com?id=365939>

747.Rintoul, Stuart, The Wailing: A National Black Oral History (W. Heinemann Australia, 1993)

748.Ritzer, George (ed), The Blackwell Encyclopedia of Sociology (Blackwell Publishing Ltd, 2007) <http://doi.wiley.com/10.1111/b.9781405124331.2007.x>

749.Roberts, David, Human Insecurity: Global Structures of Violence (Zed Books, 2008)

750.Robertson, Gerald B, Mental Disability and the Law in Canada (Carswell, 1994)

751.Robinson, Geoffrey, Confronting Power and Sex in the Catholic Church: Reclaiming the Spirit of Jesus (Liturgical Press, 2008)

752.Robson, Colin, Real World Research (John Wiley \& Sons, 3rd ed, 2011)

753.Rodney, Walter, How Europe Underdeveloped Africa (Black Classic Press, 2011)

754.Röhrs, Stefanie et al (eds), In Search of Equality: Women, Law and Society in Africa (UCT Press, 2014)

755.Rolls, Mitchell and Murray Johnson, Historical Dictionary of Australian Aborigines (Scarecrow Press, 2011)

756.Rosén, Hannah, Terror in the Heart of Freedom: Citizenship, Sexual Violence, and the Meaning of Race in the Postemancipation South (University of North Carolina Press, 2009)

757.Ross, Anne (ed), Indigenous Peoples and the Collaborative Stewardship of Nature: Knowledge Binds and Institutional Conflicts (Left Coast Press, 2011)

758.Ross, Susan Deller and American Civil Liberties Union, The Rights of Women: The Basic ACLU Guide to Women's Eights (Southern Illinois University Press, 3rd ed, 1993)

759.Roth, Rachel, Making Women Pay: The Hidden Costs of Fetal Rights (Cornell University Press, 2000) <http://www.amazon.com/Making-Women-Pay-Hidden- 
Rights/dp/0801436079/ref=sr_1_7_title_1_har?s=books\&ie=UTF8\&qid=1361921359\&sr=1 7\&keywords=the+hidden+gender+of+law $>$

760.Roth, Walter E, The Queensland Aborigines (Hesperian Press, 1984)

761.Rowley, Charles Dunford, Outcasts in White Australia (Penguin Books, 1972)

762. Rowse, Timothy, Rethinking Social Justice (Aboriginal Studies Press, 2012)

763. Rupesinghe, Kumar, Marcial Rubio Correa and United Nations University (eds), The Culture of Violence (United Nations University Press, 1994)

764.Ryan, W Michael, White Man, Black Man: The True Story of a White Man Who Was Initiated into an Aboriginal Tribe (Jacaranda, 1969)

765.Sage Handbook of Mixed Methods in Social and Behavioural Research (SAGE Publications, 2nd ed, 2010)

766.Sage Publications, The Sage Dictionary of Social Research Methods (SAGE Publications, 2006)

767.Sa'dāwī, Nawāl and Sharif Hatatah, Woman at Point Zero (Zed Books, 1983)

768.Sa'dāwī, Nawāl, The Nawal El Saadawi Reader (Zed Books, 1997)

769.Sa'dāwī, Nawāl, A Daughter of Isis: The Autobiography of Nawal El Saadawi (Zed Books, 1999)

770.Sa'dāwī, Nawāl, Walking Through Fire the Later Years of Nawal El Saadawi (Zed Books, 2009) <http://public.eblib.com/choice/publicfullrecord.aspx?p=474804>

771.Sa'dāwī, Nawāl, The Essential Nawal El Saadawi: A Reader (Zed Books, 2010)

772.Sapsford, Roger and Victor Jupp, Data Collection and Analysis (Sage Publications, 2nd ed, 2006)

773. Sawyer, Amos, The Emergence of Autocracy in Liberia: Tragedy and Challenge (Institute for Contemporary Studies, 1992)

774.Sawyer, Amos, Beyond Plunder: Toward Democratic Governance in Liberia (L. Rienner Publishers, Inc., 2005)

775.Schaap, Andrew, Gary Foley and Edwina Howell (eds), The Aboriginal Tent Embassy: Sovereignty, Black Power, Land Rights and the State (Routledge, 2013)

776.Schabas, William A, An Introduction to the International Criminal Court (Cambridge University Press, 4th ed, 2011)

777.Schabas, William A, Routledge Handbook of International Criminal Law (Routledge, 2013)

778.Schissel, Bernard, The Legacy of School for Aboriginal People: Education, Oppression, and Emancipation (Oxford University Press, 2003)

779. Schlütter, Birgit, Developments in Customary International Law: Theory and the Practice of the International Court of Justice and the International Ad Hoc Criminal Tribunals for Rwanda and Yugoslavia (Martinus Nijhoff Publishers, 2010)

780.Schmider, Joann, Heather Nancarrow and Queensland Centre for Domestic and Family Violence Research, Aboriginal and Torres Strait Islander Family Violence Facts and Figures (Queensland Centre for Domestic and Family Violence Research, Central Queensland University, 2007) <http://www.noviolence.com.au/public/factsheets/indigenousfactsheet.pdf >

781.Sémelin, Jacques, Purify and Destroy: The Political Uses of Massacre and Genocide (Columbia University Press, 2007)

782.Sen, Amartya, Inequality Reexamined (Harvard University Press, 1995)

783.Sen, Amartya, Development as Freedom (Alfred A. Knopf, 1999)

784.Sen, Amartya, Identity and Violence: The Illusion of Destiny (W.W. Norton and Co., 2006)

785.Sen, Amartya, The Idea of Justice (Harvard University Press, 2009)

786. Sentencing Council, Sentencing Children and Young People: Overarching Principles and Offence Specific Guidelines for Sexual Offences and Robbery - Definitive Guideline (Sentencing Council for England and Wales, 2017)

787. Sesay, Amadu, Post-War Regimes and State Reconstruction in Liberia and Sierra Leone (Council for the Development of Social Science Research in Africa, 2009)

788. Settlement: A History of Australian Indigenous Housing (Aboriginal Studies Press, 2000)

789. Shapland, Joanna, Restorative Justice in Practice: Evaluating What Works for Victims and Offenders (Routledge, 2011)

790. Sharpley, Deborah, Criminal Litigation: Practice and Procedures (The College of Law Publishing, 2010)

791. Sheldon, Kathleen E, Historical Dictionary of Women in Sub-Saharan Africa (Scarecrow Press, 2005)

792. Sheleff, Leon Shaskolsky, The Future of Tradition: Customary Law, Common Law, and Legal Pluralism (F. Cass, 2000)

793. Shell-Duncan, Bettina and Ylva Hernlund, Female 'Circumcision' in Africa: Culture, Controversy, and Change (Lynne Rienner Publishers, 2000) 
794. Shelton, Austin J, The Igbo-Igala Borderland: Religion and Social Control in Indigenous African Colonialism (State University of New York Press, 1971) <http://www.sunypress.edu/p-389-theigbo-igala-borderland.aspx>

795. Shelton, Dinah (ed), Encyclopedia of Genocide and Crimes Against Humanity (T-Z) (Macmillan Reference, 2005) vol 3

796.Shick, Tom W, Emigrants to Liberia, 1820-1843; An Alphabetical Listing (Department of Anthropology, University of Delaware, 1971)

797. Shick, Tom W, Behold the Promised Land: A History of Afro-American Settler Society in Nineteenth-Century Liberia (Johns Hopkins University Press, 1980)

798. Short, Damien, Reconciliation and Colonial Power: Indigenous Rights in Australia (Ashgate, 2008)

799. Siebel, Hans Dieter, Traditional Organizations and Economic Development. Studies of Indigenous Co-operatives in Liberia. (Praeger, 1974)

800.Sifris, Ronli Noa, Reproductive Freedom, Torture and International Human Rights: Challenging the Masculinisation of Torture (Routledge, 2014)

801.Simm, Gabrielle, Sex in Peace Operations (Cambridge University Press, 2013) <http://www.cambridge.org/asia/catalogue/catalogue.asp?isbn=9781107030329\&ss=cop>

802. Singer, Peter W, Children at War (University of California Press, 2006)

803.Singh, Kultar, Quantitative Social Research Methods (Sage Publications, 2007)

804.Sing'Oei, Korir and Ridwan Laher, Indigenous People in Africa: Contestations, Empowerment and Group Rights (African Books Collective, 2014)

<http://ebookcentral.proquest.com/lib/concordiaab-ebooks/detail.action?docID=1707230>

805.Skaine, Rosemarie, Women Political Leaders in Africa (McFarland and Co, 2008)

806.Slapper, Gary, The English Legal System (Routledge, 11th ed, 2010)

807. Slaughter, Joseph R, Human Rights, Inc.: The World Novel, Narrative Form, and International Law (Fordham University Press, 1st ed, 2007)

808. Slavicek, Louise Chipley, The Prohibition Era Temperance in the United States (Chelsea House, 2009)

$<$ http://search.ebscohost.com/login.aspx?direct=true \&scope $=$ site $\& d b=$ lebk $\& d b=$ nlabk $\& A N=25$ 7301>

809.Smart, Carol, Feminism and the Power of Law (Routledge, 1989)

810.Smart, Carol, Regulating Womanhood: Historical Essays on Marriage, Motherhood and Sexuality (Routledge, 1992)

811.Smith, Babette, A Cargo of Women: Susannah Watson and the Convicts of the Princess Royal (Allen and Unwin, 2nd ed, 2008)

812.Smith, Graham, The Issue of Research and Maori (Research Unit for Maori Education, University of Auckland, 1992) <http://link.kotui.org.nz/portal/The-Issue-of-research-and-Maoried-Research/yCmT1jGvddc/>

813.Smith, Linda Tuhiwai, Decolonizing Methodologies: Research and Indigenous Peoples (University of Otago Press, 2nd ed, 2012)

814.Smythe, Dee, Rape Unresolved: Policing Sexual Offences in South Africa (UCT Press, 2015)

815.Spears, George, Gender and Violence in the Mass Media: Report (Erin Research for Health Canada, 1993)

816.Spivak, Gayatri Chakravorty, The Post-Colonial Critic: Interviews, Strategies, Dialogues (Routledge, 1990)

817.Spivak, Gayatri Chakravorty, A Critique of Postcolonial Reason: Toward a History of the Vanishing Present (Harvard University Press, 1999)

818. Sriram, Chandra Lekha, Olga Martin-Ortega and Johanna Herman, Peacebuilding and Rule of Law in Africa: Just Peace? (Routledge, 2010)

819.Stark, Evan, Coercive Control the Entrapment of Women in Personal Life (Oxford University Press, 2007)

<http://search.ebscohost.com/login.aspx ?direct=true \&scope=site $\& d b=$ nlebk\&db=nlabk \&AN=19 1217>

820.Starr, Frederick, Liberia: Description, History, Problems (The University of Virginia, 1913) <https://books.google.com/books/about/Liberia.html?id=-7JWAAAAYAAJ>

821.Stauffer, Robert B, D Elwood Dunn and Miriam Leitner, Constitutional Documents of the United States of America, 1776-1860 Supplement, Hawai'i and Liberia (Walter de Gruyter, 2008) <http://public.eblib.com/choice/publicfullrecord.aspx?p=364720>

822.Steady, Filomina Chioma, Women and Leadership in West Africa: Mothering the Nation and Humanizing the State (Palgrave Macmillan, 1st ed, 2011)

823.Steckel, Richard H and Roderick Floud (eds), Health and Welfare During Industrialization (University of Chicago Press, 1997) 
824.Steiner, Henry J, International Human Rights in Context: Law, Politics, Morals - Text and Materials (Oxford University Press, 3rd ed, 2008)

825.Stone, Dan, The Historiography of Genocide (Palgrave Macmillan, 2010)

826. Stone, Sharman Nance, Aborigines in White Australia: A Documentary History of the Attitudes Affecting Official Policy and the Australian Aborigine, 1697-1973 (Heinemann Educational, 1974) <http://catalog.hathitrust.org/api/volumes/oclc/1655220.html>

827. Strakosch, Elizabeth, Neoliberal Indigenous Policy: Settler Colonialism and the 'Post-Welfare' State (Palgrave Macmillan, 2015)

828. Streissguth, Thomas, Liberia in Pictures (Twenty-First Century Books, 2006)

829. Strelein, Lisa, Compromised Jurisprudence: Native Title Cases Since Mabo (Aboriginal Studies Press, 2nd ed, 2009)

830.Strunk, William, The Elements of Style (Allyn and Bacon, 4th ed, 1999)

831.Stubbs, Julie, Women, Male Violence, and the Law (Institute of Criminology, Sydney University Law School, 1994)

<http://books.google.com.au/books/about/Women_male_violence_and_the_law.html?id=e_BA AQAAIAAJ\&redir_esc $=\mathrm{y}>$

832.Summons, John, Massacre at Myall Creek (Cambridge University Press, 1993)

833. Sutton, Peter, The Politics of Suffering: Indigenous Australia and the End of Liberal Consensus (Melbourne University Pub, 2011)

834.Suzack, Cheryl, Indigenous Women and Feminism: Politics, Activism, Culture (UBC Press, 2010)

835.Swain, Tony, Deborah Bird Rose and Australian Association for the Study of Religions (eds), Aboriginal Australians and Christian Missions: Ethnographic and Historical Studies (Australian Association for the Study of Religions, 1988)

836.Swain, Tony, A Place for Strangers: Towards a History of Australian Aboriginal Being (Cambridge University Press, 1993)

837.Taffe, Sue, Black and White Together FCAATSI: The Federal Council for the Advancement of Aborigines and Torres Strait Islanders, 1958-1973 (University of Queensland Press, 2005)

838. Tamanaha, Brian Z, On the Rule of Law: History, Politics, Theory (Cambridge University Press, 2004)

839.Tamanaha, Brian Z, Law as a Means to an End: Threat to the Rule of Law (Cambridge University Press, 2006)

840.Taplah, Lawrence D, Liberia, a Bulwark of Rage My First Home (Authorhouse, 2015)

841.Tatz, Colin Martin and Keith R McConnochie, Black Viewpoints: The Aboriginal Experience (Australia and New Zealand Book Co, 1975)

842.Tatz, Colin Martin, With Intent to Destroy: Reflecting on Genocide (VERSO, 2003)

843.Tatz, Colin Martin, Aboriginal Suicide Is Different: A Portrait of Life and Self-Destruction (Aboriginal Studies Press, 2nd ed, 2005)

844.Taylor, Christopher C, Sacrifice as Terror: The Rwandan Genocide of 1994 (Berg, 1999)

845. Taylor, Wayne C, The Firestone Operations in Liberia (National Planning Association, 1956)

846.Telling Stories: Indigenous History and Memory in Australia and New Zealand (Allen and Unwin, 2001)

847.Terris, Daniel, The International Judge: An Introduction to the Men and Women Who Decide the World's Cases (Brandeis University Press; Published by University Press of New England, 2007)

848.The Cambridge Companion to Human Rights Law (Cambridge University Press, 2012)

849.The Cambridge Companion to International Law (Cambridge University Press, 2012)

850.The Carter Centre and The Ministry of Justice, Handbook for Civil Society Partners: Community Education and Awareness Program on the Rule of Law (The Carter Centre, 2008)

$<$ https://www.google.com/\#q=What+is+a+Constitution?++Black's+Law+Dictionary+Fifth+Edit ion+defines+"Constitution"+as:+"The+organic+and+fundamental+law+of+a+nation+or+state, >

851.The Changing Constitution (Oxford University Press, 6th ed, 2007)

$<$ http://www.wildy.com/isbn/9780199205110/the-changing-constitution-6th-ed-paperbackoxford-university-press>

852.The Changing Face of Conflict and the Efficacy of International Humanitarian Law (Martinus Nijhoff Publishers, 1999)

853.The Future of UN Human Rights Treaty Monitoring (Cambridge University Press, 2000)

854.The International Handbook of Gender and Poverty: Concepts, Research, Policy (Edward Elgar, 2010)

855.The Law of International Responsibility (Oxford University Press, 2010)

856.wa Thiong'o, Ngũgĩ, Decolonising the Mind: The Politics of Language in African Literature (J. Currey ; Heinemann, 1986)

857.Third World Women and the Politics of Feminism (Indiana University Press, 1991) 
858. Thobani, Sunera, Exalted Subjects: Studies in the Making of Race and Nation in Canada (University of Toronto Press, 2007)

859.Thomson, Anne, Critical Reasoning: A Practical Introduction (Routledge, 3rd ed, 2009)

860.Thornberry, Patrick, International Law and the Rights of Minorities (Clarendon Press, Reissue, 1992)

861.Thornberry, Patrick, Indigenous Peoples and Human Rights (Manchester University Press, 2002)

862.Thornton, Margaret, Public and Private: Feminist Legal Debates (Oxford University Press, 1995)

863.Tink, Andrew, Lord Sydney: The Life and Times of Tommy Townshend (Australian Scholarly Publishing, 2011)

864. Tomaszewski, Irene and Debbie Ollis, Gender and Violence Project: Position Paper (Australian Government Publishing Service, 1993)

865.Tong, Rosemarie, Feminist Thought A Comprehensive Introduction (Taylor and Francis, 2013)

866.Toohey, Paul, The Killer Within: Inside the World of Bradley John Murdoch (Allen and Unwin, 2007)

867.Toohey, Paul, Last Drinks: The Impact of the Northern Territory Intervention (Black Inc., 2008)

868. Treiman, Donald J, Quantitative Data Analysis: Doing Social Research to Test Ideas (JosseyBass, 1st ed, 2009)

869. Trewin, Dennis, Year Book Australia 2001 (Australian Bureau of Statistics, Centenary of Federation, 2005) <http://books.googleusercontent.com/books/content?req=AKW5Qae2u2O14EJpVaHz5PhoQUuwmdmwxrqnTBcnNbgzkDFjnt0md53MBrilsuusGk1oPiKj3tups73Sot 1KGfM3rq024HUe12RBFCuLqWhqBU4E1Cs9nM7q79JsNxwTNrmMp7h9fSXynIN_Ym8MBSttP3m1ZKQRpqa1Sqr9sdhQM1XpH_3FqLTJu1To_euN61-

XwKjjmfUbphj4cmNsi5V8EBuxkM1OFPiafHasO3z9zL_p3ux9zFal30dfj4U4MRjIpINb1>

870.Trouillot, Michel-Rolph, Silencing the Past: Power and the Production of History (Beacon Press, 2001)

871.Tually, Selina, Debbie Faulkner and Cecile Cutler, Women, Domestic and Family Violence and Homelessness a Synthesis Report (Office for Women, Department of Families, Housing, Community Services and Indigenous Affairs, 2008)

<http://www.ofw.facs.gov.au/publications/synthesis_report04/Women,\%20Domestic\%20and\%2 0Family\%20Violence\%20Synthesis\%20Report\%20(Flinders\%20University\%202008).pdf>

872.Tugendhat, Helen and Eleanor Ditaan-Bang-oa, Realising Indigenous Women's Rights: A Handbook on the CEDAW (Tebtebba Foundation, Forest Peoples Program and Asia Indigenous Women's Network, 2013)

873.Turbulent Peace: The Challenges of Managing International Conflict (United States Institute of Peace Press, 2001)

874. Turnbull, Clive, The Black War: The Extermination of the Tasmanian Aborigines (F. W. Cheshire, 1948)

875.Turshen, Meredeth and Clotilde Twagiramariya, What Women Do in Wartime: Gender and Conflict in Africa (Zed Books Ltd, 1998)

876.Tyler-McGraw, Marie, An African Republic: Black \& White Virginians in the Making of Liberia (The University of North Carolina Press, 2007) <http://www.amazon.com/AfricanRepublic-Virginians-Franklin-American/dp/0807831670>

877.Uglow, Jennifer S, Frances Hinton and Maggy Hendry (eds), The Northeastern Dictionary of Women's Biography (Northeastern University Press, 3rd ed, 1999)

878.Uhr, John and Ryan Walter, Studies in Australian Political Rhetoric (ANU E Press, 2014)

879.UN Children's Fund, Every Child Counts: Revealing Disparities, Advancing Children's Rights. (United Nations Children's Fund, 2014) <http://www.unicef.org/sowc2014/numbers/>

880.UN Children's Fund, The State of the World's Children 2015: Reimagine the Future Innovation for Every Child (United Nations Children's Fund, 2014)

881.UN Development Fund for Women, Not a Minute More: Ending Violence Against Women (UNIFEM, 2003)

882.Uncommon Ground: White Women in Aboriginal History (Aboriginal Studies Press for the Australian Institute of Aboriginal and Torres Strait Islander Studies, 2005)

883.Unger, Roberto Mangabeira, The Critical Legal Studies Movement: Another Time, A Greater Task (Verso, 2015)

884. United Nations, Women, Peace and Security: Study Submitted by the Secretary-General Pursuant to Security Council Resolution 1325 (2000) (United Nations, 2002) <http://www.un.org/womenwatch/daw/public/eWPS.pdf>

885.United Nations, Human Rights and Prisons: A Compilation of International Human Rights Instruments Concerning the Administration of Justice (United Nations, 2005)

886. Van Ness, Daniel W, Restoring Justice: An Introduction to Restorative Justice (LexisNexis: Anderson Pub, 4th ed, 2010) 
887. VanderStoep, Scott W and Deirdre D Johnston, Research Methods for Everyday Life: Blending Qualitative and Quantitative Approaches (Jossey-Bass, 1st ed, 2009)

888. Veth, Peter Marius, Peter Sutton and Margo Neale (eds), Strangers on the Shore: Early Coastal Contacts in Australia (National Museum of Australia Press, 2008)

889. Victoria. Sentencing Advisory Council, Maximum Penalties for Sexual Penetration With a Child Under 16: Report (Sentencing Advisory Council, 2009)

$<$ https://sentencingcouncil.vic.gov.au/sites/sentencingcouncil.vic.gov.au/files/maximum_penalti es_for_sexual_penetration_with_a_child_under_16_report.pdf >

890.Victorian Aborigines Advancement League, Victims or Victors?: The Story of the Victorian Aborigines Advancement League (Hyland House, 1985)

891.Vinck, Patrick, Phuong Pham and Tino Kreutzer, Talking Peace: A Population-Based Survey on Attitudes about Security, Dispute Resolution, and Post-Conflict Reconstruction in Liberia (Human Rights Centre, University of Berkeley, California, 2011)

$<$ http://www.peacebuildingdata.org/node/627>

892.Violence and Belonging: The Quest for Identity in Post-Colonial Africa (Routledge, 2005)

893. Violence and the Body: Race, Gender, and the State (Indiana University Press, 2003)

894. Visible Women: Essays on Feminist Legal Theory and Political Philosophy (Hart Publishing, 2002)

895. Voorhoeve, JJC, From War to the Rule of Law: Peacebuilding After Violent Conflicts (Amsterdam University Press, 2007)

896. Wallace, Mike and Alison Wray, Critical Reading and Writing for Postgraduates (SAGE Publications, 2nd ed, 2011)

897. Walsh, Anthony and Craig Hemmens, Law, Justice, and Society: A Sociolegal Introduction (Oxford University Press, Fourth, 2016) <https://global.oup.com/academic/product/law-justiceand-society-9780190272753?cc=us\&lang=en\&\#>

898. War in the Tribal Zone: Expanding States and Indigenous Warfare (School of American Research Press ; Distributed by the University of Washington Press, 1992)

899. Ward, Ian, Introduction to Critical Legal Theory (Cavendish, 2nd ed, 2004)

900.Watson, Irene, First Nations Peoples, Colonialism and International Law: Raw Law (Routledge, 2015) <http://www.routledge.com/books/details/9780415721752/>

901.Waugh, Colin M, Charles Taylor and Liberia: Ambition and Atrocity in Africa's Lone Star State (Zed Books, 2011)

902. Weatherburn, Donald James, Arresting Incarceration: Pathways Out of Indigenous Imprisonment (Aboriginal Studies Press, 2014)

903.W.E.B. Du Bois (Chelsea House Publishers, 2001)

904. Webster, Kim et al, Australians' Attitudes to Violence Against Women Full Technical Report: Findings From the 2013 National Community Attitudes Towards Violence Against Women Survey (NCAS) (VicHealth, 2014) <http://www.vichealth.vic.gov.au/Publications/Freedomfrom-violence/2013-National-Community-Attitudes-towards-Violence-Against-WomenSurvey.aspx>

905.Weitekamp, Elmar GM and Hans-Jürgen Kerner, Restorative Justice: Theoretical Foundations (Willan Pub, 2002)

906. West, Barbara A, A Brief History of Australia (Facts On File, 2010)

907.West, Cornel, Race Matters (Vintage Books, 2nd ed, 2001)

908. Westerlund, David, African Indigenous Religions and Disease Causation: From Spiritual Beings to Living Humans (Brill, 2006)

909.Wilkinson, Richard G and Michael G Marmot (eds), The Solid Facts (World Health Organization, Regional Office for Europe, 2nd ed, 2003)

910.Williams, Nancy M, Two Laws: Managing Disputes in a Contemporary Aboriginal Community (Australian Institute of Aboriginal Studies, 1987)

911.Williams, Patricia J, The Alchemy of Race and Rights (Harvard University Press, 1991)

912.Williams, Sarah, Hybrid and Internationalised Criminal Tribunals: Selected Jurisdictional Issues (Hart Pub, 2012)

913. Williams, Susan Hoffman, Constituting Equality: Gender Equality and Comparative Constitutional Law (Cambridge University Press, 2009)

914.Wills, Anita L, Pieces of the Quilt: The Mosaic of an African American Family (Booksurge, 2009)

915.Wilson, Tikka Jan and Link-Up (N.S.W.) Aboriginal Corporation, In the Best Interest of the Child? Stolen Children: Aboriginal Pain, White Shame (Aboriginal History, 1997)

916.Windschuttle, Keith, The Fabrication of Aboriginal History (Macleay Press, 2002)

917.Wing, Kenneth, The Law and the Public's Health (Health Administration Press, 7th ed, 2007)

918. Wold, Joseph Conrad, God's Impatiences in Liberia (W. B. Eerdmans Publishing Company, 1968) 
919.Wolf, Diane L (ed), Feminist Dilemmas in Fieldwork (Westview Press, 1996)

920. Wolf, Eric R, Thomas Hylland Eriksen and Noel Lallana Diaz, Europe and the People Without History (University of California Press, 2010)

921. Wollstonecraft, Mary, A Vindication of the Rights of Woman: With Structures on Political and Moral Subjects (J Johnson, 1792)

<https://scholarsbank.uoregon.edu/xmlui/bitstream/handle/1794/785/vindication.pdf>

922. Women and International Human Rights Law (Transnational, 1999)

923. Women and the Law in Australia (LexisNexis Butterworths, 2010)

924. Women and Violence (Zed Books, 1994)

925. Women's Role in Aboriginal Society (Australian Institute of Aboriginal Studies, 2nd ed, 1974)

926. Woodson, Carter Godwin, The Education of the Negro Prior to 1861 - A History of the Education of the Coloured People of the United States from the Beginning of Slavery to the Civil War (Putnam, 1915)

927. Woodson, Carter Godwin, The Mis-Education of the Negro (The Associated Publisher, 1933) <https://devontekwatson.files.wordpress.com/2013/10/miseducation-text.pdf>

928. Woolford, Andrew John, Informal Reckonings: Conflict Resolution in Mediation, Restorative Justice, and Reparations (Routledge-Cavendish, 1st ed, 2008)

929. Woons, Marc (ed), Restoring Indigenous Self-Determination: Theoretical and Practical Approaches (E-International Relations, 2014)

930.Working Memory and Education (Academic Press, 2006)

931. Working the Ruins: Feminist Poststructural Theory and Methods in Education (Routledge, 2000)

932. Worrall, Anne, Offending Women: Female Lawbreakers and the Criminal Justice System (Routledge, 1990)

933. Wreh, Tuan, The Love of Liberty: The Rule of President William V. S. Tubman in Liberia, 1944-1971 (C. Hurst, 1976)

934.Wreh, Tuan, Cases, Statutes, and Materials on Liberian Labor Law (Wreh News Agency, 1977)

935.Wrigley, Chris, Kingship and State: The Buganda Dynasty (Cambridge University Press, 2002)

936. Wulah, Teah, The Forgotten Liberian: History of Indigenous Tribes (AuthorHouse, 2005)

937. Wykes, Maggie, Violence, Gender and Justice (SAGE, 2009)

938.Xanthaki, Alexandra, Indigenous Rights and United Nations Standards: Self-Determination, Culture and Land (Cambridge University Press, 2007)

939. Yap, Mandy and Nicholas Biddle, Towards a Gender-Related Index for Indigenous Australians (Centre for Aboriginal Economic Policy Research, ANU, 2009)

940. Yin, Robert K, Case Study Research: Design and Methods (SAGE, 5th ed, 2014)

941.Zehr, Howard, Changing Lenses: A New Focus for Crime and Justice (Herald Press, 3rd ed, 1990)

942.Zernova, Margarita, Restorative Justice: Ideals and Realities (Ashgate, 2007)

\section{Book Section}

1. Ackerman, Robert J, 'Alcoholism and the Family' in Claudia Black et al (eds), Children of Alcoholics: Selected Readings (National Association for Children of Alcholics, 1995) 143 <http://www.nacoa.org/Selected\%20refs_2002.pdf>

2. Alfred (Mohawk), Taiaiake, 'Sovereignty' in Sovereignty Matters: Locations of Contestation and Possibility in Indigenous struggle for Self-determination (University of Nebraska Press, 2006) 33

3. Association of Female Lawyers in Liberia, 'Hundreds of Victims Silently Grieving' in Meredeth Turshen and Clotilde Twagiramariya (eds), What Women Do in Wartime: Gender and Conflict in Africa (Zed Books Ltd, 1998) 128

4. Baker, Richard, 'Coming in? The Yanyuwa as a Case Study in the Geography of Contact History' in Valerie Chapman and Peter Read (eds), Terrible Hard Biscuits: A Reader in Aboriginal History (Allen and Unwin, 1996) 123

5. Barcham, Manuhuia, '(De)Constructing the Politics of Indigeneity' in Duncan Ivison, Paul Patton and Will Sanders (eds), Political Theory and the Rights of Indigenous Peoples (Cambridge University Press, 2002) 137

6. Bell, Diane, 'Representing Aboriginal Women: Who Speaks for Whom?' in Oliver Mendelsohn and Upendra Baxi (eds), The Rights of Subordinate Peoples (Oxford University Press, 1996) 221

7. Bern, John and Susan Dodds, 'On the Plurality of Interests: Aboriginal Self-Government and Land Rights' in Duncan Ivison, Paul Patton and Will Sanders (eds), Political Theory and the Rights of Indigenous Peoples (Cambridge University Press, 2002) 163

8. Bielefeld, Shelley and Will Sanders, 'Neoliberalism and the Return of the Guardian State: Micromanaging Indigenous Peoples in a New Chapter of Colonial Governance' in Engaging Indigenous Economy: Debating Diverse Approaches (ANU E Press, 2016) 155 
9. Bielefeld, Shelley, 'The Intervention, Stronger Futures and Racial Discrimination: Placing the Australian Government under Scrutiny' in Elisabeth Baehr and Barbara Schmidt-Haberkamp (Eds), And there 'll be NO Dancing'. Perspectives on Policies Impacting Indigenous Australia Since 2007 (Cambridge Scholars Publishing, 2017) 145

10. Bond, Johanna, 'Violence against Women' in Voices of African Women: Women's Rights in Ghana, Uganda, and Tanzania (Carolina Academic Press, 2005) 75

11. Carby, Hazel V and Heidi Safia Mirza, 'White Woman Listen! Black Feminism and the Boundaries of Sisterhood' in Black British Feminism: A Reader (Routledge, 1997) 45

12. Cornell, Drucilla, 'The Philosophy of the Limit: Systems Theory and Feminist Legal Reform' in Drucilla Cornell, Michel Rosenfeld and David Gray Carlson (eds), Deconstruction and the Possibility of Justice (Taylor and Francis, 2016) 68

13. Costa, Pietro, 'The Rule of Law: A Historical Introduction' in Pietro Costa and Danilo Zolo (eds), The Rule of Law, History, Theory and Criticism (Springer, 2007) 73

14. Crawford, James, 'Legal Pluralism and Indigenous Peoples' in Oliver Mendelsohn and Upendra Baxi (eds), The Rights of the Subordinated Peoples (Oxford University Press, 1996) 178

15. Cruickshank, Joan, "To Exercise a Beneficial Influence over a Man”: Marriage, Gender and the Native Institutions in Early Colonial Australia' in Evangelists of Empire?: Missionaries in Colonial History (eScholarship Research Centre, 2008) 115 <http://repository.unimelb.edu.au/10187/3155>

16. Cunneen, Chris, 'Restorative Justice, Globalization and the Logic of Empire' in Borders and Crime: Pre-Crime, Mobility and Serious Harm in an Age of Globalization: Transnational Crime, Crime Control and Security (Palgrave Macmillan, 2012) 147

17. Dallmayr, Fred, 'Hermeneutics and the Rule of Law' in Drucilla Cornell, Michel Rosenfeld and David Gray Carlson (eds), Deconstruction and the Possibility of Justice (Taylor and Francis, 2016) 283

18. Davis, Angela J, 'Prosecution and Race: The Power and Privilege of Discretion' in Susan D Carle (ed), Lawyers' Ethics and the Pursuit of Social Justice: A Critical Reader (New York University Press, 2005) 245

19. Dodson, Patrick L, 'What Happened to Reconciliation?' in Jon C Altman and Melinda Hinkson (eds), Coercive Reconciliation: Stabilise, Normalise, Exit Aboriginal Australia (Arena Publications Association, 2007) 21

20. Dunn, Daniel Elwood, 'Liberia' in Dinah Shelton L (ed), Encyclopedia of Genocide and Crimes Against Humanity (Macmillan Reference, 2005) vol 2, 648

21. Edmund, Husserl, 'Pure Phenomenology, Its Method, and Its Field of Investigation' in The Phenomenology Reader (Routledge, 2002) 624

22. Evans, Raymond and A Dirk Moses, "Plenty Shoot "Em": The Destruction of Aboriginal Societies along the Queensland Frontier' in Genocide and Settler Society: Frontier Violence and Stolen (Berghahn Books, 2004) 150

23. Flood, Michael, 'Current Practices to Preventing Sexual and Intimate Partner Violence' in Holly Johnson, Bonnie S Fisher and Veronique Jaquier (eds), Critical Issues on Violence Against Women: International Perspective and Promising Strategies (Routledge, 2014) 1

24. Flood, Michael, 'Men's Anti-Violence Activism and the Construction of Gender-Equitable Masculinities' in Angels Carabi and Jose Armengol (eds), Moving Ahead: Alternative Masculinities for a Changing World (Palgrave MacMillan, 2014) 244

25. Flood, Michael, 'Preventing Violence against Women and Girls' in Gender in Organizations: Are Men Allies or Adversaries to Women's Career Advancement? (Edward Elgar, 2014) 405

26. Flood, Michael, 'Men and Gender Equality' in Michael Flood and Richard Howson (eds), Engaging Men in Building Gender Equality (Cambridge Scholars Publishing, 2015) 1

27. Flood, Michael, 'Preventing Male Violence' in Catherine L Ward and Peter D Donnelly (eds), Oxford Textbook of Violence Prevention: Epidemiology, Evidence, and Policy (Oxford University Press, 2015) 201

28. Haggis, Jane, 'Thoughts on a Politics of Whiteness in a (Never Quite Post) Colonial Country: Abolitionism, Essentialism and Incommensurability' in Thoughts on a Whiteness of Politics (Aboriginal Studies Press, 2004) 57

29. Hahn, Niels, 'The Experience of Land Grab in Liberia' in Handbook of land and water grabs in Africa: foreign direct investment and food and water security (Routledge, 2012) 512

30. Hanisch, Carol, 'The Personal Is Political' in Shulamith Firestone and Anne Koedt (eds), Women's Liberation (Notes From the Second Year - Radical Feminism, 1969) 76 <http://library.duke.edu/digitalcollections/wlmpc_wlmms01039/>

31. Hatty, Suzanne E, Nanette J Davis and Stuart Burke, 'No Exit: Violence, Gender and the Streets' in Mark Israel and Chris Sumner (eds), Proceedings of the 8th International Symposium on Victimology (Flinders University, 1996) 46 
32. Heydon, JD, 'Brisbane, Sir Thomas Makdougall (1773-1860)' in Australian Dictionary of Biography (National Centre of Biography, Australian National University, 1966) $<$ http://adb.anu.edu.au/biography/brisbane-sir-thomas-makdougall-1827>

33. Hilden, Patricia Penn and Leece M Lee, 'Indigenous Feminism: The Project' in Cheryl Suzack et al (eds), Indigenous Women and Feminism: Politics, Activism, Culture (University of British Columbia Press, 2010) 56

34. Huhndorf, Shari M and Cheryl Suzack, 'Indigenous Feminism: Theorising the Issues' in Cheryl Suzack et al (eds), Indigenous Women and Feminism: Politics, Activism, Culture (University of British Columbia Press, 2010) 1

35. Johnston, Harry H, 'Liberia' in Geographical Journal: Including the Proceedings of the Royal Geographical Society (Edward Stanford, 1905) 131

36. Kalbfleisch, Elizabeth, 'Bordering in Feminism: Space, Solidarity, and Transnationalism in Rebecca Belmore's Vigil' in Cheryl Suzack et al (eds), Indigenous Women and Feminism: Politics, Activism, Culture (University of British Columbia Press, 2010)

37. Kimmel, Michael S, 'Who's Afraid of Men Doing Feminism?' in Tom Digby (ed), Men doing feminism (Routledge, 1998)

38. Kohen, JL, 'Pemulwuy (1750-1802)' in Australian Dictionary of Biography (National Centre of Biography, Australian National University, 2005) http://adb.anu.edu.au/biography/pemulwuy

39. Lennox, Corinne and Damien Short, 'Indigeneity' in Damien Short and Corinne Lennox (eds), Handbook of Indigenous People's Rights (Routledge: Taylor \& Francis Group, 2015) 1

40. Lubkemann, Stephen C, Deborah H Isser and Philip AZ Banks, 'Unintended Consequences: Constraint of Customary Justice in Post-Conflict Liberia' in Deborah H Isser (ed), Customary Justice and the Rule of Law in War-Torn Societies (United States Institute of Peace Press, 2011) 193

41. Maiga, Soyata, 'Gender and Indigenous Peoples' Rights' in Korir Sing'Oei and Ridwan Laher (eds), Indigenous People in Africa: Contestations, Empowerment and Group Rights (Africa Institute of South Africa, 2014) 64

42. McCalla Vickers, Jill, 'Memoirs of an Ontological Exile: The Methodological Rebellions of Feminist Research' in Geraldine Finn and Angela Rose Miles (eds), Feminism in Canada (Black Rose Books, 1982) 57

43. McLachlan, ND, 'Macquarie, Lachlan (1762-1824)' in Australian Dictionary of Biography (National Centre of Biography, Australian National University, 1967)

$<$ http://adb.anu.edu.au/biography/macquarie-lachlan-2419>

44. Morel, Cynthia, 'The Endorois Community versus Kenya' in Korir Sing'Oei and Ridwan Laher (eds), Indigenous Peoples in Africa: Contestation, Empowerment and Group Rights (Africa Institute of South Africa, 2014) 194

45. Moreton-Robinson, Aileen, 'Whiteness, Epistemology and Indigenous Representation' in Whitening race: Essays in social and cultural criticism (Aboriginal Studies Press, 2004) 75

46. Morphy, Frances, 'Australia's Indigenous Protected Areas: Resistance, Articulation, and Entanglement in the Context of Natural Resource Management' in Françoise Dussart and Sylvie Poirier (eds), Entangled Territorialities: Negotiating Indigenous Lands in Australia and Canada (University of Toronto Press, 2017) 70

47. Morse, Janice M, 'Principles of Mixed Methods and Multimethod Research Designs' in Abbas Tashakkori and Charles Teddlie (eds), Handbook of Mixed Methods in Social and Behavioural Research (Sage, 2nd ed, 2003) 189

48. Mukundi, George and Tuuli Karjala, 'Advocacy for Indigenous Peoples' Rights in Africa: Dynamics, Methods and Mechanisms' in Korir Sing'Oei and Ridwan Laher (eds), Indigenous People in Africa: Contestations, Empowerment and Group Rights (Africa Institute of South Africa, 2014) 104

49. Naples, Nancy A and Emily Clark, 'Feminist Participatory Research and Empowerment: Going Public as Survivors of Childhood Sexual Abuse' in Heidi Gottfried (ed), Feminism and Social Change: Bridging Theory and Practice (University of Illinois Press, 1996) 160

50. Ndahinda, Felix, 'Historical Development of Indigenous Identification and Rights in Africa' in Korir Sing'Oei and Ridwan Laher (eds), Indigenous People in Africa: Contestations, Empowerment and Group Rights (Africa Institute of South Africa, 2014) 24

51. Paust, Jordan J, 'Basic Forms of International Law and Monist, Dualist, and Realist Perspectives' in Marko Novkovic (ed), Basic Concepts of Public International Law - Monism and Dualism (Faculty of Law, University of Belgrade, 2013) 244

52. Schia, Niels Nagelhus, 'Reforms, Customs and Resilience: Justice for Sexual and Gender-Based Violence in Liberia' in Anastasia Powell, Nicola Henry and Asher Flynn (eds), Rape Justice: Beyond the Criminal Law (Palgrave Macmillan, 2015) 143

53. Sherwood, Henry Noble, 'Mississippi Valley Historical Review 2' in Staudenraus (ed), The African Colonization Movement, 1816-1865 (Columbia University Press, 1961) 484 
54. Silverstein, Ben, 'Indirect Rule in Australia: A Case Study in Settler-Colonial Difference' in Fiona Bateman and Lionel Pilkington (eds), Studies in Settler Colonialism (Palgrave Macmillan UK, 2011) $90<$ http://link.springer.com/10.1057/9780230306288>

55. Simić, Olivera, 'Sexual Conduct and Peacekeeping' in Regulation of Sexual Conduct in UN Peacekeeping Operations (Springer Berlin Heidelberg, 2012) 1 <http://www.springerlink.com/index/10.1007/978-3-642-28484-7_1>

56. Simms, Marion, 'Women in Parliament' in Brian Galligan and Winsome Roberts (eds), Oxford Companion to Australian Politics (Oxford University Press, 2007) 686

57. Smith, Patricia, 'Four Themes in Feminist Legal Theory: Difference, Dominance, Domesticity, and Denial' in The Blackwell Guide to the Philosophy of Law and Legal Theory (Blackwell Pub, 2005) 90

58. Spivak, Gayatri Chakravorty, 'Can the Subaltern Speak?' in Cary Nelson and Lawrence Grossberg (eds), Marxism and the Interpretation of Culture (MacMillan Education, 1988) 271

59. Stavenhagen, Rodolfo, 'Making the Declaration Work' in Making the Declaration work: The United Nations Declaration on the Rights of Indigenous Peoples (Inter-Agency Working Group on Indigenous Affairs, 2009) 352

60. Suzack, Cheryl, 'Emotion before the Law' in Cheryl Suzack et al (eds), Indigenous Feminism: Politics, Activism, Culture (University of British Columbia Press, 2010) 126

61. Tatz, Colin, Oliver Mendelsohn and Upendra Baxi, 'A Question of Rights and Wrongs' in The Rights of the Subordinated Peoples (Oxford University Press, 1996) 159

62. Toubia, Nahid, 'Women's Reproductive and Sexual Rights' in Gender Violence and Women's Human Rights in Africa (Centre for Women's Global Leadership, 1994) 42

63. Turshen, Meredeth, 'The Political Economy of Rape: An Analysis of Systematic Rape and Sexual Abuse of Women during Armed Conflict in Africa' in Caroline ON Moser and Fiona C Clark (eds), Victors, Perpetrators or Actors: Gender, Armed Conflict and Political Violence (Zed Books, 2001) 55

64. Tushnet, Mark V, 'Critical Legal Theory' in Martin P Golding and William A Edmundson (eds), The Blackwell Guide to the Philosophy of Law and Legal Theory (Blackwell Pub, 2005) 80

65. Vansina, Jan, 'Upstarts and Newcomers in Equatorial Africa (C1815-1875)' in Philip Curtin et al (eds), African History: From Earliest Times to Independence (Longman Pearson, 1995) 376

66. Walker, Lyn, Michael Flood and Kim Webster, 'Violence against Women: A Key Determinant of Health and Well-Being' in Helen Keleher and Colin MacDougall (eds), Understanding Health: A determinants Approach (Oxford University Press, 2nd ed, 2009) 352

67. Watson, Irene, 'Aboriginal Women's Laws and Lives: How Might We Keep Growing the Law?' in Elliott Johnston, Martin Hinton and Daryle Rigney (eds), Indigenous Australians and the Law (Routledge-Cavendish, 2nd ed, 2008) 15

68. Weatherburn, Donald James and Lucy Snowball, 'Is There a Cultural Explanation for Indigenous Violence? A Second Look at the NATSISS' in Boyd Hunter and Nicholas Biddle (eds), Survey Analysis for Indigenous Policy in Australia (Australian National University Press, 2012) 223

69. Young, Laura A and Abraham Korir Sing'Oei, 'Access to Justice for Indigenous Peoples in Africa' in Indigenous Peoples' Access To Justice, Including Truth And Reconciliation Processes (Academic Commons, Columbia University, 2014) 89 <https://academiccommons.columbia.edu/catalog/ac:184797>

70. Zolo, Danilo, 'The Rule of Law: A Critical Reappraisal' in Pietro Costa and Danilo Zolo (eds), The Rule of Law, History, Theory and Criticism (Springer, 2007) 3

71. Zubrick, Stephen R et al, 'Social Determinants of Aboriginal and Torres Strait Islander Social and Emotional Wellbeing' in Nola Purdie, Pat Dudgeon and Roz Walker (eds), Working Together: Aboriginal and Torres Strait Islander Mental Health and Wellbeing Principles and Practice (Commonwealth of Australia, 2010) 76

\section{Conference Paper}

1. AIC, 'Without Consent: Confronting Adult Sexual Violence' in Proceedings of a Conference held 27-29 October 1992 in Melbourne (Australian Institute of Criminology, 1993) 405 <http://aic.gov.au/media_library/publications/proceedings/20/recom.pdf>

2. Aldunate, Raquel, 'Sexual Assault: A Public Responsibility' in Proceedings of a Conference held 27-29 October 1992 (Australian Institute of Criminology, 1993) 166 <http://www.aic.gov.au/media_library/publications/proceedings/20/aldunate.pdf>

3. Alvares, Esther, 'A Women's Refuge for Bourke: A Community Initiative' in Proceedings of a conference held 23-25 June 1992 (Australian Institute of Criminology, 1992) 179

4. Blow, Reg, 'The Dooligar Justice Centre: A Post-Royal Commission Response to Aboriginal Correctional Issues' in Proceedings of a conference held 23-25 June 1992 (Australian Institute of Criminology, 1993) 185 
5. Boyne, Steven, 'The PhD Literature Review: Its Structure and Contribution' in Margaret Jolly and PK Wong (eds), The Proceedings of the Plymouth Postgraduate Symposium (University of Plymouth, 2009) 299

6. Braxton, Gloria J, 'Political Leadership in Liberia: Historical and Contemporary Perspectives on the Role of Female Chiefs and Tribal Governors' in First International Conference on Women in Africa and the African Diaspora (AAWS, 1992) 217

7. Bugg, Damian, 'The Independence of the Prosecutor and the Rule of Law' in Rule of Law: The Challenges of a Changing World (Law Council of Australia, 2007) 1

8. Byrnes, Lynette and Susan Kendall, 'Only a Witness' in Proceedings of a Conference held 2729 October 1992 (Australian Institute of Criminology, 1993) 55 <http://aic.gov.au/media_library/publications/proceedings/20/byrnes.pdf>

9. Commonwealth of Australia, 'Aboriginal Welfare' in Initial Conference of Commonwealth and State Aboriginal Authorities (Commonwealth Government, 1937) 35 <https://aiatsis.gov.au/sites/default/files/catalogue_resources/20663.pdf>

10. Crake, Mark, 'Who Is the Rapist? A Series of Case Studies' in Proceedings of a Conference held 27-29 October 1992 (Australian Institute of Criminology, 1993) 277

<http://aic.gov.au/media_library/publications/proceedings/20/crake.pdf>

11. Cull, Denise, 'The Treatment of Rapists: A Measure of Prevention' in Proceedings of a Conference held 27-29 October 1992 (Australian Institute of Criminology, 1993) 263 <http://aic.gov.au/media_library/publications/proceedings/20/cull.pdf>

12. Cunneen, Chris, 'Judicial Racism' in Proceedings of a conference held 23-25 June 1992 (Australian Institute of Criminology, 1993) 1

13. Davis, Byron, 'The Inappropriateness of the Criminal Justice System - Indigenous Australian Criminological Perspective' in Symposium on Mapping the Boundaries of Australia's Criminal Justice System (Australian Institute of Criminology, 1999) 1

14. Dick, Darren and Tom Calma, 'Social Determinants and the Health of Indigenous Peoples in Australia - A Human Rights Based Approach' in International Symposium on the Social Determinants of Indigenous Health (Australian Human Rights Commission, 2007) 10

15. Dodson, Patrick L, 'Doctrine I: An Indigenous Doctrine of Discovery Post Terra Nullius' in Thinking for Yourself: A Conference in Honour of Robert Manne (La Trobe University, 2013) 1

16. Easteal, Patricia Weiser, 'Beliefs about Rape: A National Survey' in Proceedings of a Conference held 27-29 October 1992 (Australian Institute of Criminology, 1993) 21 <http://aic.gov.au/media_library/publications/proceedings/20/esteal1b.pdf>

17. Easteal, Patricia Weiser, 'Rape Prevention: Combatting the Myths' in Proceedings of a Conference held 27-29 October 1992 (Australian Institute of Criminology, 1993) 314 <http://aic.gov.au/media_library/publications/proceedings/20/esteal4b.pdf>

18. Evans, Raymond, "I Cannot Say the Numbers That Were Killed": Assessing Violent Mortality on the Queensland Frontier' in Conflict in History (Author's Original Manuscript (preprint version), 2014) 1 <http://papers.ssrn.com/sol3/papers.cfm?abstract_id=2467836>

19. Flood, Michael, ‘Engaging Men From Diverse Backgrounds in Preventing Men's Violence Against Women' in Stand Up! (The Australian Migrant \& Refugee Women's Alliance, 2013) 1

20. Fraser, Lionel, 'Aboriginal People and the Courts' in Proceedings of a conference held 23-25 June 1992 (Australian Institute of Criminology, 1993) 1 <http://www.aic.gov.au/media_library/publications/proceedings/21/fraser.pdf>

21. Frey, Ronald and Peter Douglas, 'What Is It about Men That Makes Them Do the Things They Do?' in Proceedings of a Conference held 27-29 October 1992 (Australian Institute of Criminology, 1993) 241 <http://aic.gov.au/media_library/publications/proceedings/20/frey.pdf>

22. Galliano, Grace et al, 'Victim Reactions during Rape/Sexual Assault: A Preliminary Study of the Immobility Response and Its Correlates' in Proceedings of a Conference held 27-29 October 1992 (Australian Institute of Criminology, 1993) 107 <http://aic.gov.au/media_library/publications/proceedings/20/galliano.pdf>

23. George, Amanda, 'Strip Searches: Sexual Assault by the State' in Proceedings of a Conference held 27-29 October 1992 (Australian Institute of Criminology, 1993) 211 <http://aic.gov.au/media_library/publications/proceedings/20/george.pdf>

24. Gilbert, Keith, 'Rape and the Sex Industry' in Proceedings of a Conference held 27-29 October 1992 (Australian Institute of Criminology, 1993) 189 <http://aic.gov.au/media_library/publications/proceedings/20/gilbert.pdf>

25. Glaser, William, 'Profiling the Rapist: The Prediction of Dangerousness' in Proceedings of a Conference held 27-29 October 1992 (Australian Institute of Criminology, 1993) 287 <http://aic.gov.au/media_library/publications/proceedings/20/glaser.pdf>

26. Goldsmith, Marlene, 'Sexual Offenders and Pornography: A Casual Connection?' in Proceedings of a Conference held 27-29 October 1992 (Australian Institute of Criminology, 1993) 253 <http://aic.gov.au/media_library/publications/proceedings/20/goldsmith.pdf> 
27. Goreng-Goreng, Tjanara, 'The Effects of Addiction/Alcoholism, Acculturation, Physical, Emotional and Sexual Violence on the Education of Aboriginal Children' in The Family: Our Hopes and Challenges (Association for Baha'i Studies Australia, 1995) http://bahai

28. Hall, Anne and Helen Last, 'Violence against Women in the Church Community: Project Anna' in Proceedings of a Conference held 27-29 October 1992 (Australian Institute of Criminology, 1993) 197 <http://aic.gov.au/media_library/publications/proceedings/20/hall.pdf>

29. Hayes, Susan, 'Sexual Violence against Intellectually Disabled Victims' in Proceedings of a Conference held 27-29 October 1992 (Australian Institute of Criminology, 1993) 201 <http://aic.gov.au/media_library/publications/proceedings/20/hayes.pdf >

30. Heenan, Melanie and Helen McKelvie, 'Towards Changing Procedures and Attitudes in Sexual Assault Cases' in Proceedings of a Conference held 27-29 October 1992 (Australian Institute of Criminology, 1993) 361

<http://aic.gov.au/media_library/publications/proceedings/20/heenan.pdf>

31. Hennessy, Annette, 'Indigenous Sentencing in Queensland Magistrates Court - Murri Court' in Rule of Law: The Challenges of a Changing World (Law Council of Australia, 2007) 1

32. Hiskey, Garry, 'The North West Circuit Court: (Pitjantjatjara Lands): A Personal Perspective' in Proceedings of a conference held 23-25 June 1992 (Australian Institute of Criminology, 1993) 151

33. Isaac, Joseph T, 'The Liberian Civil War: Child Soldiers, Rape, and Higher Education' in International Association of University Presidents (African Methodist Episcopal Zion University, 2014) 1

34. Jallah, David, 'Notes, Presentation by Professor and Dean of the Louis Arthur Grimes School of Law, University of Liberia' in Conference Learning from Each Other - Enriching the Law School Curriculum in an Interrelated World (Kenneth Wang School of Law, 2007) 4 <http://www.ialsnet.org/meetings/enriching/JallahDavid.pdf>

35. Johnston, LF, 'Aboriginal Welfare' in Initial Conference of Commonwealth and State Aboriginal Authorities (The Commonwealth of Australia, 1937) 35 <http://archive.aiatsis.gov.au/referendum/20663.pdf>

36. Kane, Penny, 'Gender Differentials in Violence and Their Implications' in Violence and Health" Proceedings of a WHO Global Symposium, 12-15 October 1999 (World Health Organization, 2000)

37. Lloyd, Jane and Nanette Rogers, 'Crossing the Last Frontier: Problems Facing Aboriginal Women Victims of Rape in Central Australia' in Without Consent: Confronting Adult Sexual Violence (Australian Institute of Criminology, 1992) 149 <http://www.aic.gov.au/publications/previous\%20series/proceedings/1-27/20.html>

38. Mansell, Michael, 'Law Reform and the Road to Independence' in Proceedings of a conference held 23-25 June 1992 (Australian Institute of Criminology, 1993) 9

39. McSherry, Bernadette, 'Legislating to Change Social Attitudes: The Significance of Section 37(a) of the Victorian Crimes Act 1958' in Proceedings of a Conference held 27-29 October 1992 (Australian Institute of Criminology, 1993) 373

<http://aic.gov.au/media_library/publications/proceedings/20/mcsherry.pdf>

40. Memmott, Paul, 'Mwerre Anetyeke Mparntwele (Sitting down Good in Alice Springs): A Project by Tangentyere Council' in Proceedings of a conference held 23-25 June 1992 (Australian Institute of Criminology, 1993) 47

41. Moloney, Dannye, 'Sexual Assault: The Police Investigation Perspective' in Proceedings of a Conference held 27-29 October 1992 (Australian Institute of Criminology, 1993) 399 <http://aic.gov.au/media_library/publications/proceedings/20/moloney.pdf>

42. Moran, Amanda, 'Patterns of Rape: A Preliminary Queensland Perspective' in Proceedings of a Conference held 27-29 October 1992 (Australian Institute of Criminology, 1993) 35 <http://aic.gov.au/media_library/publications/proceedings/20/moran.pdf>

43. O'Brien, Kate, 'Victim Credibility in Acquaintance Rape Cases: The Influence of Complainant Intoxication and Expectations about Alcohol-Involved Sexual Behaviour' in Proceedings of the Australian Psychological Society 42nd Annual Conference (APS, 2007) 302 $<$ http://researchoutput.csu.edu.au/R/?func=dbin-jumpfull\&object_id=13839\&local_base=GEN01-CSU01>

44. O’Donnell, Marg, 'Mediation within Aboriginal Communities: Issues and Challenges' in Proceedings of a conference held 23-25 June 1992 (Australian Institute of Criminology, 1993) 35

45. Pease, Bob and J Carlos Valazquez, 'Talking to Men in the Workplace about Sexual Assault against Women' in Proceedings of a Conference held 27-29 October 1992 (Australian Institute of Criminology, 1993) 341

<http://aic.gov.au/media_library/publications/proceedings/20/pease.pdf> 
46. Pirie, Kathryn and Sheryl Cornack, 'What Is Obscene - the Language or the Arrest That Follows?' in Proceedings of a conference held 23-25 June 1992 (Australian Institute of Criminology, 1993) 139

47. Polkinghorne, Esma, 'Sexual Assault and HIV/AIDS: The Implications' in Proceedings of a Conference held 27-29 October 1992 (Australian Institute of Criminology, 1993) 133 <http://aic.gov.au/media_library/publications/proceedings/20/polk.pdf>

48. Poropat, Analise, 'Understanding Women's Rape Experiences and Fears' in Proceedings of a Conference held 27-29 October 1992 (Australian Institute of Criminology, 1993) 115 <http://aic.gov.au/media_library/publications/proceedings/20/propata.pdf>

49. Reekie, Gail and Paul Wilson, 'Rape, Resistance and Women's Rights of Self-Defence' in Proceedings of a Conference held 27-29 October 1992 (Australian Institute of Criminology, 1993) 349 <http://aic.gov.au/media_library/publications/proceedings/20/reekie.pdf>

50. Scheffer, John W, 'Sexual Offence Intelligence: Proactive Approaches for Police' in Proceedings of a Conference held 27-29 October 1992 (Australian Institute of Criminology, 1993) 385 <http://aic.gov.au/media_library/publications/proceedings/20/scheffer.pdf>

51. Scutt, Joycelynne (ed), 'Rape Law Reform: A Collection of Conference Papers' in Proceedings of a National Conference on Rape Reform, held in Hobart, Tasmania from 28-30 May 1980 (Australian Institute of Criminology, 1980) 318 <http://www.aic.gov.au/media_library/archive/events-other/rape-law-reform.pdf>

52. Scutt, Joycelynne, 'Judicial Vision: Rape, Prostitution and the "Chaste Woman"' in Proceedings of a Conference held 27-29 October 1992 (Australian Institute of Criminology, 1993) 173 <http://aic.gov.au/media_library/publications/proceedings/20/scutt.pdf>

53. Sidoti, Chris, 'The Commonwealth's Responsibility for Aboriginal Young Offenders' in Proceedings of a conference held 23-25 June 1992 (Australian Institute of Criminology, 1993) 1 <http://www.aic.gov.au/media_library/publications/proceedings/21/sidoti.pdf>

54. Southwood, Stephen, 'Equality of the Law and the Sentencing of Aboriginal Offenders under the Sentencing Act (NT)' in Rule of Law: The Challenges of a Changing World (Law Council of Australia, 2007) 1

55. Spangaro, Joanna, 'Rape and "Real Rape"' in Proceedings of a Conference held 27-29 October 1992 (Australian Institute of Criminology, 1993) 15 <http://aic.gov.au/media_library/publications/proceedings/20/spangaro.pdf>

56. Stuart, Donna, 'No Real Harm Done: Sexual Assault and the Criminal Justice System' in Proceedings of a Conference held 27-29 October 1992 (Australian Institute of Criminology, 1993) 95 <http://aic.gov.au/media_library/publications/proceedings/20/stuart.pdf>

57. Thomas, Carol, 'Sexual Assault: Issues for Aboriginal Women' in Proceedings of a Conference held 27-29 October 1992 (Australian Institute of Criminology, 1993) 139 <http://aic.gov.au/media_library/publications/proceedings/20/thomas.pdf>

58. Thomas, Carol and Joanne Selfe, 'Aboriginal Women and the Law' in Proceedings of a conference held 23-25 June 1992 (Australian Institute of Criminology, 1993) 1

<http://www.aic.gov.au/media_library/publications/proceedings/21/thomas.pdf>

59. Tomaszewski, Irene, 'Preventing Adult Sexual Assault: Violence, Gender and Power, and the Role of Education' in Australian Institute of Criminology Conference Proceedings Held on 2729 October 1992 (Australian Institute of Criminology, 1993) 331

60. University of Sydney, 'Sharing Country: Land Rights, Human Rights and Reconciliation after Wik' in Land Rights, Human Rights and Reconciliation After Wik (Research Institute for Humanities and Social Sciences, 1997) 119

61. Various Authors, 'Commitment to Indigenous Health: Local and National Contributions to Meeting the Challenges' (2013)

62. Wallace, Stephen, 'Professional Responsibility for Sexual Violence: A Study of Self-Interest, Mythology and Exculpation' in Proceedings of a Conference held 27-29 October 1992 (Australian Institute of Criminology, 1993) 295 <http://aic.gov.au/media_library/publications/proceedings/20/wallace.pdf>

63. Weiser Easteal, Patricia, 'Survivors of Sexual Assault: A National Survey' in Proceedings of a Conference held 27-29 October 1992 (Australian Institute of Criminology, 1993) 73 <http://aic.gov.au/media_library/publications/proceedings/20/esteal2b.pdf>

64. Yawa, Miriam, 'Gender and Violence' in Third Australian Women and Policing Conference: Women and Policing Globally, Canberra 20-23 October 2002 (2002)

65. Yeats, Mary Ann, 'Aboriginal Customary Law and Sentencing' in The Judicial Conference of Australia Colloquium (Judicial Conference of Australia, 2007) $25<$ http://jca.asn.au/wpcontent/uploads/2013/11/2007-MaryAnnYeats.pdf> 


\section{Document}

1. Aboriginal Child Sexual Assault Taskforce (NSW), 'Aboriginal Child Sexual Assault Taskforce - Review of the Literature' <https://www.indigenousjustice.gov.au/resources/aboriginal-childsexual-assault-taskforce-review-of-the-literature/>

2. Aboriginal Peak Organisation of the Northern Territory, 'Aboriginal Peak Organisations Northern Territory Submission to the Senate Community Affairs Inquiry' <http://www.clc.org.au/files/pdf/120206-Submission-APO_NT_Stronger_Futures_Sub-SenateFinal.pdf $>$

3. Anderson, AM, 'Restorative Justice, the African Philosophy of Ubuntu and the Diversion of Criminal Prosecution' <https://www.ncjrs.gov/App/Publications/abstract.aspx?ID=202433>

4. AnTAR, Queensland, 'Queensland Stolen Wages Fact Sheet' <http://www.reconciliation.qut.edu.au/issues/recweek/StolenWagesFactSheet.pdf>

5. Australian Human Rights Commission, 'Stronger Futures in the Northern Territory Bill 2011 and Two Related Bills: Australian Human Rights Commission - Submission to the Senate Community Affairs Legislation Committee' <https://www.humanrights.gov.au/sites/default/files/content/legal/submissions/2012/20120206_s tronger.pdf>

6. Benwell, Richard and Oonagh Gay, 'The Separation of Powers' $<$ http://www.parliament.uk/business/publications/research/briefing-papers/SN06053/theseparation-of-powers>

7. Braaf, Rochelle and Robyn Gilbert, 'Domestic Violence Incident Peaks: Seasonal Factors, Calendar Events and Sporting Matches'

<http://www.austdvclearinghouse.unsw.edu.au/PDF\%20files/Stakeholder\%20paper_\%202.pdf>

8. Brizee, Allen et al, 'Literary Theory and Schools of Criticism'

$<$ https://owl.english.purdue.edu/owl/owlprint/722/>

9. Bryant, Colleen, 'Identifying the Risks for Indigenous Violent Victimization' <http://www.indigenousjustice.gov.au/briefs/brief006.pdf>

10. Byrnes, Andrew, 'The Convention on the Elimination of All Forms of Discrimination against Women and the Committee on the Elimination of Discrimination against Women: Reflections on Their Role in the Development of International Human Rights Law and as a Catalyst for National Legislative and Policy Reform' $<$ http://law.bepress.com/cgi/viewcontent.cgi?article=1212\&context=unswwps-flrps10>

11. Central Australian Aboriginal Alcohol Programmes Unit, 'Submission to the Senate Committee on the Stronger Futures in the Northern Territory Bill 2011'

12. Central Land Council, 'Submission to the Senate Standing Committee on Community Affairs Inquiry into the Stronger Futures in Northern Territory Bill 2011 and Two Related Bills'

13. Centre for Justice and Accountability, 'Center for Justice and Accountability Draft Manual on Liberian Constitution: Appendices'

14. Committee Secretariat, 'Indigenous Australians, Incarceration and the Criminal Justice System'

15. Concerned Australians, 'Submission to the Senate Inquiry into the Stronger Futures in the Northern Territory Bill 2011 and Two Related Bills'

16. Cunneen, Chris, 'Crime, Justice and Indigenous People'

17. David Unaipon College of Indigenous Education and Research, 'More Aboriginal and Torres Strait Islander Teachers Initiative' $<$ http://matsiti.edu.au/docs/MATSITI-project-plan.pdf $>$

18. Davies, Katharine, 'Policy Analysis: Sexual Violence in Liberian Schools' < http: //isites.harvard.edu/fs/docs/icb.topic1203171.files/Panel\%207\%20-

$\% 20$ Do\%20No\%20Harm/Davis_Katharine_908653150_Liberia_Sexual_Violence_In_Schools.p df.>

19. Department of Families, Housing, Community Services and Indigenous Affairs, 'Submission to the Senate Community Affairs Committee Inquiry into the Stronger Futures in the Northern Territory Bill 2011 and Two Related Bills'

20. Dunn, D Elwood, 'Liberia and Independent Africa, 1940s to 2012: A Brief Political Profile' $<$ https://books.google.com/books?id=seTnAgAAQBAJ\&dq=building+little+america+in+liberia \&source=gbs_navlinks_s $>$

21. Equality Now, 'Liberia: Enact a Law Banning FGM as a Matter of Urgency' $<$ http://www.equalitynow.org/take_action/fgm_action372>

22. Fileborn, Bianca, 'Sexual Assault Laws in Australia' $<$ https://www3.aifs.gov.au/acssa/pubs/sheets/rs1/>

23. Foley, Gary, 'Black Power in Redfern 1968-1972'<https://vu.academia.edu/GaryFoley>

24. Foley, Gary, 'How to Steal the Human Rights of Aboriginal People' <https://vu.academia.edu/GaryFoley>

25. Foley, Gary, 'Warren Mundine: The White Sheep of the Family' <http://www.kooriweb.org/foley/essays/tracker/tracker26.html> 
26. Foley, Gary, 'History, Nationalism and ANZAC Day'

<http://www.kooriweb.org/foley/essays/pdf_essays/anzac\%20day.pdf>

27. Frankland, Kathy, 'A Brief History of Government Administration of Aboriginal and Torres Strait Islander Peoples in Queensland'

<http://www.slq.qld.gov.au/_data/assets/pdf_file/0008/93734/Admin_History_Aboriginal_and _Torres_Strait_Islanders.pdf>

28. Frimpong, Alexander KD, 'Two Hundred Years after the Abolition of the Transatlantic Slave Trade: Issues and Perspectives' $<\mathrm{http}: / / \mathrm{www}-$

personal.umich.edu/ dahowell/frempong/Frempong_WorkingPaper_SlaveTradeCivilWar.doc>

29. GLOBAL, 'GLOBAL Response to President Ellen Johnson Sirleaf State of the Nation Address to the Liberian People' <http://www.global-lr.org>

30. Government of Australia, Ministers for Territories, 'The Policy of Assimilation: Decision of Commonwealth and State Ministers at the Native Welfare Conference, Canberra, January 26th and 27th, 1961' <http://archive.aiatsis.gov.au/referendum/18801.pdf>

31. Government of Canada, 'Department of Justice - Compendium Annex: Family Violence Initiative' <http://www.justice.gc.ca/eng/rp-pr/cj-jp/fv-vf/annex-annexe/toc-tdm.html>

32. Government of Liberia, 'National Plan of Action for the Prevention and Management of Gender Based Violence in Liberia'

33. Government of Liberia, 'Government and UN Joint Programme to Prevent and Respond to Sexual Gender Based Violence'

34. Government of Liberia, 'Standard Operating Procedures for GBV Services at "One Stop Centre"' $<$ http://www.undp.org/content/dam/liberia/docs/docs/One\%20Stop\%20Centres\%20for\%20SGB V\%20services\%20final.pdf $>$

35. Government of Liberia, 'The One Stop Centre: Providing Immediate and Appropriate Care and Services to Survivors of SGBV' <https://undg.org/wp-content/uploads/2014/07/Liberia-SGBVJP-One-Stop-Fact-Sheet.pdf>

36. Gunn, Peter and Rebecca Kippen, 'Household and Family Formation in Nineteenth Century Tasmania Dataset' $<$ http://www.femaleconvicts.org.au/index.php/convictinstitutions/children/pregnancy-and-children>

37. Gunstone, Andrew, 'Indigenous Stolen Wages: History and Reparations' <https://www.tasa.org.au/wp-content/uploads/2014/12/Gunstone.pdf>

38. House of Lords Information Office, 'History of the House of Laws' <http://www.lordspublications.parliament.uk/pdf/H-076.pdf>

39. Human Rights Law Centre, 'Inquiry into the Stronger Futures in the Northern Territory Bill 2011: Submission to the Senate Community Affairs Legislation Committee'

40. Indigenous Law Centre UNSW, 'Sexual Violence and Indigenous Victims: Women, Children and the Criminal Justice System'

41. Inter-Parliamentary Union, 'Women in Politics: 2015' $\langle$ http://archive.ipu.org/pdf/publications/wmnmap15_en.pdf>

42. Jacobs, Margaret D, 'Western History: What's Gender Got to Do with It?' $\langle$ http://digitalcommons.unl.edu/historyfacpub/114>

43. Julalikari Council Aboriginal Corporation, 'Submission to the Senate Committee on Community Affairs: Draft Stronger Futures in the Northern Territory Bill 2011 and Two Related Bills'

44. Kabbah, Hanatu, 'A Guide to the Liberian Legal System and Legal Research' <http://www.nyulawglobal.org/globalex/Liberia1.htm>

45. Maru, Vivek, 'The Challenges of African Legal Dualism: An Experiment in Sierra Leone'

46. Ministry of Foreign Affairs, 'Law Reform Commission of Liberia: Strategic Plan 2011-2016' <http: //liblrc.org/uploads/3/2/5/8/3258104/lrc_strategic_plan.pdf.>

47. Nagel, Mechthild, 'Ubuntu and Indigenous Restorative Justice' $<\mathrm{http}: / /$ www.africaworkinggroup.org/>

48. National Congress of Australia's First Peoples, 'Statement to the Senate Standing Committee on Community Affairs on Conditions Affecting Aboriginal Communities in the Northern Territory Including the Proposed Stronger Futures in the Northern Territory Bill (2011) and Accompanying Bills'

49. Obata, Kazuko and Jason Lee, 'Languages of Aboriginal and Torres Strait Islander Peoples - A Unique Australian Heritage'

<http://www.abs.gov.au/ausstats/abs@.nsf/Previousproducts/1301.0Feature\%20Article42009\%E $2 \% 80 \% 9310$ ?opendocument $\&$ tabname $=$ Summary \&prodno $=1301.0 \&$ issue $=2009 \% 9610 \&$ num $=$ \&view=>

50. QLD Government, 'Appropriate Terminology, Indigenous Australian Peoples' <http://www.ipswich.qld.gov.au/_data/assets/pdf_file/0008/10043/appropriate_indigenous_ter minoloy.pdf $>$ 
51. Queensland Health, 'Guidelines for Aboriginal and Torres Strait Islander Terminology' 〈http://www.health.qld.gov.au/atsihealth/documents/terminology.pdf>

52. Rasch, David A and Meenah Rasch, 'Overcoming Writer's Block and Procrastination for Attorneys, Law Students, and Law Professors' < http://law.bepress.com/usclwps-lss/98>

53. Reconciliation Australia, 'Apology to Stolen Generations: Questions and Answers' 〈https://www.qcaa.qld.edu.au/downloads/approach2/indigenous_read012_0801.pdf>

54. Reconciliation Australia, 'Welcome to Country Q \& A Factsheet' $\langle$ http://www.unisa.edu.au/Documents/QA-welcome-to-country.pdf >

55. Secretariat of National Aboriginal and Islander Child Care, 'Inquiry into the Stronger Futures in the Northern Territory Bill: SNAICC Submission to the Senate Community Affairs Legislation Committee'

56. Sex Discrimination Commissioner of the Human Rights and Equal Opportunity Commission, 'Submission to the Northern Territory Law Reform Committee Inquiry into Aboriginal Customary Law in the Northern Territory' < https://www.humanrights.gov.au/sage-submissioninquiry-aboriginal-customary-law-nt>

57. Staff Reporter, 'Homelessness in the ACT - a Snapshot' <http://www.actshelter.net.au/_literature_93363/Homelessness_in_the_ACT>

58. Sustainable Development Institute, 'Iron Ore' <http://www.sdiliberia.org/sites/default/files/publications/Community\%20Relations\%20in\%20C hina\%20Union's\%20Concession.pdf>

59. Tangentyere Council Inc., 'Submission to the Senate Standing Committee in Community Affairs Inquiry into the Stronger Futures in the Northern Territory Bill 2011 and Two Related Bills'

60. The People's Alcohol Action Coalition, 'Submission from the People's Alcohol Action Coalition (PAAC) to the Committee's Inquiry into the Stronger Futures in the Northern Territory Bill 2011 and Two Related Bills'

61. The Uluru Peoples, 'Uluru Statement from the Heart' $<$ https://www.referendumcouncil.org.au/sites/default/files/201705/Uluru_Statement_From_The_Heart_0.PDF>

62. Tomaino, John, 'Aboriginal (Nunga) Courts' $\langle$ http://www.ocsar.sa.gov.au/docs/information_bulletins/ib39.pdf>

63. Tudball, Libby, 'The Intervention: A Study Guide' <www.roninfilms.com.au/get/files/1089.pdf>

64. UN Mission in Liberia, 'Fact-Sheet: Implementation of UNSCR 1820 in Post-Conflict Liberia'

65. UN Women, Australia, 'UN Women Australia Membership Brochure' <https://unwomen.org.au/sites/default/files/121219\%20Membership\%20Brochure\%20FINAL.p df>

66. World Bank Group, 'Empowering Girls and Young Women in Liberia: Adolescent Girls Initiative' <http://siteresources.worldbank.org/EXTGENDER/Resources/AGILiberiaBrief.pdf>

\section{Email}

1. ACT Government, 'Additional Info: Aboriginal and Torres Strait Islander Community Members/Family Violence' (2014).

2. Cara Gleeson, 'Follow-up on gender violence and the rule of law in Aboriginal Australia' (2014).

3. Tony Leewaye, 'Timing is wrong, Minister Tah: Don't politicize prosecutions ahead of 2011' (2010) <https://groups.yahoo.com/neo/groups/OnLiberianMedium/conversations/topics/51796>.

4. Tenneh Seah, 'Survivor's Assistant' (2010).

\section{Encyclopaedia}

1. The Editors of Encyclopaedia Britannica, 'Welfare State' $\langle$ https://www.britannica.com/topic/welfare-state>

Film

1. ABC News, Ngarigu Claim (2011) <http://www.youtube.com/watch?v=e-IzT2n0Ges>.

2. Abigail Disney, Pamela Hogan \& Gini Reticker, Women, War \& Peace (2011) $<$ http://www.pbs.org/wnet/women-war-and-peace/> at 30 April 2013.

3. Brendan Fletcher, Mad Bastards (2010) <http://www.madbastards.com.au> at 20 February 2013.

4. IRIN, Forced to Flee - Liberia's Child Soldier (2009) <http://www.youtube.com/watch?v=sUybR8RfXLU〉.

5. Darlene Johnson, Stolen Generations (2000) <www.tomzubrycki.com> at 1 May 2013.

6. Law Institute of Victoria \& Victoria Bar Association, Legal Aid Matter (2013).

7. Adam Manalo-Camp, Australian Aboriginal Genocide (2008) <http://www.youtube.com/watch?v=Z7eubc-Yk3M\&feature=related> at 5 June 2013.

8. Quentin McDermott, A Matter of Life and Death" (2012). 
9. T. Christian Miller, Jonathan Jones \& Propublica, Firestone and the Warlord: The Untold Story of Firestone, Charles Taylor and the Tragedy of Liberia (2014).

10. Julie Nimmo, Intervention Katherine, NT: The success and failures of the Emergency Intervention as experienced by Indigenous communities living in the Katherine region (2008)

<http://www.roninfilms.com.au/feature/1087/intervention-katherine.html> at 20 February 2013.

11. Phillip Noyce, Rabbit-Proof Fence (2002).

12. Tangentyere Research \& Vincent Lamberti, Intervention: Stories from the Inside (2007).

13. Jessica Vale, Small Small Thing: The Olivia Zinnah Story (2012) <http://www.jessicavale.com>.

14. Thornton Warwick, Samson and Delilah: True Love (2009).

15. Jane Worthington \& Mawunyo Gbogbo, Insight: Punch Drink (2012) <http://www.sbs.com.au/insight/episode/overview/492/Punch-Drunk> at 21 May 2013.

\section{Forum Post}

1. Carol Roe, 'My granddaughter died in a cell begging for help. Please give us answers' Change.Org (2014) <https://www.change.org/p/my-granddaughter-died-in-a-cell-begging-forhelp-please-give-us-answers $>$.

2. Deborah L. Rhode, 'The "woman question"' Gender Matters (2000) <http://www.yale.edu/wff/gendermatters/pdf/GM_Rhode.pdf> at 25 May 2013.

\section{Hearing}

1. Prince Johnson: Contemporary History of the Conflict" Institutional and Thematic Inquiry Hearing 2014.

\section{Interview}

1. International Center for Transitional Justice Interview with Eduardo Gonzalez (2013) $<$ http://www.ictj.org/news/transitional-justice-and-struggle-indigenous-rights > at 24 September 2014.

2. Cameron Boyd Interview with Maureen Phillips, Angela Williams, \& Karen Willis (Australian Centre for the Study of Sexual Assault, 2008).

3. Interview with Michele Williams (Australian Centre for the Study of Sexual Assault, 2008).

\section{Journal Article}

1. Abeya, Sileshi, Mesganaw Afework and Alemayeh Yalew, 'Intimate Partner Violence against Women in West Ethiopia: A Qualitative Study on Attitudes, Woman's Response, and Suggested Measures as Perceived by Community Members' (2012) 9(1) Reproductive Health 14

2. Abramowitz, Sharon and Mary H Moran, 'International Human Rights, Gender-Based Violence, and Local Discourses of Abuse in Postconflict Liberia: A Problem of “Culture”?' (2012) 55(02) African Studies Review 119

3. Acemoglu, Daron and James A Robinson, 'Why Is Africa Poor?' (2010) 25(1) Economic History of Developing Regions 21

4. Ackerman, Ruthie, 'When Things Fall Apart' (2010) 47(1) UN Chronicle 46

5. Adams, Laura S, 'Beyond Gender: State Failure to Protect Domestic Violence Victims as a Basis for Granting Refugee Status' (2002) 24(2) Thomas Jefferson Law Review 239

6. Adams, Rene and Yasmin Hunter, 'Surviving Justice: Family Violence, Sexual Assault and Child Sexual Assault in Remote Aboriginal Communities in NSW' (2007) 7(1) Indigenous Law Bulletin 26

7. Åkerlund, Nina, 'Caring or Vulnerable Children? Sibling Relationships When Exposed to Intimate Partner Violence' [2017] Children \& Society $<$ http://doi.wiley.com/10.1111/chso.12215>

8. Alcoff, Linda and Laura Gray, 'Survivor Discourse: Transgression or Recuperation?' (1993) 18(2) Signs: Journal of Women in Culture and Society 260

9. Alexander, Renata, 'Moving Forwards or Back to the Future?: An Analysis of Case Law on Family Violence under the Family Law Act 1975 (Cth)' (2010) 33(3) University of New South Wales Law Journal 907

10. Alfred, Gerald Taiaiake, 'Colonialism and State Dependency' (2009) 5(2) Journal de la Santé Autochtone 42

11. Alfred, Taiaiake and Jeff Corntassel, 'Being Indigenous: Resurgences against Contemporary Colonialism' (2005) 40(4) Government and Opposition 597

12. Allan, Trevor RS, 'Dworkin and Dicey: The Rule of Law as Integrity (Reviews)' (1988) 8(2) Oxford Journal of Legal Studies 266

13. Allan, Trevor RS, 'The Rule of Law as the Rule of Reason: Consent and Constitutionalism' (1999) 115(2) Law Quarterly Review 221 
14. Allan, Trevor RS, 'Law, Justice and Integrity: The Paradox of Wicked Laws' (2009) 29(4) Oxford Journal of Legal Studies 705

15. Allen, William E, 'Historical Methodology and Writing the Liberian Past: The Case of Agriculture in the Nineteenth Century' (2005) 32 History in Africa 21

16. Allen, William E and D Elwood Dunn, 'Ellen Johnson Sirleaf Is the 24th Not 23rd President of Liberia: A New Interpretative History’ (2008) 33(1) Liberian Studies Journal 64

17. Allen, William E, 'Making History in the Bedroom: Americo-Liberians and Indigenous Liberians Sexual Unions, 1880s- c. 1950s' (2009) 34(2) Liberian Studies Journal 16

18. Allison, Fiona et al, 'Sentencing and Punishment in the Indigenous Justices of Peace Courts' (2012) 16(1) Australian Indigenous Law Reporter 15

19. Allison, Fiona, Melanie Schwartz and Chris Cunneen, “"That's Discrimination!” Indigenous Peoples' Experiences of Discrimination in the Northern Territory' (2013) 8(5) Indigenous Law Bulletin 8

20. Altman, Jon C, 'The Political Ecology and Political Economy of the Indigenous Land Titling “revolution" in Australia' (2014) Indigenous Law Speaker Series Maori Law Review: A Monthly Review of Law Affecting Maori online

21. Anderson, Kay and Colin Perrin, "The Miserablest People in the World": Race, Humanism and the Australian Aborigine' (2007) 18(1) The Australian Journal of Anthropology 18

22. Andrews, Penelope, 'Violence against Aboriginal Women in Australia: Possibilities for Redress within the International Human Rights Framework' (1997) 60(3) Albany Law Review 917

23. Anghie, Antony, 'Colonialism and the Birth of International Institutions: Sovereignty, Economy, and the Mandate System of the League of Nations' (2002) 34 New York University Journal of International Law 513

24. Aning, Emmanuel Kwesi, 'Gender and Civil War: The Cases of Liberia and Sierra Leone' (1998) 1(4) Civil Wars 1

25. An-Na'im, Abdullahi A, 'The Contingent Universality of Human Rights: The Case of Freedom of Expression in African and Islamic Contexts' (1997) 11 Emory International Law Review 29

26. An-Na'im, Abdullahi Ahmed, 'Taming the Imperial Impulse: Realising a Pragmatic Moral Vision' (2011) 46(13) Economic \& Political Weekly 50

27. An-Na'im, Abdullahi Ahmed, 'Critical Reflections on Torture, Religion and Politics' (2013) 103(2) The Muslim World 259

28. An-Na'im, Abdullahi Ahmed, "Editorial Note: From the Neocolonial "transitional" to Indigenous Formations of Justice' (2013) 7(2) International Journal of Transitional Justice 197

29. Anonymous, 'LIBERIA: Safe House for Survivors' (2008) 45(7) Africa Research Bulletin: Political, Social and Cultural Series 17611B

30. Anthony, Thalia, 'Sentencing Indigenous Offenders' (2010) 7(March) Indigenous Justice Clearinghouse Research Briefs 1

31. Arabena, Kerry, 'Preachers, Policies and Power: The Reproductive Health of Adolescent Aboriginal and Torres Strait Islander Peoples in Australia' (2006) 17(2) Health Promotion Journal of Australia: Official Journal of Australian Association of Health Promotion Professionals 85

32. Armstrong, Susan, 'Is Feminist Law Reform Flawed? Abstentionists and Sceptics' (2004) 20(43) Australian Feminist Law Journal 43

33. Astor, Hilary and Rosalind Croucher, 'Fractured Families, Fragmented Responsibilities Responding to Family Violence in a Federal System' (2010) 33(3) University of New South Wales Law Journal 854

34. Atkinson, Judy, 'Violence in Aboriginal Australia: Colonisation and Gender' (1990) 14(2) Aboriginal and Islander Health Worker 5

35. Atkinson, Judy, 'Violence against Aboriginal Women: Reconstruction of Community Law - the Way Forward' (2001) 5(11) Indigenous Law Bulletin 19

36. Atkinson, Judy, 'Voices in the Wilderness - Restoring Justice to Traumatised Peoples' (2002) 25(1) University of New South Wales Law Journal 233

37. Attenbrow, Val, 'The Aboriginal Prehistory and Archaeology of Royal National Park and Environs: A Review' (2012) 134 Proceedings of the Linnean Society of New South Wales B39

38. Attwood, Bain, 'The Law of the Land or the Law of the Land?: History, Law and Narrative in a Settler Society' (2004) 2(1) History Compass 1

39. Aucoin, Louis, 'Building the Rule of Law and Establishing Accountability for Atrocities in the Aftermath of Conflict' (2007) 3(1) The Journal of Diplomacy and International Relations 33

40. Audi, Robert, 'Practical Reason and the Status of Moral Obligation' (2010) 39(5) Canadian Journal of Philosophy 197

41. Auty, Kate, "“Growing up" the Koori Court (Gerund), Shepparton: Development Discourse and Innovation in Courts of Summary Jurisdiction' (2004) 7(4) Journal of Australian Indigenous Studies 18 
42. Bachman, John and Reese T Jones, 'Personality Correlates of Cannabis Dependence' (1979) 4(4) Addictive behaviours 361

43. Bacon, Laura, 'Liberia's Gender-Sensitive Police Reform: Improving Representation and Responsiveness in a Post-Conflict Setting' (2015) 22(4) International Peacekeeping 372

44. Bagshaw, Dale and Donna Chung, 'Gender Politics and Research: Male and Female Violence in Intimate Relationships’ (2000) 8 Women Against Violence: An Australian Feminist Journal 4

45. Bailey, Cate, Martine Powell and Sonja Brubacher, 'Reporting Rates of Child Sexual Abuse in Indigenous Communities in Two Australian Jurisdictions' (2017) 68 Child Abuse \& Neglect 74

46. Ballah, Heneryatta, 'Ethnicity, Politics and Social Conflict: The Quest for Peace in Liberia' [2003] CiteSeerX 52

47. Barnes, Gail, 'Private Violence, Gendered Justice' (1999) 24(2) Alternative Law Journal 67

48. Barnes, Mario L, 'Empirical Methods and Critical Race Theory: A Discourse on Possibilities for a Hybrid Methodology' [2016] Wisconsin Law Review 443

49. Barnhart, Melynda H, 'Sex and Slavery: An Analysis of Three Models of State Human Trafficking Legislation' (2009) 16(4) William \& Mary Journal of Women and the Law 83

50. Barnidge, Ellen et al, 'A Participatory Method to Identify Root Determinants of Health: The Heart of the Matter' (2010) 4(1) Progress in Community Health Partnerships: Research, Education, and Action 55

51. Barta, Tony, 'Sorry, and Not Sorry, in Australia: How the Apology to the Stolen Generations Buried a History of Genocide’ (2008) 10(2) Journal of Genocide Research 201

52. Barter, Alice, Razi Sarouche and Victoria Williams, 'Why the Caged Bird Sings: Issues with the Royal Commission into Institutional Responses to Child Sexual Abuse' (2014) 8(13) Indigenous Law Bulletin 7

53. Bartlett, Katharine T, 'Feminist Legal Methods' (1990) 103(4) Harvard Law Review 829

54. Behrendt, Larissa, 'Consent in a (Neo)Colonial Society: Aboriginal Women as Sexual and Legal "Other"” (2000) 15(33) Australian Feminist Studies 353

55. Bell, Derrick A, 'Who’s Afraid of Critical Race Theory?' (1995) 4 University of Illinois Law Review 893

56. Bell, Diane, 'Speaking about Rape Is Everyone's Business' (1989) 12(4) Women's Studies International Forum 403

57. Bell, Diane, 'A Reply to "the Politics of Representation"” (1990) 6(2) Anthropological Forum 158

58. Bell, Diane, 'Intra-Racial Rape Revisited: On Forging a Feminist Future beyond Factions and Frightening Politics' (1991) 14(5) Women's Studies International Forum 385

59. Bell, Diane, 'White Women Can't Speak?' (1996) 6(2) Feminism and Psychology 197

60. Betty T. Izumi et al, 'The One-Pager: A Practical Policy Advocacy Tool for Translating Community-Based Participatory Research into Action' (2010) 4(2) Progress in Community Health Partnerships: Research, Education, and Action 141

61. Beyan, Amos Jones, 'The American Colonization Society and the Socio-Religious Characterization of Liberia: A Historical Survey, 1822-1900’ (1984) 10(2) Liberian Studies Journal 1

62. Beyan, Amos Jones, 'Transatlantic Trade and the Coastal Area of Pre-Liberia' (1995) 57(4) The Historian 757

63. Bielefeld, Shelley, 'Income Management and Indigenous Women: A New Chapter of Patriarchal Colonial Governance?' 39(2) University of New South Wales Law Journal 843

64. Bingham, Tom H, 'The Rule of Law' (2007) 66(01) The Cambridge Law Journal 67

65. Bishop, Russell, 'Freeing Ourselves from Neo-Colonial Domination in Research: A Maori Approach to Creating Knowledge' (1998) 11(2) International Journal of Qualitative Studies in Education 199

66. Blackstock, Michael D, 'The Aborigines Report (1837): A Case Study in the Slow Change of Colonial Social Relations' (2000) 20(1) The Canadian Journal of Native Studies 67

67. Blamo, J Bernard, 'Nation-Building in Liberia: The Use of Symbols in National Liberation' (1971) 4(1) Liberian Studies Journal 21

68. Bledsoe, Caroline, 'The Political Use of Sande Ideology and Symbolism' (1984) 11(3) American Ethnologist 455

69. Blume, Till, 'Implementing the Rule of Law in Integrated Missions: Security and Justice in the UN Mission in Liberia' (2008) 6(3) Journal of Security Sector Management 1

70. Bly, Antonio T, "Pretends He Can Read”: Runaways and Literacy in Colonial America, 17301776' (2008) 6(2) Early American Studies: An Interdisciplinary Journal 261

71. Blythe, Stacy et al, 'The Challenges of Being an Insider in Storytelling Research' (2013) 21(1) Nurse Researcher 8

72. Bolger, Audrey, 'Wangkajunga Women: Stories from the Desert' (1997) 11 Aboriginal History 102 
73. Bond, Johanna, 'International Intersectionality: A Theoretical and Pragmatic Exploration of Women's International Human Rights Violations' (2003) 52(1) Emory Law Journal 71

74. Borba, Christina PC et al, 'A Mental Health Needs Assessment of Children and Adolescents in Post-Conflict Liberia: Results from a Quantitative Key-Informant Survey’ (2016) 9(1) International Journal of Culture and Mental Health 56

75. Borrows, John, ‘Aboriginality and Treaty Rights and Violence against Women' (2013) 50(3) Osgoode Hall Law Journal 699

76. Boyd, Cameron, 'The Impacts of Sexual Assault on Women' [2011] (April) Australian Institute of Family Studies 1

77. Brady, Helen, 'The Power of Precedents: Using the Case Law of the Ad Hoc International Criminal Tribunals and Hybrid Courts in Adjudicating Sexual Violence and Gender-Based Crimes at the ICC' (2012) 18(2) Australian Journal of Human Rights 75

78. Braithwaite, John, 'Doing Justice Intelligently in Civil Society' (2006) 62(2) Journal of Social Issues 393

79. Brenner, Hannah, 'Transcending the Criminal Law's “One Size Fits All” Response to Domestic Violence' (2013) 19(4) William \& Mary Journal of Women and the Law 301

80. British Crown, 'Governor Phillips Instructions, 1787' (1914) 1(1788-1796) Historical Records of Australia 9

81. Brooks, Rosa Ehrenreich, 'Feminism and International Law: An Opportunity for Transformation' (2002) 14 Yale Journal of Law and Feminism 345

82. Brooks, Rosa Ehrenreich, 'The New Imperialism: Violence, Norms, and the "Rule of Law", (2003) 101(7) Michigan Law Review 2275

83. Brown, Ken, "Customary Law: Sex with under-Age "Promised Wives"' (2007) 32(1) Alternative Law Journal http://www.austlii.edu.au/au/journals/AltLawJ1/2007/4.html

84. Brown, Robert T, 'Simon Greenleaf and the Liberian Constitution of 1847' (1980) 9(2) Liberian Studies Journal 51

85. Brown, Ron, ‘Australian Indigenous Mental Health' (2001) 10 Australian and New Zealand Journal of Mental Health 33

86. Brown Sherman, Mary Antoinette, 'Barclay Women in Liberia - Two Generations: A Biographical Dictionary’ (2005) XXX(1) Liberian Studies Journal 28

87. Brownlee, Kimberley, 'Retributive, Restorative and Ritualistic Justice' (2010) 30(2) Oxford Journal of Legal Studies 385

88. Buchan, Bruce, 'The Empire of Political Thought: Civilization, Savagery and Perceptions of Indigenous Government' (2005) 18(2) History of the Human Sciences 1

89. Buchan, Bruce, 'Savagery and Civilization: From Terra Nullius to the "Tide of History"' (2006) 6(1) Ethnicities 5

90. Buchanan, Elizabeth A and Erin E Hvizdak, 'Online Survey Tools: Ethical and Methodological Concerns of Human Research Ethics Committees’ (2009) 4(2) Journal of Empirical Research on Human Research Ethics 37

91. Buchanan, Fiona and Sarah Wendt, 'Opening Doors: Women's Participation in Feminist Studies about Domestic Violence’ [2017] Qualitative Social Work 147332501769408

92. Buchowska, Natalia, 'Violated or Protected. Women's Rights in Armed Conflicts after the Second World War' (2016) 2(2) International Comparative Jurisprudence 72

93. Bulloch, Hannah and William Fogarty, 'Freeing the "Aboriginal Individual": Deconstructing "Development as Freedom" in Remote Indigenous Australia' (2016) 60(3) Social Analysis 76

94. Bunch, Charlotte, 'Women's Rights as Human Rights: Toward a Re-Vision of Human Rights' (1990) 12(4) Human Rights Quarterly 486

95. Burchfiled, Shelley and Antoinette Braybrook, 'Improving Law and Justice Outcomes for Indigenous Women and Children' (2009) 7(12) Indigenous Law Bulletin 6

96. Burrowes, Carl Patrick, 'Textual Sources of the 1847 Liberian Constitution' (1998) 23(1) Liberian Studies Journal 1

97. Buti, Antonio, 'International Law Obligations to Provide Reparations for Human Rights Abuses' (1999) 6(4) Murdoch University Electronic Journal of Law http://worldlii.austlii.edu.au/au/journals/MurUEJL/1999/41.html\#Australia's\%20National\%20In quiry_T

98. Butterly, Lauren, 'Unfinished Business in the Straits: Akiba v Commonwealth of Australia [2013] HCA 33' (2013) 8(8) Indigenous Law Bulletin 1

99. Buxton-Namisnyk, Emma, 'Does an Intersectional Understanding of International Human Rights Law Represent the Way Forward in the Prevention and Redress of Domestic Violence against Indigenous Women in Australia?' (2015) 18(1) Australian Indigenous Law Review 119

100.Byrne, Gary, 'Prevalence and Psychological Sequelae of Sexual Abuse among Individuals with an Intellectual Disability: A Review of the Recent Literature' [2017] Journal of Intellectual Disabilities 1 
101.Cahir, Fred and D Ian Clark, 'The Case of Peter Mungett: Born out of the Allegiance of the Queen, Belonging to a Sovereign and Independent Tribe of Ballan' (2009) 8 Provenance: The Journal of Public Record Office Victoria 15

102. Caprioli, Mary and Mark A Boyer, 'Gender, Violence, and International Crisis' (2001) 45 Journal of Conflict Resolution 503

103. Carastathis, Anna, 'The Concept of Intersectionality in Feminist Theory' (2014) 9(5) Philosophy Compass 304

104.Carothers, Thomas, 'The Rule of Law Revival' (1998) 77(2) Foreign Affairs 95

105. Carothers, Thomas, 'Promoting the Rule of Law Abroad: The Problem of Knowledge' (2003) 34 Carnegie Endowment for International Peace 1

106.Carothers, Thomas, 'Rule of Law Temptations' (2009) 33(1) Carnegie Endowment for International Peace 49

107. Carrington, Don, 'Who Cares about the Men? [Problems of Aboriginal Men]' (1999) 19 Indigenous Leadership 17

108. Carrington, Kerry, 'Does Feminism Spoil Girls? Explanations for Official Rises in Female Delinquency’ (2006) 39(1) Australian and New Zealand Journal of Criminology 34

109. Carrington, Kerry and John Scott, 'Masculinity, Rurality and Violence' (2008) 48(5) British Journal of Criminology 641

110. Carrington, Kerry, Alison McIntosh and J Scott, 'Globalization, Frontier Masculinities and Violence: Booze, Blokes and Brawls’ (2010) 50(3) British Journal of Criminology 393

111.Carrington, Kerry, 'Punitiveness and the Criminalisation of the Other: State Wards, Unlawful Non-Citizens and Indigenous Youth' (2011) 1(1) Somatechnics 30

112. Carter, Nicole A, 'Critical Race Feminism: An Educational Perspective' (2012) 4(1) PowerPlay 1

113. Carvalho, Benjamin de and Niels Nagelhus Schia, 'Sexual and Gender-Based Violence in Liberia and the Case for a Comprehensive Approach to the Rule of Law' (2011) 14(1) Journal of International Relations and Development 134

114.Celucien, Joseph, 'Prophetic Religion, Violence, and Black Freedom: Reading Makandal's Project of Black Liberation through a Fanonian Postcolonial Lens of Decolonization and Theory of Revolutionary Humanism' (2012) 3(4) Journal of Race, Ethnicity, and Religion 1

115.Chalk, Frank, 'The Anatomy of an Investment: Firestone's 1927 Loan to Liberia' (1967) 1(1) Canadian Journal of African Studies 12

116.Chandler, James, 'Introduction: Doctrines, Disciplines, Discourses, Departments' (2009) 35(4) Critical Inquiry 729

117. Chapman, Stephanie, 'Getting It Together: Gender, Violence and Indigenous Students' (1995) Sep/Oct(1) The Gen: Newsletter of the Gender and Equity Network 3

118. Charlesworth, Hilary, 'Feminists Critique of International Law and Their Critics' (1995) 13(1) Third World Legal Studies 1

119. Chaudhuri, J Pal, 'British Reaction to the Firestone Investment in Liberia' (1972) 5(1) Liberian Studies Journal 25

120.Chopra, Tanja and Deborah Isser, 'Access to Justice and Legal Pluralism in Fragile States: The Case of Women's Rights' (2012) 4(02) Hague Journal on the Rule of Law 337

121. Chua, Sarah Xin Yi and Tony Foley, 'Implementing Restorative Justice to Address Indigenous Youth Recidivism and Over-Incarceration in the ACT: Navigating Law Reform Dynamics' (2014) 18(1) Australian Indigenous Law Reporter 138

122. Church, RJ Harrison, 'The Firestone Rubber Plantations in Liberia' (1969) 54(4) Geography 430

123. Clancy, LJ et al, 'Arterial Catecholamines in Hypoxic Exercise in Man' (1975) 49(5) Clinical Science and Molecular Medicine 503

124.Clapham, Andrew, 'The Role of the Individual in International Law' (2010) 21(1) European Journal of International Law 25

125.Clark, Haley, 'Sexual Assault Forum, Melbourne: Organised by Victorian Women Lawyers, June 2007' (2008) 17 Australian Centre for the Study of Sexual Assault Newsletter 22

126.Clarke, Jennifer, 'Communication Not Liable: Cubillo and Gunner v Commonwealth' (2000) 5(2) Indigenous Law Bulletin 11

127. Coghlan, Sarah and Melanie Millsteed, 'Identifying the Differences between Generalist and Specialist Family Violence Perpetrators: Risk Factors and Perpetrator Characteristics' (2017) 8 Crime Statistics Agency Briefing Note 1

128. Cohen, Cynthia Price, 'The United Nations Convention of the Rights of the Child: A Feminist Landmark' (1997) 3(3) William and Mary Journal of Women and the Law 29

129. Cohen, Dara Kay and Amelia Hoover Green, 'Duelling Incentives: Sexual Violence in Liberia and the Politics of Human Rights Advocacy' (2012) 49(3) Journal of Peace Research 445

130. Cohen, Ronald, 'Ethnicity: Problem and Focus in Anthropology' (1978) 7(1) Annual Review of Anthropology 379 
131.Collins, Lisa and Jenny Mouzos, 'Deaths in Custody: A Gender-Specific Analysis' [2002] (238) Australian Institute of Criminology Trends and Issues 1

132. Collins, Patricia Hill, 'What's in a Name? Womanism, Black Feminism, and Beyond' (1996) 26(1) The Black Scholar: Journal of Black Studies and Research 9

133. Conaghan, Joanna, 'Reassessing the Feminist Theoretical Project in Law' (2000) 27(3) Journal of Law and Society 351

134.Connors, Libby, 'Women on the South-East Queensland Frontier' (2008) 15(2) Queensland Review 19

135.Coombs, Steven J and Ian D Smith, 'The Hawthorne Effect: Is It a Help or a Hindrance in Social Science Research?' (2003) 6(1) Change: Transformations in Education 97

136.Cornell, Stephen, 'Processes of Native Nationhood: The Indigenous Politics of Self-Government' (2015) 6(4) International Indigenous Policy Journal 1

137. Couture, Amanda L, Arshia Zaidi and Eleanor Maticka-Tyndale, 'Reflexive Accounts: An Intersectional Approach to Exploring the Fluidity of Insider/Outsider Status and the Researcher's Impact on Culturally Sensitive Post-Positivist Qualitative Research' (2012) 8(1) Qualitative Sociology Review 86

138. Cowlishaw, Gillian, 'Introduction: Representing Racial Issues' (1993) 63(3) Oceania 183

139. Cowlishaw, Gillian, 'Governing Sex: Removing the Right to Take Responsibility' (2014) 3(1) International Journal of Crime, Justice and Social Democracy 35

140.Cox, Deborah, 'Aboriginal Healing Project' (2008) 17 Australian Centre for the Study of Sexual Assault Newsletter 18

141.Crawley, Karen, 'Unintended Consequences: Representations of Rwandan Women and Their Children Born from Rape' (2012) 31(S1) Australian Feminist Law Journal 87

142. Crenshaw, Kimberlé, 'Demarginalising the Intersection of Race and Sex: A Black Feminist Critique of Anti-Discrimination Doctrine, Feminist Theory and Antiracist Politics' (1989) 140 The University of Chicago Legal Forum 139

143. Crenshaw, Kimberlé, 'Mapping the Margins: Intersectionality, Identity Politics, and Violence against Women of Colour' (1991) 43(6) Stanford Law Review 1241

144. Crenshaw, Kimberlé, 'Race, Gender, and Sexual Harassment' (1992) 65 California Law Review 1467

145. Crenshaw, Kimberlé, 'Twenty Years of Critical Race Theory: Looking Back to Move Forward' (2011) 43(5) Connecticut Law Review 1253

146.Cripps, Kyllie, 'Indigenous Family Violence: From Emergency Measures to Committed Long Term Action' (2007) 11(2) Australian Indigenous Law Review 6

147.Cripps, Kyllie and Leanne Miller, 'Mutant Messages: Victoria's Indigenous Family Violence 10 Year Plan' (2008) 7(7) Indigenous Law Bulletin 15

148. Cripps, Kyllie and Hannah McGlade, 'Indigenous Family Violence and Sexual Abuse: Considering Pathways Forward' (2008) 14(2-3) Journal of Family Studies 240

149.Cripps, Kyllie, 'Indigenous Family Violence: A Statistical Challenge' (2008) 39(Supplement 5) Injury $\mathrm{S} 25$

150.Cripps, Kyllie, 'White Man's Law, Traditional Law, Bullshit Law: Customary Marriage Revisited" (2009) 10 Balayi: Culture, Law and Colonialism 59

151.Cripps, Kyllie et al, 'Victims of Violence among Indigenous Mothers Living with Dependent Children' (2009) 191(9) The Medical Journal of Australia 481

152.Cripps, Kyllie and Leanne Miller, 'Mutant Messages 2: Victoria’s Indigenous Family Violence Plan' (2009) 7(12) Indigenous Law Bulletin 10

153. Cripps, Kyllie and Leanne Miller, 'Mutant Messages 3: Victoria’s Indigenous Family Violence Plan' (2010) 7(18) Indigenous Law Bulletin 10

154.Cripps, Kyllie, 'Speaking up to the Silences: Victorian Koori Courts and the Complexities of Indigenous Family Violence' (2011) 7(26) Indigenous Law Bulletin 31

155.Cripps, Kyllie and Robert McCreery, 'Indigenous Engagement with the Royal Commission into Institutional Responses to Child Sexual Abuse' (2013) 8(5) Indigenous Law Bulletin 22

156. Cristodorescu, R, '[Use of bethanidine sulfate in the treatment of arterial hypertension]' (1975) 27(4) Revista De Medicina Interna, Neurologe, Psihiatrie, Neurochirurgie, DermatoVenerologie. Medicina Interna 279

157. Crowder, Michael, 'Indirect Rule: French and British Style' (1964) 35(3) Africa: Journal of the International African Institute 197

158.Cunneen, Chris and Terry Libesman, 'Removed and Discarded: The Contemporary Legacy of the Stolen Generations' (2002) 7(4) Australian Indigenous Law Reporter 1

159. Cunneen, Chris and Julia Grix, 'The Limitations of Litigation in Stolen Generations Cases' (2004) 15 An AIATSIS Research Discussion Paper 1

160.Curran, Liz and Mary Anne Noone, 'Access to Justice: A New Approach Using Human Rights Standards’ (2008) 15(3) International Journal of the Legal Profession 195 
161.Curthoys, Ann and Clive Moore, 'Working for the White People: An Historiographic Essay on Aboriginal and Torres Strait Islander Labour' (1995) 69 Labour History 1

162.D'abbs, Peter, 'Controlling "Rivers of Grog": The Challenge of Alcohol Problems in Australian Indigenous Communities’ (2010) 37 Contemporary Drug Problems 499

163. Dako-Gyeke, Mavis and Ernestina Adu, 'Challenges and Coping Strategies of Refugees: Exploring Residual Liberian Refugees’ Experiences in Ghana’ (2017) 16(1) Qualitative Social Work 96

164.Dalton, John T and Tin Cheuk Leung, 'Why Is Polygyny More Prevalent in Western Africa? An African Slave Trade Perspective' (2014) 62(4) Economic Development and Cultural Exchange 579

165.Daly, Kathleen, 'Different Ways of Conceptualizing Sex/Gender in Feminist Theory and Their Implications for Criminology’ (1997) 1(1) Theoretical Criminology 25

166.Daly, Kathleen, 'Restorative Justice and Sexual Assault: An Archival Study of Court and Conference Cases' (2006) 46(2) British Journal of Criminology 334

167.Daniel, Kasomo, 'An Assessment of Religious Syncretism. A Case Study in Africa' (2012) 2(3) International Journal of Applied Sociology 10

168.Darawsheh, Wesam and Mandy Stanley, 'Reflexivity in Research: Promoting Rigour, Reliability and Validity in Qualitative Research' (2014) 21(12) International Journal of Therapy and Rehabilitation 560

169. Darcy, Shane, 'Prosecuting the War Crime of Collective Punishment: Is It Time to Amend the Rome Statute' (2010) 8 Journal of International Criminal Justice 29

170.Das, Veena, 'Violence, Gender, and Subjectivity' (2008) 37(1) Annual Review of Anthropology 283

171.David, Magdalene S, 'The Impact of Rural Transformation on the Productive Role of Liberian Women: The Case of Rice Production' (1987) 3(4) Liberian Forum 27

172.David, Soniia, 'Health Expenditure and Household Budgets in Rural Liberia' (1993) 3(1) Health Transition Review 57

173.Davis, Aisha Nicole, 'Intersectionality and International Law: Recognising Complex Identities on the Global Stage’ (2015) 28(1) Harvard Human Rights Journal 205

174.Davis, Megan, 'How Do Aboriginal Women Fare in Australian Democracy?' (2007) 6(28) Indigenous Law Bulletin 9

175.Davis, Megan, 'The Challenges of Indigenous Women in Liberal Democracies' (2007) 7(1) Indigenous Law Bulletin 20

176.Davis, Megan, 'Indigenous Struggles in Standard-Setting: The United Nations Declaration on the Rights of Indigenous Peoples' (2008) 9(2) Melbourne Journal of International Law 439

177. Davis, Megan, 'A Reflection on the Royal Commission into Aboriginal Deaths in Custody and Its Consideration of Aboriginal Women's Issues' (2011) 15(1) Australian Indigenous Law Review 25

178.Davis, Peggy C, ‘Law as Microagression’ (1989) 98 Yale Law Journal 1559

179.Dawson, Myrna and Danielle Sutton, 'Similar Sentences, Similar Crimes? Using Deep Sample Analysis to Examine the Comparability of Homicides and Punishments by Victim-Offender Relationship' (2017) 49 International Journal of Law, Crime and Justice 58

180.Day, Andrew et al, 'Indigenous Family Violence: An Attempt to Understand the Problems and Inform Appropriate and Effective Responses to Criminal Justice System Intervention' (2012) 19(1) Psychiatry, Psychology and Law 104

181.D’Azevedo, Warren L, 'A Tribal Reaction to Nationalism (Part 1)' (1967) 1(2) Liberian Studies Journal 1

182.D’Azevedo, Warren L, 'A Tribal Reaction to Nationalism (Part 2)' (1969) 21(1) Liberian Studies Journal 43

183.D’Azevedo, Warren L, 'A Tribal Reaction to Nationalism (Part 3)’ (1969) 2(2) Liberian Studies Journal 99

184.D’Azevedo, Warren L, 'A Tribal Reaction to Nationalism (Part 4)' (1970) 3(1) Liberian Studies Journal 1

185.Defeis, Elizabeth F, 'U.N. Peacekeepers and Sexual Abuse and Exploitation: An End to Impunity' (2008) 7(2) Washington University Global Studies Law Review 185

186.Defeis, Elizabeth F, 'The United Nations and Women - A Critique' (2011) 17(2) William \& Mary Journal of Women and the Law 395

187.Dempsey, Michelle Madden, 'What Counts as Domestic Violence? A Conceptual Analysis' (2006) 12(2) William \& Mary Journal of Women and the Law 301

188.Dennison, Susan and Benoit Leclerc, 'Developmental Factors in Adolescent Child Sexual Offenders: A Comparison of Nonrepeat and Repeat Sexual Offenders' (2011) 38(11) Criminal Justice and Behaviour 1089 
189.Dennison, Susan M and Carleen M Thompson, 'Intimate Partner Violence: The Effect of Gender and Contextual Factors on Community Perceptions of Harm, and Suggested Victim and Criminal Justice Responses' (2011) 26(3) Violence and Victims 347

190.Dharamsi, Shafik et al, 'Saving Africa: A Critical Study of Advocacy and Outreach Initiatives by University Students' (2013) 3(1) Journal of Global Citizenship \& Equity Education 53

191.Dodson, Mick, 'Citizenship in Australia: An Indigenous Perspective (A Call for Structured and Comprehensive Representation of Indigenous People in Australia's Constitution' (1997) 22(2) Alternative Law Journal 57

192.Dodson, Mick, 'Customary Law and the Sentencing of Indigenous Offenders' (2008) 20(5) Judicial Officers' Bulletin 37

193.Dodson, Mick, 'Constitutional Recognition of Indigenous Australians' (2012) 57 Papers on Parliament 11

194.Doron, Assa and Ira Raja, 'The Cultural Politics of Shit: Class, Gender and Public Space in India' (2015) 18(2) Postcolonial Studies 189

195.Douglas, Stacy and Suzanne Lenon, 'Introduction: Special Focus on Law and Decolonisation' (2014) 29(2) Canadian Journal of Law and Society 141

196.Dove, Nah, 'African Womanism: An Afrocentric Theory' (1998) 28(5) Journal of Black Studies 515

197.Drake, Alan M, 'Aimed at Protecting Ethnic Groups or Women? A Look at Forced Pregnancy under the Rome Statute' (2012) 18(3) William \& Mary Journal of Women and the Law 595

198. Drakopoulou, Maria, 'Feminism, Governmentality and the Politics of Legal Reform' (2008) 17(1) Griffith Law Review 330

199.Dunn, D Elwood (ed), 'Mary Antoinette Brown Sherman: 1926-2004' (2005) XXX(1) Liberian Studies Journal 1

200.Dunn, Kevin M et al, 'Indigenous Australians’ Attitudes towards Multiculturalism, Cultural Diversity, “race” and Racism' (2010) 13(4) Journal of Australian Indigenous Issues 19

201.Dwyer, Sonya Corbin and Jennifer L Buckle, 'The Space between: On Being an Insider-Outsider in Qualitative Research' (2009) 8(1) International Journal of Qualitative Methods 54

202.Dyson, Heydon, 'Judicial Activism and the Death of the Rule of Law' (2004) 10(4) Otago Law Review 493

203.Eames, Geoffrey M, 'Criminal Law and Sentencing Issues amongst Indigenous Communities: Questions from Aurunkun' (2008) 12(2) Australian Indigenous Law Review 22

204.Easteal, Patricia, Lorana Bartels and Sally Bradford, 'Language, Gender and "Reality": Violence against Women' (2012) 40(4) International Journal of Law, Crime and Justice 324

205.Eatock, Cathy, 'End Violence against Aboriginal Women' [2013] (954) Greenleft Weekly <https://www.greenleft.org.au/content/end-violence-against-aboriginal-women>

206.Eberechi, Ifeonu, 'Armed Conflicts in Africa and Wester Complicity: A Disincentive for African Union's Cooperation with the ICC' (2009) 3 African Journal of Legal Studies 53

207.Edelman, David J, 'Politics of Liberia: The Conservative Road to Development (Review)' (1977) 15(3) The Journal of Modern African Studies 512

208.Editors, 'From the Law School' (1965) 6(1) Liberian Law Journal 34

209.Editors, 'A Report on the Liberian Customary Law Research Project' (1968) 4(1) Liberian Law Journal 67

210.Editors, 'Notes: The Law School' (1968) 4(2) Liberian Law Journal 127

211.Editors, 'State of South Australia v Lampard-Trevorrow' (2010) 14(1) Australian Indigenous Law Review 100

212.Elder, Catriona, 'What Is the White in White Australia? A Reading of A. O. Neville, Australia's Coloured Minority' [1998] The Olive Pink Society Bulletin 28

213.Elizabeth, Vivienne, Nicola Gavey and Julia Tolmie, ““. . . He's Just Swapped His Fists for the System” The Governance of Gender through Custody Law' (2012) 26(2) Gender \& Society 239

214.Ellinghaus, Katherine, 'Regulating Koori Marriages: The 1886 Victorian Aborigines Protection Act' (2001) 25(67) Journal of Australian Studies 22

215.Ellinghaus, Katherine, "Absorbing the "Aboriginal Problem": Controlling Interracial Marriage in Australia in the Late 19th and Early 20th Centuries' (2003) 27 Aboriginal History 183

216.Ellinghaus, Katherine, 'Biological Absorption and Genocide: A Comparison of Indigenous Assimilation Policies in the United States and Australia' (2009) 4(1) Genocide Studies and Prevention 59

217.Ellis, George W, 'Political Institutions in Liberia' (1911) 5(2) The American Political Science Review 213

218.Erchak, Gerald and Caroline H Bledsoe, 'Women and Marriage in Kpelle Society' (1982) 84(2) American Anthropologist 495

219.Escobar, Arturo, 'Power and Visibility: Development and the Invention and Management of the Third World' (1988) 3(4) Cultural Anthropology 428 
220.Falcón, Sylvanna M, 'Transnational Feminism and Contextualized Intersectionality at the 2001 World Conference Against Racism' (2012) 24(4) Journal of Women's History 99

221.Falkner, Roland P, 'The United States and Liberia' (1910) 4(3) The American Journal of International Law 529

222.Fallon Jr., Richard H, “The Rule of Law” as a Concept in Constitutional Discourse' (1997) 97(1) Columbia Law Review 1

223.Farmer, Paul, 'Diary: Ebola' (2014) 26(23) London Review of Books 38

224.Faulks, John, "“Condemn the Fault and Not the Actor?” Family Violence: How the Family Court of Australia Can Deal with the Fault and the Perpetrators. [This Article Is Based on a Keynote Address Delivered at the Conference Responding to Family Violence: National Perspectives Local Initiatives (2010: Canberra).]' (2010) 33(3) University of New South Wales Law Journal 818

225.Fergusson, David M and L John Horwood, 'Exposure to Interparental Violence in Childhood and Psychosocial Adjustment in Young Adulthood' (1998) 22(5) Child Abuse and Neglect 339

226. Fitzgerald, Jacqueline and Don Weatherburn, 'Aboriginal Victimisation and Offending: The Picture from Police Records' (2001) 26(4) Aboriginal and Islander Health Worker 26

227.Fitzgerald, Kate, 'Problems of Prosecution and Adjudication of Rape and Other Sexual Assaults under International Law' (1997) 8(4) European Journal of International Law 638

228. Fitzgerald, Tony, 'Cape York Justice Study' (2001) 6(4) Australian Indigenous Law Reporter 104

229.Flood, Michael and Bob Pease, 'Factors Influencing Attitudes to Violence against Women' (2009) 10(2) Trauma, Violence, and Abuse 125

230.Flood, Michael, 'Involving Men in Efforts to End Violence against Women' (2011) 14(3) Men and Masculinities 358

231.Ford, Chandra L and Collins O Airhihenbuwa, 'Critical Race Theory, Race Equity, and Public Health: Toward Antiracism Praxis’ (2010) 100(S1) American Journal of Public Health S30

232.Forster, Christine, 'The Stolen Generation and the Victims Compensation Tribunal: The "writing in" of Aboriginality to "Write out" a Right to Compensatory Redress for Sexual Assault' (2002) 25(1) University of New South Wales Law Journal 185

233.Frost, Malcolm, 'The Three Rules of Being Aboriginal: Anxiety and Violence in Central Australia' [2014] (1) Australian Aboriginal Studies 90

234.Galtung, Johan, 'Violence, Peace and Peace Research' (1969) 6(3) Journal of Peace Research 167

235.Galtung, Johan, 'Cultural Violence' (1990) 27(3) Journal of Peace Research 291

236.Gardam, Judith, 'A Feminist Analysis of Certain Aspects of International Humanitarian Law' (1992) 12 Australian Yearbook of International Law 265

237. Gardner, John, 'Rationality and the Rule of Law in Offences against the Person' (2009) 53(03) The Cambridge Law Journal 502

238. Genoway, Edwin, 'Liberia: BNI Officer Linked to Sex Trade, Human Trafficking' [2013] The New Dawn <http://allafrica.com/stories/201307170811.html>

239. Gert, Joshua, 'Moral Reasons and Rational Status' (2003) 37(Supp Vol 33) Canadian Journal of Philosophy

240.Gillespie, James Edward, 'The Transportation of English Convicts after 1783' (1922) 13(3) Journal of the American Institute of Criminal Law and Criminology 359

241.Gleeson, Kate, 'The Money Problem: Reparation and Restorative Justice in Catholic Church's toward Healing Program' (2015) 26(3) Current Issues in Criminal Justice 317

242.Goetz, Aaron T, 'The Evolutionary Psychology of Violence' (2010) 22(1) Psicothema 15

243. Golub, Stephen, 'Beyond the Rule of Law Orthodoxy: The Legal Empowerment Alternative' [2003] (41) Carnegie Paper 1

244. Gooda, Mick, Emilie Priday and Louise McDermott, 'Looking beyond Offenders to the Needs of Victims and Communities' (2013) 8(5) Indigenous Law Bulletin 13

245.Goodhart, Arthur, L, 'Determining the Ratio Decidendi of a Case' (1930) 40(2) Yale Law Journal 161

246.Gordon, Sue, Kay Hallahan and Darrell Henry, 'Putting the Picture Together, Inquiry into Response by Government Agencies to Complaints of Family Violence and Child Abuse in Aboriginal Communities' (2002) 7(4) Australian Indigenous Law Reporter 49

247. Grandin, Greg, 'The Instruction of Great Catastrophe: Truth Commissions, National History, and State Formation in Argentina, Chile, and Guatemala' (2005) 110(1) The American Historical Review 46

248.Gray, Stephen, 'The Elephant in the Drawing Room: Slavery and the Stolen Wages Debate' (2007) 11(1) Australian Indigenous Law Review 30

249. Greene, Jennifer C, ‘Toward a Methodology of Mixed Methods Social Inquiry’ (2006) 13(1) Research in the Schools 93 
250.Greene, Jennifer C, 'Is Mixed Methods Social Inquiry a Distinctive Methodology?' (2008) 2(1) Journal of Mixed Methods Research 7

251. Greene, Lorenzo T, 'Mutiny on the Slave Ships' (1944) 5(4) Phylon 346

252.Greer, Pam, 'Report to Domestic Violence Committee' (1989) 13(4) Aboriginal and Islander Health Worker 14

253.Greer, Pam, Debbie French and Jo Campbell, 'Weaving the Net' (2010) 34(4) Aboriginal and Islander Health Worker 14

254.Gregg, Jessica et al, 'Interpretations of Interpretations: Combining Community-Based Participatory Research and Interpretive Inquiry to Improve Health' (2010) 4(2) Progress in Community Health Partnerships: Research, Education, and Action 149

255.Gregory, Robert J, 'Tribes and Tribal: Origin, Use, and Future of the Concept' (2003) 1(1) Studies of Tribes and Tribals 1

256. Grigg, Sue and Johnson Guy, 'Homeless Women and Violence: Rethinking the Connection' (2007) 20(4) Parity 9

257. Grimshaw, Patricia, 'The Fabrication of a Benign Colonisation? Keith Windschuttle on History' (2004) 35(123) Australian Historical Studies 122

258. Grina, Eve M, 'Mainstreaming Gender in Rule of Law Initiatives in Post-Conflict Settings' (2011) 17(2) William and Mary Journal of Women and the Law 435

259. Gunstone, Andrew, 'Indigenous Stolen Wages and Campaigns for Reparations in Victoria' (2014) 8(12) Indigenous Law Bulletin 3

260.Guseh, James S, 'Sexual Harassment in Liberia: A Review' (1994) 19(2) Liberian Studies Journal 183

261.Hahn, Niels, 'US Covert and Overt Operations in Liberia, 1970s to 2003' (2015) 6(2) Africa and Francophonie Air \& Space Power Journal 19

262.Haider, Aliya, 'Adolescents under International Law: Autonomy as the Key to Reproductive Health' (2008) 14(5) William and Mary Journal of Women and the Law 605

263.Haines, Robin and John McDonald, 'Skills, Origins and Literacy: A Comparison of the Bounty Immigrants into New South Wales in 1841, With the Convicts Resident in The Colony' (2002) 42(2) Australian Economic History Review 132

264.Hamelin, Christine et al, 'Childhood Sexual Abuse and Adult Sexual Health among Indigenous Kanak Women and Non-Kanak Women of New Caledonia' (2010) 34(9) Child Abuse and Neglect 677

265.Hammill, Jan, 'Granny Rights: Combatting the Granny Burnout Syndrome among Australian Indigenous Communities' (2001) 44(2) Development 69

266. Hammill, Jan, 'The Culture of Masculinity in an Australian Indigenous Community' (2001) 44(3) Development 21

267.Harding, Sandra, 'The Method Question' (1987) 2(3) Hypatia 19

268. Harris, Angela P, 'Race and Essentialism in Feminist Legal Theory' (1990) 42(3) Stanford Law Review 518

269.Harris, Angela P, 'Equality Trouble: Sameness and Difference in Twentieth-Century Race Law' (2000) 88(6) California Law Review 1923

270.Harris, Angela P, 'Gender, Violence, Race, and the Criminal Justice' (2000) 52 Stanford Law Review 777

271.Harris, Angela P, 'Heteropatriarchy Kills: Challenging Gender Violence in a Prison Nation' (2011) 37 Washington University Journal of Law \& Policy 13

272.Harris, Cheryl I, 'Whiteness as Property' (1993) 106(8) Harvard Law Review 1707

273.Harrison, Graham, 'The Africanization of Poverty: A Retrospective on "Make Poverty History", (2010) 109(436) African Affairs 391

274.Haskins, Victoria, "Lovable Natives" and 'tribal Sisters': Feminism, Maternalism, and the Campaign for Aboriginal Citizenship in New South Wales in the Late 1930s' (1988) 24(2) Hecate 8

275.Hassan-Morlai, Patrick Matthew, 'Evidence in International Criminal Trials: Lessons and Contributions from the Special Court for Sierra Leone' (2009) 3 African Journal of Legal Studies 96

276. Heath, Mary, 'Lack of Conviction: A Proposal to Make Rape Illegal in South Australia' (2007) 27 Australian Feminist Law Journal 175

277.Hendrickson, WA and KB Ward, 'Atomic Models for the Polypeptide Backbones of Myohemerythrin and Hemerythrin' (1975) 66(4) Biochemical and Biophysical Research Communications 1349

278.Hernandez-Truyol, Berta Esperanza, 'Sex, Culture, and Rights: A Re/Conceptualization of Violence for the Twenty-First Century’ (1997) 60(3) Albany Law Review 607

279.Hill, Linda Kelly, 'Equal Protection Misapplied: The Politics of Gender and Legitimacy and the Denial of Inheritance' (2006) 13(3) William \& Mary Journal of Women and the Law 129 
280.Hirsch, Michal Ben-Josef, M MacKenzie and Megan Sesay, 'Measuring the Impacts of Truth and Reconciliation Commissions: Placing the Global "success" of TRCs in Local Perspective' (2012) 47(3) Cooperation and Conflict 386

281.Hoddie, Matthew, 'Preferential Policies and the Blurring of Ethnic Boundaries: The Case of Aboriginal Australians in the 1980s' (2002) 50(2) Political Studies 293

282.Hogg, Russell and Kerry Carrington, 'Violence, Spatiality and Other Rurals' (2003) 36(3) Australian and New Zealand Journal of Criminology 293

283. Holder, Burleigh, 'A History of Crozierville' (1970) 3(1) Liberian Studies Journal 21

284.hooks, bell, 'Theory as Liberatory Practice' (1991) 4(1) Yale Journal of Law and Feminism 1

285. Horowitz, Carol R, Mimsie Robinson and Sarena Seifer, 'Community-Based Participatory Research from the Margin to the Mainstream: Are Researchers Prepared?' (2009) 119(19) Circulation 2633

286.Horton, Jessica, 'Rewriting Political History: Letters from Aboriginal People in Victoria 18861919’ (2012) 9(2) History Australia 157

287. Hovane, Victoria, 'White Privilege and the Fiction of Colour Blindness: Implications for Best Practice Standards for Aboriginal Victims of Family Violence' (2006) 27 Australian Domestic \& Family Violence Clearinghouse Newsletter 8

288. Hovane, Victoria and Dorinda Cox, 'Closing the Gap on Family Violence: Driving Prevention and Intervention through Health Policy' (2011) 21 Australian Domestic \& Family Violence Clearinghouse Issue Paper 1

289. Howe, Adrian, 'Addressing Child Sexual Assault in Australian Aboriginal Communities - the Politics of White Voice' (2009) 30 Australian Feminist Law Journal 41

290.Huggins, Jackie et al, 'Letter to the Editors: Response to "Speaking About Rape Is Everyone's Business"' (1991) 14(5) Women's Studies International Forum 505

291.Huggins, Jackie, Rita Huggins and Jane M Jacobs, 'Kooramindanjie: Place and the Postcolonial' (1995) 39(1) History Workshop Journal 165

292.Hunt, Alan, 'The Theory of Critical Legal Studies' (1986) 6(1) Oxford Journal of Legal Studies 1

293.Hunt, Paul, 'Missed Opportunities: Human Rights and the Commission on Social Determinants of Health' (2009) 16(1 Suppl) Global Health Promotion 36

294.Hunter, Ann, 'The Boundaries of Colonial Criminal Law in Relation to Inter-Aboriginal Conflict ('inter Se Offences') in Western Australian in the 1930s-1840s' (2004) 8(4) Australian Journal of Legal History 251

295.Hunter, EM, 'The Intercultural and Socio-Historical Context of Aboriginal Personal Violence in Remote Australia' (1991) 26(2) Australian Psychologist 89

296.Hunter, Rosemary, 'Deconstructing the Subjects of Feminism: The Essentialism Debate in Feminist Theory and Practice' (1996) 6 The Australian Feminist Law Journal 135

297.Hunter, Rosemary, 'Narratives of Domestic Violence' (2006) 28(4) Special Issue on Gender, Sexuality and Reproduction 733

298.Hunter, Rosemary C, 'The Mirage of Justice: Women and the Shrinking State' (2002) 16(53) Australian Feminist Law Journal 53

299.Hunter, SV, 'Constructing a Sense of Self Following Early Sexual Experiences with Adults: A Qualitative Research Study' (2007) 13(4) Psychotherapy in Australia 12

300.Indermaur, David, 'Young Australians and Domestic Violence' [2001] (195) Australian Institute of Family Studies 1

301.Indigenous Law Bulletin, 'Strong Indigenous Women Speak on Leadership' (2007) 7(1) Indigenous Law Bulletin 2

302.Ingelaere, Bert, 'Peasants, Power and Ethnicity: A Bottom-up Perspective on Rwanda's Political Transition' (2010) 109(435) African Affairs 273

303.Irie, Fumiko et al, 'Effects of Gender, Indigenous Status and Remoteness to Health Services on the Occurrence of Assault-Related Injuries in Children and Adolescents' (2012) 43(11) Injury 1873

304.Irwin, Katherine and Karen Umemoto, 'Being Fearless and Fearsome: Colonial Legacies, Racial Constructions, and Male Adolescent Violence' (2012) 2(1) Race and Justice 3

305.Isenberg, Beth Ann, 'Genocide, Rape, and Crimes against Humanity: An Affirmation of Individual Accountability in the Former Yugoslavia in the Karadzic Actions' (1997) 60(3) Albany Law Review 1051

306.Jacobs, Margaret D, 'Maternal Colonialism: White Women and Indigenous Child Removal in the America West and Australia, 1840-1940' (2005) 36(4) The Western Historical Quarterly 453

307.Jacqui, True, 'The Political Economy of Violence against Women: A Feminist International Relations Perspective' (2010) 32(1) Australian Feminist law Journal 39

308. Jalloh, Chernor and Alhagi Marong, 'Ending Impunity: The Case for War Crimes Trials in Liberia' (2005) 1 African Journal of Legal Studies 53 
309.Järvisalo, J and NE Saris, 'Action of Propranolol on Mitochondrial Functions--Effects on Energized Ion Fluxes in the Presence of Valinomycin' (1975) 24(18) Biochemical Pharmacology 1701

310.Jewkes, Rachel, Michael Flood and James Lang, 'From Work with Men and Boys to Changes of Social Norms and Reduction of Inequities in Gender Relations: A Conceptual Shift in Prevention of Violence against Women and Girls' [2014] The Lancet 1

311.Joachim, Kersten, 'A Gender Specific Look at Patterns of Violence in Juvenile Institutions: Or, Are Girls Really “More Difficult to Handle”?' (1990) 18(4) International Journal of the Sociology of Law 473

312.John, Edward St, 'Lords Break from Precedent: An Australian View' (1967) 16(3) International and Comparative Law Quarterly 808

313.Johnson, Kirsten et al, 'Association of Combatant Status and Sexual Violence with Health and Mental Health Outcomes in Postconflict Liberia' (2009) 300 Journal of American Medical Association 676

314.Johnson, Larissa Gabrielle and Anthony Beech, 'Rape Myth Acceptance in Convicted Rapists: A Systematic Review of the Literature' (2017) 34 Aggression and Violent Behavior 20

315.Johnson, R Burke and Anthony J Onwuegbuzie, 'Mixed Methods Research: A Research Paradigm Whose Time Has Come’ (2004) 33(7) Educational Researcher 14

316.Johnston, Kerensa, 'Everything in Context: Indigenous Women, International Human Rights Law and Discrimination - Is International Human Rights Law the Way Forward?' (2007) 7(1) Indigenous Law Bulletin 17

317.Johnston, Louise, 'Tuskegee in Liberia: The Politics of Industrial Education, 1927-1935' (1980) 9(2) Liberian Studies Journal 61

318.Jordash, Wayne and Penelope Van Tuyl, 'Failure to Carry the Burden of Proof: How Joint Criminal Enterprise Lost Its Way at the Special Court for Sierra Leone' (2010) 8 Journal of International Criminal Justice 591

319.Joseph, Joshua H, 'Gender and International Law: How the International Criminal Court Can Bring Justice to Victims of Sexual Violence' (2008) 18(1) Texas Journal of Women and Law 61

320.Juan, Shao-Chiu, Heather M Washington and Megan C Kurlychek, 'Breaking the Intergenerational Cycle: Partner Violence, Child-parent Attachment, and Children's Aggressive Behaviours' [2017] Journal of Interpersonal Violence 088626051769299

321.Kaiser, Joshua and John Hagan, 'Gendered Genocide: The Socially Destructive Process of Genocidal Rape, Killing, and Displacement in Darfur' (2015) 49(1) Law and Society Review 69

322. Kakuru, Doris M and Gaynor G Paradza, 'Reflections on the Use of the Life History Method in Researching Rural African Women: Field Experiences from Uganda and Zimbabwe' (2007) 15 Gender \& Development 287

323. Kalra, Naira, Gian Luca Di Tanna and Claudia García-Moreno, 'Training Healthcare Providers to Respond to Intimate Partner Violence against Women' [2017] (2) Cochrane Database of Systematic Reviews 1

324.Keal, Paul, "“Just Backward Children": International Law and the Conquest of Non-European Peoples' (1995) 49(2) Australian Journal of International Affairs 191

325.Keenan, Sarah, 'Moments of Decolonization: Indigenous Australia in the Here and Now' (2014) 29(2) Canadian Journal of Law and Society 163

326.Kelly, Fiona, 'Producing Paternity: The Role of Legal Fatherhood in Maintaining the Traditional Family’ (2009) 21(2) Canadian Journal of Women and the Law/Revue Femmes et Droit 315

327. Kennedy, Stephen B, 'Developing Capacity to Protect Human Research Subjects in a PostConflict, Resource-Constrained Setting: Procedures and Prospects' (2006) 32(10) Journal of Medical Ethics 592

328.Kieh, George Klay, 'Women, Sexual Harassment and Employment Opportunities in Liberia' (1993) 28(2) Liberian Studies Journal 189

329.Kimpton, Tammy M, 'Racism, Health and Constitutional Recognition' (2014) 200(11) The Medical Journal of Australia 614

330.King, Bryn, 'Psychological Theories of Violence' (2012) 22(5) Journal of Human Behaviour in the Social Environment 553

331.Kirby, Hon Justice Michael, ‘The Rights of Subordinated Peoples' [1996] The Australian Law Journal - Longer Book Reviews <http://www.lawfoundation.net.au/ljf/app/EE714F7BB0D34949CA2571A800003AE9.html>

332.Klein, Julie T, 'Evaluation of Interdisciplinary and Transdisciplinary Research' (2008) 35(2) American Journal of Preventive Medicine S116

333.Kleinhans, Martha-Marie and Roderick A Macdonald, 'What Is a Critical Legal Pluralism?' (1997) 12(02) Canadian Journal of Law and Society 25

334.Kleven, Thomas, 'The Supreme Court, Race, and the Class Struggle' (1981) 9(3) Hofstra Law Review 795 
335.Kollehlon, Konia T, 'Religious Affiliation and Fertility in Liberia' (1994) 26(04) Journal of Biosocial Science 493

336.Konvitz, Milton R, 'The Liberian Code of Laws' (1958) 2(2 (Summer)) The Journal of African Law 116

337.Kozel, Randy J, 'State Decisis as Judicial Doctrine' (2010) 67 Washington and Lee Law Review 411

338.van Krieken, Robert, 'Is Assimilation Justiciable? Lorna Cuillo \& Peter Gunner v Commonwealth’ (2001) 23(2) Sydney Law Review 239

339.Kune, Randall, 'The Stolen Generations in Court: Explaining the Lack of Widespread Success Litigation by Members of the Stolen Generations' (2011) 30(1) University of Tasmania Law Review 32

340.Kutin, Jozica, Roslyn Russell and Mike Reid, 'Economic Abuse between Intimate Partners in Australia: Prevalence, Health Status, Disability and Financial Stress' (2017) 41(3) Australian and New Zealand Journal of Public Health 269

341.Kynoch, Gary, 'Reassessing Transition Violence: Voices from South Africa's Township Wars, 1990-4' (2013) 112(447) African Affairs 283

342.Lambert-Pennington, Katherine, "“Real Blackfellas": Constructions and Meanings of Urban Indigenous Identity' (2012) 20(2) Transforming Anthropology 131

343.Lanford, Anna, 'Sex Education, Rape Culture, and Sexual Assault: The Vicious Cycle' (2016) 27(1) Furman Humanities Review 61

344.Langton, Marcia, 'Rum, Seduction and Death: “Aboriginality” and Alcohol' (1993) 63(3) Oceania 195

345.Larbalestier, Jan, 'The Politics of Representation: Australian Aboriginal Women and Feminism. -and a Reply by Bell, Diane' (1990) 6(2) Anthropological Forum 143

346.Larcombe, Wendy, 'Sex Offender Risk Assessment: The Need to Place Recidivism Research in the Context of Attrition in the Criminal Justice System' (2012) 18(4) Violence Against Women 482

347.Larcombe, Wendy et al, “I Think It's Rape and I Think He Would Be Found Not Guilty”: Focus Group Perceptions of (Un)Reasonable Belief in Consent in Rape Law' (2016) 25(5) Social \& Legal Studies 611

348.Latimer, Jeff, Craig Dowden and Danielle Muise, 'The Effectiveness of Restorative Justice Practices: A Meta-Analysis' (2005) 85(2) The Prison Journal 127

349.Lattas, Andrew, 'Essentialism, Memory and Resistance: Aboriginality and the Politics of Authenticity' (1993) 63(3) Oceania 240

350.Law Reform Commission of Western Australia, 'Aboriginal Customary Laws: Final Report' (2010) 10(4) Australian Indigenous Law Reporter 89

351.Lawrence III, Charles R, 'The Id, the Ego, and Equal Protection: Reckoning with Unconscious Racism' (1987) 39(2) Stanford Law Review 317

352.Lawson, Benjamin S, 'A 1930s African-American View of Liberia: George S Schuyler' (1995) XX(2) Liberian Studies Journal 247

353.LeBow, Michael D, Penny S Goldberg and Al Collins, 'Eating Behaviour of Overweight and Nonoverweight Persons in the Natural Environment' (1977) 45(6) Journal of Consulting and Clinical Psychology 1204

354.Lee, Heman, 'An Interview with Louise Taylor' (2009) 7(12) Indigenous Law Bulletin 19

355.Lee, Lloyd L, 'The Fundamental Laws: Codification for Decolonization?' (2013) 2(2) Indigeneity, Education and Society 117

356.Leeson, Peter T and Christopher J Coyne, 'Sassywood' (2012) 40(4) Journal of Comparative Economics 608

357.Liebling-Kalifani, Helen et al, 'Women War Survivors of the 1989-2003 Conflict in Liberia: The Impact of Sexual and Gender-Based Violence' (2011) 12(1) Journal of International Women's Studies 1

358.de Lint, Willem et al, 'Crime Victims' Self-Medication: Findings from a Study in South Australia’ (2017) 23(2) International Review of Victimology 159

359.Lloyd, Jane, 'Ngaanyatjarra Pitjantjatjara Yankunytjatjara: Women's Council Welcomes State and Territory Legislation That Will Protect Aboriginal Children from Abuse' (2004) 6(1) Indigenous Law Bulletin 28

360.Lloyd, Jane, 'Violent and Tragic Events: The Nature of Domestic Violence-Related Homicide Cases in Central Australia' [2014] (1) Australian Aboriginal Studies 99

361.Lopez, Gerardo R, 'Reflections on Epistemology and Standpoint Theories: A Response to "a Maori Approach to Creating Knowledge"' (1998) 11(2) International Journal of Qualitative Studies in Education 225

362.Lucas, Emma T, 'Sexual Abuses and Wartime Crimes against Women and Children: The Case of Liberia' (1997) 22(2) Liberian Studies Journal 240 
363.Lucashenko, Melissa, 'Violence against Indigenous Women: Public and Private Dimensions' (1996) 2(4) Violence Against Women 378

364.Lumby, Bronwyn and Terri Farrelly, 'Family Violence, Help Seeking \& the Close-Knit Aboriginal Community: Lessons for Mainstream Service Provision’ [2009] (19) Australian Domestic \& Family Violence Clearinghouse Issue Paper 1

365.Macdonald, Alison, 'Women and Children Experiencing Family Violence Are the Face of Homelessness' (2007) 20(5) Parity 21

366. Macfarlane, Peter, 'The Importance of Ethics and the Application of Ethical Principles to the Legal Profession' (2009) 13(1) Journal of South Pacific Law http://www.paclii.org/journals/fJSPL/vol06/8.shtml

367.Mack, Kathy, 'B v R: Negative Stereotypes and Women's Credibility' (1994) 2(2) Feminist Legal Studies 183

368. Mack, Kathy, 'Gender Awareness in Australian Courts: Violence against Women' (2004) 5(2-3) Criminal Law Forum 788

369.Mackey, Eva, 'Unsettling Expectations: (Un)Certainty, Settler States of Feeling, Law, and Decolonization' (2014) 29(2) Canadian Journal of Law and Society 235

370.MacKinnon, Catharine A, 'Feminism, Marxism, Method, and the State: An Agenda for Theory' (1982) 7(3) Signs 515

371.Madley, Benjamin, ‘From Terror to Genocide: Britain's Tasmanian Penal Colony and Australia's History Wars' (2008) 41(1) Journal of British Studies 77

372.Mahood, Kim, 'Kartiya Are like Toyotas' (2012) 36 Griffith Review http://griffithreview.com/edition

373.Makar, AB et al, 'Formate Assay in Body Fluids: Application in Methanol Poisoning' (1975) 13(2) Biochemical Medicine 117

374.Malone, Linda A, 'Women and War' (2006) 12(2) William \& Mary Journal of Women and the Law 297

375.Mama, Amina, 'Is It Ethical to Study Africa? Preliminary Thoughts on Scholarship and Freedom' (2007) 50(1) African Studies Review 1

376.Manderson, Desmond, 'Crocodile Tears' (2002) 7(30) Indigenous Law Bulletin 8

377. Manderson, Desmond, 'From Uunger to Love: Myths of the Source, Interpretation, and Constitution of Law in Children's Literature' (2003) 15(1) Law and Literature 87

378. Manderson, Desmond, 'Not yet: Aboriginal People and the Deferral of the Rule of Law' (2008) 29/30 Arena Journal 219

379. Manderson, Desmond, 'Modernism, Polarity, and the Rule of Law' (2012) 24(2) Yale Journal of Law and the Humanities 475

380.Manderson, Desmond, 'The Law of the Image and the Image of the Law: Colonial Representation of the Rule of Law' (2013) 57 New York Law School Law Review 153

381.Marchetti, Elena and Kathleen Daly, 'Indigenous Courts and Justice Practices in Australia' (2004) 277 Trends \& Issues in Crime and Criminal Justice 1

382. Marchetti, Elena, 'Indigenous Women and the RCIADIC - Part I' (2007) 7(1) Indigenous Law Bulletin 6

383.Marchetti, Elena, 'Indigenous Sentencing Courts' (2009) 5 Indigenous Justice Clearinghouse Research Briefs 1

384. Marchetti, Elena, 'Indigenous Sentencing Courts and Partner Violence: Perspectives of Court Practitioners and Elders on Gender Power Imbalances during the Sentencing Hearing' (2010) 43(2) Australian and New Zealand Journal of Criminology 263

385.Marchetti, Elena, 'Culture versus Gender How the Mainstream Criminal Court System Is Still Getting It Wrong' (2011) 7(26) Indigenous Law Bulletin 27

386. Marchetti, Elena, 'Victims or Offenders: Who Were the 11 Indigenous Female Prisoners Who Died in Custody and Were Investigated by the Australian Royal Commission into Aboriginal Deaths in Custody?' (2012) 19(1) International Review of Victimology 37

387. Markovich, David, 'Genocide, a Crime of Which No Anglo-Saxon Nation Could Be Guilty' (2003) 10(3) Murdoch University Electronic Journal of Law <http://www.austlii.edu.au/au/journals/MurUEJL/2003/27.html>

388. Marshall, WL, 'The Role of Attachments, Intimacy, and Loneliness in the Aetiology and Maintenance of Sexual Offending' (1993) 8(2) Sexual and Relationship Therapy 109

389. Martin, Guy, 'The Dynamics of Violence in Central Africa and; Africa's World War: Congo, the Rwandan Genocide, and the Making of a Continental Catastrophe (Review)' (2009) 56(2) Africa Today 92

390.Martin, Karen and Booran Mirraboopa, 'Ways of Knowing, Being and Doing: A Theoretical Framework and Methods for Indigenous and Indigenist Re-search' (2003) 27(76) Journal of Australian Studies 203 
391.Martínez, Julia and Claire Lowrie, 'Colonial Constructions of Masculinity: Transforming Aboriginal Australian Men into "Houseboys"” (2009) 21(2) Gender \& History 305

392. Massing, Andreas W, 'Materials for a History of Western Liberia: Samori and the Malinke' (1978) 8(1) Liberian Studies Journal 49

393. Massing, Andreas W, 'A Segmentary Society between Colonial Frontiers: The Kisse of Liberia, Sierra Leone and Guinea, 1892-1913' (1980) 9(1) Liberian Studies Journal 1

394.Mathews, Judith R, Therese L Mathews and Emily Mwaja, "Girls Take Charge": A Community-Based Participatory Research Program for Adolescent Girls' (2010) 4(1) Progress in Community Health Partnerships: Research, Education, and Action 17

395.Maxwell, Jack, "“Two Systems of Law Side by Side”: The Role of Indigenous Customary Law in Sentencing' (2015) 19(2) Australian Indigenous Law Review 97

396. M'baye, Babacar, 'The Economic, Political, and Social Impact of the Atlantic Slave Trade on Africa' (2006) 11(6) The European Legacy 607

397.McCormack, Timothy LH, 'Selective Reaction to Atrocity: War Crimes and the Development of International Criminal Law' (1997) 60(3) Albany Law Review 681

398. McCullough, Megan B, 'The Gender of the Joke: Intimacy and Marginality in Murri Humour' (2014) 79(5) Ethnos 677

399.McEvoy, Frederick D, ‘Some Proposals for Liberian Archeology’ (1970) 111(1) Liberian Studies Journal 129

400.McFarlane, Judith et al, 'The Intergenerational Impact of Intimate Partner Violence against Mothers on Child Functioning over Four Years' [2017] Journal of Family Violence <http://link.springer.com/10.1007/s10896-017-9913-8>

401.McGlade, Hannah, 'Justice as Healing: Developing Aboriginal Justice Models to Address Child Sexual Assault' (2007) 7(1) Indigenous Law Bulletin 10

402.McGlade, Hannah, 'The Royal Commission and International Child Rights Law' (2014) 8(13) Indigenous Law Bulletin 19

403.McGrath, Ann, “"Modern Stone Age Slavery”: Images of Aboriginal Labour and Sexuality” (1995) 69 Labour History 30

404.McGrath, Ann (Ann Margaret), 'Consent, Marriage and Colonialism: Indigenous Australian Women and Coloniser Marriages' (2005) 6(3) Journal of Colonialism and Colonial History 16

405.McGregor, Russell, “"Breed out the Colour” or the Importance of Being White' (2002) 33(120) Australian Historical Studies 286

406.McInnes, Elspeth, 'Single Mothers, Social Policy and Gendered Violence' (2002) 13 Women Against Violence: An Australian Feminist Journal 18

407.McKinnon, Don, 'The Rule of Law in Today's Africa' (2006) 32(4) Commonwealth Law Bulletin 649

408.McLaren, Lindsay, Lynn McIntyre and Sharon Kirkpatrick, 'Rose's Population Strategy of Prevention Need Not Increase Social Inequalities in Health' (2010) 39 International Journal of Epidemiology 372

409.Medie, Peace A, 'Fighting Gender-Based Violence: The Women's Movement and the Enforcement of Rape Law in Liberia' (2013) 112(448) African Affairs 377

410.Medland, Rowena, 'Re-Victimisation of the Victim: Family Violence Issues Facing Indigenous Women in Cape York' (2007) 7(1) Indigenous Law Bulletin 29

411.Meghana, RaoRane, 'Aiming Straight: The Use of Indigenous Customary Law to Protect Traditional Cultural Expressions' (2006) 15(3) Pacific Rim Law and Policy Journal 827

412.Melville, Angela and Rosemary Hunter, “"As Everybody Knows” Countering Myths of Gender Bias in Family Law' (2001) 10(1) Griffith Law Review 124

413. Memmott, Paul and Catherine Chambers, 'Good Practice in Indigenous Family Violence Prevention - Designing and Evaluating Successful Programs' (2006) 11 Australian Domestic \& Family Violence Clearinghouse Issue Paper 1

414. Merry, Sally Engle, 'Rights Talk and the Experience of Law: Implementing Women's Human Rights to Protection from Violence' (2003) 25(2) Human Rights Quarterly 343

415.Miller, Randall M, “Home as Found”: Ex-Slaves and Liberia' (1975) 6(2) Liberian Studies Journal 92

416.Moran, Mary H, 'Gender and Aging: Are Women “warriors” among the Glebo of Liberia?' (2000) 25(2) Liberian Studies Journal 25

417. Moreton-Robinson, Aileen, 'Troubling Business: Difference and Whiteness within Feminism' (2000) 15(33) Australian Feminist Studies 343

418. Moreton-Robinson, Aileen, 'The Possessive Logic of Patriarchal White Sovereignty: The High Court and the Yorta Yorta Decision' (2004) 3(2) Borderlands

<http://www.borderlands.net.au/vol3no2_2004/moreton_possessive.htm>

419.Morgan, G, 'Assimilation and Resistance: Housing Indigenous Australians in the 1970s' (2000) 36(2) Journal of Sociology 187 
420.Morito, Bruce, 'The Rule of Law and Aboriginal Rights: The Case of the Chippewas of Nawash' (1999) 19(2) Canadian Journal of Native Studies 263

421. Morrison, Zoe, 'What Is the Outcome of Reporting Rape to the Police' (2008) 17 Australian Centre for the Study of Sexual Assault Newsletter 4

422. Morrow, Glenn R, 'Plato and the Rule of Law' (1941) 50(2) The Philosophical Review 105

423. Morton-Thomas, Patricia, 'Aboriginal Death in Katherine after Release from Custody Sparks Calls for Inquiry, Justice' [2012] Greenleft Weekly https://www.greenleft.org.au/node/52622

424. Moses, Dirk A, 'Moving the Genocide Debate beyond the History Wars' (2008) 54(2) Australian Journal of Politics and History 248

425.Mossman, Mary Jane, 'Feminism and Legal Method: The Difference It Makes' (1987) 3(147) Wisconsin Women's Law Journal 147

426.Mouthaan, Solange, 'The Prosecution of Gender Crimes at the ICC: Challenges and Opportunities' (2010) 17 University of Warwick School of Law Legal Studies Research Paper 1

427. Mouzos, Jenny, 'Indigenous and Non-Indigenous Homicides in Australia: A Comparative Analysis' [2001] (210) Australian Institute of Criminology Trends and Issues 1

428. Mudaliar, Sanushka, 'Stolen Wages and Fiduciary Duties: A Legal Analysis of Government Accountability to Indigenous Workers in Queensland' (2003) 8(3) Australian Indigenous Law Reporter 1

429.Mujuzi, Jamil Ddamulira, 'Steps Taken in Rwanda's Efforts to Qualify for the Transfer of Accused from the ICTR' (2010) 8 Journal of International Criminal Justice 237

430.Mullally, Siobhán, 'Domestic Violence Asylum Claims and Recent Developments in International Human Rights Law: A Progress Narrative?' (2011) 60(02) International and Comparative Law Quarterly 459

431.Mullan, DJ, 'Fairness: The New Natural Justice' (1975) 281(25) University of Toronto Law Journal 281

432.Mullins, Gerry and Margaret Kiley, "“It's a PhD, Not a Nobel Prize": How Experienced Examiners Assess Research Theses' (2002) 27(4) Studies in Higher Education 369

433.Murdocca, Carmela, 'Visual Legalities of Race and Reparations' (2014) 29(2) Canadian Journal of Law and Society 219

434.Murray, Suellen, 'Violence against Homeless Women: Safety and Social Policy' (2011) 64(3) Australian Social Work 346

435.Nagy, Rosemary, 'The Truth and Reconciliation Commission of Canada: Genesis and Design' (2014) 29(2) Canadian Journal of Law and Society 199

436. Nancarrow, Heather, 'The Emergency Response to Family Violence in the Northern Territory: Where's the Evidence?' (2007) 7(1) Indigenous Law Bulletin 14

437. Nancarrow, Heather, 'Time Is of the Essence: Progress on the National Council's Plan for Australia to Reduce Violence against Women and Their Children. [National Council to Reduce Violence Against Women and Their Children.]' (2010) 33(3) University of New South Wales Law Journal 836

438. Naples, Nancy A, 'Deconstructing and Locating Survivor Discourse: Dynamics of Narrative, Empowerment, and Resistance for Survivors of Childhood Sexual Abuse' (2003) 28(4) Signs: Journal of Women in Culture and Society 1151

439. National Democratic Institute, 'Working for Democracy and Making Democracy Work' (2016) 37 NDI Liberia E-Newsletter 1

440.Naylor, Bronwyn, 'Effective Justice for Victims of Sexual Assault: Taking up the Debate on Alternative Pathways' (2010) 33(3) University of New South Wales Law Journal 662

441.Ndulo, Muna, 'African Customary Law, Customs, and Women's' (2011) 18(1) Indiana Journal of Global Legal Studies 87

442. Neville, Alisoun, 'Cubillo v Commonwealth: Classifying Text and the Violence of Exclusion' (2005) 5 Macquarie Law Journal 31

443. Newman, Debra Lynn, 'Labourers into the Harvest: Liberian Working Women in the Nineteenth Century' (1988) 4(7) Liberian Forum 36

444.Nguyen, Giang et al, 'Partnering to Collect Health Services and Public Health Data in Hard-toReach Communities: A Community-Based Participatory Research Approach for Collecting Community Health Data' (2010) 4(2) Progress in Community Health Partnerships: Research, Education, and Action 115

445.Niarchos, Catherine N, 'Women, War, and Rape: Challenges Facing the International Tribunal for the Former Yugoslavia' (1995) 17(4) Human Rights Quarterly 649

446. Nicholas, Stephen and Peter R Shergold, 'Intercounty Labour Mobility during the Industrial Revolution: Evidence from Australian Transportation Records' (1987) 39(4) Oxford Economic Papers 624

447.Nicol, Danny, 'The Human Rights Act and the Politicians' (2004) 24(3) Legal Studies 451 
448. Nowrojee, Binaifer, "'Your Justice Is Too Slow": Will the ICTR Fail Rwanda's Rape Victims?' (2005) 10 United Nations Research Institute for Social Development Occasional Paper 1

449. Nylund, Bo Viktor and Ida Margarita Hyllested, 'Impact of Armed Conflict on Children and Its Recognition on the Global Humanitarian and Human Rights Agenda' (2010) 2(1) Journal of Human Rights Practice 71

450. Obasogie, Osagie K, 'Foreword: Critical Race Theory and Empirical Methods' (2013) 3(2) UC Irvine Law Review 183

451.O'Brien, Louise, Corinne Henderson and Jenna Bateman, 'Finding a Place for Healing: Women Survivors of Childhood Sexual Abuse and Their Experience of Accessing Services' (2007) 6(2) The Australian e-Journal for the Advancement of Mental Health <http://search.informit.com.au/documentSummary;dn=476893247996391;res=IELHEA>

452. O’Connor, Manjula, 'Dowry-Related Domestic Violence and Complex -Post-Traumatic Stress Disorder: A Case Report' [2017] Australasian Psychiatry 1

453.O'Connor, Pam, 'Indigenous Policy, Native Title and the Rule of Law' (1998) 5(4) Agenda 501

454.O'connor, Vivienne, 'Traversing the Rocky Road of Law Reform in Conflict and Post Conflict States: Model Codes for Post Conflict Criminal Justice as a Tool of Assistance' (2006) 16(3-4) Criminal Law Forum 231

455. Oko Elechi, O, Sherill VC Morris and Edward J Schauer, 'Restoring Justice (Ubuntu): An African Perspective' (2010) 20(1) International Criminal Justice Review 73

456. Okon, Ekanem, 'Towards Defining the "right to a Family" for the African Child' 12(2) African Human Rights Law Journal 373

457. Oosterveld, Valerie, 'The Special Court for Sierra Leone's Consideration of Gender-Based Violence: Contributing to Transitional Justice?' (2008) 10(1) Human Rights Review 73

458. Oosterveld, Valerie, 'Gender and the Charles Taylor Case at the Special Court for Sierra Leone' (2012) 19(1) William \& Mary Journal of Women and the Law 7

459. Ormond-Parker, Lyndon, 'Aboriginal Remains Return Home' (2003) 5(24) Indigenous Law Bulletin 4

460. Osborne, DM, 'Women Seeking Asylum for Claims Based on Rape or Domestic Violence Still Get a Skeptical Hearing in the U.S. [The Gender Gap]' (2006) 28(2) American Lawyer 74

461. Osuri, Goldie, Tanja Dreher and Elaine Laforteza, "AActiing Sovereign” in the Face of Gendered Protectionism' (2009) 8(1) Borderlands 1

462. Ottersen, Ole Petter et al, 'The Political Origins of Health Inequity: Prospects for Change' (2014) 383(9917) The Lancet 630

463. Oxley, Deborah, 'Living Standards of Women in Prefamine Ireland' (2004) 28(2) Social Science History 271

464.Paisley, Fiona, 'Race and Remembrance: Contesting Aboriginal Child Removal in the Inter-War Years' (1997) 8(November) Australian Humanities Review <http://www.australianhumanitiesreview.org/archive/Issue-November-1997/paisley.html>

465.Paisley, Fiona, 'Race Hysteria, Darwin 1938' (2001) 16(34) Australian Feminist Studies 43

466.Parashar, Archana, 'Essentialism or Pluralism: The Future of Legal Feminism' (1993) 6(2) Journal of Women and the Law 328

467.Parkinson, Patrick, Atlanta Webster and Judy Cashmore, 'Lawyers' Interviews with Clients about Family Violence' (2010) 33(3) University of New South Wales Law Journal 929

468.Pascoe, John, 'Family Violence, Homelessness and the Family Law Act 1975 (Cth)' (2010) 33(3) University of New South Wales Law Journal 895

469.Pasternak, Shiri, 'Jurisdiction and Settler Colonialism: Where Do Laws Meet?' (2014) 29(2) Canadian Journal of Law and Society 145

470.Pease, Bob, 'Naming Violence as a Gender Issue : Victimisation, Blame and Responsibility' (1996) 1 Women Against Violence 33

471.Pease, Bob, 'Rethinking the Significance of Attitudes in Preventing Men's Violence against Women' (2008) 43(4) Australian Journal of Social Issues 547

472.Pejic, Jelena, 'The Tribunal and the ICC: Do Precedents Matter?' (1997) 60(3) Albany Law Review 841

473.Penglase, Bethia, '1788: That Illiterate "Freight of Misery”? -Literacy of First Fleet Convicts-' (1989) 75(2) Journal of Royal Australian Historical Society 99

474.Perell, Paul M, 'State Decisis and Techniques of Legal Reasoning and Legal Argument' (1987) 3(2) Legal Research Update 1

475.Peterson, Nicolas, “'Studying Man and Man's Nature”: The History of the Institutionalism of Aboriginal Anthropology' (1990) 2 Australian Aboriginal Studies 3

476.Peterson, Nicolas and Francesca Merlan, 'Two Takes on Social Problems in Central Australia' [2014] (1) Australian Aboriginal Studies 88

477.Phelps, Andrea R, 'Gender-Based War Crimes: Incidence and Effectiveness of International Criminal Prosecution' (2006) 12(2) William \& Mary Journal of Women and the Law 499 
478.Pierre, James AA, 'Opening Address of the March 1975 Term of the Supreme Court of Liberia' (1975) 6(1) Liberian Law Journal 45

479.Pimentel, David, 'Can Indigenous Justice Survive?: Legal Pluralism and the Rule of Law' (2010) 32(2) Harvard International Review 32

480.Pimentel, David, 'Rule of Law Reform without Cultural Imperialism? Reinforcing Customary Justice through Collateral Review in Southern Sudan' (2010) 2(01) Hague Journal on the Rule of Law 1

481.Pimentel, David, 'Legal Pluralism in Post-Colonial Africa: Linking Statutory and Customary Adjudication in Mozambique' (2011) 14(1) Yale Human Rights and Development Journal 1

482.Plotzki, Eugene P, 'The Bong Mine Venture' (1992) 17(1) Liberian Studies Journal 66

483.Post, Robert, 'Debating Disciplinarity' (2009) 35(Summer) Critical Inquiry 749

484.Powell, Andrea, 'Problematizing Polygyny in the Historical Novels of Chinua Achebe: The Role of the Western Feminist Scholar' (2008) 39(1) Research in African Literatures 166

485.Powell, Martine B, 'Investigating and Reporting Child Sexual Abuse: Review and Recommendations for Clinical Practice' (1991) 26(2) Australian Psychologist 77

486.Pradhan, SN, 'Aggression and Central Neurotransmitters' (1975) 18 International review of neurobiology 213

487.Press, Robert M, “'Guided by the Hand of God”: Liberian Women Peacemakers and Civil War' (2010) 8(1) The Review of Faith \& International Affairs 23

488.Prichard, James Cowles, 'The Physical and National History of Mankind' (1847) XXIV(IV) The British and Foreign Medical Journal of Practical Medicine and Surgery 49

489.Prince, N, 'Women's Experience of Crimes of Personal Violence: A Gender Analysis of the 1991 Queensland Crime Victims' Survey' (1992) 11(5) Queensland Nurse 6

490.Pritchard, Sarah and Charlotte Heindow-Dolman, 'Indigenous Peoples and International Law: A Critical Overview’ (1998) 3(4) Australian Indigenous Law Reporter 473

491.Purdy, Jeanine, 'I Suspect You and Your Friends Are Trifling with Me' : Encounters between the Rule of Law and the Ruled' (2001) 15 Australian Journal of Law \& Society 67

492. Quarmyne, Maakor, 'Witchcraft: A Human Rights Conflict between Customary/Traditional Laws and the Legal Protection of Women in Contemporary Sub-Saharan Africa' (2011) 17(2) William \& Mary Journal of Women and the Law 475

493. Queensland Coroner's Court, 'Findings of Inquest into the Death of Mulrunji' (2010) 10(4) Australian Indigenous Law Reporter 85

494.Queensland Coroner's Court, 'Inquest into the Death of Mulrunji' (2010) 14(1) Australian Indigenous Law Review 118

495.Quick, Diana, 'Rebuilding Education from Scratch in Liberia' (2005) 11(Supplement) Forced Migration Review 18

496. Ramsey, Carolyn B, 'Domestic Violence and State Intervention in the American West and Australia, 1860-1930' (2011) 86(1) Indiana Law Journal 185

497.Raz, Joseph, 'Responsibility and the Negligence Standard' (2010) 30(1) Oxford Journal of Legal Studies 1

498.Read, Peter, 'The Stolen Generations, the Historian and the Court Room' (2002) 26 Aboriginal History 51

499.Read, Peter, 'Reflecting on the Stolen Generations' (2014) 8(13) Indigenous Law Bulletin 3

500.Rees, Susan et al, 'Lifetime Revalence of Gender-Based Violence in Women and the Relationship with Mental Disorders and Psychosocial Function' (2011) 306(5) JAMA 513

501.Rees, Susan J and Derrick M Silove, 'Gender-Based Violence and the Threat to Women's Mental Health' (2011) 195(8) The Medical Journal of Australia 434

502. Reilly, Timothy F, 'The Louisiana Colonization Society and the Protestant Missionary, 18301860' (2002) 43(4) Louisiana History: The Journal of the Louisiana Historical Association 433

503.Reser, Joseph P, 'The "Socio-Historical" Argument and Construction of "Aboriginal Violence": A Critical Review of Hunter (1991)' (1991) 26(3) Australian Psychologist 209

504.Reynolds, Henry, 'After Mabo, What about Aboriginal Sovereignty' [1996] (April) Australian Humanities Review http://www.australianhumanitiesreview.org/archive/Issue

505.Reynolds, Henry, 'The Stolen Children -- Their Stories: An Afterword' [1998] (February) Australian Humanities Review http://www.australianhumanitiesreview.org/archive/Issue

506.Rich, Jeremy M, 'Independence Comes to the Chief's Daughters: A Gabonese Family Story of Marriage and Decolonization' (2009) 56(2) Africa Today 27

507.Richards, Eric, 'An Australian Map of British and Irish Literacy in 1841' (1999) 53(3) Population Studies 345

508. Riddell, James C et al, 'Clan and Chiefdom Maps of the Ma (Mano) and Da (Gio)' (1971) 4(2) Liberian Studies Journal 157 
509. Rigney, Lester-Irabinna, 'Internationalization of an Indigenous Anticolonial Cultural Critique of Research Methodologies: A Guide to Indigenist Research Methodology and Its Principles' (1999) 14(2) Wicazo Sa Review 109

510.Rigney, Lester-Irabinna, 'A First Perspective of Indigenous Australian Participation in Science: Framing Indigenous Research towards Indigenous Australian Intellectual Sovereignty’ (2001) 7 Kaurna Higher Education Journal 1

511.van Rijswijk, Honni and Thalia Anthony, 'Can the Common Law Adjudicate Historical Suffering?' (2012) 36(2) Melbourne University Law Review 618

512. Rincon, Jairo Munive, 'Ex-Combatants, Returnees, Land and Conflict in Liberia' (2010) 05 Danish Institute for International Studies Working Paper 24

513.Rizzo, Christie J et al, 'Individual and Relationship Characteristics of Adolescent Girls With Histories of Physical Dating Violence' [2017] Journal of Interpersonal Violence 1

514. Robert, Hannah, 'Disciplining the Female Aboriginal Body: Inter-Racial Sex and the Pretence of Separation' (2001) 16(34) Australian Feminist Studies 69

515.Roberts, Heather, 'Telling a History of Australian Women Judges through Courts' Ceremonial Archives' (2014) 40(1) Australian Feminist Law Journal 147

516. Robinson, Michelle and Di Watson, 'Guest Editor's Introduction: Domestic Violence Gendered Abuse' (1995) 14(1) Social Alternatives 5

517. Rowe, Suzanne E, 'Legal Research, Legal Writing, and Legal Analysis: Putting Law School into Practice' (2000) 29 Stetson Law Review 1193

518. Rowse, Timothy, 'Rethinking Aboriginal "Resistance": The Community Development Employment (CEPD) Program' (1993) 63(3) Oceania 268

519.Rubio-Marin, Ruth, 'Reparations for Conflict-Related Sexual and Reproductive Violence: A Cecalogue' (2012) 19(1) William and Mary Journal of Women and the Law 69

520.Ryan, Lyndall, 'Risdon Cove and the Massacre on 3 May 1804: Their Place in Tasmanian History [Paper Presented at the "Tasmanian Aboriginal History: Fabrication or Fact?" Conference, University of Tasmania, Launceston, 16 May 2003]' (2004) 9 Tasmanian Historical Studies 107

521.Ryan, Lyndall, 'The Black Line in Van Diemen's Land (Tasmania), 1830' (2013) 37(1) Journal of Australian Studies 1

522. Salter, Michael, 'Invalidation: A Neglected Dimension of Gender-Based Violence and Inequality' (2012) 1(1) International Journal for Crime, Justice and Social Democracy 3

523.Sandhu, SS, P Nelson and WJ Warren, 'Potable Water Quality in Rural Georgetown County' (1975) 14(4) Bulletin of Environmental Contamination and Toxicology 465

524.Sawyer, Amos, 'The Making of the 1984 Liberian Constitution: Major Issues and Dynamic Forces' (1987) 12(1) Liberian Studies Journal 1

525.Scalia, Antonin, 'The Rule of Law as a Law of Rules' (1989) 56(4) The University of Chicago Law Review 1175

526. Schabas, William A, 'Reservations to the Convention on the Elimination of All Forms of Discrimination Against Women and the Convention on the Rights of the Child' (1997) 3(1) William \& Mary Journal of Women and the Law 79

527. Schabas, William A, 'The Banality of International Justice' (2013) 11(3) Journal of International Criminal Justice 545

528. Schimmel, Jessica, 'Killing without Murder: Aboriginal Assimilation Policy as Genocide' (2005) 13(7) The Lehigh Review 35

529. Seelinger, Kim Thuy, 'Domestic Accountability for Sexual Violence: The Potential of Specialized Units in Kenya, Liberia, Sierra Leone and Uganda' (2014) 96(894) International Review of the Red Cross 539

530. Shotton, Anna, 'A Strategy to Address Sexual Exploitation and Abuse by United Nations Peacekeeping Personnel' (2006) 39 Cornell International Law Journal 97

531. Shweder, Richard and Fuambai S Ahmadu, 'Disputing the Myth of the Sexual Dysfunction of Circumcised Women: An Interview with Fuambai S. Ahmadu' (2009) 25(6) Anthropology Today 14

532. Simić, Olivera, 'Gender, Conflict, and Reconciliation: Where Are the Men, What about Women?’ (2005) 10 Journal of Political Theory and Research on Globalization, Development and Gender Issues 1

533. Simić, Olivera, 'Sexual Abuse of Women and Exploitation of Children by Peacekeepers: Case of Bosnia and Herzegovina and Democratic Republic of Congo' (2005) 10 Journal of Political Theory and Research on Globalization, Development and Gender Issues 1

534. Simic, Olivera, 'Rethinking “Sexual Exploitation” in UN Peacekeeping Operations' (2009) 32(4) Women's Studies International Forum 288

535.Simić, Olivera, 'Who Should Be a Peacekeeper?' (2009) 21(3) Peace Review 395 
536. Simien, Evelyn M, 'Doing Intersectionality Research: From Conceptual Issues to Practical Examples' (2007) 3(02) Politics \& Gender 264

537. Simpson, Paul et al, 'Assessing the Public's Views on Prison and Prison Alternatives: Findings from Public Deliberation Research in Three Australia Cities' (2015) 11(2) Journal of Public Deliberation 1

538. Sleath, Emma and Ray Bull, 'Police Perceptions of Rape Victims and the Impact on Case Decision Making: A Systematic Review’ (2017) 34 Aggression and Violent Behaviour 102

539. Smith, Philippa Mein, 'Blood, Birth, Babies, Bodies' (2002) 17(39) Australian Feminist Studies 305

540.Sovran, Steven, 'Understanding Culture and HIV/AIDS in Sub-Saharan Africa' (2013) 10(1) SAHARA-J: Journal of Social Aspects of HIV/AIDS 1

541.Spark, Ceridwen, 'Gender and Radiance' (2001) 27(2) Hecate 38

542. Spencer, Arthur, 'Anglo-Saxon Law in Liberia' (1909) XXI(1) The Green Bag 1

543. Spigelman, James, 'The Principle of Legality and the Clear Statement Principle' (2005) 79 Australian Law Journal 769

544. Stansell, Christine, 'Global Feminism in a Conservative Age Possibilities and Pieties since the 1980’ (2010) 57(2) Dissent 49

545.Steels, Brian and Dot Goulding, 'When It's a Question of Social Health and Well-Being, the Answer Is Not Prison' (2009) 7(12) Indigenous Law Bulletin 15

546. Steels, Brian, 'Processes for Developing a Restorative Justice Model in a Regional Area: A Feasibility and Implementation Study' (2010) 10(4) Australian Indigenous Law Reporter 101

547. Stein, Nan, 'A Rising Pandemic of Sexual Violence in Elementary and Secondary Schools: Locating a Secret Problem' (2005) 12 Duke Journal of Gender Law \& Policy 33

548. Stephens, Beth, 'Conceptualizing Violence under International Law: Do Tort Remedies Fit the Crime?’ (1997) 60(3) Albany Law Review 579

549. Strange, Carolyn, ‘A Case for Legal Records in Women's Gender History’ (2010) 22(2) Journal of Women's History 144

550. Strickland, Rennard J, 'Genocide-at-Law: An Historic and Contemporary View of the Native American Experience’ (1986) 34(4) Kansas Law Review 713

551. Stringer, Rebecca, 'Impractical Reconciliation: Reading the Intervention through the HugginsBell Debate' (2012) 27(71) Australian Feminist Studies 19

552.von Struensee, Vanessa, 'The Contribution of Polygamy to Women's Oppression and Impoverishment: An Argument for Its Prohibition' (2005) 2 Murdoch University Electronic Journal of Law < http://www.austlii.edu.au/cgibin/sinodisp/au/journals/MurUEJL/2005/2.html?stem=0\&synonyms=0\&query=rape >

553.Stubbs, Julie and Julia Tolmie, 'Battered Women Charged with Homicide: Advancing the Interests of Indigenous Women' (2008) 41(1) Australian and New Zealand Journal of Criminology 138

554.Stubbs, Julie, 'Relations of Domination and Subordination: Challenges for Restorative Justice in Responding to Domestic Violence' (2009) 33(3) University of New South Wales Law Journal 970

555.Sullivan, Jo M, 'Mississippi in Africa: Settlers among the Kru, 1835-1847' (1978) 8(2) Liberian Studies Journal 79

556. Sutton, Robert I and Barry M Staw, 'What Theory Is Not' (1995) 40(3) Administrative Science Quarterly 371

557. Suzack, Cheryl, 'Indigenous Women and Transnational Feminist Struggle: Theorizing the Politics of Compromise and Care' (2010) 10(1) CR: The New Centennial Review 179

558. Swaisland, Charles, 'The Aborigines Protection Society, 1837-1909' (2000) 21(2) Slavery and Abolition 265

559. Swiss, S et al, 'Violence against Women during the Liberian Civil Conflict' (1998) 279(8) JAMA: the journal of the American Medical Association 625

560.Syfert, Dwight N, 'The Origins of Privilege: Liberia Merchants, 1822-1847' (1975) 6(2) Liberian Studies Journal 109

561.Tatz, Colin, 'Confronting Australian Genocide' (2001) 25 Aboriginal History 16

562.Tayler-Smith, K et al, 'Sexual Violence in Post-Conflict Liberia: Survivors and Their Care' (2012) 17(11) Tropical Medicine \& International Health 1356

563. Taylor, Margaret, David Schmitt and Parimal Roy, 'Undermining the Social Foundations: The Impact of Colonisation on the Traditional Family Structure of the Goulburn Tribes' (2003) 27 Aboriginal History 208

564. The American Colonisation Society, 'Forty-Ninth Annual Report of the American Colonisation Society’ (1866) 42(2) African Repository 33 
565. The Clearinghouse, 'Pathways to Safety: An Interview about Indigenous Family Violence with Pam Greer, Indigenous Training and Development Consultant' [2001] (5) Australian Domestic \& Family Violence Clearinghouse Issue Paper 1

566. Thielen-Wilson, Leslie, 'Troubling the Path to Decolonization: Indian Residential School Case Law, Genocide, and Settler Illegitima' (2014) 29(2) Canadian Journal of Law and Society 181

567. Tolbert, David, 'United Nations Reform and Supporting the Rule of Law in Post-Conflict Societies’ (2006) 19 Harvard Human Rights Journal 29

568. Tomison, Adam M, 'Exploring Family Violence: Links between Child Maltreatment and Domestic Violence' (2000) 13(Winter) Australian Institute of Family Studies 1

569.Tonkin, Elizabeth, 'Sasstown's Transformation: The Jlao Kru, 1888-1918' (1978) 8(1) Liberian Studies Journal 1

570.Tonkin, Elizabeth, 'Queen and Quean: Managing and Imagining Power and Gender in Sasstown, Liberia' (2001) 38 Focaal: Tijdschrift voor Antropologie 141

571.Tood-Gher, Jaime, 'Policing Bodies, Punishing Lives: The African Women's Protocol as a Tool for Resistance of Illegitimate Criminalisation of Women's Sexualities and Reproduction' (2014) 14 African Human Rights Law Journal 735

572. Torrey, Morrison, 'Feminist Legal Scholarship on Rape: A Maturing Look at One Form of Violence against Women' (1995) 2(1) William and Mary Journal of Women and the Law 35

573. Towler, Anna, Areana Eivers and Ron Frey, 'Warning Signs of Partner Abuse in Intimate Relationships: Gender Differences in Young Adults' Perceptions of Seriousness' [2017] Journal of Interpersonal Violence 088626051769686

574. Tushnet, Mark, ‘A Critical Legal Studies Perspective' (1990) 38(1) Cleveland State Law Review 137

575.Tyldum, Guri and Anette Brunovskis, 'Describing the Unobserved: Methodological Challenges in Empirical Studies on Human Trafficking' (2005) 43(1-2) International Migration 17

576.University of Wisconsin Press, 'Sanniquellie Conference' (1962) 16(2) International Organization 444

577.de la Vega, Connie and Chelsea E HaleyNelson, 'The Role of Women in Peacekeeping and Peacemaking: Devising Solutions to the Demand Side of Trafficking' (2006) 12(2) William and Mary Journal of Women and the Law 437

578. Verdeja, Ernesto, 'Reconciliation(s): Transitional Justice in Postconflict Societies (Book Review)' (2009) 24(3) Canadian Journal of Law and Society 435

579. Verdonk, Petra and Tineke Abma, 'Intersectionality and Reflexivity in Medical Education Research' (2013) 47(8) Medical Education 754

580.Vickers, Jill, 'Territorial Pluralism and Family-Law Reform: Conflicts between Gender and Culture Rights in Federation, North and South' (2013) 40(1) Politikon 57

581. Vijeyarasa, Ramona, 'Facing Australia's History: Truth and Reconciliation for the Stolen Generations' (2007) 7(4) Sur: International Journal on Human Rights 127

582. Villmoare, Brian et al, 'Early Homo at 2.8 Ma from Ledi-Geraru, Afar, Ethiopia' (2015) 347(6228) Science 1352

583. Waldron, Jeremy, 'Stare Decisis and the Rule of Law: A Layered Approach' (2011) 11(75) Public Law and Legal Theory Research Paper Series 1

584. Wallström, Margot, 'Introduction: Making the Link between Transitional Justice and ConflictRelated Sexual Violence' (2012) 19(1) William \& Mary Journal of Women and the Law 1

585.Wane, Njoki, '[Re]Claiming My Indigenous Knowledge: Challenges, Resistance, and Opportunities' (2013) 2(1) Decolonization: Indigeneity, Education \& Society 93

586. Wang, Jiangyu, 'The Rule of Law in China: A Realistic View of the Jurisprudence, the Impact of the WTO, and the Prospects for Future Development' [2004] Singapore Year Book of Legal Studies 347

587. Wang, Shirley Kohsin, 'Violence \& HIV/AIDS: Violence against Women and Girls as a Cause and Consequence of HIV/AIDS' (2010) 17(2) Duke Journal of Gender Law \& Policy 313

588. Wangmann, Jane, 'Gender and Intimate Partner Violence: A Case Study from NSW' (2010) 33(3) University of New South Wales Law Journal 945

589. Wasserstrom, Richard A, 'The Obligation to Obey the Law' [1962] University of California Law Review 780

590.Watson, Irene, 'Aboriginal Women's Laws and Lives: How Might We Keep Growing the Law?' (2007) 26 The Australian Feminist Law Journal 95

591. Watson, Irene, 'Aboriginality and the Violence of Colonialism' (2009) 8(1) Borderlands 1

592. Watson, Paul J, 'The Real North? Jedda and the Centring of the Australian Male' (1996) 19(2) Northern Perspective 16

593.Webb, Jill, 'Indigenous Peoples and the Right to Self-Determination' (2012) 7(13) Journal of Indigenous Policy 75 
594.Weeks, Wendy, 'Managing Violence against Women in the Face of Unequal Gender Power Relations : A Review of Recent Feminist Accounts of Violence in Families' (1992) 17(2) Children Australia 32

595. Wexler, Steve and A Irvine, 'Aristotle and the Rule of Law' (2006) 23(1) Polis: The Journal of the Society for Greek Political Thought 116

596. Wharton, Rebecca, 'A New Paradigm for Human Trafficking: Shifting the Focus from Prostitution to Exploitation in the Trafficking Victims Protection Act' (2010) 16(3) William and Mary Journal of Women and the Law 753

597. White, CMN, ‘African Customary Law: The Problem of Concept and Definition’ (2009) 9(02) Journal of African Law 86

598. Wilcox, Karen, 'Connecting Systems, Protecting Victims: Towards Vertical Coordination of Australia's Response to Domestic and Family Violence' (2010) 33(3) University of New South Wales Law Journal 1013

599. Wilets, James D, 'Conceptualizing Private Violence against Sexual Minorities as Gendered Violence: An International and Comparative Law Perspective’ (1997) 60(3) Albany Law Review 989

600.William, C Allen, 'Barclay Women in Liberia - Two Generations: A Biographical Dictionary' (2000) XXV(1) Liberian Studies Journal 44

601.Williams, Mary Spiers, 'Why Are There No Adult Community Courts Operating in the Northern Territory of Australia?' (2013) 8(4) Indigenous Law Bulletin 7

602. Windschuttle, Keith, 'White Settlement in Australia: Violent Conquest or Benign Colonisation?' (2003) 31 Melbourne Historical Journal 1

603. Wolf, Patrick, 'Nation and MiscegeNation: Discursive Continuity in the Post-Mabo Era' (1994) 36 Social Analysis: The International Journal of Social and Cultural Practice 93

604. Wolfe, Patrick, 'Settler Colonialism and the Elimination of the Native' (2006) 8(4) Journal of Genocide Research 387

605. Wood, Asmi, 'Constitutional Reform 2013: What Are We Trying to Achieve?' (2012) 37(3) Alternative Law Journal 156

606.wood, Elizabeth Jean, 'Conflict-Related Sexual Violence and the Policy Implications of Recent Research' [2015] (894) International Review of the Red Cross 1

607. Worthen, Miranda et al, "I Stand like a Woman": Empowerment and Human Rights in Context of Community-Based Reintegration of Girls Mothers Formerly Associated with Fighting Forces and Armed Groups' (2010) 2(1) Journal of Human Rights Practice 49

608. Wreh, Tuan, 'Trial by Ordeal in Liberia' (1975) 6(1) Liberian Studies Journal 1

609. Wright, Michael T et al, 'Building an International Collaboration on Participatory Health Research' (2010) 4(1) Progress in Community Health Partnerships: Research, Education, and Action 31

610.Wunder, John R, 'Indigenous Peoples, Identity, History, and Law: The United States and Australian Experience' (1998) 4(1) Law Text Culture 81

611.Xanthaki, Alexandra, 'Indigenous Rights in International Law over the Last 10 Years and Future Developments' (2009) 10(1) Melbourne Journal of International Law 27

612. Yassi, Annalee et al, 'The Ethics of Ethics Reviews in Global Health Research: Case Studies Applying a New Paradigm' (2013) 11(1) Journal of Academic Ethics 83

613. Yodanis, Carrie L, 'Gender Inequality, Violence against Women, and Fear: A Cross-National Test of the Feminist Theory of Violence Against Women' (2004) 19(6) Journal of Interpersonal Violence 655

614.Zannettino, Lana, ““ . . . There Is No War Here; It Is Only the Relationship That Makes Us Scared": Factors Having an Impact on Domestic Violence in Liberian Refugee Communities in South Australia' (2012) 18(7) Violence Against Women 807

615.Zavala, Miguel, 'What Do We Mean by Decolonizing Research Strategies? Lessons from Decolonizing, Indigenous Research Projects in New Zealand and Latin America' (2013) 2(1) Decolonization: Indigeneity, Education \& Society 55

616.Zehr, Howard, 'Doing Justice, Healing Trauma: The Role of Restorative Justice in Peacebuilding' (2008) 1(1) South African Journal of Peacebuilding 1

\section{Letter}

1. Samson Ceasar, 'Liberian letters: Samson Ceasar to Henry F. Westfall 1834 June 2' (1834) <http://search.lib.virginia.edu/catalog/uva-lib:501740>.

2. Samson Ceasar, 'Liberian letters: Samson Ceasar to Henry F. Westfall 1835 August 3' (1835) <http://search.lib.virginia.edu/catalog/uva-lib:501742>.

3. Cyrus L. Gray, 'Resignation of the President Sirleaf Letter from GLOBAL' (2014).

4. National Leadership, 'Open Letter to the Prime Minister on Remote Communities' (2014). 
5. Karl J. O’Callaghan, 'Response to Four Corners from Western Australia Police' (2012) <http://www.abc.net.au/4corners/documents/domestic2012/WA_Police_Response.pdf>.

6. Michael O'Donnell, 'Social Security Legislation Amendment Bill, 2011; Stronger Futures in the Northern Territory Bill 2011, and Stronger Futures in the Northern Territory (Consequential and Transitional) Bill 2011.' (2014).

\section{Magazine Article}

1. Bennett, Jr., Lerone, 'What's in a Name? Negro vs. Afro-American vs. Black' (1967) 23 Ebony 46

2. Flomoku, Pewee and Lemuel Reeves, 'Formal and Informal Justice in Liberia' (2012) 44(23) Accord 44

3. Kahn, Andrew and Jamelle Bouie, 'The Atlantic Slave Trade in Two Minutes' [2015] Slate <http://www.slate.com/articles/life/the_history_of_american_slavery/2015/06/animated_interacti ve_of_the_history_of_the_atlantic_slave_trade.html>

4. Kerins, Sean, 'Aboriginal Landowners Angry after Warning NT Mine Is Poisoning Fish, Leaking Toxins' [2014] New Matilda <https://newmatilda.com/2014/10/31/aboriginallandowners-angry-after-warning-nt-mine-poisoning-fish-leaking-toxins>

5. Koryon, Bendu, 'Ellen Johnson-Sirleaf: Presidential Aspirant or War Criminal' [2005] TLC Africa $<$ http://www.tlcafrica.com/politics_ejs2.htm>

6. Latson, Jennifer, 'This Is Why Australia Has "National Sorry Day"' [2015] Time <http://time.com/3890518/national-sorry-day/>

7. McQuire, Amy, 'Protestors Gather to Express Outrage over Death of Ms Dhu' [2014] New Matilda <https://newmatilda.com/2014/10/23/protestors-gather-express-outrage-over-death-mrsdhu>

8. Reeves, Noeleen, 'This Is His Mark: Convicts and Literacy in Colonial Western Australia' (1985) 30(3) Westerly 50

9. Sandy, Yewa, 'Defense Officials Claim Shaki Kamara's Corpse' [2014] The Daily Observer <http://www.liberianobserver.com/security/defense-officials-claim-shaki-kamara's-corpse>

10. Windschuttle, Keith, 'The Fabrication of Aboriginal History' (2003) Summer(Summer) The Sydney Papers 20

\section{Manuscript}

1. ACT Government, Legislative Assembly for the ACT: Question and Answer Time, Week 12 Hansard, 29 October 2014 <http://www.hansard.act.gov.au/hansard/2014/week12/3765.htm>

2. Berryman, Hannah, Explaining the Advantages and Disadvantages of the Doctrine of Stare Decisis, Strode's College Essay Competition Paper, 2014 <http://www.peterjepson.com/law/SL1-Berryman.pdf >

3. Bloodworth, Sandra, Gender Relations in Aboriginal Society: What Can We Glean from Early Explorers' Accounts?, 1991 <http://www.anu.edu.au/polsci/marx/interventions/gender.htm>

4. Cross, Emily J, Critical Legal Studies: Challenging Tradition Legal Thought, National Collegiate Honors Council, 2012 <nchchonors.org/wp.../Cross-Emily-University-of-MontanaPaper.pdf>

5. Dagan, Tsilly and Talia Fisher, Rights for Sale, Private Document, 2010

6. Huggins, Jackie, Papers of Jackie Huggins, Archival Document, 2014

7. Jackson Jr., Joseph Q, Recycling Impunity in Liberia, Private Document, 22 May 2010

8. Kinash, Shelley, Paradigms, Methodology and Methods, Quality, Teaching and Learning Paper, 2006 <http://www.bond.edu.au/prod_ext/groups/public/@pub-tlsgen/documents/genericwebdocument/bd3_012336.pdf $>$

9. Knudsen, Susanne V, Intersectionality - A Theoretical Inspiration in the Analysis of Minority Cultures and Identities in Textbooks, Private Document, 2006

10. Lester, Stan, An Introduction to Phenomenological Research, Academic paper, 1999 $<$ www.sld.demon.co.uk/resmethy.pdf>

11. McDonald, David, Aboriginal Deaths in Custody and Aboriginal Incarceration: Looking Back and Looking Forward, 6 November 2014

12. Oxman-Vega, Veronica, Policies towards Gender-Based Violence: National Approaches Australia, Argentina and Chile (2002-2012), Thesis Proposal Review, 12 August 2013

13. The US District Court, Pennsylvania, Indictment of Jucontee Thomas Woewiyu, Court Indictment, 30 January 2014

14. Vaughan, Liz, Who Were the First Australians? From Where and When Did They Come? Do the out-of-Africa Models and Archaeological Data from the Southern Arc Match?, Academic Course Essay, 2013 <http://uwa.academia.edu/LVaughan> 
15. Williams, David C and Jallah A Barbu, A Commentary on the Meaning of the Constitution of the Republic of Liberia, Legal Document, 1 April 2009

<http://webcache.googleusercontent.com/search?q=cache:uZK8odGFyAIJ:ccd.indiana.edu/proje cts/liberia-

programs+A+COMMENTARY+ON+THE+MEANING+OF+THE+CONSTITUTION+OF+TH $\mathrm{E}+\mathrm{REPUBLIC}+\mathrm{OF}+\mathrm{LIBERIA} \& \mathrm{~cd}=1 \& \mathrm{hl}=\mathrm{en} \& \mathrm{ct}=\mathrm{clnk}>$

\section{Newspaper Article}

1. ABC News, 'Rosalie Kunoth-Monks Inspires with Her Q\&A Speech: "I Am Not the Problem"” ABC News $Q \& A$ (Sydney, NSW), 10 June $2014<$ http://www.news.com.au/national/rosaliekunothmonks-inspires-with-her-qa-speech-i-am-not-the-problem/story-fncynjr21226949124486>

2. Aborigines Conference, 'Our Historic Day of Mourning and Protest: Aborigines Conference Held at Australian Hall 26th January 1938' The Australian Abo Call (Sydney, NSW), April 1938 2

3. Adams, Shar, 'Inclusion the Key to "town Camps" Solution' Epoch Times (Sydney, NSW), 10 November 2009 http://www.theepochtimes.com/n2/australia/aborigines

4. Allan, Susan, 'Eleven-Year-Old Aboriginal Boy Commits Suicide' World Socialist Web Site (Geraldton, WA), 8 December 2014 https://www.wsws.org/en/articles/2014/12/08/suic

5. Australian Human Rights Commission, 'National Stolen Generations Reparations Scheme Needed' AHRC Media Releases (Sydney, NSW), 21 November 2017

$<$ https://www.humanrights.gov.au/news/media-releases/national-stolen-generations-reparationsscheme-needed>

6. Azango, Mae, 'Taking More, Giving Less - Nimba Decry Arcelor Mittal's Operation' Front Page Africa (Monrovia Liberia), 2014

<http://www.frontpageafricaonline.com/index.php/business-tech/280-ta...-more-giving-lessnimba-citizens-decry-arcelor-mittal-s-operations>

7. Azango, Mae, 'The Cost of FGM to Liberian Girls' Front Page Africa (Monrovia, Liberia), 2014 <http://www.asafeworldforwomen.org/global-news/africa/liberia/2184-mae-azango-thecost-of-fgm-to-liberian-girls.html>

8. Azango, Mae, 'Liberian "Slaves in Lebanon"? Girls Turned into Sex Objects' Front Page Africa (Monrovia, Liberia), 12 September 2014 <http://allafrica.com/stories/201409121068.html>

9. Azango, Mae, 'Liberia: Married at 13 - Young Girls Forced Into Adulthood in Liberia' FrontPageAfrica (Monrovia, Liberia), 7 November 2014 $<$ http://allafrica.com/stories/201411071717.html>

10. Azango, Mae, 'Outgoing President Sirleaf Abolishes Female Genital Mutilation, Signs Domestic Violence Bill’ FrontPageAfricaonline.com (Monrovia, Liberia), 22 January 2018 $<$ https://frontpageafricaonline.com/index.php/news/6691-outgoing-president-sirleaf-abolishesfemale-genital-mutilation-signs-domestic-violence-bill>

11. Barrass, Tony, 'Aboriginal “child Sex Ring” Exposed' The Australian (Kalumburu, WA), 17 April $2007<$ http://www.theaustralian.com.au/news/nation/aboriginal-child-sex-ringexposed/story-e6frg6nf-1111113355850>

12. Batha, Emma, 'Liberia Bans Female Genital Mutilation - but Only for a Year' Reuters (Monrovia, Liberia), 25 January $2018<\mathrm{https}$ ://www.reuters.com/article/us-liberia-fgmlaw/liberia-bans-female-genital-mutilation-but-only-for-a-year-idUSKBN1FE1N7>

13. BBC, 'First Female Law Lord Appointed' BBC News (London; UK), 24 October 2003 <http://news.bbc.co.uk/2/hi/uk_news/3210003.stm>

14. BBC, 'South Africa Apartheid Assassin de Kock Parole' BBC News (London, UK), 30 January $2015<$ http://www.bbc.com/news/world-africa-31054912?print=true>

15. BBC News, 'Death Penalties for Delhi Gang Rape' BBC News (London, UK), 13 September 2013 <http://www.bbc.com/news/world-asia-india-24078339>

16. Blenkin, Max, 'Hawke Govt Launched Aboriginal Death Probe' The Australian (Sydney South, NSW), 1 January 2014 <http://www.theaustralian.com.au/news/latest-news/hawke-govtlaunched-aboriginal-death-probe/story-fn3dxiwe-1226792800340>

17. Boddy, Natasha, 'Cultural Advisers Appointed to Support Aboriginal and Torres Strait Islander Children in Care' Canberra Times (Canberra, ACT), 5 January 2015

$<$ http://www.canberratimes.com.au/act-news/cultural-advisers-appointed-to-support-aboriginaland-torres-strait- islander-children-in-care-20150104-12hnpj.html>

18. Boley, Tecee, 'Walking Dead - Liberia's Lutheran Church Massacre Victims Still Carry Bullets, Scars' All Africa (Monrovia, Liberia), 31 July 2013 <http://allafrica.com/stories/201307310769.html>

19. Borteh, George J, 'Angel Togba's Mother Pushes Supreme Court to Act' All Africa (Monrovia), 21 May $2013<$ http://allafrica.com/stories/201305220776.html> 
20. Boserio, Gail, 'Domestic Abuse of Indigenous Women a "National Crisis"' Australian Broadcasting Corporation (Sydney, NSW), 4 May 2015

<http://www.abc.net.au/radionational/programs/latenightlive/crisis-of-domestic-abuse-ofindigenous-women/6442954>

21. Brennan, Bridget, 'Rethink Aboriginal Town Camps: Mick Gooda' ABC News (Alice Springs, N.T), 3 March 2014 <http://www.abc.net.au/news/stories/2011/03/03/3153800.htm?site=alicesprings>

22. Brennan, Lina and Alice Williams, "Family Violence Does Not Have a Colour" Daily Life (Melbourne, VIC), 24 November 2014 http://www.dailylife.com.au/news

23. Brooks, Calvin, 'Official: Over 500,000 Suffer Mental Illness Due to War, Ebola' Liberian News Agency (Monrovia, Liberia), 7 March 2015 <http://www.liberianewsagency.org>

24. Butty, James, 'Liberia's Justice Minister Resigns' Voice of America (Monrovia, Liberia), 7 October 2014 <http://www.voanews.com/articleprintview/2475000.html>

25. Butty, James, 'Backlash over Liberian President's Executive Order' Voice of America (Monrovia, Liberia), 8 December 2014 <http://www.voanews.com/content/backlash-overliberian-presidents-executive-order/2549911.html>

26. Campbell, Janjay F, 'Liberia Security Is Stable, but Fragile' All Africa (Washington D. C.), 20 September 2013 <http://search.proquest.com/docview/1041259436?accountid=8330>

27. CBC News, 'Rehtaeh Parsons Case to Get Independent Review' Canadian Broadcasting Corporation (Halifax, NS), 15 April $2013<$ http://www.cbc.ca/news/canada/novascotia/story/2013/04/15/ns-rehtaeh-bully-independent-review.html>

28. CBC News, 'Rehtaeh Parsons Suspects in Court to Face Child Porn Charges' Canadian Broadcasting Corporation (Halifax, NS), 15 August 2013

<http://www.cbc.ca/news/canada/nova-scotia/story/2013/08/15/ns-rehtaeh-parsons-accusedappearance.html>

29. Chesler, Phyllis, 'New Study Shows Half of Liberian Girls, Women Undergo Female Genital Mutilation' Breitbart (Los Angeles, CA), 14 December 2014

<http://www.breitbart.com/national-security/2014/12/11/new-study-showing-half-of-liberiangirls-women-undergo-fgm-not-a-surprise/>

30. Cordingley, Glen, 'Station Gives Yawuru a New Start' The West Australian (Broome, WA), 3 September $2014<$ https://au.news.yahoo.com/thewest/business/wa/a/24881704/station-givesyawuru-chance-to-rebuild/>

31. Coughlan, Sean, 'Asia Pops Biggest Global School Rankings' BBC News (London), 13 May 2015 <http://www.bbc.com/news/business-32608772>

32. Cox, Eva, "Work with Us Not for Us" to End the Indigenous Policy Chaos' The Conversation (Sydney, NSW), 14 December 2014 <http://theconversation.com/work-with-us-not-for-us-toend-the-in...20not $\% 20$ for $\% 20$ us $\% 20$ to $\% 20$ end $\% 20$ the $\% 20$ Indigenous $\% 20$ policy $\% 20$ chaos $>$

33. Crouch, Joanne, 'Somalia: Amisom Troops Commit Brutal Gang Rape in Mogadishu, Somalia' All Africa (Kampala, Uganda), 14 August 2013

<http://allafrica.com/stories/201308150540.html?viewall=1>

34. Daley, Paul, 'Why Does the Australian War Memorial Ignore the Frontier War? The Battle between Aboriginal People and the Settlers Is at the Heart of Nationhood but Absence from War Dead Commemorations' The Guardian (Canberra, ACT), 12 September 2013

<http://www.theguardian.com/world/2013/sep/12/australian-war-memorial-ignores-frontierwar>

35. Dalieh, Patience Handful, 'Liberia: Ebola Hits the Family - but Won't Stop Us from Helping' All Africa (Monrovia, Liberia), 18 August 2014

<http://allafrica.com/stories/201408181508.html?fb_action_ids=1473249009597061\&fb_action _types $=$ og.comments $>$

36. Dash, Leon, 'Liberian Soldiers Taunt, Shoot 13 Former Leaders' The Washington Post (Monrovia, Liberia), 23 April 1980 http://www.washingtonpost.com/wp

37. Dash, Leon, 'Liberian Revolt Preserves Old Structure' Washington Post (Washington, DC), 29 December 1980 <https://www.washingtonpost.com/archive/politics/1980/12/29/liberian-revoltpreserves-old-structure/aaeb2874-07bd-4ecd-8f4e-fb5a58f442e8/>

38. Davidson, Helen, 'Prison Songs: "Welcome to the Berrimah Hilton - Prepare to Be Amazed"" The Guardian (Darwin, NT), 1 January 2015 <http://www.theguardian.com/tv-andradio/2015/jan/02/prison-songs-berrimah-hilton?CMP=ema_632>

39. Daygbor, EJ Nathaniel, 'Land Bill Reaches Capitol Building' The New Dawn (Monrovia, Liberia), 7 August 2015 <http://www.thenewdawnliberia.com/news/8108-land-bill-reachescapitol-building>

40. Dayton, Leigh and Stuart Rintoul, 'Genes Map Aborigines' Arrival in Australia' The Australian (Sydney, NSW), 23 September $2011<$ http://www.theaustralian.com.au/news/healthscience/genes-map-aborigines-arrival-in-australia/story-e6frg8y6-1226144089835> 
41. Diemer, Kristin, ‘Australians Still Trivialise and Excuse Violence against Women' The Conversation (Sydney, NSW), 17 September $2014<$ http://theconversation.com/australians-stilltrivialise-and-excuse-

v...ans\%20still\%20trivialise\%20and\%20excuse\%20violence\%20against\%20women>

42. Dingle, Sarah, 'Why Was Nobody Watching?' Australian Broadcasting Corporation (Yatala, SA), 2 November 2014

<http://www.abc.net.au/radionational/programs/backgroundbriefing/2014-1102/5847612\#transcript>

43. Dixon, Winnie, 'Senator Kupee Seeks Enactment of Child Support Act' Liberian News Agency (Monrovia, Liberia), 24 October 2014 <http://www.liberianewsagency.org/pagesnews.php?nid=3071>

44. Dodson, Shannan, 'Too White, Too Black, or Not Black Enough? This Is Not a Question for Others to Decide' The Guardian (Sydney, NSW), 8 June 2017

$<$ http://www.theguardian.com/commentisfree/2017/jun/09/too-white-too-black-or-not-blackenough-this-is-not-a-question-for-others-to-decide>

45. Economywatch, 'Why Liberia Has Not Been Able to Break Its Resource Curse' Oil Price (London, UK), 25 November $2012<$ http://oilprice.com/Geopolitics/Africa/Why-Liberia-HasNot-Been-Able-to-Break-its-Resource-Curse.html $>$

46. Executive Mansion News, 'Liberian President Issues Executive Order on Land Sales' Front Page Africa (Monrovia, Liberia), 26 December 2013 $<$ http://www.frontpageafricaonline.com/index.php/news/214-liberian-pr...ive-order-on-landsales?tmpl=component $\&$ print $=1 \&$ layout $=$ default $\&$ page $=>$

47. Executive Mansion of Liberia, 'President Sirleaf Grants Executive Clemency to 32 Inmates in Prison across the Country’ Executive Mansion News (Monrovia, Liberia), 23 December 2014 http://www.emansion.gov.lr/2press.php?news_id=3166

48. Feneley, Rick, 'Deadly Awards Founder Gavin Jones Dies after Funding Cut' The Sydney Morning Herald (Sydney, NSW), 14 July 2014 <http://www.smh.com.au/entertainment/deadlyawards-founder-gavin-jones-dies-after-funding-cut-20140714-zt78p.html>

49. Feng, Sonia and Melanie Pearce, 'Bloody Part of Australian History Laid Bare in Bathurst' $A B C$ News (Orange, NSW), 15 August 2017 <http://www.abc.net.au/news/2017-08-15/scars-ofmartial-law-laid-bare-in-bathurst/8804586>

50. Ford, Liz, 'UN to Measure Women's Rights Progress over Past 20 Years' The Guardian (London, UK), 2014 <http://www.theguardian.com/global-development/2014/apr/07/unwomens-rights-progress-cairo-agreement/print>

51. Freeman, Colin, "The Liberian Slum Where Ebola Spreads Death among Killer Virus "Deniers", Telegraph (Monrovia, Liberia), 8 August 2014

<http://www.telegraph.co.uk/news/worldnews/africaandindianocean/libe...ian-slum-whereEbola-spreads-death-among-killer-virus-deniers.html>

52. Gbala, Bai M, 'Decentralisation of Political and Administrative Power in Liberia' The Perspective (Atlanta, GA), 30 June 2004 <http://www.theperspective.org/2004/june/decentralization.html>

53. Goah, Bernard Gbayee, 'Is President Ellen Johnson-Sirleaf of Liberia Immune from Prosecution, or Not?' Front Page Africa (Monrovia, Liberia), 18 October 2013

<http://www.frontpageafricaonline.com/old/op-ed-editorial/lettercomments/7273-is-presidentellen-johnson-sirleaf-of-liberia-immune-from-prosecution-or-not.pdf>

54. Gordon, Glenna, 'In Liberia, Sirleaf's Past Sullies Her Clean Image' Time (Monrovia, Liberia), 3 July 2009 <http://content.time.com/time/world/article/0,8599,1908635,00.html>

55. Gordon, Michael, 'So What Was All That About?' Canberra Times (Canberra, ACT), 5 December 20159

56. Grant, Stan, 'I Can Tell You How Adam Goodes Feels. Every Indigenous Person Has Felt It' The Guardian (Sydney South, NSW), 30 July 2015

<http://www.theguardian.com/commentisfree/2015/jul/30/i-can-tell-you-how-adam-goodesfeels-every-indigenous-person-has-felt-it>

57. Gregory, Laurel, 'Equip Liberia' Global News (Vancouver, BC), 28 May 2012 <http://globalnews.ca/news/249834/blog-equip-liberia/>

58. Guilbert, Kieran, 'Liberian Wins Children's Peace Prize for Defending Victims of Violence, Rape’ Thomson Reuters Foundation (Dakar, Senegal), 9 November 2015 <http://www.trust.org/item/20151109150153-i0muy>

59. Harmon, William Q, 'TWP Warned against Political Dominance, Exclusion' The Daily Observer (Monrovia, Liberia), 9 July 2015

60. Harrison, Dan, 'Third Woman on High Court Bench' The Age (Canberra, ACT), 4 February 2009 <http://www.theage.com.au/national/third-woman-on-high-court-bench-200902037wv2.html?skin=text-only $>$ 
61. Harrison, Dan, 'Patrick Dodson Warns Aboriginal People Will Be Refugees in Their Own Country If Communities Close’ The Sydney Morning Heralds (Sydney, NSW), 21 November 2014 http://www.smh.com.au/action/printArticle?id=63429039

62. Heyden, Tom, 'The 10 Greatest Controversies of Winston Churchill's Career' BBC News (London, UK), 21 January 2015 <http://www.bbc.com/news/magazine-29701767>

63. Hogan, Caelainn, 'Women Hardest Hit by Ebola in West Africa' The Star (Toronto, ON), 18 August 2014

<http://www.thestar.com/news/world/2014/08/15/women_hardest_hit_by_ebola_in_west_africa. html>

64. Howard, John, 'John Howard: The Transcript' Crikey: Independent Media, Independent Minds (Canberra, ACT), 21 June 2013 <http://www.crikey.com.au/2007/06/21/john-howard-thetranscript/>

65. Howden, Daniel, 'Warlord to Kingmaker: An Audience with Prince Johnson' The Independent (London, UK), 15 October 2011 http://www.independent.co.uk/news/world/africa/warlord

66. James, Felicity, 'Stolen Generation given Voice on Child Sex Abuse' ABC News (Sydney, NSW), 10 October 2013 <http://www.abc.net.au/news/2013-10-10/royal-commission-childsexual-abuse-stolen-generations-darwin-s/5013720?\&section=news $>$

67. Jeffries, Stuart, 'Angela Davis: "Unbroken Line of Police Violence in US Back to Slavery" The Guardian (London, UK), 14 December 2014 http://www.theguardian.com/global/2014/dec/14/angela

68. Johnson, Bettie, '49 Year-Old Alleged Rapist Indicted on Multiple Charges' Front Page Africa (Monrovia, Liberia), 9 March 2015 <http://frontpageafricaonline.com/index.php/news/4679-49year-old-alleged-rapist-indicted-on-multiple-charges $>$

69. Johnson, Comfort M, 'Judge Sentences Man to 25 Years for Killing His Girlfriend' Liberian News Agency (Monrovia, Liberia), 9 March 2015 <http://www.liberianewsagency.org/pagesnews.php?nid=4178>

70. Jones, Roby, 'Minister Shines Light on Dark Side of NT Life' Australian Broadcasting Corporation (Alice Springs, NT), 4 April 2013 <http://www.abc.net.au/news/2013-04-04/alisonanderson-on-territory-domestic-violence/4609524>

71. Jones, Virginia and Annie Schubert, 'Indigenous Canberra: Connecting the Dots' Australian Broadcasting Corporation (Canberra, ACT), 7 July 2011 <http://www.abc.net.au/local/stories/2011/07/07/3263280.htm>

72. Jr, Genoway, Edwin, 'Ex-Presidential Guard Deputy Arrested in Assault Case: "Monster Hooked", Front Page Africa (Monrovia, Liberia), 17 September 2015 $<$ http://frontpageafricaonline.com/index.php/news/6287-ex-presidential-guard-deputy-arrestedin-assault-case?tmpl=component\&print=1\&layout=default\&page $=>$

73. Jullien, Maud, 'DR Congo Woman 'saw Col Egangela Order Gang-Rape' BBC News (London, UK), 22 August 2014 <http://www.bbc.com/news/world-africa-28898298?print=true>

74. Karmo, Henry, 'Most Corrupt-National Integrity Barometer Rates Liberia's Judiciary' Front Page Africa (Monrovia, Liberia), 20 December 2013 <http://www.frontpageafricaonline.com/index.php/news/161-most-corrupt...tes-liberia-sjudiciary?tmpl=component $\&$ print $=1 \&$ layout $=$ default $\&$ page $=>$

75. Karmo, Henry, 'Most Corrupt: National Integrity Barometer Rates Liberia's Judiciary with Very Low Marks’ Front Page Africa (Monrovia, Liberia), 20 December 2013

$<$ http://www.frontpageafricaonline.com/old/news/general-news/7758-most-corrupt-nationalintegrity-barometer-rates-liberias-judiciary.pdf>

76. Kay, Kira, 'For Liberia, Natural Resources Are Blessings, Curses on Road to Democracy' PBS Newshour (Arlington, VA), 31 October $2011<$ http://www.pbs.org/newshour/bb/world-julydec11-liberia_10-31/>

77. Keita, Abraham M, 'Keita Delicates Award to Shaki Kamara and Liberian Children' The Perspective (Atlanta, GA), 11 November 2015 <http://www.theperspective.org/2015/1111201501.php>

78. Kennedy, Duncan, 'Eddie Mabo, the Man Who Changed Australia' BBC News (London, UK), 6 June $2012<$ http://www.bbc.com/news/magazine-18291022>

79. Kesselly, Sr., Sam Van, 'Remembering April 12 after 34 Years' Front Page Africa (Monrovia, Liberia), 15 April $2014<$ http://www.frontpageafricaonline.com/index.php/oped/commentaries...il-12-after-34-years?tmpl=component\&print=1\&layout=default\&page=>

80. Knaus, Christopher, 'More Jail Time for Convicted Paedophile' The Canberra Times (Canberra, ACT), 7 November $2014<$ http://www.canberratimes.com.au/act-news/more-jail-time-forconvicted-paedophile-20131107-2x2ni.html>

81. Kollie, Ballah, 'Judge Hands Rape Case to Jurors' Liberian News Agency (Monrovia, Liberia), 17 March 2014 <http://www.liberianewsagency.org/pagesnews.php?nid=775> 
82. Kristof, Nicholas, 'Ellen Johnson Sirleaf and War Crimes?!' New York Times (Monrovia, Liberia), 3 July 2009 <http://kristof.blogs.nytimes.com/2009/07/03/ellen-johnson-sirleaf-andwar-crimes/?_r=0>

83. Lane, Sarah and Jeremy Thompson, 'Abbott Calls for New Intervention in NT Towns' $A B C$ News (Alice Springs, NT), 21 March 2011 <http://www.abc.net.au/news/stories/2011/03/21/3169134.htm?site=indigenous\&topic=latest>

84. Langsam, David, 'Quest for the Missing Dead' The Guardian (Sydney, NSW), 24 February 1990 <http://dingonet.com/questfor.htm>

85. Lazuta, Jennifer, 'Liberia Literacy Program Targets Women' VOA (Dakar, Senegal), 7 August 2013 <http://www.voanews.com/content/liberia-literacy-program-reaches-women-in-midlife/1725157.html>

86. Lee, Jane, 'Changes Proposed to Laws on Rape' The Age (Melbourne, VIC), 25 October 2013 <http://www.theage.com.au/victoria/changes-proposed-to-laws-on-rape-20131024-2w4f3.html>

87. Liberian News Agency, 'MICAT Plans National Dialogue on Dunn Committee Report' LINA Bulletin (Monrovia, Liberia), 2 September 20152

88. Loewenstein, Antony, 'Indigenous Incarceration Rates Are a National Shame' The Guardian (Online), 1 November 2013 http://www.theguardian.com/commentisfree/2013/nov/01/indigenous

89. Lomax, Selma, 'Rural Boost - EJS Dedicates Chief Suakoko Centre for Women' All Africa (Monrovia, Liberia), 11 June 2014 <http://allafrica.com/stories/201406110497.html>

90. Maitreyee, 'Delhi Gangrape Redux? This Time a Minor Raped inside a Bus' One India (Online), 15 April 2013 <Read more at: http://news.oneindia.in/2013/04/15/delhi-minor-raped-inside-abus-driver-held-1193979.html>

91. Makhetha, Tankiso, 'Teens Accused of Rape, Murder of Girl, 14' IOL News (Pretoria), 27 March 2013 <http://www.iol.co.za/news/crime-courts/teens-accused-of-rape-murder-of-girl-141.1492436\#.UWw7i7_UO5o>

92. Makhetha, Tankiso, 'Teens Accused of Girl's Rape, Murder Released | IOL News' IOL News (Pretoria, Johannesburg), 28 March $2013<$ https://www.iol.co.za/news/crime-courts/teensaccused-of-girls-rape-murder-released-1493161>

93. Malkin, Bonnie, 'Australian Prime Minister Kevin Rudd Descended from Thieves' The Telegraph (London, UK), 31 July 2008 <http://www.telegraph.co.uk/news/worldnews/australiaandthepacific/australia/2479134/Australi an-prime-minister-Kevin-Rudd-descended-from-thieves.html>

94. Masters, Emma, 'Remote Indigenous Outstation Rejects Federal Policy and Opens Own School' ABC News (Darwin, NT), 22 July $2015<$ http://www.abc.net.au/news/2015-07-22/remote-ntindigenous-community-opens-own-school/6639220>

95. McDonald, Philippa and Riley Stuart, 'Nearly 2,000 Catholic Church Figures Implicated in Child Sex Abuse Report' ABC News (Sydney, Australia), 6 February 2017

$<$ http://www.abc.net.au/news/2017-02-06/royal-commission-into-child-sexual-abuse-begins-insydney/8242600>

96. McQuire, Amy, 'Historic Victory for Aboriginal Queenslander Sparks New Hope on Stolen Wages' New Matilda (Redfern, NSW), 6 February 2015 https://newmatilda.com/2015/02/06/historic

97. Medhora, Shalailah, 'Northern Australia Plan Aims to Make Region an "Economic Powerhouse", The Guardian (Canberra, ACT), 18 June 2015

$<$ http://www.theguardian.com/business/2015/jun/18/northern-australia-plan-aims-to-makeregion-an-economic-powerhouse>

98. Moodle, Claire, 'Stolen Generation Test Case Likely to Go to Trial' ABC News (Canberra, ACT), 31 July $2012<$ http://www.abc.net.au/news/2012-07-31/stolen-generation-test-case-likely-to-goto-trial/4166720>

99. Moore, Jina, 'Liberia's “Rape Court”: Progress for Women and Girls Delayed?' Christian Science Monitor (Kigali, Rwanda), 10 October 2010 <http://www.csmonitor.com/World/Africa/Africa-Monitor/2010/1010/Liberia-s-Rape-CourtProgress-for-women-and-girls-delayed >

100.Moore, Jina, 'Mob Destroys Ebola Center in Liberia Two Days after It Opens' BuzzFeed News (Monrovia, Liberia), 17 August $2014<$ http://www.buzzfeed.com/jinamoore/two-days-after-itopens-mob-destroys-ebola-center-in-liberia\#eus94x>

101.Nagbe, Prince, 'LNP/WACPS Records 2,267 Cases of Violence against Women' Liberian News Agency (Monrovia, Liberia), 4 December 2014 <http://allafrica.com/stories/201412082766.html>

102. National Rugby League, '\$1 Million Granted to Prevent Violence against Women and Children' National Rugby League (Paddington, NSW), 2 April 2015 <http://www.nrl.com/\$1-million- 
granted-to-prevent-violence-against-women-andchildren/tabid/10874/newsid/88495/default.aspx>

103. Newa, Mark B, 'Liberia: 10 Rape Victims Died in 2013 - Says Gender Minister Duncan-Cassel' All Africa (Online), 21 November 2013 <http://allafrica.com/stories/201311210459.html>

104. Nyenatiee, Florene, 'Conference on Criminal Justice Opens' The News (Online), 28 March 2013 <http://thenewslib.com/news/1654-conference-on-criminal-justice-opens>

105.Nyenuh, Alphonso W, 'The War Crimes Case against Tom Woewiyu - Why the US Must Prosecute' Front Page Africa (Monrovia, Liberia), 13 June 2014 $<$ http://www.frontpageafricaonline.com/index.php/op-ed/commentaries-features/1938-the-warcrimes-case-against-tom-woewiyu-why-the-u-s-must-prosecute>

106. Onishi, Norimitsu, 'Clashes Erupt as Liberia Sets a Quarantine' The New York Times (Monrovia, Liberia), 20 August 2014 <http://www.nytimes.com/2014/08/21/world/africa/ebola-outbreakliberia-quarantine.html?smid=fb-share\&_r=1\#>

107.Parke, Erin, 'Three Hurt as Bomb Thrown at Aboriginal Community' Australian Broadcasting Corporation (Canberra, ACT), 28 August 2013 http://www.abc.net.au/news/2013

108.Pearlman, Jonathan and Joel Gibson, 'When I Was Fauna: Citizen's Rallying Call' Sydney Morning Herald (Sydney, NSW), 23 May 2007 <http://www.smh.com.au/news/national/when-iwas-fauna-citizens-rallying-call/2007/05/22/1179601412706.html>

109.Pressly, Linda, 'Saving Girls from the "Cutting Season"' BBC News (Dar es Salaam, Tanzania), 1 April 2015 http://www.bbc.com/news/magazine

110.Purefoy, Christian, 'Former Liberian Warlord “finds God," Seeks Presidency' CNN (Monrovia, Liberia), 5 August 2010 <http://www.cnn.com/2010/WORLD/africa/08/05/johnson.liberia.religion/>

111.Rennell, Tony, 'The Founding Fathers of Australia: The Story of Convicts Shipped to the New World' Daily Mail (London), 25 July 2007 <http://www.dailymail.co.uk/news/article470887/The-founding-fathers-Australia-The-story-convicts-shipped-New-World.html>

112. Reuters, 'Liberia Troops Accused of Massacre in Church' New York Times (Monrovia, Liberia), 31 July 1990 <http://www.nytimes.com/1990/07/31/world/liberia-troops-accused-of-massacrein-church.html?pagewanted=print $>$

113. Reuters, 'Liberian Troops Accused of Massacre in Church' The New York Times (Monrovia, Liberia), 31 July 1990 <http://www.nytimes.com/1990/07/31/world/liberia-troops-accused-ofmassacre-in-church.html>

114. Roberts, D Ignatius, '2 Nabbed for "Gang Rape"' Heritage (Monrovia, Liberia), 25 April 2014 <http://allafrica.com/stories/201404250768.html>

115. Royal London, 'How Did the City of Brisbane Get Its Name?' The Telegraph (London, UK), 23 July 2016 <http://www.telegraph.co.uk/only-in-britain/thomas-makdougall-brisbane-born/>

116. Rubenstein, Kim, 'Rethink Needed as New High Court Justice Appointment Seems to Maintain Gender Imbalance' Canberra Times (Canberra, ACT), 12 December 2014 http://www.canberratimes.com.au/action/printArticle?id=64016628

117.Safi, Michael, 'Could This Experiment in Bourke Be the Answer to Australia's Indigenous Incarceration Crisis?' The Guardian (Bourke, NSW), 18 June 2015

$<$ http://www.theguardian.com/australia-news/2015/jun/18/maragnuka-re-imagining-indigenouscommunity-out-the-back-o-bourke>

118. Scobie, Claire, 'The Long Road Home: Aborigines Reclaim Their Ancestors' Remains from British Museums' The Guardian (Sydney, NSW), 27 June 2009

<http://www.theguardian.com/world/2009/jun/28/aborigines-reclaim-ancestors-remains>

119. Shah, Sonia, 'Judge Rules Rape of Aboriginal Girl "Traditional”' Women's eNews (North Queensland, Australia), 29 November $2002<$ http://womensenews.org/2002/11/judge-rules-rapeaboriginal-girl-traditional/>

120. Shaw, Barbara, 'The NT Intervention - Six Years On' New Matilda (Alice Springs, NT), 21 June 2013 <https://newmatilda.com/2013/06/21/nt-intervention-six-years>

121. Sieh, Rodney, 'Firestone Mirred in Slave Labour Charges in Liberia' All Africa (Monrovia, Liberia), 21 November 2005 <http://www.laborrights.org/in-the-news/firestone-mirred-slavelabor-charges-liberia>

122.Sieh, Rodney, "“I Was Framed”: Canadian Accused of Rape in Liberian Pins Hope on DNA' Front Page Africa (Monrovia, Liberia), 25 June 2014 $<$ http://www.frontpageafricaonline.com/index.php/news/2057-i-was-framed-canadian-accusedof-rape-in-liberian-pins-hope-on-dna>

123. Sirleaf, James, 'Ellen Johnson Sirleaf Unconsciously Supported Charles Taylor' The Perspective (Atlanta, GA), 8 September 2014 http://www.theperspective.org/2014/0908201404.php

124.Spiers Williams, Mary, 'High Court to Give "Full Weight" to Indigenous Disadvantage' The Conversation (Melbourne, VIC), 4 October 2013 <http://theconversation.com/high-court-togive-full-weight-to-indigenous-disadvantage-18880> 
125.Staff Reporter, ‘Australia's Day of Rejoicing' Sydney Morning Herald (Sydney, NSW), 27 January 193811

126. Staff Reporter, 'Sirleaf Starts to Form Government, Some Appointments Spark Protest' IRIN News (Geneva, Switzerland), 14 February 2006 <http://www.irinnews.org/report/58143/liberiasirleaf-starts-to-form-government-some-appointments-spark-protest>

127. Staff Reporter, 'Caldwell Residents Want Speedy Trial in Freeman's Rape Case' The Analyst (Monrovia, Liberia), 4 June 2010 <http://allafrica.com/stories/201006040191.html>

128. Staff Reporter, 'A Bloody Lie! - As Caesar Freeman Victim Vanishes in Tin Air: Freeman Lingers behind Bars, Victim Runs Free' National Chronicle (Monrovia, Liberia), 28 July 20101

129. Staff Reporter, 'Over Five Months in Jail on Rape Claims, a Govt. Official Appears for Trial' All Africa (Monrovia, Liberia), 28 September 2010 <http://allafrica.com/stories/201010041090.html>

130. Staff Reporter, 'Hundreds of Kenyan Teachers Sacked over Sex Abuse' BBC News (London, UK), 7 October 2010 <http://www.bbc.com/news/world-africa-11492499>

131.Staff Reporter, 'Profile: Ellen Johnson-Sirleaf' Al Jazeera (Monrovia, Liberia), 7 October 2011 <http://www.aljazeera.com/news/africa/2011/10/201110794610186521.html>

132. Staff Reporter, 'Archaeologists Find Graves Containing Bodies of 5,000 Slaves on Remote Island: Africans Died in Custody of Royal Navy in 1800s, after Being Seized from Ships of Slave Traders, and Were Buried on St. Helena' The Guardian (London, UK), 8 March 2012 http://www.theguardian.com/world/2012/mar/08/slave

133. Staff Reporter, 'Liberia Suspends Exports of Unprocessed Rubber' Reuters (Monrovia, Liberia), 19 April $2013<$ http://www.reuters.com/article/2013/04/19/liberia-rubberidUSL5N0D62RV20130419>

134.Staff Reporter, 'Liberia Becomes Human Trafficking Hub: As Police Arrest Lebanese Duo' Front Page Africa (Monrovia, Liberia), 15 July 2013

<http://www.frontpageafricaonline.com/old/politics/42-politics/6550...ecomes-humantrafficking-hub-lebanese-duo-groomed-sex-slaves.html>

135. Staff Reporter, 'History and Us: Elijah Johnson, Great Liberian Pioneer' Daily Observer (Monrovia, Liberia), 10 December 2013 <http://www.liberianobserver.com/history-us/historyand-us-elijah-johnson-great-liberian-pioneer $>$

136. Staff Reporter, 'Who Failed; Who Passed? Liberian Gov't 2013 Grades Are In' Front Page Africa (Monrovia, Liberia), 23 December 2013

<http://www.frontpageafricaonline.com/index.php/politic/189-who-fail...v-t-2013-grades-arein?tmpl=component\&print=1\&layout=default\&page $=>$

137. Staff Reporter, 'Liberia: Rich but Poor - African Progress Panel Lists Resource Cursed' Front Page Africa (Monrovia, Liberia), 8 May 2014

<http://www.frontpageafricaonline.com/index.php/politic/1585-liberia-rich-but-poor-africaprogress-panel-lists-resource-cursed-nations >

138. Staff Reporter, 'Woewiyu Pleads Not Guilty - Judge Denies Him Bail in Fraud Case' Front Page Africa (Monrovia, Liberia), 19 May 2014 <http://allafrica.com/stories/201405201200.html>

139. Staff Reporter, 'Arcelor Mittal Attack Is Attack on Liberia's Economy, Sirleaf Says' Front Page Africa (Monrovia, Liberia), 11 July 2014

<http://www.frontpageafricaonline.com/index.php/politic/2266-arcelormittal-attack-is-attack-onliberia-s-economy-sirleaf-says>

140.Staff Reporter, 'As Liberia Govt Seeks Clarification from U.S. on Visa Revocations, Kabineh J'aneh, Eugene Nabbe, and Geraldine Doe-Sheriff Prevented from Entering the USA' Hints News Network (Monrovia, Liberia), 24 July 2014 <http://hintsnewsnetwork.com/?p=3646>

141.Staff Reporter, 'Independent Aboriginal Death in Custody Inquiry Not Needed: Premier Colin Barnett' ABC News (Perth, WA), 1 October 2014 <http://www.abc.net.au/news/2014-10-02/callfor-separate-inquest-into-death-of-wa-aboriginal-woman/5785702>

142.Staff Reporter, "No Contradiction - T. C. Gould Says EJS Can Suspend Rights' Front Page Africa (Monrovia, Liberia), 14 October 2014

<http://www.frontpageafricaonline.com/index.php/news/3344-no-contradiction-liberia-barchief-says-ejs-can-suspend-rights>

143. Staff Reporter, 'Aboriginal Man Dies in Casuarine Prison as Hundreds Rally around WA to Protest Deaths in Custody’ ABC News (Sydney, NSW), 24 October 2014 $<$ http://www.abc.net.au/news/2014-10-23/corrective-services-investigate-death-of-prisoninmate/5836126>

144. Staff Reporter, ' $\$ 3.5 \mathrm{~m}$ Study into Violence against Women' The Australian (Canberra, ACT), 31 October 2014 <http://www.theaustralian.com.au/news/latest-news/m-study-into-violenceagainst-women/story-fn3dxiwe-1227108578765> 
145.Staff Reporter, 'President Sirleaf Accepts Education Min-Designate's Withdrawal Request' Liberian News Agency (Monrovia, Liberia), 6 December 2014 <http://www.liberianewsagency.org/pagesnews.php?nid=3506>

146. Staff Reporter, “'War Crimes List” - Cultures of Impunity Unlikely to Continue' All Africa (Monrovia, Liberia), 5 March 2015 <http://allafrica.com/stories/201503051419.html>

147.Staff Reporter, 'War Crimes Lists' Front Page Africa (Monrovia, Liberia), 5 March 2015 $<$ http://www.frontpageafricaonline.com/index.php/news/4664-war-crimes-list-culture-ofimpunity-unlikely-to-continue>

148. Staff Reporter, 'Triggs Marks 800 Years of Magna Carta at ANU Event' ANU News (Canberra, ACT), 16 June 2015 <http://www.anu.edu.au/news/all-news/triggs-marks-800-years-of-magnacarta-at-anu-event>

149.Staff Reporter, 'EPS “Monster”: Ellen Protection Detail Deputy Sacked over Beating' Front Page Africa (Monrovia, Liberia), 15 September 2015 http://frontpageafricaonline.com/index.php/news/6264

150.Staff Reporter, 'Sweden Turns over Crime Lab to LNP' The Analyst (Monrovia, Liberia), 26 October $2015<\mathrm{http}: / /$ allafrica.com/stories/201510261583.html>

151.Staff Reporter, 'Liberia: Gang Rapists Still at-Large - Rape Victim Aunt Plead to Government' FrontPageAfrica (Monrovia) (Monrovia, Liberia), 3 November 2015 $<$ http://allafrica.com/stories/201511030767.html>

152.Staff Reporter, 'Milestone for Justice Research' Cowra Guardian (Cowra, NSW), 8 January 2016 <http://readnow.isentia.com/Temp/84653/522241051.pdf>

153. Staff Writer, 'When Justice Peeks' Washington Examiner (Washington, DC), 20 September $2010<$ http://www.washingtonexaminer.com/when-justice-peeks/article/130193>

154.Staff Writer, 'Liberia: Dismal Court Performance' The Informer (Monrovia Liberia), 9 August $2012<\mathrm{http}: / /$ allafrica.com/stories/201208141119.html?viewall=1>

155. Staff Writer, 'Green Advocates Wants EPA Revoke Sime Darby's Permit' Public Agenda News (Monrovia, Liberia), 2013

$<$ http://www.publicagendanews.com/index.php?option=com_content \& view=article\&id=3191:gr een-advocates-wants-epa-revoke-sime-darbys-permit-\&catid=1:latest-news\&Itemid=2>

156. Staff Writer, 'Statutory Rape: Equip-Liberia Country Director Arrested' Microscope News (Monrovia, Liberia), 2013 <http://microscopeliberia.com/news.html>

157. Staff Writer, 'Liberian President Signs Pledge to End Violence against Women, Girls' Xinhau News Agency - CEIS (Woodside, CA), 20 February 2013 <http://search.proquest.com/docview/1289853770>

158. Staff Writer, 'Liberia: High Cases of Rape Reported' All Africa (Monrovia, Liberia), 22 November 2013 <http://allafrica.com/stories/201311220415.html>

159. Staff Writer, 'Liberia: Redoubling Efforts in Uncompromisingly and Robustly Battling Rape in Liberia' All Africa (Monrovia, Liberia), 4 December 2013 <http://allafrica.com/stories/201312040706.html>

160. Staff Writer, 'Guilty for Human Trafficking \& Gang Rape' Heritage (Monrovia, Liberia), 2014 $<$ http://www.news.heritageliberia.net/index.php/inside-heritage/most-commented/2552-guiltyfor-human-trafficking-gang-rape>

161. Staff Writer, 'Liberian Witches Say Power Is in the Blood, so Victims Should Be Eaten Alive' The East African (Nairobi, Kenya), $2014<\mathrm{http}: / / \mathrm{www}$. theeastafrican.co.ke/news//2558/545722/-/view/printVersion/-/yq0f5nz/-/index.html>

162. Staff Writer, 'President Sirleaf Launches Anti-Human Trafficking Five-Year National Action Plan - Says Government Is Ready for the Fight' All Africa (Monrovia, Liberia), 25 March 2014 <http://allafrica.com/stories/201403260652.html?viewall=1>

163.Staff Writer, 'Liberia: UNMIL Wants TRC Report Implemented' The New Dawn (Monrovia, Liberia), 4 July 2014 <http://allafrica.com/stories/201407040725.html>

164. Staff Writer, 'America Ready for Liberians Accused of War Crimes?' Heritage (Monrovia, Liberia), 29 July 2014 <http://allafrica.com/stories/201407291149.html>

165. Stephens, Richard, 'Supreme Court Suspends Case of 48 Former Lawmakers' Liberian News Agency (Monrovia, Liberia), 11 December 2014 <http://allafrica.com/stories/201412120690.html>

166. Stevens, Melissa, 'Howard's Secret Criminal Past' The Daily Telegraph (London, UK), 14 February 2007 <http://www.dailytelegraph.com.au/news/nsw/howards-secret-criminalpast/story-e6freuzi-1111112988170>

167. Stewart, Gboko, 'Desperate Times Call for Unorthodox Measures: Unchecked Rape Crisis Could Barren Liberian Women' Front Page Africa (Monrovia, Liberia), 29 November 2013 $<\mathrm{http} / / / \mathrm{www}$.frontpageafricaonline.com/old/op-ed-editorial/lettercom...ox-measures-uncheckedrape-crisis-could-barren-liberian-women.html> 
168. Sungbeh, Tewroh-Wehtoe, 'Woewiyu's Arrest by US Officials Confirms Our Inability to Pursue Our Own War Criminals’ The Liberian Dialogue (Atlanta, GA), 15 May 2014 $<$ http://theliberiandialogue.org/2014/05/15/woewiyus-arrest-by-us-officials-confirms-ourinability-to-pursue-our-own-war-criminals/>

169. Swan, Jonathan, 'Wootten Warns of Unrealistic Hopes for Finding Closure' The Sydney Morning Herald (Canberra, ACT), 14 November $2012<$ http://www.smh.com.au/federalpolitics/political-opinion/wootten-warns-of-unrealistic-hopes-for-finding-closure-2012111329aj2.html>

170. Sydney, Robert Milliken, 'Australia Accused of Genocide against Aborigines' The Independent (London, UK), 24 May 1997 <http://www.independent.co.uk/news/world/australia-accused-ofgenocide-against-aborigines-1263163.html >

171. Tamba, Gloria T, 'Draft Mental Health Bill Gains Support' Daily Observer (Monrovia, Liberia), 2014 <http://www.liberianobserver.com/politics/draft-mental-health-bill-gains-support>

172. Tamba, Gloria T, 'MoE Vows to Stop “Sex for Grades” in Universities' Daily Observer (Monrovia, Liberia), 8 September 2015 <http://www.liberianobserver.com/education/moe-vowsstop-"sex-grades"-universities>

173.Taylor, Paige, 'Aborigines Were Building “Stone Houses” 9000 Years Ago' The Australian (Perth, WA), 4 September 2016

$<$ http://at.theaustralian.com.au/link/30ef4873a7c8aaa2b80d01a12680df77?domain=theaustralian .com.au>

174. The Staff Reporter, 'The Churchill You Didn't Know' The Guardian (London, UK), 28 November 2002 <http://www.theguardian.com/theguardian/2002/nov/28/features11.g21>

175. Tierney, John, 'A New Debate on Female Circumcision' TierneyLab (New York, NY), 30 November $2007<$ https://tierneylab.blogs.nytimes.com/2007/11/30/a-new-debate-on-femalecircumcision/?hp>

176. Times Wire Services, 'Hundreds Die in Massacre by Liberian Troops: Civil War - as Many as 600 Refugees Are Killed in a Church, Survivors Say the Soldiers Were President Doe's' Los Angeles Times (Monrovia, Liberia), 31 July 1990 <http://articles.latimes.com/1990-0731/news/mn-1189_1_civil-war>

177.TLC Africa, 'Justice for Angel: Hans Williams and Mardea Paykue, Sentence to Death by Hanging' The Liberian Connection (Monrovia, Liberia), 10 March 2014 http://www.tlcafrica.com/news_justice_for_angel_3_10.htm

178. Toby, Peter N, 'Liberia: Judges Blamed for Corruption' All Africa, 1 April 2013 $<$ http://allafrica.com/stories/201304011074.html>

179. Toe, Jerome W, 'Zoes Convicted of Forced Initiation’ Daily Observer (Monrovia, Liberia), 11 July 2011

180. Triggs, Gillian, 'Gillian Triggs on Magna Carta: Alice Tay Lecture in Law and Human Rights in Full' The Guardian (Canberra, ACT), 15 June 2015 <http://www.theguardian.com/australianews/2015/jun/15/australia-and-the-magna-carta-how-the-coalition-and-labor-agree-on-lawsthat-violate-our-freedoms>

181.Tweh, Jefferson D, 'Liberia: MOGD Takes Anti-Rape Awareness to Public Schools' All Africa (Online), 8 November 2013 http://allafrica.com/stories/201311081747.html

182.Unsworth, Genine, 'Indigenous Girls Academy Kicking Goals' Australian Broadcasting Corporation (South West, WA), 1 April 2010

<http://www.abc.net.au/local/stories/2010/04/01/2862623.htm>

183. Valdmanis, Richard, 'Exclusive: Resource Deals Audit Overshadows Liberia Anti-Graft Push' Reuters (Dakar), 1 May 2013 <http://www.reuters.com/article/2013/05/01/us-liberia-resourcesidUSBRE9400QY20130501>

184. Wandia, Mary, 'Liberia Needs to Muster the Courage to Ban FGM' The Guardian (Monrovia, Liberia), 27 April 2016 <http://www.theguardian.com/global-development/2016/apr/27/liberiacourage-to-ban-fgm-ellen-johnson-sirleaf $>$

185. Weber, Dave, 'Stolen Generation Family Ordered to Pay Court Costs after "test Case" Fails in WA' Australian Broadcasting Corporation (Perth, WA), 10 June 2015 $<$ http://www.abc.net.au/news/2015-05-09/stolen-generation-family-must-pay-courtcosts/6457256>

186. Weedee, Emmanuel, 'Over 60 per Cent of Liberia's Rain Forest Offered to Logging Companies' Heritage (Monrovia, Liberia), 4 September 2012 $<$ http://allafrica.com/stories/201209200720.html>

187. Weedee-Conway, Emmanuel, 'Ellen Gets Tough - Several Suspended without Pay' Heritage (Monrovia, Liberia), 21 July 2014 <http://allafrica.com/stories/201407211449.html>

188. Wellington, Patrick G, 'Nimba Prison Boss Pushes for Speedy Trials' Liberian News Agency (Sanniquellie), 10 February $2015<$ https://www.facebook.com/micatliberia1?fref=nf> 
189. Wellington, Patrick G, 'Lawyer Cautions Chiefs against Trial by Ordeal' Liberian News Agency (Sannequellie, Nimba), 13 February 2015 <www.liberianewsagency.org>

190. William, Wade CL, 'Sande Shutdown: Traditional Leaders and GOL Suspend Women's Secret Society' Front Page Africa (Monrovia, Liberia), 30 March 2012

$<$ http://www.frontpageafricaonline.com/index.php?option=com_content\&view=article\&id=2852 :grebo-bush-shutdown-traditional-leaders-gol-suspend-womens-secretsociety\&catid=42:politics \&Itemid=109>

191.Williams, Wade CL, 'As War Crimes Prosecution Debate Heats up; Prince Johnson Threatens Trouble If’ Front Page Africa (Monrovia, Liberia), 25 May 2012

$<$ http://www.frontpageafricaonline.com/old/news/general-news/3231-as-war-crimesprosecution-debate-heats-up-prince-johnson-threatens-trouble-if-.html>

192.Williams, Wade CL and Tecee Boley, 'Liberia: Lebanese Man Video Taped Sex Act with Liberian Girls, Ages 7-15' All Africa (Monrovia, Liberia), 18 April 2013 <http://allafrica.com/stories/201304190928.html>

193.Worsley, Ben, 'Indigenous Referendum: Australians Invited to Join Community Conference on Recognition Vote' ABC News (Sydney, NSW), 6 July $2015<$ http://www.abc.net.au/news/201507-06/australia-big-enough-for-indigenous-referendum-says-abbott/6598144>

194. Yangian, Kennedy L, 'Couple Lawyers Pray Supreme Court for Acquittal in Angel Death' Front Page Africa (Monrovia, Liberia), 8 May 2014

$<$ http://www.frontpageafricaonline.com/index.php/news/1586-couple-lawyers-pray-supremecourt-for-acquittal-in-angel-death>

195. Young, Finlay, 'Love in the Time of Ebola: Meeting the Locals Struggling to Cope with an Epidemic' Newsweek (Monrovia, Liberia), 20 August 2014

<http://www.newsweek.com/2014/08/29/love-time-ebola-meeting-locals-struggling-copeepidemic-265615.html>

\section{Podcast}

1. ABC Radio National, Classic LNL: Sir Ronald Wilson (September 8, 2001)

<http://mpegmedia.abc.net.au/rn/podcast/2008/02/lnl_20080215_2200.mp3> at 22 March 2013.

2. Susan Lawler, Environmental Impact of Mining in Victoria (29 August 2012)

<https://itunes.apple.com/us/itunes-u/australian-history/id391323919?mt=10>.

\section{Presentation}

1. ABC News, 'Rosalie Kunoth-Monks Inspires with Her Q\&A Speech: "I Am Not the Problem"” ABC News $Q \& A$ (Sydney, NSW), 10 June $2014<$ http://www.news.com.au/national/rosaliekunothmonks-inspires-with-her-qa-speech-i-am-not-the-problem/story-fncynjr21226949124486>

2. Aborigines Conference, 'Our Historic Day of Mourning and Protest: Aborigines Conference Held at Australian Hall 26th January 1938' The Australian Abo Call (Sydney, NSW), April 1938 2

3. Adams, Shar, 'Inclusion the Key to "town Camps" Solution' Epoch Times (Sydney, NSW), 10 November 2009 http://www.theepochtimes.com/n2/australia/aborigines

4. Allan, Susan, 'Eleven-Year-Old Aboriginal Boy Commits Suicide' World Socialist Web Site (Geraldton, WA), 8 December 2014 https://www.wsws.org/en/articles/2014/12/08/suic

5. Australian Human Rights Commission, 'National Stolen Generations Reparations Scheme Needed' AHRC Media Releases (Sydney, NSW), 21 November 2017

$<$ https://www.humanrights.gov.au/news/media-releases/national-stolen-generations-reparationsscheme-needed>

6. Azango, Mae, 'Taking More, Giving Less - Nimba Decry Arcelor Mittal's Operation' Front Page Africa (Monrovia Liberia), 2014

<http://www.frontpageafricaonline.com/index.php/business-tech/280-ta...-more-giving-lessnimba-citizens-decry-arcelor-mittal-s-operations >

7. Azango, Mae, 'The Cost of FGM to Liberian Girls' Front Page Africa (Monrovia, Liberia), 2014 <http://www.asafeworldforwomen.org/global-news/africa/liberia/2184-mae-azango-thecost-of-fgm-to-liberian-girls.html>

8. Azango, Mae, 'Liberian “Slaves in Lebanon"? Girls Turned into Sex Objects' Front Page Africa (Monrovia, Liberia), 12 September 2014 <http://allafrica.com/stories/201409121068.html>

9. Azango, Mae, 'Liberia: Married at 13 - Young Girls Forced Into Adulthood in Liberia' FrontPageAfrica (Monrovia, Liberia), 7 November 2014 <http://allafrica.com/stories/201411071717.html>

10. Azango, Mae, 'Outgoing President Sirleaf Abolishes Female Genital Mutilation, Signs Domestic Violence Bill’ FrontPageAfricaonline.com (Monrovia, Liberia), 22 January 2018 
<https://frontpageafricaonline.com/index.php/news/6691-outgoing-president-sirleaf-abolishesfemale-genital-mutilation-signs-domestic-violence-bill>

11. Barrass, Tony, 'Aboriginal “child Sex Ring” Exposed' The Australian (Kalumburu, WA), 17 April $2007<$ http://www.theaustralian.com.au/news/nation/aboriginal-child-sex-ringexposed/story-e6frg6nf-1111113355850>

12. Batha, Emma, 'Liberia Bans Female Genital Mutilation - but Only for a Year' Reuters (Monrovia, Liberia), 25 January $2018<$ https://www.reuters.com/article/us-liberia-fgmlaw/liberia-bans-female-genital-mutilation-but-only-for-a-year-idUSKBN1FE1N7>

13. BBC, 'First Female Law Lord Appointed' BBC News (London; UK), 24 October 2003 <http://news.bbc.co.uk/2/hi/uk_news/3210003.stm>

14. BBC, 'South Africa Apartheid Assassin de Kock Parole' BBC News (London, UK), 30 January 2015 <http://www.bbc.com/news/world-africa-31054912?print=true>

15. BBC News, 'Death Penalties for Delhi Gang Rape' BBC News (London, UK), 13 September 2013 <http://www.bbc.com/news/world-asia-india-24078339>

16. Blenkin, Max, 'Hawke Govt Launched Aboriginal Death Probe' The Australian (Sydney South, NSW), 1 January 2014 <http://www.theaustralian.com.au/news/latest-news/hawke-govtlaunched-aboriginal-death-probe/story-fn3dxiwe-1226792800340>

17. Boddy, Natasha, 'Cultural Advisers Appointed to Support Aboriginal and Torres Strait Islander Children in Care' Canberra Times (Canberra, ACT), 5 January 2015

$<$ http://www.canberratimes.com.au/act-news/cultural-advisers-appointed-to-support-aboriginaland-torres-strait- islander-children-in-care-20150104-12hnpj.html>

18. Boley, Tecee, 'Walking Dead - Liberia's Lutheran Church Massacre Victims Still Carry Bullets, Scars’ All Africa (Monrovia, Liberia), 31 July 2013

<http://allafrica.com/stories/201307310769.html>

19. Borteh, George J, 'Angel Togba's Mother Pushes Supreme Court to Act' All Africa (Monrovia), 21 May 2013 <http://allafrica.com/stories/201305220776.html>

20. Boserio, Gail, 'Domestic Abuse of Indigenous Women a "National Crisis"' Australian Broadcasting Corporation (Sydney, NSW), 4 May 2015

$<$ http://www.abc.net.au/radionational/programs/latenightlive/crisis-of-domestic-abuse-ofindigenous-women/6442954>

21. Brennan, Bridget, 'Rethink Aboriginal Town Camps: Mick Gooda' ABC News (Alice Springs, N.T), 3 March 2014 <http://www.abc.net.au/news/stories/2011/03/03/3153800.htm?site=alicesprings>

22. Brennan, Lina and Alice Williams, "Family Violence Does Not Have a Colour" Daily Life (Melbourne, VIC), 24 November 2014 http://www.dailylife.com.au/news

23. Brooks, Calvin, 'Official: Over 500,000 Suffer Mental Illness Due to War, Ebola' Liberian News Agency (Monrovia, Liberia), 7 March 2015 <http://www.liberianewsagency.org>

24. Butty, James, 'Liberia's Justice Minister Resigns'Voice of America (Monrovia, Liberia), 7 October 2014 <http://www.voanews.com/articleprintview/2475000.html>

25. Butty, James, 'Backlash over Liberian President's Executive Order' Voice of America (Monrovia, Liberia), 8 December 2014 <http://www.voanews.com/content/backlash-overliberian-presidents-executive-order/2549911.html>

26. Campbell, Janjay F, 'Liberia Security Is Stable, but Fragile' All Africa (Washington D. C.), 20 September 2013 <http://search.proquest.com/docview/1041259436?accountid=8330>

27. CBC News, 'Rehtaeh Parsons Case to Get Independent Review' Canadian Broadcasting Corporation (Halifax, NS), 15 April $2013<$ http://www.cbc.ca/news/canada/novascotia/story/2013/04/15/ns-rehtaeh-bully-independent-review.html>

28. CBC News, 'Rehtaeh Parsons Suspects in Court to Face Child Porn Charges' Canadian Broadcasting Corporation (Halifax, NS), 15 August 2013

<http://www.cbc.ca/news/canada/nova-scotia/story/2013/08/15/ns-rehtaeh-parsons-accusedappearance.html $>$

29. Chesler, Phyllis, 'New Study Shows Half of Liberian Girls, Women Undergo Female Genital Mutilation' Breitbart (Los Angeles, CA), 14 December 2014

$<$ http://www.breitbart.com/national-security/2014/12/11/new-study-showing-half-of-liberiangirls-women-undergo-fgm-not-a-surprise/>

30. Cordingley, Glen, 'Station Gives Yawuru a New Start' The West Australian (Broome, WA), 3 September $2014<$ https://au.news.yahoo.com/thewest/business/wa/a/24881704/station-givesyawuru-chance-to-rebuild/>

31. Coughlan, Sean, 'Asia Pops Biggest Global School Rankings' BBC News (London), 13 May 2015 <http://www.bbc.com/news/business-32608772>

32. Cox, Eva, "Work with Us Not for Us" to End the Indigenous Policy Chaos' The Conversation (Sydney, NSW), 14 December 2014 <http://theconversation.com/work-with-us-not-for-us-toend-the-in...20not $\% 20$ for $\% 20$ us $\% 20$ to $\% 20$ end $\% 20$ the $\% 20$ Indigenous $\% 20$ policy $\% 20$ chaos $>$ 
33. Crouch, Joanne, 'Somalia: Amisom Troops Commit Brutal Gang Rape in Mogadishu, Somalia' All Africa (Kampala, Uganda), 14 August 2013

<http://allafrica.com/stories/201308150540.html?viewall=1>

34. Daley, Paul, 'Why Does the Australian War Memorial Ignore the Frontier War? The Battle between Aboriginal People and the Settlers Is at the Heart of Nationhood but Absence from War Dead Commemorations' The Guardian (Canberra, ACT), 12 September 2013

<http://www.theguardian.com/world/2013/sep/12/australian-war-memorial-ignores-frontierwar>

35. Dalieh, Patience Handful, 'Liberia: Ebola Hits the Family - but Won't Stop Us from Helping' All Africa (Monrovia, Liberia), 18 August 2014

<http://allafrica.com/stories/201408181508.html?fb_action_ids=1473249009597061\&fb_action _types=og.comments>

36. Dash, Leon, 'Liberian Soldiers Taunt, Shoot 13 Former Leaders' The Washington Post (Monrovia, Liberia), 23 April 1980 http://www.washingtonpost.com/wp

37. Dash, Leon, 'Liberian Revolt Preserves Old Structure' Washington Post (Washington, DC), 29 December 1980 <https://www.washingtonpost.com/archive/politics/1980/12/29/liberian-revoltpreserves-old-structure/aaeb2874-07bd-4ecd-8f4e-fb5a58f442e8/>

38. Davidson, Helen, 'Prison Songs: "Welcome to the Berrimah Hilton - Prepare to Be Amazed"" The Guardian (Darwin, NT), 1 January $2015<\mathrm{http} / /$ www.theguardian.com/tv-andradio/2015/jan/02/prison-songs-berrimah-hilton?CMP=ema_632>

39. Daygbor, EJ Nathaniel, 'Land Bill Reaches Capitol Building' The New Dawn (Monrovia, Liberia), 7 August 2015 <http://www.thenewdawnliberia.com/news/8108-land-bill-reachescapitol-building>

40. Dayton, Leigh and Stuart Rintoul, 'Genes Map Aborigines' Arrival in Australia' The Australian (Sydney, NSW), 23 September $2011<$ http://www.theaustralian.com.au/news/healthscience/genes-map-aborigines-arrival-in-australia/story-e6frg8y6-1226144089835>

41. Diemer, Kristin, ‘Australians Still Trivialise and Excuse Violence against Women' The Conversation (Sydney, NSW), 17 September $2014<$ http://theconversation.com/australians-stilltrivialise-and-excuse-

v...ans\%20still\%20trivialise\%20and\%20excuse\%20violence\%20against\%20women>

42. Dingle, Sarah, 'Why Was Nobody Watching?' Australian Broadcasting Corporation (Yatala, SA), 2 November 2014

<http://www.abc.net.au/radionational/programs/backgroundbriefing/2014-1102/5847612\#transcript>

43. Dixon, Winnie, 'Senator Kupee Seeks Enactment of Child Support Act' Liberian News Agency (Monrovia, Liberia), 24 October 2014

<http://www.liberianewsagency.org/pagesnews.php?nid=3071>

44. Dodson, Shannan, 'Too White, Too Black, or Not Black Enough? This Is Not a Question for Others to Decide' The Guardian (Sydney, NSW), 8 June 2017

<http://www.theguardian.com/commentisfree/2017/jun/09/too-white-too-black-or-not-blackenough-this-is-not-a-question-for-others-to-decide>

45. Economywatch, 'Why Liberia Has Not Been Able to Break Its Resource Curse' Oil Price (London, UK), 25 November $2012<$ http://oilprice.com/Geopolitics/Africa/Why-Liberia-HasNot-Been-Able-to-Break-its-Resource-Curse.html $>$

46. Executive Mansion News, 'Liberian President Issues Executive Order on Land Sales' Front Page Africa (Monrovia, Liberia), 26 December 2013

<http://www.frontpageafricaonline.com/index.php/news/214-liberian-pr...ive-order-on-landsales?tmpl=component $\&$ print $=1 \&$ layout=default\&page $=>$

47. Executive Mansion of Liberia, 'President Sirleaf Grants Executive Clemency to 32 Inmates in Prison across the Country’ Executive Mansion News (Monrovia, Liberia), 23 December 2014 http://www.emansion.gov.lr/2press.php?news_id=3166

48. Feneley, Rick, 'Deadly Awards Founder Gavin Jones Dies after Funding Cut' The Sydney Morning Herald (Sydney, NSW), 14 July 2014 <http://www.smh.com.au/entertainment/deadlyawards-founder-gavin-jones-dies-after-funding-cut-20140714-zt78p.html>

49. Feng, Sonia and Melanie Pearce, 'Bloody Part of Australian History Laid Bare in Bathurst' $A B C$ News (Orange, NSW), 15 August 2017 <http://www.abc.net.au/news/2017-08-15/scars-ofmartial-law-laid-bare-in-bathurst/8804586>

50. Ford, Liz, 'UN to Measure Women's Rights Progress over Past 20 Years' The Guardian (London, UK), 2014 <http://www.theguardian.com/global-development/2014/apr/07/unwomens-rights-progress-cairo-agreement/print $>$

51. Freeman, Colin, "The Liberian Slum Where Ebola Spreads Death among Killer Virus "Deniers"” Telegraph (Monrovia, Liberia), 8 August 2014 
<http://www.telegraph.co.uk/news/worldnews/africaandindianocean/libe...ian-slum-whereEbola-spreads-death-among-killer-virus-deniers.html>

52. Gbala, Bai M, 'Decentralisation of Political and Administrative Power in Liberia' The Perspective (Atlanta, GA), 30 June 2004

<http://www.theperspective.org/2004/june/decentralization.html>

53. Goah, Bernard Gbayee, 'Is President Ellen Johnson-Sirleaf of Liberia Immune from Prosecution, or Not?' Front Page Africa (Monrovia, Liberia), 18 October 2013

$<$ http://www.frontpageafricaonline.com/old/op-ed-editorial/lettercomments/7273-is-presidentellen-johnson-sirleaf-of-liberia-immune-from-prosecution-or-not.pdf>

54. Gordon, Glenna, 'In Liberia, Sirleaf's Past Sullies Her Clean Image' Time (Monrovia, Liberia), 3 July 2009 <http://content.time.com/time/world/article/0,8599,1908635,00.html>

55. Gordon, Michael, 'So What Was All That About?' Canberra Times (Canberra, ACT), 5 December 20159

56. Grant, Stan, 'I Can Tell You How Adam Goodes Feels. Every Indigenous Person Has Felt It' The Guardian (Sydney South, NSW), 30 July 2015

<http://www.theguardian.com/commentisfree/2015/jul/30/i-can-tell-you-how-adam-goodesfeels-every-indigenous-person-has-felt-it>

57. Gregory, Laurel, 'Equip Liberia' Global News (Vancouver, BC), 28 May 2012 <http://globalnews.ca/news/249834/blog-equip-liberia/>

58. Guilbert, Kieran, 'Liberian Wins Children's Peace Prize for Defending Victims of Violence, Rape' Thomson Reuters Foundation (Dakar, Senegal), 9 November 2015 <http://www.trust.org/item/20151109150153-i0muy>

59. Harmon, William Q, 'TWP Warned against Political Dominance, Exclusion' The Daily Observer (Monrovia, Liberia), 9 July 2015

60. Harrison, Dan, 'Third Woman on High Court Bench' The Age (Canberra, ACT), 4 February $2009<$ http://www.theage.com.au/national/third-woman-on-high-court-bench-200902037wv2.html?skin=text-only>

61. Harrison, Dan, 'Patrick Dodson Warns Aboriginal People Will Be Refugees in Their Own Country If Communities Close' The Sydney Morning Heralds (Sydney, NSW), 21 November 2014 http://www.smh.com.au/action/printArticle?id=63429039

62. Heyden, Tom, 'The 10 Greatest Controversies of Winston Churchill's Career' BBC News (London, UK), 21 January 2015 <http://www.bbc.com/news/magazine-29701767>

63. Hogan, Caelainn, 'Women Hardest Hit by Ebola in West Africa' The Star (Toronto, ON), 18 August 2014

<http://www.thestar.com/news/world/2014/08/15/women_hardest_hit_by_ebola_in_west_africa. html>

64. Howard, John, 'John Howard: The Transcript' Crikey: Independent Media, Independent Minds (Canberra, ACT), 21 June 2013 <http://www.crikey.com.au/2007/06/21/john-howard-thetranscript/>

65. Howden, Daniel, 'Warlord to Kingmaker: An Audience with Prince Johnson' The Independent (London, UK), 15 October 2011 http://www.independent.co.uk/news/world/africa/warlord

66. James, Felicity, 'Stolen Generation given Voice on Child Sex Abuse' ABC News (Sydney, NSW), 10 October 2013 <http://www.abc.net.au/news/2013-10-10/royal-commission-childsexual-abuse-stolen-generations-darwin-s/5013720?\&section=news $>$

67. Jeffries, Stuart, 'Angela Davis: "Unbroken Line of Police Violence in US Back to Slavery"' The Guardian (London, UK), 14 December 2014 http://www.theguardian.com/global/2014/dec/14/angela

68. Johnson, Bettie, '49 Year-Old Alleged Rapist Indicted on Multiple Charges' Front Page Africa (Monrovia, Liberia), 9 March 2015 <http://frontpageafricaonline.com/index.php/news/4679-49year-old-alleged-rapist-indicted-on-multiple-charges $>$

69. Johnson, Comfort M, 'Judge Sentences Man to 25 Years for Killing His Girlfriend' Liberian News Agency (Monrovia, Liberia), 9 March 2015 <http://www.liberianewsagency.org/pagesnews.php?nid=4178>

70. Jones, Roby, 'Minister Shines Light on Dark Side of NT Life' Australian Broadcasting Corporation (Alice Springs, NT), 4 April 2013 <http://www.abc.net.au/news/2013-04-04/alisonanderson-on-territory-domestic-violence/4609524>

71. Jones, Virginia and Annie Schubert, 'Indigenous Canberra: Connecting the Dots' Australian Broadcasting Corporation (Canberra, ACT), 7 July 2011 <http://www.abc.net.au/local/stories/2011/07/07/3263280.htm>

72. Jr, Genoway, Edwin, 'Ex-Presidential Guard Deputy Arrested in Assault Case: "Monster Hooked"' Front Page Africa (Monrovia, Liberia), 17 September 2015 <http://frontpageafricaonline.com/index.php/news/6287-ex-presidential-guard-deputy-arrestedin-assault-case?tmpl=component\&print=1\&layout=default\&page=> 
73. Jullien, Maud, 'DR Congo Woman 'saw Col Egangela Order Gang-Rape' BBC News (London, UK), 22 August 2014 <http://www.bbc.com/news/world-africa-28898298?print=true>

74. Karmo, Henry, 'Most Corrupt-National Integrity Barometer Rates Liberia's Judiciary' Front Page Africa (Monrovia, Liberia), 20 December 2013

<http://www.frontpageafricaonline.com/index.php/news/161-most-corrupt...tes-liberia-sjudiciary?tmpl=component \&print=1\&layout=default\&page $=>$

75. Karmo, Henry, 'Most Corrupt: National Integrity Barometer Rates Liberia's Judiciary with Very Low Marks’ Front Page Africa (Monrovia, Liberia), 20 December 2013

$<$ http://www.frontpageafricaonline.com/old/news/general-news/7758-most-corrupt-nationalintegrity-barometer-rates-liberias-judiciary.pdf >

76. Kay, Kira, 'For Liberia, Natural Resources Are Blessings, Curses on Road to Democracy' PBS Newshour (Arlington, VA), 31 October $2011<$ http://www.pbs.org/newshour/bb/world-julydec11-liberia_10-31/>

77. Keita, Abraham M, 'Keita Delicates Award to Shaki Kamara and Liberian Children' The Perspective (Atlanta, GA), 11 November 2015 <http://www.theperspective.org/2015/1111201501.php>

78. Kennedy, Duncan, 'Eddie Mabo, the Man Who Changed Australia' BBC News (London, UK), 6 June $2012<$ http://www.bbc.com/news/magazine-18291022>

79. Kesselly, Sr., Sam Van, 'Remembering April 12 after 34 Years' Front Page Africa (Monrovia, Liberia), 15 April $2014<$ http://www.frontpageafricaonline.com/index.php/oped/commentaries...il-12-after-34-years?tmpl=component\&print=1\&layout=default\&page=>

80. Knaus, Christopher, 'More Jail Time for Convicted Paedophile' The Canberra Times (Canberra, ACT), 7 November 2014 <http://www.canberratimes.com.au/act-news/more-jail-time-forconvicted-paedophile-20131107-2x2ni.html>

81. Kollie, Ballah, 'Judge Hands Rape Case to Jurors' Liberian News Agency (Monrovia, Liberia), 17 March 2014 <http://www.liberianewsagency.org/pagesnews.php?nid=775>

82. Kristof, Nicholas, 'Ellen Johnson Sirleaf and War Crimes?!' New York Times (Monrovia, Liberia), 3 July 2009 <http://kristof.blogs.nytimes.com/2009/07/03/ellen-johnson-sirleaf-andwar-crimes/?_r=0>

83. Lane, Sarah and Jeremy Thompson, 'Abbott Calls for New Intervention in NT Towns' $A B C$ News (Alice Springs, NT), 21 March 2011

<http://www.abc.net.au/news/stories/2011/03/21/3169134.htm?site=indigenous\&topic=latest>

84. Langsam, David, 'Quest for the Missing Dead' The Guardian (Sydney, NSW), 24 February $1990<$ http://dingonet.com/questfor.htm>

85. Lazuta, Jennifer, 'Liberia Literacy Program Targets Women' VOA (Dakar, Senegal), 7 August 2013 <http://www.voanews.com/content/liberia-literacy-program-reaches-women-in-midlife/1725157.html >

86. Lee, Jane, 'Changes Proposed to Laws on Rape' The Age (Melbourne, VIC), 25 October 2013 <http://www.theage.com.au/victoria/changes-proposed-to-laws-on-rape-20131024-2w4f3.html>

87. Liberian News Agency, 'MICAT Plans National Dialogue on Dunn Committee Report' LINA Bulletin (Monrovia, Liberia), 2 September 20152

88. Loewenstein, Antony, 'Indigenous Incarceration Rates Are a National Shame' The Guardian (Online), 1 November 2013 http://www.theguardian.com/commentisfree/2013/nov/01/indigenous

89. Lomax, Selma, 'Rural Boost - EJS Dedicates Chief Suakoko Centre for Women' All Africa (Monrovia, Liberia), 11 June 2014 <http://allafrica.com/stories/201406110497.html>

90. Maitreyee, 'Delhi Gangrape Redux? This Time a Minor Raped inside a Bus' One India (Online), 15 April 2013 <Read more at: http://news.oneindia.in/2013/04/15/delhi-minor-raped-inside-abus-driver-held-1193979.html $>$

91. Makhetha, Tankiso, 'Teens Accused of Rape, Murder of Girl, 14' IOL News (Pretoria), 27 March 2013 <http://www.iol.co.za/news/crime-courts/teens-accused-of-rape-murder-of-girl-141.1492436\#.UWw7i7_UO5o>

92. Makhetha, Tankiso, 'Teens Accused of Girl's Rape, Murder Released | IOL News' IOL News (Pretoria, Johannesburg), 28 March $2013<$ https://www.iol.co.za/news/crime-courts/teensaccused-of-girls-rape-murder-released-1493161>

93. Malkin, Bonnie, 'Australian Prime Minister Kevin Rudd Descended from Thieves’ The Telegraph (London, UK), 31 July 2008

<http://www.telegraph.co.uk/news/worldnews/australiaandthepacific/australia/2479134/Australi an-prime-minister-Kevin-Rudd-descended-from-thieves.html>

94. Masters, Emma, 'Remote Indigenous Outstation Rejects Federal Policy and Opens Own School' ABC News (Darwin, NT), 22 July 2015 <http://www.abc.net.au/news/2015-07-22/remote-ntindigenous-community-opens-own-school/6639220> 
95. McDonald, Philippa and Riley Stuart, 'Nearly 2,000 Catholic Church Figures Implicated in Child Sex Abuse Report' ABC News (Sydney, Australia), 6 February 2017

$<$ http://www.abc.net.au/news/2017-02-06/royal-commission-into-child-sexual-abuse-begins-insydney/8242600>

96. McQuire, Amy, 'Historic Victory for Aboriginal Queenslander Sparks New Hope on Stolen Wages' New Matilda (Redfern, NSW), 6 February 2015 https://newmatilda.com/2015/02/06/historic

97. Medhora, Shalailah, 'Northern Australia Plan Aims to Make Region an "Economic Powerhouse", The Guardian (Canberra, ACT), 18 June 2015

<http://www.theguardian.com/business/2015/jun/18/northern-australia-plan-aims-to-makeregion-an-economic-powerhouse>

98. Moodle, Claire, 'Stolen Generation Test Case Likely to Go to Trial' ABC News (Canberra, ACT), 31 July $2012<$ http://www.abc.net.au/news/2012-07-31/stolen-generation-test-case-likely-to-goto-trial/4166720>

99. Moore, Jina, 'Liberia's “Rape Court”: Progress for Women and Girls Delayed?' Christian Science Monitor (Kigali, Rwanda), 10 October 2010

<http://www.csmonitor.com/World/Africa/Africa-Monitor/2010/1010/Liberia-s-Rape-CourtProgress-for-women-and-girls-delayed>

100.Moore, Jina, 'Mob Destroys Ebola Center in Liberia Two Days after It Opens' BuzzFeed News (Monrovia, Liberia), 17 August $2014<$ http://www.buzzfeed.com/jinamoore/two-days-after-itopens-mob-destroys-ebola-center-in-liberia\#teus $94 \mathrm{x}>$

101.Nagbe, Prince, 'LNP/WACPS Records 2,267 Cases of Violence against Women' Liberian News Agency (Monrovia, Liberia), 4 December 2014 <http://allafrica.com/stories/201412082766.html>

102. National Rugby League, '\$1 Million Granted to Prevent Violence against Women and Children' National Rugby League (Paddington, NSW), 2 April 2015 <http://www.nrl.com/\$1-milliongranted-to-prevent-violence-against-women-andchildren/tabid/10874/newsid/88495/default.aspx>

103. Newa, Mark B, 'Liberia: 10 Rape Victims Died in 2013 - Says Gender Minister Duncan-Cassel' All Africa (Online), 21 November 2013 <http://allafrica.com/stories/201311210459.html>

104. Nyenatiee, Florene, 'Conference on Criminal Justice Opens' The News (Online), 28 March 2013 <http://thenewslib.com/news/1654-conference-on-criminal-justice-opens>

105. Nyenuh, Alphonso W, 'The War Crimes Case against Tom Woewiyu - Why the US Must Prosecute' Front Page Africa (Monrovia, Liberia), 13 June 2014

$<$ http://www.frontpageafricaonline.com/index.php/op-ed/commentaries-features/1938-the-warcrimes-case-against-tom-woewiyu-why-the-u-s-must-prosecute>

106. Onishi, Norimitsu, 'Clashes Erupt as Liberia Sets a Quarantine' The New York Times (Monrovia, Liberia), 20 August 2014 <http://www.nytimes.com/2014/08/21/world/africa/ebola-outbreakliberia-quarantine.html?smid=fb-share\&_r=1\#>

107.Parke, Erin, 'Three Hurt as Bomb Thrown at Aboriginal Community' Australian Broadcasting Corporation (Canberra, ACT), 28 August 2013 http://www.abc.net.au/news/2013

108.Pearlman, Jonathan and Joel Gibson, 'When I Was Fauna: Citizen's Rallying Call' Sydney Morning Herald (Sydney, NSW), 23 May $2007<$ http://www.smh.com.au/news/national/when-iwas-fauna-citizens-rallying-call/2007/05/22/1179601412706.html>

109.Pressly, Linda, 'Saving Girls from the "Cutting Season"' BBC News (Dar es Salaam, Tanzania), 1 April 2015 http://www.bbc.com/news/magazine

110.Purefoy, Christian, 'Former Liberian Warlord “finds God," Seeks Presidency' CNN (Monrovia, Liberia), 5 August 2010

<http://www.cnn.com/2010/WORLD/africa/08/05/johnson.liberia.religion/>

111. Rennell, Tony, 'The Founding Fathers of Australia: The Story of Convicts Shipped to the New World' Daily Mail (London), 25 July $2007<$ http://www.dailymail.co.uk/news/article470887/The-founding-fathers-Australia-The-story-convicts-shipped-New-World.html>

112. Reuters, 'Liberia Troops Accused of Massacre in Church' New York Times (Monrovia, Liberia), 31 July 1990 <http://www.nytimes.com/1990/07/31/world/liberia-troops-accused-of-massacrein-church.html?pagewanted=print $>$

113. Reuters, 'Liberian Troops Accused of Massacre in Church' The New York Times (Monrovia, Liberia), 31 July 1990 <http://www.nytimes.com/1990/07/31/world/liberia-troops-accused-ofmassacre-in-church.html $>$

114.Roberts, D Ignatius, '2 Nabbed for “Gang Rape”" Heritage (Monrovia, Liberia), 25 April 2014 <http://allafrica.com/stories/201404250768.html>

115. Royal London, 'How Did the City of Brisbane Get Its Name?' The Telegraph (London, UK), 23 July 2016 <http://www.telegraph.co.uk/only-in-britain/thomas-makdougall-brisbane-born/> 
116. Rubenstein, Kim, 'Rethink Needed as New High Court Justice Appointment Seems to Maintain Gender Imbalance' Canberra Times (Canberra, ACT), 12 December 2014 http://www.canberratimes.com.au/action/printArticle?id=64016628

117. Safi, Michael, 'Could This Experiment in Bourke Be the Answer to Australia's Indigenous Incarceration Crisis?’ The Guardian (Bourke, NSW), 18 June 2015 $<$ http://www.theguardian.com/australia-news/2015/jun/18/maragnuka-re-imagining-indigenouscommunity-out-the-back-o-bourke>

118. Scobie, Claire, 'The Long Road Home: Aborigines Reclaim Their Ancestors' Remains from British Museums' The Guardian (Sydney, NSW), 27 June 2009 <http://www.theguardian.com/world/2009/jun/28/aborigines-reclaim-ancestors-remains>

119. Shah, Sonia, 'Judge Rules Rape of Aboriginal Girl "Traditional"' Women's eNews (North Queensland, Australia), 29 November $2002<$ http://womensenews.org/2002/11/judge-rules-rapeaboriginal-girl-traditional/>

120. Shaw, Barbara, 'The NT Intervention - Six Years On’ New Matilda (Alice Springs, NT), 21 June 2013 <https://newmatilda.com/2013/06/21/nt-intervention-six-years>

121. Sieh, Rodney, 'Firestone Mirred in Slave Labour Charges in Liberia' All Africa (Monrovia, Liberia), 21 November 2005 <http://www.laborrights.org/in-the-news/firestone-mirred-slavelabor-charges-liberia>

122. Sieh, Rodney, "I Was Framed”: Canadian Accused of Rape in Liberian Pins Hope on DNA' Front Page Africa (Monrovia, Liberia), 25 June 2014 $<$ http://www.frontpageafricaonline.com/index.php/news/2057-i-was-framed-canadian-accusedof-rape-in-liberian-pins-hope-on-dna>

123. Sirleaf, James, 'Ellen Johnson Sirleaf Unconsciously Supported Charles Taylor' The Perspective (Atlanta, GA), 8 September 2014 http://www.theperspective.org/2014/0908201404.php

124. Spiers Williams, Mary, 'High Court to Give "Full Weight" to Indigenous Disadvantage' The Conversation (Melbourne, VIC), 4 October $2013<$ http://theconversation.com/high-court-togive-full-weight-to-indigenous-disadvantage-18880>

125.Staff Reporter, 'Australia's Day of Rejoicing' Sydney Morning Herald (Sydney, NSW), 27 January 193811

126. Staff Reporter, 'Sirleaf Starts to Form Government, Some Appointments Spark Protest' IRIN News (Geneva, Switzerland), 14 February $2006<$ http://www.irinnews.org/report/58143/liberiasirleaf-starts-to-form-government-some-appointments-spark-protest>

127. Staff Reporter, 'Caldwell Residents Want Speedy Trial in Freeman's Rape Case' The Analyst (Monrovia, Liberia), 4 June 2010 <http://allafrica.com/stories/201006040191.html>

128. Staff Reporter, 'A Bloody Lie! - As Caesar Freeman Victim Vanishes in Tin Air: Freeman Lingers behind Bars, Victim Runs Free' National Chronicle (Monrovia, Liberia), 28 July 20101

129. Staff Reporter, 'Over Five Months in Jail on Rape Claims, a Govt. Official Appears for Trial' All Africa (Monrovia, Liberia), 28 September 2010 $<$ http://allafrica.com/stories/201010041090.html>

130. Staff Reporter, 'Hundreds of Kenyan Teachers Sacked over Sex Abuse' BBC News (London, UK), 7 October 2010 <http://www.bbc.com/news/world-africa-11492499>

131. Staff Reporter, 'Profile: Ellen Johnson-Sirleaf' Al Jazeera (Monrovia, Liberia), 7 October 2011 <http://www.aljazeera.com/news/africa/2011/10/201110794610186521.html>

132. Staff Reporter, 'Archaeologists Find Graves Containing Bodies of 5,000 Slaves on Remote Island: Africans Died in Custody of Royal Navy in 1800s, after Being Seized from Ships of Slave Traders, and Were Buried on St. Helena' The Guardian (London, UK), 8 March 2012 http://www.theguardian.com/world/2012/mar/08/slave

133. Staff Reporter, 'Liberia Suspends Exports of Unprocessed Rubber' Reuters (Monrovia, Liberia), 19 April $2013<$ http://www.reuters.com/article/2013/04/19/liberia-rubberidUSL5N0D62RV20130419>

134.Staff Reporter, 'Liberia Becomes Human Trafficking Hub: As Police Arrest Lebanese Duo' Front Page Africa (Monrovia, Liberia), 15 July 2013

<http://www.frontpageafricaonline.com/old/politics/42-politics/6550...ecomes-humantrafficking-hub-lebanese-duo-groomed-sex-slaves.html>

135. Staff Reporter, 'History and Us: Elijah Johnson, Great Liberian Pioneer' Daily Observer (Monrovia, Liberia), 10 December 2013 <http://www.liberianobserver.com/history-us/historyand-us-elijah-johnson-great-liberian-pioneer $>$

136. Staff Reporter, 'Who Failed; Who Passed? Liberian Gov't 2013 Grades Are In' Front Page Africa (Monrovia, Liberia), 23 December 2013 <http://www.frontpageafricaonline.com/index.php/politic/189-who-fail...v-t-2013-grades-arein?tmpl=component \&print $=1 \&$ layout $=$ default $\&$ page $=>$

137. Staff Reporter, 'Liberia: Rich but Poor - African Progress Panel Lists Resource Cursed' Front Page Africa (Monrovia, Liberia), 8 May 2014 
<http://www.frontpageafricaonline.com/index.php/politic/1585-liberia-rich-but-poor-africaprogress-panel-lists-resource-cursed-nations >

138. Staff Reporter, 'Woewiyu Pleads Not Guilty - Judge Denies Him Bail in Fraud Case' Front Page Africa (Monrovia, Liberia), 19 May 2014

$<$ http://allafrica.com/stories/201405201200.html>

139. Staff Reporter, 'Arcelor Mittal Attack Is Attack on Liberia's Economy, Sirleaf Says' Front Page Africa (Monrovia, Liberia), 11 July 2014

<http://www.frontpageafricaonline.com/index.php/politic/2266-arcelormittal-attack-is-attack-onliberia-s-economy-sirleaf-says $>$

140.Staff Reporter, 'As Liberia Govt Seeks Clarification from U.S. on Visa Revocations, Kabineh J'aneh, Eugene Nabbe, and Geraldine Doe-Sheriff Prevented from Entering the USA' Hints News Network (Monrovia, Liberia), 24 July 2014 <http://hintsnewsnetwork.com/?p=3646>

141. Staff Reporter, 'Independent Aboriginal Death in Custody Inquiry Not Needed: Premier Colin Barnett' $A B C$ News (Perth, WA), 1 October 2014 <http://www.abc.net.au/news/2014-10-02/callfor-separate-inquest-into-death-of-wa-aboriginal-woman/5785702>

142. Staff Reporter, "No Contradiction - T. C. Gould Says EJS Can Suspend Rights' Front Page Africa (Monrovia, Liberia), 14 October 2014

<http://www.frontpageafricaonline.com/index.php/news/3344-no-contradiction-liberia-barchief-says-ejs-can-suspend-rights>

143. Staff Reporter, 'Aboriginal Man Dies in Casuarine Prison as Hundreds Rally around WA to Protest Deaths in Custody' ABC News (Sydney, NSW), 24 October 2014 $<$ http://www.abc.net.au/news/2014-10-23/corrective-services-investigate-death-of-prisoninmate/5836126>

144.Staff Reporter, ' $\$ 3.5 \mathrm{~m}$ Study into Violence against Women' The Australian (Canberra, ACT), 31 October 2014 <http://www.theaustralian.com.au/news/latest-news/m-study-into-violenceagainst-women/story-fn3dxiwe-1227108578765>

145. Staff Reporter, 'President Sirleaf Accepts Education Min-Designate's Withdrawal Request' Liberian News Agency (Monrovia, Liberia), 6 December 2014 <http://www.liberianewsagency.org/pagesnews.php?nid=3506>

146.Staff Reporter, “"War Crimes List” - Cultures of Impunity Unlikely to Continue' All Africa (Monrovia, Liberia), 5 March 2015 <http://allafrica.com/stories/201503051419.html>

147.Staff Reporter, 'War Crimes Lists' Front Page Africa (Monrovia, Liberia), 5 March 2015 $<$ http://www.frontpageafricaonline.com/index.php/news/4664-war-crimes-list-culture-ofimpunity-unlikely-to-continue>

148. Staff Reporter, 'Triggs Marks 800 Years of Magna Carta at ANU Event' ANU News (Canberra, ACT), 16 June $2015<$ http://www.anu.edu.au/news/all-news/triggs-marks-800-years-of-magnacarta-at-anu-event>

149. Staff Reporter, 'EPS “Monster”: Ellen Protection Detail Deputy Sacked over Beating' Front Page Africa (Monrovia, Liberia), 15 September 2015 http://frontpageafricaonline.com/index.php/news/6264

150.Staff Reporter, 'Sweden Turns over Crime Lab to LNP' The Analyst (Monrovia, Liberia), 26 October 2015 <http://allafrica.com/stories/201510261583.html>

151.Staff Reporter, 'Liberia: Gang Rapists Still at-Large - Rape Victim Aunt Plead to Government' FrontPageAfrica (Monrovia) (Monrovia, Liberia), 3 November 2015 $<$ http://allafrica.com/stories/201511030767.html>

152. Staff Reporter, 'Milestone for Justice Research' Cowra Guardian (Cowra, NSW), 8 January 2016 <http://readnow.isentia.com/Temp/84653/522241051.pdf>

153. Staff Writer, 'When Justice Peeks' Washington Examiner (Washington, DC), 20 September 2010 <http://www.washingtonexaminer.com/when-justice-peeks/article/130193>

154. Staff Writer, 'Liberia: Dismal Court Performance' The Informer (Monrovia Liberia), 9 August $2012<$ http://allafrica.com/stories/201208141119.html?viewall=1>

155. Staff Writer, 'Green Advocates Wants EPA Revoke Sime Darby's Permit' Public Agenda News (Monrovia, Liberia), 2013

$<$ http://www.publicagendanews.com/index.php?option=com_content\&view=article\&id=3191:gr een-advocates-wants-epa-revoke-sime-darbys-permit-\&catid=1:latest-news\&Itemid=2>

156. Staff Writer, 'Statutory Rape: Equip-Liberia Country Director Arrested' Microscope News (Monrovia, Liberia), 2013 <http://microscopeliberia.com/news.html>

157. Staff Writer, 'Liberian President Signs Pledge to End Violence against Women, Girls' Xinhau News Agency - CEIS (Woodside, CA), 20 February 2013 $<$ http://search.proquest.com/docview/1289853770>

158. Staff Writer, 'Liberia: High Cases of Rape Reported' All Africa (Monrovia, Liberia), 22 November $2013<$ http://allafrica.com/stories/201311220415.html> 
159. Staff Writer, 'Liberia: Redoubling Efforts in Uncompromisingly and Robustly Battling Rape in Liberia' All Africa (Monrovia, Liberia), 4 December 2013

<http://allafrica.com/stories/201312040706.html>

160.Staff Writer, 'Guilty for Human Trafficking \& Gang Rape' Heritage (Monrovia, Liberia), 2014 <http://www.news.heritageliberia.net/index.php/inside-heritage/most-commented/2552-guiltyfor-human-trafficking-gang-rape>

161.Staff Writer, 'Liberian Witches Say Power Is in the Blood, so Victims Should Be Eaten Alive' The East African (Nairobi, Kenya), $2014<$ http://www.theeastafrican.co.ke/news//2558/545722/-/view/printVersion/-/yq0f5nz/-/index.html>

162. Staff Writer, 'President Sirleaf Launches Anti-Human Trafficking Five-Year National Action Plan - Says Government Is Ready for the Fight' All Africa (Monrovia, Liberia), 25 March 2014 <http://allafrica.com/stories/201403260652.html?viewall=1>

163. Staff Writer, 'Liberia: UNMIL Wants TRC Report Implemented' The New Dawn (Monrovia, Liberia), 4 July 2014 <http://allafrica.com/stories/201407040725.html>

164. Staff Writer, 'America Ready for Liberians Accused of War Crimes?' Heritage (Monrovia, Liberia), 29 July 2014 <http://allafrica.com/stories/201407291149.html>

165.Stephens, Richard, 'Supreme Court Suspends Case of 48 Former Lawmakers' Liberian News Agency (Monrovia, Liberia), 11 December 2014 <http://allafrica.com/stories/201412120690.html>

166. Stevens, Melissa, 'Howard's Secret Criminal Past' The Daily Telegraph (London, UK), 14 February 2007 <http://www.dailytelegraph.com.au/news/nsw/howards-secret-criminalpast/story-e6freuzi-1111112988170>

167. Stewart, Gboko, 'Desperate Times Call for Unorthodox Measures: Unchecked Rape Crisis Could Barren Liberian Women' Front Page Africa (Monrovia, Liberia), 29 November 2013 $<$ http://www.frontpageafricaonline.com/old/op-ed-editorial/lettercom...ox-measures-uncheckedrape-crisis-could-barren-liberian-women.html>

168.Sungbeh, Tewroh-Wehtoe, 'Woewiyu's Arrest by US Officials Confirms Our Inability to Pursue Our Own War Criminals' The Liberian Dialogue (Atlanta, GA), 15 May 2014 <http://theliberiandialogue.org/2014/05/15/woewiyus-arrest-by-us-officials-confirms-ourinability-to-pursue-our-own-war-criminals/>

169. Swan, Jonathan, 'Wootten Warns of Unrealistic Hopes for Finding Closure' The Sydney Morning Herald (Canberra, ACT), 14 November $2012<$ http://www.smh.com.au/federalpolitics/political-opinion/wootten-warns-of-unrealistic-hopes-for-finding-closure-2012111329aj2.html>

170.Sydney, Robert Milliken, 'Australia Accused of Genocide against Aborigines' The Independent (London, UK), 24 May 1997 <http://www.independent.co.uk/news/world/australia-accused-ofgenocide-against-aborigines-1263163.html>

171. Tamba, Gloria T, 'Draft Mental Health Bill Gains Support' Daily Observer (Monrovia, Liberia), 2014 <http://www.liberianobserver.com/politics/draft-mental-health-bill-gains-support>

172. Tamba, Gloria T, 'MoE Vows to Stop “Sex for Grades” in Universities' Daily Observer (Monrovia, Liberia), 8 September 2015 <http://www.liberianobserver.com/education/moe-vowsstop-"sex-grades"-universities>

173.Taylor, Paige, 'Aborigines Were Building "Stone Houses" 9000 Years Ago' The Australian (Perth, WA), 4 September 2016

<http://at.theaustralian.com.au/link/30ef4873a7c8aaa2b80d01a12680df77?domain=theaustralian .com.au>

174. The Staff Reporter, 'The Churchill You Didn't Know' The Guardian (London, UK), 28 November 2002 <http://www.theguardian.com/theguardian/2002/nov/28/features11.g21>

175.Tierney, John, ‘A New Debate on Female Circumcision' TierneyLab (New York, NY), 30 November 2007 <https://tierneylab.blogs.nytimes.com/2007/11/30/a-new-debate-on-femalecircumcision/?hp $>$

176. Times Wire Services, 'Hundreds Die in Massacre by Liberian Troops: Civil War - as Many as 600 Refugees Are Killed in a Church, Survivors Say the Soldiers Were President Doe's' Los Angeles Times (Monrovia, Liberia), 31 July 1990 <http://articles.latimes.com/1990-0731/news/mn-1189_1_civil-war>

177.TLC Africa, 'Justice for Angel: Hans Williams and Mardea Paykue, Sentence to Death by Hanging' The Liberian Connection (Monrovia, Liberia), 10 March 2014 http://www.tlcafrica.com/news_justice_for_angel_3_10.htm

178. Toby, Peter N, 'Liberia: Judges Blamed for Corruption' All Africa, 1 April 2013 <http://allafrica.com/stories/201304011074.html>

179. Toe, Jerome W, 'Zoes Convicted of Forced Initiation' Daily Observer (Monrovia, Liberia), 11 July 2011 
180.Triggs, Gillian, 'Gillian Triggs on Magna Carta: Alice Tay Lecture in Law and Human Rights in Full' The Guardian (Canberra, ACT), 15 June 2015 <http://www.theguardian.com/australianews/2015/jun/15/australia-and-the-magna-carta-how-the-coalition-and-labor-agree-on-lawsthat-violate-our-freedoms>

181. Tweh, Jefferson D, 'Liberia: MOGD Takes Anti-Rape Awareness to Public Schools' All Africa (Online), 8 November 2013 http://allafrica.com/stories/201311081747.html

182.Unsworth, Genine, 'Indigenous Girls Academy Kicking Goals' Australian Broadcasting Corporation (South West, WA), 1 April 2010

<http://www.abc.net.au/local/stories/2010/04/01/2862623.htm>

183. Valdmanis, Richard, 'Exclusive: Resource Deals Audit Overshadows Liberia Anti-Graft Push' Reuters (Dakar), 1 May 2013 <http://www.reuters.com/article/2013/05/01/us-liberia-resourcesidUSBRE9400QY20130501>

184. Wandia, Mary, 'Liberia Needs to Muster the Courage to Ban FGM' The Guardian (Monrovia, Liberia), 27 April 2016 <http://www.theguardian.com/global-development/2016/apr/27/liberiacourage-to-ban-fgm-ellen-johnson-sirleaf $>$

185. Weber, Dave, 'Stolen Generation Family Ordered to Pay Court Costs after "test Case" Fails in WA' Australian Broadcasting Corporation (Perth, WA), 10 June 2015 <http://www.abc.net.au/news/2015-05-09/stolen-generation-family-must-pay-courtcosts/6457256>

186. Weedee, Emmanuel, 'Over 60 per Cent of Liberia's Rain Forest Offered to Logging Companies' Heritage (Monrovia, Liberia), 4 September 2012 <http://allafrica.com/stories/201209200720.html>

187. Weedee-Conway, Emmanuel, 'Ellen Gets Tough - Several Suspended without Pay' Heritage (Monrovia, Liberia), 21 July 2014 <http://allafrica.com/stories/201407211449.html>

188. Wellington, Patrick G, 'Nimba Prison Boss Pushes for Speedy Trials' Liberian News Agency (Sanniquellie), 10 February 2015 <https://www.facebook.com/micatliberia1?fref=nf>

189. Wellington, Patrick G, 'Lawyer Cautions Chiefs against Trial by Ordeal' Liberian News Agency (Sannequellie, Nimba), 13 February 2015 <www.liberianewsagency.org>

190. William, Wade CL, 'Sande Shutdown: Traditional Leaders and GOL Suspend Women's Secret Society’ Front Page Africa (Monrovia, Liberia), 30 March 2012

<http://www.frontpageafricaonline.com/index.php?option=com_content\&view=article\&id=2852 :grebo-bush-shutdown-traditional-leaders-gol-suspend-womens-secretsociety\&catid=42:politics\&Itemid=109>

191.Williams, Wade CL, 'As War Crimes Prosecution Debate Heats up; Prince Johnson Threatens Trouble If’ Front Page Africa (Monrovia, Liberia), 25 May 2012

<http://www.frontpageafricaonline.com/old/news/general-news/3231-as-war-crimesprosecution-debate-heats-up-prince-johnson-threatens-trouble-if-.html>

192.Williams, Wade CL and Tecee Boley, 'Liberia: Lebanese Man Video Taped Sex Act with Liberian Girls, Ages 7-15’ All Africa (Monrovia, Liberia), 18 April 2013

<http://allafrica.com/stories/201304190928.html>

193.Worsley, Ben, 'Indigenous Referendum: Australians Invited to Join Community Conference on Recognition Vote' ABC News (Sydney, NSW), 6 July 2015 <http://www.abc.net.au/news/201507-06/australia-big-enough-for-indigenous-referendum-says-abbott/6598144>

194. Yangian, Kennedy L, 'Couple Lawyers Pray Supreme Court for Acquittal in Angel Death' Front Page Africa (Monrovia, Liberia), 8 May 2014

$<$ http://www.frontpageafricaonline.com/index.php/news/1586-couple-lawyers-pray-supremecourt-for-acquittal-in-angel-death>

195. Young, Finlay, 'Love in the Time of Ebola: Meeting the Locals Struggling to Cope with an Epidemic' Newsweek (Monrovia, Liberia), 20 August 2014

<http://www.newsweek.com/2014/08/29/love-time-ebola-meeting-locals-struggling-copeepidemic-265615.html>

\section{Radio Broadcast}

1. Australian Broadcasting Corporation, 'Sir Ronald Wilson', Australian Identity (In Bed With Phillip), 9 August 2001 <http://www.abc.net.au/rn/features/inbedwithphillip/episodes/204-sirronald-wilson/>

2. Australian Broadcasting Corporation, 'Crown Prosecutor Speaks out about Abuse in Central Australia', Lateline, 15 May 2006 <http://www.abc.net.au/lateline/content/2006/s1639127.htm> 


\section{Report}

1. Abbey, Antonia and Lydia Guy Ortiz, 'Alcohol and Sexual Violence Perpetration' (Private Document 5U1V/CE324010-05, VAWNet: A Project of the National Resource Center on Domestic Violence, December 2008) 17

2. Abdulai, Emmanuel Saffa, 'Strengthening of Prosecution of SGBV Offences Through Support to the Sexual and Gender Based Crimes Unit (SGBV CU)' (Government Report, United Nations Populations Fund (UNFPA) and Government of Liberia, November 2010) 51 <http://mdtf.undp.org/document/download/6383>

3. Aboriginal and Torres Strait Islander Social Justice Commissioner, 'Social Justice Report' (Government Report 6, Human Rights and Equal Opportunity Commission, 2005) 390 $<\mathrm{http} / / / \mathrm{www}$.humanrights.gov.au/our-work/aboriginal-and-torres-strait-islander-socialjustice/publications/social-justice-report-6>

4. Aboriginal and Torres Strait Islander Social Justice Commissioner, 'Social Justice and Native Title Report 2014' (Government Report 5, Australian Human Rights Commission, 2014) 148 $<$ https://www.humanrights.gov.au/our-work/aboriginal-and-torres-strait-islander-socialjustice/publications/social-justice-and-nati-0>

5. Aboriginal Justice Centre and ACTCOSS, 'Circles of Support: Towards Indigenous Justice Prevention, Diversion and Rehabilitation' (ACT Council of Social Services Incorporated, 2008) $102<$ https://www.actcoss.org.au/sites/default/files/public/publications/2008-report-circles-ofsupport-towards-indigenous-justice.pdf $>$

6. ACT Government, 'Strengthening the Ngambra Circle Sentencing Court' (Government, Attorney General's Department, Law Courts and Tribunals, January 2010) 66 $<$ https://justice.act.gov.au/resources/attachments/paper_StrengtheningtheNgambraCircleSentenci ngCourt_LPB_2010.pdf >

7. ACT Government, 'ACT Aboriginal and Torres Strait Islander Population: A Demographic Analysis' (Government, Policy Division, ACT Chief Minister's Department, July 2010) 40 <http://www.cmd.act.gov.au/__data/assets/pdf_file/0011/154487/ACT-Aboriginal-Torres-StraitIslanders.pdf>

8. ACT Government, 'The ACT Women's Plan 2010-2015: 2013 Progress Report' (ACT Government - Community Services, 2013) 60

9. ACT Government, 'The Australian Capital Territory Chief Health Officer's Report 2014' (Government Report, Department of Health, May 2014) 126 <https://www.health.act.gov.au/sites/default/files/ACT\%20Chief\%20Health\%20Officers\%20Re port\%202014.pdf>

10. ACT Government, 'ACT Aboriginal and Torres Strait Islander Justice Partnership 2015-2018' (Monitoring and Reporting Framework, Attorney General's Department and ACT Aboriginal and Torres Strait Islander Elected Body, 2015) $48<\mathrm{http} / / /$ atsieb.com.au/wpcontent/uploads/2015/07/50467-ACT-JACS-ATSIEB-Justice-Agreement-15-18.pdf>

11. ACT Government Community Services, 'A Picture of Women in the ACT' (Government Report, ACT Government - Community Services, 2013) 87

$<$ http://www.communityservices.act.gov.au/_data/assets/pdf_file/0004/517981/A-Picture-ofWomen-in-the-ACT-2013.pdf>

12. ACT Health, 'Annual Report 2013-2014' (Government, ACT Government Health Directorate, 2014) 280 <http://www.health.act.gov.au/datapublications/reports/annual-reports/2013-2014annual-report/section-f-financial-management/f4>

13. ACT Women, ‘ACT Women's Plan 2010-2015: An Act Government Strategic Framework to Improve the Status and Lives of Women and Girls' (Government Report, Department of Health Care Services, 2010) 28

<http://www.communityservices.act.gov.au/_data/assets/pdf_file/0016/122506/ACT_Womens _Plan_2010_-15.pdf>

14. Ahuja, Naysa, 'Feminist Jurisprudence: The Need to Understand the Woman's Question and It's Implications on Women in the Indian Patriarchal Society' (Women's Studies and Development Centre, University of Delhi, 2010) 18 <http://www.academia.edu/1562885/The_Need_to_Understand_the_Womans_Question_and_its _Implication_on_Women_in_Patriarchal_Society>

15. Allard, Troy et al, 'Police Diversion of Young Offenders and Indigenous Over-Representation' (Government Report 390, Australian Institute of Criminology, 2010) 6 〈http://www.aic.gov.au/publications/current\%20series/tandi/381-400/tandi390.html>

16. Amnesty International, 'Liberia: No Impunity for Rape - A Crime Against Humanity and a War Crime' (NGO, Amnesty International, 14 December 2004) 46 <https://www.amnesty.org/en/documents/AFR34/017/2004/en/> 
17. Australian Bureau of Statistics, 'Bridging the Data Gaps for Family, Domestic and Sexual Violence, Australia' (Government Report, Australian Bureau of Statistics, 2013) 68 <http://www.abs.gov.au/ausstats/abs@.nsf/Lookup/4529.0.00.002main+features132013>

18. Australian Bureau of Statistics, 'Defining the Data Challenge for Family, Domestic and Sexual Violence Australia' (Government Report 4529.0, Australian Bureau of Statistics, 2013) 79 <http://www.abs.gov.au/ausstats/abs@.nsf/mf/4529.0/>

19. Australian Bureau of Statistics, 'National Aboriginal and Torres Strait Islander Social Survey, 2008' (Government Report, Australian Bureau of Statistics, 2013) 119 <http://www.abs.gov.au/ausstats/abs@.nsf/mf/4714.0/\#>

20. Australian Government, 'Australian National Action Plan on Women, Peace and Security 20122018' (Government Report, Australian Government Office for Women, 2012) 64 $<$ https://www.dss.gov.au/our-responsibilities/women/publications-articles/governmentinternational/australian-national-action-plan-on-women-peace-and-security-2012-2018>

21. Australian Government, 'National Aboriginal and Torres Strait Islander Health Plan 2013-2023' (Government Report 10290, Department of Health and Ageing, 2013) 66 <http://www.health.gov.au/internet/main/publishing.nsf/content/B92E980680486C3BCA257BF 0001BAF01/\$File/health-plan.pdf>

22. Australian Government, 'Stronger Futures in the Northern Territory Progress Report - Part 1' (Government Report, Department of the Prime Minister and Cabinet, 24 May 2014) 11 <http://www.dpmc.gov.au/PUBLICATIONS/stronger_futures_NT_progress/index.cfm>

23. Australian Government, 'Stronger Futures in the Northern Territory Progress Report - Part 2' (Government Report, Department of the Prime Minister and Cabinet, 24 May 2014) 53 <http://www.dpmc.gov.au/PUBLICATIONS/stronger_futures_NT_progress/index.cfm>

24. Australian Human Rights Commission, 'Social Justice Report 2007' (Government Report 2, Office of the Aboriginal and Torres Strait Islander Social Justice Commissioner, 11 February 2008) 435

<https://www.humanrights.gov.au/sites/default/files/content/social_justice/sj_report/sjreport07/p df/sjr_2007.pdf>

25. Australian Human Rights Commission, 'Social Justice Report 2009: Aboriginal and Torres Strait Islander Social Justice Commissioner' (Government Report No. 1/2010, Australian Human Rights Commission, 2009) 222

26. Australian Human Rights Commission, 'The Suspension and Reinstatement of the RDA and Special Measures in the NTER' (Government Report, Australian Human Rights Commission, 2011) 24

$<$ https://www.humanrights.gov.au/sites/default/files/content/racial_discrimination/publications/r da-nter/NTERandRDAPublication12\%20December2011.pdf>

27. Australian Human Rights Commission, 'Independent Interim Report on CEDAW: Australian Human Rights Commission Report to the Committee on the Elimination of All Forms of Discrimination against Women' (Government Report, Australian Human Rights Commission, 31 August 2012) 25

<http://www2.ohchr.org/english/bodies/cedaw/docs/followup/ngos/AHRC_Australia.pdf>

28. Australian Human Rights Commission, 'Social Justice Report 2012: Aboriginal and Torres Strait Islander Social Justice Commissioner' (Government Report, Australian Human Rights Commission, 26 October 2012) 242 <http://www.humanrights.gov.au/our-work/aboriginal-andtorres-strait-islander-social-justice/publications/social-justice-report-11>

29. Australian Institute of Criminology, 'Australian Crime: Facts and Figures' (Government Report, Australian Institute of Criminology, 2012) 179

<http://www.aic.gov.au/documents/0/B/6/\%7B0B619F44-B18B-47B4-9B59-

F87BA643CBAA\%7Dfacts11.pdf>

30. Australian Institute of Criminology, 'Annual Report 2012-13' (Government Report, Australian Institute of Criminology, 2013) 141

<http://www.aic.gov.au/publications/current\%20series/annualreport/11-20/2013.html>

31. Australian Law Reform Commission, 'Recognition of Aboriginal Customary Laws (ALRC Report 31)' (Government Report 31, Australian Law Reform Commission, 12 June 1986) 737 <http://www.alrc.gov.au/publications/report-31>

32. Australian Law Reform Commission, 'Family Violence - A National Legal Response' (Government Report, Australian Law Reform Commission and the NSW Law Reform Commission, 2010) 2455 <http://www.alrc.gov.au/sites/default/files/pdfs/publications/ALRC114_WholeReport.pdf>

33. Australian Law Reform Commission and New South Wales Law Reform Commission, 'Family Violence - A National Legal Response: Summary Report' (2010) 78

<http://www.alrc.gov.au/sites/default/files/pdfs/publications/Report\%20Summary.pdf> 
34. Australian Law Reform Commission and New South Wales Law Reform Commission, 'Family Violence and Commonwealth Laws - Improving Legal Frameworks' (Government Report ALRC Report 117, Australian Human Rights Commission, 2011) 581

<http://www.alrc.gov.au/sites/default/files/pdfs/publications/whole_alrc_117.pdf>

35. Australian Law Reform Commission, 'Equality Before the Law: Justice for Women (Part 1)' (Discussion Paper 54, Australian Law Reform Commission, 19 July 2012) 236

36. Australian Law Reform Commission, 'Incarceration Rates of Aboriginal and Torres Strait Islander Peoples’ (Discussion Paper 84, Australian Law Reform Commission, 19 July 2017) 236 $<$ https://www.alrc.gov.au/publications/indigenous-incarceration-rates-dp84>

37. Australian Medical Association, 'Report Card on Indigenous Health: Treating the High Rates of Imprisonment of Aboriginal and Torres Strait Islander Peoples as a Symptom of the Health Gap - And Integrated Approach to Both' (Private Report, Australian Medical Association, November 2015) 32 <https://ama.com.au/2015-ama-report-card-indigenous-health-closing-gap-indigenousimprisonment-rates $>$

38. Baker, Ashleigh and Tracy Cussen, 'Deaths in Custody in Australia: National Deaths in Custody Program 2011-12 and 2012-13' (Monitoring Reports 26, Australian Institute of Criminology, 2015) 76 <http://aic.gov.au/publications/current\%20series/mr/21-40/mr26.html>

39. Bartels, Lorana, 'Diversion Programs for Indigenous Women' (Government Report 13, Australian Institute of Criminology, 2010) 12

<http://www.aic.gov.au/publications/current\%20series/rip/1-10/13.html>

40. Biddle, Nicholas, 'Measures of Indigenous Wellbeing and Their Determinants Across the Lifecourse' (CAEPR Lecture Series 2, Centre for Aboriginal Economic Policy Research, Australian National University, 19 May 2011) 1 <http://caepr.anu.edu.au/sites/default/files/page/2011/01/Lecture02Paper.pdf>

41. Bigge, John Thomas, 'Report of the Commissioner of the Inquiry on the State of Colony of New South Wales' (Government Report, Colonial Parliament of New South Wales, 1822) 186 <http://www.jenwilletts.com/commissioners_of_enquiry.htm>

42. Blagg, Harry, 'Youth Justice in Western Australia' (Government Report, Commissioner for Children and Young People Western Australia, 17 December 2009) 38

43. Boxall, Hayley, Adam M Tomison and Shann Hulme, 'Historical Review of Sexual Offence and Child Sexual Abuse Legislation in Australia: 1788-2013' (Government Report, Australian Institute of Criminology, 2014) 108

44. Braaf, Rochelle and Isobelle Barrett Meyering, 'Seeking Security: Promoting Women's Economic Wellbeing Following Domestic Violence' (Australian Domestic and Family Violence Clearinghouse, 2011) 137

45. Bruce, John W and Boakai N Kanneh, 'Reform of Liberia's Civil Law Concerning Land: A Proposed Strategy - Report to the Land Commission' (Government Report, Land Reform Commission, 16 February 2013) 109

46. Bryant, Colleen and Matthew Willis, 'Pornography Awareness: A Process of Engagement with Northern Territory Indigenous Communities' (Government Report 34, Australian Institute of Criminology, 2009) 86

47. Bureau of Democracy Human Rights and Labour, 'Liberia: 2013 Human Rights Reports' (International Report, United States Department of State, 27 February 2014) 27 <https://www.state.gov/documents/organization/220339.pdf>

48. Canberra Rape Crisis Centre, 'Canberra Rape Centre Annual Report 2010-2011' (ACT Government, 2011) 22

49. Carcach, Carlos and Toni Makkai, 'Review of Victoria Police Statistics' (Government Report 45, Australian Institute of Criminology, 2002) 1

50. Carter, Edie, 'Aboriginal Women Speak Out About Rape and Child Sexual Abuse: A Report of an Adelaide Survey’ (Adelaide Rape Crisis Centre Inc. 1987) 33

51. Chamberlain, Chris and David Mackenzie, 'Counting the Homeless 2006: Australian Capital Territory' (Government, Australian Institute of Health and Welfare, June 2009) 59 <http://www.aihw.gov.au/WorkArea/DownloadAsset.aspx?id=6442465036>

52. Chrisholm, Richard, 'Family Courts Violence Review: A Report by Professor Richard Chisholm' (Government Report, Attorney General's Department, 27 November 2009) 275

53. Clinton Foundation and Bill and Melinda Gates Foundation, 'The Full Participation Report: Highlights' (The Clinton Foundation, 2015) 1

54. Collins, Lisa and Muzammil Ali, 'Deaths in Custody in Australia: 2002 National Deaths in Custody Program (NDICP) Annual Report' (Government Report 56, Australian Institute of Criminology, 2003)

55. Commonwealth Director of Public Prosecutions, ‘Annual Report 2011-2012' (Commonwealth Department of Public Prosecution, 2012) 296 
56. Commonwealth of Australia, 'Bringing Them Home: National Inquiry into the Separation of Aboriginal and Torres Strait Islander Children from Their Families' (Government Report, Human Rights and Equal Opportunity Commission, 1997) 524

57. Commonwealth of Australia, 'Northern Territory Emergency Response: Report of the NTER Review Board' (Government Report, Ministry of Families, Housing, Community Services and Indigenous Affairs, October 2008) 130

<http://www.nterreview.gov.au/docs/report_nter_review/docs/Report_NTER_Review_October0 8.pdf>

58. Commonwealth of Australia, 'The Shape of the Australian Curriculum: History' (Government Policy, National Curriculum Board, May 2009) 16 〈http://docs.acara.edu.au/resources/Australian_Curriculum_-_History.pdf〉

59. Commonwealth of Australia, 'Our North, Our Future: White Paper on Developing Northern Australia' (Policy Document, Department of the Prime Minister and Cabinet, 2015) 189 $<$ https://northernaustralia.dpmc.gov.au/sites/default/files/papers/northern_australia_white_paper. pdf $>$

60. Commonwealth of Australia, 'Redress and Civil Litigation Report' (Government, Royal Commission into Institutional Responses to Child Sexual Abuse, 2015) 668 <https://www.childabuseroyalcommission.gov.au/policy-and-research/redress>

61. Constitution Review Committee, 'Preliminary Summary of Views of the Liberian People as Expressed During the Consultations and Sectorial Meetings in 73 Liberian Electoral Districts and the Diaspora 2013-2014' (Government, Constitution Review Committee, 18 August 2015) 80

62. Coorey, Lyla, 'Child Sexual Abuse in Rural and Remote Australian Indigenous Communities A Preliminary Investigation' (Government Report, The Senate, 2001) 122 $<$ http://www.aph.gov.au/ /media/wopapub/senate/committee/indigenousaffairs_ctte/hearings/lyl a_coorey_report_march05_pdf.ashx>

63. Copland, Mark, 'Stolen Wages - An Opportunity for Justice?' (Background Report, Australian Catholic Social Justice Council, 2006) 8

$<$ http://www.socialjustice.catholic.org.au/publications/discussion-guides/60-stolen-wages-anopportunity-for-justice>

64. Corrin, Jennifer, Sarah-Jane Bennett and Alison Chen, 'Pleading and Proof of Indigenous Customary Law in Queensland Courts' (TC Beirne School of Law's Centre for Public and International Comparative Law, University of Queensland, 2010) 161 <http://www.law.uq.edu.au/documents/cpicl/Pleading-and-Proof-of-Indigenous-CustomaryLaw.pdf>

65. Council of Australian Government, 'The National Plan to Reduce Violence against Women and Their Children 2010 - 2022 (The National Plan)' (Department of Families, Housing, Community Services and Indigenous Affairs, 2010) 61

66. Crossette, Barbara, 'The State of the World Population - From Conflict and Crisis to Renewal:; Generations of Change' (UN Report, United Nations Populations Fund, 2010) 116

67. Cussen, Tracy and Matthew Lyneham, 'ACT Family Violence Intervention Program Review' (Government Report, Australian Institute of Criminology, 2012) 184 〈http://www.aic.gov.au/media_library/publications/tbp/tbp052/tbp052.pdf>

68. Department of Child Protection, 'WA Strategic Plan for Family and Domestic Violence 20092013' (Government Report DCP76/1209, Government of Western Australia, 2009) 12

69. Department of Education and Training, 'ACT School Census' (Government Report, ACT Government, February 2015) 10

<http://www.det.act.gov.au/_data/assets/pdf_file/0003/714522/2015-Feb-CensusPublication.pdf $>$

70. Department of Families, Housing, Community Services and Aboriginal Affairs, 'Northern Territory Emergency Response Taskforce - Final Report to Government' (Government Report, Department of Families, Housing, Community Services and Indigenous Affairs, June 2008) 42 $<$ http://www.fahcsia.gov.au/our-responsibilities/indigenous-australians/publicationsarticles/closing-the-gap-in-the-northern-territory-including-northern-territory-emergencyresponse/northern-territory-emergency-response-taskforce-final-report-to-government>

71. Department of Human Services and VicHealth, 'The Health Cost of Violence: Measuring the Burden of Disease Caused by Intimate Partner Violence - A Summary Findings' (Government Report, Victorian Health Promotion Foundation, 2010) 44

72. Dodson, Patrick L, 'Royal Commission into Aboriginal Deaths in Custody: National Report Volumes 1-4' (Government Report, Royal Commission into Aboriginal Deaths in Custody, 15 April 1991) 
73. Doherty, Justine, 'An Increasing Indigenous Populations? Implications for the Criminal Justice System' (Government Report 32, Office of Crime Statistics, Attorney-General's Department, 2002) 19

74. Dunn, D Elwood, 'Liberia: Countries at the Crossroads' (Private Report, Freedom House, 2012) $18<$ https://freedomhouse.org/report/countries-crossroads/2012/liberia\#.VPoEfCm-0jR>

75. Eastwood, Christine and Wendy Patton, 'The Experiences of Child Complainants of Sexual Abuse in the Criminal Justice System' (Government Report, Australian Criminology Research Council, 2002) 156 <https://www.ncjrs.gov/App/publications/abstract.aspx?ID=196600>

76. Equality Now, 'The World's Shame: The Global Rape Epidemic - How Laws Around the World Are Failing to Protect Women and Girls from Sexual Violence' (Private Report, Equality Now, 2017) 68 <https://www.equalitynow.org/sites/default/files/EqualityNowRapeLawReport2017_Single\%20 Pages.pdf>

77. Ferdinand, Angeline, Yin Paradies and Margaret Kelaher, 'Mental Health Impacts of Racial Discrimination in Victorian Aboriginal Communities Experiences of Racism Survey: A Summary' (Private Document P105D, VicHealth, 2012) 8

78. Flood, Michael and Lara Fergus, 'An Assault on Our Future: The Impact of Violence on Young People and Their Relationships' (White Ribbon Foundation, 2008) 56

79. Flory, Rani, 'Whittlesea CALD Communities Family Violence Project: Scoping Exercise Report' (Private Report, Whittlesea Community Futures, September 2012) 81

80. Foster, Dulce et al, 'A House with Two Rooms: Final Report of the Truth and Reconciliation Commission of Liberia Diaspora Project' (Dispute Resolution Institute, 2009) 626

81. Gerdes, Felix, 'Liberia's Post-War Elite: A New Era of Inclusive Ownership or Old Wine in New Bottles?' (Private Report, Universitat Hamburg, 2011) 68

82. Gerdes, Felix, 'The Evolution of the Liberian State: A Study in Neo-Patrimonial State Formation and Political Change' (Private Report, Universitat Hamburg, 2013) 62

83. Gompert, David et al, 'Making Liberia Safe Transformation of the National Security Sector' (Private Document, RAND National Defense Research Institute, 2007) 118 <http://www.rand.org/content/dam/rand/pubs/monographs/2007/RAND_MG529.pdf>

84. Governance Commission and Ministry of Gender and Development, 'From the Sidelines to the Forefront: Ensuring a Gender-Responsive Foundation for Liberia's National Decentralization Process - A Review and Analysis of Barriers, Opportunities and Entry Points' (Government Report, Governance Commission, 2013) 84

85. Government of Australia, 'Indigenous Young People With Cognitive Disability and Australian Juvenile Systems: A Report by the Aboriginal and Torres Strait Islander Social Justice Commissioner' (Government Report, Human Rights and Equal Opportunity Commission, 2005) 43

86. Government of Australia, 'Footprints in Time: The Longitudinal Study of Indigenous Children Key Summary Report from Wave 1' (Government, Department of Social Services, 2009) 64 <https://www.dss.gov.au/about-the-department/publications-articles/researchpublications/longitudinal-data-initiatives/footprints-in-time-the-longitudinal-study-ofindigenous-children-1sic/key-summary-report-from-wave-1-2009>

87. Government of Australia, 'Footprints in Time: The Longitudinal Study of Indigenous Children Key Summary Report from Wave 2' (Government, Department of Social Services, 2011) 69 <https://www.dss.gov.au/about-the-department/publications-articles/researchpublications/longitudinal-data-initiatives/footprints-in-time-the-longitudinal-study-ofindigenous-children-lsic/key-summary-report-from-wave-2>

88. Government of Australia, 'Footprints in Time: The Longitudinal Study of Indigenous Children' (Government, Department of Social Services, 2012) 100 <https://www.dss.gov.au/about-thedepartment/publications-articles/research-publications/longitudinal-data-initiatives/footprints-intime-the-longitudinal-study-of-indigenous-children-lsic/key-summary-report-from-wave-3>

89. Government of Australia, 'Closing the Gap in the Northern Territory Monitoring Report January - June 2012 (Part One)' (Government Report, Department of Families, Housing, Community Services and Indigenous Affairs, June 2012) 31 <http://www.dss.gov.au/sites/default/files/documents/01_2013/part_1_nter_monitoring_report_3 1jan.pdf>

90. Government of Australia, 'Closing the Gap in the Northern Territory: Monitoring Report January - June 2012 (Part Two)' (Government Report, Department of Families, Housing, Community Services and Indigenous Affairs, June 2012) 108 <http://www.dss.gov.au/sites/default/files/documents/01_2013/part_2_nter_monitoring_report_3 1jan.pdf>

91. Government of Australia, 'Footprints in Time: The Longitudinal Study of Indigenous Children Report from Wave 4' (Government, Department of Social Services, 2013) 71 
<https://www.dss.gov.au/about-the-department/publications-articles/researchpublications/longitudinal-data-initiatives/footprints-in-time-the-longitudinal-study-ofindigenous-children-lsic/key-summary-report-from-wave-4>

92. Government of Australia, 'The Coalition's 2030 Vision for Developing Northern Australia: A White Paper on Developing Northern Australia' (Government Report, Liberal Party, June 2013) 46 <http://www.liberal.org.au/2030-vision-developing-northern-australia>

93. Government of Australia, 'National Drug Strategy Household Survey' (Government Report, Australian Institute of Health and Welfare, 2014) 162

94. Government of Australia, 'Footprints in Time: The Longitudinal Study of Indigenous Children Report from Wave 5' (Government, Department of Social Services, 2015) 118 <https://www.dss.gov.au/about-the-department/publications-articles/researchpublications/longitudinal-data-initiatives/footprints-in-time-the-longitudinal-study-ofindigenous-children-lsic/key-summary-report-from-wave-5>

95. Government of Liberia and UNICEF, 'National Policy on Girls' Education' (Policy Report, Ministry of Education, 2005) 40

96. Government of Liberia, 'National Plan of Action for the Prevention and Management of Gender Based Violence in Liberia (GBV-POA)' (Government Policy, Ministry of Children, Gender and Social Development, November 2006) 43

97. Government of Liberia, 'United Nations Development Assistance Framework 2008-2012' (Government Report, Ministry of Planning and Economic Affairs, 2007) 60

98. Government of Liberia, 'Bomi County Development Agenda' (Government Report, Ministry of Planning and Economic Affairs, 2008) 70 <http://www.mia.gov.lr/doc/Bomi\%20CDA_web.pdf>

99. Government of Liberia, 'Bong County Development Agenda' (Government Report, Ministry of Planning and Economic Affairs, 2008) 86 <http://www.mia.gov.lr/doc/Bong\%20CDA_web.pdf>

100.Government of Liberia, 'Gbarpolu County Development Agenda' (Government Report, Ministry of Planning and Economic Affairs, 2008) 68 <http://www.emansion.gov.lr/doc/GbarpoluCDA.pdf>

101. Government of Liberia, 'Grand Bassa County Development Agenda' (Government Report, Ministry of Planning and Economic Affairs, 2008) 64 <http://www.mia.gov.lr/doc/Grand\%20Bassa\%20CDA_web.pdf>

102. Government of Liberia, 'Grand Cape Mount County Development Agenda' (Government Report, Ministry of Planning and Economic Affairs, 2008) 107 <http://www.mia.gov.lr/doc/Grand\%20Cape\%20Mount\%20CDA_web.pdf>

103. Government of Liberia, 'Grand Gedeh County Development Agenda' (Government Report, Ministry of Planning and Economic Affairs, 2008) 76 <http://www.mia.gov.lr/doc/Grand\%20Gedeh\%20CDA_web.pdf>

104.Government of Liberia, 'Grand Kru County Development Agenda' (Government Report, Ministry of Planning and Economic Affairs, 2008) 76 <http://www.mia.gov.lr/doc/Grand\%20Kru\%20CDA_web.pdf>

105.Government of Liberia, 'Lofa County Development Agenda 2008-2012' (Government Report, Ministry of Planning and Economic Affairs, 2008) 116

106. Government of Liberia, 'Margibi County Development Agenda' (Government Report, Ministry of Planning and Economic Affairs, 2008) 70 <http://www.mia.gov.lr/doc/Margibi\%20CDA_web.pdf>

107.Government of Liberia, 'Maryland County Development Agenda 2008-2012' (Government Report, Ministry of Planning and Economic Affairs, 2008) 68

108. Government of Liberia, 'Montserrado County Development Agenda 2008-2012' (Government Report, Ministry of Planning and Economic Affairs, 2008) 82

109. Government of Liberia, 'Nimba County Development Agenda 2008-2012' (Government Report, Ministry of Planning and Economic Affairs, 2008) 70

110. Government of Liberia, 'Prevention and Response to Sexual Exploitation \& Abuse in Liberia: A Case Study’ (Government Policy, Ministry of Children, Gender and Social Development, 2008) 48

111. Government of Liberia, 'River Cess County Development Agenda' (Government Report, Ministry of Planning and Economic Affairs, 2008) 66 $<$ http://emansion.gov.lr/doc/RivercessCDA.pdf>

112. Government of Liberia, 'River Gee County Development Agenda' (Government Report, Ministry of Planning and Economic Affairs, 2008) 76 <http://www.emansion.gov.lr/doc/RiverGeeCDA.pdf>

113. Government of Liberia, 'Liberia Poverty Reduction Strategy Program' (Government Report, The Government of Liberia, April 2008) 190 <http://emansion.gov.lr/doc/Final\%20PRS.pdf> 
114.Government of Liberia and United Nations, 'Government and UN Joint Programme to Prevent and Respond to Sexual Gender Based Violence' (Public-Private, Joint Programme to Prevent and Respond to SGBV in Liberia, 13 June 2008) 36 <http://www.unliberia.org/doc/SGBVJpf2008.pdf>

115. Government of Liberia, 'A System in Transition: The 2007/08 National School Census Report' (Government Report, Ministry of Education, October 2008) 112

116. Government of Liberia, 'Liberia National Gender Policy: National Gender Policy Strategic Results Framework and Plan (2010-2015)' (Government Policy, Ministry of Children, Gender and Social Development, 2009) 59

117. Government of Liberia, 'National Standard Operating Procedures for Prevention and Response to Sexual Gender-Based Violence in Liberia' (Government Policy, Ministry of Children, Gender and Social Development, 2009) 40

118. Government of Liberia, 'The Liberia National Action Plan for the Implementation of United Nations Resolution 1325' (Government Policy, Ministry of Children, Gender and Social Development, 2009) 75

119. Government of Liberia, 'Liberia's Report on Beijing +15' (Government Report, Ministry of Children, Gender and Social Development, March 2009) 35

120.Government of Liberia, 'A Case for System Transformation: The 2008/09 National School Census Report' (Government Report, Ministry of Education, 2010) 115

121.Government of Liberia, 'The 52nd Legislature: Rules and Procedures of House of Representatives' (Government Rules, National Democratic Institute \& USAID, 2010) 58 <http://legislature.gov.lr/sites/default/files/Rules_and_Procedures_of_House_Rep._Book\%20(fi nal).pdf>

122. Government of Liberia and Swedish International Development Cooperation, 'In-Depth Study on Reasons for High Incidence of Sexual and Gender Based Violence in Liberia Recommendations on Prevention and Response' (Government Report, Ministry of Gender \& Development, October 2011) 70

123. Government of Liberia, 'Study on Operations of Sande School' (Government Report, Ministry of Children, Gender and Social Development, April 2011)

124. Government of Liberia, 'Sinoe County Development Agenda' (Government Report, Ministry of Planning and Economic Affairs, 2012) 84 <http://www.emansion.gov.lr/doc/SinoeCDA.pdf>

125.Government of Liberia, 'Lift Liberia Poverty Reduction Strategy' (Government Report, Ministry of Planning and Economic Affairs, February 2012) 42 <https://www.imf.org/external/pubs/ft/scr/2012/cr1245.pdf>

126. Government of Liberia, '150-Day Action Plan: Implementation Report' (Government Report, Ministry of Information, Cultural Affairs and Tourism, 28 February 2012) 49 <http://www.liberianembassyus.org/uploads/PDFFiles/150-Day\%20Report.pdf>

127. Government of Liberia, 'Exploring GBV Prevention in Liberia' (Government Report, Joint UN GBV Program, 2013) 24

128. Government of Liberia, 'Agenda for Transformation: Steps Toward Liberia Rising 2030' (Government Report, Liberia Development Agency, Ministry of Finance and, 15 April 2013) 216

129. Government of Liberia, 'Liberia Demographic and Health Survey 2013' (Government Report, Liberia Institute of Statistics and Geo-Information Services, August 2014) 480 <http://dhsprogram.com/what-we-do/survey/survey-display-435.cfm>

130. Government of Queensland, 'The Health of Queenslanders 2014: Fifth Report of the Chief Health Officer Queensland' (Government Report, Department of Health, 2014) 208 $<$ https://www.health.qld.gov.au/publications/research-reports/reports/cho-report/cho-fullreport.pdf>

131.Government of Western Australia, 'WA Country Health Service Annual Report, 2013-14' (Government Report, Western Australia Country Health Service, 2014) 158

<http://ww2.health.wa.gov.au/ /media/Files/Corporate/Reports\%20and\%20publications/Annual $\% 20$ reports/wachs_annual_report2014.ashx>

132.Green Advocates and Forest Peoples Programme, "We Who Live Here Own the Land" Customary Land Tenure in Grand Cape Mount, and Community Recommendations for Reform of Liberia's Land Policy \& Law' (Forest Peoples Programme, December 2012) 26

133. Hanasz, Paula, 'The Social Sciences Shape the Nation' (Public Report, Academy of the Social Science in Australia Inc., 2017) $154<$ http://www.assa.edu.au/publication/the-social-sciencesshape-the-nation/>

134.Hardoon, Deborah and Finn Heinrich, 'Global Corruption Barometer' (Private Report, Transparency International, 2013) 48 <http://www.wingia.com/web/files/news/61/file/61.pdf>

135.Henderson, Keith, Charles Jakosa and Charles Gibson, 'Evaluation of the Rule of Law Programs in Liberia' (Private Report, USAID, April 2009) 88 
136. Heuvel, Adriana Vanden et al, 'The Health and Welfare of Australia's Aboriginal and Torres Strait Islander Peoples' (Government Report, Australian Institute of Health and Welfare, 2015) $200<$ http://www.aihw.gov.au/WorkArea/DownloadAsset.aspx?id=60129551281>

137. House of Representatives Standing Committee on Social Policy and Legal Affairs, 'Advisory Report: Marriage Equality Amendment Bill 2012 and Marriage Amendment Bill 2012' (Text, The Parliament of the Commonwealth of Australia, June 2012) 67

<https://www.aph.gov.au/Parliamentary_Business/Committees/House_of_Representatives_Com mittees?url=spla/bill\%20marriage/report/final.pdf $>$

138. Human Rights and Equal Opportunity Commission, 'Inquiry into Stolen Wages' (Human Rights and Equal Opportunity Commission, 2006) 10 <https://www.humanrights.gov.au/inquiry-stolenwages>

139.Human Rights and Equal Opportunity Commission, 'Aboriginal \& Torres Strait Islander Social Justice Commissioner Report' (Government Report, Australian Human Rights Commission, 11 February 2008) 435 <http://www.humanrights.gov.au/publications/social-justice-report-2007>

140.Human Rights Watch, ‘Liberia: Country Summary’ (NGO Report, Human Rights Watch, 2014) 5 <http://www.hrw.org/sites/default/files/related_material/liberia_3.pdf>

141.Human Rights Watch, 'World Report 2014: Events of 2013' (NGO, Human Rights Watch, 2014) 682

142.Hunt, Janet, 'Engaging with Indigenous Australia - Exploring the Conditions for Effective Relationships with Aboriginal and Torres Strait Islander Communities' (Government Report Issue Paper \#5, Closing the Gap Clearinghouse, Australian Government, October 2013) 54

143. Indigenous Health Adelaide, 'Social Determinants and Indigenous Health: The International Experience and Its Policy Implications' (Symposium Report, Commission on Social Determinants of Health, Government of South Australia, Canadian National Collaborating Centre for Aboriginal Health, 30 March 2007) 41

<http://www.who.int/social_determinants/resources/indigenous_health_adelaide_report_07.pdf>

144.International Business Publications, 'Liberia: Export-Import, Trade and Business Directory' (Private Document, International Business Publications, 2011) 294

145.International Crisis Group, 'Liberia: Resurrecting the Justice System' (107, International Crisis Group, 6 April 2006) 1

<http://www.operationspaix.net/IMG/pdf/ICG_liberia_resurrecting_the_justice_system_200604-06_.pdf>

146.International Crisis Group, 'Liberia: How Sustainable Is the Recovery' (Private Document African Report No 177, International Crisis Group, 19 August 2011) 38 <http://www.crisisgroup.org/ /media/Files/africa/west-africa/liberia/177\%20Liberia\%20$\% 20$ How $\% 20$ Sustainable\%20is\%20the\%20Recovery.pdf $>$

147.International Crisis Group, 'Liberia: Time for Much-Delayed Reconciliation and Reform' (Policy Briefing African Briefing No 88, International Crisis Group, 12 June 2012) 20 <http://www.crisisgroup.org/ /media/Files/africa/west-africa/liberia/b088-liberia-time-formuch-delayed-reconciliation-and-reform.pdf>

148.International Women's Rights Action Watch and ESCR-Net, 'Participating in ICESCR and CEDAW Reporting Processes: Guidelines for Writing on Women's Economic, Social and Cultural Rights in Shadow/Alternative Reports' (NGO, International Women's Rights Action Watch Pacific Asia and Economic Social and Cultural Rights Net, 2010) 88

149. Irish Consortium on Gender Based Violence, 'Addressing School Related Gender Based Violence: Learning from Practice' (Government Report Learning Brief No. 10, Irish Consortium on Gender Based Violence, 2013) 8

150.Isser, Deborah H, 'Looking for Justice: Liberian experiences with and perceptions of local justice options' (USIP Report 63, United States Institute of Peace, 2009) 104 $<$ http://www.usip.org/publications/looking-justice-liberian-experiences-and-perceptions-localjustice-options>

151.Jennings, Kathleen M, 'Protecting Whom? Approaches to Sexual Exploitation and Abuse in UN Peacekeeping Operations' (UN Report Fafo 36, Allkopi As, 2008) 80 <http://www.fafo.no/pub/rapp/20078/20078.pdf>

152.Johnston, Elliott, 'Royal Commission into Aboriginal Deaths in Custody (v1-5)' (Government Report, Royal Commission into Aboriginal Deaths in Custody, 1991) 600

153.Kilpatrick, Dean G et al, 'Drug-Facilitated, Incapacitated, and Forcible Rape: A National Study' (Government Report 219181, National Crime Victims Research \& Treatment Center, 1 February 2007) 72

154.Kinnane, Stephen et al, 'Fitzroy Valley Alcohol Restriction Report: An Evaluation of the Effects of Alcohol Restrictions in Fitzroy Crossing Relating to Measurable Health and Social Outcomes, Community Perceptions and Alcohol Related Behaviours after a 12 Month Period.' (Research 
Report, The University of Notre Dame Australia and The Drug and Alcohol Office, Western Australia, July 2009) 143

155. Koorie Women Mean Business, Indigenous Law Centre UNSW and YWCA Australia,

'Australian Aboriginal and Torres Strait Islander Women's Parallel NGO Report:

Implementation of the Convention on the Elimination of All Forms of Discrimination Against

Women' (NGO, Koorie Women Mean Business, Indigenous Law Centre UNSW, YWCA

Australia, 2009) 71

<http://www2.ohchr.org/english/bodies/cedaw/docs/ngos/Australian_ATSI_Women.pdf>

156.Land Commission, 'Land Rights Policy' (Government Policy, Land Reform Commission, 21

May 2013) 26

<http://www.sdiliberia.org/sites/default/files/publications/Liberia's\%20Land\%20Rights\%20Poli cy\%202013_0.pdf>

157.Law Council of Australia, 'Policy Statement: Rule of Law Principles' (Independent Report ABN 85005260 622, Law Council of Australia, March 2011) 6

158.Law Reform commission of Liberia, 'Law Reform Commission Annual Report 2011' (Law Reform Commission of Liberia, 2011) 17

<http://liblrc.org/uploads/3/4/5/5/34556057/lrc_annual_report_2011.pdf>

159.Law Reform commission of Liberia, 'Law Reform Commission of Liberia Annual Report 2012' (Law Reform Commission of Liberia, 2012) 4

<http://liblrc.org/uploads/3/4/5/5/34556057/lrc_annual_report_2012.pdf>

160.Law Reform Commission of Western Australia, 'Aboriginal Customary Laws: The Interaction of Western Australian Law with Aboriginal Law and Culture' (Private Report Project 94, Law Reform Commission of Western Australia, September 2006) 432

<http://www.lrc.justice.wa.gov.au/_files/p94_fr.pdf>

161.Lawyers Committee for Human Rights, 'First Steps: Building the Justice System in Liberia' (Public Report, Lawyers Committee for Human Rights, December 1991)

162.Liberia Institute of Statistics and Geo-Information Services et al, 'Liberia Demographic Health Survey 2007' (Liberia Institute of Statistics and Geo-Information Services, June 2008) 410 <http://www.measuredhs.com/pubs/pdf/FR201/FR201.pdf>

163.Liberia Institute of Statistics and Geo-Information Services, 'National Population and Housing Census' (Government Report, Liberia Institute of Statistics and Geo-Information Services, 2009) 352

164.Liberia Institute of Statistics and Geo-Information Services et al, 'Liberia Demographic and Health Survey 2013' (Government Report, LISGIS, 2014) 480

165.Linacre, Susan, 'Women's Experience of Partner Violence' (Government Report ABS Catalogue no. 4102.0, Australian Bureau of Statistics, 2007) 10

<http://www.ausstats.abs.gov.au/ausstats/subscriber.nsf/0/61292430E027131DCA25732F001C A53A/\$File/41020_Women's\%20experience\%20of\%20partner\%20violence_2007.pdf>

166.Ling, Ted, 'Government Records About the Australian Capital Territory' (Government Report 22, National Archives of Australia, 2011) $280<$ http://guides.naa.gov.au/records-about-northernterritory/index.aspx>

167.Ling, Ted, 'Government Records About the Australian Capital Territory' (Government Report 25, National Archives of Australia, 2013) $280<$ http://guides.naa.gov.au/records-aboutact/index.aspx>

168.Logan, Greg and Eddie Clarke, 'State Education in Queensland: A Brief History' (Government Report No. 2, Policy and Information Services Branch, Queensland Department of Education, 1984) 28 <http://education.qld.gov.au/library/docs/edhistory/stateedu.pdf>

169.Lyneham, Matthew and Andy Chan, 'Deaths in Custody in Australia to 30 June 2011'

(Monitoring Reports 20, Australian Institute of Criminology, 2013) 222

<http://www.aic.gov.au/publications/current\%20series/mr/1-20/20.html>

170.Madden, Shane, 'The Circle Court in the ACT - An Overview and Its Future' (Government, ACT Magistrate Court, 1 September 2007) 28 <http://www.aija.org.au/Ind\%20Courts\%20Conf\%2007/Papers/Madden.pdf>

171. Massalee, Abel Z, 'The Population of Liberia' (Government Report, Ministry of Planning and Economic Affairs, 1974) 58

172.McCall, M, 'Deaths in Custody in Australia: 2003 National Deaths in Custody Program Annual Report' (Government Report 12, Australian Institute of Criminology, 2003)

173.McConvell, Patrick, Doug Marmion and Sally McNicol, 'National Indigenous Languages Survey Report 2005' (Government Report, Australian Institute of Aboriginal and Torres Strait Islander Studies, 2005) $255<$ http://aiatsis.gov.au/publications/products/national-indigenouslanguages-survey-report-2005> 
174.McPherson, Malcolm and Kpedee Woiwor, 'National Human Development Report 2010: Liberia’ (UNDP, United Nations Development Program, 2010) 67

<http://hdr.undp.org/sites/default/files/liberia_2010.pdf>

175.Médecins Sans Frontières, 'Shattered Lives: Immediate Medical Care Vital for Sexual Violence Victim' (NGO, Médecins Sans Frontières, March 2009) 36

176. Memmott, Paul et al, 'Violence in Indigenous Communities: Report to Crime Prevention Branch of the Attorney-General's Department' (Government Report, Crime Prevention Branch, Attorney General's Department, Commonwealth of Australia, January 2001) 129

177. Meyers-Brittain, Jillian, 'Drug and/or Alcohol Facilitated Sexual Assault - A Growing Concern' (Government Report, Regional Violence Prevention Specialists of the Attorney General's Department, April 2001) 16

178. Mikkelsen, Caecillie et al, 'The Indigenous World 2014' (International Report, The International Work Group for Indigenous Affairs, May 2014) 597 <http://www.iwgia.org/iwgia_files_publications_files/0671_I2014eb.pdf>

179. Ministry of Council of Education and Early Childhood Development and Youth Affairs, 'Aboriginal and Torres Strait Islander Education Action Plan 2010-2014' (Government Report, Ministry of Council for Education, 2012) 49

<http://scseec.edu.au/site/DefaultSite/filesystem/documents/ATSI\%20documents/2012\%20ATS I\%20Report/ATSIEAP\%202012\%20Report.pdf>

180.Ministry of Health and Social Welfare, 'Socio-Economic Determinants of Health (SDH) in Liberia' (Government Report, Ministry of Health and Social Welfare, 2012) 34

181. Minority Rights Group International and Beth Walker, 'State of the World's Minorities and Indigenous Peoples 2013' (Minority Rights Group International, 2013) 248

182. Moore Stephens, 'Liberia Extractive Industries Transparency Initiative (LEITI): Post Award Process Audit' (Government Report, Liberia Extractive Industries Transparency Initiative, May 2013) 148

<http://www.leiti.org.lr/uploads/2/1/5/6/21569928/leiti_post_award_process_audit_final_report. pdf $>$

183. Morgan, Anthony and Amanda McAtamney, 'Key Issues in Alcohol-Related Violence' (Government Report 4, Australian Institute of Criminology, 2009) 8

184. Mouzos, Jenny and Toni Makkai, 'Women's Experience of Male Violence: Findings from the Australian Component of The International Violence Against Women Survey (IVAWS)' (Government Report 56, Australian Institute of Criminology, 2004) 162

185.Mouzos, Jenny and Lance Smith, 'Partner Violence Among a Sample of Police Detainees' (Government Report 0015, Australian Institute of Criminology, 2007) 6

186. Northern Territory Department of Education, 'Learning Lessons: An Independent Review of Indigenous Education in the Northern Territory' (Government Report, Northern Territory Department of Education, 1999) 218

187. Northern Territory Law Reform Committee, 'Report of the Laws Relating to the Investigation and Prosecution of Sexual Assault in the Northern Territory' (Government Report, Northern Territory Law Reform Commission, 17 December 1999) 53

<http://www.nt.gov.au/justice/policycoord/documents/lawmake/Sexual\%20AssaultInvestigation. pdf $>$

188. Northern Territory Law Reform Committee, 'Report on Aboriginal Customary Law' (Northern Territory Law Reform Committee, 2003) 50

<http://www.nt.gov.au/justice/policycoord/documents/lawmake/ntlrc_final_report.pdf>

189. O’Dea, Daniel John, 'Faith Barnes' (Royal Commission into Aboriginal Deaths in Custody, 5 November 1990) 25

<http://www.austlii.edu.au/au/other/IndigLRes/rciadic/individual/brm_fb/2.html>

190. Office of the United Nations High Commissioner for Human Rights, 'Human Rights Indicators: A Guide to Measurement and Implementation' (Office of the United Nations High Commissioner for Human Rights, 2012) 188 <http://www.ohchr.org/Documents/Publications/Human_rights_indicators_en.pdf>

191.Ogloff, James RP et al, 'Child Sexual Abuse and Subsequent Offending and Victimisation: A 45 Year Follow-up Study' (Government Report 440, Australian Institute of Criminology, 2012) 6

192.O'Leary, Cath, Judy Putt and Robin Holder, 'NPYWC Women's Council - Domestic and Family Violence Service: A History and Overview' (Australian National Research Organisation for Women's Safety Ltd (ANROWS), September 2016) 21 <http://media.aomx.com/anrows.org.au/NPYDFVS\%20overview\%20FINAL\%202016.pdf>

193. O’Leary, Cath, Judy Putt and Robin Holder, ‘Alice Springs Women's Shelter: A History and Overview’ (Text, Australian National Research Organisation for Women's Safety Ltd (ANROWS), October 2016) 24

<http://media.aomx.com/anrows.org.au/ASWS\%20overview\%20FINAL\%202016.pdf> 
194. Omanyondo, Marie-Claire O, 'WHO Report on Sexual Gender-Based Violence and Health Facility Needs Assessment' (UN Consultant Report, World Health Organization, 9 September 2005) 63 <http://www.who.int/hac/crises/lbr/Liberia_RESULTS_AND_DISCUSSION13.pdf>

195.O’Neill, John Patrick, 'Census of Population and Housing: Part 3 - Overseas-Born Population' (Population: Related Characteristics Volume 2, Commonwealth Bureau of Census and Statistics, Commonwealth of Australia, 30 June 1966) 90

<http://www.ausstats.abs.gov.au/ausstats/free.nsf/0/EDE3C1DB8B4FD932CA257880008214E1 /\$File/1966\%20Census\%20-\%20Volume\%202\%20Population\%20-

\%20Related\%20Characteristics\%20-\%20Part\%203\%20Overseas-Born.pdf>

196. Open Society Foundation, 'Justice Programs for Public Health: A Good Practice Guide' (Private Report, Open Society Foundation, 2015) 138

197.Palmer, Jonathan, 'Information Paper: Aboriginal and Torres Strait Islander Peoples Perspectives on Homelessness' (Government Report 4736.0, Australian Bureau of Statistics, 2014) 1

198.Pease, Bob and Ann Carrington, 'Men as Allies in Preventing Violence against Women: Principles and Practices for Promoting Accountability' (White Ribbon Australia, March 2017) $32<$ https://www.whiteribbon.org.au/wpcontent/uploads/2017/03/WhiteRibbonResearchPaper_LR.pdf >

199.Pinheiro, Paolo Sergio, 'World Report on Violence Against Children' (UN, United Nations Children's Fund, 2006) 327 <http://www.unicef.org/lac/full_tex(3).pdf>

200.Population Council, 'The Adolescent Experience In-Depth: Using Data to Identify and Reach the Most Vulnerable' (NGO, United Nations Populations Fund, 2007) 52

201.Population Health Research Centre, 'Health Status of Women in the ACT' (46, ACT Government, 2008) 66

202.ProRights Consulting, 'Proceedings Report: African Preparatory Meeting for the World Conference on Indigenous Peoples' (Conference Proceeding, World Conference on Indigenous Peoples, December 2012) 35

203.Pugel, James, 'What the Fighters Say: A Survey of Excombatants in Liberia' (UNDP, United Nations Development Program, April 2007) 74

204.Putt, Judy, Robin Holder and Cath O'Leary, 'Domestic Violence Crisis Service (ACT): A History and Overview' (Australian National Research Organisation for Women's Safety Ltd (ANROWS), October 2016) 41

<http://media.aomx.com/anrows.org.au/DVCS\%20\%20overview\%20FINAL\%202016.pdf>

205.Queensland Government, 'For Our Sons and Daughters Queensland Government Strategy to Reduce Domestic and Family Violence 2009-2014' (Government Report, Ministry of Community Services and Housing; Ministry for Women; Ministry for Police, and Minister for Child Safety, 2009) 13

206.Queensland Taskforce on Women and the Criminal Code, 'Report on the Taskforce on Women and the Criminal Code' (Government Report, Office of Women's Policy, 2000) 366

207.Reading, Loppie Charlotte and Fred Wien, 'Health Inequalities and Social Determinants of Aboriginal Peoples' Health' (National Collaborating Centre for Aboriginal health, 2009) 47 <http://www.nccah-ccnsa.ca/docs/social\%20determinates/nccah-loppie-wien_report.pdf>

208. Robertson, Boni, 'The Aboriginal and Torres Strait Islander Women's Task Force on Violence Report' (Queensland Department of Aboriginal and Torres Strait Islander Policy and Development, 2000) 328

209. Rosenau, William et al, 'Corporations and Counterinsurgency' (Private Report, RAND National Defense Research Institute, 2009) 57

<http://www.rand.org/content/dam/rand/pubs/occasional_papers/2009/RAND_OP259.pdf>

210. Royal Commission into Institutional Responses to Child Sexual Abuse, 'Analysis of Claims of Child Sexual Abuse Made With Respect to Catholic Church Institutions in Australia' (Royal Commission into Institutional Responses to Child Sexual Abuse, 2017) 282

<https://childabuseroyalcommission.gov.au/getattachment/f0b33690-aea6-4f56-9e1288e72157273f/Analysis-of-claims-of-child-sexual-abuse-made-with>

211. Royal Commission into Institutional Responses to Child Sexual Abuse, 'Final Report Recommendations' (Government, Commonwealth of Australia, November 2017) 115 <https://www.childabuseroyalcommission.gov.au/recommendations>

212. Rumbold, Victoria, 'Sexual and Gender-Based Violence in Africa: Literature Review' (NGO, Population Council, 2008) 61

213.Sarkar, Madhumita and Timothy Paulus, 'County Consultation on Draft Domestic Violence Law - Issue Paper' (Public Report, Ministry of Gender and Development, UNFPA, Embassy of Sweden, October 2013) 53 <http://www.undp.org/content/dam/liberia/docs/docs/Domestic\%20Violence\%20Issue\%20Paper .pdf. $>$ 
214.Save the Children UK, 'Unspeakable Crimes Against Children: Sexual Violence in Conflict' (Save the Children Fund, April 2013) $50<$ http://www.savethechildren.org.uk/resources/onlinelibrary/unspeakable-crimes-against-children $>$

215.Schia, Niels Nagelhus and Benjamin de Carvalho, "'Nobody Gets Justice Here!": Addressing Sexual and Gender-Based Violence and the Rule of Law in Liberia' (NUPI Working Paper 761, The Norwegian Institute of International Affairs, 2009) 28 <https://brage.bibsys.no/xmlui/bitstream/handle/11250/276643/SIP-5-09-Schia-de+Cavalhopdf.pdf? sequence=3>

216. Scott, Gloria Musu et al, 'Report of the Constitution Review Committee Covering the Period 30 August 2012 - 1 March 2015' (Government Report, Constitution Review Committee, 2015) 184

217. Seelinger, Kim Thuy, Helen Silverberg and Robin Mejia, 'The Investigation and Prosecution of Sexual Violence' (University Report, University of Berkeley Human Rights Center, May 2011) 71

218. Segal, Murray D, 'Independent Review of the Police and Prosecution Response to the Rehtaeh Parsons Case' (Ministry of Justice and Attorney General Office, 8 October 2015) 157 <https://novascotia.ca/segalreport/Parsons-Independent-Review.pdf>

219. Sharples, Natalie, Tim Jones and Catherine Martin, 'Honest Accounts? The True Story of Africa's Billion Dollar Losses' (Policy Report, Health Poverty Action and Curtis Research, July 2014) 40

220.Simmons, Pam, 'Just One Violent Incident: Gendered Violence and Its Impact on Children' (Office of the Guardian for Children and Young People, 2011)

221.Simpson, Paul et al, 'Views on Alternatives to Imprisonment: A Citizens Jury Approach' (Private Document, Lowitja Institute, 2014) $48<$ https://www.lowitja.org.au/lowitjapublishing/L031>

222. Skelton, Fiona et al, 'Footprints in Time: The Longitudinal Study of Indigenous Children Up and Running' (Government 95, Australian Institute of Family Studies, 2014) 11 <https://aifs.gov.au/sites/default/files/fm95d.pdf>

223. Smith, Russel G et al, 'Counting the Cost of Crime in Australia: A 2011 Estimate' (Government Report 129, Australian Institute of Criminology, 2014) 103

224. Soutphommasane, Tim, Ting Lim and Anna Nelson, 'Freedom from Discrimination: Report on the 40th Anniversary of the Racial Discrimination Act - National Consultation Report' (Government, Australian Human Rights Commission, 5 November 2015) 104 <https://www.humanrights.gov.au/sites/default/files/document/publication/RDA40_report_2015 _AHRC.pdf>

225. Staff Reporter, 'Pinjarra Battle/Massacre 1834' (Public-Private, Mudurah Community Museum, 2015) 4 <http://www.mandurahcommunitymuseum.org/downloads/Pinjarra\%20Massacre.pdf>

226. Standing Committee on Legal and Constitutional Affairs, 'Unfinished Business: Indigenous Stolen Wages' (Government, The Senate, December 2006) <https:

//www.aph.gov.au/ /media/wopapub/senate/committee/legcon_ctte/completed_inquiries/2004_0 7/stolen_wages/report/report_pdf.ashx.>

227. Standing Council on School Education and Early Childhood, and Education Services Australia, 'Aboriginal and Torres Strait Islander Education Action Plan 2010-2014: 2012 Annual Report' (Education, Standing Council on School Education and Early Childhood, 2013) 378 <http://www.scseec.edu.au/site/DefaultSite/filesystem/documents/ATSI\%20documents/2012\%2 0ATSI\%20Report/ATSIEAP\%202012\%20Report.pdf>

228. State of Tasmania, 'Stolen Generations of Aboriginal Children Act 2006: Report of the Stolen Generations Assessor' (Government Report, Office of the Stolen Generations Assessor, Department of Premier and Cabinet, February 2008) 30

229. State of Victoria, 'Measuring the Toll: The Family Violence Index' (Government Policy, Ministry for the Prevention of Family Violence, 2015) $8<$ https://www.viclabor.com.au/wpcontent/uploads/2015/05/Family-Violence-Index.pdf>

230. State of Victoria, 'Royal Commission into Family Violence: Summary and Recommendations' (Parl Papers No 132, Victorian Government, March 2016)

<http://files.rcfv.com.au/Reports/Final/RCFV-All-Volumes.pdf>

231. Steering Committee for the Review of Government Service Provision, 'Overcoming Indigenous Disadvantage: Key Indicators 2011' (Productivity Commission, 2011) 830

232. Steering Committee for the Review of Government Service Provision, 'Overcoming Indigenous Disadvantage: Key Indicators 2014' (Government Report, Productivity Commission, 2014) 3252 <http://www.pc.gov.au/_data/assets/pdf_file/0007/179260/key-indicators-2014-report.pdf>

233. Stolen Wages Taskforce, 'Reconciling the Past: Government Control of Aboriginal Monies in Western Australia, 1905-1972' (Department of Indigenous Affairs, Western Australia, 2008) 108 
<http://www.daa.wa.gov.au/Documents/Stolen\%20Wages/Report_of_the_Stolen_Wages_Taskf orce_2008.pdf>

234. Taylor, Annabel et al, 'Domestic and Family Violence Protection Orders in Australia: An Investigation of Information Sharing and Enforcement: State of Knowledge Paper' (Government Report Issue 16, Australian National Research Organisation for Women's Safety Ltd (ANROWS), 17 December 2015) 68 <http://media.aomx.com/anrows.org.au/s3fspublic/16_4.1\%20Legal\%20WEB_FINAL_0.pdf>

235. Taylor, Natalie and Jenny Mouzos, 'Community Attitudes to Violence Against Women Survey 2006: A Full Technical Report' (Government Report, Australian Institute of Criminology, 2006) 164

236. Taylor, Natalie and Judy Putt, 'Adult Sexual Violence in Indigenous and Culturally and Linguistically Diverse Communities in Australia' (Government Report 345, Australian Institute of Criminology, 2007) 6 <http://www.aic.gov.au/documents/1/D/F/\%7B1DF7DB51-E301-4666BEB2-78763EE00B71\%7Dtandi345.pdf>

237. The Acquire Project, 'Traumatic Gynecologic Fistula: A Consequences of Sexual Violence in Conflict Settings' (Private Document, Addis Ababa Fistula Hospital, Engendered Health, Ethiopian Society of Obstetricians and Gynecologists, Synergie des Fammes pour les Victimes des Violence Sexuelles, May 2006) 58

238. The Human Rights and Equal Opportunity Commission, 'Submission of the Human Rights and Equal Opportunity Commission to The Senate Legal and Constitutional References Committee: Inquiry into Stolen Wages S' (Government, Human Rights and Equal Opportunity Commission, 1 August 2006) $10<$ https://www.humanrights.gov.au/inquiry-stolen-wages>

239. The Liberia Rights and Development Advocacy Network, 'A Situation Review of the Government of Liberia's Response to the Ebola Outbreak' (NGO, The Liberia Rights and Development Advocacy Network, 11 September 2014) 26

240.The National Council to Reduce Violence against Women and their Children, 'The Cost of Violence against Women and Their Children' (Government Report, Department of Families, Housing, Community Services and Indigenous Affairs, March 2009) 84

<https://www.dss.gov.au/sites/default/files/documents/05_2012/vawc_economic_report.pdf>

241.The National Council to Reduce Violence against Women and their Children, 'Domestic Violence Laws in Australia' (Government Report FaHCSIA10236.0906, Department of Families, Housing, Community Services and Indigenous Affairs, June 2009) 258

$<$ https://www.dss.gov.au/sites/default/files/documents/05_2012/domestic_violence_laws_in_aus tralia_-_june_2009.pdf>

242. The Referendum Council, 'Final Report of the Referendum Council' (Indigenous Employment and Recognition, Department of the Prime Minister and Cabinet, 30 June 2017) 183 $<$ https://www.referendumcouncil.org.au/final-report>

243.The Senate - Community Affairs Reference Committee, 'Commonwealth Contribution to Former Forced Adoption Policies and Practices’ (Government Report, February 2012) 337

244. 'The Shame of War: Sexual Violence Against Women and Girls in Conflict' (UN Report, Office for the Coordination of Humanitarian Affairs \& Integrated Regional Information Network, 2007) 139 <http://lastradainternational.org/lsidocs/IRIN-TheShameofWar-fullreport-Mar07.pdf>

245. The Taskforce, 'Not Now, Not Ever: Putting an End to Domestic and Family Violence in Queensland' (Government Report, The Special Taskforce on Domestic and Family Violence in Queensland, 28 February 2015) 374 <https://www.qld.gov.au/community/getting-supporthealth-social-issue/dfv-read-report-recommendation/index.html>

246. Thomson, Neil et al, 'Overview of the Health of Indigenous People in Western Australia 2013' (Academic, Australian Indigenous HealthInfoNet, September 20131) 76 <http://www.healthinfonet.ecu.edu.au/uploads/docs/wa-overview-2013.pdf>

247. Tomczyk, Basia et al, 'Women's Reproductive Health in Liberia: The Lofa County Reproductive Health Survey January-February 2007' (NGO, Centre for Disease Control and Prevention, 2007) 133

248. Trewin, Dennis, 'Selected Social and Housing Characteristics' (Government Report, Australian Bureau of Statistics, 2001) 136 <http://www.abs.gov.au/AUSSTATS/abs@.nsf/0/1EA78AFE3DE2EDCACA256BDA0073EB5 3? OpenDocument>

249. Truth and Reconciliation Commission of Canada, 'Honouring the Truth, Reconciling for the Future: Summary of the Final Report of the Truth and Reconciliation Commission of Canada' (Government Report, Truth and Reconciliation Commission of Canada, 2015) 388 <http://www.trc.ca/websites/trcinstitution/File/2015/Findings/Exec_Summary_2015_05_31_we b_o.pdf> 
250.Truth and Reconciliation Commission of Liberia, 'TRC Final Reconciliation Initiatives County Consultations and National Reconciliation Conference' (Government Report, Truth and Reconciliation Commission, July 2009) 10

251.Truth and Reconciliation Commission of Liberia, 'Truth and Reconciliation Report' (Government Report Volume 1-2, Government of Liberia, 19 December 2009) 107

252.Truth and Reconciliation Liberia, 'Towards National Reconciliation and Dialogues: The Palava Hut or Peace Forums' (Government Policy 3, The Truth and Reconciliation Commission, 2009) 148

253.Tsey, Komla et al, 'Improving Indigenous Community Governance Through Strengthening Indigenous and Government Organisational Capacity' (Government Report 10, Closing the Gap Clearinghouse, Australian Government, January 2012) 15

254.UN Children's Fund, 'Female Genital Mutilation/Cutting: A Statistical Overview and Exploration of the Dynamics of Change' (UN Report, United Nations Children's Fund, 2009) 194

255.UN Children's Fund et al, 'Breaking the Silence on Violence against Indigenous Girls, Adolescents and Young Women: A Call to Action Based on an Overview of Existing Evidence from Africa, Asia Pacific and Latin America' (UN Report, United Nations Children's Fund, May 2013) 75

256.UN Children's Fund, 'Hidden in Plain Sight: A Statistical Analysis of Violence Against Children' (UN Document, United Nations Children's Fund, 2014) 206

257.UN Children's Fund, 'Ending Violence against Children: Six Strategies for Action' (UN Report, United Nations Children's Fund, September 2014) 68 <http://www.unicef.org/publications/index_74866.html>

258.UN Development Fund for Women, 'Who Answers to Women? Gender and Accountability' (UN Report, United Nations Development Fund for Women, 2008) 152 <http://reliefweb.int/report/world/who-answers-women-gender-and-accountability-progressworlds-women-20082009>

259.UN Development Program, 'National Human Development Report 2006: Liberia - Mobilizing Capacity for Reconstruction and Development' (UN Document, United Nations Development Program, July 2006) 76 <http://www.lr.undp.org/NHDR\%2706_web.pdf>

260.UN Girls' Education Initiative, 'Gender and EFA 2000-2015: Achievements and Challenges' (UN Report, United Nations Education, Scientific and Cultural Organisation, 2015) 57 <http://unesdoc.unesco.org/images/0023/002348/234809E.pdf>

261.UN In Liberia, 'United Nations Development Assistance Framework for Liberia 2008-2012' (UN, Office of the Special Representative of the Secretary-General, May 2007) 60

262.UN Mission in Liberia, 'Human Rights in Liberia's Rubber Plantations: Tapping into the Future' (UN Mission in Liberia, 2006) 88 <http://www.refworld.org/docid/473dade10.html>

263.UN Mission in Liberia and Government of Liberia, 'One Programme: United Nations Development Assistance Framework 2013-2017' (Public Report, Ministry of Planning and Economic Affairs, 13 February 2013) 99 <http://www.unicef.org/liberia/UNDAF_20132017.pdf>

264.UN Mission in Liberia Legal and Judicial System Support Division, 'Research on Prevalence and Attitudes to Rape in Liberia September to October 2008' (UN Consultant Report, UN Mission in Liberia, 2009) 87

265.UN Office of Internal Oversight Services, 'Evaluation of the Enforcement and Remedial Assistance Efforts for Sexual Exploitation and Abuse by the United Nations and Related Personnel in Peacekeeping Operations' (UN Report General Assembly A/RES/61/26 B, Inspection and Evaluation Division, Office of Internal Oversight Services, 12 July 2015) 52 $<$ https://oios.un.org/page/download2/id/13>

266.UN Office of the Special Adviser on Gender Issues and Advancement of Women and The Secretariat of the United Nations Permanent Forum on Indigenous Issues, 'Gender and Indigenous Peoples' (United Nations, February 2010) 36

267.UN Security Council, 'UN Secretary General Report: The Rule of Law and Transitional Justice in Conflict and Post-Conflict Societies' (UN Document S/2004/616, United Nations, 23 August 2004) 24

268.UN Women, 'In Pursuit of Justice: Progress of the World's Women' (UN Document, United Nations Women, 2012) $166<$ http://progress.unwomen.org>

269.UNDP, 'Human Development Report 2015: Liberia' (UN, United Nations Development Program, 2015) 7 <http://hdr.undp.org/sites/all/themes/hdr_theme/country-notes/LBR.pdf>

270.United Nations, 'The World's Women 2015: Trends and Statistics' (UN Report, Statistic Division, Department of Economic and Social Affairs, 2015) 260

271.United Nations Department of Peacekeeping Operations, 'Review of the Sexual Violence Elements of the Judgments of the International Criminal Tribunal for the Former Yugoslavia, the 
International Criminal Tribunal for Rwanda, and the Special Court for Sierra Leone in the Light of Security Council Resolution 1820' (Peacekeeping Best Practices Section, Department of Peacekeeping Operations, 2010) 104

<http://www.icty.org/x/file/Outreach/sv_files/DPKO_report_sexual_violence.pdf>

272.United Nations Development Programme, 'Global Programme on Strengthening the Rule of Law and the Human Rights for Sustaining Peace and Fostering Development: 2016 Annual Report' (UN Report, United Nations Development Programme, 2017) 148

273.University of British Columbia, 'Of Truth and Reconciliation - UBC Annual Report 2013-2014' (University Report, University of British Columbia, 2014) http://annualreport.ubc.ca/letter

274.US Agency for International Development, 'A Guide to Programming Gender-Based Violence Prevention and Response Activities' (Private Report, United States Agency for International Development, 2009) 17

275.US Department of Labour, 'Findings on the Worst Forms of Child Labor' (Government Report, United States Department of Labour, Bureau of International Labour Affairs, 2012) 896

276.US Department of Labour, 'Findings on the Worst Forms of Child Labour: Liberia' (Government Report, United States Department of Labour, Bureau of International Labour Affairs, 2014) 7 <http://www.dol.gov/ilab/reports/child-labor/findings/2014TDA/liberia.pdf>

277.US Department of State, 'Trafficking in Persons Report' (Government, Office of the Under Secretary for Civilian Security, US Department of State, July 2015) 382 <http://www.state.gov/documents/organization/245365.pdf>

278. VicHealth, 'Australian's Attitudes to Violence against Women: Summary' (Government Report P-MW-184, Victoria Health Promotion Foundation, September 2014) 8

279. Viswanathan, Meera et al, 'Community-Based Participatory Research: Assessing the Evidence.' (Volume 99, Agency for Healthcare Research and Quality, 2004) 296

280. Walters, Adrianne and Shannon Longhurst, 'Over-Represented and Overlooked: The Crisis of Aboriginal and Torres Strait Islander Women's Growing Over-Imprisonment' (NGO Report, Human Rights Law Centre, May 2017) 51

281. Western Australia Coroner, 'Inquest into the Death of Andrea Louise Pickett' (Coroner Inquest, Perth Coroners Court, 2012) 64 <http://www.aph.gov.au/DocumentStore.ashx?id=f5aa63db14c1-4ef4-9705-02e10e7fdb42\&subId=303034>

282. Western Australia Government, 'Department of Education Annual Report 2013-14' (Government, Department of Education, 2014) 157 $<$ http://www.education.wa.edu.au/home/detcms/public-education/content/aboutus/publications/annual-reports/2012-2014/department-of-education-annual-report-20132014.en?cat-id=14662810>

283. White, Seodi and Rosemarie James, 'An Analysis of Laws from a Gender Perspective in Liberia: Final Assessment Report' (Government Report, Office of the Gender Advisor (UNMIL) and Ministry of Gender Development, 1 August 2009) 55

284. Wilkins, Roger, 'Families, Incomes and Jobs' (Government Report 9, Melbourne Institute of Applied Economic and Social Research, 2014) 144

285. Wilkins, Roger, 'The Household, Income and Labour Dynamics in Australia Survey: Selected Findings from Waves 1 to 12' (Government, Melbourne Institute of Applied Economic and Social Research, 2015) 97

<https://www.melbourneinstitute.com/downloads/hilda/Stat_Report/statreport_2015.pdf>

286. Williams, Rhodri C, 'Beyond Squatters' Rights" Durable Solutions and Development-Induced Displacement in Monrovia, Liberia' (Private Report, Norwegian Refugee Council, 2011) 31

287. Willis, Matthew, 'Non-Disclosure of Violence in Australian Indigenous Communities' (Government Report 405, Australian Institute of Criminology, 2011) 11

288. Wily, Liz Alden, 'So Who Owns the Forest? An Investigation into Forest Ownership and Customary Land Rights in Liberia' (Private Report, The Sustainable Development Institute, 2007)

289. Women Solidarity, 'Baseline Study Report: On the Knowledge, Perceptions and Attitudes of the Practice of Female Genital Mutilation in Six Districts in Nimba, Bong and Margibi County/Liberia' (Private Report, Open Society Initiative of West Africa (OSIWA), 25 April 2013) 32

290.Women's Centre for Health Matters, Domestic Violence Crisis Service and Women With Disabilities ACT, 'Women With Disabilities Accessing Crises Services' (Government Report, Women Services Network, 2009) 51

291. World Bank Group, 'Voice and Agency: Empowering Women and Girls for Shared Prosperity' (UN Report, World Bank, 2014) 226

292. World Bank Group, 'Can Skills Training Increase Employment for Young Women? The Case of Liberia' (UN, Adolescent Girls Initiative - The World Bank, 1 January 2015) 17 
$<$ http://documents.worldbank.org/curated/en/2015/01/23805000/can-skills-training-increaseemployment-young-women-case-liberia>

293. World Medical Association, 'Violence Prevention: The Evidence' (Private Document, World Health Organization, 2010) 134

294.Wundersitz, Joy, 'Indigenous Perpetrators of Violence: Prevalence and Risk Factors for Offending' (Research and Public Policy Series 105, Australian Institute of Criminology, 2010) 129

295.Zaballa, Angela et al, 'A Conversation in Gender Equality' (Australian Human Rights Commission, March 2017) 40 <https://www.humanrights.gov.au/our-work/sexdiscrimination/publications/conversation-gender-equality-2017>

\section{TV Broadcast}

1. Peter Andrikidis \& Lisa Matthews, 'Rogue Nation' ABC TV Documentary (2008) <http://www.abc.net.au/tv/documentaries/interactive/roguenation/>.

2. Mark Lewis, 'Voyage of the Courtesans' Secrets of the Dead (2005) <http://www.pbs.org/wnet/secrets/voyage-of-the-courtesans/159/> at 28 April 2015.

3. Mark Lewis, 'The Floating Brothel' Timewatch Documentary (2006).

4. Saving David Waines, The Fifth Estate (2015) <http://www.cbc.ca/fifth/episodes/20142015/saving-david-waines>.

5. Ronan Sharkey \& Dora Weekley, 'First Contact' (2014).

\section{Thesis}

1. Anders, Wendy, Family Violence in Indigenous Communities: What Is the Impact of Domestic Violence on Indigenous Families? (Bachelor Honours of Arts (Honours) Thesis, Yooroang Garang School of Indigenous Health Studies, University of Sydney, 1999)

2. Aporosa, S Apo, Yaqona (Kava) and Education in Fiji: Investigating 'Cultural Complexities' from a Post-Development Perspective (PhD Thesis, Massey University, 2014)

3. Atkinson, Caroline Lisbeth, The Violence Continuum: Australian Aboriginal Male Violence and Generational Posttraumatic Stress (PhD Thesis, Charles Darwin University, 2008) <http://laalespace.cdu.edu.au/eserv/cdu:44891/Thesis_CDU_44891_Atkinson_C.pdf>

4. Bambrick, Hilary Jane, Child Grown and Type 2 Diabetes Mellitus in a Queensland Aboriginal Community (PhD Thesis, The Australian National University, 2003) <https://digitalcollections.anu.edu.au/bitstream/1885/46071/31/05chapter4.pdf>

5. Bielefeld, Shelley, The Dehumanising Violence of Racism: The Role of Law (PhD Thesis, Southern Cross University, 2010)

<http://epubs.scu.edu.au/cgi/viewcontent.cgi?article=1174\&context=theses>

6. Booth, Sarah, Teaching Aboriginal Curriculum Content in Australian High Schools (Master of Education (Research), Edith Cowan University, 2014)

<http://ro.ecu.edu.au/cgi/viewcontent.cgi?article=2523\&context=theses>

7. Brown, Mary Antoinette Grimes, Education and National Development in Liberia, 1800-1900 (PhD Thesis, Faculty of Graduate Studies, Cornell University, 1967)

8. Caine, Augustus Feweh, A Study and Comparison of the West African 'Bush' School and the Southern Sotho Circumcision School (Master of Arts, Northwestern University, 1959)

9. Crow, Rebekah, Colonialism's Paradox: White Women, 'Race' and Gender in the Contact Zone 1850-1910 (PhD Thesis, Arts, Media and Culture, Griffith University, 2003)

10. Dharamsi, Shafik, Discursive Constructions of Social Responsibility ( $\mathrm{PhD}$ Thesis, University of British Columbia, 2003) <https://circle.ubc.ca/handle/2429/15940>

11. Fisher, Stephen, Involving Men to End Violence Against Women: A Critical Approach (PhD Thesis, Deakin University, 2014)

12. Foley, Ashley M, Terra Nullius: The Aborigines in Australia (Bachelor Honours of Arts (Honours) Thesis, Salve Regina University, 2009)

<http://digitalcommons.salve.edu/cgi/viewcontent.cgi?article=1033\&context=pell_theses>

13. Fox, Early Lee, The American Colonisation Society 1817-1840 (PhD Thesis, John Hopkins University, 1917)

14. Gal, Tali, Victims to Partners: Child Victims and Restorative Justice (PhD Thesis, The Australian National University, 2006)

15. Gonway-Gono, Yar Donleh, Looking in and Coming Out: A Critical Inquiry in the Life Histories and Moral Dilemmas of Liberian Women in Atlanta (PhD Thesis, Emory University, 2001)

16. Hardy Agueh, Kade Anna, Liberia's Higher Education: An Agenda for Virtual and Distance Education in Urban and Rural Settings (Master of Arts, University of Victoria, 2015)

17. Heaton, Adam Paul, 'I Stopped To Think' Aboriginal Anti-Racism Pedagogy in Middle School (PhD Thesis, Charles Darwin University, 2013) 
18. Hoff, Joanna Tenneh Diggs, The Role of Women in National Development in Liberia, 1800-1900 (PhD Thesis, University of Illinois at Urbana-Champaign, 1989)

19. Hudec, Petr, Aboriginal Australians and the Impact of the White Man (Bachelor Honours of Arts (Honours) Thesis, Department of English Language and Literature, Faculty of Education, Masaryk University, 2011) <https://is.muni.cz/th/327483/pedf_b/Aboriginal_Australians_and_the_Impact_of_the_White_M an_Petr_Hudec.pdf>

20. Jones, Hannah Abeodu Bowen, The Struggle for Political and Cultural Unification in Liberia, 1847-1930 (PhD Thesis, Northwestern University, 1962)

21. Latifi, Mohammad, Multinational Companies and Host Partnership in Rural Development - A Network Perspective on the Lamco Case (PhD Thesis, Department of Business Studies, Uppsala University, 2004) 〈http://www.diva-portal.org/smash/get/diva2:165468/FULLTEXT01.pdf>

22. Leppard, Christine Jessie, 'The Unfortunates': Prostitutes Transported to Van Diemen's Land 1822-1843 (PhD Thesis, University of Tasmania, 2013)

23. Marchetti, Elena, Missing Subjects: Women and Gender in the Royal Commission into Aboriginal Deaths in Custody (PhD Thesis, Faculty of Arts, Griffith University, 2005)

24. Muir, Alycia, Why All the Secrecy? A History of the Aboriginal Activism of Redfern (Bachelor Honours of Arts (Honours) Thesis, The University of Newcastle, 2005)

25. Muller, Elizabeth M, Absorption and Assimilation: Australia's Aboriginal Policies in the 19th and 20th Centuries (Bachelor Honours of Arts (Honours) Thesis, Boston College, 2011) <https://dlib.bc.edu/islandora/object/bc-ir:102082/datastream/PDF/view>

26. Newman, Debra Lynn, The Emergence of Liberian Women in the Nineteenth Century (PhD Thesis, Howard University, 1985)

<http://books.google.com.au/books/about/The_Emergence_of_Liberian_Women_in_the_N.html ?id=pd22pwAACAAJ\&redir_esc $=\mathrm{y}>$

27. Patton, Shirley, Leaving the War Zone - Fifty (Three) Ways to Leave Your Lover: A Feminist Analysis of Fifty-Three Women's Pathways to Leaving a Male Partner Who Assaulted Them (PhD Thesis, School of Sociology and Social Work, University of Tasmania, 2005) <eprints.utas.edu.au/362/2/02Whole.pdf>

28. Penglase, Bethia M, Literacy in Colonial New South Wales 1788-1881 (PhD Thesis, University of New Castle, 1986)

29. Ramirez Espinosa, Naayeli Esperanza, Indigenous Struggles for Land Rights in Canada, Japan and Mexico: Delgamuukw, Nibutani Dam and Zirahuen (PhD Thesis, University of British Columbia, 2014) <https://circle.ubc.ca/.../ubc_2014_spring_ramirezespinosa_naayeli.pdf?...1>

30. Sigler, Phil S, The Attitudes of Free Blacks Towards Emigration to Liberia (PhD Thesis, Boston University, 1969)

31. Smallwood, Gracelyn, Human Rights and First Australians'Well-Being (PhD Thesis, James Cook University, 2011)

32. Smith, Diane Evelyn, Cultures of Governance and the Governance of Culture: Indigenous Australians and the State (PhD Thesis, The Australian National University, 2011)

33. Sullivan, Katherine Maree, Motivating and Maintaining Desistance from Crime: Male Aboriginal Serial Offenders' Experience of 'Going Good' (PhD Thesis, The Australian National University, 2012)

34. Tokpa, Henrique F, Education and Other Determinants of Income Among Heads of Households in Rural Liberia (PhD Thesis, Florida State University, 1988)

35. Wilson, Henrique Boye, Firestone and Liberia: A Case Study in One-Sidedness (Master of Arts, University of Massachusetts Lowell, 2007)

\section{Video Recording}

1. Africa's Maryland (WBAL-TV Baltimore, 2007)

2. AnTAR, It's Time for a New Approach - Trisha's Story (2014) <https://www.youtube.com/watch?v=ja7DUI437kU>

3. Australian Aboriginal Genocide (You Tube, 2008) <http://www.youtube.com/watch?v=Z7eubcYk3M\&feature=youtube_gdata_player $>$

4. Australian Broadcasting Corporation, The Apology to the Stolen Generations of Australia (ABC, 2008) <http://australia.gov.au/about-australia/australian-story/sorry-day-stolen-generations>

5. Australian Broadcasting Corporation, National Apology for Forced Adoptions (2013) <http://www.youtube.com/watch?v=5hVbokTpYeg>

6. Australian News, John Howard Restates Opposition to Indigenous Apology (You Tube, 2008) <https://www.youtube.com/watch?v=pn4I-NhhR1w>

7. Bradbury, David and Stewart Young, State of Shock (Frontline Films, 1989) 
8. Brown Skin Baby (They Took Me Away) (Globaloneness Project, 1970)

<https://www.globalonenessproject.org/library/interviews/song-brown-skin-baby-they-took-meaway $>$

9. Brown, Warren, Edmund Barton and the Velvet Soap Advertisement (Film Australia and Ryebuck Media, 2007) <http://dl.nfsa.gov.au/module/1100/>

10. Calvert, Frances, The Tombstone Opening (2012) <http://www.roninfilms.com.au/video/858/0/8080.html>

11. Chappell, Bill, Australian General's Frank Talk on Sexual Abuse Wins Fans (2013) <http://www.npr.org/blogs/thetwo-way/2013/06/14/191684468/australian-generals-frank-talkon-sexual-abuse-wins-fans $>$

12. Cilaire, Conan Le, Liberia Execution (1980) <https://www.youtube.com/watch?v=DnDGgvrD2bM>

13. Concerned Australians, Enough Is Enough - Statement on the Stronger Futures in the Northern Territory Bill 2011 and Two Related Bills (2011) <http://vimeo.com/33827160>

14. Coote, Gillian, Island of Lies (Australia Broadcasting Corporation, 1991) <http://www.roninfilms.com.au/feature/428/island-of-lies.html>

15. Council for Aboriginal Reconciliation, Walking Together, Talking Business, and Making Things Rights (National Recording Studios, 1993)

16. Curnoe, Darren, How Did We Get Here? - Are Races Real? (UNSWTV, 2015) <https://www.youtube.com/watch?v=8C4te2CTleo>

17. Gates Jr., Henry Louis, Slavery Secret: ‘Africans Sold Other Africans into Slavery’ (PBS, 2010) <https://www.youtube.com/watch?v=TtRaG_bokds>

18. Gillard, Julia, National Apology for Forced Adoptions (Attorney-General's Department, Government of Australia, 2013)

<http://www.ag.gov.au/About/ForcedAdoptionsApology/Pages/default.aspx >

19. Keating, Paul, Prime Minister Paul Keating's Speech at Redfern (AIATSIS, Government of Australia, 1992)

20. Kendell, Jeni and Tracie Walsh, Cry From the Heart (Gaia Films, 1999) <https://www.screenaustralia.gov.au/the-screen-guide/t/cry-from-the-heart-1999/13562/>

21. Kokkinos, Ana, Australia on Trial: Episode 1 - Mount Rennie Rape Trial (2012) <http://www.youtube.com/watch?v=NYhKIkJOG20>

22. Melville, Kirsti, Red Dirt Dreaming Part One - The Kimberley (Australia Broadcasting Corporation, 2013)

23. Mhando, Martin, Liyarn Ngarn (2007) <http://www.imdb.com/title/tt2199740/>

24. Norwegian Refugee Council, 'Another War' - A Documentary Film about Sexual Gender Based Violence (2010) <https://vimeo.com/17083011>

25. Perkins, Rachel, The First Australians: Episodes 1-7 (Blackfella Films, 2008)

26. Plan Liberia, Daughters of War (Plan Liberia, 2014) <http://www.trust.org/item/20140609105720-me5ov/?source=fiTheWire>

27. Saban, Sinem, Our Generation: Land, Culture, Freedom (Sinem Saban \& Damien Curtis, 2010)

28. Sinclair, Paul, Big Boss (2012) <http://www.roninfilms.com.au/feature/8078/big-boss.html>

29. 'Sorry? Nothing's Changed!' Uncle Bob Randall on the National Apology - Part 1 of 2 (The Juice Media, 2009) <http://www.youtube.com/watch?v=GK6n1UGPeBc\&feature=youtube_gdata_player>

30. Took The Children Away (Apra Amcos, 1990) <https://www.youtube.com/watch?v=aywDT6yHMmo>

31. Torres, Mitch, Jandamarra's War (Electric Pictures Pty Ltd., 2011)

32. Vadiveloo, David, Beyond Sorry: Beyond the Conflicts, Beyond the Politic (Ronin Films, 2003) <http://caama.com.au/beyond-sorry-2003>

33. Weatherburn, Donald James, Arresting Incarceration: Pathways out of Indigenous Imprisonment (2014)

34. Wolochatiuk, Tim, We Were Children (2012) <http://www.nfb.ca/film/we_were_children>

35. Young Women and Crime: Australasian Youth Justice Conference, Australian Institute of Criminology 2013 (Criminology TV, 2013) <https://www.youtube.com/watch?v=4pAZc611WiY>

\section{Webpage}

1. Aboriginal Affairs, Stolen Generation Reparations Scheme and Funeral Assistance Fund (2017) New South Wales <https://www.aboriginalaffairs.nsw.gov.au/healing-and-reparations/stolengenerations/reparations-scheme $>$

2. African Union, Structure of the Organisation: Women and Gender (2013) Women, Gender and Development Directorate <http://www.africaunion.org/structure_of_the_commission/women,\%20gender\%20and\%20development.htm> 
3. AHRC Admin, About Family and Domestic Violence (25 September 2015) Australian Human Rights Commission <https://www.humanrights.gov.au/our-work/family-and-domesticviolence/about-family-and-domestic-violence>

4. AIATSIS, To Remove and Protect (2013) Australian Institute of Aboriginal and Torres Islander Studies <http://www.aiatsis.gov.au/collections/exhibitions/remove/act/legislation.html>

5. AIATSIS, Mabo Case (2014) Explore History and Rights < http://aiatsis.gov.au/explore/historyrights/topic/mabo-case>

6. Alfred-Kamara, Michaela, Elizabeth Khawajkie and David Mason, Impact on Africa, Caribbean, Americas and Europe (2015) Breaking the Silence: Learning About the Transatlantic Slave Trade <http://old.antislavery.org/breakingthesilence/main/07/index.shtml>

7. Andrews, Daniel, World First Index To Measure Family Violence (17 May 2015) Premier of Victoria <http://www.premier.vic.gov.au/world-first-index-to-measure-family-violence/>

8. Anonymous, Liberia from 1930 to 1944: The Kru Campaign (2016) Liberia <http://personal.denison.edu/ waite/liberia/history/30-44.htm>

9. ANROWS, Funds Available from New Research Body to Improve Women's Safety (16 May 2014) ANROWS - Australia's National Research Organisation for Women's Safety $<$ http://www.anrows.org.au/resources/media/for-the-media/funds-available-new-research-bodyimprove-womens-safety>

10. Attorney-General's Department, Rule of Law (2017) Australian Government <https://www.ag.gov.au/About/Pages/Ruleoflaw.aspx>

11. Aukot, Ekuru, Augusta Pshorr and Sam Zota, Constitution Review Committee Presents Final Report to President Sirleaf (18 August 2015) UNDP in Liberia $<$ http://www.undp.org/content/liberia/en/home/presscenter/articles/2015/08/18/constitutionreview-committee-presents-final-report-to-president-sirleaf.html>

12. Australian Broadcasting Corporation, Women and Democracy (1998) Women and Votes <http://www.abc.net.au/ola/citizen/women/women-home-vote.htm>

13. Australian Bureau of Statistics, Population Composition: Indigenous Languages (1999) Australian Social Trends, 1999 <http://www.abs.gov.au/ausstats/abs@.nsf/2f762f95845417aeca25706c00834efa/aadb12e0bbec 2820ca2570ec001117a5!OpenDocument>

14. Australian Bureau of Statistics, Chapter - Division 02 - Acts Intended to Cause Injury (2 June 2011) 1234.0 - Australian and New Zealand Standard Offence Classification (ANZSOC) <http://www.abs.gov.au/ausstats/abs@.nsf/Latestproducts/604F197FD705B5ADCA2578A2001 40AEC?opendocument>

15. Australian Bureau of Statistics, Estimates of Aboriginal and Torres Strait Islander Australians, June 2011 (3238.0.55.001) (30 August 2013) Statistics by Catalogue Number <http://www.abs.gov.au/ausstats/abs@.nsf/mf/3238.0.55.001>

16. Australian Bureau of Statistics, Prisoners in Australia, 2014 (11 December 2014) Australian adult prisoner numbers climb to ten year high of 33,791 <http://www.abs.gov.au/ausstats/abs@.nsf/mf/4517.0>

17. Australian Bureau of Statistics, Aboriginal and Torres Strait Islander Prisoner Characteristics (8 December 2016) 4517.0 - Prisoners in Australia, 2016 <http://www.abs.gov.au/ausstats/abs@.nsf/Lookup/by\%20Subject/4517.0 2016 Main\%20Featu res Aboriginal\%20and\%20Torres\%20Strait\%20Islander\%20prisoner\%20characteristics 5>

18. Australian Bureau of Statistics, Census: Aboriginal and Torres Strait Islander Population (27 June 2017) Australian Bureau of Statistics: Media Release <http://www.abs.gov.au/ausstats/abs@.nsf/MediaRealesesByCatalogue/02D50FAA9987D6B7C A25814800087E03?OpenDocument>

19. Australian Crimes, Australian Crimes: The Aussie Criminal Record (2009) True Australian Crime Stories <http://australiancrimes.com/crimes/9rapistshung.html>

20. Australian Government, Australian Suffragettes (5 March 2010) Australian Suffragettes <http://australia.gov.au/about-australia/australian-story/austn-suffragettes>

21. Australian Government, Australian Government ComLaw (2013) ComLaw <http://www.comlaw.gov.au>

22. Australian Government, Law and Justice (2013) Law and Justice <http://australia.gov.au/topics/law-and-justice>

23. Australian Government, Drug and Alcohol Facilitated Sexual Assault Bibliography (4 March 2013) Australian Government: Australian Institute of Family Studies <http://www.aifs.gov.au/acssa/research/drugalcohol.php>

24. Australian Institute of Family Studies, Intergenerational Transmission of Abuse and Neglect (2015) Child Family Community Australia <https://aifs.gov.au/cfca/bibliography/intergenerational-transmission-abuse-and-neglect> 
25. Australian Institute of Health and Welfare, Services, Workforce and Spending (March 2015) Health workforce <http://www.aihw.gov.au/workforce/>

26. Australian Law Reform Commission, Aboriginal Customary Laws (30 July 2010) Australian Government: Australian Law Reform Commission <http://www.alrc.gov.au/inquiries/aboriginalcustomary-laws>

27. Australian's International Public Affairs, Australia Facts (2015) About Australia $<$ http://www.about-australia.com/facts/>

28. Australians Together, Mabo: The Beginning of Native Title (2015) Discover Stories <http://www.australianstogether.org.au/stories/detail/mabo-native-title>

29. Australians Together, Discover Stories: Era 3 - Assimilation (2017) Australians Together $<$ http://www.australianstogether.org.au/stories/detail/assimilation>

30. Baue, William, Alien Tort Claims Act Lawsuit Alleges Slavery and Child Labour on Liberian Plantation (30 December 2005) Social Funds Sustainable Investment News <http://www.socialfunds.com/news/article.cgi/1897.html>

31. Biidwewidam Indigenous Masculinities Project, Indigenous Masculinities, Identities and Achieving Bimaadiziwin (IMB) (8 February 2013) Biidwewidam $<$ http://www.indigenousmasculinities.com/>

32. Blyden, Ruth, Blyden, Edward Wilmont (1832-1912) (2015) Black Past <http://www.blackpast.org/gah/edward-wilmot-blyden-1832-1912>

33. Brooks, Julia, Ending the Culture of Impunity for Sexual and Gender-Based Violence in Conflict (16 December 2014) ATHA <http://www.atha.se/blog/ending-culture-impunity-sexual-andgender-based-violence-conflict $>$

34. Business, Northern Territory Department of, Northern Territory Government of Australia (4 August 2015) History of the Northern Territory

<http://www.australiasnorthernterritory.com.au/Living/Pages/history-nt.aspx>

35. Central Australian Aboriginal Congress, Social Determinants of Health (2013) Aboriginal Health <http://www.caac.org.au/aboriginal-health/social-determinants-of-health/>

36. Chayes, Abram et al, Critical Race Theory (2017) The Bridge - Legal Theory: Critical Theory <https://cyber.harvard.edu/bridge/index.htm>

37. City of Stirling, Stirling (2016) City of Stirling <http://www.stirling.wa.gov.au:80/Council/Suburbs/Pages/Stirling.aspx>

38. Commonwealth of Australia, Australian Immigration Fact Sheet 8. Abolition of the 'White Australia' Policy (15 April 2013) Fact Sheet 8 - Abolition of the 'White Australia' Policy <http://www.immi.gov.au/media/fact-sheets/08abolition.htm>

39. Commonwealth Parliament, Indigenous Affairs, Indigenous Affairs (2014) Parliament of Australia

<http://www.aph.gov.au/about_parliament/parliamentary_departments/parliamentary_library/pu bs/rp/budgetreview201415/indigenous?print=1>

40. Corbin, Kent, Petitioning President of the Republic of Liberia President Ellen Johnson Sirleaf to Liberate David Waines (2014) Change.Org <https://www.change.org/p/president-ellen-johnsonsirleaf-liberate-david-waines\#petition-letter $>$

41. Cornell University Law School, Critical Legal Theory (26 June 2014) Legal Information Institute <http://www.law.cornell.edu/wex/critical_legal_theory>

42. Creative Spirits, Compensation for Stolen Generation Members - Creative Spirits (2013) Aboriginal Culture: Politics and Media $<$ http://www.creativespirits.info/aboriginalculture/politics/compensation-for-stolen-generationmembers $>$

43. Danelius, Hans, Convention Against Torture and Other Cruel, Inhuman or Degrading Treatment or Punishment (2013) Audiovisual Library of International Law <http://legal.un.org/avl/ha/catcidtp/catcidtp.html>

44. Department of Aboriginal Affairs, Stolen Wages Reparation Scheme WA (2012) Stolen Wages <http://www.daa.wa.gov.au/en/Stolen-Wages/>

45. Department of Arts and Museum, Northern Territory Government, Aboriginal Houseboys in Darwin - Department of Arts and Museums (2012) Northern Territory Government: Department of Arts and Museums <http://artsandmuseums.nt.gov.au/ntas/stories/aboriginal-houseboys-indarwin\#.UWnXnL_UO5o>

46. Department of State Development, Stolen Generations Reparations Scheme (2017) Government of South Australia <https://statedevelopment.sa.gov.au/aboriginal-affairs/stolen-generationsreparations-scheme $>$

47. Department of the Prime Minister and Cabinet, Aboriginal Women (5 March 2010) Women in Colonial Times <http://www.australia.gov.au/about-australia/australian-story/women-incolonial-times $>$ 
48. Duva, Anjali Mitter, Liberia and the United States: A Complex Relationship (2002) Global Connections: Liberia <http://www.pbs.org/wgbh/globalconnections/liberia/essays/uspolicy/>

49. Eltis, David and Martin Halbert, Voyages: Summary Statistics (2013) The Trans-Atlantic Slave Trade Database <http://www.slavevoyages.org>

50. Faber-Castell, AW, Australian History Timeline (2010) Products: Australian History Timeline $<$ http://www.faber-castell.com.au/50589/Products/Playing-Learning/Products/AustralianHistory-Timeline/splrn_index1.aspx>

51. Faculty of Education and Arts, School of Humanities and Social Sciences, The Wellington Valley Project: Reverend Watson's Letter (7 March 2013) The University of New Castle Australia <http://www.newcastle.edu.au/school/hss/research/publications/the-wellington-valleyproject/watson/preamble.html $>$

52. Federal Court of Australia, Native Title Guide (2015) Law and Practice <http://www.fedcourt.gov.au/law-and-practice/areas-of-law/native-title>

53. Female Convicts Research Centre Inc, Female Convicts (2015) Female Convicts Research Centre <http://www.femaleconvicts.org.au>

54. Finance, Department of, Canberra - Australia's Capital City (4 February 2010) Australia's Stories <http://www.australia.gov.au/about-australia/australian-story/canberra-australias-capitalcity>

55. Finance, Department of, Australian Suffragettes (5 March 2010) Australian Stories <http://www.australia.gov.au/about-australia/australian-story/austn-suffragettes>

56. French, David, For Hillary Clinton, Feminism Means 'Blame Men First,' and to Disagree Is 'Misogyny' (2015) National Review <http://www.nationalreview.com/article/430509/hillaryclintons-feminism-gender-gap-works-against-her>

57. Government of Australia, Home (2006) Australian Aborigines League <http://www.aiatsis.gov.au/collections/exhibitions/dayofmourning/background.html>

58. Government of Australia, Australian Institute of Aboriginal and Torres Strait Islander Studies (9 April 2013) AIATSIS <http://aiatsis.gov.au/>

59. Government of Australia, Convicts and the British Colonies in Australia: A Penal Colony (2014) Australian Stories <http://www.australia.gov.au/about-australia/australian-story/convicts-andthe-british-colonies $>$

60. Government of Australia, Close the Gap (16 July 2014) Close The Gap Campaign, NACCHO <http://www.naccho.org.au/aboriginal-health/close-the-gap-campaign/>

61. Government of Australia, Convicts and the British Colonies in Australia (4 November 2014) Convicts and the British Colonies in Australia <http://www.australia.gov.au/aboutaustralia/australian-story/convicts-and-the-british-colonies $>$

62. Government of Liberia and UN, Combating Sexual and Gender Based Violence in Liberia (2009) <http://stoprapenow.org/uploads/features/SGBVemail.pdf>

63. Government of Queensland, History of Stolen Wages and Savings in Queensland - Aboriginal and Torres Strait Islander Affairs, Department of Aboriginal and Torres Strait Islander and Multicultural Affairs (29 April 2011) Aboriginal and Torres Strait Islander Affairs, Department of Aboriginal and Torres Strait Islander and Multicultural Affairs (Queensland Government) $<$ http://www.datsima.qld.gov.au/atsis/aboriginal-torres-strait-islander-peoples/claims-andentitlements/history-of-stolen-wages-and-savings-in-queensland>

64. Government of Queensland, Aboriginal and Torres Strait Islander Community Histories (2015) Government <http://www.qld.gov.au/atsi/cultural-awareness-heritage-arts/communityhistories/index.html $>$

65. Graves, Benjamin, Fanon on 'National Culture' (2010) Political Discourse - Theories of Colonialism and Postcolonialism <http://www.postcolonialweb.org/poldiscourse/fanon/fanon2.html>

66. Graves, Benjamin, Fanon on 'The Pitfalls of National Consciousness' (2010) Political Discourse - Theories of Colonialism and Postcolonialism <http://www.postcolonialweb.org/poldiscourse/fanon/fanon3.html>

67. Graves, Benjamin, Frantz Fanon: An Introduction (2010) Political Discourse - Theories of Colonialism and Postcolonialism <http://www.postcolonialweb.org/poldiscourse/fanon/fanon1.html>

68. Guthrie, Jill, Reducing Incarceration Using Justice Reinvestment: An Exploratory Case Study (2016) National Centre for Indigenous Studies <http://ncis.anu.edu.au/cowra/>

69. Haebich, Anna and RHW Reece, Neville, Auber Octavius (1875-1954) (1988) Australian Dictionary of Biography <http://adb.anu.edu.au/biography/neville-auber-octavius-7821>

70. Hardy, William, Riches \& Misery: The Consequences Of The Atlantic Slave Trade (25 February 2014) OpenLearn <http://www.open.edu/openlearn/history-the-arts/history/riches-misery-theconsequences-the-atlantic-slave-trade> 
71. Harper, Douglas, Online Etymology Dictionary (2014) Online Etymology <http://www.etymonline.com/index.php?term=ethnic>

72. Harvard University Law School, Legal Theory: Critical Theory (26 June 2014) The Bridge <http://cyber.law.harvard.edu/bridge/CriticalTheory/critical1.htm>

73. Hayes, Roger, Living by the 'Rule of Law' (8 September 2010) The British Constitution Group: Fighting to Reassert Our Constitution and the Rule of Law <http://www.thebcgroup.org.uk/article/living-rule-law>

74. Health Info Net, Galambany Circle Sentencing Court (24 March 2014) Australian Indigenous <http://www.healthinfonet.ecu.edu.au/key-resources/programs-projects?pid=1470>

75. Heiss, Anita, Government Policy in Relation to Aboriginal People (2013) Barani <http://www.sydneybarani.com.au/sites/government-policy-in-relation-to-aboriginal-people/>

76. Holsoe, Svend E and Megan MacDonald, Liberian Government Archives, 1828-1911 (2016) Indiana University Archives Online <http://webapp1.dlib.indiana.edu/findingaids/view?doc.view=entire_text\&docId=VAB6927>

77. ICTY, Gang Rape, Torture and Enslavement of Muslim Women Charged in ICTY's First Indictment Dealing Specifically with Sexual Offences. (27 June 1996) UN ICTY Press $<$ http://www.icty.org/sid/7334>

78. Indiana University, The Liberian Constitutions (2004) The Declaration of Independence <http://www.onliberia.org/con_declaration.htm>

79. International Labour Right Forum, Stop Firestone Coalition Celebrates Victory as Liberian Supreme Court Decision Approves Union Election on Firestone Plantation (21 December 2007) Press Release <http://www.laborrights.org/releases/stop-firestone-coalition-celebrates-victoryliberian-supreme-court-decision-approves-union>

80. Inter-Parliamentary Union, Women's Suffrage (2013) Women in Politics $<$ http://www.ipu.org/wmn-e/suffrage.htm>

81. Jawort, Adrian, Denise Juneau: First American Indian Congresswoman? (6 November 2015) Indian Country Today Media Network.com $<$ http://indiancountrytodaymedianetwork.com/2015/11/06/denise-juneau-first-american-indiancongresswoman-162341>

82. Jessica, Jessica, African Doctor: Is Female Circumcision so Awful? (30 November 2007) Jezebel $<$ http://jezebel.com/328601/african-doctor-is-female-circumcision-so-awful>

83. Justice Education Society, Aboriginal Restorative Justice Remedies (2016) Aboriginal Restorative Justice Remedies <http://www.justiceeducation.ca/research/aboriginalsentencing/restorative-justice >

84. Kanubah, Julius, Rape Suspect's Family Raises Concern (7 September 2010) Operation We Care for Liberia <https://owcl.wordpress.com/2010/09/07/rape-suspects-family-raises-concern/>

85. Karanja, Rufus, My Two Cents on Impact of Kenya's Elections on Diplomatic Relations (14 April 2013) Rufus Karanja Blog: On the journey to being a Diplomat $<$ http://rufuskaranja.wordpress.com/2013/04/14/my-two-cents-on-impact-of-kenyas-electionson-diplomatic-relations/>

86. Kieh, George, 11 Questions: George Kieh, Politician - The Liberian Listener (26 March 2013) 11 Questions <http://www.liberianlistener.com/2013/03/26/11-questions-george-kiehpolitician/>

87. Korff, Jens, Stolen Generations Timeline (31 July 2015) Creative Spirits <http://www.creativespirits.info/aboriginalculture/politics/stolen-generations-timeline>

88. Kraaij, Fred PM van der, Iron Ore: The Start of Operations of Liberia's First Iron Ore Mine (2015) Liberia: Past and Present <http://www.liberiapastandpresent.org/ODP/IronOre/IronOreC.htm>

89. Lewis, M Paul, Gary F Simons and Charles D Fennig, Languages of the World: Australia (2015) Ethnologue <http://www.ethnologue.com/country/AU/languages>

90. Library of Congress, American Colonization Society (Prints and Photographs Reading Room, Library of Congress) (22 October 2010) Records and photographs of the American Colonization Society <http://www.loc.gov/rr/print/coll/007.html>

91. Lillian Goldman Law Library, Yale Law School, The Code of Hammurabi (2008) The Avalon Project: Documents in Law, History and Diplomacy <http://avalon.law.yale.edu/subject_menus/hammenu.asp>

92. Magistrates' Court of Victoria, Koori Court (18 April 2012) Magistrates' Court of Victoria <http://www.magistratescourt.vic.gov.au/jurisdictions/specialist-jurisdictions/koori-court>

93. Manjoo, Rashida, United Nations Human Rights Office of the High Commissioner (11 March 2014) United Nations Human Rights <http://www.ohchr.org/EN/NewsEvents/Pages/DisplayNews.aspx?NewsID=14448\&LangID=E $>$ 
94. McMaster University, Timeline of African History: Ancient African Civilizations (2008) African and African Diaspora Studies

<http://www.humanities.mcmaster.ca/africanhistory/studying_africa/ancient.html>

95. Ministry of Information, Culture and Tourism, Welcoming The National Traditional Council As An Autonomous Body (20 July 2012) Welcoming the National Traditional Council as an Autonomous Body <http://www.micatliberia.com/index.php/media/new-

liberia/opinions/editorials/744-welcoming-the-national-traditional-council-as-an-autonomousbody>

96. Morris, Barry and Andrew Lattas, Embedded Anthropology and the Intervention - Arena (September 2010) Arena: The website of left political, social and cultural commentary <http://www.arena.org.au/2010/09/embedded-anthropology-and-the-intervention/>

97. National Archives of Australia, Royal Commission into Aboriginal Deaths in Custody - Fact Sheet 112 (2015) Government <http://www.naa.gov.au/collection/fact-sheets/fs112.aspx>

98. National Archives of Australia, Royal Commission into Aboriginal Deaths in Custody - Fact Sheet 112 (2015) Fact Sheets <http://www.naa.gov.au/collection/fact-sheets/fs112.aspx>

99. National Archives of Australia, Social History: Your Story, Our History (2015) Women transported: myth and reality <http://www.naa.gov.au/collection/publications/papers-andpodcasts/social-history/women-transported.aspx $>$

100.National Archives of Australia, The Northern Territory of South Australia, 1863-1911 (2015) Commonwealth Government Records about the Northern Territory <http://guides.naa.gov.au/records-about-northern-territory/part1/chapter1/index.aspx >

101. National Association for the Advancement of Coloured People, NAACP History: Carter G. Woodson (2015) NAACP History <http://www.naacp.org/pages/naacp-history-Carter-G.Woodson>

102. National Centre of Biography, Peris, Nova (1971-?) (10 August 2017) Indigenous Australia $<$ http://ia.anu.edu.au/biography/peris-nova-17821>

103.National Library of Australia, Bringing Them Home Oral History Projects (2013) Oral Projects <http://pandora.nla.gov.au/pan/133365/20120410-1246/www.nla.gov.au/oh/bth/index.html>

104.Neate, Beth, Now and Then: Moola Bulla Station (19 March 2012) ABC Open What's Your Story <https://open.abc.net.au/posts/now-and-then-moola-bulla-50ga3yn>

105.Netherlands Centre for Indigenous Peoples, Definition of Indigenous Peoples (1 November 2010) Indigenous Peoples Definition <http://indigenouspeoples.nl/indigenouspeoples/definition-indigenous>

106. New South Wales Government, Incidents between Aboriginal People in NSW and the British Colonisers 1770-1792 (19 November 2010) Board of Studies NSW - K6 Educational Resources <http://k6.boardofstudies.nsw.edu.au/go/hsie/background-sheets/british-colonisers-1770-1792/>

107. New South Wales Government, Full Transcript - Establishment of the Native Institution, 1814 - State Records NSW (2013) Lachlan Macquarie: Visionary and Builder $<\mathrm{http} / / / \mathrm{www}$.records.nsw.gov.au/state-archives/digital-gallery/lachlan-macquarie-visionary-andbuilder/public-notices/full-transcript-establishment-of-the-native-institution-1814>

108.Northern Territory Department of Health, Aerial Medical Services (3 October 2014) Aerial Medical Services 〈http://health.nt.gov.au/Hospitals/Aerial_Medical_Services/index.aspx >

109.Northern Territory Department of Health, Hospitals (29 June 2015) Hospitals <http://health.nt.gov.au/Hospitals/>

110.NSW Department of Education, Racism. No Way.: Fact Sheets - Terra Nullius (2010) Teaching Resources <http://www.racismnoway.com.au/teaching-resources/factsheets/10.html>

111.NSW Government, Family \& Community Services (4 January 2015) About Us <https://www.facs.nsw.gov.au/about_us>

112.NSW HSC Online, HSC Online - Heritage and Identity (2013) Aboriginal Studies <http://hsc.csu.edu.au/ab_studies/part2/heritage/heritage_and_identity/hipolicies.htm>

113.NYU Law, International Law Research (18 March 2013) LibGuides at NYU Law $<$ http://nyulaw.libguides.com/content.php?pid=45600\&sid=676200>

114. Office of Parliamentary Education, Parliamentary Education Office (5 October 2012) Closer Look: Australian Constitution <http://www.peo.gov.au/students/fact_sheets/australian_constitution.html>

115.Parliamentary Education Office, How Australian Formed Its Constitution (2015) The Australian Constitution <http://www.peo.gov.au/learning/closer-look/the-australian-constitution/howaustralia-formed-its-constitution.html>

116.Parramatta City Council, What Is Heritage: Parramatta City Council (23 April 2013) What is Heritage <http://www.parracity.nsw.gov.au/build/heritage/what_is_heritage>

117.Parramatta Female Factory Precinct, Convicts and Characters (2015) Parra Girls <http://www.parragirls.org.au/convict-connections.php> 
118.Payne, Elizabeth, Government Denies Watering down UN Resolution on Sexual Violence (12 June 2013) www.ottawacitizen.com

<http://www.ottawacitizen.com/news/Government+denies+watering+down+resolution+sexual+ violence/8517354/story.html>

119.Perth Dead Persons Society, Convict Ships to Australia (2002) Convicts to Australia $<$ http://members.iinet.net.au/ perthdps/convicts//shipNSW1.html>

120.Philippa Crosbie, Christine Tennent, Subject Guides. Aboriginal Studies. Aboriginal Studies Home. (2013) Aboriginal Studies

<http://libguides.library.usyd.edu.au/content.php?pid=27935\&sid=203386>

121.Port Arthur Historic Sites, The Australian Convict Sites (2011) Cascades Female Factory Historic Site <http://www.femalefactory.org.au/history/the_australian_convict_sites>

122. Queensland, c=AU; o=The State of Queensland; ou=Parliament of, Queensland Parliament Marks Apology to Stolen Generations, 13 February 2008 (2011) The Queensland Parliament $<$ https://www.parliament.qld.gov.au/get-involved/events-and-activities/2008/2008-02-13ApologyToStolenGeneration>

123. Queensland Government, Creation of a State (5 March 2013) About Queensland and its government <https://www.qld.gov.au/about/about-queensland/history/creation-of-state/>

124. Queensland Government, Interesting Facts about Queensland (2015) About Queensland: Statistical Facts <https://www.qld.gov.au/about/about-queensland/statistics-facts/facts/>

125. Queensland Studies Authority, The History of Aboriginal Land Rights in Australia (1800s1980s) (December 2007) Queensland Government <http://www.qsa.qld.edu.au/downloads/approach/indigenous_res006_0712.pdf>

126. Racism No Way, Fact Sheet: Edward Koiki Mabo 1936-1992 (2015) Teaching Resources <http://www.racismnoway.com.au/teaching-resources/factsheets/54.html>

127.RECOGNISE, Constitutional Recognition of Indigenous Australians - RECOGNISE (2013) RECOGNISE <http://www.recognise.org.au/>

128. Restorative Justice Council, What Is Restorative Justice / Restorative Justice Council (2013) Restorative Justice: Providing Quality Assurance and the National Voice for Restorative Practice <http://www.restorativejustice.org.uk/what_is_restorative_justice/\#.UjBvORYm5WA>

129.Robertson, Steve, Understanding Men and Health Masculinities, Identity, and Well-Being (2007) <http://site.ebrary.com/id/10229844>

130.Rollback the Intervention, Justice for Kwementyaye Briscoe - Fact Sheet (2 October 2012) Death in Custody <http://rollbacktheintervention.wordpress.com/deaths-in-custody/\#briscoefactsheet>

131. Royal Australian Navy, HMAS Stirling (2018) About the Royal Australian Navy <http://www.navy.gov.au/establishments/hmas-stirling>

132. Royal Commission into Institutional Responses to Child Sexual Abuse, About Us, Redress, and Public Hearings (2015) Government <https://www.childabuseroyalcommission.gov.au>

133.Ryan, Lyndall et al, Colonial Frontier Massacres in Eastern Australia: 1788-1872 (2017) The Centre for 21st Century Humanities, University of Newcastle

$<$ https://c21ch.newcastle.edu.au/colonialmassacres/>

134.Sambol-Tosco, Kimberly, The Slave Experience: Education, Arts, and Culture (2004) Slavery and the Making of America <http://www.pbs.org/wnet/slavery/experience/education/history2.html>

135. Save the Kimberly, Save the Kimberley: Wilderness, Culture, Heritage (2013) Home <http://www.savethekimberley.com/>

136. Say No, Commit to Ending Violence Against Women and Girls (2013) Say No Unite to End Violence Against Women <http://saynotoviolence.org/commit>

137. Solnit, Rebecca, A Rape a Minute, a Thousand Corpses a Year (24 January 2013) Tomgram: Rebecca Solnit, The Longest War <http://www.tomdispatch.com/post/175641/>

138. South West Aboriginal Land and Sea Council, The Noongar People (2015) History <http://www.noongar.org.au/noongar-people-history.php>

139. Staff Reporter, South Australia Loses Appeal against \$775,000 Payout to Bruce Trevorrow (22 March 2010) The Australian <http://www.theaustralian.com.au/news/nation/south-australialoses-appeal-against-775000-payout-to-bruce-trevorrow/story-e6frg6nf-1225843750085>

140. Staff Reporter, Stronger Futures Laws Condemned after Passing Senate (28 June 2012) ABC News <http://www.abc.net.au/news/2012-06-29/stronger-futures-laws-rushed-throughsenate/4100288>

141.Staff Reporter, Coniston Massacre (2015) First Australians <http://www.nma.gov.au/exhibitions/first_australians/resistance/coniston_massacre>

142.Staff Reporter, Transcript: Declaration of Martial Law (2015) Bells Falls Gorge: An Interactive Investigation < http://www.nma.gov.au/engage-learn/schools/classroomresources/multimedia/interactives/bells_falls_gorge_html/cabinet_items/transcript_declaration_o f_martial_law> 
143.Staff Reporter, Florida Teen, War Criminal: The Life of an 'American Warlord' (4 April 2015) Author Interviews <http://www.npr.org/2015/04/04/396384872/florida-teen-war-criminal-thelife-of-an-american-warlord>

144.Staff Reporter, The 13-Year-Old Girl Sent on a 'day-Trip' to Australia (29 October 2015) BBC News Magazine <http://www.bbc.com/news/magazine-34656346>

145.Stand for Free, Australian Government: Stop 'Stronger Futures' and Support Aboriginal SelfDetermination in the NT (2012) Change.org <https://www.change.org/p/australian-governmentstop-stronger-futures-and-support-aboriginal-self-determination-in-the-nt >

146. State Library of New South Wales, Eora: Aboriginal Sydney (7 June 2011) Indigenous Australians Discover Collections <http://www.sl.nsw.gov.au/discover_collections/history_nation/indigenous/eora/>

147. State Library of Queensland, 880 Convict Voyages to Australia (2015) Convict Records <http://www.convictrecords.com.au/timeline>

148. Strong-Boag, Veronica et al, Africa Women Suffrage and beyond: Confronting the Democratic Deficit (2013) Women Vote <http://womensuffrage.org/?page_id=203>

149.Szoke, Helen, Racism exists in Australia - are we doing enough to address it? (14 December 2012) Australian Human Rights Commission

<https://www.humanrights.gov.au/news/speeches/racism-exists-australia-are-we-doing-enoughaddress-it $>$

150.Taddonio, Patrice, How We Uncovered Firestone's Deal with Charles Taylor - Firestone and the Warlord (18 November 2014) FRONTLINE

<http://www.pbs.org/wgbh/pages/frontline/inside-frontline/how-we-uncovered-firestones-dealwith-charles-taylor/>

151.Tait, Narelle, Lateline - 22/09/2003: The Story of Maria Locke . Australian Broadcasting Corp (22 September 2003) Lateline <http://www.abc.net.au/lateline/content/2003/hc48.htm>

152.Teage, Hilary, Liberian Declaration of Independence (1847) One Liberia <http://onliberia.org/con_declaration.htm>

153.The American Colonization Society, Liberia's 1839 Constitution (2013) TLC Africa <http://www.tlcafrica.com/constitution-1839.htm>

154. The Australasian Institute of Judicial Administration, Indigenous Issues and Indigenous Sentencing Courts (11 November 2014) Australasian Therapeutic Jurisprudence Clearinghouse <http://www.aija.org.au/index.php/research/australasian-therapeutic-jurisprudenceclearinghouse/indigenous-issues-and-indigenous-sentencing-courts>

155. The Carter Centre, Liberia Access to Justice Project Partnerships (4 October 2013) The Carter Centre: Waking Peace. Fighting Disease. Building Hope

<http://www.cartercenter.org/news/features/p/access_to_information/liberia-mama-tumeh.html>

156.The Sydney Line, Henry Reynolds vs. Keith Windschuttle on Aboriginal History (12 November 2000) The Sydney Line: Keith Windschuttle

<http://www.sydneyline.com/Gould's\%20Book\%20Arcade\%20debate.htm>

157.Thinking Girl, Feminist Friday - Intersectional Identity (12 May 2006) Thinking Girl - because women are people too <https://thinkinggirl.wordpress.com/2006/05/12/feminism-fridayintersectional-identity/>

158. Thomas, Steve, Convicts Records of Australia (2018) Convict Records $<$ https://convictrecords.com.au>

159.Thorpe, Robbie, The Bathurst Massacres (2015) Treaty Republic <http://treatyrepublic.net/content/bathurst-massacres>

160.Tobin, Mark and Mark Colvin, Campaign for Recognition of Massacre Victims (8 November 2010) PM with Mark Covin <http://www.abc.net.au/pm/content/2010/s3060567.htm?source=rss >

161.Toe, J Aloysius, Liberia: Elections, Justice, Corruption and the Role of the International Community (24 February 2011) National Endowment for Democracy

$<$ http://www.ned.org/liberia-elections-justice-corruption-and-the-role-of-the-internationalcommunity>

162.Truth and Reconciliation Commission of Liberia, Lutheran Church Massacre Victim: 'My Body Was Covered with Blood and Human Brain' (2009) Press Release <http://trcofliberia.org/press_releases/129>

163.Truth and Reconciliation Commission of Liberia, Press Releases: Prince Johnson Displayed Doe's Skull...Commany Wesseh (2013) Press Release <http://trcofliberia.org/press_releases/91>

164.Tyler-McGraw, Marie, Martha Ann Ricks: Domestic Patriot (1 May 2008) Virginia Emigrants to Liberia, Virginia Centre for Digital History, University of Virginia <http://www.vcdh.virginia.edu/liberia/index.php?page=Stories\&section=Martha\%20Ricks>

165.UN Women, Liberian Women Building Peace - Progress of the World's Women (2011) UN Women: Progress of the World's Women <http://progress.unwomen.org/case-study-liberia/> 
166.UN Women, UN Women - United Nations Entity for Gender Equality and the Empowerment of Women (2011) UN Women: United Nations Entity for Gender Equality and the Empowerment of Women <http://www.unwomen.org/>

167.UN Women, Australia \& Liberia Response to Ending Violence Against Women (5 April 2013) Say No Unite to End Violence Against Women <http://saynotoviolence.org/commit>

168. United Nations, Doctrines of Dispossession: Racism against Indigenous Peoples (2001) World Conference Against Racism <http://www.un.org/WCAR/e-kit/indigenous.htm>

169. United Nations, Short History of CEDAW Convention (2009) Short History of CEDAW Convention <http://www.un.org/womenwatch/daw/cedaw/history.htm>

170.United Nations, UN Rule of Law Website (2013) United Nations Rule of Law $<$ http://www.unrol.org>

171.United Nations, The United Nations and Decolonisation (2017) History <http://www.un.org/en/decolonization/history.shtml>

172.United Nations, International Day of the World's Indigenous Peoples (9 August 2017) $<$ http://www.un.org/en/events/indigenousday/>

173.United Nations News Service, New UN Human Rights Office to Open in Liberia in Early 2018 (4 August 2017) UN News Service Section <https://www.un.org/apps/news/story.asp?NewsID=57313\#.WbbY760ZPHI>

174.US Immigration and Customs Enforcement, Liberian Human Rights Violator Removed from US (29 March 2012) News Releases - ICE Newsroom <http://www.ice.gov/news/releases/liberianhuman-rights-violator-removed-us>

175.WHRI, Women's Human Rights Education Institutes (14 April 2013) Women's Human Rights Institutes Six-Week Institute and CEDAW for Change <http://learnwhr.org/>

176. World Health Organisation, WHO: Female Genital Mutilation (2014) Female Genital Mutilation $<$ http://www.who.int/mediacentre/factsheets/fs241/en/>

177. World Health Organisation, Violence against Women (November 2016) WHO <http://www.who.int/mediacentre/factsheets/fs239/en/>

178.WSWS Reporting Team, Conditions of Aboriginal People in Alice Springs and the Town Camps (7 April 2008) World Socialist Web Site <http://www.wsws.org/en/articles/2008/04/alicea07.html>

179.Zahidi, Saadia, 2095: The Year of Gender Equality in the Workplace, Maybe (28 October 2015) 2095: The Year of Gender Equality in the Workplace, Maybe | World Economic Forum <https://www.weforum.org/agenda/2014/10/2095-year-gender-equality-work-maybe/> 